\title{
Der Siedlungs- und Bestattungsplatz Nortmoorer Hammrich
}

\section{Untersuchungen zur Besiedlungsgeschichte des Landkreises Leer (Ostfriesland)}

\author{
Römische Kaiserzeit bis Frühmittelalter
}

\author{
Dissertation \\ zur \\ Erlangung der Doktorwürde
}

\author{
vorgelegt der \\ Philosophischen Fakultät \\ der \\ Georg-August-Universität Göttingen \\ von \\ Petra Rosenplänter \\ im Februar 2010
}




\section{Eidesstattliche Versicherung}

Hiermit versichere ich an Eides statt, dass ich die eingereichte Dissertation (Der Siedlungsund Bestattungsplatz Nortmoorer Hammrich. Untersuchungen zur Besiedlungsgeschichte des Landkreises Leer (Ostfriesland). Römische Kaiserzeit bis Frühmittelalter) selbstständig und ohne unerlaubte Hilfe verfasst habe. Anderer als der von mir angegebenen Hilfsmittel und Schriften habe ich mich nicht bedient. Alle wörtlich oder sinngemäß den Schriften anderer Autorinnen oder Autoren entnommenen Stellen habe ich kenntlich gemacht. Die Abhandlung ist noch nicht veröffentlicht worden und noch nicht Gegenstand eines Promotionsverfahrens gewesen.

gez. Petra Rosenplänter

1. Gutachter

2. Gutachter

3. Gutachter

4. Prüfungsvorsitz
Prof. Dr. H.-K. Willroth (Seminar für Ur- und Frühgeschichte)

Prof. Dr. H. Döhl (Seminar für klassische Archäologie)

Prof. Dr. T. Nagel (Seminar für Arabistik)

Prof. Dr. P. Aufgebauer (Institut für historische Landesforschung)

Tag der mündlichen Prüfung 30.07.2014 


\section{Vorwort}

Der Untere Emsbereich mit seinen ausgedehnten Niederungsgebieten steht im Zentrum der vorliegenden Studie zur Besiedlungsgeschichte des Landkreises Leer. Ausgangspunkt ist die paradigmatische Aufarbeitung des Siedlungs- und Bestattungsplatzes Nortmoorer Hammrich während der römischen Kaiserzeit bis zum Frühmittelalter.

Großräumige siedlungsarchäologische Untersuchungen zum gewählten Zeitraum liegen für das Arbeitsgebiet bereits über 40 Jahre zurück. So basiert der Forschungsstand zur kaiserzeitlichen Keramiktypologie des ostfriesischen Materials weitgehend auf den Studien von ERDNIB (1938) und SCHMID (1962; 1965). Auch das Chronologiesystem zur mittelalterlichen Keramik im ostfriesischen Raum stützt sich auf ältere Arbeiten. Maßgeblich sind stratigraphische Untersuchungen aus dem kriegszerstörten Emden aus der Mitte der 50er Jahre des 20. Jahrhunderts (HAARNAGEL 1965; STILKE 1995).

Inzwischen hat sich das Fundvolumen aufgrund intensiver denkmalpflegerischer Betreuung durch den Archäologischen Dienst der Ostfriesischen Landschaft erheblich vergrößert. Hinzugekommen sind seit den 70er Jahren des 20. Jahrhunderts naturwissenschaftliche Untersuchungsmethoden, die im südlichen Ostfriesland vermehrt durchgeführt wurden. Die im Grundwasserbereich oft bemerkenswert gute Erhaltung organischer Materialien aus botanischen und archäologischen Fundzusammenhängen ermöglichen neue Erkenntnisse über die Vegetations- und Umweltgeschichte der Unteren Emsregion.

Mein besonderer Dank gilt Herrn Prof. Dr. Karl-Heinz Willroth, der die Arbeit betreute und mein Studium förderte. Das Niedersächsische Ministerium für Wissenschaft und Kultur übernahm von 2001 bis 2004 die Förderung des Forschungsvorhabens. Dies erlaubte eine Anstellung am Seminar für Ur- und Frühgeschichte der Universität Göttingen, naturwissenschaftliche Untersuchungen und dazugehörige Grafikarbeiten ${ }^{1}$. Die vorliegende Arbeit wurde im Wintersemester 2009/2010 von der Philosophischen Fakultät der GeorgAugust-Universität Göttingen als Dissertation angenommen.

\footnotetext{
${ }^{1}$ Gefördert mit Mitteln des Landes Niedersachsen
} 
Bedanken möchte ich mich an dieser Stelle für die Arbeitsmöglichkeiten und die freundliche Aufnahme bei allen Mitarbeitern des Archäologischen Dienstes der Ostfriesischen Landschaft. Dr. Wolfgang Schwarz und Dr. Ralf Bärenfänger waren durch ihre stete Diskussionsbereitschaft eine wertvolle Hilfe. Herr Dr. Schwarz überließ mir in dankenswerter Weise bisher unpublizierte Grabungsbefunde und Funde.

Das Niedersächsische Landesmuseum Hannover, Abteilung Urgeschichte, stellte weiteres Fundmaterial bereit. Gedankt sei insbesondere dem Leiter der Abteilung Ur- und Frühgeschichte Herrn Martin Schmidt M.A. für Restaurierungsarbeiten. Prof. Dr. Siegmar v. Schnurbein stellte mir die umfangreiche Bibliothek der RGK in Frankfurt a. M. zur Verfügung. Prof. Dr. Hartmut Döhl (Universität Göttingen) förderte die Forschung zu einer Terra Sigillata Nachahmung aus dem Nortmoorer Hammrich. Dr. W. Haio Zimmermann unterstützte mich mit seinem fachlichen Rat und gewährte Einblick in das Fundmagazin des Niedersächsischen Institutes für historische Küstenforschung, Wilhelmshaven.

Für weiterführende Hinweise bin ich Dr. Henny Groenendijk (Provinzarchäologie Groningen), Prof. Dr. Ion Ionita (Universität Bukarest), Prof. Dr. Michael Erdrich (Universität Nijmegen) dankbar. Dr. Jutta Möller ermöglichte die Sichtung wichtiger Fundortakten im Landesdenkmalamt Hannover, Referat Archäologie. Mein besonderer Dank gilt den Mitarbeitern des Staatsarchives Stiftung Preußischer Kulturbesitz, Berlin-Charlottenburg, für die gewährte Unterstützung und die Einsicht in historische Fundberichte des 19. und frühen 20. Jahrhunderts.

Für die naturwissenschaftliche Analyse ausgewählter Metall-, Glas- und Keramikfunde sowie die Anfertigung von Makroaufnahmen sei Dr. Andreas Kronz vom Geowissenschaftlichen Zentrum der Universität Göttingen herzlich gedankt. Dr. Birgit Großkopf vom Anthropologischen Institut Göttingen übernahm die anthropologischen Untersuchungen der Brandbestattungen aus Nortmoor und Brinkum. Herr Andreas Verges ermöglichte die Röntgenaufnahmen aller Metallfunde des frühmittelalterlichen Gräberfeldes Brinkum. Die Reinzeichnung der Fundobjekte erstellte Frau Barbara Kluczkowski, soweit diese nicht von der Verfasserin vorgenommen wurden. Redaktionellen Beistand erfuhr die vorliegende Arbeit durch Dr. Heinz-Peter Koch und Dr. Stefan Höppner. Die Familie Weppner stand mir hilfreich zur Seite. Diese Arbeit ist meinen Eltern Inge und Walter Rosenplänter gewidmet. 


\section{Inhaltsverzeichnis}

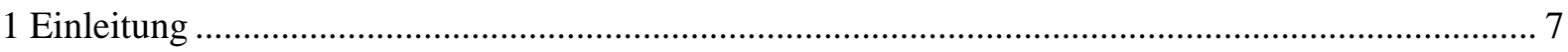

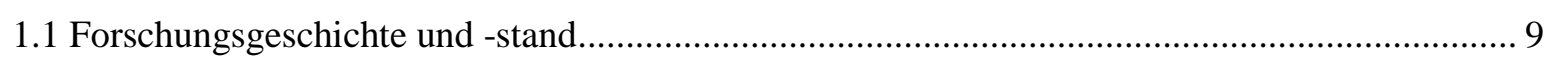

2 Abgrenzung des Arbeitsgebietes und seine naturräumliche Gliederung ....................................... 19

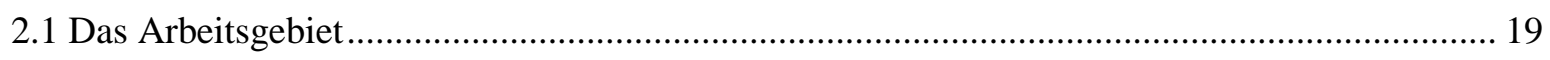

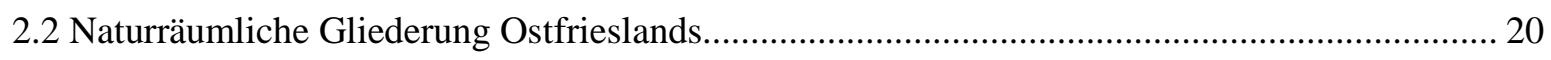

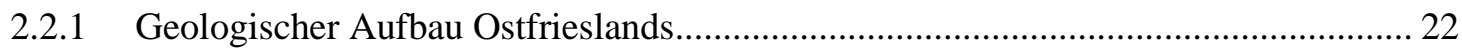

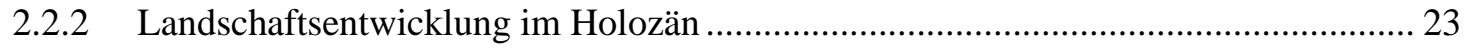

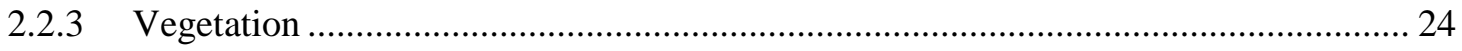

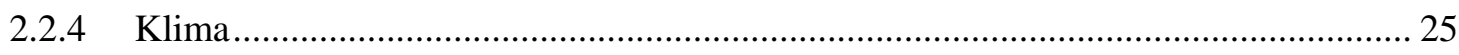

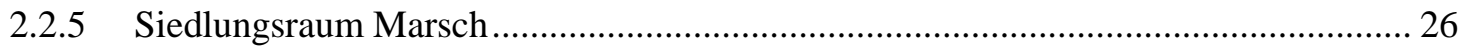

2.2.6 Naturräumliche Gliederung im Untersuchungsgebiet ............................................. 27

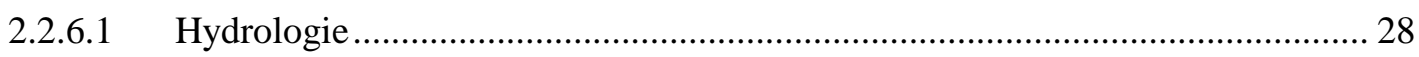

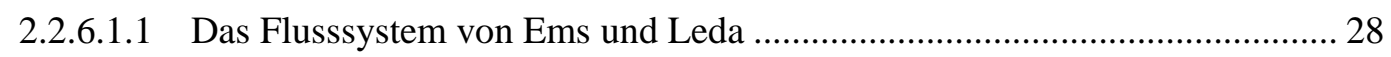

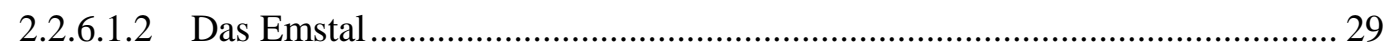

2.2.6.1.3 Grundwasserhaushalt im Untersuchungsgebiet ......................................... 31

2.2.6.1.4 Die Leda-Jümme-Region ......................................................................... 31

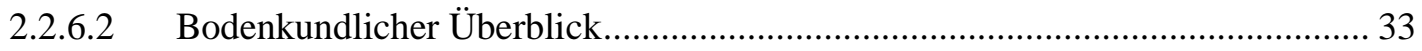

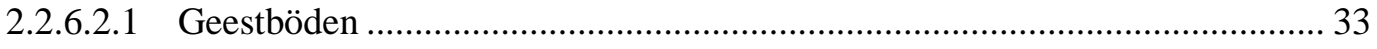

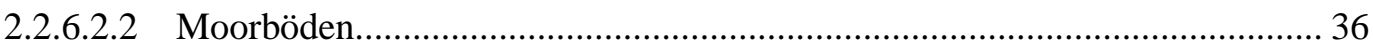

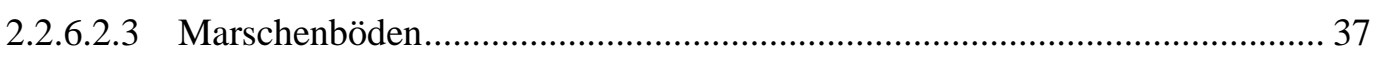

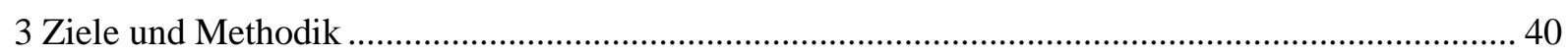

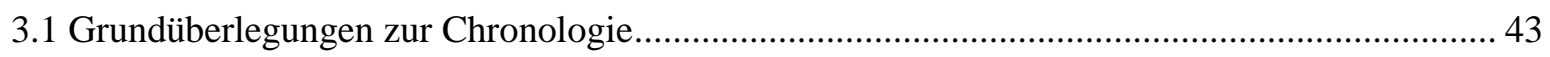

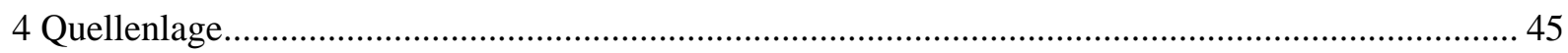

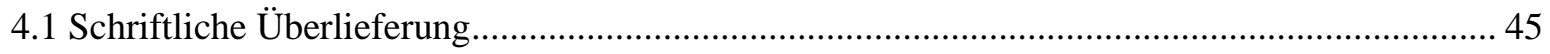

4.1.1 Römische Quellen zu den Chauken............................................................................ 45

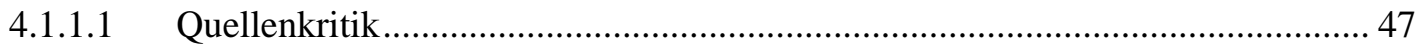

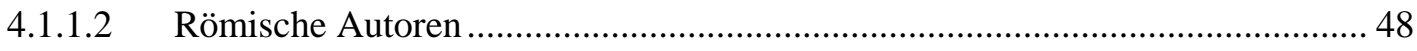

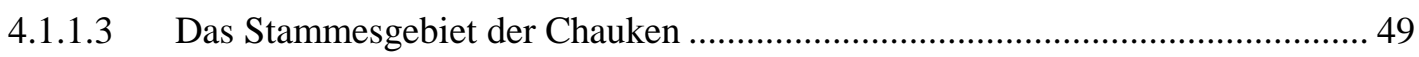

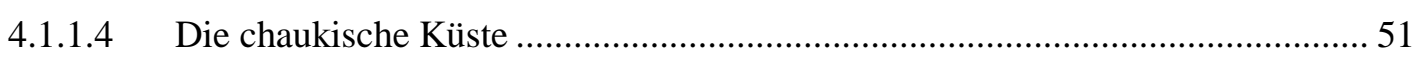

4.1.1.5 Die geopolitische Lage der Emsregion in der römischen Kaiserzeit................... 55

4.1.1.6 Wegeverhältnisse in Norddeutschland ................................................................ 59

4.1.1.7 Ein römischer Stützpunkt an der Nordsee? ..................................................... 61

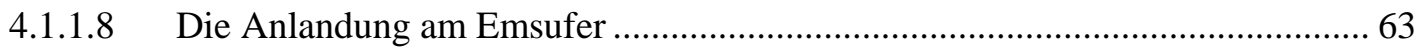

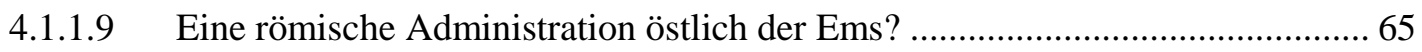

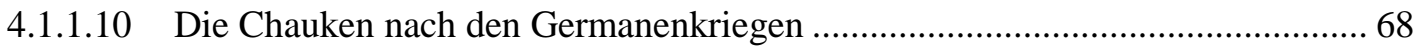

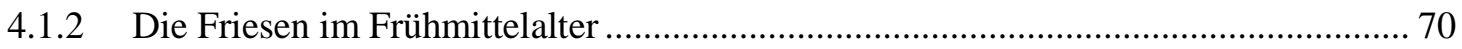




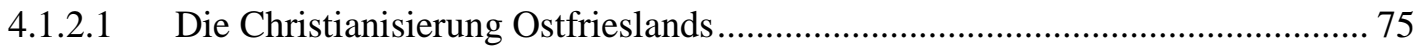

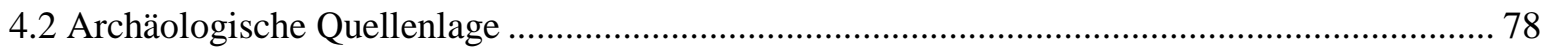

4.2.1 Geschichte der Sammlungen, erste Ausgrabungen, Forschungsinstitutionen .............. 78

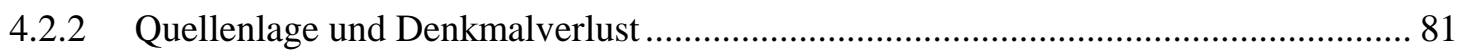

4.2.3 Fundstellen im Landkreis Leer............................................................................ 84

4.2.4 Exkurs zu römischen Fundmünzen in der Unteren Emsregion .................................... 91

5 Der Siedlungs- und Bestattungsplatz Nortmoorer Hammrich........................................................ 95

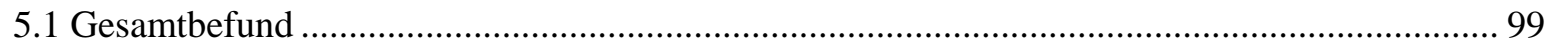

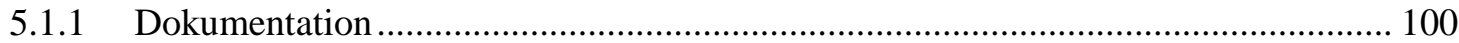

5.1.2 Aufbereitung der Grabungsdokumentation ................................................................. 101

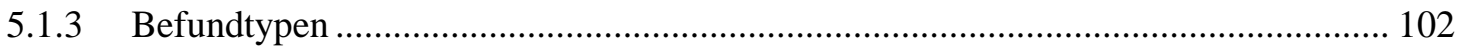

5.1.4 Befundverteilung und Siedlungsausdehnung ......................................................... 104

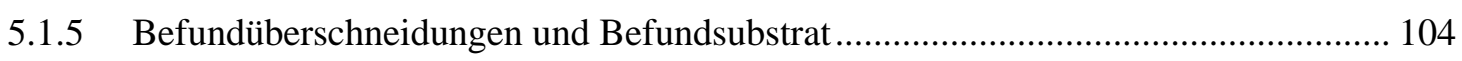

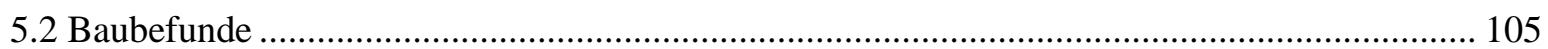

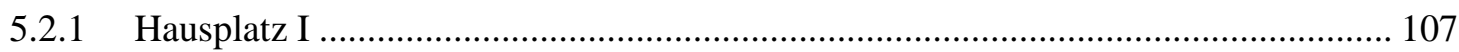

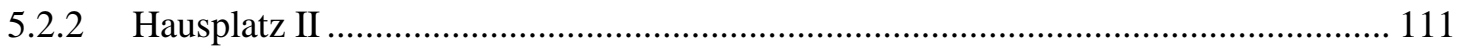

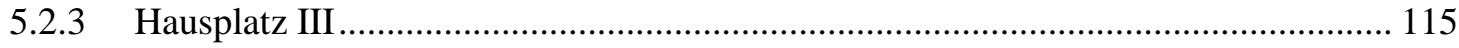

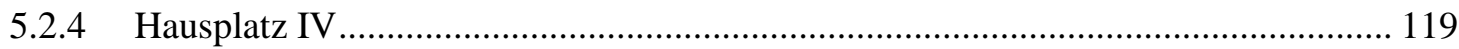

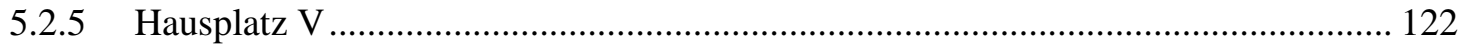

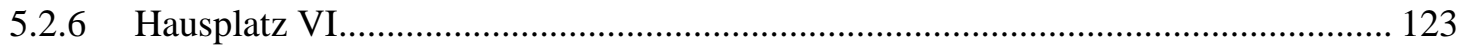

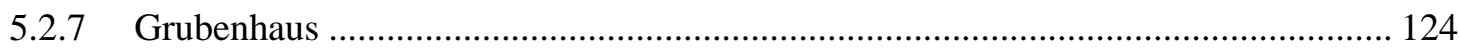

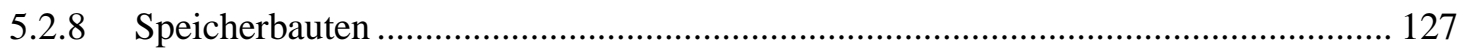

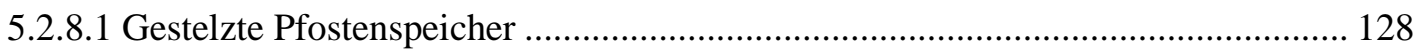

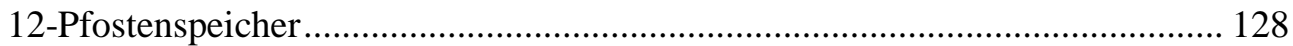

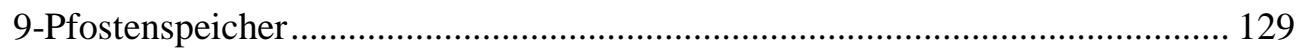

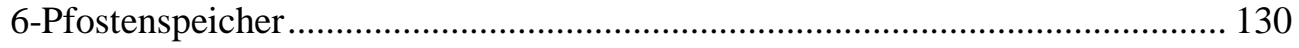

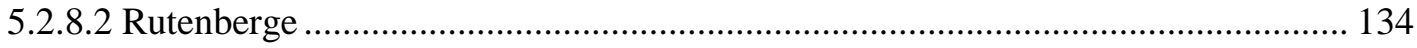

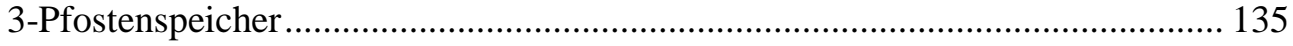

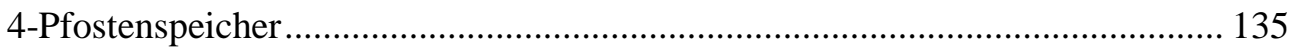

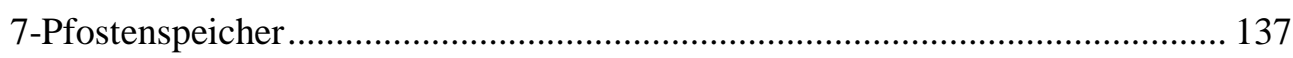

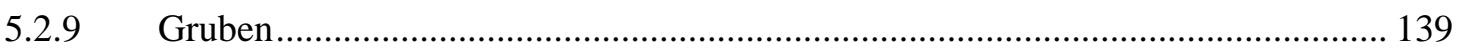

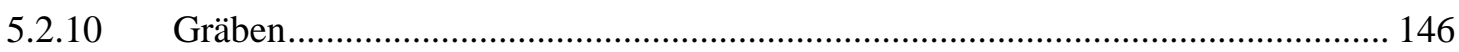

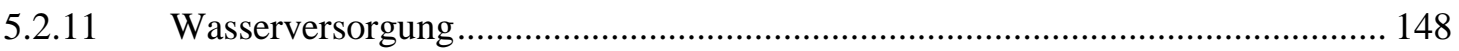

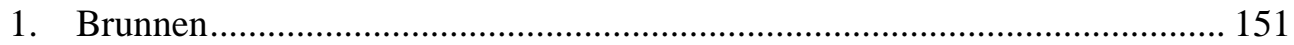

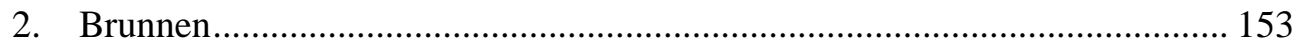

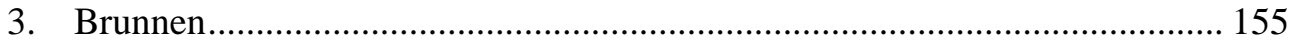

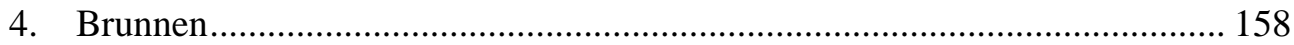




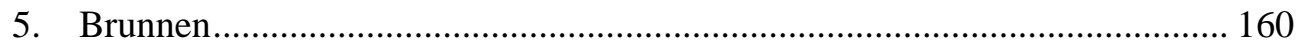

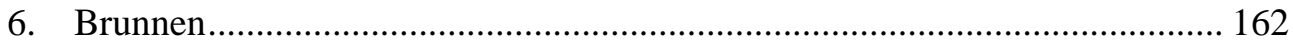

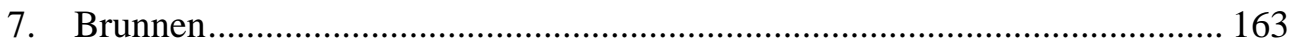

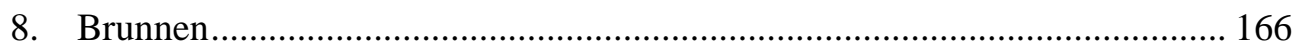

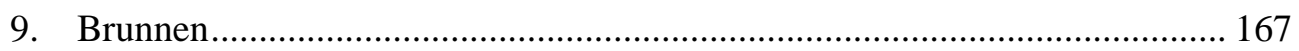

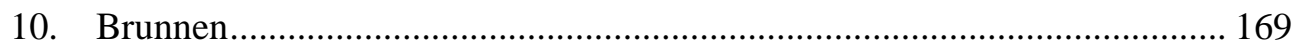

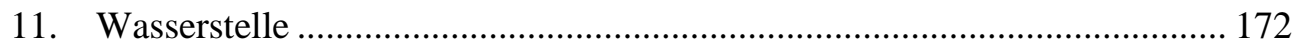

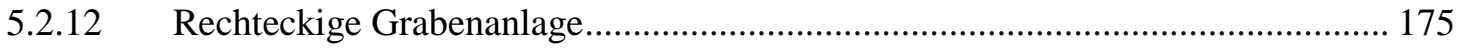

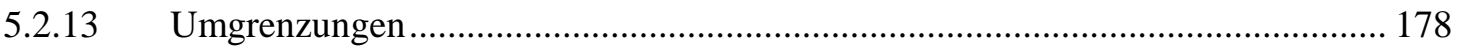

5.2.14 Pfostenstellung unbekannter Bedeutung .............................................................. 186

5.2.15 Kulturhistorische Einordnung der Hausbefunde ................................................. 187

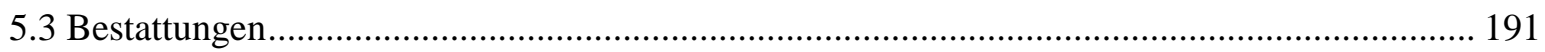

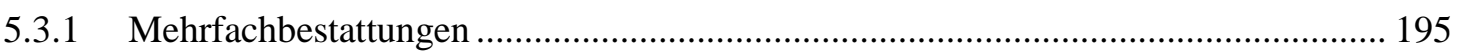

5.3.2 Pathologische Veränderungen und Sterbealter............................................................ 196

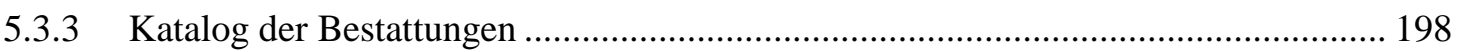

5.3.4 Kaiserzeitliche Bestattungsplätze im Unteren Emsgebiet ......................................... 201

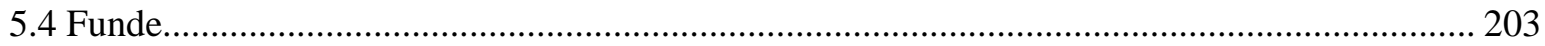

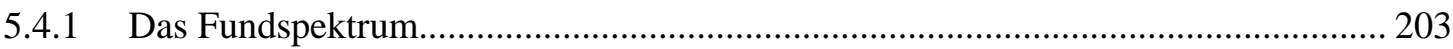

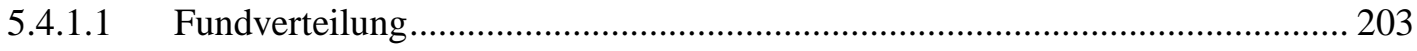

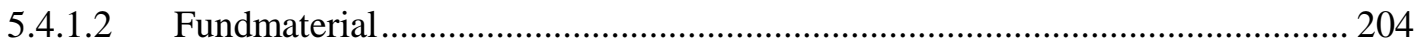

5.4.1.3 Zeitliche Einordnung der Funde - ein Überblick ............................................. 206

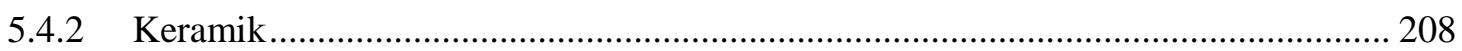

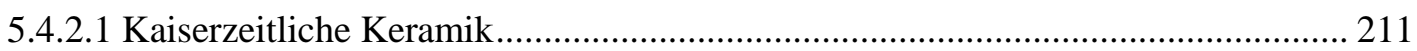

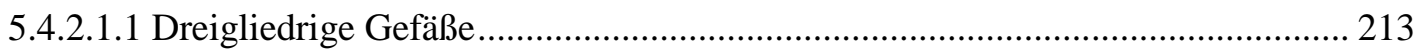

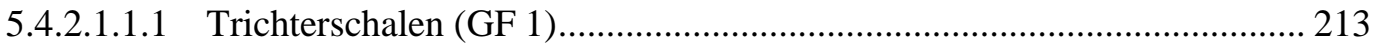

5.4.2.1.1.2 Trichternäpfe (GF 2) ........................................................................ 219

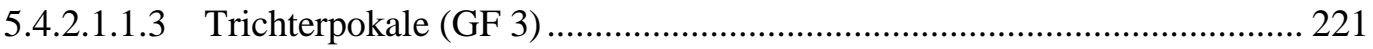

5.4.2.1.1.4 Weitmündige Töpfe (GF 7) ……………........................................... 221

5.4.2.1.1.4.1 Töpfe mit gerade ausgestelltem Rand (GF 7.1)............................... 223

5.4.2.1.1.4.2 Töpfe mit verdicktem Rand (GF 7.2) ............................................ 224

5.4.2.1.1.4.3 Töpfe mit kurz ausbiegendem Rand (GF 7.3) .................................. 226

5.4.2.1.1.4.4 Töpfe mit s-förmigem Profil (GF 7.4)................................................ 229

5.4.2.1.1.4.5 Töpfe mit steiler Schulter und senkrechtem Rand (GF 7.5)............. 230

5.4.2.1.1.4.6 Töpfe mit senkrechtem Rand und flacher Schulter (GF 7.6) ............ 231

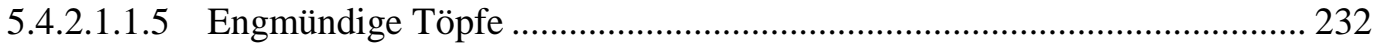

5.4.2.1.1.5.1 Engmündige Töpfe mit ausgewendetem Rand (GF 7.7) ................... 232

5.4.2.1.1.5.2 Engmündige Töpfe mit senkrechtem Rand (GF 7.8) ....................... 234 
5.4.2.1.1.5.3 Engmündige doppelkonische Töpfe (GF 7.9) …............................. 235

5.4.2.1.1.6 Becherförmige Gefäße (GF 14) ………................................................... 237

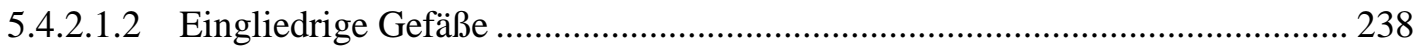

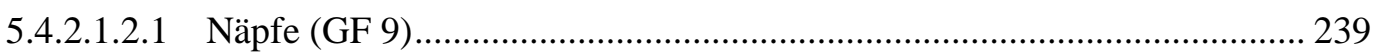

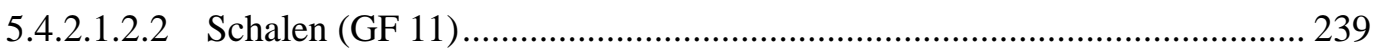

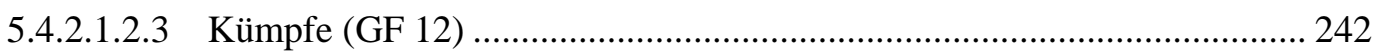

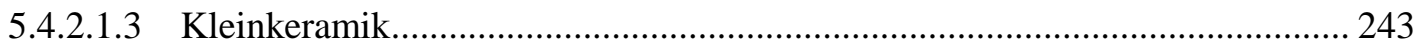

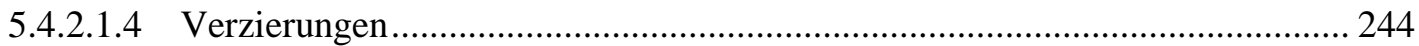

5.4.2.1.4.1 Geometrische Muster (VF 1) ................................................................. 245

5.4.5.1.4.1.1 Waagerechte Rillen- und Ritzverzierungen (VF 1.1)....................... 245

5.4.5.1.4.1.2 Vertikale Rillen- und Ritzverzierungen (VF 1.2) ............................ 246

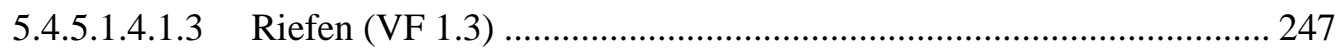

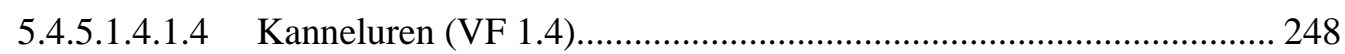

5.4.5.1.4.1.5 Flechtbänder (VF 1.5) ................................................................... 248

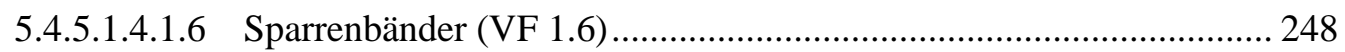

5.4.5.1.4.1.7 Kastenförmige Verzierungen (VF 1.7) ........................................... 249

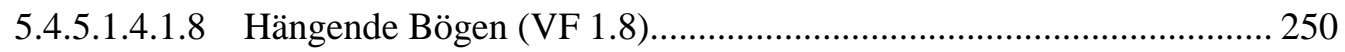

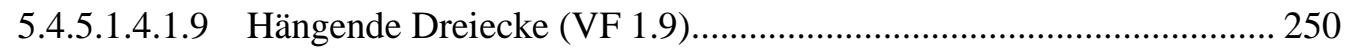

5.4.5.1.4.1.10 Bäumchenmuster (VF 1.10) ........................................................... 251

5.4.5.1.4.1.11 Kamm- und Besenstrich (VF 1.11) .............................................. 251

5.4.2.1.4.2 Stempel, Eindrücke, Einstiche (VF 2) ................................................... 252

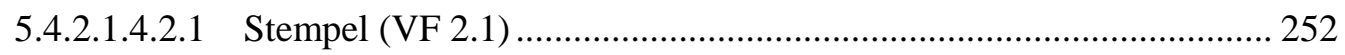

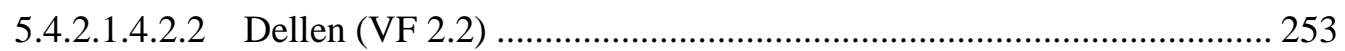

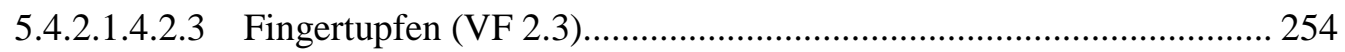

5.4.2.1.4.2.4 Fingernagel-Kerben (VF 2.4) ...................................................... 255

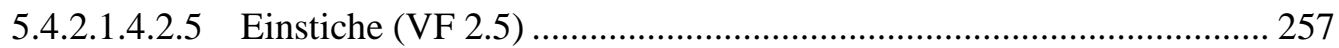

5.4.2.1.4.3 Plastische Verzierungen (VF 3) ............................................................. 258

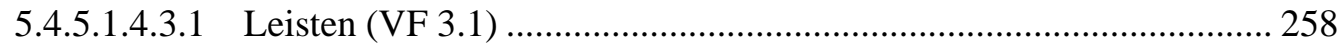

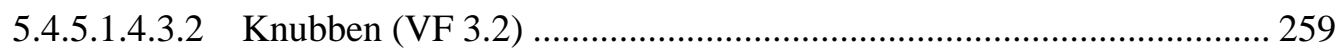

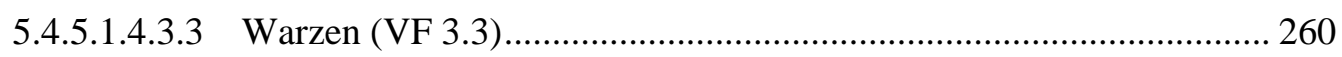

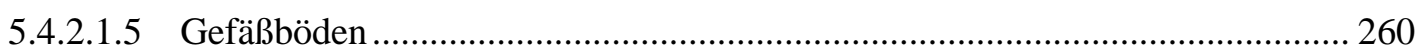

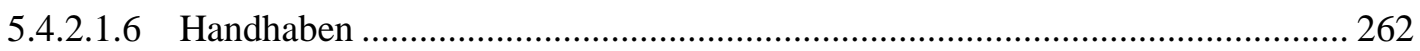

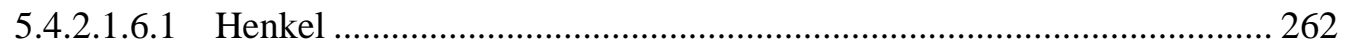

5.4.2.1.6.2 Griffknubben, -lappen und -ösen........................................................ 265

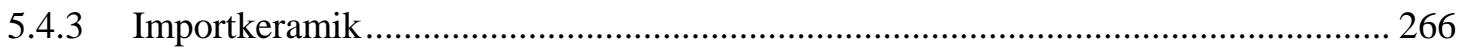

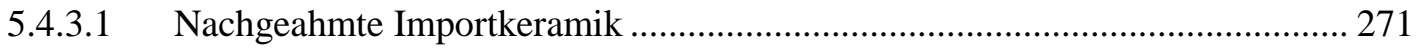

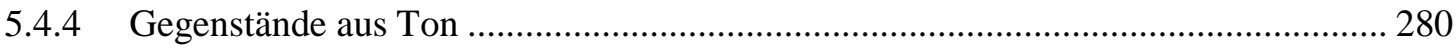




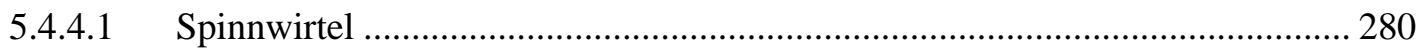

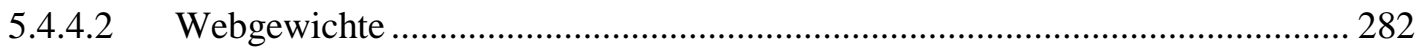

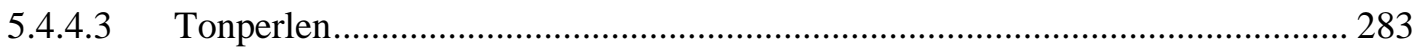

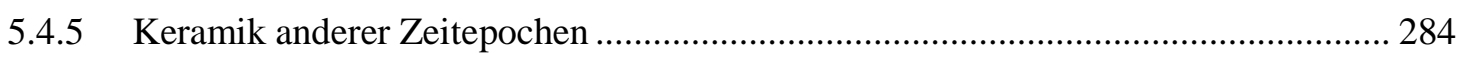

5.4.5.1 Bronze- und eisenzeitliche Keramik.............................................................. 284

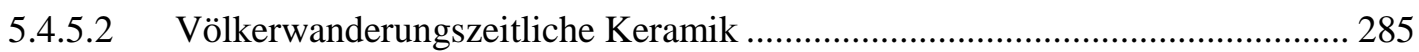

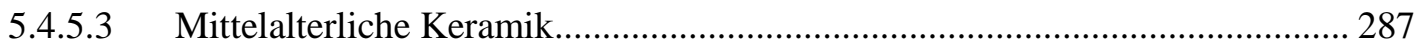

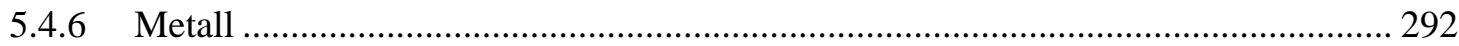

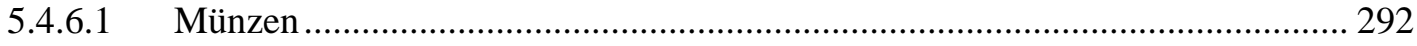

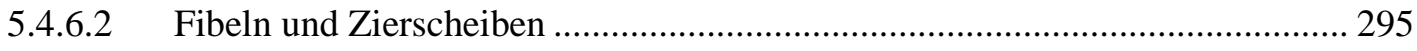

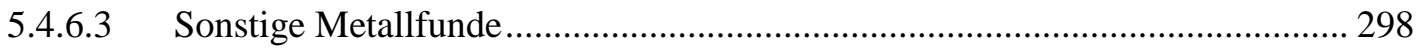

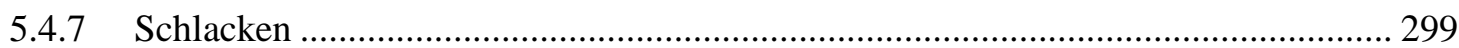

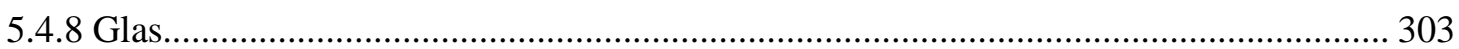

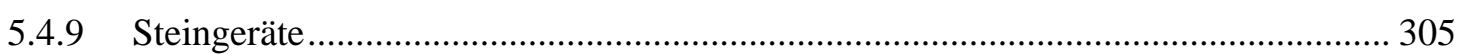

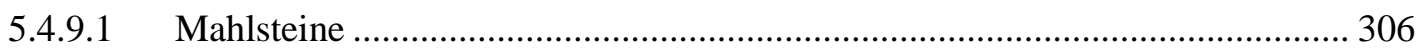

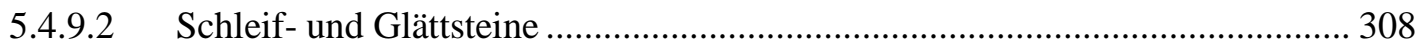

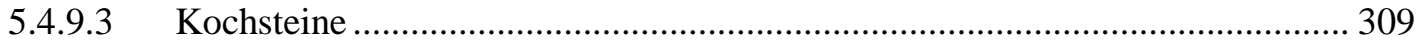

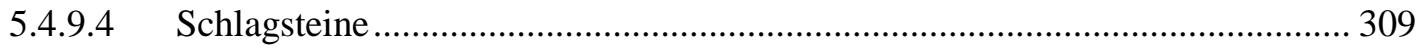

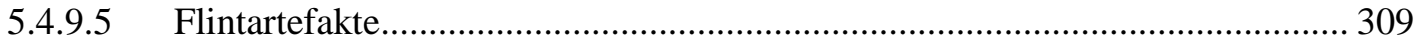

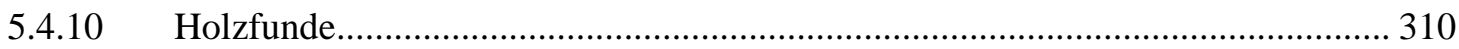

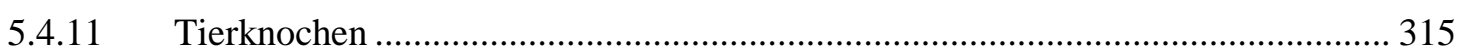

5.5 Zusammenfassung der relativ- und absolutchronologischen Ergebnisse ........................... 316

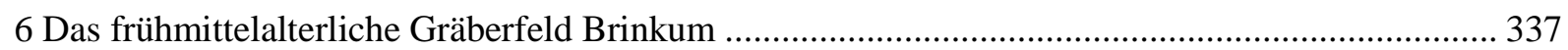

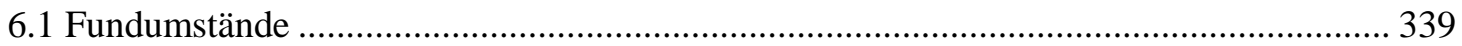

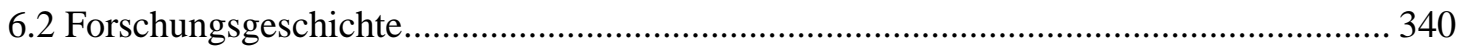

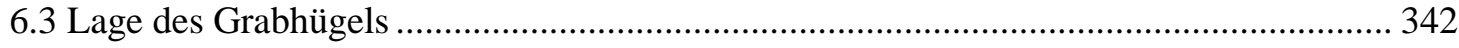

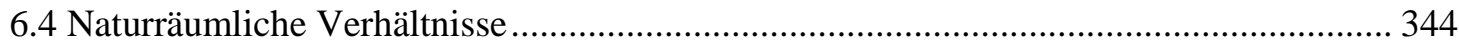

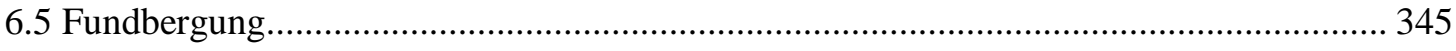

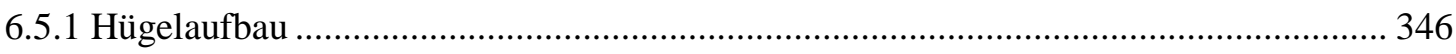

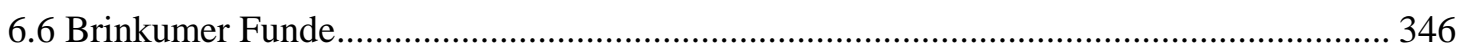

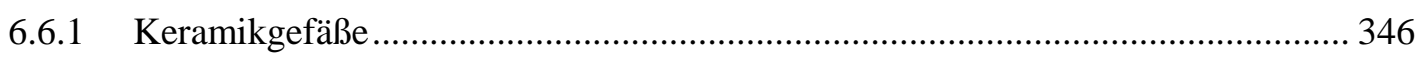

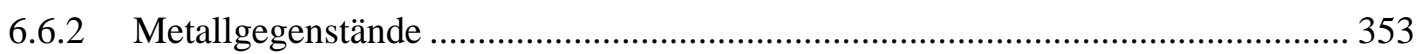

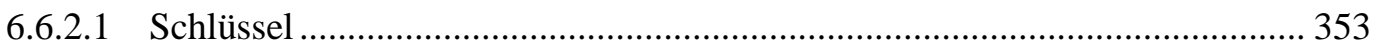

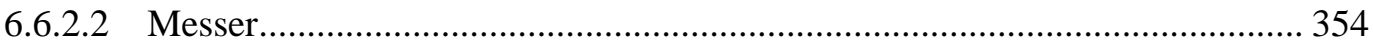

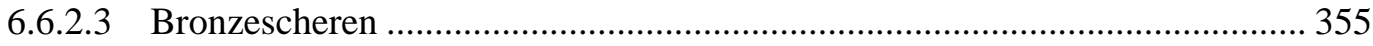

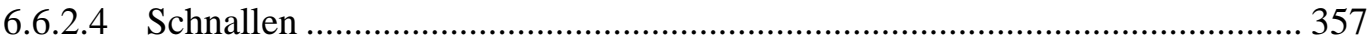

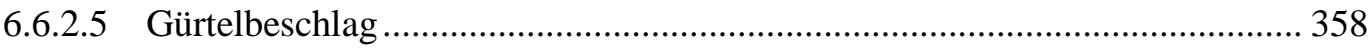




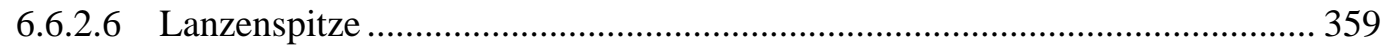

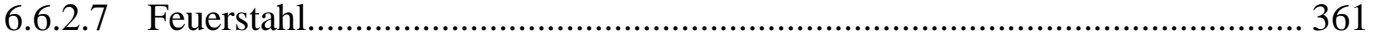

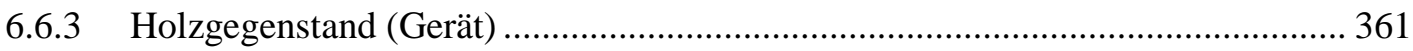

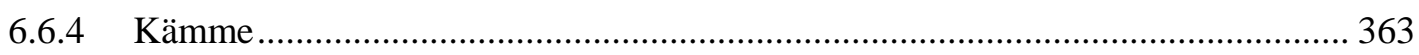

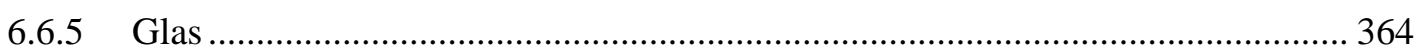

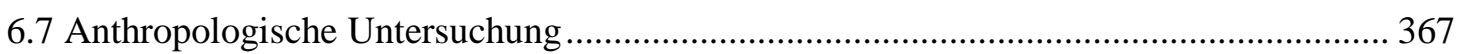

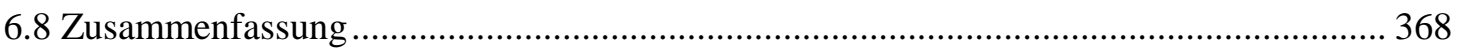

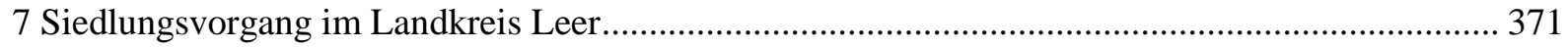

7.1 Naturräumliche Bedingungen im Untersuchungsraum ................................................. 373

7.2 Fundstellen der römischen Kaiserzeit ................................................................................. 375

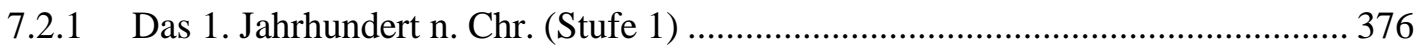

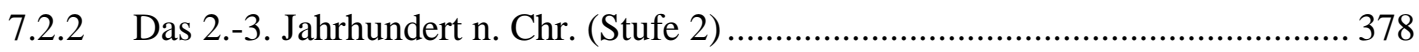

7.2.3 Siedlungsmuster in der Römischen Kaiserzeit................................................... 382

7.3 Fundstellen der Völkerwanderungszeit ......................................................................... 385

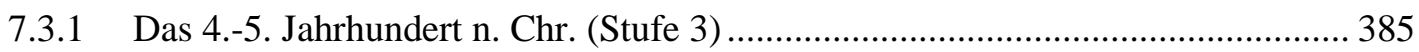

7.4 Fundstellen des Frühmittelalters .............................................................................. 387

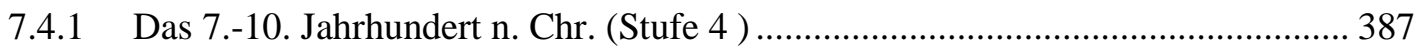

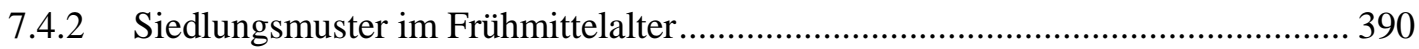

7.5 Ergebnisse der siedlungsarchäologischen Untersuchungen ............................................. 395

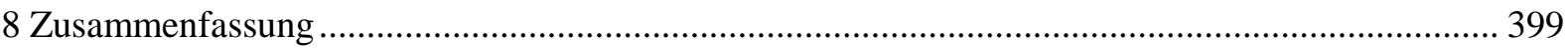

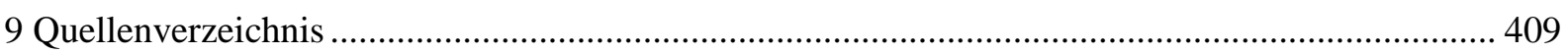

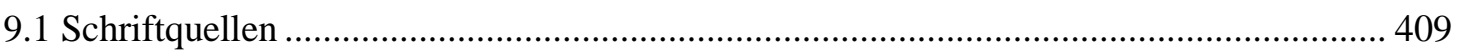

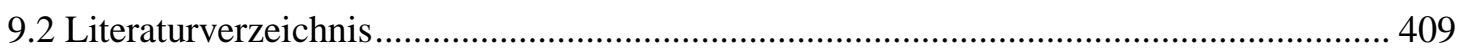

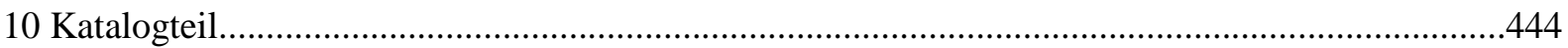

10.1 Vorbemerkungen zum Befundkatalog Nortmoorer Hammrich..................................444

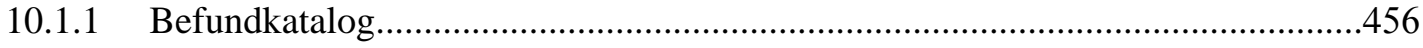

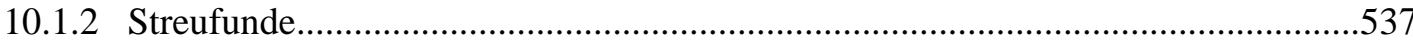

10.1.3 Bodenprofile Grabung Nortmoorer Hammrich P 1 bis P 8.....................................541

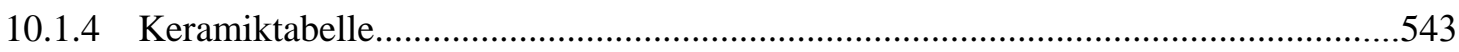

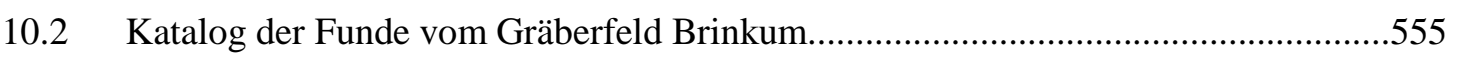

10.3 Vorbemerkungen zum Fundstellenkatalog für den Landkreis Leer................................559

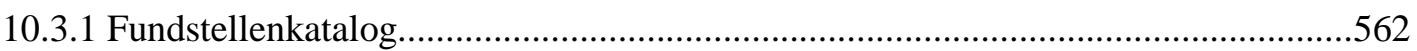

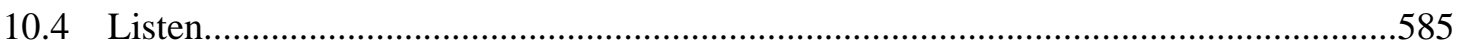

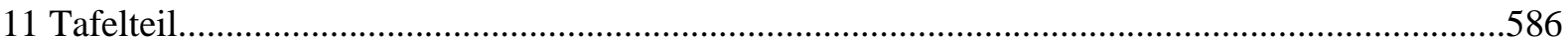




\section{Einleitung}

Gegenstand der vorliegenden Studie ist die Besiedlungsgeschichte im nordwestlichen Niedersachsen (Abb. 1). Der regionale Schwerpunkt liegt im Landkreis Leer (Ostfriesland). $\mathrm{Zu}$ den intensiv besiedelten Regionen zählen die Flussmarsch des Unteren Emsgebietes, insbesondere ihre Uferwälle, die flussnahen Flugsanddünen und Geestdurchragungen sowie die angrenzenden Geestränder. $\mathrm{Zu}$ verschiedenen Zeiten wurde auch die Hohe Geest aufgesucht.

Der gewählte Arbeitszeitraum umfasst die römische Kaiserzeit, widmet sich den wenigen Zeugnissen der Völkerwanderungszeit und schließt im Frühmittelalter mit dem 10. Jahrhundert ab. Die hochmittelalterliche Siedlungsphase wird exemplarisch behandelt, um nicht den Rahmen der Arbeit zu sprengen.

Die Arbeit knüpft im Westen an ein durch Mittel der Deutschen Forschungsgemeinschaft finanziertes Projekt über die Besiedlungsgenese des Reiderlandes an, die vom Niedersächsischen Institut für historische Küstenforschung in Wilhelmshaven durchgeführt wurde (1962 bis 1972). Der nach Osten anschließende Oldenburger Raum ist Bestandteil eines Dissertationsvorhabens über die kaiser- und völkerwanderungszeitliche Siedlung Gristede, Landkreis Bad Zwischenahn (KAUFMANN in Vorbereitung). Nach Norden und Süden begrenzten siedlungsfeindliche Hochmoore, die ehemals der Oldenburgisch-Ostfriesischen Geest vorgelagert waren, das Untersuchungsgebiet.

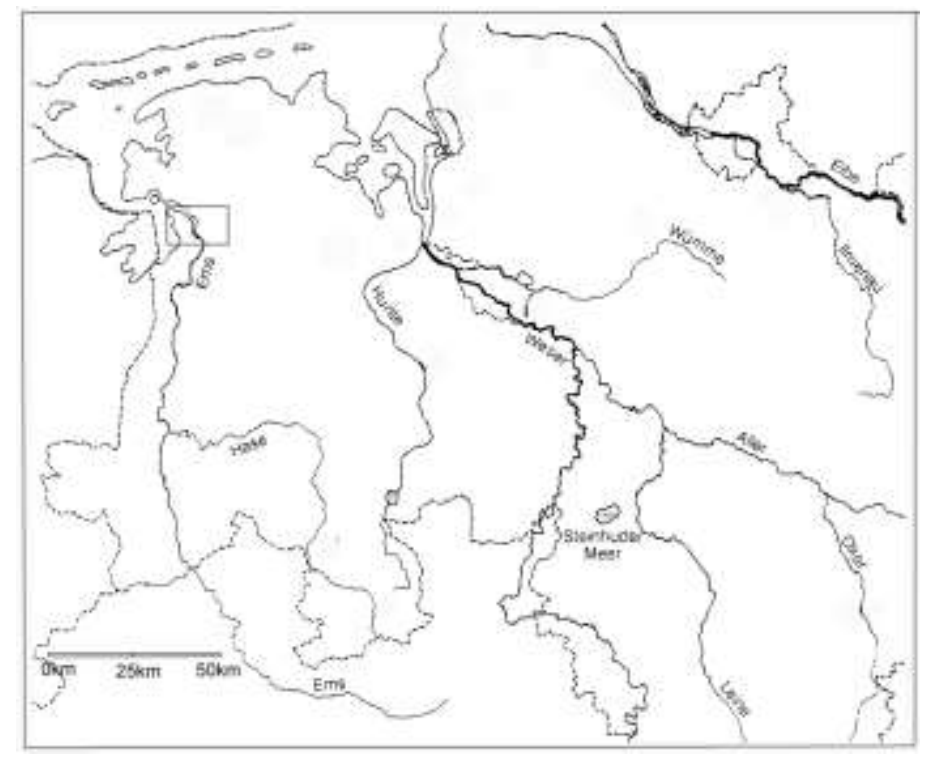

Abb. 1

Norddeutschland mit der historischen Küstenlinie um 1500.

Das Untersuchungsgebiet ist schwarz umrandet.

Ausgangspunkt der vorliegenden Untersuchung ist der mehrphasige Siedlungsplatz Nortmoorer Hammrich. Bei den Ausgrabungen in den Jahren 1996 bis 1998 wurde umfangreiches Fundmaterial 
der römischen Kaiserzeit (um Christi Geburt bis ca. 350 n. Chr.) und des Früh- und Hochmittelalters (um 900 bis 1150 n. Chr.) geborgen. Die Siedlung zeichnet sich durch verschiedene Hofkomplexe, bestehend aus Wohn- und Speicherbauten, Brunnen, Werkgruben und Umgebungszäunen aus. Aufgrund der weitgehend ungestörten Stratigraphie und der guten Erhaltungsbedingungen für organisches Material werden detaillierte Aussagen zur Wirtschafts- und Siedlungsweise ermöglicht. Gute chronologische Differenzierungen erlauben die $\mathrm{zu}$ verschiedenen Zeitphasen erfolgten Kleiablagerungen, die im Randbereich der Nortmoorer Düne Funde wie auch Befunde überdeckten.

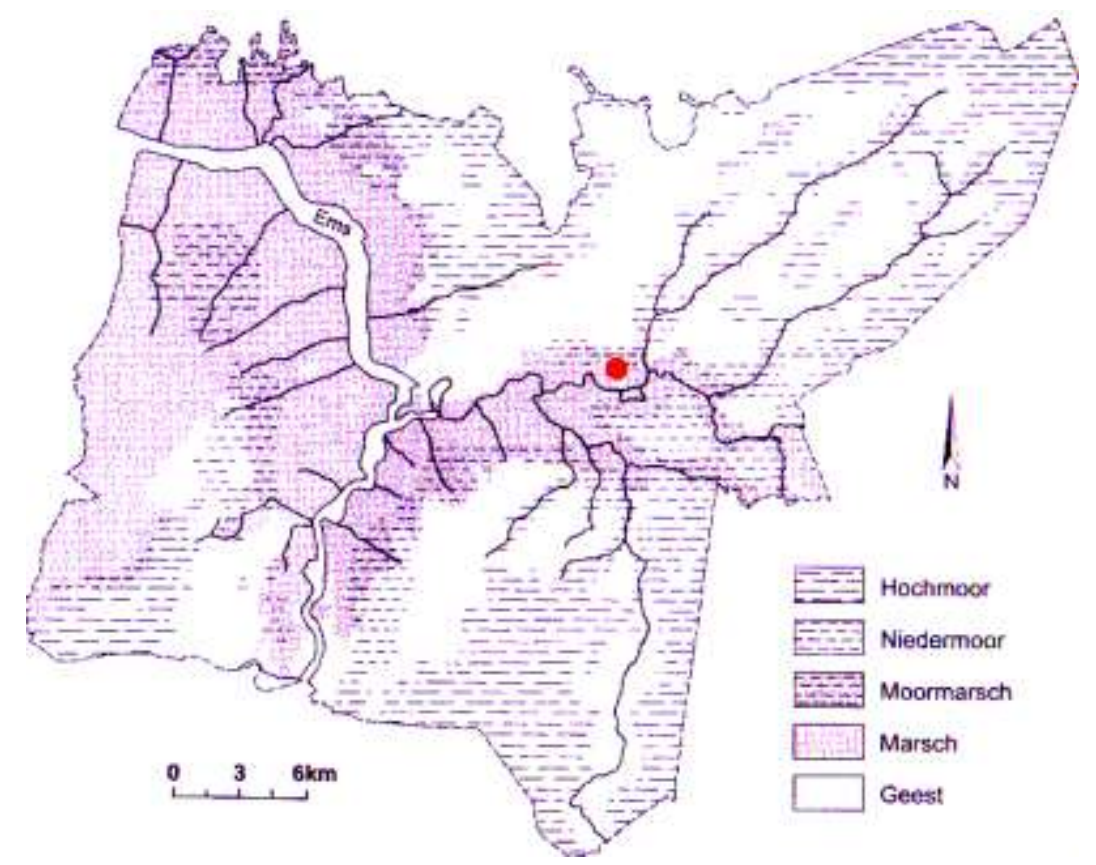

Abb. 2

Das Arbeitsgebiet und der Naturraum im Landkreis Leer (Quelle: Ostfriesische Landschaft). rot: Lage des Fundortes Nortmoorer Hammrich.

Grundlage der Studie bildet die Analyse des datierenden Fundmaterials aus der mehrperiodischen Siedlung Nortmoorer Hammrich (Abb. 2). Die Funde werden getrennt nach den Zeitabschnitten römische Kaiserzeit bis Völkerwanderungszeit und frühes bis hohes Mittelalter vorgelegt. Neben einer Verfeinerung der Keramikchronologie wird ein Vergleich der Siedlungsstrukturen vor dem Hintergrund naturräumlich angrenzender Gebiete vorgenommen. Im Rahmen einer Referenzanalyse werden die nordöstlichen Niederlande (Ost-Groningen), das nördliche Emsland und die Wesermarsch herangezogen.

Seit der letzten summarischen Vorlage kaiserzeitlicher Siedlungs- und Bestattungsplätze in Niedersachsen durch RÖTTING 1985 ist eine erhebliche Zunahme des Quellenmaterials zu verzeichnen. Eine Vielzahl von Fundstellen ist bei Fundbergungen der letzen Jahrzehnte in 
Ostfriesland durch den Einsatz des Archäologischen Dienstes der Ostfriesischen Landschaft hinzugekommen. Größere kaiserzeitliche Siedlungskomplexe konnten im Landkreis Leer u.a. in Backemoor, Nortmoor und im Westerhammrich dokumentiert werden. Vor diesem Hintergrund können für das Untersuchungsgebiet Aussagen zu Hausbau, Siedlungsgröße und -struktur vertiefend vorgenommen werden, die es zugleich ermöglichen, die Region in die Hauslandschaft der Küstengebiete der südlichen Nordsee stärker einzubinden.

Ein Hauptanliegen der Arbeit ist es die kulturellen Eigenständigkeiten bzw. Abhängigkeiten anhand siedlungsarchäologischer und -geografischer Untersuchungen herauszuarbeiten. Insbesondere der Frage nach Kontinuität wie Diskontinuität für den untersuchten Zeitraum wird nachgegangen. Die günstige geographische Lage der Flussmarsch von Ems und Jümme war für die überregionalen Kontakte der lokalen Gruppen von nicht zu unterschätzender Bedeutung.

In die Studie einbezogen ist die archäologische Landesaufnahme der Makroregion. Dies umfasst die bis 2004 publizierten Siedlungs- und Bestattungsplätze sowie Einzelfunde in Fluss- und Moorgebieten. Einbezogen wurde die archäologische Landesaufnahme des Archäologischen Dienstes der Ostfriesischen Landschaft Aurich, des Niedersächsischen Landesdenkmalamtes Hannover und der Stiftung Preußischer Kulturbesitz Berlin-Charlottenburg. Eingang in die Arbeit fanden eine große Zahl an Vorberichten aus der Fundchronik des Emdener Jahrbuches, den archäologischen Mitteilungen aus Nordwestdeutschland und den Nachrichten aus Niedersachsens Urgeschichte.

\subsection{Forschungsgeschichte und -stand}

Erste Ansätze einer wissenschaftlichen Dokumentation archäologischer Fundstellen erfolgten 1879 mit der Schrift von TERGAST über „die heidnischen Alterthümer Ostfrieslands“. Bereits 1893 erfassten MÜLLER/REIMERS die damals bekannten ostfriesischen Bodendenkmäler. Ihre Arbeit wurde von ZYLMANN (1933) zu einer schematischen Gesamtdarstellung der ostfriesischen Urgeschichte vollendet und um den Bestand aller ostfriesischen Museen und Sammlungen ergänzt.

Kleinere Grabungen erfolgten im Untersuchungsgebiet bereits ab den 20er Jahren des 20. Jahrhunderts unter Mitwirkung von VAN GRIFFEN und dem „Verein zur Errichtung einer Altertümersammlung“. Hervorzuheben sind die Aktivitäten in Emden-Nesserland (1922) und in Bentumersiel (1929). Das unstratifizierte Material aus Jemgumkloster (später umbenannt in Bentumersiel) mit seinen römischen Funden wurde grob in das 1. bis 4. Jahrhundert n. Chr. datiert (ZYLMANN 1930, 27-34). Die annähernd zeitgleiche reiderländische Siedlung Eppingawehr ist bisher nur als Vorbericht publiziert (SCHROLLER 1936). Derzeit wird das Fundmaterial von Herrn JaN KLAUKE im Rahmen einer Magisterarbeit am Seminar für Ur- und Frühgeschichte der Universität Göttingen bearbeitet.

In den 1930er Jahren ließ das Provinzialmuseum Hannover weitere Notbergungen im Landkreis Leer vornehmen. 1936 untersuchten HAARNAGEL und GENRICH östlich von Leer das kaiserzeitliche 
Brandgräberfeld Amdorf nahezu vollständig. Es kamen weitere Notbergungen in Logabirum, Eppingawehr und Nortmoor-Plaggenburg hinzu. Die Dokumentationen dieser frühen Grabungen gelten als weitgehend verschollen.

Neben Fundmeldungen und kleineren Aufsätzen lagen lange Zeit nur wenige umfassende Untersuchungen zum kaiserzeitlichen Besiedlungsgeschehen in Ostfriesland vor. ERDNIß (1939) gab in seiner Dissertation über „Die Chauken, ihre räumliche Abgrenzung auf Grund der Bodenfunde“ erstmals eine zusammenfassende Übersicht des kaiserzeitlichen Fundmaterials aus dem Küstengebiet der südlichen Nordsee. Die Beschränkung auf Einzelfunde und die geringe Anzahl der vorliegenden Grabungen ermöglichte kaum Aussagen über die kulturelle Stellung der Region. Durch den 2. Weltkrieg inhibiert, konnte der zugehörige Tafelteil mit der Keramik des 1. bis 3. Jahrhunderts n. Chr. erst 1965 publiziert werden (SCHMID 1965). Der regionale Schwerpunkt dieser Studie lag nun jedoch im Elbe-Weser-Gebiet, während ostfriesisches Keramikmaterial nur vereinzelt behandelt wurde. SCHMID griff bei der Bearbeitung der Marschenkeramik zudem auf südelbische Urnenbestattungen zurück, deren kaiser- und völkerwanderungszeitliche Funde PLETTKE bereits 1920 vorgelegt hatte.

Aufgrund des schlechten Forschungsstandes für Keramikformen der älteren Kaiserzeit im Elbe-WeserDreieck war damals eine stärkere Einbeziehung von Grabinventaren aus Schleswig-Holstein erforderlich. Als Basis einer lokalen Keramiktypologie für die jüngere Kaiserzeit im Nordseeküstengebiet diente u.a. das Gräberfeld Westerwanna. Für die Region Cuxhaven gelang es WALLER einen älterkaiserzeitlichen Gräberfeldhorizont herauszuarbeiten (WALLER 1933; 1936; 1959; 1960). Eine Gesamtvorlage aller Grabinventare unterblieb bisher. Für das umfangreiche Fundmaterial von Altenwalde wird dies nachgeholt (FUNKE, in Vorbereitung).

Eine grundlegende Studie zu Keramikgruppen aus dem Gebiet der südlichen Nordsee legte TISCHLER vor (TISCHLER 1937; 1954). Für die ältere römische Kaiserzeit stellte er anhand des Gräberfeldes Fuhlsbüttel Zweihenkel- und Dreiknubbentöpfe als charakteristisch heraus. SCHMID orientierte sich an den von TISCHLER vorgelegten Kriterien und ergänzte diese durch stratigraphisch geborgene Keramik aus den Marschengrabungen (SCHMID 1969d).

Bei der Beurteilung kaiserzeitlicher Keramik stützen sich bis heute viele Studien auf die USLARSCHE Arbeit zu Westgermanischen Bodenfunden aus Mittel- und Westdeutschland (UsLAR 1938). Selbst neuere Arbeiten adaptieren das dortige Typologie- und Chronologieschema vorbehaltlos, wie SCHMIDT 2002 bei der Aufarbeitung älterkaiserzeitlicher Fundkomplexe in Südniedersachsen. Mit Ausnahme von Uslar II ist jedoch die unscharfe Formenansprache zu hinterfragen.

Der Kenntnisstand über die kaiserzeitliche Besiedlung in Ostfriesland konnte seit dem durch umfangreiche Grabungsaktivitäten erheblich erweitert werden. Im Zentrum interdisziplinär ausgerichteter Forschungen des Niedersächsischen Landesinstitutes für historische Küstenforschung 
Wilhelmshaven standen die reiderländischen Orte Jemgumkloster, Bentumersiel und HatzumBoomborg. Konzentrierten sich die siedlungsarchäologischen Untersuchungen auf den Emsuferwall (BRANDT 1972, 1974, 1977a), so bezogen die landschaftsgeologischen Studien auch das Hinterland mit ein (BEHRE 1970, 1972).

In der Emsuferwallsiedlung Bentumersiel waren die oberen Siedlungshorizonte vor Beginn der Grabungen bereits durch Tonentnahme einer nahen Ziegelei zerstört. Es gelang jedoch die ältesten Schichten zu erfassen, die den Siedlungsbeginn in die Spätlatènezeit datieren. In den zwei folgenden Horizonten fanden sich jeweils Überreste eines dreischiffigen kaiserzeitlichen Hallenhauses ohne Stallteil. Speicherbauten und Viehställe komplettieren die Hofanlage.

Erst der dritte Siedlungshorizont wies einen auffällig hohen Anteil römischer Importfunde auf, die zwei verschiedenen Zeithorizonten angehörten (UlbERT 1977). Frühsüdgallische Terra Sigillaten sowie Metallfragmente römischer Militaria der spät-augusteisch-tiberischen Zeit stehen vermutlich mit römischen Truppenbewegungen im Gebiet der Unteren Ems in Zusammenhang und kennzeichnen die Fundstelle als ein Versorgungsdepot (BRANDT 1977a). Dies korreliert mit den aufgedeckten Befunden, die als bestimmendes Element der Siedlung eine auffällig hohe Anzahl an Zäunen, Gräben und Wegen aufwiesen; im Gegensatz zur eher lockeren Bebauung des Gesamtareals. In das 2. bis 3. Jahrhundert $\mathrm{n}$. Chr. datieren die übrigen römischen Funde, die aus verschiedenen Manufakturen vom Rhein und aus Gallien stammen und Ausdruck für Handel und Austausch mit der Germania libera sind. Eine Bearbeitung der einheimischen Keramik erfolgte bisher nicht.

Bei der Untersuchung der Nachbarsiedlung Hatzum-Boomborg gelang es LÖBERT (1982) eine Parallelisierung des jüngeren Fundhorizontes mit dem Siedlungshorizont 3 von Bentumersiel vorzunehmen. Infolge des auftretenden römischen Imports kann dieser Horizont in die 1. Hälfte des 1. Jahrhunderts n. Chr. datieren werden (LÖBERT 1982, 84-85, 95). Darüber hinaus ist eine chronologische Gliederung der Keramik des jüngeren Fundhorizontes nicht möglich. Für das 4./5. Jahrhundert n. Chr. deutet der geringe Fundniederschlag auf einen Abbruch der Besiedlung in Hatzum-Boomborg hin.

Für die Flussmarsch der Ems wird eine zeitgleiche Errichtung sowohl von Flachsiedlungen als auch von erhöhten, eher bäuerlich geprägten Wohnplätzen belegt; vermutlich begründet in einer differenzierten Wirtschaftsweise (BRANDT 1974, 73). Konnte die zu ebenere Erde gelegene Umschlagplatz Bentumersiel infolge der höher auflaufenden Winterfluten meist nur in den Sommermonaten genutzt werden, ermöglichte eine Niveauerhöhung bei der benachbarten Siedlung Jemgumkloster eine ganzjährige Nutzung.

Während noch vor kurzem der Forschungstand im südlichen Ostfriesland von 19 kaiserzeitlichen Siedlungen am linken Emsufer dominiert wurde (BRANDT 1977, Abb. 1; RÖTTING 1985, Beilage 1), gelang inzwischen auch für das gegenüberliegende Ufer der Nachweis eines intensiven Siedlungsgeschehens. Vorberichte liegen aus dem Stadtgebiet Leer im Westerhammrich und bei 
Hohegaste vor (BÄRENFÄNGER 1993a; STILKE 1995). Bei dem zuletzt genannten Fundort setzt die Besiedlung im 1. Jahrhundert n. Chr. ein und weist einen deutlichen Fundschwerpunkt im 2. bis 3. Jahrhundert n. Chr. auf.

Weitere kaiserzeitliche Siedlungsspuren sind aus dem Hinterland der Ems bekannt, wobei ihre flussorientierte Lage auffällt. Wenige Kilometer von Leer entfernt sind dies die größeren Siedlungen Nortmoorer Hammrich und Backemoor (vgl. BÄRENFÄNGER 1997, 347-348; BÄRENFÄNGER 2000, 99102; BUSCH-HELLwIG 2008). Gemeinsam ist beiden ihre Lage auf einer Geestdurchragung, die von einer fruchtbaren Niederungszone umgeben war.

Von der ostfriesischen Geest liegen neuere Arbeiten vor, die sich mit kaiserzeitlichen Siedlungen aus dem Landkreis Wittmund beschäftigen (GROTELÜSCHEN 2000; LEHMANN 2002; KREIBIG 2006).

Der geestrandnahe Siedlungsplatz Nenndorf wurde bereits am Ende des 1. Jahrhunderts v. Chr. aufgesucht. Eine kontinuierliche Besiedlung setzte im 1. Jahrhundert ein und bestand im nördlichen Siedlungsbereich bis in die Mitte des 2. Jahrhunderts n. Chr. Am Fundmaterial zeigen sich Kultureinflüsse aus verschiedenen Regionen. Verbindungen zum Elbe-Weser-Dreieck belegen die vorkommenden Trichterschalen. Ebenfalls adaptiert wurden Verzierungsmuster niederrheinischwestfälischer Keramikformen. Den herrschenden friesischen Einfluss geben weitmündige Töpfe, vergleichbar denjenigen aus der niederländischen Terpenregion, wieder (GROTELÜSCHEN 2000, 38).

Bei der Erweiterung des Nenndorfer Baugebietes 2002 wurden erneut kaiserzeitliche Baubefunde aufgedeckt, die eine platzkonstante Besiedelung bis in das 3. Jahrhundert n. Chr. belegen (KREIBIG 2006). Auf überregionale Handelsbeziehungen weisen Terra Nigra Keramik, rheinische Basaltlava und der, in Ostfriesland bisher singuläre, Fund eines römischen Fingerhutes aus Messing hin. Zudem gelang für den norddeutschen Raum erstmalig der Nachweis eines Speichergebäudes römischen Typs (KREIBIG 2006, 52-56). Bautechnisch ähnliche Speicher stammen aus der Siedlung Rijswijk, Provinz Friesland (BLOEMERS 1978).

Die Geestsiedlung Brill wurde in den Jahren 1966 und 1976 von der Archäologischen Forschungsstelle Aurich freigelegt (SCHWARZ 1979). Unter Einbeziehung von 20 weiteren kaiserzeitlicher Fundstellen rekonstruiert LEHMANN 2002 die Siedlungskammer der Briller Gaste. Unberücksichtigt bleibt bei dieser siedlungsgeographischen Betrachtung das zugehörige Fundmaterial der Fundstellen im Umfeld der Siedlung Brill. Primär erstellt der Autor eine Typochronologie der lokalen kaiserzeitlichen Keramik und datiert die verschiedenen Randfragmente auf 100 Jahre. Um Christi Geburt setzte die lokale Entwicklung situlenartiger Gefäße mit geschweiften Unterteil ein und wurde im 2./3. Jahrhundert von Trichtergefäßen abgelöst. Für das 3./4. Jahrhundert dominierten weitmündige Topfformen gefolgt von Trichterpokalen, zweigliedrigen und steilwandigen Schalen. Im 5. Jahrhundert überwogen im Formenrepertoire weitmündige, schwach s-förmige Gefäße und engmündige Töpfe mit stark ausgewendetem Rand. Die kulturelle Einordnung des kaiserzeitlichen 
Siedlungsmaterials weist auf überregionale Kontakte in die nördlichen Niederlande und das WeserEms-Gebiet hin. Hingegen fehlen Rhein-Weser-germanische Ornamente, die erst weiter südlich an Einfluss gewinnen (LEHMANN 2002, 183).

Für die Siedlung Brill konnten 21 Langhäuser mit Nebengebäuden und Pfostenspeicher sowie eine große Anzahl an Grubenhäusern aus dem Befundplan herausgearbeitet werden. Vergleichbar den Häusern der Feddersen Wierde wurden abgewalmte Dächer rekonstruiert. Der Nachweis von Steilgiebeln, wie sie aus Flögeln vorliegen, gelang nicht. Auch fehlten bei den Briller Gebäuden konstruktive Übereinstimmungen zur niederländischen Hauslandschaft. Für Brill wird eine kontinuierliche Besiedlung vom 1. bis in die erste Hälfte des 5. Jahrhunderts mit höchstens drei zeitgleich bestehenden landwirtschaftlichen Betrieben festgestellt. Damit grenzt sich die Siedlung deutlich gegen die in der Gemarkung wandernden Siedlungen ab (vgl. SCHMID 1977a, 36). Die einheimische Bevölkerung auf der ostfriesischen Geest nahm nur in geringem Umfang sächsische Verzierungsformen auf, während im Land Wursten der neue kulturelle Einfluss erheblich größer war (vgl. BÄRENFÄNGER et al. 1997a, 45).

Ab dem 2. Jahrhundert v. Chr. kommt es im Küstenraum der südlichen Nordsee zur Gründung zahlreicher Flachsiedlungen (SCHMID 1982, 77). Im 1. Jahrhundert sind es zunächst Einzelgehöfte mit ihren Nebenbauten, die eine kleine bäuerliche Landwirtschaft betreiben. Der Marschensaum wird zunehmend dichter besiedelt. Mit Einsetzen höherer Sturmflutpegel wurden in der jüngeren Kaiserzeit zunächst Einzelpodeste für die Wohnbauten errichtet, bevor diese schließlich zu dorfartigen Siedlungen zusammenwuchsen.

Eine Veränderung in der Siedlungsstruktur ist seit dem 2. Jahrhundert n. Chr. auch auf der Geest festzustellen. Die bis dahin vorherrschenden, verstreut liegenden Einzelgehöfte ordneten sich nun dorfartig um zentrale Plätze an (SCHWARZ 1997, 272), die sich von der Umgebung durch Zäune abgrenzten (ZIMMERMANN 1992, 21). Für den Landkreis Wittmund ist eine Abnahme der Fundstellenzahl während der Kaiserzeit festzustellen. Dies wurde jedoch nicht notwendigerweise durch eine Bevölkerungsreduktion herbeigeführt (SCHWARZ 1997, 268, 271, Abb. 2). Vielmehr wird dieses Verbreitungsbild als Folge einer veränderten Siedlungsstruktur angesehen, hinter der sich ein Wandel der gesellschaftspolitischen Organisationsform und / oder der Wirtschaftsweise wiederspiegelt (SCHWARZ 1999, 24). In Flögeln kommt es auch im 4./5. Jahrhundert noch nicht zur Auflösung des bestehenden Dorfes. Zwar entzerrt sich die bisher kompakte Siedlungsstruktur der sieben Einzel- und Mehrbetriebsgehöfte etwas, dennoch scheint der Charakter einer gemeinsamen Siedlung beibehalten worden zu sein (ZIMMERMANN 1992, 21).

Die Völkerwanderungszeit fand lange Zeit nur wenig Beachtung. Erst SCHMID (1965b, 1969c) legte eine zusammenfassende Betrachtung sächsischer Kulturelemente im nordwestdeutschen Küstengebiet vor. Mit dem Aufkommen neuer Keramikformen, deren Ursprung in den sächsisch besiedelten 
Gebieten östlich der Weser liegt, nimmt die einheimische Ware ab. Für das niedersächsische Küstengebiet wird im 6. Jahrhundert ein völliger Abbruch der Siedlungstätigkeit postuliert (NIEMEIER 1972). Dies legt auch die von JACOB-FrIESEN (1974, 619) für diese Zeit festgestellte relative Fundarmut in Ostfriesland nahe.

Es finden sich in letzter Zeit aber auch vermehrt Hinweise auf eine bis in das 6. Jahrhundert reichende Siedlungstätigkeit in Ostfriesland. Aufgrund der schwierigen Quellenlage ist der sächsische Horizont im Untersuchungsgebiet nur vereinzelt fassbar. Zwei völkerwanderungszeitliche Siedlungen liegen aus dem Landkreis Leer vor. In Loga-Leegkamp entdeckte man mehrere Hausgrundrisse und einen mit Spaltbohlen eingefassten Brunnen. Dendrochronologische Untersuchungen ergaben ein Fälldatum von „416 -6/+8“ und „417 -6/+8“ (BÄRENFÄNGER 1996, 358; 1997b, 457-458). Sächsische Keramik weist für die auf dem rechten Emsufer gelegene Siedlung Hohegaste auf eine bis in die Mitte des 5. Jahrhunderts reichende Siedlungsdauer hin (STILKE 1995b). Inwieweit der Fundhorizont der frühen Völkerwanderungszeit im Siedlungsmaterial des Westerhammrichs vertreten ist, wird erst eine genaue Materialvorlage klären (BÄRENFÄNGER in Vorbereitung).

Bei dem von SCHWARZ 1997 untersuchten Stichprobengebiet an der Nordseeküste im Landkreis Wittmund zeigt sich eine bis in das 5. Jahrhundert reichende Siedlungskontinuität von einem großen Teil der bereits seit der römischen Kaiserzeit aufgesuchten siedlungsgünstigen Plätze (SCHWARZ 1997, 268, 271, Abb. 3). Eine vergleichbare Entwicklung nahm die Geestsiedlung Flögeln-Eekhöljen, wo es erst im frühen 6. Jahrhundert zu einer Siedlungsverlagerung kam (ZIMMERMANN 1992, 19).

Wurde bis vor kurzem davon ausgegangen, dass im Küstengebiet des Landkreises Wittmund die Siedlungen spätestens im 5. Jahrhundert aufgegeben wurden (SCHWARZ 1997, 272-273), so wird dies unter Berücksichtigung der Entdeckung einer frühmittelalterlichen Siedlung in Esens und der völkerwanderungs- und merowingerzeitlichen Altfunde aus Nordorf bei Esens im Landkreis Wittmund nur noch eingeschränkt haltbar sein (vgl. BÄRENFÄNGER 2000, 229-230, Abb. 18). Inzwischen belegen auch vegetationsgeschichtliche Untersuchungen aus Dunum und Rahe sowie archäologische Befunde aus Damsum, Schweinsdorf und Warnsath für das nördliche Ostfriesland eine bis in das 6 . Jahrhundert reichende Siedlungskontinuität (BÄRENFÄNGER 2001, 288). Bisher konnte die Frage nach Hiatus oder Fundlücke jedoch nicht zweifelsfrei geklärt werden.

Erst im frühen Mittelalter setzte eine verstärkte Auf- bzw. Neubesiedlung Ostfrieslands ein. Bevorzugt aufgesucht wurden vorher unbesiedelte Gebiete auf der Geest und in der Marsch (WASSERMANN 1985; REINHARDT 1969). In der Emsmarsch untersuchte BRANDT (1979) die reiderländischen Orte Jemgum und Hatzum. Neben Bohrprofilen von beiden Plätzen liegen derzeit nur aus Hatzum Grabungsergebnisse vor, nach denen sechs von sieben Siedlungshorizonte in das Frühmittelalter datieren. Fand die Gründung der Siedlung im 7./8. Jahrhundert noch zu ebener Erde auf dem Uferwall statt, erfolgte bereits im ausgehenden 8. Jahrhundert eine künstliche Niveauerhöhung. Die 
Straßenorientierung der Hausgiebel sowie die bei beiden Orten gemeinsame Lage an einem schiffbaren Wasserlauf weisen auf einen neuen Typ der Handwerker- und Handelssiedlung hin, zu der auch die frühstädtische Siedlung Emden gehört (BRANDT 1977b). Die von HAARNAGEL (1959; 1984) geleitete Stadtkerngrabung auf der Emdener Langwurt ist von maßgeblicher Bedeutung für den Forschungsstand zu frühstädtischen Siedlungen an der deutschen Nordseeküste. Eine Korrelation der Siedlungshorizonte verschiedener Schnittflächen wird jedoch erschwert durch die in künstlichen Straten durchgeführte Grabung.

Erst STILKE nimmt 1995 eine Angleichung der Schichten unter chronologischen Aspekten vor (STILKE 1995a). Mit der Aufarbeitung des keramischen Fundmaterials wird eine grobe Einteilung in drei künstliche Schichten pro Jahrhundert ermöglicht. In der Gebrauchskeramik dominiert im Frühmittelalter muschelgrusgemagerte Grauware (STILKE 1993a). Sie tritt ebenfalls im Nortmoorer Hammrich auf und lässt von einem erneuten Einsetzen der Besiedlung im späten 8. Jahrhundert ausgehen. Bislang ist die Herkunft dieser, im südlichen Nordseeküstenraum typischen, Warenart nicht schlüssig geklärt.

Für das frühmittelalterliche Siedlungswesen im Untersuchungsgebiet sind bäuerliche Gehöftsiedlungen kennzeichnend, wie sie im Landkreis Leer sowohl in Hollen (SCHWARZ 1995b; SCHÄFER in Vorbereitung) als auch in Hesel, dort mit insgesamt 13 Hofanlagen (BÄRENFÄNGER 1994), vorliegen. Anhaltspunkte auf eine soziale Schichtung haben Ausgrabungen der „Alten Boomborg“, einer frühmittelalterlichen Burganlage bei Hatzum im Reiderland erbracht. Die zugehörige Siedlung wurde um 900 ebenerdig gegründet und erst im 10./11. Jahrhundert erhöht (BRANDT 1977b). Hinweise auf überregionale Kontakte geben zwei aus der Leda bei Leer geborgene fränkische Schwerter des 8./9. Jahrhunderts (STEIN 1967). Ein Schatzfund von ca. 800 Sceattas bei Hesel zeigt bereits für diese Zeit einen entwickelten Handelsverkehr mit Geldumlauf an (BERGER / STOESS 1988, 120-122).

In Dunum konnten die Standorte zugehöriger Gehöfte am Rande der frühmittelalterlichen Siedlungskammer lokalisiert werden. Mit Umstellung der Wirtschaftsweise auf den intensiven Roggenbau entwickelten sich neue Siedlungsstrukturen und platzkonstante Dörfer (BEHRE 1976). Untersuchungen in der Wesermarsch und im Oldenburger Raum weisen auf einen ähnlichen Siedlungsvorgang hin (FÖRST 1991; ZOLLER 1972 a).

In Bezug auf Grabfunde ist eine schlechte Quellenlage zu vermerken. Kaiserzeitliche Gräberfelder sind aus der Region nördlich und östlich der Jümme in geringem Umfang bekannt, jedoch alt gegraben und selten dokumentiert. In den 30er Jahren des 20. Jahrhunderts wurden bei Straßenbauarbeiten Urnengräber bei Leer, Nortmoor-Plaggenburg und Detern aufgedeckt (SCHMID 1965b). Lange Zeit nur als Fundplatznotiz bekannt war das Gräberfeld von Bonnhausen/Amdorf nahe Leer (ERDNIB 1939, 30). 
Bei der Sichtung des Materials 1997 fand sich neben kaiserzeitlicher auch römische Keramik, die neben der Terra Sigillata der Barbotine-Ware angehören (ROSENPLÄNTER 2002, 244-246, Taf. 1-5).

Völkerwanderungszeitliche Bestattungen fehlen nach bisherigem Kenntnisstand im Untersuchungsgebiet. Indessen gelang es aus dem Wattenmeer vor Ostbense im Landkreis Wittmund zwei Körperbestattungen der frühen Völkerwanderungszeit zu bergen, die mit umfangreichen Beigaben versehen waren (BÄRENFÄNGER et al. 1997). Die frühmittelalterliche Siedlungskammer Dunum mit ihrer zentralen Nekropole wurde von REINHARDT (1969) und SCHMID (1972; 1984b) untersucht. Bei dem einzigen fast vollständig untersuchten Gräberfeld Ostfrieslands mit 778 Gräbern des späten 7. bis 10. Jahrhunderts erschließt sich anhand der fünf Gräbergruppen eine soziale Differenzierung. Eine Kartierung von Gräberfeldern der Merowinger- und Karolingerzeit in Niedersachsen legten 1979 HELLFAIER und LAST vor. Erneut mit Grabfunden des 8. und 9. Jahrhunderts im nördlichen Randgebiet des Karolingerreiches beschäftigte sich KLEEMANN (2002). Er verweist für das südliche Ostfriesland auf zwei einzelne Körpergräber in Holtland und Filsum. Die Brinkumer Urnengräber werden anhand ihrer Beigaben in das 7./8. Jahrhundert n. Chr. datiert (KLEEMANN 2002, 320, Abb. 106).

Der derzeitige Bearbeitungsstand kaiser-, völkerwanderungszeitlicher und frühmittelalterlicher Siedlungen über das nordwestliche Niedersachsen hinaus stellt sich regional uneinheitlich dar. Aus dem erweiterten Umfeld liegen Publikationen einzelner Siedlungsgrabungen vor. Von 1969 bis 1976 beschäftigte sich ein DFG-Schwerpunktprogramm intensiv mit der vor- und frühgeschichtlichen Besiedlung im Nordseeküstenraum. In diesen Kontext gehören die Siedlungen Feddersen Wierde (HAARNAGEL 1959; 1964; 1979), die Siedlungskammern Gristede (ZOLLER 1972a, 1972b) und Flögeln (SCHMID/ZIMMERMANN 1976). Die Untersuchung in Flögeln-Eekhöltjen vermittelt wichtige Einblicke in die Siedlungsstruktur einer Geestrandbesiedung des 1. bis 6. Jahrhunderts n. Chr. Ein überregionaler Vergleich der Haus- und Siedlungsformen wird jedoch durch die fehlende Komplettvorlage aller Befunde erschwert. Auch steht eine Gesamtpublikation der Funde noch aus. Derzeit nur in Vorberichten liegt die Siedlung Gristede im Landkreis Ammerland vor (ZOLLER 1972a, 1972b; KAUFMANN in Vorbereitung). Zusammenfassende Untersuchungen zum kaiserzeitlichen Hausbau erfolgten durch TRIER (1969) und BRABANDT (1993). BRABANDT gelang allerdings keine Neugliederung des bis dahin publizierten Hausbestandes.

Intensive Betrachtungen zur Besiedlungsgeschichte existieren für das Elbe-Weser-Gebiet (SCHÖN 1988; SCHMID/ZIMMERMANN 1976; ZIMMERMANN 1991, 1992), Ost-Groningen (GROENENDIJK 1993), das mittlere Niedersachsen (RADDATZ 1981) und Nordostniedersachsen (HARCK 1972/73; NÜSSE 2003). Die Besiedlungsgeschichte der Flussmarsch im Kreis Wesermarsch wurde von FöRST (1991) aufgearbeitet. Ihre Stufengliederung belegt für die Flachsiedlung Huntebrück-Wührden eine 
Siedlungskontinuität von der Bronze- bis in die beginnende Völkerwanderungszeit. Wie die nur selten auftretenden Keramiktypen HW 2c und HW 3c belegen, kam es am Übergang zur Spätlatènezeit zu einem Besiedlungsrückgang, der vermutlich eine direkte Folge der Dünkirchen-I-Transgression darstellte. Die in der Mitte des 1. Jahrhundert v. Chr. einsetzende Regression begünstigte eine Wiederbesiedlung der Flussmarsch. Erst im 5. Jahrhundert brach die Besiedlung aufgrund der Dünkirchen-II-Transgression erneut ab. Im Unterschied zum Küstengebiet trat dieses Ereignis in der Flussmarsch zeitlich verzögert auf (FÖRST 1991, 110).

Aus den nördlichen Niederlanden liegen weiterführende Untersuchungen zum kaiserzeitlichen Siedlungswesen vor. Die in Wijster aufgedeckten Hausgrundrisse datieren in das 2. bis 5. Jahrhundert n. Chr. und konnten in sechs Konstruktionstypen eingeteilt werden (VAN Es 1967; 1970; VAN Es et al. 1998). Die Untersuchungen in Paddepoel bestätigten seine Forschungen (VAN ES 1968). Ebenfalls in der Provinz Drenthe ging WATERBolK der Frage der Siedlungskontinuität nach und entwickelte eine Haustypologie mit der Datierungen auf etwa 200 Jahre vorgenommen werden können (WATERBOLK 1979, 1982).

\section{Exkurs zum römischen Import im Unteren Emsgebiet}

Lange Zeit wurden dieselben Fundstellen mit römischem Import, wie sie bereits ZYLMANN 1933 durch die Aufnahme ostfriesischer Sammlungen bekannt machte, vorgelegt (EGGERS 1951). So zeigte sich die ostfriesische Geest zunächst weitgehend importfrei, während die Untere Emsregion eine Fundhäufung aufwies. Für den Landkreis Leer kartierte ERDRICH 2001 neun römischen Import führende Fundorte und neun weitere Stellen mit römischen Münzen (ERDRICH 2001, Beilage 1 u. 2). Jenseits der Unteren Ems wird bei ihm die Region in einem Radius von etwa 50km nahezu fundleer dargestellt und eine erhöhte Fundkonzentration ist erst wieder in der Wesermarsch und in der niederländischen Provinz Drenthe feststellbar. Jedoch können bei genauerer Betrachtung des vorliegenden Fundmaterials für die Untere Emsregion weitere römische Funde ergänzt werden.

Bei Ausgrabungen in den 90er Jahren des 20. Jahrhunderts wurden im Nortmoorer Hammrich sowohl Terra Sigillata, verschiedene Terra Sigillata Nachahmungen und mehrfach auch Terra Nigra gefunden. Ergänzt wird dies durch den Fund römischen Glases und eines Denar Kaiser Trajans. Aus der wenige Kilometer entfernten Siedlung Westerhammrich/Stadt Leer liegt eine römische Tutulusfibel und eine bronzene Marsstatuette vor. Die dort aufgefundene große Anzahl an Buntmetallfragmenten weist zudem auf eine lokale Bronzeverarbeitung hin (BÄRENFÄNGER 1993, 52-55).

Römische Münzfunde, deren Metallwert die lokale Bevölkerung schätzte und deren frühe Exemplare im 1. Jahrhundert n. Chr. vermutlich im Zuge römischer Truppenbewegungen nach Ostfriesland gelangten, stammen von verschieden Fundorten im Landkreis Leer (BERGER / STOESS 1988, 122-129). Eine größere Anzahl entdeckte man in Bentumersiel sowie zwischen Bingum und Soltborg. Ein um 1858 geborgener Münzschatz aus Filsum soll etwa 600 Denare enthalten haben und datierte in das 2. 
Jahrhundert n. Chr. Weitere römische Münzfunde aus Mooren und Niederungen liegen im südlichen Ostfriesland vor. Ein spätantiker Dupondius entstammte der Ems bei Weener. Auffällig ist den Münzfunden ihre Nähe zu Binnenflüssen, wie Ems, Leda und Jümme.

In Bezug zu älterkaiserzeitlichen Fibelfunden zeigte sich Ostfriesland lange Zeit fundleer (COSACK 1979, Karte 1). Ebenso fehlten für die Region zwischen Ems und Weser bei der von ERDRICH (1992; 2002) erfolgten Neuaufnahme römischer Funde in Niedersachsen sowohl Almgren VII,2-Fibeln wie auch Schalenfibeln. Funde aus der kaiserzeitlichen Siedlung Brill im Landkreis Wittmund belegen inzwischen, dass auch die ostfriesische Geest nicht völlig frei von römischem Import war. Neben einer römischen Emailfibel des 3. Jahrhunderts n. Chr. gelang hier der bisher einzige Nachweis römerzeitlicher Pigmentreste von Ägyptisch Blau in der Germania libera (LEHMANN 2003, 615-621). Römische Funde aus Ostfriesland fanden Eingang in verschiedene Studien. Die grundlegende Arbeit zu römischem Import im freien Germanien von EGGERS $(1951,1955)$ behandelt die seinerzeit bereits bekannten Funde, die er zu einem absolutchronologischen Schema ausarbeiten wollte (vgl. ERDRICH 2001, 4-5).

Mit dem römischen Warenverkehr in der Germania libera beschäftigte sich KUNOW (1983). In seiner Literaturstudie sieht er diesen durch römische Fernhändler abgewickelt, einen germanischen Zwischenhandel lehnt er jedoch ab. BERKE (1990) untersuchte römische Bronzegefäße, Terra Sigillata und germanische Fibeln im mitteleuropäischen Barbaricum, wobei eine aussagefähige chronologische Gliederung der Funde unterbleibt. Auch hier handelt es sich um eine reine Literaturarbeit. Im Unterschied dazu wird von LUND-HANSEN (1987) eine typologisch und chronologische Analyse der Originalfunde aus dem Skandinavischen Raum in Vergleich mit dem europäischen Barbaricum vorgenommen. 


\section{Abgrenzung des Arbeitsgebietes und seine naturräumliche Gliederung}

\subsection{Das Arbeitsgebiet}

Das Untersuchungsgebiet liegt im südlichen Ostfriesland und entspricht den heutigen Verwaltungsgrenzen des Landkreises Leer im Regierungsbezirk Aurich (Abb. 3). Naturräumliche Grenzen bildeten bis zu ihrer neuzeitlichen Kolonisation ausgedehnte Hochmoorflächen im Norden, Süden und Westen. Der heute landschaftsprägende Dollart formte sich erst infolge mittelalterlicher Sturmfluten und Meereseinbrüche heraus, die weite Bereiche des Reiderlandes neugestalteten. Die Oldenburgische Landesgrenze grenzt das Untersuchungsgebiet nach Osten hin ab.

Der Landkreis Leer umfasst die ostfriesischen Gemeinden Brinkum, Bunde, Detern, Filsum, Firrel, Hesel, Holtland, Stadt und Gemeinde Leer, Jemgum, Moormerland, Neukamperfehn, Nortmoor, Ostrhauderfehn, Rhauderfehn, Schwerinsdorf, Uplengen und Westoverledingen. Seit dem Mittelalter bzw. der frühen Neuzeit bestehen als Vorläufer der o.g. Gemeinden vier Landesverbände, zu denen das Moormer-, Lengener-, Overledinger- und Reiderland gehört.

Nicht berücksichtigt in der nachstehenden Studie wurde das Saterland südöstlich der Leda, da es verwaltungstechnisch dem Regierungsbezirk Oldenburg angehört.

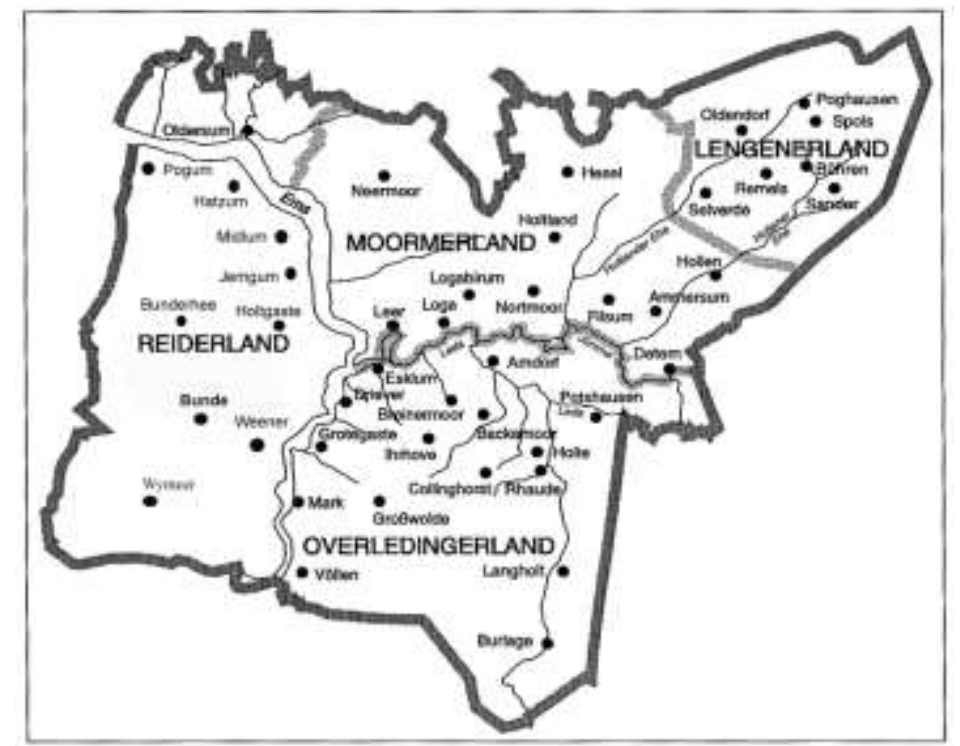

Abb. 3

Landschaften und Orte des Landkreises Leer (nach WIEMANN 1966).

Kartographisch wird das Untersuchungsgebiet durch die TK 50 Blatt: L 2710/Leer (Ostfriesland) abgedeckt, bezieht den angrenzenden Teil der TK 50 Blatt L 2708/Emden und L 2910/Papenburg mit ein. Ergänzend sei auf die TK 25 verwiesen: 2610/Moomerland, 2611/Hesel, 2612/Uplengen, 
2709/Dollart, 2710/Leer (Ostfriesland), 2711/Nortmoor, 2809/Bunde, 2610/Weener und 2811/Rhauderfehn.

Auf der Geestplatte des Moormerlandes befinden sich die Hauptorte Hesel, Holtland, Neermoor, Loga, Logabirum und Leer. Bereits in prähistorischer Zeit wurden Geestrücken und trockene Höhenlagen als Wegstrecken genutzt, da Hoch- und Niedermoore weite Teile des Moormer-, Overledinger- und Reiderlandes bedeckten. Ein alter Heerweg verlief entlang des Geestrandes parallel zur Jümme, ein weiterer Heerweg von Aurich über Hesel nach Leer (WIEMANN 1969, 440, Abb. 10). Gute Verkehrsanbindungen bestehen von Hesel über den Geestrücken unter anderem nach Holtland, Brinkum und Nortmoor sowie über die Jümme ins Oldenburgische Land. Nach Norden gelangt man von Hesel aus in das ostfriesische Binnenland.

Östlich der Geest schließt sich das ehemals durch ein Hochmoor stark zergliederte Lengenerland an. Zur Entwässerung dieser Region dienen die Holtlander und Holler Ehe. Hauptorte sind hier Remels, Oldendorf, Sander und Poghausen.

Südlich der Leda liegt das Overledingerland mit seinen Geestorten Backemoor, Collinghorst, Holte und Ihrhove. Auf dem Emsuferwall liegen eine Vielzahl von kleineren Marschendörfern, wie Esklum, Kloster Mühle, Driever, Grotegaste, Mark, Milting und Völlen.

Links der Ems erschließt sich die weite Moormarsch des Reiderlandes mit den uferparallelen Siedlungen Weener, Kirchbogum, Bingum, Jemgum, Mildlum, Citzum, Coldeborg, Ditzum und Pogum. Landeinwärts existieren mit Bunde und Diele nur wenige Altsiedlungen. Wymeer, Boen, Bunderhee, Böhmerwald und Marienchor sind spätmittelalterliche Siedlungen, die nach dem Aufstreckverfahren gründet wurden (WASSERMANN 1985, Beilage).

\subsection{Naturräumliche Gliederung Ostfrieslands}

Geest, Moor und Marsch sind die bestimmenden Landschaftsräume Ostfrieslands. Sie waren verschiedenen klimatischen wie auch vegetationsgeschichtlichen Veränderungen unterworfen und haben entscheidend den Siedlungsablauf beeinflusst.

Den Kern Ostfrieslands bildet eine im Pleistozän geformte Geest, die von einem nacheiszeitlichen Niedermoorstreifen umgeben war. Etwa im 4. Jahrtausend v. Chr. entstanden auf der Geest die bis in die frühe Neuzeit landschaftstypischen Hochmoore (BEHRE 1995, 47). Die NordoldenburgischOstfriesische Geest verläuft von Oldenburg bis Norden und besitzt eine annährend ovale Form. Sie ist durch die Hunte-Leda-Niederung von der Cloppenburger-Geest getrennt. Nach Süden schließt sich der südostfriesische Geestkern an, der zur Nienburg-Meppener-Geest einschließlich des Hümmlings gehört. An der Küste wird Ostfriesland von einem holozänen Marschengürtel begrenzt, der als Flussmarsch von Ems und Jümme bis zu 17km weit in das Landesinnere reicht (Abb. 4). 
Geringe Höhenunterschiede sind kennzeichnend für die Landschaftsgestalt der ostfriesischen Halbinsel. Während die Geest selten Geländehöhen von über $+15 \mathrm{~m}$ NN erreicht, liegen weite Bereiche der Marsch und der Niederungen um oder sogar unter 0m NN. Der aufgelandete Uferwall der Jümme weist beispielsweise Höhen von $+1,5 \mathrm{~m}$ NN auf, während das landseitige Sietland stellenweise bis auf $1 \mathrm{~m}$ NN abgesunken ist. Freepsum in der Krummhörner Marsch ist mit -2,4m NN sogar der am tiefsten gelegene Ort in Ostfriesland (SEEDORF 1992, 307, Abb. 161).

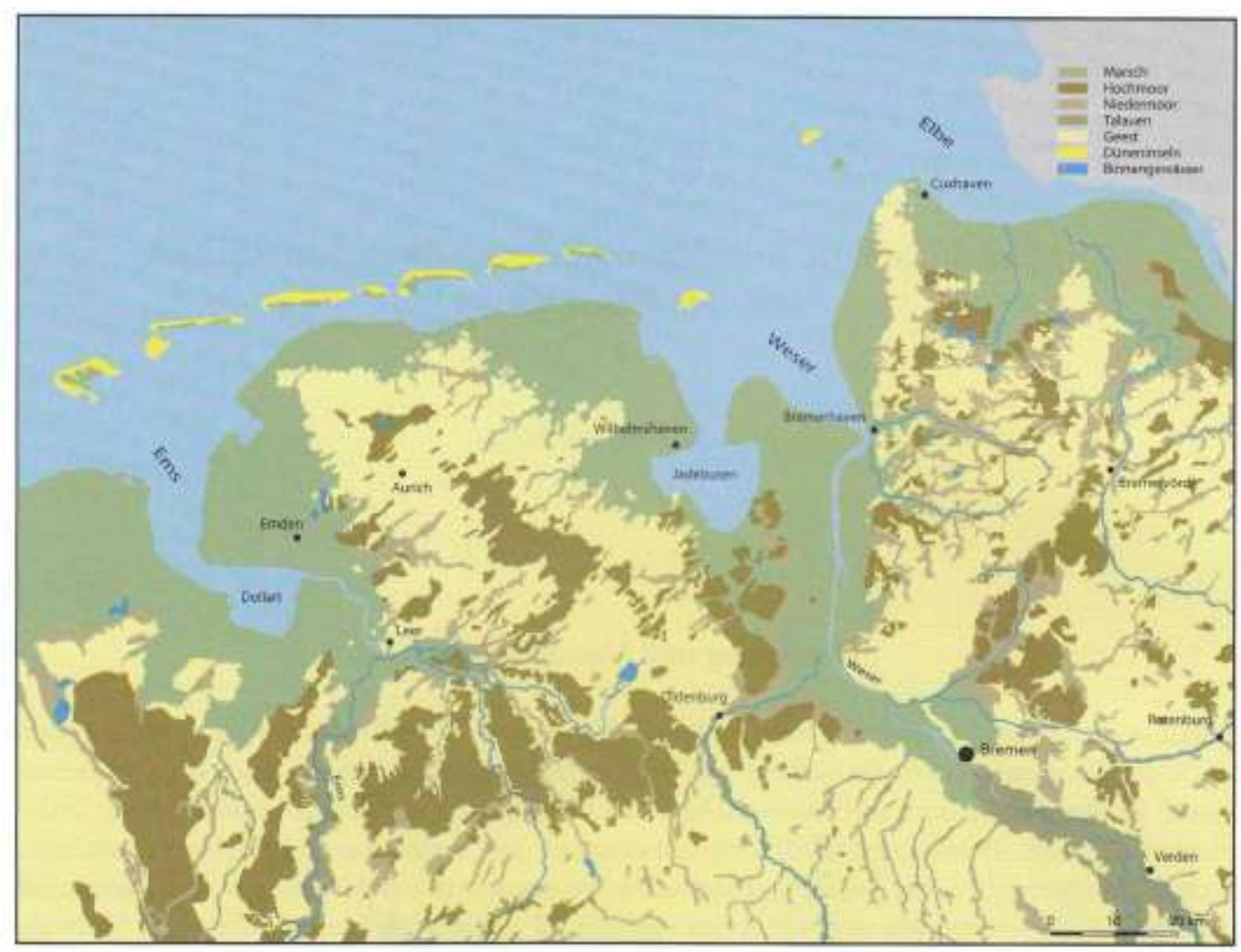

Abb. 4

Verteilung der Landschaftseinheiten im nördlichen Niedersachsen.

(nach BEHRE 1999, 13, Abb.1).

Behindert wird die natürliche Entwässerung des flachen Hinterlandes durch eine am Küstensaum höher aufsedimentierte „Junge Marsch“. Die Tieflage der „Alten Marsch“ schuf großflächige Vernässungsgebiete und erlaubt oft nur eine Grünlandnutzung. Landeinwärts geht der wasserreiche Boden in Moormarsch über oder grenzt unmittelbar an den Geestrand an (SEEDORF 1992, 127). Weite Bereiche der Geest weisen stauwasserführende Bodenschichten auf. Die hydrographischen Bedingungen im Küstenraum sind eng mit den Transgressions- und Regressionsphasen der Nordsee verknüpft. Dabei ist eine zentrale Fragestellung der historischen Küstenforschung das chronologische und kausale Verhältnis zwischen Besiedlungsvorgängen in der Marsch und den Phasen des Küstenholozäns. 
Eine differenzierte Standortbeschreibung unter Berücksichtigung der Bodentypen und des Ausgangsmaterials der Bodenbildung für das Untersuchungsgebiet erschließt sich über die Bodentypenkarte des Landesvermessungsamtes Hannover (Tafel 127-128). Die vier Hauptbodenarten Geest, Marsch, Moor und Moormarsch gibt die Abb. 5 wieder.

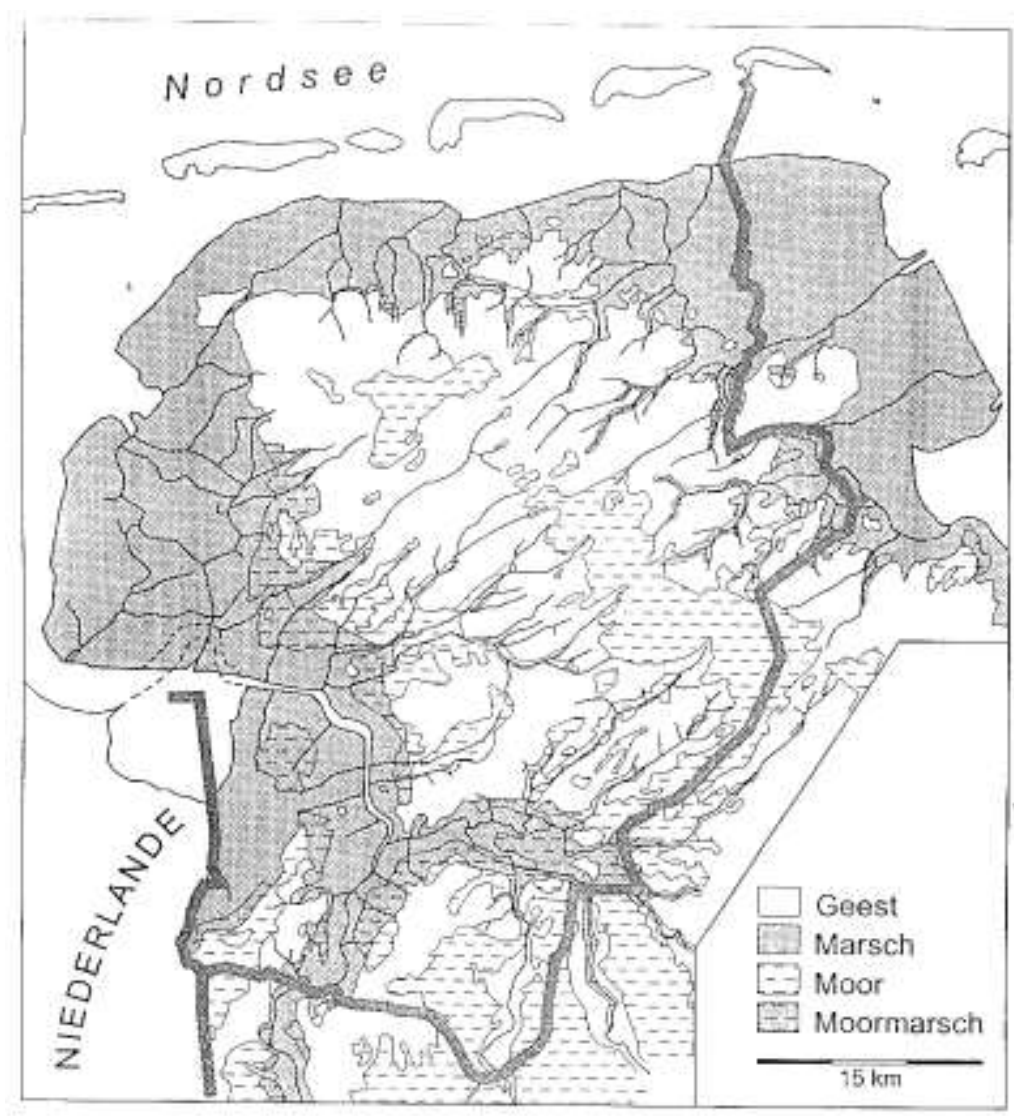

Abb. 5

Naturraum Ostfriesland. Böden vereinfacht nach der Bodenübersichtskarte (Quelle: Ostfriesische Landschaft).

\subsubsection{Geologischer Aufbau Ostfrieslands}

Während der Elster- und Saalekaltzeit erreichten skandinavische Gletscher den niedersächsischen Küstenraum. Im Zuge des Drenthe-I-Vorstoßes gelangte neben großformatigem Geschiebe feinmineralisches Material bis an den Ostrand des Unterwesertales. Die zurückgelassenen Grundmoränen formten die heutige Grundstruktur Ostfrieslands. Erosive Vorgänge führten zur Bildung zahlreicher von Südwest nach Nordost verlaufender Tälchen (STREIF 2000, 18-19, Tab. 1). Am Ende des Elster-Glazials setzten sich Beckensedimente in Bodensenken und subglazialen Rinnen ab. Das als Lauenburger Ton bezeichnete Füllmaterial ist ein wichtiger geologischer Leithorizont. Seine Sedimente erstrecken sich nördlich von Groningen bis ins schleswig-holsteinische Lauenburg. 
In der Eem-Warmzeit kam es erstmals zur Bodenbildung und Ausbreitung einer wärmeliebenden Waldflora, die im Frühglazial durch Tundrenvegetation ablöst wurde (SEEDORF 1992, 82). Die eemzeitlichen Flüsse Ems und Weser orientierten sich in ihrem Verlauf an saalezeitlichen Schmelzwasserrinnen. Der Rand des Warthe-Endmoränengebietes begrenzte das Eem-Meer des SaaleWeichsel-Interglazials. Weite Bereiche bis zu den Ostfriesischen Inseln wurden überflutet (UERKVITZ 1997, 26), so dass erstmals annähernd die heutige Küstenlinie erreicht wurde (SEEDORF 1992, 83).

In der Weichsel-Kaltzeit lag Ostfriesland im Periglazialgebiet und die weitgehend vegetationslose Landschaft war dem Klima ungeschützt ausgesetzt. Es entstanden reliefarme Landschaften, die sich bis heute durch nährstoff- und kalkarme Böden auszeichnen. Sandverwehungen am Ende der letzten Eiszeit überzogen weite Teile der ostfriesischen Geest mit einer Flugsandschicht. Aus den Talsandflächen der Unteren Ems und des „Leda-Hunte-Urstromtales“ wurde umfangreiches Sandmaterial freigeweht. Partiell kam es zur Dünenbildung (SINDOWSKI 1969, 24).

\subsubsection{Landschaftsentwicklung im Holozän}

Mit dem Ende des Boreals setzte die holozäne Landschaftsentwicklung in Ostfriesland ein. Der nacheiszeitliche Meeresspiegelanstieg überflutete weite Areale des vorher vereisten Nordseebeckens. Unter Einfluss der Meeresströmungen verlagerte sich die zunächst nördlich der ostfriesischen Inseln liegende Wattküste näher zur heutigen Küstenlinie hin. Im frühen Atlantikum wurde annährend die Gestalt der niedersäsischen Küste herausgebildet, wobei der Meeresspiegel noch etwa 20-25m unter dem heutigen lag. Mit der Größenreduktion des Watts wurde gleichsam seine Wasserspeicherfähigkeit verringert. Gewaltige Strömungsveränderungen und höher auflaufende Sturmfluten folgten (SINDOWSKI 1969, 33). Im Subboreal erreichte das Meer an einigen Stellen den Geestrand. Parallel zum Meeresspiegel stieg im Küstenraum der Grundwasserstand an. In der Jungsteinzeit lag der Meeresspiegel bereits bei -5m NN (SEEDORF 1992, 87-89).

Seit dem Holozän haben wiederholt auftretende Ingressionsphasen die Küstengestalt geformt. Sich abwechselnd schichtende Süßwassersedimente und Basistorfe bildeten die ostfriesische Marschenund Wattenregion heraus. In ihrer Ablagerungsmächtigkeit und Ausdehnung kann die Entwicklung der Meeresspiegelschwankungen von Trans- und Regressionsphasen nachgezeichnet werden. Wie ein Vergleich einzelner Regressionsphasen vor der niederländischen und deutschen Nordseeküste aufzeigt, waren sie regional unterschiedlich stark ausgeprägt (vgl. BEHRE 2003, 32). Die verschiedenen Überflutungsserien der südlichen Nordsee sind in eine ältere Calais- und jüngere Dünkirchenfolge eingeteilt. Die jüngere Transgression umfasst fünf bis sechs Phasen, deren letzte im Mittelalter stattfand (BEHRE 1987, 12-14). In den Transgressionsphasen bedeckten marine Sedimente den Küstenraum. Der steigende Meeresspiegel begünstigte entlang der Geestränder Niedermoorwachstum (SINDOWSKI 1969, 26-27). Für die deutsche Nordseeküste sind inzwischen sieben Regressionsphasen bekannt, in denen es zu einem temporären Absinken des Meeresspiegels 
kam (BEHRE 2003, 23, Tab. 1). Mit jeder Regression erfolgte eine Aussüßung des Küstenraumes und meist setzte auch ein verstärktes Moorwachstum in den Niederungen ein.

\subsubsection{Vegetation}

Zwar wies Ostfriesland im Alleröd bereits eine geschlossene Walddecke auf, diese verschwand jedoch in der jüngeren Tundrenzeit infolge einer Klimaverschlechterung wieder und abermals setzten Sandverwehungen ein (SCHWARZ 1995, 16). Erst mit Beginn der Nacheiszeit um 8300 v. Chr. kam es im Küstengebiet zu einer endgültigen Bewaldung. Anfangs dominierten Kiefer-Birken-Wälder, die um 6500 v. Chr. durch Eichenmischwälder verdrängt wurden. Eine erneute Temperaturabnahme begünstigte ab etwa 4000 v. Chr. die Ausbreitung von Hainbuchen (vgl. SEEDORF 1992, 85). Die regionale Vegetationsentwicklung kann anhand radiokarbondatierter Pollenprofile rekonstruiert werden.

Für die vorliegende Studie ist die Vegetationsentwicklung in den jüngeren Metallzeiten im Küstenraum der südlichen Nordsee von Bedeutung. Der in der Eisenzeit noch vorherrschende Eichenwald verschwand infolge einer Klimaänderung. Abgelöst wurde dieser auf den nährstoffarmen ostfriesischen Böden von anspruchslosen Buchen. Als Tiefwurzler ist es ihnen möglich auch noch aus beträchtlicher Tiefe Nährstoffe und Wasser zu beziehen (SEEDORF 1992, 334). Flächen mit zu trockenen und schlecht durchlüfteten Sandböden wurden hingegen von Buchen gemieden, an ihrer Stelle breiteten sich Eichen und Kiefern aus, während in vernässten Gebieten Mooreichen und -birken vorherrschten.

Im küstennahen Sietland ist der Salzgehalt des Bodens bestimmend für die Vegetation. Während die Marsch aufgrund häufiger Überschwemmungen weitgehend baumfrei war, standen beiderseits der Uferwälle an der Unteren Ems Galeriewälder (BEHRE 1970; 1985). Doch bereits für die vorrömische Eisenzeit und die nachfolgende römische Kaiserzeit fehlt die als Kennart der Hartholzaue bekannte Ulme im botanischen Material. In den Baubefundhölzern von Bentumersiel und Jemgumkloster fanden sich stattdessen überwiegend Erlenholz, gefolgt von Eiche, Weide und Esche (BEHRE 1972; 1977). Ausgedehnte Erlenbruchwälder, lokal auch „Wolden“ genannt, stellten nahezu unzugängliche Wälder dar, so bildeten die weitflächigen Moore eine offene Landschaft. Während Ulme und Eiche einen höheren Standort bevorzugten, zeugte Weidenholz auf die Nähe der unteren Hartholzaue zum MThw (mittleres Tidehochwasser). Zwischen dem 1. Jahrhundert v. Chr. und um Christi Geburt dominieren in den paläobotanischen Pflanzenresten vorwiegend Süßwasserformen. Aufgefundene Schilfröhrichte und Flutrasen weisen auf regelmäßige Überflutungen der Region hin, die in dieser Zeit Prielränder und Senken überdeckten (BEHRE 1970). Das Vegetationsbild prägten darüber hinaus Feuchtwiesen und Weißkleeweiden, letztere sind Ersatzgesellschaften der Hartholzaue (ELLENBERG 
1963, 704). Einsetzendes Hochmoorwachstum legt für das Ems-Hinterland in dieser Zeit einen sinkenden Grundwasserstand nahe.

Für die ökologischen Verhältnisse in der Völkerwanderungszeit sowie dem Frühmittelalter steht aus der Emsregion wenig botanisches Material zur Verfügung. Dennoch zeichnet sich in den Pollenanalysen deutlich eine Abnahme von Siedlungsanzeigern, wie Getreideunkräuter, ab (BEHRE 1972, 164-184). Zeitgleich finden sich im Material vermehrt Baumpollen, die eine Wiederbewaldung der Region belegen. Waren es zunächst Pionierpflanzen wie Birke und Esche wurden diese bald darauf von Buchen und Eichen abgelöst. All dies lässt auf einen weiträumigen Rückgang ackerbaulicher Landwirtschaft schließen.

Eine natürliche Wiederbewaldung der ostfriesischen Sandböden erfolgte bis in das frühe Mittelalter, aber bereits ab dem 10. Jahrhundert $n$. Chr. gelten die natürlichen Wälder als weitgehend abgeholzt (BEHRE 1995, 10). Die Galeriewälder der Uferwälle dürften spätestens um 1000 verschwunden gewesen sein. Dies blieb nicht ohne Folgen für die Böden, deren Wasserspeicherfähigkeit durch Waldrodung maßgeblich reduziert wurde. Plaggenschlag und Tierverbiss beschleunigten beginnende Erosionsvorgänge und ließen eine weitläufige Heidelandschaft in der nordwestdeutschen Altmoränenlandschaft entstehen (BEHRE 2002, 61, Abb. 19).

Auf der weitgehend entwaldeten Geest nahmen Sandverwehungen in starkem Maße zu. Erst im 18. Jahrhundert kam es zu systematischen Aufforstungen, die dieser Entwicklung entgegenwirken sollten. Die von der preußischen Verwaltung dazu ausgewählten schnell wachsenden Kieferbestände verschlechterten jedoch das bestehende, bereits saure, Bodenmilieu. Weitere Aufforstungen erfolgten mit der Allmendeauflösung im 19. und 20. Jahrhundert. Verbliebende Acker- und Grünlandflächen wurden mit Wallhecken umgrenzt, die bis heute das Landschaftsbild prägen.

\subsubsection{Klima}

Das ozeanische Küstenklima an der ostfriesischen Küste wird von Westwinden dominiert, die Luftströmungen vom Meer herbeiführen. Es sorgt für gleichmäßige Niederschläge zu allen Jahreszeiten, milde Winter und relativ kühle Sommer. Die Klimaentwicklung ist eng an den Golfstrom gebunden und um $+5^{\circ} \mathrm{C}$ wärmer als auf dem Breitengrad üblich. Aufgrund der geringen Höhenunterschiede sind in Ostfriesland kaum thermische Höhenstufen festzustellen.

Das maritime Klima im Landkreis Leer zeichnet sich durch eine mittlere Julitemperatur von $16,5^{\circ} \mathrm{C}$ aus, während die mittlere Januartemperatur um $+1^{\circ} \mathrm{C}$ liegt. Hinzu kommen im Jahresdurchschnitt 160 bis 180 frostfreie Tage und etwa nur 20 bis 25 Tage mit einer Schneedecke (SEEDORF 1992, 219, Tab. 27). Diese günstigen Klimaelemente ermöglichen eine lange Vegetationsperiode. Sowohl die ostfriesische Geest wie auch die Marschen zeichnen sich durch relativ gemäßigte 
Sommertemperaturen aus. Moorgebiete und Niederungen neigen hingegen zur Nebelbildung. Aufgrund fehlender Wärmespeicherung kann es dort selbst in Sommernächten zu Bodenfrösten kommen, wenn sie durchfallende Kaltluft von der Geest erreicht werden.

\subsubsection{Siedlungsraum Marsch}

Erstmals suchten Siedler der Zejiener Kultur die nordniederländische Marsch auf, als diese in der Dünkirchen-0-Transgression Höhenlagen zwischen -1,5m und -2m NN aufwies (vgl. WATERBOLK 1966; SCHWARZ 1995, 18). Allein in den Rückzugsphasen der Nordsee war eine Besiedlung der Marsch durch den Menschen möglich.

Während der Regression 2 senkte sich der Meeresspiegel erheblich ab. Mit Aussüßung des Brackwassers wurde zwischen Dollart und Leybucht ein Moorwachstum des oberen Torfes ermöglicht (vgl. WiLDVANG 1915, Taf. I-IV). Die erste deutsche Marschensiedlung entstand um 900 v. Chr. in der Wesermarsch. Nahe der Rodenkirchen-Hahnenknooper Mühle konnte zu ebener Erde bei einer NN-Höhe von -1m gesiedelt werden (STRAHL 2002, 76-83). Nach kurzer Unterbrechung mit erneutem Meeresspiegelanstieg (D-I-a) begann um 800 v. Chr. eine erneute Regression (3), die es ermöglichte die Emsmarsch bei Jemgum erfolgreich zu besiedeln (HAARNAGEL 1957). In dieser Zeit setzte ein langsamer Temperaturabfall ein. Dieser war jedoch unregelmäßigen Schwankungen unterworfen, so dass das Klima in verschiedenen Zwischenphasen kurzfristig wärmer wurde (WILLERDING 1992, 332374). Dies ging einher mit einer bedeutenden Höhenzunahme des Hochmoores (BEHRE 2003, 48). Während in der Seemarsch Siedlungen bereits um 700 v. Chr. wieder aufgegeben werden mussten, behaupteten sich in der Flussmarsch die Menschen noch bis um 300 v. Chr. (BEHRE 2005, 24; SCHWARZ 1995, 18).

Während die D-I-Transgression in den Niederlanden den dortigen Wurtenbau begründete (WATERBOlK 1967), erfolgte ein vergleichbarer Podestbau an der deutschen Nordseeküste erst in der römischen Kaiserzeit (BEHRE 2004, 29). Zu Beginn der subatlantischen Transgression wurde auf den Emsuferwall noch $\mathrm{zu}$ ebener Erde bei $-0,70 \mathrm{~m}$ NN gesiedelt und erst vor der langanhaltenden Dünkirchen-I-b-Transgression wurde dieser Naturraum verlassen (BEHRE 2003, 32-33).

Zwischen 200 v. Chr. bis etwa 100 n. Chr. kam es zu einer kurzen Sedimentationspause. Die neu gebildete fossile Oberfläche ermöglichte eine Wiederbesiedlung der Emsmarsch. Meeresspiegel- und Grundwasserabsenkung fanden im küstennahen Gebieten mit solcher Schnelligkeit statt, dass sich nur an wenigen Stellen Vermoorungen nachweisen ließen. Mit fortschreitender Bodenbildung und infolge schnell fallender Grundwasserstände bot der kalkreiche Marschboden einen besseren landwirtschaftlichen Ertrag als die nährstoffarme Geest. Eine allgemein positive Klimaentwicklung begünstigte die niedrig liegenden Siedlungsräume im Küstengebiet (UERKVITZ 1997, 265). 
Für die römische Kaiserzeit kann eine Zweiteilung in eine wärmere und tendenziell trockene ältere und eine kühlere und feuchtere jüngere Klimaphase vorgenommen werden (JANKUHN 1977, 370-372). Positiv wirkte sich auch der gleichzeitig fallende Sturmflutpegel aus, der im 2. bis 1. Jahrhundert v. Chr. von etwa $+1,20 \mathrm{~m} \mathrm{NN}$ auf $-0,65 \mathrm{~m}$ NN sank (BEHRE 2005, 25).

Erst ab dem 1. Jahrhundert n. Chr. erfolgte ein erneuter Anstieg der Sturmfluthöhe. Wollte man bei steigendem MThw und Sturmflutspiegel die prädestinierte Siedlungslage beibehalten, war eine Aufhöhung der Wohnplätze unumgänglich. Doch trotz mehrmaliger Niveauanpassung gelang es nur wenigen Marschensiedlungen die zunehmende Versalzung des Grundwassers zu bewältigen. Die Regression 4 endete mit Beginn der D-II-Transgression im 3. Jahrhundert n. Chr. (vgl. BEHRE / HAARNAGEL 1984, 74, Abb. 2).

Angesichts sich stetig verschlechternder Lebens- und Wirtschaftsbedingungen setzte spätestens im 5 . Jahrhundert n. Chr. ein Bevölkerungshiatus ein. Im Zuge der Regression 5 (350-700 n. Chr.) erfolgte zwar ein erneuter Landgewinn an der Küste, jedoch ist für die Marsch erst ab dem 7. Jahrhundert eine erneute Besiedlung festzustellen (SCHMID 1988, 133-164).

Anfangs noch als Flachsiedlungen angelegt, war infolge der D-III-a Transgression ein neuer Podestbau notwendig, der damit die zweite deutsche Wurtenphase einleitete. Versuchte man zunächst das tiefliegende Marschenland durch Ringdeiche zu schützen, war es bald unumgänglich küstenparallele Deiche zu errichten. Bereits im 13. Jahrhundert bestand eine geschlossene Deichlinie an der niedersächsischen Nordseeküste (BEHRE 1995, 26).

Da von nun an eine anthropogene Gestaltung des Küstenraums erfolgte, kann die zeitliche Tiefe der Regression 6 nur mutmaßlich mit bis 1000 n. Chr. angegeben werden (BEHRE 2003, 39). Unterbrochen von der D-III-b Transgression, die bis $1450 \mathrm{n}$. Chr. reichte, folgte die Regression 7 mit schnell sinkendem MThw. Im 15. Jahrhundert erreichen die gewaltigen Meereseinbrüche ihre größte Ausdehnung und schufen Überflutungszonen, die eine Sturmflutgefahr verringerten. Ab 1700 setzte die D-IV Transgression ein und mit Beginn einer globalen Erwärmung steigt sowohl der Meeresspiegel wie auch das MThw wieder an.

\subsubsection{Naturräumliche Gliederung im Untersuchungsgebiet}

Das Untersuchungsgebiet wird überwiegend durch die zentrale Flussmarsch von Ems, Leda und Jümme geprägt. Parallel zu den Flussläufen entwickelte sich eine breite Niederungszone, die ihrerseits von Hochmooren umgeben war. Der nordöstliche Teil des Landkreises Leer wird durch eine trockene Altmoränenlandschaft geformt, die sich durch eine geringe natürliche Bodenfruchtbarkeit auszeichnet. Die o.g. Flussmarschgebiete übernehmen für die Siedlungsentwicklung des Raumes eine wichtige Funktion und werden deshalb an dieser Stelle eingehend erläutert. 


\subsubsection{Hydrologie}

\subsection{Das Flusssystem von Ems und Leda}

Die Ems entspringt südlich des Teuteburger Waldes auf einer Höhe von $+134 \mathrm{~m}$ NN und durchfließt als Flachlandfluss in nahezu südnördlicher Ausrichtung auf $370 \mathrm{~km}$ Länge Nordwestdeutschland. Dabei legt der Fluss $255 \mathrm{~km}$ in Niedersachsen zurück. Nach Durchquerung des nördlichen Münsterlandes endet die Obere Ems bei Rheine. Ab hier schiffbar erreicht die Mittlere Ems das Emsland bis zum Wehr Herbrum südwestlich von Papenburg (SEEDORF 1992, 276), um dann auf 60km Länge als Untere Ems den Landkreis Leer zu durchfließen, bevor der Fluss in den Dollart mündet. Reste des ursprünglich wesentlich größeren Meereseinbruchs erstrecken sich westlich der heutigen Emsmündung bei Pogum auf 100km². Über die anschließende Außenems gelangt man in die Nordsee. Zum Schutz der Unteren Ems vor Sturmfluten wurde 2002 das große Emssperrwerk bei Gandersum vollendet.

Die Ems hat bei Leerort eine Breite von $210 \mathrm{~m}$. Etwa 6km nördlich von Leer auf der Höhe von Jemgum beträgt die Flussbreite bereits $300 \mathrm{~m}$ und an der Dollartmündung 700m. Neuzeitliche Flussbegradigungen haben zur Erhöhung der Fließgeschwindigkeit geführt, so dass die Tidegrenze inzwischen das Binnenland bei Herbrum erreicht hat. Auch in den Emszuflüssen Leda und Jümme ist der Tidehub inzwischen merklich spürbar. Gleichzeitig sinkt der Grundwasserstand durch diese Maßnahmen weiter. In prähistorischer Zeit war vermutlich ein Großteil des Flusssystems nutzbar. Wie Berechnungen zeigen, gelang es römischen Militärtransportern vom Typ Triemene mit einer kompletten Besatzungsstärke (150 Mann) Inlandsflüsse wie die Ems mit weniger als 1,5m Tiefgang zu befahren (siehe S. 64). Gegenwärtig ist die Ems von Rheine bis zur Nordseeküste auf einer Gesamtlänge von $238 \mathrm{~km}$ schiffbar. Flachboote mit geringem Tiefgang können die Ems auch weiter Flussaufwärts befahren.

Ein größerer Nebenfluss der Mittleren Ems ist die ebenfalls im Teuteburger Wald entspringende Hase. Oberhalb von Lingen tritt die Aa bei Gleesen in die Ems und entwässert ein ausgedehntes Sand- und Moorgebiet an der niedersächsisch-westfälischen Grenze.

Auf ostfriesischem Gebiet mündet die Leda bei Leer als bedeutenster Zufluss in die Ems, nachdem sie vorher die Jümme, die aus dem oldenburgischen Raum in östlicher Richtung entwässert, integrierte. Gemeinsam mit ihren Zuflüssen entwässert die Leda ein Areal von 3000km² (SEEDORF 1992, 279). Die seit dem 19. Jahrhundert industriell betriebene Moorkultivierung und die Entwässerung der Niederungen setzten dort gespeicherte Wassermassen frei. In Folge verbreiterten sich die Unterläufe von Ems und Jümme. Im 20. Jahrhundert wurden beide Flüsse größtenteils begradigt und zusätzlich durch Ausbaggerungen vertieft. Weite Bereiche des angrenzenden und unter NN befindlichen Sietlandes sind ohne eine ständige künstliche Absenkung des Grundwasserspiegels landwirtschaftlich nicht mehr nutzbar. 


\subsection{Das Emstal}

Das 2 bis $4 \mathrm{~km}$ breite Emstal stellt sich dem Betrachter als eine nahezu weitgehend tischebene Fläche dar, die beiderseits von tonhaltigen Uferwällen begrenzt wird. Der Uferrücken der Unteren Ems erreicht oft nur Höhen von $+0,3$ bis $+1 \mathrm{~m}$ NN. Mit wachsender Entfernung zur Ems fällt die rezente Geländeoberfläche nach Südwesten auf bis zu $-1,2 \mathrm{~m}$ NN ab. Das Sietland mit seinen Niedermooren wurde während der spätmittelalterlichen Dollartbildung flächig von Tonsedimenten bedeckt, die das Gebiet westlich der Ems zusätzlich einnivellierten.

Landschaftstypisch sind für das Emstal parallellaufende Dünen und Flussterrassen. Weite Bereiche der Oberen Ems und der Hase werden von Talsandflächen eingenommen. Spätglaziale Westwinde haben die Terrassenkanten des Oberen und Mittleren Emstals unterschiedlich stark ausgeprägt. Während der rechte Uferwall stärker versandete und von Dünen eingenommen wurde, konnte das mit Auewald bewachsene linke Ufer sich zum Altsiedelland entwickeln (SEEDORF 1992, 278).

Die Mittlere Ems begleitet ein breiter Dünenstreifen, bei der Unteren Ems fehlt eine Terrassenbildung. Das Untere Emstal prägen Sanderflächen, die infolge von Sedimenteintragungen des Schmelzwasserabflusses vor der Endmoräne entstanden sind (WILDVANG 1924; 1929, 25-27). Vorherrschende Westwinde unterstützten die Bildung von Flugsanddünen entlang der östlichen Talseiten von Ems, Jümme und Leda (SEEDORF 1992, 117). Heute werden die Flüsse beidseitig von Deichen eingefasst.

Strömungsänderungen haben in prähistorischer Zeit zu einschneidenden Flussverlagerungen der Ems geführt. Dies ist insbesondere für die landschaftsgeschichtliche Rekonstruktion der Unteren Emsregion von Bedeutung, da sich mit der Strömung auch der Einfluss des THws änderte wie auch der Salzgehalt des Grundwassers auf die flussnahen Niederungen beeinflusst wird.

Ursprünglich war der Flutstrom der Nordsee durch die mäandrierende Ems deutlich weniger stark ausgeprägt. Bis zum mittelalterlichen Dollarteinbruch, der eine dramatische Umgestaltung der Strömungsverhältnisse in der Ems zur Folge hatte, ist von einem eher geringen Tideeinfluss in der Region auszugehen. Bevor es zu einschneidenden Flussbettverlagerungen kam, wurde der Flutstrom der Ems derartig verlangsamt, dass das MThw bei Jemgumkloster vermutlich unter $2 \mathrm{~m}$ lag (UERKVITZ 1997, 242). Das aktuelle MThw beträgt heute bei Emden $+3,03 \mathrm{~m} \mathrm{NN}$, nahe Bentumersiel etwa $+2,6 \mathrm{~m}$ $\mathrm{NN}$ und beim Wehr in Hebrum $+2,1 \mathrm{~m}$ NN.

Küstennahe Flachlandflüsse weisen eine verstärkte Mäanderbildung auf. Dies war auch im Unteren Emsgebiet der Fall, wo infolge dessen relativ breite Flussauen entstanden (vgl. SEEDORF 1992, 118119). Zwar ist die Ems in ihrem Unterlauf heute größtenteils begradigt, zahlreiche verlandete 
Flussschleifen sind in historisch-topographischen Karten verzeichnet und können teilweise noch im Gelände ausgemacht werden.

Für den Emsverlauf von Völlen bis Pogum weisen die Preußische Landesaufnahme von 1898, wie auch die historische Karte von La Croq von 1805, allein zehn inzwischen verlandete Flussschleifen auf. Für Jümme und Leda sind je vier Altarme beiderseits des Jümmiger Hammrichs belegt. In den Verlauf der beiden Binnenflüsse wurde im Verhältnis zur Ems weit weniger stark eingegriffen.

Die aktuelle TK 25 (1997), Blatt 2810 Weener, verzeichnet südöstlich von Weener einen ca. 700m langen Altarm. Eine große verlandete Emsschleife befand sich ehemals wenige hundert Meter nordöstlich von Weener entfernt am rechten Emsufer zwischen Coldemüntje und Dorenborg. Eher schwach ausgeprägt ist eine südlich von Bingum auf Höhe der Stadt Leer liegende Flussschleife zwischen Kirchbogum und Coldam. Die in die Ems mündende Leda weist bei Leer einen stark mäandrierenden Verlauf auf. Ehemals diente der Altarm mit einer annähernd $360^{\circ}$ Flussbiegung als bedeutender Stadthafen für die Untere Emsregion.

In die Ems hineinragende und den Flutstrom behindernde kleinere halbinselartige Geländevorsprünge sind durch moderne Deichbaumaßnahmen meist gekappt. Zu nennen sind hier die Flussbiegungen bei Nesserland, Jemgum, der Nesse bei Leer, Kloster Muhde, Haseborg bei Weener, Mark und zuletzt Nesseborg auf der Höhe von Diele. Ein heute zum Reiderland gehörendes Areal zwischen Jemgum und Jemgumgaste war ehemals Teil einer Halbinsel, die dem rechten Emsufer angehörte und ist erst im Zuge eines Emsdurchbruchs an die linke Uferseite gelangt (WILDVANG 1930, 16). Ohne den Schutz des Flussdeiches würde ihre prädestinierte Lage am Prallhang bei natürlicher Ufererosion diesen Prozess umkehren und der gegenüberliegende Gleithang würde verlanden.

Im Mittelalter kam es zu gewaltigen Flussverlagerungen in deren Folge sich nachhaltig die Strömungsbedingungen der Ems veränderten. Durch die Gewalt der Flutströme wurde u.a. die Emsschleife in Höhe Nesserland durchbrochen und eine ursprünglich zum Reiderland gehörige Halbinsel komplett abgetrennt. Sie ist bis heute Bestandteil des rechten Emsufers.

Die Strömungsveränderungen ließen langsam den Emder Hafen verlanden. 1509 war Emden von seiner direkten Emsanbindung abgeschnitten und die Ems verlagerte sich weiter nach Süden. Um den Fluss wieder in seinen alten Verlauf zu zwingen wurde das neue Flussbett mit Eichenbohlen verschlossen, jedoch ohne bleibenden Erfolg. Ein weiterer Effekt der geänderten Strömungsverhältnisse im Zusammenhang mit dem Durchbruch der stark mäandrierenden Ems bei Nesserland war, dass nun die auflaufenden Sturmfluten nicht mehr in den Dollart gelenkt wurden. Stattdessen erreichte die Flut direkt die Untere Ems und konnte in ihrem Unterlauf eintreten. Infolge des nun fehlenden Strömungswirbels verlandete mit der Zeit der Dollart, womit die im 16. Jahrhundert einsetzenden Einpolderarbeiten auf natürliche Weise beschleunigt wurden. 


\subsection{Grundwasserhaushalt im Untersuchungsgebiet}

Bis in die frühe Neuzeit wurde die Besiedelbarkeit tiefliegender Küstenregionen durch einen nah unter der Oberfläche anstehenden Grundwasserstand beeinflusst. Der Anstieg des Meeresspiegels infolge verschiedener Transgressionen hob im Mündungsgebiet der Küstenflüsse den Flussspiegel an. Dies beeinflusste im Unterlauf der Flüsse der Grundwasserspiegel. Eine Versalzung im unteren Bereich des Grundwasserleiters ist für die Jümme-Marsch festzustellen und nimmt aufgrund der künstlichen Entwässerung stetig zu. In der Krummhörn ist es bereits zur fast vollständigen Versalzung der Grundwasserleiter gekommen (SEEDORF 1992, 253).

Ehemals wurde in der Marsch der Grundwasserbedarf über Zisternen und flache Brunnen gedeckt, heute sind es Fernwasserleitungen von der Geest. Einen Hinweis auf ein Absinken des Grundwasserspiegels, und damit eine wichtige hydrologische Marke, stellt der Übergang vom Niedermoor zum Hochmoor dar. Dieser setzt ein, wenn das Niedermoor nicht mehr aus dem Grundwasser gespeist wird und das Moor sich nur noch mit Regenwasser versorgen kann (BEHRE 2003, 20). Im Reiderland begann um Christi Geburt infolge der Regression 4 dieser Wechsel, als der bestehende Schilftorf durch Hochmoor abgelöst wurde (BEHRE 1986b, 20).

Kaum grundwasserergiebig ist die niedere Geest mit ihrer gering mächtigen Sandschicht. Talsandniederungen und Urstromtäler neigen stattdessen eher zur Vermoorung, wobei freisetzende Huminsäuren und mineralische Bodenbestandteile, wie Eisen und Mangan, das Grundwasser verunreinigen. Die oft schlechte Grundwasserqualität in den Niederungen wird auf hochreichende Salzstöcke zurückgeführt (SEEDORF 1992, 247). Hochgelegene Geestrandbereiche Ostfrieslands verfügen aufgrund einer mächtiger pleistozänen Sandauflage über ergiebige Grundwasservorkommen und einem nur mäßigen Oberflächenabfluss.

\subsection{Die Leda-Jümme-Region}

Die Jümme-Niederung ist Teil der Hunte-Leda-Niederung, die sich am Südwestrand der ostfriesischoldenburgischen Geest auf etwa $60 \mathrm{~km}$ entlang zieht. Der westliche Teil des Niederungsgebietes wird hydrologisch von Jümme und Leda bestimmt, die gemeinsam in die Ems entwässern, während die Hunte aufgrund einer südöstlich von Oldenburg gelegenen Wasserscheide nur in den südöstlichen Rand der Niederung einfließt.

Östlich von der Kreisstadt Leer erschließt sich auf einer Fläche von ca. 40qkm die Jümme-Niederung, deren zentrales Herzstück der Jümmiger Hammrich bildet. Jümme und Leda umfließen zangenförmig den 2000ha großen Jümmiger Hammrich und vereinigen sich an seiner Westseite. Am Wilthauser Hörn, etwa $1 \mathrm{~km}$ östlich von Leer-Loga, mündet die Jümme in die Leda, die nun eine Flussbreite von bis zu 50m aufweist und südlich von Leer in die Ems einmündet. Am Leda-Jümme Zusammenfluss 
hat die Flussmarsch noch eine Breite von $3 \mathrm{~km}$ und verjüngt sich nach Osten, nahe Stickhausen, auf etwa 300m. Beiderseits der Flüsse erstreckt sich eine ausgedehnte Niederungslandschaft.

Die Leda-Jümme-Region stellt eine weitgehend ebene Fläche dar, die Höhen zwischen $+1,5 \mathrm{~m}$ bis $0 \mathrm{~m}$ NN erreicht. Zum Jümmiger Hammrich fällt das Gelände bis $-0,5 \mathrm{~m}$ NN ab. Südlich von Nortmoor bedecken Niedermoore abwechselnd mit tonigen Sedimentschichten das ausgedehnte Niederungsgebiet des Jümmiger Hammrichs. Südlich der Leda schließt der Backemoorer Hammrich an, ein Niederungsgebiet, welches sich von Breinermoor bis Potshausen ausdehnt. Nach Süden schließt sich der Hochmoorkomplex des Holter Moores an.

Bis zur Eindeichung von Jümme und Leda im 20. Jahrhundert wurde die Leda-Jümme-Region regelmäßig überschwemmt. Insbesondere die Frühlingshochwasser nach Einsetzen der Schneeschmelze im Hinterland führten bei dem in der Niederung noch gefrorenen Boden zu enormen Überflutungen. Bei der letzten großen Überschwemmung 1918 war der Jümmiger Hammrich und angrenzende Areale wochenlang unpassierbar.

Die sich nördlich der Leda-Jümme-Niederung anschließende und von Leer nach Hesel reichende Geestplatte bildet eine Wasserscheide zwischen den Entwässerungssystemen von Jümme und Ems. Großflächige Moorgebiete waren bis in die frühe Neuzeit der Geest im Westen vorgelagert; ihr Abfluss wurde jedoch durch den hohen Uferwall der Ems behindert.

Hielten die Hochmoore in erster Linie Oberflächenwasser zurück und fungierten bis zu ihrer Abtorfung als natürliche Wasserspeicher, so speicherten die vorgelagerten Niedermoorkörper das anstehende Grundwasser. Dies änderte sich mit Anlage zahlreicher Vorfluter und Gräben, die zur Entwässerung der weiten Moor- und Niederungslandschaft dienten. Erst der moderne Einsatz von Schöpfwerken ermöglichte eine langfristige Absenkung der Wasserstände in den oft unter NN liegenden Gebieten im südlichen Ostfriesland.

In die Leda entwässert eine weite Niederungslandschaft vom südlichen Ostfriesland, einschließlich der Geesthöhen des Hümmlings, bis zum Zwischenahner Meer mit einer Größe von 3000qkm (SEEDORF 1992, 278-279). Die weiten Moorgebiete im Süden des Landkreises Leer sind von einem Netz an Kanälen und zahlreichen Schlottgräben (Sieltiefs) durchzogen. Hierzu zählen u.a. das Schatteburger Sieltief, Holter Sieltief, Potshauser Sieltief, Holterfehnkanal, Rhaudermoorschlott, Idafehnschloot sowie der Elisabethfehn-Kanal. Als größerer Zufluss direkt in die Leda entwässert der Hauptfehnkanal, der sein Wasser aus dem Burlage-Langholter-Tief und dem Langholter Meer bezieht. Die Sater-Ems ist im angrenzenden oldenburgischen Gebiet der nächste natürliche Zufluss in die Leda.

In die Leda entwässern ab dem Wilthauser Hörn (Zusammenfluss von Jümme und Leda) die südlichen 
Tiefs, wie das Backemoorer Tief, Breinermoorer Sieltief und der Haferfennen- und Nettelburger Schloot. Ein größerer Zufluss ist der Polderkanal. Von Norden hinein entwässert das Loga Sieltief. Die Moorgebiete um Rauderfehn werden über das künstlich verbreiterte Langholter Tief entwässert, welches bei Potshausen in die Leda mündet.

Das Einzugsgebiet der Jümme umfasst im Wesentlichen die Zentralmoore des Geestrückens, die zahlreiche Entwässerungskanälen (Tiefs) durchziehen. Der einzige größere natürliche Zufluss in die Jümme ist das Holtlander Ehetief, welches das Moorgebiet nordöstlich von Holte entwässert. Kleinere Zuflüsse in die Jümme sind der Rüschewehrenschloot, Sachschloot, Heimschloot sowie das Riementappentief, und Filsumer Sieltief. Zur kommerziellen Moorentwässerung wurde der Nordgeorgsfehnkanal unweit von Stickhausen angelegt. Für die Entwässerung des Jümmiger Hammrichs sorgt das Pieper Sieltief.

Seit 1954 reguliert das Leda-Sperrwerk bei Leer die Ableitung des Oberflächenwassers und schützt das Hinterland vor Sturmfluten. Das mittlere Tidehochwasser beträgt bei Einmündung in die Jümme am Wilthauser Hörn $+1,4 \mathrm{~m}$ NN. Bis zu $3 \mathrm{~m}$ hohe Deiche begleiten den Fluss und zwängen die Jümme in ein enges Flussbett. Renaturierungen entlang der Leda schufen Ende der 90er Jahre des 20. Jahrhunderts südöstlich des Jümmiger Hammrichs Überflutungsareale, die heute eine natürliche Landschaftszonierung wiedergeben.

\subsubsection{Bodenkundlicher Überblick}

\subsection{Geestböden}

Nördlich der Jümme-Niederung beginnen die Ausläufer der Nordoldenburgisch-Ostfriesischen-Geest. Das Gelände steht südlich des Geestranddorfes Nortmoor um $+/-0 \mathrm{~m} N \mathrm{~N}$, im Ort bei $+2 \mathrm{~m} \mathrm{NN}$, um $3 \mathrm{~km}$ nördlich in Brinkum Höhen von $+7,8 \mathrm{~m}$ NN zu erreichen. Der südwestlichste Geestausläufer der Hauptgeest weist im Stadtgebiet von Leer eine NN-Höhe von $+6 \mathrm{~m}$ auf. Im altbesiedelten Ortsteil Leer-Loga sind es bereits Höhen um +7,3m NN.

Nordöstlich von Hesel erreicht die sandige Altmoränenlandschaft im Landkreis Leer ihre maximale Höhe von $+17 \mathrm{~m}$ NN, dacht nach Süden hin leicht ab, um dann im zentralen Teil Ostfrieslands Geländehöhen von bis zu $+18,5 \mathrm{~m}$ NN zu erreichen. Dabei fungiert die zentrale ostfriesische Geest als Wasserscheide zwischen Jümme und Ems.

Während der Saale-Kaltzeit drangen letztmalig Gletscher in den südostfriesischen Raum und darüber hinaus bis an den Rand der Mittelgebirge vor. Ein Zeugnis davon ist die Reiderländer-Overledinger Stauchmoräne, die etwa $5 \mathrm{~km}$ südwestlich von Leer beginnt. Größere Geestinseln existieren im reiderländischen Bunde-Weener, in Steenfelde-Collinghorst und nahe Stickhausen-Detern. Die Geländehöhen sind Bestandteil eines Endmoränenzuges mit bogenförmigem Verlauf, dessen 
Querachse zwischen Weener und Steenfelde verlief (WILDVANG 1930, 11-12). Nördlich von Weener beginnend verläuft der Höhenzug durch die Stadt Weener in Richtung Stapelmoor und erreicht bei den „Dieler Alpen“ nahe Diele Geländehöhen von +7,9m NN. Jenseits der Ems setzt sich der Höhenzug in den Tunxdorfer-Bergen östlich von Papenburg bei $+16,5 \mathrm{~m}$ NN fort, bevor er bei der Ortschaft Ihren bei +9,3m NN endet (WILDVANG 1924, 11-13).

Das Ausgangsmaterial der Bodenbildung im Untersuchungsgebiet bildet Geschiebedecksand über Geschiebelehm. Vorherrschend sind Pseudogley-Braunerden, Plaggenesch und örtliche Pseudogleye. Podsole finden sich auf der Geest wie auch in Flugsandsedimentationen. Sie zeichnen sich durch Nährstoffarmut aus. Rendzinen stellen frühe Stadien der Bodenentwicklung auf jungen Oberflächen dar (SEEDORF 1992, 182).

Während sich Rendzinien auf Kalk bilden, entstehen Regosole auf Sand und werden über Zwischenstufen zu Braunerde, Parabraunerde oder Podsol. Podsolregosole bilden sich vornehmlich aus Jungdünensand (SEEDORF 1992, 183, Abb. 101). Im Küstengebiet überwiegen sauer-kalkfreie Lockergesteine, die dem A-C-Boden Regosol entsprechen.

Östlich von Brinkum liegen lehmige und oft staunasse Sandböden vor, die südlich von Logabirum in wasserdurchlässige Tonböden und Moorböden übergehen. Nördlich der Holtländer Nücke bis nach Neuefehn erstrecken sich grundwasserbeeinflusste Sandböden.

Die Holtlander Nücke entwässert westlich von Brinkum in die Ems, die Holtlander Ehe in die Jümme. Die geringe Bodenfruchtbarkeit der nährstoffarmen und unter Staunässe stehenden Geestböden beeinträchtigte den Ackerbau auf den verfügbaren Flächen.

Die Sandböden östlich der Ems, deren Material mit der Saale-Eiszeit nach Ostfriesland gelangten, zeichnen sich durch Kalkarmut und ein saures Bodenmilieu aus. In dieser Region ist die Flugsanddecke weniger mächtig, so dass der Pflughorizont bereits den Geschiebelehm erfasst und Siedlungsspuren zerstört hat (SCHWARZ 1996, 21).

Verbreitet an der Nordost-Flanke der Geest steht als Beckensediment Lauenburger Ton an, der im Reiderland auch als Pottklei bezeichnet wird. Dieser liegt durch glaziale Vorstöße gefaltet dicht unter der Oberfläche vor und war für zahlreiche lokale Ziegeleien im 19. Jahrhundert ein wichtiger Wirtschaftsfaktor.

Bereits mit der Ausbreitung der Trichterbecherkultur fanden auf der ostfriesischen Geest erste folgenreiche naturräumliche Veränderungen statt. Rodungen und ganzjährige Waldweide ließen großflächige Heideflächen entstehen (BEHRE 2000, 33). Fehlende Regenerationsphasen degenerierten den von sich aus bereits nährstoffarmen Geestboden (BEHRE 2002, 45, Abb. 5).

In der Bronzezeit beschleunigte sich die Desertifikation der Geestböden. Ein erhöhter Bauholzbedarf und intensive Schafsbewirtschaftung führten zum Abtrag der schützenden Grasoberfläche. Die neu 
entstandenen Heideflächen begünstigten eine Podsolisierung und änderten entscheidend den Wasserhaushalt des Bodens.

Infolge einer Klimaverschlechterung versuchte der Mensch bereits in der vorrömischen Eisenzeit die nährstoffarmen Böden durch Plaggenhieb aufzuwerten, wie es u.a. für die Region Hesel belegt ist (BÄRENFÄNGER 1998b, 36-37, Abb. 30-34). Der ständige Nährstoffentzug ließ die Geestböden verarmen und nur ein alljährlicher Humusauftrag ermöglichte eine Weiterbewirtschaftung. Das System der „prae celic fields“ veranschaulichen Feldanlagen in Flögeln-Haselhörn. Mit der Zeit entstanden wallartige Felder, die höher liegende Areale ihrerseits vor Vernässung schützten (BEHRE 2002, 48-49). Wurden jedoch keine ausreichenden Ruhezeiten für die ihrer Grasnarbe beraubten Böden eingehalten, führte dies zur Freilegung von Wehsanden. Pollenprofile zeigen überwehte Podsolböden an, so dass WILDVANG (1935b) von einer subborealen Reaktivierung glazifluviatiler Flugsande ausgeht.

Die enorme Stärke äolischer Sandverwehungen zwang die eisenzeitlichen Bewohner der Provinz Drenthe zur Aufgabe ihrer Geestsiedlungen (WATERBOLK 1962, 9-46). Um Christi Geburt trugen relativ trockene Vegetationsverhältnisse zur Dünenbildung bei (HAYEN 1966b, 280-307). Untersuchungen zeigen jedoch, dass ein Großteil der Dünenausbreitung erst im jüngeren Holozän erfolgte (PYRITZ 1972). Insbesondere mittelalterliche und neuzeitliche Plaggenwirtschaft schuf im Küstenraum Böden, die als Esch oder Gaste bezeichnet werden.

Zwar wurden einige Flächen bereits im Frühmittelalter angelegt (SEEDORF 1992, 195), mit wachsendem Landbedarf und steigender Bevölkerungsanzahl dehnten sich die Plaggenböden aber spätestens im Spätmittelalter über ihre alten Ackerflächen hinaus aus. Die mit Dung angereicherten Plaggen sorgten für einen erhöhten Humusgehalt der Gaste. Um jedoch die Ernteerträge stabil zu halten, musste dieser Vorgang regelmäßig wiederholt werden. Unzureichende Brachzeiten ließen die abgeplaggten Heideflächen immer mehr verarmen.

Mit Einführung des intensiven Roggenanbaus kam es zu einer ganzjährigen und oft einseitigen Bewirtschaftung der Ackerflächen, was schließlich die natürliche Landschaftsgestalt nachhaltig veränderte (BEHRE 1995, 10). Der ständige Nährstoffentzug ließ immer größere Heideareale entstehen, mit der unmittelbaren Folge von Bodenerosion, Bildung von Flugsand und einer Gefährdung des Kulturlandes. Mangels Alternativen wurde die Düngemethode bis in das 19. Jahrhundert beibehalten und erst durch den neuzeitlichen Einsatz von Mineraldünger abgelöst (BEHRE 2000, 38).

Die naturräumlichen Bedingungen begrenzten den besiedelbaren Raum auf höher gelegene, trockene Areale. Bevorzugt wurden Geestrandlagen mit Übergang zu fruchtbaren Niederungen. Mit Beginn der Plaggenwirtschaft wurde ein Standortwechsel in die Feldflur der Geest bei abnehmender Bodenqualität nicht mehr erforderlich. 


\subsection{Moorböden}

Einem noch größeren anthropomorphen Wandel als Geestböden waren die ostfriesischen Moorgebiete unterworfen. Ursprünglich bedeckten die im feuchten Küstenklima verbreiteten Moore etwa 2/3 der Fläche Ostfrieslands, heute existieren noch sechs größere Torflagerstätten mit einer Gesamtfläche von $150 \mathrm{~km}^{2}$. Nährstoffarme Hochmoore der Geest stellten siedlungsfeindliche Räume dar, während die flachgründigen Niedermoore sich durch Entwässerung relativ leicht kultivieren ließen und mit Erlenbruchwäldern bewachsen waren.

Die Torfbildung in der Jümme- und Ems-Niederung resultiert aus rückgestautem Wasser, welches aufgrund des geringen Geländegefälles nicht zügig abfliesen konnte. Der Moorkörper selbst besteht aus nicht zersetztem organischem Material und entwickelt sich in Arealen mit Wasserbedeckung. Die in den Gewässern verfügbaren Mineralien bieten hinreichend Nährstoffe für die Torfmoose. Verfügbarer Kalk kann die sauren Huminsäuren binden, so dass der Torf lediglich schwach saurer ansteht (WASSERMANN 1985, 20).

Der nährstoffreiche Boden mit seinen Süßgräsern eignet sich hervorragend als Wiesenland, wobei die Bodenqualität durch Kalkentzug stetig abnimmt und Sauergräser sich ausbreiten. Übergangsmoore, d. h. Niedermoore mit Hochmoortorfdecke, gingen in grundwasser-beeinflusste Sandböden bei Hesel, Hasselt, Remels und Großoldendorf über und waren temporär nur eingeschränkt besiedelbar.

Die auffällig parallele Ausrichtung von Kleintälern auf der Geest ist vermutlich in Verbindung mit dem Abfließen eiszeitlicher Schmelzwasser zu sehen (SEEDORF 1992, 111). In den Tälern kam es zu vermehrter Hochmoorbildung, die den Geestrücken zwischen Leer und Hesel stark zergliederte. Die nordwestlich von Brinkum liegenden Fehnorte, wie Warsingfehn, Jhringsfehn und Neukamperfehn, verweisen auf Moore und ihre neuzeitliche Kultivierung. Ausgedehnte Moorgebiete schlossen sich von Detern bis zum Stapelermoor an. Teile des Uplenger Moores sind bis heute erhalten und bildeten eine natürliche Grenze zum Oldenburger Land. Die holozäne Transgression begünstigte die Bildung eines Niedermoortorfes. Anhand der Sedimente und Torfschichten wird die lokale Umweltgeschichte der Jümme-Niederung rekonstruierbar. Der zentrale Moorbereich des Jümmiger Hammrichs wurde bereits im Spätmittelalter kultiviert, bis die Besiedlung aufgrund der Staunässe an den Geestrand verlagert wurde (ROSENPLÄNTER 2002).

Der Emsuferwall im Reiderland bildete sich infolge regelmäßiger Überflutungen mit tonigen Sedimenten heraus. Im Hinterland entstand durch Sedimentdefizit eine niedrigere Fläche, die vermoorte und die landschaftstypischen Hochmoore ausbildete.

Zwar konnten die ostfriesischen Moore lange Zeit ihre ursprüngliche Gestalt beibehalten, wurden aber seit der frühen Neuzeit umso intensiver bewirtschaftet. Im Zuge der Fehn- und Brandmoorkultur nahm 
man seit dem 17. Jahrhundert zahlreiche ostfriesische Hochmoore unter Kultur. Die Entwässerung führte zu starken Oberflächensackungen und setzte enorme Wassermassen frei, die vorher im Moorkörper gebunden waren

Da die natürliche Entwässerung in der flachen Küstenregion von sich aus bereits behindert ist, führte dies im Binnenland zu einem rasch steigenden Grundwasserspiegel, dem allein dauerhaft arbeitende Schöpfwerke Abhilfe schaffen können. Inzwischen sind im Zuge des industriell betriebenen Torfabbaus große Moorgebiete auf der Geest und in den Niederungen zerstört worden.

Schon Plinius berichtet von einer frühen Nutzung des Rohstoffes Torf im 1. Jahrhundert n. Chr., der von den Halligbewohnern vor der Küste Ostfrieslands als Heizmaterial verwendet wurde (Plinius hist.nat. XVI, 2). Literarisch belegt ist auch die Friesensalz-Gewinnung aus Salztorf, dessen Abbau im 18. Jahrhundert die vollständige Zerstörung der Hallig Bant zur Folge hatte (SEEDORF 1992, 138; vgl. BEHRE 2005, 35-38).

Große Hochmoorflächen bestanden südlich der Leda, sind jedoch inzwischen weitgehend abgetorft. Ausgangspunkt ihrer Kultivierung waren Fehnorte wie Rhauderfehn, Westrhauderfehn, Elisabethfehn u.a.m. Auch im Hinterland der Ems bestanden ehemals große Moorflächen. Vereinzelt haben sich bis heute rezente Moorgebiete zwischen Papenburg und Meppen erhalten. Kleinere Moore sind inzwischen nahezu komplett entwässert. Flurnamen wie Nüttermoor, Neermoor, Veenhusen u.a.m. weisen für die Region nördlich der Jümme auf zahlreiche kleine Moorgebiete hin.

Noch 1944 fanden sich im südlichen Ostfriesland nahezu zusammenhängende Moorböden mit einer Stärke von mehr als $1 \mathrm{~m}$ im entwässerten Zustand; Zeugen ehemaliger Hochmoorkomplexe. Im nördlichen Teil des Untersuchungsgebietes dominierten anmoorige Böden umgrenzt von Flachmooren und Moorerden (OvERBECK 1944, Beilage).

Lediglich vom Veenhuser Königsmoor nördlich von Leer hat sich eine Restfläche von 7,2km² erhalten. Eine größere Moorfläche existiert noch östlich und westlich von Papenburg. Das Bourtanger Moor im Emsland vermittelt einen Eindruck von diesem ehemals landschaftsprägenden Naturraum. Zwar gehört es mit seiner Gesamtfläche von $157,4 \mathrm{~km}^{2}$ zu den größten Flächenmooren in Niedersachsen, wird durch den derzeitigen Torfabbau aber fortlaufend kleiner (SEEDORF 1992, 167).

\subsection{Marschenböden}

Dem seeseitigen Geestrand vorgelagert ist der Naturraum Marsch. Bis zu ihrer Eindeichung lagen die maritim gebildeten Seemarschen im direkten Einflussbereich der Nordsee. Erst durch die Erwärmung nach der Weichseleiszeit und des dadurch ausgelösten Meeresspiegelanstieges bildete sich die heutige Küstenform heraus. Verschiedene Überflutungsperioden begründeten eine Schichtenabfolge von Sand-Schluf-Ton/Klei. Aussüßungen des Meerwassers führten zur Vermoorung, die sich in den abwechselnden Schichtstärken der Bodentypen abzeichnet (BEHRE 2004, 28, Abb. 2). Während sich die schweren Sedimente im nahen Küstenbereich ablagerten und zu einem natürlichen Uferwall 
aufwuchsen, vermoorte der perimarine Bereich. Der ansteigende Meeresspiegel und zusätzliche Störungen im natürlichen Entwässerungssystem ließen vernässtes Sietland entstehen. Mit dem Meeresspiegelanstieg im Atlantikum kam es zur Bildung einer Flussmarsch, die aus Ablagerungen von Süß- und Brackwassersedimenten entstand.

Die küstennahen Marschenböden generieren sich als Seemarsch über den Status Kalkmarsch zur Kleimarsch. Ursprünglich mit Hilfe maritimer Sedimente aufgeschlickt, zeichneten sich die Marschen durch fruchtbare Böden und bestes Weideland aus. Seit dem Seedeichbau findet, mit Ausnahme von Deichbrüchen oder planmäßigen Überflutungsaktionen, kein natürlicher Nährstoffzuwachs mehr statt. Somit entkalkt die alte Marsch permanent und eine Bewirtschaftung ist nur mit Zugabe von Kunstdünger möglich.

Die Seemarsch als kalkreicher, mariner Schlick wies ursprünglich noch einen Salzgehalt von $2 \%$ auf und war relativ locker gefügt. Mit der Zeit entkalkte die Seemarsch und verfestigte sich in ihrem Bodengefüge, so dass hier nur eine Grünlandnutzung ertragreich möglich ist.

Mit 2-4m Klei überschlickte Torfschichten charakterisieren die Moormarsch. Sie findet sich in tiefgelegenen Regionen, wie dem Sietland, wo ein hoher Grundwasserstand das Moorwachstum begünstigt hat. Ihre landwirtschaftliche Nutzung ist aufgrund des sauren Bodenmilieus und der Kalkarmut nur eingeschränkt als mäßige Grünlandnutzung möglich.

Brackmarschböden liegen im Mischbereich von Salz- und Süßwasser vor und sind mehr oder weniger schwach kalkhaltig. Kalkbrackmarsch findet sich in Vordeicharealen, während ältere Brackmarsch meist eingedeicht ist. Ein hoher Grundwasserstand lässt sie zunehmend versauern, so dass sie sich oft nur noch als Grünland nutzen lassen (SEEDORF 1992, 186-187).

Die Süßwassermarsch entsteht überwiegend ohne den Einfluss von Meerwasser. Es sind meist schwere tonreiche und weitgehend kalkfreie Böden. Letzteres behindert eine landwirtschaftliche Nutzung mit Ausnahme der Grünlandbewirtschaftung. Die leichten Flussmarschböden auf den Uferwällen eignen sich nach erfolgter Bodenmelioration und entsprechender Kalkung eher für den Ackerbau (SEEDORF 1992, 187). Eine unmittelbare Kultivierungsfolge ist sowohl bei Marschen- wie auch Moormarschböden die durch Wasserentzug erfolgte Bodensackung. Da Überschwemmungen ausbleiben, wird die Marsch nicht weiter aufsedimentiert. Die Niveauabsenkung erhöht das Versalzungsrisiko der küstennahen Böden durch eindringendes Seewasser und die Vernässungsgefahr durch rückgestautes Binnenwasser.

Die Marsch von Ems und Jümme ist landschaftlich unterschiedlich stark ausgeprägt. Südlich des Straßendorfes Nortmoor erstreckt sich das weitläufige Niederungsgebiet der Leda-Jümme-Senke. Die Jümme-Niederung zeichnet sich durch eine geringe Uferwallbildung und einen relativ schmalen 
Flussmarschsaum aus, der am Zusammenfluss von Jümme und Leda eine maximale Breite von 4km aufweist. Verschieden mächtige Torfschichten und Kleiablagerungen späterer Überschwemmungen haben den nördlichen Teil des Urstromtals aufsedimentiert.

Die Flussmarsch der Leda reicht bis zum Holtlander Tief auf Höhe der Ortschaft Potshausen, während die Marsch der Jümme erst kurz vor Stickhausen, nahe der ehemaligen Oldenburgischen Landesgrenze, ausläuft.

Bis zum Bau der mittelalterlichen Deiche stand die ostfriesische Küstenregion unter Einfluss der Gezeiten. Hinter einem bis zu $2 \mathrm{~m}$ aufsedimentiertem Hochland erstreckte sich eine tieferliegende Marschenzone. Das Sietland bot weite Überschwemmungsgebiete für auflaufende Meeresfluten, die das Land im Gegenzug mit einer fruchtbaren Schlickschicht bedeckten. Die junge Marsch nahe bzw. auf dem Uferwall ist nährstoffreich und insofern ertragreicher für den Ackerbau, während die alte Marsch im Sietland tiefer lieg, dadurch eher vernässt und von geringerer Bodenqualität ist.

Die Untere Emsregion war in der römischen Kaiserzeit durch einen flussbegleitend niedrigen natürlichen Uferwall und einer davor gelagerten Überflutungszone geprägt. Der niedrig ausgebildete Uferwall der Flüsse hielt Sturmfluten selten stand, jedoch wird das MThw in der Unteren Ems in der Zeit um Christi Geburt relativ gering ausgeprägt gewesen sein. Insbesondere die deutlich ausgebildete Flussschleife der Ems bei Emden verlangsamten die Strömungsverhältnisse. Doch bereits die römischen Quellen bezeugten für das Mündungsgebiet der Ems einen starken Einfluss der Gezeiten (Plinius hist.Nat. XVI, 2; Cassius Dio LIV, 32, 2.3).

Östlich der Ems herrschen relativ hohe und trockene Uferwälle vor, hinter denen sich ein niedriges und mit Kleiablagerungen mehrfach überschlicktes Niederungsmoor anschloss. Die alte Marschenoberfläche im Reiderland zeichnet sich durch geringe Geländehöhen aus, die in der Regel unter $0,0 \mathrm{~m}$ NN liegen. Vom Uferwall der Ems $(+0,7 \mathrm{~m} \mathrm{NN})$ fällt das Areal nach Südwesten bis auf $-1,2 \mathrm{~m}$ NN zum Sietland hin ab. Der aus Torf und marinem bis brackigem Ton bestehende geologische Untergrund weist bei Wasserentzug ein destabiles Gefüge auf. Seit dem Mittelalter erfolgte durch die Anlage künstlicher Gräben sowie durch eine lokale Prielerosion eine Sackung des Niedermoortorfs mit anschließender Humifizierung. Bei der Setzung kam es zu einer 80\% Verdichtung des Torfes (UERKVITZ 1997, 56).

Die Flussmarsch bot aufgrund ihrer scharfen geologischen Gliederung nur wenige Möglichkeiten für eine Besiedlung. Siedlungsgünstig war der Uferwall, auf dem sich die Ansiedlungen befanden und von dem aus die fruchtbare Marsch bewirtschaftet wurde. Die Besiedlung erfolgte auf einem breiten und leicht erhöht liegenden Uferwall der Ems. Erst mit dem Einbruch des Dollarts wurden die Niedermoore großflächig mit Tonsedimenten überdeckt (BEHRE 1970, 45). 
Waren die Flachsiedlungen in der Marsch lange Zeit den Meeresfluten ausgeliefert, schützte man zunächst die Hausplätze mit einem Podestbau, während Ringdeiche die Sommerweiden sicherten. Als dies nicht mehr ausreichte, begann im 11. Jahrhundert die Anlage von Seedeichen, die im 13. Jahrhundert die ostfriesische Halbinsel nahezu komplett umgrenzten (SEEDORF 1992, 90).

Zunächst waren die Oberflächenveränderungen in der Marsch infolge des mittelalterlichen Seedeichbaus noch gering. Die Reduktion der natürlichen Überflutungsflächen erhöhte jedoch an der Küste die Gefahren einer Sturmflut. Zusammen mit einer erneuten Transgression kam es zu den großen mittelalterlichen Meereseinbrüchen an Unterems und Jade.

Mit abgeschlossener Bedeichung erhöhten sich seit dem 13. Jahrhundert sukzessiv Stauwirkung und Sturmflutpegel in der Unteren Ems-Region. Die zeitgleich durchgeführten Entwässerungen hatte beträchtliche Geländesackungen zur Folge. Der anschließende spätmittelalterliche Dollarteinbruch verursachte großflächige Überflutungen und bedeckte die reiderländischen Moore mit einer $20-50 \mathrm{~cm}$ mächtigen Tonschicht. Die kalkreichen sandigen Tonböden eigneten sich gut als Ackerland.

Erst ab dem 15. Jahrhundert konnten die neu entstandenen Buchten von Dollart, Ley- und Harlebucht durch Einpolderungsarbeiten zurückgedrängt werden (SEEDORF 1992, 312, Abb. 166). Die neu entstandenen Buchten kappten die Zuflüsse für die bestehenden Meerbusen teilweise oder sogar ganz. Eine Folge waren u.a. die Verlandung der Bucht von Sielmönken in der Krummhörn und der Maadebucht bei Jever (BEHRE 2003, 43-44, Abb. 16).

\section{Ziele und Methodik}

Ziel der Studie ist es, neben einer allgemeinen Bestandsaufnahme archäologischer Fundstellen aus dem Untersuchungszeitraum im Landkreis Leer, den Siedlungs- und Bestattungsplatz Nortmoorer Hammrich vorzulegen. Dies beinhaltet die wissenschaftliche Auswertung der Grabungsdokumentation und aller Funde, um so die kulturhistorische Stellung innerhalb des Unteren Emsgebietes und im überregionalen Kontext bestimmen zu können.

Die Befundvorlage der Siedlung Nortmoorer Hammrich bildet einen wichtigen Bestandteil der vorliegenden Arbeit. In diesem Abschnitt werden die Baustrukturen, die zu baulichen Einheiten von Gebäuden, Speichern oder Zäunen rekonstruiert werden, vorgelegt. Da chronologisch relevante Befundüberschneidungen selten auftreten, wird das keramische Material aus den Befunden herangezogen, um diese zeitlich einzuordnen. Mit Ausnahme der fundreichen hausbegleitenden Gruben und einiger Vorratsgruben verfügen Baubefunde jedoch nur über geringe Fundmengen. Dennoch können einzelne Siedlungsphasen untereinander abgegrenzt werden. Bei Wohnbauten wird eine geschätzte Bestandszeit der eingetieften Pfostenbauten von 40-60 Jahren angenommen und dies 
mit dem zugehörigen Keramikrepertoire verknüpft. Grundbedingung ist hierbei eine massive Bauweise mit Pfostendurchmessern von über $35 \mathrm{~cm}$, die eine konstruktive Funktion übernehmen konnten. Die Siedlungsüberreste gehören verschiedenen Zeitstufen an, die sich durch unterschiedliche Bauweisen voneinander abheben. Während die bronzezeitliche Phase eine eher isolierte Lage ihrer Wohnbebauung aufweist, ist die kaiserzeitliche Siedlung durch nah beieinanderstehende Wohn- und Speicherbauten geprägt, die von Zäunen umhegt war. Für die jüngerkaiserzeitliche Siedlungsphase bestehen vereinzelte Befundüberschneidungen.

Generell einschränkende Faktoren bei der Befundinterpretation sind schlechte Erhaltungsbedingungen. Ist die ursprüngliche Oberfläche, d.h. der ehemalige Laufhorizont, durch Bodeneingriffe weitgehend erodiert und gestört, geht dies zumeist auch einher mit tiefreichenden Störungen der archäologischen Fundstelle. Oft verschwinden flach eingetiefte Befunde spurlos. Einen letzten Hinweis auf abgetragene Siedlungsgruben können verstreut liegende Holzkohlereste oder gebrannte Lehmbrocken geben. Sind gering eingetiefte Pfostengruben noch rudimentär erhalten, so ist doch häufig eine konstruktiv bedingte Schrägstellung im Profil nicht mehr festzustellen. Dies kann bei Gebäudegrundrissen eine Zuordnung zu einem Konstruktionstyp erschweren bzw. unmöglich machen. Die erhaltenen Baubefunde aus der Siedlung Nortmoorer Hammrich erlauben gleichwohl Aussagen über die Siedlungs- und Wirtschaftsweise ihrer Bewohner. Übergreifende Fragestellungen ergeben sich in Bezug auf die bäuerlichen Siedlungsstrukturen, den Grad der Organisationsform sowie für die Bereiche Handwerk und Handel im Unteren Emsgebiet. Hierzu werden vergleichend Baubefunde aus überregionalen Siedlungsgrabungen einbezogen.

Ziel der Materialvorlage ist es die bisher schwer fassbare lokale Keramik zeitlich besser einzuordnen. Günstig ist das relativ große Aufkommen von Importgefäßen und ihre Vergesellschaftung mit einheimischer Ware. Dennoch zeigt sich die Masse des Keramikmaterials chronologisch unsensibel. So ist zu untersuchen, ob übergreifend von Gefäßgruppen feste Gestaltungsprinzipien abzuleiten sind, die es erlauben, Gefäße verschiedener Funktion als zeitlich nah bzw. zeitgleich zu stellen.

Das keramische Fundgut wird nach dem bestehenden typologisch-chronologischen System gegliedert (SCHMID 1965; VAN Es 1970; WATERBOLK 1978; LeHMANN 2002; STILKE 1995), jedoch entsprechend neuerer Erkenntnisse modifiziert. Die Materialbasis für das Untere Emsgebiet hat sich seit der letzten Aufnahme vor über 40 Jahren erheblich erweitert und eine sorgfältige Aufarbeitung des vorhandenen Fundmaterials ist unerlässlich. Ein überregionaler Vergleich erfolgt mit angrenzenden Gebieten (u.a. FöRST 1991; GAEDTKE-ECKARDT 1991; HALPAAP 1994).

Anhand des Fundmaterials können kulturelle Beziehungen vielfältiger Art zwischen Ostfriesland und den benachbarten Kulturräumen aufgezeigt werden. Nachgegangen wird der Frage nach Dauer und Intensität der Kontakte, die sich unter anderem in (proto-) friesischen, elbgermanischen oder 
niederrheinisch-westfälischen Keramikformen manifestierten. Zahlreiche Importfunde östlich der Unterems aus dem Bereich der flussnahen Niederungen belegen für die römische Kaiserzeit, wie auch für das Mittelalter, eine Anbindung an ein überregionales Handelsnetz. Damit relativiert sich die bisher hervorgehobene Bedeutung des Reiderlandes.

Ein weiteres Ziel der Arbeit ist die Erstellung eines Fundstellenkataloges für den Landkreis Leer, wofür sämtliche Fundstellen der römischen Kaiserzeit bis zum Frühmittelalter zusammengestellt wurden. Altfunde bis 1972 der archäologischen Landesaufnahme und die in der Literatur erwähnte Fundstellen bilden die Basis der siedlungsarchäologischen Analyse. Fundmaterial aus dem Untersuchungsgebiet, welches nach 1972 geborgen wurde, findet summarisch Eingang in die Studie. Hier behält sich der Archäologische Dienst der Ostfriesischen Landschaft zukünftige Publikationsrechte vor.

Das archäologische Quellenmaterial des behandelten Zeitraumes wird in seinen wesentlichen Ergebnissen vorgelegt. Insgesamt wurden 69 Fundstellen aus dem Untersuchungsgebiet aufgenommen. In einigen Fällen sind diese mehrperiodig. Terminologisch stellt eine Fundstelle ein übergeordneter Begriff dar, der teilbar ist. Somit erhöht sich bei mehrperiodischen Fundstellen nicht die Gesamtzahl der Fundstellen. Aufgenommen wurden Siedlungs-, Bestattungsplätze, Depot- und Flussfunde. Unberücksichtigt blieben undatierte Plätze und Fundstreuungen.

Die Grundlage der historischen Regionalforschung bildet die archäologische Landesaufnahme. Bei ihrer Auswertung ist für jede Fundstelle der Quellenwert zu überprüfen. Die Fundumstände (wie Oberflächen- oder Prospektionsfund, Rettungs- oder Plangrabung, sowie Altfund oder ein jüngerer Fund) beeinflussen direkt die Qualität der Fundstelle. Ihre Aussagefähigkeit steht zudem inhärent mit dem Erhaltungszustand der Fundstelle und einer sorgfältigen Fundbergung in Verbindung; letzteres war im Arbeitsgebiet qualitativen Schwankungen unterworfen (vgl. Kap. Quellenlage). Unerlässlich ist darüber hinaus eine fachgerechte Grabungsdokumentation.

Die Fundplatzdichte hängt jedoch nicht nur von der Intensität der bodendenkmalpflegerischen Betreuung ab. Zu berücksichtigen sind natürliche sowie anthropogen bedingte Bodenauf- oder abträge, die die Fundstellenauffindung und somit die Fundkartierung entscheidend beeinflussen können.

Basierend auf der archäologischen Landesaufnahme wird der Siedlungsablauf im Arbeitsgebiet unter Einbeziehung der sich wandelnden Landschaftsgestalt untersucht. Angestrebt ist darüber hinaus eine Naturraumanalyse und die Rekonstruktion von Lebens- und Umweltverhältnissen für den untersuchten Zeitraum. Aufschluss über die Vegetations- und Klimaentwicklung geben Pollenanalysen und ${ }^{14} \mathrm{C}$ Datierungen. 
Durch die Gegenüberstellung der verschiedenen Besiedlungsvorgänge sind Veränderungen im Siedlungsmuster fassbar. Es schließt sich die Frage nach der Regionalität dynamischer Prozesse an. Untersucht werden die Ursachen für die in der römischen Kaiserzeit an der Unteren Ems und in Teilen der nördlichen Niederlande festgestellten Siedlungsverdichtung.

Bisher ungeklärt ist der Umfang der völkerwanderungszeitlichen Siedlungskontinuität im Untersuchungsgebiet. Hinter dem oft auch als Siedlungsrückgang bezeichneten Vorgang werden verschiedene Faktoren wie zufällige Fundlücken, Änderungen im Siedlungswesen, lokale Siedlungsverlegung oder Schwierigkeiten bei der Keramikdatierung vermutet (vgl. WATERBOLK 1979). Bei der Analyse der Siedlungsabläufe zeigt sich, dass einige Siedlungen kontinuierlich bis in die Völkerwanderungszeit bestehen blieben, während bei anderen in der römischen Kaiserzeit ein vollständiger Siedlungsabbruch zu beobachten ist und auch im Frühmittelalter keine Neubesiedlung erfolgte. $\mathrm{Zu}$ untersuchen ist, inwieweit dies eine Folge schwerwiegender ökologisch-ökonomischer Veränderungen war. Bei der Auf- bzw. Neubesiedlung Ostfrieslands im Frühmittelalter stellt sich die Frage, inwieweit dieser Prozess Teil einer, möglicherweise geplanten, Kolonisationsbewegung war.

Von der Bearbeitung ausgenommen wurde die Seemarsch der Krummhörn im Nordwesten Ostfrieslands, um das umfangreiche Fundmaterial auf ein bearbeitungsfähiges Maß zu reduzieren. Zudem ergeben sich im Gebiet der fruchtbaren Altmarsch andere Fragestellungen als für den ausgewählten Naturraum.

\subsection{Grundüberlegungen zur Chronologie}

Historische Aussagen und die Rekonstruktion des Kulturverhaltens sind ein Ziel einer Materialanalyse. Ausgehend von den Funden und Befunden wird eine kulturhistorische Einteilung des Siedlungsplatzes Nortmoorer Hammrich vorgenommen. Die Vorlage des Fundmaterials erfolgt hierbei nach Materialgruppen getrennt. Den überwiegenden Teil machen Keramikscherben verschiedener Zeitstufen aus, gefolgt von Steinartefakten und wenigen Metallobjekten, wie zum Beispiel einer römischen Münze. Ergänzt wird das Fundrepertoire durch wenige Glasfragmente. Menschliches Skelettmaterial entstammt neun Brandbestattungen von der Nortmoorer Düne.

Die Typenbildung der Keramik erfolgt anhand der Randausformung, ergänzend über die Schulterform und die Warenart. Aufgenommen wurden aussagefähige Scherben, d.h. Rand-, Boden- und verzierte Wandungsscherben sowie Henkel- und Deckelfragmente. Bestehende Typologien aus dem nordwestdeutschen Küstengebiet sowie der südlich anschließenden Gebiete werden am Material überprüft und gegebenenfalls überarbeitet.

Einen Großteil der wissenschaftlichen Arbeiten beschäftigt sich mit der deskriptiven / ausführlichen 
Vorlage des umfangreichen archäologischen Fundmaterials, während die chronologische Einordnung im Verhältnis nur einen kleinen Teil ausmacht. Oft berufen sich die Untersuchungen auf ältere Keramikstudien von denen das Material nur in Ausschnitten publiziert vorliegt. Ein Circulus vitiosus ist bei einer solchen Vorgehensweise impliziert. Die Überprüfbarkeit der verwendeten Chronologieregeln ist eine Grundforderung an typologische Reihen.

Anhand einer Datierung des keramischen Materials sollen die bestehenden Epochengrenzen zwischen der römischen Kaiserzeit, der Völkerwanderungszeit und dem Frühmittelalter näher eingegrenzt werden. Dabei gilt es zu klären, inwiefern am Fundmaterial ein Umbruch erkennbar ist, wie eine Stufe definiert wird und ob es eine Chronologieregel für zwei Objekttypen gibt. Nach STEUER $(1979,43)$ folgen Objektstufen kontinuierlich, z. T. überlagernd, aufeinander. Die typo-chronologische Sensibilität archäologischer Funde variiert jedoch. So sind beispielsweise bei Grabbeigaben frühgeschichtlicher Kulturen wie den Merowingern aufgrund der Umlaufzeiten des Materials typologische Änderungen in einem Zeitraum von weniger als 50 Jahren nicht mehr feststellbar (vgl. KNORR 2001, 6). Es stellt sich die Frage, inwieweit derartige Beobachtungen auf das keramische Fundmaterial einer Siedlung übertragbar sind. Eine von einigen Autoren vorgenommene gegenseitige Bezugnahme des datierenden Materials birgt die Gefahr von Zirkelschlüssen und ist deshalb zu vermeiden.

Da aus dem Unteren Emsgebiet eine auffällige Häufung römischer und römisch beeinflusster Funde vorliegen, werden Vergleichsstudien in diese Arbeit integriert. Ein Augenmerk liegt insbesondere auf germanischen Fundstellen, die provinzialrömische Funde oder deren Derivate aufweisen.

Unter den Importen erlauben Münzfunde einen 'terminus post quem', innerhalb der eine Münzprägung vorgenommen wurde. Da die Münzlaufzeit jedoch mitunter mehrere hundert Jahre betragen kann, ist dies nur ein ungefährer Richtwert, der durch weitere Funde zu erhärten ist. Einen besseren Datierungsansatz geben Keramikimporte der Terra Sigillata Keramik. Insbesondere TS Typen mit kurzer Verwendungsdauer und einer Vergesellschaftung mit einheimischen Funden können als `terminus post' verwendet werden.

Die bisherigen Datierungen werden unter Vorbehalt berücksichtigt, zumal diese oftmals von südfranzösischen oder italienischen Manufakturreihen abgeleitet werden. Es ist daher von einer zeitlich verzögerten Übernahme dort hergestellter Produkte auszugehen. Diese Vorgehensweise eignet sich auch bei in-situ geborgener Pingsdorfer Importkeramik.

Naturwissenschaftliche Datierungsverfahren gewinnen zunehmend an Bedeutung. Sie dienen i.d.R. als 'terminus post quem'. Unsicherheiten in der ${ }^{14} \mathrm{C}$-Analyse können zu abweichenden Werten führen, die im übrigen Fundmaterial nicht wiedergegeben werden. Dendrochronologische Analysen ermöglichen einen 'terminus at', müssen jedoch in Relation gesehen werden $\mathrm{zu}$ einem oftmals 
untersuchungsbedingten Toleranzfaktor, der zwischen ${ }^{+/ 10}$ bis ${ }^{+/-70}$ Jahren liegen kann.

Bei Befunden mit zahlreichen Holzeinbauten größerem Umfangs kann es zu einer längeren Nutzungsdauer kommen. Zu berücksichtigen ist auch eine mögliche Sekundärverwendung der Hölzer. So im Fall einer 6m durchmessenden Wasserstelle (B 11; Kat.Nr. 195) in Nortmoor. Die dendrodatierten Hölzer weisen ein abweichendes Fälldatum von fast 100 Jahren auf. In dieser Zeit kam es zu zahlreichen Ausbesserungsarbeiten; teilweise mit zweitverwendeten Hölzern, die Ausarbeitungen aus anderen konstruktiven Zusammenhängen aufwiesen. Wird dies nicht erkannt, kann es zu verfälschten Laufzeitintervallen und somit entstellten Datierungen führen.

Letztlich sei noch auf die Ausgrabungsart hingewiesen. Erfolgt die Fundbergung in künstlichen Starten wird der Schichtzusammenhang der Funde gestört. Darüber hinaus ermöglichen stratifizierte Funde eher Aussagen über eine zeitliche Beziehung zueinander, wobei prinzipiell das untenliegende Objekt, wenn es in-situ ist, älter zu datieren ist als das darüber liegende Objekt.

\section{Quellenlage}

\subsection{Schriftliche Überlieferung}

Die schriftlichen Quellen über Ostfriesland können in eine römische und mittelalterliche Überlieferungsphase getrennt werden, wobei sich deutliche Schwankungen in der Quellenlage abzeichnen. So weisen die römischen Quellen einen Schwerpunkt im 1. Jahrhundert n. Chr. auf, während es in den folgenden Jahrhunderten nur sporadisch Nachrichten von den Küstenvölkern am nördlichen Ocean gibt. Die in augustäischer Zeit reiche Quellenlage rechtfertigt es sich intensiver mit den nordgermanischen Volksstämmen, insbesondere mit den Chauken, zu beschäftigen. Nachgegangen wird hierbei der Frage der Ausdehnung und Größeentwicklung des chaukischen Siedlungsgebietes, möglichen römischen Kontaktzonen an der deutschen Nordseeküste und ob sich im Unteren Emsgebiet eine wie auch geartete römische Administration ausbildete.

Von dem zweiten Überlieferungsstrang, der friesischen Frühgeschichte in Ostfriesland, existieren hingegen kaum Archivalien. Hier sind es nur wenige Quellen die einen Einblick in die frühe Missionsgeschichte wie die territoriale Eroberung Norddeutschlands unter fränkischen Vormacht geben.

\subsubsection{Römische Quellen zu den Chauken}

Norddeutschland gelangte erstmals im Zuge einer militärischen Großoffensive unter Kaiser Augustus in das Blickfeld römischer Außenpolitik. Es folgte eine fast 30-jährige Kampagne, die vielfach durch kriegerische Auseinandersetzungen mit den Stämmen der Germania magna bestimmt war und ihren Höhepunkt in den Jahren 12 v. Chr. bis 16 n. Chr. erreichte.

Die folgenschwere Niederlage im 'bellum Varianum' 9 n. Chr. und gescheiterte 
Wiedereroberungsfeldzüge unter Tiberius und Germanicus dienten römischen Autoren als Anstoß für eine intensivere Beschäftigung mit den rechtsrheinischen Stämmen, die sich in einer reichen literarischen Tätigkeit manifestierte. Von der ursprünglichen Informationsfülle, auf die verschiedene antike Schriften verweisen, ist jedoch nur ein geringer Teil erhalten.

Gleichwohl stellt die römische Überlieferung eine wichtige Primärquelle über die um Christi Geburt im Küstenraum der südlichen Nordsee siedelnden Stämme dar. Insbesondere die an dem Ems ansässigen Chauken hatten im Zuge verschiedener Flottenexpeditionen mehrfach direkten Kontakt mit dem römischen Heer.

Erstmals 12 v. Chr. fanden die Chauken aufgrund ihrer Unterwerfung durch Drusus Erwähnung in den Quellen. In den folgenden Jahren kam es zu wiederholten Begegnungen bei kombinierten Land- und Seeaktionen des römischen Militärs (Abb.6). Hierbei wurde das chaukische Siedlungsgebiet als Ausgangspunkt für Truppenbewegungen in die Lipperegion und Wesermarsch genutzt. Die im Zuge frühaugustäischer Seeexpeditionen erworbenen Erkenntnisse bildeten auch noch bei Ptolemaios den geographischen Wissenstand um die Mitte des 2. Jahrhunderts n. Chr.

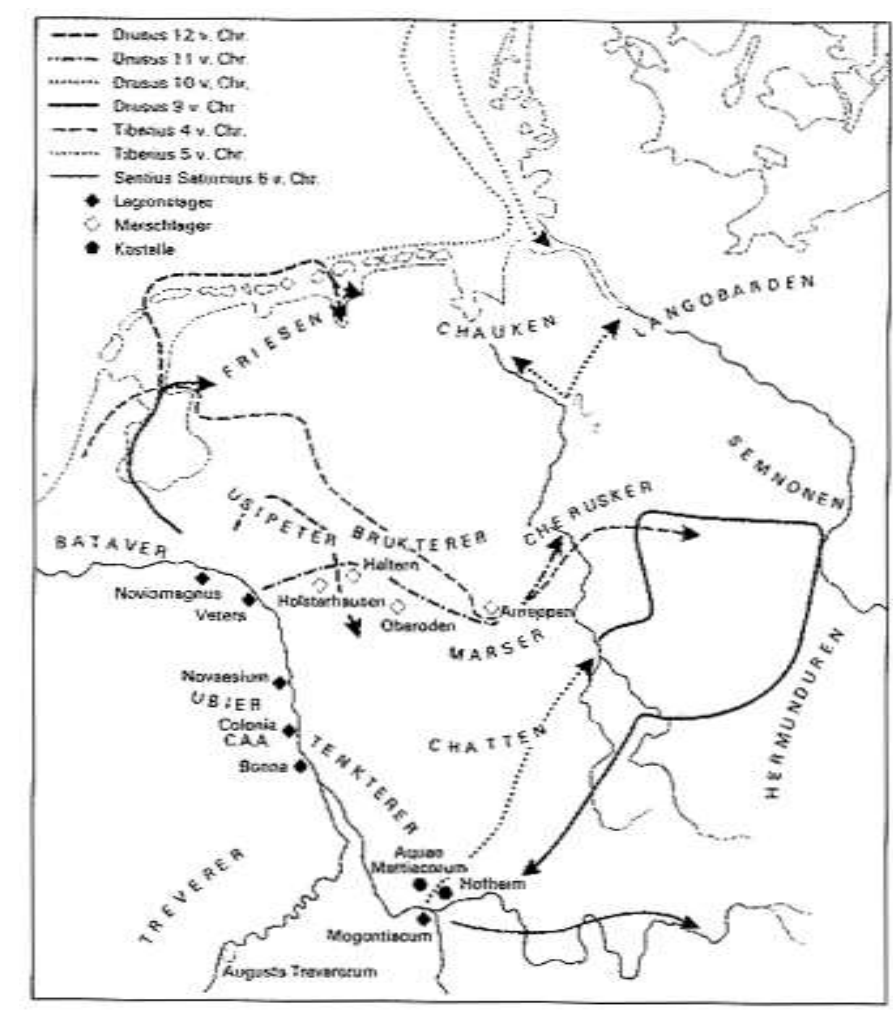

Abb. 6

Römische Unternehmungen in Germanien von 12 v. Chr. bis $6 \mathrm{n}$. Chr. (aus: WOLFRAM 1991, 46).

Während römische Quellen des 1. Jahrhunderts n. Chr. über die Anwohner der südlichen Nordseeküste 
umfänglich vorliegen, so existieren aus der späteren Kaiserzeit kaum noch schriftliche Zeugnisse. Diese vermeintliche Überlieferungslücke ist ein Ergebnis des schicksalhaften Richtungswechsels in der Germanenpolitik.

Unter Tiberius vollzog sich eine Neuorientierung an der Nordgrenze des römischen Reiches. $16 \mathrm{n}$. Chr. wurde mit dem Abzug römischer Truppen aus dem norddeutschen Raum das Ende der Germanenkriege eingeleitet. Eine Vielzahl der rechtsrheinischen Militärlager wurde aufgegeben. Freiwerdende Kapazitäten konnten von nun an aussichtsreicher im Britannienfeldzug eingesetzt werden (BERNECKER 1989, 321). Die hohe Legionsstärke am Rhein blieb jedoch weiterhin erhalten (JAHN 2001, 263).

In der Folgezeit orientierte sich die Reichspolitik stärker an einer indirekten und eher diplomatisch orientierten Einflussnahme auf die rechtsrheinischen Stämme. Da diese Vorgehensweise Erfolg versprach, ließ auch das Interesse der römischen Geschichtsschreiber an dieser Region nach. Eher vereinzelt kam es noch zu gezielten kriegerischen Aktionen in der Germania magna.

Auf dem Westufer der Rheins werden nach 47 n. Chr. zur Kontrolle der Grenzzone zahlreiche Kastelle errichtet und damit die statische Funktion der Grenzeziehung weiter festgeschrieben (ERDRICH 1995, 53). Der römische Herrschaftsanspruch in der Germania magna verlagerte sich zunehmend in westund süddeutsche Gebiete, die im Zuge des Limesbaus ab 80 n. Chr. bald ein fester Bestandteil des römischen Reiches wurden. Unter Claudius wurden schließlich sämtliche noch bestehende rechtsrheinische Lager geräumt (BERNECKER 1989, 83-84).

\subsubsection{Quellenkritik}

Ungeachtet der Informationsfülle, die die erhaltenen Schriftquellen über die Germania magna bieten, zeichnen sie sich aber durch eine römisch-zentristische Perspektive aus. Gemeinsam ist ihnen eine zumindest tendenziöse Verzerrung der Ereignisse, wobei die antiken Autoren in erster Linie militärisch relevante Vorkommnisse herausstellten.

Sie berichten über Aufstände, Truppenbewegungen und heldenhaftes Verhalten. Gelegentlich auch über Eigenheiten einheimischer Völker, verstummen jedoch oft ganz in Bezug auf allgemeine Beziehungen im interkulturellen Bereich oder wie sie im Handel bestanden haben.

Das Germanienbild der römischen Autoren bestimmte ein oft eher eingeschränkter Informationszugang, wie ihn zugängliche Senatsakten oder öffentliche Verlautbarungen des Princeps gestatteten (TIMPE 1999, 718). Nur wenigen Autoren kannten die Germania magna aus eigener Anschauung. Auch ist zu bedenken, dass es in der Antike generell nicht unüblich war Werke anderer Schriftsteller in eigene Manuskripte einzuarbeiten; oft ohne die verwendeten Quellen anzugeben. Der Quellenwert konnte je nach Zielsetzung des Autors divergieren. So finden sich hinter scheinbar neutralen Schilderungen, wie beispielsweise dem Weser-Feldzug unter Germanicus, kritische 
Untertöne am Regierungsstil des herrschenden Kaisers Tiberius (vgl. TIMPE 1968, 22; JAHN 2001, 4), während dasselbe Ereignis bei Cassius Dio ausgesucht Cäsaren-freundlich ausgeführt wird (vgl. ELMERS 1999, 597).

Neben dem römischen Bildungsbürgertum bildete immer auch die politische Elite, insbesondere die herrschende Kaiserfamilie, eine Zielgruppe für die Schriften der antiken Autoren. Bereits unter Augustus wurden Tätigkeitsberichte und Kaiserbiographien planmäßig in Auftrag geben, die sich in erster Linie durch Konformität und Staatstreue auszeichneten (JOHNE 1976). Die Bandbreite römischer Quellen über die Germania magna reicht von ethnographisch-kartographischen Studien, wie bei Ptolemaios, bis hin zu politisch motivierten Ausführungen, die oft auch eine Spiegelung innerrömischer Verhältnisse zum Ziel hatten. Diese grundsätzlichen Überlegungen sind bei der Quellenvorlage zu beachten.

\subsubsection{Römische Autoren}

Neben eher allgemein gehaltenen Darstellungen, wie bei Strabon (64/65 v. bis 23 n. Chr.) und Pomponius Mela (um 43/44 n. Chr.), finden sich nur wenige Autoren, die den Norden Germaniens aus eigener Anschauung kannten. Einer der bekanntesten Geschichtsschreiber, C. Plinius Secundus Maior (23/24 bis 79 n. Chr.), nahm 47 n. Chr. an einer Strafexpedition zu den Chauken teil und veröffentlichte später seine Erlebnisse (Plin.nat.hist. IV,98-100; IV,16,2-6). Er widmete sein Hauptwerk 'bella Germaniae' dem Andenken an Drusus, der als erster römischer Feldherr bis an die Elbe vorstieß. Von Plinius umfangreichem Werk, 20 Büchern über die Germanenkriege und 31 Bände zur römischen Geschichte, ist allein die 'Naturalis historia' komplett erhalten. Teilweise kompensiert wird der Verlust durch die Schriften von Tacitus (55 bis nach 115 n. Chr.), der Plinius Werk in seiner 'Germania' und den `Annalen’ einfließen ließ (vgl. JoHNE 2006, 206). Tacitus Werk merkt man indes den Hader mit dem von Tiberius veranlassten Abbruch der Germanenkriege an (Tac.ann. I,11,1; II,26,2; vgl. JAHN 2001, 268). Tacitus publizierte seine Ethnographie der Germanen 98 n. Chr., im Anschluss folgten die Historien in 14 Büchern und die Annalen in 16 Büchern; von beiden Werken blieben nur Fragmente erhalten. Schwerpunkt beider Werke war die römische Staatsaristokratie, wobei ein übermäßiger Hang zur Moralisierung auffällt. Seine „Germania“ beschäftigte sich neben einer allgemein gehaltenen Einführung, mit dem öffentlichen und privaten Leben der Germanen. Genutzt wurden damals zugängliche, heute jedoch unwiederbringlich verlorene literarische Quellen. Somit steht Tacitus in der Tradition antiker Schriftsteller und übernahm, wo es ihm sinnvoll erschien, Beschreibungen anderer Werke. Tacitus stellt die Einfachheit und Sittenstrenge der Germanen heraus, wobei er immer bemüht war, dem römischen Leser einen Spiegel vorzuhalten.

Erhalten ist der Zeitzeugenbericht des Velleius Paterculus (9 v. bis um 31 n. Chr.), der kurz nach Christi Geburt eine Flottenfahrt vom Rhein ausgehend in die Nordsee und von dort die Elbe hinunter 
begleitete (Vell.Pat. hist.romana II,100). Velleius Dienst als römischer Offizier führte ihn in den Jahren 4 bis 6 und 10 bis 12 n. Chr. nach Germanien. Seine 29/30 n. Chr. fertiggestellten Schriften zeichnen sich durch eine tiefe Verbundenheit zu dem von ihm verehrten Tiberius aus (vgl. JOHNE 2006, 133). Schließlich ergänzen kaiserliche Verlautbarungen die Quellenlage zu den Ereignissen im fernen Germanien. Erwähnenswert ist die 'Res gestae Divi Augusti', die erste offizielle Lebensbeschreibung der Taten Kaiser Augustus.

In die antike Küstenbeschreibung Germaniens sind vermutlich auch Erfahrungsberichte von Soldaten und Fernhändlern eingeflossen. Zwar fehlen direkte Belege, einen Hinweis geben u.a. die im `Bellum Gallicum' überlieferten nautischen Anweisungen an römische Handelsschiffe (Bell.Gall. I,39). Caesar erwähnt, für eine geplante Britannienreise Kaufleute und Händler befragt zu haben (vgl. JOHNE 2006, 69). Letztmalig wird die norddeutsche Küstenregion um 222 n. Chr. im Geschichtskompendium des römischen Konsuls Cassius Dio erwähnt.

\subsubsection{Das Stammesgebiet der Chauken}

Mehrfach wird in den antiken Quellen das niedersächsische Küstengebiet als Siedlungsraum der Chauken genannt. So berichtet Ptolemaios, ein um 100 bis um 175 n. Chr. in Alexandria lebender griechischer Mathematiker und Geograph: „Das Land am Ocean bewohnen oberhalb der Brukterer die Friesen bis zur Ems. Hinter diesen sitzen die kleinen Chauken bis zur Weser, dann die großen Chauken bis zur Elbe, anschließend bis zur Landenge der Kimbrischen Halbinsel die Sachsen“ (Ptol. Geographica II,11,7.9 u. 7.16). Ansonsten werden die Lokalitäten genannt und teils listenhaft, teils mit topographischen Bezügen abgehandelt (KEHNE 1995, 29).

Auch Plinius und Tacitus erwähnen eine Zweiteilung der Chauken in `Chauki miniori`, die zwischen Ems und Weser wohnen, und den östlich angrenzenden 'Chauki majori' (Plin.nat.hist. IV,99,16,2; Tac.ann. II,11,19). Anhaltspunkte, ob sich hinter dieser Einteilung eine Angabe über das verwandtschaftlich-hierarchische Verhältnis zwischen beiden Gruppen verbirgt oder einfach eine Größenangabe des jeweiligen Stammesgebietes bzw. der Gruppestärke, fehlen bisher. Eventuell ist der Zusatz `miniori` im Zusammenhang mit Abstammung oder Alter des Chauken-Teilstammes zu sehen. Auch gibt es Überlegungen den Namenszusatz mit einem Doppelkönigtum, ähnlich wie Tacitus es für die Friesen andeutete (Tac.germ. XXXIV), gleichzusetzen (HAARNAGEL 1980, 395).

Wohl geht Tacitus, wenn er auf die besondere Größe des chaukischen Stammesgebietes hinweist, von den kleinen und großen Chauken als einem gemeinsamen Stammesverbund aus. Er berichtet, dass der südlichste Bereich ihres Territoriums bis zu den Chatten reichte. Diese hatten zuvor Teile des cheruskischen Stammesgebietes erobert und ihren Einflussbereich so nach Norden erweitert. Als weitere Nachbarvölker werden Angrivarier, Brukterer, Chamaven, Chasuarier und Dulgubner genannt. Zur Bevölkerungsstärke der Chauken vermerkt Tacitus: „Diese riesige Landfläche besitzen die Chauken nicht bloß, sondern sie füllen sie auch ganz aus:..“ (Tac.germ.XXXV). Zahlenmäßige 
Angaben sind nicht überliefert.

Die äußeren Grenzen des Siedlungsgebietes der kleinen Chauken bildeten die Ems im Westen und die Weser im Osten. Ihre südöstlichen Nachbarn waren die Angrivarier, deren Stammesgebiet an das der Friesen grenzte, die westlich der Ems lebten. Die Angrivarier schützten sich vor den südlich wohnenden Cheruskern durch einen Grenzwall (vgl. BERNECKER 1989, 290-291, Anm. 5; Tac.ann. II,8,4; II,19,3). Dieser wurde 15 n. Chr. Austragungsort einer entscheidenden Schlacht zwischen der germanischen Koalitionsarmee und dem römischen Heer (Tac.ann IXX-XXII; JAHN 2001, 252-255). Eine Gebietserweiterung der Chauken ist für die Mitte des 1. Jahrhunderts überliefert, als die kleinen Chauken, die bis dato an der Unteren Ems ansässigen Ampsivariern, in den Süden verdrängten (Tac.ann. XIII,55). Letztere wanderten in friesisches Gebiet ein, wo sie in der römischen Militärzone jedoch keine Aufnahme erhielten und erneut vertrieben wurden. Ein weiteres Nachbarvolk der kleinen Chauken waren die zwischen Ems und Hase siedelnden Chasuarier (Tac.germ. XXXV), während westlich der Weser bis zur Elbe sich das Siedlungsgebiet der großen Chauken erstreckte. Somit erscheint das gesamte niedersächsische Küstengebiet im 1. Jahrhundert $\mathrm{n}$. Chr. fest in chaukischer Hand.

War nun die Nordgrenze des chaukischen Territoriums durch die niedersächsische Küstenlinie begrenzt, sind mit Ausnahme von Ems und Weser keine topographischen Details zum Grenzverlauf überliefert. Die Quellen erwecken den Anschein, dass die genannten Gewässer feste Grenzmarken darstellten. Dem wiederspricht jedoch ein recht einheitlich wirkendes Fundmaterial beiderseits der Flüsse. Wie ein Quellenvergleich zeigt, liegen auch bei anderen germanischen Stämmen unpräzise Angaben über ihre Wohngebiete vor. Die wenigen überlieferten Ortsangaben orientierten sich häufig an naturräumlichen Gegebenheiten. Dies waren in der „terra incognita“ in erster Linie Flüsse, große Waldgebiete, Höhenrücken u.a.m., die mit Richtungsangaben wie nördlich, östlich etc. versehen wurden (CALLIES 1995, 179; TEEGEN 1995, 123).

Norddeutschland wurde in frühaugustäischer Zeit wiederholt, bald jährlich von römischen Truppen durchquert. Auffällig sind demgegenüber die recht knappen Aussagen in den antiken Quellen zu germanischen Stammesgrenzen. Hier verbergen sich sicherlich nur zum Teil geringe Kenntnisse der topographischen Begebenheiten. Wahrscheinlicher ist, dass militärisch relevantes Wissen nicht allgemein zugänglich war und die römischen Autoren auch kaum eine Intention hatten, ihrem Publikum präzise Grenzverläufe im fernen Germanien anzugeben. Weder war die germanische Topographie der zentrale Punkt ihrer geschichtlich orientierten Werke, noch wurde sie als wichtig eingestuft.

Die häufige Nennung größerer Flüsse steht vielmehr in der literarischen Tradition griechischer Gelehrter, wie dem 700 v. Chr. lebenden Hesiod, in der Flüsse oft als geographische Ordnungsgrößen 
anführt wurden (BERNECKER 1989, 33). Zudem waren die in der Germania magna den Einheimischen bekannten Wege für Ortsfremde schwer auffindbar (vgl. TIMPE 1989, 86). So stellten die damaligen (Wege-) Verhältnisse römische Truppenbewegungen vor nicht zu unterschätzende Schwierigkeiten. Dies auch, weil Streckenmessungen im barrierereichen Germanien oft problematisch waren. Hier boten sich Flussläufe als eine wichtige Orientierungsmöglichkeit an, um sich im unbekannten Terrain zu orientieren (vgl. JOHNE 2006, 92).

Schwierigkeiten bei der geographischen Einteilung germanischer Stammesgebiete ergaben sich u.a. durch den hohen Mobilitätsfaktor der Bevölkerung (vgl. Bell.Gall. IV,4,1). So stehen hinter den überlieferten Ortsangaben nur selten genau abgrenzte Areale, als vielmehr Siedlungsräume, die den Römern zu einem bestimmten Zeitpunkt bekannt waren.

Eine Vielzahl von Quellen verweisen auf innergermanische Wanderungen, bei denen (Teil-) Stämme ihre Wohnorte verließen, ob nun aus eigenen Antrieb oder weil sie vertrieben wurden. Aufgrund der hohen Mobilität der indigenen Bevölkerung konnten sich Siedlungsgebiete in relativ kurzer Zeit verschieben. Überliefert sind große Massenumsiedlungen, wie die von 40.000 Sugambrern 8 v. Chr. (WOLTERS 1999, 604-606). Daneben gab es häufiger wohl kleinere Gebietsverlagerungen bei germanischen Stämmen. So vertrieben im Jahre $58 \mathrm{n}$. Chr. Chauken die im Unteren Emsgebiet ansässigen Amsivarier (Tac.ann. II,8; XIII,55). Letztere begaben sich auf Wanderschaft und ließen sich am römisch besetzten Niederrhein nieder, was ihnen der römische Statthalter nicht erlaubte (SCHMIDT 1938, 87).

Germanische Wanderbewegungen wurden von den antiken Autoren oftmals erst dann registriert, wenn römische Interessen berührt wurden. Dies war beispielsweise bei den weit im Norden Germaniens wohnenden Chauken eher selten der Fall. Kam es zum Abbruch des direkten Kontaktes, wurden die bis dahin bekannten Informationen über die germanische Stammesgruppe in der Überlieferung weitergetragen, ohne das es zu einem neuen Erkenntnisgewinn kam.

Für die kleinen Chauken bedeutet dies, dass die Größe ihres Siedlungsgebietes um Christi Geburt ungefähr bekannt war und es sich bereits Mitte des 1. Jahrhunderts nach Süden verschob. Danach verblieben sie in ihrem angestammten Siedlungsgebiet, jedenfalls wurden spätere Gebietsänderungen in den Quellen nicht mehr vermerkt.

\subsubsection{Die chaukische Küste}

In Bezug auf topographische Details sind die literarischen Darstellungen der Germanenkriege meist wenig erschöpfend. Dies erklärt sich u.a. aus dem Bestreben der Autoren ihrem Lesepublikum mit Vorliebe das Bekannte und Typische am römischen Germanienbild zu präsentieren (JAHN 2001, 5). Eine häufig wiederkehrende Vorstellung behandelte den unwegsamen und undurchdringlichen Wald, der als Topos für die Wildheit und Barbarei seiner Bewohner angesehen wurde. Demgegenüber waren die bereits zur römischen Kaiserzeit zumeist entwaldeten Geest- und Marschgebiete Ostfrieslands 
wenig eindrucksvoll und fanden in den antiken Quellen keine Erwähnung.

Anders verhielt es sich mit den Naturgewalten der Nordsee, deren Gezeiten für die Römer ein in ihrem Ausmaß unberechenbares Erlebnis darstellten. Obschon sich Ebbe und Flut zwar in regelmäßigen Abständen wiederholten, stellten insbesondere starke Herbststürme und eine Kombination von Ebbe und Niedrigwasser in den Mündungsbereichen norddeutscher Flüsse die das ruhigere Mittelmeer gewohnten Römer vor enorme Schwierigkeiten.

Bereits früh lernte Drusus die Tücken der Gezeiten kennen. 12 v. Chr. blieb die Flotte vor der ostfriesischen Küste im Schlick stecken, als sie von der Ebbe überrascht wurde. Erst befreundete Friesen befreiten sie aus ihrer misslichen Lage (Cassius Dio LIV,32,1-3; Tac.ann. IV,72,1). 9 v. Chr. erfolgte eine zweite Seeexpedition bei der Ems, Weser und Elbe erreicht wurden. Nach den ersten Flottenfahrten in die südliche Nordsee erlahmte zunächst das römische Interesse an der Ems-Region. Auch eine weitere Elberkundungsfahrt unter Leitung von Domitius Ahenobarbus 3 v. Chr. änderte wenig an dem bestehenden Status quo (Dio LV,10; Tac.ann. IV,44).

Ausgangspunkt der Flottenreisen waren die Rheinbasen. Mit zunehmender Entfernung zu diesen bot sich das Untere Emsgebiet als Zwischenstation an. Dazu später mehr.

Unter Tiberius fanden erneut Schiffsexpeditionen bis zur Ems und darüber hinaus statt. Überliefert ist für $5 \mathrm{n}$. Chr. das letztmalige Erreichen der Elbe in einer kombinierten Flotten-Landheeroperation, bei der die Elbe jedoch aufgrund einer Verordnung von Kaiser Augustus nicht überschritten werden durfte (Strabon VII,1,4). Schon ein Jahr vorher gelangte ein römischer Schiffsverband bis an die Nordspitze Jütlands, dem sogenannten Kimbernkap (Plin.nat.hist. II,167; IV,96; vgl. Ptol. II,11). Im Anschluss an die Kapfahrt wird für das Jahr $4 \mathrm{n}$. Chr. ein Winterlager an der Nordseeküste rekonstruiert, bevor Tiberius ungewöhnlich früh im Folgejahr die Elbe erreichte (JOHNE 2006, 143-146).

Nach einer mehrjährigen Pause setzten die Flottenfahren wieder ein, als Tiberius die Emsmündung 10 und $11 \mathrm{n}$. Chr. aufsuchte. Tiberius übergab $13 \mathrm{n}$. Chr. das Oberkommando der Rheinlegionen an Germanicus (Tac.ann. IV,5.2). Der Sohn des Drusus unternahm 15 n. und 16 n. Chr. weitere Flottenfahrten an die Ems, um von hier ins Lippe-Ems-Dreieck zu gelangen (BERNECKER 1989, 289290; Abb.7).

Bereits um 330 v. Chr. wurde das Wattenmeer der Nordsee vom griechischen Geograph Pytheas von Massila aufgesucht (Plin.nat.hist. XXXVII,35). Auch Polybios erwähnt in seiner im 2. Jahrhundert v. Chr. verfassten Geographica die wechselnden Gezeiten und das raue Küstenklima des nördlichen Ozeans (Geograph. Hyphegensis). Ältere Nachrichten liegen in den Werken von Homer und Poseidonios vor, werfen jedoch ein mythologisch verklärtes Bild auf den Rand der antiken Oekumene (Strabon I1,6-7sq.p). Über die geographischen Gegebenheiten an der Nordseeküste waren die Römer also einigermaßen unterrichtet. Dies zeigen insbesondere die Angaben von Strabon, der in seinem um 18 n. Chr. verfassten Werk über das römische Reichsgebiet auch die germanische Nordseeküste 
beschreibt (Stabon VII).

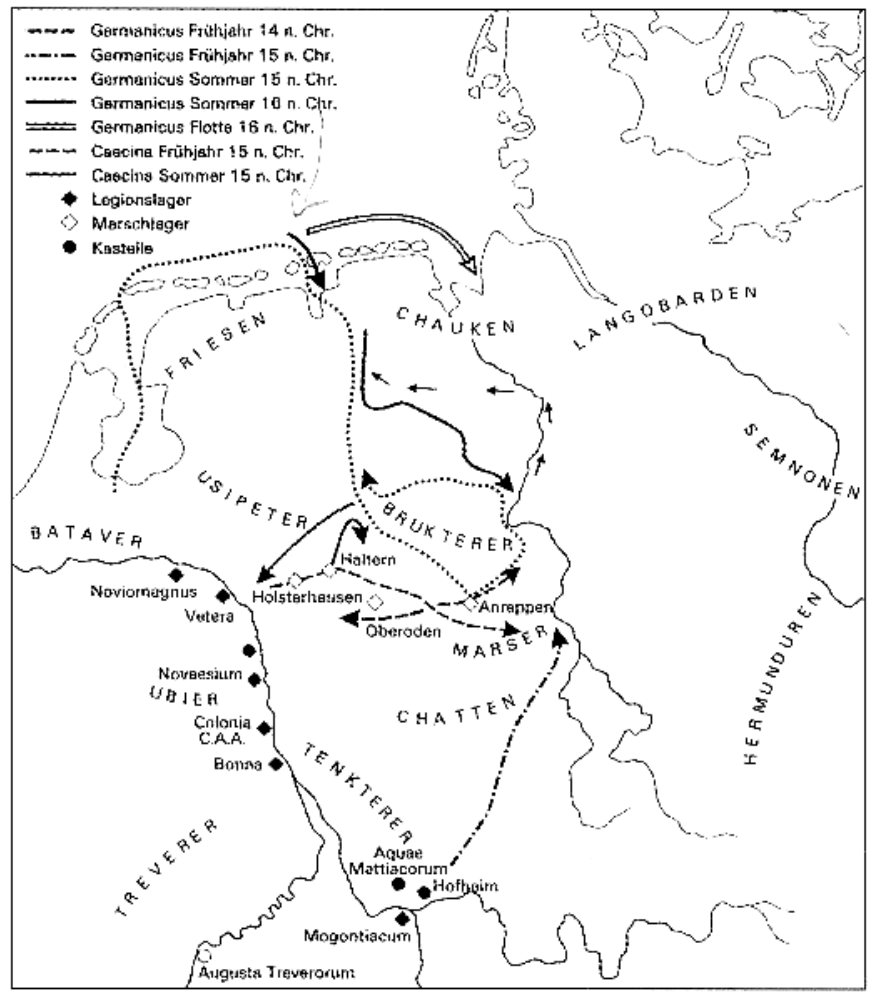

Abb. 7

Römische Unternehmungen nach Germanien von 14 bis 16 n. Chr.

(aus: WOLFRAM 1991, 47).

Überliefert sind für die frühaugustäische Zeit folgenschwere Havarien vor der germanischen Nordseeküste. Zwar segelten die römischen Versorgungsschiffe meist im Schutz der Küste, wurden jedoch des Öfteren auf ihrem Rückweg von der Ems mit mächtigen Herbststürmen konfrontiert. Die Erfahrung einer jahreszeitlich schwankenden Sturmsequenz machten neben Drusus auch die Schiffsverbände unter Tiberius und Germanicus.

Anschaulich schildert hierbei Tacitus die Gefahren einer Sturmflut, die das Heer des Germanicus $15 \mathrm{n}$. Chr. bei seinem Rückmarsch von der Unteren Ems beträchtlich dezimierte (Tac.ann. II,24,2-3; II,25,12). Zunächst erfolgte der Fußmarsch römischer Truppen entlang der friesischen Nordseeküste noch zu ebener Erde, wenig später wurde dieser von den einströmenden Wassermassen massiv behindert. Dies deutet darauf hin, dass das Truppenkontingent sich vermutlich nicht im Marschland, sondern in dem bei Ebbe wasserfreien Vorland bewegte und die Gefahren einer auflaufenden Sturmflut sträflich unterschätzte. Im folgenden Jahr wurden germanische Hilfstruppen auf den Weg zur Ems von den Gezeiten überrascht und es kam zu großen Verlusten (Tac.ann. II,8,124).

Eine besonders schwere Havarie ereignete sich nach der Schlacht von Idistaviso $16 \mathrm{n}$. Chr. als ein 
Großteil des Truppenabzugs über die Nordsee erfolgte (Tac.ann. II,23-24). Die Legionen marschierten aus der Gegend von Rinteln nach Norden und trafen gemeinsam mit Germanicus an der Ems ein, wo die römische Flotte wartete. In der Aussenems wurden die ausfahrenden Schiffe von einem gewaltigen Herbststurm überrascht. Eindrücklich beschrieben ist, wie sich die kenternden Schiffe ihres zusätzlichen Gewichtes entledigten und dazu Pferde, Vieh, Gepäck und Waffen ins Meer warfen. Der Dreiruderer von Germanicus rettete sich an die chaukische Küste (Tac.ann. II,24,2), wo sich auch andere, leidlich intakte, Schiffe nach dem Sturm sammelten. Verstreute Besatzungsmitglieder wurden von den Inseln geborgen, bereits verkaufte Söldner von den Angrivariern ausgelöst (JAHN 2001, 255, Anm. 1521). Die gesamte Darstellung weist auf eine gefährliche Springflut hin (FLACH 1995, 143166). Anschließend wurden die überlebenden Soldaten in ein Winterlager geführt und großzügig von Germanicus belohnt (Tac.ann. II,26,1). Auch Plinius und Starbon beschreiben eindrücklich den Gezeitenlauf der Nordsee (Plin.nat.hist. IV,97; XVI,2-6; Strabon VII,1,3). Auf eine Beschreibung vergleichbarer Ereignisse in Zusammenhang mit Meeresgewalten an der deutschen Nordseeküste wird hier verzichtet.

Plinius persönliche Erlebnisse an der deutschen Nordseeküste heben sich von den anderen Quellen durch eine außergewöhnliche Beschreibung hervor, die erstmalig einen Einblick in die Lebensbedingungen der indigenen Bevölkerung vermitteln (Plin.nat.hist. XVI,2-4). Demnach wohnten einige von ihnen auf Erdhügeln (Wurten) gleich „Schiffbrüchigen“ bei Flut und gleich „Gestrandeten“ bei Ebbe. Ihre Bewohnter verwenden „Erde“ (Torf) als Heiz- und Baumaterial und ernährten sich von Fisch, ihre Netze fertigen sie aus Binsen und Schilf. Trinkwasser bezogen die Bewohner aus Regenwassergruben (Thing/Zisternen) vor den Wohnhütten. Insgesamt erschien Plinius das Leben der Bewohner als ärmlich. Brennholz fehlte, ebenso wie natürlicher Bewuchs. Viehzucht war aufgrund fehlender Weideflächen nicht möglich. Vermutlich hat sich das beschriebene Szenario vor der ostfriesischen Küste zugetragen, wo Plinius von der Seeseite aus chaukische Fischer beobachtete, die auf einer relativ weit vom Festland entfernten Hallig wohnten (vgl. HAARNAGEL 1980, 114). Hingegen verstummt Plinius, wenn es um den Alltag der einheimischen Marschbewohner geht; möglicherweise war dies für seine Leser weniger bizarr.

Eine Besonderheit ist die Nennung vorgelagerter Nordseeinseln bei Plinius und Strabon. Insgesamt 23 an der Zahl, wird die Stellung der 'insula burcana' hervorgehoben. Die der chaukischen Küste vorgelagerte Insel Burcana, auch als Byrchanis überliefert, wurde von Drusus erobert, der 12 v. Chr. die Brukterer bei einem Schiffgefecht auf der Ems besiegte (Strabon VII,1,3; VII,7,3). Weitere Details über Lage, Größe, Aussehen oder ihre Bewohner sind nicht überliefert. Einziger Hinweis bietet die vermutlich namengebende altnordische Wortwurzel 'burkn' (Gebüsch, Gesträuch, Farnkraut), die auf einen landschaftsprägenden niedrigen Bewuchs hinweist. Plinius nennt die Insel „Bohneninsel“ (Plin.nat.hist IV, 96-97). Die 1780 untergegangene Insel Bant wird mit dem antiken Burcana 
gleichgestellt, wobei ihre Lage im Juister Watt gegenüber der ehemalige Bucht Sielmönken vermutet wird (HAARNAGEL 1980, 115). In der Antike war die Insel bedeutend größer als die neuzeitlich kartographierte Restinsel. Ihr Name ging später auf Borkum über.

Weitere naturräumliche Gegebenheiten Ostfriesland haben keinen Eingang in die Quellen gefunden. Durch ihre Fahrten die Ems hinunter war den Römern die Flussmarsch sicherlich geläufig, da sie sich jedoch kaum von anderen unterschied, unterblieb eine Erwähnung. Die weiträumigen Moorbarrieren am Geestrand wurden wohl wahrgenommen, haben aber ebenso wenig zur Erkundung des Hinterlandes eingeladen, wie auch die dahinter anschließende unfruchtbare Geestlandschaft.

\subsubsection{Die geopolitische Lage der Emsregion in der römischen Kaiserzeit}

Ausgangspunkt der römischen Okkupationsbestrebungen in der Germania magna waren germanische Überfälle auf provinzialrömisches Reichsgebiet, die 17/16 v. Chr. in der Niederlage des Lollius und der völligen Aufreibung seiner Legion endeten (Vell. II,97,1-2; Cassius Dio LIV,20,4-6).

Nach Neubewertung der militärischen Situation von römischer Seite aus folgte die Verlegung innergallischer Legionen an den Rhein zur Vorfeldsicherung der bis dahin durchlässigen Grenze (WOLTERS 1990, 153-160). Als Auslöser für Überfälle wurden neben der Beutegier der eingedrungenen Stämme ihre Vertreibung aus den angestammten Gebieten, ausgelöst durch elbgermanische Wanderbewegungen, angesehen. Beabsichtigt war daher früh schon deren Ausschaltung (ERDRICH 1995, 50-56).

Da die entfernt liegenden Siedlungsgebiete der Elbgermanen schwer zugänglich waren und auf dem Landweg kaum für ausreichend Nachschub zu sorgen war, reifte in der römischen Führung der Plan dies mit Hilfe kombinierter Land-Wasser-Operationen zu erreichen. Ähnlich wie bei der Eroberung Galliens sollten nun germanische Flüsse als Einfallstore für die Legionen dienen (JAHN 2001, 26-29).

Ausgangspunkt der Nordsee-Expeditionen waren die rheinischen Flottenstützpunkte in Nijmegen, Xanten und Bonn. Vier Jahre nach der Lollius-Niederlage begannen über Rhein und Nordsee römische Vorstöße in die Siedlungsgebiete von Friesen, Chauken und Brukterer, gefolgt von Feldzügen in das Lippegebiet und an die Weser (11 v. Chr.), bevor das römische Heer 9 v. Chr. die Elbe erreichte.

Früh erkannte Drusus die fehlende Infrastruktur in Germanien als Manko für eine erfolgreiche Okkupationspolitik. Auf die Schwierigkeit eines gefahrlosen Landmarsches durch die Germania magna verweisen auch zahlreiche antike Quellen (u.a. Mela III, 29). Das für römische Verhältnisse unzureichende Wegesystem gab Anlass sich verstärkt germanischen Flüssen zu zuwenden. Hierbei folgte Drusus zeitgenössischem geografischen Wissen, nachdem die germanischen Hauptflüsse Ems, Weser und Elbe parallel zum Rhein verliefen (Strabon VII,1,3), wobei die in das Nordmeer mündende Ems eine wichtige Bedeutung zukommen sollte. 
Zunächst noch durch das weitläufige Rheindelta behindert, veranlasste Drusus, als eine der ersten Maßnahmen nach der Lollius-Niederlage, den Bau eines künstlichen Kanals im friesischen Siedlungsgebiet. Der 12 v. Chr. erstmals erwähnte Kanal der `fossa Drusiana’ ermöglichte nun eine durchgängige Wasserstrasse, die vom Rhein aus über das Ijsselmeer bis in die Nordsee führte (JAHN 2001, 39-40). Nach seiner Fertigstellung war die Küstenregion für die Rheinflotte gut erreichbar (Cassius Dio LIV 32), da sich die Strecke zwischen Niederrhein und Ozean erheblich verkürzte (Fluvius II 30,26; Sueton Claud. I). Als unmittelbare Folge erlebten die in die Nordsee mündenden Flüsse Norddeutschlands eine militärisch-strategische Aufwertung. Nach dem Bau des Kanals gelangten römische Flottenverbände zügig und ungestört vor kriegerischen Übergriffen über den Seeweg in den Norden Germaniens. Schiffbare Flüsse erleichterten den Truppentransport und ihre Versorgung (Strabon VII,1,3).

Obwohl weder Chauken, Friesen noch Brukterer sich an den Gallieneinfällen beteiligt hatten, entschloss sich Drusus die dort wohnenden Stämme zu unterwerfen. Dies war wohl der geographisch besseren Erreichbarkeit ihrer Siedlungsräume geschuldet; man kann auch sagen die verkehrspolitische günstige Lage war für die Invasion ausschlaggebend. Der Ems kam dabei als erste Anlaufstelle an der chaukischen Nordseeküste eine besondere Rolle zu.

Im Herbst 12 v. Chr. durchfuhr Drusus mit seiner Flotte den nach ihm benannten Kanal, der folglich bereits vorher bestanden haben musste. Entlang der Küste fahrend gelangte die Flotte an die ostfriesische Halbinsel, vorbei an den vorgelagerten Nordseeinseln, und fuhr schließlich in die Emsmündung ein (Strabon VII,1,3 p. 290 C). Vorher jedoch wurde die Nordseeinsel 'Burcana' erfolgreich belagert und es folgte ein anschließendes Seegefecht mit den Brukterer auf der Ems. Die frühe römische Anwesenheit im Unteren Emsgebiet stellte jedoch ein eher kurzes Gastspiel bei den Chauken dar. Zwar kam es offiziell zu ihrer Unterwerfung, führte jedoch weder zu einer Tributverpflichtung, noch mündete sie in einer ständigen Stationierung römischer Soldaten.

Im Anschluss an die Seexpedition des Drusus suchten römische Kriegsschiffe wiederholt die ostfriesische Küste auf. Mehrfach berichten römische Quellen von der Ems (lat. Amisius, Amisiae) als eine geeignete und oft genutzte Wasserstrasse im friesisch-chaukischen Grenzgebiet, um von der Nordsee in das germanische Hinterland zu gelangen. Überliefert sind Fahrten in die Ems, Truppenausschiffungen und der Weitermarsch in Richtung Weser und Lippe.

Die Versorgung erfolgte über mitgeführten Proviant, eingehandelte Waren oder geraubte Güter. Darüber hinaus sind Versorgungsdepots entlang norddeutscher Flüsse wahrscheinlich, jedoch selten nachzuweisen. Einer der wenigen Bekannten ist der Stapelplatz Bentumersiel im Unteren Emsgebiet.

Die Untere Emsregion bot dabei eine günstige geografische Ausgangsbasis, waren die Schiffe doch hier vor Sturmfluten sicher, eine leichte Anlandung möglich und die Versorgung gesichert. Mit größer 
werdender Entfernung von den Rheinbasen bot sich die Untere Emsregion als Zwischenstation an, bevor man weiter der Küste entlangfahrend Weser und Elbe aufsuchte. Die Ems ermöglicht eine direkte Zuwegung in die Haase. Von ihr ist nach etwa 20km Fußmarsch die Hunte zu erreichen. Die Hunte mündet in die Weser, von wo aus man ins Landesinnere gelangt.

Nach ersten Erkundungsfahrten bis hinauf zur Nordspitze Jütlands nahm das Interesse an der deutschen Nordseeküste zunächst wieder ab. Erst im Zuge einer neuen Militärstrategie und einer stärkeren Einbeziehung dieser Region in eine offensive Okkupationspolitik änderte sich dies. Wiederholt erfolgten von nun an Fahrten römischer Flottenstreitkräfte an die norddeutsche Küste. Mehrfach nutzte man dazu die Kanalpassage, um Ems, Weser und Elbe zu erreichen. Belegt sind Durchfahrten von Drusus (12 und 9 v. Chr.), Ahenobarbus (3 v. Chr.), Tiberius (4, 5 und 12 n. Chr.) und Germanicus (15 und 16 n. Chr.). Weitere Fahrten sind wahrscheinlich, werden in den Quellen jedoch nicht aufgeführt.

Insgesamt ist die Bedeutung der Schiffspassage vom Rheindelta an die deutsche Nordseeküste nicht zu unterschätzen, ermöglichte sie doch den schnellen Transport von ausgeruhten Soldaten, Begleitpferden und Ausrüstungsgegenständen, während der Landweg langwierig und gefährlich war. Beispielsweise ist für das Jahr 15/16 n. Chr. der Transport ganzer Kohorten über den Seeweg in die Untere Emsregion überliefert (Tac.ann. II,8,1-2; Tac.ann. II,5,3-4). Nachdem die römische Flotte die Emsmündung erreicht hatte, blieb sie am linken Ufer zurück, während die Truppe übersetzte und zur Weser weiter marschierte (Tac.ann. II,8,1-2). Auch wenn die Anzahl von 1000 Transportschiffen zu hoch erscheint, so ist es doch ein Hinweis auf die wichtige Funktion der Schiffsroute.

Um die geopolitische Lage der Ems besser beurteilen zu können, sollen die Nordseepassagen von Elbe und Weser näher erläutert werden. In den Quellen wird die Rolle der Elbpassage hervorgehoben, insbesondere ihre Bedeutung als östlichste „Reichsgrenze“ in Germanien. Betrachtet man jedoch ihren militärischen Stellenwert, ist dies nicht haltbar. Auch eine Zerschlagung des elbgermanischen Machtzentrums fand zu keiner Zeit statt. Römische Truppen haben zwar mehrfach Gebiete westlich der Elbe unterworfen, jedoch war dies meist nur von kurzer Dauer, da die weiträumigen Gebiete militärisch kaum zu kontrollieren waren (JAHN 2001, 11, 71-72). Ob die Elbe letztlich Endziel einer frühaugustäischen Eroberungspolitik war, ist umstritten (WELWEI 1999, 678-688; Busch 1995; LEHMANN 1995, 123-141) und soll hier letztlich auch nicht behandelt werden.

In der ersten Angriffsphase wird die Elbe häufiger in den Quellen erwähnt. Als spektakulär gilt die für 5 v. Chr. überlieferte Truppenvereinigung an der Elbe (Vetellius II,106-107). Wie weit die römische Flotte dabei über die Elbe ins Landesinnere eindrang, ist den Quellen nicht zu entnehmen. Die Lokalisierung erfolgte über bisher unbekannte germanische Stammesterritorien. Zur Disposition 
stehen Plätze nahe Lauenburg, Hitzacker oder Magdeburg (JAHN 2001, 57, Anm.312). Möglicherweise gelangte die Flotte bis zu den Hermuduren (vgl. JOHNE 2006, 141).

Nach Drusus war Ahenobarbus der zweite römische Heerführer, der zur Elbe gelangte und der einzige, der den Fluss 3 v. Chr. überquerte (Cassius Dio 55,10a,2; Wolters 1999, 616). Als Tiberius wenig später als letzter römischer Feldherr bis an die Elbe vordrang, bestand bereits ein von Augustus erlassenes Verbot über den Fluss zu setzten (Strabon VII,1,4), wohl in der berechtigten Annahme, die dort wohnenden Stämme gegen sich aufzubringen.

Auch wird es nach der Erkundung Jütlands 5 n. Chr. der römischen Führung unmöglich erschienen sein, eine Flottenunterstützung östlich der Elbe fortzuführen, jedenfalls nicht ohne die römische Militärlogistik über Gebühr zu beanspruchen (vgl. WOLTERS 1999, 621; 2000, 42). Noch Germanicus nutze bei seinen Feldzügen 15 und $16 \mathrm{n}$. Chr. die bestehende Infrastruktur seiner Vorgänger. Eine der größten Truppenbewegungen in Nordwestdeutschland begann im Frühling 15/16 n. Chr., als vier Legionen auf o.g. 1000 Schiffen über den Rhein an die Ems gebracht wurden. Im Sommerfeldzug 15 n. Chr. begann eine „Dreizangenoperation“ (Tac.ann. I,60-68) bei der vier Legionen durchs Land der Brukterer bis an die Ems marschierten, während die Kavallerie durch das friesische Gebiet heranritt (JAHN 2001, 219). Weitere vier Legionen gelangten über den Flottenweg an die Ems (Tac. ann. I,60,2), um von dort die Weser zu erreichen. Zwar sind die Schlachten bei Idistaviso und am Angrivarierwall für die Römer als erfolgreich überliefert worden, doch der Feldzug blieb östlich der Weser stecken (SCHMIDT 1938, 34) Somit war das offizielle Ziel, nämlich die Gebiete bis zur Elbe zu „befrieden“, nicht erreicht.

Eine von Tacitus überlieferte Rede Germanicus an seine Soldaten stellte die Elbe als Grenzlinie einer geplanten römischen Provinz Germania dar (Tac. ann. II,14,4). De facto wurde bereits in der `res gestae divi Augusti' dieser Herrschaftsanspruch erhoben. Es bleibt jedoch fraglich, ob sich dies praktisch umsetzen ließ (WOLTERS 1990, 202). Mit der Rückbeorderung von Germanicus wurden die Kampfhandlungen in Norddeutschland $17 \mathrm{n}$. Chr. auf kaiserlichen Befehl hin endgültig eingestellt (Tac.ann. II,25,2-4).

Ebenfalls von römischen Flottenkontingenten mehrfach aufgesucht wurde die Wesermündung, um von hier aus ins Landesinnere zu gelangen. Überliefert sind verschiedene Einfahrten römischer Schiffe und Flussquerungen durch kaiserliche Feldherren (JOHNE 2006, 90). Nach Umfahren der ostfriesischen Halbinsel entdeckte Drusus 11 v. Chr. als erster diesen Fluss. Eine Überquerung mitsamt dem römischen Heerestross erfolgte jedoch erst zwei Jahre später. $4 \mathrm{n}$. Chr. war es Tiberius, der das Gebiet östlich der Weser aufsuchte und mit seinem Heer inmitten Germaniens überwinterte. Von der Wesermündung gelangte die Flotte flussabwärts über die Leine bis in die Werra. Neuste Grabungsergebnisse aus Hedemünden bei Göttingen belegen frühe militärische Auseinandersetzungen zwischen dem römischen Heer und germanischen Kriegern in Südniedersachsen (GROTE 2000, 27-59). 
Ein Sommerlager wurde $9 \mathrm{n}$. Chr. unter Varus an der Weser abgehalten, bevor im September desselben Jahres die germanische Koalitionsarmee drei seiner Legionen vernichtend schlug. Erst Jahre später gelang es Tiberius in zahllosen Kämpfen den Status Quo, wie vor der Varusschlacht, in Germanien wiederherzustellen (Vel.Pat II,105,1-3; Johne 2006, 137).

Die in den Jahren 11 und 12 n. Chr. von Tiberius geführten Expeditionen in rechtsrheinische Gebiete zielten darauf $a b$ weit in das germanische Binnenland vorzudringen. Belegt sind kombinierte Militäraktionen von Teilen der Rheinflotte und des Landheeres (Vell.Pat. II,121,1). Problematisch waren hierbei die langen und kaum zu schützenden Nachschublinien.

Letztmalig wurde die als 'Visurgis' überlieferte Weser $16 \mathrm{n}$. Chr. von Germanicus und seinem gewaltigen Heer erreicht. Noch im selben Jahr fand am Weserufer bei Idistaviso (Rinteln) eine der letzten Schlachten der Germanienkriege statt, bevor das römische Interesse an dieser Region mit der Abberufung von Germanicus schlagartig nachließ (TIMPE 1968).

\subsubsection{Wegeverhältnisse in Norddeutschland}

Die ungünstigen naturräumlichen Gegebenheiten in Norddeutschland behinderten nachhaltig eine römische Okkupation und die dazu erforderlichen Truppenbewegungen (Cassius Dio 56, 19, 5-20). Um diesen Zustand zu beheben, sammelten frühaugustäische Expeditionen gezielt militärisch relevante Informationen über die innergermanische Topographie, günstigste Verkehrsanbindungen und Wegstrecken zwischen wichtigen Lokalitäten (JAHN 2001, 23). Dies erforderte umfangreiche Langstreckenmessungen, deren Beherrschung vorausgesetzt werden kann, berücksichtigt man, dass frühe römische Expeditionen als erste die Gestalt des Nordmeers angeben konnten (BERNECKER 1989, 443-446).

Welchen hohen Stellenwert länderspezifische „Datensammlungen“ hatten, belegt die von Augustus veranlasste kartographische Aufnahme des Imperium romanum, deren sichtbares Ergebnis die berühmte Weltkarte auf dem Marsfeld in Rom darstellte (Plin.nat.hist. III, 3, 17; IV, 81.98.99). Die dafür grundlegende Arbeit an den Commentarien des Agrippas benötigte bis zu ihrer Fertigstellung 20 Jahre. Noch Plinius nutzte Agrippas Werk bei der Aufzählung damals bekannter und in den Ozean mündender Flüsse Germaniens. Neben dem Rhein waren dies Ems, Weser, Elbe und Weichsel (Plin.nat.hist. IV, 100).

Mehrfach berichten die Quellen von einem Anlandungsplatz am Unterlauf der Ems, um von hier aus weitere Erkundungen vorzunehmen. Diese führten sowohl entlang der Nordseeküste wie auch die Untere Ems flussaufwärts in den Süden. Dort behinderten jedoch weiträumige Moor- und Heidelandschaften die römischen Marschkolonnen.

So bemühte sich der römische Legat L.D. Ahenobarbus früh um eine Verbesserung der lokalen Infrastruktur. Abhilfe boten die von ihm errichteten ganzjährig nutzbaren Bohlenwege. Die von 
Tacitus überlieferten 'pontes longi' (Knüppeldämme) ermöglichten ein zügiges Überbrücken vernässter Niederungen und Moorgebiete. Erstmals 4 v. Chr. sind die „Langen Brücken“ überliefert und sollten sowohl von Einheimischen wie auch von Römern genutzt worden sein. Ihre genaue Lage ist bisher nicht lokalisiert, vermutlich wurden sie zwischen dem Lippeeinzugsgebiet und der Unteren Ems errichtet (vgl. JOHNE 2006, 126).

Erneut aufgesucht wurden die `pontes longi` als römische Truppen unter Führung von Germanicus diese auf ihrem Weg in die Lipperegion benutzen. Niederrheinische Legionen nutzten den Überweg über die 'pontes longi', um von der mittleren Ems kommend nach Vetera zu gelangen. Letztmalig erwähnt wurden die „Langen Brücken“ bei der Entscheidungsschlacht gegen die Brukterer und Cherusker. Ihr Zustand wurde $15 \mathrm{n}$. Chr. als morsch und ausbesserungswürdig beschrieben (Tac.ann. I,63,3-4).

Die großen norddeutschen Flüsse eigneten sich zwar gut um über weite Distanzen in die germanische Tiefebene vorzustoßen (TIMPE 1989, 95). Als ungünstig stellte sich jedoch ihr Süd-Nord-Verlauf heraus. Daher wandte man sich verstärkt Lahn und Lippe zu, an deren Ufern Vorposten und Kastelle angelegt wurden. Günstig war auch die direkte Zuwegung in die Lippe ('Lupia') vom Rhein aus.

Das Lippetal mit seiner West-Ost Orientierung bot sich an, um ins Landesinnere Germaniens zu gelangen. Am Ufer der Lippe entstanden im Verlauf der Militäroffensive verschiedene Befestigungen, um einen zügigeren Transport von Truppen und Versorgungsmaterial zu gewährleisten (JOHNE 2006, 94, 129-131). Die Emsquelle im westfälischen Münsterland, südwestlich von Detmold, wurde lediglich durch einen Höhenzug vom Lipperaum getrennt und konnte nach 80km Fußmarsch erreicht werden.

Im Vorfeld der Feldzüge kam es spätestens um Christi Geburt zum Ausbau der Lippestrasse, einer Flussparallelen Wegtrasse, die streckenweise mit dem Hellweg übereinstimmte (vgl. JOHNE 2006, 84, 92). Überliefert sind auf rechtsrheinischem Gebiet zwischen Lippe und Ruhr weitere Militärstrassen, die Tiberius 10/11 n. Chr. im silva Heissi anlegen ließ, um verlustfrei das Winterlager zu erreichen (Dio LVI,24,6; Vell. II,120,1-2).

Nur wenige Quellen berichten über die wegetechnischen Pionierarbeiten römischer Einheiten im rechtsrheinischen Raum. Allein Velleius erwähnt Schneisen, die in den Wald geschlagen wurden, um ein Fortkommen überhaupt erst zu ermöglichen (Vell.Pat.II,120,2; 121,1-3; JOHNE 2006, 127-128). 'Via militariae' (Militärstraßen) mussten in der waldreichen Mittelgebirgsregion erst mühsam angelegt werden, waren aber für die angespannte Sicherheitslage der Römer um so wichtiger (JAHN 2001, 2425).

Insgesamt betrachtet beschränkte sich in der norddeutschen Tiefebene die lokale Infrastruktur auf größere Flüsse, wie Ems und Weser, und wenige 'pontes longi'. Hinzu kamen einzelne 
Wegeverbindungen zwischen germanischen 'residenzia' (TIMPE 1989, 83-117). Der Norden Germaniens blieb jedoch in allem eine amphibisch geprägte Küstenregion mit ausgedehnten Moorbarrieren. Im Binnenland dominierten dichte Wälder, Sümpfe und bergiges Terrain (TIMPE 1998, 86). Die linearen Strukturen und befestigte Wege gewohnten Römer wurden in Nordgermanien vor recht hohe Anforderungen gestellt. Dichtes Unterholz in den Wäldern und Sumpfgebiete mit engen Passagen eigneten sich gut für Überfälle auf den römischen Heerestross (TIMPE 1989, 92). Bald verstanden die im Guerillakampf erprobten Germanen dies zu ihrem Vorteil zu nutzen (Strabon I, 10).

\subsubsection{Ein römischer Stützpunkt an der Nordsee?}

Um die schwierige Sicherheitslage an der germanischen Außengrenze zu verbessern, wurden im Zuge der Germanenkriege zwischen 12 v. und 9 v. Chr. nicht nur acht Legionen aus Gallien direkt an den Rhein verlegt. An Maas, Elbe und Weser entstanden Befestigungen und Wachposten, wobei es sich insgesamt um 50 Kastelle gehandelt haben soll (Florus II,30,25-27). Diese Anzahl galt lange als zu hoch angesetzt, möglicherweise jedoch verbergen sich hinten den o.g. Stationen archäologisch schwer nachweisbare Marschlager und Versorgungsdepots, die darüber hinaus nur temporär genutzt wurden (vgl. JOHNE 2006, 109).

Überliefert sind für die frühaugustäische Zeit wenigstens neun größere rechtsrheinische Militärlager, die wichtige Kontroll- und Versorgungsaufgaben übernahmen. Neben den bekannteren wie Noviomagnus (Nijmegen) und Vetera (Xanten), wird als römischer Stützpunkt an der Nordseeküste für das Jahr 28 n. Chr. ein Kastell namens Flevum erwähnt (Tac.ann. IV,72; VIII,55). Das Lager Flevum diente zur Überwachung der Friesen und war ein Stützpunkt der Rheinflotte (BECHERT, T. I WiLliAMS J.H. 1995, 33). Wie vergleichbare Lager diente es der Truppenversorgung und verkürzte als Zwischenstation den Anmarschweg (JAHN 2001, 64).

Das Castra Vetera ermöglichte eine Zuwegung durch das Lippetal bis in die Münsterländische Bucht und konnte gegenüber der Lippemündung lokalisiert werden (SCHÖNBERGER 1985, 397; JAHN 2001, 38). De Lage von Flevum ist jedoch bisher ungeklärt.

Zur Disposition stehen Standorte an der Rheinmündung nahe dem Fluss Velsen (BECHERT / WILLEMS 1995, Abb. 2, 8). TAAYKE (1996, Teil V, 191) hält eine vorgeschobene Position im chaukischen Siedlungsgebiet für denkbar. Der in Flevum enthaltender Namensbestandteil 'Evum' könnte als weiterer Hinweis dienen.

Velleius deutet ebenfalls die Lage von Flevum an, berichtet er doch für das Jahr 4/5 n. Chr. von einem Winterlager eines römischen Verbandes in Germanien (Vell.Pat. II,105,3). Die fragmentiert erhaltene Ortsangabe 'caput Juliae fluminis' lässt Platz für Spekulationen. Während bisher von einer Stationierung an der Lippequelle ausgegangen wird (JOHNE 2006, 146), so weisen ältere philologische 
Untersuchungen auf ein Lager an der Emsmündung hin (HARTKE 1984, 111-118;). Diese Option gründet sich auf einer Übersetzung von 'caput’ als Mündung und 'Juliae' als >al<llisiae, letzteres stellt eine Analogie zu 'Amisiae', einen für die Ems überlieferten Namen dar (vgl. Tac.ann. II,8,1-2; Tac.ann. II,5,3-4). Dies wäre demnach ein weiterer Beleg für ein römisches Winterlager an der Ems.

Nach Plinius bezeichnet 'Flevum' hingegen einen Rheinmündungsarm und den dort ansässigen Flottenstützpunkt (Plin.nat.hist. IV,96-106). Nach Tacitus wurde Flevum 15/16 n. Chr. errichtet und musste im Anschluss an den Angriff der Friesen 28 n. Chr. wiederhergestellt werden, wurde jedoch bald danach aufgegeben (Tac.ann LXXII,1-3). Dies könnte begründet sein in dem militärischen Bedeutungsverlust der friesischen Territorien in Bezug zu ihrer Funktion als Aufmarschgebiet gegen das östliche Germanien (WILL 1987, 31, 42). Weiterführende Zitate zu den Friesen sind JAHN zu entnehmen (2001, 271, Anm. 1616).

Andere Quellen berichten über einen bis in den Dezember 4/5 n. Chr. reichenden Feldzug in Nordgermanien, in deren Anschluss die Truppen in Germanien überwinterten (Vell. II,105,3). Dies stellt somit eine der frühsten Erwähnungen für ein im inneren Germaniens überwinterndes Heer dar. Berücksichtigt man die Größe eines Truppenkontingentes ist eine Versorgung nur bei einer bereits bestehenden Infrastruktur vor Ort möglich.

Weiter bemerkt Velleius, dass Tiberius nach einem Kurzaufenthalt in Rom im Jahr 4 n. Chr. sogleich wieder in das germanische Winterlager reiste. Für das Folgejahr ist die Erkundung des Nordmeeres bis zum Kap Skagen und die Einfahrt in die Elbe mit anschließender Vereinigung mit dem Landheer überliefert.

Allein aus logistischen Gründen werden sich die Ereignisse so jedoch nicht abgespielt haben können. Für das Jahr 5 n. Chr. beabsichtigte der römische Generalstab eine kombinierte See- und Landaktion, in der ein gemeinsames Vorgehen gegen die Elbgermanen erfolgen sollte (GLÜSING 1989. 74). Für die Seestreitkräfte impliziert dies den Transport von Material und Mannschaften an die Elbe. Dieser umfangreiche Nachschub wurde, wenn man Velleius Bericht folgt, mit auf die Expedition, die von der friesischen Küste über die Nordsee bis an das Nordkap Dänemarks, genommen.

Bei einer derartigen Fahrt ins Unbekannte stellt es jedoch ein kaum zu kalkulierbares Risiko dar, rechtzeitig an dem vereinbarten Elb-Treffpunkt einzutreffen, um sich mit dem Landheer zu vereinigen. Ohne zuvor entsprechend Erkundigungen über maritime Verhältnisse, Fahrrinnen, Uferlinien u.a.m. einzuholen, wäre zudem eine Koordination kaum planbar gewesen (KEHNE 1995, 27).

Eher plausibel ist es daher, dass die Flotte bereits $4 \mathrm{n}$. Chr. die Kapreise unternahm, dann an der germanischen Küste überwinterte, um im Folgejahr mit frischen Vorräten versorgt die Elbeinfahrt zu wagen (JOHNE 2006, 142-147). Dazu bot sich ein vorgeschobener Posten an, wie beispielsweise eine Umladestation oder ein Verpflegungsdepot am Unterlauf der Ems.

In diesem Zusammenhang sei auf einen frühaugustäischen Umschlagplatz an der linken Emsuferseite hingewiesen: Bentumersiel im Reiderland (BRANDT 1974; vgl. BERNECKER 1989, 311, 316). Von hier 
stammen zahlreiche frühaugustäische Militaria. Die aufgedeckten baulichen Strukturen stehen weniger mit einem Militärlager in Verbindung, eher weist die Anordnung von Wegen, Gräben und Zäunen auf den Standort eines Stapel- bzw. Handelsplatzes hin. In denselben frühkaiserzeitlichen Zeithorizont gehört ein 1863 südlich von Bingum entdeckter Münzschatz, deren jüngste Münze ein Prägedatum um 2 v. Chr. aufweist (ZYLMANN 1930, 33). Weitere römische Münzfunde aus dem Unteren Emsgebiet stehen eventuell mit der frühaugustäischen Anwesenheit in Verbindung (vgl. ERDRICH 2002, 43-48).

Eine militärische Station an der Ems ist für die frühe Kaiserzeit durchaus vorstellbar, insbesondere, wenn man berücksichtigt, dass bereits weit ins innere Germaniens vorgeschobene Kastelle keine Einzelfälle waren. Dies zeigt u.a. das Beispiel des kürzlich an der Werra entdeckten römischen Stützpunktes im südniedersächsischen Hedemünden (GROTE 2006). Er gilt derzeit als das am weitesten nach Osten vorgeschobene Lager in Germanien. Die Gründung erfolgte zwischen 11 bis $9 \mathrm{v}$. Chr., wobei es wenigstens bis 8 oder 7. v. Chr. genutzt wurde; möglicherweise besaß das Lager noch 15 und 16 n. Chr. im Laufe des Feldzuges unter Germanicus eine Funktion.

Wahrscheinlich wurde aus der Emsregion ein Teil der für die Elbexpedition im Jahre $5 \mathrm{n}$. Chr. benötigten Nahrungsmittel bezogen. Um sich längerfristig die Bereitschaft der chaukischen Bevölkerung zu sichern, Vieh und Getreide zur Truppenversorgung abliefern, ist dabei von einer monetären oder vergleichbaren Gegenleistung auszugehen. Dies könnte auch den relativ hohen Anteil frühaugustäischer Funde im Unteren Emsgebiet erklären. Einen Teil der Truppenverpflegung, der aus haltbaren Nahrungsmitteln bestand, wurde sicherlich bei den Flottenfahrten von den Heimatbasen mitgeführt. Grundnahrungsmittel wie Getreide, Fleisch und Wasser bezog man dagegen vor Ort. Tacitus Bericht über den Friesenaufstand 28 n. Chr. ist insofern von Interesse, da eine Versorgung römischer Truppen durch Erzeugnisse des Marschlandes erwähnt wird (Tac.ann. IV,72).

\subsubsection{Die Anlandung am Emsufer}

Mehrfach berichten Quellen von der Anwesenheit römischer Schiffe an der Ems, die wohl im Unteren Emsgebiet recht günstige Bedingungen für eine Anlandung vorfanden. Die Lage der Schiffslände wird jedoch nicht näher umschrieben, nur, dass sie sich nicht weit stromaufwärts befunden hat (Tac.ann. II,8,127). Belege auf einen Bootsanleger gibt es weder literarisch noch archäologisch. Diese sind aufgrund der gewaltigen mittelalterlichen Flussverlagerungen in der Westems wohl auch nicht mehr zu erwarten.

Erst durch den mittelalterlichen Dollarteinbruch und neuzeitliche Flussbegradigungen veränderten sich die Strömungsverhältnisse in der Unterems nachhaltig. In der Zeit davor wurde der Fluss in seinem Mündungsbereich durch einen stark mäandrierenden Verlauf gekennzeichnet. Somit ist für die römische Kaiserzeit von einem relativ flachgründigenen Uferbereich auszugehen, der einen 
Bootsanleger erübrigte.

Interessant ist in diesem Zusammenhang ein Bericht über eine 15 n. Chr. von Germanicus vorgenommene Seeexpedition an die Emsmündung. Von hier drang das römische Heer gemeinsam mit chaukischen Hilfstruppen in das Ems-Lippe-Dreieck ein, um den Ort der Varusschlacht aufzusuchen (vgl. BERNECKER 1989, 289).

Tacitus berichtet ausführlich über den Aufenthalt an der Ems (Tac.ann. I,38; I,60). Nach Einfahrt in die Ems landete die Flotte am linken Emsufer an. Während sich die Offiziere von den mitgeführten Pferden ans nahe Ufer tragen ließen, watete die Besatzung durch das flache Wasser. Sodann wurde, um an das gegenüberliegende Ufer zu gelangen (Tac.ann. II,8), in mehrtägiger Arbeit eine Brücke über den Fluss errichtet. Möglicherweise wurde zunächst eine Pontonbrücke aus Fässern und Planken konstruiert, die einen trockenen Übergang hinreichend gestattete.

Unklar ist das Motiv für den Brückenbau. Ein schnelles Übersetzen mit Booten war durchaus machbar, zumal die Ems in der römischen Kaiserzeit leicht zu überwindende Uferwälle besaß. Strategische Gründe für den Brückenbau über die Ems scheiden aus, da die militärische Dominanz des römischen Heeres im Unteren Emsgebiet keine ernsthaften Gegner zu erwarten hatte. Auch Tacitus bemängelte der mehrtägigen Brückenbau, der schlussendlich dazu führte, dass die Hilfstruppen von den Watten bedrängt wurden (Tac.ann. II,8,2-8,3).

Vielleicht zielte Germanicus mit dem Bau auf eine propagandistische Aufwertung seiner Militäraktion, in dem er eine Anlehnung an berühmte Brückenschläge suchte, wie sie beispielsweise sein Vater Drusus über die Lippe 11 v. Chr. (Cassius Dio LIV,33,1-2) oder Caesar über den Rhein 55 v. Chr. vornehmen ließ (Bell.gall. IV,4,4,1-15,5 u. 16-19).

Wiederholt berichten die antiken Quellen von in die Ems einfahrende 'Triremen'. Es handelt sich hiermit um ein mittelschweres, dreirangiges Kampfschiff mit einer maximalen Länge von $34 \mathrm{~m}$. Der so bezeichnete Bootstyp besaß eine Breite von 4,4m, die sich durch lange Ruderausleger beidseitig um etwa 60cm erhöhte. 10 Matrosen machten das Schiff manövrierfähig (JAHN 2001, 203). Ausgestattet mit einer hohen Transportkapazität konnten bis zu 150 Soldaten, Kavallerie-Pferde und Ausrüstungsgegenstände befördert werden. Nachbauten dieses Schiffstyps besitzen eine Verdrängung von etwa 45 Tonnen. Die leichte Bauweise, ein hoher Schwerpunkt über dem Wasserspiegel und ein niedriger Freibord machten die Schiffe jedoch sturmanfällig; insbesondere Frühjahrs- und Herbststürme der Nordsee stellten eine nicht zu unterschätzende Gefahr dar (TILLEY 2004).

In der frühaugustäischen Zeit wird es durch die regelmäßige Anwesenheit römischer Schiffe zu Kontakten vielfältiger Art zwischen Chauken und Römern gekommen sein. Sicherlich war die Anlandungsstelle an der Unteren Ems ein geeigneter Platz dafür. 


\subsubsection{Eine römische Administration östlich der Ems?}

Hinweis auf eine römische Administration im Bereich der Unteren Ems sind den Quellen nicht direkt zu entnehmen. Lediglich zwei antike Autoren berichten von einer römischen Besatzung der Insel Burcana. So erwähnt Cassius Dio eine 'praesidia', die von Drusus auf der eroberten Insel anlegt wurde (Cassius Dio LIV,32). Über Dauer und Umfang schweigt die Quelle. Bei Florus ist überliefert, dass 'custodiae' und 'praesidia' in frühaugustäischer Zeit zur Sicherung von Küste und Flussläufe verbreitet waren, jedoch die Anlage auf Burcana nur von kurzer Dauer war (Florus II,30,26).

Dies weist eher auf einen militärischen Vorposten hin, weniger wird es sich um eine lokale Verwaltungseinheit gehandelt haben. Tacitus stützt diese Deutung, spricht er doch von 'praesidia' als einer befestigten Station (Tac.ann. II,11,1). Vorstellbar wäre eine schanzenartige Erde-HolzKonstruktion. $\mathrm{Ob}$ diese auch administrative Funktionen übernommen hat, ist eher unwahrscheinlich (vgl. WOLTERS 1990, 159-165).

Zwar fand 12 v. Chr. die offizielle Niederwerfung der Chauken durch Drusus statt, es kam jedoch zunächst weder zu einem Freundschaftsvertrag noch hatte die Bevölkerung Tribut zu leisten. Auch die ansonsten üblichen Reglementarien fanden mit Ausnahme einer formalen Annerkennung der römischen Überlegenheit nicht statt. Im Unterschied zu den benachbarten Friesen, die zur selben Zeit bereits einen Foederaten Status erhielten und tributpflichtig wurden, waren die Chauken davon befreit.

Bis zum nächsten Flottenbesuch bei den Chauken vergingen Jahre, so dass sich Tiberius genötigt sah, den Stamm erneut zu unterwerfen (Vell.Pat. II, 106,1). Dies legt nahe, dass zwischen 12 v. Chr. bis 4/5 n. Chr. von einer weitgehenden Eigenständigkeit auszugehen ist, in der sich der Stamm ohne Beeinflussung von römischer Seite selbst verwaltete (WOLTERS 1990, 221).

Auch in der Zwischenzeit nahmen die Chauken eine neutrale Haltung ein; jedenfalls beteiligten sie sich nicht am 'immensum bellum’, einem ersten großen Aufstand germanischer Stämme gegen die römische Vorherrschaft. Es folgte ein von 1 bis $4 \mathrm{n}$. Chr. dauernder regelrechter Vernichtungskrieg gegen alle Stämme der Germania magna, die südlich der Chauken wohnten (Vell.Pat. II,140,2). Als Auslöser gilt die einsetzende Provinzialisierung Germaniens, die neben der Tributpflicht auch auf die Einführung römischen Rechts abzielte. Da die Chauken von einer römischen Einflussnahme in ihre inneren Angelegenheiten verschont blieben, sahen sie wohl auch keinen Anlass dazu sich aufzulehnen.

Die erneute Niederwerfung der Chauken, die $5 \mathrm{n}$. Chr. erfolgte, hatte eine andere Qualität als die vorhergehende. Tiberius verlangte nun von den bezwungenen Chauken ihre Waffen vor dem Tribunal des Imperators niederzulegen. Im Gegenzug erhielten sie den amicitia-Status (Vell. II,106,1). Mit der Aufnahme in die römische Waffenkameradschaft (Tac.ann. I,60,119) war der Stamm verpflichtet, Hilfstruppen zu stellen. Erneut waren die Chauken von Abgaben und Steuern befreit.

Auch mit anderen Stämmen am nördlichen Ocean, mit Ausnahme die Elbgermanen, schloss Tiberius 
während seines Feldzuges Freundschaftsverträge, ohne das diese jedoch zu Tributen verpflichtet wurden (GLÜSING 1989, 74). Von römischer Seite bestand also kein Interesse an einer Einmischung in die Stammesangelegenheiten der nördlichen Völker Germaniens; ganz zu schweigen von der Einrichtung einer römischen Administration. Vielmehr sollte mit den Verträgen pro forma ihr Wohlverhalten besiegelt werden, was zunächst auch gelang.

Bis 9 n. Chr. waren es meist nur einzelne Stämme, die sich gegen Rom auflehnten. Mit zunehmender Eskalation der Situation sah sich Rom einer größer werdenden germanischen Koalitionsarmee gegenüber. Während sich infolge der Auseinandersetzungen von 9 bis $16 \mathrm{n}$. Chr. nahezu alle Stämme zwischen der Rhein, Main und Weser am Aufstand beteiligten, waren die Chauken weiterhin bündnistreu (JAHN 2001, 1). Ebenso loyal verhielten sich in dieser Zeit Bataver, Canefaten und Friesen.

Mit Ausnahme der Friesen waren die o.g. Stämme von Tributleistungen befreit. Als Gegenleistung bestanden die Römer jedoch auf freien Truppendurchzug und die Stellung von Hilfstruppen. Daneben könnte der Grund für das Wohlverhalten der Chauken die gute Erreichbarkeit und häufige Anwesenheit römischer Flottenverbände an der Emsmündung gewesen sein (vgl. JOHNE 2006, 209).

Ein erhöhtes Konfliktpotential zwischen Chauken und Römern bestand in der frühaugustäischen Zeit nicht. Stattdessen kamen die Chauken bereitwillig ihrer Verpflichtung nach Hilfstruppen zu stellen. Unter Germanicus kämpften Chauken auf römischer Seite sowohl 15 n. Chr. am Angrivarierwall, wie auch 16 n. Chr. bei Ideavisto. Die Kriegsschauplätze befanden sich im Territorium von benachbarten Stämmen der kleinen Chauken. Ideavisto lag zwischen der Weser und umliegenden Anhöhen (Tac.ann. II,16,1). Als Austragungsort bietet sich das Weserknie zwischen Minden und Rinteln an (vgl. GoETZ / WelWEI 1995, 106). Der Angrivarierwall ist vermutlich bei Leese am Steinhuder Meer zu lokalisieren (JAHN 252-255; Anm. 1503).

In der 'res gestae divi Augusti’ wird für das Jahr 13/14 n. Chr. ein römisches Herrschaftsgebiet von der Ems bis an die Elbe zwar ausgewiesen (Aug.res.gest. XXVI,2), aber ohne Germanien explizit als Provinz herauszustellen. Auch verzichtet die Quelle darauf, den römischen Herrschaftsanspruch in seiner Umsetzung zu konkretisieren.

Auffällig ist auch, dass nur wenige zeitgenössische Quellen den Begriff ‘provincia' in Bezug auf die Germania magna verwenden. Und dies in einem Kontext, der eher auf eine militärisch geprägte Struktur schließen lässt und weniger auf eine Verwaltungseinheit (Florus II,30,22,29), wie sie beispielsweise für die etablierte Provinz Gallien bestand (JAHN 2001, 21-22). Auch der Kaiserbiograph Velleius Paterculus betont, dass Germanien unter Tiberius nur zu einer „fast“ tributpflichtigen Provinz gemacht worden war (Vell. I,97,4). Es bestand also, ganz im Unterschied zu den Provinzen Gallia und Hispania, kein regulärer census in Germanien (JAHN 2001, 62-63), auch wenn das Land seit 6 n. Chr. 
als weitgehend befriedet galt (Vell. II,108,1).

Auch bei Florus fehlen territoriale Angaben für die 'provincia Germania'. Ihm nach zufolge galt Germanien eher besiegt als unterworfen (Florus II, 30, 30). Die Einschätzung traf sicherlich auch auf die Nordstämme, wie auch auf die Chauken, zu. Diese galten als faktisch unterworfen, gerieten jedoch nicht in permanente Abhängigkeit, auch folgte keine römische Einflussnahme in ihre inneren Angelegenheiten. Das römische Militär hatte somit nur eine unzureichende Herrschaftsgewalt in der Germania magna (WELWEIL 1999, 681). Es gibt keinen Hinweis darauf, dass die Gebiete zwischen Rhein und Elbe vor oder nach der Varusschlacht unter römischer Herrschaft standen; d.h. tributpflichtig waren.

Das ursprüngliche Ziel, die Zerschlagung des elbgermanischen Störfaktors, wurde in der gesamten römischen Okkupationszeit nicht erreicht. Stattdessen bildete sich in Böhmen als zusätzliche Gegenmacht zu Rom das Reich des Marbods heraus. Und selbst trotz der äußersten Brutalität während der großen Germanenkriege wurde die innergermanische Opposition nicht kleiner, sondern größer.

Die in Germanien verbreiteten vorstaatlichen Strukturen einer stammesorientierten Gesellschaft haben, trotz zahlreicher erfolgreicher Militäraktionen der Römer, verhindert, dass Germanien zu einer steuerzahlenden Provinz wurde. Letztlich widersprach das römische Rechts- und Verwaltungssystem der germanischen Stammestradition, die auf dem Gefolgschaftsprinzip aufgebaut war.

Wohl gab es in der Germania magna bereits einzelne etablierte Ortschaften um bedeutende Kastelle. Cassius Dio führt als Bestandteil römischer Provinzialisierung den Bau von Winterlagern sowie die Gründung von wirtschaftlichen Zentren 'agorai' und 'poleis' in den okkupierten Gebieten aus (Cassius Dio LVI,18,2). Ptolemaios erwähnt sogar 94 germanische `poleis'. JAHN (2001, 65) vermutet wohl zurecht, dass darunter Siedlungszentren einer bäuerlichen Bevölkerung zu verstehen sind, die sich aufgrund ihrer naturräumlich günstigen Lage oder ihrer Bedeutung für den Handel auszeichnete. In der Nähe römischer Legionslager ist davon auszugehen, dass regionale Märkte veranstaltet worden sind (GLÜSING 1889, 75). Als Beispiel für einen friedlichen Austausch von Waren und handwerklichen Techniken können Waldgirmes in Hessen und Haarhausen in Thüringen angeführt werden (RASBACH / BECKER 2003; DUSEK 1992).

In Norddeutschland hat sich nach bisheriger Quellenlage die römische Herrschaftsausübung an wenigen Plätzen konzentriert. Überliefert ist beispielsweise ein Kastell bei den Friesen (Plin nat.hist. XXV,21). Die Anlage wurde im Jahr 15/16 n. Chr. errichtet (Tac.ann. LXXII,1-3), ob sie sich jedoch wie bei Tacitus erwähnt im Territorium der Chauken befand (Tac.ann. I, 38,1; LXXII,1-3), ist bisher umstritten. Obwohl es in der Unteren Emsregion in frühaugustäischer Zeit zur wiederholten Anwesenheit römischer Flottenverbände kam, gibt es keine Belege für eine römische Administration vor Ort. Ebenso fehlen bis dato Überreste römischer Militärbauten im chaukischen Stammesgebiet. 


\subsubsection{Die Chauken nach den Germanenkriegen}

Die in frühaugustäischer Zeit im germanischen Küstengebiet bestehende römische Vormachtstellung, die sich vorwiegend im militärischen Bereich manifestierte, löste sich innerhalb weniger Jahrzehnte auf.

Die Chauken gelten in dieser Zeit noch als treue Bundesgenossen der Römer, die rechtschaffend und allerseits angesehen unter den Germanen sind. Nach Tacitus gehen von ihnen keine ungerechten Kriege aus. Jeder lebe friedlich für sich, wobei der Stamm reich an Männern und Pferden ist (Tac. germ. XXXV). Diese durchweg positive Charakterisierung beruht auf der bereitwilligen Stellung chaukischer Hilfstruppen in den Germanenkriegen.

Im rechtsrheinischen Raum existierten nur wenige „Klientenstaaten“ im juristischen Sinne, wie die Friesen und Bataver, doch auch bei ihnen gab es keine dauerhafte rechtliche Abhängigkeit vom römischen Reich.

In der frühaugustäischen Zeit stellten die Chauken für die Römer einen wichtigen Stabilitätsfaktor im germanischen Küstenraum dar. Während der Germanenkriege und auch danach verhielten sie sich loyal. Zwar vertrieben sie Mitte des 1. Jahrhunderts die Angrivarier von der Weser (SCHMIDT 1938, 35); hierbei handelte es sich jedoch um eine ,integrierende Expansion“. Es lag wohl auch daran, dass die Ausdehnung ihres Stammesterritoriums römischen Interessen nahekam, da sie sich letztlich gegen die spätestens seit dem Bataveraufstand feindlichen Brukterer richtete.

Recht schnell beendeten Aufstände und Überfälle die über einen längeren Zeitraum friedliche Phase bei Batavern, Canninefaten, Chauken und Friesen (JAHN 2001, 71; KUNOW 1987, 76). So rebellierten die seit 12 v. Chr. tributpflichtigen Friesen mehrfach gegen die Anhebung ihrer jährlichen Abgaben. Sowohl für 21 und $28 \mathrm{n}$. Chr. sind Aufstände der Küstenbewohner überliefert. In diesem Zusammenhang werden $28 \mathrm{n}$. Chr. erstmals nach den Germanenkriegen wieder Chauken erwähnt, da sie sich an dem Aufstand beteiligten (Tac.ann. IV, 72-4).

Vorausgegangen sind dem großen friesischen Aufstand 28 n. Chr. gewaltige soziale Spannungen. Auslöser war die unverhältnismäßige Erhöhung der jährlichen Abgaben, die viele friesische Familien in die Sklaverei führten. Der neue römische Statthalter Olennius erkannte die bisherige Selbstverwaltung der friesischen Stämme nicht mehr an und strebte eine römische Provinzherrschaft an (JOHNE 2006, 209). Nachdem Beschwerden zu keiner Besserung führten, folgten gewaltsame Übergriffe gegen steuereintreibende Soldaten und der römische Verwalter musste sich schließlich in das Kastell 'Flevum' an der Nordseeküste retten (SCHMIDT 1938, 73). Eine chaukisch-friesische Allianz konnte das römische Militär vertreiben und zog plündernd durch die heutigen Niederlande (Tac.ann IV,72-73).

Als unmittelbare Folge römischen Desinteresses an diesem Konflikt entstand de fakto ein rechtsfreier 
Raum, in dem sich die germanische Stammesgesellschaft wieder etablieren konnte. Erst $41 \mathrm{n}$. Chr. gelangten die Friesen wieder unter römische Vorherrschaft. Ihnen wurde eine römische Verwaltung und Gesetze auferlegt ,und damit sie seine Einrichtungen nicht umstürzten, legte er bei ihnen ein Kastell an“ (Tac.ann. XI, 43).

Die Kontrolle der germanischen Küste, die unter Tiberius $16 \mathrm{n}$. Chr. faktisch aufgegeben wurde, versuchte Kaiser Claudius wieder zu erringen. Auslöser waren 41 n. Chr. chaukische Piratenüberfälle entlang der nordgallischen Küste, die sich jedoch, obwohl zurückgeschlagen, nicht so einfach von römischer Seite unterbinden ließen (Tac.ann. XI,18-19, Suet. Claud XXIV; Dio LX,8).

Auch die vom Legat Corbulo angeordnete Ermordung des regionalen Führers Gannascus, der Teil einer erstarkenden Opposition, sowohl bei den Chauken wie auch bei den Friesen war, führte nicht zum gewünschten Ergebnis (SCHMIDT 1938, 34-35). Statt der erhofften bedingungslosen Unterwerfung der Chauken, kam es $47 \mathrm{n}$. Chr. zur Eskalation der Ereignisse, die in einem Volksaufstand mündeten. Um den Konflikt nicht weiter auszudehnen, folgte ein Abzug der römischen Truppen an den Rhein (Tac.ann. XI,18-20). Den Chauken gelang es somit weiterhin ihre Eigenständigkeit zu bewahren (SCHMID 1965, 38), wohl auch deshalb, weil sich das Imperium Aufgaben in anderen Teilen des Reiches widmen müsste. Insbesondere der beginnende Britannienkrieg und der Bau einer Invasionsflotte forderte hierfür alle verfügbaren Kräfte (BERNECKER 1989, 318).

Aufschluss über das chaukische Selbstverständnis in flavischer Zeit gibt Plinius, der $47 \mathrm{n}$. Chr. unter Corbula die Chauken besuchte (Plin.nat.hist XVI,2; X,54; XI,223; XII,98; XVII,47; XXXI;20). Die kleinen Chauken seien, obwohl sie in ärmlichen Verhältnissen lebten, stolz auf ihre Unabhängigkeit. „Und diese Menschen behaupten, falls sie heute vom römischen Volk besiegt werden sollten, sie würden Sklaven. Es ist wirklich so: Viele verschont das Schicksal zu ihrer Strafe“ (Plin.nat.hist XVI,2).

$\mathrm{Zu}$ einer „Romanisierung“ chaukischer Bevölkerungsteile wird es nicht gekommen sein. Es erfolgte keine gezielte Rekrutierung von Adligen, wie dies für andere Germanenstämme, insbesondere für die Cherusker, überliefert ist (GLÜSING 1989, 74). Wohl auch, weil es bei den Chauken keine vergleichbare Sozialstruktur gab.

Nach der Strafexpedition 47 n. Chr. schien sich die Lage wieder zu beruhigen, jedenfalls schweigen die Quellen bezüglich weiterer Piratenüberfälle. $\mathrm{Zu}$ einer vollständigen Kontrolle des friesischchaukischen Küstengebietes kam es jedoch auch weiterhin nicht.

Während nämlich andernorts innergermanische Wanderbewegungen, die letztlich römisches Reichsgebiet betrafen, streng geahndet wurden, war dies an der Unteren Ems nicht der Fall. Den 
kleinen Chauken gelang es $58 \mathrm{n}$. Chr. die an der Emsmündung lebenden Ampsivarier in friesisches Siedlungsgebiet abzudrängen (Tac.ann. 13,55). Da deren Gebiet römisch okkupiert und tributpflichtig war, wurde sie auch von hier vertrieben. Wobei der flüchtende Volksstamm nicht zu den Chauken zurückverwiesen wurde. Weitere Gebietserweiterungen erreichten die Chauken durch Vertreibung der Angrivarier von der Weser, die daraufhin in das Gebiet der Brukterer einfielen (Tac.germ. 33,2).

Wird noch von Tacitus die friedliche Gesinnung der Chauken hervorgehoben, so änderte sich die Situation mit dem Zusammenbruch römischer Einflussnahme in der Emsregion radikal. Gewaltsame Auseinandersetzungen zwischen Chauken und römischen Soldaten sowie angrenzenden Stämmen folgten innerhalb von weniger als 50 Jahren. Auch am Chattenkrieg unter Kaiser Domitian beteiligten sich Stämme westlich der Weser, zu denen neben Friesen, Brukterer, Bataver auch Chauken gehörten (Tac.ann. IV,72,4; XII,27,28; XIII,57; Dio LXVII,5). Die weiterhin angespannte Situation zeigt der Verlauf des Bataveraufstandes 69-70 n. Chr. An diesem beteiligten sich Friesen und Chauken auf beiden Seiten (Tac.hist. IV, 12, 79; V, 19). So berichtet Tacitus von einer gemischten friesischchaukischen Kohorte, die in Tolbiacum von der Bevölkerung getötet wurde (Tac.hist. IV, 79).

Letztmalig sind chaukische Piratenüberfälle auf die gallisch-römische Küste 170 n. Chr. überliefert (SCHMIDT 1938, 36). Erst mit dem Bau von kleineren Kastellen an der niederländischen und belgischen Küste gelang es die betroffenen Regionen vor weiteren Überfallen zu schützen. Nach der erfolgreichen Rückschlagung der Piraten erhielt Didius Iulianus 172 n. Chr. einen Triumph.

Vorausgegangen waren den Übergriffen der Ausbruch der Markomannenkriege 166 n. Chr., die erst 180 n. Chr. endeten. Es folgte 170 n.Chr. ein Vorstoß der Chatten auf das Rheingebiet, zudem sind in dieser Zeit weitere germanische Angriffe auf Rheinprovinzen und auf den Rhein-Donau-Limes überliefert. Die fast zeitgleich erfolgten Übergriffe durch Markomannen, Langobarden und Sarmaten waren für die Sicherheitslage an der Donaugrenze zwischen Wien und Budapest jedoch von weit größerem Gefährdungspotential (ERDRICH 1995, 57), als die sporadischen Piratenüberfälle an der Nordseeküste.

Für das Jahr 213 n. Chr. berichtet Cassius Dio (Dio 77,14,3), dass germanische Gesandte der OceanStämme in Rom von Kaiser Caracalla Geldleistungen erhielten, um weiterhin in Bündnisverträgen den Frieden zu wahren. Hierzu haben sicherlich neben den Friesen auch chaukische Krieger gezählt. Ein letztes Mal wird gegen Ende des 2. Jahrhunderts n. Chr. von Chauken am Rhein berichtet (WENSKUS 1981, 396), wobei es sich vermutlich um chaukische Kaufleute handelte, die am Niederrhein die Region Overijssel besuchten. Danach bricht die Überlieferung ab.

\subsubsection{Die Friesen im Frühmittelalter}

Die Friesen werden ebenfalls erstmals 12 v. Chr. in den römischen Quellen erwähnt. Ihr angestammtes 
Siedlungsgebiet lang zwischen Zuidersee und der Ems.

Auch bei der Friesen ist eine Unterteilung in zwei eigenständige Stammesgruppen (Große und Kleine Friesen) überliefert (Tac.germ. c. XXXIV), wobei die Vlie als Grenzfluss fungierte (SCHMIDT 1938, 71). Plinius bezeichnet die Wohnsituation in der durch weiträumige Binnenseen und Moore geprägten Landschaft als „Inseln“ (Plin.hist.nat. IV 101). Während der Germanenkriege hielten die Friesen zu Rom. Erst 28 n. Chr. kam es zu einem Volksaufstand bei dem gegen eine erhöhte Tributlast erfolgreich vorgegangen wurde. Nach einer kurzen Phase der Autonomie führten chaukisch-friesische Piratenüberfälle 41 und $47 \mathrm{n}$. Chr. zu römischen Vergeltungsschlägen und schließlich zur vollständigen Unterwerfung der Friesen.

In der Völkerwanderungszeit fehlen Nachrichten über das chaukisch-friesische Küstengebiet. Seine Bewohner scheinen sich, wenn überhaupt, nur zu einem geringen Teil an den großen europäischen Wanderbewegungen dieser Zeit beteiligt zu haben. Ihre östlichen Nachbarn, die Sachsen, überschritten eventuell schon ab dem 3. Jahrhundert die untere Elbe und ließen sich im heutigen Niedersachsen nieder. In welchem Tempo sich diese Entwicklung vollzog, ist nicht abschließend geklärt und derzeit weiterhin Thema des wissenschaftlichen Diskurses. Durch Assimilierung benachbarter Stämme wuchs der sächsische Stammesverband beständig an, während die „idigenen“ Völker ihren Eigennamen einbüßten. Es ist zu überlegen, ob auch das Verschwinden der Chauken im 3 Jahrhundert in diesen Kontext zu sehen ist (vgl. CAPELLE 1998).

Die von Friesen bewohnte Region, ein relativ schmaler Küstenstreifen der von der Wesermündung bis nach Flandern reichte, wurde nur an ihren Rändern von der sächsischen Wanderbewegung berührt. In das Stammesgebiet der Friesen gingen die ehemals chaukischen Siedlungsgebiete vollständig ein. Die Friesen erweiterten ihr Territorium schließlich bis nach Dorostate (Wijk bij Duursteede) und Brügge und schufen damit die Frisia Magna. Erster König der Friesen wird Adulfus in der ersten Hälfte des 7. Jahrhunderts (SCHMIDT 1938, 77). Fragen nach der Kontinuität der antiken „Frisii“ des Tacitus zu den Friesen des Frühmittelalters sind bis dato nicht eindeutig zu beantworten.

Die Überlieferung aus dem ostfriesischen Raum setzt erst wieder im Frühmittelalter ein, so dass die historischen Prozesse davor kurz angerissen werden.

Von den von Friesen bewohnten Küsten gingen im 5. Jahrhundert erste Eroberungszüge nach Britannien aus (SCHMIDT 1938, 76, Anm. 5). Sachsen, Angeln und Jüten, möglicherweise auch Friesen, beteiligten sich an der Eroberung der britischen Insel, wo bereits um 600 das Bistum Canterbury gegründet wurde. Die erfolgreiche Kolonisation hatte neben neu gegründeten Königreichen weitere Zuwanderungen aus dem Heimatland zur Folge. Dennoch verblieben Bevölkerungsteile auf dem Festland, wie u.a. die großen Gräberfelder von Bremen-Mahndorf, Dörverden und Liebenau aufzeigen. 
Sowohl Sachsen wie Friesen bildeten keine geschlossene staatliche Einheit, sondern verfügten über einen lockeren Verband kleinräumiger und autonom verwalteter Siedlungsgebiete. Das in 70 bis 80 Gaue untergliederte Sachsenreich wurde weitgehend dezentral regiert und bestand sowohl aus freiwillig angeschlossenen wie auch unterworfenen Stämmen (WULF 1991, 321-323). Über die frühe Organisationsform der Friesen ist wenig bekannt. Es wird sich vermutlich ebenfalls um einen Stammesverbund gehandelt haben, dessen lokale Gruppen sich selbst verwalteten.

Erst ab dem 8. Jahrhundert verbesserte sich die Quellenlage. Ausgangspunkt war die unter Karl dem Großen erfolgte Heidenmissionierung Norddeutschlands. Vorab wurden Sachsen und Friesen mit einem über 30-jährigen Krieg (772 bis 804) überzogen, der seinen Höhepunkt in den Massenhinrichtungen beim „Blutgericht von Verden“ (782) hatte. Nach erfolgreicher Niederschlagung des Aufstandes kam es zu tiefgreifenden Umstrukturierungen. Es wurde ein Netz von Heerstraßen errichtet sowie Burgen und Pfalzen gebaut. Zumeist erfolgte die Verwaltung durch einheimische Adlige.

Nach der im 8. Jahrhundert langsam vollzogenen Eingliederung in das fränkische Reich entwickelte sich in den von Friesen bewohnten Gebieten im Unterschied zu den sächsischen Reichsteilen kein eigenes Stammesherzogtum. Entscheidend ist, dass dort wo Adelsherrschaften fehlten, die Bewohner direkt dem König zugeordnet waren. Im Zuge der Normanneneinfälle Anfang des 9. Jahrhunderts wurden die Friesen von der Heeresfolge außerhalb Frieslands freigestellt, da sie ausschließlich für die Landesverteidigung zuständig sein sollten (SCHMIDT 1975, 14). Doch zunächst fehlten viele ehemals grundbesitzende Friesen in diesem Verband, da sie ihr Eigenerbe beim Sachsenaufstand verwirkt hatten. Erst mit der Rehabilitierung der entrechteten Friesen 814 unter Ludwig dem Frommen erwarben die freien Friesen die Königsfreiheit (VAN LENGEN 1995, 114).

Das in der Landesverteidigung erprobte genossenschaftliche Handeln bewährte sich auch im Küstenschutz. Aufgrund höher auflaufender Sturmfluten wurden nun Deich- und Sielbau die zentralen Aufgaben der nach wie vor von der Heeresfolge freigestellten Friesen. Einzige direkte Abgabe an den König bildete der Königzins, der auch Garant ihrer Königsfreiheit war.

Formal hatten vom König belehnte Grafen die Oberhoheit über die friesischen Gaue. Dies beinhaltete die Ableistung einer Schutzsteuer und die Anerkennung der Reichsgewalt (SCHMIDT 1975, 17). Als zentrale Herrschaftsorte entwickeln sich u.a. Emden, Leer und Jever. Vielfach ließen sich die Grafen durch Schulzen vertreten.

Im Laufe des Mittelalters bildeten sich auf der ostfriesischen Halbinsel 14 Landesgemeinden heraus, die mit der Zeit ein ernst zu nehmendes Gegengewicht zu den Grafen darstellten (Abb. 8). Für das südliche Ostfriesland bestanden mit dem Lengener-, Moormer-, Overledinger-, Reider- und Saterland 
fünf Landesgemeinden. Im Emsgau, der sich zwischen Emden, Leer und Weener erstreckte, herrschten die westfälischen Grafen von Werl. Ihre Komintatsrechte wurden in der ersten Hälfte des 12. Jahrhunderts durch die Grafen von Ravensberger abgelöst und gingen erst 1252/53 auf die Bischöfe von Münster über (RAMM 1995, 116-117).

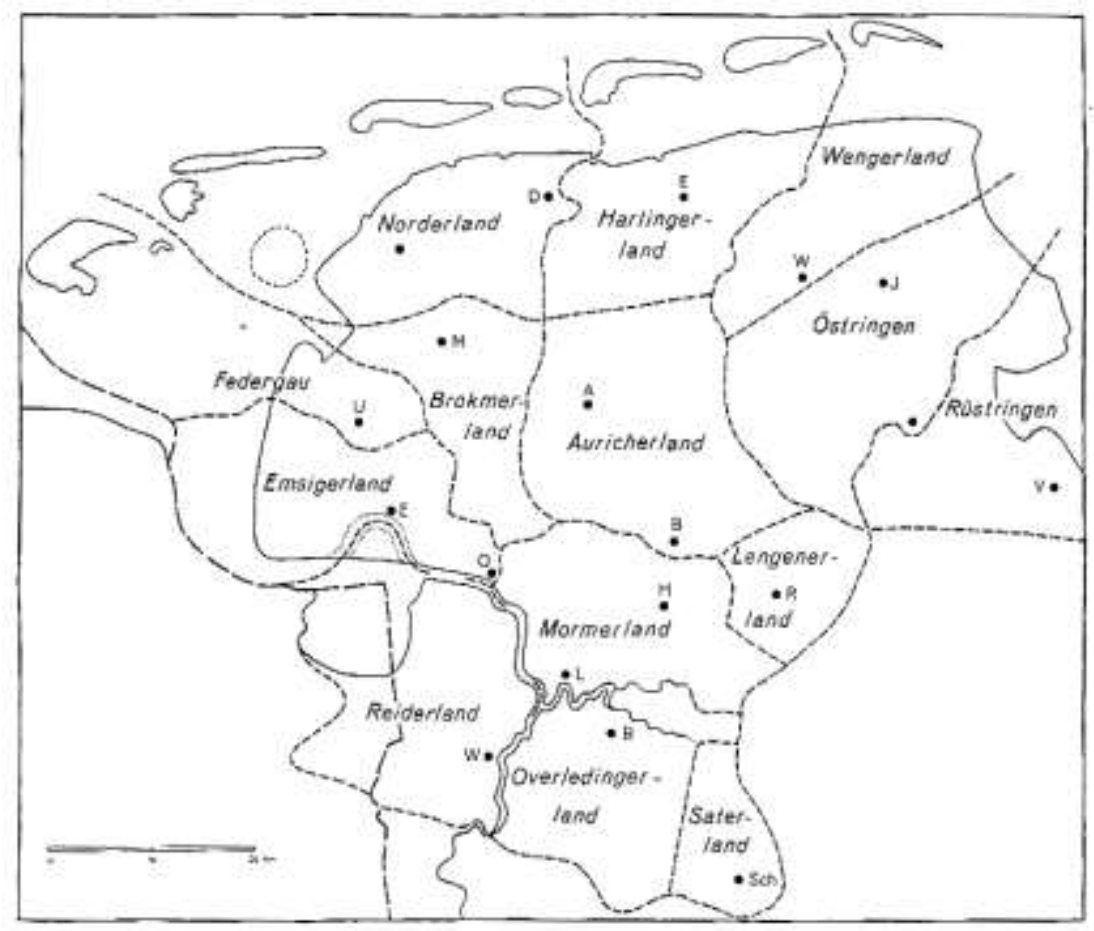

Abb. 8

Die ostfriesischen Landesgemeinden im Mittelalter (SCHMIDT 1975, 31).

Mit zunehmender Selbstständigkeit der Landesgemeinden, die sich zudem in größeren Verbände organisierten, schwand der Einfluss der als Fremdherrscher empfundenen Grafen und ihrer Verwalter. Wohlhabende Marschenbauern weckten bei den Grafen zwar Begehrlichkeiten, konnten sich aber gegen diese erfolgreich zur Wehr setzen. Auch Bernhard der II., Herzog von Sachsen, gelang es 1058 nicht die Abtrünnigen zur Räson zu bringen und sein Feldzug scheiterte am starken Widerstand der Ostfriesen (vgl. Adam III, 42). Legendär ist die Fehde der Östringen, bei der die Friesen 1153 und 1156 die Allianzarmee vom Oldenburger Grafen Christian und Heinrich dem Löwen erfolgreich schlugen (RAMM 1995, 124). Adam von Bremen erwähnt erstmals den friesischen „Pagus Morsati“, wo die Einwohner sich dem Steueranspruch verweigerten und sich erfolgreich den gerüsteten Invasoren entgegenstellten. Mit „Morsati“ sind vermutlich die Bewohner des späteren Overledingerund Moormerlandes, eventuell auch des Lengenerlandes gemeint (SCHMIDT 1975, 25-26).

Die Machtstellung der Grafen beruhte auf der Hausmacht der sie vertretenden Schulzen. Zunächst lag die Rechtsprechung bei dieser Instanz bevor die Landesgemeinden dazu übergingen auch diese 
Funktion auszuführen und sich schlussendlich eine eigene Rechtsprechung gaben. Ihre Freiheitsrechte sind in den siebzehn Küren überliefert, die wohl um 1080 entstanden (VAN LENGEN 1995, 114). Eine zusätzliche Legitimation erfolgte auf der Ebene von Landeskirchen und Kirchenpatronen mit der auch dem Repräsentationswillen der Landesgemeinden Nachdruck verliehen wurde und der sich im Hochmittelalter in gewaltigen Kirchenbauten manifestierte (SCHMIDT 1987, 84). Die überdimensionierten Sakralbauten, wie Marienhafe, Emden und Reepsholt vermitteln ein Bild des Reichtums und Geltungsbewusstseins.

Basierend auf dem frühmittelalterlichen Seehandel, einer prosperierenden Landwirtschaft und einer auf Export der landwirtschaftlichen Produkte (an erster Stelle Vieh und friesisches Tuch) orientierten Wirtschaftsform entwickelte sich zunehmend eine gesellschaftliche Differenzierung.

SCHWARZ (2003a, 83) vertritt die Meinung, dass die Gewinnung des Raseneisenerzes einen erheblichen Beitrag zur Landesentwicklung leistete, so z. Bsp. zum Bau der großen Kirchen im Brookmerland.

Hierbei zeigt das mehrfach überlieferte Burgenbauverbot in den Landesverfassungen die große Verunsicherung der freien Friesen gegenüber führenden Persönlichkeiten, die sich über die Gemeinschaft erheben könnte, um diese zu beherrschen. Dass dies jedoch nicht auf Dauer zu verhindern war, zeigt u.a. die einzige erhaltene Häuptlingsburg in Bunderhee; eine Burganlage des 15. Jahrhunderts im Landkreis Leer (Abb. 9).

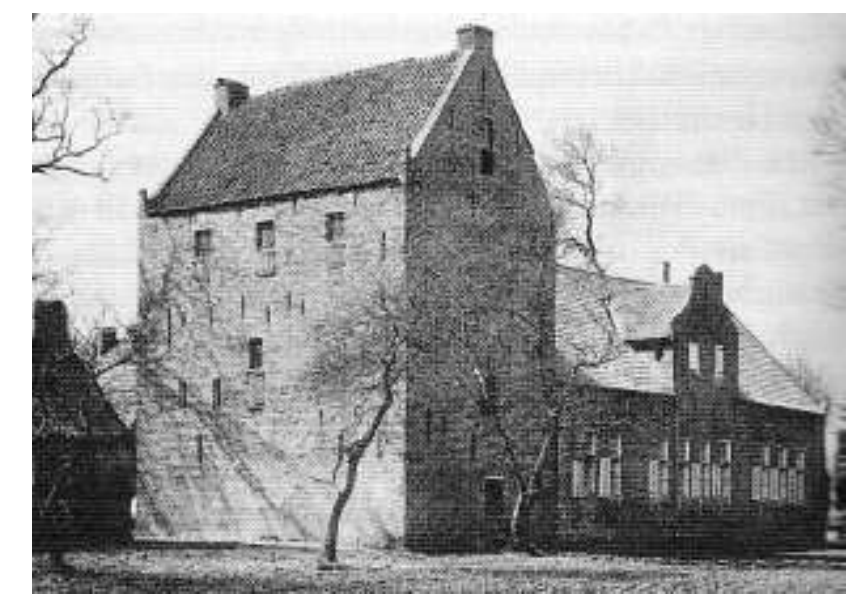

Abb. 9

Das Steinhaus von Bunderhee im Landkreis Leer

In den autonom agierenden Landesgemeinden wurde die sprichwörtliche friesische Freiheit schließlich im Zuge eines umfassenden Strukturwandels im Spätmittelalter langsam unterminiert. Mit der stärker sich ausbildenden sozialen Schichtung der Bevölkerung wurde es wohlhabenden Familien möglich ihren wirtschaftlichen Erfolg in politischen Einfluss umzuwandeln. In der ersten Hälfte des 14. Jahrhunderts bildeten sich vielerorts souveräne Häuptlingstümer heraus (VAN LENGEN 1995, 124). Zur Entstehung einer übergeordneten Führung kam es in Ostfriesland jedoch erst unter der Grafenfamilie der Cirksena im 15. Jahrhundert. 


\subsubsection{Die Christianisierung Ostfrieslands}

Ersten Missionsversuchen der Friesen durch eine Missionszelle in Utrecht nach 550 war kein dauerhafter Erfolg beschieden. Dies änderte sich erst mit der Weihung Willibrords 695 zum Erzbischof von Utrecht. Die Mission stand von nun an im Zusammenhang mit der fränkischen Eroberungspolitik unter Pippin dem Mittleren, bis nach dessen Tod 714 und der Rückeroberung durch Radbod die Mission zusammenbrach (HAIDUCK 1992, 14). Nach Radbods Tod 719 entspannte sich die Lage und Willibrord zog wieder in Utrecht ein. 733 schlug Karl der Große das friesische Heer an der Bordena. Im Anschluss wurden die Friesen tributpflichtig. Dies betraf jedoch nur die linksemsischen Gebiete; Ostfriesland blieb weiterhin selbstständig (SCHMIDT 1938, 80).

Ein erneuter Versuch der Friesenmission durch Bonifatius kann mit seiner Ermordung 754 in Dokkum als gescheitert erklärt werden. Eine unmittelbare Folge war die Herabstufung Utrechts zu einem einfachen Bistum, welches nun dem Erzbistum Köln unterstellt wurde.

Im Zuge der Sachsenkriege wurde von fränkischer Seite aus die Christianisierung zum wiederholten Male angetrieben. Sowohl Willehad wie auch der friesische Missionar Liudger mussten jedoch vor dem sächsischen Aufstand weichen und konnten erst nach deren Niederschlagung 785 in friesische Gebiete zurückkehren. Als Ausgangspunkt für die Christianisierung Norddeutschalands gelten die neu gegründeten Bistümer im niedersächischen Küstengebiet Bremen und Hamburg. Ziel war der Aufbau einer Verwaltung, die Einnahme von Kirchensteuer und die Mehrung klösterlichen Grundbesitzes.

Liudger erhielt auf der ostfriesischen Halbinsel den Ems- und Federgau sowie die Insel Bant. Um 800 gründete er das Kloster Werden an der Ruhr. Für das 9. Jahrhundert finden sich in den Klosterarchivalien zahlreiche Schenkungen von friesischen Ländereien im Emsgau (SCHMIDT 1975, 10). Demnach verfügte das Kloster über Grundbesitz sowohl in der Emsmarsch, in Loga und einigen Geestsiedlungen, wie in der Krummhörn. Verschiedene Schenkungseinträge unter Nennung ostfriesischer Ortsnamen sind auch in Urkunden der Klöster Fulda und Corvey erhalten geblieben.

Die Schriftlichkeit der einheimischen Bevölkerung begrenzte sich auf wenige Runeninschriften, während fränkische Gelehrte mit dem Lex Saxonum (802) und Lex Friesionum einheimische Stammesrechte aufzeichneten. Gleichzeitig wurde ein einheitliches System zur Einteilung der Grafschaften, der Befugnisse ihrer Schulzen und lokalen Ratgeber geschaffen (VAN LENGEN 1995, 115).

Wenige vorher erlassene Sondergesetze, wie die „Capitulatio de partibus Saxoniae“ (um 785), befassten sich ausführlich mit der Christianisierung der heidnischen Friesen und Sachsen. Ihr Gegenstand war ein harter Strafkanon bei Zuwiderhandlungen gegen das Verbot vorchristlicher Rituale. So war die als heidnisch empfundene Brandbestattung bei Todesstrafe verboten. Allgemein 
wird von einem Übergang zur Körperbestattung um 800 ausgegangen, wobei es zunächst sicherlich noch zu einem Nebeneinander beider Bestattungen gekommen ist, wie es sich im Gräberfeld Dunum abzeichnet (SCHMID 1969b).

Erste kirchliche Strukturen begannen sich bald nach Gründung des Bistums Bremen 787 herauszubilden. Unter Bischof Willehad wurde die Christianisierung maßgeblich vorangetrieben. Vermehrte Normanneneinfälle an den Küsten in Norddeutschland behinderten die Christianisierung ebenso wie die mangelnde Bereitschaft der Friesen den neuen Glauben anzunehmen. Mit der Zerstörung der Hammaburg 845 kommt es zu einem Stillstand in der Mission der skandinavischen Länder, die ihren Ausgangspunkt im Hamburger Bistum hatte.

Bereits Ende des 8. Jahrhunderts erfolgte die Trennung Ostfrieslands in je einen Zuständigkeitsbereich der Diözesen Bremen und Münster. Das Kloster Werden besaß vom 9. bis 11. Jahrhundert zahlreiche Besitzungen im Unteren Emsgebiet. Ein Teil im südlichen Ostfrieslands fiel an das Bistum Osnabrück. In seinem Bereich wurde der bischöfliche Einfluss bereits früh beim Patronatsrecht zurückgedrängt und es herrschte weitgehend Selbstbestimmung bei der Wahl (HAIDUCK 1992, 17). Mit der Rückdrängung gräflicher Herrschaftsstrukturen und dem zunehmenden Selbstbewusstsein, auch in den anderen friesischen Landesgemeinden, entstand das Genossenschaftspatronat. Es entwickelte sich somit auch im religiösen Belangen eine Sonderstellung der Friesen. Diese gestattete es ihnen ohne Einspruch vom Bischof auf eigenem Grund eine Kirche zu errichten und den Priester frei zu wählen (BUMA / ABEL 1963, 112).

Zum frühen Kirchenbau in Ostfriesland gibt es nur wenige Belege schriftlicher Art. So nennt die Vita des Hl. Liudger ein von ihm veranlasstes Fischwunder „bei seiner Kirche in Leer“. Bischof Altfrid berichtete in der Vita S. Liudgeri, das Liudger um 800 die Kirche in Hleri (Leer) am Fluss Lade (Leda) gründete. Ihr Standort ist nicht überliefert. Möglicherweise handelte es sich um die bis 1787 bestandene alte Ortskirche in Leer nahe der ehemaligen Ledaschleife am alten Leeraner Stadthafen (HAIDUCK 1992, 189).

Die frühe Phase der Christianisierung im 8./9. Jahrhundert hat die friesische Bevölkerung jedoch nicht vollständig durchdrungen. Weiterhin wurden die bekannten Gräberfelder, wie Zetel, Schortens, Cleverns und Dunum, genutzt, auch wenn nun sich öfter christliche Symbole in den mit Beigaben ausgestatteten Gräbern finden.

Der Bau früher Kirchen ist archivarisch nur schwer fassbar. Zwar finden sich in spätmittelalterlichen Quellen Berichte über frühe Missionserfolge und erste Patrozinien. Doch eher wahrscheinlich ist, dass es sich hierbei um Rückschreibungen handelt, die den Anspruch der Kirche auf bestimmte Besitzungen und die Kontinuität des Glaubens belegen sollten. Ob die Kirche von Leer also bereits im frühen 9. Jahrhundert bestand oder ob es sich bei der Überlieferung um eine spätere Verklärung der 
frühen Friesenmission handelte, ist daher nicht zu klären. Die frühe Missionsgeschichte wurde im Hochmittelalter identitätsstiftend für die erstarkten Landesgemeinden.

Der Bau erster Holzkirchen wird in den Quellen nicht explizit erwähnt, ist jedoch archäologisch in Ostfriesland ab dem 10. Jahrhundert fassbar. Hinweise auf eine frühe Holzbauphase finden sich bei Kirchen im Emsgebiet, so in Bunde, Leer und Middels (HAIDUCK 1992, 144, 197, 199) und von der ostfriesischen Geest, wie in Etzel, Fulkum, Jever und Leerhafe (HAIDUCK 1992, 162; 164; 177; 193). Die einsetzende Bautätigkeit zeigt für die Kirchen oft eine Randlage in den Siedlungen. Vor ihrer Errichtung wurde meist ein Kirchhügel aufgeschüttet. Erst mit der Landnahme auf der Geest, die eine unmittelbare Folge des ewigen Roggenbaus und dazu notwenigen Plaggendüngung war, wurden Kirchen mit der Siedlungsneugründung im Zentrum des Dorfes errichtet. Nach mehreren Bauphasen mit sich ablösenden Holzkirchen folgten im 12. Jahrhundert Tuffsteinkirchen und wenig später erste Backsteinbauten. Beispielhaft sein hier auf den Kirchenbau von Etzel, eines der ältesten klösterlichen Anwesen in Ostfriesland, verweisen (HAIDUCK 1992, 161-163). Waren es für Kirchenbauten im sächsischen Bereich meist adlige Stifter, so traten in Ostfriesland wohlhabende Familien, Häuptlinge oder Landesgemeinden als Bauherren auf.

Der Mangel an Archivalien zur mittelalterlichen Geschichte Ostfrieslands steht inhärent in Verbindung mit der Säkularisierung der zahlreichen ostfriesischen Klöster (Abb. 10). Die 28 in Ostfriesland nachgewiesenen Ordensgemeinschaften stellten nicht nur religiöse Zentren dar, sondern waren wichtige landwirtschaftliche Großbetriebe mit politischem Einfluss (BÄRENFÄNGER 1997, 14). Nach ihrer Auflösung wurde nicht nur das Inventar, sondern oft sogar das Steinmaterial sämtlicher Klostergebäude bis auf ihre Grundmauern verkauft. Die zugehörigen Archivalien gingen verloren, soweit sie nicht vom Mutterkonvent übernommen wurden. 


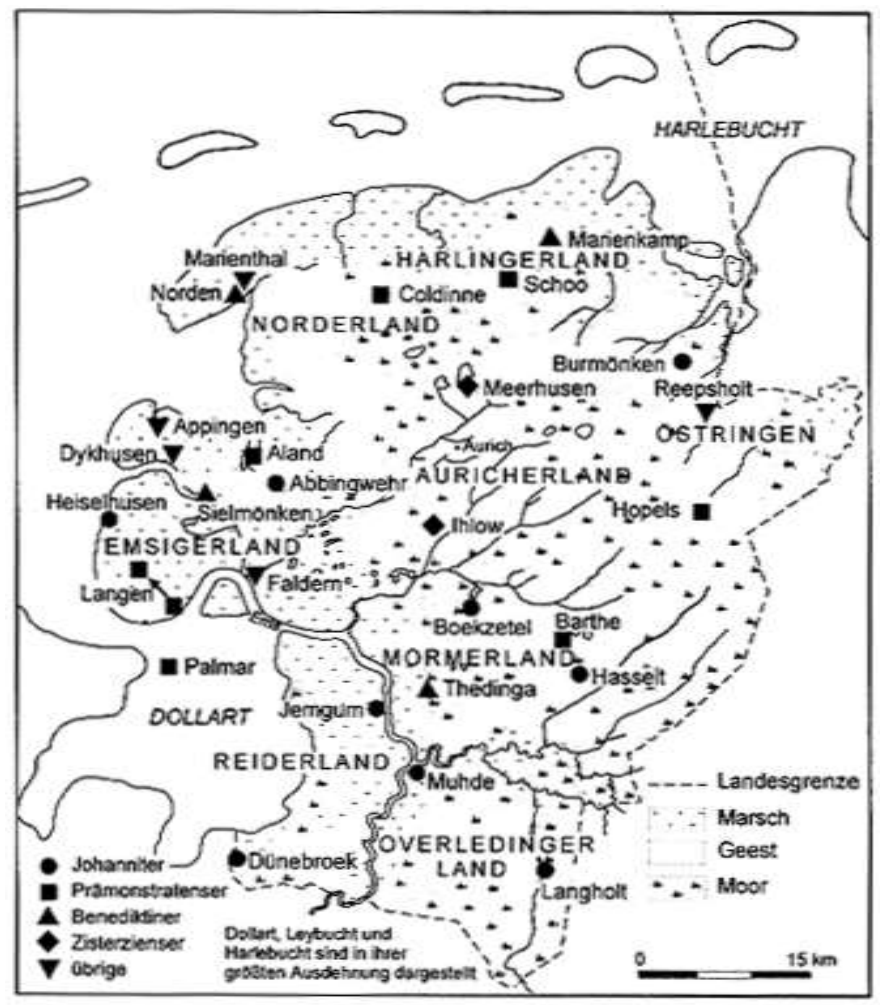

Abb. 10

Die Lage mittelalterlicher Klöster im Naturraum Ostfriesland (nach BÄRENFÄNGER 1997, 14).

\subsection{Archäologische Quellenlage}

Die Quellenlage steht in Abhängigkeit von der Intensität denkmalpflegerischer Tätigkeiten und dem Umfang der in den Boden eingreifenden Maßnahmen. Dabei stellt eine gute Quellenlage die grundlegende Voraussetzung für einen guten Forschungsstand dar (JANKUHN 1978).

\subsubsection{Geschichte der Sammlungen, erste Ausgrabungen, Forschungsinstitutionen}

Ein Interesse an der lokalen Heimatgeschichte bildete sich in Ostfriesland bereits Anfang des 19. Jahrhunderts im Zuge der Romantik heraus. 1820 erfolgte die Gründung der "Emdischen Gesellschaft für bildende Kunst und vaterländische Alterthümer zu Emden“. Unter Rose und Brandes fanden erste Fundbergungen statt, deren Überlieferung in Teilen erhalten ist (ROSE 1878). Die archäologischen Funde gelangten u.a. in die Emder Sammlung und wurden ab 1870 der Öffentlichkeit zugänglich gemacht.

Schon 1890 wurde in Leer ein eigener „Verein zur Errichtung einer Altertümersammlung“ gegründet, der 21 Jahre später in den „Verein für Heimatschutz und Heimatgeschichte“ überging. Die archäologischen Exponate der Sammlung nahm ZYLMANN in den 20er Jahren des 20. Jahrhunderts auf und publizierte sie anschließend (ZYLMANN 1933). Nach 1934 fand über einen langen Zeitraum keine systematische Erfassung der Fundeingänge statt. Ein ähnliches Schicksal hatten die in örtlichen 
Heimatmuseen aufbewahrten Sammlungsbestände. Erst Mitte der 90er Jahre des 20. Jahrhunderts konnten archäologische Altfunde aus dem Heimatmuseum Leer sowie des Fehn- und Schifffahrtsmuseums Westrhauderfehn und verschiedener Privatsammlungen wieder erfasst werden (SCHWARZ/STUTZKE 1998). Archäologische Funde des Reiderlandes, darunter römische Militaria, verwahrt das 1919 gegründete volkskundliche Museum Weener. Die umfangreiche reiderländische Sammlung wurde inzwischen systematisch aufgenommen (SCHWARZ/REIMANN in Vorbereitung). SCHWARZ ist es darüber hinaus zu verdanken, dass erstmals Fundmaterial der archäologischen Landesaufnahme und Altfunde des Ostfriesischen Landesmuseums in Emden, betrieben von der Emdischen Gesellschaft für bildende Kunst und vaterländische Altertümer, in die lokale Besiedlungsgeschichte einbezogen werden konnten (SCHWARZ 1990).

Fundbergungen unter wissenschaftlicher Leitung namhafter Forscher, wie W. van Es, K.-H. JacobFriesen, W. Haarnagel und A. Genrich erfolgten im Landkreis Leer bereits seit den 20er Jahren des 20. Jahrhunderts. Fundumstände wurden oft nur kursorisch vermerkt und die zugehörige Dokumentation gilt meist als verschollen (SCHWARZ 2005, 60).

Während ein Teil der Funde in ostfriesischen Heimatmuseen verblieb, gelangten einige Funde in das Provinzialmuseum Hannover. Herausragende Funde erhielt das Volkskundliche Museum Berlin, deren Sammlungsbestände durch den 2. Weltkrieg stark beschädigt wurden. In der Dauerausstellung des Kunstgewerbemuseums Berlin ist derzeit ein massiv goldener frühmittelalterlicher Fingerring ausgestellt. Den ausdrucksstarken Ring ziert eine plastische Löwenfigur, sein Fundort wird allgemein mit Ostfriesland angegeben (Abb. 11).

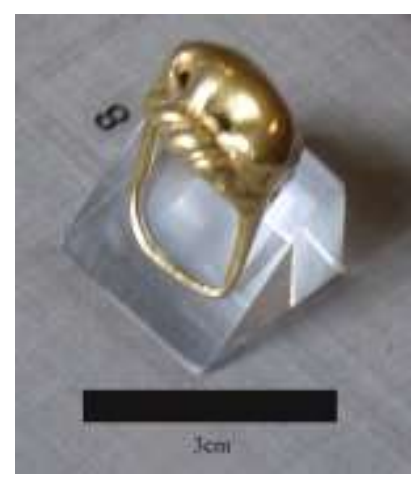

Abb. 11

Goldener Fingerring aus Ostfriesland

Einen wichtigen Anteil an der Erforschung der ostfriesischen Küstenregion hat die 1938 durch das Landesmuseum Hannover gegründete Provinzialstelle für Marschen- und Wurtenforschung: das „Institut für historische Küstenforschung“ in Wilhelmshaven.

Durch den Kriegsbeginn 1939 unterbrochen, konnten die Forschungsarbeiten erst in den 50er Jahren wiederaufgenommen werden (SCHMID 1999, 32). In Ostfriesland fanden im Vorfeld von 
Wiederaufbaumaßnahmen im kriegszerstörten Emden erste Grabungen statt, die wichtige Erkenntnisse zur Genese der Stadtwurt ermöglichten und in den 1960er Jahren in einen DFG geförderten Forschungsschwerpunkt mündeten (HAARNAGEL 1955, 1959, 1984). Ein weiteres DFG Projekt beschäftigte sich von 1963 bis 1969 und von 1975 bis 1976 mit der Besiedlungsgeschichte im Reiderland (HAARNAGEL 1957, 1969; BEHRE 1970, 1972, 1977, 1986; BRANDT 1972, 1974, 1977a, 1977b, 1979). Die interdisziplinäre Einbindung naturwissenschaftlicher Methoden war wegweisend für die siedlungsarchäologische Forschung.

Einer kontinuierlichen Betreuung archäologischer Bodendenkmale von Wilhelmshaven aus stand jedoch die verkehrstechnisch ungünstige Lage Ostfrieslands entgegen. Um Fundmeldung und -inventarisation im Regierungsbezirk Aurich zu verbessern, entstand 1951 eine an die Ostfriesische Landschaft angegliederte „Arbeitsgruppe Vorgeschichte“. Erste Schritte in der archäologischen Regionalforschung nach dem 2. Weltkrieg sind K.-H. Marschalleck zu verdanken.

Bereits 1963 begann in Ostfriesland eine systematische Erfassung archäologischer Denkmäler, während diese in anderen Regionen Niedersachsens erst mit Inkrafttreten des Niedersächsischen Denkmalschutzgesetzes 1974 erfolgte.

Die archäologische Landesaufnahme beinhaltete planmäßige Begehungen ausgewählter Flächen und Kartierung der ostfriesischen Fundstellen durch einen Geländetechniker. Bis zur Einstellung der o.g. Verfahrenweise 1984 wurden rund ein Drittel der Fläche des Regierungsbezirkes Aurich aufgesucht. Der regionale Schwerpunkt lag hierbei im Küstengebiet sowie im nördlichen und westlichen Teil des Landkreises Leer (SCHWARZ 1990, 14-16). Als Ergebnis der systematischen Begehungen zeigte sich für den Kreis Leer in den Gemeinden Logabirum, Brinkum, Holtland, Filsum und Nortmoor eine deutlich erhöhte Fundstelleanzahl als ursprünglich bekannt (SCHMID 1969a, 184-188, Abb. 12).

Die lokale Bodendenkmalpflege in Ostfriesland wurde von 1972 bis 2008 von W. Schwarz geleitet, im Anschluss übernahm R. Bärenfänger die Leitung des Archäologischen Dienstes. Die Abteilung ist an eine Körperschaft öffentlichen Rechts, der Ostfriesischen Landschaft in Aurich, angegliedert. Ihr sind essentielle Beiträge zur archäologischen Landesaufnahme und zur Erforschung der ostfriesischen Urund Frühgeschichte zu verdanken (u.a. SCHWARZ 1990, 1998, 1999, 2002, 2003; BÄRENFÄNGER 1994, 1995, 1996b, 2001).

Ein mit der Zeit sich wandelnder Aufgabenbereich der „Archäologischen Landesaufnahme“, auch eine Folge verstärkter Ausgrabungstätigkeiten, begründete 1989 die Umbenennung der Abteilung in „Archäologische Forschungsstelle“, die seit 2002 unter dem Namen „Archäologischer Dienst“ der Ostfriesischen Landschaft tätig ist. Seit 2007 leiten S. König und J. Kegler den Archäologischen Dienst. 
Heute stellen Fundbergung, Dokumentation und wissenschaftliche Auswertung eine zentrale Aufgabe der archäologischen Abteilung der Ostfriesischen Landschaft dar. Personell wird dies geleistet von zwei Wissenschaftlern, drei Grabungstechnikern, zwei Sachbearbeitern, einem Grafiker und einer Vielzahl von temporären Mitarbeitern. Nicht unerwähnt bleiben dürfen die ehrenamtlichen Helfer, die durch ihre Mitarbeit einen wichtigen Beitrag leisten.

\subsubsection{Quellenlage und Denkmalverlust}

Evident ist, wie die Quellenlage in Ostfriesland den Forschungsstand beeinflusste. So erscheint bei RÖTTING (1985) die Geest in der römischen Kaiserzeit weitgehend siedlungsleer, während sich dies bei näherer Betrachtung als eine Folge der Fundumstände darstellt. So begünstigte das seit dem 19. Jahrhundert verstärkte Abgraben von Wurten zur Humusgewinnung die einseitige Hervorhebung urund frühgeschichtlicher Fundplätze in der Marsch, während diese auf der Geest unbeachtet blieben (vgl. SCHWARZ 1990, 15, 132).

Auch im Marschgebiet kann die Quellenlage regional beträchtlich divergieren. Zahlreiche Bodendenkmale wurden mit Intensivierung der Bodennutzung zerstört. Mit der dort bereits früh einsetzenden Fundaufsammlung erhöhte sich die Fundstellenanzahl, wie dies u.a. für römische Funde in den nordöstlichen Niederlanden belegt ist (vgl. EGGERS 1951, 25; VOLKERS 1991, 176). Für die untere Emsregion wird hingegen eine deutlich geringere Importdichte vermerkt (ERDRICH 2001, vgl. Beilage 1). Anfang der 50er Jahre des 20. Jahrhunderts nicht erkannte größere kaiserzeitliche Siedlungen im Binnenland zwischen Ems und Weser wurden mit Beginn der regionalen Bodendenkmalpflege entdeckt (u.a. HAARNAGEL 1964, 1969, 1979; SCHWARZ 1979; ZOLLER 1972a, 1972b, 1975; ZIMMMERMANN 1976, 1992a). Auch in den ostfriesischen Marschgebieten hat sich die Fundstellenzahl maßgeblich erhöht. Für Geestrandgebiete im südlichen Ostfriesland ist ein vergleichsweise dichter Fundniederschlag festzustellen (SCHMID 1969a, Taf. 12 u. 13; SCHWARZ 1999, 5-32).

Im Zuge einer intensiven denkmalpflegerischen Betreuung und systematischer Geländebegehungen zeigt sich für den Landkreis Leer eine deutliche Zunahme der Fundstellen. Die vermehrte Auffindung archäologischer Fundstellen in den letzten 50 Jahren steht inhärent in Beziehung mit der Intensität von Bodeneingriffen im Untersuchungsgebiet. Waren es früher meist Zufallsfunde, die in geringer Tiefe aufgefunden wurden, so sind heute tiefgreifende Erdarbeiten keine Seltenheit mehr.

Die Anzahl des archäologischen Quellenmaterials hat sich in den letzten 100 Jahren veringert, d.h. die Denkmalsubstanz nimmt insgesamt ab. Dies steht u.a. in Zusammenhang mit der Art der Bodeneingriffe und dem höheren Flächenverbrauch der modernen Industriegesellschaft. Die Intensivierung der Landwirtschaft sowie Grundwasserabsenkungen tun ihr übriges. Organische 
Materialien, seit Jahrtausenden im Feuchtbodenmilieu konserviert, vergehen nun innerhalb weniger Jahre.

Wie rasant der Verlust an Denkmalsubstanz im Untersuchungsgebiet vorschreitet, wird im Folgenden verdeutlicht. Von den 52 noch 1893 kartierten vorgeschichtlichen Grabhügeln bei Logabirum, existierten 1935 ganze zehn Hügel als flache Geländeerhebung. Bei Flurbegehungen in den 60er Jahren des 20. Jahrhunderts wurden nur noch Bodenverfärbungen von sechs nahezu vollständig zerstörten Grabhügeln beobachtet (SCHMID 1969a, 182; SCHWARZ 2000, 310-312, Abb. 195). Komplett abgetragen wurde im 19. Jahrhundert auch das bronzezeitliche Grabhügelfeld südlich von Hesel an der alten Heerstraße Leer-Aurich. Das gewonnene Material diente als Auftragsboden für die durch Plaggenhieb geschädigten Geestflächen.

Neben dem Abtrag von Wurten in der Marsch und Grabhügeln auf der Geest war es insbesondere die ostfriesische Moorlandschaft, die im großen Stil Opfer des Torfabbaus wurde. Ehemals weite Moorflächen im Süden und Nordosten des Landkreises Leer, sowie im Reiderland sind inzwischen weitgehend abgetorft und kultiviert.

Der unkontrollierte Torfabbau führte in der Vergangenheit zu unwiederbringlichen Verlusten in der Denkmalsubstanz. Herausragende Funde aus abgetorften Arealen im Landkreis Leer vermitteln einen Eindruck davon (SCHWARZ/STUTZKE 1998, 20, 25, 93, 96, 105). Insbesondere organische und metallene Fundobjekte, die im Sandboden i.d.R. bereits vergangen sind, erhalten sich im anaeroben feuchten Milieu der Moore. Oft treten die im Moor verborgenen Fundstellen erst mit ihrer Abtorfung zutage und können dann nicht mehr fachgerecht dokumentiert werden.

Den „Rückzug“ des Moorkörpers veranschaulicht das Schicksal eines urgeschichtlichen Grabhügels bei Collinghorst im Landkreis Leer. Dieser war zu Beginn des 20. Jahrhunderts noch ganz vom Moor bedeckt war. 1981 fanden sich auf der inzwischen abgetorften und planierten Sandoberfläche lediglich noch schwach sichtbare Bodenverfärbungen, die auf seinen ehemaligen Standort hinwiesen (SCHWARZ/STUTZKE 1998, 49-50). Großflächige Grundwasserabsenkungen zerstören derzeit die Reste dieses einzigartigen Naturraumes in Norddeutschland und haben vermutlich den Verlust weiterer Denkmalsubstanz zur Folge (vgl. SCHNEIDER 2008, 17-18).

Große Bereiche des Landkreises Leer sind durch Moor- und Marschgebiete geprägt. Während es auf der Hohen Geest häufiger zu Sandentnahmen über mehrere Hektar kam, wobei unentdeckte Bodendenkmale rücksichtslos zerstört wurden, blieb die Untere Emsregion davon weitgehend verschont. Die relative Sandarmut hatte jedoch fatale Folgen für eine Vielzahl an Geestdurchragungen und Flugsanddünen im Untersuchungsgebiet. Bei Bodeneingriffen wurden diese, oft bereits seit dem Neolithikum besiedelten trockene Standorte, planmäßig ausgesandet. Die relativ hohe Siedlungsfrequenz einiger dieser Plätze belegen umfangreiche Fundaufsammlungen. Noch Mitte der 60er Jahre des 20. Jahrhundert sammelten interessierte Bürger zahllose Keramikscherben und 
Flintartefakte, sowohl von Dünen im Westerhammrich wie auch im Nortmoorer Hammrich, auf (SCHWARZ/STUTZKE 1998, 39-41). Bei den Aussandungsarbeiten im Westerhammrich/Stadt Leer wurde eines der letzten Megalithgräber in Ostfriesland zerstört (BAKKER 1979). Die rudimentären Reste eines weiteren Großsteingrabes konnten Grabungstechniker 1980 in einer Sandgrube bei Brinkum-Meerhausen lokalisieren (SCHWARZ 1981, 192). Die bis in die 80er Jahre des 20. Jahrhunderts dünne Personaldecke der Bodendenkmalpflege hatte dem Bodenabbau kaum etwas entgegen zu setzen.

In Ostfriesland wird die Erfassung der Fundstellen in großem Umfang vom jeweils vorherrschenden Naturraum beeinflusst. Dies trifft nicht nur auf vom Moor überwucherte Bodendenkmäler zu, auch holozäne Sedimente können archäologische Fundstellen verdecken, so dass diese kaum auffindbar sind und nur bei tiefgreifenden Bodeneingriffe freigelegt werden. Im Mündungsbereich der Holtlander Ehe in die Jümme beispielsweise wurden steinzeitliche Artefakte erst in einer Tiefe von vier Metern entdeckt (SCHWARZ 1998, 16).

Auch in der Marsch ist mit einer Kleiüberdeckung älterer Fundstellen zu rechnen, die meist zufällig bei Bodenaufschlüssen zu Tage treten (ScHWARZ 1990, 15). Siedlungsgünstige Uferwälle der Ems waren in der Zeit vor dem Deichbau starken Überschwemmungen ausgesetzt. Stellenweise liegen dort Fundstellen außerhalb der historischen Deichbaulinie in der Flussmarsch von Ems und Jümme und sind nur noch durch Zufall aufzufinden. In den 30er Jahren des 20. Jahrhunderts häuften sich die von Mitarbeitern des Wasserwirtschaftsamtes Leer entdeckten Fundstellen. Unter einer bis zu $1 \mathrm{~m}$ mächtigen Kleischicht fand man am Zusammenfluss von Jümme und Leda ein kaiserzeitliches Gräberfeld (ERDNIß 1939, 29). Im Zuge von Uferbefestigungsarbeiten am Ledaarm vor Leer wurden zwei fränkische Schwerter aufgefunden (JACOB-FRIESEN 1931, 208), die möglicherweise in Zusammenhang mit einer wohl frühmittelalterlichen Anlegestelle zu sehen sind (BÄRENFÄNGER 1998c, 31).

Eine Überdeckung anthropogener Hinterlassenschaften erfolgte in den niedersächsischen Geestgebieten auch durch mittelalterliche Plaggenaufträge. Derartige Aufträge schützen zwar archäologische Fundstellen, verhindern jedoch häufig ihre Entdeckung, die dann erst infolge massiver Bodeneingriffe erfolgen kann. Bekannte Beispiele hierfür stellen kaiserzeitliche Siedlungen auf dem Gristeder Esch bei Bad Zwischenahn sowie auf der Briller Gaste im Landkreis Wittmund dar, deren Reste unter einem mächtigen künstlichen Bodenauftrag erhalten blieben (ZOLLER 1957; LEHMANN 2002).

Derzeit steht eine systematische Aufnahme von Plaggenböden für das Untersuchungsgebiet noch aus. Nach bisherigem Kenntnisstand ist von einem regionalen Bodenauftrag in den Geestgebieten nördlich der Jümme auszugehen (SCHMID 1969a). Neuere Grabungen belegen auch für den Bereich der Heseler Gaste, südwestlich des Ortes Hesel einen bis zu $1 \mathrm{~m}$ mächtigen humosen Plaggenesch, der einen 
eisenzeitlichen Flugsandhorizont bedeckte (BÄRENFÄNGER 1998b, 45, Abb. 51). Ein weniger hoher Bodenauftrag überbedeckte das kaiserzeitliche Gräberfeld in Logabirum (ZYLMANN 1933, 100).

Mit den Aufträgen gelangen teilweise Fundstücke von anderen Plätzen zu ihrem Fundort. SCHWARZ (1990, 15) geht jedoch davon aus, dass „die Ackertätigkeit auf dem Sandboden - trotz stellenweisen Bodenauftrags - für die archäologische Landesaufnahme eine gleichmäßige Funddichte bewirkte“.

\subsubsection{Fundstellen im Landkreis Leer}

Der Fundstellenkatalog dieser Arbeit beruht auf Akten der archäologischen Landesaufnahme des Archäologischen Dienstes der Ostfriesischen Landschaft Aurich und der Kartei des Niedersächsischen Landesamtes für Denkmalpflege. Einbezogen wurden Vorberichte der archäologischen Fundchronik des Emder Jahrbuches, der Nachrichten aus Niedersachsens Urgeschichte, des archäologischen Mitteilungsblattes aus Nordwestdeutschland. Diesen Arbeiten wurde die chronologische Einordnung der Fundstellen entnommen. Soweit publizierte Abbildungen vorliegen ist dies im Fundstellenkatalog vermerkt. Auch bisher unpublizierte Altfunde aus dem Landkreis Leer, insbesondere aus dem Reiderland, fanden Eingang in die Untersuchung und sind im Tafelteil abgebildet.

Umfangreiches Fundmaterial stammt aus Siedlungsgrabungen der letzten Jahre und ist für spätere Publikationen des archäologischen Dienstes der Ostfriesischen Landschaft vorgesehen. Die Fundvorlage für die Makroregion selbst kann aufgrund der Größe des Arbeitsgebietes nur in summarischer Form erfolgen. Die Materialaufnahme erfolgte bis 2004.

Aufgenommen wurden Fundstellen der römischen Kaiserzeit, der Völkerwanderungszeit und des Frühmittelalters. Insgesamt liegen aus dem Landkreis Leer 69 Fundstellen vor. Die Verteilung der Fundarten zeigt das Diagramm 1. Es handelt sich insgesamt um 45 Siedlungsplätze, 17 Bestattungsplätze und 10 Depotfunde, worunter sechs umfangreiche Münzschatzfunde fallen. Separat wurde ein Gewässerfund aufgenommen (FStNr. 32). Die übrigen Fundstellen verteilen sich auf zwei Bohlenwege und zwei Werkplätze. Die zu beobachtende Differenz in der Fundstellenanzahl erklärt sich aus einer Mehrfachnennung einiger Fundstellen innerhalb verschiedener Fundstellenarten. So liegen von fünf Fundstellen sowohl Siedlungs- wie Bestattungsplätze vor (FStNr. 02; 20; 27; 35; 61), bei einem Fundort wird zusätzlich eine lokale Metallverarbeitung vermutet (FStNr. 35).

Etwa 1/4 der Fundstellen sind mehrperiodig. Es handelt sich um nachstehende Fundstellen: FStNr. 01; $02 ; 07 ; 18 ; 21 ; 23 ; 24 ; 26 ; 27 ; 31 ; 34 ; 34 \mathrm{~b} ; 36 ; 37$; evtl. $47 ; 58 ; 61 ; 64$. Es wurden nur gesicherte Fundstellen berücksichtigt, nicht jedoch Fundstreuungen ohne Siedlungsindikatoren, wie Hüttenlehm, Mahlsteine, Webgewichte u.a.m., da sie ggf. auch durch einen Bodenauftrag entstehen können. Depotfunde wurden nur aufgenommen, wenn ihre Fundumstände und Datierung als sicher angesehen werden können. 


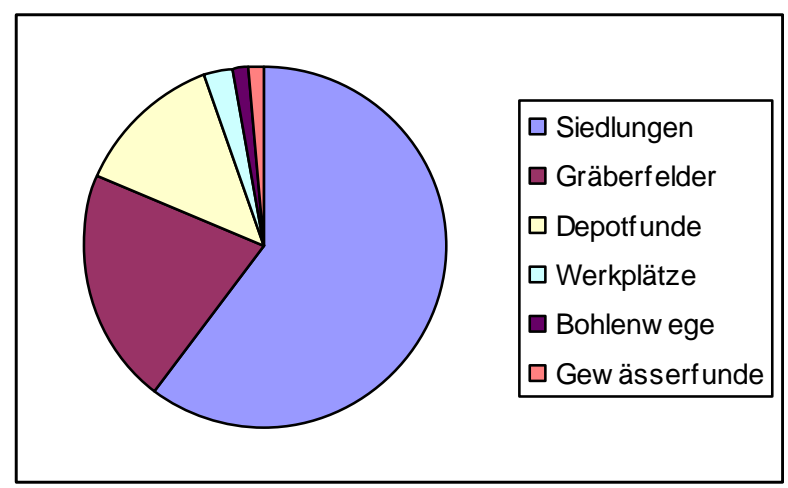

Diagramm 1 Verteilung der Fundarten im Untersuchungsgebiet

Bisher undatierte Wurten blieben für die Fundstellenaufnahme unberücksichtigt. Zwar handelt es sich eventuell um eisen- und kaiserzeitliche Wohnpodeste, da aber eine archäologische Untersuchung derzeit noch aussteht, ist nicht belegbar, ob sie während der Dünkirchen-II-Transgression errichtet worden sind.

Im Katalogteil erfolgt die Fundstellenvorlage nach nachstehendem Schema: Lage / Koordinaten; Gattung / Naturraum / Datierung; Fundumstände; Befundbeschreibung; Fundvorlage; Quellennachweis. Konkordanzlisten liegen für die Gemeinden, die Fundortdatierungen und Fundgattungen im Anhang vor. Die Fundstellen sind nach ihrer Datierung und Fundgattung kartiert.

Die meisten Fundstellen finden sich in der Gemeinde Jemgum $(n=22)$, die mit der Gemeinde Weener $(n=2)$ einen Grossteil des nordwestlichen Bereiches des Reiderlandes und des erhöhten Emsufers einnimmt (Diagramm 2). Ein erhöhtes Aufkommen von Fundstellen besteht auch auf dem gegenüberliegenden Ufer der Ems und am Unterlauf der Leda. Aus dem Stadtgebiet Leer liegen mit dem Ortsteil Loga zusammen fünf Stellen vor. In der nördlich anschließenden Region Moormerland sind es vier Fundorte. Die Samtgemeinde Hesel ist mit neun Fundstellen vertreten. Mit fünf Stellen folgt der Anteil in den Gemeinden Uplengen und Detern, die allesamt in Randbereichen des Untersuchungsgebietes liegen. Von den Geestrandgemeinden Nortmoor und Filsum liegen je drei Fundstellen vor. Die Geestgemeinden Brinkum und Holtland sind mit je zwei Fundstellen vertreten. In den weitgehend mit Hochmoor bedeckten Gemeinden Westoverledingen und Rhauderfehn finden sich $1-2 \%$ der Fundstellen.

Die Fundumstände der hier aufgeführten 69 Fundstellen sind weitgehend bekannt (Diagramm 3). Der größte Teil der Fundstellen wurde beim Abtrag des Oberbodens entdeckt ( $n=48)$, bei 29 von ihnen folgte im Anschluss eine archäologische Untersuchung. 


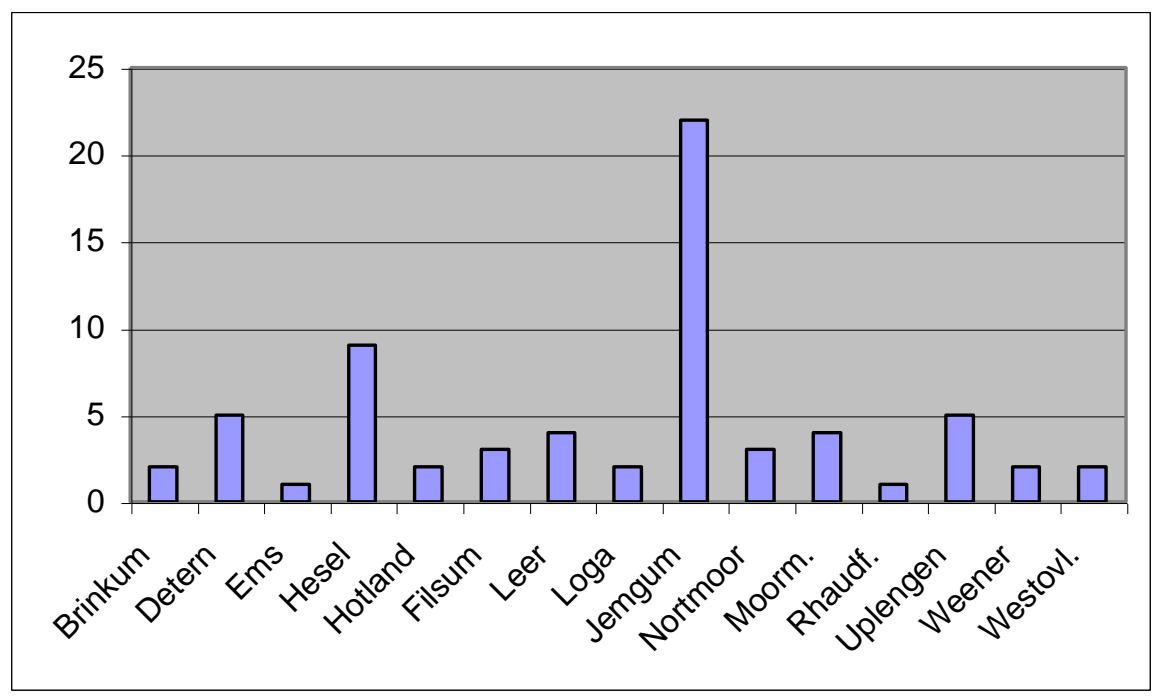

Diagramm 2 Verteilung der Fundstellen nach Gemeinden

Ems $=$ Fluss Ems; Moorm. $=$ Moormerland; Westovl. $=$ Westoverledingen

In den meisten Fällen wurden die Fundumstände näher differenziert (Diagramm 3). So zeigen sich, naturräumlich bedingt, unterschiedliche Fundumstände. Während in der Flussmarsch Deichbaumaßnahmen ( $n=2)$ oder der Abbau von Tonlagerstätten $(n=4)$ zur Entdeckung führten, war es in der Niederungszone die Reinigung von Entwässerungsgräben $(n=3)$ und in Moorgebieten der Torfabbau (n=5). Die näheren Fundumstände des einzigen Flussfundes, der 1858 in der Ems geborgen wurde, sind nicht überliefert. Funde beim Straßenbau betreffen die im 19. Jahrhundert gebaute Chaussee Leer-Hesel ( $n=3)$. Die allgemein bei Oberflächenbegehungen entdeckten Fundstellen haben einen Anteil von 4,5\% (n=3).

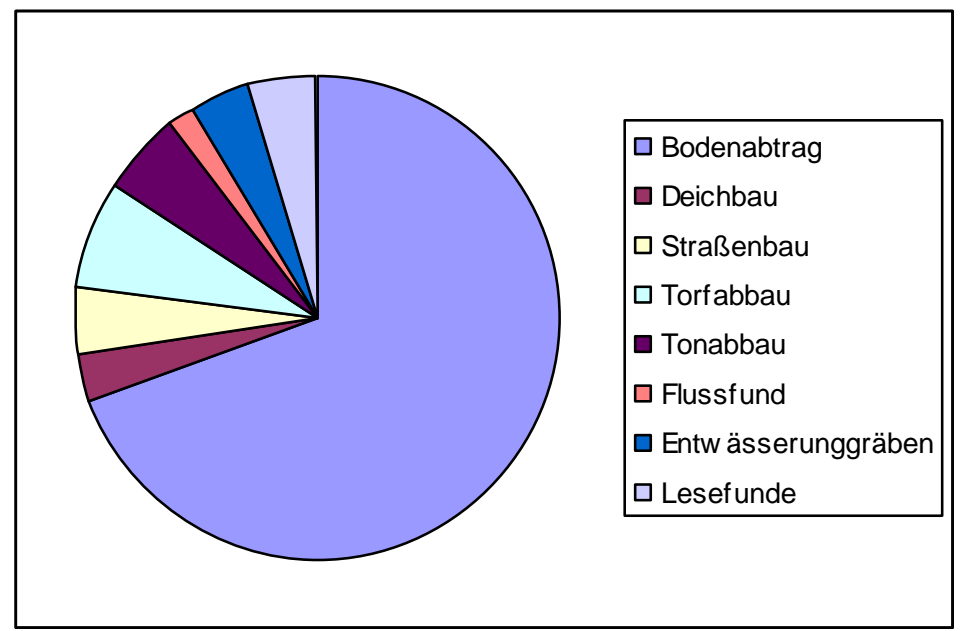

Diagramm 3 Art der Fundumstände

Entdeckt wurden die Fundstellen im Landkreis Leer oftmals als Zufallsfunde von interessierten Laien oder bei Feldbegehungen von ehrenamtlichen Heimatpflegern $(n=39)$. Darüber hinaus sind eine 
Vielzahl von Fundstellen im Rahmen von baubegleitenden Maßnahmen durch Mitarbeiter des archäologischen Dienstes und ihrer Vorgängerinstitutionen entdeckt worden ( $\mathrm{n}=30)$.

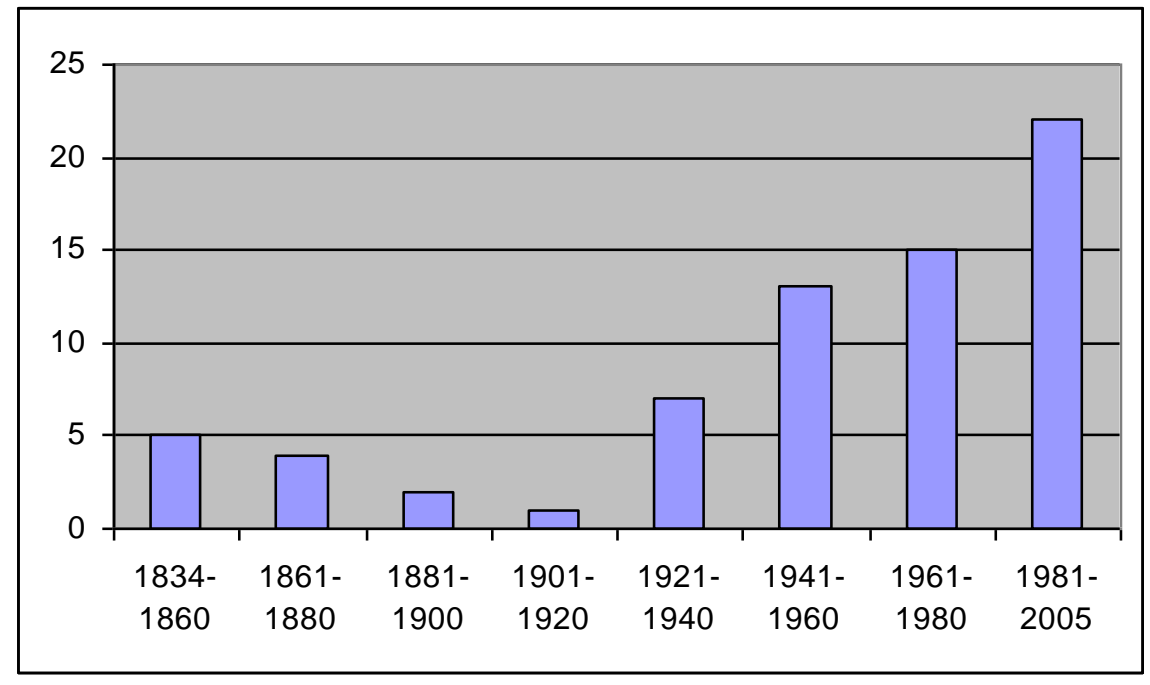

Diagramm 4 Auffindungszeit der Fundstellen im Landkreis Leer

Im Diagramm 4 wird die Auffindungszeit der Fundstellen im Arbeitsgebiet wiedergegeben. Deutlich ist eine Zunahme der Fundstellenzahl erkennbar. Angegeben ist die Erstnennung der Fundstelle. Bei 36 der 69 Fundstellen fand eine archäologische Maßnahme statt. An mache Orten, wie in Bentumersiel oder im Westerhammrich bei Leer, folgten im Laufe der Jahre mehrere Ausgrabungen.

Im Zeitraum zwischen 1834 bis 1900 wurden insgesamt elf Fundstellen aufgedeckt. Bei diesen handelt es sich ausschließlich um zufällige Entdeckungen von Altertümern. Zumeist handelt es sich um Metallobjekte, oft Münzfunde, selten Schmuck oder Waffen. Da dem Fundobjekt i.d.R. mehr Aufmerksamkeit gezollt wurde, sind nur selten Befundumstände überliefert.

War das 19. Jahrhundert stark von Zufallsfunden geprägt, kommt es Anfang des 20. Jahrhunderts vielerorts zum Ankauf und bewussten Ansammeln von Funden. Aus dem Arbeitsgebiet erwarb die prähistorische Sammlung in Hannover 1906 die kompletten Beigaben der frühmittelalterlichen Nekropole Brinkum (FStNr. 46).

Bereits in den 20er Jahren des 20. Jahrhunderts mehrten sich Fundmeldungen ( $\mathrm{n}=7)$, insbesondere in der Emsmarsch; dies geht möglicherweise auf die Initiative von Zylmann zurück, der im Auftrag des Landesvermessungsamtes Hannover geologische Bohrungen im Unteren Emsgebiet durchführte. Tonentnahmen nahe des Altsiedellandes am Emsuferwall begründen hier eine hohe Fundstellendichte. Die ersten Ausgrabungen fanden in den 30er Jahren des 20. Jahrhunderts durch die Provinzialstelle für Wurtenforschung im Landkreis Leer statt. Dennoch gab es in dieser Zeit auch immer wieder Zufallsfunde, wie beim Torfabgraben durch den Reichsarbeitsdienst der NSDAP 1938 (FStNr. 18). 
Während des 2. Weltkrieges kommt die Fundstellenaufnahme in Landkreis Leer zum Erliegen. Mit einsetzender Bautätigkeit in der Nachkriegszeit kommt es zu einem sprunghaften Anstieg der Fundstellenanzahl $(n=13)$. Eine der frühsten Ausgrabungen im Landkreis Leer fand unter Leitung von Genrich und Haarnagel 1948-1949 in Brinkum statt (FStNr. 45). Es folgten in den 50er Jahren erste Fundbergungen auf dem Emsufer, im Stadtgebiet Leer (FStNr. 23; 26; 29; 35; 38), bei Filsum (FStNr. 55) und Detern (FStNr. 62).

Anfang der 1960er Jahre wurde die Arbeitsgemeinschaft Urgeschichte bei der Ostfriesischen Landschaft gegründet. Doch trotz einer nun institutionellen Einbindung der archäologischen Denkmalpflege fand dies zunächst kaum Niederschlag in der Fundstellenzahl im Landkreis Leer. Dies lag u.a. daran begründet, dass der in Aurich beheimatete Mitarbeiter K.-H. Marschalleck weder über einen eigenen Etat noch ein Fahrzeug verfügte. Bis 1972 waren es sieben Fundstellen, die von Heimatforschern gemeldet wurden. Weitere drei entdeckte man im Rahmen des DFG Schwerpunktprogrammes auf dem linken Emsufer. Nach Gründung der Archäologischen Forschungsstelle 1972 kamen in den Folgejahren fünf weitere Fundstellen dazu.

Seit den 80er Jahren des 20. Jahrhunderts nimmt die Fundstellenzahl im Arbeitsgebiet kontinuierlich zu und hat sich somit bis 2005 auf insgesamt 22 neu entdeckte Fundstellen erhöht. Neben dem größeren Flächenverbrauch im Zuge neuer Baugebiete und einer immer intensiver werdenden Landwirtschaft, wird dies sicherlich auch durch die Intensität der denkmalpflegerischen Betreuung positiv beeinflusst worden sein; seit 1988 gehören drei Grabungstechniker zum festen Mitarbeiterstab des Archäologischen Dienstes.

Ein Beispiel für die Etablierung der archäologischen Denkmalpflege in Ostfriesland ist die denkmalpflegerische Betreuung des Landkreises Leer. Seit Anfang der 90er Jahre des 20. Jahrhunderts existiert im zentralen Geestort Hesel eine Außenstelle des Archäologischen Dienstes der Ostfriesischen Landschaft. Die zu beobachtende Häufung von Fundstellen in der Samtgemeinde Hesel ist zwar verursacht durch vermehrte Bodeneingriffe, doch erst mit einer lokal verwurzelten Denkmalpflege werden deren Anliegen stärker berücksichtigt. Dies zeigt sich sowohl an der MidalPipeline, die als Erdgastrasse den Landkreis Leer durchquert (FStNr. 36; 47; 48; 49; 57), wie bei den im Heseler Baugebieten entdeckten Fundstellen (FStNr. 11; 13; 14; 46; 49; 50).

Kartiert man die Fundstellen im Arbeitsgebiet, so zeigt sich in den vier Hauptlandschaftsräumen Flussmarsch, Geestrand, Hohe Geest und Moor eine recht differenzierte Verteilung. Der Vollständigkeit halber wird auch der Einzelfund aus der Ems aufgenommen. In Diagramm 5 zeigt sich eine unterschiedliche Verteilung der Fundstellen in den jeweiligen Naturräumen. 


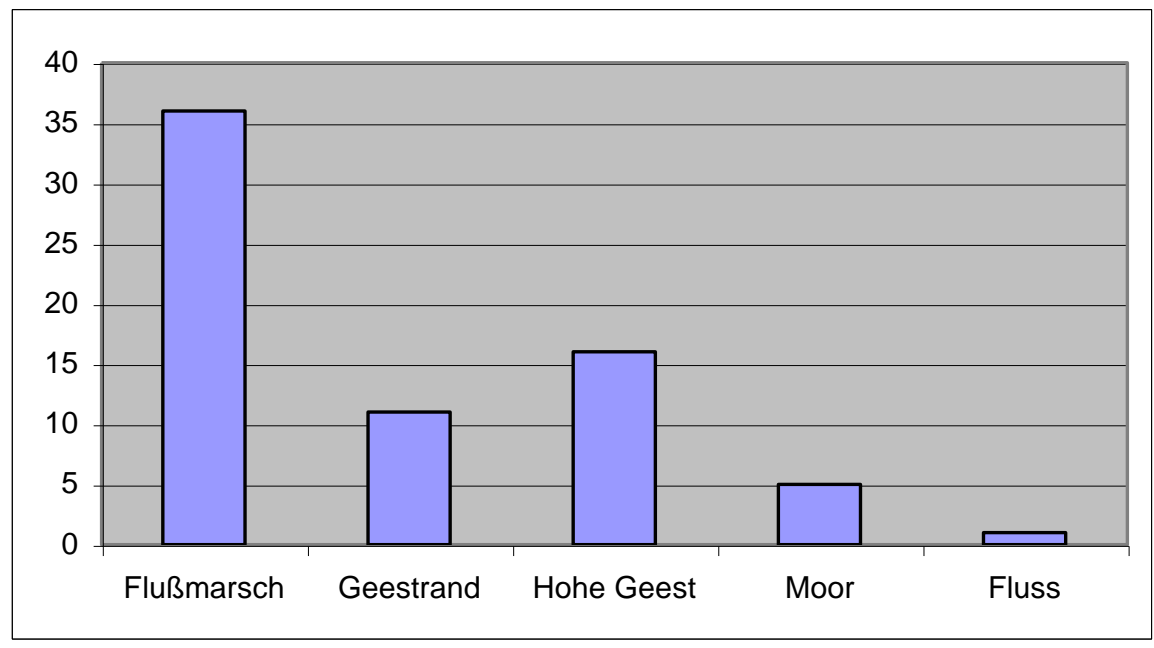

Diagramm 5 Naturräumliche Verteilung der Fundstellen im Arbeitsgebiet

Deutlich fällt die mit 36 Plätzen erhöhte Fundstellenanzahl in der Flussmarsch auf. Gefolgt von einer Häufung auf der Hohen Geest $(n=16)$ und am Geestrand $(n=11)$. Fünf Plätze entdeckte man beim Torfabgraben im Moor, wozu zwei Bohlenwege, zwei Depotfunde und ein alt gegrabenes Brandgrab mit Bad Nauheimer Fibel gehören. Das kostbare Exemplar eines römischen Fingerringes fand man im Moor bei Meinersfehn (Abb. 12). Bei dem einzigen Flussfund handelt es sich um den Zufallsfund eines Tongefäßes mit römischen Münzen aus der Ems.

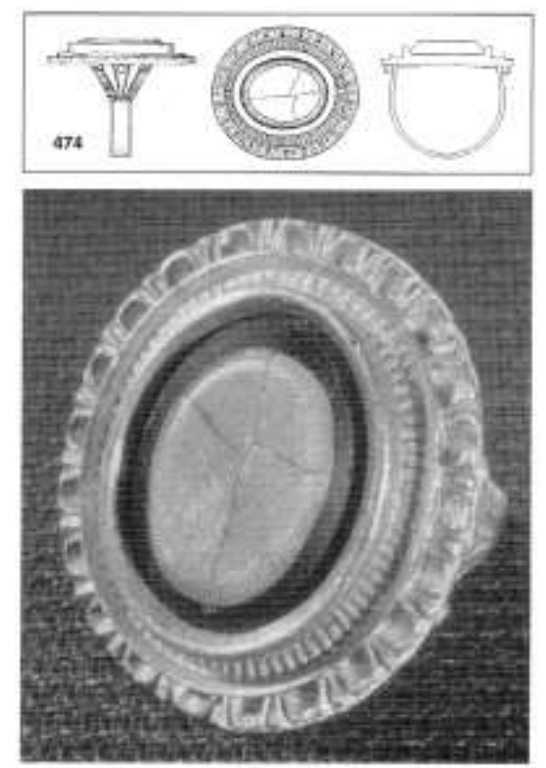

Abb. 12

Moorfund in Meinersfehn. Ein römischer Fingerring (nach SCHWARZ/STUTZKE 1998, 94, Kat.Nr. 474). 
Die nachstehende Tabelle gibt die Verteilung der Fundstellen im jeweiligen Naturraum und im untersuchten Zeitraum wieder (Tabelle 1).

Bei der naturräumlichen Verteilung der Fundstellen im Arbeitsgebiet zeigt sich in der römischen Kaiserzeit und der Völkerwanderungszeit eine deutliche Bevorzugung von Standorten in der Flussmarsch. Erst im Frühmittelalter verlagern sich die Plätze von dort auf die Hohe Geest. Während der Geestrand in der römischen Kaiserzeit bereits stark aufgesiedelt war, scheint diese Region später nicht mehr zu den bevorzugten Siedelflächen zu gehören. Ebenso nimmt die Deponierung von Gegenständen im Moor ab.

\begin{tabular}{|c|c|c|c|c|c|c|}
\hline \multicolumn{2}{|c|}{} & \multicolumn{5}{|c|}{ Naturraum } \\
\hline Zeit & $\boldsymbol{\Sigma}$ & Hohe Geest & Geestrand & Flussmarsch & Moor & Fluss \\
\hline Rkzt. & 50 & 4 & 11 & 30 & 4 & 1 \\
\hline Vwzt. & 14 & 3 & 1 & 9 & 1 & - \\
\hline FMa & 28 & 13 & 3 & 11 & 1 & - \\
\hline
\end{tabular}

Tab. 1

Verteilung der Fundstellen im Naturraum Unteres Emsgebiet

(Mehrfachnennung mehrperiodiger Fundstellen möglich)

Bei der Verteilung der Fundstellen zeigt insbesondere der linke Emsuferwall, und hier die Gemeinden Jemgum und Weener, eine deutlich höhere Fundstellenkonzentration auf, während die auf der gegenüberliegenden Flussseite als sehr gering bezeichnet werden kann.

Im Reiderland wurden 18 von insgesamt 25 kaiserzeitlichen Siedlungen entdeckt. Lediglich fünf Plätze wurden noch in der Völkerwanderungszeit weiter bewohnt und auch bei den übrigen sieben Siedlungen finden sich nur zwei mit völkerwanderungszeitlicher Siedlungskeramik. Im Anschluss bricht bei allen Fundstellen in der Flussmarsch die Besiedlung ab und es kommt erst im Frühmittelalter bei sieben Plätzen zur Wiederbesiedlung. Zwei weitere werden im Hochmittelalter erneut besiedelt.

Die nachstehende Tabelle 2 visualisiert das Verhältnis der Fundstellenanzahl in den Gemeinden des Landkreises Leer und gibt Auskunft über die Anzahl der Fundstellen in den Zeitstufen römische Kaiserzeit bis Frühmittelalter. Die absoluten Zahlen lassen für die römische Kaiserzeit in fast allen Gemeinden die höchste Funddichte erkennen $(n=50)$, während in der Völkerwanderungszeit die Funddichte deutlich abnimmt $(n=14)$, um im Frühmittelalter erneut anzusteigen $(n=28)$. 


\begin{tabular}{|l|c|c|c|c|c|}
\hline \multicolumn{1}{|c|}{ Gemeinde } & $\begin{array}{c}\text { Fundstellen } \\
\text { absolut }\end{array}$ & $\begin{array}{c}\text { Fundstellen } \\
\text { mehrperiodig } \\
\text { (Rkz - Vwzt - F-Ma) }\end{array}$ & \multicolumn{3}{|c|}{ Rkz } \\
Vwzt & F-Ma \\
\hline Brinkum & 2 & --- & --- & --- & 2 \\
\hline Detern & 4 & 1 & 4 & 1 & --- \\
\hline Ems (Fluss) & 1 & ---- & 1 & --- & --- \\
\hline Filsum & 3 & --- & 2 & --- & 1 \\
\hline Hesel & 9 & --- & 1 & --- & 8 \\
\hline Holtland & 2 & 3 & 2 & 1 & 1 \\
\hline Jemgum & 19 & 14 & 19 & 6 & 7 \\
\hline Leer (Stadt/Gde.) & 9 & 3 & 8 & 2 & 2 \\
\hline Moormerland & 4 & --- & 3 & --- & 1 \\
\hline Nortmoor & 3 & 2 & 2 & 1 & 2 \\
\hline Rhauderfehn & 1 & --- & 1 & --- & -- \\
\hline Uplengen & 5 & 1 & 1 & 2 & 3 \\
\hline Weener & 2 & 2 & 3 & --- & 1 \\
\hline Westoverledingen & 2 & 1 & 2 & 1 & --- \\
\hline Summe & $\mathbf{6 9}$ & $\mathbf{2 7}$ & $\mathbf{5 0}$ & $\mathbf{1 4}$ & $\mathbf{2 8}$ \\
\hline
\end{tabular}

Tab 2

Verteilung der Fundstellen in den Gemeinden

Die erhöhte Gesamtzahl ist begründet durch die Aufnahme auch mehrperiodiger Fundstellen. Dies führt zu Mehrfachzählungen einzelner Fundstellen, die zu verschiedenen Zeiten aufgesucht wurden. Dennoch überwiegen im Untersuchungsgebiet kaiserzeitliche Fundstellen gegenüber denen anderer Zeitabschnitte. Eine abschließende Bewertung der vorgelegten Quellenlage erfolgt im Kapitel „Siedlungsgeographische Analyse“ (Kap. 7).

\subsubsection{Exkurs zu römischen Fundmünzen in der Unteren Emsregion}

Von verschiedenen Fundstellen im Landkreis Leer stammen römische Fundmünzen (Diagramm 6). Deutlich fällt ihr Bezug zu Flüssen auf. So finden sich entlang der Ems (FStNr. 02; 32; 33; 40) und Jümme (FStNr. 54; 61) sechs gesicherte Fundstellen mit meist einer größeren Anzahl an Münzen. Weitere sieben Münzhorte aus dem Untersuchungsgebiet gelten als verschollen. Da ihre Fundumstände, die Anzahl sowie ihr Prägedaten ihrer Münzen gar nicht oder nur bruchstückhaft überliefert sind, wurden sie nicht in den Fundstellenkatalog aufgenommen. 
Die römischen Fundmünzen im Unteren Emsgebiet haben zum überwiegenden Teil einen Prägeschwerpunkt im 1. Jh. v. Chr. bis Ende 1. Jh. n. Chr.

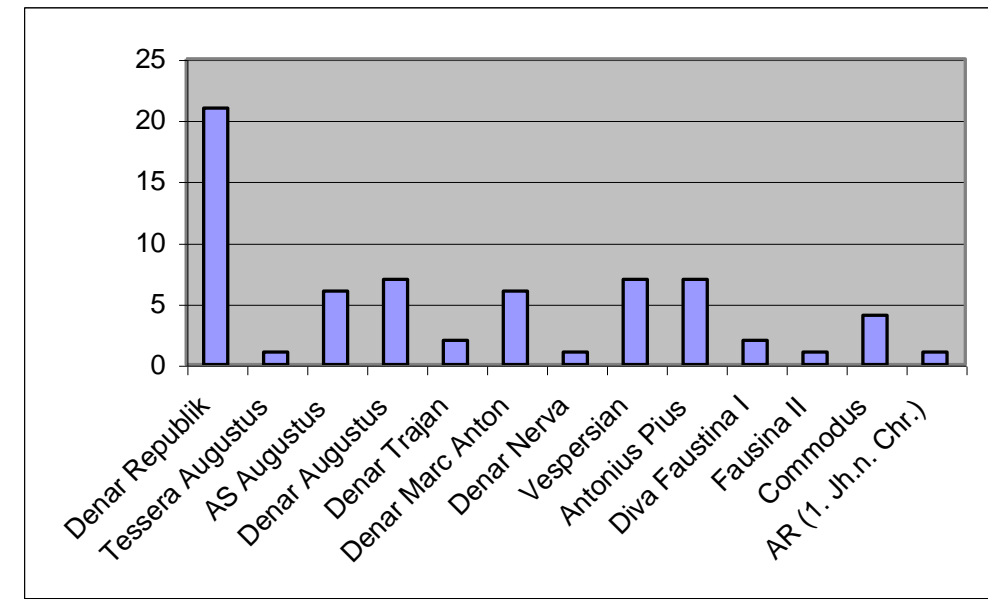

Diagramm 6 Verteilung römischer Münzen im Landkreis Leer

Einer der jüngsten Münzfunde im Untersuchungsgebiet stammt von der Nortmoorer Düne. Es handelt sich um einen Denar Trajan und eine nicht mehr identifizierbare Kupfermünze.

In Filsum fand man 1858 einen ungewöhnlich großen Denarhort. Es soll sich um „Mehrere Rollen von 1/4 Fuß Länge“ mit einer Vielzahl an „Denare von Trajan und Hadrian“... „wohl 2 Pfund“ gehandelt haben (MOMMSEN 1885, 39, 229; vgl. BERGER / STOESS 1988, 126-127, Nr. 2011).

Bei der folgenden Münzaufzählung bezeichnete die erste Jahreszahl die Caesar-Prägung, die zweite Jahreszahl die Augustus-Prägung. Von der ursprünglichen Fundmenge ( $>50$ Denare) sind sieben Vespasian (69/71 bis 75 n. Chr.), sechs Antonius Pius (145/171 bis 160 n. Chr.), zwei Diva Faustina I (141/161 n. Chr.), fünf Marc Aurel (161 bis 170/171 n. Chr.), je ein Divus Antonius Pius (161 n. Chr.) und eine Faustina II (161/176 n. Chr.), vier Commodus (183/184 bis 190/191 n. Chr.) sowie ein AR (1.-2. Jh. n. Chr.) und eine weitere, inzwischen verschollene, Münze überliefert. Die übrigen Münzrollen wurden aus Unkenntnis im nahen Bach versenkt. Drei vermutlich zu diesem Hortfund zugehörige Denare wurden 1963 nahe Filsum geborgen (ROSE 1878; BERGER / STOESS 1988, 137-138, FMRD VII, 2011, Nr. 2032; RosKAMP 1964, 33-34). Die etwa 3g schweren Münzen waren ein Denar Titus (80 n. Chr.) und zwei Commodus (181 u. 186 n. Chr.). Nur wenige Kilometer östlich von Nortmoor entfernt entdeckte man in Detern und dem benachbarten Stickhausen eine unbestimmte Anzahl römischer Münzen (ERDNIß 1939, 30 ; ERDRICH 2002, 46).

Auch aus der Region südlich von Jümme und Leda sind eine unbestimmte Menge an römischen Münzen überliefert (ERDRICH 2002, 48), so aus Osterhörn, Gemeinde Ostrhauderfehn und Collinghorst, Gemeinde Westrhauderfehn. 
Ein besonderer Fundschwerpunkt römischer Münzen zeichnet sich im Reiderland ab. Bereits 1875 entdeckte man in Oldendorp in der Gemeinde Jemgum „ein paar römische Münzen, darunter eine Tessera aus Augustus' Zeit“ (Tergast 1879, Abb. 26; MÜLlER / REIMERS 1895, 316; ZYLMANN 1930, 27, 29-30; BERGER / STOESS 1988, 127-128, Nr. 2013).

Aus Bingum-Soltborg stammen wenigstens 18 Denare und einige AE, die in der Zeit zwischen 150/14 v. Chr bis 2 v. /14 n. Chr. geprägt wurden (BERGER / STOESS 1988, 123-124, Nr. 2008; ERDRICH 2002, 46). Es wird sich um einen Schatzfund gehandelt haben, da man sie ,im Klei etwa sieben Fuß tief in der Erde gefunden“ hat (ZYLMANN 1930, 30; BERGER /STOESS 1988, 123-125, Nr. 2008; ERDRICH 2002, 46, XIX-12-3/3.1). Die Königliche Münzsammlung Hannover erhielt 1864 insgesamt 15 Silberdenare und drei Kupfermünzen, die sie jedoch 1930/31 zum Erwerb eines mittelalterlichen Altars versteigerte. Bei den inventarisierten Münzen handelte es sich meist um Münzen der römischen Republik (150-43/42 v. Chr.), dazu ein Marc Anton (33/32 v. Chr.), sechs Augustus (30/27 v. Chr. 14 n. Chr.), ein AR (27 v./14 n. Chr.) und zwei AS (10-3 v. Chr.).

Eine größere Anzahl an römischen Münzen entdeckte man in Bentumersiel, einem römischen Stapelplatz. Bereits vor 1928 fand man vier AS des Augustus (28 v. / 14 n. Chr.; 16/2 v.Chr.; zwei AS (10/3 v. Chr.) und diverse Denare der Zeit $42 . / 43$ v. Chr. (ZYLmAnn 1930, 29-33, Taf. II, Abb. 23-31, Taf. III, Abb. 39-61). Ein Gefäß mit römischen Münzen wurde 1858 in der Ems geborgen. Zuletzt anzuführen ist ein Dupondius Caligula (37/41 n. Chr.), der als Einzelfund bei Weener geborgen wurde (ERDRICH 2002, 47). Ein spätkaiserzeitlicher Solidus Kaiser Valenttinian II belegt den Endpunkt römischer Fundmünzen im südlichen Ostfriesland. Die zwischen 388/392 geprägte Münze wurde bei Rorichum am östlichen Emsufer entdeckt (BERGER / STOESS 1988, 128, Nr. 2015).

Lediglich eine Fundstelle mit römischen Münzen ist von der ostfriesischen Geest im Landkreis Leer bekannt. Mitte des 19. Jahrhunderts entdeckte man nahe dem Oldehof bei Hesel einen Hortfund römischer Silbermünzen. „Von einem Münzfund, der sehr geheim gehalten wurde, erhielten wir einige Stücke zum Andenken. Zwei römische Silbermünzen des Nerva und Trajan besaß ich bis 1861. Wo die übrigen Münzen - es mögen an die 100 gewesen sein - blieben, ist mir nicht bekannt.“ (SUNDERMANN 1922, 31-36; SCHÖNINGH 1973, 41).

Die Verteilung der Münzfunde zeigt eine deutliche Bevorzugung entlang der Flussläufe von Ems und Jümme. Meist handelt es sich um Hortfunde größeren Umfanges, die hier eingegraben wurden. In zwei Fällen (Detern/Stickhausen) fand man sie in der Nähe eines kaiserzeitlichen Bestattungsplatzes. Einige Münzen stammen aus Moorgebieten im südlichen Ostfriesland (Ost- und Westrhauderfehn). Nur in zwei Fällen liegen die Münzen in einem Siedlungskontext, wie in Bentumersiel und Nortmoor, vor. Die zeitliche Tiefe der Fundmünzen deckt zumeist die frühe bis mittlere Kaiserzeit ab, wobei sich Schwerpunkte in frühaugustäischer Zeit und in der Mitte des 2. Jahrhunderts abzeichnen.

Als Schatzfunde können neben den Denarhorten auch Schmuckniederlegungen bezeichnet werden. Im 
Untersuchungsgebiet wurden diese überwiegend in der Flussmarsch, selten auch auf der Geest angetroffen. Schmuckfunde sind nur aus Moorgebieten im Unteren Emsraum bekannt. Anders als ihr Prägedatum vermuten lässt, können sie eine längere Umlaufzeit aufweisen. Einzelfundmünzen, wie sie aus Siedlungskontexten vorliegen, können oft als reine Verlustfunde gelten.

Einziger frühmittelalterlicher Münzschatzfund im Landkreis Leer stammt aus dem Kloster Barthe bei Hesel und datiert in das 8. Jahrhundert n. Chr. (BÄRENFÄNGER 1997, 19, Abb. 9). 


\section{Der Siedlungs- und Bestattungsplatz Nortmoorer Hammrich}

Der Fundplatz Nortmoorer Hammrich liegt etwa $1,5 \mathrm{~km}$ südlich vom Nortmoor inmitten der weitläufigen Niederung der Leda-Jümme-Senke (Abb. 13); etwa 8km östlich von der Kreisstadt Leer. Die Ausgrabungsstelle befand sich auf einer west-ost-orientierten Sanddüne 300m nördlich der Jümme. Die Karte 5.1 (Anhang) zeigt einen Ausschnitt aus dem DGK 1987 Blatt „Nortmoor - Am Deich“, 2711/21. Verschiedene mächtige Torfschichten und Kleiablagerungen haben den nördlichen Teil des Urstromtales aufsedimentiert (vgl. Kap. 2.2 Geologie).

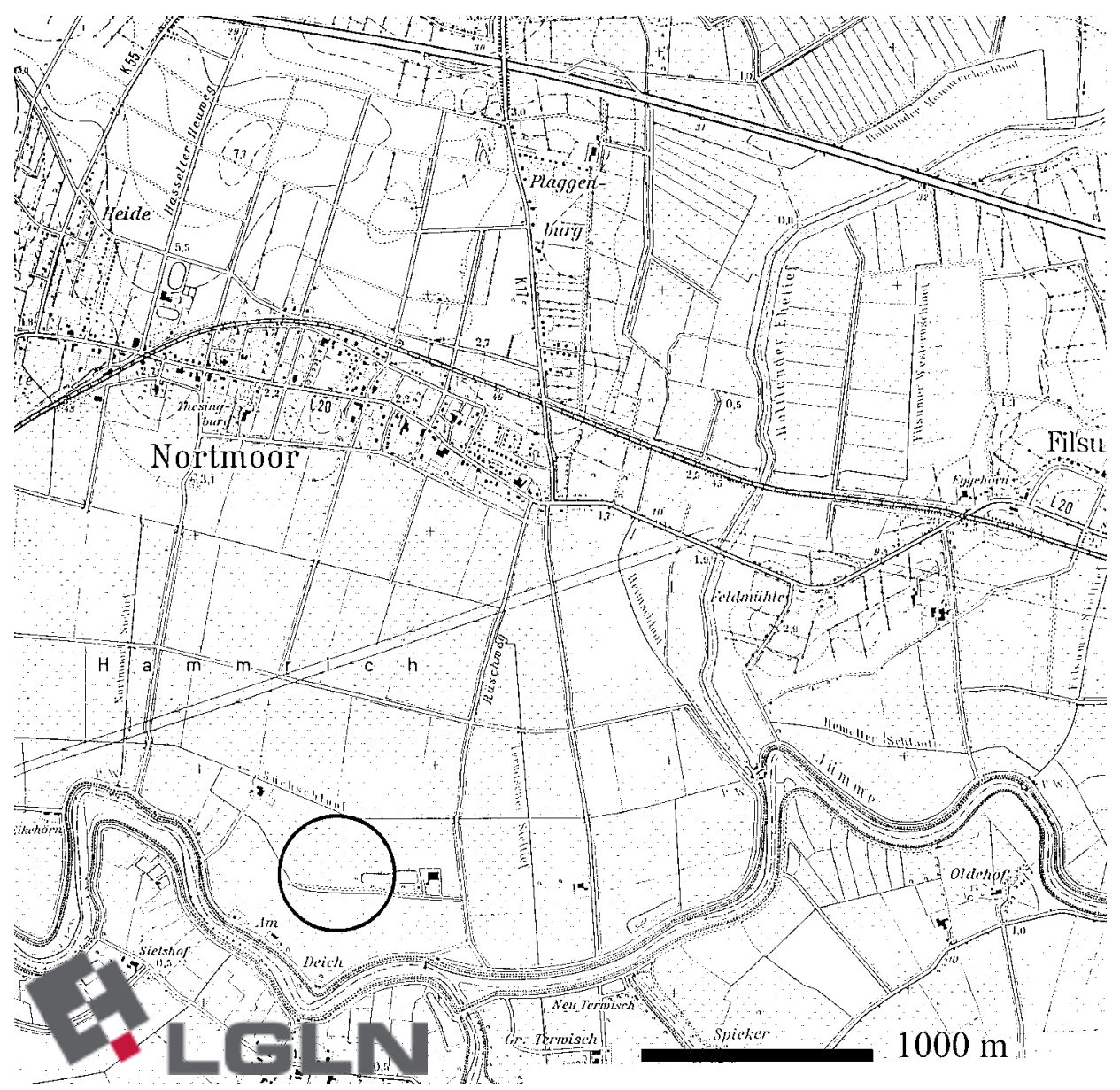

Abb. 13

Topografische Lage der Nortmoorer Düne (DGK 1987)

Bodenabtrag und Aussandungen hatten bereits lange vor Beginn der großflächigen Aussandungsarbeiten 1996, dessen Aushubmaterial zur Erhöhung des nahen Jümmedeiches diente, den Dünenzug in seiner Längenausdehnung erheblich reduziert. So verzeichnete die Preußische Landesaufnahme von 1898 drei Dünen, die sich über eine Fläche von etwa 100x500m in Ost-WestRichtung erstreckten (Abb. 14). Der östliche Dünenteil verflachte infolge intensiver landwirtschaftlicher Nutzung bis er weitgehend einnivelliert bzw. eingeebnet war. 


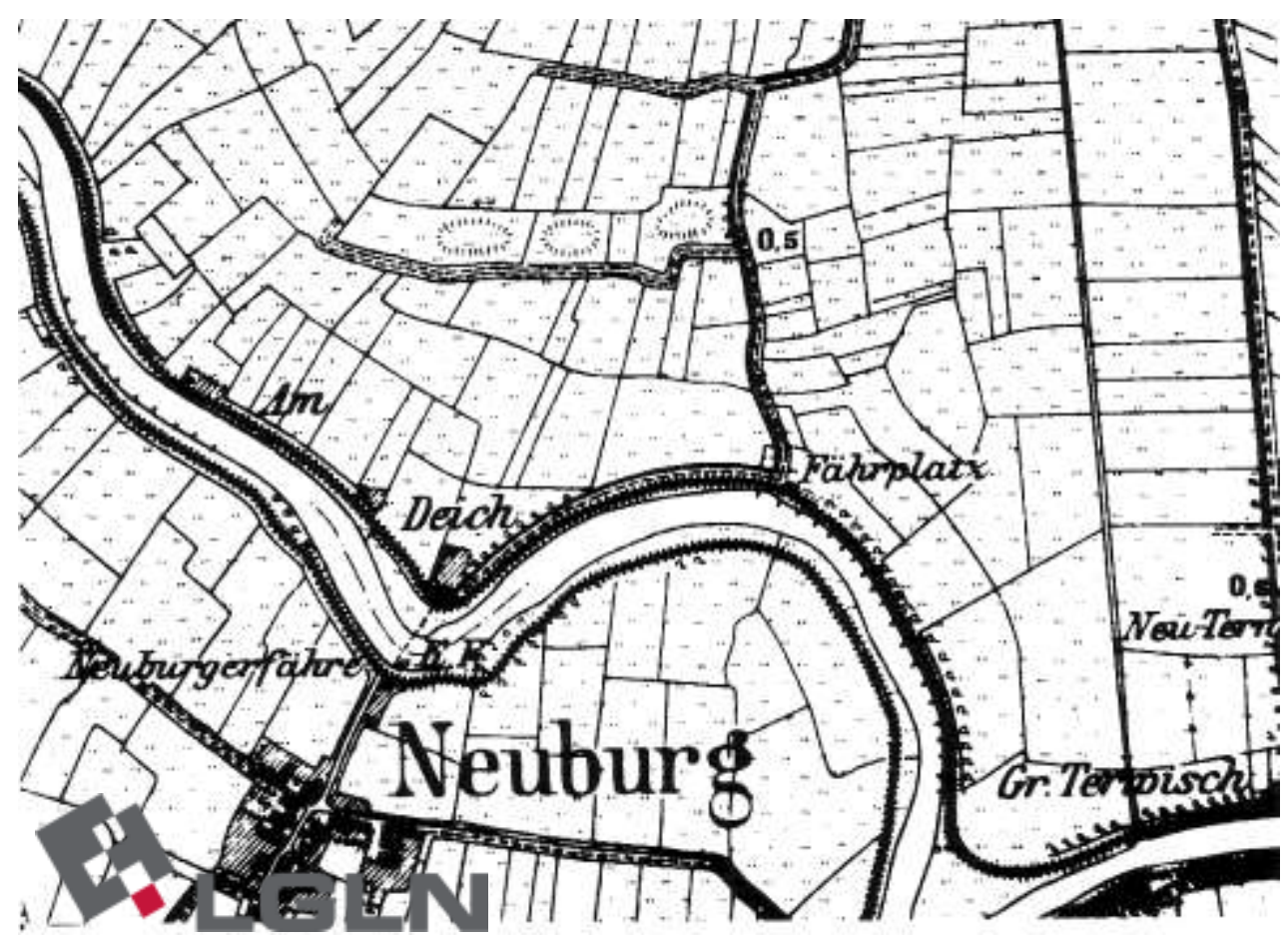

Abb. 14

Detailplan Preußische Landesaufnahme 1897, die Nortmoorer Düne

In der DGK 1976 ist noch eine Restlänge von etwa 70m erkennbar. Wenig später wurde diese Fläche einplaniert und auf ihr ein Aussiedlerhof errichtet. Eine Luftbildaufnahme der britischen Luftaufklärung von 1941 lässt den Verlauf des Nortmoorer Dünenzuges gut erkennen (Tafel 117), bevor dieser in den 60er Jahren des 20. Jahrhunderts massiv umgestaltet wurde.

Im Rahmen eines Verkopplungsverfahrens wurde der mittlere Dünenbereich nahezu komplett abgegraben. An seiner Stelle entstand eine 150m lange und etwa 40-60m breite Teichanlage. Von diesen Maßnahmen verschont blieb ein 200m langes Teilstück vom westlichen Dünenrand, der bis zu Beginn der Arbeiten weitgehend intakt vorlag.

Einen Hinweis auf frühere Bodeneingriffe geben die NN-Höhenangaben in den Karten der niedersächsischen Landesvermessung. In der DGK 1976 und 1987 wird für die Sanddüne eine maximale Geländehöhe von +1,40m NN verzeichnet. Bei einem erneuten Nivellement 1995 stand ein Großteil der Dünenkuppe bei $+0,76 \mathrm{~m}$ NN an, während nur noch westlich des Teichareals Höhen von $+1,26 \mathrm{~m}$ NN festzustellen waren.

Die Jümme-Niederung zeichnet sich durch sehr geringe Höhendifferenzen aus. Im Nortmoorer Hammrich und im südlich anschließenden Jümmiger Hammrich nivelliert die Landschaft um $+/-0 \mathrm{~m}$ NN. Nur in der Nähe des Flussdeiches der Jümme liegen Höhen zwischen $+1 \mathrm{~m}$ bis $+1,40 \mathrm{~m}$ NN vor. 
Neuzeitliche Entwässerungen des eingedeichten Hinterlandes verursachen großflächige Geländeabsackungen, so dass inzwischen Tieflagen von bis zu $-0,5 \mathrm{~m}$ NN erreicht wurden. Die Ortschaft Nortmoor befindet sich am nahen Geestrand und erstreckt sich als langgezogenes Straßendorf auf einer Höhenlinie von $+2,2 \mathrm{~m}$ NN. Wenige hundert Meter nördlich werden bereits Höhen von $+5,5 \mathrm{~m}$ NN erreicht und 1,2km vom Ortskern entfernt steigt das Gelände auf $+7,3 \mathrm{~m} \mathrm{NN}$ an. Der Höhenrücken der Oldenburgisch-Ostfriesischen Geest erreicht im Landkreis Leer östlich von Hesel bei $+15 \mathrm{~m}$ NN seine höchste Geländehöhe.

Die Niveauabsenkungen und der sich ausdehnende Einflussbereich des Tidenhubes im Unterlauf der Jümme machten in den 90er Jahren des 20. Jahrhunderts eine Erhöhung der Deichlinie über mehrere hundert Meter Länge erforderlich. Das dazu notwendige Bodenmaterial sollte aus der nahen Nortmoorer Düne gewonnen werden (Abb. 15). Im Rahmen der Bauleitplanung wurde die archäologische Abteilung der ostfriesischen Landschaft um eine Stellungnahme ersucht. Mit Überprüfen der Fundortakten verdeutlichte sich schnell die siedlungsarchäologische Relevanz der Fundstelle.

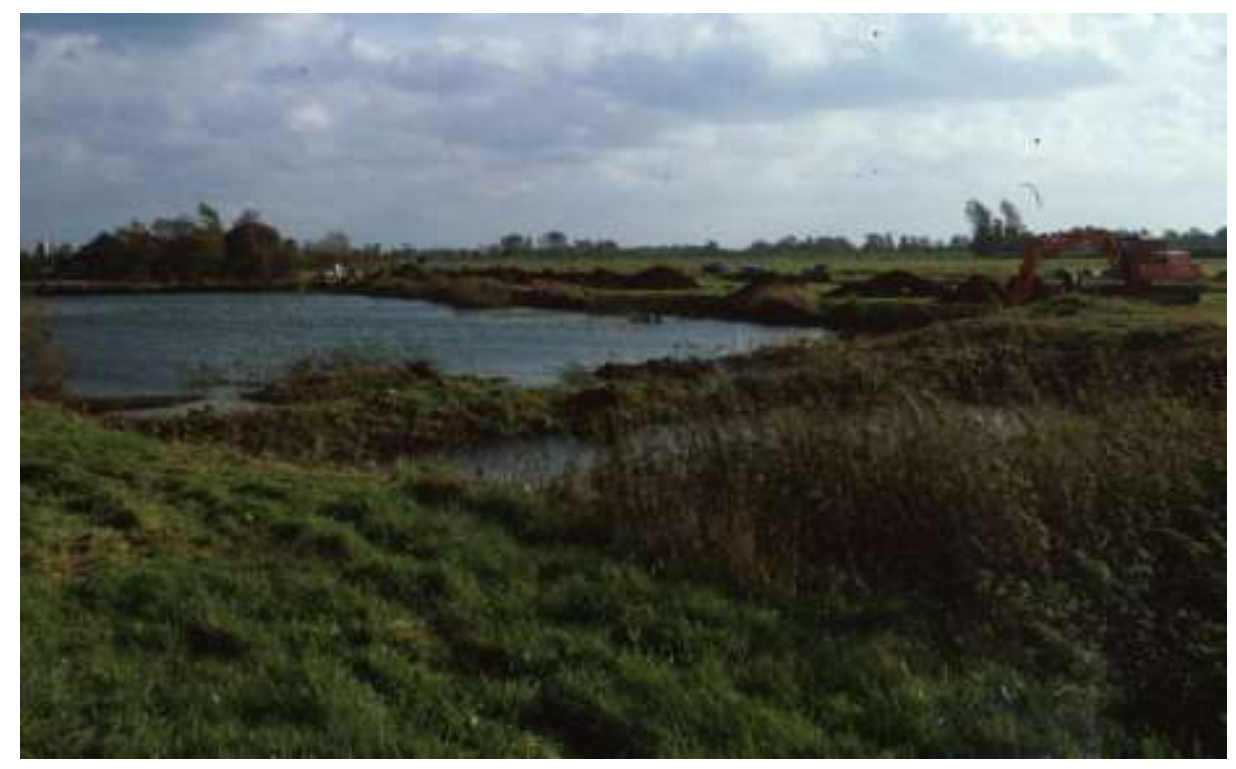

Abb. 15

Die Nortmoorer Düne mit Blick nach Südost. Beginn der Baggerarbeiten 1996.

Der Nortmoorer Dünenzug war durch eine Vielzahl von Keramikfunden seit den 60er Jahren des 20. Jahrhunderts bekannt. Vermerkt ist in den Ortsakten für das Jahr 1964 u. a. eine Begehung durch den wissenschaftlichen Mitarbeiter der Ostfriesischen Landschaft Herrn K. Wilhelmi. Leider wurde von weiterführenden Untersuchungen damals abgesehen und so ging wichtige Denkmalsubstanz bei den nachfolgenden Aussandungsarbeiten verloren. Erst wieder im Vorfeld des oben erwähnten 
Genehmigungsverfahrens zum Sandabbau wurden von archäologischer Seite Mitte der 90er Jahre Begehungen durchgeführt.

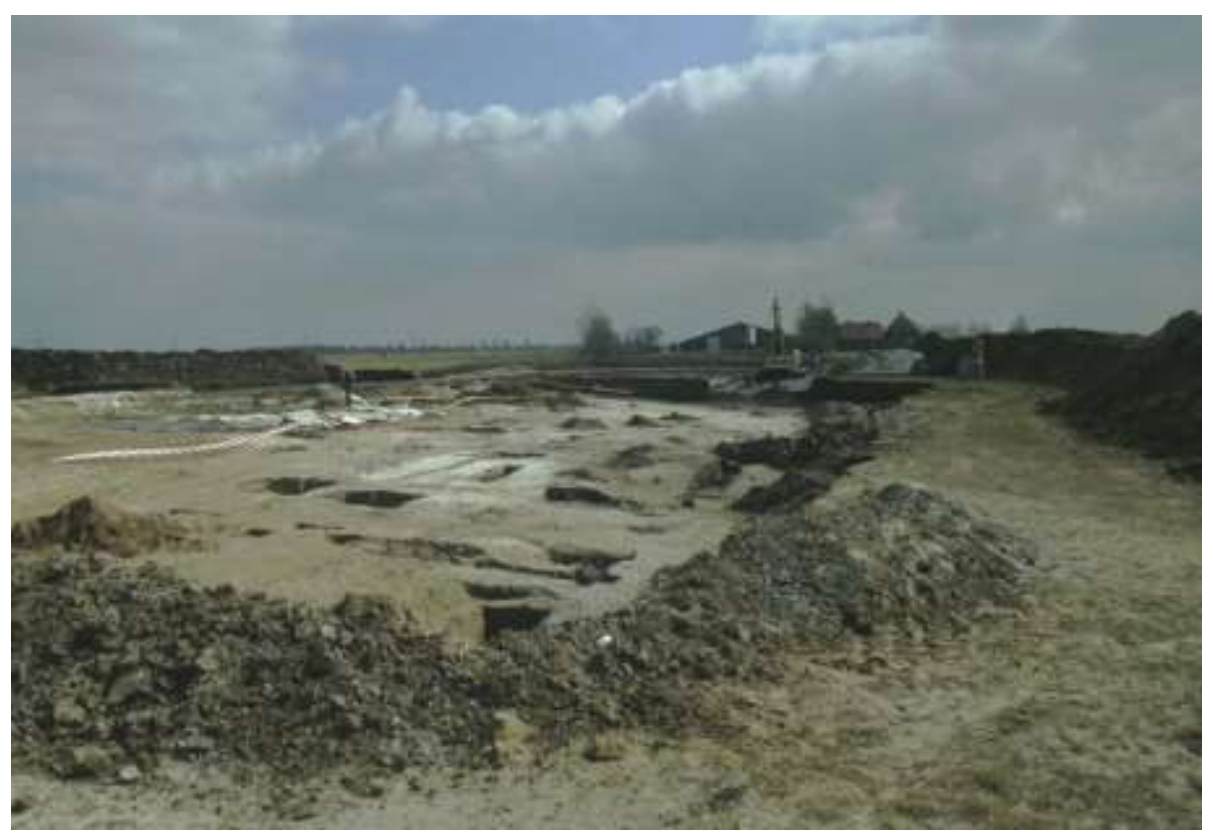

Abb. 16

Die Nortmoorer Düne mit Blick nach ONO. Abtrag des Oberbodens 1996.

Hinweise auf Fundmaterial führende Schichten erbrachten Geländebohrungen durch die Verfasserin. Recht schnell zeigte sich bei der baubegleitenden Ausgrabung die Bedeutung der Fundstelle (Abb. 16).

Unter einem bis zu $80 \mathrm{~cm}$ mächtigen Oberboden gelang es, auf der Düne die Abfolge der Bodenschichten bis hinab auf den pleistozänen Sandboden zu erfassen. Mit Ausnahme der Dünenkuppe war dieser von wechselnden Torf- und Kleischichten bedeckt. Von Interesse sind insbesondere die in den 30er Jahren des 20. Jahrhunderts durchgeführten geologischen Untersuchungen im Leda-Jümme-Gebiet, die den Nortmoorer Dünenzug mit einbezogen, als im Zuge von Vorarbeiten für die geologische Übersichtskarte von Ostfriesland Bohrungen quer durch den Nortmoorer und Jümmiger Hammrich bis nach Backemoor erfolgten (WILDVANG 1938, 1939). Demnach besteht die Nortmoorer Sanddurchragung aus einer nacheiszeitlichen Düne, die durch Sedimentablagerungen und Moorschichten überlagert wurde (Abb. 17). Jüngste geologische Bohrungen im Bereich der Nortmoorer Düne bestätigten diese Ergebnisse (KoRPILLA 2004, unpubl. Diplomarbeit). 


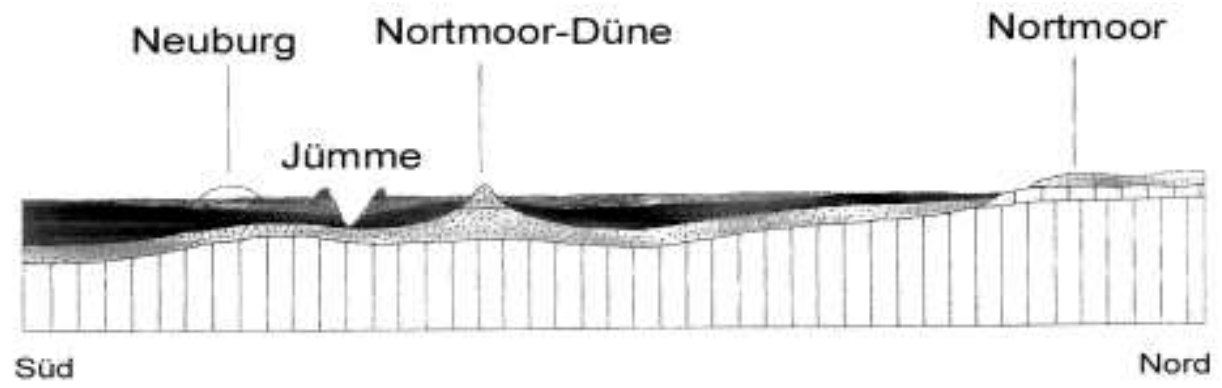

Abb. 17

Vereinfachter geologischer Schnitt von Nortmoor nach Neuburg (nach Wildvang 1938)

Im Untersuchungsgebiet steht die höchste Stelle des Sanduntergrundes bei $+0,46 \mathrm{~m} \mathrm{NN}$ an und fällt zu den Randbereichen der Düne relativ schnell auf Werte unter -1 bis $-2 \mathrm{~m}$ NN ab. Den Bereich der eiszeitlichen Geestkuppe kennzeichnet die konzentrische Verbreitung von Gley-Podsol, der fein bis mittel sandig vorliegt. Nördlich und östlich der Düne schließt sich Moormarsch an. Tiefgründige Entwässerungen haben in den letzten Jahren durch Zersetzen der Niedermoorböden zu erheblichen Bodenabsackungen geführt. Die darüber liegenden Flussmarsch-Böden liegen durchschnittlich mit einer Mächtigkeit von bis zu 1m vor und weisen auf häufige Überschlickungen durch die Jümme hin. Die Sandkuppe verfügt partiell über geringmächtige Kleiauflagen, die zum Rand hin deutlich zunehmen.

\subsection{Gesamtbefund}

Auf dem erhaltenen westlichen Dünenzug erfolgten von 1996 bis 1998 umfangreiche Ausgrabungen der Archäologischen Forschungsstelle der Ostfriesischen Landschaft. Dabei entdeckte man auf der verbleibenden Restkuppe eine meist recht gut erhaltene Denkmalsubstanz, die differenzierte Aussagen in landschafts- und siedlungsgeschichtlicher Hinsicht ermöglichen (Abb. 18).

Ein erstes Aufsuchen des mehrperiodigen Siedlungsplatzes ist bereits für die Zeit vor der Vermoorung festzustellen. Der älteste Kulturhorizont mit Flintabschlägen befindet sich unter dem Torf. Pollenanalytische Untersuchungen belegen den Anbau von Getreide während einer kurzen Phase in der Bronzezeit, wie auch in vorrömischer Eisenzeit (FREUND 1996a). In den über dem Torf anschließenden Kleiablagerungen, die die Ränder des Dünenzuges überdeckt haben, zeigen die zahlreich aufgefundenen Keramikscherben eine intensive Siedlungstätigkeit für die römische Kaiserzeit und das Mittelalter an.

Der westliche Teil der Düne zeichnet sich durch vorwiegend kaiserzeitliches Fundmaterial aus, während weiter östlich ein hoher Anteil mittelalterlicher Keramikwaren in das Sediment eingelagert war. Auf eine mittelalterliche Transgression, bei der die Flachmoore der Jümme-Niederung von einer 
Schlicktonschicht bedeckt wurden, weisen die in der basalen Kleilage gefundenen frühmittelalterlichen Tonscherben hin.

Doch auch die Möglichkeit, dass mehrere Meereseinbrüche zwischen der Eisenzeit und dem Mittelalter das Torfwachstum im Nortmoorer Hammrich beendet haben, ist in Betracht zu ziehen.

Die letzten landschaftsformenden Überflutungen erfolgten erst im Hochmittelalter. Hierauf weisen die unter einer einziehenden Kleischicht geborgenen pingsdorfartigen Gefäße in einem Baumstammbrunnen hin.

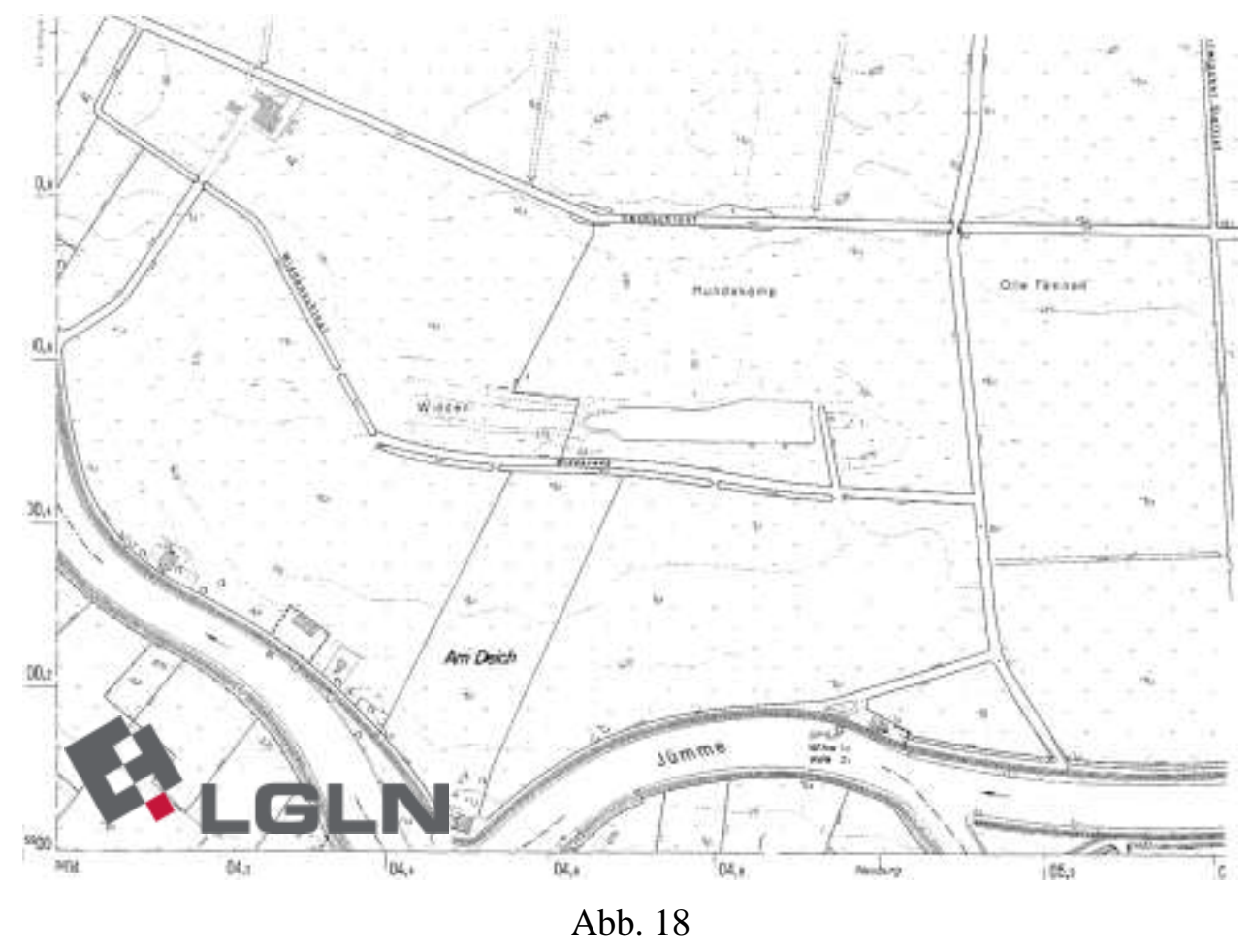

Lage und Höhenrelief der Nortmoorer Düne in der DGK 1987

Insgesamt weist die ungewöhnliche Fund- wie Befunddichte auf eine ehemals hohe Siedlungsintensität der Nortmoorer Region hin. Für den Dünenzug kann somit ein Verlust von wenigstens $2 / 3$ der ursprünglichen Denkmalsubstanz als wahrscheinlich angegeben werden. Dies ist umso betrüblicher, da seine günstige topographische Lage im Übergangsbereich vom Niedermoor zur Flussmarsch auf eine Besiedlung des gesamten Areals in ur- und frühgeschichtlicher Zeit schließen lässt.

\subsubsection{Dokumentation}

Die besonderen Bedingungen unter der die baubegleitenden Ausgrabungen auf der Nortmoorer Düne erfolgten, machen es erforderlich die angewendeten Dokumentationstechniken vor Ort und die daraus resultierenden Schwierigkeiten bei der Aufarbeitung der Grabungsdokumentation näher zu erläutern. 
Die Arbeiten zur Deicherhöhung der Jümme standen in einem engen zeitlichen Rahmen und nötigten zu einem zügigen Sandabbau. Um den Fortgang der parallel verlaufenden Aussandung, die bis zu einer Tiefe von 18m erfolgte, nicht zu behindern, begann die Freilegung der Befunde an der östlichen Grabungsgrenze und erfolgte ausschließlich in westlicher Richtung. Vorab wurde die Grabungsfläche in ein Vermessungsnetz von 10x10m eingeteilt und anschließend an der südlichen Grabungsgrenze beginnend in 10 bis $20 \mathrm{~m}$ breiten Streifen nach Norden hin untersucht. Insgesamt gelang es, auf diese Weise, eine Fläche von 1,5ha zu dokumentieren. Da die Ausgrabung mit wenigen Unterbrechungen ganzjährig erfolgte war die Grabungsfläche, ungeschützt dem Wetter ausgesetzt. Großflächige Sandverwehungen, insbesondere im Herbst und Winter, behinderten die Arbeiten und einsetzende Bodenerosion führte stellenweise zum Abtrag von Befunden.

Die Befundaufnahme in den Jahren 1996 bis 1998 erfolgte mit einem Feldpantographen und wurde durch Fotos dokumentiert, gelegentlich wurden Zwischenplana und colorierte Profilzeichnungen angefertigt. Planazeichnungen liegen im Maßstab 1:50, Detailzeichnungen im M 1:20 und M 1:10 vor. Die dokumentierten Flächen sind über den Quadrantenplan zu erschließen (Tafel 116). Für die in verbalisierter Form erfolgte Dokumentation wurde für jeden Befund ein standardisiertes Formblatt angelegt und durch Befundskizzen ergänzt.

Die lokale Grabungsleitung oblag einem angelernten Grabungstechniker der Ostfriesischen Landschaft. Dies begünstigte bei der mehrjährigen Ausgrabungstätigkeit eine technisch einheitliche Arbeitsweise und eine zumeist gleichartige Befundansprache. Jedoch sind die Pauschalisierungen bei der Ansprache der Bodensubstrate im Nachhinein kaum noch zu berichtigen.

\subsubsection{Aufbereitung der Grabungsdokumentation}

Bereits während der Ausgrabung erfolgte eine Kategorisierung der Befunde in Pfostengruben, Gruben, Gräben, Wandgräbchen u.a.m. Zunächst wurde diese Einteilung übernommen, anhand der Dokumentation überprüft und gegebenenfalls ergänzt. Als hilfreich erwies sich in diesem Zusammenhang die zumeist gute Qualität der Fotodokumentation. Auf der gesamten Fläche wurden 1290 Befundnummern vergeben.

Eine Besonderheit sind die in Nortmoor erhaltenen Kleischichten als Zeugen verschiedener Überschwemmungen, die mehrfach den Nortmoorer Hammrich aufsedimentierten. Sowohl im Schichtverlauf der Hauptprofilwände, wie auch in einigen Befunden, in die Flusssediment hineingeflossen ist, zeichnet sich ein ähnliches Bild ab. Eine genaue Datierung einzelner Kleischichten stellt sich jedoch als schwierig dar. So ist eine zweifelsfreie Zuordnung der älteren, oft verblassten Kleischichten aufgrund der bei der Ausgrabung gewählten Dokumentationstechnik (Foto/SW-Dia) im Nachhinein nur allgemein in die römische Kaiserzeit möglich. Indes gut abgrenzbar sind 
mittelalterliche Sedimentablagerungen, die sich durch ihre Farbintensität (dunkelgrau) und eine meist größere Schichtstärke auszeichnen.

Im Rahmen dieser Studie wurde die Befunddokumentation digitalisiert und mit den Grafikprogrammen Adobe Photoshop und CorelDraw nachbearbeitet. Im Grabungsplan sind Pfostengruben schwarz hervorgehoben. Ihre Abgrenzung zu Pfostenstandspuren erfolgt über die Katalognummer und wird im Text erwähnt. Gruben und Gräben sind in grauer Farbe, Wandgräbchen in hellgrauer Farbe wiedergegeben. Anlagen, die der Wasserversorgung dienten und mit Flechtwerk ausgesteifte Gruben, werden durch ein hellgraues Wellenmuster gekennzeichnet. Die modernen Bodenentwässerungssysteme verblieben als beherrschende Formation im Übersichtsplan der Grabung Nortmoorer Hammrich (Tafel 126).

In einigen Fällen wurden natürliche Verfärbungen im Gesamtplan kenntlich gemacht, wenn sich Hinweise auf eine Verbindung zu rekonstruierten Bauten fanden. Hier sei auf die von ZIMMERMANN (1998, 51, Abb. 35) vertretene Auffassung bezüglich nachträglich durch Pflanzenwuchs zerstörter Befunde hingewiesen, die sich dem Archäologen im Profil als natürliche Störung darstellen können. Eine ausführliche Diskussion erfolgt an gegebener Stelle. Kleinere Störungen, wie Tiergänge, Baumstammspuren und geologische Störungen wurden aus dem Plan entfernt.

Ein Gesamtplan der Befunde ohne störende Bezeichnungen (Tafel 126) und ein dreiteiliger Faltplan mit Angabe der Befundnummern (Tafel 123-125) befinden sich im Anhang. Die während der Ausgrabung erfolgte Fotodokumentation bildet die Grundlage für eine Befundvorlage auf CD-ROM im Anhang. Einer besseren Vergleichbarkeit dienen die aus dem Grabungsplan herausgestellten Baustrukturen. Grundrisse von Gebäuden und Speicherbauten mit den zugehörigen Profiltiefen sind im einheitlichen Maßstab 1:200 bzw. 1:100 wiedergegeben.

\subsubsection{Befundtypen}

Insgesamt wurden 1290 Befunde während der Ausgrabung dokumentiert. Bei etwa 18,6\% der Befunde handelt es sich um Störungen unterschiedlicher Art, u.a. Tiergänge, Baumstammspuren oder geologische Störungen. Für diese inhomogene Gruppe wurde im Befundkatalog die Umschreibung „Verfärbung“ gewählt. Das gesamte Areal war zudem durchzogen von neuzeitlichen Drainagen, die der modernen Bodenentwässerung dienten und das Grabungsareal tiefgreifend störten. Es verbleiben 1050 archäologische Befunde, wozu Pfostengruben, Gruben, Gräbchen, Brunnenanlagen, Bestattungen u.a.m. zählen.

Pfostengruben stellen die größte Gruppe unter den Befunden. Ihr Anteil liegt bei 59,5\% ( $n=625)$. Pfostenstandspuren, die als primäres Merkmal einer Pfostengrube gelten, existieren in geringer Anzahl $(n=63)$. Den Pfostengruben zugerechnet werden Reste von Holzpfählen, die in den Untergrund eingetrieben worden sind, auch ohne das eine Grube ausgehoben werden musste. Die Pfostengruben 
weisen zumeist einen runden bis ovalen Umriss im Planum auf, selten sind rechteckige oder quadratische Formen belegt. Der Durchmesser der Pfostengruben reicht von wenigen Zentimetern bis über einen Meter. Größere Pfostengruben im östlichen Siedlungsbereich datieren mehrheitlich in die mittelalterliche Siedlungsphase.

Die bis zu mehreren Dezimetern tiefen Profile der Pfostengruben sind meist von muldenförmiger Gestalt. Es kommen auch schräg eingetiefte oder senkrecht verlaufende Pfostengruben vor. Die Sohle der Pfostengrube ist oftmals muldenförmig ausgeformt, nur vereinzelt v-förmig oder horizontal abgeflacht. Befindet sich der Befundtyp im Pfostenverband eines Gebäudes, kann er recht sicher als Pfostengrube angesprochen werden. Nicht immer zweifelsfrei ist eine Abgrenzung zur Kategorie der Gruben. Zum einen können rudimentär erhaltene kleinere Vorratsgruben als Reste von Pfostengruben fehlinterpretiert werden. Zum anderen existierten Pfostengruben von beachtlichem Durchmesser und Profiltiefe, wie sie beispielsweise für mittelalterliche Rutenberge typisch sind und in ihrer Gestalt eher Gruben ähneln. Auch ist nicht auszuschließen, dass Pfostengruben ohne primäres Pfostenmerkmal d.h. ohne Standspur und aufgrund fehlender konstruktiver Umgebungsbefunde als Grube angesprochen werden.

Siedlungsgruben $(n=196)$ sind über das gesamte Areal verteilt und gelten als zweithäufigste Befundkategorie, gefolgt von Siedlungsgräben $(n=62)$. Aus ihnen stammt prozentual das meiste Fundmaterial. Sie zeichnen sich durch vielfältige Nutzungsmöglichkeiten aus, die von Sand/Lehmentnahmegruben über Werkgruben bis hin zu Vorrats- und Abfallgruben reichen. Eine Klärung ist nicht in jedem Fall möglich. Relativ sicher in ihrer Funktion anzusprechen sind diejenigen Gruben mit nachweisbaren Einbauten. Hierbei kann es sich um Reste einer hölzernen Konstruktion handeln bzw. um vergangene organische Reste, die im Profil Aufschluss über die ursprüngliche Nutzung geben.

Ehemalige Feuerstellen weisen oftmals einen erhöhten Anteil an Holzkohle, Rotlehm oder verziegeltem Lehm auf und sind in vier Fällen aus der Siedlung bekannt (Kat.Nr. 378, 559, 566, 613). Darüber fanden sich flächige Scherbenkonzentrationen in der Art einer Pflasterung, wie sie ähnlich auch in Flögeln vorliegen (ZIMMERMANN 1992, 147). Ob es sich hierbei ebenfalls um die Reste eines Herdunterbaus handelte, ist bisher ungeklärt.

Insgesamt stammen aus Nortmoor acht Brandbestattungen (Kat.Nr. 365, 366, 367, 370, 428, 480, 498, 569), nur zwei davon wurden in Urnen beigesetzt (Kat.Nr. 480, 569), die übrigen bestanden aus in Holzkohle eingebettete Leichenbrandlager. Bei einer 70x100cm großen Grube, die knapp über ihrer Grubensohle ein gut sichtbares HK-Band aufwies, handelte es sich möglicherweise um die Reste einer weiteren Bestattung (Kat.Nr. 369). 


\subsubsection{Befundverteilung und Siedlungsausdehnung}

Die Befunde konzentrierten sich vorzugsweise oberhalb einer Höhenlinie von $+1 \mathrm{~m}$ NN auf der Dünenkuppe und nehmen eine Fläche von etwa 30x200m ein. Vereinzelt wurden Areale bis zu $+0,7 \mathrm{~m}$ NN aufgesucht. In den Tieflagen darunter beginnen stärker vernässte Bereiche, die dem anstehenden Grundwasserstand und natürlichen Überschwemmungen ausgesetzt waren und sich nicht zur Besiedlung eigneten.

Ein digitales Höhenrelief visualisiert die topographische Situation der Nortmoorer Sanddüne (Tafel 115). Der Plan basiert auf einem Feinnivellement, welches während der Ausgrabung durchgeführt wurde und wird in $20 \mathrm{~cm}$ Höhenabständen wiedergegeben. Die Nortmoorer Düne erhebt sich durchschnittlich 1,4-1,7m über dem Umgebungsniveau.

Hauptsiedlungsareal war somit die erhöht liegende Dünenkuppe, wo sich ein breiter Streifen mit Befunden und Funden entlang zog. Zur westlichen Grabungsgrenze dünnte die Befundanzahl stark aus und der Siedlungsrand kann im Wesentlichen als erfasst gelten. Zur Nordseite begrenzte ein Abraumberg der zeitgleich durchgeführten Aussandungen die Grabungsfläche. Sondagegrabungen wiesen nur vereinzelt Befunde nach, so dass die Siedlungsgrenze vermutlich erreicht wurde.

Auch zum südlichen Dünenrand hin verringerte sich die Befunddichte erheblich und unterschritt selten eine NN-Höhe von $+1 \mathrm{~m}$. Eine hohe Befunddichte war am östlichen Grabungsrand nahe der ehemaligen Geländekuppe zu beobachten. Um die neuzeitliche Teichanlage zog sich ein Band mit Gruben von recht beachtlicher Größe und einer Vielzahl an Pfostengruben. Zusammen mit reichen Keramikfunden lässt dies auf eine Fortsetzung des Siedlungsareals in östliche Richtung schließen.

\subsubsection{Befundüberschneidungen und Befundsubstrat}

Verhältnismäßig selten waren Überschneidungen bei archäologischen Baubefunden festzustellen. Dies erschwerte eine stratigraphische Abfolge bei den rekonstruierten Gebäudeeinheiten und wird im Einzelfall angesprochen. Dennoch gelang es durch die räumliche Nähe einzelner Funktionsbereiche mehrere Hofkomplexe, bestehend aus Hauptgebäude, angrenzenden Speicherbauten und Brunnenanlagen, herauszuarbeiten. Zaunreihen grenzten die Höfe untereinander und gegen das Umland ab.

Teilweise beträchtliche Störungen der archäologischen Befundlage verursachten zwei neuzeitliche Drainagesysteme, die das Grabungsareal von Südost nach Nordwest und von Nordost nach Südwest durchschnitten. Die älteren Entwässerungsgräben griffen aufgrund ihrer Breite von bis zu $1 \mathrm{~m}$ stärker in den Boden ein und enthielten entsprechend mehr Fundmaterial im Vergleich zu den nur $20 \mathrm{~cm}$ breiten Ost-West verlaufenden jüngeren Drainagegräben. 
Das Verfüllungsmaterial der Befunde bestand in der Regel aus sandigem, gering humosem Substrat von graubrauner bis hellgrauer Färbung. Zu beobachten waren in einigen Befunden Eintragungen von weißem Feinsand, der ein Ergebnis der lokalen Podsolbildung darstellt. Die Abfolge der natürlichen Bodenschichten 1 bis 9 erschließt sich über den Befundkatalog.

Wie bereits erwähnt, wurde das Siedlungsareal mehrfach von Sedimentablagerungen überdeckt. Differenziert werden können wenigstens zwei zeitlich unabhängige Überschwemmungen, deren Ablagerungen weite Flächen überdeckten und in noch nicht verfüllte Befunde einliefen. Dies ermöglicht in einigen Fällen eine chronologische Ansprache. So lassen sich mittelalterliche Befunde infolge der sie bedeckenden grauen oxidierten Kleischicht und ihres oftmals höheren humosen Bodenanteils von vorgeschichtlichen Befunden abgrenzen. Einige Befunde, die von sandig-tonigen Sedimentanteilen (Klei) überdeckt waren, weisen auf einen älteren Überschwemmungshorizont hin, der aufgrund des Fundmaterials kaiserzeitlich datiert werden kann. Pfostengruben älterer Baubefunde, wie die eines bronzezeitlichen Hauses im westlichen Siedlungsbereich, waren von feinsandiger Verfüllung und von blass hellgrauer Farbe.

Bestand bei Befunden ein konstruktiver Zusammenhang mit Umgebungsbefunden, so wurden diese als gleichzeitig angesprochen. $\mathrm{Zu}$ berücksichtigen ist hierbei eine nach Funktion unterschiedliche Nutzungsdauer. So fanden sicherlich Ausbesserungsarbeiten an Gebäuden statt. U. a. gelangten sekundär genutzte Hölzer in Brunnenanlagen der Siedlung. Dendrochronologische Untersuchungen belegen beispielsweise für eine Wasserstelle eine bis zu 100 Jahre lange Nutzungsphase (vgl. Kap. 5.2.11). Allein anhand der Verfärbungen von Pfostenbefunden eines Gebäudes sind kaum Rückschlüsse auf einzelne Bauphasen möglich, da sie sich in ihrer Färbung oftmals nur wenig unterscheiden.

Diese grundsätzlichen Beobachtungen fließen in die Überlegungen zur Siedlungschronologie ein. Einbezogen werden die aus den Baubefunden stammenden Fundmaterialen und die Ergebnisse der naturwissenschaftlichen Datierungsmethoden.

Eine zumeist gute Erhaltung von Holz und Flechtwerk lag dann vor, wenn die Befunde stärker eingetieft waren und sich über längere Zeiträume im Grundwasserbereich befunden haben.

\subsection{Baubefunde}

Die in Nortmoor aufgefundenen Gebäudegrundrisse datieren von der Bronzezeit bis ins Mittelalter, gehören jedoch überwiegend der römischen Kaiserzeit an. Nachfolgend werden die Nortmoorer Hausplätze hintereinander vorgestellt. Dies ermöglicht eine bessere Vergleichbarkeit. Die Bauten sind im Maßstab 1:200 aus dem Gesamtplan herausgelöst und mit ihren Pfostentiefen grafisch dargestellt. 
Intensive landwirtschaftliche Bewirtschaftung hat die Bodenerosion auf der exponiert liegenden Sanddüne beschleunigt. Reste eines Laufhorizontes fanden sich $\mathrm{zu}$ keinem der Baukomplexe. Pfostentiefen von meist unter $40 \mathrm{~cm}$ lassen auf den Verlust von wenigstens $40 \mathrm{~cm}$ schließen, wie ein Vergleich mit konstruktiven Pfosten von der Feddersen Wierde zeigt (vgl. ZIMMERMANN 1986, 172). Für Nortmoor kam es nicht zur Anwendung der Phosphatanalyse. Wie aussagekräftig diese Methode für kaiserzeitliche Siedlungen sein kann, belegen die Ergebnisse aus Flögeln-Eekhöltjen (ZIMMERMANN 1992, 104), auf die hier jedoch nicht näher eingegangen werden kann.

Der Begriff Langhaus wird im vorliegenden Zusammenhang für dreischiffige ebenerdige Gebäude verwendet, die in Längsrichtung gegliedert sind und hier oft einen ihrer Zugänge hatten. Bautechnisch stellen Langhäuser den dominierenden Haustyp im Küstenraum der südlichen Nordsee dar (ZIMMERMANN 1992, 42). Die freigelegten Gebäudegrundrisse variieren teilweise beträchtlich in ihrer Längen- und Breitenerstreckung. So erreichen Gebäude in der Geestsiedlung Flögeln Längen von 5,30-63,50m (ZIMMERMANN 1992, 42). Aus dem ostfriesischen Brill liegen Hauslängen von 7,737,6m vor (LEHMANN 2002, 118), während in der Feddersen Wierde kein Haus länger als 29,4m war (HAARNAGEL 1984, 172; 179, 114). In der jüngeren römischen Kaiserzeit konnten durchaus auch Gebäudelängen von 30-35m erreicht werden (ZIMMERMANN 1984, 57). Eine überregional einheitliche Längenentwicklung kaiserzeitlicher Gebäude konnte bisher jedoch nicht festgestellt werden (BRABANDT 1992, 61).

Der Hauptwohnraum kaiserzeitlicher Häuser hatte meist eine Breite von etwa 3m und war von zwei schmaleren Seitenschiffen begleitet (vgl. LEHMANN 2002, 95). Während eine Stückelung der Längsverbindungen durchaus üblich war, mussten für die Dachbalken der Querverbindung aus statischen Gründen ganze Balken verwendet werden (HALPAAP 1994, 255-256). In Brill überwiegen Gebäudebreiten von 5,5 bis 6m (LEHMANN 2002, 118).

Für die Flögelner Häuser des 1. bis 3. Jahrhunderts n. Chr. liegen Gebäudebreiten zwischen 5-6m vor (bei 37 von 77 entdeckten Hausgrundrissen), während 24 Häuser eine Breite von über 6m aufwiesen (bei den übrigen handelt es sich um Kurzhäuser). Nur in wenigen Siedlungen treten Gebäudebreiten von bis zu 7m auf (LEHMANN 2002, Haus 20; HAARNAGEL 1979, Haus 29; ZiMMERMANN 1992, Haus 24). Grundsätzlich weist ein breiter Mittelteil auf einen erhöhten Raumbedarf der Bewohner hin. Möglicherweise kennzeichnete die größere Gebäudebreite einen höheren sozialen Status ihrer Bewohner (vgl. ZIMMERMANN 1988, 473). Hingegen wird die beträchtliche Abnahme der Gebäudebreite auf nur noch $4 \mathrm{~m}$ als Folge eines siedlungsbedingten Rückganges der Holzbestände im 6. Jahrhundert gesehen (ZIMMERMANN 1992, 139).

Um verkürzte Häuser handelt es sich bei Gebäuden, die innerhalb des Hauptschiffes maximal fünf Pfostenpaare aufweisen, wovon sich nur eine Querverbindung im Wohnbereich befindet. Hierbei nicht 
mit einbezogen sind tragende Pfosten an den Schmalseiten (ZIMMERMANN 1992, 102). Diese von ZIMMERMANN definierte Untergruppe des Typs 1 erscheint als stark reduzierter Hausgrundriss, der im wesentlichen die Eingangssituation widerspiegelt. Der derartig reduzierte Raumbedarf zeichnet, wenn man so will, die Keimzelle des Hauses aus.

Die formale Gliederung prähistorischer Langhäuser erfolgt in der Regel nach der Stellung ihrer Innenpfosten. Problematisch wird dies, wenn durch einfaches Fortlassen oder Nachsetzen von einem Pfostenpaar eine andere Typzugehörigkeit formuliert wird. Hier kommt der Klärung der Gebäudefunktion eine immanente Bedeutung zu, ist aufgrund lückenhafter Befundlage jedoch nicht immer eindeutig zu klären.

Die Form der Pfostengrube gibt einen Hinweis auf ihre statische Funktion. Während kurze Hölzer noch eingetrieben werden konnten und sich an den Außenseiten kaiserzeitlicher Gebäude befinden, wurden längere Hölzer oft eingegraben und deuten auf Pfosten des inneren Gerüstes besonders tragfähiger Konstruktionen hin (BRABANDT 1992, 22).

Für Nortmoor konnten weitgehend parallelwandige Wohnbauten rekonstruiert werden, die eine zweioder dreischiffige Konstruktion aufwiesen. Jedoch gelang es nicht in allen Fällen eine Zuordnung einzelner Pfosten unzweifelhaft vorzunehmen. Um weitere Grundrisse ausfindig zu machen, wurden Pfostenreihungen auf Übereinstimmungen überprüft. In Einzelfällen ermöglichte eine einheitliche Befundverfärbung die Zugehörigkeit von Pfosten zu erkennen. So fand sich beispielsweise bei einem bronzezeitlichen Gebäudegrundriss in den Pfostengruben ein homogenes hellgraues Bodensubstrat. Innerhalb eines Gebäudes können die Befundverfärbungen jedoch auch stark schwanken. Hierbei ist es die Frage, inwieweit aufgrund der Farbintensität auf unterschiedliche Funktionen der Pfosten und einzelner Bauglieder geschlossen werden kann. In Brill wurde eine weitgehende Gleichverteilung bei der Farbverteilung von Mittelständern, Wand-, Giebel- und Stützpfosten sowie den Boxentrennwänden angetroffen (LEHMANN 2002, 95).

\subsubsection{Hausplatz I}

Kat.Nr. 316-317; 319-323; 344; 351-355; 357-362; 364; 381; 393; 433-447; 451-453; 497; 508

Taf. 83

Am Nordrand der Dünenkuppe wurde in den Quadranten 46-48,6/55-55,5 ein WNW-OSO orientierter Hausgrundriss freigelegt. Von der ursprünglichen Konstruktion des dreischiffigen Gebäudes sind die dachtragenden Pfostengruben des Mittelschiffes, wenige Außenpfosten sowie zwei den Giebelseiten angehörende Pfostengruben erhalten. Überliefert sind insgesamt 39 Pfostengruben. In 12 Fällen fanden sich Pfostenstandspuren (Kat.Nr. 319; 320; 321; 322; 344; 350; 358; 440; 442; 441; 444; 508). Rekonstruiert werden kann eine Gebäudelänge von wenigstens 26,5m bei einer Hausbreite von bis zu 6m. Der Flächeninhalt von Haus 1 betrug rechnerisch 148,8qm. Dies erklärt sich aus der Größe des 
östlichen Stallbereichs mit 75,6qm (14x5,4m), einem zentralen Gebäudeteil mit 25,2qm (4,2x6m) und dem westlichen Wohnbereich mit 48qm (8x6m). Die Orientierung des Nortmoorer Gebäudes entspricht den im Elbe-Weser-Dreieck vorherrschenden Windrichtungen aus westnordwestlicher Richtung (ZIMMERMANN 1992, 154-155), während in der ostfriesischen Geest Nordwestwinde überwogen (LEHMANN 2002, 146-147).

Vom Hauptschiff sind 26 Pfostengruben bis in eine Tiefe von maximal $36 \mathrm{~cm}$ erhalten. Die Eintiefungen variieren zwischen 5 und $36 \mathrm{~cm}$ bei einem arithmetischen Mittel von $19,7 \mathrm{~cm}$. An der südlichen Langseite wird in fünf Fällen eine Pfostentiefe um die $30 \mathrm{~cm}$ erreicht. An dieser Gebäudeseite steht der gewachsene Boden bei $+1,50 \mathrm{~m} \mathrm{NN}$ an, während er zur Nordseite auf $+1,30 \mathrm{~m}$ NN abfällt.

Der Abstand der Innenpfosten variiert zueinander zwischen 1,4-2m. Im östlichen Gebäudeteil zeigen die gegenüberliegenden Pfostenpaare zu ihrem benachbarten Pfosten jeweils den gleichen Abstand. Eine derartige Regelhaftigkeit ist für die westliche Haushälfte nicht immer festzustellen. Die nicht ganz einheitliche Flucht der Pfostenbefunde wurde möglicherweise durch Verwendung von unregelmäßigem Bauholz verursacht (vgl. ZIMMERMANN 1988, 468).

Die östliche Gebäudehälfte wird durch wenigstens sieben Querriegel gebildet (Kat.Nr. 317, 319-323; 352-355; 358-361). Ein weiterer Querriegel nahe der Hausmitte ist wahrscheinlich, nimmt man für die Pfostengrube Kat.Nr. 381 einen gegenüberliegenden Pfostenbefund an. Die größere Spannweite zwischen den östlichsten Querriegeln Kat.Nr. 319 / 317 und Kat.Nr. 322 / 323 deutet auf das Erreichen des Hausendes hin, wie dies auch für den Haustyp 1 aus Flögeln belegt ist (ZIMMERMANN 1992, 44, Abb. 14, H58 u. H125). Folglich wäre die vorgesetzte Position der Pfostengrube Kat.Nr. 316 ein Bestandteil des nahen Ostgiebels.

Dem westlichen Gebäudeteil sind fünf Querauflieger zuzuordnen. Es zeigen sich hier zwischen den einzelnen Pfostengruben einer Längsseite weniger regelmäßige Abstände, die zwischen 1,4-2m liegen können (Kat.Nr. 433; 435; 437; 441; 443-446; 497). Die leicht diagonal verschobene Position von Pfostengrube Kat.Nr. 445 zu Kat.Nr. 446 lässt auf einen Reparaturpfosten schließen.

Das Mittelschiff in der westlichen Haushälfte weist insgesamt eine größere Spannweite auf und ist etwa $60 \mathrm{~cm}$ breiter als der östliche Hausteil. Der größere Raumbedarf von bis zu $3 \mathrm{~m}$ deutet auf eine Wohnraumnutzung hin. Auf eine zentrale Herdstelle in diesem Bereich deuten die aus Kat.Nr. 434 stammenden gebrannten Lehm- und Holzkohlebrocken.

Flach eingetiefte Außenpfosten sind zumeist nicht mehr erhalten. Die geringe Tiefe der übrigen Pfostenbefunde von Haus I lässt vermuten, dass sich die Grabungsfläche wesentlich unter dem ehemaligen Laufhorizont befand (vgl. HAARNAGEL 1984, 172).

Von der nördlichen Langseite des Hauses haben sich vier Pfostengruben des Seitenschiffes erhalten. Ihre Tiefe liegt zwischen $5 \mathrm{~cm}$ bis maximal $30 \mathrm{~cm}$ bei einem Mittel von 12,25cm (Kat.Nr. 344; 351; 442; 447). Die Pfostenstandspur Kat.Nr. 344 (T 16cm) befindet sich in direkter Flucht des 
Hauptschiffes zu den Pfostengruben Kat.Nr. 323 und Kat.Nr. 317. Dies ist auch bei Kat.Nr. 362 an der südlichen Langseite zu beobachten (Kat.Nr. 258; 355). Pfostengrube Kat.Nr. 351 ist geringfügig diagonal nach Osten verschoben und befindet sich nicht mehr in Flucht mit Kat.Nr. 352. Eventuell weist diese Position auf einen Reparaturpfosten hin. Ihr recht beachtlicher Durchmesser von 70x45cm unterstützt dies, zumal an dieser Stelle ein Zugang eher unwahrscheinlich wäre.

Als östlichster Außenpfosten des südlichen Seitenschiffes ist Kat.Nr. 316 mit einer Tiefe von noch $6 \mathrm{~cm}$ erhalten. Der Pfostenbefund wird mit der 14m entfernten Pfostengrube Kat.Nr. 362 einem recht schmalen Seitenschiff zugeordnet. Das Seitenschiff in der östlichen Haushälfte weist durchschnittlich eine Breite von $1 \mathrm{~m}$ auf. Im zentralen Gebäudeteil erhöht sich diese auf 1,20m. Für den westlichen Gebäudeteil fehlen entsprechend eindeutige Pfostenbefunde. Pfostengrube Kat.Nr. 436 (Planum 45x32cm) und Kat.Nr. 442 (Planum 78x58cm) stehen sich zwar als Außenpfosten des Seitenschiffes annähernd gegenüber, ihr ungleicher Durchmesser steht einem Vergleich entgegen. Kat.Nr. 442 zeigt eine $30 \mathrm{~cm}$ tiefe Pfostenspur. Dies deutet auf eine Zugangsituation hin. Am westlichen Ende des Gebäudes steht eine Pfostengrube mit ähnlicher Pfostenstärke (Kat.Nr. 447: Planum 90x58cm). Seine geringe Tiefe spricht gegen einen Zugangsbereich und deutet eher auf einen Reparaturpfosten hin.

Im Mittelteil des Gebäudes ist eine Reihe von vier Wandpfosten leicht nach außen versetzt (Kat.Nr. $436,453,452,364)$ und gehört zum $1 \mathrm{~m}$ breiten Seitenschiff.

Die südöstliche Zugangssituation mit ihrer vorgelagerten Pfostenreihung weist Ähnlichkeiten mit einem Hausgrundriss aus Westerrohrstedt an der nordfriesischen Küste auf (BRABANDT 1993, 37, 40, Tafel. 16,5). Vergleichbar angeordnet sind die fünf dem Hauptschiff vorgelagerten Pfosten, wobei das dreischiffige Gebäude in Nordfriesland in den Abmessungen kleiner ausfällt. Auch im niederländischen Bennekom, Provinz Gelderland, findet sich eine verwandte Pfostensetzung im südlichen Eingangsbereich eines Hauses (BRABANDT 1993, 27, Tafel. 40,4). Der Grundriss weist ähnlich schmale Seitenschiffe mit enger Pfostenstellung auf, ist in seiner Längserstreckung dem Nortmoorer Gebäude gegenüber mit $17 \mathrm{~m}$ bedeutend kürzer.

Auf eine antithetische Zugangssituation im mittleren Gebäudeteil von Hausplatz I deuten zwei mächtige Pfostengruben hin. Kat.Nr. 453 hat einen Counterpart in der Grube Kat.Nr. 442. In Letzterer war eine Pfostenstandspur (Dm $15 \mathrm{~cm}, \mathrm{~T} 30 \mathrm{~cm})$ erhalten, während der südliche Pfosten Kat.Nr. 453 oberhalb der Grubensohle einen Stein enthielt. Eventuell existierten in der westlichen Haushälfte weitere Eingänge. Hierauf deuten die relativ großen Pfostengruben Kat.Nr. 447 und 497 hin. Aufgrund der schlechten Erhaltung der Außenpfosten ist die Türsituation jedoch nicht fassbar. Möglicherweise bestanden Zugänge zum Haus an den Gebäudelangseiten, wie dies für vergleichbare Bauten belegt ist (ZIMMERMANN 1992, 142; vgl. LEHMANN 2002, 128-129). Hierzu verhindern jedoch die mangelhaften Erhaltungsbedingungen der kaum eingetieften Giebelwände eine Aussage. Sowohl vom Westgiebel (Kat.Nr. 508), wie auch vom Ostgiebel (Kat.Nr. 316) ist jeweils nur ein Pfostenbefund überliefert. Über die Giebelkonstruktion kann im vorliegenden Fall keine Aussage getroffen werden. Optional ist von einem Walmgiebel auszugehen (vgl. ZIMMERMANN 1992, 152). Möglicherweise spiegeln 
Pfostenbefunde im Mittelteil (Kat.Nr. 438; 439; 440; 442; 442) den Verlauf der westlichen Giebelseite wieder.

Aufgrund der schlechten Erhaltungsbedingungen wurden keine Wandgräbchen aufgedeckt. Unklar ist, ob es zu einer Längsverschiebung des Hauskomplexes in westlicher Richtung kam. Da dort nur wenige Pfostengruben in einer gemeinsamen Flucht vorliegen (Kat.Nr. 500; 507), ist eine zweite Bauphase nicht gesichert und eine chronologische Abfolge kaum vorzunehmen.

Keramikfunde innerhalb des Hauses entstammen einem Graben und 11 Pfostengruben. Die Fundverteilung beschränkt sich, mit einer Ausnahme (Kat.Nr. 355), auf den Südwestbereich des Gebäudes. Bei dem Fundmaterial überwiegen Wandungsscherben $(n=98)$ und wenige Gefäßböden $(n=6)$, die allgemein in die römische Kaiserzeit zu datieren sind. Die erhaltenen 18 Randscherben sind mit wenigen Ausnahmen meist stark fragmentiert. Drei signifikante Randprofile konnten aus dem Graben 434 geborgen werden. Zwei der Scherben besitzen einen mehrfach facettierten Rand (Kat.Nr. 434,1-3; vgl. FöRST 1994, Taf. 64, 480). Insgesamt datieren die Keramikfunde in die römische Kaiserzeit, aufgrund ihres recht hohen Fragmentierungsgrades ist eine Feindatierung kaum möglich. Eine recht große Zahl der Pfostengruben des Gebäudes enthielten Reste von Holzkohle ( $n=25)$. Die Holzkohle war gleichmäßig über dem gesamten Gebäudekomplex verstreut. Das Verteilungsbild deutet auf einen Brand hin, wobei die relativ geringe Menge an Holzkohle pro Pfostengrube erhaltungsbedingt zu erklären ist.

Hausplatz I ist nur ungenügend erhalten. So konnten beispielsweise keine Wandgräbchen oder Reste eines umgebenden Grabensystems nachgewiesen werden. Die wenigen Pfostengruben der Seitenschiffe und Giebelenden weisen in ihrer Anordnung deutliche Übereinstimmungen mit Haus 49 aus Flögeln auf (Zimmermann 1992, 64, Abb. 34, 67, Haus 49). Dort sind die Außenpfosten leicht diagonal zum Hauptschiff verschoben, die Spannweite der haustragenden Pfosten ist im Mittelteil des Gebäudes geringer und nimmt zum Hausende hin wieder zu. Das 24,8x5,8m große Haus besitzt zwei gegenüberliegende Eingänge an den Längsseiten und einen an der westlichen Schmalseite. In seiner Konstruktionsweise vergleichbar ist in Backemoor das wenigstens 23,2x5,8m große Haus 4 (BÄRENFÄNGER 2001a, 22-23).

Die Aufteilung des Gebäudes in ein breites Mittelschiff und zwei schmale Seitenschiffe ist für dreischiffige Hallenhäuser der römischen Kaiserzeit charakteristisch (vgl. BRABANDT 1993, 37). Haus 1 entspricht in seinem Aufbau dem Flögelner Typ 1, dessen Grundkonstruktion sich über vier Jahrhunderte kaum veränderte und vom 1. bis 5. Jahrhundert vorkommt. Eine Untergliederung in verschiedene Untertypen erfolgte in Flögeln schematisch, da die Übergänge sich fließend darstellen (vgl. ZIMMERMANN 1992, 46, 139). Die Innengliederung des Haustyps 1c in Flögeln vermittelt ein recht gutes Bild, aufgrund der Erhaltungsbedingungen ist auch eine Zugehörigkeit zu 1d nicht auszuschließen (vgl. ZIMMERMANN 1992, 44, Abb. 14; 67, Haus 11; 70, Haus 9). 
ZIMMERMANN $(1986,57)$ stellt bei Wohnbauten in Flögeln eine stetige Verlängerung der Grundrisse im Laufe der römischen Kaiserzeit fest, wobei der Stallteil im Vergleich zum Wohnbereich weniger an Länge zunimmt. Schließt man sich dem postulierten Längenwachstum kaiserzeitlicher Gebäude an, würde man das Nortmoorer Haus 1 mit einer Grundrisslänge von wenigstens 26,4m in das 2. Jahrhundert n. Chr. datieren.

Bei der Breitenentwicklung kaiserzeitlicher Gebäude ist ein diametraler Bautrend zu beobachten. Im Laufe der Kaiserzeit werden die Wohnbauten immer schmaler (ZIMMERMANN 1986, 57). So liegt in Flögeln die Hausbreite zunächst zwischen 5,5m und 7m im 1. Jahrhundert und verringert sich im 3./4. Jahrhundert auf eine regelhafte Breite 5,5m (BRABANDT 1992, 62-63). Von der Feddersen Wierde liegen für das 3. Jahrhundert noch Gebäudebreiten von $5,6 \mathrm{~m}$ vor, die sich in den folgenden Jahrhunderten auf rund $5 \mathrm{~m}$ verringerten. Ein Vergleich mit der niederländischen Hauslandschaft in der Provinz Drenthe zeigt die lange Laufzeit verwandter Häuser in Wijster, die noch zwischen 395-430 n. Chr. datiert werden (BRABANDT 1993, 141, Taf. 69, 1).

\subsubsection{Hausplatz II}

Kat.Nr. 472; 476-479; 481-489; 491-494; 502-506; 527-530; 532-536; 539-542; 544-548; 556-564; $566-568 ; 570-571 ; 573-578 ; 580 ; 583 ; 585$; 606-627; 629-633; 636-638; 640; 648; 655; 664-665; 670$673 ; 675-676 ; 686$

Taf. 84

Auf Dünenkuppe konnte in den Quadranten 54,8-53,8 / 52,5-54,2 ein WNW-OSO orientierter Hausgrundriss freigelegt werden. Von dem Langhaus ist die östliche Gebäudehälfte verhältnismäßig gut erhalten, die westliche Hälfte liegt stark fragmentiert vor.

12 dachtragende Pfostengruben des Mittelschiffes haben sich von dem ursprünglich dreischiffigen Gebäude erhalten. Während die östliche Giebelseite nahezu komplett vorliegt, ist der Westgiebel weitgehend verloren gegangen. Eine Vielzahl von Pfostengruben, die zum Teil in einer Flucht liegen, lassen sich nicht mehr eindeutig zuordnen. Eventuell waren sie Bestandteil verschiedener Ausbesserungsphasen, wobei sie sicherlich nicht zeitgleich bestanden haben werden. Die ursprüngliche Eingangssituation erschließt sich aus dem Grundriss nicht mehr. Die Befundlage des Gebäudes ist zudem gestört durch Drainagegräben und einem älterkaiserzeitlichen Begräbnisplatz (vgl. Kap. Bestattungen), von dem sich zwei Urnenbestattungen im Bereich des nordöstlichen Gebäudeteiles befanden.

Von dem maximal 27m langen und 6,5m breiten Gebäude haben sich 98 Pfostenbefunde erhalten. Hierzu zählen 64 Pfostengruben der östlichen Gebäudehälfte und 24 Pfostengruben aus dem zentralen Bereich. Der Hauswestteil ist nur mit 10 Pfostengruben überliefert. Zugehörig zum Gebäude sind zwei Feuerstellen (Kat.Nr. 559; 613), einige hausbegleitende Wandgräbchen (Kat.Nr. 527; 532; 493) und Gräben (Kat.Nr. 670; 637; 627). 
Die Binnenkonstruktion dieses Gebäudes zeichnet sich nicht so klar ab wie bei Hausplatz I. Allein die Gebäudebreite von 6,5m legt eine dreischiffige Bauweise nahe. Die Pfostenbefunde im Hauptschiff haben sich auf $15 \mathrm{~m}$ Länge erhalten. Zugehörig sind je sechs Pfostengruben vom südlichen Hauptschiff (Kat.Nr. 617; 610; 564; 562; 556; 491) und vom nördlichen Schiff (Kat.Nr. 481; 483; 568; 570; 624; 636). Die Pfostentiefe variiert zwischen 2-38cm, wobei ihr Erhaltungszustand an der Gebäudesüdseite meist günstiger war. Im Profil zeichnen sich kasten- bis muldenförmige Pfostenbefunde ab. Die geringe Tiefe der Pfostengruben mit einem Häufigkeitsmaximum zwischen $12-27 \mathrm{~cm}$ weist darauf hin, dass sich vom damaligen Laufhorizont nichts erhalten hat.

Die Pfostenbefunde Kat.Nr 610 und 617 sind ebenso wie die Pfostengruben Kat.Nr. 556 und 662 regelhaft 3,5m voneinander entfernt. Die Entfernung zwischen Kat.Nr. 566 zu 610 beträgt bereits $6,7 \mathrm{~m}$. So sind weitere Querriegel zu vermuten, die sich jedoch nicht erhalten haben. Auf einen Reparaturpfosten weist die Position des Pfostenbefundes Kat.Nr. 564 hin, der sich in Flucht des Querriegels befand und etwa 1,7m westlich von Kat.Nr. 562 entfernt lag. Vom nördlichen Hauptschiff ist der Abstand der Pfostenbefunde zueinander weniger regelhaft und liegt zwischen 2,4-4m.

Während die Pfostengruben im westlichen Schiff einen Gefachabstand von 3,2m aufweisen, verringert sich dies bei den Innenpfosten im östlichen Gebäudeteil auf 1,2-3m. Im zentralen Teil fehlen gesicherte Pfostengruben, da dieser Bereich durch eine moderne Drainage stark gestört ist. Die Breite des nördlichen Seitenschiffes beträgt $2 \mathrm{~m}$, die des südlichen $1,5 \mathrm{~m}$.

Die ungewöhnliche Pfostenhäufung innerhalb des östlichen Gebäudeteils kann ein Hinweis auf verschiedene Einbauten unbekannter Funktion sein. Denkbar wären Zwischenwände aus Flechtwerk, die einzelne Regionen im Haus separierten (ZIMMERMANN 1992, 147-150; HAARNAGEL 1979, 89). Darüber hinaus könnten die bisher nicht eindeutig zu interpretierenden Pfostenbefunde eventuell mit dem durch Urnenfunde belegten Bestattungsplatz in Verbindung stehen.

Vom östlichen Gebäudeteil sind 28 wandhaltende Außenpfosten und zwei Wandgräbchen überliefert. Zwischen den Pfosten besteht ein regelhafter Abstand von 0,8-1m zueinander. Am Ostgiebel ist ein $3 \mathrm{x} 0,5 \mathrm{~m}$ langes und $25 \mathrm{~cm}$ tiefes Wandgräbchen erhalten (Kat.Nr. 493). Gemeinsam mit sechs nahezu in Flucht liegenden Pfostengruben ist hier das Hausende erreicht worden. Die in 1m Entfernung vom Ostgiebel stehenden Innenpfostenpaare lassen ein Walmdach rekonstruieren (ZIMMERMANN 1992, 152). Vom Westgiebel haben sich lediglich zwei Pfostengruben erhalten (Kat.Nr. 664; 655), eventuell bestand auch hier ein gerader Hausabschluss.

An der südlichen Außenwand ist ein $4 \mathrm{~m}$ langes und bis zu $40 \mathrm{~cm}$ breites Wandgräbchen erhalten (Kat.Nr. 532). Zwischen den nördlich anschließenden Außenpfosten und dem noch $5 \mathrm{~cm}$ eingetieften Wandgräbchen verbleibt ein Abstand von wenigen Zentimetern, meist fehlt er jedoch ganz. Vermutlich handelt es sich daher um die Überreste eines Fundamentgrabens für eine außen angebrachte Flechtwerkmatte, die als Außenwand fungierte. Für einen wandparallelen Traufgraben ist die Distanz hingegen zu gering (LEHMANN 2002, 101-102). Um einen solchen handelt es sich möglicherweise bei dem $60 \mathrm{~cm}$ südlich vorgelagerten Gräbchen Kat.Nr. 527. 
Auf eine Länge von 8m sind in der östlichen Gebäudehälfte sowohl die südliche (Kat.Nr. 506; 533537; 541-547) wie die nördliche Außenwand (Kat.Nr. 476-478; 487-488; 502; 573-577) erhalten. Die dicht nebeneinander gesetzten Pfosten lassen zunächst keinen Eingang erkennen. Eine auffällige Pfostenstellung ist sowohl an der nördlichen wie der gegenüberliegenden südlichen Hausseite feststellbar. Der Wandpfosten Kat.Nr. 502 wird auf der Innen- und Außenseite durch einen weiteren Pfosten eingefasst (Kat.Nr. 479; 583). Im Süden wird Kat.Nr. 544 im Gebäudeinneren von einem Pfosten begleitet, sein Counterpart wird vermutlich durch das Wandgräbchen Kat.Nr. 532 verdeckt.

Der Befund weist beidseitig der Hauslängsseite auf eine zusätzliche Stütze hin. Auffällig sind die Pfostentiefen von bis zu 30cm, die auf stabilisierende Türpfosten deuten (LEHMANN 2002, 124). Eine Zugangsmöglichkeit von $80 \mathrm{~cm}$ Breite entspricht auch den von der Feddersen Wierde gemessenen Türbreiten, während in Flögeln eine Türbreite von 95-1,25cm bevorzugt wurde (ZIMMERMANN 1992, 142, Abb. 110).

Vom Westteil des Gebäudes sind nur wenige Außenwandpfosten überliefert. Ihre unregelhaften Abstände von 0,8-4m zeigen deutlich den mangelhaften Erhaltungszustand in diesem Gebäudeteil. Hinweise auf etwaige Zugänge fehlen hier. Hausbegleitende Gruben finden sich sowohl südlich wie nördlich des Gebäudes (Kat.Nr. 627; 637; 670).

Im Mittelteil des Gebäudes haben sich Überreste zweier Herdstellen erhalten (Kat.Nr. 559; 613). Die gebrannten Lehm und Holzkohle enthaltenden Gruben lagen 10m voneinander entfernt. Während die größere Herdstelle fundleer war, enthielt die kleinere kaiserzeitliche Keramik und einen konischen Spinnwirtel (Taf. 37). Ein weiteres Spinnwirtelfragment entstammt einer anderen Pfostengrube des Hauses (Kat.Nr. 675).

Verhältnismäßig häufig enthielten Pfostengruben des Hauses Keramikscherben (Kat.Nr. 472; 476; 482; 483; 484; 485; 486; 556; 560; 562; 566; 609; 614; 638; 673; 686). Auch in einem zum Gebäude zugehörigen Wandgräbchen (Kat.Nr. 532) und einer Grube (Kat.Nr. 493) fand sich Keramik. Meist handelte es sich um stark fragmentierte Scherben, die nur allgemein in die römische Kaiserzeit zu datieren sind. Ungewöhnlich viele Funde entstammen den hausbegleitenden Gräben (Kat.Nr. 627; 637; 670). Neben wenigen langen Randscherben der GF 7.5 überwiegen kurze facettiert-verdickte Gefäßränder der älteren Kaiserzeit. Die wenigen Scherben von Importgefäßen der RheinWesergermanischen Drehscheibenware (Kat.Nr. 627-6) und einer Terra Nigra Schale (Kat.Nr. 627-4) sind in das 2./3. Jahrhundert zu datieren.

Trotz der teilweise schlechten Befunderhaltung kann Hausplatz II als ein dreischiffiges Wohnstallgebäude der älteren römischen Kaiserzeit angesprochen werden. Die Pfosten des Mittelteils sind mit 8 Gefachen überliefert. Vom Ostteil sind sowohl das Giebelende wie auch die wandtragenden Außenpfosten erhalten. Die Lage der Herdstellen weisen einen Wohnbereich im Gebäudemitte und im östlichen Bereich aus, während folglich der Wirtschaftsteil im sich anschließenden westlichen Teil zu 
finden ist. Es fehlen, vermutlich aufgrund der schlechten Erhaltungsbedingungen, die weniger stark eingetieften Pfosten der Stallboxen (vgl. ZIMMERMANN 1992, 150).

Die Pfostenbefunde lassen nicht in allen Fällen die funktionale Innengliederung erkennen. Unregelmäßigkeiten bei den Pfostenstellungen der Wandfluchten bedingen sich durch die Schwierigkeiten bei der Beschaffung gerade gewachsenen Bauholzes. Einige Pfostengruben wurden in ihrem oberen Teil durch Klei überdeckt. Dies spricht für eine zeitnahe Überschwemmung des Areals.

Merkmale vom Hausplatz II sind ein breites Mittel- und ein schmales Seitenschiff. Dies trifft auf die meisten dreischiffigen Häuser der römischen Kaiserzeit zu. Hinzu kommt seine rechteckige Grundform mit enger Stellung der Außenwandpfosten und ein gerader Giebelabschluss, der dem Typ 1b in Flögeln entspricht (ZimMERMANN 1992, 44, Abb. 14). Die letzten Innenpfostenpaare stehen nahe der Giebelwand oder direkt an der Schmalseite. Nach ZIMMERMANN $(1992,152)$ wird wenigsten bis zur Höhe des Querverbandes der Giebel steil hochgezogen sein. Denkbar ist dann eine Dachkonstruktion in Art eines Walm- oder Krüppelwalmes. Einige Häuser vom Typ 1 besitzen zudem im Westteil des Gebäudes einen größeren Abstand der Innenpfosten.

Auch in Brill finden sich Wohnbauten vergleichbarer Konstruktion. Das Langhaus 4 zeigt ein nahe am Giebel stehendes Innenpfostenpaar (LEHMANN 2002, Taf. 86). Die Abstände zwischen den kürzeren Fächern liegen durchschnittlich bei 1,77m, die zwischen einem Doppelfach im Mittel bei 3,44m.

Für Brill wird bei kaiserzeitlichen Langhäusern ein einheitliches Baumaß von 1,8m beobachtet; wobei eine 10\% abweichende Meßungenauigkeit berücksichtigt wurde (LEHMANN 2002, 145-146). Haus 4 gehört in die erste Bauphase der Siedlung in das 1. und 2. Jahrhundert (LEHMANN 2002, 155).

Ebenfalls in diesem Zeitfenster wird der Nortmoorer Hausplatz II errichtet worden sein. Einen Hinweis auf eine frühe Datierung gibt sein gerade ausgeführter Giebel und der rechteckige Grundriss. Nach BRABANDT fehlen abgerundete Schmalseiten im 1. Jahrhundert und kommen erst langsam im 2. Jahrhundert auf (BRABANDT 1993, 45-46). Während sie noch beim Nortmoorer Hausplatz II fehlen, sind sie für den nachfolgenden Hausplatz III nachweisbar.

Für die zeitliche Einteilung des Hausplatzes II können Hausbefunde aus den Niederlanden herangezogen werden. Der kaiserzeitliche Hausgrundriss Wijster 80 mit seinen enggestellten Außenpfosten und schmalem Seitenschiff datiert zwischen 150-185 n.Chr. (VAN Es 1967, 365). Zwischen 100 v. bis 100 n. Chr. datieren die Gebäude vom Typ Noordbarge. Hier weist Noordbarge 25 in einigen Details Übereinstimmungen mit dem Nortmoorer Hausplatz II auf (HUIJTS 1992, 98-99, Fig. 94). Neben der 3-Schiffigkeit und der engen Stellung der Außenpfosten findet sich bei dem niederländischen Haustyp eine auffällige Doppelpfostenstellung an einigen Positionen nahe der eigentlichen Gebäudeaußenwand. Diese Pfosten sind leicht diagonal zum nächsten Außenpfosten verschoben. Der nicht ausreichend erhaltende Gebäudegrundriss in Nortmoor steht einer weiterführenden Interpretation jedoch entgegen. 


\subsubsection{Hausplatz III}

Kat.Nr. 664-669; 672-674; 676-678; 680-683; 700-702; 704; 708-712; 714-722; 723-724; evtl. 727; 728; 729; 736-738; 759-768 (evtl. 762); 770-776 (evtl. 771, 773, 774); 787; 821-831; 833; 852; 856; 892; 896 (Verfärbung); 917; 921-923; 925; 926; 929-936 (evtl. 935); 1030-1037; 1044; 1045; 1047; 1048; 1050; 1051; 1053; 1054; 1056; 1058-1066; evtl. 1064; 1071; 1072; evtl. 1074; evtl. 1081 Taf. 85-88

Auf der Dünenkuppe zeichnen sich in den Quadranten 54/42 bis 53/45 die Überreste eines 45m langen und $7 \mathrm{~m}$ breiten Gebäudes ab. Vom WNW-OSO orientierten Haus haben sich beide Giebel und eine Vielzahl an Pfostenbefunden erhalten. Insgesamt können 109 Pfostengruben, fünf Wandgräbchen sowie zwei Herdstellen dem Gebäude zugeordnet werden.

Ein Großteil der Pfosten war niedrig eingetieft und ist nicht mehr erhalten. Moderne Drainagen haben den Grundriss in seinem Mittelteil stark gestört. Die Deutung des Gesamtbefundes wird dadurch erheblich erschwert. Die verbliebenen Pfostenbefunde ermöglichen es jedoch nicht einen zweiphasigen Baukomplex $\mathrm{zu}$ rekonstruieren. Es fehlen eindeutige Hinweise auf eine Längsverschiebung, auch wenn die Gebäudelänge dies durchaus gestatten würde (vgl. AHRENS 1974, 77-92). Trotz der schlechten Erhaltung weist die Grundrissform, insbesondere die Pfostenbefunde im Ostteil des Gebäudes, auf ein dreischiffiges Wohnstallgebäude hin.

Die Außenpfosten der nördlichen Langseite zeichnen sich mit einigen Unterbrechungen relativ gut ab, während von der gegenüberliegenden Außenwand noch sieben Pfosten vorliegen. Fast vollständig erhalten sind hingegen die Schmalseiten.

Die Pfostengruben weisen mit $3-24 \mathrm{~cm}$ eine geringe Tiefe auf. Berücksichtigt man die bei Ausgrabungen der Feddersen Wierde gemachten Beobachtungen, so ist in der Regel von einer ursprünglichen Pfostentiefe von $80-90 \mathrm{~cm}$ bei Innenpfosten und $20-30 \mathrm{~cm}$ bei Außenpfosten auszugehen (HAARNAGEL 1984b, 172). Da die Grabungsfläche wesentlich unter dem alten Laufhorizont lag, hat sich ein Großteil der geringer eingetieften Pfosten nicht erhalten.

Die östliche Gebäudehälfte ist etwas besser erhalten. Dort finden sich einige in Flucht liegende Innenpfosten, die ein $4 \mathrm{~m}$ breites Mittelschiff bilden (Kat.Nr. 681; 683; 714; 715; 716; 764; 766). Die Gefachlänge zwischen den einzelnen Pfostengruben beträgt 1,2-2m. Auch hier gibt die geringe Tiefe der Pfostengruben (3-18cm) den schlechten Erhaltungszustand des Gebäudes wieder. Während das nördliche Seitenschiff mit einer Breite von 1-1,2m relativ schmal ausgebildet ist, erscheint das südliche Seitenschiff mit $1,5 \mathrm{~m}$ im Verhältnis dazu breit. Unregelmäßigkeiten bei der Stellung der Innenpfosten können eine Folge von unterschiedlichen Qualitäten des Bauholzes sein (vgl. ZIMMERMANN 1992, 144).

Im Mittelteil des Gebäudes ist die Innenpfostenstellung mit wenigen Ausnahmen gestört (Kat.Nr. 825830; 917), so dass Aussagen über die Binnengliederung unter Vorbehalt erfolgen. Die Dreischiffigkeit scheint hier beibehalten worden zu sein, wobei die Seitenschiffe deutlich breiter angelegt sind als im 
Ostteil des Gebäudes. Von einem Wohnbereich wird im Ost- und Mittelteil des Gebäudes auszugehen sein, da dort je eine Herdstelle lokalisiert wurde (Kat.Nr. 763; 831). Ihre Lage nahe der Mittelachse des Hauses ist typisch für kaiserzeitliche Häuser (ZIMMERMANN 1992, 147; HAARNAGEL 1979, 121).

Die nördliche Außenwand des Gebäudes sind 22 Pfostengruben zuzuordnen (Kat.Nr. 667; 770; 771; 821-824; 833; 926; 929-936; 1059; 1064-1066; 1072), der südlichen Längswand noch 7 Pfosten (Kat.Nr. 708; 711; 759; 761; 762; 788; 1031). Im Westteil des Gebäudes beträgt der Abstand der in Flucht liegenden Außenwandpfosten 0,8-1m. Hinweise auf vergleichbare Pfostenabstände finden sich von verschiedenen Bereichen der ansonsten nur fragmentarisch erhaltenen Gebäudeaußenwand (Kat.Nr. 710; 711; 822; 823). In einigen Fällen ist ein doppelt so großer Pfostenabstand festzustellen, der jedoch vermutlich überlieferungsbedingt zu erklären ist (Kat.Nr. 761; 762; 788; 821; 822). Für einfache Flechtwerkstaken wird der Abstand der Außenwandpfosten zu groß gewesen sein. So setzt TRIER $(1969,76)$ eine Distanz von 0,3-0,4m voraus. Es ist daher zu vermuten, dass die Wandpfosten eine zusätzliche Stützfunktion hatten (vgl. ZIMMERMANN 1992, 140). Die Pfosten der nördlichen Außenwand liegen noch $2-33 \mathrm{~cm}$ eingetieft vor, bei einer Häufung von $6-17 \mathrm{~cm}$. An der südlichen Außenwand ist bei den wenigen erhaltenen Pfosten eine Tiefe von $5-17 \mathrm{~cm}$ überliefert. Es überwiegen muldenförmige Pfostengruben, selten vertreten sind kasten- oder v-förmige.

Die meist nur ungenügend erhaltenen Längsseiten lassen kaum Aussagen über mögliche Zugänge zum Gebäude zu. Eventuell waren an der nordwestlichen Langseite die schräg eingetieften Doppelpfosten Kat.Nr. 933 und 934 gemeinsam mit einem sich außen befindlichen Pfosten Kat.Nr. 936 Teil einer Eingangssituation indem sie den Türbereich zusätzlich abstützten. Die Türbreite von $0,85 \mathrm{~m}$ ist für kaiserzeitliche Gebäude zwar recht schmal, kann jedoch noch bei rund 20\% der Häuser in Flögeln nachgewiesen werden, wobei Türbreiten zwischen $90-130 \mathrm{~cm}$ deutlich überwiegen (ZIMMERMANN 1992, 142-143).

Vom apsidenartigen Westgiebel sind sieben Pfostengruben erhalten (Kat.Nr. 1032; 1033; 1034; 1037; 1044; 1047; 1081). Zwei vorgelagerte Pfosten stellen möglicherweise Reparaturpfosten in der Giebelwand dar (Kat.Nr. 1030; 1045). Auf eine abgeteilte Kammer im Giebel weist eine nur 3,3m von der Giebelspitze entfernte Pfostenreihe hin (Kat.Nr. 1036; 1048; 1059; 1050).

Vom konvexen Ostgiebel sind fünf Pfostengruben und ein Wandgräbchen erhalten (Kat.Nr. 667-669; 677; 678; 721). Die Pfostentiefen variieren zwischen $2-23 \mathrm{~cm}$, wobei sie, mit einer Ausnahme, alle Holzkohlestücke enthielten. Im weiteren Verlauf sind die Giebelpfosten durch eine $260 \mathrm{~cm}$ breite runde Grube gestört. Auf eine Erweiterung des Ostgiebels in östliche Richtung weisen fünf vorgelagerte Pfosten, die einen 1,4m tiefen und $7 \mathrm{~m}$ langen, leicht nach außen gewölbten Bereich bilden (Kat.Nr. 696; 722, 727, 728, 738). Möglicherweise wurde später ein weiterer Vorbau ergänzt, der bis zu 3m vom eigentlichen Ostgiebel entfernt errichtet wurde. Auch diese Pfostenreihe zeichnet sich durch eine konvexe Wölbung aus (Kat.Nr. 664; 665; 672; 673; 676; 723-725; 736; 737). Die Anbauten erweiterten die Nutzfläche um etwa 16qm. 
Hinweise auf eine Binnengliederung geben drei schmale Wandgräbchen im Westteil des Gebäudes, die sich auf eine Länge von 112-172cm erhalten haben (Kat.Nr. 922, 923, 930). Die 26-28cm breiten Gräbchen lagen dicht beieinander, teils parallel, teils rechtwinklig und dienten eventuell dazu, einzelne Bereiche zu separieren.

Südlich des Hauses sind zwei Traufgräben (hausparallele Gräben mit muldenförmigen Querprofil) erhalten (Kat.Nr. 702; 836). Nach ihrer Entfernung von der Außenwand zu schließen ist der Dachüberstand mit 2-2,4m ungewöhnlich breit, wie ein Vergleich mit Flögeln zeigt, wo die Traufgräben durchschnittlich 1,5m von der Außenwand entfernt liegen (ZIMMERMANN 1986, 76).

23 Pfostengruben enthielten überwiegend kleinteilige Keramikscherben und datieren den Hausplatz III in das 2./3. Jahrhundert (Kat.Nr. 678, 681 (Taf. 41), 704, 709, 712, 717, 722, 767, 770, 776, 833, 917, 923, 925, 926, 929, 932, 934, 1035, 1045, 1056, 1060, 1072). Besonders fundreich war eine vermutlich zur Abfallentsorgung genutzte Grube in der nördlichen Ecke des Ostgiebels (Kat.Nr. 703). Insgesamt fanden sich 394 Keramikscherben, u.a. 42 Randscherben, 340 Wandungsscherben und 10 Flachböden. Kaiserzeitliche Scherben fanden sich auch in der zentralen Feuerstelle (Kat.Nr. 831). Vom leicht abgerundeten Ostgiebel haben sich zwei 1,5-1,7m lange und $15-30 \mathrm{~cm}$ breite Wandgräbchen erhalten (Kat.Nr. 721; 723), die beide kaiserzeitliche Keramik, u.a. kurz facettierte Randscherben enthielten. Auch die Traufgräben enthielten kaiserzeitliche Keramik mit lang ausbiegenden und kurz facettierten Rändern.

Insgesamt vermittelt der Hausplatz III einen, wenn auch stark gestörten, Eindruck eines kaiserzeitlichen Gebäudes und gehört nach TRIER $(1969,29)$ zur Gruppe der rechteckigen Langhäuser. Die gestörte Binnengliederung des Gebäudes lässt eine Interpretation nur unter Vorbehalt zu. Für den Ostteil ist eine dreischiffige Konstruktion wahrscheinlich, im Westbereich ist sie nur stark fragmentiert erhalten. Zur Datierung herangezogen werden können Keramikfunde aus den hausbegleitenden Gräben. Hier überwiegen kurze verdickte Ränder und wenige längliche parallelseitige Randformen. Eine kleine napfartige Schale mit seitlichen Griffzapfen datiert in das 1.-4. Jahrhundert n. Chr. (vgl. LeHMANN 2002, 50-51, Taf. 30, 20-10). Randscherben von Kümpfen sind nicht datierungsrelevant. Die stark fragmentierten Keramikscherben in den Pfostengruben datieren allgemein in die Kaiserzeit. Auf eine Datierung in die jüngere Kaiserzeit weisen neben der Dreischiffigkeit die Gebäudeausmaße, apsidenartige Schmalseiten und die im Giebel untergebrachten Kammern hin.

So erreichen Flögelner Häuser des 2./3. Jahrhunderts n. Chr. in Einzelfällen Längen von bis zu 61,2m, wobei sie durchschnittlich 38,7m lang sind (ZIMMERMANN 1992, 139). Während in Flögeln Gebäudelängen von 36-45m an 14 Gebäuden vorkommen, sind in vier Fällen auch Gebäudelängen von über $45 \mathrm{~m}$ anzutreffen. Ebenso verhält es sich mit der durchschnittlichen Gebäudebreite von 6,06m in Flögeln, bei einer Maximalbreite von 6,35m (ZIMMERMANN 1992, 139). In Brill sind bei 
Langhäusern Breiten zwischen 4,2-6,1m beobachtet worden, wobei oft längere Häuser in die späte Kaiserzeit datieren (LEHMANN 2002, 118, 155). Nachkaiserzeitliche Häuser sind in den Niederlanden breiter als Gebäude der vorausgegangenen Epochen (WATERBOLK 1982, 134).

Einen Hinweis auf eine späte Datierung gibt bei dem Nortmoorer Hausplatz III sein abgerundeter bis apsidenartiger Giebel. Abgerundete Schmalseiten sind kein ausschließliches Merkmal völkerwanderungszeitlicher Gebäude, sondern kommen bereits in jüngerkaiserzeitlichen Hausgrundrissen vor (BRABANDT 1993, 64). Derartige abgerundete Schmalseiten kommen bei kaiserzeitlichen Gebäuden regelhaft ab dem 3. Jahrhundert auf, während sie im 2. Jahrhundert noch sehr selten sind (BRABANDT 1993, 45-46).

Während im vorliegenden Fall bei dem Nortmoorer Haus III der Ostgiebel nur schwach gewölbt ist, fällt der apsidenartige Westgiebel auf. Gerundete Schmalseiten treten schon am älterkaiserzeitlichen Haustyp A I in Wijster auf (HAARNAGEL 1984b, 180). Auch älterkaiserzeitliche Häuser in BremenGrambke verfügen über ein apsidenartiges Hausende (BRANDT 1963, 397). Bereits bei ältereisenzeitlichen Gebäuden im niederländischen Elp finden sich ähnliche Konstruktionsmerkmale (HUIJTS 1992, 56, Fig 43, 61, Fig. 47) und auch im Harburger Raum weisen eisenzeitliche Hausgrundrisse leicht gerundete Schmalseiten auf (AHRENS 1974, 87).

Hausplatz III ähnelt den aus Bennekom als Haustyp A I oder A II vorgelegten kaiserzeitlichen Langhäusern. Ein dreischiffiges Haus mit abgerundeten Schmalseiten verfügt sogar, wie das Nortmoorer Haus II, über eine Gebäudebreite von 7m (VAN ES u.a. 1985, 546, Abb. 13).

Aus Brill ist für das Langhaus 10 anhand einer vorgelagerten Innenpfostenreihe eine Kammerbildung nahe dem Ostgiebel belegt (LEHMANN 2002, 105-106, Taf. 92, LH 10). Anhand der Befundvorlage ist nicht zu klären, ob das Gebäude eine abgerundete oder trapezförmige Schmalseite ausbildete. Das 24,5x5,6m große Gebäude wird gemeinsam mit dem durch eine trapezförmige Schmalseite charakterisierte Langhaus 12 dem Typ Wijster A zugeordnet, der in das 2. Jahrhundert $\mathrm{n}$. Chr. datiert (LEHMANN 2002, 154; vgl. WATERBOLK 1982, 104). BRABANDT $(1993,24)$ äußert sich kritisch zur Datierung des Typs Wijster A, zumal VAN Es als typischen Vertreter des Typs ein Wijster II A Gebäude (255-290 n. Chr.) anführt, jedoch nachvollziehbare Kriterien für seine Datierung nicht vorlegt.

Giebelseitig abgetrennte Kammern kommen erstmals im 2. Jahrhundert auf, häufiger sind sie jedoch an Gebäuden im 3. Jahrhundert zu beobachten (BRABANDT 1993, 46-48). Abtrennung von Giebelvorbauten, wie in Nortmoor beobachtet, finden sich auch bei Flögelner Langhäusern (Zimmermann 1992, 57, Abb. 27). So zeigt Haus 119 eine vorgesetzte Pfostenreihe am Ostgiebel, die zusätzlichen Stauraum schuf. Ein konvexer Westgiebel mit einer durch eine Pfostensetzung abgeteilten Innenstruktur gehört zu Haus 135 (ZIMMERMANN 1992, 87, Abb. 59). In Flögeln kommen 
die abgeteilten Räume am Hausende, hier als Vorbau bezeichnet, häufiger im Wohn- als im Stallteil vor (ZIMMERMANN 1992, 148).

Im Binnenland finden sich Häuser mit, wenn auch nur leicht, gerundetem Giebel im 3. Jahrhundert n. Chr., so in der Siedlung Soest-Ardey (HALPAAP 1994, 258, Abb. 75, 3). Noch in der völkerwanderungszeitlichen Siedlung Hjemsted Banke, auf der südlichsten Nordseeinsel Dänemarks, treten apsidenartige Schmalseiten bei Gebäuden auf (ETHELBERG 1988, 132, Abb. 12).

\subsubsection{Hausplatz IV}

Kat.Nr. 1132-1134; 1136-1138; 1141; 1142; 1176-1180; 1187-1200; 1203-1208; 1219-1223

Taf. 89

Am westlichen Ende der Grabungsfläche in den Quadranten 55/53 bis 36/37 ist der Grundriss eines bronzezeitlichen Gebäudes erhalten. Dem NNO-SSW orientierten Komplex können 37 Pfostengruben zugeordnet werden. Die Pfostengruben sind meist zwischen $6-35 \mathrm{~cm}$ eingetieft, im Mittel $10-16 \mathrm{~cm}$. Die Pfostenerhaltung fand sich weit unter dem ursprünglichen Laufhorizont. So sind flach eingetiefte Pfosten zumeist erodiert und der Grundriss ist nicht vollständig überliefert. Reste von Wandgräbchen oder von einer Feuerstelle fehlen. Die Pfostenbefunde sind verfüllt mit einem hellgrau bis hellbraungrauen Feinsand.

Die erhaltene Gebäudelänge beträgt 11,2m bei einer Gebäudebreite von maximal 5,6m. Im Norden ist die Schmalseite zwar nicht vollständig erhalten, es zeichnet sich jedoch ein halbrunder Hausabschluss ab. Der südliche Hausabschluss ist gerade ausgebildet und verfügte eventuell über einen Windschutz. Der Grundriss zeigt ein drei- bis vierschiffiges Gebäude mit annähernd gleichmäßig angeordneten Pfosten innerhalb der jeweiligen Schiffe. Vom westlichen Außenschiff sind sieben Außenpfosten, die einen Abstand von 1,4-2m untereinander ausweisen, überliefert (Kat.Nr. 1179; 1187; 1199; 1200; 1200; 1208; 1219). Die östliche Außenpfostenreihe ist mit fünf Pfostengruben erhalten, wobei die Pfosten zwischen 1-4m voneinander entfernt stehen (Kat.Nr. 1132; 1133; 1134; 1141; 1142). Im Süden des Hauses weisen beide Außenschiffe jeweils eine Breite von 1m auf, während sich der Abstand in der nördlichen Hälfte auf 1,5m erhöht. Das südliche Innenschiff ist 1-1,6m breit. Im Unterschied dazu verringert sich der Pfostenabstand im nördlichen Innenschiff auf 0,8-1m.

Es überwiegen runde Pfostengruben mit einem Durchmesser von $20-30 \mathrm{~cm}$. Während Reste von Standspuren nur einmal festzustellen sind (Kat.Nr. 1200), findet sich ein erhöhtes Aufkommen von v-, u- und kastenförmigen Pfostengruben (Kat.Nr. 1141; 1142; 1176; 1177; 1187; 1189; 1190; 1192; $1195 ; 1200 ; 1202 ; 1203 ; 1219-1222)$, wobei die meisten Pfosten eine eckig-ovale Planumsform aufweisen.

Die Pfosten der Außenwand sind in ihrer Längserstreckung zwischen 1,2-3m voneinander entfernt, so dass davon auszugehen ist, dass einige Pfostengruben nicht überliefert sind. Vergleiche weisen bei 
ähnlichen Bauten auf einen einheitlichen Pfostenabstand von 1-1,2m hin (KrEIBIG 2006, 26, Abb. 4). Relativ regelhaft verteilt sind die Pfostenstellungen im Gebäude selbst. Deutlich zeigt sich eine Dreiteilung in einen dreischiffigen „Vorbau“ mit einer Grundfläche von 6qm, einen vierschiffigen Mittelteil mit relativ enger Pfostenstellung (8,5qm) und einen größeren Wohnbereich mit 12,5qm.

Der halbrunde Giebel wird 2,5qm Platz geboten haben. Die abgerundete Giebelform deutet auf einen ursprünglich abgewalmten Giebel hin. Für den geraden Hausabschluss der südlichen Schmalseite kann ein Steilgiebel rekonstruiert werden (Kat.Nr. 1142; 1176; 1177; 1208). Pfostengrube Kat.Nr. 1180 ist um $1 \mathrm{~m}$ südlich versetzt; seine Lage deutet auf einen Windschutz oder ein kleines Vordach hin (vgl. KREIBIG 2006, 37).

Einzelne „Ausreißer“ in der Pfostenstellung finden sich im südlichen Innenschiff. Derartige Abweichungen können ein Hinweis auf Reparaturphasen sein oder sind durch Verwendung von ungleichem Baumaterial entstanden. Von der südlichen Schmalseite sind vier Pfostengruben mit kastenförmigem Profil und 16-20cm Tiefe überliefert (Kat.Nr. 1142; 1176; 1177; 1208). Der Abstand der Pfosten innerhalb einer Pfostenreihe ist nicht regelhaft. Im Nordbereich des Gebäudes liegen Abstände von 1,6m vor. Im mittleren Gebäudeteil ist eine Häufung von eng stehenden Pfosten mit Abständen von 0,8-1,6m zu beobachten, während im Südteil eine Pfostendistanz von meist $1 \mathrm{~m}$ anzutreffen ist. Die Pfostentiefen innerhalb der Pfostenreihen zeigen keine einheitlichen Werte auf. Sowohl Innen- wie auch Außenpfosten können Profiltiefen von bis zu $35 \mathrm{~cm}$ aufweisen. Die Pfostentiefen der westlichen Außenpfostenreihe reichen von 10-35cm (Mittelwert $18 \mathrm{~cm}$ ), die der östlichen Außenpfostenreihe von 4-20cm (Mittelwert 13cm).

Hinweise auf Viehboxen fehlen bzw. zeichnen sich im vorliegenden Grundriss nicht mehr ab. Für eine Aufstallung würde sich am ehesten der Gebäudemittelteil eignen. Bei vergleichbaren Grundrissen werden in diesem Bereich an den Längsseiten zwei gegenüberliegende Eingänge rekonstruiert (vgl. BÄRENFÄNGER 1998b, 32; KREIBIG 2006, 27).

Doppelpfosten finden sich im Bereich der Außenwänden an beiden Hauslängsseiten (Kat.Nr. 1133/1134; 1179/1208), wie auch im Mittelschiff (Kat.Nr. 1136/1137; 1138/1194; 1188/1189; 1191/1192). Im südlichen Innenschiff sind Doppelpfostenstellungen als regelhafte Querriegel zu beobachten (Kat.Nr. 1138/1194; 1188/1189/1190; 1191/1192). Sie sind diagonal versetzt und weisen zueinander einen Abstand von 0,4-0,7cm auf. Bei Kat.Nr. 1190 wird es sich vermutlich um einen nachgesetzten Reparaturpfosten handeln, da er unweit südlich von Kat.Nr. 1188 gesetzt ist. Eine Dreier-Pfostenstellung findet sich vor dem Nordgiebel (Kat.Nr. 1220/1221/1222).

Leider liegen aus den Pfostengruben kaum datierbare Funde vor. Aus der Pfostenverfüllung Kat.Nr. 1221, nahe am Nordgiebel stammt ein horizontal abgestrichenes Randfragment, das dem HB Typ 4 entspricht und mit PP IV E zu parallelisieren ist (LÖBERT 1982, 93). HK-Fragmente finden sich nur in Pfostengruben der östlichen Außenseite. 
Aus den Niederlanden und Deutschland liegen für die zeitliche Einordnung des Hausgrundrisses mehrere vergleichbare Gebäudekomplexe vor. Vierschiffige bronzezeitliche Grundrisse vom Typ Emmerhout aus der Provinz Drenthe zeigen auffällige Analogien zu dem Nortmoorer Hauskomplex auf. Der west-ost-orientierte Hausgrundriss aus Nijnsel weist einen geraden Hausabschluss im Westen und eine gebogene Giebelfront im Osten auf (HUITS 1992, 46-47, Fig. 34). Die Seitenschiffe sind mit 0,7-1,25m meist ebenso breit wie bei Hausplatz IV. Ein hier festgestellter maximaler Pfostenabstand von $1,5 \mathrm{~m}$ wird möglicherweise durch einen nicht erhaltenen Pfostenbefund zu begründen sein.

Im Unterschied zu bronzezeitlichen Gebäuden aus dem niederländischen Nijsel, wo Distanzen von 1,55-2,55 und 3,60-3,90m vorliegen, sind in Nortmoor die Mittelschiffe oft nur 1-1,4m breit. Lediglich im Südteil finden sich Abstände von bis zu 3m. Für Nijsel konnte zudem eine Feuerstelle innerhalb der westlichen Haushälfte festgestellt werden, deren Umfeld pfostenfrei war. Die regelhafte Unterbrechung der Pfostenstellung findet sich auch bei dem Nortmoorer Grundriss im Bereich des geraden Hausabschlusses, jedoch gibt es hier keinen Anhaltspunkt auf eine Feuerstelle. Der aus Angelsloo stammende Grundriss 19 zeigt eine vierschiffige Konstruktion mit beidseitig abgerundeten Schmalseiten und wird in die mittlere Bronzezeit datiert (HuITs 1992, 48-49, Fig. 37).

Die in Nortmoor auffällige Doppelpfostenstellung findet sich bereits bei Gebäuden in Hijken. Der vollständig erhaltene Grundriss 5 weist eine Länge von etwa $34 \mathrm{~m}$ und eine Breite von 5,6m auf (HuITs 1992, 38-39, Fig. 25). Die Außenpfosten bestehen regelhaft aus eng stehenden Doppelpfosten. Während zum Nordgiebel hin eine enge Pfostenstellung zu beobachten ist, ist die südliche Gebäudehälfte durch einen größeren freien Raum gekennzeichnet.

Auch im ostfriesischen Nenndorf finden sich Parallelen zum Nortmoorer Bau. Hausgrundriss 1 verfügt sowohl über einen gerundeten Hausabschluss an der einen Schmalseite wie einen geraden Giebel an der gegenüberliegenden Seite (KreIBIG 2006, 27, Abb. 4). Eng stehende Doppelpfosten, wie sie in Nortmoor zu beobachten sind, fehlen jedoch. Vom gleichen Fundplatz stammt ein 30x6,7-7m großes Gebäude mit einem dreischiffigen Grundriss, der regelhaft über doppelte Außenpfosten verfügte (KreIBIG 2006, 36-41, Abb. 23). Die Gebäude werden in die mittlere Bronzezeit datiert, wobei Hausgrundriss 1 möglicherweise schon als eisenzeitlich angesprochen wird (KREIBIG 2006, 29).

Bronzezeitliche Gebäude aus Hesel im Landkreis Leer zeigen vergleichbare Konstruktionsmerkmale. Haus 1 bis 3 zeichnen sich durch eine meist regelhafte Doppelpfostenstellung aus, die sowohl an den Außenschiffen wie im Mittelschiff anzutreffen sind (SCHWARZ 1996, 21-50). Das 34x6,8m große Haus 2 besitzt abgerundete Schmalseiten und datiert nach der ${ }^{14} \mathrm{C}$ Methode in die mittlere Bronzezeit (1520-1395 cal B.C.; BÄRENFÄNGER 1999b, 33). Während bei dem NW-SO orientierten Haus der NW-Teil dreischiffig vorliegt, ist die südöstliche Hälfte zweischiffig. Auch hier findet sich die auffällige Doppelpfostenstellung in den Außenwänden. 
Bei Haus 3 in Hesel ist zudem die bereits am Nortmoorer Hausplatz IV festgestellte leicht diagonal verschobene Stellung der Pfosten gut erkennbar (BÄRENFÄNGER 1999b, 34, Abb. 28). Auch Haus 3 in Nenndorf besitzt doppelte Außenpfostenreihen, die dort jedoch meist parallel angeordnet sind (KREIBIG 2006, 36-43, Abb. 23). Der Grundriss des Gebäudes wird nach Übereinstimmungen mit Grundrissen in Hesel und Hijken ebenfalls in die mittlere Bronzezeit datiert. Die durchgeführte Phosphatanalyse auf dem Hausplatz 3 weist im Ostteil des Gebäudes eine Konzentration von 300 ppm P. auf, die nach KREIBIG jedoch nicht als Hinweis auf eine Stallfunktion gewertet werden kann (KreiBig 2006, 42). Nach Schwarz (mündl. Mitteilung 2008) liegt Hausplatz 3 direkt südlich eines kaiserzeitlichen Hauses, so dass der Phosphat-Eintrag vermutlich zu einem späteren Zeitpunkt erfolgte.

\subsubsection{Hausplatz V}

Kat.Nr.: 292-295; 303; 304; 306-309; 338-342

Taf. 90

Die Reste eines weiteren Hauses finden sich an der östlichen Grabungsgrenze nahe der Dünenkuppe in den Quadranten 47/48 bis 54/55. Die Geländeoberfläche steht zwischen $+1,40$ bis $+1,44 \mathrm{~m} \mathrm{NN}$ an.

Erhalten haben sich die Schmalseiten des Gebäudes und wenige Pfostengruben aus dem Mittelteil. Der NNW-SSO orientierte Hausplatz weist eine Länge von wenigstens $11,8 \mathrm{~m}$ und eine Breite von 4,5m auf. Das Befundsubstrat besteht aus hellgrau-hellbraunem Sand.

Der Grundriss liegt stark fragmentiert mit nur 15 Pfostengruben vor, so dass eine Rekonstruktion unter Vorbehalt erfolgt. Die Grundrissform, wie die charakteristisch ausgeformten Giebelseiten, die Gebäudegröße und -orientierung weisen einige auffällige Analogien mit Haus IV auf, so dass es sich wohl ebenfalls um die Reste eines urgeschichtlichen Gebäudes handelt.

Vom konvexen Nordgiebel haben sich vier Pfostengruben, die in Abständen von 0,9-1,1m gesetzt sind, erhalten (Kat.Nr. 338-341). Sie sind im Planum 20x20cm bis $24 \times 20 \mathrm{~cm}$ groß und $8-18 \mathrm{~cm}$ eingetieft. Die leicht gerundete Form des Hausendes weist auf einen Walmgiebel hin.

Vom Außenschiff sind sieben Pfostenbefunde überliefert (Kat.Nr. 304; 306; 307; 309; 342; 292; 295). In einem Fall ist eine doppelte Außenpfostenstellung belegt (Kat.Nr. 307). Trotz der nur rudimentären Erhaltung der äußeren Pfosten kann an zwei Stellen ein Abstand zwischen den Pfosten mit 0,8-1,2m angegeben werden.

Vom Mittelteil des Gebäudes sind nur zwei Innenpfosten (Kat.Nr. 303; 308) und vier Außenpfosten überliefert (Kat.Nr. 304; 306; 307 (Doppelpfosten)). Vom gerade abgeschlossenen Südgiebel haben sich vier Pfosten erhalten (Kat.Nr. 292-295). Die Pfosten der Schmalseite sind über die gesamte Gebäudebreite von 4,8m überliefert und weisen einen regelhaften Abstand von 1,1m auf. Sie verfügen wie die Pfosten des Nordgiebels über eine quadratische Pfostenform $(25 \times 25 \mathrm{~cm})$, sind aber nur bis in eine Profiltiefe von maximal $5 \mathrm{~cm}$ überliefert. Möglicherweise handelte es sich bei dem fast doppelt so 
großen (Kat.Nr. 292) um einen Reparaturpfosten.

Im Mittelteil sind Doppelpfosten mit einem Durchmesser von 39x21 cm und 28x25cm (Kat.Nr. 307) überliefert. Der im Schnitt muldenförmige Pfosten war noch $6 \mathrm{~cm}$, der v-förmig eingetiefte $13 \mathrm{~cm}$ tief erhalten. Pfostenbefunde die weiter südlich sind, zeichneten sich nur noch schwach im Planum ab. Keramikfunde liegen aus den Pfostengruben des Hausplatzes V nicht vor. Nicht dem Gebäude zugehörig ist der Pfostenbefund Kat.Nr. 305, der eine kleihaltige Füllschicht aufweist und aufgrund seines Fundmaterials in die römische Kaiserzeit datiert.

Eine Zuordnung des stark gestörten Gesamtbefundes kann nur unter Vorbehalt erfolgen. Die 15 erhaltenen Pfosten des Gebäudes weisen jedoch aufgrund ihrer signifikanten Stellung in die Bronzezeit bzw. vorrömische Eisenzeit. Die sich im Grundriss recht gut abzeichnenden Gebäudeschmalseiten mit einem konvexen und einem geraden Abschluss, die für derartige Bauten kennzeichnende Doppelpfostenstellungen und auch die Ausmaße des Hauses entsprechen Gebäuden dieses Zeithorizontes. Eine Dreischiffigkeit des Gebäudes ist trotz mangelhafter Erhaltung denkbar, wenn man die wenigen Pfostengruben im Gebäudemittelteil mit den in Flucht liegenden Giebelpfosten verbindet. Ebenso wie bereits bei Haus IV beobachtet, zeigen die Füllungen der Pfostenbefunde eine auffällig feinsandige Konsistenz und zeichnen sich im gewachsenen Boden nur schwach mit einer blass hellgrauen Substratfarbe ab. Sowohl Hausplatz IV und V sind auf dem Dünenkamm errichtet worden.

\subsubsection{Hausplatz VI}

Kat.Nr. 1129-1131; 1143-1162

Taf. 91

Im nordwestlichen Randbereich der Düne findet sich in den Quadranten 54/37 und 55/37 ein NNOSSW ausgerichtetes Gebäude, dem auf einer Grundfläche von 6,1x2,5m noch 23 Pfostengruben zuzuordnen sind. Es handelt sich um eine einschiffige Konstruktion. Aus der näheren Umgebung liegen keine weiteren dem Bau zugehörigen Pfostenbefunde vor.

Die östliche Außenpfostenreihe besteht aus acht Pfosten (Kat.Nr. 1143-1150), der westlichen gehören sieben Pfostengruben an (Kat.Nr. 1154-1160). Im südlichen Bereich sind die Längsseiten 2m voneinander entfernt, im nördlichen Teil bis zu 2,5m. Während die Pfosten meist eng gesetzt sind (0,4-1m), findet sich im nördlichen Gebäudeteil zu beiden Seiten eine Unterbrechung von 1,5m, bei der es sich möglicherweise um einen Durchgang handelte. Hinweise auf Türpfosten in diesem Bereich geben zwei $80 \mathrm{~cm}$ der Westseite vorgelagerte Pfostengruben (Kat.Nr. 1161; 1162). Doppelte Außenpfosten sind in drei Fällen überliefert (Kat.Nr. 1146/1147; 1149/1150; 1159/1160). 
An der SSW-Schmalseite zeichnet sich eine leicht konvexe Außenwand ab (Kat.Nr. 1129; 1130). Der Gebäudeabschluss der gegenüberliegenden Schmalseite ist nicht überliefert. Die Pfostengruben sind im Planum rund bis eckig geformt. Ihre Größe reicht von 20x20cm bis 70x40cm, im Mittel 25x30cm. Die Profiltiefe der meist kastenförmigen bis zylindrischen Gruben liegt zwischen 9-34cm, regelhaft bei $19-31 \mathrm{~cm}$. Relativ einheitliches Bodensubstrat verfüllte die Pfostengruben mit grauem Klei oder grauem tonigen Sand. Das Fundmaterial in vier Pfostengruben besteht aus kleinteiligen und grob gemagerten Wandungsscherben, die oxidierend gebrannt sind. Funktionsbestimmende Funde fehlen.

Der vorliegende Grundriss weist auf ein einschiffiges Gebäude hin. Ähnliche Häuser kleineren Ausmaßes kommen im freien Germanien in der gesamten Kaiserzeit vor. Sie erreichen zumeist Längen von 4-9m, können im Einzelfall bis zu 18m lang sein (BRABANDT 1993, 31-32). Eine Gebäudebreite, wie im vorliegenden Fall, von maximal 2,5m ist recht selten, jedoch für Bauten dieses Typs nicht ungewöhnlich. So ist für die Siedlung Nebel in Nordfriesland ein nur 5,8x2,5m großes Gebäude belegt (HINGST 1987, 90, Abb. 10).

Parallelen zum Nortmoorer Komplex finden sich auch im dänischen Vorbasse (HVASS 1978, 79. Fig 9). Ebenso wie Haus VI in Nortmoor besitzt dieses 7,8x4m große Gebäude abgerundete Schmalseiten und eine Doppelpfostenstellung an den Gebäudeecken sowie im Mittelteil. Aus Wijster liegt ein einschiffiges kleines Gebäude mit abgerundetem Ost- und gerade ausgebildetem Westgiebel vor, welches in den Zeitraum von 255-290 n. Chr. datiert (VAN Es 1967, Fig 32, 365). VAN Es (1967, 384) bezeichnet derartige Bauten als Kleinhäuser und geht bei ihnen aufgrund festgestellter Feuerstellen im Gebäude von einer Wohnraumnutzung aus.

Während in Wijster durchschnittliche Gebäudelängen von $8,52 \mathrm{~m}$ beobachtet wurden, sind die einschiffigen Gebäude aus Flögeln durchschnittlich 5,12m lang. Die dortigen Kleingebäude besitzen zumeist einen rechteckigen Grundriss. Leicht abgerundete Schmalseiten hat das 6x2,5m große Haus 100 in Flögeln (ZIMMERMANN 1992, 91, Abb. 63, H 100). Die als Nebengebäude bezeichneten Bauten datieren in die 2. Hälfte des 5. bis 1. Hälfte des 6. Jahrhunderts (ZIMMERMANN 1992, 103-104).

\subsubsection{Grubenhaus}

Kat.Nr. 215; 216; 217; 219; 233; 234; 236-238

Taf. 92

Ein mögliches Grubenhaus findet sich nahe der östlichen Grabungskante in den Quadranten 55/51 bis 55/52. Der Komplex liegt auf der Dünenkuppe bei einer NN Höhe von $+1,66 \mathrm{~m}$ direkt an der Abbruchkante der Teichanlage. Von Nord nach Süd steigt das Geländeniveau von $+1,36 \mathrm{~m}$ auf $+1,71 \mathrm{~m}$ $\mathrm{NN}$ an. Aus der näheren Umgebung liegt keine Wohnbebauung vor. 20m südlich, auf der dem Fluss zugewandten Dünenseite, befindet sich die kaiserzeitliche Wasserstelle Kat.Nr. 195. Das Grubenhaus 
wurde während der Ausgrabung nicht erkannt. Eine Profilzeichnung liegt als Umzeichnung des Grabungsfotos vor.

Der grubenhausförmige Befund besitzt die Maße von maximal 4,5/3,5x3,5/2,8m. Im Planum A1 zeigt sich eine oval-eckige Verfärbung (Kat.Nr. 216). Der Nordbereich des Grubenhauses ist weniger klar abgegrenzt und erscheint eher eckig-abgerundet mit einem Annex im NO. Für die Flächenberechnung wurde deshalb ein Durchschnittsmaß von 2,8x3,5m (9,8qm) verwendet. Der errechnete LängenBreiten-Index beträgt 1:1,25 und weicht nur unwesentlich vom durchschnittlichen Index von Flögelner Grubenhäuser ab (ZIMMERMANN 1992, 185). Die Größe Briller Grubenhäuser liegt mit durchschnittliche 9qm (LEHMANN 2002, 158) nur unwesentlich über dem Nortmoorer.

Die Eintiefung des Grubenhauses ist nicht einheitlich, sondern schwankt zwischen $60-80 \mathrm{~cm}$. Richtung Süden flacht die Grube auf eine Stärke von $50 \mathrm{~cm}$ ab. Im Profil zeigt sich eine mulden- bis kastenförmige Grube. Die Grubenfüllung besteht aus einer unteren Schicht grob durchmischten, hellweißen und braunen Sandes, worüber eine Einfüllung mit graugrünem Klei folgt. Eine von Süden schräg in die Grube einlaufende und etwa $2-4 \mathrm{~cm}$ starke Holzkohleschicht überbedeckt die unteren Bodenschichten. Die relativ hoch liegende Brandschicht gelangte erst dann in die Grube als diese weitgehend verfüllt war. Abschließend deckt eine Klei-Sand-Schicht die Grubenverfüllung ab.

Innerhalb des Grubenhauses finden sich eingetiefte Pfostengruben, die erst beim Abtrag des Planums entdeckt wurden. Die Pfostengruben sind an den abgerundeten Ecken und den Seiten randlich der Grube Kat.Nr. 216 eingetieft worden (Kat.Nr. 233: 234; 236, 237; 238). Weitere Pfostengruben liegen $10 \mathrm{~cm}$ (Kat.Nr. 215; 219) und 50cm (Kat.Nr. 217) außerhalb des Grubenhauses. Aufgrund ihrer räumlichen Nähe, ihrer Größe und ihres Verfüllmaterials besteht möglicherweise ein Bezug zum Gebäude.

Innerhalb des Grubenhauses beträgt der Abstand der Pfosten zueinander zwischen 0,7-2m. In mehreren Fällen ist ein regelhafter Abstand von 0,7-1m festzustellen. Weitere Pfosten an der Ostseite des Grubenhauses sind wahrscheinlich, jedoch durch die nahe Abbruchkante der Teichanlage nicht überliefert. Reste einer Firstpfostenreihe wurden nicht dokumentiert.

Der Umfang der eckig bis eckig-rundlichen Pfosten liegt nahezu einheitlich zwischen $35 \times 20 \mathrm{~cm}$ und $35 \times 25 \mathrm{~cm}$. Auffällig ist das Aufkommen von kasten- und u-förmigen Pfostengruben (Kat.Nr. 215; 234; 236; 237; 238). Recht unterschiedlich sind hingegen die Eintiefungen der Pfosten, die zwischen 4 $50 \mathrm{~cm}$ liegen und im Mittel 19-35cm betragen. Die tiefsten erhaltenen Pfostengruben befinden sich in der NO- und SSW-Seite des Grubenhauses. Möglicherweise zum Grubenhaus zugehörig sind drei Pfostengruben, die nur wenige Dezimeter $(10-50 \mathrm{~cm})$ von der Osthälfte entfernt liegen (Kat.Nr. 215; 217; 219). Knapp außerhalb des eigentlichen Grubenhauses liegende Pfosten sind keinesfalls ungewöhnlich (ZIMMERMANN 1992, 177, GH 46; 183, GH 41). 
Der oval-eckige Umriss und die randlichen Pfostengruben weisen Parallelen mit Grubenhäusern in Flögeln auf (vgl. ZIMMERMANN 1992, 175, Abb. 136, GH 120). Da die Befundlage an der Westseite des Hausplatzes V durch die nahe Grabungskante gestört ist, könnte es sich eventuell um ein Grubenhaus vom 6-Pfosten-Typ gehandelt haben (vgl. ZIMMERMANN 1992, 179, GH 129-A). Bei dem vorliegenden Gebäude ist auch eine Ansprache als Wandpfostenhaus denkbar (ZIMMERMANN 1992, 178, GH 96). In beiden Fällen handelt es sich um dachtragende Wandpfosten, die eine einschiffige Konstruktion bilden. Die Eckpfosten der 6-Pfosten-Konstruktion stützten vermutlich ein Sparrendach, während die Giebelpfosten die Rahmenkonstruktion trugen oder als Firstpfosten dienten.

Der hohe Fundanteil an Keramikscherben (n=997) ist keinesfalls unüblich für Grubenhäuser und deutet im vorliegenden Fall auf eine sekundäre Nutzung als Abfallgrube hin. Aus der Grubenverfüllung stammen des weiteren drei Terra Nigra Scherben, 1/2 Tonperle und zwei Granitsteine. Vermutlich gelangten die Funde erst nach Auflassung des Gebäudes in die Grube. Sie geben keinen Hinweis auf die Nutzung des Grubenhauses.

Grubenhäuser gelten allgemein als traditionelle Produktionsorte für Textilien. Funde von Webgewichten sind daher zu erwarten (vgl. TRIER 1969, 36), fehlen aber in Nortmoor ebenso wie in Brill (LEHMANN 2002, 55).

Auch sind keine Längsgruben, wie sie aus anderen Grubenhäusern vorliegen und dort in einem konstruktiven Bezug zu ehemals aufgestellten Gewichtswebstühlen gestellt werden, beobachtet worden. Möglicherweise diente das Nortmoorer Grubenhaus als Speichersilo für Getreide oder andere landwirtschaftliche Produkte. In Grubenhäusern in Flögeln fand man verkohlte Getreidereste, die auf eine Lagerung hinweisen (ZimMERMANN, 1992, 216). Noch bis Mitte des 19. Jahrhunderts sind in osteuropäischen Ländern Grubenhäuser in Art eines Erdsilos u.a. als Werkstatt oder Lageraum genutzt worden (ZIMMERMANN 1992, 186, 211).

Um eingetiefte Arbeits- und Vorratsräume zu errichten, boten sich in der Flussmarsch Bereiche auf Geestdurchragungen oder Sanddünen an. So wurde in Nortmoor auf dem am höchsten gelegenen Dünenteil das Grubenhaus angelegt. Wie ein Vergleich mit der Höhenlage kaiserzeitlicher Brunnen zeigt, herrschte in dieser Sieldungsphase ein relativ niedriger Grundwasserstand, der nicht die Sohle des Grubenhauses erreicht haben dürfte. Grubenhäuser liegen ansonsten eher in Geestsiedlungen vor, während sich die niedere Marsch aufgrund ihres hohen Grundwasserstandes nicht zur Anlage von Grubenhäusern eignet.

In der römischen Kaiserzeit und Völkerwanderungszeit sind 2-Pfosten- und 6-Pfosten-Grubenhäuser weit verbreitet. Zumeist überwiegen in den Siedlungen Grubenhäuser mit 6 und mehr Pfosten, so in Wijster und Bremen-Mahndorf (VAN Es 1967, 78, Fig. 37-117; BRANDT 1969, 62). In Flögeln gehören nur 1/3 der Grubenhäuser dem 6-Pfosten-Typ an (ZIMMERMANN 1992, 158). Erste Anlagen sind für 
das 1. Jahrhundert belegt, meist kommen sie jedoch erst im ausgehenden 2. Jahrhundert auf. Für die Feddersen Wierde konnten sie im 3. Jahrhundert im Siedlungshorizont 5 festgestellt werden (HAARNAGEL 1979, 109-112). In Brill wurden 31 Grubenhäuser aufgedeckt, doch nur Grubenhaus 2184 mit seiner 5-Pfostensetzung ähnelt dem Nortmoorer Bau (LEHMANN 2002, 158-162, Taf. 112). Auch hier liegen zwei Pfostengruben knapp außerhalb des Gebäudes. Diese waren tiefer als die Grube eingetieft, was in Nortmoor nicht der Fall ist. Während in Brill drei Grubenhäuser durch Fibelfunde in die Zeit zwischen 400 bis Mitte des 5. Jahrhunderts datiert sind, streuen die übrigen Funde über einen großen Zeitraum in der römischen Kaiserzeit (LEHMANN 2002, 161).

\subsubsection{Speicherbauten}

Bei Speicherbauten variiert die Anzahl der Pfostensetzungen zwischen 4 und 20 Pfosten (ZIMMERMANN 1992, 244). Gestelzte Speicher sind in Siedlungen weit verbreitet, wobei 4- bis 6Pfostenspeicher meist häufiger anzutreffen sind als Speicher mit 9, 12 oder mehr Pfosten (MÜLLERWILlE 1977, 166). Obertägige Speicherbauten dienten vermutlich überwiegend zur Aufbewahrung von Saatgetreide (ZIMMERMANN 1992, 243). Im Unterschied dazu lagerte man in Rutenbergen ungedroschenes Getreide, Gras oder Laubheu.

Aus Nortmoor ist eine Reihe von gestelzten Speicherbauten verschiedener Bautypen bekannt, die über das gesamte Siedlungsareal verteilt sind. Vorwiegend befinden sich die Speicherbauten jedoch unmittelbar neben den Wohnbauten. In unmittelbarer Nähe zum Hausplatz II haben sich die Pfostenbefunde von je einem 12-, 9- und 6-Pfostenspeicher erhalten. Zwei 4-Pfostenspeicher liegen nur $5 \mathrm{~m}$ vom Gebäude entfernt. Auch Hausplatz III können ein 4- und zwei 6-Pfostenspeicher zugeordnet werden.

Während sich zwischen Speichern und Gebäuden der kaiserzeitlichen Siedlung Nortmoor allein schon aufgrund ihrer räumlichen Nähe ein Bezug herstellen lässt, ist dies für die mittelalterlichen Rutenberge nicht der Fall. Ihre zeitgleiche Wohnbebauung fehlt bzw. erstreckte sich auf dem bereits in den 60er Jahren des 20. Jahrhunderts zerstörten Ostteils der Nortmoorer Düne.

Auch 3- und 4-Pfostenspeicher liegen in Nortmoor vor. Ihre einfache Bauweise aus drei bis vier eingetieften Pfosten erschwert eine eindeutige Ansprache und dies insbesondere dann, wenn sie nicht separat liegen, sondern in einer Häufung von umgebenden Pfostenbefunden (vgl. ZIMMERMANN 1992, 229).

Um es bei der großen Anzahl an Pfostenbefunden zu vermeiden, Pfostenspeicher frei zu konstruieren (vgl. VAN Es 1967, 87), werden nur nachvollziehbare Speichergrundrisse vorgelegt. Bei Speicherbauten wird von einer gewissen Regelmäßigkeit der Pfostengrößen, Maximalabständen der 
Pfostengruben zueinander und einer nicht zu großen Abweichung der Pfostentiefe ausgegangen. Darüber hinaus ergeben sich sicherlich weitere Pfostenspeicher, die jedoch aufgrund von Störungen u.a.m. nicht mehr im Siedlungsareal erkennbar sind.

\subsubsection{Gestelzte Pfostenspeicher}

\section{2-Pfostenspeicher}

Speicher 1, Kat.Nr. 470a-m

Speicher 2, Kat.Nr. 142; 143; 145; 146; evtl.152; 153; 155; 157; 157a; 158a; evtl. 144, 149 und 175

Taf. 93

Einer der größten gestelzten Speicher (SP 1) in Nortmoor fand sich im zentralen Bereich der Grabungsfläche in den Quadranten 53/45 bis 54/45. Das Geländeniveau steigt von West nach Ost von $+1,48 \mathrm{~m}$ NN auf $+1,56 \mathrm{~m} \mathrm{NN}$ an. Etwa $2 \mathrm{~m}$ südöstlich lag der Hausplatz II.

Dem sich gut im Planum A1 abzeichnenden 12-Pfostenspeicher gehören die Pfostengruben Kat.Nr. 470a bis 470m an. Eine bemerkenswerte Regelmäßigkeit zeichnet die Pfostensetzung des Speichers 1 aus. Die 12 Pfostengruben ordnen sich zu drei Reihen von je 4 Pfosten. Da der Speicher isoliert steht, ist er eindeutig anzusprechen. Es handelt sich um einen einphasigen Speicherbau und es sind, mit Ausnahme der möglichen Doppelpfosten Kat.Nr. 470k und 4701, keine Reparaturstellen erkennbar. Der Speicher ist west-ost-orientiert und die Pfosten sind regelmäßig angeordnet. Der Pfostenabstand der N-S Achse beträgt 1,8-2m, in der W-O Achse 1-1,2m.

Die Pfostengruben des Speichers sind im Planum A1 meist rund bis oval (Kat.Nr. 470a,b,e,g,k,l,m), seltener eckig (Kat.Nr. 470c,d,f,h). Es überwiegen kastenförmig-zylindrische Profile (Kat.Nr. 470,a,b,c,d,g,i,k,m), neben muldenförmigen (Kat.Nr. 470,e,f,h,l). Relativ einheitlich sind die Durchmesser der Pfostengruben, die von $22 \times 24 \mathrm{~cm}$ bis $33 \times 39 \mathrm{~cm}$ (bzw. $40 \mathrm{~cm})$ reichen. Die erhaltenen Pfostentiefen sind mit $5-28 \mathrm{~cm}$ recht flach. Standspuren mit Tiefen von $12-20 \mathrm{~cm}$ fanden sich in fünf Pfostengruben (Kat.Nr. 470d,g,h,k,l).

Sämtliche Gruben sind einheitlich mit hellgrauem Klei-Sand-Gemisch verfüllt. Einige weisen Holzkohlereste auf (Kat.Nr. 470a,b,g). Nur aus wenigen stammen Keramikfunde. Neben einer hellgelben, hart gebrannten Wandungsscherbe, vermutlich provinzialrömischer Import, handelte es sich um stark fragmentierte kaiserzeitliche Scherben.

Mit seiner Grundfläche von 12qm entspricht er der oberen Größenklasse dieses Typs bei Speichern in Flögeln, die zwischen 8,4-12,42qm groß sind (vgl. ZIMMERMANN 1992, 241). SP 31 hat zwischen den Pfosten seiner 4er-Reihe einen geringeren Abstand als zwischen den 3er-Reihen und gleicht damit dem Nortmoorer 12-Pfostenspeicher (ZIMMERMANN 1992, 238, Abb. 185, SP 31). 12-Pfostenspeicher sind relativ selten in Siedlungen anzutreffen. Unter den 132 Speichergrundrissen in Flögeln gehören lediglich fünf diesem Typ an. 
Ein aus 12-Pfosten bestehender Speicherbau (SP 2) befand sich wenige Meter südlich der Teichanlage im Quadranten 53/52. Erhalten sind von dem 3,8x4,3m großen Speicher 12 Pfostengruben. Die Pfostenabstände sind in der 3er- und 4er-Reihe unterschiedlich. Während die Pfosten der N-S-Achse 1-1,1m von einander entfernt sind, erhöht sich der Abstand in der O-W-Achse auf $2 \mathrm{~m}$.

Im Planum A1 sind die Pfostenbefunde eckig bis oval mit einem Durchmesser von $28 \mathrm{~cm}$ bis $36 x 55 \mathrm{~cm}$ (im Mittel 35cm). Die u- bis muldenförmigen Pfostengruben sind zwischen 20-40 cm (im Mittel 27$33 \mathrm{~cm}$ ) eingetieft. In sechs Pfostengruben haben sich Standspuren mit einer Tiefe von bis zu $23 \mathrm{~cm}$ erhalten. Die beiden östlichen Pfostengruben Kat. 142 und 143 stehen in Flucht zu den westlich angrenzenden Pfostengruben und auch ihr Abstand entspricht dem zwischen Bef. 146 und Kat.Nr. 153, so dass sie dem Speicher zugerechnet werden können. Bei dem Doppelpfosten Kat.Nr. 157/157a wird es sich vermutlich um eine Reparaturstelle gehandelt haben. Der Flächeninhalt des Nortmoorer Speichers beträgt wenigstens $15,96 \mathrm{qm}$ und ist damit nur unwesentlich größer als der von 12Pfostenspeichern in Flögeln (ZIMMERMANN 1992, 241).

Eventuell stellen die an der Westseite des Speichers liegenden Pfostengruben (Kat.Nr. 152 und 175) Überreste einer Speichervergrößerung dar. Pfostendurchmesser und -tiefe entsprechen dem 12Pfostenspeicher, wobei Pfostengrube Kat.Nr. 175 teilweise gestört ist. Beide Pfosten liegen in Flucht mit Kat.Nr. 153, 155 und 157. Der durch die Abbruchkante gestörte Geländeverlauf lässt eine Weiterführung des Speichers in nördlicher Richtung offen.

Westlich des Speichers schließen sich ein $45 \mathrm{~cm}$ breiter Graben (Kat.Nr. 159) und dahinter ein 10m langes und $15 \mathrm{~cm}$ breites Gräbchen an (Kat.Nr. 107). Beide liegen in ihrer Ausrichtung parallel zur Westseite des Speichers und könnten mit diesem gemeinsamen Bestandteil einer zaunparallelen Anlage sein, wie sie ZIMMERMANN (1992, 252, Abb. 198, PR 5/6) in Flögeln vorlegt. Dort gehören sie in Siedlungsbereiche des 3. bis 4./5. Jahrhunderts und lagen oft nördlich ihrer zugehörigen Gehöfte (ZIMMERMANN 1992, 248).

\section{9-Pfostenspeicher}

Speicher 3, Kat.Nr. 794; 795; 797; 799; 800; 803; 804; 814

Taf. 93

Nordwestlich von Haus III haben sich acht Pfosten eines 9-Pfostenspeichers (SP 3) erhalten (Kat.Nr. 794; 795; 797; 799; 801; 803; 804; 814). Der 3,1x3,2m bis 3,5m große Speicher hat einen regelhaften Pfostenabstand. Diese sind in der O-W-Erstreckung 1,5-1,6m voneinander entfernt, während die Pfostengruben der S-N-Achse mit 1,1m dichter beieinanderstehen. Die nur noch gering eingetieften Pfostenbefunde (7-18cm) haben einen Durchmesser von 30-70x40cm. Der Doppelpfosten Kat.Nr. 814 enthielt gebrannten Lehm und Holzkohle.

9-Pfosten-Speicherbauten finden sich in zahlreichen kaiserzeitlichen Siedlungen im norddeutschen Küstengebiet und in den angrenzenden Regionen. So liegen vergleichbare Speicher aus dem 
benachbarten Hohegaste, Landkreis Leer vor (STILKE 1995, 205, 207, Abb. 3). Die dortigen 9-PfostenSpeicher hatten die Maße von 6,2-10,4qm und einen quadratischen bis rechteckigen Grundriss, der zumeist N-S orientiert war. In Nenndorf weist ein 9-Pfostenspeicher einen Flächeninhalt von 9qm auf (GROTELÜSCHEN 2000, 22), während in Brill der Speicher mit 7,54qm etwas kleiner ausfällt (LEHMANN 2002, 116). Die im Westerhammrich bei Leer ausgegrabenen 9-Pfostenspeicher sind annähernd quadratisch und weisen eine Grundfläche von 11qm auf (BÄRENFÄNGER 1999, 12). Somit liegt der Nortmoorer Speicher mit einem Flächeninhalt von etwa 10,5qm im oberen Bereich dieses Speichertyps.

Regional können bei 9-Pfostenspeichern die Abstände zwischen den einzelnen Pfosten differieren. Für Flögeln ist bei 9-Pfostenspeichern generell ein geringerer Abstand zwischen den Pfosten zu beobachten, der selten größer als 1m ist (ZimMERMANN 1992, 237, Abb. 184). Aus Bennekom stammende Speicher zeichnen sich meist durch regelmäßige Pfostenabstände von maximal 2,5m aus. Ungewöhnlich sind die Grundflächen der Speicher, die zwischen 12,25-20qm liegen können (VAN ES u.a. 1985, 572).

\section{6-Pfostenspeicher}

Speicher 4, Kat.Nr. 1011; 1012; 1013; 1014; 1015; 1016; 1027

Speicher 5, Kat.Nr. 595; 596; 600; 601; 602; 604

Speicher 6, Kat.Nr. 630; 634;644; 645; evtl. 646; 647; 649

Speicher 7, Kat.Nr. 523; 524; 525; 526; 528; 529; 530

Taf. 94-95

6-Pfostenspeicher finden sich in den Quadranten 53/43, 55/38 und 55/40 und können aufgrund ihrer räumlichen Nähe dem Hausplatz III zugeordnet werden. Speicher 7 im Quadrant 53/44 weist einen Bezug zu Hausplatz II auf.

Deutlich zeichnet sich nordwestlich vom Hausplatz III im Quadrant 55/38 ein 6-Pfostenspeicher ab (SP 4). Der NO-SW orientierte Speicher 4 liegt isolier. Von ihm haben sich fünf Pfostengruben (Kat.Nr. 1011; 1012; 1014; 1015; 1016) und eine Grube mit Pfostengrube (Kat.Nr. 1013; 1027) erhalten. Die Grundfläche des Speichers beträgt 1,5x1,8-2,1m. Der Abstand der Pfosten liegt in seiner W-O Achse um 1,5m, während er in der N-S Erstreckung mit 0,5-0,8m bedeutend geringer ist. Es sind rund-ovale Pfostengruben mit einem Durchmesser von $23-25 \mathrm{~cm}$. Die Pfostentiefen schwanken nur geringfügig zwischen $4-20 \mathrm{~cm}$. Auf eine Reparaturstelle in der Nordwestecke des Speichers deutet die Größe (51x43cm) der Pfostengrube Kat.Nr. 1027 hin. Sämtliche Pfostenbefunde enthielten HolzkohleBröckchen.

Wenige Meter vom Ostgiebel des Hausplatzes III entfernt befand sich im Quadrant 53/43 ein weiterer 6-Pfostenspeicher (SP 5; Kat.Nr. 595; 596; 600; 601; 602; 604). Die Kantenlänge des Speichers 
beträgt 2,5x2-2,5m. An der West- und Ostseite des Speichers sind die Pfosten regelhaft $0,8-1 \mathrm{~m}$ voneinander entfernt. Die Spannbreite zwischen der W-O-Achse ist mit 2,2-2,5m bedeutend größer. Dies liegt vor allem darin begründet, dass der nördliche Pfostenbefund der Ostseite etwa $50 \mathrm{~cm}$ aus der Flucht liegt (Kat.Nr. 604). Auf einen nachgesetzten Pfosten weist die längliche Pfostengrube Kat.Nr. $602(46 \times 29 \mathrm{~cm})$ hin, die zudem als einzige Keramik enthielt. Es überwiegen zumeist eckige Pfostenbefunde mit einem Durchmesser zwischen 23-34cm und einem kastenförmigen Profil von 9$20 \mathrm{~cm}$. Nur in einem Fall war bei SP 5 eine zylindrische Pfostengrube bis zu $34 \mathrm{~cm}$ eingetieft.

Ein 6-Pfostenspeicher befand sich nordwestlich von Hausplatz II in den Quadranten 54/43-55/43. Dem Speicher SP 6 können sechs Pfostengruben zugeordnet werden (Kat.Nr. 630; 634; 644; 645; evtl. 646; 647; 649). Pfostengrubetiefe reicht von 37 bis $60 \mathrm{~cm}$; t teilweise mit erhaltener Pfostenstandspur. Die Grundfläche des Speichers beträgt 1,6x3,4m. Es handelt sich um einen einphasigen Bau. Während der Ausgrabung wurde der Speicher nicht als solcher erkannt.

Auffällig ist der annähernd regelhafte Pfostenabstand zwischen 1,5m in der O-W-Achse und 1,5-1,8m in der S-N-Achse des Speichers. Mit Ausnahme einer Doppelpfostengrube (Kat.Nr. 649), die mit $60 \mathrm{~cm}$ besonders tief eingegraben war, sind keine Ausbesserungsphasen erkennbar. Im Planum A1 beträgt der Pfostendurchmesser bei einfachen, meist eckigen, Gruben zwischen $23 \times 25$ bis $33 \times 43 \mathrm{~cm}$. Der Doppelpfosten Kat.Nr. 649 ist im Unterschied dazu 38x75cm groß. Die Pfostentiefen schwanken geringfügig zwischen $37-60 \mathrm{~cm}$ (Mittelwert 43). Standspuren sind mit 9-50 cm Tiefe überliefert (Bef. 645, 647, 649). In einem Fall hat sich der Holzrest eines Pfostens in einer Tiefe von $41 \mathrm{~cm}$ erhalten (Kat.Nr. 645). In einer Reihe von Pfostengruben fand man Holzkohle Bröckchen (Kat.Nr. 630, 644, 645, 646, 647, 649), dies deutet möglicherweise auf ein Abbrennen des Speichergebäudes hin. Kaiserzeitliche Scherben fanden sich in zwei Pfostengruben (Kat.Nr. 647; 649).

Einen Hinweis auf die mögliche Zugangssituation zum gestelzten Speicher gibt ein nah an seiner Westseite entfernter Pfostenbefund (Kat.Nr. 646). Bei dem 40cm eingetieften Pfosten könnte es sich um eine erhabene Trittstufe handeln, um vom Boden aus leichter die erhöhte Speicherplattform zu erreichen.

Südlich des Ostteils des Hausplatzes II befand sich ein Speicherbau mit sieben Pfosten (SP 7, Kat.Nr. 523; 524; 525; 526; 528; 529; 530). Der Speicher ist parallel zum Gebäude ausgerichtet und etwa 70$80 \mathrm{~cm}$ von seiner Außenwand entfernt. Vom NNO-SSW orientierten Speicher sind sieben Pfosten und ein Wandgräbchen erhalten. Im Planum A1 ist ein leicht trapezförmiger Grundriss $(2,4-2,6 \times 3,6-4,6 \mathrm{~m})$ zu erkennen.

Die Pfosten in der südlichen Reihe stehen einheitlich im Abstand von 1,6m zueinander. In der nördlichen Pfostenreihe sind die Pfosten mit 1-2,2m weniger regelmäßig. Drei der Pfostenbefunde 
liegen einheitlich 2,2m voneinander entfernt. Die wesentlich geringeren Pfostenabstände zwischen den Pfosten Kat.Nr. 528 und 529 sind durch einen später nachgesetzten Pfosten (Kat.Nr. 526) entstanden. Im Planum A1 zeichnen sich die Pfostengruben rund-oval bis eckig ab und sind 15-50x32cm groß (Mittelwert $24 \times 27 \mathrm{~cm}$ ). Ihre Profiltiefe reichte von $5-17 \mathrm{~cm}$ mit einer Häufung um $14 \mathrm{~cm}$. Für die Pfostenbefunde Kat.Nr. 524, 530 haben sich Pfostenstandspuren erhalten, die bis in den gewachsenen Boden eingetieft sind. Auf eine Ausbesserung der SW-Seite des Speichers deutet die 32x50 cm große Grube hin (Kat.Nr. 523). Eine weitere Reparaturstelle ist an der NO-Seite des Speichers zu lokalisieren. Die zunächst nur aus drei Pfosten (Kat.Nr. 528; 529; 530) bestehende Flanke wird mit einem Reparaturpfosten (Kat.Nr. 526) zusätzlich stabilisiert.

Ein $4 \mathrm{~m}$ langes und bis zu $30 \mathrm{~cm}$ breites Wandgräbchen (Kat.Nr. 527) verläuft dicht innerhalb der Pfostenreihe Kat.Nr. 528 und 529, wobei es den Reparaturpfosten Kat. Nr. 526 randlich schneidet. Vermutlich handelt es sich hierbei um das Fundamentgräbchen einer Flechtwerkwand, mit deren Hilfe ein Bereich abgetrennt wurde.

Von der Feddersen Wierde (HAARNAGEL 1979, 148, Abb. 40, SH 4/Haus 10) und Flögeln (ZIMMERMANN 1992, 244, SH 3 SpH13), sind Gräbchen zwischen den äußeren Speicherpfosten belegt, die dazu dienten einen zusätzlichen Raum unter den Speichern zu schaffen. Möglicherweise war dies auch in Nortmoor der Fall. Die gering eingetieften Gräbchen haben sich zumeist nicht erhalten.

Mit 3,75-10,25qm decken die Nortmoorer 6-Pfostenspeicher die gesamte Bandbreite der auch in Brill nachgewiesenen Grundfläche (4-11qm) für diesen Typ ab (LEHMANN 2002, 116, Taf. 105). Dominieren in Brill annähernd quadratische Speicher, sind die Nortmoorer länglich rechteckig konstruiert. Dies ist auch bei Speichern dieses Typs in Flögeln der Fall (ZIMMERMANN 1992, 234, Abb. 181).

Die Pfostenabstände der Nortmoorer Speicher können als relativ einheitlich bezeichnet werden. Meist ist die 3er Pfostenreihe eng gestellt (0,5-1,6m), während die Distanz zur gegenüberliegenden Pfostenreihe meist doppelt so groß ist (1-2,5m). 6-Pfosten-Speicher mit ungleichem Pfostenabstand in der W-O- bzw. S-N-Achse finden sich auch bei Speichern in Flögeln, wobei der Abstand zwischen der 3er und 2er Reihe oft doppelt so groß ist (ZIMMERMANN 1992, 234, Abb. 181). Die 3erPfostenstellung ist dabei zwischen 1,6-2,1m von der gegenüber liegenden Reihe entfernt. Das in der römischen Kaiserzeit auch weit größere Spannbreiten bei 6-Pfostenspeicher überbrückt werden konnten, zeigt das Beispiel eines 10,5qm großen Speichers im 5km entfernten Hohegaste, bei dem die 3er Pfostenreihen 3,2m Abstand zueinander aufweisen (STILKE 1995, 205, 207, Abb. 3). 
Gestelzte Pfostenspeicher sind für Siedlungen im Gebiet der südlichen Nordsee nicht nur für die Römische Kaiserzeit typisch. Bereits in der vorrömischen Eisenzeit und der Bronzezeit finden sich Speicherbauten (ZIMMERMANN 1992, 243-244). Setzungen von 4-20 Pfosten werden zumeist als gestelzte Speicher bezeichnet. In Flögeln sind gestelzte Speicher in der gesamten Besiedlungsphase des 1.-5. Jahrhunderts belegt. Im 4.-5. Jahrhundert dominieren zaunparallele Speicher (ZIMMERMANN 1992, 244).

Darüber hinaus ist ein für lange Zeit in Ostfriesland unbekannter kaiserzeitlicher Speichertyp hervorzuheben. Die römischen Speichergebäude imitierende Form einer Horrea gelang es in Nenndorf B nachzuweisen. Fünf parallele schmale Gräben mit in regelmäßigen Abständen eingetieften Pfostengruben werden als Schwellbalkenkonstruktion rekonstruiert, die als Basis für das aufgehende Bauwerk dienten (KREIBIG 2006, 52- 56, Abb. 39).

Eine Konzentration von Speichern in bestimmten Bereichen ist bei kaiserzeitlichen Siedlungen von der Feddersen Wierde (HAARNAGEL 1979, 123), in Wijster (VAN Es 1967, 87) und in Flögeln (ZIMMERMANN 1992, 229) zu beobachten. Die Speicherbauten liegen dabei, wie in Hohegaste, relativ dicht beieinander (STILKE 1995, 205; Abb. 2).

Auch die Nortmoorer Speicher sind innerhalb der Siedlung nah beieinander positioniert, wobei mehrfach ein bis vier Speicher einem Hausplatz zugeordnet werden können. Eine Akkumulation von 6-Pfostenspeichern umgibt die beiden kaiserzeitlichen Hausplätze II und III. Die Grundflächen der Nortmoorer 6-Pfostenspeicher reichen von 3,75qm (SP 4), 5,44qm (SP 6), 6,25qm (SP 5) bis zu 10,25qm (SP 7). Zwei 12-Pfostenspeicher (SP 1 u. 2) und ein 9-Pfostenspeicher (SP 3) können zudem Hausplatz II zugeordnet werden.

Die Pfostenlöcher waren sorgfältig angelegt und meist von runder Form. Die eingelassenen Pfosten waren in einigen Fällen an ihrer Unterseite flach abgebeilt. Pfostenstandspuren waren nur selten festzustellen. Es überwiegen rechteckige und quadratische Speicher mit meist regelhaft voneinander entfernt eingegrabenen Pfosten. Tiefen von meist 30cm unter dem Grabungsplanum A1 zeigen, dass die Pfosten etwa 70-80cm unter der ursprünglichen Oberfläche eingetieft waren. Hinweise auf einen umlaufenden Fundamentgraben liegen für Speicherbauten aus Nenndorf A vor (GROTELÜSCHEN 2000, 22), diese fehlen in Nortmoor ebenso wie Querverstrebungen zwischen den Pfosten (vgl. STILKE 1995, 205, 207, Abb. 3). Eine große Anzahl an 4- und 6-Pfostenspeichern fand sich in Wijster (VAN Es 1967, 87-94), Bennekom (VAN Es 1985, 572) und Brill (LEHMANN 2002, 114-116).

Nicht immer gelingt eine Zuordnung von Gebäuden und Speicherbauten, wie dies in Nortmoor meist möglich ist. Für die gut dokumentierte Siedlung Soest-Ardey konnten nur ansatzweise wenige der 17 dokumentierten Speicher, hier überwogen 4-Pfostenspeicher, den 13 Großbauten zugeordnet werden 
(HALPAAP 1994, 266-267). Wirtschaftbetrieben von der Feddersen Wierde waren oft nur ein bis maximal zwei Speicher zuzuordnen.

\subsubsection{Rutenberge}

Erntespeicher mit einem höhenverstellbaren Dach und ohne Außenwände werden gemein hin als Rutenberg bezeichnet. Das gelagerte Erntegut, oft Heu oder ungedroschenes Getreide, war optimal durch die anpassungsfähige Überdachung geschützt, zudem diese sich je nach Rauminhalt des Speichers beliebig anpassen ließ (LEHMANN 2002, 114).

Meist handelt es sich um Konstruktionen aus 3-9 Pfosten. Bei Speicherbauten mit mehr als vier Pfosten befand sich im Zentrum des radial angelegten Speichers oft ein zentraler Pfosten, an dem das variable Dach angebracht wurde und je nach Bedarf auf- und abgesenkt werden konnte (ZIMMERMANN 1995, 207). Ansonsten erfolgte die Befestigung des Daches an den äußeren Pfosten. Aufgrund dieser konstruktiven Besonderheit werden Speicher dieses Typs separat vorgelegt.

In bronzezeitlichen Siedlungen in den Niederlanden finden sich erstmals Hinweise auf Rutenberge (vgl. VerLINDE 1991, 39). Einzelne Speicher sind versprengt bis an die Weser belegt (KOSSACK u.a. 1984, 261, Abb. 93). In der vorrömischen Eisenzeit werden erste Vertreter bereits im Emsland (ZOLLER 1972b, 196-219), wie auch im oldenburgischen Hinterland nachgewiesen (ZOLLER 1972a, 122). Der Bautyp verbreitet sich zunehmend in der römischen Kaiserzeit von den Niederlanden bis nach Jütland (KOSSACK u.a. 1984, 261, Abb. 93; ZIMMERMANN 1992, 243-244).

In der Kaiserzeit handelt es sich meist um kleinere Rutenberge, deren Pfosten einen geringeren Durchmesser aufweisen als die mächtigen Rutenberge des Mittelalters. Für das kaiserzeitliche Gristede sind Rutenberge mit vier bis fünf Pfosten dokumentiert (ZOLLER 1972a, 111). Im ostfriesischen Brill dominieren dagegen 3- bis 4-Pfostenspeicher (LEHMANN 2002, 114-115). Für durchschnittliche Rutenberge nimmt LEHMANN (2002, 115; Anm. 556) im Vergleich mit mittelalterlichen Quellen des 12. Jahrhunderts eine Höhe von 3,5-4m an.

Möglicherweise handelte es sich bei den dreier Pfostenkonstruktionen in Bentumersiel ebenfalls um Rutenberge (BRANDT 1977, 17). Für diese Speicherbauten führt ZIMMERMANN überzeugend aus, dass eine eindeutige Unterscheidung zwischen gestelzten 4-Pfostenspeichern und Rutenbergen anhand des archäologischen Befundes kaum möglich ist (ZIMMERMANN 1992, 229-230). Auch in der Völkerwanderungszeit sind Rutenberge im Küstenraum bekannt, so aus Bremen-Gramke (BRANDT 1958, 205-215) und in Flögeln (ZIMMERMANN 1992, 229).

Im Mittelalter ist der Rutenberg von den Niederlanden bis nach Dänemark verbreitet. Es sind nun mächtige Speicher mit einem Radius von 8-12m und einem Pfostengrubendurchmesser von 1m und darüber hinaus. Hier seien die Speicherbauten in Gasselte (WATERBOLK 1979, 227-230) und Dalem 
(ZIMMERMANN 1991, 37-46; KOSSACK u.a. 1984, 262, Abb. 94) angeführt. Von frühmittelalterlichen Gehöften in Hesel liegen fünf Rutenberge mit 3-, 4- und 6-Pfostenstellungen vor (BÄRENFÄNGER 1999, 50-51, Abb. 58-59).

\section{3-Pfostenspeicher}

Speicher 8, Kat.Nr. 136; 137; 138

Speicher 9, Kat.Nr. 287; 289; 290

Taf. 95

Um bei Dreier-Konstellationen von Pfostengruben nicht einem „granary making“ zu verfallen (vgl. VAN Es 1967, 87) sind bei dem nachfolgenden Speichertyp nur separat liegende Grundrisse mit weitgehend gleichmäßigen Abständen der Pfostengruben berücksichtigt worden.

Im Quadranten 53/53 fand sich eine regelmäßige Dreierpfostensetzung mit einer Seitenlänge von 0,9x1,1x1,2m (Kat.Nr. 136; 137; 138). Der Speicher SP 8 zeichnet sich aufgrund seiner isolierten Lage gut im Planum A1 ab. Die Entfernung der Pfostenmittelpunkte zueinander betrug 70-90 cm. Der Pfostenumfang variierte zwischen $25-35 \mathrm{~cm}$ bei recht flachen Eingrabungen der Pfostengruben von 8$13 \mathrm{~cm}$. Es handelt sich hier um einen verhältnismäßig kleinen Speicher. Vergleichbare 3Pfostenspeicher in Brill weisen bereits ein Kantenmaß von 2,2-3,2m auf (LEHMANN 2002, 114-115, Taf. 103). Speicher mit ein Kantenmaß von 1,5-3,3m liegen aus dem frühmittelalterlichen Borne vor (VERLINDE 1989, Abb. 14b).

Ein wesentlich größerer 3-Pfostenspeicher befand sich im Quadranten 53/48. Drei mächtige Pfostengruben mit Durchmessern von 0,8-1m bilden einen Rutenberg (SP 9). Vom Grubenmittelpunkt gemessen sind die Gruben 1,7-2m von einander entfernt (Kat.Nr. 287; 289; 290). Die mulden- bis kastenförmig eingetieften Pfosten waren noch 9-13cm eingetieft. Die enorme Pfostenstärke deutet auf einen mittelalterlichen Speicherbau hin. Diese Datierung wird zusätzlich gestützt durch mittelalterliche Keramikfunde aus einem Pfostenbefund (Kat.Nr. 290). Auch aus dem Geestdorf Hesel finden sich in der frühmittelalterlichen Siedlung dreieckige Speicher, die sich in ihrer Orientierung, Abmessung und Pfostendimension gleichen (BÄRENFÄNGER 1998b, 51, 53, Abb. 59 u. 61).

\section{4-Pfostenspeicher}

Speicher 10, Kat.Nr. 549; 550; 553; 554

Speicher 11, Kat.Nr. 661; 662; 784; 786

Speicher 12, Kat.Nr. 657; 658; 659; 684

Speicher 13, Kat.Nr. 592; 595; 596; 597

Taf. 95-96

Vierpfosten-Speicher weisen einen annähernd gleichseitigen Grundriss im Planum auf und sind meist quadratisch, rechteckig oder trapezförmig. Eine Abgrenzung zwischen 4-Pfosten-Speichern 
herkömmlichen Typs und den offenen Speicheranlagen (Rutenberge) ist im archäologischen Befund nicht eindeutig zu treffen. Nach ZIMMERMANN (1992, 229) handelt es sich bei 4-Pfostenspeichern auch in kaiserzeitlichen Siedlungen häufig um Rutenberge.

Eine regelmäßige Pfostensetzung aus vier Pfostenbefunden im Quadranten 55/44 kann diesem Speichertyp zugeordnet werden (Kat.Nr. 549, 550, 553, 554). Der Speicher SP 10 hat eine quadratische Form mit einer Länge von 2,4-2,5m und einer Breite von 2,2m. Die mit 16-27cm nur gering eingetieften Pfostengruben weisen ein u-förmig bis zylindrisches Profil auf. Die im Planum runden bis eckigen Gruben sind 22-66x30 cm groß, im Mittel 22-32x30cm. Bei dem SW-Pfosten Kat.Nr. 550 wird es sich aufgrund seiner Größe um einen Ersatzpfosten gehandelt haben.

Aus den Quadranten 54/41 und 54/42 stammen zwei 4-Pfosten-Speicher, die sich nördlich vom Hausplatz III erstrecken. Die beiden nebeneinanderliegenden Speicher verfügen über einen versetzten Grundriss mit Seitenlängen von 1,1-1,8m. Die Pfosten des rhombischen Speichers SP 11 besitzen im Planum A1 einen Durchmesser zwischen 15-23cm (Kat.Nr. 657, 658, 659, 684). Bei den 18-22cm eingetieften eckigen Gruben sind in drei Fällen Pfostenstandspuren $(7-18 \mathrm{~cm})$ nachgewiesen (Kat.Nr. 657, 659, 684). Der wenige Meter westlich entfernte Speicher SP 12 ist im Grundriss trapezförmig mit einer Kantenlänge von 1,2-1,3x1,8m (Kat.Nr. 657; 658; 659; 684). Die Pfostengruben sind im Planum 0,28-1 m groß, im Profil mulden- bis u-förmig und zwischen $6-38 \mathrm{~cm}$ eingetieft. Um eine mögliche Ausbesserungsstelle handelt es sich bei Kat.Nr. 786. Keramikfragmente datieren beide Speicher in die römische Kaiserzeit.

Ein in seiner Form ungewöhnlicher 4-Pfostenspeicher liegt an der östlichen Schmalseite von Hausplatz III. Der Y-förmige Speicherbau SP 13 besitzt einen zentralen Pfosten (Kat.Nr.597), nordöstlich davon zwei Pfosten (Kat.Nr. 596; 598) und im Südwesten einen einzelnen Pfosten (Kat.Nr. 592). Die Pfosten sind untereinander zwischen 0,70-0,80m voneinander entfernt.

Die Pfostendurchmesser liegt im Mittel bei $20 \mathrm{~cm}$; die Eintiefung sind nur rudimentär erhalten (6$15 \mathrm{~cm})$. Die vier für sich separat liegenden Pfostengruben ähneln den bekannten 5- und 7-pfostigen Speicherbauten mit zentraler Pfostenstellung. Es könnte sich bei dem Nortmoorer Exemplar demnach um eine verkleinerte Form einer Heuberge bzw. eines Rutenberges gehandelt haben.

Für SP 10-12 vom Typ des 4-Pfostenspeichers liegen aus kaiserzeitlichen Siedlungen Parallelbefunde vor. Im Westerhammrich bei Leer war bei einer 4-Pfostenspeichersetzung eine Seitenlänge von $2 \times 2 \mathrm{~m}$ anzutreffen (BÄRENFÄNGER 1999d, 166), während in Brill weniger rechteckige 4-Pfosten-Speicher dominierten, sondern Speicher mit trapezförmig oder parallelogrammartig angeordneten Kanten (LEHMANN 2002, 115, Taf. 104).

Mit einem Flächeninhalt von knapp 2qm sind die Nortmoorer Speicher, im Vergleich zu Flögeln, im 
unteren Größenbereich der 4-Pfostenspeicher. Dort werden Flächengrößen von 1,5-21,3m erreicht (ZiMMERMANN 1992, 229, 231-233, Abb. 178-180). Rechteckige Speicher mit annähernd gleichem Pfostenabstand sind hier ebenso vertreten wie langrechteckige Speicher bei denen die Distanz zwischen den Pfosten von 0,9x1,5m und 2x3,3m schwanken kann.

Denkbar ist bei Konstruktionen mit vier, rechtwinklig zueinanderstehenden, Pfosten auch eine Nutzung als Unterstand oder als pferchähnliche Anlage. Vergleichbare Baustrukturen finden sich in der Siedlung Bennekom, Provinz Gelderland (VAN Es u.a. 1985, 573).

\section{7-Pfostenspeicher}

Speicher 14, Kat.Nr. 241; 245; 248; 249; 250; 251; 256; 281; 289

Speicher 15, Kat.Nr. 16; 17; 18; 19; 88; 91; 92; 95

Taf. 97

Im östlichen Siedlungsbereich traten die mächtigen Standspuren von zwei Speicherbauten, dem Typ nach mittelalterliche Rutenberge, zutage. Sie zeichnen sich durch eine enorme Spannweite von bis zu $9 \mathrm{~m}$ und mächtige Pfostengruben mit einer Größe von bis zu $160-220 \mathrm{~cm}$ aus.

In den Quadranten 52-53/49 liegt ein mächtiger Speicher (SP 14) mit einem Durchmesser von 9m vor. Deutlich zeichnet sich im Planum ein radial angelegter Speicher ab. Sein Gerüst besteht aus sechs im Kreis angelegten Pfostengruben, die eine zentrale Pfostengrube umgeben.

Ihr Pfostendurchmesser beträgt im Planum A1 zwischen $80-150 \mathrm{~cm}$, im Mittel um $100 \mathrm{~cm}$. Die Pfostengruben sind regelhaft in einem Abstand von $4 \mathrm{~m}$ in den gewachsenen Boden eingetieft. Ihre Profiltiefen sind zwischen $15-67 \mathrm{~cm}$ erhalten, meist mit mulden- bis kastenförmigem Profil. Pfostenstandspuren haben sich bei drei Gruben in einer Tiefe bis zu $15-35 \mathrm{~cm}$ erhalten. Der zentrale Mittelpfosten Kat.Nr. 248 trennt sich erst im Profil vom Rest eines AH 6 (Kat.Nr. 247). Die Mächtigkeit der Gruben weist insgesamt auf ursprünglich schwere Pfosten hin, die hoch aufragten, um an ihnen das verstellbare Dach aufzuhängen.

Möglicherweise handelte es sich bei der längsrechteckigen Pfostengrube Kat.Nr. 249 um einen Ersatzpfosten des Speichers. Hierauf weist seine ungewöhnliche Größe von 160x90cm hin, wie auch seine Lage zwischen dem Mittel- und einem Außenpfosten (Kat.Nr. 248; 250).

Das Füllmaterial der Pfostengruben bestand recht gleichförmig aus Klei bzw. tonigem Sand in ihrem oberen Bereich und einer unteren sandigen Schicht. In den Pfostengruben fand sich harte Grauware und wenige Scherben Muschelgrus gemagerter Keramik sowie umgelagertes kaiserzeitliches Fundmaterial. Es fanden sich zudem zwei kalzinierte Rinderzähne und Holzkohle-Bröckchen.

Einen massiv gebauten Rutenberg (SP 15) fand man im Quadranten 53/53. Die nahe Teichböschung hatte bereits den nördlichen Bereich des Speichers zerstört. Die Menge an Pfostenbefunden deutet darauf hin, dass es sich um eine zweiphasige Anlage handelte. So verbargen sich in den Pfostenbefunden Kat.Nr. 18, 91 und 95 ein bis zwei weitere Pfostengruben. Rekonstruiert werden 
kann ein äußerer Pfostenkreis (SP 15a) mit sieben Pfostengruben (Kat.Nr. 19; 18; 16; 17; 88; 91a, 92), die etwa in einem Abstand von 1,5m zueinanderstanden. Von der inneren Pfostensetzung (SP 15b) sind im Südteil des Speichers noch fünf Pfostensetzungen erhalten (Kat.Nr. 17a; 18a; 91a; 91b; 91c). Der Speicher wird jeweils aus 7-8 Pfosten und einem Mittelpfosten bestanden haben und besaß vermutlich einen Durchmesser von $7 \mathrm{~m}$.

Im Planum A1 haben die Pfostengruben meist einen annähernd runden Durchmesser von 1-2m. Lediglich zwei der größeren Pfostengruben zeichnen sich ungestört im Planum mit einem Durchmesser von 160-180cm ab (Kat.Nr. 16, 19). Die übrigen Pfostengruben sind mehr oder weniger stark gestört. Insbesondere der Grabenkomplex Kat.Nr. 91 beeinträchtigt den Westteil des Speichers durch seinen Verlauf. Hingegen relativ gut zeichnen sich die Pfostengruben des Rutenberges, die bis zu 40-58cm eingetieft sind, ab. Zur Datierung des Speichers kann die in den Pfostengruben aufgefundene Keramik herangezogen werden. Nahezu alle Befunde des Speichers enthielten mittelalterliche Keramik, so Muschelgrus gemagerte Scherben, harte Grauware und in einigen Fällen pingsdorfartige Keramik. Darüber hinaus fanden sich Tierknochenfragmente, Holzkohle-Bröckchen und Flintartefakte. Kaiserzeitliche Keramik gelangte vermutlich mit dem Bodenaushub in die Pfostengruben.

Mittelalterliche Gebäude liegen in Nortmoor nicht vor, so dass Aussagen zur Gehöftstruktur und der räumlichen Einbindung der Speicherbauten nicht möglich sind. Vermutlich befand sich das mittelalterliche Siedlungsareal im bereits in den 60er Jahren des 20. Jahrhunderts ausgesandeten östlichen Dünenteil und ist damit unwiederbringlich zerstört. Auf eine wohlhabende mittelalterliche Siedlung weisen nicht nur die beiden mächtigen Rutenberge hin. Hierauf deutet auch der nur wenige Meter östlich vom Speicher 15 entfernte mittelalterliche Sodenbrunnen (B 4; Kat.Nr. 26), aus dessen Brunnenfüllung zwei fast komplette Pingsdorfer Tonkrüge stammen.

Beide Rutenberge zeichnen sich durch ihre Dimensionierung, was sowohl den Speicherdurchmesser wie auch den mächtigen Pfostenumfang betrifft, aus. Vergleichbare Anlagen weisen zumeist einen Durchmesser von 4-6m auf. Frühmittelalterliche Gehöfte in Hesel verfügen noch über kleinere, nur 34,5m große Rutenberge (BÄRENFÄNGER 1998b, 48, Tab. 1). Im hochmittelalterlichem Dalem überwiegen noch bis zu 5,5m große Rutenberge, während gestelzte Speicher selten auftraten (ZIMMERMANN 1991, 42-45, Abb. 7). Erst aus dem mittelalterlichen Leegkamp in Leer-Loga sind sechspfostige Rutenberge mit einem Durchmesser von 7,2m belegt. Ein benachbartes Haus (29x10m) bestand vermutlich zeitgleich mit einem nahen Brunnen, der anhand von Hölzern dendrochronologisch auf $1142^{+/-2}$ datiert wird (BÄRENFÄNGER 1998c, 32). Aus dem mittelalterlichen Hollen, Gemeinde Uplengen, liegen Rutenberge mit Durchmessern von bis zu 8,5m vor (mündliche Mitteilung SCHÄFER, Dissertationsvorhaben in Vorbereitung). Im mittelalterlichen Gasselte sind es vorwiegend 6- und 7- 
Pfostenspeicher mit einem Durchmesser von 6-7,5m (WATERBOLK / HARSEMA 1979, 238). 8-pfostige Rutenberge sind hingegen in Odoorn belegt (WATERBOLK 1973, 56).

\subsubsection{Gruben}

Kat.Nr. 10; 25; 27; 29; 31; 32; 34; 42; 43; 44; 46; 49; 50; 52; 52a; 52b; 55; 66; 74; 93; 94; 98; 117; $118 ; 119 ; 122 ; 126 ; 134 ; 135 ; 115 ; 120 ; 123 ; 158 ; 166 ; 167 ; 169 ; 181 ; 187 b ; 188 ; 189 ; 190 ; 192 ; 196$; $200 ; 207 ; 210 ; 212 ; 221 \mathrm{a} ; 222 ; 223 ; 225 ; 226 ; 227 ; 228 ; 230 ; 231 ; 239 ; 243 ; 257 ; 258 ; 264 ; 277 ; 298$; $301 ; 330 ; 331 ; 332 ; 343 ; 345 ; 351 ; 357 ; 362 ; 363 ; 369 ; 371 ; 373 ; 374 ; 375 ; 376 ; 377 ; 378 ; 379 \mathrm{a}$; 379b; 380; 382; 384; 385; 386; 395; 396; 401; 403; 405; 408; 409; 410; 411; 412; 415; 418; 422; 424; 425; 426; 434; 435; 440; 441; 442; 447; 451; 453; 462; 464; 468; 475; 497; 499; 509; 510; 512; 520; $522 ; 559 ; 562 ; 581 ; 582 ; 583 ; 599 ; 613 ; 614 ; 635 ; 642 ; 656 ; 679 ; 687 ; 697 ; 701 ; 703 ; 743 ; 748 ; 751$; $752 ; 753 ; 755 ; 756 ; 758 ; 763 ; 779 ; 786 ; 790 ; 797 ; 799 ; 800 ; 806 ; 807 ; 811 ; 812 ; 814 ; 816 ; 831 ; 832$; 834; 840; 844; 848; 857; 867; 888; 891; 894; 885; 898; 899; 900; 901; 927/1070; 928; 939; 943; 969; $1013 ; 1018 ; 1070 ; 1082 ; 1086 ; 1110 ; 1111 ; 1113 ; 1120 ; 1139 ; 1263 ; 1272 ;$ evtl. $1280 ; 1284 ; 1289$

Gruben unterschiedlicher Form und Größe verteilen sich über die gesamte Grabungsfläche. Sie sind neben den Pfostengruben die häufigste Befundart. Zum überwiegenden Teil handelt es sich um Gruben mit einem kleinen Durchmesser von 0,6-1,99m ( $\mathrm{n}=161)$. Mittelgroße Gruben, die zwischen 2$3,3 \mathrm{~m}$ groß sind, liegen in 33 Fällen vor (Kat.Nr. 27; 93; 94; 135; 158; 188; 223; 330; 331; 369; 376; 408; 412; 462; 475; 499; 509; 582; 635; 656; 703; 755; 763; 807; 811; 844; 928; 939; 969; 1018; 1263; evtl. 1280; 1289). Zwei Gruben gehören mit Abmessungen von bis zu 5x7m in die Kategorie der großen Gruben (Kat.Nr. 943; 1082). Befunde, die zwar durchaus als Grube anzusprechen sind, bei denen es sich jedoch eindeutig um Brunnengruben handelt, werden an gegebener Stelle behandelt.

Im Planum A1 dominieren rundlich-elliptisch bis ovale kleine Gruben. Es ist nicht ausgeschlossen, dass sich unter diesen Gruben nicht erkannte Pfostengruben befinden. Deutlich seltener sind in dieser Gruppe eckige oder langrechteckige Gruben. Es überwiegen mulden- und wannenförmige vor kastenförmigen Grubenprofilen. Die Tiefen reichen von 5-80cm, mit einer Häufung zwischen 15$25 \mathrm{~cm}$.

In die Kategorie der mittleren Gruben herrschen im Planum A1 längliche und eckig/rechteckige Formen vor, während runde (Kat.Nr. 223; 369; 703; 763) oder unregelmäßige (Kat.Nr. 1018) nur gelegentlich vorkommen. Deutlich überwiegen auch hier muldenförmige Profile vor kastenförmigen (Kat.Nr. 223; 330; 331; 807; 1289) oder v-förmigen (Kat.Nr. 93). Die großen Gruben sind im Planum länglich bis amorph ausgebildet und im Profil muldenförmig zwischen $20-50 \mathrm{~cm}$ erhalten (Kat.Nr. 78; 943; 1082). Dokumentiert sind Tiefenwerte von $8-75 \mathrm{~cm}$, wobei die Gruben meist zwischen $30-46 \mathrm{~cm}$ eingetieft sind. 
Die Vielfalt der Grubenformen, sowohl im Planum wie im Profil, deutet bei dieser Befundgruppe auf einen ebenso differenzierten Verwendungszweck hin. Aufgrund mangelnder Erhaltung, bei der nur noch die Grubensohle erfasst wird, sind den Deutungsmöglichkeiten enge Grenzen gesetzt.

Siedlungsgruben hatten im Laufe ihres Bestehens oft verschiedene Funktionen inne. Wurden sie zur Entnahme von Sand oder Klei, als Speicher- oder Werkgruben verwendet, fanden sie ihre letzte Nachnutzung meist als Abfallgrube. Oft ist nur die zuletzt erfolgte Verwendung nachvollziehbar. Eine Vielzahl an Gruben enthält Keramik, teilweise gebrannten Lehm, Steine oder Holzkohle-Bröckchen. Gruben mit Schlacken oder Tierknochen sind eher selten.

In Nortmoor sind vielfach nur die unteren Grubenbereiche erhalten, während die oberen Bereiche durch die Folgen von Landwirtschaft und Bodenerosion zerstört wurden. Ungünstig für die Auswertung erwies sich zudem die bei der Ausgrabung gewählte Dokumentationstechnik in Form von Fotoaufnahmen. Profilzeichnungen von Gruben fehlen meist, sofern sie nicht skizzenhaft im Befundbuch erfolgten. Somit kann ein Großteil der Gruben in Nortmoor nur allgemein dieser Befundart zugesprochen werden. Eine nähere Darstellung erfolgt deshalb nur bei Gruben, die sich durch ihren Aufbau oder Inhalt besonders auszeichnen. In den meisten Fällen zeigten sich bei den Gruben weder in Planum noch im Profil ausreichende Hinweise, um ihre ehemalige Funktion zu erschließen.

Brandreste, wie Holzkohle und kalzinierte Knochen, enthalten einige Gruben aus dem zentralen Dünenbereich in den Quadranten 53-54/47 und 54/46. Viel Holzkohle enthielten die lang-rechteckigen Gruben Kat.Nr. 365; 366; 370 und die runde Grube Kat.Nr. 428. Leichenbrand stammt aus zwei Urnenbestattungen und fünf Brandgrubengräbern. Aus der eckigen Grube Kat.Nr. 378 stammen 6kg Holzkohle. Die Grube wird geschnitten von Kat.Nr. 379, die aufgrund ihres Grubeninhaltes in die ältere Kaiserzeit datiert. Bestattungen und Feuerstellen werden an entsprechender Stelle vorgestellt (Kap. 5.3 Bestattungen).

Große Mengen an Holzkohle und gebrannten, teils sogar verziegeltem Lehm, deuten auf Feuerstellen hin. Im Hausplatz II lokalisiert sind die Herdgruben im Mittelschiff (Kat.Nr. 613) und im Ostteil (Kat. 559) des Gebäudes, so dass von einer Gleichzeitigkeit mit dem Hausplatz ausgegangen werden kann. In Haus III liegt eine ähnliche Fundsituation vor. Bei der Grube Kat.Nr. 831 mit einem hohen Anteil an gebranntem Lehm, wird es sich gleichfalls um eine Feuerstelle gehandelt haben. Die eckige Grube befindet sich im mittleren Gebäudeteil.

Die Feuerstelle Kat.Nr. 277 enthielt die recht beachtliche Menge von 3,8kg gebranntem Lehm, der bei der ovalen Grube $(80 \times 60 \mathrm{~cm})$ aus dem $30 \mathrm{~cm}$ durchmessenden inneren Kern stammt. Datierende Funde fehlen. Auch die wenigen Umgebungsbefunde sind wenig aussagefähig. Die Feuerstelle ist $8 \mathrm{~m}$ NNO vom Rutenberg SP 14 und ebenso weit vom Hausplatz V entfernt. 
Innerhalb von zwei Gebäuden finden sich Gruben, die aufgrund ihres keramischen Fundmaterials in die römische Kaiserzeit zu datieren sind. Haus III hat zumeist runde Gruben mit einem Durchmesser von 1,40-2m (Kat.Nr. 703, 763, 891), die zwischen 30-70cm eingetieft sind. Sie enthielten jeweils HK und Keramik, in einem Fall auch gebrannten Lehm (Kat.Nr. 763). Von bescheidener Breite ist die längliche Grube Kat.Nr. 679 (180x60cm). Mit einer Ausnahme konzentrieren sich die Gruben auf den Ostteil des Gebäudes. Auch innerhalb von Haus I liegt im zentralen Teil des Mittelschiffes eine 180x80cm große Grube (Kat.Nr. 357) vor, die HK und Keramik enthält. Aufgrund ihrer Lage innerhalb der Gebäude ist zu vermuten, dass diese als Vorratsgruben gedient haben, bevor man sie als Abfallgruben benutzte.

Unter den Oberbegriff Siedlungsgruben fallen die sogenannten Erdspeicher. Die Gruben dienten als Speicher von Getreide oder anderem vergänglichen Lagergut. Getreidereste waren mit bloßem Auge in Nortmoor nicht festzustellen, eine Schlämmung der Grubeninhalte erfolgte nicht. Allenfalls beobachtet wurde eine Schichtung innerhalb der Gruben, wie auch durch Holzkohlestaub verfärbte Grubeninhalte. Größere Holzkohle-Brocken waren eher selten anzutreffen.

Auffällig ist die meist recht geringe Tiefe der Gruben in Nortmoor. Mit Ausnahme der Brunnengruben ist keine Grube tiefer als $80 \mathrm{~cm}$ in den Sandboden eingegraben. Vermutlich hat die Bodenfeuchtigkeit und der hohe Grundwasserspiegel die Anlage von tiefen Vorratsgruben als wenig sinnvoll erscheinen lassen. Die Vorteile einer Getreidelagerung im Boden überwogen, trotz der dafür ungünstigen Bodenbedingungen, wie sie auf einer flachen Sanddüne im Niederungsbereich herrschen. Eine luftdichte Lagerung in Erdsilos erhält bei Saatgetreide über lange Zeit die Keimfähigkeit. In Gruben gelagertes Brotgetreide kann noch Jahre später genießbar sein (ZIMMERMANN 1992, 264). Um dies zu gewährleisten, mussten die Vorratsgruben entsprechend vorbehandelt werden.

Eine systematische Abdichtung von Grubenwänden mit Lehm, wie es beispielsweise für Gruben in Wijster belegt ist (VAN Es 1967, 120), konnte in Nortmoor nicht festgestellt werden. Stattdessen findet sich in einigen Fällen ein dünnes HK-Band auf der Grubensohle, welches sich bei einigen Gruben entlang der Grubenwandung erhalten hat. Die HK-Bänder können Stärken zwischen 1-8cm aufweisen (Kat.Nr. 93; 187b; 343; 412; 422; 426; 464; 895; 1070; 1284). Auch hier zog sich die HK-Schicht entlang der Sohle und der Grubenwand (Kat.Nr. 187b; 895; 928; 1284). Finden sich in den Gruben dagegen Holzkohleschichten in höheren Lagen, wird es sich nur selten um Übereste der primären Grubenfunktion gehandelt haben.

Neben größeren HK-Brocken ist eine Schwarzfärbung des Grubeninhaltes zu beobachten, letzteres ein Hinweis auf Holzkohlestaub. Dies weist auf ein Ausbrennen der Silogruben vor ihrer Verwendung 
hin. Zudem können holzkohlehaltige Schichten auch auf Back- und Röstgruben hinweisen (SCHWARZ 2002, 98). In Bennekom fanden sich in Siedlungsgruben häufig Spuren von HK, Lehm und verkohltem Getreide (VAN ES u.a. 1985, 580-581). Sogenannte Ofengruben, die dort dem Typ A I angehören und sich durch ein asymmetrisches Längsprofil mit einer steilen und einer flachen Wandung auszeichnen (VAN ES u.a. 1985, 579-580), fehlen in Nortmoor hingegen.

In Nortmoor sind es zumeist kleine Gruben, die über eine HK-Bänderung und einen hohen Anteil an Holzkohle aufzeigen. Unter diesen überwiegen diejenigen Gruben mit rundovalem Durchmesser im Planum vor denen mit rechteckigen. Meist sind die Gruben muldenförmig eingetieft. Schwemmlinien auf der Grubensohle weisen in einigen Fällen auf ein längeres Offenstehen der Grube hin (Kat.Nr. 834; 891). Die aufgelassenen Gruben versandeten langsam und brachen ein. Wurden sie im Winter offengelassen, verflachten sich ihre Ränder meist stark. So kann ursprünglich von Gruben mit steilerer Wandung ausgegangen werden (vgl. ZIMMERMANN 1992, 262).

Auch unter den Befunden ohne Brandspuren finden sich sicherlich Gruben, die zur Vorratshaltung dienten. Eine Reihe von Gruben haben im Planum A1 einen nahezu kreisrunden Durchmesser von 0,91,40m (Kat.Nr. 98; 119; 120; 123; 380; 403; 756; 832; 891; 895; 1086; 1070; 1113; 1120). Sie sind über die gesamte Siedlung verteilt, meist nicht mehr als drei Gruben innerhalb eines Radius von 10m. Rundovale Gruben mit einem Durchmesser von 1,7-2m sind eher in den Randbereichen der Siedlung anzutreffen (Kat.Nr. 243; 223, 635; 703; 763; 807; 927/1070; 1272; 1280; 1289). Zumeist haben die Gruben ein mulden- oder trichterförmiges Profil von 30-60cm Tiefe. Andernorts sind runde Erdspeicher mit steiler Wandung durch Getreidefunde in ihrer Funktion belegt. So beispielsweise in Rullstorf, Landkreis Lüneburg (BEHRE 1990, 141-165).

Speichergruben mit Holzeinbauten fehlen in Nortmoor bzw. die Einbauten haben sich in den flach eingetieften Gruben nicht erhalten. Hinweise auf inzwischen vergangene Versteifungen der Grubenwand geben scharfkantige Profilverläufe mit humosen Kanten. Stellenweise fand sich eine dünne Trennschicht, wobei es sich wahrscheinlich um eine ehemalige Holzverschalung oder ähnliches gehandelt haben wird. Unterirdische Silos können auch mit Flechtwerk ausgekleidet gewesen sein (VAN Es u.a. 1985, 578).

Unter den Siedlungsgruben existiert eine Gruppe mit flacher Grubensohle. Die Gruben sind im Planum oval, rechteckig oder viereckig, so dass sich hier keine Kategorisierung ableiten lässt. Ein Teil der Gruben kastenförmig eingetieft mit senkrechten Grubenwänden (Kat.Nr. 120; 122; 425; 510; 562). Daneben existieren trichterförmige Grubenprofile (Kat.Nr. 223; 369; 440), wie auch kastenförmig abgetiefte Gruben, die sich erst im oberen Grubenbereich verbreitern (Kat.Nr. 425). Gruben mit flacher Sohle und steiler Wandung gehören in Wijster dem Typ I B an, der kennzeichnend für 
Kellergruben ist (VAN Es 1967, 117). In diesen Deutungshorizont gehören vermutlich langrechteckige Gruben, wie sie in Nortmoor mit Grubenlängen von 1-1,77m und einer Breite von 0,55-0,7m auftreten (Kat.Nr. 94; 109; 116; 181; 345; 435; 450; 512; 520; 599; 752; 758; 760; 840; 845; 893; 900; 901; $1117 ; 1281 ; 1284)$.

Bei mittelgroßen Gruben mit länglich-rechteckiger Aufsicht und einer Länge zwischen 2-3m (Mittelwert 2,20m) und einer Grubenbreiten zwischen 0,85-1,45m (Mittelwert 1,20m), finden sich vorwiegend muldenförmige Profile (Kat.Nr. 27; 188; 408; 412; 462; 499; 509; 582; evtl. 635; 656; 703; 755; 811; 928; evtl. 939; 1263). Nur zwei Gruben dieser Untergruppe besitzen ein kastenförmiges Profil (Kat.Nr. 330; 331). Getreidekörner als ein eindeutiger Beleg für eine Silolagerung fehlen in Nortmoor. Dies ist nicht weiter verwunderlich, da eine Schlämmung der Grubeninhalte unterblieb und Getreidereste mit bloßem Auge nur schwer zu erkennen sind. Dennoch ist eine Erdsilolagerung in Nortmoor wahrscheinlich.

Dominieren in zahlreichen Publikationen runde Erdspeicher mit steiler Wandung und teils beachtlicher Tiefe in der Gruppe der typischen Vorratsgruben, so stellt dies vermutlich eine Folge des Wiedererkennungswertes in der Grubenansprache dar. Inzwischen finden sich vermehrt rechteckige, meist gering eingetiefte Gruben, die als Erdspeicher verwendet wurden. So liegen aus einem kaiserzeitlichen Gebäude in Bennekom rechteckige Gruben vor, die vermutlich zur Vorratshaltung dienten (BRABANDT 1993, 42, Taf. 84,3). Auch in Flögeln, wo zwar ovale Erdspeicher überwiegen, sind unter den Speichergruben rechteckige Gruben vertreten (ZIMMERMANN 1992, 262-264, 269, Abb. 212). Hier diente als wichtiges Erkennungsmerkmal eine Rotsand-Konzentration auf der Grubensohle, die beide Grubentypen auswiesen. Getreide- wie Holzkohlefunde stärken die Ansprache als Speicher.

Wahrscheinlich als Arbeitsgrube anzusprechen ist die Grube Kat.Nr. 188, die große Mengen an Keramik und Holzkohle enthielt, zudem Flint, Schlacke-Brocken, gebrannten Lehm, Tierknochen und Steine wie auch einen Spinnwirtel. Tendenziell sind es überwiegend kleinformatige Gruben mit rundovalem bis länglichem Durchmesser im Planum (Kat.Nr. 49; 94; 167; 583; 756; 806; 814) aus denen Keramik, gebrannter Lehm und Flint stammen. Nur zwei Gruben (Kat.Nr. 130; 763) besitzen einem Radius von $2 \mathrm{~m}$. Werkgruben können dabei unterschiedliche Funktion erfüllen (vgl. VAN ES 1985, 623) auf die hier jedoch mangels aussagekräftiger Belege nicht näher eingegangen wird.

Möglicherweise um eine Rottungsgrube oder ähnliches handelt es sich bei Kat.Nr. 395 (Abb. 18). Die mit Flechtwerk ausgesteifte Grube im Quadranten 58/55 liegt an der Nordgrenze der Siedlung und ist einer der nördlichsten Befunde. Das Flechtwerk war weitmaschig geflochten und wies zahlreiche Lücken auf, so dass hier weniger an eine ausgesteifte Brunnengrube zu denken ist. 
Infolge des hohen Grundwasserspiegels ist auch von einer Speicherung eines trockenen Lagergutes abzusehen. Die deckende Torfschicht 5, die nördlich des Befundes noch eine Mächtigkeit von $13 \mathrm{~cm}$ aufwies $(+0,33$ bis $+0,46 \mathrm{~m}$ bis $\mathrm{NN})$, bewahrte die Bodenfeuchtigkeit und begünstigte die Holzerhaltung.

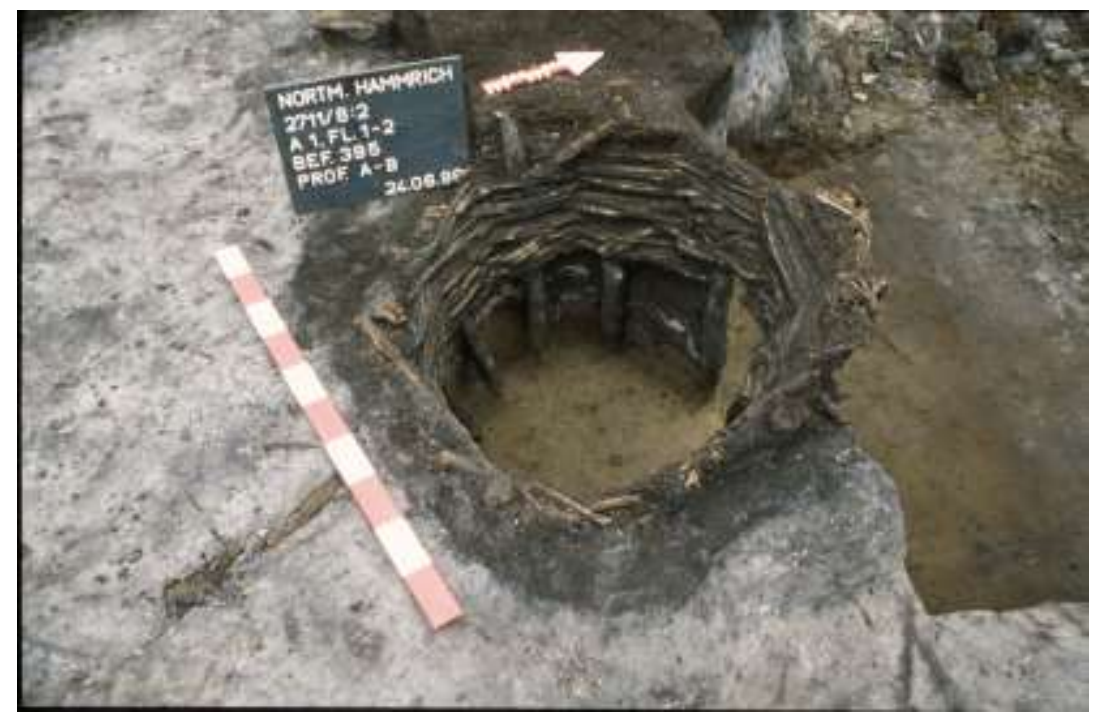

Abb. 18

Blick in die ausgegrabene Werkgrube Kat.Nr. 395

Im Planum A1 zeichnete sich eine dunkelbraune runde und etwa 1 Meter durchmessende Verfärbung ab unter der man ein ovales Korbgeflecht mit einem Durchmesser von $70 \mathrm{~cm}$ entdeckte. Die Grube war in die Schichten 5 und 7 eingetieft.

Während die Grubensohle bei $-0,07 \mathrm{~m}$ NN anstand, war das Korbgeflecht bis in eine Höhe von $+0,48 \mathrm{~m}$ NN erhalten. Die Grube war mit Torf angefüllt. In ihrem unteren Bereich fanden sich weiße Sandeintragungen mit einer Stärke von $5-10 \mathrm{~cm}$.

Der Weidenkorb bestand aus 11 Holzstaken, die an ihrem unteren Ende angebeilt waren, um sie besser in den gewachsenen Boden einzutreiben. Um die unten ineinanderlaufenden 5-7cm durchmessenden Staken wand sich ein relativ grobes Flechtwerk mit 12 Lagen Weidenruten von unterschiedlicher Stärke (zwischen 0,5-2,0cm). Dieses setzte jedoch erst $23 \mathrm{~cm}$ über der Grubensohle ein. Das Flechtwerk war im oberen Bereich der Holzstaken auf ca. $40 \mathrm{~cm}$ eingeflochten. So entstand ein ovaler Korb mit einem Durchmesser von 80x90cm, wobei der Boden ausgespart blieb. Im Anschluss wurde die Baugrube mit Bodenmaterial aufgefüllt (395d). Keramikscherben, wie der Rand einer Trichterschale und zweier Gefäßränder mit kurz-verdickter Randlippe, datieren in die ältere Kaiserzeit. Das zerscherbte Material, darunter auch zwei Fehlbrände, gelangte erst nach Aufgabe der Anlage in die Grube. Umgebungsbefunde fehlen weitgehend. Zwar schloss sich wenige Meter westlich ein 
Gemenge von unsystematisch verteilten Holzfragmenten an; anthropogene Bearbeitungsspuren fehlen jedoch.

Hinweise auf eine lokale Metallverarbeitung geben Schlackenfunde aus dem Siedlungsareal. Wenige Gruben sind schlackehaltig (Kat.Nr. 188; 748). Ihre Anzahl ist für eine verlässliche Schlussfolgerung bezüglich lokaler Ausheiz- und Schmiedeherde jedoch zu gering. Die restlichen Schlacken stammen zum Großteil aus Gräben. Ferner fand man diverse Schlacke-Brocken als Lesefunde über die gesamte Düne verstreut. Die Fundgruppe Metallschlacken wird separat vorgelegt (vgl. Kap. Schlacken). Zur Bedeutung von Schlacken sei auf die kaiserzeitliche Siedlung Bennekom verwiesen (vgl. VAN ES 1985, 582, Abb. 24-25).

Möglicherweise handelte es sich bei einigen Gruben um von Regenwasser gespeiste Wasserstellen (Kat.Nr. 475; 834; 844; 891). Das eingeschwemmte Material in Form feiner weißer oder gelber Sandbänder auf der Grubensohle weist auf stehendes Wasser hin und legt ein längeres Offenstehen der Gruben nahe. In wenigen Fällen wurde auch eine undurchlässige Schicht durch das Auskleiden der Grube mit Lehm erzeugt (Kat.Nr. 1082; 999).

Dies muss jedoch nicht notwendigerweise mit einer Nutzung als Wasserreservoire verbunden gewesen sein. Dies zeigt das Beispiel zweier Siedlungsgruben im 4km entfernten Hohegaste. Dort gelang es bei den 2,8x2,3m und 2,8x3m durchmessenden Gruben eine 10-40 cm starke Tonschicht, die flächig die gesamte Grubenwand bedeckte, zu dokumentieren (STILKE 1995, 209). Die so präparierten Gruben dichteten den sandigen Untergrund wasserundurchlässig ab. Einer Deutung als Zisterne wiederspricht ihre nur noch flach muldenförmige Gestalt von $20 \mathrm{~cm}$ Tiefe. Möglicherweise kann daher eine, wenn auch bisher unbekannte, Funktion im Hand- oder Hauswerk in Betracht gezogen werden.

Einige der eher unspezifischen Gruben in Nortmoor wurden möglicherweise zur Lehmentnahme angelegt. Derartige Siedlungsgruben finden sich in nahezu allen kaiserzeitlichen Siedlungen. Mit Häcksel gemischter tonhaltiger Kleiboden eignet sich zum Verputzen von Flechtwerkwänden an Gebäuden und Umzäunungen (HAARNAGEL 1979, 80-84; ZIMMERMANN 1992, 140). Oftmals erfolgte eine sekundäre Nutzung als Latrine oder Abfallgrube. Belegt ist die spätere Nutzung als Fäkaliengrube in Nortmoor nicht. Es ist jedoch davon auszugehen, dass sich entsprechende Latrinen in der Nähe der Wohnbebauung befunden haben, wie es beispielsweise von der Feddersen Wierde überliefert ist (HAARNAGEL 1979, 115).

Zum Großteil gehören die Gruben der kaiserzeitlichen Siedlungsphase an. Eine kleine Gruppe von Gruben enthält mittelalterliche Funde, wie Muschelgrus gemagerter Keramik und / oder harte Grauware (Kat.Nr. 10; 25; 27; 31; 32; 44; 46; 49; 50;115; 120; 123; 169; 190 (?); 212; 223; 345; 409; $410 ; 411 ; 425)$. 


\subsubsection{Gräben}

Kat.Nr. 78; 125; 141; 160; 165; 187; 202; 254; 278; 346; 383; 392; 400; 402; 427; 429; 432; 434; 455; 463a; 493; 513; 515; 516; 517; 518; 521; 551; 579; 584; 627; 637; 651; 653; 670; 691; 698; 702; 731; 744; 745; 746; 748; 757; 760; 796; 810; 836; 845; 859; 869; 884; 885a; 893; 906; 915; 982; 1089; $1118 ; 1207 ; 1233 ; 1279$

Differenzieren lassen sich hausbegleitende Gräben $(n=6)$, von Gräben innerhalb der Gebäude $(n=2)$ und sonstige Gräben, meist unbekannter Funktion, wobei letztere eindeutig überwiegen ( $n=53)$. Die Nortmoorer Gräben zeichnen sich durch ein meist hohes Fundaufkommen aus, insbesondere an Keramikscherben, gefolgt von kalzinierten Knochenstücken, Steinen sowie Lehm- und HK-Brocken. Dies alles deutet an, dass ihre letztmalige Verwendung im Bereich der Abfallentsorgung zu suchen ist.

Zwei Hausplätze (II und III) sind in Nortmoor von Gräben umgeben (Kat.Nr. 493; 627; 637; 670; 702; 836). Ihre Maße variieren zwischen 0,30-1,20m in der Breite und 0,17-43cm in der Tiefe (Mittelwert 25cm). Die 1,40-6,5m langen Gräben verlaufen weitgehend parallel zur Hauslängsseite. Ihr Abstand zur Pfostenreihe gibt in etwa den Überhang des Daches an, der zwischen 0,4-1,2m betragen haben wird. Ob die Gräben ehemals die gesamte Hauslänge begleiteten, ist nicht mehr zu klären.

Südwestlich von Haus II ist ein 1m breiter und 6,5m langer Graben erhalten (Kat.Nr. 637). Von der Langseite des Hauses ist der Graben 1-1,3m entfernt. Der muldenförmige und bis zu $35 \mathrm{~cm}$ eingetiefte Graben datiert anhand des keramischen Materials in die ältere römische Kaiserzeit. Das Gebäude verfügt über zwei weitere hausbegleitende Gräben kleineren Ausmaßes (Kat.Nr. 627; 670). Auch diese Gräben sind annähernd langrechteckig, jedoch mit einem Abstand von 0,4m an die Gebäudeaußenseite herangerückt. Die 3,4m langen und 1-1,2m breiten Gräben sind ebenfalls reich an kaiserzeitlichem Fundmaterial, darunter eine silberne Zierscheibe und Terra nigra-artige Schalen (Taf. 39; 41).

Haus III besitzt zwei hausparallele Gräben an seiner Südseite. Die 4,5-6m langen und 35-80cm breiten Gräben liegen in einer Flucht (Kat.Nr. 702; 836). Möglicherweise ist die 10,9m große Unterbrechung zwischen ihnen erhaltungsbedingt. Der Dachüberstand wird in etwa $1,2 \mathrm{~m}$ betragen haben. In den Traufgräben sammelte sich das Regenwasser und die nahen Lehmwände der Gebäude wurden vor Feuchtigkeit geschützt. Auch in diesen Gräben fanden sich zahlreiche kaiserzeitliche Keramikscherben.

Ungewöhnlich ist in den vorgetragenen Beispielen, dass sie an einem Gebäude je nach Hausseite unterschiedliche Entfernungen zum Haus aufweisen. Dieselbe Beobachtung wurde bei kaiserzeitlichen Gebäuden in Flögeln gemacht. Nach ZIMMERMANN $(1992,151)$ weist dies auf unterschiedlich tief 
hinabgezogene Dachüberhänge hin. Hohe Phosphatwerte in diesem Areal lassen bei Wohnbauten in Flögeln auf einen Abtritt schließen und finden sich auf der Südseite der Gebäude (ZIMMERMANN 2015, 18). Diese bot Mensch und Tier eher Schutz vor Nässe bzw. Wind als die wetterausgesetzte Hausseite, die den im Küsterraum vorherrschenden kalten Nordwinden ausgesetzt war.

Vereinzelt finden sich Gräben innerhalb von Gebäuden. Über die gesamte Querbreite des Mittelschiffes von Hausplatz I verläuft im Westteil des Gebäudes ein 500x90cm großer Graben. Kat.Nr. 434 war zwischen $22-43 \mathrm{~cm}$ eingetieft und enthielt HK-Brocken, gebrannten Lehm, Keramikscherben und einen Flintabschlag. Im Profil war deutlich eine Schichtung mit tonigem Sand und einem Sand-Klei-Gemisch erkennbar. Die Schwemmlinien oberhalb der Grabensohle weisen auf ein längeres Offenstehen des Grabens hin.

Im Ostteil des Gebäudes II liegt nahe der nördlichen Langseite ein 2,1m langer und 0,85m breiter Graben (Kat.Nr. 582). Der nur $13 \mathrm{~cm}$ eingetiefte Befund weist eine homogene Verfüllschicht auf, die keine Rückschlüsse auf seine ursprüngliche Funktion erlauben. Nach Aufgabe des Grabens wurde dieser zur Abfallentsorgung genutzt. Das keramische Material datiert in die Kaiserzeit.

Eine Häufung kaiserzeitlicher Gräben ist in den Quadranten 52/41 bis 56/46 zu beobachten. Es handelt sich hierbei sowohl um Gräben, die diagonal zur Dünenlangseite verlaufen (Kat.Nr. 744; 579; 515; 516) wie um weitgehend parallel ausgerichtete Gräben (Kat.Nr. 432; 455; 436a; 513; 517; 518; 521; 551; 584; 691). Unter der letztgenannten Gruppe sind vier L-förmige Gräben (Kat.Nr. 513; 521; 584; 691). Während die Breite der Gräben relativ einheitlich zwischen 0,7-1,6m (Mittelwert 1,3m) liegt, können sie Längen zwischen 5-15,9m erreichen.

Die aus der Umgebung der Hausplätze I und II stammenden Gräben (Kat. 432; 513; 521 und 551) sind anhand stratigraphischer Abfolgen zu den Speicherbauten SP 5 und 6 als relativchronologisch älter anzusehen. Denkbar ist eine Funktion als Lehmentnahmegräben für die Flechtwerkswände der benachbarten Gebäude. Aufgrund ihres großen Abstandes zum Hausplatz III könnte es sich bei den Gräben Kat.Nr. 516 und 744 um Entwässerungsgräben gehandelt haben (vgl. HAARNAGEL 1979, 160). Bei von den Gebäuden entfernter liegenden Gräben kann es sich um Entwässerungsgräben der Hofstellen gehandelt haben. Schwemmlinien im unteren sohlenahen Bereich weisen auf ein längeres Offenstehen von einigen Gräben hin. Möglicherweise gehörten sie zu einem System von Entwässerung- und/oder Begrenzungsgräben. Ihr reiches Fundmaterial datiert die langrechteckigen, wie auch die L-förmigen Gräben in die römische Kaiserzeit, schwerpunktmäßig in das 2. und 3. Jahrhundert. 
Bei einem Großteil der Gräben ist ihre Funktion nicht mehr zu ermitteln, da sie weder im Planum noch im Profil besondere Auffälligkeiten zeigen. Einzig die letzte Nutzung der Gräben ist durch den hohen Fundanteil im Bereich der Abfallentsorgung zu sehen.

\subsubsection{Wasserversorgung}

Zur Wasserversorgung der Siedlung Nortmoorer Hammrich dienten Brunnen und Wasserentnahmegruben. Insgesamt gelang es 10 Brunnen und eine Wasserstelle vollständig zu dokumentieren. Die meisten Anlagen gehören der kaiserzeitlichen Siedlung des 1.-3. Jahrhunderts an. Drei Brunnen können anhand ihrer Konstruktionsweise sowie den frühmittelalterlichen Keramikfunden aus ihrer Brunnengrube in die mittelalterliche Siedlungsphase datiert werden.

Während die oberen Brunnenwandungen in den meisten Fällen bereits vergangen waren, erhielten sich tiefer eingebrachte Einbauten aufgrund des hohen Grundwasserspiegels.

Verwendung als Brunnenschacht fanden ausgehöhlte Baumstämme, Flechtwerk-Konstruktionen oder mehrteilige Rahmenwerke. Als Baumaterial für einige Nortmoorer Brunnen diente Weichholz (Erle, Birke, Weide). Für konstruktiv wichtige Bauteile verwendete man Eichenholz. Sorgfältig ausgearbeitete Verzapfungen stabilisierten das Rahmenwerk und senkrecht eingebrachte Staken verstärkten die Kastenkonstruktion.

Die nachstehende Gegenüberstellung ermöglicht einen direkten Vergleich für die im folgenden einzeln dargestellten Anlagen der Nortmoorer Wasserversorgung (Tab. 4).

Rahmeneinbauten fanden sich bei drei Brunnen (Kat.Nr. 265; 335; 740). Einen ausgehöhlten Baumstamm als Brunnenröhre wiesen vier Anlagen auf (Kat.Nr. 26; 394; 650; 1084). Die Überreste zweier Flechtwerkkonstruktionen dienten ebenfalls als Brunneneinbau (Kat.Nr. 409; 747). In einem Fall wurde ein Schachtbrunnen nachgewiesen (Kat.Nr. 140). Mit 6,5m ungewöhnlich groß war eine Wasserstelle nahe der Dünenkuppe gelegen (Kat.Nr. 195). Aus ihrer Verfüllung stammte eine hölzerne Treppenstufe, die nach dendrochronologischer Analyse in das Jahr „126 n. Chr. ${ }^{+/ 10 “ ~}$ datiert.

Zu den größeren Anlagen der lokalen Wasserversorgung gehörten die rechteckigen Kastenbrunnen. Im Planum A 1 nahmen sie eine Fläche von 1-1,7qm ein. Mit den geringsten Abmessungen hatten Baumstammbrunnen mit einem Durchmesser von $43 / 53 \mathrm{~cm}$ bis $90 \mathrm{~cm}$, sowie die mit Flechtwerk ausgesteiften Anlagen. Die kaiserzeitliche Wasserstelle mit einem Durchmesser von 6-6,50m stellte mit Abstand die größte Anlage der Nortmoorer Wasserversorgung dar.

Die Anlagen zur Wasserversorgung fanden sich in Nortmoor vorwiegend auf der flusszugewandten Seite der Düne. Nur vier Brunnen wurden auf der Dünennordseite entdeckt (Kat.Nr. 394; 409; 335; 650). Die Höhenlage der Geländeoberkante war bei den einzelnen Brunnen zwischen $+0,28 \mathrm{~m}$ bis 
$+1,52 \mathrm{~m} \mathrm{NN}$ anzutreffen, wobei zur Errichtung eines Brunnens eine Geländehöhe von $+0,9 \mathrm{~m}$ bis $+1,35 \mathrm{~m}$ NN bevorzugt wurde. Nur zwei Anlage lagen zwischen $+0,34$ und $+0,65 /+0,8 \mathrm{~m} \mathrm{NN}$ (Höhe Planum A 1).

\begin{tabular}{|c|c|c|c|c|c|}
\hline Brunnentyp & $\begin{array}{l}\text { Kat. } \\
\text { Nr. }\end{array}$ & $\begin{array}{l}\text { Gelände } \\
\text {-Höhe } \\
\text { NN }\end{array}$ & $\begin{array}{l}\text { Brunnensohle NN / } \\
\text { erhaltene Höhe der } \\
\text { Brunnenfassung NN }\end{array}$ & \multicolumn{2}{|c|}{$\begin{array}{l}\text { Maße / Form } \\
\text { im Planum A1 }\end{array}$} \\
\hline Kastenbrunnen & 740 & $\begin{array}{l}+0,34 \text { bis } \\
+0,41 \mathrm{~m}\end{array}$ & $\begin{array}{l}-0,45 \mathrm{~m} \\
+0,44 \mathrm{~m}\end{array}$ & $\begin{array}{l}\text { Holzrahmen oben u. unten, } \\
\text { Holzstakenwand }\end{array}$ & $\begin{array}{l}1,7 \mathrm{x} 1,3-1,7 \mathrm{~m} \\
\text { viereckig }\end{array}$ \\
\hline Kastenbrunnen & 265 & $\begin{array}{l}+1,12 \text { bis } \\
+1,18 \mathrm{~m}\end{array}$ & $\begin{array}{l}+0,25 \mathrm{~m} \\
+0.80 \mathrm{~m}\end{array}$ & $\begin{array}{l}\text { Holzrahmen oben, } \\
\text { Holzstakenwand }\end{array}$ & $\begin{array}{l}1 \mathrm{x} 1 \mathrm{x} 1 \mathrm{~m} \\
\text { quadratisch }\end{array}$ \\
\hline Kastenbrunnen & 335 & $\begin{array}{l}+1,20 \text { bis } \\
+1,36 \mathrm{~m}\end{array}$ & $\begin{array}{l}+0,46 \mathrm{~m} \\
+0,86 \mathrm{~m}\end{array}$ & Holzrahmen unten & $\begin{array}{l}1,7 \times 1,55 \mathrm{~m} \\
\text { viereckig }\end{array}$ \\
\hline $\begin{array}{l}\text { Baumstamm- } \\
\text { brunnen }\end{array}$ & 26 & $\begin{array}{l}+1,25 \text { bis } \\
+1,34 \mathrm{~m}\end{array}$ & $\begin{array}{l}+0,42 \mathrm{~m} \\
+1,00 \mathrm{~m}\end{array}$ & $\begin{array}{l}\text { Baumstammring, } \\
\text { lose Holzstaken }\end{array}$ & $\begin{array}{l}0,9 \mathrm{~m} \\
\text { rund }\end{array}$ \\
\hline $\begin{array}{l}\text { Baumstamm- } \\
\text { brunnen }\end{array}$ & 650 & $\begin{array}{l}+1,30 \text { bis } \\
+1,45 \mathrm{~m}\end{array}$ & $\begin{array}{l}-0,20 \mathrm{~m} \\
+0,80 \mathrm{~m}\end{array}$ & $\begin{array}{l}\text { Baumstammring, } \\
\text { Stakenboden, Sodenwand }\end{array}$ & $\begin{array}{l}0,60 \mathrm{~m} \\
\text { rund }\end{array}$ \\
\hline $\begin{array}{l}\text { Baumstamm- } \\
\text { brunnen }\end{array}$ & 394 & $\begin{array}{l}+0,65 \text { bis } \\
+0,80 \mathrm{~m}\end{array}$ & $\begin{array}{l}+0,50 \mathrm{~m} \\
+0,78 \mathrm{~m}\end{array}$ & $\begin{array}{l}\text { Baumstammring, } \\
\text { lose Holzstaken }\end{array}$ & $\begin{array}{l}0,43-0,53 \mathrm{~m} \\
\text { rund }\end{array}$ \\
\hline $\begin{array}{l}\text { Baumstamm- } \\
\text { brunnen }\end{array}$ & 1084 & $+1,35 \mathrm{~m}$ & $\begin{array}{l}+0,73 \mathrm{~m} \\
+1,20 \mathrm{~m} \\
\text { (geschätzte Oberkante) }\end{array}$ & $\begin{array}{l}\text { dünne humose Trennschicht } \\
\text { als Überrest der vergangenen } \\
\text { Brunnenwandung }\end{array}$ & $\begin{array}{l}0,4 \mathrm{~m} \\
\text { rund }\end{array}$ \\
\hline $\begin{array}{l}\text { Flechtwerk- } \\
\text { Konstruktion }\end{array}$ & 409 & $+1,05 \mathrm{~m}$ & $\begin{array}{l}+/-0 \mathrm{~m} \\
+0,64 \mathrm{~m}\end{array}$ & geflochtener Korb & $\begin{array}{l}1,1 \mathrm{x} 0,68 \mathrm{~m} \\
\text { oval }\end{array}$ \\
\hline $\begin{array}{l}\text { Flechtwerk- } \\
\text { Konstruktion }\end{array}$ & 747 & $\begin{array}{l}+1,20 \text { bis } \\
+1,37 \mathrm{~m}\end{array}$ & $\begin{array}{l}+0,65 \mathrm{~m} \\
+0,85 \mathrm{~m}\end{array}$ & $\begin{array}{l}\text { Flechtwerk um Holzstaken } \\
\text { geflochten }\end{array}$ & $\begin{array}{l}0,9 \mathrm{~m} \\
\text { rund }\end{array}$ \\
\hline Schachtbrunnen & 140 & $\begin{array}{l}+0,95 \text { bis } \\
+1,10 \mathrm{~m}\end{array}$ & $\begin{array}{l}+0,10 \mathrm{~m} \\
+0,60 \mathrm{~m}\end{array}$ & lose Holzstaken & $\begin{array}{l}1,4 \mathrm{~m} \\
\text { rund }\end{array}$ \\
\hline Wasserstelle & 195 & $\begin{array}{l}+1,30 \text { bis } \\
+1,52 \mathrm{~m}\end{array}$ & $\begin{array}{l}+0,32 \mathrm{~m} \\
+0,97 \mathrm{~m}\end{array}$ & $\begin{array}{l}\text { lose Holzstaken, senkrecht } \\
\text { stehend, z.T. liegend } \\
\text { zwei Treppenstufen erhalten }\end{array}$ & $\begin{array}{l}6 x 6,5 \mathrm{~m} \\
\text { rund }\end{array}$ \\
\hline
\end{tabular}

Tab. 4

Die Nortmoorer Brunnenanlagen. Angegeben sind die Oberkante der Brunnenanlagen (Planum A1), die Brunnensohle sowie die maximale NN-Höhe der Holzerhaltung, Einbauten und ihrer Maße.

Unterschiedlich tief waren die Anlagen ausgekoffert. Hier finden sich Tiefenwerte von $-0,45 \mathrm{~m}$ bis $+0,97 \mathrm{~m}$ NN. Es zeichnet sich für die Brunnensohlen eine Häufung zwischen $+0,25$ bis $+0,50 \mathrm{~m} \mathrm{NN}$ ab. 
Die Tiefe der Brunnen lässt Rückschlüsse auf ehemalige Wasserstände zu und so ist, wenn auch nur im kleinräumigen Umfeld, eine diesbezügliche Umweltrekonstruktion möglich.

Manchemal scheinen die Dimensionen der Brunnengruben mit Durchmessern von 0,4-0,6m, wie bei dreien der vier Baumstammbrunnen (Kat.Nr. 394; 650; 1084), recht gering gewesen zu sein. Um ausreichend Wasser zu schöpfen, wird dies bei den hoch anstehenden grundwasserführenden Schichten in Nortmoor dennoch genügt haben.

Gibt das obere Ende der Hölzer das Niveau an, unterhalb dessen ein dauerfeuchtes Milieu herrschte, so sind hier Schwankungen von $+0,44 \mathrm{~m}$ bis $+1 \mathrm{~m}$ NN zu vermerken. Oberhalb davon waren die Hölzer durch Sauerstoffzufuhr verrottet. Bei acht Brunnen ist die obere Brunnenfassung in eine NN Höhe zwischen $+0,78 \mathrm{~m}$ bis $+1 \mathrm{~m}$ NN erhalten.

Dendrochronologische Untersuchungen waren für Hölzer aus drei Anlagen beim Labor DELAG in Auftrag gegeben worden. Während die Brunnen Kat.Nr. 26 und 740 keine verwertbaren Ergebnisse erbrachten, liegen aus der Wasserstelle Kat.Nr. 195 dendrodatierte Hölzer von „>97 n. Chr.“ bis „>186 n. Chr." vor, die eine Nutzungsdauer von nahezu 100 Jahren wahrscheinlich machen.

Mit Ausnahme von zwei Brunnengruben lag der Grundwasserspiegel während der Ausgrabung unterhalb der Brunnensohle. Dies deutet zusammen mit der meist recht guten Holzerhaltung, die bis in eine Höhe von $+1,01 \mathrm{~m}$ NN reichte, darauf hin, dass erst in neuerer Zeit der Grundwasserspiegel abgesenkt wurde. Hierfür sind die seit den 60er Jahren des 20. Jahrhunderts durchgeführten Entwässerungsmaßnahmen in der Jümme-Niederung verantwortlich.

Auf einen eher handwerklich genutzten Bereich weisen mehrere Brunnenanlagen im westlichen Bereich der Siedlung. Es handelt sich hierbei um Brunnen bzw. brunnenähnliche Anlagen, die holzversteifte oder ausgeflochtene Einbauten aufweisen. Aus technisch-funktionaler Sicht ergibt sich die Möglichkeit für Rottungsgruben, um organische Materialien in einem feuchten Milieu geschmeidig zu machen. Insbesondere die massive Hebevorrichtung bei Kat.Nr. 740 und seine durch das umgebende Moor wohl recht saure Wasserqualität lassen für die Anlage eine Nutzung als Brunnen weniger wahrscheinlich erscheinen, sondern deuten eher auf eine Werkgrube, eventuell eine Gerbergrube, hin.

Nicht immer kann eine eindeutige Abgrenzung zwischen Brunnen und Werkgruben vorgenommen werden. Die Höhe des örtlichen Grundwasserspiegels im Verhältnis zum Basisniveau steht bei einigen Anlagen einer Ansprache als Vorratsgrube entgegen, weil in ihnen nichts trocken eingelagert werden konnte.

Die dennoch recht große Anzahl an Brunnen zeigt, dass den kaiserzeitlichen Gehöften in Nortmoor wenigstens 1-2 dieser Anlagen angehörten. Es fällt außerdem auf, dass die Brunnen unregelmäßig 
über die gesamte Düne verteilt sind. Dies ist im Unterschied zu Flögeln zu sehen, wo eine Konzentration der Brunnen im östlichen Siedlungsteil stattfand und selbst in diesem Bereich nicht jeder Hof des 2./3. Jahrhunderts seine eigene Wasserversorgung besaß (ZIMMERMANN 1992, 292).

\section{Brunnen}

Kat.Nr. 740

Taf. 42; 56; 99

Im Vergleich zu den übrigen Brunnen ist die Anlage Kat.Nr. 740 am Besten erhalten und vermittelt eindrucksvoll die Konstruktion eines kaiserzeitlichen Holzrahmenbrunnens. Der Brunnen fand sich auf der südlichen Dünenseite nahe der Grabungsgrenze. Die Oberfläche stand zwischen $+0,9 \mathrm{~m}$ und $+1 \mathrm{~m} \mathrm{NN}$ an.

Im Planum A1 war im Quadranten 52/42 eine annähernd rechteckige Verfärbung mit den Maßen von $3,4 \times 3,6 \mathrm{~m}$ zu erkennen. Unter einer grauen kleihaltigen Bodenverfärbung entdeckte man die Brunnenanlage. Bis in einer Höhe von $+0,44 \mathrm{~m}$ NN war das Holz der oberen Rahmenkonstruktion erhalten. Nördlich des Brunnens fanden sich zwei eingetriebene Baumstämme einer zugehörigen Hebekonstruktion, die auf einer Länge von 2,13m erhalten waren.

Die Baugrube war in die Torfschicht 5 und den darunter anschließenden pleistozänen Sandboden eingetieft. Ein räumlicher Bezug zu Baukomplexen in der Umgebung fehlt. Hausplatz III lag etwa $19 \mathrm{~m}$ nordwestlich von der Anlage, Hausplatz II war 27m nordöstlich davon entfernt.

Die Oberkante des 1,30-1,70x1,70m großen Kastens befand sich nur 10cm unter der Grabungsfläche. Der Nordsüd orientierte Brunnenkasten war direkt in den Torfboden eingetieft. Seine Sohle wurde bei $-0,45 \mathrm{~m}$ NN erreicht. Im Profil zeichnete sich ein trapezförmiger Brunnenschacht ab (Abb. 19).

Die Seitenwände der Anlage bestanden aus Birkenholzstaken, die senkrecht bzw. leicht schräg in den Boden eingeschlagen wurden. Mittels eines Rahmenwerkes aus bearbeiteten Weich- und Eichenhölzern waren die Staken miteinander versteift. Dokumentiert werden konnte ein oberes und ein unteres Rahmenwerk. Vermutlich war diese Bauweise dem starken Bodendruck und dem hohen Grundwasserstand in der Dünenrandlage geschuldet.

Das untere Rahmenwerk wies ein Innenmaß von 1,10x1,10m auf (Kat.Nr. 740d). Die Rundhölzer waren längs gespalten und grob bearbeitet. Um die Stabilität der Rahmenkonstruktion zu erhöhen, wurden die Enden der Kanthölzer durchlocht bzw. zapfenartig ausgearbeitet und ermöglichten so eine haltbare Eckverbindung. An diese wurden im Anschluss dann 6-8cm durchmessende Holzstaken dicht nebeneinander angesetzt bzw. eingeschlagen. 


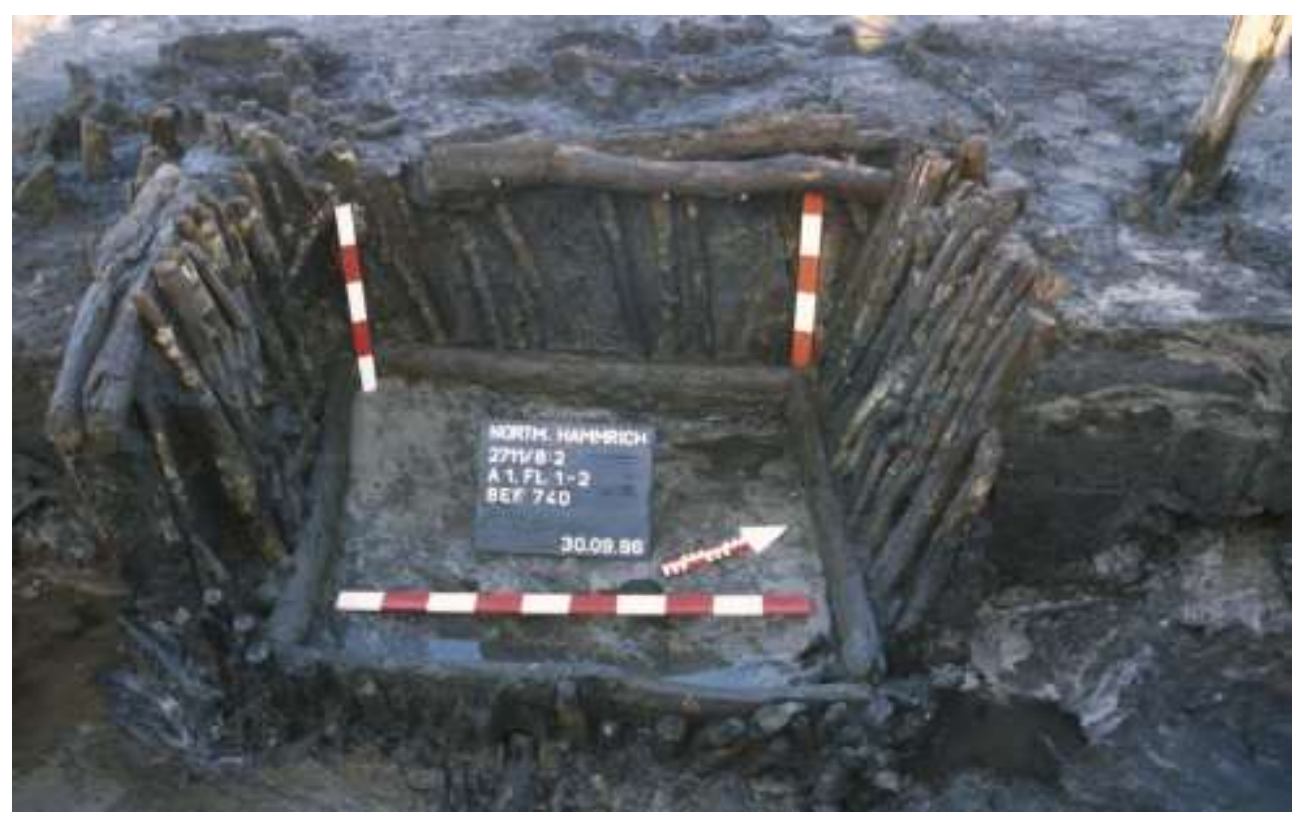

Abb. 19

Hölzerne Rahmenkonstruktion Brunnen 1. Rechts im Bild ein Eichenstamm der Hebekonstruktion.

Die durchschnittlich 1-1,2m langen Birkenholzstaken wurden teilweise bis $\mathrm{zu} 25 \mathrm{~cm}$ unter der Brunnensohle in den gewachsenen Boden eingetrieben. Danach wurde das obere Rahmenwerk eingesetzt. Deren Hölzer waren beidseitig mit Nut oder Zarge versehen (Abb. 20). Auf eine spätere Reparaturstelle am oberen Rahmen weist die doppelte Stakenreihe an der Südseite hin.

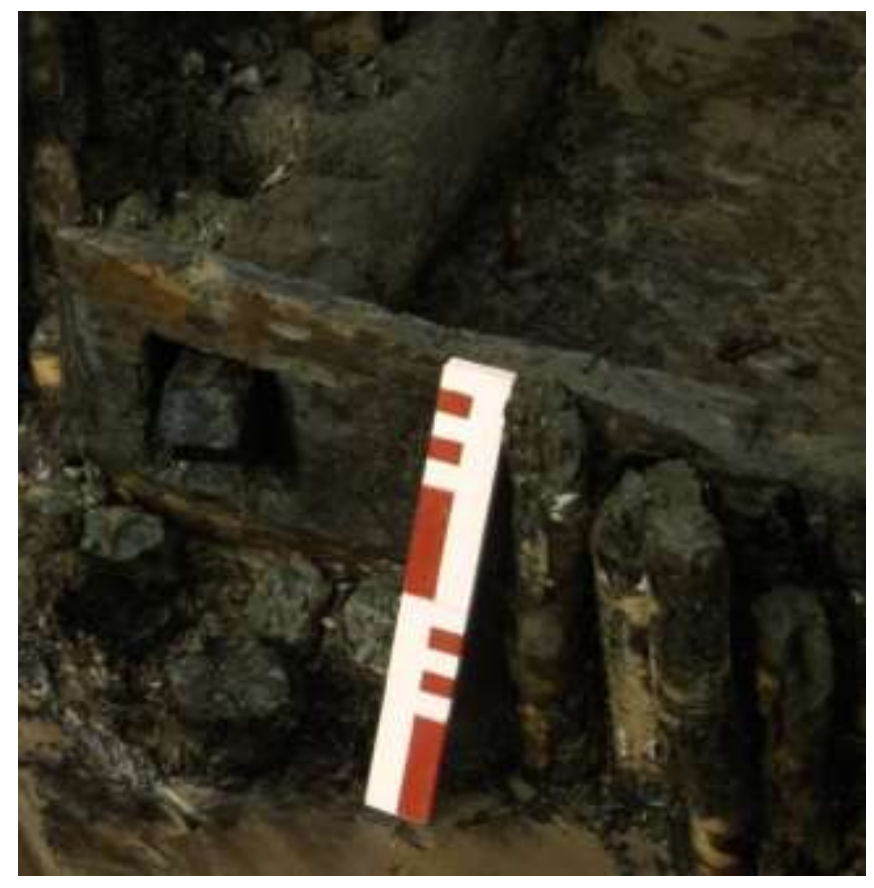

Abb. 20

Die Eckverzapfung bei Brunnen 1. Maßstabgröße 20cm 
Nördlich der Anlage befanden sich in $50 \mathrm{~cm}$ Entfernung zwei senkrecht stehende pfostenartige Baumstämme von recht beachtlicher Größe, die noch $37 \mathrm{~cm}$ über den oberen Brunnenkasten hinaus aufragten. Die 2,10m langen und 12cm durchmessenden Eichenstämme waren an ihrem Ende auf etwa $35 \mathrm{~cm}$ fünfeckig bebeilt und mit einer Pfostenspitze versehen. Sie standen senkrecht in einer $1 \mathrm{~m}$ tiefen Pfostengrube und waren in ihrem unteren Viertel zusätzlich $40 \mathrm{~cm}$ in den Boden eingerammt. Die räumliche Nähe der Stämme lässt einen funktionalen Zusammenhang vermuten. Wahrscheinlich handelte es sich um eine Hebekonstruktion für den Kastenbrunnen (vgl. ZIMMERMANN 1992, 294-296, Abb. 236). Nördlich des Kastenbrunnens fand sich oberhalb der Torfschicht eingebrachter grauer Sand, der mit weißen Schwemmlinien durchzogen war und eine langsame Verfüllung dieses Areals nahelegt. Hinweise auf eine obertägige Befestigung des unmittelbaren Brunnenumfeldes finden sich an der Süd- und Westseite der Anlage in einer Häufung von Staken, Ast- und Wurzelwerk. Die lose eingebrachten Hölzer dienten wohl als Bodenbefestigung im vernässten Arbeitsbereich des Brunnens.

Die Baugrube war in den gewachsenen Boden eingetieft und weitgehend mit Torf aufgefüllt. Die Brunnenverfüllung bestand aus stark humosem Torf, der partiell mit weißem Sand durchsetzt war (Kat.Nr. 740b). Die Torfeinfüllung hat vermutlich den Brunnenschacht versteift und ein zu schnelles Zusanden verhindert. Wahrscheinlich hatte die Torffüllung der Brunnengrube eine Filterwirkung auf das gesammelte Wasser; ähnlich wie heute beispielsweise in der Aquaristik und beim Brunnenbau Torffilteranlagen zur Wasserreinigung genutzt werden. Das Wasser wird hierbei sandfrei und in seiner Qualität verbessert (entsäuert).

Flach bearbeitete Hölzer stammten aus dem Brunneninneren. Sie gelangten als spätere Verfüllung hierher. Ein konstruktiver Zusammenhang konnte nicht festgestellt werden. Aus der Brunnenverfüllung bei $+0,17 \mathrm{~m}$ NN stammt ein provinzialrömisches Importgefäß. Nach seiner Machart Terra Nigra-artig datiert das Gefäß in das 2./3. Jh. n. Chr. (Taf. 42, Kat.Nr. 740-1). Das Schulterfragment eines ähnlichen Keramikgefäßes stammte aus einer Höhe von $+0,10 \mathrm{~m}$ NN (Kat.Nr. 740k). Unter dem Fundmaterial fanden sich kaiserzeitliche Wandungsscherben und wenige Holzkohle-Bröckchen. Die Anlage ist im 3. Jahrhundert aufgegeben worden.

\section{Brunnen}

Kat.Nr. 265

Taf. 22; 101

Im Quadranten 52/48 entdeckte man die Reste eines weiteren Brunnens (Kat.Nr. 265). Unter einer 20cm mächtigen Sedimentschicht aus Klei, die im Planum einen runden Durchmesser von etwa 2,5m aufwies, kam ein etwa ein Quadratmeter großer Kastenrahmen zu Tage, dessen Brunnensohle bei der Ausgrabung noch wasserführend war (Abb. 21).

Die maximale Holzerhaltung des Brunnens reichte bis in eine Höhe von $+0,8 \mathrm{~m}$ NN. Die Brunnensohle 
wurde bei $+0,25 \mathrm{~m}$ NN angetroffen. Die Anlage wurde an ihrer südlichen und westlichen Seite von der Zaunreihe Kat.Nr. 262 bogenförmig eingeschlossen. Hausplatz 1 befand sich $18 \mathrm{~m}$ nördlich.

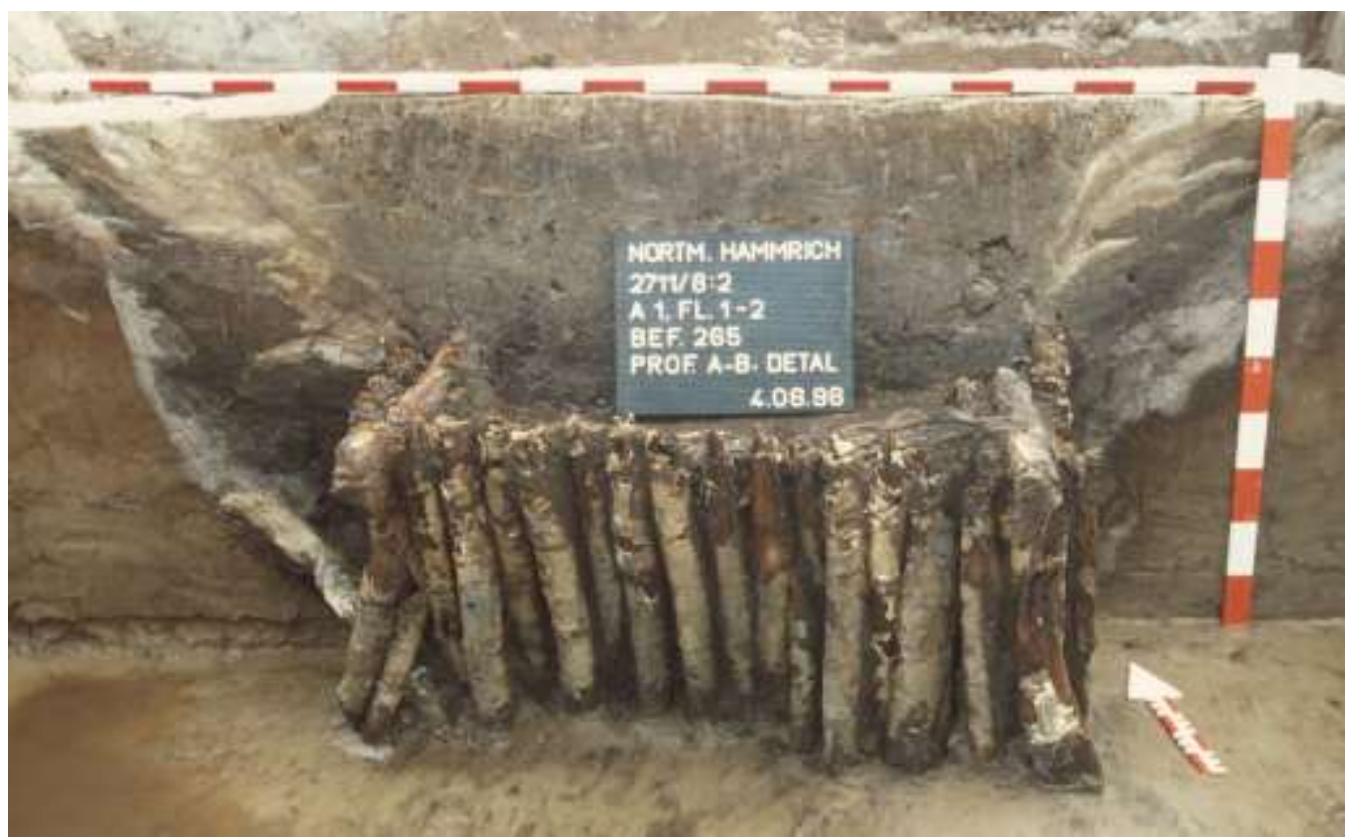

Abb. 21

Brunnen 2 mit unterer Rahmenkonstruktion

Auch hier bildete ein hölzernes Rahmenwerk die zentrale Konstruktion der Brunnenanlage. Ein Rahmen aus Kanthölzern $(8 \times 10 \mathrm{~cm})$ von 0,8-1,1m Länge bildete den oberen Brunnenrand. Die Enden der Einzelhölzer waren an ihren Enden teilweise miteinander verzapft (Kat.Nr. 265b). Die Seitenlänge der Rahmenkonstruktion betrug 1,1x0,8-0,9m.

Der Rahmen wurde zusätzlich verstärkt durch dicht beieinanderstehende Staken aus Birkenholz (Kat.Nr. 265a), die sich auf einer Länge von $1 \mathrm{~m}$ erhalten haben. An ihrer unteren Seite angespitzt, waren die $7-10 \mathrm{~cm}$ dicken Holzstaken wenigstens $10 \mathrm{~cm}$ unter die Brunnensohle in den gewachsenen Boden getrieben worden. An der Ost-, Süd- und Westseite befanden sich die Stakenreihen auf der Brunnenaußenseite des Rahmenwerks und standen meist dicht beieinander: Die innere Stakenreihe der Nordseite war weniger regelhaft gesetzt und mit einem zweiten Innenkantholz zusätzlich stabilisiert; möglicherweise ein Hinweis auf eine spätere Reparaturstelle. Die Brunnengrube wies ein trapezförmiges Profil auf und verjüngte sich zur Brunnensohle auf eine Fläche von $80 x 80 \mathrm{~cm}$. Reste eines unteren Rahmenwerks fanden sich nicht.

Die Brunnenverfüllung bestand aus vier verschiedenen Schichten. An der Brunnensohle überwogen eine sandige Füllschicht durchmischt mit Torfresten. Von unten bis zum Rahmenwerk nahm die torfig-sandige Bodenstruktur stetig zu, bis sie in eine Torfschicht überging (Kat.Nr. 265g). Überlagert war das Rahmenwerk mit einer tonigen Sandschicht, die mit Holzkohle durchsetzt war. Die Verfüllung der Baugrube war mit hellweißem Dünensand und darüber mit hellbraunem humosen Sand erfolgt. Das Fundmaterial der Grubenverfüllung bestand aus Holzkohle-Brocken, gebranntem Ton und 
Keramikscherben. Es handelte sich um Randscherben schalen- und topfartiger Gefäße, die in die ältere römische Kaiserzeit datieren.

Überdeckt wurde die Anlage durch zwei in die Brunnengrube regelrecht „hereinfließende“ Kleischichten. Das obere Bodensediment war stärker tonhaltig (Bodenschicht 2), die sich darunter befindliche Schicht bestand aus tonigem Sand (Kat.Nr. 265f). Beide Bodenschichten datieren in die römische Kaiserzeit.

\section{Brunnen}

Kat.Nr. 335

Taf. 101

Auch diese Brunnengrube war im Planum A1 von einer 3,5x3m großen Kleischicht überdeckt. Die Geländeoberfläche fiel von Ost nach West von $+1,4$ auf $+1,3 \mathrm{~m} \mathrm{NN}$ ab. In der bis zu $90 \mathrm{~cm}$ muldenförmig eingetieften Brunnengrube entdeckte man während der Ausgrabung erst in einer Tiefe von $+0,7 \mathrm{~m}$ NN einen Holzrahmen aus grob gearbeitetem Nadelholz (Abb. 22).

Der Brunnen befand sich an der Nordseite der Düne im Quadranten 55/49 in einem befundarmen Areal. So fällt eine einzelne nur $60 \mathrm{~cm}$ von der Brunnenanlage entfernte Pfostengrube besonders auf. Möglicherweise handelte es sich bei diesem $30 \mathrm{~cm}$ durchmessenden Befund um den Rest einer ehemaligen Hebekonstruktion. Aus der näheren Umgebung sind keine weiteren Befunde überliefert.

Die Anlage unterscheidet sich in ihrer Konstruktion wesentlich von den vorherigen Holzrahmenbrunnen. Es handelte sich hier um lose übereinander gelegte Hölzer mit geringen Bearbeitungsspuren. Ihre Oberflächenbearbeitung war wenig sorgfältig und stellenweise unterblieb sie ganz. Deutlich erkennbar ist die krumme Wuchsrichtung, wie auch einzelne Astabzweigungen des verwendeten Holzes.

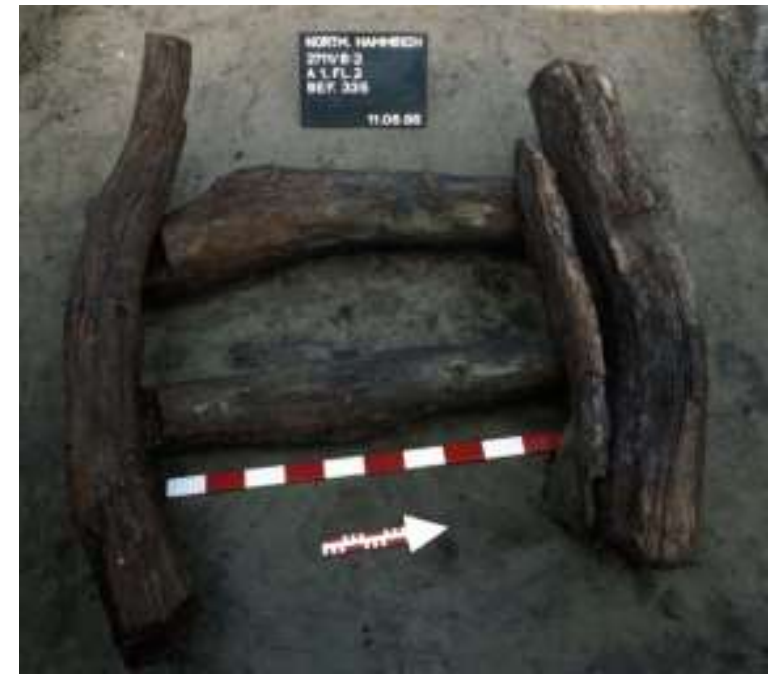

Abb. 22

Aufsicht auf die untere Rahmenkonstruktion von Brunnen 3 
Erhalten hat sich von der Brunnenanlage nur die Holzkonstruktion des Unterbaus. Der Rahmen bestand aus vier 1,5-1,7m langen Nadelhölzern, die einen Durchmesser von 18-25cm aufwiesen. Die untenliegenden Rundhölzer lagen parallel in einem Abstand von $35 \mathrm{~cm}$ zueinander. Sie waren an beiden Enden flach abgebeilt. Dies bildete die Auflagefläche für die quer liegenden oberen Rundhölzer, die aufgrund ihrer Krümmung zwischen 0,93-1,13cm voneinander entfernt lagerten.

Die in den gewachsenen Sandboden eingetiefte Brunnengrube hatte nahe der Sohle bei $+0 \mathrm{~m}$ NN noch einen Durchmesser von 1,1m. Die Hölzer der Rahmenkonstruktion waren in einer tonhaltigen Torfschicht eingebettet, die eine feine Bänderung mit Klei und Sand aufwies (Abb. 23).

An den Rändern der Baugrube fanden sich Bodeneintragungen aus weißem bis grauen Sand. Geschichtete Torfsoden, wovon sich wenigstens drei Reihen an der Brunnensohle erhalten haben, übernahmen wohl eine Filterfunktion. Sie waren durch eine feine Sandbänderung getrennt. Westlich der Brunnengrube fanden sich Reste eines alten Laufhorizontes (Kat.Nr. 335 h), der aus verhärtetem tonigen Sand bestand. Die darunterliegende Sandschicht stammt aus 7a und kann als Grubenversturz interpretiert werden (Kat.Nr. 335g). Darunter schlossen sich die Überreste eines älteren Laufhorizontes an (Kat.Nr. 335f).

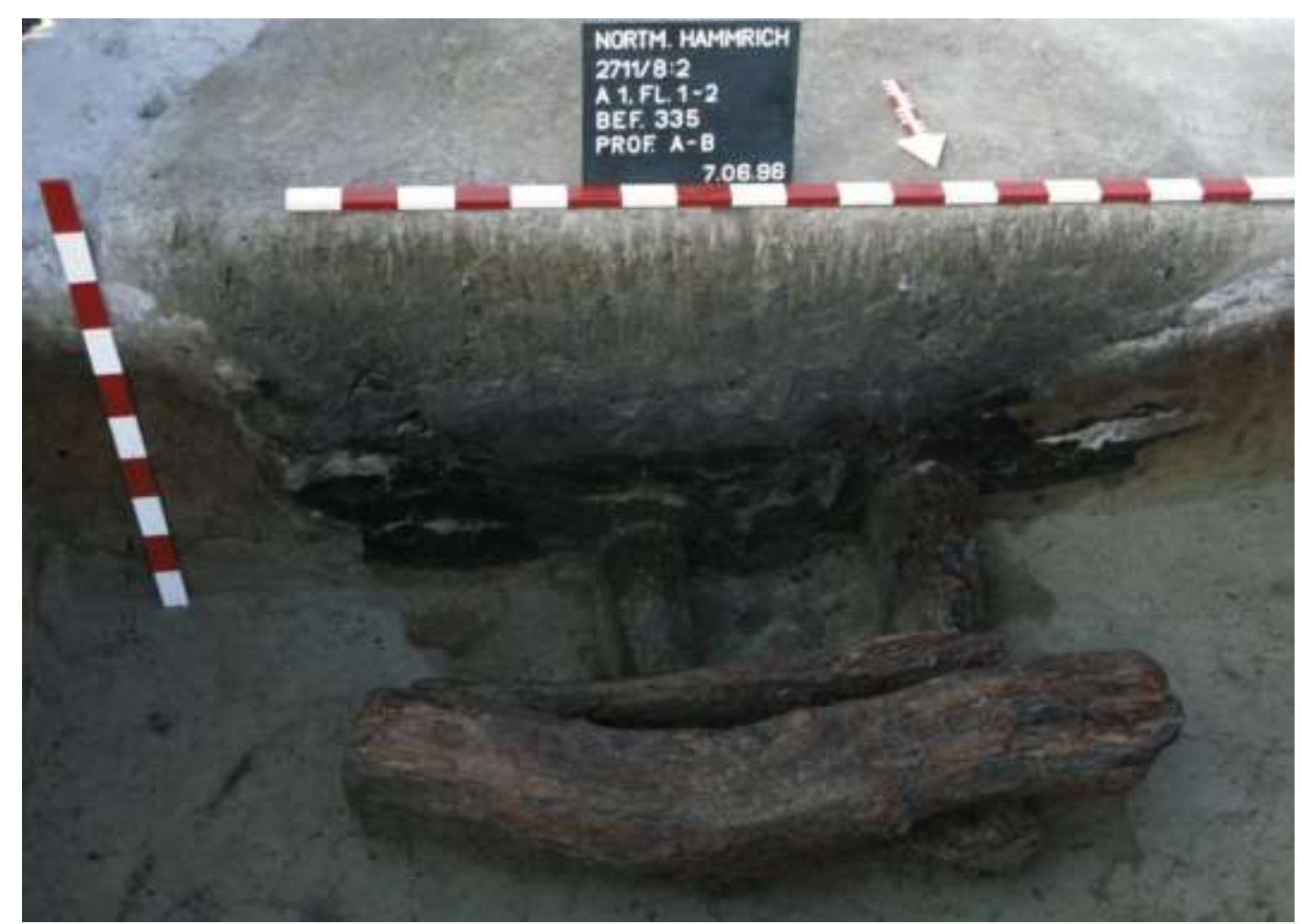

Abb. 23

Profilschnitt durch den Erdsodenbrunnen mit hölzernem Unterbau

Die Brunnengrube war von einer $35 \mathrm{~cm}$ mächtigen Klei-Sand-Schicht überdeckt unter der sich eine 
weitere, jedoch weniger mächtige tonige Sandschicht verbarg. Die untere Schicht aus tonigem Sand war mit Holzkohle durchsetzt und wird der Bodenschicht 3 zugeordnet. Es hat den Anschein, dass beide im Profil muldenförmigen Sedimentschichten in die offenstehende Brunnengrube hineingeflossen sind, die Brunnengrube also zum Zeitpunkt der Überschwemmung noch offenstand.

Bei dem zerscherbten Fundmaterial aus der Anlage handelt es sich um stark fragmentierte mittelalterliche Wandungsscherben. Konstruktive Übereinstimmungen bestehen $\mathrm{zu}$ einem Sodenbrunnen mit hölzerner Substruktion aus Hesel-Meeräcker (BÄRENFÄNGER 1998b, 49, 58, Abb.69). Das dort gewonnene Fälldatum von ,791 ${ }^{+10 /-10} \mathrm{n}$. Chr.“ und die gleichfalls schlichte Bauweise der Unterkonstruktion aus lose übereinander gelegtem stärkeren Astholz, ermöglichen es auch den Nortmoorer Brunnen in das frühe Mittelalter zu datieren.

Kaiserzeitliche Kastenbrunnen sind im Unterschied zu mittelalterlichen verhältnismäßig selten in Ostfriesland. Meist handelte es sich um Baumstammbrunnen oder Flechtwerkskonstruktionen, die den Brunnenschacht verkleideten (BÄRENFÄNGER 1998e, 290). Zwei der drei Nortmoorer Kastenbrunnen sind in die mittlere Kaiserzeit zu datieren. Konstruktive Übereinstimmungen bestehen zwischen der Anlage Kat.Nr. 265 und dem Kastenbrunnen Kat.Nr. 740. Beide Anlagen hatten ein verzapftes Rahmenwerk aus Kantholz sowie eine Versteifung der Außenwände mit Birkenstaken. Die Stabilisierung erfolgte durch eingeschlagene Längsstaken. Beide Brunnengerüste wiesen ein trapezförmiges Profil auf. Auch ihre leichte NNO-Ausrichtung entspricht sich. Im Unterschied zu Bef. 740 besaß Kat.Nr. 265 jedoch kein unteres Rahmenwerk. Vermutlich war es auch nicht notwendig, da der Seitendruck bei der kleineren Brunnenanlage geringer war. Deutlich unterscheidet sich diese Rahmenkonstruktion von der hölzernen Substruktion des mittelalterlichen Brunnens Kat.Nr. 335.

Im Landkreis Leer sind in drei weiteren kaiserzeitlichen Siedlungen Brunnenanlagen mit Kasteneinbauten entdeckt worden. Vergleichbar sorgfältig wie die Rahmeneinbauten von Kat.Nr. 265 und 740 wurden in der kaiserzeitlichen Siedlung Westerhammrich Brunnen aus senkrechten Bohlen und Holzstaken errichtet, die zwischen dem 2. bis 4. Jahrhundert genutzt wurden. Für einen Rahmenbrunnen wird die Aufgabe des Brunnens im 4. Jahrhundert nahegelegt, da sich in seiner Rahmung eine spätrömische Tutulus-Fibel fand (BÄRENFÄNGER 1999d, 166, Abb. 103 u. 104).

Eine andere rechteckige Brunnenkonstruktion entdeckte man bei Ausgrabungen in Hohegaste. Ähnlich wie in Nortmoor wurde hier um einen 1,1x1,6m großen Rahmen, der die Brunnenbasis bildete, die Rundhölzern schräg eingetieft und reichten über die Sohle hinab (STILKE 1995, 207-209, Abb. 4). Der kleinere der beiden Brunnen aus Backemoor besteht aus einem doppelten Eichenholz-Rahmenwerk und angespitzten Birkenholzstaken. Die mit ,275+81-6، und ,305 +8/-6، abgeleiteten Fälljahre weisen, gemeinsam mit Versandungsspuren nahe der Brunnensohle, auf eine eher kurze Nutzungsdauer hin (BÄRENFÄNGER 2000a, 75-77). 
Rahmenbrunnen in Flögeln bestehen zwar aus Spaltbohlen, sind hier durch Verkämmung an ihren Enden ineinandergefügt (ZIMMERMANN 1992, 286, Abb. 228). Bei einer Anlage von der Feddersen Wierde verstärken zwei verzapfte Bohlenrahmen senkrechte Bretter zu einem Brunnenkasten (HAARNAGEL 1979, 168-170). Aus dem niederländischen Bennekom liegt eine Vielzahl viereckiger Kastenbrunnen vor (VAN ES u.a. 1985, 575-577, Abb. 22). Die meisten verfügten über ein Rahmenwerk und ihre Wandung wurde aus dicht beieinanderstehenden Pfählen gebildet (W 6), die an ihrem unteren Ende teilweise angespitzt waren (W 16). Da nur in einem Fall die Brunnensohle ergraben werden konnte, fehlen Erkenntnisse über ein mögliches unteres Rahmenwerk.

Eine Differenzierung zwischen Brunnen und Gruben, die der Vorratshaltung oder als Arbeitsgruben dienten, ist jedoch nicht immer zweifelsfrei möglich. Das rechteckige Format bei kleineren Anlagen erinnert an Siedlungsbefunde. So finden sich in Wijster verschiedene Vorratsgruben mit hölzerner Kastenkonstruktion (VAN Es 1967, 116-117). BÄRENFÄNGER (1998e, 289) vermutet bei der Rahmenkonstruktion in Holtgaste, Landkreis Leer, eine Nutzung als Werkgrube, zumal sich in der Mistfüllung der Grube das Halbfabrikat einer Schale befand.

\section{Brunnen}

Kat.Nr. 26

Taf. 10; 11; 56; Taf. 102

Innerhalb einer länglich-amorphen Bodenverfärbung von $3 \times 4 \mathrm{~m}$ Durchmesser zeichnete sich an der Oberfläche ein Befund ab, der eindeutig als mittelalterliche Brunnenanlage anzusprechen ist (Abb. 24). In der Brunnenverfüllung aus humosem Klei-Sand entdeckte man u.a. Pingsdorfer Amphoren (NN-Höhe $+0,69 \mathrm{~m}$ ), so dass die Nutzungsphase des Brunnens in das 10. Jahrhundert datiert werden kann. Etwa 5m westlich der Anlage befand sich ein großer mittelalterlicher Rutenberg. Nach Norden war die Grabungsfläche durch die nahe Teichanlage bereits gestört.

An der östlichen Grabungsgrenze in den Quadranten 53-54/54 fand sich eine hölzerne Brunneneinfassung, die aus einem ausgehöhlten Baumstamm bestand. Der Boden der Brunnengrube ist mit einer Lage Staken bedeckt. Die Brunnensohle wurde in einer Tiefe von $+0,42 \mathrm{~m}$ NN erreicht. Die darunter liegende Sohle der Holzstaken erstreckte sich von $+0,34 \mathrm{~m}$ bis $+0,44 \mathrm{~m}$ NN. 


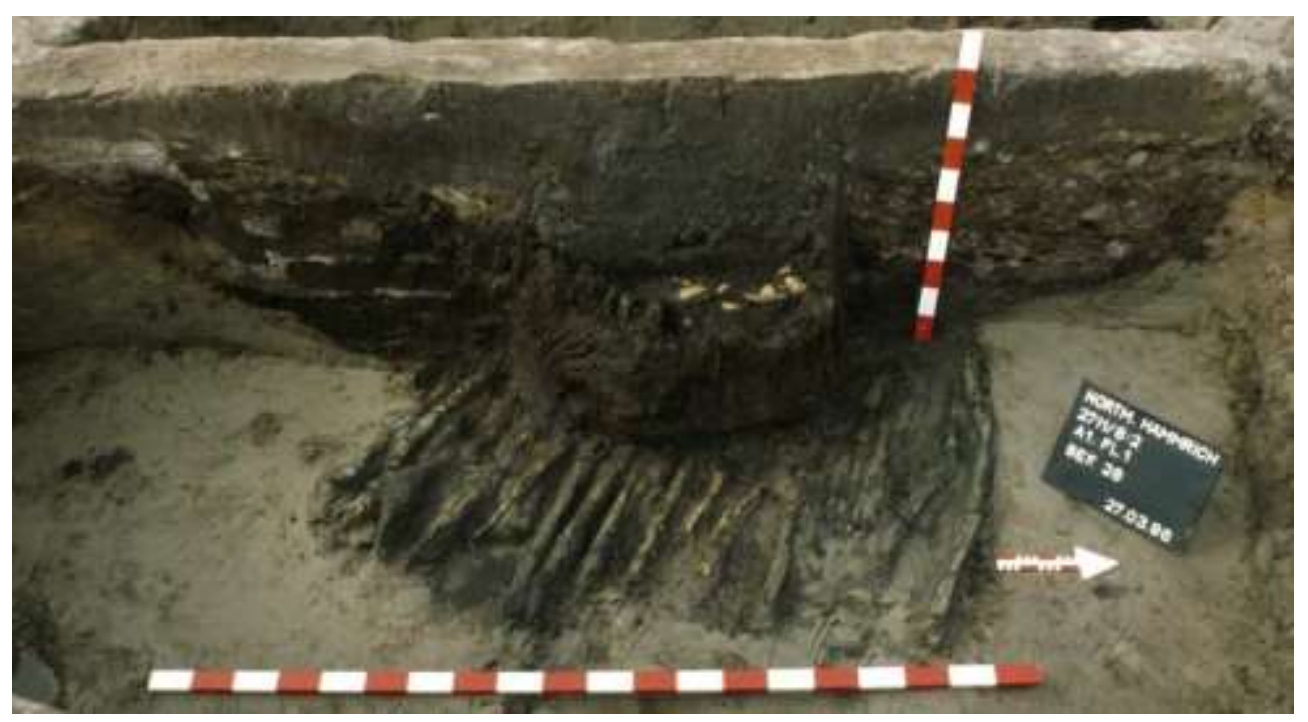

Abb. 24

Baumstammbrunnen 4. Pingsdorfer Scherben in der Brunnenverfüllung

Der $55 \mathrm{~cm}$ hohe ausgehöhlte Baumstammbrunnen hatte einen Durchmesser von etwa 90cm und war bis auf eine Höhe von $+1,01 \mathrm{~m}$ NN erhalten. An seiner Oberfläche wies der Eichenholzbaumstamm nur geringfügige Bearbeitungsspuren auf. Der Unterbau des Brunnens bestand aus 18 WO orientierten Rundhölzern, die weitgehend parallel nebeneinanderlagen. Die 3-5cm durchmessenden Holzstaken besaßen eine Länge von 1,6-1,8m und reichten damit 30-60cm über die Seiten die Brunnenröhre hinaus. An der äußeren Brunnenwandung lagerte eine Holzbohle aus Eichenholz (Kat.Nr. 26c), deren Funktion bisher ungeklärt ist. Eventuell handelte es sich um eine Verstärkung, der an dieser Stelle dünneren Brunnenwandung.

Aus der Brunnenverfüllung stammen zwei nahezu komplett erhaltene Pingsdorfer Amphoren (Kat.Nr. 26-1 u. 26-2) sowie ein Tüllenrand und einige Wandungsscherben dieser Ware. Ergänzt wird das mittelalterliche Fundrepertoire durch Wandungsscherben der harten Grauware. Aus dem Brunnen stammen $7 \mathrm{~kg}$ gebrannter Granitstein, ein Mahlsteinfragment aus Basalt und zwei Kalksteine. Es fanden sich zudem kalzinierte Knochenfragmente, Tierzähne, gebrannter und ungebrannter Lehm. Ein Holzstück wies auffällige Hackspuren auf (Abb. 25). Kaiserzeitliche Scherben und Flintabschläge gelangten vermutlich mit dem Bodenaushub in den Brunnen. 


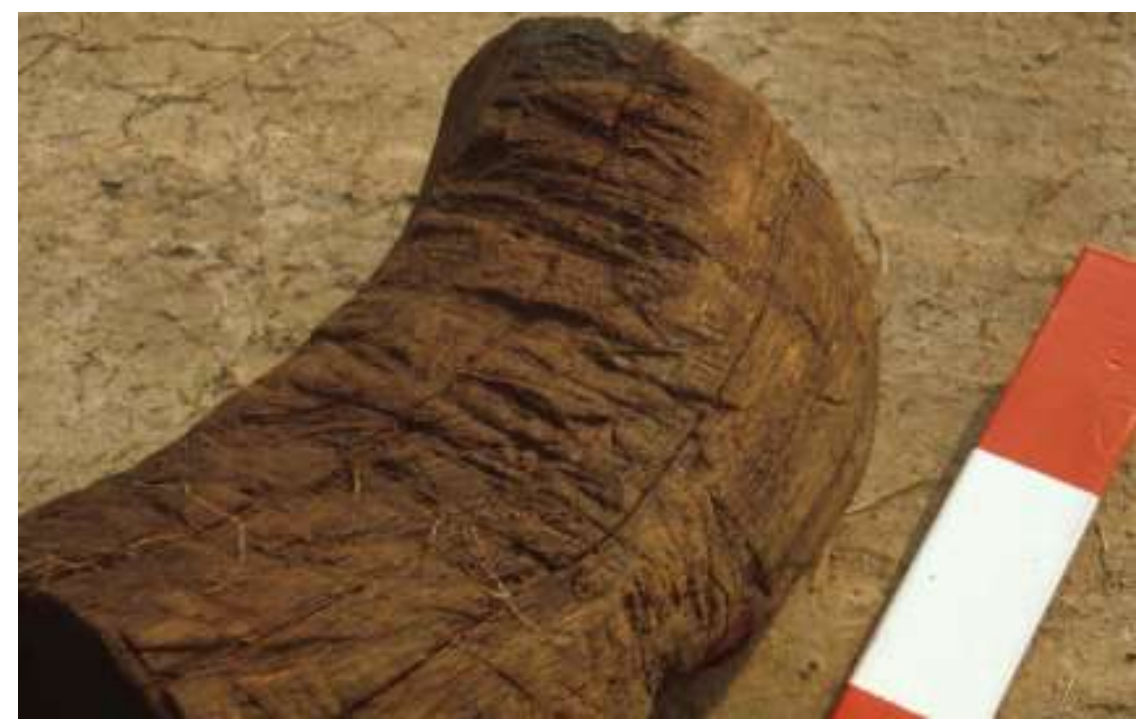

Abb. 25

Holz mit mittelalterlichen Hiebspuren aus Brunnen 4

Der nördliche Teil der Brunnengrube war angefüllt mit hellbraunem und weißem Sand und durchmischt mit dunkelbraunem Humus. Das relativ homogene Schichtpaket weist auf eine schnelle und planvolle Verfüllung der Baugrube hin. Im südlichen Grubenbereich entdeckte man $10 \mathrm{~cm}$ aufgeschichtete Torfsoden (Kat.Nr. 26e). Diese dienten wohl weniger zur Stabilisierung der Konstruktion, als dass sie eine Filterwirkung übernahmen.

Überdeckt war der gesamte Befund von zwei mehrere Dezimeter mächtigen Kleischichten, die in unmittelbarem Zusammenhang mit großräumigen Überschwemmungen des Dünenareals stehen. Die obere sandige Kleischicht stand bei einer NN Höhe von $+1,25 \mathrm{~m}$ bis $+1,34 \mathrm{~m}$ an und wies eine Stärke von durchschnittlich $20 \mathrm{~cm}$ auf, dünnte zu den Seiten auf $10 \mathrm{~cm}$ aus. Die darunterliegende Kleischicht floss in den oberen Teil des Brunnens und war wesentlich toniger. Ihre Oberkante lag zwischen $+1,02$ und $+1,24 \mathrm{~m} \mathrm{NN}$, während die Unterkante zwischen $+0,85 \mathrm{~m}$ und $+1,18 \mathrm{~m} \mathrm{NN}$ anstand. Durch die aus der Brunnenverfüllung stammende Keramik können die Überschwemmungshorizonte ins Mittelalter datiert werden. Konstruktive Elemente, insbesondere die der Sodenschichtung, datieren den Brunnen ebenfalls in die mittelalterliche Siedlungsphase.

\section{Brunnen}

Kat.Nr. 394

Taf. 26; 103

Ein $60 \mathrm{~cm}$ hoch erhaltener Baumstammbrunnen befand sich auf der nördlichen Dünenseite nahe der Grabungsgrenze im Quadranten 57/54. Das Areal zeichnete sich durch eine geringe Befunddichte aus. Ein direkter Bezug zu Umgebungsbefunden war nicht feststellbar. 
Im Planum A1 zeigte sich eine ovale Verfärbung von $53 \times 58 \mathrm{~cm}$, die in Schicht 5 eingetieft war. Die Torfschicht stand bei $+0,78 \mathrm{~m}$ NN an und wies eine Schichthöhe von $35 \mathrm{~cm}$ auf. Innerhalb der Verfärbung wurde ein ovaler Baumring entdeckt, der an seiner Westseite von vier Holzbohlen und einer Starke eingefasst war. Der im Planum noch $58 \times 47 \mathrm{~cm}$ große Brunnen verjüngte sich zur Bodensohle trichterförmig bis zu einem Durchmesser von $43 \mathrm{~cm}$.

Der Brunnen bestand aus vier passenden $60 \mathrm{~cm}$ langen Segmenten mit einer Wandstärke von 4-4,5cm. Die Höhe der maximalen Holzerhaltung der Brunneneinbauten reichte knapp über die Oberkante der Torfschicht. Im Unterschied zum vorherigen Baumstammbrunnen Kat.Nr. 26, wurde der ausgehöhlte Baumstamm mit seinem unteren Ende zusätzlich in den Boden getrieben $(+18 \mathrm{~cm} \mathrm{NN})$. Hierauf weist die etwa 20-25cm über dem unteren Ende des ausgehöhlten Baumstammes anstehende Sohle der Brunnengrube.

In der Brunnenröhre sind zwei Verfüllschichten zu differenzieren. Die obere Verfüllung war mit tonigem Torf durchsetzt und grenzte sich deutlich von der darunterliegenden Schicht aus hellgelben Sand ab. Diese untere Schicht wies eine stark wellige Sohle mit schwankender Mächtigkeit von 3$10 \mathrm{~cm}$ auf (Kat.Nr. 394d). Vermutlich handelt es sich hierbei um Ausschachtungsspuren (Abb. 26).

An der West- und Südwestseite der Grube fanden sich vier Holzbohlen und eine Starke, die senkrecht in den Boden außerhalb der Brunnröhre eingeschlagen worden sind. Die bis zu $40 \mathrm{~cm}$ langen Hölzer waren in ihrem unteren Bereich auf $10 \mathrm{~cm}$ stumpf angebeilt. Die nahe an der Brunnenröhre eingesetzten Hölzer dienten wohl zur Stabilisierung des Brunnenringes.

Aus der Brunnenverfüllung stammen vorwiegend kaiserzeitliche Scherben. Datierungsrelevant sind die Randfragmente von topfartigen Gefäßen mit einem kurzen dreieckig verdickten Rand sowie eines engmündigen Gefäßes mit Henkel, Typ Friesentopf, die in das 1. bis 2. Jahrhundert n. Chr. datieren. Ergänzt wird das Repertoire durch einen Topf mit extrem kurzer, umbiegender Randlippe.

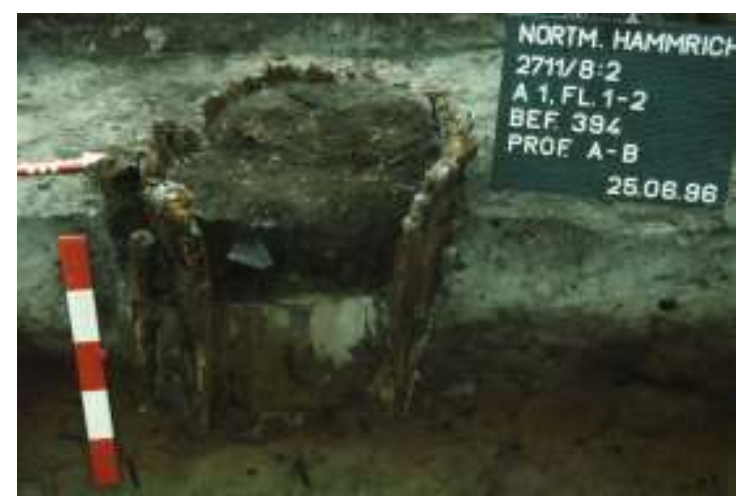

Abb. 26

Profilschnitt durch den Brunnen 5.

In der Brunnenverfüllung steckt kaiserzeitlichen Randscherbe 


\section{Brunnen}

Kat.Nr. 650

Taf. 104

Der dritte Baumstammbrunnen befand sich im zentralen Siedlungsbereich, im Quadranten 55/42. Hausplatz III lag etwa 16m südlich vom Brunnen. Zunächst wurde eine graue Bodenverfärbung in Planum A1 entdeckt, unter der sich die Brunnenanlage verbarg. Die Geländeoberfläche stand zwischen $+0,6$ bis $+0,8 \mathrm{~m} \mathrm{NN}$ an.

Der Baumstamm hatte einen ovalen Durchmesser von rund $60 \mathrm{~cm}$ und eine Wandstärke von $4-6 \mathrm{~cm}$. Die Holzerhaltung lag bei $+0,88 \mathrm{~m}$ NN und reichte bis zur Brunnensohle bei $-0,20 \mathrm{~m}$ NN herab.

Auch hier bestand die Brunnenröhre aus einem ausgehöhlten Baumstamm. Sein Holz wies sowohl auf der Außen- wie der Innenseite diverse Glättungsspuren auf (Abb. 27). Um einen geraden Abschluss im Bereich der Brunnensohle zu erhalten, war die Unterseite des Baumstammes abgebeilt.

In einem Abstand von 5-15cm waren um den Brunnen herum 33 Hölzer senkrecht eingetieft. Die Stakensetzung bestand aus $5 \mathrm{~cm}$ durchmessenden Rundhölzern. Die 60-90 cm langen Hölzer waren an ihrem Enden spitz angebeilt und schräg in den Boden eingetieft (Abb. 28). An der Westseite der Brunnenwandung fanden sich zusätzlich fünf gespaltene $60 \mathrm{~cm}$ lange und $4-6 \mathrm{~cm}$ starke Eichenholzbohlen. Die kreisförmig eingeschlagenen Hölzer stabilisierten die mit Torf ausgefüllte Baugrube; vielleicht dienten sie auch zusätzlich dazu, den Bodendruck auf den Brunnenschacht zu verringern und das Wasser zu filtern.

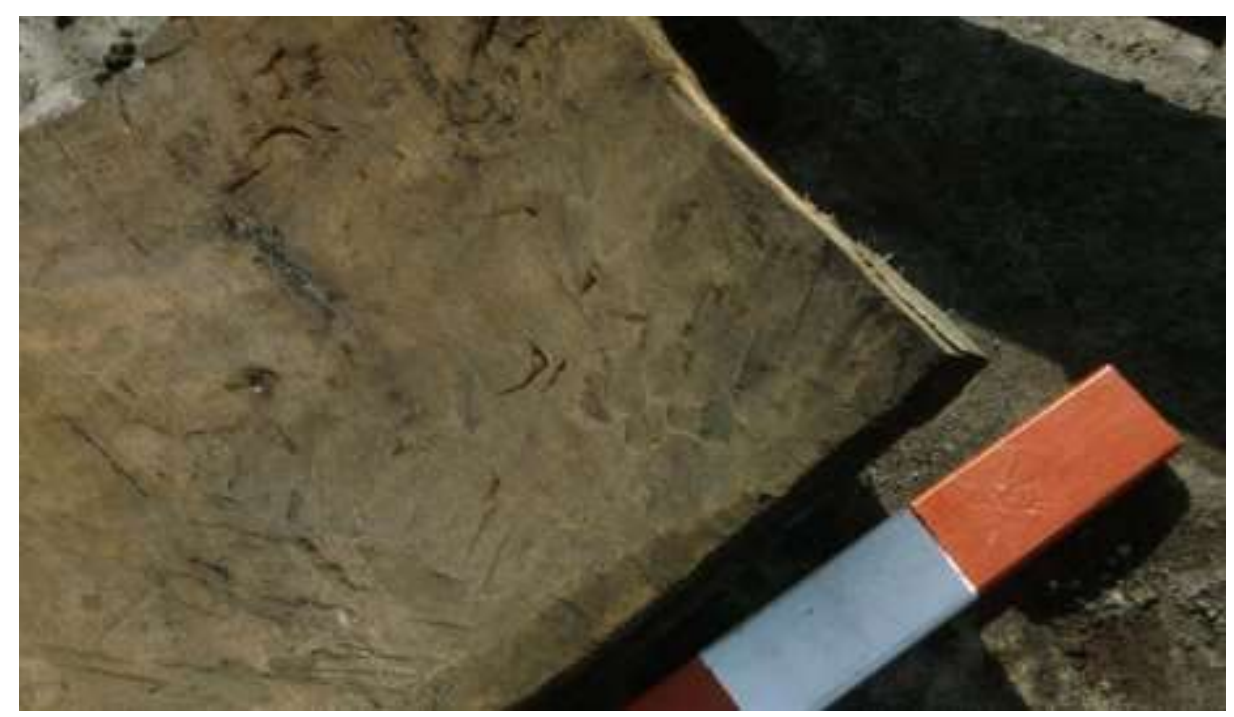

Abb. 27

Innenseite des ausgehöhlten Baumstammbrunnen B 6 mit deutlichen Glättspuren 
Die Verfüllung der Baugrube bestand aus einer Mischung von Torf und pleistozänem Sand, während die Verfüllung zwischen Brunnenwand und Holzstaken aus tonig humosem Torf bestand (Kat.Nr. 650d). Unterhalb der Brunnensohle war die Baugrube mit pleistozänem Sand aufgefüllt (Kat.Nr. 650f), der durchsetzt war mit der Torfverfüllung der Brunnenröhre (Kat.Nr. 650b). Die Brunnenfüllung bestand aus einer homogenen torfig-humosen Schicht (Kat.Nr. 650b) und füllte die Brunnenröhre nahezu vollständig. Darunter setzte eine muldenförmige Schicht aus hellgelbem Sand ein.

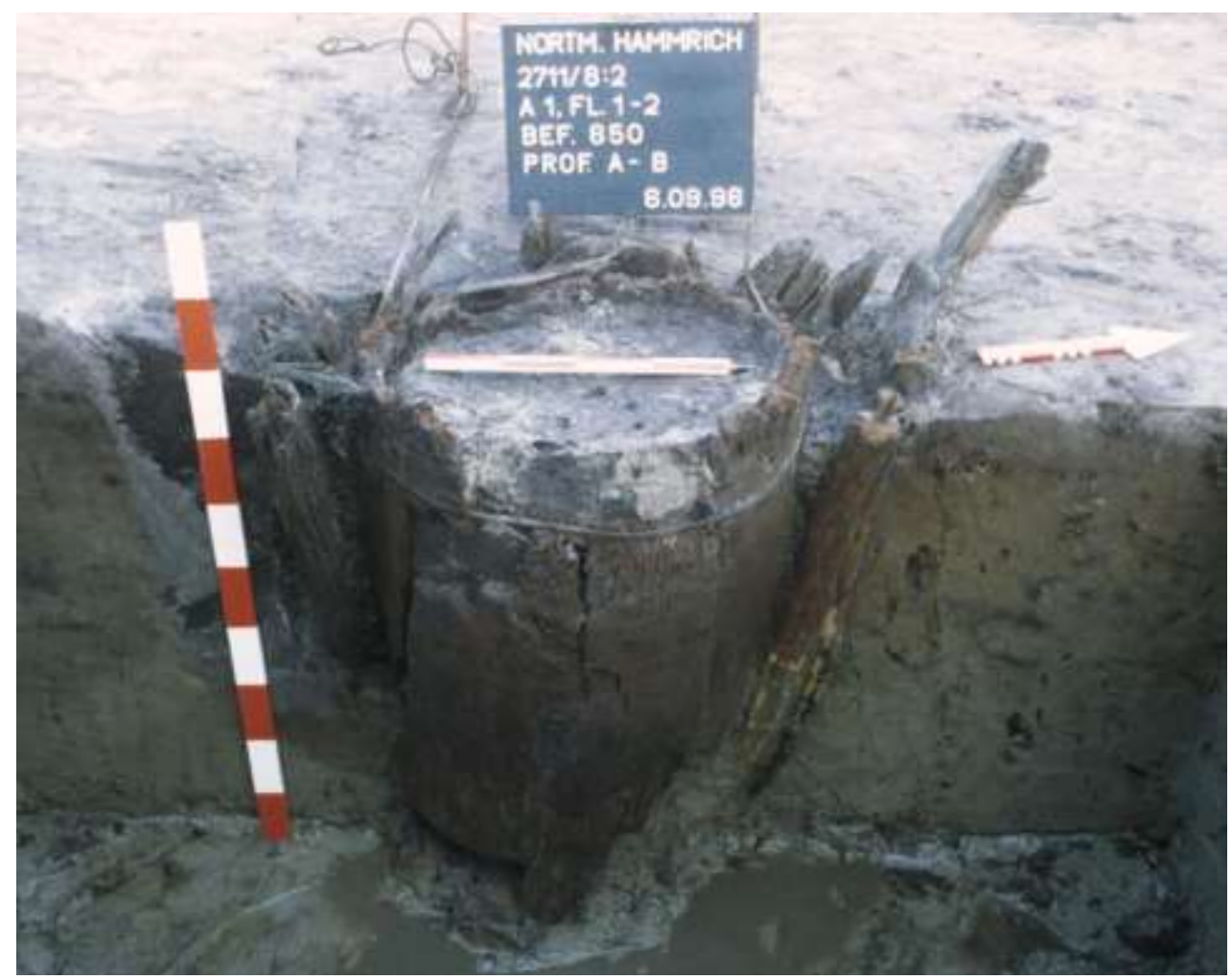

Abb. 28

Brunnen 6 droht durch hohen Grundwasserstand bei der Bergung abzukippen

\section{Brunnen}

Kat.Nr. 1084

Einer der westlichen Brunnen der Siedlung befand sich im Quadranten 53/38, nur 8m südlich vom Hausplatz III entfernt. Unter einer im Planum A1 rundovalen Verfärbung von $70 \mathrm{~cm}$ Durchmesser, verbarg sich ein bereits vergangener Baumstammbrunnen. Da die Anlage während der Ausgrabung nicht als Brunnen erkannt wurde, existiert keine Profilzeichnung.

Die inzwischen vergangene Brunnenwand bestand aus organischem Material, vermutlich einem ausgehöhlten Baumstamm. Die im Schnitt kastenförmige Röhre war bis zu 52cm eingetieft, während die Baugrube nur 30-44cm ausgehoben wurde (Abb. 29). Im Profil zeichnet sich die Brunnengrube als dünne schwarze Trennschicht mit einem Durchmesser von $40 \mathrm{~cm}$ ab, die sich zur Sohle hin um etwa 
$5 \mathrm{~cm}$ verringerte. Die ehemalige Brunnenwandung reichte über die Grubensohle noch $10 \mathrm{~cm}$ in den gewachsenen Boden hinein (NN-Höhe $+0,73 \mathrm{~cm}$ ).

Der Befund vermittelt eindrucksvoll die Konstruktionsweise derartiger Brunnen. Nach Aushub einer Grube setzte man den Baumstamm ein und grub den Sand unter ihm ab, wodurch er langsam nach unten rutschte. Erst in den letzten $10 \mathrm{~cm}$ wurde der Baumstamm durch starke Schläge weiter eingetieft.

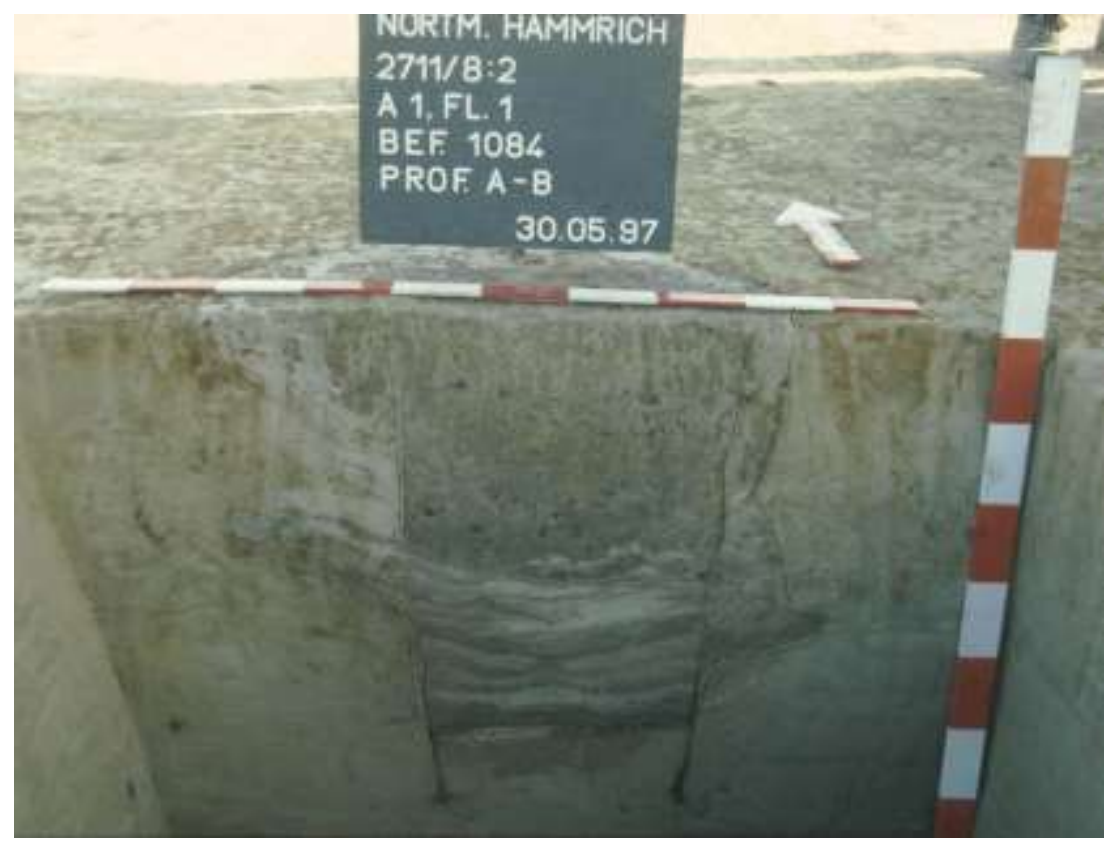

Abb. 29

Brunnen B 7 mit vergangener Brunnenröhre (ausgehöhlter Baumstamm)

Rückschlüsse auf den Füllvorgang gibt die Ausrichtung der Füllschichten und ihre Zusammensetzung. Die gerade ausgebildete Brunnensohle bestand aus einer $20 \mathrm{~cm}$ mächtigen und fein gebänderten Sandschicht, darüber schloss sich ein verfestigtes Klei-Sand-Gemisch an. Die obere Füllschicht enthielt Holzkohle und wenige, wohl kaiserzeitliche Keramikscherben.

Es zeigen sich bei den vier Nortmoorer Baumstammbrunnen zwei verschiedene Konstruktionsweisen. Die Baumstammbrunnen Kat.Nr. 394, 650 und 1084 weisen deutliche Übereinstimmung untereinander auf. Alle Brunnen besitzen eine kastenförmige Baugrube, die zunächst ausgehoben wurde, um den Baumstamm einzusetzen. Der Brunnenschacht mit dem ausgehöhlten Baumstamm wurde dann zusätzlich in den Boden getrieben. Nahe an der Wandung stabilisierten Spaltbohlen und Holzstaken den Brunnenkorpus. Aufgrund der schlechten Erhaltungsbedingungen sind bei Kat.Nr. 1084 Brunnenwandung und etwaige Holzstaken bereits vollständig vergangen. Der Durchmesser des Baumstammes lag zwischen 40-60cm. Die Grubensohle wurde bei $+0,73 \mathrm{~m}$ NN erreicht.

Der vierte Baumstammbrunnen fällt durch seinen ungewöhnlichen Durchmesser von $90 \mathrm{~cm}$ auf, der die der kaiserzeitlichen Baumstammbrunnen bei weitem übertrifft. Eine großzügige Stakenlage unter der 
Brunnensohle, wie auch Torfsoden um den Brunnenschacht, hatte eine zusätzliche Filterwirkung.

Während die Brunnen Kat.Nr. 394, 650 und 1084 in der römischen Kaiserzeit errichtet wurden, datiert Kat.Nr. 26 in die frühmittelalterliche Siedlungsphase. Für die Brunnen ist aufgrund der Befundlage nicht mehr zu entscheiden, ob ihr Baumstamm ehemals bis oberhalb der alten Oberfläche reichte oder in eine erweiterte trichterförmige Brunnengrube mündete.

In Ostfriesland dominierte während der römischen Kaiserzeit bei der Aussteifung der Brunnenröhren die Verwendung von Flechtwerk. Mehrfach ist dies auch in Kombination mit einem ausgehöhlten Baumstamm belegt. Hierfür finden sich diverse Beispiele aus dem Landkreis Leer. So entdeckte man im Westerhammrich bei Leer einen Brunnen mit einer äußeren Flechtwerkkonstruktion und einen darin eingesetzten Baumstamm. Ein weiterer Baumstammbrunnen hatte vorgesetzte Kanthölzer und datiert anhand der dendrochronologischen Ergebnisse „,nach 206“ (BÄRENFÄNGER 1998d, 105; 1999, 166).

Durch die Nortmoorer Befunde mehren sich inzwischen auch die Belege für Baumstammbrunnen ohne diese Umkleidung, deren Aufgabe möglicherweise im Bereich eines Grobfilters lag. Eventuell machte die Dünenrandlage derartige Filter in Nortmoor überflüssig. Denkbar ist auch, dass das gewonnene Wasser nicht dem menschlichen Genuss diente, sondern anderweitig, beispielsweise zur Viehtränke oder Gartenbewässerung, verwendet wurde. Die kaiserzeitliche Besiedlung bricht bereits Mitte des 3. Jahrhunderts ab und mit ihr die Nutzung der Brunnen. Dennoch wird in der Makroregion auch in den folgenden Jahrhunderten an der Errichtung von Baumstammbrunnen festgehalten.

Dies belegt eindrucksvoll ein völkerwanderungszeitlicher Baumstammbrunnen aus Hollen. Das Fälldatum der mit Holzdübeln verstärkten Anlage wird mit „>478 n. Chr.“ angegeben. Der Baumstamm wies einen Außendurchmesser von knapp 1m auf und war bis in eine Höhe von 1,35m erhalten (BÄRENFÄNGER 1995, 26-27, Abb. 12). In Gristede entdeckte man einen aus einem halbierten Eichenstamm bestehenden Brunnen, dessen Hälften mit Holznägeln verzapft waren (ZOLLER 1975, 41). Aus seiner Verfüllung stammt kaiser- und völkerwanderungszeitliche Keramik.

Kaiserzeitliche Baumstammbrunnen in Flögeln zeichnen sich durch eine verhältnismäßig aufwendige Konstruktion aus. Hier diente der Baumstammbrunnen i.d.R. als unterer Einsatz für eine trichterförmige Brunnengrube. Die bis in eine Tiefe von $6 \mathrm{~m}$ abgetieften Brunnen waren am Rand mit größeren Feldsteinen bzw. Findlingen befestigt (ZIMMERMANN 1992, 282-283, 290).

Überregionale Parallelen sind aus dem niederländischen Bennekom belegt. Unter 15 Anlagen befanden sich zwei Baumstammbrunnen, wovon einer aus zwei ineinander geschobenen Segmenten bestand (VAN ES u.a. 1985, 575-577, Abb. 22). Der ausgehöhlte Baumstamm diente zur Stabilisierung der Brunnensohle, während sich die Brunnengrube zur Geländeoberfläche hin trichterförmig erweiterte. Inwiefern eine oberirdische Befestigung erfolgte, ist nicht überliefert. Sinnvoll erscheint jedoch eine Umhegung, um Kinder und Tiere am Hineinfallen zu hindern. 
Noch mittelalterliche Brunnenbauer nutzten die Vorteile massiver Brunnenröhren aus ausgehöhlten Baumstämmen. Derartig verstärkt war den Anlagen eine recht lange Nutzungszeit beschieden. Mächtige Baumstämme von bis zu 80cm Durchmesser und einer erhaltenen Länge von 1,8m, wie sie im Rysumer Vorwerk entdeckt wurden, sind Zeugen davon. Ein mittelalterlicher Baumstammbrunnen in Loga-Leegcamp war zudem von Torfsoden umgeben, die wohl eine zusätzliche Filterwirkung übernahmen. Aus der Brunnenfüllung stammt u.a. ein spätmittelalterliches Wagenrad und Teile einer Wagenachse (BÄRENFÄNGER 1995, 30-32, Abb. 15.1). Fassbrunnen mit bis zu drei übereinander gestellten Daubenfässern lösten später die doch recht aufwendigen Baumstammbrunnen ab. Die im Mittelalter weit verbreiteten Sodenbrunnen stellten eine weit kostengünstigere Alternative im Brunnenbau dar, war das Baumaterial in Form von Gras-, Heide-, Klei- oder Torfsoden recht einfach abzubauen. Etwa 75\% der bekannten ostfriesischen Brunnen bestanden aus aufgestapelten Soden, meist wurde zur Stabilisierung ein hölzerner Unterbau verwendet (BÄRENFÄNGER 1995, 18-22). Dies war wohl auch bei dem in Torfsoden eingebetteten Nortmoorer Kastenrahmenbrunnen Kat.Nr. 335 der Fall.

\section{Brunnen}

Kat.Nr. 747

Taf. 107

Mit einem Durchmesser von 2,1x2m zeichnete sich im Quadranten 52/41 eine weitere Brunnenanlage $\mathrm{ab}$, deren vermutliche Brunnenröhre aus einem Weidenkorb bestand. Etwa 10m südlich von Hausplatz III gelegen, war das Umgebungsareal der Anlage verhältnismäßig stark durch Gräben gestört. Das Terrain fiel innerhalb des Befundes von $+1,35 \mathrm{~m}$ NN im Norden auf $+1,20 \mathrm{~m} N \mathrm{~N}$ im Süden ab. Erst $50 \mathrm{~cm}$ unter der Oberfläche wurde bei $+0,85 \mathrm{~m}$ NN der eigentliche Brunnen entdeckt.

Befund 747 zeigte sich im Planum A1 als eine rund-ovale Verfärbung aus sandigem Klei und tonigem Sand. Erst unter einer weiteren Schicht aus gelbem Sand und Torf (Kat.Nr. 747c) erschien eine runde Flechtwerkkonstruktion von $90 \mathrm{~cm}$ Durchmesser. Die Holzerhaltung war durch den relativ hohen Torfanteil, der geringfügige Grundwasserschwankungen ausglich, noch recht gut.

Das ovale korbartige Behältnis war auf einer Höhe von $50 \mathrm{~cm}$ erhalten, wies jedoch keinen Boden auf. Die 1-2cm breiten Weidenruten waren um 10, etwa $4 \mathrm{~cm}$ dicken, Birkenholzstaken geflochten, die an ihren eingetieften Enden angespitzt und dicht nebeneinander in Schicht 7 getrieben waren. So entstand ein recht weitmaschiges Geflecht (Abb. 30), welches ein relativ zügiges Versanden der Grube bedingte. Die Oberkonstruktion ragte aus dem Grundwasserbereich hinaus und ist vergangen. So sind Aussagen zur Nutzung nur unter Vorbehalt zu treffen. Es ist jedoch wahrscheinlich, berücksichtigt man geläufige Brunnensubstruktionen in Ostfriesland, dass es sich um einen Brunnen gehandelt haben wird. 


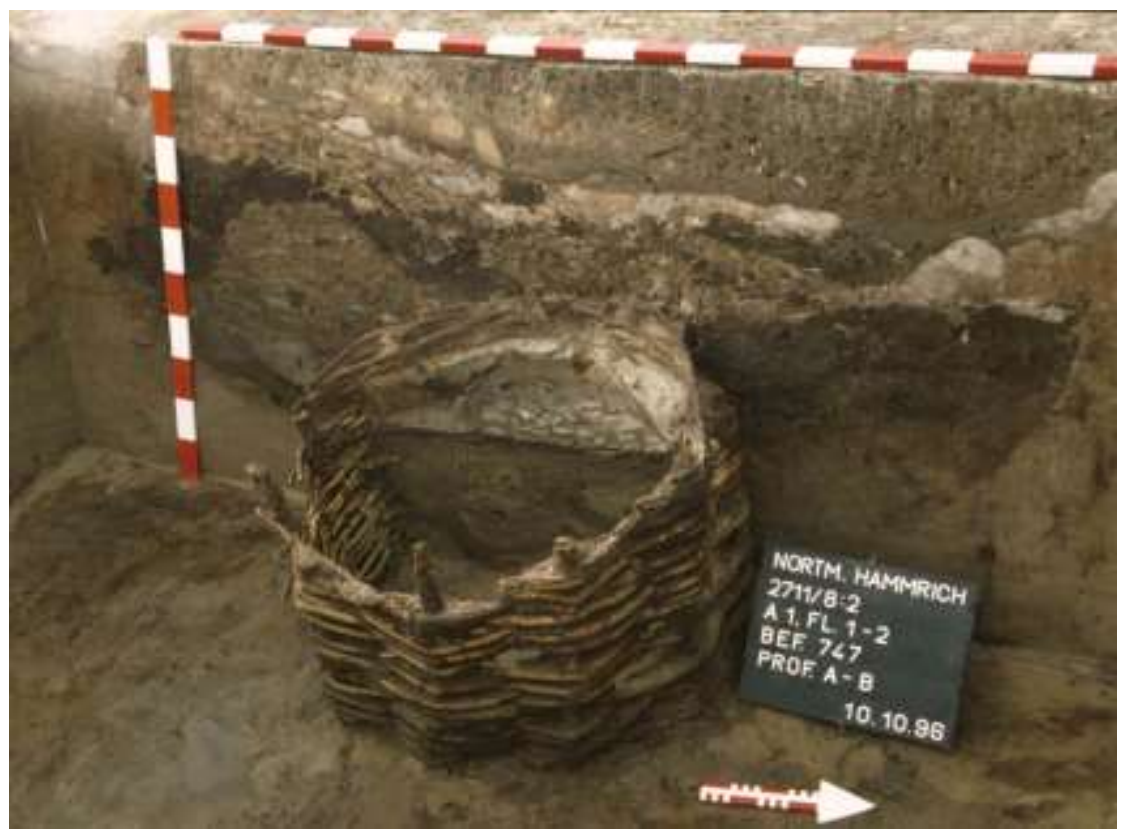

Abb. 30

Brunnen mit Flechtwerk als Brunnenschacht

Die Baugrube wurde in den gewachsenen Boden eingetieft. Nach Einbringen der Flechtwerkkonstruktion wurde die Grube erneut verfüllt. Die Südseite wies zu unterst Bodeneintragungen aus braunem Sandboden der Schichten 7 und 7 a (Kat.Nr. 747g) auf, mit einer kleinen Einlagerung aus grauem Sand aus der oberen Schicht 7 (Kat.Nr. 747f). Teilweise abgedeckt wurden beide Schichten durch eine Mischung aus Sand aus 7 und 7a, Torf aus 5 und Klei aus 3 (Kat.Nr. 747e). Der gesamte Befund war überlagert von einer mit Klei angereicherten Torfschicht, die stellenweise Holzkohle-Brocken enthielt (Kat.Nr. 747d). Zwei Überschwemmungshorizonte bedeckten die Anlage, die aufgrund ihrer Beschaffenheit den Bodenschichten 2 und 3 zuzuordnen sind.

Da die Baugrube mit Torfresten durchmengt war und diese den gesamten Befund zwischen $1 \mathrm{~m}$ bis $0,55 \mathrm{~m}$ NN abdeckte, ist es durchaus denkbar, dass es sich bei dem eingebrachten Material um zusätzliches Filtermaterial handelte; möglicherweise wurde der Brunnen zu einem späteren Zeitpunkt als Rottungsgrube genutzt.

Aus dem Brunnen stammen stark fragmentierte Keramikscherben. Unter dem überwiegend kaiserzeitlichen Material fanden sich auch fünf Wandungsscherben der harten Grauware. Letztere sind durch Sedimentablagerung (Kleischicht 3) in den Befund gelangt.

\section{Brunnen}

Kat.Nr. 409

Taf. 27; 104 
Im Quadranten 56/51 an der Nordseite des Siedlungsplatzes fand man unter einer runden Verfärbung von $2 \mathrm{~m}$ Durchmesser einen 68x110cm großen Korb mit intaktem Boden (Abb. 31).

Die Geländehöhe im Planum A1 betrug +1,05m NN. Der untere Abschluss des Korbes wurde bei $+0,02 \mathrm{~cm}$ NN knapp über der Grubensohle erreicht. Ursprünglich handelte es sich um einen Flechtwerkkorb, der vermutlich primär zur Vorratshaltung diente, bevor er sekundär im Brunneneinbau verwendet wurde.

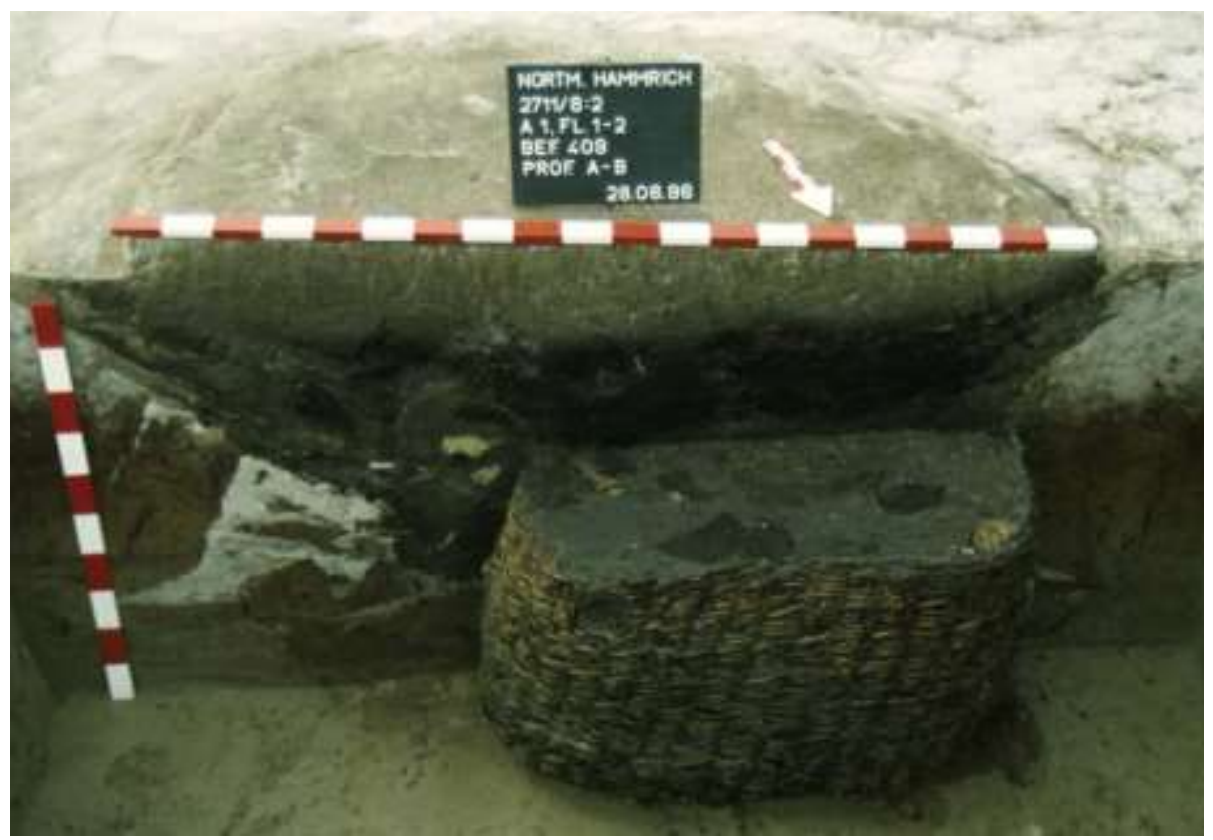

Abb. 31

Geflochtener Korb in sekundärer Verwendung als Brunnenschacht

Der leicht beutelförmige Korb war mit seiner Höhe von $64 \mathrm{~cm}$ vollständig erhalten. Er bestand aus eng geflochtenen Weidenruten mit einer Stärke von $0,6-1 \mathrm{~cm}$. Senkrechte Hölzer bildeten mit $2-4 \mathrm{~cm}$ nebeneinanderliegenden und ca. $1 \mathrm{~cm}$ dicken Weidenhölzern das Korbgerüst. In Abständen von etwa $8 \mathrm{~cm}$ waren jeweils zwei um die $1 \mathrm{~cm}$ starken Hölzer miteinander verdreht und geflochten. Der Korb hatte eine marmorierte Verfüllung aus Klei 3, Torf 5 und Sand 7. An der Westseite standen in den beiden Ecken jeweils eine Birkenstake von 10-12cm Durchmesser, die ca. 30cm in Schicht 7 eingetrieben worden war, jedoch nicht mit dem Korbgeflecht direkt verbunden war. Auch hier vermutlich um die Konstruktion zu stabilisieren.

Über dem Korb fand sich eine 18-22cm dicke Schicht rotbraunen Torfes (Kat.Nr. 409c), die eventuell für die günstigen Erhaltungsbedingungen verantwortlich war. Nach Aufgabe der Brunnengrube gelangten Keramik, Tierknochen und $1 / 2$ Spinnwirtel in den Befund. Muschelgrus gemagerte Keramik datiert den Brunnen in die mittelalterliche Siedlungsphase. 
Auch über dieser Brunnenanlage wurden wieder zwei Sedimentabdeckungen dokumentiert. Während die obere aus einem Sand-Kleigemisch bestand, wird die untere als toniger Klei aufgeführt. Dies weist wiederum auf wenigstens zwei in zeitlichem Abstand erfolgten Überschwemmung des Areals hin.

Während der Brunnenkorb Kat.Nr. 409 ein Unikat darstellt, finden sich für den zweiten Nortmoorer Weidenkorb diverse Parallelen. Ebenfalls vergleichsweise gut erhalten ist das Exemplar eines Weidenrutenkorbes aus der kaiserzeitlichen Siedlung Hohegaste, Stadt Leer (STILKE 1995, 207-209, Abb. 4 Mitte). Wie das Nortmoorer Exemplar bestand er aus unten zylindrisch sich verjüngenden Staken, um die Weidenruten geflochten waren. Der Korb hatte noch einen Durchmesser von 50cm und war $40 \mathrm{~cm}$ hoch erhalten. Die geringen Dimensionen lassen zwar eine Nutzung im Bereich der Vorratshaltung in Betracht ziehen, die Tiefenlage weist jedoch eher auf eine, wenn auch ungewöhnliche, Brunnenkonstruktion hin.

Aus der nahen kaiserzeitlichen Siedlung Westerhammrich stammen drei Brunnen mit Flechtwerkkonstruktion (BÄRENFÄNGER 1998e, 290, Abb. 3-5). Ein kaiserzeitlicher Geflechtbrunnen enthielt zusätzlich einen Baumstamm. Hier diente die äußere Flechtwerkkonstruktion vermutlich als Filterfunktion, um weniger stark verunreinigtes Wasser zu gewinnen.

\section{Brunnen}

Kat.Nr. 140

Taf. $13 ; 53$

Aus dem östlichen Grabungsbereich liegt in den Quadranten 53/52-53 eine wohl ebenfalls als Brunnen anzusprechende Anlage vor.

Im Planum A1 zeichnete sich eine ovale Verfärbung mit einem Durchmesser von 2,2x3m ab. Die Anlage verbarg sich unter mächtigen Klei- und tonigen Sandschichten, die regelrecht in die Brunnengrube eingeflossen waren. Die Geländeoberkante stand im Planum A1 bei $+1,1 \mathrm{~m}$ NN, während die Grubensohle bei $-0,1 \mathrm{~m}$ NN erreicht wurde. Um die Anlage fanden sich größere Gräben (Kat.Nr. 135; 141; 156). Die Verbindung zum westlich direkt anschließenden Graben Kat.Nr. 141 wurde im Profil nicht geklärt. Das Areal war nach Osten von überwiegend mittelalterlichen Siedlungsreste geprägt. Hier fanden sich u.a. die Überreste von einem Baumstammbrunnen und drei Rutenbergen.

Im Planum A2 zeichnete sich eine annähernd runde Brunnengrube ab, die bei $+0,68 \mathrm{~m}$ NN noch einen Durchmesser von etwa 1,4m aufwies. Im Profil zeigte sich eine trichterförmige Brunnengrube. Die ursprünglich aus organischem Material bestehende Brunnenwandung war weitgehend vergangen (Abb. 32). Eventuell stellen die auf der Brunnensohle entdeckten Holzstaken Überreste eines Einbaus dar. Die Höhe der maximalen Holzerhaltung lag bei +0,6m NN. Knapp oberhalb der Brunnensohle bei $+0,01 \mathrm{~m} \mathrm{NN}$ verjüngte sich die Brunnengrube auf $90 \mathrm{~cm}$. Da in einer Tiefe von $+/-0 \mathrm{mNN}$ 
grundwasserführende Schichten angeschnitten wurden, wird die Deutung als Brunnen damit gestützt.

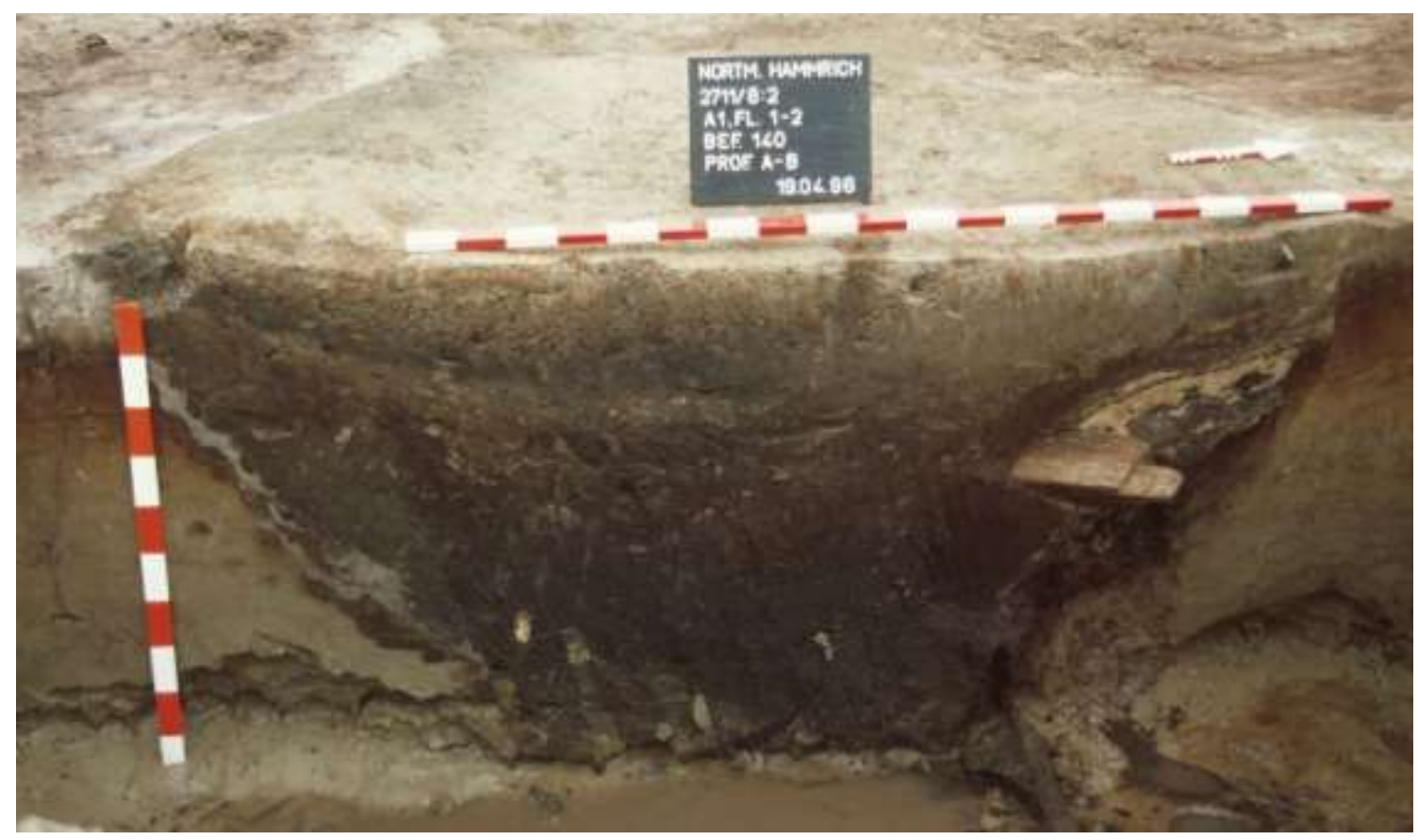

Abb. 32

Schachtbrunnen Kat.Nr. 140. Im Nordprofil steckt ein hölzernes Werkstück

Die Grubensohle war an ihrer Südseite mit einer Schwemmschicht aus eingewehtem Bleichsand mit Torfresten durchmischt, während die westliche Grubenfüllung aus einer reinen Torfschicht bestand. Darüber schloss ein Torf-Sand-Gemisch die Brunnengrube und auch den nördlichen Teil der Baugrube ab. Die rechteckige Brunnengrube wurde in mehreren Schichten verfüllt. Im Profil wechselten sich Schichten mit Sand, Torf-Sand und Torf ab. Die groben Schichtpakete deuten auf ein zügiges Verfüllen der Grube hin. Die muldenförmige Baugrube war beidseitig maximal 40cm breiter als die eigentliche Brunnengrube. Im südlichen Grubenbereich fand sich als Aushubmaterial gelber Sand und brauner Podsol (140d). Darüber lagerte die eigentliche Verfüllung der Baugrube. Aus ihrem oberen Bereich in der Schicht 140c, stammt eine 20x45cm große und $4 \mathrm{~cm}$ breite Holzbohle. Die bearbeitete Bohle wies eine zentrierte Bohrung und eine zapfenartige Ausarbeitung auf (Kat.Nr. 140h). Da es sich um ein sekundär verworfenes Bauholz handelt, erfolgt seine Ansprache im Kapitel 5.4.6 (Holzobjekte).

Bau- und Brunnengrube waren nahezu vollständig abgedeckt mit einer Sandschicht, deren unterer Bereich auf etwa $10 \mathrm{~cm}$ aus einer Mischung von weißem Bleichsand und gelbem Sand bestand (Kat.Nr. 140f). Eventuell handelt es sich hier um eine alte Oberfläche, die sich auf einer Länge von $2,5 \mathrm{~m}$ erhalten hat. Über dieser Sandschicht fanden sich Reste einer bis zu $16 \mathrm{~cm}$ mächtigen Kleischicht, die an den Rändern der Grube muldenförmig ausstrich und in der sich Muschelgrus 
gemagerte Scherben fanden.

Die wenigen erhaltenen Holzreste können keinem konstruktiven Verbund mehr zugeordnet werden. In der Grubensohle befanden sich mehrere Staken aus 20cm langem Birkenholz. Ihre unteren Spitzen waren angebeilt bis zu 40-50 cm in den gewachsenen Boden eingetrieben worden. Dies erfolgte ohne ein erkennbares System. Mit Ausnahme lose eingebrachter Holzstaken fehlen weitere hölzerne Einbauten innerhalb der Brunnengrube. Reste einer Randbefestigung der Anlage wurden bei der Ausgrabung nicht festgestellt bzw. waren nicht mehr erhalten. Weitere Staken gelangten vermutlich im Zuge der Grubenverfüllung in die Baugrube.

Vermutlich handelt es sich um eine einfache Brunnenkonstruktion unter Verwendung von Holzstaken und / oder Flechtmatten. Sollte zu ihrer Stabilisierung konstruktives Bauholz verwendet worden sein, so wurde dieses nach Aufgabe des Brunnens entfernt, denn es sind nur einzelne Staken nahe der Sohle blieben geblieben. Denkbar ist auch, dass es sich um ein Wasserloch ohne konstruktive Befestigung handelte, welches regelmäßig gereinigt wurde. Hierfür sprechen die Schräg der Wandung und die Zuleitungsgräben des Oberflächenwassers.

Aussagen zur Nutzungsdauer der Anlage sind kaum zu treffen, da eine Stratifizierung des aufgefundenen Keramikmaterials während der Ausgrabung nicht erfolgte. Vermutlich handelte es sich um eine einphasige Anlage. Reparaturstellen waren nicht anzutreffen.

Da sowohl der Brunnen wie die Baugrube von einer Kleischicht überdeckt sind, war zur Zeit der Überschwemmung noch eine flache Mulde im Gelände vorhanden. Der Brunnen, eingegraben in die natürlichen Bodenschichten 6, 7a und 7, ist somit älter als die Sedimentationsschicht, die vermutlich der Schicht 2 entspricht.

Im Planum A1 zeichnet sich an der westlichen Seite des Brunnens eine Überschneidung zum benachbarten Graben Kat.Nr. 141 ab. Ebenso wie der Brunnen Kat.Nr. 140 weist auch der Graben eine einziehende obere sandige Kleischicht auf; er war also zu dieser Zeit noch in seinem oberen Bereich offenstehend und wurde von der Sedimentablagerung überdeckt.

Eine mittelalterliche Datierung der Anlage gilt als wahrscheinlich. Die Bauweise zeigt auffällige Parallelen zu einer des 9./10. Jahrhunderts, die im nahen Hesel entdeckt wurde (BÄRENFÄNGER 1998e, 289, Abb. 1). Während dort jedoch die Wasserschöpfstelle nur durch Oberflächenwasser gespeist wurde (sie reichte in den wasserundurchlässigen anstehenden pleistozänen Untergrund hinein), so war der Nortmoorer Brunnen grundwasserabhängig bzw. könnte als Teich Oberflächenwasser gesammelt haben.

Aus der Brunnengrube stammt u.a. harte Grauware und Muschelgrus gemagerte Keramik sowie eine Steinzeugscherbe. Aussagekräftige Profillängen sind unter dem stark zerscherbten Keramikmaterial selten. Die meisten Randscherben gelangten wohl mit dem Bodenaushub in den Brunnen. Es handelt sich um überwiegend kurze dreieckig verdickte Ränder, wie sie typisch für frühkaiserzeitliche 
Keramik sind. Nur wenige Scherben waren verziert. Ein Bandhenkel ist mit einer kleinen Einstichreihe dekoriert (Kat.Nr. 140-8). Ein Randfragment gehört einem sehr dünnwandigen Terra Nigra Gefäß an (Kat.Nr. 140-5). Das Fundrepertoire wird ergänzt durch eine facettierte Tonperle (Kat.Nr. 140-10), kalzinierte Knochenfragmente, Glättsteine, Kalkstein, Abschläge sowie eine Vielzahl an Objekten, die mit Feuer in Kontakt gekommen sind, gebrannte Quarzsteine und Flintabschläge sowie 3,5kg gebrannter Lehm.

\section{Wasserstelle}

Kat.Nr. 195

Taf. 16-18; 53; 54; 105, 106

Eine der größten Anlagen der Nortmoorer Wasserversorgung fand sich in den Quadranten 52/51 und 53/51. Im Planum A1 zeichnete sich eine etwa rundovale 6,50m große und fast kreisrunde Verfärbung ab, die nahezu komplett von einer Sand-Klei-Schicht abgedeckt war. Um die Anlage grabungstechnisch entsprechend zu dokumentieren, wurde der Befund mit einem Kreuzschnitt in vier Quadranten eingeteilt, wobei zwischen den Quadranten jeweils ein $50 \mathrm{~cm}$ breiter Profilsteg stehen blieb.

Innerhalb der Anlage stieg das Geländeniveau von Süd nach Nord von $+1,28 \mathrm{~m} \mathrm{NN}$ auf $+1,50 \mathrm{~m} \mathrm{NN}$ an. Die Grubensohle wurde bei $+0,32 \mathrm{~m}$ NN erreicht. In der Wasserstelle lag die Höhe der maximalen Holzerhaltung bei $+0,97 \mathrm{~m}$ NN. Die meisten Hölzer fanden sich zwischen $+0,54$ bis $+0,88 \mathrm{~m}$ NN .

Ursprünglich war die Anlage von einem rechtwinklig orientierten Zaunsystem umschlossen (vgl. Kapitel Umzäunungen), von dem sich an vier Seiten die Reste der Zaungräbchen erhalten haben (Kat.Nr. 106; 107; 129a-c; 164).

Befundüberschneidungen mit zwei $0,5-0,7 \mathrm{~m}$ breiten Gräben waren im Norden der Anlage zu beobachten. Während der 4m lange Graben Kat.Nr. 202 von ihr geschnitten wurde, war der 8,6m lange Graben Kat.Nr. 187 mit der Wasserstelle verbunden. Nach Osten fand sich eine Häufung von Pfostengruben und Gräben. Ein weitgehend befundleerer Raum schloss hingegen sich südlich der Anlage an. Den Bereich nordwestlich der Wasserstelle störten zwei moderne Gruben (Kat.Nr. 185; 186).

Die Wasserstelle bestand aus einer runden Grube mit einem Durchmesser von 6x6,5m. Im Schnitt zeigte sich eine muldenförmige Gestalt. Beim Abtiefen fand man eine Stakensetzung, die einen ovalen Kreis mit einem Durchmesser von 3,50-3,80m bildeten. Die in einem Abstand von 20-30cm stehenden Holzstaken waren senkrecht in die Sohle eingerammt. Zwischen den $1 \mathrm{~m}$ langen und $8 \mathrm{~cm}$ durchmessenden Staken war partiell noch Flechtwerk erhalten. Lose deponierte Hölzer oberhalb der Sohle sollten wohl verhindern, dass der Grund beim Wasserschöpfen zu sehr aufgewühlt wird (Abb. 33). 


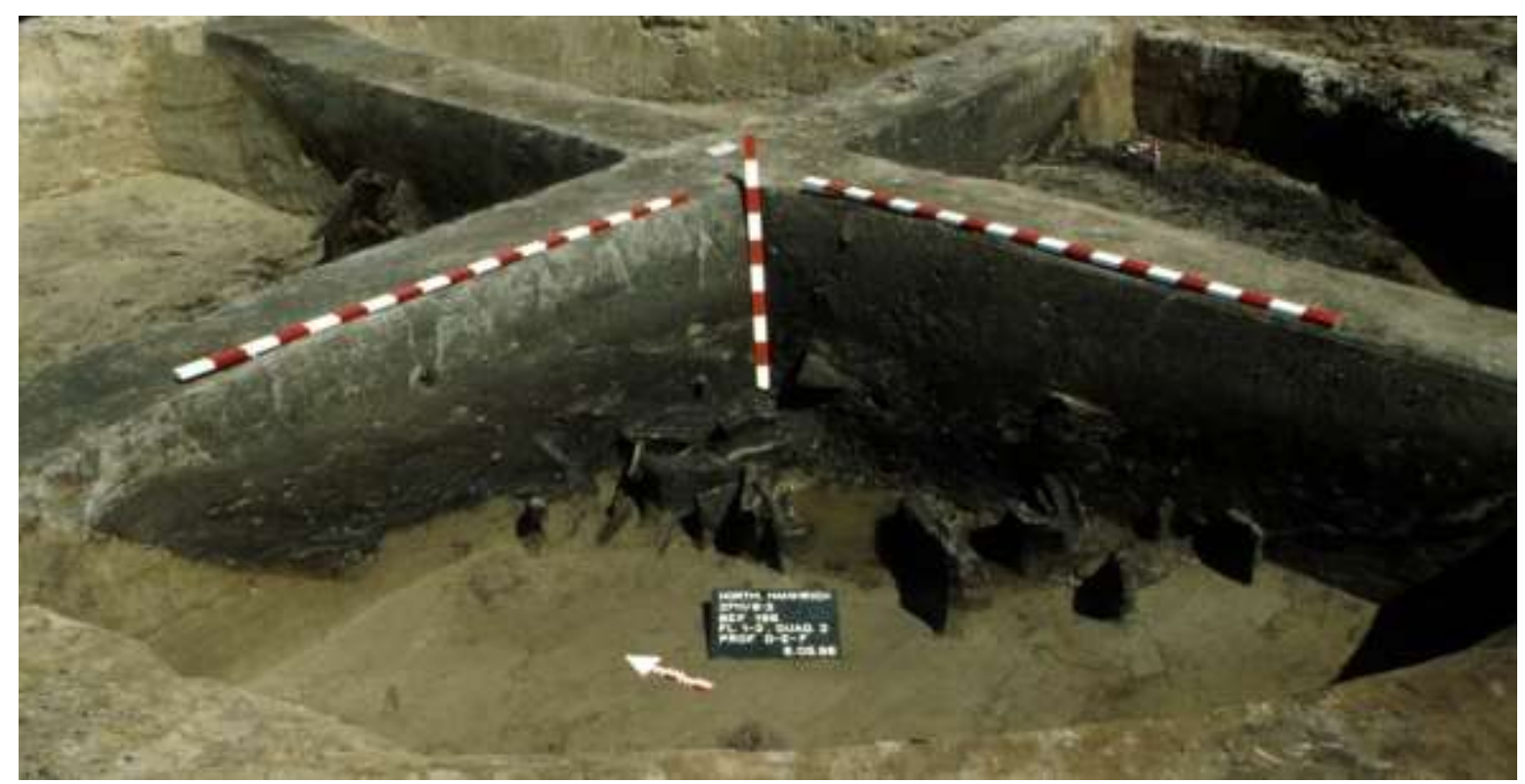

Abb. 33

Die kaiserzeitliche Wasserschöpfstelle (B 11), Profil D-E-F

Zur Grubenmitte war das aus etwa $2 \mathrm{~cm}$ dicken Ästen und Strauchwerk bestehende Flechtwerk abgeknickt und zusammengedrückt. Vermutlich hatte die Grube dadurch ihre Funktionsfähigkeit verloren und verlandete langsam. Die eingestürzte oder eingedrückte Stakenwand wurde mit Abfallholz unterschiedlicher Größe überlagert, denen in der Regel keine Primärfunktion zuzuweisen war. Dies deutet auf eine Nutzung der aufgelassenen wannenförmigen Grube als Abfallgrube hin.

Ablagerungen auf der Grubensohle stellen die Reste einer humosen Nutzungsschicht dar, die auf ein längeres Offenstehen der Wasserstelle hinweisen. Eine längerfristige Nutzung der Wasserstelle zeigen in diesem Kontext auch die von einem hölzernen Einbau gewonnenen dendrochronologischen Ergebnisse auf. Beim Abbau des Profilsteges der Wasserstelle entdeckte man ein Sitzbank-ähnliches Objekt bei dem es sich um die Stufen einer hölzernen Treppe handelte (Abb. 34). 


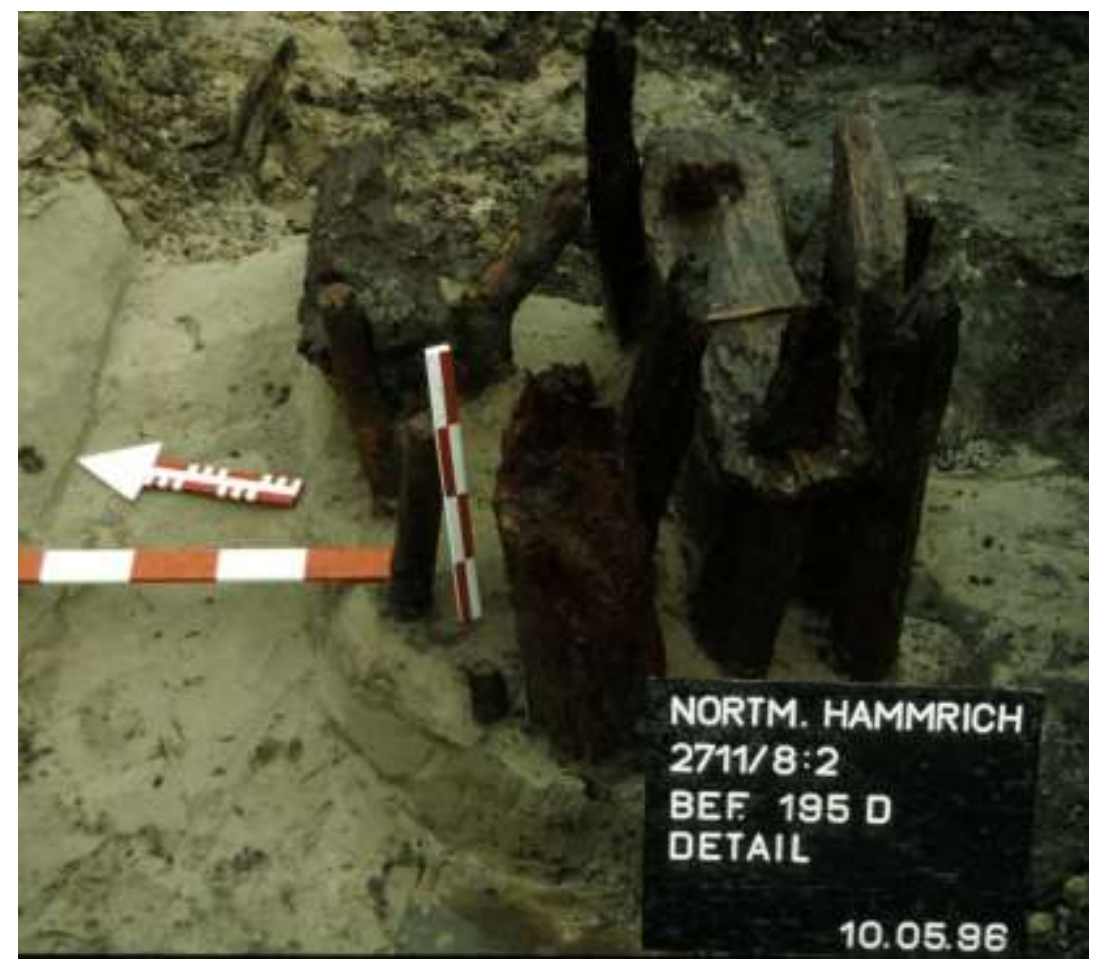

Abb. 34

Detailfoto der zweistufigen Treppe in der Wasserstelle (B 11)

An der Innenseite der Stakenreihe standen sechs Staken aus gespaltenem angespitzten Eichenholz (L: $1 \mathrm{~m}$; Dm: ca. $10 \mathrm{~cm}$ ), die etwa $60 \mathrm{~cm}$ in den gewachsenen Boden getrieben worden waren. Zwei Staken waren mit einem Stück Holz, in den passenden quadratischen Löchern ausgespart waren, verbunden. Das Fälldatum eines hölzernen Bauteiles wird mit „126 n. Chr. ${ }^{+/ 10 ، ~}$ angegeben werden. Mit der Treppe konnte ein Höhenunterschied von $0,8 \mathrm{~m}$ überwunden werden.

Die Haupt-Verfüllung der Grube war stark humos bis anmoorig und von zahlreichen unregelmäßigen Sandwirbeln durchzogen (Kat.Nr. 195c). Auf ein Offenstehen der aufgelassenen Wasserstelle deutet die, im Profil sich deutlich abzeichnende, mit Schwemmlinien durchzogene muldenförmig eingetiefte Grube hin. Die zunächst im Gelände noch sichtbare Grube füllte eine geringmächtige tonig-sandige Schicht aus (Kat.Nr. 195b), wobei sie nahezu gleichmäßig die Wasserstelle abdeckte und zu den Rändern über sie hinausstrich. Die Tonhaltigkeit des Bodens der Füllung und die Art der flächigen Ausbreitung deuten darauf hin, dass es sich bei ihr um Relikte eines Überschwemmungshorizontes handelt. Eine bis $\mathrm{zu} 35 \mathrm{~cm}$ mächtige Kleischicht deckte die vorhergegangene Sedimentschicht schließlich vollständig ab (Kat.Nr. 195a).

Die Wasserzufuhr erfolgte bei dieser Anlage wohl in erster Linie durch von oben zulaufendes Oberflächenwasser. Bei der Größe des Reservoirs wird dies für eine ständige Wasserführung jedoch kaum ausreichend gewesen sein. Möglicherweise diente daher der im nördlichen Randbereich mit der 
Wasserstelle verbundene Graben Kat.Nr. 187 zur Versorgung mit Oberflächenwasser. Wenn auch keine wasserführende Schicht angeschnitten wurde, so wird der auf der Düne recht hohe Grundwasserstand ein Austrocknen der Wasserstelle verhindert haben. Mit einer bei $+0,32 \mathrm{~m}$ NN anstehenden Sohle liegt die Anlage im Mittelfeld der Nortmoorer Brunnen.

Aus der Wasserstelle existieren vier dendrodatierte Hölzer, deren abgeleitete Fälljahre zwischen „97 n. Chr.“ bis „186 n. Chr.“ liegen. Demnach könnte von einer etwa 100-jährigen Nutzungsdauer der Anlage ausgegangen werden. Doch einzig das mit „126 n. Chr.“ datierte Holz der Treppenstufe, das in die Anlage verbaut wurde, gibt ein festes Eckdatum für die Nutzungsphase der Wasserstelle.

Keramik überwiegt mit einer Stückzahl von 3000 Scherben im Fundgut der Wasserstelle deutlich. Unter einer Vielzahl von kaiserzeitlichen Rand-, Wand- und Bodenscherben sind drei ungewöhnliche Terra Sigillata Nachahmungen (Kat.Nr. 195-1,-2,-3) und eine dünnwandige Terra Nigra Schale (Kat.Nr. 195-5) hervorzuheben, die in das 2. Jahrhundert datieren. Es überwiegen im Fundgut frühkaiserzeitliche Randfragmente von Trichterschalen, becherförmigen Gefäßen sowie eng- und weitmündigen Töpfen. Ergänzt wird das Repertoire von einem Webgewicht mit k-förmiger Einritzung (Kat.Nr. 195-23), einem Spinnwirtel (Kat.Nr. 195-24), wenigen Wetzsteinen und diversen Tierzähnen und -knochen. Es fanden sich zudem wenige mittelalterliche Scherben, wie Muschelgrus gemagerte Keramik und Pingsdorfer Ware, die wohl als Oberflächenfund aus der abschließenden Kleischicht aufgesammelt worden sind.

\subsubsection{Rechteckige Grabenanlage}

Kat.Nr. 383; 392

Taf. 25; 98

An der südlichen Siedlungsgrenze befindet sich in den Quadranten 52/46 bis 53/47 eine durch zwei Gräben gebildete Grabenanlage. Die einzelnen Schenkel der Anlage liegen in etwa rechtwinklig zueinander. Innerhalb der Grabenanlage steigt die Geländehöhe von Süd nach Nord von $+0,98 \mathrm{~m}$ auf $+1,38 \mathrm{~m} \mathrm{NN}$ an.

Gebäudegrundrisse fehlen in der unmittelbaren Nähe der Grabenanlage. Sowohl Hausplatz I wie Haus II sind etwa $15 \mathrm{~m}$ nördlich bzw. nordwestlich entfernt. Etwa 3,5m südlich von der Grabenanlage verläuft die Zaunsetzung Kat.Nr. 100. Die Zaunreihe Kat.Nr. 265 biegt kurz vor Erreichen der Ostseite der Anlage nach Norden ab.

Den Hauptteil der rechteckigen Grabenanlage bildet der Graben Kat.Nr. 383. Dieser hat im Planum A1 eine maximale Ausdehnung von 12,8m (W-O) x 11,3m (S-N). Auffällig ist sein fast kantigrechteckig ausgebildeter Grabenverlauf. Nach Süden wird der dreischenklige Graben von einem 
wesentlich kürzeren Graben abgeschlossen. Kat.Nr. 392 liegt zwischen den seitlichen Tangenten von Kat.Nr. 383, berührt diese jedoch nicht (Taf. 98). Beide Gräben sind zwischen $50-58 \mathrm{~cm}$ in den gewachsenen Boden eingetieft und verfügen über ein annähernd kastenförmiges Profil.

Der auf drei Seiten ein Rechteck einfassende Graben Kat.Nr. 383 besitzt eine Fläche von 9x10m. Die maximale Grabenbreite beträgt 2,5m. Durchschnittlich ist der Graben 1,2-1,8m breit. Im Planum A1 zeigt sich deutlich ein rötlich-graubraunes Grubenfüllung aus oxidiertem Klei. Darunter schließt sich eine Grube (Füllung mit dunkler Sandschicht) an, die in den pleistozänen Sand eingetieft ist.

Der 7,2m lange und 1,2-2,2m breite, leicht unförmige, Graben Kat.Nr. 392 bietet zu beiden Seiten kleinere Durchlässe $(0,4$ und $1,11 \mathrm{~m})$. Der kastenförmig abgetiefte Graben (Tiefe $50 \mathrm{~cm})$ ist weitgehend mit sterilem hellgelben Sand verfüllt. Zuunterst findet sich eine Deckschicht mit hellgrauem Bleichsand, die im südlichen Grabenbereich von einem Sand-Klei-Gemisch bedeckt wird.

Während das Grabenprofil Kat.Nr. 392 dem Nordprofil E-F von Kat.Nr. 383 in etwa gleicht, sind die Profilverläufe seiner Längsseiten stärker geschichtet. Deutlich zeichnen sich im unteren Bereich starke Einschwemmungen bzw. Einblasungen von weißem und hellgelben Feinsand ab (Profil A-B, C-D). Die durchgängig beobachtete grob geschichtete Verfüllung der Gräben deutet auf ein längeres Offenstehen hin. Eine Sand-Kleischicht bedeckt abschließend beide Gräben. Dies steht in Verbindung mit einer bzw. mehrerer kurz hintereinander erfolgten Überschwemmungen durch Flusssedimente der nahen Jümme. Aus dem größeren Graben stammt kaiserzeitliches Keramikmaterial, darunter der Gefäßrand einer Terra Nigra Scherbe. Der kleinere Graben Kat.Nr. 392 war dagegen fundleer.

Mit Ausnahme von drei Gruben und einem Zaungräbchen ist das innere Grabenareal befundleer. Pfostensetzungen sind weder innerhalb des eingegrenzten Areals noch innerhalb der Grabenanlage selbst festzustellen. Drei kleinere Gruben (Kat.Nr. 384; 385; 387) befinden sich in der NW-Ecke der Anlage. Während die 50x170cm große Grube (Kat.Nr. 384; 385) wenige HK-Bröckchen enthielt, war die benachbarten rundlichen Gruben (Kat.Nr. 365) fundleer. Rechtwinklig in die NW-Ecke der Grabenanlage laufen von Nord und West zwei Gräbchen (Kat.Nr. 372 und 386) hinein, wobei das kürzere Gräbchen im Westgraben verschwindet. Aufgrund ihrer stratigraphischen Abfolge sind sie als älter zu werten. Vier Pfostengruben befinden sich außerhalb der Grabenanlage an deren SüdwestSeite. Ob die Pfostengruben in einem rechten Winkel ausgerichteten Pfostenbefunde Kat.Nr. 388-391 mit der Anlage in Verbindung stehen, ist unklar.

Aus der rechtwinkligen Grabenanlage stammen wenige kaiserzeitliche Keramikscherben. Darunter finden sich zwei Scherben einer Importware; eine Terra nigra-artige Rand - und eine Wandungsscherbe (Taf. 25; Kat.Nr. 383-1), die vermutlich in das 2./3. Jahrhundert n. Chr. datieren. Des weiteren fanden sich ein situellenförmig Gefäßfuß (Kat.Nr. 383-3), sowie die Randscherben eines in die mittlere Kaiserzeit datierenden Topfes der GF 7.2 mit nach außen gewendetem Rand (Kat.Nr. 383-2). 
Ungewöhnlich ist die rechteckige Grundrissform der Nortmoorer Grabenanlage und ihr nahezu befund- wie fundleerer Innenraum, der Platz für Interpretationen lässt. Zwar existieren keine direkten Parallelen im niedersächsischen Küstengebiet, es finden sich jedoch gewisse Übereinstimmungen zu den sogenannten hufeisenförmigen Anlagen, die im Anschluss vorgestellt werden. Mehrfachanlagen dieses Typs liegen aus Gristede (4), Flögeln (3) und Einswarden (2) vor. Bisherige Einzelanlagen sind in Brill, Eppingawehr und Nortmoor belegt.

Die Anlagen in Flögeln verfügen bisher als einzige über eindeutig zugehörige Einbauten in Form kleiner Grubenhäuser, die im Zentrum der Anlagen eingetieft waren (ZIMMERMANN 1992, 221-223, Abb. 171-172). Die dortigen drei hufeisenförmigen Grabenanlagen datieren in das 1.-2. Jahrhundert $n$. Chr. Zwei der Anlagen sind nach Süden, die dritte Anlage nach Westen hin geöffnet. Mit 10x10m Größe kommt Anlage I der Nortmoorer Grabenanlage vom Flächeninhalt am nächsten. Ebenso wie diese besitzt sie keine Pfostenspuren in den Grabenanlagen. Zwar finden sich datierende Keramikscherben in den Flögelner Grabenanlagen, Funde die etwas zur Funktion aussagen fehlen jedoch.

Aus Nordenham-Einswarden liegen zwei ähnliche Grabenanlagen vor (ZIMMERMANN 1992, 226, Abb. 175). Anlage 1 wies eine deutliche Hufeisenform (25x5m) auf und es fanden sich im Graben dicht beieinanderstehende Pfostenbefunde. Der rechteckige Umriss der Nortmoorer Grabenanlage findet seine Parallele in der Anlage 2. Die 5,9x7,5m große Anlage mit einer Grabenbreite von 1-1,5m verfügt über abgerundete Außenkanten und einem annähernd rechtwinkligen Innenraum (3-3,4x6m). Innerhalb der insgesamt nur 42qm großen Konstruktion, die in die frühe Kaiserzeit datiert wird, fanden sich keine Befunde.

Mit 55qm etwas größer ist die u-förmige Grabenanlage in Brill. Die nach NO offene Anlage (7x7,8m) weist im hinteren Bereich eine Reihe von drei Pfosten auf. Zwei der offenen Nordostseite mittig vorgelagerte Pfostenbefunde werden als Abschlussfunktion gedeutet (LEHMANN 2002, 155-156, Taf. 107).

Kleinere Anlagen mit umgebenden Graben sind aus Eppingawehr, Landkreis Leer, und Gristede, Landkreis Ammerland, bekannt. Die nur 16qm große Anlage in Eppingerwehr wird in die späte Latènezeit datiert. Hier wurden innerhalb des umgebenden Grabens Flechtwerkreste beobachtet. Im Anlagezentrum entdeckte man sechs gruppierte Pfostengruben. Leichenbrand einer gestörten Bestattung und Keramik fand man am Durchgang (SCHROLLER 1940, 96). Diese Interpretation steht derzeit zur Diskussion. Nach Strahl soll es sich bei der o.g. Anlage um einen eingehegten Speicher und bei dem Leichenbrand um gebrannte Tierknochen handeln (STRAHL 2003, 356-358).

Aus Gristede liegen vier kleinere hufeisenförmige Bauten vor, die von der Kaiserzeit bis in die 
beginnende Völkerwanderungszeit datieren (ZOLLER 1972b, 323-325). In Anlage 42/1 fanden sich Pfostensetzungen an der offenen Anlagenseite und im Graben selber (ZOLLER 1975, 39, Abb. 2). Die übrigen waren zumeist weitgehend befundfrei. Auf der 30x25m großen Fläche, die die Bauten einnahmen, wurden Gruben mit Scherben, Holzkohle und Haustierknochen beobachtet (ZOLLER 1975, 40).

Mit Ausnahme von Flögeln und Eppingawehr sind keine rechteckigen Einbauten in den Grabenanlagen festzustellen. Vereinzelt existieren im Anlageninneren jedoch Pfostenreihen. Eine Abschlussfunktion der an einer Seite ansonsten offenen Anlagen findet sich in Brill, Gristede und Flögeln durch Pfostenbefunde. In Nortmoor übernimmt dies ein Graben.

Die bisherigen Deutungsmöglichkeiten für die Anlagen reichen von Kult- bis hin zu Profanbauten. ZIMMERMANN $(1992,228)$ hält darüber hinaus bei den Flögelner Grabenanlagen eine Nutzung für Spezialwerkstätten in Grubenhäusern oder auch als Speicherbauten für möglich. Für die Nortmoorer Grabenanlage ist dies nicht zu verifizieren. Hierfür fehlen eindeutige Pfostenbefunde aus der Anlage. In den Außengräben fanden sich keine Pfostengruben bzw. wurden während der Ausgrabung nicht als solche erkannt. Die Grabenanlage diente vermutlich weder als Umgrenzung für ein Gebäude noch ist eine Funktion als Entwässerungsgraben wahrscheinlich.

\subsubsection{Umgrenzungen}

Kat.Nr. 20; 48; 62; 100;106;107;110;129; 164;262;347; 372; 386; 514; 585; 723; 742; 746/860/903; 776; 836; 866; 869; 886; 902a-f; 903; 922; 1020; 1095; 1172; 1173; 1174; 1216

Aus der Siedlung liegen eine große Anzahl schmaler Gräbchen unterschiedlicher Länge vor. Diese sind zwischen 15 und $40 \mathrm{~cm}$, meist 20 und $25 \mathrm{~cm}$, breit. Im Profil zeigen sich Tiefen von $3-30 \mathrm{~cm}$. Größtenteils sind die Gräbchen 10 und $20 \mathrm{~cm}$ eingetieft. Es überwiegen mulden- bis kastenförmige Profile, selten v- oder trapezförmige.

Die Längen der Gräbchen variieren zwischen kurzen Abschnitten von wenigen Dezimetern bis zu 90m erreichen. Die Gräbchen liegen meist in Flucht, so dass sich längere Zaunabschnitte im Planum abzeichnen. Selten sind Biegungen in ihrem Verlauf festzustellen. Ein Großteil der Gräbchen weist mehr oder weniger lange Unterbrechungen auf, die vermutlich überlieferungsbedingt sind.

Stellenweise fanden sich in den Gräbchen noch Pfostenreste. Diese bestanden meist aus runden Hölzern, die entweder am unteren Ende angespitzt oder flach ausgearbeitet waren. Die Pfosten sind teils bis unter die Gräbchensohle eingeschlagen worden. Obertägig dienten die Pfosten vermutlich als Befestigung von Zaunsegmenten. Flechtwerkteile, die als Teilstuicke angebracht waren, sind von der Feddersen Wierde belegt (vgl. SCHMID/ZIMMERMANN 1976, 8). Denkbar ist auch, dass über längere Strecken biegsame Weidenäste mit den Pfosten regelrecht verflochten wurden. 
In Nortmoor liegen drei verschiedene Zauntypen vor. $\mathrm{Zu}$ unterscheiden sind lange, meist lineare, Außenzäune, die die Siedlung zum Umland abgrenzten. Innerhalb der Siedlung existierten zudem diverse Hofumzäunungen. Umzäunungen liegen dann vor, wenn einzelne Gräbchen in einer Flucht liegen und zu einem Zaunsystem verbunden werden können. Sie zeichnen sich in Nortmoor durch eine meist einheitliche Breite aus und können Längen von 90m erreichen. Ferner fanden sich durch Zäune separierte kleinere Areale. Soweit ersichtlich dienten diese als Schutzzäune, um den Zugang der umhegten Siedlungsbereiche zu reglementieren, vermutlich damit Wild- und Haustiere ferngehalten wurden. Bei einigen kürzeren Gräbchen ist ihre ursprüngliche Funktion nicht mehr zu erschließen, da sie keinen erkennbaren Bezug zu Umgebungsbefunden aufweisen (Kat.Nr. 20; 48; 62; 386; 773; 836; $853 ; 898 ; 1104)$. Ob es sich bei ihnen um Zaungräbchen gehandelt hat, sei daher zur Disposition gestellt.

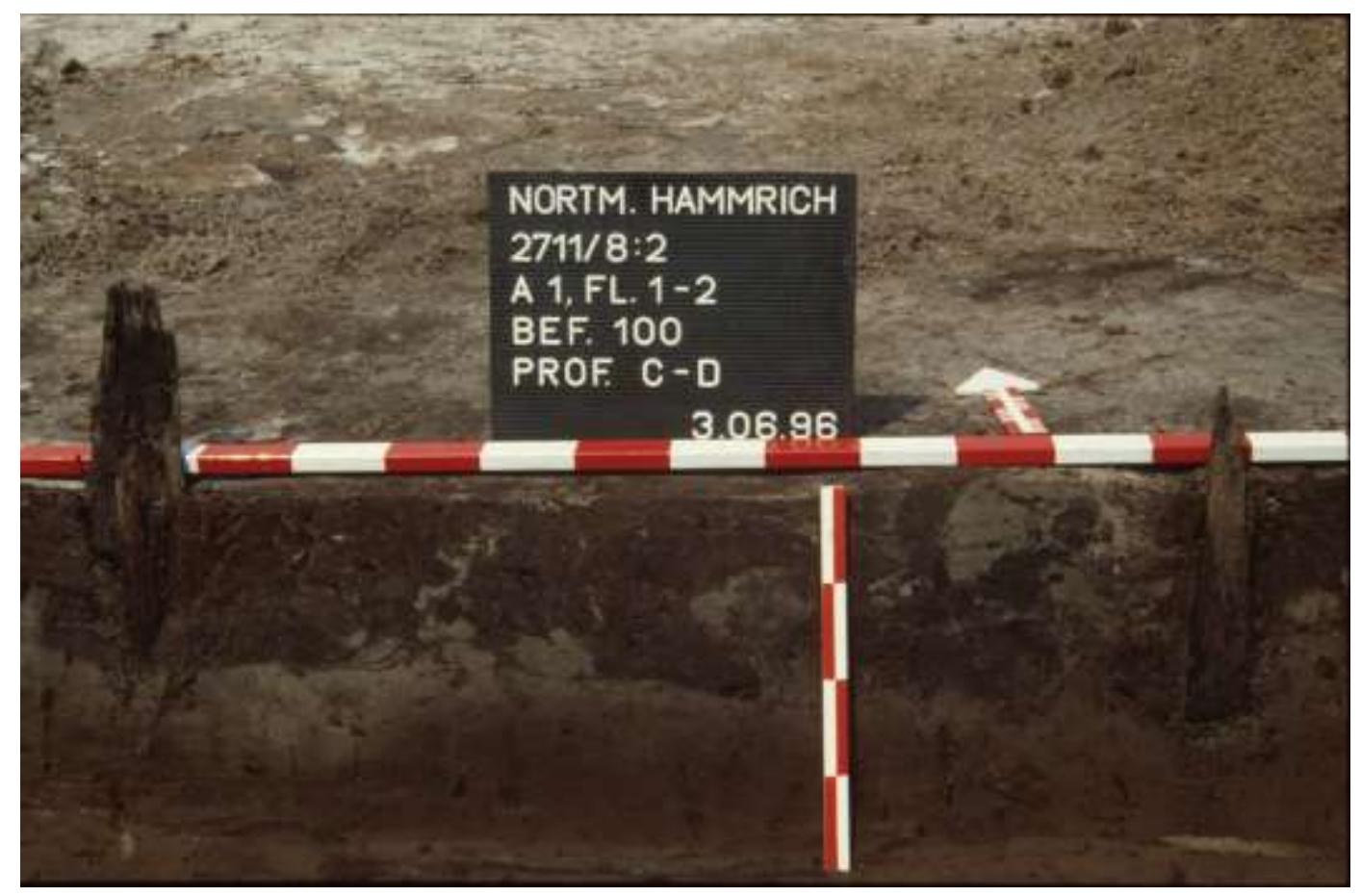

Abb. 35

Zaungräbchen mit Holzstakensetzung (Kat.Nr. 100)

An der Südseite der Siedlung haben sich die Überreste zweier parallel verlaufender Zaunreihen erhalten (Kat.Nr. 100; 106), die in einer Entfernung von 4,2m zueinander verlaufen. Die O-Worientierten Gräbchen begrenzen das Siedlungsareal zur umgebenden Jümme-Niederung. Während vom nördlichen Gräbchen (Kat.Nr. 106) eine Teilstrecke von $25 \mathrm{~m}$ erhalten ist, kann das südliche Gräbchen (Kat.Nr. 100) auf 90m Länge verfolgt werden Die Abbildung zeigt die regelhaft in $1 \mathrm{~m}$ Entfernung erfolgte Setzung von Holzstaken (Abb. 35). Kleinere Unterbrechungen in seinem Verlauf sind vermutlich überlieferungsbedingt. 
Einheitlich ist nicht nur die Ausrichtung beider Zäune, sondern auch die Gräbchenbreite von $13-14 \mathrm{~cm}$. Der nördliche Zaun war noch bis zu $10 \mathrm{~cm}$ eingetieft, während der südliche eine Tiefe von $15-25 \mathrm{~cm}$ aufwies. Hier waren auch die Erhaltungsbedingungen für die Holzstaken günstiger. Im Gräbchenprofil gut erkennbar, sind die in regelmäßigen Abständen von 0,5-1m eingeschlagenen Zaunpfosten. Sie wurden abwechselnd links und rechts von der Mitte des Gräbchens versetzt aufgefunden. Die bis in eine Länge von $30 \mathrm{~cm}$ erhaltenen Staken besaßen angebeilte Enden, um sie besser in den Boden schlagen zu können. Mit „136 ${ }^{+/ 10} \mathrm{n}$. Chr.“ liegt vom Südzaun ein dendrochronologisches Datum für einen Holzpfosten vor. Im Profilsteg 3 ist das Gräbchen Kat.Nr. 100 bis zu 46cm eingetieft. Zudem ist eine $40 \mathrm{~cm}$ tiefe Pfostenstandspur erhalten. Das Zaungräbchen schneidet im Profilsteg Bodenschicht 6, die zusammen mit dem Zaun von der Kleischicht 3 überlagert wird. Die Bodenschichten 4 und 5 fehlen (Abb. 36). Diese Schichtabfolge entspricht derjenigen in Profilsteg 1 und 2.

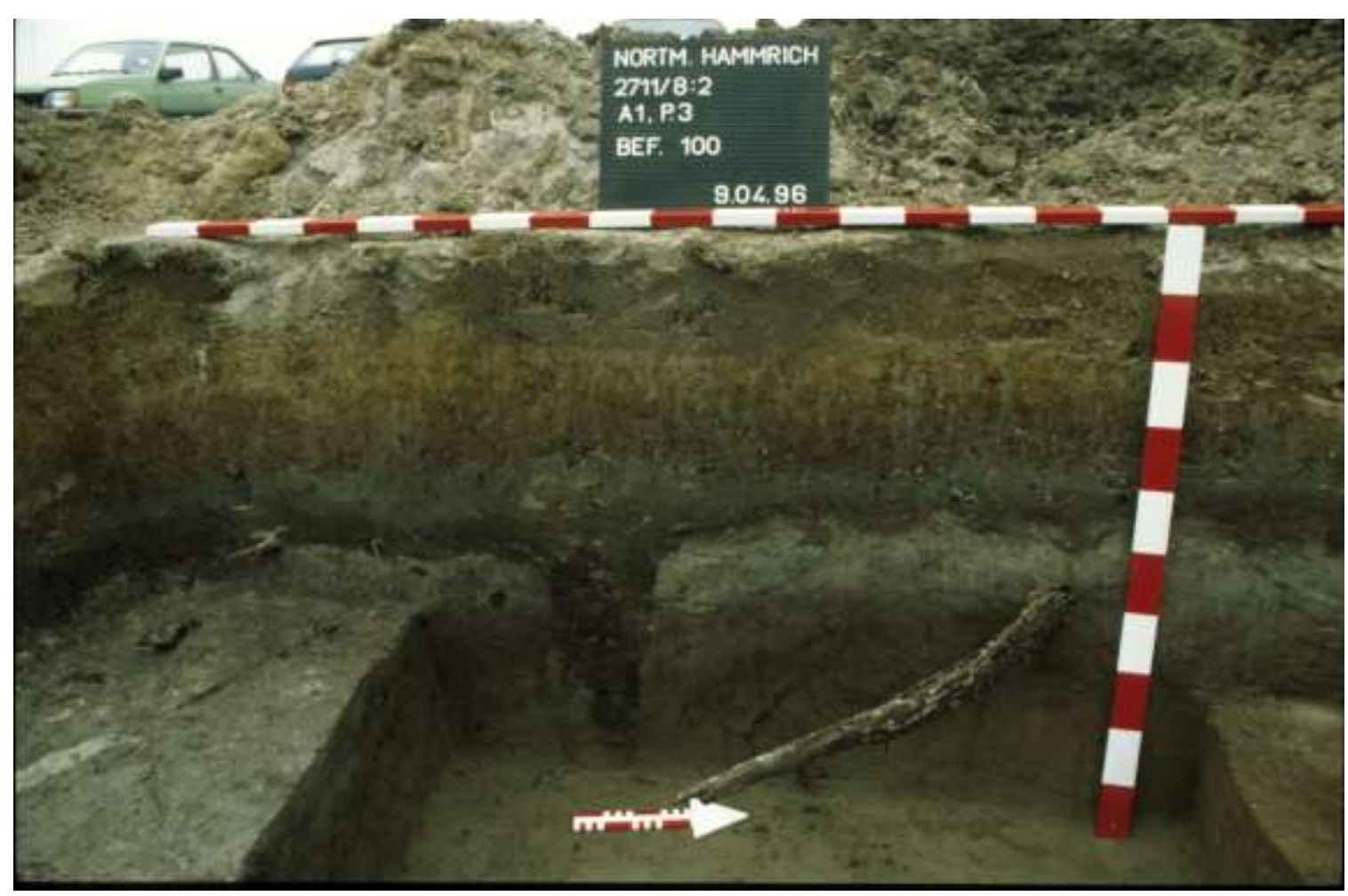

Abb. 36

Profil 3 zeigt ein Zaungräbchen und eine kaiserzeitliche Überschwemmungsphase

Während der Zaun Kat.Nr. 106 nach 25m abbricht und unter einer Drainage verschwindet, beginnt etwa 4m nördlich mit Kat.Nr. 262 ein neuer Zaun, der auf eine Länge von 27,1m verfolgt werden kann. Dieser verläuft zunächst einige Meter parallel zu dem etwa $7 m$ entfernten Südzaun Kat.Nr. 100, bevor er in einem flachen Winkel nach Nordwesten abweicht. Nach 19,8m biegt das Zaungräbchen Kat. 262 in einem Bogen nach Norden, um dann nach 7,3m plötzlich abzubrechen. 
Die drei annähernd parallel verlaufenden Zaunreihen werden wahrscheinlich nicht gleichzeitig bestanden haben. Da Überschneidungen der Zaunsegmente fehlen, ist die Abfolge der Zäune unbekannt. Allgemein haben eingetiefte Holzstaken mit einem Durchmesser von 8 bis $10 \mathrm{~cm}$ im feuchten Bodenmilieu nur eine ungefähre Haltbarkeit von 7 Jahren, bevor sie von unten wegfaulen. Tauscht man die Holzstaken nicht in regelmäßigen Abständen aus, wird der Zaun nicht lange darüber hinaus bestand haben. Es ist daher zu vermuten, dass die Zäune oder Zaunabschnitte mit der Zeit erneuert wurden.

Die angetroffenen Pfostentiefen lassen auf Zäune mit einer Höhe von maximal 1,2m oberhalb der Oberfläche vermuten. Höhere Zäune hätten eine stabilere Ausführung in Form von stärkeren Holzpfosten benötigt. Diese sind trotz der allgemein guten Holzerhaltung in Nortmoor nicht nachzuweisen. Nach dem vorliegenden Befund schließt sich für die Außenzäune in Nortmoor eine fortifikatorische Bedeutung aus. Eine Stabilisierung der Fundamentgräben mit Eichenpfosten, wie sie beispielsweise von der Feddersen Wierde bekannt ist (HAARNAGEL 1979, 166-162), hätte sich im grundwassernahen Bereich am Fuß der Nortmoorer Düne voraussichtlich erhalten. Die zur Jümme gewandten langen Zaunreihen hatten wahrscheinlich die Funktion einer Außenbegrenzung des Siedlungsareals. Vermutlich dienten sie dazu, Tiere fern zu halten bzw. domestizierte Tiere auf dem Siedlungsplatz einzuzäunen oder auszuzäumen.

Aus dem SO Bereich der Siedlung liegen in den Quadranten 52-53/51-52 vier im rechten Winkel zueinander verlaufende Wandgräbchen vor (Kat.Nr. 106; 107; 129a-c; 164). Im südlichen Bereich sind die Gräbchen recht gut erhalten, während sie im nördlichen Teil durch Gräben und Gruben gestört wurden. Die Südbegrenzung des eingehegten Areals bildet auf $11 \mathrm{~m}$ Länge der Zaun Kat.Nr. 106. Von ihm biegt rechtwinklig das Gräbchen Kat.Nr. 107 nach Norden ab und kann noch auf 10m Länge verfolgt werden, bevor es unter einem Graben verschwindet. Von der gegenüberliegenden Westseite haben sich lediglich drei kürzere Gräbchenreste mit einer Länge von insgesamt $3 \mathrm{~m}$ erhalten (Kat.Nr. 129a-c). Die Pfostenstandspuren der Gräbchen zeugen von z.T. schrägen Eintiefungen.

Eine nördliche Begrenzung erfährt das eingefriedete Areal wohl durch das Zaungräbchen Kat.Nr. 164. Seine O-W-Orientierung entspricht dem gegenüberliegenden Zaun Kat. 107. Zwar ist Kat.Nr. 164 stark gestört, der rechtwinklige Verlauf von Kat.Nr. 164 und 107 macht es allerdings wahrscheinlich, dass von einer Gleichzeitigkeit beider Zäune auszugehen ist. Hierauf deuten auch die einheitlichen Breitenmaße der Gräbchen (13-15cm), ihr u- bis muldenförmiges Profil, und die in regelmäßigen Abständen von 12-18cm eingetieften Pfostenstandspuren, hin. Das leicht zur östlichen Außenseite versetzte Gräbchen Kat.Nr. $110(270 \times 10 \mathrm{~cm})$ ist eventuell als eine Reparaturphase anzusehen. Fundmaterial aus den Gräbchen datiert kaiserzeitlich. Das etwa 11x15m umfriedete Areal umgrenzt die große kaiserzeitliche Wasserstelle Kat.Nr. 195. Wahrscheinlich wurde das Areal ,großflächig“ 
abgezäunt, um die Zugangsmöglichkeiten für frei umherziehendes Vieh zu begrenzen und die Wasserstelle vor Verunreinigungen zu schützen.

Teil eines anderen Zaunsystem sind diverse Zaungräbchen von der westlichen Siedlungsgrenze. Der südlichen Außenumhegung am Dünenfuß gehört ein 31m langes NW-SO orientiertes Gräbchen an (Kat.Nr. 1095). Im Planum A1 zeigt das linear verlaufende Gräbchen recht unterschiedliche Breitewerte von $15-25 \mathrm{~cm}$. Auf Überreste von vergangenen Holzstaken weisen die in dem meist nur noch $7 \mathrm{~cm}$ eingetieften Gräbchen stellenweise festgestellte Tiefen von bis $\mathrm{zu} 22 \mathrm{~cm}$ hin. In südwestlicher Richtung hat das Gräbchen drei, dicht beieinanderliegende, jeweils 3,9m lange Annexe unbekannter Funktion (Kat.Nr. 1164; 1165; 1102). An seinem Westende verbindet sich das Hauptgräbchen Kat.Nr. 1095 mit den rechtwinklig NNO-SSW laufenden Gräbchen Kat.Nr. 1172 und 1174. Hinweis auf eine gegenseitige Überlagerung der Wandgräbchen fehlen.

Etwa $5 \mathrm{~m}$ nördlich der gemeinsamen Schnittstelle der Wandgräbchen biegt ein weiteres Gräbchen (Kat.Nr. 1173) rechtwinklig nach Westen und deutet auf eine Fortsetzung des Zaunsystems nach NW, verliert sich jedoch nach 6m unter einer Drainage. Während das eine Gräbchen (Kat.Nr. 1174) 7m nach SSW verfolgt werden kann, weist das zweite (Kat.Nr. 1172) nach NNO und ist auf einer Länge von 11,3m erhalten. In seiner Flucht liegt das 11m lange Wandgräbchen Kat.Nr. 1216. Es handelt sich hier um eine den gesamten Dünenkamm erstreckende 36m lange Zaunreihe (Kat.Nr. 1172/1174/1216). In einigen Bereichen sind Pfostenstandspuren in ca. $30 \mathrm{~cm}$ Abständen festzustellen. Die Verfüllung in den Gräbchen besteht aus grauem Sand und grauem tonigen Sand. Allein das Fundamentgräbchen des Südzauns ist mit grauem Klei verfüllt; wiederum ein Hinweis auf Sedimentablagerungen durch die nahe Jümme.

Um die Überreste einer Hofumzäunung wird es sich bei drei in Flucht liegenden Fundamentgräbchen im Westteil der Siedlung handeln. Die Gräbchen Kat.Nr. 860/903/746 liegen in einer Flucht etwa 9m südlich vom Hausplatz III und weitgehend parallel zu dessen südlicher Hausaußenseite. Die Zaunreihe besteht aus drei Segmenten, die z.T. gestört durch die moderne Drainage, gemeinsam eine Länge von $42 \mathrm{~m}$ aufweisen und sich über die Quadranten 53/37 bis 52/41 erstrecken. Die Gräbchenbreite beträgt einheitlich $20 \mathrm{~cm}$. Das u- bis kastenförmige Profil ist 20-30cm eingetieft. Das Fundamentgräbchen Kat.Nr. 860 verläuft zudem annähernd parallel zum Südzaun (Kat. 1095). Fundmaterial aus dem Gräbchen datiert kaiserzeitlich. Erwähnenswert ist eine kleine unverzierte Trichterschale mit kurzem ausbiegenden Rand (Kat.Nr. 860-1).

Reste zweier kürzerer Fundamentgräbchen liegen in den Quadranten 53/38 und 53/39 vor. Die NNOSSW orientierten Gräbchen sind mit Längen von $4,2 \mathrm{~m}$ und $7 \mathrm{~m}$ erhalten. Ihre rechtwinklige Ausrichtung auf die nahe Zaunreihe Kat.Nr. 860 weist auf das Separieren eines kleineren Bereichs, beispielsweise einer Gartenfläche, hin. In dem $34 \mathrm{~cm}$ breiten und $5-18 \mathrm{~cm}$ abgetieften Gräbchen Kat.Nr. 
902 fanden sich 12 Pfostengruben mit Resten von Holzstaken. Die in einem Abstand von $20 \mathrm{~cm}$ eingetieften Pfostenbefunde bestehen aus einer Doppelreihe und sind diagonal versetzt. Erhalten sind die in das Zaungräbchen eingelassener Flechtwerkreste. $7 \mathrm{~m}$ östlich davon entfernt findet sich ein weiteres Zaungräbchen (Kat.Nr. 886). Das nur $14 \mathrm{~cm}$ breite Gräbchen, welches stellenweise durch Tiergänge gestört ist, ist noch bis $7 \mathrm{~cm}$ tief erhalten.

Aus dem Randbereich der Siedlung liegen zwei lineare Stakensetzungen vor. Zugehörige Zaungräbchen fehlen. Sowohl von der Süd- wie von der Nordseite finden sich die Reste einer Zaunreihe, bei der beide Stakenreihen nahezu gradlinig aufeinander zulaufen (Kat.Nr. 458; Kat.Nr. 514). Zwischen den Stakenreihen besteht eine beträchtliche Lücke von $38 \mathrm{~m}$.

Im Quadranten 51/52-53 ist die südliche Zaunreihe auf einer Länge von $8 \mathrm{~m}$ zu beobachten (Kat.Nr. 458). Die Gräbchenbreite beträgt $10 \mathrm{~cm}$, die Pfostengruben haben einen Abstand von $25-40 \mathrm{~cm}$. Erhalten sind 18 angebeilte Holzstaken. Im Quadranten 51/55-56 findet sich die zweite Zaunreihe (Kat.Nr. 514). Diese ist noch auf einer Länge von $3 \mathrm{~m}$ erhalten und besteht aus 8 Holzstaken von $10 \mathrm{~cm}$ Durchmesser. Die in Abständen von 38-44cm gesetzten angebeilten Hölzer sind zwischen $10-28 \mathrm{~cm}$ in den Boden getrieben worden.

Die Orientierung beider Stakenreihen deutet darauf hin, dass es sich um ein Zaunsystem handelte, welches möglicherweise die gesamte Düne in N-S Richtung querte und eventuell zu einer Hofabgrenzung gehörte. Setzt man einen linearen Verlauf voraus könnte die Zaunreihe sogar in etwa mittig zwischen den beiden Hausplätzen I und II verlaufen sein.

An der nördlichen Grabungsgrenze in den Quadranten 57/48 und 57/50 wurde eine Gruppe von unregelmäßige Stakensetzungen beobachtet (Kat.Nr. 347a-c; 348a-c; 349; 350). Die 40x5cm langen Hölzer bestanden aus einer runden Starke und zwei vierkantig gespaltenen Hölzern, die allesamt angebeilt und in einer Entfernung von $40-50 \mathrm{~cm}$ voneinander im stumpfen Winkel zueinanderstanden (Kat.Nr. 347a-c; Abb. 37). Weitere schräg eingetiefte Rundhölzer fanden sich 10m südwestlich (Kat.Nr. 348; 348a-b). Möglicherweise gehörten auch zwei runde Holzstaken (Kat.Nr. 349; 350) zu der Abgrenzung. In einiger Entfernung schließt sich östlich eine Häufung unbearbeiteter Holzstaken an (Qu. 57/54). Ob es sich um die Übereste einer nördlichen Außenbegrenzung oder ob die Holzstaken zur Befestigung des moorigen Untergrundes dienten, ist nicht mehr zu klären. Ihr unregelmäßiger und wenig linearer Verlauf ermöglicht keine eindeutige Ansprache. 


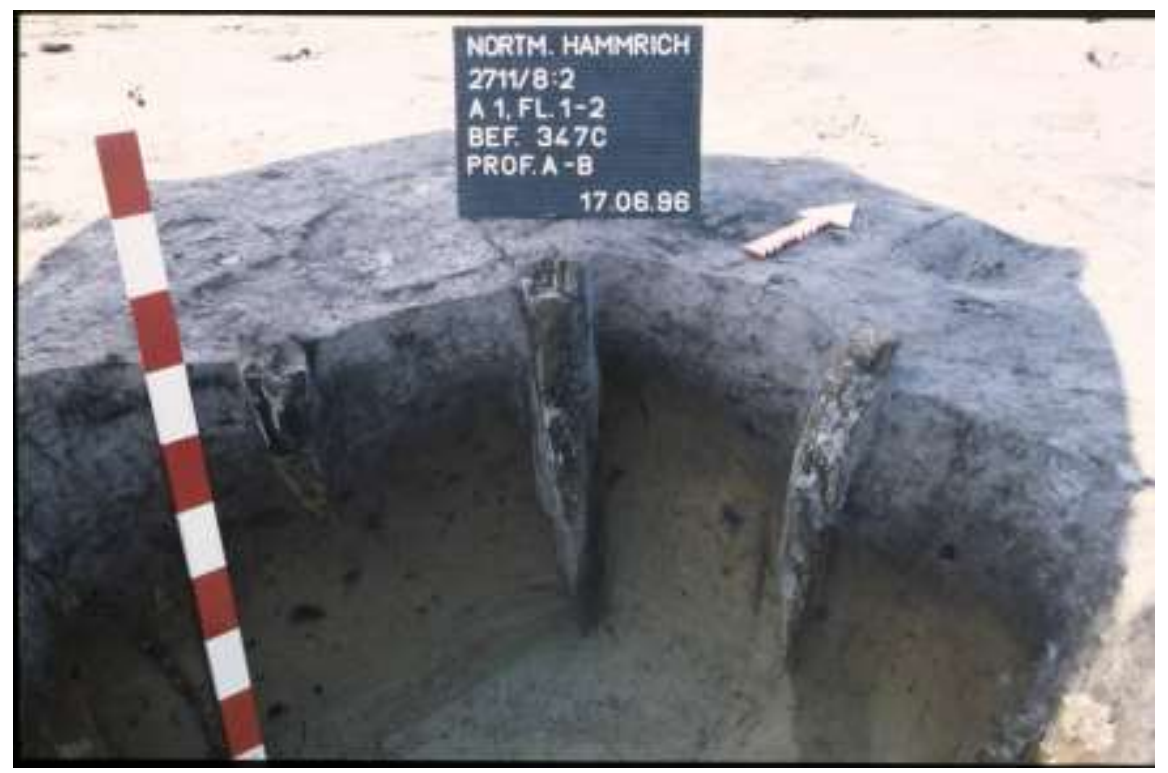

Abb. 37

Angebeilte Holzstaken einer vermutlichen Zaunsetzung in-situ

Kurze Sequenzen von Pfostensetzungen haben sich im Grundwasserbereich am äußersten Rande des südlichen Siedlungsbereiches erhalten. Drei Holzpfosten (Kat.Nr. 585) bildeten eine leicht bogenförmige Pfostenreihe, die etwa 5m nordöstlich von der Brunnengrube Kat.Nr. 747 entfernt war. Die angespitzten Staken mit einem Durchmesser von 9-12cm sind in Abständen von $14-25 \mathrm{~cm}$ in den Boden eingetrieben worden. An anderer Stelle in den Quadranten 51/41 sind drei 50x12cm große und $2 \mathrm{~cm}$ hohe Holzbretter senkrecht stehend in den Torf eingerammt worden (Kat.Nr. 742). Sie sind in ihrem unteren Bereich angebeilt und stehen etwa $13 \mathrm{~cm}$ voneinander entfernt (Abb. 38).

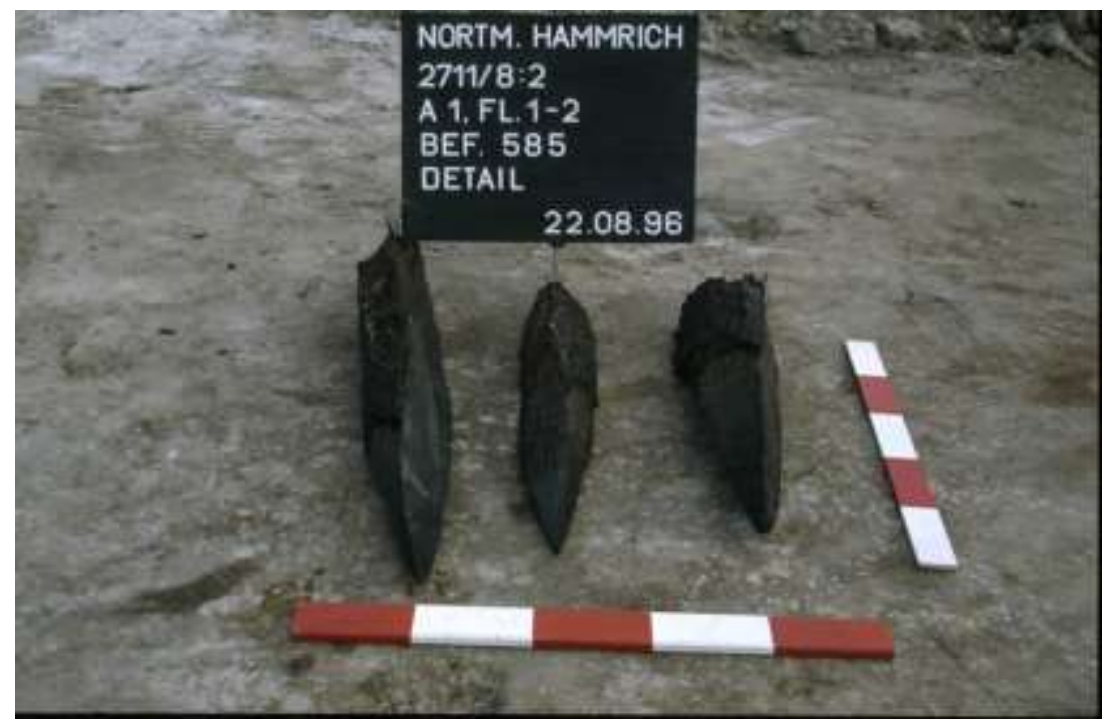

Abb. 38

Zaunpfosten kurz nach ihrer Bergung 
Verhältnismäßig gut zeichnen sich in Nortmoor die Zaunreihen an der Südseite der Düne, die die Siedlung zur Jümme-Niederung hin begrenzten, ab. Hier sind im grundwassernahen Bereich stellenweise Holzstaken erhalten. Die nur schwach eingetieften Zaungräbchen sind überlieferungsbedingt nicht immer erhalten. Ihr Verlauf ist z.T. lückenhaft und ihre Spur verliert sich zur Dünenkuppe hin.

Die Gräbchen zeichnen sich durch eine relativ einheitliche Breite von $15-25 \mathrm{~cm}$ aus. Zu beobachten ist weiterhin, dass innerhalb der Zaunreihen regelhafte Abstände zwischen den Einzelpfosten eingehalten wurden. Die angebeilten Staken wurden $30 \mathrm{~cm}, 50 \mathrm{~cm}$ oder bis $\mathrm{zu} 1 \mathrm{~m}$ voneinander entfernt in den Boden eingetrieben. Ähnliche Pfostenabstände $(0,4-0,5 \mathrm{~m}$ u. $1,15 \mathrm{~m})$ finden sich in Vorbasse (HVASS 1978, 62, 64), während in Brill die durchschnittliche Pfostendistanz 0,72cm beträgt (LEHMANN 2002, 157).

In Nortmoor sind für die Zaunpfosten zumeist runde Hölzer verwendet worden. Nur in Einzelfällen sind Vierkanthölzer oder flach ausgearbeitete Bretter belegt. Oft ist der untere Abschluss zugespitzt, bisweilen gerade ausgearbeitet. Pfostendurchmesser von 10-15 cm sind die Regel, selten werden Werte von $20 \mathrm{~cm}$ erreicht. Sowohl die geringen Pfostendurchmesser, wie die Abstände der Holzstaken zueinander, deuten weniger auf palisadenartige Umhegungen, als auf schlichte WeidenFlechtwerkzäune hin.

Die teilweise recht enge Stellung der Staken weist auf einen erhöhten Stabilitätswert hin, den der Zaun zu gewährleisten hatte. Reparaturstellen sind nicht im Befundbild nachzuweisen. Zwar überwiegen in Nortmoor die Hinweise auf Holzstakenzäune mit einer Flechtwerkkonstruktion, jedoch existieren auch einige Belege für die Verwendung von Vierkanthölzern und Holzbrettern. Diese Art der Zaunkonstruktion ist aufwendiger und benötigt entsprechend mehr Bauholz, weshalb sie in einer weitgehend baumfreien Umgebung, wie sie die Jümme-Niederung darstellt, eher selten umgesetzt wurde. Im Unterschied dazu sind von der Geestsiedlung Gristede weniger Flechtwerkszäune, dafür um so mehr Planken-, Bretter- und Schwellenzäune nachzuweisen (ZOLLER 1972, 118-119).

Ein bestimmendes Element der Siedlung Nortmoor sind lange lineare Zaunreihen. Diese finden sich am südlichen und westlichen Randbereich der Siedlung. Die Teilstücke mit unterschiedlicher Länge gehörten wenigstens zwei Umzäunungskomplexen an, die mehrere Bauphasen aufwiesen. Innerhalb des bebauten Areals finden sich rechtwinklig angeordnete Zaunsegmente, die Teilflächen der Siedlung abzäunen. Die Einfriedungen grenzen das Siedlungsareal gegenüber dem Umland ab und Hofkomplexe mit Wohn- und Nebengebäuden.

Wie eine auf „136 ${ }^{+/ 10}$ n. Chr.“ dendrochronologisch datierte Zaunstake des äußeren Südzauns belegt, wurde der Außenzaun bereits recht früh errichtet. Die Zaunumhegung der Wasserstelle wird wenig später errichtet worden sein. Aus der Wasserstelle liegen verwertbare Holzstücke vor, deren Fälldaten mit Chr. ">97 n. Chr.“ und „>186 n. Chr.“. Die übrigen Zäune können aufgrund ihrer Ausrichtung, die 
meist Bezug auf die kaiserzeitliche Bebauung des Areals im 1.-2. Jahrhundert n. Chr. nimmt, datiert werden.

In der jütländischen Dorfsiedlung Hodde sind ein gemeinsamer, die Gesamtsiedlung abgrenzender, Außenzaun und mehrere umgehegte Einzelareale aufgedeckt worden. Die so gegliederte Bebauung gehört einer Siedlungsphase des 1. Jahrhunderts vor bis ins 1. Jahrhunderts n. Chr. an (HVASS 1975, 142-158). Aus Flögeln sind im 1. Jahrhundert hingegen kaum Zäune bekannt. Dies ändert sich abrupt im 2./3. Jahrhundert als ein großer Umgrenzungszaun neun Wohnbauten mit ihren Speichern einhegte (SCHMID / ZIMMERMANN 1976, 56). Umhegungen kaiserzeitlicher Siedlungen finden sind auch in Wijster, Provinz Groningen, und Fochteloo, Provinz Friesland (VAN Es 1967; VAN GRIFFEN 1958, 5171). Großräumige Außenzäune sind in Wijster noch im 4. Jahrhundert bekannt. Benachbarte blockförmig eingezäunte Parzellen, die über keine Bebauungsreste verfügen, werden als Feldeinteilungen gedeutet (VAN Es 1967, 87). Die unterschiedliche Größe der abgeteilten Areale in Fochteloo gilt als Hinweis auf einen divergierenden Besitzstand unter den Bewohnern und letztlich auf eine soziale Gliederung innerhalb der Siedlung (vgl. REINHARDT 1969, 207). Für Zeijen, Provinz Drenthe, nimmt VAN GRIFFEN $(1950,94-99 ; 1958,48)$ eine befestigte Siedlung an, die mit mehreren palisadenartigen Zäunen und davor ausgehobenen Gräben umgeben war.

\subsubsection{Pfostenstellung unbekannter Bedeutung}

Kat.Nr. 870;871; 872;873;874;875;876;877; 878;878;879;880;881;1241; 1244-1248; 12501262

Im Quadranten 52/39 kam nach Abtrag des Mutterbodens eine OW verlaufende Pfostenreihe mit Pfosten zu Tage, die auf einer Länge von $8,1 \mathrm{~m}$ zu verfolgen war. Es konnten keine Querriegel oder Verbindungen der Pfostenreihen zu Umgebungsbefunden festgestellt werden.

Im Planum A1 sind die Pfosten überwiegend quadratisch bis rechteckig mit einer Größe von 13x34cm, im Mittel 14x19cm. Die Pfostengruben der 8,1m langen Pfostenreihe weisen Abstände von 0,4-1,2m auf. Eine regelmäßige Pfostensetzung mit Abständen von 0,3-0,5m findet sich im östlichen Teil der Pfostensetzung (Kat.Nr. 874-881). Die vorliegenden Pfostentiefen variieren zwischen 6-17cm. Es überwiegen kasten- bis muldenförmige Profile. Zwei Pfostengruben waren v-förmig eingetieft (Kat.Nr. 870; 878). Eventuell handelt es sich bei dem Doppelpfosten Kat.Nr. 871 um eine Reparaturstelle. Aus den Pfostengruben (Kat.Nr. 870; 879) stammen nur zwei fragmentierte Keramikscherben, die vermutlich kaiserzeitlich datieren.

Möglicherweise handelte es sich bei der linearen Pfostensetzung um die Firstpfostenreihe eines Gebäudes. Diese war als dachtragende Konstruktion stärker eingegraben, während sich flach eingetiefte wandtragende Pfosten nicht erhalten haben. Ein Bezug zu nördlich anschließenden 
Befunden ist nicht festzustellen. Weder zu einem $7 \mathrm{~m}$ langen und 0,7-1m breiten Graben (Kat.Nr. 859), noch zu einem $24 \mathrm{~m}$ langen Gräbchen (Kat.Nr. 860). Das, in einer Entfernung von 3,2-3,8m leicht versetzt zur Pfostensetzung verlaufende, Gräbchen wies diverse Pfostengruben mit einer Tiefe von $30 \mathrm{~cm}$ auf. Es grenzte den Hausplatz III zur Niederung hin ab. Ob es sich bei der linearen Pfostensetzung Kat.Nr. 870-881 um die Überreste eines zusätzlichen Außenzaunes gehandelt hat, ist nicht mehr zu entscheiden. Die geringen Pfostenabstände könnten ein Hinweis darauf sein.

Im südwestlichen Randbereich der Düne fand sich in den Quadranten 53/35 eine rudimentär erhaltene Pfostensetzung, der auf einer Fläche von 3,8x2,4m noch 19 Pfostengruben zuzuordnen sind (Kat.Nr. 1241; 1244-1248; 1250-1262). Die im Planum A1 25x14cm bis 54x36cm großen Pfosten waren durchschnittlich $10 \mathrm{~cm}$ eingetieft.

Der nördlichen Postenreihe gehören sechs Pfostengruben unterschiedlicher Größe an (Kat.Nr. 1241; $1250 ; 1256 ; 1257 ; 1261 ; 1262)$. Die südliche Pfostenreihe, bestehend aus neun Pfosten, wies drei Doppelpfostenstellungen auf (Kat.Nr. 1245/1246; 1251/1252; 1259/1260). Die Pfostenbefunde waren mit Tiefen von 3-14cm, im Mittel 5-9cm erhalten. Auffällig sind die recht geringen Abstände der Pfosten zueinander. So betrug die Distanz zwischen Nord- und Südseite nur etwa 1,1m, während die Pfostenabstände innerhalb der beiden Reihen nur noch $20-50 \mathrm{~cm}$ betrug.

Möglicherweise handelte es sich bei der vorliegenden Pfostensetzung um den Rest eines Baukomplexes. Einfache rechteckige bis viereckige Bauten mit einer beliebigen Anzahl an Pfosten liegen beispielsweise aus Wijster vor (VAN ES 1967, 96-99). Die meist nur kleinen Nebengebäude weisen keine innere Pfostensetzung bzw. Unterteilungen auf und gelten als einschiffig. In Herzsprung, Kreis Angermünde, liegen zwei vergleichbare Pfostensetzungen vor, die einschiffigen Bauten zugeordnet werden. Während Pfostenbau B mit einer Breite von $3 \mathrm{~m}$ und einer Länge von $5 \mathrm{~m}$ vollständig erfasst wurde, war der einschiffige Pfostenbau $\mathrm{C}$ ohne Anbau nur 3x3m groß (BRABANDT 1993, 113 (Nr. 115, 2 u. 3, Taf. 2, 1-2).

$\mathrm{Ob}$ es sich bei dem OW-orientierten Komplex in Nortmoor um ein derartiges Kleingebäude handelte, ist letztlich nicht mehr zu klären. Aus dem näheren Umfeld fehlen weitere Pfostenbefunde, so dass es eher unwahrscheinlich ist, dass die auffällige Pfostenreihung am NW-Ende der Siedlung ursprünglich Bestandteil eines größeren Gebäudes gewesen war.

\subsubsection{Kulturhistorische Einordnung der Hausbefunde}

Die in Nortmoor aufgedeckten Hausgrundrisse repräsentieren nicht eine lokal begrenzte Bautradition, sondern sie vereinen Merkmale, die bereits von verschiedenen Siedlungen entlang der Küstengebiete der südlichen Nordsee bekannt sind. Sie sind Teil einer Hauslandschaft, die vom Niederrhein, entlang der Nordseeküste bis nach Jütland reichte (TRIER 1967, Taf. 2). 
Die frühesten Siedlungsstrukturen in Nortmoor gehören der Bronzezeit bzw. der vorrömischen Eisenzeit an. Es handelt sich hierbei um zwei NNO-SSW orientierte Gebäude (Hausplatz IV und V). Die maximal $12 \mathrm{~m}$ langen Bauten fanden sich jeweils am westlichen und östlichen Ende der untersuchten Fläche auf dem Dünenkamm. Nur wenige Befunde dieser Siedlungsphase enthielten in Nortmoor Fundmaterial. Die Keramik war unverziert, meist von grober Machart und lag stark fragmentiert vor, was eine feinchronologische Datierung erschwert.

Charakteristisch ist beiden Gebäuden eine abgerundete Schmalseite und auf der gegenüberliegenden Giebelseite ein gerader Hausabschluss. Somit kann für die Häuser ein Walmdach im Norden und ein Steilgiebel im Süden rekonstruiert werden. Während Hausplatz IV im Grundriss drei- und vierschiffig ist, sind vom zweiten urgeschichtlichen Gebäude nur wenige Pfosten seiner Binnengliederung überliefert. Ihre Ansprache beruht auf bautypologischen Vergleichen mit Gebäudekomplexen aus dem etwa $5 \mathrm{~km}$ entfernten Hesel, wo sich Reste einer bronze- bis eisenzeitlichen Siedlung fanden (SCHWARZ 1996, 21-50). Insbesondere am Außen- wie am Mittelschiff der Heseler Bauten existieren auffällige Doppelpfostenstellungen (BÄRENFÄNGER 1996b, 33), während diese in der Geestrandsiedlung Nenndorf eher selten anzutreffen sind (KREIBIG 2006, 36-41). Für den besser erhaltenen Hausplatz IV zeigen bronzezeitliche Hausgrundrisse vom Typ Emmerhout deutliche Analogien auf (HUITS 1992, 46-47).

Kaiserzeitliche Siedungsstrukturen dominieren auf dem untersuchten Areal. Es konnten drei Langhäuser identifiziert werden, wobei es sich wohl um einphasige Bauten handelte. In einem Fall ist aufgrund seiner Länge von $45 \mathrm{~m}$ eine Längsverschiebung in der NNW-SSO-Achse eines Wohngebäudes denkbar (Hausplatz III). Der gestörte mittlere Bereich lässt hierzu jedoch keine weiterführenden Aussagen zu.

Alle langrechteckigen Grundrisse gehörten ursprünglich dreischiffigen Gebäuden an, einem seit der Bronzezeit in Ostfriesland vertretenen Gebäudetyp, der auch noch in der Völkerwanderungszeit vorkommt. Typisch sind für diesen ein breites Mittelschiff mit zwei schmalen Seitenschiffen sowie eine dreiteilige Innengliederung in Stall-, Wohn- und Wirtschaftsbereich. Meist wird eine enge Stellung der Innenpfostenpaare im Stallteil angetroffen, während sich größere Abstände der Pfostenreihen im übrigen Gebäude finden. Die von ihren Langseiten zugänglichen Gebäude verfügten zudem über einen weiteren Zugang an einer Giebelseite, der häufig als Stallteil angesprochen wird.

Die kaiserzeitliche Wohnbebauung zeichnet sich durch eine NNW-SSO Orientierung aus, die lediglich um wenige Grad abweicht. Eine Längserstreckung der Gebäude wird der im Küstenraum vorherrschenden Windrichtung geschuldet sein. Geringe Abweichungen stehen möglicherweise mit der jeweiligen Geländesituation auf der Hauptdüne in Verbindung.

Auch wenn Befundüberschneidungen weitgehend fehlen, werden die dicht beieinanderstehenden Häuser nicht gleichzeitig bestanden haben. Vielmehr ist eine bauliche Abfolge zu vermuten. Dies wird 
gestützt durch Funde aus den hausbegleitenden Gräben und Gruben, die zwischen dem 1. und 3. Jahrhundert $\mathrm{n}$. Chr. datieren. Kaum feinchronologisch relevantes Material stammt dagegen aus den Pfostenbefunden der Häuser, so dass die anschließende Rekonstruktion der Besiedlungsphasen unter Vorbehalt erfolgen muss und sich zudem auf bautypologische Vergleiche stützt.

Für die Kaiserzeit ist eine Wanderbewegung der Wohnbebauung entlang des Dünenrückens zu beobachten. Bei Hausplatz II wird es sich um den ältesten Gebäudekomplex gehandelt haben. Er wurde spätestens im 2./3. Jahrhundert durch den an der westlichen Siedlungsgrenze gelegenen Gebäudekomplex III abgelöst. Ebenfalls in die römische Kaiserzeit datiert Hausplatz I, von dem sich jedoch meist nur die stärker eingetieften Innenpfosten erhalten haben.

Die Gehöfte erstreckten sich generell in Nortmoor oberhalb einer NN-Höhe von $+1,4 \mathrm{~m}$, die somit deutlich über der Geländehöhe der umgebenden Niederung liegt. Ursprünglich kann sogar von einem Laufhorizont innerhalb der Wohnbauten von etwa $+1,9 \mathrm{~m}$ NN ausgegangen werden. Hausplatz II liegt auf dem höchsten Areal des Dünenzuges. Die Gebäude I und II finden sich wenige Meter östlich und westlich in der Längsausdehnung der Düne verschoben.

Hausplatz II besitzt eine rechteckige Grundform mit enger Stellung der Außenpfosten. Der gerade Giebelabschluss findet sich in Flögeln bei Typ $1 \mathrm{~b}$. Zu rekonstruieren ist ein Steilgiebel an der östlichen Schmalseite. Vereinzelt finden sich Doppelpfostenstellungen an den Längsseiten des Gebäudes, einem auch bei Wijster AII anzutreffenden Konstruktionsmerkmal. Haus II gehört in die erste Bauphase der kaiserzeitlichen Siedlung und datiert vermutlich in das 1.-2. Jahrhundert.

Hausplatz III befindet sich wenige Meter östlich von Gebäude II und weist eine nahezu identische Gebäudeausrichtung wie Haus II auf. Die angetroffenen abgetrennten Seitenkammern an den abgerundeten Schmalseiten des Gebäudes lassen eine Datierung in das 2.-3. Jahrhundert annehmen. Zwar können abgerundete Giebelseiten bereits bei Gebäuden der vorrömischen Eisenzeit auftreten, aber Keramikfunde und die beachtliche Gebäudelänge von maximal $45 \mathrm{~m}$ weisen auf eine spätkaiserzeitliche Datierung hin. Ein Vergleich mit Gebäude 3 in Backemoor zeigt auch in der Binnenstruktur Übereinstimmungen. Dort gilt aufgrund abgetrennter Seitenkammern eine Datierung in das 2.-3. Jahrhundert, möglicherweise sogar in das 3. Jahrhundert, als wahrscheinlich (BUSCHHELLWIG 2006, 24).

Hausplatz I ist nur ungenügend überliefert. Es wird sich auch hierbei um ein dreischiffiges WohnStall-Haus gehandelt haben. Während die Außenwandpfosten mit wenigen Ausnahmen fehlen, sind vor allem die tief eingegrabenen Innenpfosten erhalten. Diese entsprechen im Grundriss den von eisenzeitlichen Wohn-Stall-Gebäuden und sind bereits aus dem älteren Horizont von BoomborgHatzum bekannt (HAARNAGEL 1969). Anders als dort, sind die Außenpfosten jedoch leicht diagonal 
zum Hauptschiff verschoben. Parallelen zum Nortmoorer Gebäude finden sich im Typ 1 in Flögeln, der allgemein in das 1.-3. Jahrhundert datiert wird.

Mit Ausnahme von Hausplatz I ist die Binnengliederung der Nortmoorer Langhäusern nur ansatzweise überliefert, dies betrifft insbesondere den Westteil der Hausplätze II und III. Somit ist nicht gesichert, ob es in den Langhäusern auch zur Aufstallung von Vieh kam. Die wenigen engstehenden Innenpfosten reichen als Beleg hierfür nicht aus. Möglicherweise waren die Abtrennungen im Stallteil des Hauses weniger tief eingegraben und sind überlieferungsbedingt nicht erhalten. Denkbar ist jedoch auch, dass eine Aufstallung nicht im Gebäude erfolgte, sondern das Vieh in Pferche bzw. Gehege gehalten wurde. Das heute noch für seine meist milden Winter bekannte Küstenklima lässt eine derartige Möglichkeit durchaus in Betracht ziehen. Hierbei sei auf die allgemein für die römische Kaiserzeit angenommene wärmeren Klimaphase in der norddeutschen Küstenregion verwiesen (BEHRE 1977).

Der Wohnbereich wird bei zwei der drei Nortmoorer Häuser im mittleren und im östlichen Gebäudeteil anzunehmen sein. Zwei Herdstellen sind für Hausplatz II und eine Herdstelle für Hausplatz III nachgewiesen. Eine Binnengliederung innerhalb der Wohnbauten wird sicherlich mit Flechtwerkwänden erfolgt sein. Auch die nachgewiesenen Kammern in den Giebelwänden deuten auf einen zusätzlichen Bedarf an abgetrennten (Vorrats-) Räumen hin. Weitergehende Überlegungen werden durch den meist als mangelhaft zu bezeichnenden Erhaltungszustand der Pfostengruben relativiert. Der Arbeit sind alle Befundfotos in digitaler Form auf DVD beigelegt, so dass eine Überprüfbarkeit der Befundinterpretation ermöglicht.

Während Gebäude I weitgehend der Haustypologie in Flögeln entspricht, sind die Bauten II und III auf bautypologischem Weg nur unter Vorbehalt zu bestimmen. Ihr teilweise schlechter Erhaltungszustand schränkt die Ansprache ein. Auch sind bei ihnen die Hauptständer bzw. dachtragenden Pfosten nur teilweise überliefert. Konstruktive Übereinstimmungen mit Bauten aus Brill legen für Nortmoor eine Übernahme der in den Geestregionen zwischen Weser und Elbe bekannten Haustypen nahe.

Anhand der wenigen festgestellten Doppelpfosten in den Wänden ist eine eindeutige Einbindung der Nortmoorer Hausgrundrisse in die niederländische Hauslandschaft nicht sicher vorzunehmen. Gebäudebreiten von 6,5-7m, wie sie bei den Hausplätzen II und III festgestellt werden konnten, weisen jedoch auf einen erhöhten Platzbedarf hin, der mit einer raumgreifenden Bauweise in Verbindung steht.

An der östlichen Grabungsgrenze wurden die Reste eines durch die nahe Grabungskante gestörten Grubenhauses entdeckt, welches bis zu $60 \mathrm{~cm}$ in den gewachsenen Boden eingetieft war. Die Hauptkonstruktion der Anlage bestand vermutlich aus 6- bis 8-Pfosten, die die Dachkonstruktion 
trugen. Eine bautypologische Einordnung zeigt deutliche Übereinstimmungen mit kaiserzeitlichen Grubenhäusern in Flögeln wie auch in Brill. Aus dem Grubenhaus in Nortmoor stammt ausschließlich kaiserzeitliches Fundmaterial des 2.-3. Jahrhunderts. Dieses steht jedoch nicht mit der Nutzungsphase des Gebäudes in Verbindung, sondern gelangte vermutlich erst nach seiner Aufgabe hinein.

Gestelzte Speicherbauten sind seit der Bronzezeit im Küstengebiet der südlichen Nordsee bekannt und aufgrund des als universell zu bezeichnenden Bauschemas kaum zu datieren. 10 der 13 Speicher in der Nortmoorer Siedlung stehen in unmittelbarer Nähe zu kaiserzeitlichen Hausplätzen, so dass von einer zeitlichen Analogie auszugehen ist. Einige von ihnen sind darüber hinaus mit einer ihrer Speicherseiten parallel zu den Gebäuden ausgerichtet. Drei weitere Speicheranlagen zeigen darüber hinaus einen Bezug zu kaiserzeitlichen Zaunanlagen.

Es handelte sich zumeist um 4-und 6- Pfostenspeicher. Selten anzutreffen sind 3-, 9- oder 12Pfostenspeicher. Ob es sich bei dem separat liegenden SP 2 um einen zaunparallelen Speicherbau handelte, wie sie für Flögeln als Pfostenroste belegt sind, ist aufgrund seiner gestörten Lage südlich der Teichanlage nicht mehr zu bestimmen, jedoch wahrscheinlich.

Die teilweise schlechte Erhaltung der Grundrisse erschwert zwar im vorliegenden Fall eine bautypologische Einordnung, insgesamt wird jedoch deutlich, dass die Nortmoorer Gebäude eher zur Hauslandschaft des Elbe-Weser-Raumes tendieren, wie sie durch Bauten in Brill und Flögeln repräsentiert werden. Deutlich nehmen die Hausplätze I-III Bezug zum bekannten Bauschema in den deutschen Geestsiedlungen. Hinweise auf eine sich entwickelnde Einflussnahme aus dem niederländischen Raum könnte die in Nortmoor sich abzeichnende stärkere Einbindung von Doppelpfostenstellungen geben.

Eine Datierung derartiger konstruktiver Details kann jedoch nur anhand von Analogieschlüssen erfolgen. Weder gibt es aus den Baubefunden der einzelnen Hausplätze signifikante Keramikfunde noch existieren naturwissenschaftliche Datierungsergebnisse für das verwendete Bauholz. Daher ist eine relativchronologische Ansprache der aufgedeckten Hausplätze im vorliegenden Fall nur unter Vorbehalt möglich. Auch durch die lange Laufzeit der einzelnen Grundrissformen ist bei den bestehenden Haustypologien keine Präzisierung in den angrenzenden Räumen zu gewinnen.

\subsection{Bestattungen}

Kat.Nr. 365; 366; 367; 370; 428; 480; 498; 569

Auf der Dünenkuppe fanden sich im zentralen Bereich der Grabungsfläche die Überreste von acht Brandbestattungen. Es handelt sich bei ihnen um zwei Urnenbestattungen und sechs Brandgrubengräber. Bei der anthropologischen Untersuchung wurden in drei Bestattungen unter dem Leichenbrand Knochenfragmente eines zweiten Individuums entdeckt, so dass sich die Anzahl der 
Bestatteten auf insgesamt 11 Individuen erhöht.

Für die Brandgräber vom Nortmoorer Hammrich erfolgte eine ${ }^{14} \mathrm{C}$ Analyse durch das Labor der Kölner Universität. Leider erbrachte lediglich eine Holzkohlen-Probe ein Ergebnis und datiert demnach die 6. Brandbestattung (Kat.Nr. 366) in die Zeit um Christi Geburt (,20 ${ }^{+/-40}$ n. Chr."). Aus zwei Bestattungen ist jeweils eine Urne mit ihrem Inhalt überliefert. Die Trichterschalen datieren den zugehörigen Leichenbrand in das 1 . Jahrhundert $n$. Chr. Somit ergibt sich rechnerisch für die kleine Nekropole eine Belegdauer von der 2. Hälfte des 1. Jahrhundert v. Chr. bis in das 1. Jahrhundert n. Chr.

Eine Akkumulation von fünf Brandbestattungen fand sich in den benachbarten Quadranten 54/46-47 auf einer Fläche von 10x6m (Kat.Nr. 365; 366; 367; 370; 428). Die 2,5-5m voneinander entfernt liegenden Gruben waren mulden- bis kastenförmig 4-19cm eingetieft. Im Planum A1 waren sie zwischen $30-55 \mathrm{~cm}$ breit und $36-90 \mathrm{~cm}$ lang. Der in den Brandgrubengräbern recht hohe Anteil an Holzkohle muss von der Verbrennungsstelle selbst stammen.

Zwei Brandbestattungen (Kat.Nr. 480; 569) lagen 12m abseits im Quadranten 54/44. Es fanden sich neben den Urnen keine Eingrabspuren (Abb. 39). Stattdessen war die Befundlage durch Pflugspuren und die O-W verlaufende Drainage gestört. Es ist davon auszugehen, dass diese Bestattungen nicht mehr in-situ lagen. Der Rest einer weiteren Brandbestattung fand sich etwa $3 \mathrm{~m}$ nördlich von Kat.Nr. 480. Stark gestört haben sich von der $45 \times 21 \mathrm{~cm}$ großen Grabgrube Kat.Nr. 498 nur eine $3 \mathrm{~cm}$ dicke Schicht aus Holzkohle und Leichenbrand erhalten.

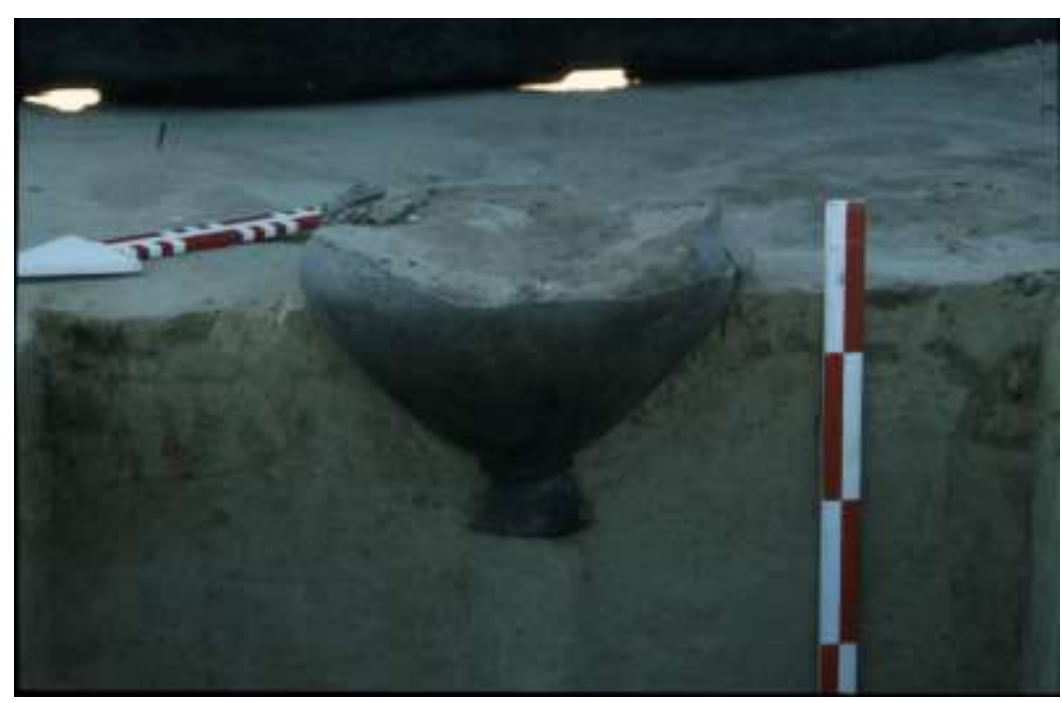

Abb. 39

Urnenbestattung (Kat.Nr. 480)

In Nähe der kleinen Nekropole lag eine Grube, die sich durch eine ungewöhnliche Menge an 
Holzkohle auszeichnet und möglicherweise mit den Bestattungen in Verbindung steht.

Etwa $7 \mathrm{~m}$ südlich von der 8. Bestattung fand man in einer 120x75m großen Grube (Kat.Nr. 378) 6kg Holzkohle. Im Profil zeichnet sich knapp über ihrer Grubensohle gut sichtbar ein HK-Band ab (Abb. 40). In der Grubenverfüllung fanden sich jedoch keine Leichenbrandreste bzw. wurden größere Knochenfragmenten während der Ausgrabung nicht entdeckt. Gestört wird die Grube in ihrem südlichen Bereich durch die Doppelgrube Kat.Nr. 379a u. b, die wenige kaiserzeitliche Scherben enthielt. Möglicherweise handelt es sich bei der stark holzkohlehaltigen Grube um den Scheiterhaufenplatz der kleinen Nekropole; hierauf deuten die räumliche Nähe zwischen Knochenlager und Verbrennungsplatz sowie die große Menge an Holzkohle hin. Parallelen existieren beispielsweise in Liebenau und Barrien, Landkreis Diepholz (BISCHOP 2002, 32).

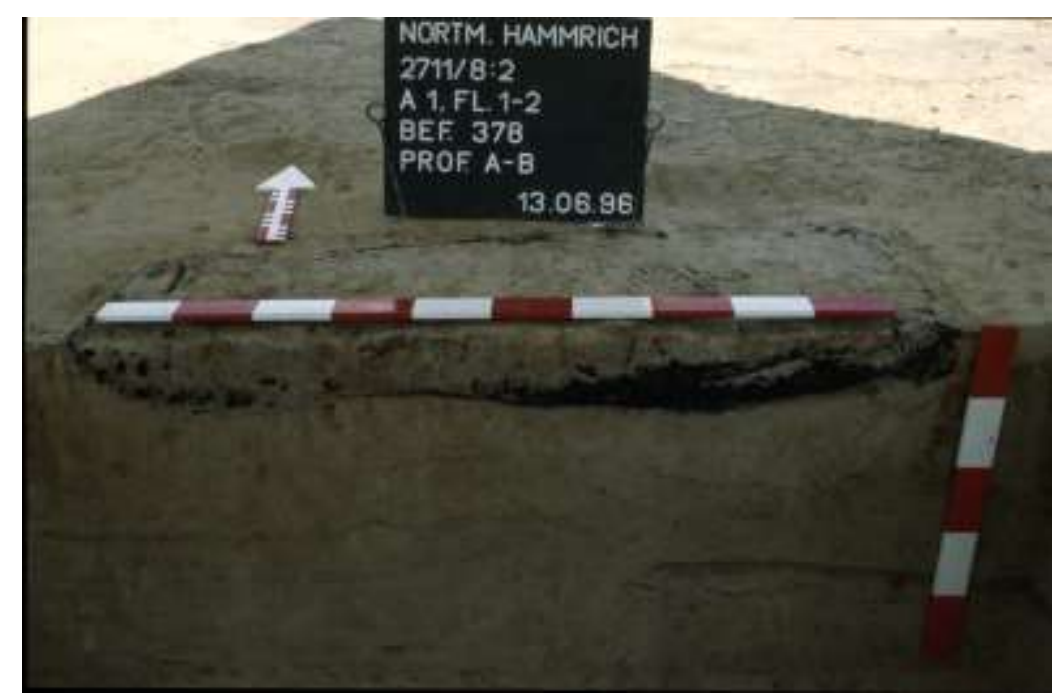

Abb. 40

Mögliche Grabgrube einer weiteren Nortmoorer Bestattung (Kat.Nr. 378)

Das kastenförmige Grubenprofil und die große Menge an Holzkohle lassen es bei Kat.Nr. 378 denkbar erscheinen, dass es sich um eine weitere Bestattung handelt. Ein vergleichbarer Grubenbefund mit einer ebenfalls großen Menge an Holzkohle liegt aus Wiesens vor (SCHWARZ 2002, 98). Hier zeichnen sich die Grabgruben durch einen rechteckigen Umriss, eine steile Wand und einen flachen Boden, jedoch ohne HK-Band, aus. SCHWARZ (2002, 99-101) bestimmt diesen Grubentyp 3 als Meilergrube. Eine als Verbrennungsplatz oder Bestattung gedeutete Grube mit mächtiger holzkohlehaltiger Brandschicht, teilweise mit roter Verfärbung des anstehenden Sandes und einzelnen kalzinierten Knochensplittern, findet sich im Westerhammrich (BÄRENFÄNGER 2000b, 421).

Die Quantität der Leichenbrände reicht von Leichenbrandgewicht eines fast vollständig erhaltenen Individuums bis zu wenigen Knochenfragmenten von insgesamt 21g. Mit 1729g verbrannter Knochen gilt das Skelett einer spätadulten Frau als komplett erhalten (mündl. Mitteilung Frau Dr. B. Großkopf 
2005).

Die Tabelle 5 verzeichnet das Gewicht des Leichenbrandes, Sterbealter und gibt das Geschlecht an. Aufgeführt sind zudem mögliche pathologische Veränderungen am Skelett. Besonders beachtenswert ist die Individuumsanzahl unter dem Leichenbrand.

\begin{tabular}{|c|c|c|c|c|c|}
\hline $\begin{array}{c}\text { Grab } \\
\text { Nr. }\end{array}$ & $\begin{array}{l}\text { Bef. } \\
\text { Nr. }\end{array}$ & $\begin{array}{c}\text { Gewicht LB } \\
\text { Gramm }\end{array}$ & $\begin{array}{c}\text { Anzahl } \\
\text { Individuen }\end{array}$ & $\begin{array}{l}\text { Sterbealter } \\
\text { (Geschlecht) }\end{array}$ & $\begin{array}{c}\text { Pathologische Veränderungen } \\
\text { am Skelett }\end{array}$ \\
\hline 1 & 480 & 1729 & 1 & spätadult (w) & $\begin{array}{l}\text { Meningitis, Abnutzung an der } \\
\text { Wirbelsäule }\end{array}$ \\
\hline 2 & 569 & 21 & 1 & adult & Resorptionslakunen \\
\hline 3 & 498 & 44,5 & 1 & adult & ----------- \\
\hline 4 & 428 & 91 & 2 & $\begin{array}{l}\text { infans, } \\
\text { Beimengung adult }\end{array}$ & ----------- \\
\hline 5 & 370 & 710 & 1 & spätadult & ---------- \\
\hline 6 & 366 & 298 & 1 & juvenal & offene Epiphysen \\
\hline 7 & 365 & 573 & 2 & $\begin{array}{l}\text { adult (w) und juvenal } \\
(?)\end{array}$ & $\begin{array}{l}\text { Entzündung des molaren } \\
\text { Bereichs im Unterkiefer }(\mathrm{w})\end{array}$ \\
\hline 8 & 367 & 269 & 2 & spätadult bis frühmatur & \\
\hline
\end{tabular}

Tab. 5

Angabe des Leichenbrandgewichtes, der Individuumsanzahl in einer Bestattung, des Sterbealters (Geschlecht) sowie möglicher pathologischer Veränderungen am Skelett

Bei der Gewichtsmessung wurden alle gröberen Verunreinigungen, wie Holzkohle, Steinchen oder Keramikbruchstücke entfernt. Die Leichenbrände liegen stark fragmentiert vor (bedingt durch das Scheiterhaufenfeuer) und sind mit einer Ausnahme nur unvollständig erhalten. Die Länge der Knochenfragmente reicht von sehr klein (unter $0,5 \mathrm{~cm}$ ) bis mittelgroß (bis $3,5 \mathrm{~cm}$ ).

Das recht unterschiedliche Gewicht der Leichenbrandpartien könnte überlieferungsbedingt zu erklären sein. Vermutlich wird es jedoch im Zusammenhang mit den Bestattungsriten zu sehen sein, bei der es zu einer selektiven Auswahl des Leichenbrandes kam. Stark divergierende Gewichte bei Leichenbrand findet man auch von anderen kaiserzeitlichen Brandgräberfeldern (RÖSING 1994, 207; LEHMANN 2002, 167).

Alle untersuchten Knochen waren vollständig verbrannt. Der Fragmentierungsgrad deutet auf einen lang anhaltenden Verbrennungsprozess bei einer konstanten Temperatur von über $800 \mathrm{Grad}$ hin. 
Hierauf weist auch das Fehlen von primären Kohlenstoffverfärbungen hin (GROßKOPF 2007, 114). Diese bleiben bei Temperaturen von unter $600 \mathrm{Grad}$ an der organischen Substanz erhalten und sind durch eine intensive Schwarzfärbung im Knocheninneren erkennbar (BISCHOP 2001, 36, Anm. 198).

Oberhalb von 800 bis etwa 1000 Grad setzen Festkörperreaktionen ein, die einem Sinterungsprozess vergleichbar sind. Zur sogenannten Knochenschmelze kommt es erst bei 1600 Grad. Jedoch bereits ab 1000 Grad kann es zur Clinker Bildung kommen, einer kleinräumigen Konkretion von Knochenschmelze (HUMMEL / SCHUTKOWSKI 1986, 1-9). Derartige „Verglasungsspuren“ sind am Nortmoorer Material nur selten festzustellen.

Nach dem Verbrennen des Leichnams kam es nicht zu einer Ablöschung des noch warmen Leichenbrandes mit Wasser, da dieser ansonsten typischen Absplitterungen aufweisen würde (GROßKOPF 2007, 24). Aufschmelzungen von Metallbeigaben bzw. Anzeichen für typische Verfärbungen an den Leichenbränden fanden sich nicht.

Belegt sind Knochen aus allen anatomischen Regionen für jede Partie. Dies lässt darauf schließen, dass bei der Aufsammlung der Leichenbrandreste keine selektive Auswahl vorgenommen wurde.

Eine Altersanalyse war bei allen Individuen möglich, bei erwachsenen Individuen erfolgte eine histologische Altersbestimmung. Schrumpfungen und Verbiegungen des Leichenbrandes beeinträchtigten die Geschlechtsbestimmung. Nur an zwei Individuen konnte eine Geschlechtsdiagnose durchgeführt werden. Bei den übrigen Individuen war dies nicht mehr möglich. Für die Rekonstruktion der Körperhöhen fehlte generell geeignetes Knochenmaterial.

\subsubsection{Mehrfachbestattungen}

Bei den vorliegenden Gräbern handelt es sich ausnahmslos um Brandbestattungen der römischen Kaiserzeit. In den beiden Urnen wurde jeweils nur ein Individuum bestattet, während die übrigen Gräber ein bis zwei Bestattungen enthielten. Aufgrund der schlechten Erhaltungsbedingungen können die Gräber nicht eindeutig als Brandgrubengräber oder Knochenlager angesprochen werden.

Nach dem Ergebnis der anthropologischen Untersuchungen sind 11 Individuen in Nortmoor bestattet worden. In drei Fällen liegen aus einem Grab jeweils Beimengungen von Leichenbrand eines weiteren Individuums vor.

Bei der nur rudimentär erhaltenen 4. Brandbestattung liegt der Leichenbrand eines etwa 8-jährigen Kindes vor, dem Knochenfragmente eines adulten Individuums beigemengt waren. Beimengungen von Knochenfragmenten erhöhten die Anzahl um zwei weitere Individuen (7. und 8. Bestattung). Bei der 8. Bestattung, die einem maturen Individuums angehört, ist ein extrem graziles Jochbein nicht eindeutig zu bestimmen. Es könnte sich um ein menschliches Knochenfragment handeln. Die Fragilität des Fragmentes erschwert jedoch eine eindeutige Abgrenzung zu einem Tierknochen. Aus einer Brandbestattung eines adulten, eher als weiblich anzusehenden Individuums, liegen 
Knochenfragmente eines juventilen Individuums vor (7. Bestattung).

Inwieweit es sich um Doppelbestattungen gehandelt hat, ist nicht eindeutig, kann jedoch auch nicht ausgeschlossen werden. Möglicherweise handelt es sich um eine Beimengung, die zufällig von der vorherigen Verbrennung in die Bestattung gelangte, als man den Leichenbrand aus dem Scheiterhaufen auflas.

\subsubsection{Pathologische Veränderungen und Sterbealter}

Am vorliegenden Material sind verschiedene Krankheitsbilder festzustellen. Eine spätadulte Frau wies neben leicht degenerativen Veränderungen an einigen Wirbelknochen, die eine alterungsbedingte Abnutzungserscheinung sein könnte, an einem Schädelfragment meningeale Reizreaktionen auf (Kat.Nr. 480; Abb. 41a u. b).
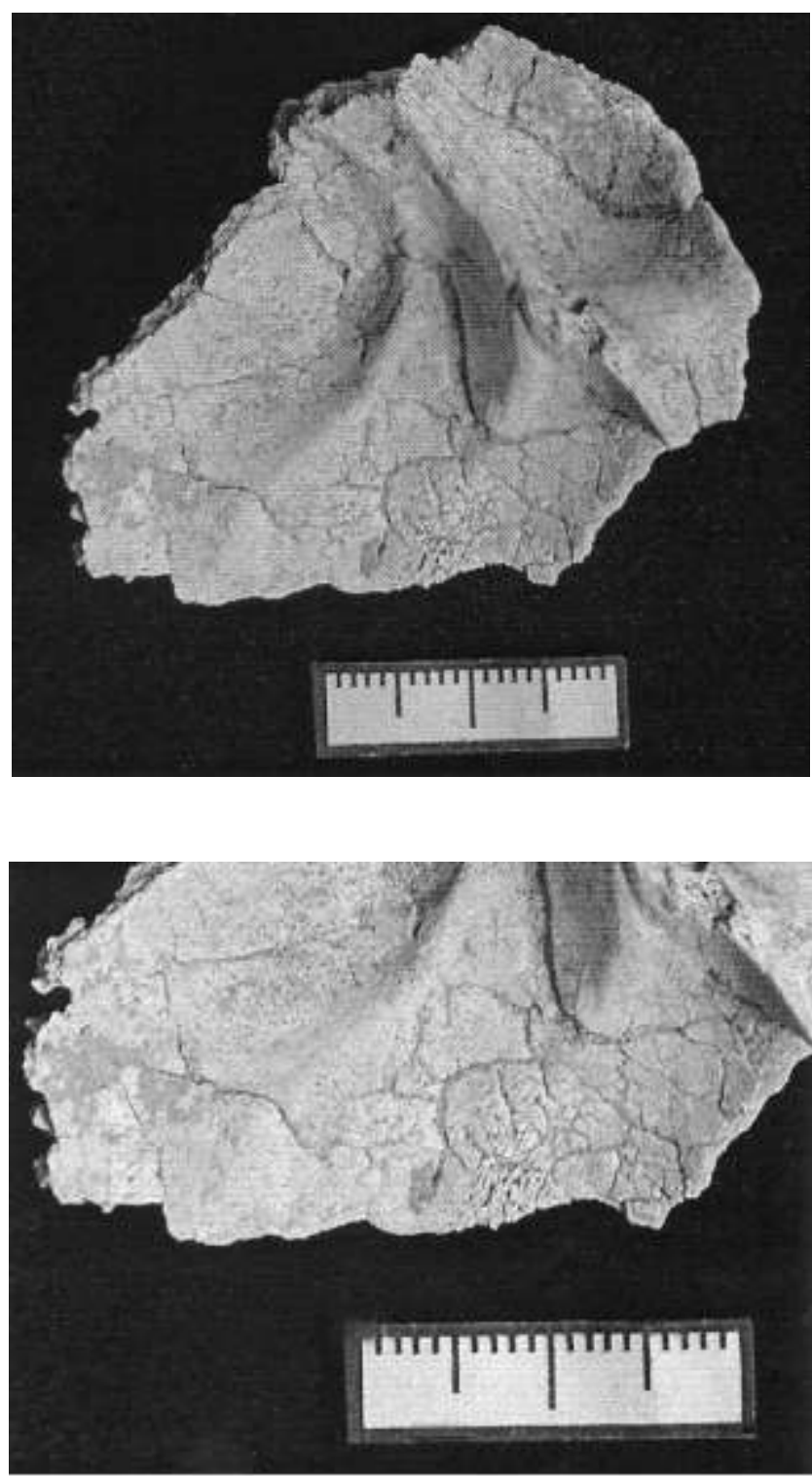

Abb. 41a u. b

a) Meningeale Reizreaktion an einem Schädelfragment. b) Detailfoto

(Quelle: B. Großkopf) 
Entzündliche Veränderungen aus dem molaren Bereich des Unterkiefers liegen bei einem adulten Induviduum vor (Kat.Nr. 365). Ausprägte Resorptionslakunen weisen bei dem Knochenmaterial eines anderen Nortmoorer Bewohners auf länger andauernde Überlastungen einzelner Partien hin, soweit die pathologischen Knochenvertiefungen nicht alterungsbedingt sind (Kat.Nr. 569; vgl. GROßKOPF 2007, 49). Die starke Fragmentierung der Knochen lässt weitere pathologische Veränderungen nicht erkennen.

Das Sterbealter liegt bei vier von elf Individuen in der adulten Lebensphase zwischen dem 20. bis 40. Lebensjahr. Insgesamt drei Individuen erreichten eine höhere Lebenserwartung und starben erst in der spätadulten bzw. maturen Altersgruppe. Es handelt sich um eine Frau, die ein Alter jenseits des 40. Lebensjahres erreichte. Auch zwei weitere Individuen in Nortmoor erreichten die Lebensphase zwischen 40-60 Jahre. Bei ihnen war jedoch keine Geschlechtsdiagnostik mehr durchführbar. Die Altersstufe Senilis wird von keinem Individuum erreicht.

Die Kindersterblichkeit in Nortmoor gilt mit drei Individuen als wenig repräsentativ. Es handelt sich um zwei Jugendliche und ein Kind unbestimmten Alters. Die reale Kindersterblichkeit wird sicherlich bedeutend höher gewesen sein, insbesondere unter Säuglingen und Kleinkindern. Zu erwarten wäre eine dreifach so große bis zu einer 40\% Sterblichkeit (CASELITZ 2000, 76-81).

Da eine Geschlechtsdiagnostik in Nortmoor nur in zwei Fällen erfolgreich war, sind weitere Ausführungen obsolet. Beide Male jedoch handelte es sich um Frauen, die im fortgeschrittenen Lebensalter starben. An ihrem Knochenmaterial waren verschiedene Krankheiten festzustellen, die aber nicht zum Tode führten. Auch wenn es sich möglicherweise nur um eine teilerfasste Nekropole handelt, so entspricht die Verteilung der Individuen in ihrem Sterbealter dem von Leichenbrandserien anderer germanischen Gräberfelder. Durchschnittlich verstarben etwa 2/3 der Bevölkerung im Erwachsenenalter (BISCHOP 2002, 40).

Mit Ausnahme der Urnen, die als Leichenbrandbehältnisse dienten, sind keine Beigaben bei den Bestattungen beobachtet worden. Offen muss dabei bleiben, ob dies ein Teil der Bestattungssitten darstellt oder überlieferungsbedingt zu erklären ist. Aufgrund der im Nortmoorer Hammrich schlechten Quellenlage der stark erodierten Grabgruben, ist ein Vergleich von Grubenquadratmetern, wie sie LEHMMANN $(2002,167)$ bei kaiserzeitlichen Gräbern in Brill vornimmt, kaum aussagefähig.

Inwieweit eine Überhügelung der drei Urnen- und fünf Brandgrubengräber erfolgte, ist nicht mehr nachzuvollziehen. Flache Brandgrubengräber treten in Westniedersachsen erst in der jüngeren vorrömischen Eisenzeit auf, wo sie zudem oft beigabenlos sind (NORTMANN 1983, 105). Da es zu 
keinen Überschneidungen innerhalb der Nortmoorer Nekropole gekommen ist, kann von einer oberirdischen Kennzeichnung der Gräber ausgegangen werden.

\subsubsection{Katalog der Bestattungen}

Durch die sorgfältige Bergung des Leichenbrandes während der Ausgrabung auf dem Dünezug im Nortmoorer Hammrich waren die Vorraussetzungen für eine anthropologische Untersuchung gegeben. Diese unternahm dankenswerterweise Frau Dr. Birgit Großkopf vom Anthropologischen Institut der Universität Göttingen 2004.

\section{Bestattung (Kat.Nr. 480)}

Planum A1: Geländehöhe $+1,45 \mathrm{~m}$ NN

Aus dem anstehenden pleistozänen Sandboden wurde eine intakte Urne mit ihrem gesamten Inhalt an Leichenbrand und humosem Sand in situ geborgen (Kat.Nr. 480). Eine Grabgrube ist schwach erkennbar (Abb. 39), sie folgt in etwa 3 - $5 \mathrm{~cm}$ dem Profil des Gefäßes.

Mit einem Gewicht von 1729 Gramm liegt ein repräsentativ überlieferter Leichenbrand vor, der mit Holzkohlebrocken durchsetzt war. Auf das Vorliegen eines weiblichen Individuums weisen die grazile Ausprägung der Schädelfragmente und die grazilen Wandstärken der Diaphysen hin. Die Altersklasse kann mit spätadult bis beginnend matur angegeben werden. Leicht degenerative Veränderungen sind an einigen Wirbelkörpern festzustellen. Betroffen sind diverse Deckplatten, ein Lumbalwirbel und ein Zwischenwirbelgelenk. Neben einer Fehlbelastung der Wirbelsäule kann dies altersdegenerativ bedingt sein. Ein Schädelfragment des Os occipitale (Schädelhinterknochen) weist eine für Meningitis typische Oberflächenstruktur auf.

Die Bestattung der etwa 40jährigen Frau erfolgte in einer reich verzierten Standfußschale (Kat.Nr. 480-1; Abb. 39; Abb. 41a u. b; Taf. 32, 480-1). Das Gefäß gehört zur Gruppe der weitmündigen Standfußschalen mit kurzem dreieckigen Rand. Die Schale ist von ihrem Schulterumbruch abwärts mit geometrischen Mustern verziert. Von den horizontalen Rillen hängen punktgesäumte Girlanden herab. Von jeder dritten Girlande verläuft bis zum Gefäßfuß ein jeweils mit einem anderen Muster verziertes Band. Der hohle Standfuß ist am Übergang zum Gefäßkörper mit einer durch Punkte hervorgehobenen Wulstleiste verziert. Die graubraune Gefäßoberfläche ist sorgfältig poliert. In Hatzum-Boomborg entdeckte man eine vergleichbare Trichterschale im Siedlungskontext. LÖBERT $(1982,94)$ datiert die der Form HB 18 angehörende Standfußschale in das 1. Jahrhundert n. Chr.

\section{Bestattung (Kat.Nr. 569)}

Planum A1: Geländehöhe $+1,47 \mathrm{~m}$ NN

Aus einer gestörten Pflugschicht, etwa 5m südwestlich von Kat.Nr. 480, stammt eine weitere Urnenbestattung (Kat.Nr. 569). In einer $17 \mathrm{~cm}$ tiefen Grube wurde eine senkrecht stehende Trichterschale, angefüllt mit Leichenbrand und dunkelgrauem Sand, geborgen. Von der 
Leichenbrandpartie sind nur 21 Gramm überliefert. Sie war von heller Farbe und nicht mit Holzkohle vermischt. Die Wandstärken weisen auf ein erwachsenes Individuum der adulten Altersklasse hin. Eine histologisch untersuchte Knochenprobe entspricht der frühmaturen Klasse, weist jedoch, wohl pathologisch bedingt, Resorptionslakunen (ehemalige Muskel- bzw. Gefäßpforten) auf. Die Ausprägung der Vertiefungen am Knochenmaterial deutet auf eine länger andauernde Überforderung hin, kann aber auch alterungsbedingt sein. Eine Geschlechtsdiagnose war nicht durchführbar. Dem Leichenbrand lag ein Tierknochenfragment bei.

Die Urne mit kurzem dreieckigen Rand war komplett erhalten, jedoch weit weniger sorgfältig ausgestaltet als die andere Urne. Die $15,7 \mathrm{~cm}$ hohe Trichterrandschale ist auf der Gefäßschulter mit vier parallelen Rillen verziert, die von zwei senkrechten Rillen unterbrochen sind (Kat.Nr. 569-1; Taf. 37, 569-1). Der abgesetzte Standfuß hat einen Durchmesser von 9cm. Die graubraune Gefäßoberfläche war poliert und innen geglättet. Von einem zweiten Gefäß haben sich ein Flachboden und wenige Wandungsscherben erhalten.

\section{Bestattung (Kat.Nr. 498)}

Planum A1: Geländehöhe $+1,47 \mathrm{mNN}$

Überreste einer weiteren Brandbestattung fanden sich ca. 2,5m nördlich von Kat.Nr. 480. Die $45 \times 21 \mathrm{~cm}$ große Grabgrube (Kat.Nr. 498) wies nur noch ein muldenförmiges Profil von $3 \mathrm{~cm}$ auf. Ihre Grubenfüllung bestand aus grau-schwarzem tonigen Sand. Die Brandbestattung wurde durch den westlichen Ausläufer eines Grabens (Kat.Nr. 432) gestört. Dessen Verfüllung bestand aus dunkelgrauem, mit Holzkohlepartikeln durchsetzten, Sand. Der 12,4x1,1m große Graben enthielt neben lokaler kaiserzeitlicher Keramik einen hohen Anteil an Terra Sigillata und Terra Nigra des 3. Jahrhunderts.

Aus der Grabgrube stammt nur sehr klein fragmentierter Leichenbrand mit einem Gesamtgewicht von 44,5 Gramm. Die schlechte Überlieferung des Knochenmaterials erlaubt keine Geschlechtsdiagnose. Wandstärken und die Struktur der Diploe weisen auf ein erwachsenes Individuum der adulten Altersklasse hin. Die aus der gestörten Grabgrube stammenden Gefäßscherben datieren in die ältere römische Kaiserzeit.

\section{Bestattung (Kat.Nr. 428)}

Planum A1: Geländehöhe $+1,48 \mathrm{~m} \mathrm{NN}$

Eine runde holzkohlehaltige Grube mit einem Durchmesser von $18 \mathrm{~cm}$ enthielt die Reste einer Brandbestattung und Beimengungen einer weiteren (Kat.Nr. 428). Die im Profil u-förmige $40 \mathrm{~cm}$ tiefe Grube war durch einen Tiergang gestört. Die erhaltenen kalzinierten Knochen gehören allen anatomischen Regionen der Partie an. Ein Individualalter von 8 Jahren +/-24 Monaten ist anhand der Zahnentwicklung bestimmbar. Der Altersansatz eines kindlichen Individuums wird gestützt durch die 
offenen Fragmente der Beckenkammapophyse. Die histologische Altersdiagnose belegt die Beimengung von Diaphysenfragmenten eines adulten Individuums.

\section{Bestattung (Kat.Nr. 370)}

Planum A1: Geländehöhe $+1,55 \mathrm{~m} \mathrm{NN}$

Etwa 5m östlich von Kat.Nr. 428 wurde eine weitere Bestattung entdeckt. Die 70x40cm große Grabgrube (Kat.Nr. 370) war mit ungewöhnlich viel Holzkohle und grauschwarzem Sand verfüllt. Aus der flach muldenförmigen und noch $6 \mathrm{~cm}$ tiefen Grube fehlen datierende Funde. Der Leichenbrand ist durch zahlreiche Holzkohlebrocken stark verfärbt. Reines Knochenmaterial liegt mit 222 Gramm vor. Weitere 488 Gramm sehr kleinteilige Knochenreste sind mit Sediment vermengt und eignen sich nicht für eine histologische Untersuchung. Die Wandstärken belegen ein erwachsenes Individuum. Mit Hilfe der histologischen Altersdiagnose ist das Sterbealter auf spätadult einzugrenzen. Eine Geschlechtsdiagnose ist an der Partie nicht durchführbar.

\section{Bestattung (Kat.Nr. 366)}

Planum A1: Geländehöhe $+1,52 \mathrm{~m}$ NN

Aus einer 90x55cm großen eckigen Grube (Kat.Nr. 366), etwa 2m nördlich von Kat.Nr. 370, sind 298 Gramm Leichenbrand überliefert. Die Grubenverfüllung mit schwarzgrauem Sand war mit dunkel gefärbtem Leichenbrand und größeren Holzkohlebrocken durchsetzt. Eine Geschlechtsdiagnose ist bei dem aufgrund seiner Knochengröße und Wandstärke als juvenil bestimmten Individuum, welches über offene Epiphysen verfügte, nicht möglich.

\section{Bestattung (Kat.Nr. 365)}

Planum A1: Geländehöhe $+1,48 \mathrm{~m}$ NN

Eine weitere Bestattung (Kat.Nr. 365) befand sich ca. 1m nördlich von Kat.Nr. 366. Die eckige, $36 \times 30 \mathrm{~cm}$ große Grube war angefüllt mit tonigem Sand und wies ein muldenförmiges noch $4 \mathrm{~cm}$ tiefes Profil auf. Eine zentrale runde Verfärbung von $10 \mathrm{~cm}$ war mit Holzkohle, Leichenbrand und kalzinierten Tierknochen durchsetzt. Optional könnte es sich hierbei um den Rest einer Speisebeigabe gehandelt haben. Der Befund war durch einen Tiergang gestört. Überliefert sind 573 Gramm dunkel verfärbte Knochenfragmente, die vereinzelt eine leicht kreidige Oberfläche aufweisen. Nur wenige Fragmente sind mit Sediment verbacken. Kleinere Keramikscherben sind nicht bestimmbar. Dem Schädel sind 145 Gramm Knochenfragmente zuzuordnen. Aus verschiedenen anatomischen Regionen liegen 266 Gramm Diaphysen- und 19 Gramm Epiphysenframente vor. Diverse Knochenfragmente gehören der Autopodien (24 Gramm), der Schuler-, Becken- und Rippenregion (33 Gramm) und der Wirbelsäule (4 Gramm) an. Die grazile Hinterhauptregion und die Wandstärken weisen auf ein eher weibliches Individuum, das aufgrund der Diploestruktur der adulten Altersklasse (20-40 Jahre) zuzurechnen ist. Ein histologisch untersuchtes Femurfragment entspricht der mittel- bis spätadulten 
Klasse. Entzündliche Veränderungen liegen aus dem Molaren-Bereich des Unterkiefers vor. HarrisLinen sind an einem unspezifischen Diaphysenfragment festzustellen. Es handelt sich hierbei um stressbedingte Wachstumshemmungen, die einhergehen können mit Krankheit, Mangelernährungen oder physischen Stress (GROßKOPF 2007, 72). Aus dem Bereich der Schädelnähte liegen drei Schaltknochen vor. Insgesamt weisen sechs Fragmente eine offene Epiphysenstruktur auf. An den unspezifischen Fragmenten ist aufgrund ihrer Feinheit nicht zu klären, ob sie menschlicher Herkunft sind. Es liegen weiterhin Schädelfragmente mit sehr geringer Wandstärke vor. Dies könnte möglicherweise auf eine Doppelbestattung, eventuell von Mutter und Kind, hindeuten. Zusätzlich befanden sich unter dem Material diverse Tierknochen.

\section{Bestattung (Kat.Nr. 367)}

Planum A1: Geländehöhe $+1,53 \mathrm{~m} \mathrm{NN}$

Eine weitere Brandbestattung (Kat.Nr. 367) entdeckte man nur 4m östlich von Kat.Nr. 370 entfernt. Die 50x40cm große Grube mit kastenförmigem Profil mit einer Tiefe von $19 \mathrm{~cm}$ war mit Holzkohle und stark dunkel verfärbtem Leichenbrand durchsetzt. Überliefert sind 269 Gramm Leichenbrand, der jedoch keine geeigneten Fragmente für eine Geschlechtsdiagnose aufweist. Auf eine mature Altersklasse deuten die verschlossenen Schädelnähte, während die Knochenbinnenstruktur der spätadulten bis frühmaturen Klasse entspricht. Bei einem extrem grazilen Jochbeinfragment ist nicht zu klären, inwieweit es sich eventuell um die Beimengung eines Kindes oder eines Tieres handelt. Ein Epiphysenfragment kann einem Tier zugeordnet werden.

\subsubsection{Kaiserzeitliche Bestattungsplätze im Unteren Emsgebiet}

Im Leda-Jümme-Gebiet wurden niedrig gelegene Bestattungsplätze bei Nortmoor-Plaggenburg, Detern-Stickhausen, Bonnhausen, Leer-Logabirum und Westerhammrich entdeckt. Es handelt sich mit Ausnahme einer kaiserzeitlichen Körperbestattung im Westerhammrich ausschließlich um Brandbestattungen.

Die Nekropolen lagen auf sandigen Geländeerhebungen am Übergangsbereich zwischen Flussmarsch und Niederung. Zumeist handelte es sich um beigabenlose Bestattungen in unverzierten Tongefäßen. Auffällig sind einige besonders sorgfältig gestaltete Trichterrandschalen und Standfußgefäße, die sich durch ihren Dekor mit senkrecht zum Gefäßkörper verlaufenden Zierbändern deutlich hervorheben.

Alt gegraben ist das Flachgräberfeld Plaggenburg, Flurname „Isbargen“, nur 1,5km nördlich von Nortmoor (FdSt.Kat. Nr. 2711/5:92). Bei dem 1935 im Rahmen von Sandabgrabungen für den Straßenbau auf einem hochgelegenen Ackerstück an der Straße nach Plaggenburg entdeckten Nekropole kamen neben Urnengräbern, diverse Knochenlager und ein Scheiterhaufenplatz zu Tage. Die Feuerstelle besaß noch einen Durchmesser von $60 \mathrm{~cm}$. Die Urnen waren mit einer $10 \mathrm{~cm}$ dicken braunen Sandschicht überdeckt und standen „frei im Sand unter der Ackerkrumme“ 
(SCHWARZ/STUTZKE 1998, 98-99). Geborgen wurden drei Trichterrandschalen mitsamt ihrem Leichenbrand. Die Tongefäße mit kurzer gewölbter Schulter datieren in die mittlere Kaiserzeit. Eine Urne war mit umlaufenden hängenden Dreiecken und Punktbändern verziert, von denen senkrecht Punktbänder zur Fußzone herabreichten, während zwei der schwarz-poliert bis bräunlich-glatten Tongefäße unverziert vorlagen (SCHMID 1965b, Taf. IX,7; SCHMID 1969, 149).

Das 1927 entdeckte Brandgräberfeld von Detern lag am östlichen Ende des Jümmiger Hammrichs nahe Stickhausen (FdSt.Kat. Nr. 2712/7:5 u. 9:11). Drei Brandgräber datieren in die ältere römische Kaiserzeit (ERDNIß 1939, 30). Sie enthielten zwischen 18 und 940g Leichenbrand und in einem Fall den Rest einer bronzenen Fibel (SCHWARZ/STUTZKE 1998, 51-52, Abb. 33). Eine weitere Brandbestattung gehört der vorrömischen Eisenzeit an.

Im nur wenige Kilometer westlich vom Nortmoorer Hammrich entfernten Gräberfeld von Bonnhausen scheint sich eine Abfolge von verschiedenen Bestattungsarten abzuzeichnen, diese sind anhand datierender Beigaben näher einzugrenzen (FdSt.Kat. Nr. 2711/7:1). Ein Urnengrab des 1. Jahrhunderts, ein Brandgrubengrab aus dem 2./3. Jahrhundert, ein Brandgrubengrab mit Knochenlager aus der jüngeren Kaiserzeit sowie ein Knochenlager des 3./4. Jahrhunderts. Insgesamt stammen 15 Bestattungen aus dem 1933 untersuchten Friedhof (SCHWARZ/STUTZKE 1998, 33-34). Auf der gegenüberliegenden Flussseite fand man 1979 eine weitere kaiserzeitliche Urne (FdSt.Kat. Nr. 2711/7:8).

Auf einer 5,5m NN hohen Geestzuge im Ortsteil Logabirum, Stadt Leer, entdeckte man 1965 einen Bestattungsplatz mit Urnen- und Brandgrubengräbern des 1.-4. Jahrhunderts $\mathrm{n}$. Chr. (FStNr. 2711/4:88). Die Ausgrabung erfolge auf einer Trassenbreite von 10x50m unter Leitung von P. Schmid. Dieser beobachtete ein „nesterartig“ angelegtes Gräberfeld unter einem ca. 0,6m hohen Bodenauftrag. Bei Anlage der mittelalterlichen Ackerbeete wurden Teile des Gräberfeldes zerstört (MARSCHENRAT 1966, 5). Dokumentiert wurden ein Brandschüttungsgrab (Nr. XXV), fünf Urnengräber mit sechs Gefäßen (Nr. XXI mit zwei Gefäßen) und neun Gruben mit Leichenbrand. In neun weiteren Gruben fand man ausschließlich Holzkohle. Überliefert sind vier weitere Urnenbestattungen und 12 Knochenlager. Die Urne XXI enthielt einen bronzenen Armring der römischen Kaiserzeit und zwei nicht mehr zu datierende Fibelfragmente. Die Anlage eines Planums unterblieb (SCHMID, unpubl. Bericht vom 6.02.1967). Möglicherweise setzte sich der Bestattungsplatz im 100m entfernten Loga fort (FStNr. 2711/4:143).

Alt gegraben ist die 1879 entdeckte Nekropole in Warsingsfehn, Moormerland (FStNr. 2611/7:1). Überliefert ist eine mit Beigaben versehene Brandbestattung der frühen Kaiserzeit. Die Bronzefibel vom Typ Nauheim gehört zu einem frühen Fibeltyp. Man fand zudem eine weitere Bronzefibel mit vier Spiralbindungen (Typ römische Aucissa) und eine schlichte, noch eisenzeitliche Urne 
(TACKENBERG 1934, 27, Taf. 7,11; EgGers 1951, Nr. 1097; STUPPERICH 1980, 93, Nr. 233; SCHWARZ 1990, 283, Kat.Nr. 690-691). Im Reiderland liegen mit Eppingawehr (FStNr. 2710/1:1 u. 43) und Midlum (FStNr. 2711/1:47) wenigstens zwei Fundstellen vor, die möglicherweise zu einer kaiserzeitlichen Grabgruppe gehört haben und sich in Siedlungsnähe befanden.

\subsection{Funde}

\subsubsection{Das Fundspektrum}

Das Fundspektrum in Nortmoor entspricht weitgehend dem einer typischen Siedlungsgrabung und reicht von Keramik, Metall, Glas, Holz bis hin zu Flechtwerk. Ungewöhnlich ist der hohe Importanteil, worauf noch näher einzugehen ist. Das Leichenbrandmaterial von den in Nortmoor geborgenen Brandbestattungen wurde bereits im vorhergehenden Kapitel vorgestellt. Für die Möglichkeit, naturwissenschaftliche Untersuchungen am Fundmaterial vornehmen zu lassen, sei dem niedersächsischen Ministerium für Kunst und Kultur für seine finanzielle Unterstützung gedankt. Die Ergebnisse der Analysen heben den Fundplatz weit über seine Region hinaus.

Die Funde werden nach Materialgruppen getrennt vorgelegt und typo-chronologisch bestimmt. Zeichnerisch dokumentiert liegt eine signifikante Auswahl von 506 Einzelobjekten vor. Diese umfassen ausgewählte, wichtige Keramikgefäße, Einzelscherben, Steinartefakte sowie metallene und hölzerne Objekte. Den Tafelteil der Fundzeichnungen ergänzen vier Fotofarbtafeln, die einen Eindruck von der Farb- und Oberflächengestaltung der Wandungsscherben vermitteln. Nicht abgebildeten Funde sind über den Fundkatalog zu erschließen. Es erfolgt eine Zuordnung in die bekannten Materialkategorien mit Angabe der Quantitäten. Eine Konkordanzliste ermöglicht den schnellen Zugriff auf das Typenspektrum.

\subsubsection{Fundverteilung}

Aufgrund ihrer naturräumlichen Gunstlage wurde die Nortmoorer Düne bereits in vorhistorischer Zeit von Menschen aufgesucht. Spätestens seit der römischen Kaiserzeit wurde die natürliche Geländeerhebung planmäßig zu Siedlungszwecken genutzt. Zeugnisse früherer Siedlungsphasen sind rudimentär erhalten. Funde wie auch Befunde zeigen eine signifikante Verteilung. So lässt sich auf dem höher liegenden Dünenbereich eine größere Befund- und Fundkonzentration feststellen, während diese zur Niederung hin sukzessiv abnimmt. Der Großteil des Fundgutes entstammt den zahlreichen Siedlungsgruben und -gräben. Darüber hinaus erwiesen sich die modernen Drainagegräben als besonders fundreich. Bei ihrer Anlage kam es zu tiefen Eingriffen in den Boden und zur Zerstörung archäologischer Befundschichten. Durchschnittlich enthielten fundführende Befunde zwischen 2-15 Scherben. Größere Gräben und Gruben konnten bis zu mehreren Hundert Scherben aufweisen. Ungewöhnlich ist eine Fundhäufung von 3000 Einzelobjekten, die aus einer kaiserzeitlichen Wasserstelle stammte (B 11, Kat.Nr. 195). Wenig ergiebig waren Pfostengruben und Zaungräbchen. 
Sie enthielten oftmals nur geringe Fundmengen oder waren bisweilen völlig fundfrei. Beigabenarm sind die Nortmoorer Bestattungen. Neben zwei Urnen enthielten die Brandgräber vornehmlich Holzkohle und verbrannte Knochenfragmente.

Aus den Kleischichten, die nahezu flächig die Randbereiche des Dünenzuges überdeckten, stammt eine ungewöhnlich hohe Scherbenanzahl. Die Sedimentablagerungen waren überwiegend mit kaiserzeitlicher Keramik durchsetzt. Mittelalterliche Warenarten machten weniger als $14 \%$ aus. Ihr Anteil nahm im östlichen Bereich der Düne stark zu. Gemeinsam mit einer erhöhten Befunddichte weisen mittelalterliche Keramikfunde auf die dort bevorzugte mittelalterliche Siedlungslage hin. Ebenfalls ohne Befundzusammenhang sind die Funde zu bezeichnen, die interessierte Laien in den 60er Jahren des 20. Jahrhunderts auf dem Dünenzug aufsammelten und wenig später an das Landesmuseum Hannover, Außenstelle Oldenburg, abgaben. Zumeist handelte es sich um Keramik und Flintartefakte. Ihre große Anzahl lässt auf eine weitreichende Zerstörung archäologischer Schichten im Dünenostteil schließen.

\subsubsection{Fundmaterial}

Keramik macht das Gros der Funde aus. Es handelt sich i.d.R. um lokale Siedlungskeramik, gefolgt von Steinartefakten sowie Objekten aus Metall und Glas. Funde der römischen Kaiserzeit und des Früh- und Hochmittelalters überwiegen. Vereinzelnd finden sich unter dem Fundmaterial auch bronze-, eisen- und völkerwanderungszeitliche Scherben. Aufnahme in den Tafelteil fanden 482 Keramikobjekte, ergänzt durch vier Farbtafel mit ausgewählten Scherben.

Die kulturgeschichtliche Einordnung stützt sich auf typologische Vergleiche, wird jedoch durch den hohen Fragmentierungsgrad erschwert. Der Gattung Keramik zugerechnet werden aus Ton modellierte und anschließend gebrannte Formen, wie Webgewichte und Spinnwirtel. Beides dient für die Siedlung Nortmoor als Nachweis lokaler Textilerzeugung. Die im Tafelteil abgebildeten Spinnwirtel vermitteln einen Eindruck von der Formenvielfalt dieses Hauswerkes (Kat.Nr. 3-57; 3-58; 188-1; 195-24; 21624; 432-12; 559-1; 584-8; 584-9). Vermutlich ebenfalls als Wirtel genutzt wurde ein sekundär durchbohrter Keramikboden (Kat.Nr. 1082-1). Die aufgefundenen, recht wuchtigen, Webgewichte weisen auf grobe Webstoffe hin (Kat. Nr. 3-62; 3-63; 195-23). Schmuckcharakter hatten kleinformatige Tonperlen (Kat.Nr. 3-55; 3-56; 78-1; 140-10; 216-24; 744-3).

Importfunde haben am Gesamtfundgut einen Anteil von $0,7 \%(\mathrm{n}=110)$. Während die Quantität durchaus im Rahmen einer ländlichen Siedlung liegt, so ist doch ihre Qualität ungewöhnlich.

Neben den wenigen Metall-(objekten) und Glasfunden überwiegen die Reste (Scherben) von Importkeramik. In die römische Kaiserzeit datieren Gefäßfragmente von Terra-Sigillata, Terra-Nigra und ihre Nachahmungen. Ergänzt wird das Repertoire durch einen Münz- und Glasfund. 
Frühmittelalterliche Funde werden von Pingsdorfer Keramikgefäßen und Mahlsteinfragmenten aus Basaltlava angeführt, die auf mittelalterliche Handelsbeziehungen zum Rheinland hinweisen.

Die zweithäufigste Fundgattung umfasst Steinartefakte mit eindeutigen Bearbeitungsspuren $(n=225)$. Aus dem Grabungsareal stammt eine Vielzahl von Feuersteinen, die als Abschläge und Trümmerstücke sowohl in gebrannter wie ungebrannter Form von der Nortmoorer Düne vorliegen. Neben Flintartefakten finden sich Bruchstücke von Schleif- und Mahlsteinen. In den Tafelteil aufgenommen wurden, als 'pars pro toto’', drei Flintartefakte (Kat.Nr. 25-1; 110-1; 110-2) und ein Schleifstein (Kat.Nr. 3-29). Von einer Abbildung der zahlreichen Klopf- (bzw. Hammer-) und Kochsteine wurde abgesehen. Hammersteine sind meist rund ausgearbeitet mit einem charakteristischen Narbenfeld. Kochsteine sind derart hoch erhitzt worden, dass ihre Struktur zerstört wurde. Sie sind oft rissig und zerfallen in Bruchstücke. Eine Abbildung ist nicht mehr sinnvoll.

Metallfunde haben einen geringen Anteil am Fundgut ( $n=7)$. Aufgrund ihres Materialwertes wurden sie häufig wiederverwendet, so dass nur verloren gegangene Metallfragmente überliefert sind. In die römische Kaiserzeit datieren zwei bronzene Fibelfragmente, wovon eine abbildungswürdig ist (Kat.Nr. 278-16). Herausragend ist der Fund eines Denar Trajans. Vermutlich auch in die römische Zeit datiert eine silberne Zierscheibe. Stark fragmentiert liegt eine bronzene Gürtelschnalle vor (Kat. 3-19). Von unbekannter Funktion ist eine runde Bleischeibe (Kat.Nr. 939-3). Gesondert aufgenommen wurden Schlackenreste, weil sie Hinweise auf eine lokale Erzaufbreitung geben. Aus Nortmoor liegen mehrere stark korrodierte Fragmente vor. Metallurgische Übereinstimmungen bestehen mit Schlackenmaterial aus dem wenige Kilometer entfernten Holtland. Während die dortigen Ofenanlagen die Produktion von Metallguss belegen, steht für Nortmoor der Nachweis aus, auch fehlen einschlägige Funde wie Guss- oder Schmelztiegel. Grundsätzlich eignet sich das in der JümmeNiederung anstehende Raseneisenerz für die Metallverarbeitung.

Dem relativ hohen Grundwasserstand sind die guten Erhaltungsbedingungen für Holz und organische Materialien geschuldet. Einblicke in die Wasserversorgung und Vorratshaltung gewähren hölzerne Brunneneinbauten sowie eingegrabene Weidenkörbe. Werkgruben runden das Bild ab. Zeichnerisch im Tafelteil abgebildet sind neben einer Brunneneinfassung (Kat.Nr. 740 d-1 bis d-4), sechs angespitzte Hölzer (Kat.Nr. 195 d-2 bis d-3 u. d-5 bis d-9) und drei ausgearbeitete Holzbohlen, letztere weisen Nut und Feder auf (Kat.Nr. 195 d-1; d-4 u. d-7). Eine weitere Bohle ist mit einer randlicher Bohrung versehen (Kat.Nr. 140 h). Im feuchten Bodenmilieu haben sich zudem drei Radsegmente (Kat.Nr. 455; 1110; 1111) sowie die Überreste einer hölzernen Treppe erhalten (Kat.Nr. 195 d-1; 195 d-4; 195 d-7).

Einige Befunde enthielten Knochenmaterial. Neben unverbrannten und kalzinierten Tierknochen, 
gelang es bei der Ausgrabung Brandschichten mit dem zugehörigen Leichenbrand von acht menschlichen Bestattungen zu bergen. Während die Brandbestattungen anthropologisch untersucht wurden (Kap. 5.3 Bestattungen), erfolgte eine Artbestimmung der Tierknochen nur, soweit es der fragmentierte Knochenzustand zuließ.

\subsubsection{Zeitliche Einordnung der Funde - ein Überblick}

Nur eine verhältnismäßig geringe Anzahl neolithischer Objekte befinden sich unter dem Nortmoorer Fundgut. Neben Abschlägen und Kernsteinen, stellen Klingenkratzer (-schaber) (Kat.Nr. 25-1; 110-1) und Klingenbruchstücke (Kat.Nr. 110-2) die größeren Gruppen dar. Sie sind vermutlich von der alten Oberfläche zufällig in Befunde mit jüngerem Fundmaterial gelangt.

Die Fundverteilung bei Flintartefakten zeigt keine Präferenzen, sondern streut über den gesamten Bereich der Düne. Neolithische Keramik liegt vom Fundplatz ebenso wenig vor wie bauliche Strukturen. Dass die Jümmeniederung dennoch in dieser Zeit aufgesucht wurde, beweist ein Siedlungsplatz der Trichterbecherkultur, der sich wenige Hundert Meter östlich am Zusammenfluss von Holtlander Ehe und Jümme befand. An der Ostseite der Ehe lag ein weiterer neolithischer Siedlungsplatz (vgl. SCHWARZ/STUTZKE 1998, Kat.Nr. 135, 118, vgl. Nr. 159).

Der Bronzezeit gehören nur wenige Scherben an. Möglicherweise bronzezeitlich ist ein grazil ausgearbeiteter Ösenhenkel (Kat.Nr. 216-15). Meist sind Wandungsscherben wegen ihrer „zeitlosen“ Machart nicht immer eindeutig anzusprechen und nur allgemein in die späte Bronzezeit oder Eisenzeit zu datieren. Hinweise auf eine zeitnahe Ansiedlung geben Gebäudereste eines vermutlich bronzezeitlichen Hauses aus dem westlichen Dünenbereich. Weitere Baubefunde sind dieser Phase nicht zuzuordnen. Demgegenüber verweisen pollenanalytische Untersuchungen auf eine Intensivierung der Siedlungstätigkeit im näheren Umfeld, dienen sie doch als Nachweis bronzezeitlicher Ackertätigkeit (FREUND 1996a).

Der für die ältere Eisenzeit charakteristische Harpstedter Rauhtopf mit einziehenden Rand, kurzem, glatten Oberteil und hohem konischen Fußteil liegt aus Nortmoor nicht vor. Hingegen fanden sich unter dem Fundmaterial diverse mit Tupfen verzierte Keramikränder, deren Randprofile in der Keramiktradition der vorrömischen Eisenzeit stehen. Kennzeichnend sind Wellenrandtöpfe der lokal nordwestdeutschen Form, während Töpfe mit s-förmigem Profil und leicht ausbiegenden Ränder einen niederrheinischen Einfluss anzeigen (vgl. HALPAAP 1994, 31). Die prädestinierte Lage auf dem erhöhten, vermutlich ganzjährig trockenen, Dünenzug bot auch in dieser Phase einen günstigen Siedlungsraum. Zwar steht für Nortmoor ein eindeutiger archäologischer Nachweis noch aus, Pollenprofile zeigen allgemein einen erhöhten Eintrag von Ackerunkräutern für diese Zeit an (FREUND 1994; 1996a; 1997). 
Die Hauptsiedlungsphase in Nortmoor setzt mit der frühen römischen Kaiserzeit ein. In dieser Zeit entstehen die meisten Gebäude und Speicherbauten. Darüber hinaus datieren wenigstens drei Brunnenanlagen, mehrere Zaunreihen, etliche Gruben und Gräben in die römische Kaiserzeit. Zwar steht Gebäude III der vorhergegangenen eisenzeitlichen Bautradition nahe, wurde aber vermutlich erst in der jüngeren Kaiserzeit errichtet. Pfostengruben wiesen im Siedlungsareal nur wenige feinchronologisch relevante Funde auf.

An dem zahlenmäßig überwiegend kaiserzeitlichen Keramikmaterial der Siedlung sind Entwicklungslinien der einheimischen Töpferware festzumachen. Hierbei zeigen Formgebung und Randgestaltung eine kulturelle Orientierung sowohl zum friesischen als auch niederrheinischen Raum auf (vgl. HALPAAP 1994, 45-47).

Für eine chaukische Siedlung ungewöhnlich ist der recht hohe römische Importanteil, deren Schwerpunkt vom 1. bis 3. Jahrhundert n. Chr. reicht. Früh datieren Scherben einer römischen Reibschüssel, einer Terra-Sigillata Schale sowie eines Denar Trajans, etwas später die aufgefundenen Terra-Nigra-artigen Gefäßreste. Zwei Scherben gehören eventuell der braunschweigischen Drehscheibenware an (Kat.Nr. 168-1 u. 187-1). Hingegen vermutlich spätkaiserzeitlich sind Fragmente einer Terra-Sigillata-artigen Ware (Kat.Nr. 195-1, 195-2; 195-3). Eine gestempelte TerraSigillata-Nachahmung ist bis dato ein Unikat in der römischen und barbarischen Welt (Kat.Nr. 520-1). Aufgrund dessen kann das Stück typo-chronologisch nur allgemein in die römische Kaiserzeit eingeordnet werden. Um einen seltenen Importfund handelt es sich auch bei dem Randfragment eines kleinen Glasgefäßes. Der geringe Randdurchmesser von $1,5 \mathrm{~cm}$ weist auf eine römische Flakonform des 1. bis 2 Jahrhunderts n. Chr. hin (Kat.Nr. 3-36).

Nur eine geringe Anzahl der Funde datiert in die Völkerwanderungszeit. Verzierung und Form weisen bei einigen Keramikscherben in ihre jüngere Phase. Befunde aus dieser Zeit liegen von der Nortmoorer Düne nicht vor. Vermutlich kam es in dieser Zeit zu einer Siedlungsausdünnung. Diese These unterstützen auch die vorliegenden Pollenprofile, weil sie für die Untere Emsregion eine deutliche Abnahme von Siedlungsanzeigern aufzeigen (FREUND 1994, 71-72).

Erst wieder im Frühmittelalter ist ein Fundanstieg in Nortmoor zu konstatieren. Aus dem Siedlungsareal liegen zahlreiche Muschelgrus gemagerte Keramikscherben vor. Komplettiert wird das frühmittelalterliche Keramikinventar durch zwei nahezu vollständig erhaltene Importgefäße der Pingsdorfer Ware sowie diverse Einzelfragmente dieser Ware (Kat.Nr. 26-5 u. 6). Größere Baubefunde aus dieser Zeit liegen aus dem untersuchten Platz nicht vor. Wegen der zeittypischen Keramikfunde sind einige Gruben in diese Phase zu datieren. Neben kaiserzeitlicher dominiert im Fundgut hochmittelalterliche Keramik, vorzugsweise harte Grauware. Die vorliegenden Randformen können dem 11. bis 13. Jahrhundert zugeordnet werden. Baubefunde liegen als Speicherbauten in 
Form von Rutenbergen vor. Auch einige Gruben datieren in diese Zeit. Reste von Wohnbauten sind nicht erhalten. Dies war auch nicht zu erwarten, da das mittelalterliche Siedlungsareal sich in der östlichen, modern gestörten Dünehälfte befand.

\subsubsection{Keramik}

Keramik stellt in der Siedlung Nortmoor die umfangreichste Fundgattung dar. Insgesamt wurden 31.500 Scherben geborgen, wobei ein Großteil der Keramik Befunden entstammte $(n=18.500)$. Überwiegend handelt sich um stark zerscherbtes Material bei dem Wandungsfragmente quantitativ dominieren (95,5\%). Auswertbar von den verbliebenen Gefäßfragmenten sind etwa 5500 Scherben, die als Rand-, Henkel-, Bodenfragmente sowie verzierte Wandungsscherben aufgenommen wurden. Hinzu kommen 12 komplett erhaltene bzw. rekonstruierbare Gefäße.

Etwa 13.000 Scherben wiesen bei ihrer Bergung keinen Befundzusammenhang auf und gehören in die Kategorie der Oberflächenfunde. Etwa ein Viertel der Scherben stammte aus modernen Drainagegräben, die in regelmäßigen Abständen das Grabungsareal durchzogen. 4065 Scherben waren regelrecht in die o.g. Kleischichten „eingebacken“.

Eine Aufnahme in die Datenbank fand nur bei Randscherben mit feststellbarem Randdurchmesser und ausreichender Profillänge statt. Somit reduzierte sich die Anzahl der auswertbaren Ränder auf 1165. Statistisch berücksichtigt wurden darüber hinaus 345 Bodenscherben, 123 Henkelfragmente und 489 verzierte Wandungsscherben. Alle übrigen Keramikscherben sind summarisch erfasst. Aufnahme in den Katalog fanden Oberflächenfunde der 60er Jahre des 20. Jahrhunderts, die im Zuge von Bodenabträgen im Ostteil der Düne aufgesammelt wurden.

Von 1290 Befunden in Nortmoor enthielten etwas weniger als die Hälfte Keramik ( $n=479)$. Die zahlreichen Keramikscherben sind weder über das Grabungsareal noch innerhalb der Befundgruppen gleichmäßig verteilt. Zwar überwiegen mengenmäßig Pfostengruben in Nortmoor, diese waren vorzugsweise fundleer oder enthielten kaum aussagefähige Keramik. Aus Gruben entstammte ein Großteil der aufgefundenen Keramik. In einige Gruben konnten Quantitäten von bis zu 356 Scherben erreicht werden, wobei das keramische Material oft stark durchmischt war. Selten wurden Keramikfunde bei der Ausgrabung stratigraphisch dokumentiert und geborgen. Dies beeinträchtigte die spätere Auswertung. Im Verhältnis zu ihrer Größe waren Brunnenanlagen, Werk- und Vorratsgruben wenig ergiebig, sie schienen wie ausgeräumt. Gräben wiederum konnten beträchtliche Keramikmengen enthalten. Nur in wenigen Fällen gelang es, eine Beziehung zwischen der jeweiligen Gruben- bzw. Grabenform und ihrem Inhalt herzustellen. Zum Großteil wird es sich um ehemalige Sandentnahme- bzw. Vorratsgruben gehandelt haben, die sekundär als Abfallgruben genutzt wurden.

Oberflächenscherben aus der oberen Kleischicht haben einen recht hohen Anteil am keramischen 
Fundmaterial. Bei der Fundaufsammlung in den Jahren 1996 bis 1998 erfolgte eine ungefähre Lokalisation über die Quadranten. Während auf der Dünennordseite die Anzahl der Keramikfunde deutlich überwiegt ( $n=2339)$, fanden sich auf der Südseite nur ein Bruchteil dieser Menge $(n=260)$. Bei 2257 Oberflächenscherben fehlen jegliche Fundangaben.

Die Ursachen der ungleichen Fundverteilung sind unbekannt. Vermutlich war die Nordseite für eine Besiedlung weniger attraktiv. Auf der Südseite kam es zu einer stärkeren Bodenerosion, die in Folge stärker Befunde und Funde zerstörte. Eventuell hängt die höhere Funddichte an der Nordseite mit einer nach Abbruch der Siedlung erfolgten Fundverlagerung zusammen. Denkbar ist, dass das Fundmaterial in Folge verschiedener Überschwemmungen an die rückwärtige Dünenseite gelangte. Einen recht hohen Fundanteil wiesen auch die das Grabungsgebiet auf einer Länge von bis zu 35m durchschneidenden Drainagen auf. Das ältere Drainagesystem A (NO-SW-Verlauf) schnitt breite, oft recht tiefe Gräben in die Düne und durchstieß dabei fundreiche Schichten. Im Verhältnis geringe Fundmengen enthielt das jüngere, sehr viel schmalere Drainagesystem B (SO-NW-Verlauf). Insgesamt betrachtet entspricht das Formenrepertoire der Oberflächenscherben weitgehend dem der verschiedenen Warenarten in den Befunden. Ergänzend sei hinzugefügt, dass aus den gestörten Siedlungsarealen qualitativ bemerkenswerte Funde, wie römischer Import u.a.m, die die Bedeutung des Fundplatzes aufwerten, stammen.

Für die Grundbeschreibung der Keramikfunde wird die deskriptive Typenaufnahme gewählt. Vorab wurde die Keramik anhand ihres Gefäßaufbaues in ein-, zwei- oder dreigliedrige Gefäße gegliedert. Differenziert werden können schalen-, schüssel-, kumpf- und topfartige Gefäßgruppen. Insbesondere letztere zeichnen sich durch eine relativ große Formenvielfalt aus. Dies betrifft sowohl die Kubatur und Gefäßvolumina als auch die Randgestaltung und den Wandungsverlauf. Kleingefäße werden gesondert vorgestellt.

Für den Fundplatz Nortmoor werden zunächst die formalen Gliederungsprinzipien bei keramischen Gefäßeinheiten herausgearbeitet. Überlegungen zur Gebrauchsweise schließen sich an. Es ist zu vermuten, dass die unterschiedliche Form bei Siedlungskeramik funktionsbedingt ist und bestimmte Nutzungsarten wiederspiegelt. Da sich Töpfe durchaus multifunktional nutzen lassen, kann selten eine ausschließliche Zuordnung einer Gefäßform zu einer einzigen Funktion erfolgen. Auch sind die Nutzungskriterien prähistorischer Gefäße nicht hinreichend bekannt.

Die Bearbeitung von Siedlungskeramik wird durch den fragmentarischen Zustand des Fundgutes eingeschränkt. So haben Randscherben zwar einen Gesamtanteil von 15\% am Keramikaufkommen, doch nur 30\% davon liefern aussagekräftige Profile. Eine typologische Einordnung kann i.d.R. nur bei den bis zum Bauchumbruch erhaltenen Gefäßrandstücken erfolgen. Eher selten ist die Gefäßform anhand des zerscherbten Gefäßunterteils, wie dies situlenartige Formen gestatten, zu bestimmen. In einer Datenbank erfasst wurden alle Randfragmente ab einer Länge von $5 \mathrm{~cm}$, verzierte Wandungsscherben, Handhaben und Bodenfragmente sowie sämtliche Sonderformen. Insgesamt 
konnten 1165 Randscherben eines Gefäßtypen zugeordnet werden. Diese relativ geringe Zahl erklärt sich dadurch, dass nur Randscherben mit feststellbarem Randdurchmesser und ausreichend langem Profil berücksichtigt wurden. Bei einzelnen Gefäßen wurden von einander abweichende Randformen beobachtet. Dies bedingt sich der Herstellungsprozess handgefertigter Keramik. Geringe Differenzen bei der Randausformung sind daher zu vernachlässigen, größere Abweichungen wurden vermerkt.

\section{Grundüberlegungen zur Typologie}

In erster Linie erfolgt die Typenbildung anhand der Ausprägung des Randes und der Randlippe. Für die Randgestaltung berücksichtigt werden Orientierung / Ausrichtung, Grund- und Lippenform. Andere Merkmale treten hinzu, wie Randdurchmesser, Schulterausformung, Wandungsdicke, Oberflächenbehandlung und mögliche Verzierungen. Bei den wenigen komplett erhaltenen Gefäßen auch ihre Bodenform. Der gewählte deskriptive Typenvergleich lässt, auf morphologischen Kriterien basierend, bei handgefertigten und in der Regel nicht standardisierten Keramikgefäßen Übergänge und Zwischenformen zu, ohne gleich einen selbstständigen Formentypus zu gestalten (LEHMANN 2000, 29). Bei der Typenbenennung werden die Typen durchnummeriert und ihre Varianten alphabetisch aufgeführt. In der Regel bilden die unter einem Typ zusammengefassten Varianten eine typologische Entwicklungsreihe (vgl. LÖBERT 1982, 20-22, Abb. 2). Ist die zeitliche Differenz zwischen aufeinanderfolgenden Varianten zu groß, kann eine typologische Ableitung ausgeschlossen werden. Nach kritischer Überprüfung der bestehenden Typologien ist zu entscheiden, ob es zu einer Anhängung oder lokalen Klassifikation des untersuchten Materials kommt. Eine Typenbildung ist meist recht gut über eine Kombinationsanalyse der Merkmale einzelner Gefäße möglich, jedoch impliziert dies noch keine chronologische Einordnung.

Die Keramik in Nortmoor stammt aus Hausgräben und benachbarten Gruben, selten aus Gruben und Pfostenbefunden innerhalb der Hausplätze. Nur einzelne naturwissenschaftliche Datierungen liegen vor. So ist eine feinere chronologische Untergliederung der Keramik auf diese Weise nicht durchführbar. Auch ist eine Abgrenzung und stratigraphische Gliederung der Befunde mit dem Ziel einer Siedlungsabfolge nur in Ansätzen möglich. Siedlungsgruben können kaum als geschlossener Fund gelten, da sie unterschiedlich lange offen lagen und dieser Zeitraum i.d.R. unbekannt ist. Ein homogenes Keramikrepertoire deutet auf kurze, ein stark durchmischter Fundkomplex eher auf längere Verfüllzeiten hin. Wichtige Fragestellungen ergeben sich u. a. zur zeitlichen Aussagekraft einer typologischen Reihe, wenn absolute Datierungen wie ${ }^{14} \mathrm{C}$ oder klar definierte und datierte Typen aus benachbarten Regionen ermöglichen, fehlen. Ist in diesem Fall anhand des vorliegenden Materials überhaupt eine feinchronologische Unterteilung möglich? „Für die Genauigkeit des Ergebnisses wesentlich sind die chronologische Empfindlichkeit der Keramik, ihre Merkmalsanalyse und die Verfüllumstände der Gruben. Welche Rolle spielen Geschwindigkeit der Verfüllung und Herkunft bzw. Entstehung des Füllmaterials? Gute Voraussetzungen haben rasch verfüllte Abfallgruben (Funde sind in einer relativ kurzen Zeitspanne eingebettet worden), hier liegt die Wahrscheinlichkeit 
gleichzeitiger Verwendung nahe. Andererseits bieten nur langsam verfüllte Gruben größere Chancen, einen repräsentativen Ausschnitt der Typen ihrer Zeit zu erhalten.“ (SCHREG 1998, 21).

\subsubsection{Kaiserzeitliche Keramik}

Bei der Bearbeitung der kaiserzeitlichen Keramik kann auf einen recht günstigen Forschungsstand, sowohl von der ostfriesischen Geest wie auch aus den benachbarten Marschenregionen verwiesen werden. Die von LEHMANN 2002 vorgelegten Studie ermöglicht eine zügige Gliederung kaiserzeitlicher Keramik. Wo dies für die Siedlung Nortmoor nicht möglich ist, wird das bestehende Schema ergänzt. Einbezogen wurden insbesondere nachstehende Untersuchungen, denen wichtige Impulse für die kaiserzeitliche Keramikbearbeitung zu verdanken sind.

Biegert, S. / Schnurbein, S. von / STEIDEL, B. / WALter. D. 2000: Beiträge zur germanischen Keramik zwischen Donau und Teutoburger Wald. Kolloquium zur germanischen Keramik des 1.-5. Jahrhunderts. 17.-18. April 1998. Kolloquium zur Vor- und Frühgeschichte Bd. 4, Bonn 2000.

Van Es, W.A., Miedema, M., Wynia, S.L. 1985: Eine Siedlung der römischen Kaiserzeit in Bennekom, Prov. Gelderland. ROB 35, 533-652, 1985.

FöRST, E. 1991: Zur Besiedlungsgeschichte der Flußmarsch im Kreis Wesermarsch. Hildesheim 1991.

HALPAAP, R. 1994: Der Siedlungsplatz Soest-Ardey. Bodenaltertümer Westfalens 30, Mainz 1994.

TAAYKE, E. 1995: Die einheimische Keramik der nördlichen Niederlande, 600 v. Chr. bis 300 n. Chr. Teil II: Nord-Drenthe. Berichten van de Rijksdienst voor het Oudheitskundig Bodemondezoek 41, 1995, 9-112.

TAAYKE, E. 1996a: Die einheimische Keramik der nördlichen Niederlande, 600 v. Chr. bis $300 \mathrm{n}$. Chr. Teil III: Mittel-Groningen. Berichten van de Rijksdienst voor het Oudheitskundig Bodemondezoek 42, 1996, 9-69.

TAAYKE, E. 1996b: Die einheimische Keramik der nördlichen Niederlande, 600 v. Chr. bis $300 \mathrm{n}$. Chr. Teil IV: Übersicht und Schlußfolgerungen. Berichten van de Rijksdienst voor het Oudheitskundig Bodemondezoek 42, 1996, 163-208.

SCHMID, P. 2005: Die Keramik der Feddersen Wierde. Probleme der Küstenforschung Bd. 29, 2006.

\section{Mengenverhältnisse kaiserzeitlicher Keramik im Fundmaterial}

Der römischen Kaiserzeit können mehr als zwei Drittel der Keramikscherben in Nortmoor zugeordnet werden. Ein Großteil der Keramik besteht aus grober Siedlungsware, während kaiserzeitliche Feinkeramik einen Anteil von etwa 8\% hat. Römischer Import und seine keramischen Nachahmungen sind mit wenigen Bruchstücken vertreten.

Das stark zerscherbte Material besteht überwiegend aus Wandungsscherben (85\%), gefolgt von Randscherben (10\%), Bodenscherben (4\%) und Handhaben verschiede Ausformungen, wie Bandhenkel, Knubben und Schnurösen (insgesamt 1\%). 


\section{Oberflächenbehandlung kaiserzeitlicher Keramik}

Einheimische kaiserzeitliche Keramik ist zumeist handgefertigt und weist insofern die typischen Abweichungen im Unterschied zu standardisierten Warenarten auf. Herstellungstechnische Kriterien wurden bei der Materialaufnahme berücksichtigt. Verstreichspuren auf den Gefäßinnenseiten stammen vermutlich von Hölzern, Fingern oder Fingerkuppen. Die Oberflächenbehandlung ist in folgende Kategorien gegliedert: sehr gut geglättet bis glänzend poliert, einfach geglättet, körnig rauh oder geschlickt. Kaiserzeitliche Feinkeramik ist gut geglättet bis glänzend poliert, meist von dunkelgrauschwarzer Farbe und zeichnet sich durch betont profilierte Ränder aus. Es fand sich unter dem Nortmoorer Material Drehscheibenware verschiedener Provinenzen, auf die zu einem späteren Zeitpunkt eingegangen wird. Das Scherbenmaterial weist eine oft sorgfältig bearbeitete bzw. geglättete Gefäßoberfläche bis zum Bauchumbruch auf, während die Gefäßunterteile nur teilweise glatt ansonsten aber geraut waren oder Schlickbewurf aufwiesen. Die Randgestaltung erfolgte sorgfältig, eine Ausnahme hier von bilden Miniatur- und große Vorratsgefäße. I.d.R. wurde die Keramik mit Granitgrus gemagert. Selten erfolgte eine Magerung mit Stroh, Häcksel oder Kalk. Es zeigte sich, dass diese Art der Magerung nicht an einen Gefäßtyp gebunden war. Der Magerungsanteil kann in vier Hauptgruppen untergliedert werden: $<0,5 \mathrm{~mm}$ (sehr fein), 0,5-1 mm (fein), 1-2 mm (mittel), $>2 \mathrm{~mm}$ (grob). Importgefäße der römischen Kaiserzeit weisen eine feine Magerung von unter 0,3mm auf.

Die Keramik wurde oxidierend und/oder reduzierend gebrannt. Eine Vielzahl von Scherben wies infolge eines uneinheitlichen Brandvorganges verschiedene Farbabläufe auf. Bei größeren Gefäßfragmenten ist ein Übergang von Orange/Ockertönen im Bereich des Gefäßoberteils (oxidierender Brand) hin zu graubraunen und schwarzen Tönen im Unterteil (reduzierender Brand) zu beobachten. Auf eine dezidierte Farbansprache wurde daher verzichtet. Feinkeramik wurde meistens reduzierend gebrannt (dunkelgrau-schwarz), was auf eine sorgfältigere Kontrolle des Brennvorganges schließen lässt. In der Farbbestimmung differenziert werden können dunkelgrau-schwarze, braungelbgraue, rotgelb-braune und gelbe Tonfarben. Der Scherbenbruch wurde nur bei stark abweichendem Farbton berücksichtigt.

\section{Gefäßformen und Randgestaltung}

Im Folgenden werden die in Nortmoor auftretenden Gefäßformen vorgestellt. Aufgrund des doch recht großen Fragmentierungsgrades des keramischen Materials erfolgt ihre Gliederung zumeist nach der formalen Gestaltung des Gefäßoberteils. Die aus dem Grabungsareal nahezu komplett erhaltenem kaiserzeitlichen Gefäße $(n=8)$ repräsentieren vier der acht Gefäßgruppen, die sich wie folgt gliedern: Weitmündige und engmündige Töpfe, Trichterschalen, Schalen/Schüsseln, Kümpfe, Näpfe, krug- und becherartige Gefäße. Sonderformen umfassen Kleinkeramik, sieb- und pitoiartige Vorratsgefäße.

Die Nortmoorer Randformen werden nach dem von LEHMANN 2002 aufgestellten Gliederungsschema 
vorgelegt (Taf. 108, 109). Seine Nomenklatur wurde zur besseren Vergleichbarkeit beibehalten (LEHMANN 2002, 31, Tafel 119).

Nachfolgende Merkmale sind bei der Materialaufnahme berücksichtigt worden: Zugehörigkeit zur jeweiligen Gefäßgattung. Diese erfolgt meist nur am Gefäßoberteil; Angabe des größten Rand- und Gefäßdurchmessers, soweit feststellbar; die Randform wird aufgeschlüsselt in die jeweilige Grundform, Lippengestaltung und Orientierung; ergänzend berücksichtigt wurden Oberflächenbehandlung, Wandungsverlauf und -stärke.

Bei gleicher Gefäßgattung, aber unterschiedlicher Randgestaltung kommt es zur Unterteilung in Varianten, wobei die Übergänge fließend sein können. Nicht immer gestattet die Randgestaltung bei handgemachter Ware eine eindeutige Zuordnung, die dann unter Vorbehalt erfolgt.

LEHMANN (2002, 30-32) stellt bei ausgewählten Gefäßformen und bestimmten Randausprägungen eine regelhafte Verknüpfung im Briller Material fest. Beispielsweise sind bestimmte Randformen, wie dreieckige Ränder vom Typ 7.1 und 7.4 auf Trichterschalen beschränkt, während andere sowohl an weit- wie engmündigen Töpfen in Erscheinung treten (vgl. Typ RF 6.2). Somit sind einzelne Randformen grundsätzlich nicht nur an eine Gefäßform gebunden, sondern können auch an anderen Formen auftreten. Hier stellt sich die Frage, ob ähnliche Randformen eine zeitliche Nähe zueinander signalisieren, wie dies bei „friesischen Henkeltöpfen“ im Westergo und Töpfen vom Eddelaker Typ der Fall ist (vgl. LÖBERT 1982, 94).

\subsection{Dreigliedrige Gefäße}

\subsection{Trichterschalen (GF 1)}

Kat.Nr. 3-12; 3-13; 3-14; 3-38; 3-40; 3-48; 91-4; 126-1; 140-6; 141-1; 178-1; 192-1; 195-4; 195-6; 202-1; 216-6; 216-10; 223-5; 265-4; 278-2; 278-3; 285-4; 369-2; 369-4; 376-2; 383-3; 395-1; 432-6; 480-1; 483-8; 513-1; 516-4 (?); 516-6; 517-3; 551-1 bis 551-3 (ein Gefäß); 551-4; 551-5; 551-7;569-1; 582-2; 584-3; 584-4; 584-5; 584-5; 627-2; 627-3; 627-9 (?); 627-10 (?); 627-13; 637-2; 637-3; 637-6; $637-9 ; 670-2 ; 698 \mathrm{a}-2 ; 745-1 ; 755-5 ; 859-2 ; 860-1 ; 884-11$

Es handelt sich bei Trichterschalen um weitmündige Gefäße, die über eine relativ kleine Standfläche verfügen. Charakteristisch sind ein hoher Umbruch und ein hohes Unterteil, von dem es in eine kleine Standfläche übergeht (LEHMANN 2002, 33). Von der kurzen und meist scharf ausgeformten Schulterpartie geht es sogleich in den Rand über. An einigen Nortmoorer Trichterschalen ist die Gefäßschulter gerundet. Auch die Randgestaltung ist vielfältig und umfasst kurz-verdickte Ränder ebenso wie länglich-schmale. Der Durchmesser von Rand- und Schulterradius stimmt bei einer Vielzahl von Trichterschalen im Wesentlichen überein (STILKE 1995, 214). Der Gefäßboden ist meist flach ausgearbeitet, einige Exemplare weisen Hohlfüße auf oder sind leicht einschwingend. Eine Unterscheidung zwischen Trichterschalen und Standfußgefäßen ermöglichen nur ganze Gefäße (vgl. LÖBERT 1982, 94). NÜSSE (2002, 41-42) führt für Trichterschalen als wesentliches 
Unterscheidungskriterium zu Standfußschalen deren sich stark verjüngende Gefäßbasis an.

Unter dem Fundmaterial befinden sich großteils Trichterschalen mit kurzem Rand. Ergänzt wird das Repertoire durch sieben senkrecht-längliche Randscherben und 10 Randfragmente von sehr fein gearbeiteten Trichterschalen. Vier Gefäße sind komplett vom Rand bis Boden erhalten. 12 Gefäßböden gehören vermutlich dem Gefäßtyp 1 an. Aufgrund des fragmentierten Zustandes ist nicht immer eine eindeutige Zuordnung möglich. Ist die Randerhaltung nicht ausreichend, kann die Gefäßform nicht mehr einwandfrei bestimmt werden.

Im Siedlungsmaterial Nortmoors überwiegen zerscherbte Trichterschalen. Zusätzlich existieren sieben fast vollständig erhaltene Gefäße. In einem Fall ist ein Fundzusammenhang mit Leichenbrand einer Brandbestattung belegt (Kat.Nr. 569-1). In unmittelbarer Nachbarschaft zu weiteren Bestattungen fand man drei Trichterschalen (Kat.Nr. 480-1; 551-4; 582-2). Diese entstammen zwar Siedlungsgruben, durch ihre räumliche Nähe und den häufigen funeralen Bezug dieses Gefäßtyps, könnte hier aber eine sekundäre Verlagerung vorliegen. Vier Gefäße weisen keinen Fundzusammenhang auf (Kat.Nr. 3-17; 3-26; 3-48), worunter sich eine Trichterschale befindet, die einen Bandhenkel auf der Schulter besitzt (Kat.Nr. 3-26).

Der Randdurchmesser der Nortmoorer Trichterschalen variiert zwischen $14-27 \mathrm{~cm}$ bei einem Mittelwert um $16 \mathrm{~cm}$, wobei der Durchmesser des Bauchumbruches um etwa 1-2cm größer ist. Für Trichterschalen sind vier Gefäßhöhen von $13-23 \mathrm{~cm}$ überliefert, ein Mittelwert scheint sich bei 16$17 \mathrm{~cm}$ abzuzeichnen. Der Höhen-Breitenindex (Gefäßhöhe geteilt durch größten Durchmesser) kann wie folgt angegeben werden: 0,$62 ; 0,64 ; 0,65 ; 0,74$. Der überwiegende Teil der Trichterschalen ist reduzierend hart gebrannt und zeichnet sich durch eine dunkelgraue geglättete Oberfläche aus. Es dominiert eine Gesteinsgrusmagerung mittlerer Körnung. Gelegentlich war die Oberfläche glänzend poliert und fein gemagert.

Die Ränder der Nortmoorer Trichterschalen sind nach außen gewendet. Es überwiegen kurze, dreieckig verdickte oder trapezförmige Randformen. Daneben kommen basal verdickte Ränder und parallelseitige Randformen vor. Wenige Ränder sind senkrecht stehend und länglich ausgebildet. Eine Sondergruppe bilden längliche nach außen gewendete Ränder, die eine leistenartige Verdickung an der Randlippe aufweisen können. Die Hauptgruppe der kurzen Ränder kann den Randformen 7.1, 7.3 und 7.6 zugeordnet werden. Es überwiegen einfach verdickte spitz-dreieckige Ränder von RF 7.1 (Kat.Nr. 192-1; 216-6; 216-10; 278-2; 285-4; 369-4; 483-8; 513-1; 517-3; 551-1; 551-2; 551-4; 551-5; 551-7; 569-1; 584-4; 637-2; 637-9; 670-2; 755-5; 860-1), die meist beidseitig abgestrichen sind. Selten kommen länglich-dreieckige Randformen vor (Kat.Nr. 195-4). Basal verdickte Ränder sind in ihrer Grundform den kurzen dreieckigen Randformen verwandt, unterscheiden sich von diesen durch eine stärkere Wölbung der inneren Randlippe (Kat.Nr. 517-3; 584-3; 584-5). Sie entsprechen RF 7.4, wobei 
einige Nortmoorer Exemplare kürzer und stärker nach außen gewendet sind. Eine andere Variante sind Trichterschalen mit dreieckigem Rand von RF 7.3, deren Randlippe und basale Seite abgestrichen ist (Kat.Nr. 3-14; 3-17; 141-1; 265-4; 480-1; 516-4; 516-6; 551-1 (551-1 bis -3: ein Gefäß); 637-3; 7451). Etwas schmaler ist der Rand einer anderen Trichterschale ausgebildet (Kat.Nr. 3-26). Ausgewendete kurze viereckige Ränder haben eine parallelseitige Randform und einen leicht abgeschrägten Randabschluss (RF 7.6). Die Randlippe kann einfach abgestrichen oder leicht gerundet sein (Kat.Nr. 3-14; 178-1; 637-2). Fast rechtwinklig nach außen gewendet ist ein dieser Gruppe zugehöriges Randfragment mit verdickter Randlippe (Kat.Nr. 3-13). Die Ansprache als Trichterschale beruht auf dem ausgeprägten Umbruch und seinem steilen Wandungsverlauf. Eventuell handelt es sich hier um ein frühkaiserzeitliches Randfragment, welches nah an spätlatènezeitlichen Töpfertraditionen bei weitmündigen Schalen steht (vgl. SCHMID 2006, 39). Lediglich eine Trichterschale besitzt einen kurzen rundlich-unverdickten Rand (Kat.Nr. 860-1). Obschon die Randgestaltung an weitmündige Terrinen erinnert, so weist doch der hohe Umbruch auf eine Trichterschale hin. Im Profilverlauf ähnelt dieses Stück der verzierten Trichterschale Kat.Nr. 551-4.

Eine eigenständige Randform bilden senkrecht ausgerichtete längliche Ränder (Kat.Nr. 202-1; 627-2; 637-6). Diese sind außen abgestrichen, innen leicht basal verdickt, meist mit gerundetem Randabschluss (RF 7.5). Eine Ausnahme bildet Kat.Nr. 202-1, die sich zur Randlippe hin verjüngt. Charakteristisch sind die hoch ansetzenden gerundeten Schulterumbrüche. Unter den bisherigen Randformen bei Trichterschalen sticht eine Gruppe von ausgewendeten langen schlanken Rändern heraus (Kat.Nr.: 3-38; 140-6; 376-2; 395-1; 432-6; 582-2; 627-9 (?); 627-10 (?); 859-2.). Einige Ränder von RF 7.2 weisen eine leistenartige Randlippe auf, wobei zwei Gefäßränder unter Vorbehalt zugeordnet wurden. In Brill äußerst selten und eher schlank ausgeführt, sind in Nortmoor die Vertreter dieser Randform basal leicht verdickt. Die Ränder sind durchschnittlich $3 \mathrm{~cm}$ lang, die Gefäßschulterpartie ist stark gewölbt und geht dann in einem $45^{\circ}$ Winkel in eine kleine Standfläche über. Insgesamt wirken die Schalen grazil, zumal ihre Wandungen relativ dünnwandig sind $(<6 \mathrm{~mm})$. Bereits TISCHLER (1937, 24-28; 1956, 57) stellte weitmündige Töpfe mit den markanten Merkmalen der Trichterschalen heraus, die er als „Schale vom Hodorfer Typ“ bezeichnete. Neben dem kurzen, oft verdickt nach außen stehendem Rand waren weitere Kriterien, die hoch ansetzende Schulter, die die größte Gefäßbreite anzeigt und ein deutlicher Gefäßumbruch, der scharf bis bauchig ausgeformt war. Diese treffen ebenso wie die Beschreibung eines gradwandigen bis konischen Unterteiles und verschieden gestaltender Bodenformen auf die Nortmoorer GF $1 \mathrm{zu}$.

Formal unterscheiden sich in Nortmoor Trichterschalen mit scharf profiliertem, stumpfwinkligen Bauchumbruch von Trichterschalen mit eher gerundetem Bauchumbruch. Dabei scheinen Trichterschalen mit scharfem Umbruch in der Mehrzahl zu sein. Bei den Trichterschalen überwiegt ein verdickter Umbruch, der durch einen innenseitigen Wandungsknick noch verstärkt werden kann. 
Bei Trichterschalen mit einer gerundeten Schulterpartie dient der hohe Umbruch als Indiz für die GF 1. Die Nortmoorer Trichterschalen zeichnen sich durch eine kurze Gefäßschulter und ein langes Unterteil aus, welches wie bei Schalen der Feddersen Wierde gewölbt oder konisch sein kann (HAARNAGEL 1979: SCHMID 1981a).

Die Standflächen von Nortmoorer Trichterschalen sind variationsreich. Neben Flachböden sind leicht konvexe Böden, Standplatten wie auch hohle Standfüße belegt (Kat.Nr. 3-40; 3-48; 126-1; 195-6; 223 5; 383-3; 480-1; 569-1; 627-3; 627-13; 698a-2; 884-11). Der Bodendurchmesser reicht von 6-10,8cm, wo bei sich ein Mittelwert bei $8 \mathrm{~cm}$ abzeichnet. Am eindruckvollsten ist der repräsentative hohle Standfuß (Kat.Nr. 447-1), der zudem mit diagonalen Riefen verziert ist. Zwei weitere Fragmente von erhabenen Standfüßen finden sich unter dem Fundmaterial (Kat.Nr. 3-40; 195-6). Aufgrund ihrer konkaven Wandung können der GF 1 vermutlich auch drei weitere Böden zugerechnet werden (Kat.Nr. 126-1; 627-13; 698a-2). Eine Standplatte befindet sich an einem Komplettgefäß (Kat.Nr. 5691), dem ein weiteres Fußfragment aus Nortmoor gleicht (Kat.Nr. 627-3). Für Trichterschalen überliefert sind facettierte Standfüße, wie sie auch aus Nortmoor vorliegen (Kat.Nr. 223-5, 884-12). Einen Hinweis auf eine situlenförmige Trichterschale bietet der Streufund Kat.Nr. 3-48, dessen Gefäßunterteil stark einzieht und in einer kleinen Standfläche mündet. Die ebenfalls stark eingezogene Wandung im Bodenbereich weist bei wenigstens drei weiteren Bodenfragmenten auf situlenförmige Trichterschalen mit einem Bodendurchmesser von 6-8cm (Kat.Nr. 3-42, 383-3; 884-11) hin. Belegt sind auch schlichte Flachböden (Kat.Nr. 3-17; 3-26).

Beim Gefäßtyp 1 sind verschiedene Dekormuster beliebt, meist in Form geometrischer Ritzungen. Bevorzugte Verzierungszone ist der Bereich knapp unterhalb des Umbruchs. Meist geht die Hauptverzierung von mehreren waagerechten Zierrillen aus und setzt sich Gefäßabwärts fort, wobei es nie zu einer flächendeckenden Verzierung kommt. Eher schlicht gestaltet ist eine Trichterschale mit vier umlaufenden Zierrillen, die von kurzen senkrechten Strichen unterbrochen wird (Kat.Nr. 569-1). Bei einer anderen Trichterschale befinden sich drei umlaufende Zierrillen oberhalb des Bauchumbruches (Kat.Nr. 551-5). Drei Trichterschalen sind zusätzlich mit hängenden Dreiecken verziert (Kat.Nr. 192-1; 278-2; 551-4). Beliebt sind unterhalb des Bauchumbruches Verzierungen mit einer von zwei Zierrillen eingefassten Punktreihe (Kat.Nr. 216-6). Geometrische Muster, wie hängende punktgesäumte Dreiecke und umlaufende Punktbänder verweisen in das 2./3. Jahrhundert (SCHMID 1965b, 26). In einem Fall war eine Trichterschale mit kleinen quadratischen Einstichen dekoriert (Kat.Nr. 192-1).

Von Rillen eingefasste Punktreihen sind ein Kennzeichen des 2./3. Jahrhunderts n. Chr., kommen darüber hinaus aber auch in den zeitlich angrenzenden Stufen vor (FÖRST 1991, 39). Bei einer prächtig verzierten Trichterschale (Kat.Nr. 480-1) sind unterhalb der umlaufenden Zierrillen hängende punktgesäumte Girlanden eingeritzt, von denen in gleichmäßigen Abständen sechs verschieden 
gestaltete Zierleisten herabreichen. Hier beginnt die Zierzone oberhalb des Umbruchs und reicht bis in die Fußzone herab. Sehr sorgfältig ist diese in ihrer Ausführung, die sich zudem durch einen abwechslungsreichen Dekorstil auszeichnet. Aus Hatzum-Boomburg stammt eine ebenso verzierte Trichterschale, die dem Typ 18 zugeordnet ist (LÖBERT 1982, 60, Taf. 53, 927). Auch wenn es dort aufgelegte senkrechte Leisten sind, die von hängenden Dreiecken ausgehen, so entsprechen sich Dekor (waagerechte Rillen, gefolgt von Zierzone mit umlaufendem geometrischem Muster und senkrecht laufenden Zierbändern mit Abschluss durch waagerechte Punktreihen am Fußübergang) und Gefäßkubatur (trapezförmiger dreieckiger Randabschluss, hoher gerundeter Umbruch und hohler Standfuß) weitgehend. LÖBERT $(1982,94)$ datiert die der Form HB 18 angehörende Standfußschale in das 1. Jahrhundert n. Chr. Eine Trichterschale aus Nord-Drenthe mit bis zur Bodenzone reichenden langen vertikalen Zierbändern wird als Typ K3c in 2./3. Jahrhundert n. Chr. datiert (TAAYKE 1995, 37, 60-61, Abb. 27, 1). Eine Schale, die mit senkrecht herabhängenden Streifenband und Kreisreihe verziert ist, stammt aus der Wesermarsch (FörST 1991, Taf. 105, 17). Ein weitere Schale aus Huntebrück-Wührden ist mit wenigstens sechs senkrechten Zierbändern geschmückt, wobei sie alle gleich schlicht dekoriert sind (FöRST 1991, Taf. 90, 773). Ein Standfußgefäß aus Leeste, Landkreis Diepholz weist neben der typischen Kerbverzierung am Fuß auch ein vertikales Rillendekor auf (BISCHOP 2002, 108, Abb. 80,1).

Unter den Nortmoorer Trichterschalen findet sich eine recht große Gruppe mit kurzen rechteckigen Randprofilen, die insofern für die zeitliche Abfolge der Gefäßform von Bedeutung sind, stehen sie doch am Anfang der Entwicklung. Ausgehend von der Feddersen Wierde datiert SCHMID $(1965,20)$ kurz-rechteckige Randabschlüsse in das Ende des 1. Jahrhunderts und beginnende 2. Jahrhundert $n$. Chr. Im letzten Drittel des 1. Jahrhunderts n. Chr. kommen verdickte und facettiert-abgestrichene Ränder auf, die noch den Beginn des 2. Jahrhunderts dominieren (SCHMID 1965b, 17-18). Stark verdickte Ränder mit abgestrichener Oberfläche sind bis in das 2. Jahrhundert vertreten, wenn man die Keramik von Hodorf als Leitfunde anführt. Ihre Datierung begründet sich durch Fundvergesellschaftung kurzer Trichterschalenrändern mit Terra Sigillata und Fibeln, die dem unteren Bereich der Siedlungsschicht Ia entstammten (HAARNAGEL 1937, 68-73; SCHMID 1965B, Taf. 15, 1-5 u. 16, 1-9). Trapezförmige Ränder sieht FAENSEN $(1993,38)$ als eine typologische Weiterentwicklung der verdickt-facettierten Ränder an, letztere ähneln PP IV A. LÖBERT $(1982,94)$ betrachtet dreieckige bis trapezförmige Randformen als typologische Nachfolger, da sie sich an Trichterschalen des 3. Jahrhunderts befinden. Aus der Wesersiedlung Huntebrück-Wührden liegen nur wenige kurze dreieckige Ränder vor (FöRST 1991, 87, Taf. 53, 404-405). Es überwiegen mit dem Typ HW 11b stattdessen verdickte und schwach facettierte Ränder, die in das 1. bis 2. Jahrhundert datieren (FÖRST 1991, 88, vgl. Taf. 51-52).

Die Hauptverbreitung der Trichterschalen im nordseegermanischen Raum setzt ab dem 2. Jahrhundert 
ein, wobei sich die kurzrandigen Formen ,zeitlich nicht von einander trennen lassen“ (SCHMID 2006, 39). Meist sind es stratigraphische Fundzusammenhänge die relativchronologische Datierungen erlauben, wobei diese eher Tendenzen aufzeigen, da Randformen auch gleichzeitig vorkommen können. Im Allgemeinen kann für die ältere römische Kaiserzeit eine zeitliche Differenzierung zwischen Trichterschalen mit sehr kurzem und verdicktem Rand, die früher zu datieren sind, und Exemplaren mit einem länger ausgezogenen und dünneren Rand, festgestellt werden (GROTELÜSCHEN 2000, 59). Dies stützt die von SCHWARZ $(1997,266)$ gemachten Beobachtungen, die dieser am Keramikmaterial aus dem Landkreis Wittmund ableitete, wonach länglich-verdickt ausziehende Ränder als typisch für das 2./3. Jahrhunderts anzusehen sind.

Die sich durch eine leistenartig verdickte Randlippe auszeichnende Randform steht unter niederrheinisch-westfälischem Einfluss. SCHMID (1965b, Taf. XXI, 12; 1969, 148) datiert diese Form in das ausgehende 2. sowie das 3. Jahrhundert n. Chr.. Die wenigen langen steil ausgerichteten Randformen aus Nortmoor finden ihre Entsprechung in Gefäßrändern der Feddersen Wierde, die dort dem 3. Jahrhundert n. Chr. angehören (SCHMID 1965b, 29). Verwandte langausgerichtete Ränder finden sich in Hodorf in dem durch zweigliedrige Armbrustfibeln Almgren VIII datierten oberen Bereich der Siedlungsschicht Ia (SCHMID 2006, 40). Übergangsformen zu den Trichterpokalen des 4. Jahrhunderts schließen sich an (SCHMID 1981a, 49).

Die doch recht stark im Fundmaterial vertretenen Trichterschalen, die Einflüsse der Form Uslar II anzeigen, besitzen eine oft verdickte Randinnenseite, einen verdickten Schulterumbruch und können auch eine leistenartige Randlippe ausbilden. Zwar sind die Nortmoorer Exemplare stärker nach außen gewendet, entsprechen aber weitgehend der in Huntebrück-Wührden vorgelegten Formen (FöRST 1991, Taf. 57, 436 u. 437). Daneben treten Schalen mit senkrecht stehenden unverdickten Rändern auf, die ebenfalls der Gruppe HW 13 zugeordnet werden (FörST 1991, Taf. 56, 8334:425 u. 427). Ähnliche Randformen mit der für diesen Typ charakteristisch prononcierten Schulterknick existieren auch in Nortmoor (Kat.Nr. 17-1; 627-2; 637-6). Sie datieren in der Siedlung Gilde in das 2. Jahrhundert n. Chr. (mündl. Mitteilung Mathes).

Basal verdickte Ränder werden als typologisch alt vorgestellt. Darüber hinaus zieht FöRST (1991, 9091, Taf. 426) ein Vergleichstück aus Nortmoor heran, welches bereits SCHMID (1965b, Taf. IX, 9-11; XXV, 9) bearbeitete.

Während Trichterschalen als Leitform der nordseeküstennahen Gruppen anzusehen sind, finden sich vergleichbare Gefäße auch in der niederländischen Marschenregion. So liegen Trichterschalen aus Wijster als Typ W I A (2. Jh. n. Chr.) und W I B1-2 (Mitte 2. bis Mitte 3. Jahrhundert n. Chr.), in Padepool als PP IB (VAN Es 1965, 183-185, 290-291; 1968, 248, 262-264), sowie in LeeuwardenOldehove als Typ Id (VAN Es /MIEDEMA 1970/71, 98-99) und aus Rijswijk als I E vor (BLOEMERS 1978, 348, 384). 
Im rhein-wesergermanischen Gebiet ist eine analoge Entwicklung bei weitmündigen Schalen für das 1. Jahrhundert n. Chr. festzustellen, die in die Form der Trichterschalen einmündet. Daher nutzte USLAR (1938) die Formen Uslar I und II zur Datierung der Küstenkeramik. Durch die grundsätzliche Verschiedenheit bestimmter Formelemente und Verzierungen bei Trichterschalen in beiden Kulturkreisen kann dies nur unter Vorbehalt erfolgen (WALLER 1957, 162). Zwar ähneln sich in der frühen Kaiserzeit die Gefäßformen, führen aber spätestens ab dem 2. Jahrhundert zu einer eigenen formalen Gestaltung. Bei chaukischer Keramik westlich der Weser ist ein stärkerer Formeneinfluss aus rhein-wesergermanischen Regionen zu beobachten. Auch Gefäße mit scharfem Schulterknick und s-förmigen Randverlauf aus dem Elbe-Weser-Gebiet sind eine Adaption auf niederrheinischwestfälischer Stilelemente. SCHMID (SCHMID 1965b, 24) datiert diese Fundgruppe in das Ende des 2. Jahrhunderts n. Chr.. Aus der Wesermarsch liegen mit dem Typ HW 11 b kurze unverdickte Trichterschalenränder der Form Uslar I und I/II vor, für die eine Datierung um $200 \mathrm{n}$. Chr. wahrscheinlich gemacht wird (FÖRST 1991, 87).

Unter dem Nortmoorer Material können Trichterschalen mit abgesetztem Hals identifiziert werden, die ihre Hauptverbreitung im westfälischen und niederrheinischen Gebiet haben. Von verschiedenen Fundorten im nordwestdeutschen Küstengebiet liegen Trichterschalen mit kantigem Bauchumbruch und dreieckigem kurzen Rand vor, die in das 2. Jahrhundert n. Chr. datiert werden, während Trichterschalen mit konischem Unterteil und stark einziehender Schulter entsprechend ihres Fundhorizontes 6 in der Feddersen Wierde dem 3. Jahrhundert n. Chr. angehören (SCHMID 1981a, 46). Auf den scharfen Schulterumbruch in der älteren Phase folgen in der Feddersen Wierde Trichterschalen mit einer kurzen schwachen Schulterwölbung (SCHMID 2006, 39), die hier im Unterschied zu dem Nortmoorer Material in ein oft stark konkaves Unterteil einzieht.

\subsection{Trichternäpfe (GF 2)}

Kat.Nr. 3-2; 17-1; 17-2; 499-1; 584-2; 637-4; 755-4

Trichternäpfe zeichnen sich durch einen deutlich kleineren Durchmesser als Trichterschalen aus. Sie sind weniger ausladend und wirken in der Kubatur gedrungener und steilwandiger (LEHMANN 2002, 35). Sind die Schalen bereits an der Schulterzone abgebrochen, behindert dies eine Abgrenzung zu den Trichterschalen. Der Randdurchmesser der kleinen Trichternäpfe liegt zwischen 7,8 und 10,8cm (Tab. 6). Da kein Exemplar vollständig vorliegt, unterbleibt die Angabe des Höhen-Breiten-Index.

Im Unterschied zu Trichterschalen ist die Randausformung weniger vielfältig. Die Trichternäpfe haben zumeist einen kurzen abgerundeten, jedoch in der Grundform dreieckigen Rand (RF 7.1, 7.3) (Kat.Nr. 499-1; 584-2; 637-4). Einige Ränder sind in ihrer Grundform rundlicher und kaum verdickt ausgeprägt (Kat.Nr. 3-2). Auch senkrecht stehende, basal nur leicht verdickte Ränder (RF 7.5) 
kommen vor (Kat.Nr. 17-1; 17-2). Ein Trichternapf ist mit einem gedrungen trapezförmigen Rand versehen (Kat.Nr. 755-4), und entspricht RF 7.6. Eine ähnliche Randgestaltung existiert von einer hölzernen Schale der Feddersen Wierde, die frühkaiserzeitlich datiert wird (HAARNAGEL 1979, Taf. 44.2). Die Nortmoorer Trichternäpfe sind, mit Ausnahme von zwei Gefäßen, unverziert. Da sich die Hauptverzierungszone jedoch unterhalb des Bauchumbruchs befindet und dieser bei den Nortmoorer Randfragmenten nicht immer erhalten ist, ist diese Aussage nicht repräsentativ.

Ein Napf weist unterhalb des Umbruchs mehrere diagonal zum Gefäß laufende Rillen auf (Kat.Nr. 32). Zusätzlich war am Schulterumbruch eine ovale Zierknubbe angebracht. Eine ähnliche Verzierung findet sich an einem Gefäß aus Huntebrück-Wührden (FöRST 1991, 39, Taf. 82, 688). Auch auf dem gerundeten Schulterumbruch eines anderen Trichternapfes befindet sich ein geometrisches Muster (Kat.Nr. 755-4). Von drei umlaufenden Rillen hängen diagonale Rillenbänder herab.

In der Kubatur wirken die Näpfe bauchig, die Durchmesser von Rand- und Bauchumbruch sind oft nahezu gleich. Eine Ausnahme bildet ein profilierter Trichternapf mit einem spitzwinkligem Umbruch, der verdickt und tief ansetzt (Kat.Nr. 637-4). Der maximale Bauchdurchmesser liegt hier mit 12,2cm deutlich über dem Randdurchmesser von $10,8 \mathrm{~cm}$. Die geometrische Verzierung und der kurze Rand weisen in die ältere römische Kaiserzeit. Die Spannbreite des Index Randdurchmesser zu maximalem Bauchumfang reicht bei den Trichternäpfen von 0,80 bis 0,89 .

\begin{tabular}{|c|c|c|c|c|c|}
\hline & Kat.Nr. 3-2 & Kat.Nr. 499-1 & Kat.Nr. 584-2 & Kat.Nr.637-4 & Kat.Nr.755-4 \\
\hline Randdurchmesser/cm & 8,8 & 10 & 7,8 & 10,8 & 8,8 \\
\hline $\begin{array}{c}\text { Umbruchdurchmesser/ } \\
\mathrm{cm}\end{array}$ & 11 & 11,2 & 8,8 & 12,2 & 9,2 \\
\hline
\end{tabular}

Tabelle 6

Randdurchmesser in Bezug zum maximalen Bauchumbruch bei Trichternäpfen

SCHMID $(1965,20-22)$ sieht für das südliche Nordseeküstengebiet Trichternäpfe als typische Vertreter des 3. Jahrhunderts $\mathrm{n}$. Chr. an, die eine Übergangsform zu den Trichterpokalen darstellen. In Boomburg-Hatzum wird ein verzierter Trichternapf der Variante $7 \mathrm{~b}$ zugeordnet, die dem jüngeren Fundhorizont angehört (LÖBERT 1978, 73, 80, Tafel 41, Nr. 688). Auch aus der Geestsiedlung Brill liegen Vergleichsstücke zu den Nortmoorer Trichternäpfen vor (LEHMANN 2002, 35, Kat.Nr. 9-9, 912, 27-6, 29-2, 364, 1637, 2675-1). Trichternapfförmige Gefäße finden sich zudem unter dem Nenndorfer Material (GROTELÜSCHEN 2000, Abb. 11,7 u. 12, 3). 


\subsection{Trichterpokale (GF 3)}

Kat.Nr. 3-42; 884-12

Trichterpokale sind in Nortmoor nur anhand von Bodenfragmenten nachzuweisen. Randscherben von ausreichender Profillänge liegen nicht vor. Erhalten haben sich zwei Standplatten, die sich durch ihre ausgezogene Standfläche und die steil ansteigende Wandung auszeichnen. Ihr Radius liegt bei $6 \mathrm{~cm}$ und $7,2 \mathrm{~cm}$.

$\mathrm{Zu}$ dem ausgezogenen Standboden Kat.Nr. 3-42 finden sich in Brill gleich zwei Parallelen bei Trichterpokalen (LEHMANN 2002, Taf. 46, 453-1; Taf. 50, 1379-1). Trichterpokale besitzen eine schmale Schulter, die ohne Absatz im Rand mündet. Das Unterteil zieht oft konkav ein bevor es in einer kleinen Standfläche mündet (SCHMID 1965b, 22). In seinem unteren Profilverlauf ähnelt das Nortmoorer Fragment einem Briller Pokalgefäß (LEHMANN 2002, Taf. 46, Nr. 453-1), letzteres findet in der s-förmigen Randgestaltung Übereinstimmungen zu Gefäßen aus Westerwanna, Landkreis Cuxhaven (SCHMID 1981a, 42; 1969, 160, Abb. 1, 4, 5).

Das andere Nortmoorer Bodenfragment ist konkav gewölbt, mit sorgfältig abgestrichenen Außenkanten (Kat.Nr. 884-12). Die Oberfläche ist sehr gut geglättet, der Ton fein gemagert. Auffällig ist eine oberhalb der Bodenplatte, noch bevor die Wandung steil nach oben weiter verläuft, umlaufende Zierleiste.

In Mittel-Groningen finden sich vergleichbare Böden an hohen Standfußschalen vom Typ K7, die in der Zeit zwischen 250-375 n. Chr. vorkommen (TAAYKe 1996a, 34, 68, Abb. 28). Vergleichbare Keramik, vorzugsweise mit flachem Boden, ist von der Feddersen Wierde belegt und datiert ins 4. Jahrhundert (SCHMID 1981a, Fig. 3,1).

Trichterpokale sind eine Erscheinung der späten Kaiserzeit und können bis in das 5. Jahrhundert n. Chr. vorkommen, wobei der spätere Datierungsansatz sich auf „sächsische“ Verzierungsmuster stützt. Aus dem Landkreis Leer liegt aus Holtgaste ein Trichterpokal mit verziertem Fuß vor (STILKE 1995, 210, Abb. 5 u. 9). In Wijster sind trichterpokalähnliche Gefäße dem Typ W I D zugeordnet. Sie stehen der o.g. Gefäßform nahe, zeichnen sich jedoch durch einen runden Bauchumbruch aus und datieren in das 4. bis beginnende 5. Jahrhundert (VAN Es, 1967, 206, 324). Die Nortmoorer Fragmente sind daher vermutlich spätkaiserzeitlich.

\subsection{Weitmündige Töpfe (GF 7)}

Die weitmündigen Töpfe zeichnen sich durch eine hohe, geschlossene Form aus und sind in der Regel höher als breit (GROTELÜSCHEN 2000, 25). Dieser Gefäßtyp ist mit zahlreichen Exemplaren im 
Fundgut vertreten und stellt die am häufigsten vorkommende Gefäßform dar.

Im Unterschied zu Terrinen ist die Gefäßhöhe weitmündiger Töpfe sehr viel größer als ihre Breite (vgl. GEBERS 1977, 10). Da sich bei dem stark zerscherbten Material in Nortmoor jedoch nur selten Gefäßhöhen ermitteln lassen, ist eine eindeutige Ansprache als Terrine oder Topf in vielen Fällen nicht mehr möglich. Ähnlich ist die Situation bei fragmentierten Randstücken in Bezug auf ihre Engoder Weitmündigkeit. Generell erfolgt die Abgrenzung zu engmündigen Töpfen über ihre geschlossene Form, den bei ihnen im Verhältnis zum maximalen Durchmesser kleineren Rand- und folglich größeren Bauchdurchmesser. LEHMANN $(2002,39)$ gibt hierfür einen Indexwert von 1:0,75 an. Oft wird eine Differenzierung in eng- bzw. weitmündige Töpfe erschwert, wenn das Gefäßprofil nicht mehr bis zum maximalen Gefäßdurchmesser erhalten ist.

Ein wichtiges Unterscheidungskriterium innerhalb der weitmündigen Töpfe ist neben der Randgestaltung ihre Gefäßkubatur, insbesondere die Schulterneigung und Höhe des Umbruchs. Zumeist liegt der Umbruch im oberen Gefäßdrittel und wird in einigen Fällen mit einem Wandungsknick betont. Die Kubatur kann s-förmig, kugelig oder länglich-gestreckt sein. Oft ist die Kontur fließend ausgebildet, selten stark profiliert bis kantig. Die Gefäßform kann gebaucht bis stark gebaucht sein. Zylindrische Formen fehlen weitgehend. In der Ausbildung der Schulterform sind zwei Extrema zu beobachten. Eine Reihe von Töpfen weist eine ausgeprägt flache Schulter auf. Es existieren daneben jedoch auch extrem steilwandige Töpfe, wobei sich die meisten Töpfe durch eine mäßig gewölbte Schulter auszeichnen.

Bei weitmündigen Töpfen überwiegen kurze, nach außen geneigte Ränder, die zum Großteil verdickt sind. Die Randlippe kann rundlich, spitz zulaufend oder gerade abgestrichen sein. In ihrer Grundform dominieren dreieckig oder viereckig verdickte Ränder. Gelegentlich kommen lange basal oder mittig verdickte Ränder vor. Kolbenförmige Ränder sind nur bei wenigen Exemplaren vertreten. $\mathrm{Zu}$ beobachten ist, dass die Randgestaltung nicht an eine bestimmte Topfform gebunden ist. Der Randdurchmesser liegt zwischen 20 und 40cm. Die überwiegende Anzahl von Flachböden hat einen Durchmesser zwischen 10 und $15 \mathrm{~cm}$. Verzierungen sind kaum belegt und beschränken sich auf den unteren Gefäßteil, meist ab der Umbruchzone abwärts. Vereinzelt findet sich eine WellenrandVerzierung auf der Randlippe.

Weitmündige Töpfe mit geringem Randdurchmesser $(15-22 \mathrm{~cm})$ und einem Bauchdurchmesser unter $25 \mathrm{~cm}$ grenzen sich von den übrigen weitmündigen Töpfen durch ihre sorgfältige Oberflächengestaltung und größerer Verzierungsfreude ab. Zur besseren Vergleichbarkeit mit den „normalen“, d.h. standardgroßen Töpfen erfolgt keine gesonderte Bearbeitung, sondern die kleinen Topfformen werden entsprechend ihrer Zugehörigkeit behandelt und mit dem Synonym :k kenntlich gemacht. 
In Anlehnung an der von LEHMANN 2002 gewählten Ansprache kaiserzeitlicher Gefäßformen werden die weitmündigen Töpfe aus Nortmoor vorgelegt. Es finden sich zahlreiche Übereinstimmungen die eine Anbindung an das bestehende Typenschema ermöglichen. Darüber hinaus bestehen formenkundlich zu der von Nortmoor aus wenige Kilometer entfernten Siedlung Hatzum-Boomborg enge Anknüpfpunkte, auch wenn eine Übereinstimmung nicht in allen Fällen gegeben ist.

Bei Töpfen sind folgende Gefäßformen zu unterschieden, die sich durch eine variantenreiche Randgestaltung ausweisen:

GF 7.1: weitmündige Töpfe mit gerade ausgestelltem Rand

GF 7.2: weitmündige Töpfe mit verdicktem Rand

GF 7.3: weitmündige Töpfe mit kurz ausgebogenem Rand

GF 7.4: weitmündige Töpfe mit nicht abgesetztem Rand und s-förmigem Oberteil

GF 7.5: weitmündige Töpfe mit senkrechtem Rand und steiler Schulter

GF 7.6: weitmündige Töpfe mit senkrechtem Rand und flacher Schulter

\subsection{1 Töpfe mit gerade ausgestelltem Rand (GF 7.1)}

Kat.Nr. 3-49; 91-2; 140-3-; 178-1; 195-7; 195-16; 195-17; 265-5; 278-4; 376-1; 394-3; 403-2; 403-3; 432-1; 463-6; 468-3; 516-2; 516-4; 627-7; 627-8; 627-11; 637-2 :k; 637-8; 702-3; 745-4; 745-5; 757$10 ; 859-1 ; 943-1: 1082-2 ; 1120-2 ; 1164-1$

Über die Grundform der zugehörigen Töpfe der GF 7.1 ist aufgrund des zerscherbten Zustandes der Gefäßfragmente, die nur selten bis über den maximalen Gefäßumbruch hinaus erhalten sind, wenig bekannt. Es handelt sich um schlicht gegliederte Töpfe mit relativ hoch ansetzendem Umbruch im oberen Gefäßdrittel. Die einfachen geraden Ränder können von der Gefäßschulter durch einen leichten Profilknick, einer weichen Biegung oder gelegentlich auch mit einem schwachen Schulteransatz abgesetzt sein (LEHMANN 2002, 39-40).

Der Randdurchmesser liegt zwischen 14 und $40 \mathrm{~cm}$, bei einem Mittelwert von $26 \mathrm{~cm}$. Eine Angabe des Höhen-Breiten-Index erübrigt sich, da kein Topf komplett vorliegt.

Charakteristisch ist der gerade ausgestellte Rand, wobei die Randlippe gerade oder nach innen abgestrichen sein kann, jedoch selten gerundet ist. Die Randform umfasst länglich-schmale und kurzgedrungene Ränder, die entweder gerundet oder abgestrichen sind. Die Ränder sind senkrecht stehend (RF 2.1) oder leicht ausbiegend überliefert (RF 1.1). Es überwiegen kurze Ränder. Differenziert werden können verschiedene Randformen, die sich aus Rändern mit innen abgestrichener (RF 2.5) oder senkrecht zum Rand abgestrichener Randlippe (RF 2.1) bilden. Einige Ränder besitzen eine nach außen abgeschrägte Randlippe (Kat. 3-2; 91,4; 140-3; 178-1). Manchmal verjüngt sich der Rand zum 
Hals hin und weist am Übergang zur Schulter eine kleine Halskehle auf (Kat.Nr. 627-7; 627-8). Diese Besonderheit findet sich auch an einem anderen Randfragment, welches an der Randaußenseite mit einer inneren Randkehle und einer basalen Verdickung versehen ist (Kat.Nr. 627-11). Ein ähnliches Stück liegt aus der Siedlung Huntebrück-Wührden vor (vgl. FöRST 1994, Taf. 32, 207).

Die Gestaltung der Schulterpartie ist variabel. Sie kann steil abfallend (Kat.Nr. 278-10), stark gewölbt (Kat.Nr. 195-6) oder flach ausgebildet sein (Kat.Nr. 394-2). Vereinzelt treten Henkel in Form unterrandständiger Bandhenkel auf (Kat.Nr. 3-49). Im Unterschied zu Brill werden in der vorliegenden Studie langausgestellte Ränder mit deutlichen Merkmals-Übereinstimmungen zu Töpfen vom Typ Eddelaker (vgl. SCHMID 1965b, 27-28, Taf. XVII, Nr. 1-9) nicht als GF 7.1, sondern eigenständig in der Rubrik engmündige Gefäße abgehandelt.

Während in Brill weitmündige Töpfe mit gerade ausgestelltem Rand eine recht große Gruppe bilden (LEHMANN 2002, 39-40), gehören im Nortmoorer Keramikmaterial relativ wenige Scherben diesem Typ an. Auch sind hier die Ränder der GF 7.1 meist weniger stark abgesetzt. Bei Töpfen mit ausgestelltem Rand sind zwei Gefäßgrundformen vorzufinden. Töpfe mit kugeliger Gestalt weisen Ähnlichkeiten mit Wijster II C auf und datieren in das 2. Jahrhundert n. Chr. (VAN Es 1967, 222). In diese Zeit gehören auch die schlank-länglichen Ränder weitmündiger Töpfe, wie vergleichbare Gefäßränder aus Hodorf aufzeigen (vgl. SCHMID 1965b, 28, Nr. 11 u. 15). Weitmündige Töpfe mit geradem Rand sind in Wijster auch noch in der ersten Hälfte des 3. Jahrhunderts als Typ W II B vertreten (VAN Es 1967, 220-221).

\subsection{2 Töpfe mit verdicktem Rand (GF 7.2)}

Kat.Nr. 3-11; 3-13; 3-10; 3-15; 3-18; 66-1; 91-3; 91-4; 121-1; 195-18; 183-8; 178-1; 216-1 :k ; 216-3 :k; 216-4; 216-5 :k; 216-9; 235b-1; 278-5; 278-6; 278-7; 278-8; 369-3; 383-2; 394-4; 403-5; 403-6; 432-2; 432-5; 432-11; 434-1; 434-2; 455-3; 463-7; 463-9; 463-10; 468-1; 500a-1; 500a-2; 513-1; 515a-2; 515a-3; 515a-4; 516-5; 517-1; 517-4; 517-5; 635-1; 637-7; 637-9; 551-6; 551-7; 551-10; 5841; 635-1; 635-2; 653-3; 681-1 :k; 702-1; 702-2; 702-5; 721-1; 744-2 :k; 745-2; 745-6 ; 755-2; 755-3; 755-4 :k; 756-2 :k; 756-3; 756-4; 756-5; 756-7; 757-1; 757-4; 757-5; 757-6; 757-4; 757-7; 757-8; 7579; 757-10; 670-2; 681-1 :k (verz.); 757-1; 836-2; 836-3; 859-5; 859-5; 859-6; 884-2; 884-3; 884-4; 884-8; 884-9; 859-7; 884-6; 928-1; 928-2; 939-2; 943-2; 943-3; 1018-2; 1018-4; 1082-3; 1082-4; $1082-5 ; 1113-2 ; 1113-3 ; 1113-4 ; 1113-5 ; 1221-1$

Weitmündige Töpfe mit verdicktem Rand stellen die größte Gruppe innerhalb der Gefäßform 7 dar. Ihre Ränder weisen ein großes Formenspektrum auf und sind sehr variantenreich. Ähnlich variabel sind sie in ihrer Profilführung. Aufgrund des zerscherbten Charakters dieser Gefäßform im Fundmaterial kann lediglich pauschal etwas zur Grundform ausgesagt werden. Es existieren eher 
gedrungene Gefäße mit gewölbtem Unterteil. Bei einigen weitmündigen Töpfen findet sich eine $60^{\circ}$ steile Schulterpartie. Der maximale Bauchdurchmesser ist etwa 15\% größer als der Randdurchmesser. Daneben sind länglich gestreckte Gefäße mit konischem Unterteil vertreten. Über die Fußbildung liegen keine Informationen vor, vermutlich wurden Flachböden für diese schlichte Haushaltsware bevorzugt verwendet.

In Nortmoor fehlen komplette Gefäße, so dass lediglich auf den in Brill vorliegenden HöhenBreitenindex dieses Typs von 0,8 verwiesen werden kann (LEHMANN 2002, 40). Der größte Bauchdurchmesser liegt dort bei $28 \mathrm{~cm}$, die maximale Gefäßhöhe bei $29 \mathrm{~cm}$. Dem Autor gelang es für sein Material ein regelhaftes Verhältnis zwischen der Höhe des Gefäßoberteiles, der etwa 1/3 des Randdurchmessers entspricht, festzustellen.

Das Erscheinungsbild dieser Töpfe wird von einfach verdickten Rändern geprägt, die in verschiedener Ausformung vorkommen können. Es dominieren kurze, dreieckig verdickte Ränder, die, sowohl facettiert, als auch stark verschliffen vorkommen können und, der RF 7.1 und 7.3 angehören (Kat.Nr. 3-10; 3-15; 3-18; 66-1; 121-1; 195-18; 216-3 :k; 216-4; 216-5 :k; 216-6 :k; 216-1 :k; 278-6; 394-4; 432-5; 432-11; 455-3; 463-9; 499-1 :k; 513-1; 515a-4; 516-5; 516-6; 517-4; 551-7; 551-10; 681-1 :k; 755-5 :k; 756-2 :k; 756-3; 757-6; 757-7; 757-8; 836-3; 859-5; 884-3; 884-4; 928-1; 943-2). Weitmündige Schalen mit kleinerem Randdurchmesser sind meist verziert. Die verdickten bis spitz ausgezogenen Ränder entsprechen der Gefäßform Gw6a und ist in Nord-Drenthe an weitmündigen Töpfen des 2.-3. Jahrhunderts n. Chr. belegt (TAAYKE 1995, 24-25, Abb. 13). Daneben kommen an weitmündigen Töpfen eher lange, basal verdickte Ränder vor, deren Randlippe abgestrichen sein kann (RF 7.4). In diese Rubrik wurden Ränder mit Längen von 1,8-4cm aufgenommen (Kat.Nr. 235b-1 278-5; 383-2; 403-6; 463-7; 516-5; 517-3; 517-5; 551-6; 702-5; 745-2; 757-5; 757-6; 836-3). Auch die verwandte, mittig verdickte Variante (RF 7.5) findet sich in einigen Exemplaren (Kat.Nr. 91-3). Dieser Randtyp kommt am Gefäßtyp Gw6b im 2.-3. Jahrhundert n. Chr. vor (TAAYKE 1995, 24-26, Abb. 14). In Hatzum-Boomborg sind es Töpfe vom Typ HB 10, die den RF 7.4 und 7.5 angehören und dort in dem jüngeren Fundhorizont zu finden sind (LÖBERT 1982, 55-56, 80). Einfache kurze verdickte Ränder finden sich in Paddepoel als Gefäßtyp IV C (VAN Es 1968, 250, Fig. 43, 164). Dort überwiegen dreieckige Profile, deren Randoberfläche einfallend abgestrichen ist und die in die ältere Kaiserzeit datiert werden.

Ein Topf der RF 7.6 weist eine Rillenverzierung unterhalb des Umbruchs auf (Kat.Nr. 755-4), ein anderer einen unterrandständigen Henkelansatz (Kat.Nr. 394-4).

Viereckig-verdickte Randformen (RF 8.1), die basal verdickt, meist kaum ausgewendet sind gehören zum Repertoire bei weitmündigen Töpfen (Kat.Nr. 178-1; 216-1 :k (verz.); 278-8; 369-3 ?; 403-5; 468-1 ?; 515a-2; 584-1; 635-1; 653-3; 681-1 :k; 702-1; 721-1; 744-2 :k (verz.); 745-6 ; 755-3; 7567;756-7; 757-1; 884-6; 928-2; 939-2; 943-3; 1082-5; 1113-2; 1113-3; 1113-4). Facettiert-verdickte Ränder (RF 8.2) sind eher selten anzutreffen (Kat.Nr. 836-2; 1113-5). Aus Mittel-Groningen stammen 
Töpfe mit kurzen viereckig verdickten Rändern. Diese gehören dem Typ Gw5a an, der in das 1 . Jahrhundert n. Chr. datiert wird (TAAYKE 1996a, 22, 50, Abb. 11, 1-3).

In Brill gibt es auch „gestreckte“ Formen von facettiert-verdickten Rändern (LEHMANN 2002, 41, 2510-2). Diese sind vergleichbar mit einer Randform aus Nenndorf (GROTELÜSCHEN 2000, 33, 47, Abb. 13.2) und kommen im 2. bis ins beginnende 3. Jahrhundert vor. Vergleichbare Randformen liegen in der Wesermarsch als HW 8c vor und datieren ebenfalls in das 2./3. Jh. n. Chr. (FörST 1991, $81)$.

Unter dem Fundmaterial recht häufig sind die Vertreter der RF 8.3, die einen trapezförmig verdickten und abgestrichenen Rand haben (Kat.Nr. 183-8; 278-10; 515a-3; 517-1; 517-2; 702-2; 755-2; 756-5; 757-10; 836-1; 859-7; 884-8; 884-9; 939-2; 1082-4.). In Paddepoel finden sich Parallelen an kugeligen Gefäßen der Form PP IVD, die im 1./2. Jahrhundert vorkommen (VAN Es 1967, 210). Für MittelGroningen liegen Vergleichsstücke vom Typ Gw5c vor, die in das 1. Jahrhundert n. Chr. datiert werden (TAAYKE 1996a, 23, 50, Abb. 12,2), während sie in Nord-Drenthe fehlen.

Auch kugelig verdickte Ränder, innen meist ohne Absatz, gerundet sind im Fundmaterial vertreten (RF 8.6). Zum Teil ist die Randlippe stark ausbiegend (Kat.Nr. 3-11) oder hammerförmig (Kat.Nr. 432-2; 500a-1; 500a-2). Aus der Wesermarsch liegen mit dem Typ HW 6b basal verdickte Ränder, ähnlich RF 8.6, vor, die in das 1./2. Jahrhundert n. Chr. zu datieren sind (FörST 1991, 81, Taf. 40, 296), während die gekehlte Variante HW 6a frühkaiserzeitlich auftritt (FÖRST 1991, 81, Taf. 40, 287). Kugelig-verdickte Ränder in Mahlstedt vorwiegend ins 1. Jahrhundert n. Chr. datiert werden,kommen aber auch noch im 2. Jahrhundert vor (FAENSEN 1993, 40-42, Taf. 31.3). Auch in Ermelo gehören diese Ränder der älteren römischen Kaiserzeit an (MiEdEMA 1974, 31, Taf. 40, 292). Zu ihnen gehören Ränder ,mit einem stumpfwinkligen Übergang auf der Randinnenseite zur hoch liegenden Schulter hin“ (LEHMANN 2002, Taf. 29, 11,6).

Wenige Töpfe haben einen senkrecht stehenden Rand, der mittig verdickt ist (RF 10), wobei die Form außen betont kugelig gestaltet ist (Kat.Nr. 463-10; 757-1; 757-4; 884-2; 943-3; 1018-2; 1018-3; 10184; 1082-3; 1113-5). In wenigen Exemplaren liegen verdickte Ränder der RF 2.3 (Kat.Nr. 434-1; 4342), RF 2.4 (Kat.Nr. 745-3; 757-9) und RF 7.7 (Kat.Nr. 432-6) vor.

\subsection{3 Töpfe mit kurz ausbiegendem Rand (GF 7.3)}

Kat.Nr. 183-1; 183-4; 183-6; 183-9; 195-15; 216-7; 278-12; 369-6; 381-1; 410-3; 434-3; 463-6; 517-1; 517-2; 551-11; 551-12; 551-13; 637-5; 653-3; 702-1; 721-1; 745-6; 756-5; 757-3; 836-1; 884-6; 8848; 884-9; 884-10; 1018-1; 1082-4; 1082-5; 1113-6

Weitmündige Töpfe mit kurzem Rand weisen eine schwach gewölbte Schulter und einen meist hohen Umbruch auf. Es überwiegen hier sehr kurze Ränder, die selten Längen von $1 \mathrm{~cm}$ überschreiten. Meist 
ist der Rand gering gerundet oder abgestrichen, die Randlippe kann nach außen leicht ausgestrichen sein. Dieser Nortmoorer Gefäßtyp wirkt durch sein bauchiges Gefäßunterteil und die schwach ausziehende kurze Randlippe insgesamt gedrungen.

Ein weitmündiger Topf mit kurzem Rand, in der Art eines friesischen Henkeltopfes, ist nahezu komplett erhalten. Er besitzt einen schwach gewölbten Gefäßkörper mit hohem Umbruch, zwei gegenständige Bandhenkel und einen sehr kurzen Rand mit einer nahezu senkrecht stehenden, wenig ausbiegenden Randlippe (Kat.Nr. 183-9). Der Höhen-Breitenindex liegt bei 0,83 (Höhe 20cm, max. Breite $24 \mathrm{~cm}, \mathrm{RDm} 22,4 \mathrm{~cm}$ ). Eine Indexberechung ist für die übrigen stark fragmentiert vorliegenden Gefäßreste nicht mehr möglich.

Weitmündige Töpfe dieses Typs zeichnen sich durch eine gedrungene Form und einen kurzen Rand mit schwach ausgeprägter Randlippe aus, die gerundet, waagerecht abgestrichen oder flach gewölbt sein kann. Die Gefäße besitzen meist keinen Hals und ihr Bauchumbruch setzt oft hoch an. Einige Exemplare weisen eine gleichmäßig gewölbte Kubatur auf. Der Randdurchmesser liegt bei $22-28 \mathrm{~cm}$.

Es überwiegen kurze Randformen mit kaum ausbiegender Randlippe (Kat.Nr. 183-9; 195-15; 517-1; 517-2; 551-11; 551-12; 551-13; 637-5; 702-1; 836-1; 1018-1; 1113-6). Dabei kann die Randlippe in einem engen (RF 3.1) oder weiten Radius (RF 3.2) ausgezogen sein. Die Lippe ist entweder gerundet (RF 3.2), spitz ausgezogen (RF 3.3) oder abgeflacht (RF 2.3). Letztere kann viereckig ausgestaltet sein (Kat.Nr. 653-3; 721-1; 745-6; 884-6). Vereinzelt kommt es zu Überschneidungen mit weitmündigen Topfformen mit kurzem Rand (vgl. LeHMAnN 2002, 49-50, Taf. 45, 370-1; Taf. 43, 297-1). Der Variante RF 3.2 gehören darüber hinaus kurze, rund-verdickte Ränder an (Kat.Nr. 183-4; 183-5; 183 6; 410-3; 1018-1). Eher trapezförmig-verdickt sind Ränder von der RF 8.3 (Kat.Nr. 756-5; 884-8; 8849). Zum Teil ist die Rand- und Halspartie basal stärker eingezogen, zum Teil auch betont rund verdickt.

Weitmündige Töpfe mit kurzem, ausbiegenden Rand haben selten einen tief einsetzenden Bauchumbruch, der zudem einen markanten Knick aufweisen kann (Kat.Nr. 216-7; 278-12; 381-1). Sein Gefäßoberteil ist insgesamt stärker eingezogen und grenzt sich somit gut von den Schalenform ab (vgl. Kap. Schalen). In Brill finden sich Randscherben, die der RF 2.3 nahe kommen (LEHMANN 2002, 49-50, Taf. 43, 297-1; Taf. 45, 370-1). Handhaben sind an einigen Stücken überliefert. Dabei handelt es sich regelhaft um knapp unterrandständige Bandhenkel (Kat.Nr. 183-9; 517-2; 836-1). Diese können rechtwinklig oder gerundet oberhalb des Schulterumbruches angebracht sein. Gehenkelte Gefäße vergleichbarer Form finden sich in Hohegaste (STILKE 1995, 211, Abb. 6.16).

Ähnlich wie in Brill dominieren bei der GF 7.3 spitz ausgezogene Randformen (RF 3.3, RF 3.5), wobei in Nortmoorer auch verdickt viereckige Ränder vorkommen. Für die kurz ausgezogenen und oben abgestrichenen Ränder bei weitmündigen Töpfen finden sich zahlreiche Vergleichstücke aus 
Brill und Huntebrück-Wührden (LEHMANN 2002, Taf. 66, 2612-4; FÖRST 1991, Taf. 59-453), werden jedoch typo-chronologisch nicht näher definiert, als dass sie in die römische Kaiserzeit datieren. Aus Nenndorf B liegen keine Vergleichsexemplare für GF 7.3 vor. Am nächsten kommt ein weitmündiger Topf, der in der Rubrik unverdickte Ränder bei weitmündigen Töpfen zu finden ist (KREIBIG 2006, 77, Taf. 1, 9.6).

Verdickt facettierte Ränder wie RF 8.1 sind kennzeichnend für frühkaiserzeitliche Keramik. In Huntebrück-Wührden gehören die Ränder bauchiger Töpfe der Gruppe HW 5a/b an (FÖRST 1991, 79). Vergleichbare Randformen existieren auch in Nortmoor. Zwar fehlen dort die ansonsten typischen Winkelbandverzierungen, diese sind jedoch westlich der Weser kaum noch vertreten, während sie auf der Feddersen Wierde vorkommen (SCHMID 1958, 67-69).

In den Niederlanden sind es Töpfe des Typs Gw3 und Gw4 (TAAYKe 1995, 21-22, Abb. 8-1 u. 9-5), die in Kubatur und Randgestaltung dem Nortmoorer Gefäßen nahe kommen. TAAYKE (1995, 54-55) nimmt für die aus Nord-Drenthe stammenden Töpfe eine Erstdatierung ab 350 v. Chr. an, verweist jedoch auf eine recht lange Laufzeit bis Christi Geburt oder bis in die frühe Kaiserzeit. Einen Datierungsansatz für weitmündige Töpfe mit schwach s-förmigem Profil, langer gerader Schulter und schwach ausgeprägter Bauchwölbung geben die Vorformen friesischer Henkel, die in die frühe Kaiserzeit weisen. Ein rechtwinklig umgebogener Rand (Kat.Nr. 551-11) zeigt Parallelen zu einer Handhabe aus Brill, die durch Vergesellschaftung mit einer Armbrustfibel in das ausgehende 2. und 3. Jahrhundert datiert wird (LEHMANN 2002, 57, Taf. 62, 2137-21). Meist werden derartige Henkel allgemein in die Kaiserzeit datiert (SCHWARZ 1990, 264).

Töpfe mit kurz-verdicktem Rand und senkrecht abgestrichener Randlippe finden sich auch in HatzumBoomborg, der hier als Typ 4 sowohl einziehende Töpfe wie auch fast schalenartige Gefäße umfasst (LÖBERT 1982, 52-53; Taf. 31). Ähnlich wie in Nortmoor ist das Gefäßoberteil schwach s-förmig ausgebildet, meist von mittlerer Größe und mit einem nicht abgesetzten Rand. Dieser Typ entstammt ebenso wie HB Typ 3b und 3c dem Siedlungshorizont 6/7, der dem jüngeren Fundhorizont in HatzumBoomborg entspricht.

Auch in Nenndorf A, einer Siedlung am ostfriesischen Geestrand, treten ähnliche Gefäße wie die Nortmoorer GF 7.3 auf, werden jedoch in der Gruppe der weitmündigen Töpfe mit kurzem verdicktem Rand vorgestellt und in das 1. bis 2. Jahrhundert $n$. Chr. datieren (GROTELÜSCHEN 2000, 25-26, 30-32, vgl. Abb. 5.5; 9.1, 9.3, 10.3, 18.6). In Huntebrück-Wührden sind vergleichbare Gefäße unter HW 8c zu finden, die typologisch jünger sind als die Vorgängervarianten und werden, da sie in der oberen Fundschicht des Fb. 1 auftreten, in das 2./3. Jahrhundert n. Chr. datiert (FöRST 1994, 82, Taf. 46). In Nord-Drenthe scheint die o.g. Ausprägung dieser Gefäßform zu fehlen. TAAYKE (1995, 33-34, Abb. 21) führt zwar Keramik mit kurzem Rand an, der jedoch stärker ausgewendet ist und zudem meistens 
seitliche Verzierungen aufweist. Der dort erwähnte stark gebauchte Typ V4 wird datiert in das 1. Jahrhundert n. Chr. und tritt meistens vergesellschaftet mit den Gefäßtypen G6 und K3ab auf (TAAYKE 1995, 72, 77).

\subsection{4 Töpfe mit s-förmigem Profil (GF 7.4)}

Kat.Nr. 183-5; 183-7; 195-16; 394-2; 369-6; 409-1; 463-2; 463-10; 468-3; 551-8; 551-9; 1082-4

Weitmündige Töpfe mit s-förmigem Oberteil bilden eine eigene Gruppe, zeichnen sie sich doch durch eine ungegliederte Kubatur und einen nicht abgesetzten unverdickten Rand aus. LEHMANN $(2002,43)$ führt die Vertreter dieser Gruppe als GF 7.4 und gibt für zwei Exemplare einen Index von 0,8 an. In Nortmoor gehören nur wenige Ränder zu diesem Typ, da die meisten Ränder entweder abgesetzt und / oder verdickt sind.

Töpfe dieser Grundform sind im Fundmaterial maximal bis zu ihrem oberen Drittel erhalten. Die Gefäßwandung schwingt mehr (Kat.Nr. 551-8; 551-9; 1082-4) oder weniger s-förmig (Kat.Nr. 195-16; 369-6; 409-1) aus. Die Töpfe weisen einen Randdurchmesser von 11,4-32cm auf.

Verzierungen kommen nicht vor. Da in Nortmoor nur wenige Exemplare vorgefunden worden, sei auf die größere Bandbreite derartiger Töpfe in Brill verwiesen, die von stark geschwungenen mit nahezu gleichem Rand- und Bauchradius, über Töpfe mit steiler Schulter bis hin zu leicht konvexen oder senkrechten Unterteilen reicht.

Der Rand ist wenig oder nicht verdickt. Es überwiegen leicht ausgewendete Ränder, deren Randlippe meist gerundet, in zwei Fällen spitz ausgezogen ist. Wie in Brill finden sich unter dem Nortmoorer Material eine relativ große Spannbreite an Randformen, wenn auch in geringer Anzahl, wobei spitz ausgezogene Randformen (RF 3.3) überwiegen (Kat.Nr. 409-1; 551-8; 1082-4). Deutliche Übereinstimmungen existieren zwischen Kat.Nr. 551-8 und einem Rand aus Brill (vgl. LEHMANN 2002, Taf. 46, 455-2). Nur wenige Exemplare verfügen über einen ausgebogenen Rand (RF 3.1), vgl. Kat.Nr. 1082-4, oder einen senkrecht abgestrichenen Rand (RF 3.5), vgl. Kat.Nr. 551-9.

Die beiden Ränder Kat.Nr. 195-16 und 369-6 erinnern an eine Randform mit waagerecht abgestrichener Randlippe (RF 5.4), jedoch fehlt das bei LEHMANN $(2002$, 43) erwähnte zusätzliche Merkmal der „außen verkröpften Ränder“. Keulenförmig verdickte Ränder (RF 8.5) sind bei der GF 7.4 bereits in Brill selten und fehlen in Nortmoor völlig.

Vergleichbare Töpfe mit weichem s-förmigen Profil und gering ausgezogener Randlippe liegen aus Mahlstedt vor (FAENSEN 1993, 43), die dort in die späte Kaiserzeit bis beginnende Völkerwanderungszeit datieren. In Wijster sind schwach ausbiegende Ränder des Typs IV F im 3./4 Jahrhundert anzutreffen (VAN Es 1967, 251; 324). Nicht vor dem 3. Jahrhundert datiert ein Topf der Form IID in Wijster (VAN Es 1967, 225, Abb. 120, 413), der Kat.Nr. 463-2 ähnelt. In Hatzum- 
Boomborg gehört die Form zum Typ HB 5a (LÖBERT 1982, 103, Taf. 34, 565).

Eher bauchige Töpfe finden sich in der Feddersen Wierde in jüngeren Schichten, die in die 2. Hälfte des 4. Jahrhunderts bis in die erste Hälfte des 5. Jahrhunderts datiert werden (SCHMID 1972b, 32, Abb. 1,11). Weitmündige Gefäße mit der RF 3.2 in Wijster entsprechen Töpfen des Typs W IVB und werden dort in das 1./2. Jahrhundert datiert, können dort aber noch bis ins 5. Jahrhundert vorkommen (VAN Es 1967, 240-244).

\subsection{5 Töpfe mit steiler Schulter und senkrechtem Rand (GF 7.5)}

Kat.Nr. 3-1; 3-46; 3-47; 195-7; 216-1 :k; 216-11; 278-5; 278-10; 432-8; 432-10; 463-5; 463-8; 515a-3; $516-4 ; 551-9 ; 582-3 ; 582-5 ; 582-6 ; 627-1 ; 627-2 ; 637-6 ; 755-3$

Der Typ umfasst Gefäße mit kaum verdicktem, gerade gestellten Rand. Die Schulter ist steil und setzt hoch an. Dieser Gefäßtyp GF 7.5 unterscheidet sich von GF 7.1 durch den senkrechten Rand.

Die Töpfe haben einen meist nur leicht ausgestellten oder senkrechten Rand, dessen Randlippe gerundet (RF 5.1), waagerecht oder innen abgestrichen (RF 5.3) sein kann. Der Rand kann basal leicht verdickt oder parallelseitig sein. Der hohe Bauchumbruch ist in einigen Fällen betont gewölbt (Kat.Nr. $3-47 ; 627-2)$.

Die erhaltenen Randscherben sind mittelgrob, anorganisch gemagert und reduzierend gebrannt. Die Außenseite ist einfach geglättet. Die Randhöhe liegt zwischen 2 und $4 \mathrm{~cm}$. Der Randdurchmesser variiert zwischen 14 und $32 \mathrm{~cm}$, wobei der Mittelwert bei $26 \mathrm{~cm}$ liegt. Die Gefäßwandung unterhalb des Randes ist zwischen 0,8 und $1 \mathrm{~cm}$ stark.

Nur wenige Exemplare weisen eine Verzierung auf. Ein weitmündiger Topf ist mit einem dreireihigen umlaufenden Riefendekor verziert (Kat.Nr. 216-1:k). Er gehört aufgrund seines für weitmündige Töpfe geringen Randdurchmessers von $14 \mathrm{~cm}$ zu den Kleingefäßen und weist einen Index (RDm/Bauchumfang) von 0,94 auf. Der Topf ist verhältnismäßig fein gemagert und zeichnet sich durch eine sorgfältige Oberflächenbehandlung aus. Die sehr flache Schulterpartie eines anderen Topfes ist mit umlaufenden Riefen geschmückt (Kat.Nr. 3-47). Zwei Randfragmente verfügen über einen Wellenrand (Kat.Nr. 432-8; 627-1). Senkrechte Ränder (RF 5.1) können von gerade gestellten Rändern, die waagerecht abgestrichen sind (RF 5.3), unterschieden werden. Einige Ränder sind leicht basal verdickt (Kat.Nr. 432-8; 468-1; 627-1) oder trapezförmig (RF 8.4).

Für diese Topfform existieren recht gute Vergleichsfunde aus Brill (vgl. LEHMANN 2002, 43-44, vgl. Taf. 33, 26-3 u. 25-2). Unter den Randformen kommen, wie auch in Nortmoor, trapezförmige (RF 8.4) und waagerecht abgestrichene Ränder (RF 2.2) vor. Die in Wijster als Typ W IV A benannten Gefäße existieren in der gesamten Kaiserzeit (VAN Es 1967, 337-339, Abb. 130-131). 
Eine Entsprechung der oben vorgestellten Gefäßform findet sich in der Keramik der reiderländischen Siedlung Hatzum-Boomborg. Aus dem Siedlungshorizont 6/7 stammen die als HB Typ 6a bekannten Töpfe mit unverdicktem Rand (LÖBERT 1982, Taf. 37, 614, 616-618). Für lange Ränder der GF 7.5, deren Schulter nur schwach gewölbt ist (Kat.Nr. 3-47; 432-8; 627-1), finden sich in Hodorf Vergleichsstücke, die in das 2. Jahrhundert n. Chr. datiert werden (SCHMID 1965b, Taf. XVII, 10.11.15).

Die im Nortmoorer Keramikmaterial sehr seltene Verzierungsform findet sich häufiger in HatzumBoomborg, dort weist sie auf ältere Töpfertraditionen hin, kommt aber auch noch im jüngeren Fundhorizont vor. Hier wird eine Scherbe mit senkrecht stehendem länglich-parallelen Rand der Variante 1c an seiner Randlippe mit Fingertupfen verziert (LÖBERT 1982, 63, Taf. 20, 334). Diese Topfform datiert insgesamt jünger als die Varianten 1a und $1 \mathrm{~b}$.

Töpfe mit abgesetztem Rand und unverdickter Randlippe der Variante HB 1c/d kommen in Jemgumkloster im Siedlungshorizont 3 vor, sind zum Teil zeitgleich mit HB 2c, der hier bis in den Siedlungshorizont 6 auftritt (LÖBERT 1982, 84).

Töpfe mit Wellenrand sind auch im Fundmaterial der Siedlung Huntebrück-Wührden vertreten, wobei der Abstand der Fingertupfen auf der Oberseite der Randlippe deutlich größer ist (FöRST 1994, 35, Taf. 62-471). Das Gefäßfragment gehört dem HW 14b „Töpfe mit s-förmigen Oberteil“ an, den FöRST mit HB 3b parallelisiert (FÖRST 1994, 68) und deren Vertreter in Hatzum-Boomborg häufig mit Fingertupfen verziert sind (LÖBERT 1982, 52; vgl. Taf. 30, 496). Ein anderes Exemplar der Siedlung Huntebrück-Wührden entspricht in seiner Kubatur den Nortmoorer Stücken, wird in der Studie als HW 12b der Gruppe „Schalen mit nach außen gebogenem Rand“ zugeordnet (FöRST 1994, 89, Taf. 56-420). Fingertupfen am Rand und auf der unterrandständigen plastischen Leiste an einer Randscherbe aus Oostergo gehören zum Gefäßtyp V5 (TAAYKE 1996b, 108, Abb. 22,4). Vorratsgefäße mit Wellenrand und einer Gefäßrauung (Schlickbewurf) in der unteren Hälfte sind aus eisenzeitlichen Fundzusammenhängen belegt, kommen jedoch auch noch in der frühen Kaiserzeit in Mittel-Groningen vor (TAAYKE 1996a, 28-30, 52, Abb. 19 u. 20).

\subsection{6 Töpfe mit senkrechtem Rand und flacher Schulter (GF 7.6)}

Kat.Nr. 394-2; evtl. 627-2; 627-6; 859-3

Für die GF 7.6 sind lange Ränder mit kurz-ausgezogener Randlippe charakteristisch, wobei der senkrechte Rand durch einen Absatz betont wird. Die Randlippe ist rundstabartig und gehört der RF 5.2 an. Sie liegen in Nortmoor nur in wenigen Exemplaren vor.

Der Mündungsdurchmesser kann mit 31,2-37,6cm angegeben werden. Es handelt sich um eine sorgfältig geglättete Ware, die mittel bis feinkörnig mit Granitgrus gemagert und reduzierend gebrannt ist. In Nortmoor sind lediglich Randfragmente bis knapp zum Halsansatz erhalten, so dass bei dieser 
GF auf besser erhaltene Gefäße aus Brill verwiesen sei. Dort zeichnen sie sich durch eine flache Schulter in ihrem oberen Bereich aus, die in einen hochliegenden Bauchumbruch übergeht (LEHMANN 2002, 44).

VON USLAR (1938, 63-65, Taf. 5-6) führt vergleichbare Töpfe aus dem Nordseeküstengebiet an. Sie finden sich ebenfalls im Material von Einswarden (SCHMID 1965b, Taf. XXII, 11; Taf. XXV, 10). Auch in Huntebrück-Wührden liegen sie in recht großer Zahl vor (FöRST 1991, 90-91, vgl. Taf. 56, 427), dort datieren sie in das 2./3. Jahrhundert. Zu Vergleichszwecken sei auf Gefäße der Form IIa aus Soest-Ardey verwiesen (HALPAAP 1994, 80-81, Abb. 34, a-d). Derartige Randformen sind für die 2. Hälfte des 2. bis ins 4. Jahrhundert belegt. In der Siedlung Hatzum-Boomborg fehlt dieser Gefäßtyp ebenso wie in Nenndorf.

\subsection{Engmündige Töpfe}

Die Gruppe der engmündigen Töpfe kann in drei Haupttypen untergliedert werden, deren wesentliches Unterscheidungskriterium neben der Gefäßkubatur die unterschiedliche Randgestaltung ist.

GF 7.7 zeichnet sich durch einen sehr kurzen Rand und eine flache bis extrem flache Schulterpartie aus. Meist fehlt ein Gefäßhals, die Randgestaltung ist variantenreich, wobei oft die Randaußenseite senkrecht abgestrichen und die Randinnenseite verdickt ist.

GF 7.8 weist unverdickte senkrechte oder gering nach außen gewendete Ränder auf, deren Randlänge bis zu 2,5cm betragen kann. Die Schulter ist weniger stark abgeflacht. In einigen Fällen sind Henkel belegt.

GF 7.9 kennzeichnen lange Ränder, die oft ausgewendet und/oder basal verdickt sind. Die Randlänge variiert zwischen 2,6-4cm. Es liegen doppelkonische Gefäßprofilierungen vor. Die zum Teil mit plastischen Zierleisten am Halsansatz verzierten Töpfe gehören dem Typ Westerwanna bzw. Eddelaker an.

Bei engmündigen Töpfen fällt generell die unterschiedliche Neigung der Schulterausbildung auf. Zu differenzieren sind extrem flache Schulter-Partien von flach gewölbten. Es überwiegen im Fundmaterial engmündige Töpfe mit kurzen, verdickten Rändern. Diese weisen eine meist flache bis sehr flache Gefäßschulter auf, wobei der Neigungswinkel der Topfschulter je nach Randvariante unterschiedlich ausgeprägt stark sein kann. Bei engmündigen Töpfen mit lang-parallelseitigen Rändern dominieren die verdickten und stärker nach außen gewendeten vor den senkrechtunverdickten. Da die Randscherben nicht immer bis zum Schulterbereich erhalten sind, erfolgt die nachstehende Einteilung unter Vorbehalt.

\subsection{1 Engmündige Töpfe mit ausgewendetem Rand (GF 7.7)}

Kat.Nr. 3-11; 195-10; 235b-2; 369-3; 394-3; 394-4; 410-1; 434-1; 434-2; 468-2; 551a-3; 551-8; 55110; 637-5; 698a-1; 744-1; 745-3; 1082-2, 1082-3; 1113-1; 1120-1 
Bestimmend für die GF 7.7 ist eine flache Schulter, die relativ lang eingewölbt ist. Die Ansprache engmündiger Gefäße erfolgt über ihren Randdurchmesser in Bezug zum maximalen Bauchdurchmesser, so dass sich ein Wert von $<0,84$ ergibt. Hauptmerkmal ist die ausladende Schulterpartie, die in einem sehr flachen Winkel von $30-45^{\circ}$ verläuft.

Die Ränder sind kurz und können eine ausgezogene Randlippe aufweisen. Charakteristisch sind die RF 3.2 und 3.3, sowie RF 2.2 und 2.3. Der meist verdickte Rand ist nach außen gewendet, manchmal senkrecht ausgebildet, dann jedoch basal verdickt. Die Randgestaltung ist variantenreich. Neben rechteckig-verdickten (Kat.Nr. 195-10; 369-3; 113-1) kommen basal-verdickte (Kat.Nr. 410-1; 10823) und dreieckig-verdickte Ränder vor (Kat.Nr. 369-3). Vertreter dieser Randformen wiesen einheitlich eine extrem flache Schulterausbildung auf $\left(30^{\circ}\right)$. Engmündige Töpfe mit kurz-verdicktem Rand, der gerundet, dreieckig oder viereckig sein kann, gehören der eher groben Haushaltsware an. Der Randdurchmesser liegt zwischen 15,2-22cm, wobei Gefäße mit $18 \mathrm{~cm}$ Randdurchmesser überwiegen. Die Oberflächengestaltung ist mäßig sorgfältig, es dominieren Ocker und Brauntöne. Die Magerung besteht aus mittlerem Granitgrus. Verzierungen fehlen.

Etwas weniger ausladende Schulterpartien zeigen die facettierten Ränder dieser Gefäßform (Kat. 235b-2; 434-1; 434-2). Ein mit Handhabe erhaltenes Randfragment zeigt einen kantig abgestrichenen Rand vom Typ RF 7.3. (Kat.Nr. 235b-2). Der Bandhenkel ist unterrandständig angebracht. Engmündige Töpfe mit gleicher Kubatur finden sich als sogenannte „holsteinische Zweihenkeltöpfe“, wie sie als engmündige Töpfe aus der Feddersen Wierde vorliegen (SCHMID 2006, 156, Taf. 56). Die Kat. 434-1 und 434-2 finden Parallelen in der Wesermarsch (FöRST 1991, Taf. 119, 13 u. 14). Die aus Brake stammenden Randfragmente datieren in das 1. Jahrhundert. Um ein Unikat handelt es sich bei dem Randfragment eines eher zierlichen engmündigen Topfes (Kat.Nr. 745-3).

Ungewöhnlich ist an dem dünnwandigen senkrechten Rand mit geradem Abschluss seine nach außen gezogene Randlippe. In Nenndorf gehört ein ähnlicher Rand zu einem engmündigen Henkelgefäß (KreIBIG 2006, 79, Taf. 4, 10.20). Kantige Randgestaltungen bei engmündigen Töpfen liegen auch bei gleichartigen Gefäßen aus Huntebrück-Wührden, Landkreis Wesermarsch vor (FÖRST 1992, vgl. Taf. 88-747; 89-759).

Die sehr kurzen Ränder und die extrem flache Schulter erinnern in ihrer geschlossenen Form an antike Dinos-Gefäße, die zur Vorratshaltung dienten. In Mittel-Groningen findet sich unter dem Typ Gw5a ein ähnliches Gefäß (vgl. TAAYKE 1996a, 22, Abb. 11, 7). Aus dem südostfriesischen Raum finden sich hierzu Vergleichsfunde, die in Hatzum-Boomborg als HB 7b geführt werden und aus dem jüngeren Fundhorizont der Siedlung stammen (LÖBERT 1982, 80, Taf. 37-604, 38-623, 40-680 u. 681). Auch die GF 7.7 mit ihren unverdickten, meist senkrecht abgestrichenen Rändern stellten eine 
typische Randform der römischen Kaiserzeit dar. Hierzu finden sich insbesondere Vergleichfunde aus dem nahen Hatzum-Boomborg (LÖBERT 1982, 80, Taf. 34-551, 37-618, 38-624).

\subsection{2 Engmündige Töpfe mit senkrechtem Rand (GF 7.8)}

Kat.Nr. 3-46; 165-1; 432-1; 468-3; 551-9; 582-7; 637-8; 681-1; 745-4; 745-6; 884-2; 884-3; 884-4; $884-5 ; 943-1 ; 943-2$

Bestimmend für die GF 7.8 sind eine flache Schulter und senkrechte Ränder, die eine gerundete oder abgestrichene Randlippe aufweisen. In Brill wird von einem Bauchdurchmesser von $60 \%$ der Gefäßhöhe ausgegangen (LEHMANN 2002, 46). Eine Zuordnung erfolgt anhand der ausladenden Schulterpartie in Verbindung mit der Randform. Aufgrund des Fragmentierungsgrades der Ränder ist ihre Zugehörigkeit nicht immer zweifelsfrei möglich.

Die Randlänge liegt bei ihnen meist über 2,6cm. Es überwiegt RF 5.1. Der Randdurchmesser liegt zwischen 9,8 und $28 \mathrm{~cm}$. Der Gefäßdurchmesser von $28 \mathrm{~cm}$ erscheint bei einem engmündigen Topf hoch, berücksichtigt man seinen Rand/Umbruchindex von 0,88 kann das Randfragment zu der RF 8.3 gerechnet werden (Kat. Nr. 165-1).

Es existieren lange senkrechte Ränder (Kat.Nr. 582-4), wie auch kurze, senkrecht stehende Ränder (Kat.Nr. 468-3) über einer ausladenden Schulter. Das Randfragment einer kleinen Schale (Kat.Nr. 681-1) zeigt zwar einen kurzen umbiegenden Rand und würde formal nicht in diese Gefäßkategorie gehören. Seine bauchige Gefäßkubatur entspricht aber am ehesten der GF 7.8. Die nur 12,4cm durchmessende Schale ist weit ausladend in ihrer Schulter, oberhalb der sie drei umlaufende Riefen verzieren.

Neben kurzen senkrechten Rändern (Kat. 884-4) kommen in einigen Fällen auch außen senkrechte und innen verdickte Randformen vor (Kat. 884-2; 884-3; 884-4). Im Unterschied zu Brill sind die Ränder jedoch wesentlich kürzer ausgebildet.

Auffällig ist bei Kat.Nr. 165-1 der ungewöhnlich ausgeprägte Bauchknick, der diesen engmündigen Topf deutlich von den anderen Exemplaren unterscheidet (Kat.Nr. 278-10; 515a-3). Ähnliche Töpfe sind in Huntebrück-Wührden bekannt, jedoch in der Schulter weniger ausladend, so dass sie als Trichterschalen eingeordnet wurden (FöRST 1992, vgl. Taf. 49-374).

Die Trapezform der Nortmoorer Ränder ist auch an weitmündigen Töpfen aus der Wesermarsch belegt (FÖRST 1992, vgl. Taf. 91-789), kann jedoch nur ganz allgemein in die Kaiserzeit datiert werden. Der engmündige Topf Kat.Nr. 432-1 wiederum ist vergleichbar mit einem kleinen Topf aus HatzumBoomborg (LÖBERT 1982, Taf.40-651), der der dortigen Variante HB 7a entspricht. Allgemein ähnelt die ausgewendete Form der GF 7.7 dem aus Hatzum bekannten HB 5a und findet sich im dortigen 
jüngere Fundhorizont der Siedlung Hatzum-Boomborg, wodurch sie in die ältere römische Kaiserzeit datiert werden muss (LÖBERT 1982, 80, Taf. 34-551).

Engmündige Töpfe der GF 7.8 mit einer bis zu $40^{\circ}$ flachen Schulterpartie liegen in sieben Exemplaren vor, die zwei verschiedenen Randformen zuzuweisen sind: gerundet (Kat.Nr. 3-11; 698a-1; 744-1; 757-1) oder dreieckig (Kat.Nr. 235b-2; 884-4). Zwei Töpfe sind mit Henkeln in Art der später behandelten Henkelkrüge ausgestattet (vgl. GROTELÜSCHEN 2000, 47). Der Bandhenkelansatz ist bei den erhaltenen Henkeln engmündiger Töpfe unterrandständig (vgl. Kat.Nr. 235b-2, 696a-1).

Der knapp unter der Randlippe angebrachte Henkel bei Kat.Nr. 696a-1 war vermutlich beidseitig angebracht. Damit entspricht der Topf einem sogenannten „holsteinischen Henkeltopf“ und in die frühe Kaiserzeit datiert wird (SCHMID 2006, 52, Taf. 56a-d). Ein wenig tiefer unterhalb des Randes findet sich der Henkel eines anderen engmündigen Topfes (Kat.Nr. 235b-2), der in der älteren Kaiserzeit vorkommt (vgl. ScHMID 2006, 50, Taf. 58a). Winklig gebogene Henkel finden sich in Bentumersiel (BRANDT 1977, Abb. 14, 15-16), Einswarden (SCHMID 1965b, Taf. XXIII, 3-4) und Huntebrück-Wührden (FÖRST 1991, Taf. 67, 511). Länglich dreieckige Ränder mit stark ausbiegendem bis geknickten Rand, die teilweise mit einer plastischen Zierleiste unterhalb des Randes verziert sind und einen randständigen Doppelhenkel aufweisen, liegen auch aus Hatzum-Boomborg vor (LÖBERT 1982, 59-60, Taf. 52, 914-920, Typ 17).

\subsection{3 Engmündige doppelkonische Töpfe (GF 7.9)}

Kat.Nr. 3-7; 3-8; 3-9; 91-1; 91-2; evtl. 195-17; 403-1; 432-3; 463-5; 468-1; 468-5; 499-2; 499-4; 702$3 ; 702-3 ; 884-7 ; 884-10 ; 1070-1$

Engmündige Töpfe der GF 7.9 werden durch ihre doppelkonische Gefäßkontur mit langem Oberteil gekennzeichnet. Auf einer hohen, oft schwach gewölbten Schulterpartie setzt ein meist senkrechter oder leicht ausgewendeter Rand an. Es kommen Randlängen zwischen 2,6-4cm vor.

Die Ränder sind meist parallelseitig, können jedoch auch innen basal leicht verdickt sein. Die Randlippe kann abgerundet, spitz zulaufend oder abgestrichen sein. Teilweise sind die Ränder trichterförmig ausbiegend. Es sind die RF 2.1, 1.1 und 3.3 vertreten. Die verdickten Formen ähneln RF 7.4 und 7.5. Der Randdurchmesser kann mit 12,2-22,2cm angegeben werden. Zumeist ist die Keramik mittelfein mit Granitgrus gemagert und reduzierend gebrannt. Die Oberfläche ist zumeist sorgfältig gestaltet. An einigen Rändern sind entweder plastische Leisten oder Verzierungen in Form von Tupfen an der äußeren Randlippe und am Halsumbruch angebracht (Kat.Nr. 3-7; 3-9) oder auch plastische Leisten (Kat.Nr. 3-8; 403-1). Für die kerbenverzierte Randscherbe Kat.Nr. 3-7 findet sich aus einer kaiserzeitlichen Siedlungsgrube im oldenburgischen Delmenhorst-Blutkamp eine fast identische Entsprechung (ZOLLER 1977, 244, Abb. 3).

Da der Gefäßrand im Nortmoorer Material zumeist unterhalb des Halsansatzes abgebrochen ist, sind 
keine Angaben über das Gefäßunterteil möglich. Die auffällige Häufung der Bruchstelle in diesem Bereich lässt auf eine, durch die dort dünner werdende Wandung charakteristische Schwachstelle schließen. Ein wichtiges Indiz der Typenzuordnung ist die sich am Halsübergang auffällig verdünnende Gefäßwandung bei einigen Randscherben (vgl. Kat.Nr. 468-3). Lediglich ein engmündiger Topf dieser GF ist bis über den Schulterumbruch hinaus erhalten. Kat.Nr. 1070-2 zeichnet sich durch eine gleichbleibende Wandungsstärke und einen ausbiegenden unverdickten Rand aus. Der Umbruch setzt tief an. Das Verhältnis von Rand- zu Bauchdurchmesser kann mit einem Indexwert von 0,57 angegeben werden.

Engmündige Töpfe der GF 7.9 mit langem und teils verziertem Rand-Halsbereich liegen zumeist im Nortmoorer Material derartig fragmentiert vor, dass ihre Gefäßkubatur nur über Vergleichsfunde zu erschließen ist (vgl. SCHMID 2006, Taf. 63 d. u. e). Sie können aufgrund der typische Randform dem Typ Eddelaker zugeordnet werden, wie er in Hatzum-Boomborg vorliegt (vgl. LÖBERT 1982, Taf. 52, 914-920). Die wenigen extrem lang-ausbiegenden Ränder ähneln Töpfen der Einswardener Keramikgruppe 2 (SCHMID 1957, 52, Taf. 5, 3, 8, 10). In Mittel-Groningen datieren Vergleichsstücke in der 2. Hälfte des 3. bis ins 4. Jahrhundert (TAAYKE 1996a, 51, 68) und gehören zum Typ Gw6b (TAAYKE 1996a, 26, Abb. 114,13). Die engmündige Topfform GF 7.9 wurden bereits von PleTTKE als Typ B1 sowie A6 vorgestellt (PLeTtKe 1921, 43, Taf. XXXVIII), und ist unter der Bezeichnung Töpfe vom Eddelaker Typ bekannt (TISCHLER 1954, 46-52; SCHMID 1965b, 24-26, vgl. FÖRST 1991, 92, 97). Sie treten überregional auf, sind jedoch vorwiegend im Küstengebiet der südlichen Nordsee verbreitet.

An fünf Exemplaren konnten plastische Leisten festgestellt werden, die am Übergang zwischen Rand/Schulter angebracht worden sind. Da sieben gleichartige Ränder knapp oberhalb dieser Zone abgebrochen sind, könnte die Stückzahl im Fundgut ursprünglich größer gewesen sind. Mehrere Ränder wurden zusätzlich auf der Leiste mit Tupfen, Einkerbungen oder Eindrücken verziert (Kat.Nr. 3-7, 3-8; 3-9; 403-1; 499-4; 499-2). Ein Randfragment weist umlaufende Tupfenverzierungen an der Randaußenlippe und dem Halsübergang auf (Kat.Nr. 3-9). Ähnlich starke, plastische Leisten sind von sogenannten Leistentöpfen der Feddersen Wierde bekannt (SCHMID 2006, Taf. 63).

Plastische Leisten, wie bei Kat.Nr. 3-8, finden sich an vergleichbaren Töpfen der Feddersen Wierde (SCHMID 2006, Taf. 63 d-e). Auch in Werder-Grüneburg in der Wesermarsch kommen derartige kantige Zierleisten an engmündigen Gefäßen vor (FöRST 1991, Taf. 107, 32). Dieser Rand wird mit vergleichbaren Randprofilen aus dem Siedlungshorizont 7 der Feddersen Wierde parallelisiert (SCHMID 1977, 30) und dementsprechend in das 4. bis 5. Jahrhundert gestellt. Der engmündige Topf mit spitz ausgezogener Leiste am Randabsatz stellt eine Weiterentwicklung von HW 16 dar (FöRST 1991, 97). Der Rand mit plastischer Zierleiste, die mit Eindrücken verziert ist, ähnelt einem Gefäßrand 
aus Huntebrück-Wührden (FÖRST 1991, Taf. 92, 808).

Der Eddelaker Typ tritt im Keramikbestand der Feddersen Wierde relativ häufig mit länger ausgeformtem Rand auf (SCHMID 2006, Taf. 59 d-e). Als engmündige, bauchige Gefäße liegen Eddelaker Töpfe in Soest-Ardey (HALPAAP 1994, Abb. 26, 66) ebenso vor wie in der Wesermarsch (FÖRST 1991, 97, Taf. 107, 32) oder in Schleswig-Holstein (BANTELMANN 1955, Taf. 22, 6.9.11 NP; 1957/58, Abb. 11,5 NP). Als HW 16 datiert FÖRST (1991, 92) jüngere Ränder der engmündigen Topfform in das 2./3. Jahrhundert n. Chr., weil die Gefäße in der dortigen oberen Fundschicht Fb. I vorkommen. Derartige Töpfe sind auch im Reiderland als Typ HB 17 vertreten (LÖBERT 1982, 59-60, Taf. 52, 915-920) wie in Jemgum 2 (HAARNAGEL 1957a, Taf. III, 5). Aus der Geestsiedlung Nenndorf ist ein vergleichbarer engmündiger Topf belegt (KrEIBIG 2006, 79, 263.1), der den Nortmoorer Randformen von Kat.Nr. 463-5 und 582-7 ähnelt. Auch weiter westwärts kommt in den Niederlanden diese Gefäßform vor, dort als Typ W IIIA1 bezeichnet (VAN Es 1965, 229, 303-307).

Die jüngeren Töpfe mit ausgebogenem Rand und Leistenverzierung werden in Wijster in das 3. Jahrhundert gestellt und später von senkrecht stehenden langen Rändern abgelöst (VAN Es 1967, 266230).

Singulär ist das Randfragment eines engmündigen Henkeltopfes (Kat.Nr. 394-1, RD: 7,7cm, starker Schulterknick). Er gleicht einem sogenannten friesischen Henkeltopf und ist so wie dieser mit einem aufwippenden Henkel versehen (vgl. SCHMID 2006, 149, Taf. 56, f). In seiner Gefäßkubatur ist der Nortmoorer Henkeltopf mit einem deutlichen Schulterknick versehen. In Westergo als „friesische Henkeltöpfe“ bezeichnet, kommt diese Topfform auch in Hatzum- Boomburg mit Knopfhenkeln vor (LÖBERT 1982, 94, Taf. 55, 1015 u. 1016). Schmid datieren derartige Töpfe in das 3. Jahrhundert n. Chr. (SCHMID 1965, 25, Taf. 3.4). Einem holsteinischen Henkeltopf ähnelt der verdickt-gerundete und oben abgestriche Rand eines engmündigen Gefäßes (Kat.Nr. 884-7, RDm: 16,4cm). Auffällig ist der fast oberrandständige Henkel, der ungewöhnlich massiv wirkt. Aus demselben Befund stammt ein zweiter Henkeltopf, aber mit unterrandständigem Henkel (Kat.Nr. 884-10, RDm 18cm). Im Unterschied zu den o.g. holsteinischen Töpfen weist das Nortmoorer Exemplar einen ungewöhnlich langen Hals auf und kann mit Kat.Nr. 394-1 verglichen werden.

\subsection{Becherförmige Gefäße (GF 14)}

Kat.Nr. 195-8; 195-9; 223-2; 369-2

Im Fundmaterial findet sich eine Gefäßform, die als Tasse angesprochen werden kann. Es handelt sich um kleine Gefäße mit einem Durchmesser von $6-8 \mathrm{~cm}$. Die engmündigen Gefäße sind um die $10 \mathrm{~cm}$ hoch. Unterhalb des Randes befinden sich ein bis zwei Henkel.

Drei kleine engmündige Gefäße erinnern an becherartige Gefäße (Kat.Nr. 195-8; 195-9; 223-2). In 
einem Fall wird durch die kleine Mündung und den kugeligen Gefäßkörper auch an ein „Krüglein“ zu denken sein Kat.Nr. 369-2). In allen Fällen haben die Gefäße einen senkrecht stehenden Rand und eine kurze Schulterzone, die mehr oder weniger stark gewölbt ist. Der Bandhenkel ist unterrandständig angebracht und zieht sich bis auf den Umbruch hinab. Ein Exemplar weist einen randständigen Henkel auf. Die Handhabe hat eine Breite von maximal 2cm, bei einer Länge von bis zu $3 \mathrm{~cm}$.

In Hatzum-Boomborg weisen die becherförmigen Gefäße jeweils nur einen Henkel auf und verfügen über eine weite Gefäßmündung (LÖBERT 1982, 64, Taf. 49, 874 u. 875). Auch von der Geestsiedlung Nenndorf A sind becherförmige Gefäße bekannt und konnten in sieben Exemplaren nachgewiesen werden (GROTELÜSCHEN 2000, 28; Abb. 6,2).

In Drenthe sind weitere Stücke dieser recht seltenen Gefäßform überliefert. TAAYKE $(1995,35,59$, Abb. 23) ordnet das zweihenklige „Töpfchen“ der Kleinkeramik zu und datiert den Typ K1 in das 1. Jahrhundert n. Chr., während LÖBERT $(1982,79,95)$ derartige becherförmigen Gefäße noch in die vorrömische Zeit stellt.

Im Profilverlauf komplett erhalten ist ein kleines „,becherartiges“ Gefäß. Es ist 6,6cm hoch und besitzt zwei antithetisch angebrachte Ösen. Die $0,4 \mathrm{~cm}$ großen Ösen sind an der Gefäßschulter angebracht (Kat.Nr. 369-2). Während der kleine Flachboden einen Durchmesser von lediglich $3 \mathrm{~cm}$ ausweist, ist der Randdurchmesser doppelt so groß. Die Gefäßhöhe beträgt 6,8cm. Insgesamt macht das Kleingefäß mit dem leicht ausschwingenden Bauch bei gleichzeitig kaum ausbiegenden Rand (RF 1.1), der parallelseitig geformt ist, zwar einen weitmündigen Eindruck, dieser entsteht aber aufgrund seiner geringen Größe. Ein ähnliches Gefäß liegt aus Mittel-Groningen als vermutlich kaiserzeitliche Sonderform vor (TAAYKE 1996a, 39, Abb. 35, 5), wobei die Henkel dort höher auf der Gefäßschulter ansetzen. Im Gefäßtyp erinnert das Kleinstgefäß an einen dreigliedrigen Topf mit fließendem HalsSchulter-Übergang ähnlich einer verkleinerten Ausgabe von Ge6, der zwischen der ersten Hälfte des 2. und bis ins 4. Jahrhundert n. Chr. datiert werden kann (TAAYKE 1996a, 27, 51, Abb. 15, 1).

\subsection{Eingliedrige Gefäße}

Schalen-, schüssel-, kumpf- und napfartige Gefäße gehören der Gruppe der einteiligen Gefäßformen an. Sie treten in Nortmoor als ein- und zweigliedrige Gefäße auf, wobei im Fundmaterial eingliedrige Formen überwiegen. Eine Abgrenzung der o.g. Gefäßtypen untereinander wird durch ihren rudimentären Erhaltungscharakter erschwert. In vielen Fällen stehen eine geringe Randgröße und mangelnde Horizontierungsmöglichkeit der Gefäßfragmente einer zweifelsfreien Zuordnung entgegen und gestatten lediglich eine pauschale Ansprache. Angaben zum Höhen-Breiten-Index sind nur in Einzelfällen möglich.

Es handelt sich zumeist um mäßig hart gebrannte Keramik mit Gesteinsgrus Magerung. Ihre 
Oberfläche ist mäßig geglättet, selten geraut. Es überwiegen Brauntöne in hellen und dunklen Schattierungen, selten graue bis schwarze Farben.

Während Schalen und Schüsseln per se offene Gefäße darstellen, bilden Kümpfe und Näpfe tendenziell geschlossene Formen. Per Definitionem sind Schüsseln etwa so hoch wie breit (HINZ 1977, 10). Eine Abgrenzung zu Schalenformen kann nur anhand eines ausreichend langen Profilverlaufs erfolgen, da sich Rand- und Gefäßform nur unwesentlich unterscheiden.

Tassenförmige Gefäße mit Henkel der GF 10 nach LEHMANN (2002, Taf. 122) kommen unter dem Fundmaterial in Nortmoor nicht vor. Hier erfolgt ein Verweis auf die becherförmigen Gefäße von geringer Größe und Durchmesser der GF 14, die als Sonderform in die Typentafel aufgenommen wurden.

\subsection{Näpfe (GF 9)}

Kat.Nr. 3-4; 3-6; 3-28; 3-31; 160-1; 216-14; 223-4; 265-1; 265-2; 265-3; 703-1; 859-6

Näpfe als kleine, eingliedrige und konisch geformte schüsselartige Gefäße besitzen eine größere Gefäßhöhe relativ zu ihrem Randdurchmesser (GF 9). Bei ihnen überwiegen steile Wandungen. Mache Näpfe sind gerundet. Die Gefäße sind reduzierend gebrannt und mit Granitgrus gemagert. Meist sind sie sorgfältig ausgearbeitet und teilweise verziert.

Neben Rändern der RF 4.4 (Kat.Nr. 3-4) sind auch einbiegende Formen, wie RF 4.3 (Kat.Nr. 3-6) an Näpfen zu beobachten. Der Randdurchmesser variiert von 4,4-12cm, bei einem Mittel von $8 \mathrm{~cm}$.

Bei Näpfen fällt die Vielfalt der angebrachten Handhaben auf. Es überwiegen rand- und unterrandständige Grifflappen (Kat.Nr. 3-4, 3-28; 160-1; 216-14; 265-2; 703-1) vor Knubben (Kat.Nr. 3-6, 859-6). In einem Fall ist eine Grifföse belegt (Kat.Nr. 265-1). Ein kantig ausgearbeitetes Henkelexemplar steht waagerecht ab (Kat.Nr. 3-6). Eine randständige Griffknubbe ist viereckig ausgezogen (Kat.Nr. 265-2). Rudimentär erhalten ist ein Ösenhenkel auf der Schulterpartie einer Schalenform (Kat.Nr. 265-1). Ebenfalls auf der Gefäßschulter angebracht ist ein $3 \mathrm{~cm}$ lang erhaltener Griffzapfen, der paarig zu rekonstruieren ist (Kat.Nr. 703-1). Unterhalb des Zapfens verzieren drei senkrechte Rillen die Wandung. Ungewöhnlich ist ein oberrandständiger Grifflappen, der schräg nach oben absteht und ein länglich-trapezförmiges Profil aufweist (Kat.Nr. 160-1).

Mehrfach vertreten sind flächige Tupfeneindrücke (Kat.Nr. 3-28; 3-31), die etwa 2,2cm unterhalb des Napfrandes eingedrückt sind. Es handelt sich meist um runde und rundovale Eindrücke geringen Durchmessers $(0,2$ bis $0,6 \mathrm{~cm})$.

\subsection{Schalen (GF 11)}

Kat.Nr. 3-3; 3-5; 66-2; 119-3; 195-10; 223-4; 376-3; 381-1; 403-7; 499-3; 513-2; 516-7; 584-7; 637- 
Schalen haben eine deutlich größere Breite als zur Gefäßhöhe (vgl. LEHMANN 2002, 51). Die Schalenhöhe ist oftmals kleiner als die Hälfte des Randdurchmessers, der größer als $15 \mathrm{~cm}$ sein muss (vgl. HINZ 1977, 10-12). Zumeist haben Schalen eine einschwingende Wandung ohne Schulter und ohne ausgeprägten Rand (GF 11). Der Randdurchmesser liegt zwischen 12 und $16 \mathrm{~cm}$.

Im Nortmoorer Material sind einige Schalen mit teils ausgeprägtem Schulterumbruch versehen, was ihnen ein zweigliedriges Aussehen gibt. Es überwiegen einfach abgestrichene Ränder, die nach innen abgeschrägt sein können. Einige Exemplare verfügen über eine prononciert nach außen gewölbte Randlippe oder sind facettiert.

Die Oberflächengestaltung ist meist sorgfältig, die Innenseiten können geglättet sein, während die Außenseite aufgeraut ist. Einige Schalen sind eher etwas gröber ausgearbeitet, was auf ihre Nutzung als Alltagsgeschirr hinweist.

Die Randlippe bei Schalen ist meist rund gestaltet mit einer ausschwingenden Wandung. Es überwiegen einfache Ränder, wie RF 4.1, die leicht gerundet (Kat.Nr. 653-1; 756-8) oder verdickt sein können (Kat.Nr. 3-3; 195-10; 403-7; 939-1). RF 4.2 bildet außen einen kleinen Absatz (Kat.Nr. 3-5; 66-2; 119-3; 702-6), oder die Schale besitzt wie RF 4.5 innen eine ausgezogene Randlippe (Kat. 3763; 499-3). Daneben kommen einfach flach abgestrichene und gerade Ränder vor (Kat.Nr. 514-2; 5847; 637-11), neben trapezförmig ausgebildeten (Kat.Nr. 265-3; 516-7). Einige Exemplare verfügen über einen nach innen gelegten leicht verdickten Rand (Kat.Nr. 3-30; 403-7; 703-3) oder bilden in einigen Fällen außen einen kleinen Absatz heraus (Kat.Nr. 66-2; 702-6; 943-4).

Ungewöhnlich ist ein mit kurz ausbiegender Randlippe versehener Napf (Kat.Nr. 223-4). Er zeichnet sich durch eine hohe Wandung aus, die einen deutlichen Knick aufweist. Ein ähnlicher Napf (Kat.Nr. 381-1), mit etwas stärker einbiegender oberer Gefäßwandung fand sich im kaiserzeitlichen Haus I.

Im Nortmoorer Fundmaterial überwiegen unverzierte Schalenfragmente. Hierbei sei jedoch auf den „Fehler der kleinen Zahl“ hingewiesen, denn zuordbar zu den o.g. Gefäßformen sind i.d.R. nur die Randstücke, die zumeist unverziert sind. Die wenigen zuordbaren Wandungsscherben mit direkten Anpassstellen, weisen Einstichverzierungen auf und legen nahe, dass die bevorzugte Verzierungszone bei schalen- und schüsselartigen Gefäßen erst etwa bei 1/3 Gefäßhöhe unterhalb des Randes begann.

Verziert sind die Schalen mit Eindrücken auf bzw. knapp unterhalb der Randlippe (Kat.Nr. 3-3; 19510), selten sind nur einzelne Wandungspartien der Schale mit paarigen Eindrücken verziert (Kat.Nr. 584-7). Singulär ist ein Exemplar, welches mit parallelen Strichreihen und herabhängenden Dreiecken verziert ist (Kat.Nr. 195-10). 
Während zu Beginn der Kaiserzeit niedrige, weitmündige Schalen überwiegen, werden diese ab dem 1. Jahrhundert von steilwandigeren Gefäßen abgelöst (HALPAAP 1994, 99). Sowohl aus Brill (LEHMANN 2002, 51, Taf. 53.2 u. Taf. 122, GF 11) wie auch aus Jemgumkloster (SCHMID 1965b, 28) liegen weitmündige, flache Schalen vor, die um Christi Geburt datierten. Dieser extrem flache Typ, der eher einem Teller mit hohem Rand ähnelt, fehlt im Nortmoorer Fundmaterial weitgehend.

In Nortmoor überwiegen hingegen weitmündige hohe bis steilwandige Schalen mit leicht konvexer Wandung und einfachem Rand. Neben geradem, waagerecht angestrichenen Randabschluss kommen nach außen abgeschrägte Ränder vor, die leicht verdickt abgeplattet sind (NMH: Kat.Nr. 584-7). Gerundete unverdickte Randabschlüsse entsprechen der Form VI in Soest-Ardey und kommen seit dem 2. Jahrhundert n. Chr. vor (HALPAAP 1994, 99).

Einen Überblick der in den nördlichen Niederlanden auftretenden Schalenformen gibt TAAYKE (1996a, 35, Abb. 30). Hingegen gliedert LEHMANN (2002, Taf. 119, RF 4.1-4.4 u. 9) die Randformen seiner ostfriesischen Geestsiedlung stark auf, vernachlässigt jedoch den Wandungsverlauf. Am ehesten entspricht das Schalenrepertoire von Paddepoel Typ V A dem Nortmoorer Material (VAN Es 1968, 332-333, fig. 61-62). Während dieser Typ nach SCHMID (1965b, 29) in der gesamten römischen Kaiserzeit vorkommt, datiert VAN ES $(1968,252)$ die Randform in die späte Kaiserzeit. TAAYKE $(1990,185,155,152)$ stellt derartige Schalen in die mittlere Eisenzeit; womit insgesamt die zeitliche Bandbreite verdeutlicht wird.

Die in Nortmoor auftretenden kurzen verdickten Schalenränder weisen Übereinstimmungen mit HB 13 aus Hatzum Boomburg auf (LÖBERT 1982, 38, 57-58, Taf. 48). Nach LÖBERT handelt es sich um Näpfe, da der Randwinkel steiler steht als bei den Schalen. FöRST (1991, 71-72) setzt den Typ HB 13 mit ihrem Typ HW 21 gleich und datiert ihn in die ältere Eisenzeit. Ausgestellte Schalenränder mit breiter Randlippe vertreten eine Leitform des Horizontes 2 nach NORTMANN (1983a, 34-36).

Ferner im Fundmaterial stark vertreten sind Schalen mit stärker einziehender Wandung und rundem Randabschluss (LEHMANN 2002, Taf. 119, LH 4.1). Diese können als verdickte Ränder eine runde Randlippe aufweisen. Allein für stark verdickte Ränder ist eine nähere Datierung zwischen Spätlatènezeit und früher Kaiserzeit wahrscheinlich (GROTELÜSCHEN 2000, 33; vgl. vAN ES 1968, 252, 252-253). Steilwandigere Schalen sind zeitlich jünger und datieren allgemein in die Kaiserzeit (FöRST 1991, 71-72). In der Zeijener Kultur entsprechen diese Typ W VA (VAN Es 1965, 255-256). In Hatzum-Boomborg kommen sowohl steilwandige wie stark eingewölbte Schalenformen nebeneinander vor (LÖBERT 1982, Taf. 46-48). 
Weisen die Schalen stark verdickte Ränder auf und sind sie kantig abgestrichen, so werden sie zeitlich jünger angesehen und können noch in die römische Kaiserzeit datiert werden (FöRST 1991, 72). Eine trianguläre Randform tritt in Einswarden als Variante a der Keramikgruppe 6 neben langgezogenen, mehrfach abgestrichenen Rändern auf (SCHMID 1957, 52, 106, Abb. 6 u. 7). Auch unter dem Briller Material finden sich derartige Ränder (LEHMANN 2002, 52). Mehrfach facettierte Schalenränder sind aus Einswarden in der Wesermarsch belegt (SCHMID 1957, 106, Abb. 4-5, 8, 10-11). Die später verschollenen Grabungsunterlagen der Dorfwurt-Grabung erschweren jedoch eine Rekonstruktion des Schichtenverlaufes und führen letztlich zu einem allgemeinen Datierungsansatz der Schalentypen in die Übergangszeit von der vorrömischen Eisenzeit in die römische Kaiserzeit. Bereits VAN ES (1968, 252) verweist auf die lange Laufzeit der schlichten Schalenformen, die bereits in der Eisenzeit aufkommen und noch in der älteren Kaiserzeit belegt sind. Seine Ergebnisse werden von Taayke gestützt (TAAYKE 1996a, 55-56).

\subsection{Kümpfe (GF 12)}

Nr. 3-27; 3-30; 3-33; 10-1; 140-9; 703-3; 943-4

Kümpfe stehen den Schalen typologisch nahe, weisen im Unterschied zu diesen jedoch eine stärker einbiegende Randausformung auf, die den Gefäßen einen geschlosseneren Charakter gibt (GF 12). Auffällig ist ihre größere Höhe im Verhältnis zum Gefäßdurchmesser. Die Gefäßkubatur wirkt insgesamt gedrungen.

In Nortmoor dominieren bei Kümpfen parallelseitig abgestrichene Ränder, die waagerecht (Kat.Nr. 327) oder nach innen abgeschrägt sind (Kat.Nr. 10-1; 140-9). Daneben existieren stark gerundete Randformen (Kat.Nr. 943-4), die teilweise innen betont eingezogen und mit einem Randwulst versehen sind (Kat.Nr. 3-30; 703-3). Die RF 4.1, 4.4 und 4.5 sind bei Kümpfen anzutreffen.

Der Randdurchmesser variiert zwischen 8,8 und $24 \mathrm{~cm}$, mit einem Mittelwert bei $15 \mathrm{~cm}$. Verzierungen sind auf zwei Kümpfen belegt. In einem Fall setzt die Dellenverzierung etwa bei 1/3 der Gefäßhöhe unter dem Rand ein und zieht sich bis knapp oberhalb des Flachbodens hin (Kat.Nr. 3-33). Es handelt sich meist um runde Eindrücke geringen Durchmessers (0,2-0,6cm).

Eine Fingerkerbenzier findet sich an einem Flachboden (Kat.Nr. 3-27); vermutlich zog sich die Verzierung über den gesamten Gefäßkörper bis knapp oberhalb des Gefäßbodens hin. Da derartige Verzierungen von anderen eingliedrigen Gefäßen nicht bekannt sind, wird es sich um einen Kumpfboden gehandelt haben. Die wenigen komplett erhaltenen Kümpfe verfügen über einen flachen Gefäßboden. Neben einfachen Böden (vgl. Kat.Nr. 10-1) kommen leicht eingezogene Standböden vor (vgl. Kat.Nr. 3-27). Der Bodendurchmesser liegt zwischen 6 und $13 \mathrm{~cm}$.

Ein Unikat schmücken vertikale Streifenriefen, die unterhalb einer Griffknubbe angebracht worden 
sind (Kat.Nr. 703-1). Selten treten geraute Unterteile auf, bzw. können einer Kumpfform zugewiesen werden (Kat.Nr. 10-1).

Eingliedrige Kümpfe finden sich im Fundsmaterial kaiserzeitlicher Siedlungen in Nordwestdeutschland. Da eingliedrige Gefäße mit eingezogenem Rand vorzugsweise aus einem Siedlungskontext entstammen und sie in geschlossen Grabfunden fehlen, können sie nur allgemein in die römische Kaiserzeit datiert werden (vgl. LEHMANN 2002, 53). Verdickte Ränder werden eher in die frühkaiserzeitlichen Horizonte datieren (SCHMID 1965b, 29), während in Hatzum-Boomborg Kümpfe mit gerade abgestrichenen nach innen geneigte Ränder dem Typ 14c angehören und dort in den jüngeren Fundhorizont zu Tage kamen (LÖBERT 1982, Taf. 49, 882).

\subsection{Kleinkeramik}

Kat.Nr. 3-32; 216-13; 369-2; 455-1

Unter Kleinkeramik werden Gefäße bzw. Gefäßreste von sehr kleinem Format verstanden, dessen Bauchdurchmesser 10cm nicht überschreitet (TAAYKE 1996a, 42).

In Nortmoor gibt es nur wenige Vertreter dieser Gefäßkeramik $(n=4)$. Vollständig erhalten ist ein eierbecherartiges Schälchen (Kat.Nr. 3-32). Das nur 2,2cm hohe eingliedrige Gefäß hat einen Randdurchmesser von 3,6cm. Der Rand ist leicht abgerundet, die Wandung sehr steil und nur leicht nach außen geneigt. Mit seinem nur 2,8cm großen Flachboden und seiner innen abgerundeten Wandung könnte es durchaus die Funktion eines Eierbechers übernehmen. Die Außenseite ist mit unregelmäßig verteilten feinen Einstichen überzogen. Ein unverziertes Schälchen findet sich in Hatzum-Boomborg (LÖBERT 1982, Taf. 48, 849). Parallelen zu dem Miniatur-Schälchen existieren beispielsweise im wendländischen Güstritz, wo sie aus einem kaiserzeitlichen Fundkomplex stammen (NÜSSE 2002, Taf. 43, 350).

Das Fragment eines sehr kleinen Flachbodens gehört einem Kleinstgefäß an (Kat.Nr. 216-13). Der Boden ist leicht konkav gewölbt, besitzt einen Durchmesser von $2 \mathrm{~cm}$ und geht in eine $0,4 \mathrm{~cm}$ dünne Wandung über. Die geringe Stärke der Gefäßwandung am Übergang zum Boden, die feine Schlemmung des Tons und eine sorgfältig bearbeitete Gefäßoberfläche weist auf Feinkeramik hin. Das Bruchstück kann aufgrund seiner schlechten Erhaltung jedoch keiner gängigen Gefäßform mehr zugeordnet werden.

Ebenfalls fragmentiert erhalten ist eine leicht konkav gebogene Bodenscherbe (Kat.Nr. 455-1). Der 4,4cm durchmessende Boden geht zügig in eine konvexe Wandung über, die jedoch unregelmäßig ausgeformt ist und eine körnige bis stellenweise glatte Oberfläche besitzt. In seiner Gestalt wirkt das 
Gefäßfragment eher schlicht. Möglicherweise handelt es sich um einen der seltenen kaiserzeitlichen Becher.

Die kleine heterogene Gruppe der Miniaturgefäße stellt meist Nachbildungen regulärer Gefäßformen, wie Töpfe, Näpfe u.a.m., dar. Charakteristisch ist eine geringe Höhe von $2-8 \mathrm{~cm}$ und ein kleiner Randdurchmesser von 4-6cm. Die Ware ist reduzierend (dunkelgraue bis grauschwarze Farbe) weich bis mäßig hart gebrannt. Sind Randgestaltung und Oberflächenbehandlung unsorgfältig, deutet dies auf eine Verwendung als Kinderspielzeug hin.

\subsection{Verzierungen}

Kat.Nr. 3 Fdnr. 526, 556, 565, 568 (Farbtafel); 3-1; 3-2; 3-3; 3-5; 3-7; 3-8; 3-9; 3-10; 3-18; 3-20; 3-21; $3-22 ; 3-23 ; 3-24 ; 3-25 ; 3-27 ; 3-28 ; 3-31 ; 3-32 ; 3-33 ; 3-46 ; 3-47 ; 3-50 ; 3-51,3-52 ; 10-2 ; 26-5 ; 26-6$; 61-1; 100-1; 121-2; 140-1; 140-8; 195-1; 195-2; 195-3; 195-11; 195-12; 195-13; 195-14; 216-3; 2164; 216-5; 216-6; 216-12; 216-17; 216-18; 216-19; 216-21; 216-22; 216-23; 265 Fdnr. 582 (Farbtafel); 278-1; 278-2; 278-17; 305-1; 369-1; 369-4; 379-1; 400a-1; 400a-2; 403-1; 403-2; 432-7; 432-8; 4328;463-1; 468-4; 480-1; 499-7; 551-4; 551-5; 559 Fdnr. 674 (Farbtafel); 569-1; 584-6; 584-7; 627-1; 627 Fdnr. 525 (Farbtafel); 681-1; 703-1; 703-2; 722 Fdnr. 760 (Farbtafel); 744-2; 755-4; 755-5; 756-7; 756 Fdnr. 486 (Farbtafel); 806-1; 810-1; 840-1; 859-1; 859 Fdnr. 1070 (Farbtafel); 884-1; 884 Fdnr. 1055 (Farbtafel); 884 Fdnr. 1068 (Farbtafel); 929-1; 944 Fdnr. 1024 (Farbtafel)

Verzierte Gefäßscherben finden sich recht häufig unter dem Nortmoorer Keramikmaterial. Etwa $10,5 \%$ der Scherben sind verziert. Es überwiegen jedoch kleine Wandungsscherben mit eher geringer Aussagekraft. Im Folgenden wird daher den Verzierungselementen, die typologisch relevanten Gefäßeinheiten zuzuordnen sind, eine größere Aufmerksamkeit geschenkt (Taf. 113). Die übrigen Wandungsscherben werden summarisch abgehandelt.

Aufgrund des meist hohen Fragmentierungsgrades sind Angaben zur Platzierung der Verzierungen auf dem Gefäßkörper nur selten möglich. Als Verzierungen werden Ritzungen, Eindrücke und plastischer Dekor aufgenommen. Vertikale Glättstreifen oder Schlickrauhung von Gefäßoberflächen zählen nicht dazu.

Die hohe Anzahl aufgefundener verzierter Wandungsscherben gibt an, dass die Verzierungen eher auf dem Gefäßkörper, zumeist auf der Schulterzone und teilweise abwärts davon, angebracht wurden. Eine Zuordnung einzelner Verzierungen zu bestimmten Gefäßtypen ist aufgrund des zerscherbten Charakters des Fundmaterials kaum mehr möglich. Eine Ausnahme bilden Trichterschalen die oft mit eingeritzten Rillen und geometrischen Ritzmustern verziert sein können.

In der Minderzahl sind verzierte Randscherben. Es wurden vorwiegend Gefäße mit einem 
Randdurchmesser von unter $30 \mathrm{~cm}$ verziert. Diese zeichnen sich durch eine sorgfältigere Oberflächenbehandlung (poliert bis sorgfältig geglättet) und relative Dünnwandigkeit $(<0,8 \mathrm{~cm})$ aus. Meist gehören sie der „Feinkeramik“ an. Keramikgefäße mit einem Durchmesser von über $35 \mathrm{~cm}$ waren in der Regel unverziert. Gröber gearbeitete Siedlungskeramik (geschlickte Oberfläche, oft grob gemagert) weist häufig eine Rauhung oder Schlickung der Gefäßwandung auf.

\subsection{Geometrische Muster (VF 1)}

Geometrische Muster kommen vorwiegend auf Trichterschalen und verwandten Formen vor. Schalen mit einem geringen Durchmesser sind in Nortmoor in wenigen Fällen ebenfalls verziert. Die Verzierungszone kann unterhalb des Randes, aber in jedem Fall oberhalb des Gefäßumbruches beginnen. Dabei sind die Ritzlinien so arrangiert, dass geometrische Muster entstehen. Beliebt sind hängende Dreiecke, die von waagerecht verlaufenden Ritzlinien herabreichen (Kat.Nr. 403-2). Eine Ausnahme von dieser regelhaften Verzierung findet sich bei einem Randfragment (Kat.Nr. 3-5), bei der die Dreiecke spitz zum Rand hin zulaufen. Die Ritzlinien sind meist schmal und kaum eingetieft. Oft treten die Linien parallel laufend auf und betonen die Gefäßschulter in ihrer größten Breite oder knapp darüber liegend.

\subsection{1 Waagerechte Rillen- und Ritzverzierungen (VF 1.1)}

Kat.Nr. 3-5; 3-10; 3-47; 3-51; 61-1; 121-2; 192-1; 216-3; 216-4; 216-5; 216-6; 216-12; 216-17; 21618 ; 216-19; 278-1; 278-3; 369-4; 379-1; 403-2; 432-7; 432-8; 480-1; 499-7; 551-4; 551-5; 569-1; $584-$ 6; 744-2; 755-4; 755-5; 756 Fdnr. 486 (Farbtafel); 756 Fdnr. 486 (Farbtafel); 859-1; 859 Fdnr. 1070 (Farbtafel); 884-1; 928-1

Scherben mit Rillen- und Ritzverzierungen stellen die größte Dekorgruppe dar. Die Rillen sind schmal und durch Druck- und Zugbewegungen in die Gefäßoberfläche hineingedrückt. In einigen Fällen schneiden die linearen Muster scharfkantig ein. Sie können einzeln, paarig oder zu mehreren parallel zueinander auftreten. Häufig befinden sich horizontale Rillen unterhalb der Halszone im Bereich von Schulter und Umbruch, wobei sie die Gefäßschulter in ihrer größten Breite betonen (Kat.Nr. 195-1; 216-6; 480-1; 551-4). In wenigen Fällen auch unterhalb des Randes (Kat.Nr. 3-47; 278-1; 278-1; 2783). Es überwiegen schmale Rillen mit horizontaler Linienführung. Der Abstand der sorgfältig eingedrückten Rillen zueinander variiert zwischen 1 und $3 \mathrm{~mm}$. Unterschieden werden können horizontale (VF 1.1) von vertikalen Rillen- und Ritzverzierungen (VF 1.2).

Auf Trichterschalen sind umlaufende Rillen ein beliebtes Motiv (VF 1.1). Singulär ist ein mit zwei umlaufenden Rillen verzierter Schalenrand (Kat.Nr. 744-2), in zwei Fällen werden umlaufende Rillenverläufe durch kurze senkrechte Rillen unterbrochen (Kat.Nr. 569-1; 216-4).

Bei der einfachen Rillenverzierung der VF 1.1 können die Rillen knapp unter dem Rand ansetzen 
(Kat.Nr. 744-2), meist jedoch verzieren sie die Halszone bis knapp über den Umbruch (Kat.Nr. 755-5). Die Zone oberhalb des Schulterumbruches wird meist von zwei bis drei parallelen Rillen verziert (Kat.Nr. 551-5; 403-2). Lediglich bei je einem Exemplar sind vier (Kat.Nr. 928-1) oder sechs Rillen eingeritzt (Kat.Nr. 3-51). Eher selten setzt die Rillenverzierung auf dem Bauchumbruch ein (Kat.Nr. $216-6 ; 755-4)$.

Häufig treten waagerechte Rillen in Kombination mit anderen Verzierungen auf. Bevorzugte Verzierungszone ist die Gefäßschulter, während der untere Gefäßbereich oft unverziert ist.

Rillenpaare können runde Einstichreihen (Kat.Nr. 121-2; 216-6; 216-19; 216-21), diagonale Ritzungen (Kat.Nr. 278-1) oder viereckige Eindrücke einfassen (Kat.Nr. 192-1). Rillen bilden geometrische Muster. Belegt sind Kombinationen mit Punktreihen, Tannenzweigmustern, hängenden Dreiecken oder Girlanden. Relativ häufig sind Rillen von punktförmigen Einstichen (Kat.Nr. 121-2; 216-21; 4801) oder kleinen dreieckigen Einstichen (Kat.Nr. 10-2; 61-1) begleitet. Von horizontalen Rillen hängen Winkelbänder herab, die mit diagonalen Rillen ausgefüllt sein können (Kat.Nr. 480-1).

Einige Scherben sind mit einem ungewöhnlichen Muster verziert. Hierbei bilden Rillen einen rechteckigen Rahmen, der ein Füllmotiv mit diagonalen Rillen umgrenzt (Kat.Nr. 216-18; 216-19; 369-1). Ein erhaltenes Bodenfragment ist als einziges mit waagerechten Rillen verziert, die diagonale Rillen einfassen (Kat.Nr. 216-12). Rillen in Verbindung mit Fingernageleindrücken sind selten (Kat.Nr. 379-1).

Umlaufende oder zu Winkeln und Bögen angeordnete Rillen- und Ritzlinien finden sich als typisches Verzierungselement in kaiser- und völkerwanderungszeitlichen Siedlungen. Im südlichen Nordseegebiet kommen sie sowohl in Gräber des Elbe-Weser-Gebietes wie in Siedlungen vor (SCHMID 1965b, 23, 36). Über die gesamte Besiedlungsdauer der Feddersen Wierde treten Rillenverzierungen auf (SCHMID 1969d, Abb.1-3). Aus Hodorf und Ritsch ist rillenverzierte ältereisenzeitliche Keramik belegt (SCHMID 1965b, Taf. 18 u. 19). In Brill sind Rillenverzierungen weitgehend auf Trichterschalen und zweigliedrige Schalen begrenzt (LEHMANN 12002, 59). Auch auf Grabkeramik aus dem Landkreis Leer sind umlaufende Rillen gebräuchlich. Verzierte Trichterschalen liegen beispielsweise aus Nortmoor-Plaggenburg (SCHWARZ/STUTZKE 1998, 98, Abb. 491), Nettelburg (SchwaRZ/STUTZKe 1998, 95, Abb. 477) und Amdorf vor (SchwaRZ/STUTZKE 1998, 33, Abb. 6), die aus mittel- bis ältereisenzeitlichen Bestattungen stammen.

\subsection{2 Vertikale Rillen- und Ritzverzierungen (VF 1.2)}

Kat.Nr. 61-1; 432-7; 432-8; 584-6; 3 Fdnr. 565 (Farbtafel); 265 Fdnr. 582 (Farbtafel)

Vertikale Rillen- und Ritzverzierungen mit unregelmäßiger Linienführung finden sich auf typologisch unbestimmten Wandungsscherben (VF 1.2). Die Verzierung setzt meist erst im Bereich der unteren Gefäßwandung, vermutlich ab dem Bauchumbruch, ein und reicht bis knapp über die Fußzone, der mit 
Flachboden versehenen topfartigen Gefäße (vgl. LÖBERT 1982, Taf. 54, 972). In unregelmäßigen Abständen überziehen annähernd parallele Rillen die Gefäßoberfläche (Kat.Nr. 3 Fdnr. 565 (Farbtafel); 265 Fdnr. 582 (Farbtafel)). Vertikale Rillen, die ein Füllmotiv (Kerben, Einstiche) umfassen, kommen nur vereinzelt vor (Kat.Nr. 61-1; 432-7; 432-8; 480-1; 584-6).

Die Oberfläche ist geschlickt, selten geglättet und wenig sorgfältig ausgebildet. Der Ton ist mäßig gemagert und von gröberen Einschlüssen durchzogen. Es überwiegen oxidierend gebrannte dunkelgraue Scherben, nur wenige haben eine hellorange Tonfarbe. Dies deutet auf eine Nutzung als einfache Haushaltsware hin, deren Verzierung zur besseren Handhabung der oft großformatigen Gefäße diente. In Hatzum-Boomborg sind intentionelle Verzierungen an Einhenkeltöpfen mit kurzem facettierten Rand anzutreffen, der als Typ HB 9a dem jüngeren Fundhorizont angehört (LÖBERT 1982, 55, 80, Taf. 43, 707).

\subsection{3 Riefen (VF 1.3)}

Kat.Nr. 3-1; 3-46; 3-50; 3-52; 216-1; 216-23; 369-4; 559 Fdnr. 674 (Farbtafel); 627 Fdnr. 525 (Farbtafel); 681-1; 703-1; 722 Fdnr. 760 (Farbtafel); 756-7; 884 Fdnr. 1055 (Farbtafel); 944 Fdnr. 1026 (Farbtafel)

Riefen sind breiter als Rillen und ritzen die Gefäßoberfläche nicht ein, da sie flachgrundig eingetieft sind. In Nortmoor kommen breite Riefen, die durch einen dünnen Steg getrennt sind, vor. Diese Verzierungsart beschränkt sich auf den oberen Gefäßteil. Waagerechte Riefen sind bei weitmündigen Töpfen mit schwach s-förmigem Profil vertreten. Sie verzieren oberhalb der Gefäßschulter Töpfe mit senkrechten (Kat.Nr. 3-46; 3-52) oder kurz-verdicktem Rand (Kat.Nr. 756-7). Auch auf Napfschalen mit geringem Durchmesser sind sie zu beobachten (Kat.Nr. 216-1; 681-1). Leicht bogenförmige Riefen finden sich an zwei Exemplaren (Kat.Nr. 3-1; 722 Fdnr. 760 (Farbtafel)). Ungewöhnlich ist die Anbringung in der unteren Gefäßhälfte einer Schale (Kat.Nr. 703-1). Vier parallele Riefen zieren einen Bandhenkel (Kat.Nr. 3-50).

Zwei bis drei umlaufende parallele Riefen sind ein häufiges Verzierungselement bei mittel- und älterkaiserzeitlicher Keramik (BANTELMANN 1955, 52). In der niederländischen Forschung als „Streepband“ bezeichnet erscheinen die Rillen in Hatzum-Boomborg an bauchigen Töpfen mit stark S-förmigem Profil (vgl. LÖBERT 1982, 91-92, Taf. 35-36, 584-588).

Riefen mit teils sehr breiten Abständen finden sich auf Keramikgefäßen, deren Oberfläche ungeglättet und insgesamt grob wirkt. Die Wandungsscherben weisen senkrechte (Kat.Nr. 559 Fdnr. 674 (Farbtafel)); 703-1) oder diagonale Riefen auf (Kat.Nr. 627 Fdnr. 525 (Farbtafel)). Verbreitet sind auch Rautenmuster (Kat.Nr. 216-23; 884 Fdnr. 1055 (Farbtafel)). Da die Riefen vorwiegend im unteren Gefäßteil angebracht waren, deutet dies auf eine funktionale Verzierung hin. Sie stellen schlichte Haushaltskeramik dar und sind in kaiserzeitlichen Siedlungen verbreitet (LÖBERT 1982,Taf. 
54, 968; HalPaAP 1994, Taf. 62, 1). In Soest-Ardey finden sich senkrechte Riefen, dort als Kanneluren bezeichnet, vorwiegend in der unteren Gefäßhälfte von Gefäßen der Form II, die in das 2./3. Jahrhundert n. Chr. datiert werden (HALPAAP 1994, 77, 108).

\subsection{4 Kanneluren (VF 1.4)}

Kat.Nr. 3 Fdnr. 224 (Farbtafel); 78 Fdnr. 83 (Farbtafel); 468-4

Kanneluren sind tief in die Gefäßoberfläche eingedrückt. Sie stellen „gleichförmige lineare Eintiefungen, die ein Gefäßteil annähernd vollständig bedecken“ (LEHMANN 2002, 61) dar und sind nicht eingeritzt. In Nortmoor liegen nur wenige Exemplare dieser Verzierungsform vor. Soweit bekannt sind sie auf dem Gefäßumbruch angebracht. Ausgeführt sind breite umlaufende Kanneluren, darüber schließen sich diagonale Kanneluren an.

Die Nortmoorer Wandungsscherben mit Kanneluren gehören zu Importgefäßen. Sie zeichnen sich durch eine sorgfältige Oberflächenbearbeitung, feine Magerung und hartem Brand aus. Sowohl Verzierungsform wie Tonbearbeitung sind singulär. In Brill treten vergleichbare Verzierungen an einem schlanken Topf mit s-förmigem Profil auf (LEHMANN 2002, Taf. 67, 2734-1), während diese Verzierungsform in Hatzum-Boomborg fehlt. In die Stufe C2/3 datiert eine vom Pfingstberg bei Helmstedt stammende Urne, die Kanneluren auf ihrem Umbruch aufwies (GAEDTKE-ECKARDT 1991, 36).

\subsection{5 Flechtbänder (VF 1.5)}

Kat.Nr. 3-20; 3-22; 3-23; 3-25: 463-1

Flechtbänder bestehen aus unterschiedlich orientierten und in sich verschränkten Rillenfeldern. Die Ritzlinien sind ausschließlich auf kleinteiligen Wandungsscherben erhalten, so dass eine Aussage zur Anbringungszone kaum möglich ist. Zwei Scherben stammen aus Befunden, während die übrigen als Oberflächenfunde aufgesammelt worden sind. Neben schlichten Rillenzonen (Kat.Nr. 3-21; 3-25) finden sich mit keilstichartigen Einstichen gesäumte Bänder (Kat.Nr. 3-20). Die Felder bilden selten völlig ausgefüllte Muster (Kat.Nr. 3-23), meist entstehen freie Zwischenräume (Kat.Nr. 432-8; 463-1). Flechtbänder sind aus Brill bekannt (LEHMANN 2002, 62). Aus der Wesermarsch stammen wenige vergleichbare Stücke (FöRST 1991, Taf. 14, 36; Taf. 34, 234).

\subsection{6 Sparrenbänder (VF 1.6)}

Kat.Nr. 3-2; 216-17; 216-21; 480-1; 859 Fdnr. 1070 (Farbtafel)

Zwei- bis vierreihige Rillen begrenzen beidseitig unterschiedlich ausgerichtete kurze Rillengruppen. 
Die so gebildeten Sparrenbänder sind meist horizontal auf oder knapp unterhalb der Gefäßschulter angebracht. Einzige Ausnahme stellt die komplett erhaltene Trichterschale Kat.Nr. 480-1 dar. Hier bestehen zwei der sieben vertikal herablaufenden Zierzonen aus Sparrenbändern, die sich bis zum Fuß hinabziehen. Die große Verzierungsfreude findet sich in der differenzierten Motivik wieder. Kombiniert sind die Motive der Sparrenbänder auf dem selben Gefäß mit punktgesäumten Rillen und Girlanden.

Punktgesäumte Sparrenbänder treten verschieden kombiniert auf. Die Einstichreihen können innerhalb der Zierzone liegen und abwechselnd die umlaufenden Rillen begleiten (Kat.Nr. 216-17) oder sowohl die umlaufenden Rillen als auch das Füllmuster einfassen (Kat.Nr. 216-21). Wandungsscherben mit umlaufenden Sparrenbändern sind meist fein geschlickt und gut geglättet. Sie gehören der lokalen Feinkeramik an. Singulär ist die Randscherbe einer steilwandigen Schale, die mit einem umlaufenden Sparrenband in der oberen Gefäßhälfte verziert ist (Kat.Nr. 195-1). Es handelt sich um eine sehr gute Imitation einer Terra Sigillata Schale mit ihrem typischen roten Tonglanzüberzug (vgl. Kap. imitierte Importkeramik).

Sparrenbänder gehören im südlichen Nordseeküstengebiet $\mathrm{zu}$ den geläufigen Motiven auf kaiserzeitlicher Keramik. In Brill finden sie sich vorzugsweise auf Trichterschalen (LEHMANN 2002, 61), sie sind in Nordwestdeutschland auch auf engmündigen Töpfen belegt (SCHMID 1965b, 24, 30; LÖBERT 1981, Taf. 41, 683 u. 687). Ihre Kombination mit einem Riefensaum gilt als typisch für die ältere Kaiserzeit (SCHMID 1965B, 20). Während sie in Wijster auf Keramik des 2./3. Jahrhunderts vorkommen (VAN Es 1967, 193, Abb. 99,3), werden sie in Hatzum-Boomborg als einfache Winkelbänder der Verzierung 2 zugeordnet und gehören dem jüngeren Fundhorizont an (LÖBERT 1981, 61). Punktreihen begleitende Rillen finden sich in Huntebrück-Wührden auf einem Gefäß des 2./3. Jahrhunderts (FÖRST 1991, 39). Bereits frühkaiserzeitliche Töpfe mit verdickt facettiertem Rand sind mit, dort als Winkelbänder bezeichneten, Sparrenbändern verziert (FÖRST 1991, 79, Taf. 39, 277). Das beliebte Motiv kommt in Flögeln noch im 4./5. Jahrhundert n. Chr. vor (SCHMID 1977b, 36, Abb. $3,3)$.

\subsection{7 Kastenförmige Verzierungen (VF 1.7)}

Kat.Nr. 216-12; 216-18; 216-19

Senkrecht und waagerecht verlaufende Rillen bilden bei diesem Muster einen rechteckigen Rahmen um ein inneres Zierfeld. In Nortmoor haben zwei typologisch unrelevante Wandungsscherben und ein Bodenstück diese ungewöhnliche Verzierung. Nach Horizontierung der Gefäßteile scheint die untere Gefäßhälfte als Hauptzierzone fungiert zu haben. Es handelt sich um ein- bis zweizügige Begleitrillen, die in einem Fall mit einer Punktreihe dekoriert ist. Das Füllmotiv stellen diagonale Rillengruppen dar. Zwei Trichterschalen sind oberhalb des Gefäßumbruches mit vier umlaufenden Linien verziert, die 
von waagerechten Linien unterbrochen werden (Kat.Nr. 216-4; 569-1). Bevorzugte Verzierungszone ist die Region unterhalb der Gefäßschulter bis in den Bodenbereich. Aus Nenndorf B werden kastenförmige Verzierungen in 14 Fällen an Wandungsscherben entdeckt (KREIBIG 2006, 89).

\subsection{8 Hängende Bögen (VF 1.8)}

Kat.Nr. 480-1; 755-4; 884-1

In Nortmoor treten nur an wenigen Exemplaren hängende Bögen auf. Es handelt sich um dreireihige Bögen, die ein umlaufendes Muster bilden und von dreireihigen Rillen herabhängen. In einem Fall sind sie punktgesäumt (Kat.Nr. 480-1), meist jedoch nicht mit anderen Verzierungen kombiniert. Die Bögen sind auf bzw. knapp unter der Gefäßschulter eingeritzt.

Einfache parallele Rillen bilden auf einem Trichternapf die hängenden Bögen (Kat.Nr. 755-5). Das relativ tief eingeritzte Motiv ist etwas sorglos konzipiert, wie die sich überschneidenden und teilweise nicht beendeten Bögen anzeigen. Ein punktgesäumtes Girlandenmuster überzieht den Schulterumbruch einer komplett erhaltenen Trichterschale, deren untere Wandung mit sieben senkrecht verlaufenden schmalen Zierbändern dekoriert ist (Kat.Nr. 480-1).

Trichterschalen und Standfußgefäße im Elbe-Weser-Gebiet sind mit hängenden Bögen verziert, die in das 1.-2. Jahrhundert n. Chr. datiert werden (SCHMID 1965b, 20, 23). Das auch als halbkreisförmiges Rillenband bezeichnete Motiv findet sich auch in Huntebrück-Wührden, Kreis Wesermarsch auf einer Wandungsscherbe des 2./3. Jahrhunderts n. Chr. (FöRST 1991, Taf. 82, 684), während diese Verzierungsform in der ostfriesischen Geestsiedlung Brill fehlt.

\subsection{9 Hängende Dreiecke (VF 1.9)}

Kat.Nr. 3-5; 10-2; 121-2; 192-1; 369-1; 403-2; 756 Fdnr. 486 (Farbtafel)

Eine bevorzugte Verzierung auf Trichterschalen sind umlaufende Dreiecke. Meist sind sie unterhalb des Bauchumbruches angebracht und hängen von waagerechten Rillen herab (Kat.Nr. 121-2; 192-1; 369-1). Der Dekor tritt i.d.R. bei Trichterschalen mit kurzen Rändern auf, wobei senkrechte oder dreieckige Randstellungen überwiegen. Zumeist dominieren linksläufige (Kat.Nr. 10-2; 192-1; 369-1; 756 Fdnr. 486 (Farbtafel)) vor rechtsläufigen Dreiecken (Kat.Nr. 121-2; 403-2).

Hängende Dreiecke können begleitet sein von keilstichartigen Einstichen (Kat.Nr. 10-1) oder leicht bogenförmigen Punktreihen (Kat. Nr. 121-2). Im letzteren Fall sind sie zusätzlich eingefasst von punktgesäumten Rillen. Sie kommen auch in Kombination mit quadratischen Eindrücken vor (Kat.Nr. 192-1).

Singulär ist ein knapp unterhalb eines Schalenrandes stehendes Dreieck (Kat.Nr. 3-5). Hier handelt es sich um ein rechtsläufig schraffiertes Dreieck, welches nach unten von drei umlaufenden Rillen begrenzt wird. Stehende Dreiecke finden sich auf Wandungsscherben in der Wesermarsch. FöRST 
(1991, 40, Taf. 16, 53) weist das Muster ihrem Typ HW 2a zu, einem zweigliedrigen Terrinentyp mit gestuftem Rand/Schulterumbruch.

Ein typisches Merkmal älterkaiserzeitlicher Keramik im Elbe-Weser-Gebiet sind punktgesäumte hängende Dreiecke (SCHMID 1965B, 20). In Wijster datieren derartig verzierte Trichterschalen und engmündige Töpfe in das 2./3 Jahrhundert n. Chr. (VAN Es 1967, 190, Abb. 97,2). Für Brill liegt für die mit hängenden Dreiecken verzierten Trichterschalen derselbe Zeitansatz vor (LEHMANN 2002, 62$63)$.

\subsection{10 Bäumchenmuster (VF 1.10)}

Kat.Nr. 278-2; 551-4

Auf zwei Trichterschalen findet sich ein Bäumchenmuster (Kat.Nr. 278-2; 551-4). Es sind gegenläufige Rillen, die stumpfwinklig zulaufende Dreiecke bilden (Kat.Nr. 278-2). Die Motive sind unterhalb der Gefäßschulter angebracht. Eine in Nortmoor mit einem Bäumchenmuster verzierte Randscherbe weist zwei senkrechte Trennlinien auf (Kat.Nr. 551-4). In Brill sind auf Wandungsscherben nur einfache Trennstriche belegt (LEHMANN 2002, 63; Taf. 69, 3523-2; Taf. 76, BRSL-21). Der auch als Fischgrätmuster bekannte Dekor findet sich in Wijster auf Trichterschalen vom Typ W IA2, die in den Anfang des 2. Jahrhunderts datieren (VAN Es 1967, 185, Abb. 92, 1256), während sie in Bennekom bereits im 1. Jahrhundert vorkommen (VAN ES u.a. 1985, 595-597). Derartige Muster sind in Hatzum-Boomborg auf engmündigen Töpfen vom Typ 7b anzutreffen, der dem älterkaiserzeitlichen Fundhorizont zugeordnet ist (LÖBERT 1981, 80, Taf. 41, 687).

\subsection{11 Kamm- und Besenstrich (VF 1.11)}

Kat.Nr. 400a-1; 884 Fdnr. 1068 (Farbtafel); 944 Fdnr. 1026 (Farbtafel)

Kammstrich ist eine flächige Verzierung, die sich durch eine parallele Linienführung auszeichnet und auf die Verwendung eines mehrzinkigen Gerätes hinweist. Es können bis zu neun Zinken nachgewiesen werden (Kat.Nr. 400a-1). Überzogen mit einem linearen und/oder bogenförmigen Dekor sind dickwandig, unbestimmbare Wandungsscherben.

Unter dem Nortmoorer Fundmaterial sind Kammstrich verzierte Scherben relativ häufig. Mit einem kammähnlichen Gerät wurden meist vertikal verlaufende Rillen flächig auf der unteren Gefäßhälfte angebracht (Kat.Nr. 944 Fdnr. 1026 (Farbtafel)). Die Verzierungsart erfolgt meist von der Schulter abwärts und hörte knapp oberhalb des Flachbodens auf. Bogenförmige Muster, wie bei Kat.Nr. 401-1, sind selten. In Kombination mit vertikalen und waagerechten Linien kreuzen sich die Linien unsystematisch. Eine Entsprechung findet dieses seltene Kammstrichmotiv am ehesten in einer Wandungsscherbe aus Hatzum-Boomborg (LÖBERT 1982, Taf. 55, 983). 
Um eine intentionelle Gefäßrauung durch Ritzung handelt es sich auch beim Besenstrich. Hier sind es feine Linien, die durch das flächige Überstreichen mit einem weichen Werkzeug entstehen (Kat.Nr. 884 Fdnr. 1068 (Farbtafel)). Der Besenstrich kann eng- oder weitstehend schmale Rillen in die Wandung einritzten. Die Linienführung ist dabei vertikal zum Gefäßfuß geführt. Horizontale und diagonale Rillen sind in Nortmoor nicht belegt. Die Rillen haben oft einen unregelmäßigen Abstand zueinander. Sie können schmale und scharf eingeritzte Linien bilden oder breit und flach eingeritzt sein. Das Muster ist beschränkt auf den unteren Gefäßteil. Die graubraune Oberfläche der Scherben ist geschlickt und nur einfach geglättet. Eine Beschränkung auf einen bestimmten Gefäß- oder Randtyp ist nicht feststellbar. Die Verzierung wurde vermutlich zur besseren Handhabung vorwiegend auf relativ grober Siedlungsware angebracht.

Bereits seit der Latènezeit sind Kammstrichmuster in Mittel- und Westdeutschland bekannt (USLAR 1938, 35). Im nordwestdeutschen Gebiet treten die Verzierungen hauptsächlich auf älterkaiserzeitlichen Gefäßunterteilen auf (LEHMANN 2002, 63). LÖBERT (1982, 63-64) führt vergleichbare Gefäßverzierungen als Rauung durch Ritzung auf. In Hatzum-Boomborg finden sich vertikale, waagerechte, bogenförmige oder sich kreuzende Muster (LÖBERT 1982, Taf. 55, 980-985). Die Strichritzungen sind dort selten und nicht auf einen Fundhorizont begrenzt.

Während diese Dekorart in Brill auch eher selten vorkommt, ist sie in Nenndorf häufiger anzutreffen (GROTELÜSCHEN 2000, 28). In der Marschensiedlung Tofting ist streng gegliederter Kammstrich in frühkaiserzeitlichen Schichten belegt (BANTELMANN 1955, Taf. 21,23). Am Ende der Kaiserzeit treten vermehrt querverlaufende und bogenförmige Verzierungen auf (STEIF 1988, 104). Nach GAEDTKEECKARDT $(1991,35)$ nimmt die Kammstrichverzierung mengenmäßig in der jüngeren Kaiserzeit ab.

\subsection{Stempel, Eindrücke, Einstiche (VF 2)}

Im Nortmoorer Material sind Eindrucks-Muster relativ häufig. Die Eindrücke sind entweder mit der Fingerspitze oder dem -nagel oder mit einem Gegenstand (hölzernes Stöckchen, Flintabschlag, etc.), der ein spitzes oder stumpfes Ende aufwies, in den Ton gedrückt worden. Eindrücke kommen auf der Nortmoorer Keramik in verschiedenen Ausführungen und Kombinationen untereinander vor.

\subsection{1 Stempel (VF 2.1)}

Kat.Nr. 192-1; 195-23; 278-1

In Nortmoor gibt es nur wenige Belege für Stempelmotive. Mit einem Stempel ausgeführt sind die dekorierten Kreisaugenverzierungen an einem Trichternapf (Kat.Nr. 278-1). Auf dem 10cm durchmessenden Kleingefäß sind fünf Stempeleindrücke erhalten. Die Zierzone beginnt knapp unterhalb des Randes zunächst mit einem plastischen Wulst, der mit diagonalen Ritzungen verziert ist. Knapp darunter ist, zu Dreiergruppen angeordnet, der aus drei konzentrischen Kreisen gebildete 
Stempel eingedrückt.

Das Motiv wurde vermutlich mit einem Hornstempel geprägt, wie ein Knochenstempel von der Feddersen Wierde nahe legt (SCHMID 1980, Abb. 1,a). Einen Stempel mit Kreisaugenmuster fand man u.a. im Fundgut von Huntebrück-Wührden (FöRST 1994, 50). Zwar ist der Kreisaugendekor eher von sächsischer Keramik bekannt, dem stehen jedoch Machart und Randform des Nortmoorer Stückes entgegen. Gestempelte Motive stellen eine Entwicklung spätkaiserzeitlicher Zeit dar (BISCHOP 2001, 124-129, Abb. 105, 9). Ein beliebter Dekor an Trichterschalen des 2./3. Jahrhunderts sind beispielsweise Rosettenstempel (SCHMID 1980, Abb. 2, 1-2). Einfache Kreisstempel finden sich bereits in der jüngeren Kaiserzeit (HALPAAP 1994, 105, 108, Abb. 45, 41).

Möglicherweise um ein weiteres Stempelmotiv in Form eines Quadrates handelt es bei einer dicht ausgeführten Eindrucksreihe. Diese findet sich umlaufend unterhalb der Gefäßschulter einer Trichterschale und ist von zwei Rillenlinien eingefasst (Kat.Nr. 192-1). Für Nenndorf sind sie als flächendeckende Verzierungen belegt (GROTELÜSCHEN 2000, 29, Abb. 6, 10). Eine mit Kreis-, Eierstab- und Spiralmotiven gestempelte Wandungsscherbe (Kat.Nr. 520-1) wird im Abschnitt nachgeahmte Importkeramik behandelt.

Bodenmuster kommen in Nortmoor nicht an Gefäßkeramik vor. Einzig an der schmalen Stirnseite eines Webgewichtes findet sich ein k-artiges Zeichen (Kat.Nr. 195-23). Derartige pyramidenstumpfförmige Webgewichte stammen in Brill aus einem in die mittlere Kaiserzeit datierten Grubenhaus (LEHMANN 2002, 54). In Toftig gehören Webgewichte dieser Form dem 2. Jahrhundert n. Chr. an.

\subsection{2 Dellen (VF 2.2)}

Kat.Nr. 3-3; 3-27; 3-28; 3-31; 195-1; 584-7; 627 Fdnr. 525 (Farbtafel); 703-2; 810-1

Dellen sind eine vorwiegend auf Schalen angebrachte Dekorart. Die oft kreisrunden Dellen drückte man flach in die Wandung ein. Meist sind sie kleiner als Fingereindrücke und weisen keine Fingernagelspuren auf. Oft überziehen Dellengruppen ohne erkennbares Muster in unregelmäßigen Abständen locker den Gefäßkörper (Kat.Nr. 3-27; 3-31; 627 Fdnr. 525 (Farbtafel); 810-1). Ausgespart ist das obere Drittel der Wandung und eine kleine Zone über dem Flachboden (Kat.Nr. 3-27).

Zumeist sind es kreisrunde Dellen, selten oval geformte (Kat.Nr- 3-28). Bei der letztgenannten Griffschale zeigen sich mehrreihige Dellengruppen von wenigstens 7 Reihen übereinander. Eine andere steilwandige Schale ist segmentär mit einer Dellengruppe aus 12 regelhaft nahe beieinander eingedrückten Dellen dekoriert (Kat.Nr. 584-7). Dies ähnelt verzierten Wandungsscherben aus dem Reiderland (LÖBERT 1981, Taf. 46, 792 u. Taf. 47, 793-794). Eine durch Rillen getrennte mehrreihige Dellenreihe tritt in Nortmoor auf einer Wandungsscherbe auf (Kat.Nr. 379-1). Die Art der o.g. 
Eindrücke lässt vermuten, dass ein rundes Hölzchen mit einem Durchmesser von 2-3mm für die Verzierungen verwendet wurde.

Auch einreihige randläufige Dellenreihen verzieren Schalenränder (Kat.Nr. 3-3). Belegt sind einreihige Dellenlinien außerdem auf der fragmentarisch erhaltenen Wandung eines kumpfartigen Gefäßes (Kat.Nr. 703-3). Eine Importschale ist in ihrem Fries mit zwei schwach eingedrückten Dellen dekoriert (Kat.Nr. 195-1)

In Brill kommen Dellen auf weit- und engmündigen Töpfen vor, weniger häufig auf Kümpfen (LEHMANN 2002, 64). Während dort zweigliedrige Schalen dicht gestellte waagerechte Dellenreihen aufweisen (LEHMANN 2002, Taf. 71, 4232), fehlt in Nortmoor dieses Motiv. Schalen vom Typ S5 in Nord-Drenthe zeigen einen ebenfalls flächigen Dellendekor (TAAYKE 1995, Abb. 33, 1). Dellenmotive finden sich auf Hodorfer Schalen des 3. Jahrhunderts (SCHMID 1965b, 26). Sie gelten als typischer Dekor der friesischen Keramikware (SCHMID 1965b, 35). In der Wesermarsch sind es vorzugsweise Dellendreiergruppen (FÖRST 1991, 41).

Kleine runde Dellen zieren bei einem anderen engmündigen Topf die unterrandständige plastische Zierleiste (Kat.Nr. 403-1). In Wijster kommen plastische verzierte Leisten auf engmündigen Töpfen vom Typ W IIIB im 3. Jahrhundert vor (VAN ES 1967, 233, Abb. 126).

\subsection{3 Fingertupfen (VF 2.3)}

Kat.Nr. 3-9; 195-11; 195-12; 195-13; 400a-2; 432-8; 627-1

Randverzierungen mit Fingertupfen treten an eng- und weitmündigen Gefäßen in Nortmoor auf. Sie können als Dellenlinie knapp unterhalb eines Topfrandes angebracht sein (Kat.Nr. 3-9) oder finden sich dort als Fingertupfenmuster auf einem Schalenrand (Kat.Nr. 195-11). Auch engmündige Töpfe können mit einem leicht unterrandständigen Tupfenrand verziert sein (Kat.Nr. 195-12). An wenigen Rändern kommen länglich-ovale Eindrücke direkt oben auf der Randlippe vor (Kat.Nr. 432-8; 627-1). Fingertupfen sind an Gebrauchskeramik mit lang-senkrechtem Rand zu beobachten (Kat.Nr. 432-1; 627-1). In der Seitenansicht zeigt sich ein wellenförmiger Rand, dessen längliches Profil oft nur gering verdickt ist.

Die Zierzone ist bei den Nortmoorer Stücken in wenigen Fällen auf die Randlippe beschränkt. In regelmäßigen Abständen wurden Fingerkuppen in den feuchten Ton eingedrückt, so dass in der Seitenansicht ein Wellenrand entstehen konnte. Die Randlippe der Nortmoorer Wellenränder wurde nach dem Anbringen der Tupfen erneut glattgestrichen, womit längliche Eindrücke entstanden sind (vgl. LÖBERT 1982, 62, Taf. 29-471).

Verzierte Ränder finden sich in Nortmoor bevorzugt auf engmündigen Töpfen der GF 7.9 mit 
parallelseitigem oder leicht verdicktem Rand der RF 1.1, 2.1 oder 3.1. Auch Töpfe der GF 7.2 und 7.5 können mit Fingertupfenrändern verziert sein. In Mittel-Groningen sind mittelgroße Töpfe vom Typ V1-V5 mit Fingertupfen verziert (TAAYKE 1996a, 28-31, Abb. 18 u. 19).

Fingerkuppeneindrücke sind in Nortmoor selten auf plastischen Leisten anzutreffen. Bei einem engmündigen Topf vom Typ Eddelaker sind es unterrandständig mit den Fingerkuppen eingedrückte Fingertupfendellen (Kat.Nr. 3-9), wobei der Gefäßrand zusätzlich durch eine Fingertupfenreihe dekoriert ist. Das Gefäßunterteil Kat.Nr. 400a-2 wird mit einer diagonalen Fingertupfenreihe auf einer Leiste verziert. Gleichfalls ungewöhnlich ist ein flächiger Fingertupfen-Dekor auf der unteren Gefäßhälfte eines Topfes (Kat.Nr. 195-13). Hier sind jedoch die Tupfen regellos und unsorgfältig eingedrückt worden. Es handelt sich jeweils um Unikate unter dem Fundmaterial in Nortmoor; Vergleichsfunde sind nicht bekannt.

Fingertupfen sind sorgfältig mit der weichen Fingerkuppe nur leicht in den feuchten Ton eingedrückt und es bildet sich, im Unterschied zu scharfkantigen Fingernagel-Kerben, eine dellenartige Verzierung. Meist wurden sie von unten nach oben auf die Gefäßwandung angebracht, da sich der Wulst der Abdruckkante oberhalb des Eindruckes befindet. Sie kommen auf engmündigen Töpfen vom Eddelaker Typ sowohl auf der äußeren Randlippe wie auch auf der plastischen Zierleiste vor (Kat.Nr. 3-9). Das doppelte Fingertupfenmuster auf Gefäßrand und unterrandständiger plastischer Leiste eines Nortmoorer Stückes (Kat.Nr. 3-9) findet seine Entsprechung in einem nahezu identischen Stuick in Nord-Drenthe (TAAYKE 1995, 44, Abb. 36,2).

Gewellte und mit Fingertupfen verzierte Gefäßränder sind in Hatzum-Boomborg belegt (LÖBERT 1981, Taf. 35, 571-575). Dieser Randdekor findet sich auch in Huntebrück-Wührden hauptsächlich oberhalb der Randlippe (FÖRST 1991, 40, Taf. 111, 16 u. 17) und ist nur selten an unterrandständigen Tupfenreihen bei weitmündigen Schalen belegt (FÖRST 1991, Taf. 99, 54). Sie gelten als charakteristisch für die niederländische Terpenkeramik und treten bereits in der späten vorrömischen Eisenzeit auf (SCHMID 1965b, 34). In Paddepoel finden sie sich vorzugsweise an Töpfen der Form PP IVC und D, die in das 1. und 2. Jahrhundert datiert worden (VAN Es 1968, 268).

\subsection{4 Fingernagel-Kerben (VF 2.4)}

Kat.Nr. 3-7; 3-18; 3-24; 3-33; 100-1; 140-1; 278-17; 584-6; 840-1; Qu 57/54 568 (Farbtafel); Qu 55/51 Fdnr. 526 (Farbtafel); Qu Fdnr. 556 (Farbtafel)

Eindrücke von Fingernägeln finden sich auf einer Vielzahl von Nortmoorer Keramikscherben. Bevorzugte Verzierungszone für Fingernagelkerben war bei einigen Gefäßen wohl die untere Wandung von Schalen und Töpfen, soweit das fragmentierte Material diese Aussage zulässt.

Der Abstand der Eindrücke ist oft geringer als ein Zentimeter. Die Fingerkniffe sind oft regellos und 
ohne bestimmte Abfolge zueinander eingedrückt. Es zeigt sich eine flächendeckende und engmaschige Anlage, wohl zumeist auf der unteren Gefäßhälfte, um durch eine derartige Rauhung die Handhabung der Keramik zu verbessern (vgl. LÖBERT 1982, 63).

Bei einem Schalenrand setzt die Verzierung mittig auf dem Gefäßkörper ein und zieht sich bis zum Boden hinab (Kat.Nr. 3-18; 3-33). Belegt sind sie auf der oberen Halspartie bei engmündigen Töpfen vom Typ Eddelaker (Kat.Nr. 3-7). Bei einigen Wandungsscherben finden sich „Reihungen“ von Einkerbungen, die unterhalb des Umbruchs flächig das Gefäß bedecken (Kat.Nr. 3-18). Der Nagel zeichnet sich recht scharf im Ton ab, wobei ein Wulst aus zusammengedrücktem Ton entsteht und die jeweilige Eindrucksrichtung anzeigt (Kat.Nr. 140-1; 840-1).

Teilweise bilden sich bei nur leicht eingetieften Fingernageleindrücken lediglich halbkreisförmige Eintiefungen ohne Wulst (Kat.Nr. 3-33; 3 Fdnr. 568 (Farbtafel)). Bevorzugte Verzierungszone auf Gefäßen in Nortmoor ist die gerade oder nur leicht konvexe untere Wandung. Meist treten die Kerbungen gehäuft auf (Kat.Nr. 3-24), bilden regelrechte Clustergruppen (Kat.Nr. 3-18; 840-1) oder Reihen (Kat.Nr. 3-7; 101-1).

Eine Kombination mit anderen Verzierungen wurde selten festgestellt. So bei einer Randscherbe mit plastischer Leiste (Kat.Nr. 3-7). Ungewöhnlich sind Fingernageleindrücke auf einer Wandscherbe, die dort sowohl mit als auch ohne Wulstbildung auftreten (Kat.Nr. 840-1). In einem anderen Fall ist eine parallelseitige Randscherbe auf ihrer Randlippe mit kurzdiagonalen Fingerkerben verziert (Kat.Nr. 278-17).

Die Eindrücke wurden zumeist von links nach rechts geführt, so dass sich die Wulstkante mit dem zusammengeschobenen Ton rechts befindet. Seltener sind die Eindrücke von unten nach oben oder von oben nach unten in Reihen geführt, wie bei einer Wandungsscherbe mit zwei gegenläufige Reihen von Eindrücken, die von Rillen flankiert werden (Kat.Nr. 584-6).

Nur eine Scherbe weist Fingernageleindrücke unterhalb des Randes auf (Kat.Nr. 100-1). Ihr aufwendiger Dekor setzt $2 \mathrm{~cm}$ unterhalb der Randlippe ein und besteht aus vier umlaufenden Reihen mit dicht nebeneinander stehenden horizontalen Fingernageleindrücken. Es folgen zur Gefäßschulter wenigstens drei Reihen vertikal orientierte Verzierungsreihen mit diagonal gegeneinander stehenden Fingerkniffen. Die Scherbe besitzt einen extrem langen Rand $(>7 \mathrm{~cm})$, der ohne Profilierung übergangslos in die gleich dicke Gefäßwandung übergeht. Die dunkelgraue, grob gemagerte Scherbe ist weder geglättet noch geschlämmt. Ihr Habitus entspricht dem eines spätneolithischen Bechers.

Singulär ist auch das Motiv einer Wandungsscherbe, die mit Fingernageleindrücken verschiedener Orientierungen dekoriert ist. Die Kerben sind diagonal oder waagerecht eingedrückt. Die vertikalen Einkniffe scheinen ein radiales Muster zu bilden (Kat.Nr. 840-1). Hier handelt es sich um ein spätneolithische - frühbronzezeitliche Scherbe. 
Ein Flachboden mit situlenartiger Form ist von regelmäßigen senkrecht stehenden Einkerbungen im Findernageldekor überzogen (Kat.Nr. 140-1). Vergleichbare Stücke fehlen in Brill, wie auch in Hatzum-Boomborg. In Soest-Ardey sind an kaiserzeitlichen Gefäßen Nagelkerben sowohl in unregelmäßiger Anordnung als auch in Reihung oder schräg gestellten Einzelreihen belegt (HALPAAP 1991, 107, Taf. 28-22, 28-42, 28-45). Fingernagelverzierungen liegen in allen Zeitstufen vor und können seilbst keinen Datierungsansatz bieten (LEHMANN 2002, 36).

\subsection{5 Einstiche (VF 2.5)}

Kat.Nr. 3-20; 3-22; 3-23; 3-32; 10-2; 61-1; 121-2; 140-8; 216-6; 216-17; 216-19; 216-21; 379-1; 403$1 ; 432-7 ; 432-8 ; 480-1 ; 806-1 ; 859-1$

Reihen punktförmiger Einstiche treten in Nortmoor meist als Begleitmuster für Rillenverzierungen auf (Kat.Nr. 216-17; 216-19; 216-21). Selten stellen Einstichreihen die einzige Verzierung dar oder überziehen flächig den Gefäßkörper (Kat.Nr. 3-32). In einem Fall ziert eine Einstichreihe einen Bandhenkel (Kat.Nr. 140-2). In Nortmoor sind Punktbänder oft mit geometrischen Motiven kombiniert (Kat.Nr. 192-1; 216-6; 480-1), wobei sich die Verzierung auf Trichterschalen und -näpfe begrenzt. Die Einstiche säumen bei horizontalen Verzierungen zum einen als untere Begrenzung Rillenlinien, hängende Dreiecke oder Bögen (Kat.Nr. 859-1; 121-2; 480-1), sie können jedoch auch Sparrenbänder begleiten (Kat.Nr. 216-17).

Belegt sind lange punktgesäumte Rillen, die vertikal auf dem Gefäßunterteil verlaufen. Diese sind neben dem punktgesäumten Rillenmotiv zusätzlich mit Punktbändern verziert. In der Kombination treten ein- und zweireihige Punktbänder auf, die von zwei bis vier Rillenpaaren begleitet werden (Kat.Nr. 480-1). Eine knapp unterrandständige plastische Leiste ist mit zwei umlaufenden Einstichreihen verziert (Kat.Nr. 806-1). Eine andere diagonale Einstichreihe verziert eine plastische Schulterleiste (Kat.Nr. 195-14) und hat ihre Entsprechung in einem Topf aus Westerwanna (SCHMID 1965b, 22; 1969, 160, Abb. 1, 4, 5; 1981b, 42). Mit ovalen Einstichen verzierte Gefäßfüße kommen in Hatzum-Boomborg bei Trichterpokalen vor (LÖBERT 1982, Taf. 53, 929) und sind auch in Holtgaste anzutreffen (STILKE 1995b, 210, Abb. 5, 9).

Abgerundete Verzierungselemente ergänzen das Formenrepertoire von Einstichmustern, länglichovale (Kat.Nr. 379-1; 432-7; 432-8; 859-1) können unterschieden werden von halbkreisförmigen (Kat.Nr. 10-2). Die Einstiche säumen den äußeren Rand rillengefüllter Dreiecke oder werden von umlaufenden Rillen eingefasst. Bei den kantigen Einstichen überwiegen keilförmige (Kat.Nr. 3-20; 322; 3-23; 10-2; 61-1). Länglich dreieckige Einstiche stellen im Nortmoorer Material ein beliebtes Begleitmuster dar. Die Einstiche flankieren als Einzelreihe parallel verlaufende Rillen, begleiten 
Rillen mehrreihig (Kat.Nr. 3-2; 61-1) oder dienen als Füllmuster für Flechtbänder (Kat.Nr. 3-22). Ein ähnliches Stück liegt aus Brill vor (LEHMANN 2002, Taf. 64, 2415-2).

Die derart verzierten Wandungsscherben können gefäßtypologisch nicht zugeordnet werden, stammen jedoch fast ausnahmslos von sorgfältig geglätteten bis polierten Keramikgefäßen. Der Dekor ist mit einem spitzen Gegenstand in den feuchten / lederharten Ton eingestochen worden. Die Hauptverzierungszone punktförmiger Einstiche ist bei Trichterschalen der Bauchumbruch und die von hier abwärts angebrachten geometrischen Muster. Seltener anzutreffen sind die Einstiche am Gefäßhals (Kat. 806-1) und in der Bodenzone (Kat.Nr. 480-1).

Rillenbegleitende runde Einstiche können als Verzierung von der älteren Kaiserzeit bis in die Völkerwanderungszeit verfolgt werden (SAGGAU 1986, 78). Punktsäume für Rillenpaare werden bereits im 1./2. Jahrhundert n. Chr. beobachtet (SCHMID 1965b, Taf. IX,3). Horizontale Punktbänder ordnet SCHMID (1965b, 20) dem 2. Jahrhundert zu, während sie in Wijster bis ins 3. Jahrhundert vorkommen (VAN Es 1967, Fig. 98). Trichterschalen des 2./3. Jahrhunderts sind in Hodorf mit nach unten orientierten Punktreihen verziert (SCHMID 1965b, Taf. XIII, 4,12; XV,5). Der Zeitansatz für Punktreihen reicht in Brill bis in die späte Kaiserzeit (LEHMANN 2002, 65). Die mit vertikalen Punktbändern verzierte Standfußschale aus dem Nortmoorer Hammrich ist als jüngerkaiserzeitlich anzusprechen und datiert in das 2./3 Jahrhundert n. Chr. (BÄRENFÄNGER 1999, 77-76, Abb. 26). Eine mittelkaiserzeitliche Trichterschale aus Nortmoor-Plaggenburg ist ebenfalls mit der typischen Punktreihung und vertikalen Zierbändern dekoriert (SCHWARZ/STUTZKE 1998, 98, Abb. 127, 491).

\subsection{Plastische Verzierungen (VF 3)}

Als plastische Verzierungen kommen im keramischen Fundgut Zierleisten, Zierknubben oder Warzen vor. Sie können sowohl auf dem Ton aufgelegt oder aus der noch weichen Gefäßoberfläche vor dem Brand ausgezogen sein.

\subsection{1 Leisten (VF 3.1)}

Kat.Nr. 3-7; 3-8; 3-9; 195-14; 223-5; 400a-2; 403-1; 455-2; 480-1; 499-2; 806-1

Plastische Leisten sind in Nortmoor oft unterrandständig auf dem Gefäßhals angebracht. Sie sind auf der Wandung aufgelegt und zeigen im Querschnitt ein halbrundes bis dreieckiges Profil. Die Profildicke variiert zwischen 0,5-1cm. Zwar kommen auch unverzierte Leisten (Kat.Nr. 3-8; 455-2; 499-2) vor, es überwiegen Eindrücke in Form von Dellen (Kat.Nr. 3-9; 195-14; 403-1), Einkerbungen (Kat.Nr. 3-7) oder sie sind mit kleinen Einstichen dekoriert (Kat.Nr. 806-1). Die Leistenverzierung ist oft an engmündigen Töpfen vom Eddelaker Typ anzutreffen. Eine Ausnahme stellt Kat.Nr. 806-1 dar. Der kurze dreieckige Rand gehörte vermutlich einer weitmündigen Schale an. Auch die doppelte Einstichreihe auf der unterrandständigen Leiste ist ungewöhnlich. Die glatt polierte Oberfläche ist von 
dunkelgrauer Tonfarbe. Die vergleichbar dekorierte Randscherbe eines halslosen Topfes wurde westlich von Zeegse in Nord-Drenthe gefunden und wird wahrscheinlich in das 1. Jahrhundert n. Chr. datiert (TAAYKE 1995, 44-45, Abb. 36, 1).

Um ein Unikat handelt es sich bei einer auf der unteren Gefäßhälfte angebrachten umlaufenden Leiste, die zusätzlich mit einer Dellenreihe verziert ist (Kat.Nr. 400a-2). Die orange-rote Bodenscherbe ist geschlämmt und grob gemagert. Dieses seltene Motiv ist lediglich von einer Wandungsscherbe in Huntebrück-Wührden belegt (FÖRST 1991, 40, Taf. 80, 666).

Leicht erhabende Leisten finden sich knapp oberhalb von zwei hohlen Standfüßen (Kat.Nr. 223-5; 480-1). Kleine Einstiche betonen bei Urne Kat.Nr. 480-1 die umlaufende Fußleiste. Aus dem Westergo stammt ein mit Rippenzier dekorierter hohler Standfuß (TAAYKE 1996b, 160-161, Abb. 44, 13) und auch in östlicher Richtung sind in Huntebrück-Wührden derartige verzierte Standfüße bekannt (FÖRST 1991, Taf. 11, 29). Diese Verzierungsform ist jedoch nicht nur auf Gefäßfüße beschränkt. So zieren diagonale Kerben den Bauchumbruch einer Briller Trichterschale (LEHMANN 2002, Taf. 46, Kat.Nr. 455-1).

Plastische Leisten gelten als Charakteristikum für Töpfe vom Eddelaker Typ, kommen jedoch auch bei bauchigen Töpfen vor. Nach LÖBERT $(1982,63)$ handelt es sich bei der Leistenverzierung um aufgelegte Rippen. In Hatzum-Boomborg sind diese vorwiegend auf engmündigen Töpfen vom Typ 17 angebracht, die dem jüngeren Fundhorizont entstammen (LÖBERT 1981, 80, Taf. 52, 916). Sogenannte Leistentöpfe sind im Elbe-Weser-Gebiet anzutreffen (SCHMID 2006, Taf. 63 d u. e). In Wijster finden sie sich an Töpfen der Form W IIIB, die in das 3. Jahrhundert datieren (VAN Es 1967, 233). Fingertupfen am Rand und auf einer unterrandständigen plastischen Leiste gehören in Oostergo engmündigen Töpfe vom Typ V5 an (TAAYKE 1996b, 108, Abb. 22,4), während dieselbe Verzierungskombination in Nord-Drenthe als Sonderform aufgeführt wird (TAAYKE 1995, 44, Abb. 36, 2). Die Verzierung erscheint in Paddepoel an Töpfen vom Typ PP IIIA (VAN Es 1968, 313). In Hodorf und Tofting sind sie für das 2./3. Jahrhundert belegt (SCHMID 1965b, 28). Hingegen selten kommen im südlichen Niederelbegebiet stark eingetiefte Fingereindrücke auf plastischen Leisten vor (STIEF 1988, 171).

\subsection{2 Knubben (VF 3.2)}

Kat.Nr. 3-2; 3-4; 3-6; 670-2

Zierknubben, die aufgrund ihres geringen Formats nicht mehr als Handhaben anzusprechen sind, sind im Fundmaterial nur gelegentlich anzutreffen. In ihrer flach-ovalen Ausführung sind sie auf der Gefäßschulter eines Trichternapfes belegt (Kat.Nr. 3-2). Zum Gefäßunterteil schließt sich eine 
mehrreihige Rillenzone an. Auf der Gefäßschulter einer unverzierten Trichterschale ist eine Knubbe in Form eines stumpfen Kegels angebracht (Kat.Nr. 670-1).

\subsection{3 Warzen (VF 3.3)}

Kat.Nr. 216-22; 305-1

Nur wenige Wandungsscherben sind mit Warzen dekoriert. Es handelt sich um eine flächig angebrachte Verzierung. Rundliche oder lang-ovale Warzen überziehen dabei die Gefäßoberfläche. Sie können dicht beieinander liegen (Kat.Nr. 216-22) oder kleinere Abstände zwischen den Einzelwarzen aufweisen (Kat.Nr. 305-1). Eine Zuordnung zu einem Gefäß- oder Randtyp ist nicht möglich.

\subsection{Gefäßböden}

Kat.Nr. 3-17; 3-26; 3-27; 3-33; 3-34; 4-42; 3-43; 3-48; 10-1; 93a-2; 126-1; 140-1; 183-9; 195-6; $195-$ 19 ; 195-19; 195-20; 195-21; 195-22; 216-12; 216-13; 223-5; 223-6; 369-2; 383-3; 400a-2; 403-4; 4104 ; 455-1; 480-1; 499-5; 499-6; 516-3; 569-1; 627-3; 627-13; 637-1; 670-1; 740-1; 745-7; 745-8; 7569; 859-8; 859-9; 859-10; 884-11; 884-12; 1018-5; 1018-6; 1082-1; 1113-7; 1120-3

Bei der Betrachtung der Böden sind gegenüber den Randscherben wesentlich weniger formale Merkmale zu beobachten. 14\% der auswertbaren Scherben sind Bodenstücke. Bei einem Großteil der Bodenfragmente ist eine Zuordnung zu einem bestimmten Gefäßtyp nicht mehr möglich.

Zum Großteil handelt es sich um Granitgrus gemagerte Böden, nur wenige sind organisch gemagert. Der ermittelte Bodendurchmesser weist einen Schwerpunkt bei $15-30 \mathrm{~cm}$ auf. Grob gearbeitete Vorratsgefäße weisen einen Durchmesser von bis zu $40 \mathrm{~cm}$ auf.

Die Böden werden i.d.R. unabhängig vom Profilverlauf der Gefäßunterteile vorgelegt. Eine Ausnahme stellen hohle, konisch verlaufende Standfüße von Trichterschalen dar. Diese grenzen sich auch durch ihre meist gut geglättete und polierte Oberflächenbehandlung, wie auch durch ihre oft eher dünnere Wandung $(<0,7 \mathrm{~cm})$ von der normalen Haushaltsware ab. Ihr Bodenradius liegt zwischen $7-10 \mathrm{~cm}$. Kleinkeramik hat einen Bodenradius von 3-7cm.

Es handelt sich in Nortmoor zum überwiegenden Teil um einfache Flachböden. Der Umbruch steigt bei $80 \%$ der Böden relativ gerade oder in einem flachen Winkel empor, manchmal ist die Wandung leicht konkav eingezogen. Bei den übrigen Böden ist die Wandung steilwandig ausgebildet $\left(60-70^{\circ}\right)$. Meist gehen sie ohne besondere Merkmale in die aufsteigende Gefäßwandung über (Kat.Nr. 3-7; 3-26; 3-32; 10-1; 93a-2; 195-19; 195-20; 195-22; 183-9; 223-6; 369-2; 400a-2; 403-4; 410-4; 499-5; 516-3; 637-1; 740-1; 756-9; 859-8; 859-9; 859-10; 1018-5; 1018-6; 1113-7). 
Bei einigen Flachböden ist eine einziehende Wandung oberhalb des Gefäßfußes zu beobachten. Sie zeichnen sich zudem durch eine meist halb so dicke Gefäßwandung aus und wirken insgesamt graziler (Kat.Nr. 126-1; 195-21; 383-3; 84-11). Flache Standböden mit leicht eingewölbter Bodenunterseite sind eher selten (Kat.Nr. 3-27; 3-33; 3-43; 3-48; 195-6; 216-13; 455-1; 698a-2). Zwei dieser Böden gehören verzierten Schalen an, die mit kreisförmigen Eindrücken oder waagerechten Fingernagelkerben verziert sind (Kat.Nr. 3-27; 3-33). Drei Böden stammen von Kleinkeramik (Kat.Nr. 3-32; 216-13; 455-1). Mit Ausnahme zweier Schalen und einem mit kleinen Einstichen verzierten Miniaturgefäß sind sämtliche Flachböden unverziert. Situlenartigen Gefäßen können acht Bodenscherben zugeordnet werden (Kat.Nr. 3-48; 126-1; 140-1; 698a-2; 745-7; 745-8; 884-11).

Ein leicht abgesetzter Fuß ist knapp oberhalb des Bodens mit senkrecht gestellte Fingernagelkerben verziert (Kat.Nr. 140-1). Die bis in die Fußzone reichende Verzierung ähnelt einer aus MittelGroningen vorliegenden Standfußschale (TAAYKE 1996a, 34, Abb. 28, 1). Von der Feddersen Wierde werden Standfußschalen mit flachem Fuß in das 4. Jahrhundert datiert (SCHMID 1981a, Fig. 3).

Singulär ist die konvex geformte Wandung einer Bodenscherbe, die fast in einem $80^{\circ}$ Winkel steil in den Gefäßkörper übergeht (Kat.Nr. 3-34). Der Durchmesser des Flachbodens beträgt etwa $9 \mathrm{~cm}$.

Abgesetzte flache Standplatten sind verhältnismäßig selten (Kat.Nr. 3-42; 499-6; 569-1; 627-3; 88412). Die Böden sind massiv ausgebildet und setzen sich mit einem scharfen Umbruch von der Gefäßwand ab. Die Dicke der Bodenplatte entspricht der Absatzhöhe. Ein Unikat stellt die leicht erhabene Standplatte eines sorgfältig polierten Bodens dar (Kat.Nr. 884-12). Ungewöhnlich breit ausgezogen ist eine andere Bodenplatte (Kat.Nr. 3-42). Im Fundmaterial von Nortmoor sind diese Böden unverziert, grob Granitgrus gemagert und einfach geschlämmt. Eine Ausnahme bilden zwei relativ fein gemagerte und polierte Standplatten (Kat.Nr. 569-1; 884-12).

Standringe sind zwar nur in wenigen Exemplaren vertreten (Kat.Nr. 216-12; 223-5; 670-1; 1120-3), aber können an verschiedenen Gefäßtypen vorkommen (STIEF 1988, 278). Singulär ist ein Bodenfragment mit einer bis in die Standfläche hinabreichenden Verzierung. Ein kastenförmiger Rahmen begrenzt eine flächige Schraffur mit diagonalen Rillen (Kat.Nr. 216-12). Standringe sind an jüngerkaiserzeitlichen und völkerwanderungszeitlichen Schalenurnen zu beobachten (GAEDTKEECKARDT 1991, Taf. 9,66).

Überliefert sind in Nortmoor zwei hohle Standfüße. Beide besitzen einen verhältnismäßig geringen Durchmesser, der breiter als hoch ist (Kat.Nr. 3-40; 480-1). Um ein Unikat handelte sich bei einem extrem hohen, hohlen Standfuß, der einer gut erhaltenen Trichterschale angehört (Kat.Nr. 480-1). Der Hohlfuß des reich verzierten Gefäßes weist eine leicht erhabene plastische Leiste auf, die zusätzlich mit einer Einstichreihe betont wird. Hohlfüße dieser Art sind u.a. für den Gefäßtyp 18 in HatzumBoomborg belegt (LÖBERT 1982, Taf. 53, 927). Standfußgefäße zählen zur Feinkeramik und sind 
daher sehr sorgfältig gearbeitet. Sie datieren bei Eggers in die Stufe B2 und C1.

Bei SCHMID (1965, 23-25, Taf. VII u. VIII, 1-5) sind sie namensgebend für einen Gefäßtyp und treten im Zeitraum zwischen dem 1. und 3. Jahrhundert n. Chr. auf. Möglicherweise um den Rest eines Standfußes handelt es sich bei einem anderen Bodenfragment (Kat.Nr. 223-5). Das massiv ausgebildete Mittelteil des Bodens ist mit einer plastischen Zierleiste dekoriert. Derartige Leisten am Ansatz von Standfußgefäßen liegen von Fundstellen aus der Marsch vor. Vergleiche für dieses Stück finden sich in Westergo bei Schalen vom Typ K4 (TAAYKE 1996b, 154, Abb. 37. 23).

Wenige Gefäße sind bis in den Bodenbereich verziert. Eine Ausnahme stellen weitmündige Töpfe mit Besenstrichdekor dar, der bis knapp über den Boden verläuft. Bei der groben Haushaltsware bot dies Vorteile einer besseren Handhabung der schweren dickwandigen Töpfe.

Auch bei Schalen sind flächige und bis zum Boden reichende Verzierungszonen festzustellen. Die Außenseite ist mit regelmäßigen Einkerbungen oder Eindrücken überzogen. Selten sind Trichterschalen im Bodenbereich verziert. Meist ging die Verzierungszone nicht über den unteren Wandungsbereich hinaus. Eine Ausnahme ist die Einstichreihe auf einem hohlen Standfuß (Kat.Nr. 480-1).

Bruchstücke von Siebgefäßen gehören zum Bestand der Siedlungskeramik. Aus Nortmoor ist ein Bodenfragment mit rundlichen Durchlochungen bekannt (Kat.Nr. 509 Fdnr. 733). Zwei weitere Wandscherben gehören vermutlich einer Siebschale an (Kat.Nr. 216, 20; 703 Fdnr. 484). Sie entsprechen der Variante 11a in Hatzum-Boomborg (LÖBERT 1982, Taf. 45, 760-762). Siebgefäße werden mit Milch verarbeitenden Hauswerk in Verbindung gebracht. Sie gehören zum Bestand jüngermetallzeitlicher Siedlungen, ohne dass eine Unterscheidung in eisen- oder kaiserzeitlichen Exemplare gelingt.

\subsection{Handhaben}

Handhaben kommen bei einer Vielzahl von Gefäßtypen vor. Bei Töpfen und Henkelkrügen können sie direkt am Rand, unter der Randlippe oder an der Halszone und am Gefäßkörper angebracht sein. Bei Trichterschalen und Schalen sind sie unterrandständig. Griffknubben und -lappen können rand- oder unterrandständig angebracht sein. Henkel und Knubben schließen sich gegenseitig aus. Mit Ausnahme zweier Bandhenkel sind Handhaben unverziert. Mit Fingertupfen verzierte Gefäße weisen keine Handhaben auf.

\subsection{Henkel}

Kat.Nr. 3-26; 3-49; 3-50; 140-8; 183-9; 195-8; 195-9; 223-2; 235b-2; 278-9; 394-1; 394-4; 517-2; 698a-1; 836-1; 884-7; 884-10 
Bandhenkel sind randständig oder knapp unterrandständig angebracht und reichen oft bis zum Gefäßumbruch in der Bauchzone herab. Meist sind sie in der oberen Halspartie angebracht. Die Henkel haben i.d.R. einen flachen Querschnitt, sind 1-2cm dick und etwa 2-3,2cm breit. Ihre Länge variiert zwischen 2 und $4 \mathrm{~cm}$. Bandförmige Henkel mit kurzovalem Querschnitt (2 mal so breit wie hoch) sind doppelt so häufig wie rundovale Henkel vertreten.

Bei weitmündigen Henkeltöpfen mit geringer Profilierung ist der Henkel randständig (Kat.Nr. 223-2) oder direkt unterhalb der Randlippe angebracht (Kat.Nr. 3-49; 517-2; 836-1). Vermutlich waren die Henkel paarig angebracht, wie bei dem einzigen nahezu komplett erhaltenen friesischen Henkeltopf (Kat.Nr. 183-9). Dort reichen die wulstförmigen, abgeknickten und knapp unterrandständigen Henkel bis auf den hoch ansetzenden Gefäßumbruch hinab. Diese Topfform war bereits zu Beginn der Kaiserzeit bis in den Weserraum bekannt (SCHMID 1965B, 33-35). Sie findet sich unter dem kaiserzeitlichen Keramikmaterial von Hatzum-Boomborg (LÖBERT 1982, Taf. 32, 521), wie auch in Wijster, dort in einem Befund des 1. Jahrhunderts n. Chr. (VAN Es 1967, Fig. 132, 85), und kann in den Niederlanden noch im 3. Jahrhundert n. Chr. nachgewiesen werden. Manchmal waren Henkel mit einem knopfförmigen Fortsatz an der Oberseite verziert (vgl. SCHMID 1965b, 33, 36).

Unterschieden werden können randständige von unterrandständigen Henkelansätzen, es überwiegen leicht unterrandständige Henkel. Meist handelt es sich um Bandhenkel, einige Henkelexemplare sich reckwinklig geformt (Kat.Nr. 235b-2; 394-1; 698a-1; 884-10). In Nortmoor liegt bei Töpfen mit Henkel der Randdurchmesser zwischen 6 und 24cm. Die Ränder der Henkeltöpfe sind meist nur knapp bis unterhalb des unteren Henkelansatzes erhalten, somit kann die Gefäßform nur über Vergleiche erschlossen werden. Kat.Nr. 235b-2 kann dem Typ Westerwanna zugeordnet werden. Vom kurzverdickten Rand geht das Profil in einen unterrandständigen Henkel über, wobei der obere Henkelverlauf im Unterschied zu Töpfen der Feddersen Wierde fast waagerecht geformt ist (SCHMID 2006, 151, Taf. 58, b). Ein Unikat stellt eine mit einem einfachen Bandhenkel versehene Trichterschale dar (Kat.Nr. 3-26). Hier ist der Bandhenkel unterhalb der Randlippe appliziert. Es handelt sich um einen singulären Henkel, da auf der gegenüber liegenden Seite ein entsprechender Henkelansatz fehlt.

An engmündigen Töpfen und Krügen mit gerade aufgestellten Rand oder nur leicht betonter Randlippe finden sich häufiger Bandhenkel. Diese sind randständig oder knapp unterrandständig und reichen bis auf die Gefäßschulter. Es können wulstförmig rundliche Bandhenkel (Kat.Nr. 884-7) oder flach ausgebildete Handhaben sein. Engmündige krugähnliche Gefäße haben ebenfalls unterrandständige, oft abgewinkelte Henkel (Kat.Nr. 195-8; 884-10). Diese Henkelform existiert auch bei kleinen engmündigen Gefäßen (Kat.Nr. 195-9). Es ist zu vermuten, dass diese, auch als kleine tassenförmige Gefäße bezeichnete, Keramikform nur einen Henkel aufwies (vgl. LÖBERT 1982, 64; TAAYKE 1996a, 31, Abb. 22, 3). 
Diese für die Spätlatène- bis Kaiserzeit typische Henkelform dient als Datierungsansatz für weitmündige Töpfe. Der besagte winklig, unterrandständige Henkel mit abfallender Oberseite wird von LEHMANN (2002, 40, Taf. 80, 11-0-1) angeführt und ist auch in Nortmoor zu finden (Kat.Nr. 349).

Angewinkelte Henkel kommen in Hatzum-Boomborg bei Töpfen vom Typ 4 wie auch bei der Variante 9a vor und werden allgemein der römischen Kaiserzeit zugewiesen (LÖBERT 1982, 80). In der Geestsiedlungen Nenndorf datieren Henkelkrüge mit rechtwinkligen Henkeln in die ältere Kaiserzeit (GROTELÜSCHEN 2000, 47).

Für Brill erfolgt durch die Fundvergesellschaftung eines rechtwinklig umgebogenen Henkels mit einer Armbrustfibel eine Datierung in das ausgehende 2. und 3. Jahrhundert (LEHMANN 2002, 56). Zweihenklige Gefäße mit s-förmigem Profil finden sich u. a. im ostfriesischen Jemgumkloster und in Upleward (SCHMID 1965b, Taf. XXVI, 1; Taf. III, 5 u. 6). In Mittel-Groningen kommen an engmündigen mittelgroßen Gefäßen vom Typ Ge5 paarig rechtwinklige Henkel vor (TAAYKE 1996a, 24, Abb. 13, 2). Bei engmündigen Töpfen mit dreieckigem Rand setzten Bandhenkel unterhalb des Randes am Gefäßhals an (Kat.Nr. 235b-2). TAAYKE (1996b, 158-159, Abb. 42,4) führt diese Gefäßform als eine kaiserzeitliche Sonderform für das niederländische Westergo an.

Dies ist auch bei Töpfen mit parallelseitigem Rand eine bevorzugte Stelle für den Henkelansatz (Kat.Nr. 394-1). Nahezu randständig ist der Bandhenkel an einem stark einziehenden und beidseitig verdickten Rand eines engmündigen Gefäßes angesetzt (Kat.Nr. 698a-1). Vergleichbare rechtwinklige Bandhenkel an S-förmigen Töpfen weist Typ 5a in Hatzum-Boomborg auf (LÖBERT 1982, Taf. 34, $560,564)$.

Singulär ist ein Schalenfragment mit einem unterrandständigen Bandhenkel, der sich in Ansätzen erhalten hat und der Schale ein tassenartiges Aussehen gibt (Kat.Nr. 265-1). Tassen sind zwar für die Kaiserzeit beispielsweise aus Mittel-Groningen belegt, dort jedoch mit einem wesentlich kleineren Durchmesser vorkommend (TAAYKE 1996a, 37, Abb. 33, 4). Im unteren Emsgebiet wurden Schalen bevorzugt mit Griffknubben als Handhaben versehen (LÖBERT 1982, 58, Taf. 48, 859).

Runde Henkel kommen im Fundmaterial selten vor (Kat.Nr. 278-9). Bei den wenigen vorliegenden Exemplaren ist der Rundhenkel im oberen Gefäßteil nahe am Gefäßumbruch angebracht. Die Henkel können vom Gefäß rundlich abstehen oder sind rechtwinklig ausgeformt.

Verzierte Henkel sind außergewöhnlich selten. Lediglich zwei Bandhenkel weisen Verzierungen mit punktförmigen Einstichen (Kat.Nr. 140-2) oder vertikalen Rillen auf (Kat.Nr. 3-50). Da sie nur rudimentär erhalten sind, können keine Aussagen zum zugehörigen Gefäßtyp getroffen werden. In Hatzum-Boomborg sind Bandhenkel an den Ansätzen mit Dellen verziert, während Rillen und Einstiche nur selten vorkommen (LÖBERT 1982, 64). 


\subsection{Griffknubben, -lappen und -ösen}

Kat.Nr. 3-4; 3-6; 3-28; 160-1; 216-14; 265-1; 369-2; 627-12; 703-1

Knubben treten meist auf schalen- oder napfartigen Gefäßen auf und sind i.d.R. auf den Gefäßkörper appliziert. Sie können einzeln, paarig oder als Dreiergruppe angebracht sein. Ausgezogene Randknubben treten bei vollständig erhaltenen Gefäßen häufig als Dreiergruppe auf (LEHMANN 2002, 57). In Nortmoor sind Knubben in zwei unterschiedlichen Ausführungen bekannt. Es überwiegen Knubben mit querovalem Querschnitt (Kat.Nr. 3-4, 3-28), weniger häufig sind vertikal orientierte Griffknubben (Kat.Nr. 3-6). Sie sind knapp unterhalb der Randlippe oder auf dem Gefäßumbruch angebracht.

Knubben beschränken sich meist auf steile, hohe Näpfe und sind unter der Randzone angebracht. Einfache, eingliedrige Gefäße, die mit drei bis vier Knubben im Randbereich verziert sind, liegen aus jüngerkaiserzeitlichen und völkerwanderungszeitlichen Fundzusammenhängen vor (vgl. GAEDTKEECKARDT 1991, 80, Taf. 48, 340; HARCK 1982, Abb. 4,25.26). Querovale Knubben kommen in Einswarden um 100 n. Chr. vor (SCHMID 1965B, 32). Senkrechte Griffleisten datiert SCHWARZ (1990, 264-268, 364) allgemein in die römische Kaiserzeit.

Das Exemplar einer rechteckig ausgezogenen Knubbe ist randständig angebracht (Kat.Nr. 265-2). Diese Form findet sich in Nordwestdeutschland während der gesamten Kaiserzeit (SCHMID 1965b, 32). Vergleiche liegen aus Brill (LeHMAnN 2002, Taf. 29, 3), Hodorf (SCHMID 1965b, Taf. XVII, 14) und Wijster vor (VAN Es 1965, 312, Fig. 150). In Huntebrück-Wührden wird die als zungenförmiger Grifffortsatz bezeichnete Knubbe dem Gefäßtyp HW 21a zugeordnet (FöRST 1991, 93, Taf. 76, 589). Im Unterschied zu Nortmoor sind in Hatzum-Boomborg Knubben meist durchbohrt. Dies ermöglichte es eine Schnur durchzuziehen und die Gefäße aufzuhängen. Sind Knubben schwach ausgeprägt und sehr flach ausgeformt, dienten sie eher als plastische Verzierung. Die Schalen kommen vom älteren bis jüngeren Fundhorizont vor (LÖBERT 1982, 64).

Grifflappen sind meist horizontal ausgerichtet. An einer kleinen $12 \mathrm{~cm}$ durchmessenden Schale ist unterrandständig ein Grifflappen erhalten (Kat.Nr. 703-1), der vermutlich antithetisch an der Wandung angebracht war. In einem anderen Fall ist lediglich der Grifflappen erhalten (Kat.Nr. 627-12). Die im Profil trapezförmige Handhabe (Länge $4 \mathrm{~cm}$, Breite $2 \mathrm{~cm}$, Stärke $1,2 \mathrm{~cm}$ ) weist eine $0,6 \mathrm{~cm}$ große Durchbohrung auf. Rekonstruiert werden kann eine horizontale Anbringung des Grifflappens (vgl. LÖBERT 1981, Taf. 48, 843).

Ein singuläres Stück im Keramikinventar ist das Fragment einer Schale, die an ihrem Rand einen zipfelförmig nach oben ausgezogenen Lappen aufweist (Kat.Nr. 160-1). Ähnlich, wenn auch mit einer Fingergrube auf der Handhabe, ist eine Schale aus Brill (LEHMANN 2002, Taf. 63, 2404-5). Vergleiche 
in Nord-Drenthe fehlen, eventuell stellt sie eine Ableitung auf eine dort belegte zipfelig ausgeformte Randform eines engmündigen Gefäßes von Typ Ge6 dar (TAAYKE 1995, 24-27, Abb. 15, 4).

Ösen sind in Nortmoor selten. Ein Schalenrand weist eine 0,6x1cm große Henkelöse auf (Kat.Nr. 2651). Derartige Ösen finden sich auch bei Schalen vom Typ S 3 in Nord-Drenthe (TAAYKE 1995, 41, Abb. 31, 3). Zwei antithetisch angebrachte Ösen besitzt ein nur 6,6cm hohes Miniaturgefäß (Kat.Nr. 369-2). Die 4mm kleinen Ösen sind an der Gefäßschulter angebracht. Als Gefäßtyp erinnert das Kleinstgefäß an einen dreigliedrigen Topf mit fließendem Hals-Schulter-Übergang und ähnelt einer verkleinerten Ausgabe eines Topfes vom Typ Ge6, der zwischen der ersten Hälfte des 2. und bis ins 4. Jahrhundert n. Chr. datiert werden kann (TAAYKE 1995, 27, 51, Abb. 15, 1).

\subsubsection{Importkeramik}

Kat.Nr. 3-35; 3-37; 3-39; 140-5; 168-1; 187-1; 187b Fdnr. 448; evtl. 195-5; 195 Fdnr. (Farbtafel); 2162; 216 Fdnr. 534; 257 Fdnr. 613 (Farbtafel); 369b Fdnr. 573 (Farbtafel); 383-1; 403 Fdnr. 490; 432 Fdnr. 516 (Farbtafel); 468-4; 551 Fdnr. 483 (Farbtafel); 551 Fdnr. 483 (Farbtafel); 627-4 Fdnr. 524 (Farbtafel); 678 Fdnr. 798; 740-1; 740 Fdnr. 639; 840 Fdnr. 640 (Farbtafel)

Neben einheimischer Keramik finden sich in Nortmoor Scherben römischer Provenienz, die wenigstens drei Gefäßtypen angehören. Zu nennen sind Fragmente römischer Schüsseln vom Typ Dragendorff, einer römischen Reibschüssel und zweier Terra Nigra Krüge. Daneben kommen verschiedene Einzelfragmente vor, die keiner bestimmten Gefäßform zuzuordnen sind.

Verhältnismäßig stark vertreten ist spätkaiserzeitliche Terra nigra-artige Ware. Darüber hinaus ungewöhnlich in einer ländlichen Siedlung wie Nortmoor ist das Vorkommen an nachgeahmter römischer Keramik.

Terra Sigillata liegt als rote Glanztonware in kleinteiligen Bruchstücken von wenigen Zentimetern Größe vor. Es handelt sich um fünf unverzierte (Kat.Nr. 187b Fdnr. 448; 432 Fdnr. 516) und zwei verzierte Wandungsscherben (Kat.Nr. 403 Fdnr. 490; 551 Fdnr. 483 (Farbtafel)). Alle Fragmente sind an den Außenkanten verschliffen; dies deutet darauf hin, dass die Scherben erst nach einiger Zeit in den Boden gelangt sind.

Mit einem klassischen Eierstab verziert ist eine kleine Terra Sigillata Wandungsscherbe (Kat.Nr. 551 Fdnr. 483 (Farbtafel)). Es handelt sich um eine typische Verzierungsform, wie sie beispielsweise an römischen Schüsselformen vorkommt. Möglicherweise gehörte das Fragment einer Schüssel vom Typ Dragendorff 37 an, einer in der Germania magna beliebten mittelkaiserzeitlichen Bilderschüssel. Der ehemals rote Glanzüberzug ist fast vollständig erodiert, darunter tritt ein blass rötlicher, hart gebrannter Tonkern zu Tage. Eine Magerung mit bis zu 3mm großen Steinchen kann als relativ grob 
für diese feine Ware bezeichnet werden.

Mit einem Rest der für Terra Sigillata typischem roten Überzug überzogen ist eine $2 \mathrm{~cm}$ große Wandungsscherbe (Kat.Nr. 403 Fdnr. 490). Ihre Rückseite zeigt drei eingeritzte radiale Rillen. Möglicherweise wurden derartige Keramikscherben als Spielsteine verwendet (vgl. UlBERT 1977, 43).

Um römische Importkeramik handelt es sich bei einer fein geschlämmten Wandungsscherbe (Kat.Nr. 195 Fdnr. 899 (Farbtafel)). Die dünnwandige Scherbe ist klingend hart gebrannt und von hellgrauer Tonfarbe. Feine Drehrillen auf der Außenseite zeugen von der Herstellung auf der schnellen Drehscheibe. Größe und Neigungswinkel des Fragmentes weisen auf einen recht großen Radius des ehemaligen Gefäßes hin, bei dem es sich eventuell um eine schüsselartige Form handelte. Das Fragment stammt aus der Brunnenfüllung der mittelkaiserzeitlichen Wasserstelle.

Das Randfragment einer römischen Reibschüssel (Kat.Nr. 3-35) ist mit einem geschwungenen Kragenrand vom Typus Gose 462 ausgestattet (GoSE 1950, 39-41). Ähnliche Schüsselränder liegen aus Haltern 60 und Niederbieber 86 vor. Schalen dieses Typs sind als Haushaltsware in ihrer Form chronologisch relativ unempfindlich. Sie kommen vom 1. Jahrhundert n. Chr. bis in die spätrömische Zeit vor. Die übrigen Gefäßfragmente römischer Gebrauchskeramik sind als Wandungsscherben nicht mehr zuzuweisen.

Zur römischen Haushaltsware gehören vermutlich weitere Wandungsscherben aus dem westlichen Teil der Siedlung. Die Scherben sind klingend hart gebrannt, relativ dickwandig $(>1,1 \mathrm{~cm})$ und gehören der Gruppe der Drehscheibenware an.

Beide Scherben sind für römische Keramik teils sehr grob gemagert und weisen auf der Scherbeninnenseite recht große Drehrillen auf. Die Oberfläche einer weißlich gelben Wandungsscherbe besitzt recht große Magerungsbestandteile einer ziegelartigen Masse und zudem zahlreiche kleinere Quarzabsplisse (Kat.Nr. 840 Fdnr. 640 (Fototafel).

Eine andere Tonscherbe besticht durch ihren gelblichen Farbton (Kat.Nr. 678 Fdnr. 798). Hart gebrannte römische Gebrauchskeramik ist rauwandig, tongrundig und wurde auf einer rotierenden Drehscheibe hergestellt, wie innenseitige Drehrillen anzeigen. Helltonige Drehscheibenware wurde im Rheinland als feinere Ware im 1. - 2. Jahrhundert verwendet. Erst Ende des 3. Jahrhunderts lösten sie die rauwandigen Formen ab (GoSE 1976, 32).

Provinzialrömische Feinkeramik fand sich verschiedentlich in anderen Nortmoorer Befunden. Doch auch hier zeigt sich ein hoher Fragmentierungsgrad, der es nur selten erlaubt eine gefäßtypologische Zuordnung vorzunehmen. 
Die wenigen erhaltenen Randfragmente verfügen über lang ausbiegende Ränder (Kat.Nr 257 Fdnr. 613 (Farbtafel); 369b Fdnr. 573 (Farbtafel)). Ähnliche Randformen finden sich bei einer römischen Schüsselform vom Typ G 30-32 und in die jüngere römische Kaiserzeit datiert werden (RUPP 1987, Taf. 26). Derartig stark ausbiegende Randformen kommen unter Terra Nigra Gefäßen in Soest-Ardey nicht vor; dort überwiegen leicht vorkragende Randlippen (HALPAAP 1994, 139, Abb. 54).

Eine Reihe von Importscherben stammt aus einem 12,6m langen und 1,10m breiten Graben (Kat.Nr. 432) nordöstlich von Hausplatz II. Sieben Scherben gehören der Terra Nigra und Terra nigra-artigen Ware an, zwei sind Terra Sigillata Ware. Bei den kleinteiligen Bruchstücken ist eine Gefäßbestimmung nicht möglich. Die übrigen kaiserzeitlichen Keramikscherben aus dem Graben müssen schwerpunktmäßig in das 2. Jahrhundert n. Chr. datiert werden. Das v-förmiges Grabenprofil zeigt deutliche Brandspuren im unteren Verlauf. Die Stärke der unteren HK-Schicht kann mit $10 \mathrm{~cm}$, die der oberen mit etwa $3 \mathrm{~cm}$ angegeben werden. Auch die dunkelgrau-braune Klei-Sand Füllung war mit bis zu $2 \mathrm{~cm}$ großen Holzkohle Brocken durchsetzt. Dies deutet auf ein mehrmaliges Ausbrennen hin.

Bei Terra Nigra und nigra-ähnlichen Gefäßen handelt es sich um provinzialrömische Feinkeramik. Da sie auch in linksrheinischen Gebieten hergestellt wurde und dort im Laufe der Kaiserzeit immer mehr an Bedeutung gewinnt (TACKENBERG 1978, 367-371), wird ihre römische Herkunft zunehmend hinterfragbar (HALPAAP 1994, 138). Seit der zweiten Hälfte des 3. Jahrhunderts löste diese Keramik zunehmend die vorherrschende Terra Sigillata ab.

Die Scherben sind aus schwarz-grauem Ton und mit einer schwarzen Engobe überzogen, die sich bei den meisten Stücken in Nortmoor nur rudimentär erhalten hat (Kat.Nr. 432 Fdnr. 516 (Farbtafel). Daneben existieren auch Wandungsscherben die an ihrer Gefäßaußenseite schwarz engobiert sind (Kat.Nr. 257 Fdnr. 613 (Farbtafel), während Bruch und Innenseite einen gelblichen Farbton aufweisen. Der fragmentarische Erhaltungszustand ermöglicht bei einem Großteil der erhaltenen Wandungsscherben meist keine Zuweisung mehr. Machart und Formenspektrum weisen auf eine provinzialrömische Fertigung der Keramik hin.

Ein gut erhaltenes Terra Nigra Gefäß stammt aus der Brunnenfüllung (Kat.Nr. 740) vom Südrand der Siedlung. Bis auf die Bodenplatte ist das $34,2 \mathrm{~cm}$ große Gefäß komplett erhalten (Abb. 42). Das engmündige krugähnliche Gefäß zeichnet sich durch eine schlanke hohe Halspartie von $14 \mathrm{~cm}$ Länge und einem bauchigen Gefäßkörper aus (Kat.Nr. 740-1). Die Randlippe ist leicht ausbiegend gestaltet. Stark ausgebildet ist die Absatzkante an der Gefäßschulter. Die Drehscheibenware ist mit einer pechschwarzen Glanztonfirnis überzogen und wird ins 2./3. Jahrhundert $n$. Chr. datiert (BÄRENFÄNGER 1999a, 76). 
Aus der selben Brunnenverfüllung stammen vier passende Wandungsscherben eines weiteren Terra nirga-artigen Tongefäßes (Kat.Nr. 740 Fdnr. 639). Als Streufund überliefert ist das Oberteil eines ähnlichen Gefäßes (Kat. Nr. 3-37). Die gleichfalls hart gebrannte Ware ist fein gemagert und von dunkelgrau-schwarzer Tonfarbe.

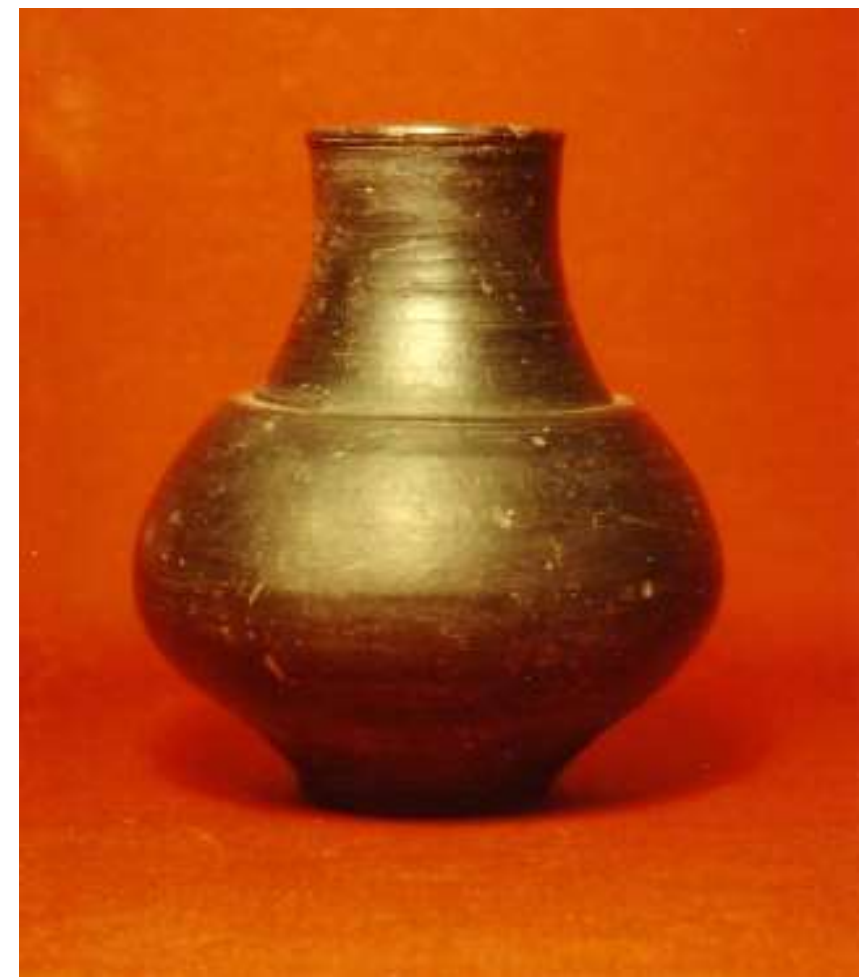

Abb. 42

Terra Nigra Gefäß aus der Brunnenverfüllung Kat.Nr. 740

Die Terra nigra-artige Randscherbe ähnelt einem doppelkonischen engmündigen Gefäß (GF 7.9). Vergleichbare Stücke finden sich jedoch weder im keramischen Material von Haarhausen (DUSEK 1992), Soest-Ardey (HALPAAP 1994) oder der Töpfersiedlung von Schwabmünchen Landkreis Augsburg (CZYSZ / SOMMER 1983). Eine gleichsam Terra nigra-artige Randscherbe stammt aus der rechteckigen Grabenanlage im Südosten der Siedlung. Der fein gemagerte und dünnwandige Rand (Kat.Nr. 383-1) ist von hellgrauer Tonfarbe. Die innen leicht abgesetzte Randlippe und ein langer kaum ausgezogener Rand gehören vermutlich zu einer weitmündigen Schale mit steilem Rand. Aufgrund der erhaltenen Randhöhe von nur $2 \mathrm{~cm}$ ist eine typologische Zuordnung nicht mehr möglich.

Unter dem Fundmaterial von Nortmoor stellen weitmündige s-förmige Schalen mit langem ausbiegenden Rand und kurzer Randlippe eine Hauptgruppe der Terra nigra-artigen Ware dar (Kat.Nr. 140-5; 168-1; 187-1; Kat.Nr. 216-2; 468-4; 627-4). Meist ist die Wandung sehr dünn (4mm) und die Ränder wirken grazil. Soweit feststellbar überwiegen Gefäßdurchmesser von 16 bis $25 \mathrm{~cm}$. Ähnliche Terra nigra-artige Schalen finden sich in Soest-Ardey (HALPAAP 1994, 139, Abb. 54,7). Ein aus 
Nortmoor stammender situlaartiger Flachboden zeigt an der Innenwandung deutliche Drehrillen (Kat. Nr. 627-13). Ein Vergleichsstück existiert in Soest-Ardey (HALPAAP 1994, 139, Abb. 54. 35).

Nicht näher bestimmbar ist ein kurzer Terra Nigra Rand (Kat. Nr. 381-1). Der nach innen gestellte Rand gehört zu einem engmündigen Gefäß mit einem Durchmesser von etwa $20 \mathrm{~cm}$. Ebenfalls um einen Import handelt es sich bei einer zweigliedrigen Schale von schwarz-grauer Tonfarbe (Kat. Nr. 195-5). Parallelen zu diesem Drehscheibengefäß sind nicht bekannt.

Fünf Gefäßfragmente können einer provinzialrömischen Drehscheibenware zugeordnet werden. Die Keramik weist feinen Granitgrus mit Glimmerbestandteilen auf und ist von grau-schwarzer bis hellgrauer Tonfarbe. Die ehemals dunkle Oberfläche ist weitgehend erodiert. Von einem engmündigen Krug hat sich eine Randscherbe mit stark umbiegender Randlippe erhalten (Kat. Nr. 3-39). Zu dem Nortmoorer Stück finden sich Parallelen in Haarhausen (DUSEK 1992, Abb. 61, 22) und in SoestArdey (HALPAAP 1994, 121, Abb. 50.24). Die überlieferten Nortmoorer Wandungsscherben sind keiner Gefäßform zuzuordnen.

Terra Nigra tritt im 3. Jahrhundert $n$. Chr. erstmals auf und entwickelt sich mit der Zeit zu einer Nachfolgekeramik der Terra Sigillata bis sie schließlich von fränkischer Drehscheibenware im 5./6. Jahrhundert abgelöst wird (HALPAAP 1994, 138). Die in Nortmoor gefundenen Gefäßfragmente weisen in die spätrömische Zeit.

Aus der Siedlung Bentumersiel liegt der umfangreichste Fundkomplex mit Terra Sigillata Fragmenten der frühsten und mittleren Kaiserzeit im Unteren Emsgebiet vor (LÖBERT 1977, 41-44). Dabei können wenigstens 11 Fragmente den Typen Dragendorff 30, 31, 33, 37 und Ludowici Typ VMk zugeordnet werden, die in das 2. und 3. Jahrhundert datiert werden (ULBERT 1977, 41). Vermutlich gelangte die Keramik als römischer Import in die Region an der Unteren Ems.

In relativ großem Umfang erreichten römische Waren, insbesondere Terra Sigillata, die niederländische Provinz Drenthe (Ulbert 1977, 42; EgGERS 1951, Karte 62). Von der Rheinmündungsgebiet gelangten Waren bis nach Skandinavien (ULBERT 1977, 44-48; LUND-HANSEN 1997). Besondere Bedeutung kam dabei den Transportwegen über Rhein und der fossa Drusaiana, dem römischen Kanalbau nahe Vechter, in das Ijsselmeer und in die nordwestlichen Niederlande zu (VOLKERS 1991, 182-183).

Für den Handel mit Keramik wird die verkehrstechnische Erschließung und der jeweils einzutauschende Gegenwert von Bedeutung gewesen sein. Tacitus erwähnt hierfür den einfachen Tauschhandel (Tac.germ V), vermutlich mit Rindern oder Rinderfellen. Überlegungen zur Organisation des Handels mit den römischen Klientenstaaten, ob nun über römische Fernhändler oder lokale Zwischenhändler, sind ERDRICH (2001) und LUND-HANSEN (1997) zu entnehmen. 


\subsubsection{Nachgeahmte Importkeramik}

Kat.Nr. 195-2; 195-3; 195-3; 551-1

Die Nachahmungen römischer Keramik sind selten (USLAR 1934; 1938, 23). Die wenigen bekannten Funde hat HEGEWISCH 2005 zusammengefasst. Um so ungewöhnlicher sind die in Nortmoor entdeckten Nachahmungen römischer Keramik. Es handelt sich um hochwertige Imitationen von Terra Sigillata, die diese in ihrer Formensprache, ihrem Glanztonüberzug und ihrer Brennhärte vortäuschen. Römische Importe erreichten die Germania Magna zumeist in der Form von fertig ausgearbeiteten Werkstücken. Wegen ihrer Kostbarkeit wurden solche „Luxusartikel“ des Öfteren lokal nachgearbeitet und imitiert.

Drei Terra sigillata-artige Scherben stammen allein aus einer Wasserstelle im östlichen Siedlungsareal. Sie zeichnen sich durch eine recht gelungene Nachahmung des typischen roten Tongrundes aus (Kat.Nr. 195-1; 195-2; 195-3). In Resten ist die glänzende Tonengobe auf den erodierten Oberflächen erhalten. Der Ton ist relativ fein und gut geschlämmt, worin sich einzelne bis zu $1 \mathrm{~mm}$ große Glimmerstücke befinden. Motiv und Anbringung der Verzierung entsprechen jedoch nicht dem römischen Vorbild.

Erhalten ist das Randfragment einer steilwandigen Schale (Kat.Nr. 195-1). Der Profilverlauf ähnelt der Schüssel vom Typ Dragendorff 37. Nachgeahmt wird die kurze ausbiegende Randlippe und eine horizontale Zierrille auf der Außenseite (vgl. HALPAAP 1994, 127, Abb. 51.27; 51.26, Taf. 63, 5). Römische Bilderschüsseln würden im Dekorfeld Vasenmotive und florale Füllornamente erwarten lassen, die eine zentrale Motivszene einrahmen. Stattdessen fassen die Rillen eine Zierzone mit hängenden Dreiecken ein. Kreisrunde Eindrücke schließen sich nach unten an. Zwei Wandungsscherben imitieren, wenn auch etwas gekonnt, römische Terra Sigillata (Kat.Nr. 195-2; 1953). Die mit applizierten Bögen bzw. Kreissegmenten verzierten Stücke fehlten im Musterrepertoire römischer oder provinzialrömischer Töpfereien.

Um eine singuläre Imitation handelt es sich bei zwei anderen Wandungsfragmenten einer sigillataähnlichen Schüssel (Kat.Nr. 520-1; Abb. 43). Die aneinanderpassenden Scherben haben eine Höhe von $8,2 \mathrm{~cm}$ und eine Breite von $12,3 \mathrm{~cm}$. Die Wandungsdicke schwankt von $0,6 \mathrm{~cm}$ bis $0,8 \mathrm{~cm}$.

Die im Folgenden besprochenen Bildschüsselfragmente entstammen einer 140x85cm großen und bis zu $12 \mathrm{~cm}$ tiefen Siedlungsgrube $(\mathrm{NN}+1,51 \mathrm{~m})$ mit muldenförmigem Profil. Die Grubenfüllung enthielt auch 30 unverzierte Wandungsscherben und einen grob gemagerten Flachboden von dunkelgrau-brauner Farbe. Beschaffenheit, Brennhärte und Ton entsprechen der lokalen nordseegermanischen Keramik. Die homogene Grubenfüllung aus sandigem Klei weist auf eine geschlossene Fundsituation hin und betont 
die zeitliche Nähe zu einem Überschwemmungshorizont, der in der römischen Kaiserzeit weite Flächen des Siedlungsareals überdeckte. (Abb. 43).

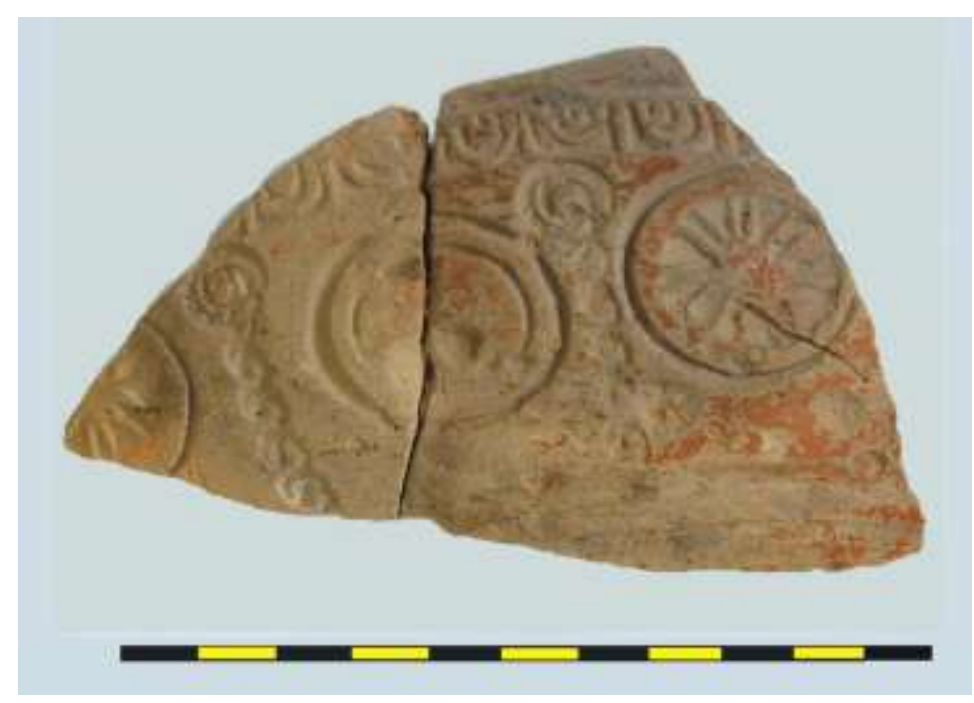

Abb. 43

Terra Sigillata Nachahmung aus dem Nortmoorer Hammrich

In technischer Hinsicht ist die Imitation, was den harten Brand und den roten Überzug betrifft, anspruchsvoll, aber nicht ungewöhnlich. Bislang singulär ist jedoch die Ausführung des Reliefdekors, denn dieser wurde nicht, wie sonst üblich, mittels einer Formschüssel erzeugt, sondern die Ornamente wurden mit einem Stempel in Negativform einzeln in die Gefäßwandung eingedrückt.

Einheitlich liegt die Höhe des erhaltenen Eierstabes bei $1 \mathrm{~cm}$, die Breite der einzelnen Elemente variiert von 1,1-1,3cm. Der Durchmesser beider Medaillons beträgt 3,2cm außen und innen von 2,2 bis 2,4cm. Bedeutend kleiner fällt die nur 1,3cm große Scheibenrosette aus. Von drei Spiralranken ist lediglich eine in ihrer gesamten Länge erhalten $(3,4 \mathrm{x} 0,5 \mathrm{~cm})$. Die Zierzone wird nach unten durch zwei horizontale Riefen abgegrenzt. Während die obere Riefe $0,5 \mathrm{~cm}$ breit ist, misst die untere nur $0,3 \mathrm{~cm}$.

Partiell erhalten sind Reste einer roten Engobe auf der äußeren Scherbenoberfläche. Der Überzug aus rotem Tonschlicker bestand wahrscheinlich aus einem mit Pottasche versetzten eisenhaltigen Tonwasserbrei (vgl. HOFFMANN 1983, 25 - 26). Die relative Stärke der roten Farbschicht deutet auf ein mehrmaliges Eintauchen des noch ungebrannten Gefäßes hin. In den Munsell Soil Color Charts entspricht der mattierte Überzug dem Farbton 2.5 YR 4V / 8C, während die Tonoberfläche mit dem Farbwert 10 YR 7V / 3C und der Bruch mit 7.5 YR 7V / 4C vergleichbar sind. Auf eine Brenntemperatur von über $950^{\circ} \mathrm{C}$ weist die versinterte Oberfläche der Engobe hin (BECHERT / VANDERHOEVEN 1988, 11). Die hellbeige Tonfarbe belegt eine oxydierende Brennweise. Erkennbar sind auf der stellenweise erodierten Scherbeninnenseite geringe Spuren von Glimmerpartikeln. Die fein 
geschlämmte Scherbe weist im Bruch verschiedene kristalline Einschlüsse auf.

Eine mineralogisch - petrographische Untersuchung durch das Geowissenschaftliche Zentrum der Universität Göttingen konnte den Kenntnisstand wesentlich erweitern ${ }^{1}$. Vorgenommen wurden eine chemische Analyse und eine Röntgenfluoreszenzanalyse (RFA). Ergebnisse der makroskopischen Befund-Mikroskopie: Neben bis zu 1mm großen Granitgrussplittern treten rötlich-rotbraune Einschlüsse auf, die als quarzgemagerte Fremdkeramik angesprochen werden können. Der Nachweis von Ziegelsplittern ist nicht ganz eindeutig, würde jedoch eine provinzialrömische Herkunft kennzeichnen, da im germanischen Raum diese Technik nicht bekannt war. Mittels Röntgendiffraktmetrie (XRD) wurden die Mineralphasen bestimmt. Eine erneute Beprobung zur Erschließung der möglichen Brenntemperatur (DTA) hätte eine weitere Materialentnahme, folglich einen weiteren Substanzverlust verursacht und unterblieb deshalb.

Die vorgenommene Clusteranalyse ermöglichte einen Vergleich mit Produkten provinzialrömischer Töpfereien. Die Diskriminanzanalyse erbrachte bisher jedoch keine Übereinstimmungen mit einer Referenzgruppe bekannter Terra Sigillata Manufakturen (Blickweiler, Heiligenberg, Rheinzabern, Sinzig am Rhein, Trier, Chèmery-Faulquemont, Lezour ${ }^{2}$ ). Während bei regulärer Terra Sigillata die $\mathrm{CaO}$ Gehalte über 5\% liegen, ist bei der ostfriesischen Scherbe sein niedriger Kalziumgehalt auffällig (Tab. 7).

\begin{tabular}{|l|l|l|l|l|l|l|l|l|l|l|l|}
\hline Masse- \% & $\mathrm{SiO}_{2}$ & $\mathrm{TiO}_{2}$ & $\mathrm{Al}_{2} \mathrm{O}_{3}$ & $\mathrm{Fe}_{2} \mathrm{O}_{3} \mathrm{~T}$ & $\mathrm{MnO}$ & $\mathrm{MgO}$ & $\mathrm{CaO}$ & $\mathrm{Na}_{2} \mathrm{O}$ & $\mathrm{K}_{2} \mathrm{O}$ & $\mathrm{P}_{2} \mathrm{O}_{5}$ & Summe \\
\hline $\mathrm{NMH}$ & 60,5 & 1,36 & 21,85 & 8,58 & 0,067 & 1,13 & 0,99 & 1,00 & 1,52 & 0,657 & 97,654 \\
\hline
\end{tabular}

\begin{tabular}{|l|l|l|l|l|l|l|l|l|l|l|l|l|l|l|}
\hline $\begin{array}{l}\text { Masse- } \\
\text { ppm }\end{array}$ & Sc & V & Cr & Co & Ni & Zn & Ga & Rb & Sr & Zr & Nb & Ba & Pb & Y \\
\hline NMH & 23 & 132 & 141 & 11 & 46 & 108 & 28 & 60 & 126 & 340 & 20 & 637 & 30 & 38 \\
\hline
\end{tabular}

Tab. 7

Chemische Analyse der Nortmoorer Keramik:

Hauptelementoxide und Spurenelemente; RFA

\footnotetext{
${ }^{1}$ Dies ermöglichte dankenswerterweise Dr. A. Kronz

${ }^{2}$ Für die Datenbankanalyse sei M. Helfert M.A. / RGK Frankfurt herzlich gedankt
} 
Dies deutet nicht darauf hin, dass bei der Tonauf- und Zubereitung römische Technologie verwendet wurde. Das mikroskopische Bild und die pauschalchemische Analyse entsprechen einander. Die hohen Alkaliwerte, wie auch Rb, Ba können auf die hohen Feldspatanteile zurückgeführt werden. Werte von über $20 \% \mathrm{Al}_{2} \mathrm{O}_{3}$ weisen auf eine relativ hochwertige Ware hin, die jedoch zugleich verhältnismäßig viele Magerungsbestandteile aufweist. Folgende Mineralphasen können nachgewiesen werden: Quarz $\left(\mathrm{SiO}_{2}\right)$, Alkalifeldspat ((Na, K), $\left.\mathrm{AlSi}_{3} \mathrm{O}_{8}\right)$, Anatas $\left(\mathrm{TiO}_{2}\right)$, Hämatit $\left(\mathrm{Fe}_{2} \mathrm{O}_{3}\right)$.

Aufgrund der nur geringfügig erhaltenen Substanz der roten Engobe unterblieb eine Beprobung. Die versinterte Oberflächengestaltung deutet auf eine römisch motivierte Manufaktur hin. Weiterführende Fragestellungen bestehen zu den verwendeten Tonvorkommen. Infolge fehlender Referenzgebiete sind dazu weitere Untersuchungen und Analysen erforderlich.

Der Dekor der TS-Nachahmung ist dem römischen Musterrepertoire entlehnt. Im Unterschied zur Reliefsigillata wurden die verwendeten Positivstempel jedoch direkt in den feuchten Ton der Trägerschüssel eingedrückt. Dadurch sind auf dem Nortmoorer Fragment alle Verzierungsmotive negativ, d. h. im spiegelbildlichen Motivverlauf, wiedergegeben. Parallelen aus dem Barbaricum oder dem provinzialrömischen Bereich sind bislang nicht bekannt.

Beide Wandungsscherben zeigen unterhalb des fehlenden Randes ein ionisches Kymation mit Eierstab. Dessen fünf komplett erhaltene Elemente bestehen jeweils aus zwei, einen schmalen Kern einfassenden Stäben und weisen in ihrer Binnenausformung geringfügige Abweichungen auf (vgl. RICKEN / FISCHER 1963, 311, Typ E 60). Möglicherweise entstanden die gleichmäßig flach in die Wandung eingedrückten Muster unter Verwendung eines Rollstempels.

In der darunter liegenden Hauptzierzone dominieren kreisförmige Medaillons in zwei Ausführungen. Erhalten haben sich zwei unterschiedliche Kreismotive: zum einen ein speichenradartiges Motiv mit Kreis (Motiv 1; Omphalos-Schale; vgl. RICKEN / FISCHER 1963, 229, Typ 0 59), zum anderen ein Doppelkreis ohne inneres Füllmotiv (Motiv 2; vgl. RICKEN / FISCHER 1963, 267, Typ K 22). Es lässt sich nicht mehr ausmachen, ob es nur diese beiden Motive in alternierender Reihenfolge gab, oder ob weitere Kreismotive vorkamen. Zwischen den Medaillons hängt von einem kleinen, dreifach konzentrischen Kreisstempel als Zierglied eine Spiralranke herab, die wohl einen „laufenden Hund“ nachahmt. Die Scheibenrosette ist in der Mitte mit einem kleinen Ring versehen. Der äußere Kreis wird von mindestens 15 Strahlen gegliedert und ähnelt einem gekerbten Kreis bzw. einem zweifachen Kringel, deren äußerer geperlt ist (vgl. RICKEN / FISCHER 1963, 236, Typ 0 127).

Nach unten abgeschlossen wird die Zierzone von zwei Riefen, die den Übergang zum fehlenden Gefäßboden betonen. Die unterschiedliche Eintiefung der verschiedenen Stempeltypen vermittelt eine Streiflichtaufnahme (Abb. 44). 


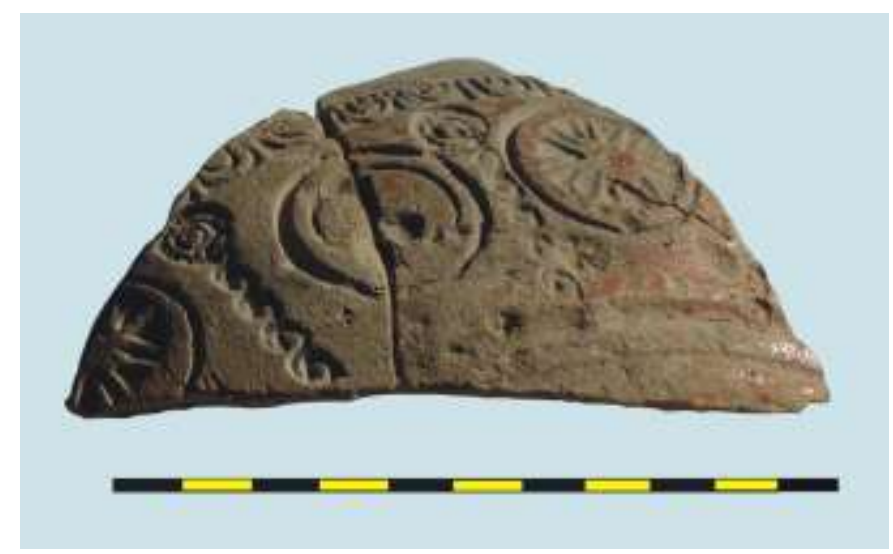

Abb. 44

Streiflichtaufnahme der Terra Sigillata

Nachahmung aus dem Nortmoorer Hammrich

Bei den Omphalos-Medaillons wurde anscheinend ein identischer Stempel verwendet, denn Speichenmuster und Dreieckszwickel weisen im Detail Übereinstimmungen auf. Jedoch führte eine Drehung der Punzenachse zu einer abweichenden Orientierung der Medaillons. Im Anschluss schnitt der Töpfer die Kreisumrandung in ihrer Kontur mit einem spitzen Utensil nach. Verhältnismäßig schwach eingedrückt sind die Spiralgirlanden. Wenig sorgfältig ist die nur rudimentär erhaltene dritte Girlande abgeformt, deren letzte Spiralwindung die obere horizontale Zierriefe schneidet.

Aufgrund einer optischen Täuschung erlauben die durch ein Binokular aufgenommenen Digitalfotos eine Positivumkehrung der eingestempelten Motive (Abb. 45). Es erscheint nun die Oberfläche des Originalgefäßes von der die Tonstempel abgenommen wurden. Scharf zeichnen sich die Konturen der Punzen ab.
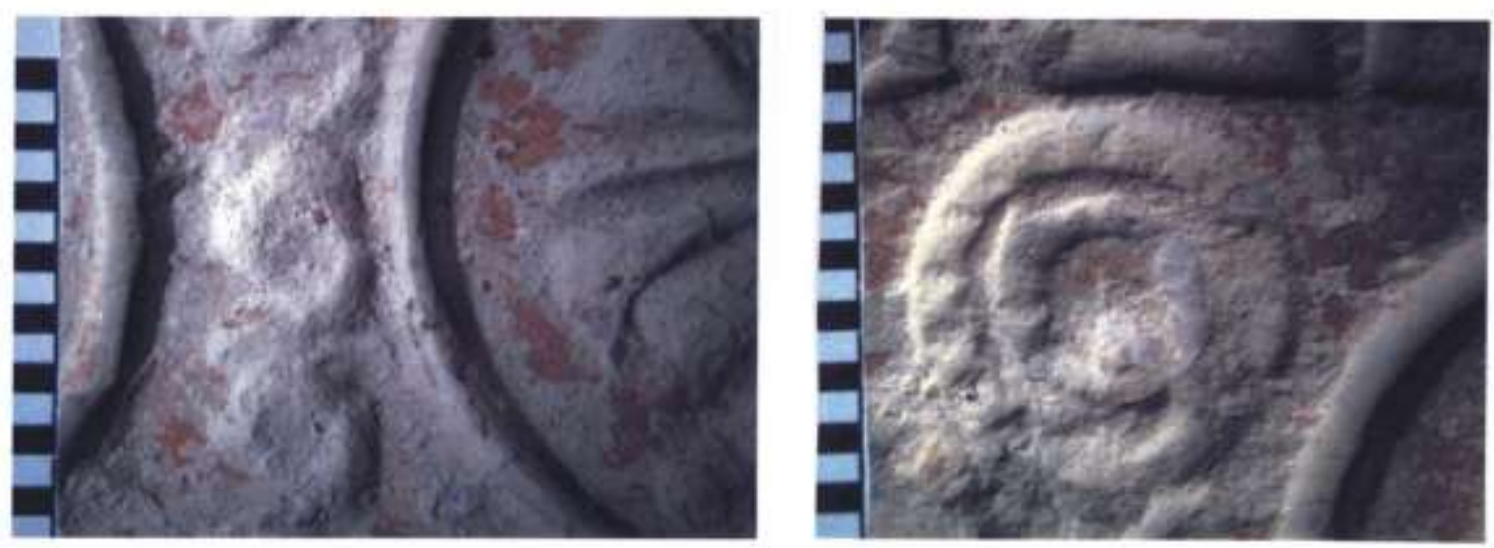

Abb. 45

Digitalfoto vom Medallion und Kreisstempel der Nortmoorer Terra Sigillata Nachahmung, Maßstabkästchen 1mm (Foto: Dr. A. Kronz 2005) 
Weitere Details sind in einer Makrovergrößerung der Scheibenrosette sichtbar. Auf ihrem äußeren Ring befinden sich diagonale Einkerbungen. Insgesamt legt die Nachahmung nahe, dass der Töpfer die „Originalstempel“ direkt verwendete, ohne wie in der Antike üblich durch die Umkehrung des Motives in einem Zwischenschritt (Erzeugung eines Negativstempels durch Abdruck) die Bildschüssel mit dem positiven Motiv zu versehen. Ein für die Herstellung in Formschüsseln wesentlicher Zwischenschritt fehlt somit.

Eine Horizontierung der TS-Nachahmung erlauben die auf der Außenseite der Scherbe umlaufenden Zierriefen. Anhand von Neigung und Wanddicke müssen die Fragmente von einer halbkugeligen Schüssel stammen. Oberhalb des Eierstabes verjüngt sich die Wandung und bildet einen kurzen Absatz mit einer $3 \mathrm{~mm}$ hohen Riefe. Die vorliegenden Fragmente entsprechen weitgehend dem Schüsseltyp Dragendorff 37. Über dem Absatz befand sich vermutlich eine unverzierte Zone, die in eine schmale Randlippe überging (Abb. 46). Den unteren Abschluss der Zierzone bilden parallele Zierriefen, die den Übergang zum Gefäßfuß angeben. Den Boden könnte ein flacher Standring oder auch ein Pokalfuß gebildet haben. Entsprechend dem Glanztonfilm bei Terra Sigillata ist die Nachahmung mit einer matt glänzenden Farbschicht überzogen worden.

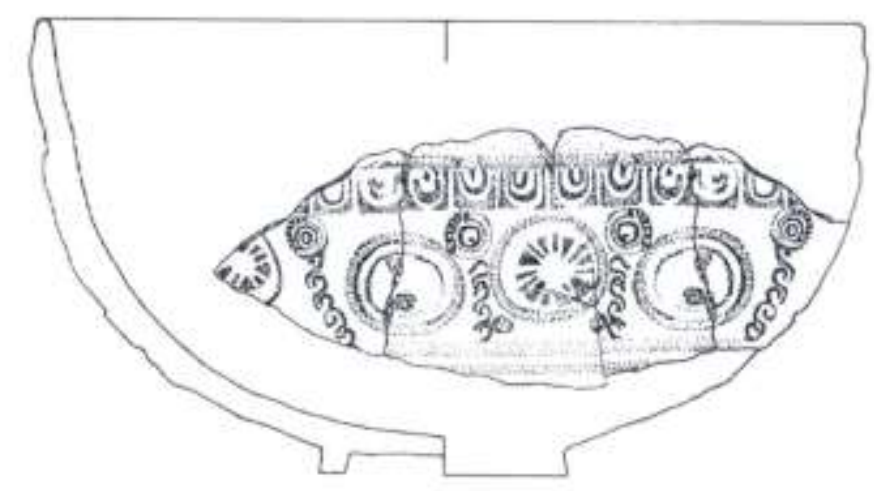

Abb. 46

Umzeichnung der Terra Sigillata Nachahmung auf die Oberfläche einer Schüssel vom Typ Dragendorff 37

Die Form Drag. 37, die sich aus Drag. 29 entwickelte, wurde in südgallischen Töpferbetrieben zwischen 65 bis 90/110 n. Chr. produziert (VANDERHOEVEN 1978, 55). In Rheinzabern gehörten die Bildschüsseln Drag. 37 zum Standardrepertoire der Sigillata-Werkstätten in der 1. Hälfte des 3. Jahrhunderts (vgl. REUTII 1983, vgl. 44-59). Eine Diskussion möglicher Produktionsorte unseres Stückes ist zum gegenwärtigen Zeitpunkt kaum zu führen, dies zeigen u.a. Arbeiten zu Terra Sigillata aus dem Kastell Vechten (POLAK 1995, 35). Ein häufiger Verzicht auf qualitätsvolle Abbildungen in der Fachliteratur erschwert zudem eine Zuordnung des ungewöhnlichen Stückes. 
Anhaltspunkte finden sich bei der ostfriesischen Nachahmung hingegen auf den Produktionsprozess, der vermutlich in mehreren Arbeitsschritten verlief. Zunächst wurden in den noch feuchten Ton der vorgedrehten Schüssel die Stempel einzeln eingedrückt. Eine Nacharbeitung erfolgte im lederharten Ton, als man die Kontur der Kreismotive nachschnitt. Anschließend überzog man das gesamte Gefäß mit einem matt glänzenden roten Tonschlamm. Wie der korrekt wiedergegebene Eierstab zeigt, hatte der Töpfer für die römische Motivanordnung ein relativ großes Verständnis. Im Unterschied zu dieser doch filigranen Arbeitsweise wirkt die Gefäßwandung, die doppelt so stark ausgeprägt ist wie vergleichbare Schüsseln aus Rheinzabern, plump. Obwohl die verwendeten Stempel ein direktes Abformen von einer regulären reliefverzierten Terra Sigillata wahrscheinlich machen, gelang bisher keine unmittelbare regionale Herleitung der als Vorbild dienenden Punzen, wenn auch einige Indizien auf das Rheinland hinweisen.

Der geschilderte Keramikfund liefert einige neue Gesichtspunkte zur Praxis der kaiserzeitlichen Keramikimitation. Die Motivanordnung des Nortmoorer Stückes entspricht weitgehend dem römischen Vorbild und wurde vom Töpfer gewissenhaft übernommen. Eigenwillig hingegen, und bisher beispiellos in ihrer Ausführung, wurde die römische Punzvorlage umgesetzt. Die Verwendung von Einzelstempeln gestattet eine neue Komposition; dessen ungeachtet wurde bei dem erhaltenen Exemplar die römische Bildsprache beibehalten und nicht ein neuer Stil initiiert. Die technische Umsetzung der Nachahmung weist auf eine lokale Anfertigung, die jedoch nicht in der Tradition friesisch-germanischer Keramikgenese steht. Auch die aufwendige Imitationstechnik grenzt sich deutlich von der lokalen Keramikware der Nordseegermanen ab.

Die ostfriesische Nachahmung stellt sich vielmehr als Teil eines Adaptionsprozesses römischer Formen im Barbaricum dar. Aus der jüngeren Kaiserzeit der Germania Magna sind verschiedentlich Imitationen römischer Gefäßformen bekannt. Vorzugsweise dienten Sigillata Schalen und Glasgefäße als Vorbild und fanden Eingang in das germanische Töpferhandwerk. Während man Motiv und Verzierung partiell übernahm, wurde die Form den lokalen Traditionen angepasst.

Für den elbgermanischen Raum wird hingegen sogar ein Bruch mit bestehenden Keramiktraditionen postuliert, der schließlich in einem allgemeinen Formwandel mündete (HEGEWISCH 2004, 227). Erhalten haben sich nur wenige Nachahmungen. Aus dem Norddeutschen Raum stammen zwei Scherben von der Barward, Landkreis Cuxhaven (Abb. 47). Das Wandfragment einer TS-ähnlichen Ware ist mit Kreisaugen verziert und gehört eventuell der Schüsselform Drag. 37 an. Die Einstempelungen sind lediglich zu 3/4 des Kreises ausgeführt und überdecken sich partiell.

Die Ansprache erfolgt als Terra Sigillata Firnisware und wird in das 2. / 3. Jahrhundert n. Chr. datiert (ERDRICH 2002, 123, XXI-02-14/1.17). Übereinstimmungen in Design und Machart bestehen mit 
Keramikgefäßen einer Töpferei am Genfer See.

Der Ton des Cuxhavener Stückes zeichnet sich durch eine hellorangerote Farbe aus und ist sehr fein geschlämmt. Sichtbare Magerungsbestandteile sind nicht festzustellen. Nur rudimentär ist der beidseitige Überzug erhalten, dessen Reste einen leuchtend orangeroten bis dunkelroten Farbton aufweisen. Die Wandungsdicke liegt zwischen 0,3 und $0,5 \mathrm{~cm}$.

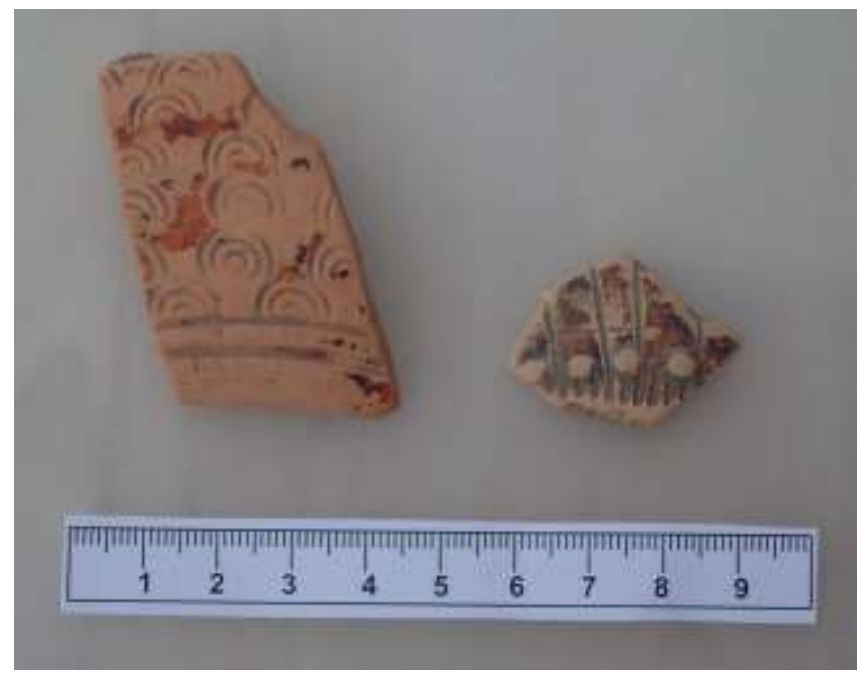

Abb.47

Terra Sigillata Nachahmungen von der Barward / Cuxhaven

Das zweite Fragment ist von beigefarbenen Ton und weist einen bräunlichroten Überzug auf. Die Verzierung besteht aus etwa $1 \mathrm{~mm}$ breiten Riefen und $3 \mathrm{~mm}$ durchmessenden Grübchen. Die Wandungsdicke beträgt $2 \mathrm{~mm}$. Auf der Innenseite verlaufen in Abständen von 0,5mm feine Drehrillen. Um eine andere Art der Nachahmung römischer Sigillata Typ Drag. 37 handelt es sich bei einer Wandungsscherbe aus den Beständen des Heidelberger Museums. Die Verzierungsanordnung, teilweise auch die Motive, scheinen eher keltischen Ursprunges zu sein. Eingestempelt sind als obere und untere Verzierungsleiste Rosetten. Alternierend wechseln menschliche Köpfe mit einfachen Kreismotiven ab und werden durch ein durchlaufendes eierstabartiges Zickzackband gegliedert (BEHN 1910, 169, Abb. 17).

Anzuführen ist in diesem Kontext die Drehscheibenware der „Braunschweiger Gruppe“, die Übereinstimmungen mit westfälisch-rheinischen Formen der späten Kaiserzeit aufweist (USLAR 1977a, 249-256). Zunächst wurde ihre Machart übernommen, schrittweise jedoch der lokalen Keramikformen angepasst. Die reduzierend gebrannte Keramik von dunkelgrau-schwarzer Farbe weist in der bevorzugten Pokalfußgefäßform Adaptionen an Terra Nigra auf, jedoch sind bei anderen Vertretern dieser Gruppe auch keltische Einflüsse nicht auszuschließen (USLAR 1977a, 255). Eine vergleichbare Entwicklung fand im angrenzenden Thüringen und Sachsen statt. 
Ein unmittelbares Zeugnis für einen Technologietransfer in der römischen Kaiserzeit bieten die Grabungsergebnisse von Haarhausen in Thüringen. Hier gelang erstmals der Nachweis einer gemischt betriebenen römisch-germanischen Töpferei auf germanischem Gebiet. Im Territorium der Hermunduren entdeckte man römische Produktionsanlagen, bestehend aus diversen Öfen und Werksgebäuden, sowie große Mengen an Drehscheibenkeramik und lokaler handgeformter Keramik (DUSEK 1992, 23-24). Vergleichbare Töpferanlagen sind aus dem Rhein-Main-Gebiet und der nördlichen Wetterau bekannt.

Die Drehscheibenware in Haarhausen zeichnet sich durch eine überwiegend graue Farbe aus. Die RFA weist auf die Verwendung lokaler Keupertone hin. Das umfangreiche Produktionsprofil verlangte für die Haarhausener Drehscheibenware eine eigene Typengliederung (DUSEK 1992, 70-98). Großteils ist die Keramik unverziert. Ein ziegelartiger Farbton tritt lediglich bei 2,5\% der Scherben auf. 5-6\% der Keramik sind mit horizontalen Rillen oder kreuzenden Wellenlinien dekoriert. Belegt sind Rädchenverzierungen und Barbotine Ware. Bevorzugtes Produkt war in Haarhausen jedoch die lokale Drehscheibenware, während handgeformte germanische Keramik nur ein Viertel der Produktion ausmachte (DUSEK 1992, 147-148). Absatzmärkte der Drehscheibenware überschneiden sich im thüringischen Nordhausen mit der Braunschweiger Drehscheibenware.

Mit Hilfe von Imitationen war prinzipiell eine Bedarfsdeckung möglich, die über reguläre Importe nicht gewährleistet oder preiswerter angeboten werden konnte. Bereits zu Beginn des 1. Jahrhunderts wurde der in der Antike geschätzte Markenartikel Terra Sigillata von südgallischen Töpfereien reproduziert. Im Zuge eines Verdrängungswettbewerbes kam es schließlich zur Verlagerung der Produktionsstätten im römischen Reich hin zu den Abnehmern im „Neuen Markt“ nahe den Provinzgrenzen. Die bevorzugte Nähe zum Absatzmarkt führte zum Aufbau neuer Manufakturen wie u.a. der von Rheinzabern. Somit steht die Nortmoorer Terra Sigillata Nachahmung in der Tradition einer an den Bedürfnissen der germanischen Bevölkerung orientierten Warenproduktion.

Abschließend sei festzuhalten, dass die Nortmoorer Nachahmung in seiner Motivik eigenwillig, jedoch nicht ungewöhnlich ist. Hingegen beispiellos ist die Umsetzung der römischen Punzvorlage. Design und Machart lassen eine Fertigung in einem noch unbekannten provinzialrömischen Produktionsort vermuten. Hinter dem Fragment steht ein Aneignen römischer Töpferkunst, wobei ein Verständnis für die Herstellungstechnik in einer Formschüssel fehlte. Einen Absatzmarkt fand die den bekannten Standards von Terra Sigillata wenig entsprechende Keramik kaum im provinzialrömischen Raum, der über hochwertigere Ware verfügten konnte. Ostfriesland, Siedlungsgebiet der Chauken und nördlichste Grenzregion der Germania Magna zum römischen Reich, befindet sich im Aufbruch aus der Rolle als Terra incognita im europäischen Barbaricum. Die Sigillata Nachahmung und diverse römische Neufunde aus dem Landkreis Leer, weisen das Hinterland östlich der Unteren Ems, im 
Zusammenhang mit neueren siedlungsarchäologischen Forschungen in der Region, vielmehr als ein prosperierendes Gebiet in der römischen Kaiserzeit aus.

\subsubsection{Gegenstände aus Ton}

\subsubsection{Spinnwirtel}

Kat.Nr. 2-3 Fdnr. 9; 3 Fdnr. 22 (2 Exemplare); 3-57; 3-58; 95 Fdnr. 237; 188-1; 195-24; 195 Fdnr. 569 u. 858; 402 Fdnr. 528; 409 Fdnr. 655; 432-12; 559-1; 584-8; 584-9; 584 Fdnr. 507 (2 Exemplare); 674 Fdnr. 675; 745 Fdnr. 1000 (2 Exemplare); 796 Fdnr. 479; 859 Fdnr. 1044, 1065; 891 Fdnr. 1035; 943 Fdnr. 1038; 1082-1

Taf. $7 ; 16 ; 18 ; 29 ; 37 ; 38 ; 48$

Die Textilerzeugung wird in Nortmoor durch eine große Anzahl an Spinnwirteln belegt. Insgesamt stammen 22 Spinnwirtel bzw. -fragmente direkt aus Befunden, vier weitere wurden als Lesefunde geborgen (Kat.Nr. 2-3 Fdnr. 9; 3-57 (Quadrant 56/53 Bef. 3 Fdnr. 522); 3-58 (Quadrant 56/54 Bef. 3 Fdnr. 22 (2 Exemplare)).

Die Spinnwirtel sind klein bis mittelgroß, ihr Gewicht beträgt zwischen 16 und 24g. Die größte Weite der zentralen Bohrung liegt zwischen 0,5 und $1 \mathrm{~cm}$. Am häufigsten sind Spinnwirtel mittleren Durchmessers (3-4cm), wobei sich ein bevorzugtes Maß von 3,4 und 3,6cm abzeichnet.

Durchmesser und Gewicht eines Spinnwirtels stehen ursächlich mit der gewünschten Fadenstärke in Verbindung, die sich kongruent verhält (LÖBERT 1982, 66). Eine schwach konisch ausgeführte Bohrung sollte ein Herausrutschen des Holzstabes verhindern (ZYLMANN 1933, 131, Abb. 212). Nicht in allen Fällen gelingt eine zweifelsfreie Abgrenzung zu Perlen, insbesondere wenn es sich um verzierte Exemplare handelt.

Sämtliche Spinnwirtel sind aus Ton gefertigt, oxidierend gebrannt und ausnahmslos mit anorganischem Gesteinsgrus gemagert. Meist ist die Oberfläche einfach geglättet, selten körnig rau. Es überwiegen helle Grautöne neben hellbraunen. Wenige Exemplare, wie ein steil-zylindrischer Wirtel (Kat.Nr. 195-24), waren sehr sorgfältig geglättet und von dunkelgrauer Tonfarbe.

Ein einfacher flacher Wirtel mit zentraler Aufwölbung (Kat.Nr. 3-57) ist den scheibenförmigen Spinnwirteln zuzurechnen, wie sie beispielsweise aus Brill vorliegen (LEHMANN 2002, Taf. 47, 4553). Daneben kommen in Nortmoor auch flach zylindrische Wirtel ohne Innenkehlung und gerader Basis vor (Kat.Nr. 188-1): Es existieren welche mit schwach ausgebildeter Innenkehle (Kat.Nr. 19524) oder mit stark konkave Innenkehle (Kat.Nr. 559-1). Die Kehlung selbst verhinderte ein Herausrutschen des befestigten Holzstabes. Konisch zulaufende Durchbohrungen, wie sie an Wirteln in Backemoor vorliegen (BUSCH-HELLWIG 2006, 57) sind in Nortmoor nicht festzustellen. 
Im Fundgut vertreten sind auch steilwandig zylindrische Wirtel, wobei die Innenkehlung nur schwach ausgeprägt ist oder sogar fehlt (Kat.Nr. 3-58; 584-8). Selten vertreten sind schlichte kugelige Formen. Zwar ähnelt Kat.Nr. 584-9 in seiner Form einer Perle, kann jedoch aufgrund der Innenkehle als Spinnwirtel angesprochen werden.

Fragmentarisch erhalten ist ein tonnenförmiger Spinnwirtel (Kat.Nr. 216-24), der mit senkrechten parallel verlaufenden Dellen verziert ist. Zwar fehlt die für Spinnwirtel signifikante Innenkehlung, diese tritt bei den Nortmoorer Exemplaren nur teilweise auf. Größe und rekonstruierter Durchmesser weisen ihn mehr als Wirtel, denn als Perle aus. Der Wirtel stammt aus der Verfüllung eines Grubenhauses (Kat.Nr. 216).

Der zweite verzierte Spinnwirtel fand sich in einem Grabenkomplex nordöstlich von Hausplatz II. Ungewöhnlich ist sein Wirteldekor mit diagonalen Rillen und die Innenräume wie Wülste wirken lassen (Kat.Nr. 432-12).

Fein ausgearbeitet ist eine kleine Kante am oberen Bohrloch von wo der Wirtel flächig bis auf die Basis verziert ist. Sehr sorgfältig erfolgte dabei die Oberflächengestaltung. Im Querschnitt flach kugelig, verfügt das Exemplar über eine leicht verengende zentrale Bohrung. Ein ähnlicher mit konzentrischen Rillen plastisch verzierter Spinnwirtel findet sich im $4 \mathrm{~km}$ südlich gelegenen Potshausen (SCHWARZ 1990, Taf. 46, 706). Der 2,15cm hohe Wirtel hatte bei einem Dm von 3,4cm einen Lochdurchmesser von 0,98cm. Bei dem 1878 entdeckten Einzelfund handelt es sich vermutlich um einen kaiserzeitlichen Spinnwirtel.

Mittelalterliche Keramik, wie Muschelgrus gemagerte Ware und Pingsdorfer Keramik, fand sich zusammen mit einem flach-ovalen Spinnwirtel in einem Graben (Kat.Nr. 402 Fdnr. 528) im nordöstlichen Teil der Siedlung.

Vermutlich ebenfalls als Spinnwirtel diente eine rund abgearbeitete Bodenscherbe (Kat.Nr. 1082-1). Der flach abgeschliffene Gefäßfuß ist mit einer zentralen Bohrung versehen. Sein geringes Gewicht und der Durchmesser von 4,8cm weisen eher auf eine Nutzung als Spinnwirtel denn als Webgewicht hin. Derartige aus einer Tonscherbe zurechtgeschlagene und durchlochte Spinnwirtel sind aus Dreye im Landkreis Diepholz bekannt (BISCHOP 2001, 67-68, Abb. 43,15). Vergleichsfunde liegen u. a. aus Huntebrück-Wührden in der Wesermarsch vor (FöRST 1992, 51-52, Taf. 96, 842).

Die Spinnwirtel sind über das gesamte Siedlungsgebiet verteilt. Meist handelt es sich um Einzelfunde, was darauf hinweist, dass sie nicht absichtlich niedergelegt wurden, sondern i.d.R. innerhalb der Siedlung verloren gingen (LÖBERT 1982, 78). 
Ein Großteil der Spinnwirtel stammt aus Gräben (Kat.Nr. 432, 584, 594, 745, 796, 859) oder großen Gruben (Kat.Nr. 95, 188, 891, 943, 1082). Ein Wirtel wurde in einer kleinen Grube geborgen (Kat.Nr. 559), in einem Fall im Grubenhaus (Kat.Nr. 216; vgl. Kap. 5.2.7). Lediglich ein Exemplar entstammt einer Pfostengrube (Kat.Nr. 674), die sich vor dem Ostgiebel von Hausplatz III befand. In einigen Fällen wurden 2-4 Spinnwirtel in einem Befund entdeckt (Kat.Nr. 584; 745). Auffällig ist die Häufung von vier Spinnwirteln aus dem L-förmigen Graben nordöstlich von Hausplatz II (Kat.Nr. 584). Ein weiterer Wirtel fand sich in der Feuerstelle nahe der Ostseite von Hausplatz II (Kat.Nr. 559). Möglicherweise befand sich in diesem Areal eine bevorzugte Stelle für die Spinnarbeit.

Ungewöhnlich ist die Formenvielfalt der Nortmoorer Spinnwirtel, die sich in fünf verschiedene Typen einteilen lässt. Neben doppelkonisch-symmetrischen kommen ovale, melonenförmige oder zylindrische Wirtel vor. Schlichte flache Wirtelformen ergänzen das Repertoire. Ihre Anzahl deutet auf eine spezialisierte Garnverarbeitung und den hohen Stellenwert der heimischen Produktion an Halbfabrikat hin. In einem Fall ist eine Vergesellschaftung mit einem Webgewicht belegt (Kat.Nr. 943 Fdnr. 988).

Anhand ihrer Fundvergesellschaftung mit zugehöriger Keramik können die Nortmoorer Wirtel in den meisten Fällen in die römische Kaiserzeit datiert werden. Vergleichbare Exemplare liegen aus Wijster vor (VAN Es 1967, 283-284, Abb. 171).

\subsubsection{Webgewichte}

Kat.Nr. 3-63; 3-64; 3 (Qu 53/53) Fdnr. 161; Bef. 3 (Fl. 0-1) Fdnr. 480; 195-23; 627 Fdnr. 524; 869 Fdnr. 1020; 943 Fdnr. 988

Taf. 9; 18

Neben Spinnwirteln belegen Webgewichte eine lokale Textilerzeugung in Nortmoor. Ausnahmslos handelt sich um pyramidale und kegelstumpfförmige Formen. Vier Exemplare wurden zufällig als Oberflächenfund entdeckt, vier weitere entstammen Befunden.

Aussagen zu Gewichtsklassen sind kaum möglich, da die meisten Webgewichte unvollständig erhalten sind. Die Webgewichte sind oxidierend gebrannt und von hellroter Farbe. Meist sind sie in ihrer Brennhärte als eher weich anzusprechen. Ihre Magerung ist relativ fein, es gibt aber auch einzelne Granitgrus-Einschlüsse. Neben einer anorganischen Magerung scheint auch organische Verwendung gefunden zu haben; hierauf deuten Schilfrizome, die wie häckselartige Einschlüsse aussehen, hin. Die Oberflächengestaltung ist meist glatt. Eine Ausnahme stellt Kat.Nr. 3-63 dar.

Kegelstumpfförmige Webgewichte mit runder Standfläche sind mit zwei Exemplaren belegt (Kat.Nr. 3-63; 3-64). Bei dem sorgfältig geglätteten Stück Kat.Nr. 3-63 ist die runde Durchlochung 1,1cm groß. 
Das andere, weniger sorgfältig gearbeitete Webgewicht, verfügt über eine ovale Durchlochung $(1,1 \times 1,8 \mathrm{~cm})$. Ein trapezförmiges und $9 \mathrm{~cm}$ hohes Webgewicht (Breite oben $4 \mathrm{~cm}$, Breite unten $8 \mathrm{~cm}$ ) liegt aus dem Graben Kat.Nr. 627 vor.

Ein gut erhaltendes pyramidales Webgewicht zeichnet sich durch abgerundete vertikale Kanten und einer viereckigen Standfläche aus (Kat.Nr. 195-23). Die Größe der Durchbohrung beträgt 3,6cm. Ungewöhnlich ist ein kreuzartiges Ritzzeichen auf dem sich verjüngenden Oberteil. In Brill wird ein vergleichbares Webgewicht aufgrund seiner Vergesellschaftung mit Basaltlava in die mittlere Kaiserzeit datiert (LEHMANN 2002, 54). Webgewichte dieser Art bezeugen die Existenz vertikaler Webstühle.

Pyramidale Webgewichte gehören bereits zum typischen Fundgut jüngermetallzeitlicher Siedlungen. Sie finden sich von der jüngeren Bronzezeit bis in die frühe Eisenzeit. Für den ostfriesischen Raum wird von einem bis in die Kaiserzeit reichenden Beharren dieser Form ausgegangen (BÉRENGER 2002, 180). In Mittel-Groningen datiert TAAYKE pyramidenstumpfförmige Webgewichte in die ältere römische Kaiserzeit (TAAYKE 1996a, 57). In Tofting wird die Form sogar in das 2. Jahrhundert n. Chr. gesetzt (BANTELMANN 1955, 59, 73). Allgemein datieren die gedrungenen Webgewichte jünger als die pyramidalen (ZIMMERMANN 1982, 127). Ringförmige Webgewichte lösen sie im 4./5. Jahrhundert n. Chr. allmählich ab (VON USLAR 1938, 137). Derartige Stücke sind im Nortmoorer Material jedoch nicht vertreten.

\subsubsection{Tonperlen}

Kat.Nr. 3-55; 3-56; 140-10; 216-24; 744-3

Taf. $7 ; 13 ; 20 ; 42$

Insgesamt liegen drei komplette und zwei nur zur Hälfte erhaltene Tonperlen vor. Es handelt sich bei den Perlen jeweils um Einzelstücke.

Das kleinste Exemplar ist eine runde Perle mit abgeflachten Seiten, einem Durchmesser von 2cm und einer Höhe 1,4cm (Kat.Nr. 3-55). Etwas größer ist eine 2cm hohe zylindrische Perle mit tiefen Umbruch und einem Durchmesser von 1,7 und 2,4cm (Kat.Nr. 3-56). Ebenfalls $2 \mathrm{~cm}$ groß ist eine ovale, achtkantig facettierte Perle, deren Durchmesser im oberen und unteren Bereich $0,8 \mathrm{~cm}$ und in der Mitte 1,9cm beträgt (Kat.Nr. 140-10). Dieselbe Größe besitzt eine runde verzierte Perle (Durchmesser 2-2,8cm), die mit diagonalen breiten Riefen verziert ist (Kat.Nr. 744-3). Der Lochdurchmesser beträgt bei den Perlen zwischen 5-7mm. Die unverzierten Exemplare erinnern in ihrer flachovalen bzw. zylindrischen Form an Spinnwirtel, aufgrund ihrer geringen Größe sind sie dazu aber nicht zu verwenden. Bei der verzierten Perle aus dem Graben Kat.Nr. 744 ist im Fundkontext eine kaiserzeitliche bis frühvölkerwanderungszeitliche Datierung anzunehmen. 
Eine mit vertikal verlaufenden plastischen Rippen verzierte Tonperle (Kat.Nr. 216-24) weist zunächst aufgrund ihrer Größe (Durchmesser 2-3,4cm, Höhe 2,8cm) und der Melonenform auf eine Nutzung als Spinnwirtel hin. In ähnlicher Art ist ein Spinnwirtel in Wohlstreck im Landkreis Diepholz dekoriert (BISCHOP 2001, 68, Abb. 43,11).

Jedoch finden sich für das Nortmoorer Stück mit seinen ausgeprägten Längsriefen auch Parallelen bei römischen Melonenperlen. Diese wurde bevorzugt in Fayencetechnik hergestellt (BORN 1975, 135136, Abb. 1 u. 4). Es sind auch gerippte Tonperlen darunter, die als Nachahmung ähnlich verzierter Glas- und Fayenceperlen gelten. Sie finden sich in der Stufe B1 und C1 bis in die jüngere Phase der späten Kaiserzeit. Das Nortmoorer Exemplar entspricht Typ 489b bei TEMPELMANN-MACZYNSKA (1985, 87, Taf. 19, 489) und gehört der Gruppe LVI römischer Tonperlen an.

Kleine Tonperlen sind chronologisch oft wenig aussagefähig. Sie sind zwischen Weser und Hunte in kaiserzeitlichen Fundzusammenhängen eher selten anzutreffen (BISCHOF 2002, 63). Im Landkreis Diepholz liegen kugelige Tonperlen nur von zwei Fundstellen vor. Nach TEMPELMANN-MACZYNSKA findet sich ihre größte Konzentration im unteren Elbe Gebiet (TEMPELMANN-MACZYNSKA 1985, 88). Eine runde Tonperle in einem Brandgrab in Neubrandenburg durch Vergesellschaftung mit einer Fibel Almgren I 10/11 wird datiert (TEMPELMANN-MACZYNSKA 1985, 87, Taf. 19, 479).

\subsubsection{Keramik anderer Zeitepochen}

\subsubsection{Bronze- und eisenzeitliche Keramik}

Kat.Nr. 7 Fdnr. 813; 7a Fdnr. 827; 216-15; 216-16

Taf. 20

Wenige Scherben können in einen bronze- bzw. eisenzeitlichen Kontext gestellt werden. Meist sind es Wandungsscherben mit einer auffälligen groben Magerung, die zudem relativ dickwandig sind $(>1,7 \mathrm{~cm})$. Es überwiegt reduzierend gebrannte Ware. Pfostengruben bronzezeitlicher Gebäude sind nahezu fundleer. Dies ist nicht weiter überraschend, da innerhalb bronzezeitlicher Siedlungskomplexe generell nur wenige Keramikscherben anzutreffen sind.

Eventuell in die Bronzezeit gehören zwei Bandhenkel aus einem ansonsten kaiserzeitlich geprägten Fundkomplex (Kat.Nr. 216-15; 215-16). Die charakteristische Form mit einem tief ansetzenden Henkel ist typisch für bronzezeitliche Kegelhalsterrinen, wie sie beispielsweise aus Brill vorliegen (LEHMANN 2002, Taf. 71, 3661-2). Generell stellt sich eine Abgrenzung eisenzeitlicher zu kaiserzeitlicher Grobkeramik jedoch als schwierig dar (mündl. Mitteilung Dr. Wolfgang SCHWARZ 2002). Meist sind Wandungsscherben wegen ihrer technisch bedingt zeitlosen Machart nicht eindeutig anzusprechen. 


\subsubsection{Völkerwanderungszeitliche Keramik}

Kat.Nr. evtl. 3-2; 3-44; 3-45; 140-4 (Farbtafel); 140-9; evtl. 216-4; 290-1; 290-2

Taf. 1, 6, 13, 19, 24, 51 (Farbtafel)

Nur wenige Scherben können als völkerwanderungszeitlich angesprochen werden. Vollständige Gefäßprofile liegen aus Nortmoor nicht vor. Erhalten haben sich oft nur kleinere Wandungsfragmente. Eine chronologische Zuweisung der Wandungsscherben ist ohne eine charakteristische Verzierung kaum möglich.

Es dominiert eine ocker-grau und ocker-rötliche Farbgebung. Die Keramik ist meist weniger hart gebrannt, als es in der römischen Kaiserzeit üblich war. Auch die Formenvielfalt im Keramikrepertoire nimmt ab. Allgemein ist die Oberflächengestaltung nur mäßig sorgfältig.

Als völkerwanderungszeitlich gelten einige verhältnismäßig lange Ränder $(>5 \mathrm{~cm})$, die relativ kleinen weitmündigen Töpfen mit schwach s-förmigen Profil angehören (Kat.Nr. 140-4; evtl. 216-4). Der Gefäßrand ist rundlich gestaltet und leicht ausbiegend, seine Wandungsstärke liegt zwischen 0,4 und $0,8 \mathrm{~cm}$. Die Oberflächenstruktur ist geglättet und mit kleinen sandigen Magerungsteilen versetzt. Die Tonfarbe ist ocker-braun und im Bruch dunkelgrau. Ein Mündungsdurchmesser kann mit 16,8cm bestimmt werden. Das Randfragment Kat.Nr. 140-4 (Kat.Nr. 140-4 (Fototafel)) zeigt Übereinstimmungen mit bauchigen Töpfen vom Urnengräberfeld Bordesholm (SAGGAU 1981, 105, Taf. 26-408). Die Gefäßgruppe wird anhand von Fibeln mit rhombischem Fuß in die späteste Belegungsphase zum Ende des 5. Jahrhunderts datiert (SAGGAU 1986, 113). Vergleichbare Randformen liegen in Issendorf mit der Gefäßform 12 vor und werden gleichfalls in das 5. Jahrhundert datiert (WEBER 1996, 97, Abb. 8).

Kümpfe sind eingliedrige Gefäße bei denen die obere Gefäßwandung mehr oder weniger einzieht. Diese Gefäßform tritt in der gesamten Kaiserzeit und darüber hinaus und davor auch in Erscheinung. Bei dem vorliegenden stärker einbiegenden Randfragment ist eine jüngere Datierung in Betracht zu ziehen, werden Ton und Machart berücksichtigt. Der Rand ist innen flach abgestrichen (Kat.Nr. 1409). Der Mündungsdurchmesser des Kumpfes beträgt $28 \mathrm{~cm}$, seine Wandungsstärke kann mit einer gleichmäßigen Stärke von 0,8cm angegeben werden. Kat.Nr. 290-2 verfügt über einen senkrecht stehenden Rand, der innen stark verdickt ist und einen Mündungsdurchmesser von 24,4cm aufweist.

HARCK (1972/73, 51-53) trennt jüngerkaiserzeitliche und völkerwanderungszeitliche Kümpfe mit dünnem Rand und verhältnismäßig kleinem Durchmesser von größeren Kümpfen mit Randwulst, die älterkaiserzeitlichen Fundzusammenhängen angehören. Nach THIEME (1976, 20-22) sind Kümpfe mit abgestrichenen, rundlichen und spitzen Rändern Bestandteil der Gruppe spätrömischer Gefäße. Diese 
ordnete er in südholsteinischen Siedlungen in die Stufe VI hin, die mit Eggers C3 und der Völkerwanderungszeit zu parallelisieren ist.

Weitmündige Gefäße mit Steilrand sind in wenigen Exemplaren belegt (Kat.Nr. 3-44; 3-45; 290-1). Charakteristisch ist der senkrecht stehende unverdickte Rand, der horizontal flach abgestrichen oder flach verschliffen ist. Die Ränder sind von der Schulter nicht abgesetzt. Die Schulter setzt hoch an und ist flach ausgebildet. Ein Mündungsdurchmesser kann mit $22 \mathrm{~cm}$ angegeben werde. Ocker bis rötlichocker dominiert die Tonfarbe. Die Oberfläche ist einfach geglättet. Mittelgrobe Magerungsbestandteile überwiegen. Neben Granitgrus wurde auch Häcksel als Magerung verwendet.

Weitmüdige bauchige Töpfe mit kurzem Zylinderrand und kugeliger Gestalt sind im südlichen Niederelbegebiet wie in Gräberfeldern Schleswig-Holsteins vertreten. In Bordesholm werden die Gefäße in das 5. Jahrhundert gestellt (SAGGAU 1986, 92). In Issendorf gehören sie der Gefäßform 8 an, die dort in den jüngeren Belegungsabschnitt des fortgeschrittenen 5. Jahrhunderts und später datiert werden (WEBER 1996, 93). Für das 5. Jahrhundert wird im Nordseeküstengebiet eine Veränderung in der Gefäßgliederung beobachtet (SCHMID 1970, 62; WATERBOLK 1972, 13), bei der sich zunehmend Gefäße verbreiten, die nur geringe Formunterschiede zu frühmittelalterlicher Keramik aufweisen (BANTELMANN 1988, 70). Vermutlich in den Übergang zur beginnenden Völkerwanderung lassen sich einigen Wandungsscherben mit buckelartiger Auswölbung in der Bauchumbruchzone einordnen (vgl. Kat.Nr. 3-2).

In Ostfriesland fehlen für die Völkerwanderungszeit selbst halbwegs vollständig untersuchte Siedlungen und Gräberfelder. Wie SCHWARZ (1997) an einem Stichprobengebiet an der ostfriesischen Nordseeküste feststellen konnte, überdauerte keine der dortigen Siedlungen das 5. Jahrhundert. Auf einen Siedlungsabbruch in dieser Zeit weisen auch die Untersuchungen zweier Siedlungen im Landkreis Leer hin. In Leer-Loga/Leegcamp (BÄRENFÄNGER 1996; 1997b) und Hohegaste (STILKE 1995) gelang es kleinere Flächen zu dokumentieren. Die Keramik zeigt an beiden Orten einen einsetzenden sächsischen Einfluss und ist reich mit plastischen Auflagen, Leisten und „Buckelmustern“ verziert. Für Loga liegt eine dendrochronologische Untersuchung eines Brunnenholzes mit dem Fälldatum , $416^{-6 /+8 c 6}$ n. Chr. vor.

Völkerwanderungszeitliche Keramik wie sie aus Ostochtersum, Landkreis Wittmund, vorliegt, weist stark gebauchte weitmündige Schalen mit tiefen Umbruch auf. Die Schulterpartie zieren umlaufende Riefen, von denen Strichbündel herabreichen können (SCHWARZ 1990, Taf. 50, 804). Gefäße mit engem Hals erinnern an Flaschenformen und sind mit Kreisstempel, umlaufenden Rillen und stehenden Bögen verziert (SCHWARZ 1990, Taf. 63, 992). Die Bodengestaltung ist meist flach, manchmal jedoch hohl Boden (ScHWARZ 1990, Taf. 51, 834). 
Schlichter gestaltet ist ein kleines Tongefäß, welches als Beigabe bei einer Mutter-Kind-Bestattung im Watt vor Ostbense entdeckt wurde. Der engmündige Topf zeichnet sich durch einen s-förmigen Wandungsverlauf mit relativ dicker Wandung aus und besitzt einen senkrechten Rand. Datiert ist das Gefäß anhand einer der Bestattung beigegebenen silbernen Scheibenfibel vom Typ Rhenen in die erste Hälfte des 5. Jahrhunderts (BÄRENFÄNGER 1997f, 4, 9, Abb. 1a). Bei genauer Betrachtung fällt die leicht konvexe Bodenform aus, die wohl schon als Anklang an die späteren Eitöpfe anzusehen ist.

\subsubsection{Mittelalterliche Keramik}

Kat.Nr. 3-59; 3-60; 3-61; 3-62 (Farbtafel); 26-1; 16 Fdnr. 58; 17 Fdnr. 367; 18 Fdnr. 51, 66 u. 123; 19 Fdnr.118; 24 Fdnr. 77; 25 Fdnr. 78; 26-2; 26-3; 26-4; 26-5; 26-6; 26 Fdnr. 36, 136, 166; 27 Fdnr. 200; 31 Fdnr.42; 32 Fdnr. 56; 44 Fdnr. 133; 46 Fdnr. 100; 48 Fdnr. 102; 49 Fdnr. 110; 50 Fdnr. 131; 69 Fdnr. 99; 78 Fdnr. 394; 78a Fdnr. 394; 82 Fdnr. 137; 86 Fdnr. 176; 88 Fdnr. 343. 347; 91-6; 91-5; 91 6; 91 Fdnr. 307u. 376; 95 Fdnr. 237; 97 Fdnr. 232; 100 Fdnr. 270; 111 Fdnr. 191; 115 Fdnr. 220; 1191; 119-3; 119-4; 120 Fdnr. 215; 123 Fdnr. 259; 140 Fdnr. 449; 145 Fdnr.284; 160 Fdnr. 282 u. 329; 185 Fdnr. 432; 190 Fdnr. 400; 195 Fdnr. 569 u. 900; 202 Fdnr. 421; 212 Fdnr. 419; 223 Fdnr. 530; 243-1; 266-1; 278-11; 278-13; 278-14; 278-15; 278 Fdnr. 567, 578 u. 580; 331-1; 331-2; 331 Fdnr. 618; 345 Fdnr. 688; 395-2; 402-1; 402-2; 402-3; 402-4; 402-5; 402 Fdnr. 527; 409 Fdnr. 655 u. 747; 410-2; 411 Fdnr. 802; 425 Fdnr. 788; 476 Fdnr. 807; 747a Fdnr. 767; 840 Fdnr. 640; 859 Fdnr. 1023 Taf. $8 ; 11 ; 12 ; 21 ; 22 ; 23 ; 24 ; 26 ; 27 ; 51$ (Farbtafel); 114

Unter dem reichhaltigen keramischen Fundgut fällt der Anteil mittelalterlicher Warenarten auf. Zumeist handelte es sich um Oberflächenaufsammlungen, eher selten stammen die Scherben aus mittelalterlichen Befunden. Belegt sind in Nortmoor Muschelgrus gemagerte Keramik, harte Grauware, pingsdorfartige Importkeramik sowie wenige Scherben der glasierten Irdenware. Die im Anschluss vorgenommene Einordnung des mittelalterlichen Fundmaterials erfolgt in Anlehnung an die Arbeit von STILKE (1995a).

Der als Magerungsbestandteil verwendete Muschelkalk hat sich bei dieser Keramik im Sandboden der Nortmoorer Düne weitgehend aufgelöst und eine genarbte (in älterer Literatur als „blasige“ bezeichnet) Oberfläche hinterlassen.

Bei der Muschelgrus gemagerten Keramik, die sich auf insgesamt 22 Befunde verteilt ist (Kat.Nr. 78; $88 ; 95 ; 100 ; 111 ; 115 ; 120 ; 140 ; 145 ; 160 ; 190 ; 195 ; 198 ; 202 ; 212 ; 223 ; 278 ; 331 ; 345 ; 402 ; 409$; $410)$, überwiegen unverzierte Wandungsscherben $(n=63)$ vor Randscherben $(n=19)$. Sowohl hier bei den Streufunden ( $\mathrm{n}=68 \mathrm{WS}, \mathrm{n}=45 \mathrm{RS}$ ) dieser Ware ist eine Konzentration in den östlichen Quadranten der Grabung festzustellen. Diese Beobachtung korrespondiert mit der Befundlage.

Unter den Randscherben überwiegen kurze gerundete und leicht keulenförmig verdickte Ränder. 
Durch den hohen Fragmentierungsgrad (die Randerhaltung beschränkt sich oft auf nur 2-3cm) können jedoch nur wenige Randscherben in Nortmoor dem Typ 1 von Stilke zugeordnet werden (Kat.Nr. 145 Fdnr. 285). Kennzeichnend für frühmittelalterliche Kugeltöpfe sind kurze ausgewendete runde Randformen, wie sie sich auch unter dem Nortmoorer Keramikmaterial finden (Kat.Nr. 3-59; 402-3). Der allgemein hohe Fragmentierungsgrad der Muschelgrus gemagerten Keramik ermöglicht jedoch kaum Aussagen über die Gefäßform. Ganze erhaltene Gefäße aus Hattersum, Ldkr. Wittmund (BÄRENFÄNGER 1992, 215-229), lassen jedoch auch für Nortmoor kugelige Töpfe vermuten. Lediglich von einem Muschelgrus gemagerten Topf konnte eine Mündungsweite, die bei 24,8cm lag, festgestellt werden (Kat.Nr. 3-59). Das obere erhaltene Gefäßprofil zeichnet sich durch eine Verdickung an der Schulterpartie aus und ist damit chronologisch jünger anzusehen. Eine Datierung in das 10. Jahrhundert ist wahrscheinlich.

Muschelgrus gemagerte Keramik wurde in Emden vorwiegend im 9. Jahrhundert, weniger häufig im 10. Jahrhundert verwendet (STILKE 1995a, 46-48). Die Keramik tritt in Haithabu erstmals um 800 auf und dominiert dort im 9. Jahrhundert (STEUER 1974, 96-98). In Hessens findet sich diese Warenart in den Siedlungsschichten III und II, die in das 9. und 10. Jahrhundert datiert werden (HAARNAGEL 1941, 117-120).

Bis etwa um 1000 n. Chr. gehörte die als Kochgefäße verwendete Muschelgrus gemagerte Ware zum Standartrepertoire von Siedlungen im Verbreitungsgebiet. Dieses reichte von der Rheinmündung entlang der Nordseeküste bis zu den nordfriesischen Inseln. Ein wenige Kilometer von Nortmoor auf der Heseler Geest entdeckter Grubenfund mit zahlreichen fehlgebrannten Scherben belegt die lokale Herstellung von Muschelgrus gemagerter Keramik im ostfriesischen Binnenland (BÄRENFÄNGER 1998b, 52, 56, 60-61, Abb. 76-78).

Aus den bauchigen und ei-förmigen Typen des 7. bis 9. Jahrhunderts entwickelten sich schließlich die Kugeltöpfe. Die als harte Grauware bezeichnete und mit feinem Gesteinsgrus gemagerte Keramikware löste im 10. Jahrhundert Muschelgrus gemagerte Keramik ab. Zunächst dominieren schlichte ausbiegende Randformen, die mit der Zeit immer variantenreicher ausgestaltet wurden.

Frühe harte Grauware zeichnet sich durch eine geringere Härte (Mohs: 3) und eher verschliffene Gefäßprofile aus. Da der Übergang jedoch fließend ist, wird eine Abgrenzung zur späteren harten Grauware erschwert.

Die in Nortmoor vorkommenden harte Grauware ist meist einheitlich hellbraun-grau mit einer dunkelgrauen Tonfärbung im Kern. Das Farbspektrum wird ergänzt durch hellorange bis beige Farbtöne. Durch eine divergente Brenntemperatur oder auch lagerungsbedingt können davon Abweichungen auftreten (vgl. STILKE 1995a, 25).

Harte Grauware war in 35 Befunden zu finden (Kat.Nr. 16; 17; 18; 19; 24; 25; 26; 27; 31; 32; 44; 46; 
$48 ; 49 ; 50 ; 69 ; 82 ; 86 ; 88 ; 91 ; 95 ; 97 ; 111 ; 115 ; 120 ; 123 ; 212 ; 266 ; 278 \mathrm{a} ; 331 ; 411 ; 425 ; 476 ; 747 \mathrm{a}$; 859). Auch hier zeigte sich wie bei der Muschelgrus gemagerten Keramik ein Verbreitungsschwerpunkt in der östlichen Siedlungshälfte. Einzige Ausreißer, wie Kat.Nr. 747a und 856, sind aufgrund ihres übrigen Keramikrepertoires kaiserzeitlich zu datieren.

In den wenigen Befunden, die harte Grauware enthielten, fanden sich zumeist nur Wandungsscherben ( $\mathrm{n}=236)$. Randscherben liegen nur aus 10 Befunden vor, drei gehören den Pfostengruben eines mittelalterlichen Rutenberges an (Kat.Nr. 88; 91; 95). Ebenso wie die übrigen Befunde mit harter Grauware (Kat.Nr. 97; 111; 115; 212; 266; 411) sind sie auf den östlichen Siedlungsbereich begrenzt. Einzige Ausnahme ist Kat.Nr. 859.

Unter den Oberflächenfunden, die während der Ausgrabung aufgesammelt wurden, ist der Anteil harter Grauware recht hoch. Streckenweise schien es, als ob die Siedlung mit einer Schicht aus mittelalterlicher Keramik gemischt mit kaiserzeitlicher Keramik bedeckt war. Dieser Effekt wurde auch dadurch gefördert, dass die mittelalterlichen Waren, insbesondere die harte Grauware, weniger stark zerscherbt waren. Die Keramik war regelrecht in einer die Düne flächig bedeckenden Kleischicht ,eingebacken“.

Frühe harte Grauware zeichnet sich durch wenig profilierte Randformen mit gering ausbiegender Randlippe aus (Kat.Nr. 3-62). Sie sind im Fundmaterial kaum vertreten. Die größte Gruppe der mittelalterlichen Grauware in Nortmoor wird durch schräg nach außen abgestrichene Ränder gebildet, die dem Typ 3 von Stilke zu zuordnen sind.

Die Varianten Typ 3.1 (Kat.Nr. 3-61) und Typ 3.2 (Kat.Nr. 91-5; 402-1; 402-2) zeichnen sich durch eine gleichmäßig kantige Randlippenform aus, während Typ 3.3 eine deutlich abgesetzte äußere Randlippe aufweist (Kat.Nr. 26-4; 91-6; 266-1; 278-11; 402-4; 402-5). Dieses Merkmal fehlt bei Typ 3.5, stattdessen wird die äußere Randlippe wieder gerundet dargestellt und es bildet sich ein Absatz auf der inneren Randlippe heraus (Kat.Nr. 3-60; 3-62; 26-1; 26-2; 119-1; 119-4; 243-1; 278 Fdnr. 580; 331-1; 395-2; 410-2), der auch noch bei Typ 3.7 dominiert (Kat.Nr. 26-3; 331-2; 97 Fdnr. 232). Typ 3.8 erscheint als eine Kombination mit einer prononcierten Randlippe (Kat.Nr. 115 Fdnr. 220; 278-13; 278-15).

Dreieckige und dachförmig abgeschrägte Ränder finden sich nur in wenigen Exemplaren. Die innen gekehlten und deutlich abgesetzten Randformen werden von STILKE (1995) in 23 Varianten unterteilt. Belegt sind die Varianten 7.1 (Kat.Nr. 95 Fdnr. 237; 411 Fdnr. 802) und Variante 7.15 (Kat.Nr. 278$14)$.

Der Randtyp 3 zeichnet sich insgesamt durch eine lange Laufzeit aus (STILKE 1995a, 59). Erste Vertreter datieren in Emden bereits in das 9. Jahrhundert, wobei die Form häufiger im 10. Jahrhundert auftritt und auch noch für das nachfolgende Jahrhundert belegt ist. 
Chronologisch frühe Varianten sind die ungekehlten Typen 3.1 bis 3.3, die jedoch auch noch im 11. Jahrhundert vorkommen können. Nun allerdings fast nur noch an kleinen Gefäßen zu finden sind (STILKE 1995, 59). Gekehlte Versionen der Typen 3.4-3.8 treten bis zum 14. Jahrhundert bei leistenverzierter Keramik auf (STILKE 1991, 123).

Nur wenige Ränder können dem spätmittelalterlichen Typ 7 zugeordnet werden. Von den 23 Varianten der in Emden in der Zeit zwischen 1100 bis 1250 bekannten Kugeltopfformen (STILKE 1995, 51) sind nur wenige in Nortmoor nachweisbar. Dies ist nicht weiter verwunderlich, da die mittelalterliche Siedlung sich in dieser Phase bereits in der Auflösung befand. Faststeinzeug und glasierte Irdenware, die in der die frühstädtischen Siedlung Emden Mitte des 13. Jahrhunderts aufkommen, fehlen in Nortmoor ebenso wie leistenverzierte Ware.

Mittelalterliche Schalenränder sind im Nortmoorer Fundgut selten anzutreffen. Möglicherweise handelte es sich bei dem Fragment Kat.Nr. 119-2 um eine solche. Es ist zu vermuten, dass Schalen und Schöpfgeräte aus Holz hergestellt wurden und das keramische Material in seiner Funktion ergänzten (BÄRENFÄNGER 1995, 34, Abb. 18). Tüllenschalen sind nur mit wenigen Fragmenten belegt, wobei sich vorwiegend die stabileren Tüllengriffe überliefert haben. Allgemein gehören Tüllenschalen erst ab dem 12. Jahrhundert zum keramischen Inventar in Ostfriesland. Ein mittelalterlicher Grapenfuß stammt aus dem Graben Kat.Nr. 402.

Für eine ländliche Siedlung wie Nortmoor recht ungewöhnlich sind die zahlreichen Scherben rheinischer Importkeramik. Die aufgefundene Pingsdorfer Keramik zeichnet sich durch eine hellgelbe Tonfarbe und eine dünne Wandung aus. Die Scherben sind verhältnismäßig hart gebrannt, ihre Oberfläche fühlt sich leicht sandig an. Sie ist häufig mit Klecksen und Tropfenlinien in roter Farbe bemalt.

Ihr zugehörig sind zwei nahezu vollständig rekonstruierbare Gefäße. Die beiden $32 \mathrm{~cm}$ und $34,8 \mathrm{~cm}$ hohen bauchigen Töpfe stammen aus der Füllschicht eines mittelalterlichen Brunnens (Kat.Nr. 26-5; 26-6). Die charakteristische rote Bemalung setzt jeweils knapp unterhalb des kolbenartig verdickten Randes an. Bei dem Tüllentopf findet sich eine breitflächige dichte Verzierung mit Wellenlinien, die sich bis über den Umbruch in das Unterteil fortsetzt. Die verhältnismäßig kleine Tülle hat einen Mündungsdurchmesser von 3,8cm (Kat.Nr. 26-5). Aus dem ostfriesischen Bedekaspel stammt ein ähnlicher Tüllentopf, bei dem sich die Bemalung auf das obere Viertel der Gefäßwandung begrenzt (SCHWARZ 1995b, 84, Abb. 15,9). Die zweite Pingsdorfer Tüllenkanne besitzt zwei randständige Bandhenkel (Kat.Nr. 26-6). Die Bemalung ist auf der Gefäßschulter locker durch Kleckslinien bestimmt. Der angesetzte schwache Wellenfuß (Standring) erhöht die Standsicherheit des kugeligen Bodens. Aus dem selben Befund stammen weitere 11 pingsdorf-artige Wandungsscherben und ein Tüllenrand. 
Pingsdorfer Ware findet sich lediglich in acht Befunden (Kat.Nr. 10; 18; 26; 185; 195; 278; 402; 840), wobei es sich mit Ausnahme der Brunnenfunde aus Kat.Nr. 26, ausschließlich um Wandungsscherben handelt. Auch bei dieser Ware fällt der hohe Anteil unter den Streufunden auf. Aus den bekannten Randscherben $(n=19)$, Wandungsscherben $(n=26)$ sowie einem Bandhenkel und drei intakten Standringen sind wenigstens drei weitere Tüllenkannen zu rekonstruieren.

Die Verbreitung Pingsdorfer Keramik zeigt deutliche Zentren im Rheinland, den nördlichen Niederlanden und entlang der norddeutschen Küstengebiete sowie mit einer Fundstreuung bis ins norddeutsche Tiefland (STEUER 1974, 130, Karte 6). Die Ausbreitung der Warenart erfolgte entlang alter See- und Fernhandelswege. Für Haithabu ist das Aufkommen hellrot bemalter Pingsdorfer Keramik bereits um 900 belegt, mit einem Schwerpunkt ab der Mitte des 10. Jahrhunderts (STEUER 1974, 131-132). Eine Vergesellschaftung von Pingsdorfer Keramik mit Muschelgrus gemagerter Ware ist in der Siedlungsschicht II in Hessens zu beobachten (HAARNAGEL 1941, 117-120). Im 11. Jahrhundert finden sich Pingsdorfer Tüllenkannen beispielsweise in Bedekaspel (SCHWARZ 1995b, 84$85)$.

Im 13. Jahrhundert kommt es zu einem Abbruch rheinischen Imports in Ostfriesland. Es ist zu vermuten, dass der nun einsetzende Entwicklungsschub bei der harten Grauware eintritt, als ab der zweiten Hälfte des 13. Jahrhunderts vermehrt lokale Töpfe mit Standlappen, -knubben und -ringen ausgestaltet wurden.

In Nortmoor setzt die mittelalterliche Siedlungsphase frühestens im 8./9. Jahrhundert ein, wie die vorliegende frühmittelalterliche Muschelgrus Ware anzeigt. Dendrochronologische Untersuchungen von mittelalterlichem Bauholz lassen sich am Nortmoorer Material leider nicht zu einer Bestätigung heranziehen. Eine frühere Datierung erscheint nicht gerechtfertig, fehlt doch der im 8./9 Jahrhundert von ostfriesischen Fundstellen belegte frühmittelalterliche Gefäße in Form von Walsumer oder Bardorfer Keramik im Nortmoorer Inventar, während sie in der nahen Brinkumer Nekropole als Urne Verwendung fand.

Einfache gerundete Ränder der lokalen harten Grauware datieren in das 10./11. Jahrhundert. Dieser zeitliche Ansatz wird durch den Pingsdorfer Import bestättigt. Die meisten Randformen der in Nortmoor vorkommenden Grauware weisen in das 11./12. Jahrhundert, wenn auch die Laufzeit einzelner Varianten durchaus länger sein kann. Randformen vom Typ 3 stellen die Masse der mittelalterlichen Kugeltöpfe. Sie markieren auch den Endpunkt der mittelalterlichen Siedlungsphase. Eine zeitliche Begrenzung erfährt die Kugeltopfware durch die Abwesenheit leistenverzierter Ware, die typisch für das 14. Jahrhundert ist (STILKE 1991). Im nur $1,5 \mathrm{~km}$ südlich gelegenen mittelalterlichen Ausbausiedlungen des Jümmiger Hammrich ist sie hingegen reichlich vorhanden 
(ROSENPLÄNTER 2002). Ebenso fehlen in Nortmoor Fragmente mittelalterlicher Krüge und Kannen. Da sie im 13. Jahrhundert selten anzutreffen sind, wundert dies nicht. Ergänzt wird dies durch die Abwesenheit in dieser Zeit beliebter werdende Kugeltöpfe mit Standlappen und -knubben.

\subsubsection{Metall}

\subsubsection{Münzen}

Kat.Nr. 513a Fdnr. 468; 743 Fdnr. 473

Ein Silberdenar wurde im zentralen Bereich der kaiserzeitlichen Siedlung in dem L-förmigen Grabe Kat.Nr. 513 entdeckt. Der $15 \mathrm{~m}$ lange und $0,7-5,5 \mathrm{~m}$ breite Graben befindet sich am nördlichen Siedlungsrand, wenige Meter nordwestlich von Hausplatz I.

Die 2,24g schwere Münze ist verhältnismäßig gut erhalten (Abb. 48; Kat.Nr. 513a Fdnr. 468). Abgebildet ist auf der Vorderseite ein umlaufender Schriftrand mit folgender Inschrift: imperium romana..ARRM....VIR (?). Der Portraitkopf stellt den mit Lorbeer bekrönten Kaiser Trajan dar, der zwischen 98 und 117 n. Chr. regierte. Der Denar wurde zwischen 103- und 11 n. Chr. geprägt. Eine stehende Roma, die in ihrer ausgestreckten Hand eine Viktoria hält, ziert die Rückseite der Münze. Ein ähnlich gut erhaltener Denar Trajans stammt aus Middels-Osterloog, Landkreis Aurich (BERGER /STOEss 1988, 117, Kat. BMC 521).

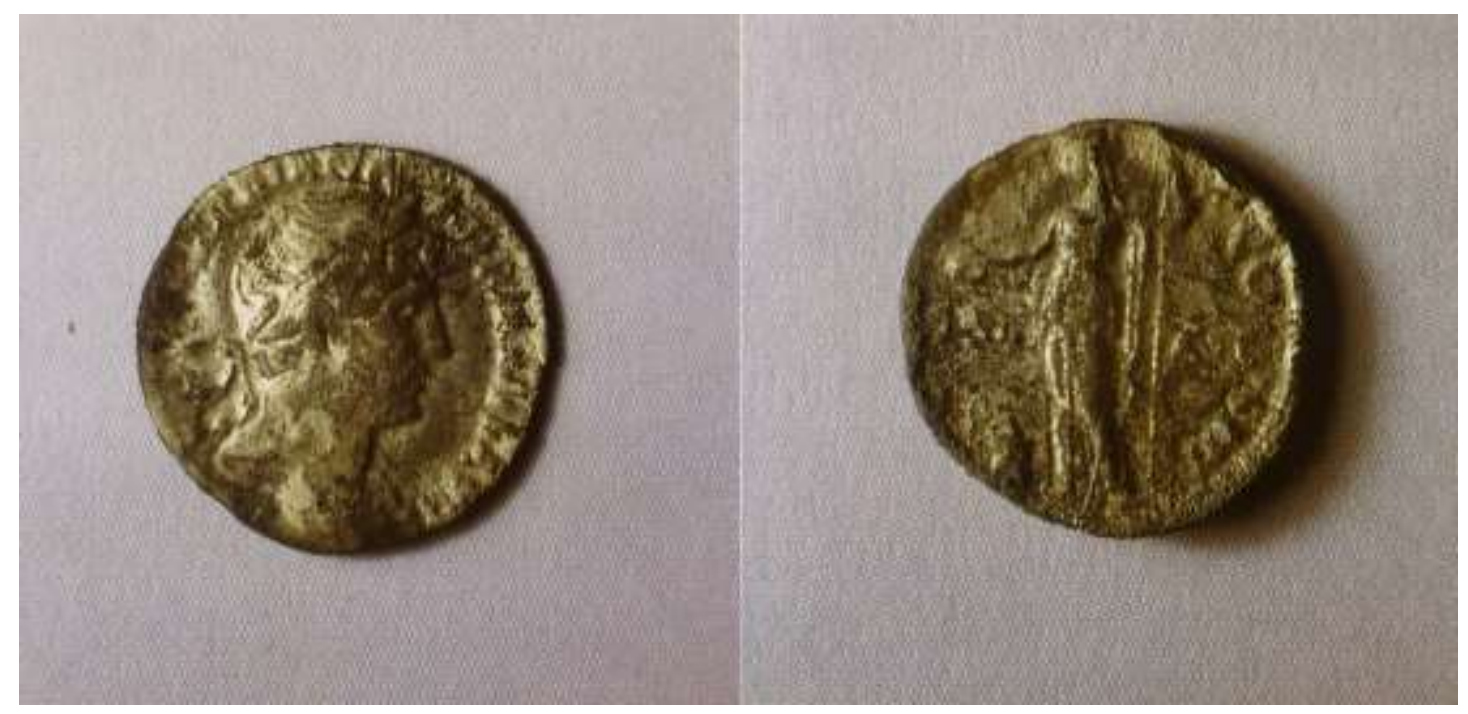

Abb. 48

Vorder- und Rückseite des Nortmoorer Denars

In Relation zur Größe enthielt der bis zu 32cm tiefe Graben nur wenig Fundmaterial, welches mit Ausnahme des Flintabschlags in die römische Kaiserzeit datiert. Neben zwei Randscherben, die einer kleinen Trichterrandschale und einer Schale angehören, fanden sich lediglich noch zwei Flachböden 
und 31 Wandungsscherben. Die Grubenverfüllung bestand aus mehreren Schichten reinen Torf und sandigen Torf, die von einer sandigen Kleischicht bedeckt waren.

Eine zweite römische Münze fand sich am Südrand der Siedlung in einer $75 \mathrm{~cm}$ durchmessenden runden Grube (Kat.Nr. 743). Wenige Meter westlich schließt sich eine anmoorige Bodensenke an. Die Brunnengrube Kat.Nr. 740 befindet sich in $12 \mathrm{~m}$ Entfernung. Die stark korrodierte 3,2cm große und 6,5mm starke Münze ist mit 22,4g relativ schwer (Kat.Nr. 743 Fdnr. 473). Ihr Kern ist aus Bronze. während die äußere Schicht vermutlich Silber legiert war. Ein Hinweis auf eine hohe Hitzeeinwirkung gibt die bereits vom Kern stark verworfene Außenhaut (Aussage des Restaurators). Ihre Erhaltung kann insgesamt als fragil bezeichnet werden. Der Bronzekern ist durchmineralisiert. Größere Fehlstellen sind insbesondere im Randbereich der Münze festzustellen. Inschriftspuren sind nur rudimentär erhalten. Auf einer Seite ist ,...COSS...“ zu lesen. Auf beiden Seiten ist ein Motiv zu erahnen, jedoch nicht mehr zu bestimmen.

Aus der Umgebung Nortmoors sind einige weitere, meist frühkaiserzeitliche, Denarfunde bekannt. Zumeist handelt es sich um Hortfunde, die bereits im 19. Jahrhundert entdeckt wurden. Ein Exkurs zu römischen Fundmünzen in der Unteren Emsregion erfolgte bereits im Kapitel archäologische Quellenlage (Kap. 4.2.4).

Aus der Jümme-Marsch liegt vom $3 \mathrm{~km}$ entfernten Filsum, etwa $12 \mathrm{~km}$ östlich von Leer, ein recht beachtlicher Münzschatz vor. Es soll sich um „Mehrere Rollen von 1/4 Fuß Länge“ mit einer Vielzahl an „Denare von Trajan und Hadrian“... „wohl 2 Pfund“ gehandelt haben (MOMMSEN 1885, 39, 229; vgl. BERGER / STOESS 1988, 126-127, Nr. 2011). Die erhaltenen Münzen stammen aus der Zeit vom Ende des 1. bis zum Ende des 2. Jahrhunderts. Sie sind kurz vor oder während des Bataveraufstandes und des Markomannenkrieges geprägt worden und gelangten eventuell als Sold in die Region. Wenige Münzen stammen aus der Regierungszeit von Kaiser Trajan und Antoninus Pius, als die Rheinprovinzen wirtschaftlich aufblühten. Drei vermutlich zu diesem Hortfund gehörende Denare, ein Titus (80 n. Chr.) und zwei von Commodus (181 u. 186 n. Chr.), fügen sich in den o.g. Prägezeitraum ein. Sie wurden 1963 nahe Filsum geborgen (ROSE 1878; BERGER / STOESS 1988, 137138, FMRD VII, 2011, Nr. 2032; ROSKAMP 1964, 33-34).

Das recht beachtliche Fundaufkommen an römischen Münzen verdeutlichen die aus der Leda-JümmeNiederung stammenden Hortfunde. So sind Münzfunde vom östlichen Ende der Jümme-Marsch bei Detern und vom benachbarten Stickhausen in unbestimmter Anzahl überliefert (ERDRIß 1939, 30 ; ERDRICH 2002, 46). Auch aus der Region südlich Leda sind eine unbestimmte Menge an römischen Münzen überliefert (ERDRICH 2002, 48), so aus Osterhörn, Gemeinde Ostrhauderfehn und Collinghorst, Gemeinde Westrhauderfehn.

Ein besonderer Fundschwerpunkt römischer Münzen zeichnet sich im Reiderland ab: so in Oldendorp 
(BERGER / StOESS 1988, 127-128, Nr. 2013) und in Bingum-Soltborg (BERGER / STOESS 1988, 123 124, Nr. 2008; ERDRICH 2002, 46). Bei letzterem wird es sich um einen Schatzfund gehandelt haben, da man ihn angeblich in einer Tiefe von etwa 2m gefunden hat (ZYLMANN 1930, 30; BERGER /STOESS 1988, 123-125, Nr. 2008; ERDRICH 2002, 46, XIX-12-3/3.1). Der Zeitraum, den die Prägezeiten der Münzen abdecken, reicht von der republikanischen und frühaugustäischen Zeit und kann mit der Anwesenheit römischer Kämpferverbände während der Germanenkriege in Beziehung gesehen werden. Dies trifft auch auf die größere Anzahl an römischen Münzfunden zu, die man in Bentumersiel, einen vermutlich römischen Stapelplatz, entdeckte. Es handelt sich überwiegend um AS des Augustus (28 v. / 14 n. Chr.; 16/2 v. Chr.; 2 AS (10/3 v. Chr.), sowie diverse Denare der Zeit 42./43 v. Chr. (ZYLMAnn 1930, 29-33, Taf. II, Abb. 23-31, Taf. III, Abb. 39-61), eines Dupondius des Caligula (37/41 n. Chr.), der als Einzelfund bei Weener geborgen wurde (ERDRICH 2002, 47), gehört der Zeit der römischen Strafexpedition gegen chaukische Priraten an.

Der mit 100 Münzen umfangreiche Hortfund vom Oldehof bei Hesel stellt den einzigen Geestfund im Landkreis Leer dar. Von der Mitte des 19. Jahrhunderts entdeckten Silbermünzen sind jedoch nur zwei des Kaisers Nerva und einer des Kaisers Trajan, geprägt zwischen 96 und 113, überliefert. Ein spätkaiserzeitlicher Solidus des Kaisers Valenttinian II. kennzeichnet den Endpunkt römischer Fundmünzen im südlichen Ostfriesland. Eine zwischen 388 und 392 geprägte Münze wurde bei Rorichum am östlichen Emsufer entdeckt (BERGER / STOESS 1988, 128, Nr. 2015).

Ein deutlicher Fundschwerpunkt für römische Münzen zeichnet sich für das untere Emsufer und die angrenzende Flussmarsch ab. Zumeist sind es Hortfunde größeren Umfanges. Einige Münzen stammen aus Moorgebieten im südlichen Ostfriesland (Ost- und Westrhauderfehn). In Detern und Stickhausen besteht möglicherweise ein Bezug zu einem nahen kaiserzeitlichen Bestattungsplatz. Münzfunde mit einem eindeutigen Siedlungskontext, wie in Bentumersiel und Nortmoor, sind hingegen selten. Die zeitliche Tiefe der Fundmünzen deckt zumeist die frühe bis mittlere Kaiserzeit $a b$, wobei sich ein Schwerpunkt in frühaugustäischer Zeit und in der Mitte des 2. Jahrhunderts abzeichnet. In einem Umkreis von etwa $50 \mathrm{~km}$ erscheint das Areal westlich der Ems-Region nahezu fundleer und eine erhöhte Fundkonzentration wird erst wieder von der ostfriesischen Geest und aus der niederländischen Provinz Drenthe verzeichnet (vgl. ERDRICH 2001, Beilage 1 u. 2).

Aus Ostfriesland liegen römische Münzen in größerem Umfang vor. Sie decken mit ihren Prägedaten fast das gesamte Bestehen des Imperium Romanum ab. Aus der Menge einzelner Münzfunde hebt sich mit 80 Denaren aus der Zeit zwischen 54/58 und 117/144 n. Chr. der Depotfund von MiddelsOsterloog heraus (BERGER / STOESS 1988, 114-118).

Übertroffen wird dieser allein durch die 564 erhaltenen Münzen des ursprünglich wenigstens 2500 
Silbermünzen umfassenden Schatzfundes von Jever, der einen Zeitraum 2. v./14. n. Chr. bis 222 und 228 n. Chr. umfasst (BERGER / StOESS 1988, 130-132). In der Krummhörner Marsch schließt der spätantike Hortfund von Hauen mit 17 Folles der Zeit von 330/335 bis 337/349 n. Chr. die Phase römischer Münzfunde ab (BERGER / STOESS 1988, 149-184).

\subsubsection{Fibeln und Zierscheiben}

Kat.Nr. 278-16; 278c Fdnr. 543; 627 Fdnr. 474

Taf. 24

Eine kleine kaiserzeitliche Fibel mit schwach gewölbtem Bügel und stumpfen Enden wurde in einem 640x230m großen Graben entdeckt (Kat.Nr. 278-16). Bei dem fragmentarisch vorliegenden Stück fehlen Nadelhalter, Nadel, ein Großteil der Sehne und ein Teil der Spirale sowie der Fibelfuß. Die noch 2,2cm lange und $3 \mathrm{~cm}$ breite Bronzefibel kann als Armbrustfibel angesprochen werden (Abb. 49). Signifikant ist die breite Spirale und die untenliegende Sehne. Die Spiralrolle besteht aus beidseitig neun Windungen und einem runden Achsenknopf. Die Fibel ist bis auf kleine Reste am hinteren Bügel verloren gegangen.

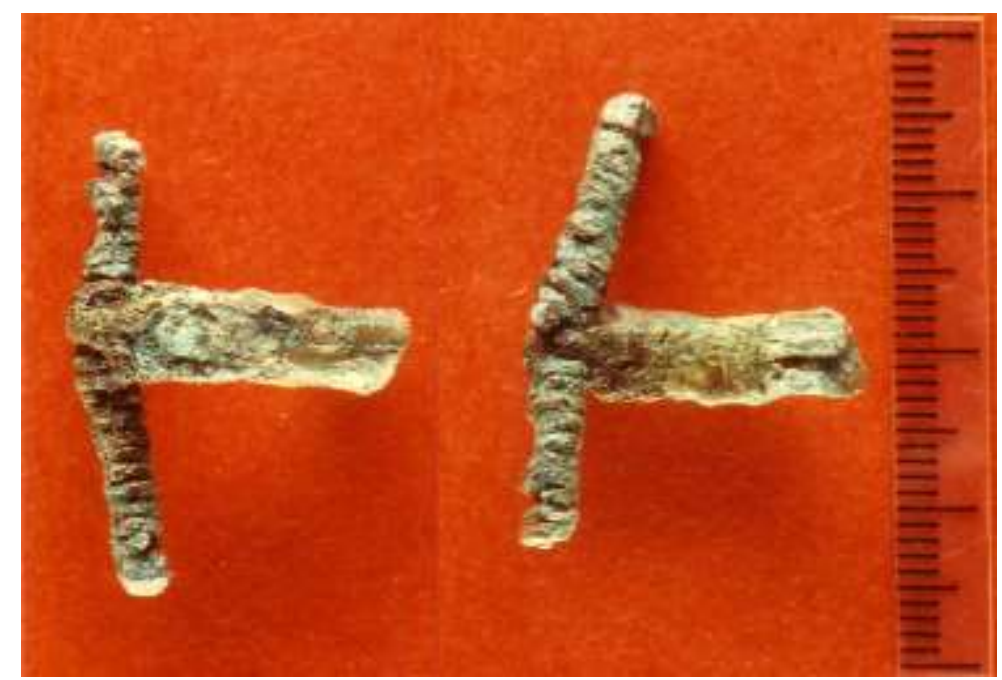

Abb. 49

Vorder- und Rückseite der Armbrustfibel

Das Fragment gehört zu den zweigliedrigen Armbrustfibeln mit hohem Nadelhalter. Die Form erinnert an Almgren VII, 196 bzw. 198 der Serie 3. Typisch sind die runden Achsknöpfchen. Das Nortmoorer Exemplar datiert in die ältere römische Kaiserzeit. Eine genaue zeitliche Bestimmung ist aufgrund des schlechten Erhaltungszustandes kaum möglich. Von der Feddersen Wierde liegt eine verwandtes Fibelfragment vor (SCHUSTER 2006, 34-37, Taf. 6, 42 u. 46). 
In einem dicken, harten Erdklumpen regelrecht verbacken mit wenigen fragilen Knochenstïckchen waren Fragmente eines bronzenen Fibelbügels, der noch eine Gesamtlänge von $1,1 \mathrm{~cm}$ aufwies (Kat.Nr. 278c Fdnr. 543). Die Fibelreste sind aufgrund ihres stark rudimentären Zustandes typologisch nicht bestimmbar.

Eine silberne Scheibe wurde in $15 \mathrm{~cm}$ Tiefe im Westteil eines 340x120 $\mathrm{cm}$ und $48 \mathrm{~cm}$ tiefen Grabens geborgen (Kat.Nr. 627). Aus der mit Holzkohle und gebranntem Lehm durchsetzten Grubenverfüllung stammen zudem hunderte Keramikfragmente, darunter Terra Nigra und anderer Drehscheibenware. Beschädigungen der Scheibenoberfläche sind lagerungsbedingt zu erklären, da sie fest mit Erde verkrustet war. Die Scheibe war von einer dicken Agh-Schicht überzogen. Das Blech an einer Seite eingerissen.

Bei dem runden Silberblech handelt es sich vermutlich um eine Schmuckscheibe. Die 1,8cm große Scheibe ist mit einer $1 \mathrm{~mm}$ breiten Randzone verziert, die wie ein umlaufender Blattkranz gestaltet ist (Kat.Nr. 627 Fdnr. 474, Abb. 50). Auf dieser Seite sind auf dem Silberblech vier sich kreuzende Linien eingraviert und unterteilen die Scheibe in acht Segmente. Die Rückseite der Scheibe ist glatt gestaltet.

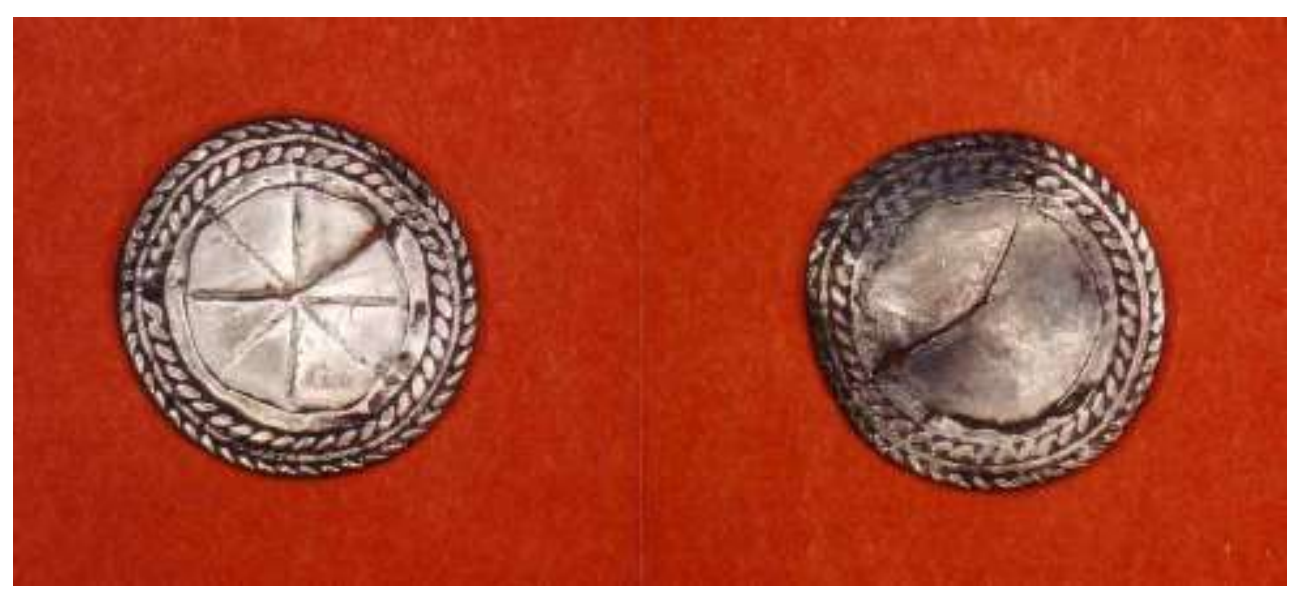

Abb. 50

Vorder- und Rückseite der Silberscheibe (Dm 1,8cm)

Eine stilistische Einordnung der Zierscheibe fällt schwer, da es sich in der vorliegenden Form um ein Unikat handelt. Schmuckscheiben der Feddersen Wierde ähneln ihr nur bedingt. Mit einem linksläufigen Wirbelmuster ist eine kleine Kupferscheibe verziert. Diese weist rückseitig fünf kleine Eintiefungen aus, so dass hier eine Verwendung als Knopf wahrscheinlich erscheint (SCHUSTER 2006, 99, Taf. 29, 243). Derartige Eintiefungen fehlen bei dem Nortmoorer Stück.

Die glatte Rückseite der Scheibe gibt keinen Hinweis auf eine mögliche Befestigung der Zierscheibe. Eventuell war die Scheibe, die einen gebörtelten Rand besitzt, eingefasst und wurde in Art einer Scheibenfibel getragen. Dies würde eine Fassung mit einer rückseitigen Armbrustkonstruktion 
bedingen; möglicherweise in Art einer Scheibenfibel, zu vergleichen mit Typ BÖHME 44a.

Silberne und mit Kupferlegierung überzogene Scheibenfibeln sind gleichfalls von der Feddersen Wierde bekannt. Ein dortiges Exemplar besitzt einen rudimentär erhaltenen rückseitigen Nadelhalter und besteht aus einer Kupferlegierung auf Silberblech (SCHUSTER 2006, 43, Taf. 8, 61).

Scheibenfibeln mit Pressblechbelag gehören dem spätkaiserzeitlichen Zeithorizont an, während Scheibenfibeln vom Typ BÖHME 44 in das 2.-3. Jahrhundert n. Chr. datiert werden. Letztere sind eher im provinzialrömischen Bereich verbreitet (BÖHME 1972, Fundliste 41; BÖHME 1974, Karte 3, 26-29). USLAR $(1939,111)$ datiert Scheibenfibeln anhand ihrer Spiralkonstruktion in das 2. Jahrhundert n. Chr. Neuere Funde weisen bei den Fibeln auf einen früheren zeitlichen Ansatz hin. Die aus LahnsteinWaldgirmes im Lahn-Dill-Kreis geborgene silberne Scheibenfibel lässt eine Datierung in spätaugustäische Zeit vermuten (BECKER /RASBACH 1998, 686, Abb. 6).

Aus demselben Befund, wie die o.g. Armbrustfibel, stammt eine flache, runde Eisenscheibe mit einem Durchmesser von etwa 2,3cm (Befund 278c, Fdnr. 543). Die eine Seite ist rau ausgearbeitet und besitzt eine kleine Erhebung am Rand, die sich zur Mitte hin absenkt. Genau an dieser Stelle befindet sich auf der anderen Seite der Rest eines Schaftes oder einer Öse. Der Zustand ist stark korrodiert, ein Metallkern ist nicht mehr erhalten. Eine typologische Zuordnung ist kaum möglich. Denkbar ist, dass es sich ehemals um einen Zierknopf oder Ziernagel gehandelt hat. Der Vergleich mit einem ähnlichen Eisenobjekt von der Feddersen Wierde weist auf eine Fibelscheibe mit rückwärtiger Nadelbefestigung hin (SCHUSTER 2006, Tafel. 8, Objekt 60; 74, Taf. 19).

Kaiserzeitliche Fibelfunde im Fundkontext einer Siedlung sind in Ostfriesland eine Seltenheit. Im Landkreis Leer sind es vorwiegend Einzelfunde, die als Hortfunde niedergelegt wurden oder einen Bestattungskontext aufweisen. Wenige Kilometer von Nortmoor entfernt stammt aus dem Brandgräberfeld Detern der Rest einer Spiralfibel der älteren römischen Kaiserzeit (SCHWARZ/STUTZKE 1998, 51-52, Abb. 115.2). Eine zweigliedrige Armbrustfibel mit hohem Nadelhalter aus Velde, Gemeinde Detern, wurde als Streufund geborgen und in die jüngere römische Kaiserzeit datiert werden (SCHWARZ/STUTZKE 1998, 104-105, Abb. 149.542).

Um einen Oberflächenfund handelt es sich auch bei der frühkaiserzeitlichen Fibel aus Hatzum (SCHMID 1969, 149, 151, Abb. 1 u. 3). Die Fundumstände eines Altfundes aus Warsingsfehn sind nicht überliefert (SCHWARZ 1990, Taf. 45, 690). Eine ausgesprochen gut erhaltene, gegossene kaiserzeitliche Bronzefibel fand man nahe Holtland im Moor (Schwarz/STUTZKE 1998, 26, Abb. 0.22). Darüber hinaus sind von zwei Fundorten im Landkreis Leer römische Fibeln bekannt. Neben der kaiserzeitlichen Siedlung im Westerhammrich, von wo eine silberne Tutulusfibel stammt (BÄRENFÄNGER 1998, 56-60), fanden sich in Bentumersiel unter dem „Militaria“ des römischen Heeres auch diverse Fibeln (ULBERT 1977). 
Für eine ländliche Siedlung wie Nortmoor ist das Fundaufkommen an Gewandfibeln als hoch anzusehen, berücksichtigt man die Größe der Ausgrabungsfläche. Aus der wesentlich größeren Geestsiedlung Brill stammen drei Armbrust-, eine Stützarm- und eine Pressblechscheibenfibel sowie eine provinzialrömische Emaille-Scheibenfibel (LEHMANN 2002, 73-75). Sie datieren vom Beginn der jüngeren Kaiserzeit bis in die frühe Völkerwanderungszeit.

\subsubsection{Sonstige Metallfunde}

Kat.Nr. 3-19; 939-3

Taf. $3 ; 47$

Ein Gürtelhakenfragment aus Bronze wurde als Streufund beim Baggern entdeckt. Es handelt sich um ein ca. 4,8cm langes und maximal 3,1 cm breites dreieckiges Metallfragment. Die Unterseite des 23 Gramm schweren Metalls ist leicht nach unten eingezogen, während die Oberseite gewölbt vorliegt. An einer Ecke des Stückes ist der Ansatz eines abgebrochenen Hakens erhalten.

Die Originaloberfläche des stark an den Rändern korrodierten Metalls ist weitgehend verloren, so dass das Stück typologisch nicht mehr bestimmbar ist. Ob die Metallaußenseite verziert war, beispielsweise wie bei den dreieckigen Gürtelhaken der Feddersen Wierde (vgl. SCHUSTER 2006, 60-61, Taf. 13), muss deshalb offen bleiben.

Aus einer großen Grube aus dem nordwestlichen Siedlungsbereich stammt eine runde Bleischeibe von 2,3cm Größe (Kat.Nr. 939-3). In seinen Proportionen ähnelt das Stück einer kleinen Zierscheibe oder einem Knopf, wobei die zentrale Durchlochung mit einem Lochdurchmesser von $0,4 \mathrm{~cm}$ für eine solche Nutzung recht ungewöhnlich ist.

Bei der 11 Gramm schweren Bleischeibe könnte es sich um eine Zierscheibe oder eine Gewichtsmarke handeln. Aus dem Fundmaterial von Bentumersiel ist ein gleichartiges Bleistück mit einem Durchmesser von $3 \mathrm{~cm}$ belegt (UlBeRT 1977, 53, Taf. 4,15 u. 15,51). Ein ähnlicher Fund von der Feddersen Wierde wird als bleierner Spinnwirtel gedeutet (SCHUSTER 2006, 95-97, Taf. 29, Nr. 237). Überliefert sind derartige metallene Wirtel u.a. aus Leeste nahe Bremen (BISCHOP 2001, 67, Abb. $35,1)$. 


\subsubsection{Schlacken}

Kat.Nr. 141 Fdnr. 296; 160 Fdnr. 281; 187b Fdnr. 447; 188 Fdnr. 305; 278 Fdnr. 566; 560 Fdnr. 803; 748 Fdnr. 586; 1089 Fdnr. 929; Qu 53/53 Fdnr. 162; Qu 55/44 Fdnr. 526; Qu 56/54 Fdnr. 557; Bef. 3 Fl. 0-1 Fdnr. 564 u. 571

Aus der Siedlung Nortmoor stammen vorwiegend kleinteilige Schlackebrocken von braun-grauer bis rötlich-brauner Farbe. Sie zeichnen sich durch ein meist geringes Gewicht und eine unregelmäßige, fast blasige, Oberfläche aus. Die rötlich-braune Farbe einiger Brocken gibt einen Hinweis auf Reste von Eisenoxid und weist auf sogenannte Fließschlacke hin (JÖNS 1997, 102). Ausgeglühte glasige Schlacken fanden sich nur in wenigen Exemplaren. Letztere entstehen beispielsweise beim Brand eines Lehmfachwerkhauses (SCHÖNBERGER 1978, 302; vgl. SCHUCANY 1996, 158).

32 Brocken mit einem Gesamtgewicht von $2,8 \mathrm{~kg}$ wurden bei Oberflächenaufsammlungen geborgen. Aus Befunden stammen 14 Schlackestücke; meist nur 30-360g schwere Brocken. Wenige Stücke zeichnen sich durch ein höheres Eigengewicht aus, was auf einen höheren Eisengehalt schließen lässt. Schlackestücke mit einer gesinterten Oberfläche sind selten, es überwiegt sprödes Schlackematerial. Doch auch letzteres kann als Verhüttungsschlacke angesprochen werden.

Die Schlackenfunde sind über die gesamte Siedlung verteilt, eine besondere Konzentration ist nicht festzustellen. Das größte Fundaufkommen von 5 Schlackestücken mit einem Gewicht von 400g entstammen einer Grube (Kat.Nr. 748) am südlichen Siedlungsrand. Etwa 5m westlich davon befindet sich eine kleine Brunnenanlage (Kat.Nr. 747), einige Meter östlich verläuft eine Grabenanlage. Ein direkter Bezug zu Umgebungsbefunden, in dem ansonsten weitgehend befundarmen Areal, fehlt jedoch.

Die übrigen Schlacken stammen zumeist aus größeren Gräben (Kat.Nr. 141; 160; 187b; 278; 1089), die auch eine Vielzahl anderer Funde enthielten und die wohl sekundär zur Abfallentsorgung dienten. Nach ihrem Fundmaterial zu urteilen, sind sie kaiserzeitlich zu datieren. Die Grube Kat.Nr. 188 enthielt 260g Schlacke, eine Pfostengrube 30g Schlackereste (Kat.Nr. 560).

Bei Verlegung einer Erdgasleitung wurden im nur 2,5km von Nortmoor entfernten Hotland die Reste von 19 kleinen Öfen erfasst (FStNr. 2711/2:131; Abb. 51). In Holtland konnten während einer Rettungsgrabung sieben Ausheizanlagen dokumentiert werden, die vermutlich in die römische Kaiserzeit datieren (BÄRENFÄNGER 1993b, 79-82; 1994a, 204, Abb. 6). Einer größeren Ofenanlage $(2,5 \times 1,35 \mathrm{~m})$ entstammte annähernd frisches Raseneisenerz. Verziegelte Lehmreste lassen einen kuppelartigen Bau rekonstruieren. 
In den Gruben, über die sich ehemals mit Lehm beworfene Rutengerüste erhoben, wurde abwechselnd Raseneisenerz und Holzkohle aufgeschichtet. Bei relativ geringen Temperaturen trennte sich das Metall als verunreinigte Luppe von der Schlacke (Ofensau). Eine Weiterbearbeitung erfolgte durch mehrmaliges Erhitzen und Hämmern der Luppe (vgl. JÖNS 1993, 65, Abb. 59).

Benachbarte meilerartige Gruben mit hoher Holzkohlekonzentration weisen auf eine lokale Herstellung von Holzkohle hin (vgl. GARBERS 1996, 103). Es gelang 14 kreisrunde Verfärbungen von 40-60 cm zu dokumentieren, beobachtet wurden zudem 6 weitere Anlagen. Die Lage an einem leicht abfallenden SW-Hang bietet günstige Windverhältnisse zur Verhüttung.
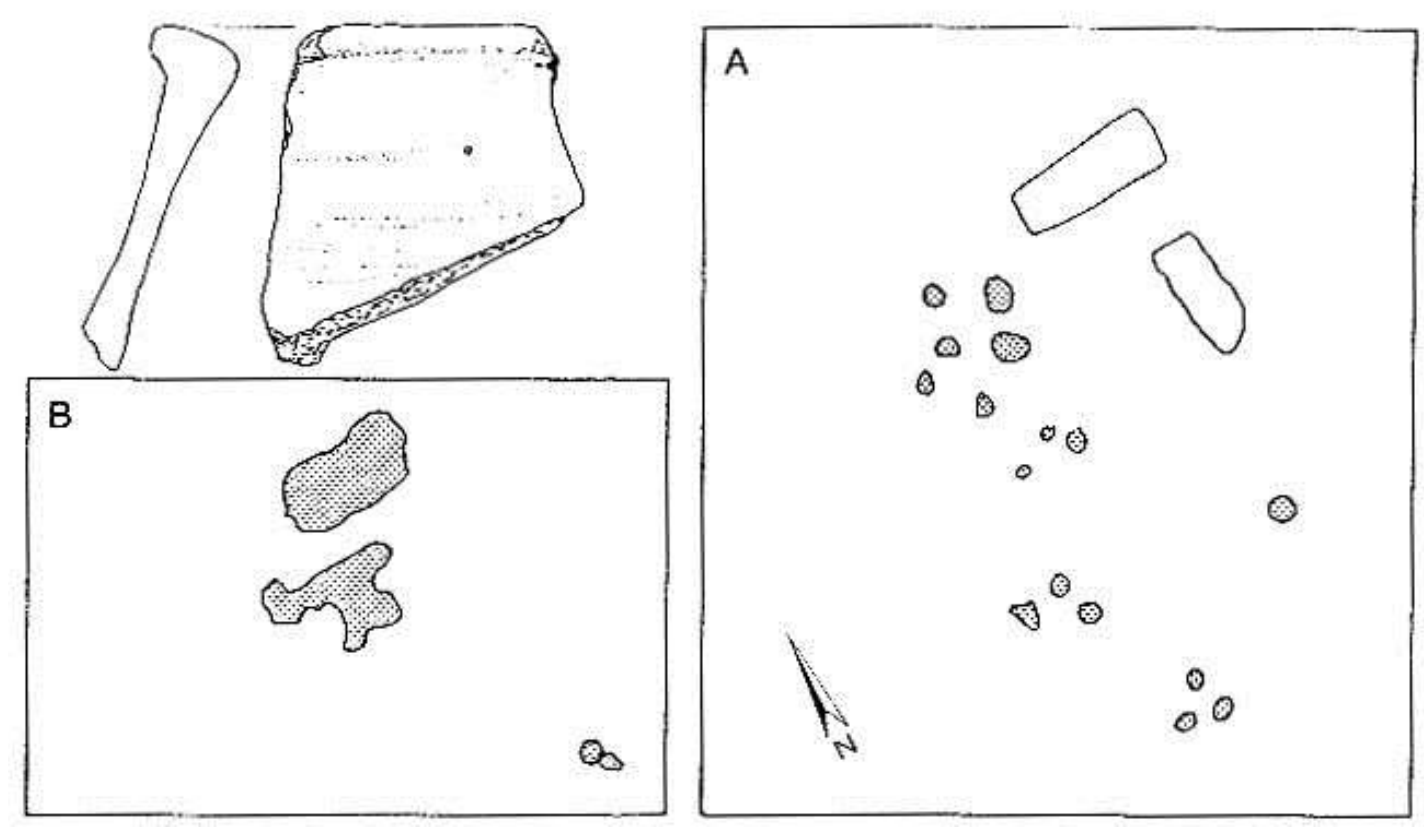

Abb. 51

Eisenverhüttungsplatz Holtland. Randscherbe (M 1:2) aus dem nördlichen Meiler. A zwei rechteckige meilerartige Gruben (ohne Füllmuster); B die Ofenanlage. Planausschnitt M 1: 200

(Zeichnung: B. Kluczkowski, Ostfriesische Landschaft).

Die Ergebnisse der archäometallurgische Analyse des Nortmoorer Materials wurde mit denen des nahen Eisenverhüttungsplatzes Holtland vorglichen (Tab. 8). Sie zeigen hohe FeO-Anteile, die von einem kohlenstoffarmen Eisen zeugen, was die Schmiedefähigkeit erhöht und auf sehr eisenreiches Ausgangserz hinweist. Erstaunlich ist der niedrige Phosphorgehalt in den Holtlander und Nortmoorer Schlacken (Kat.Nr. 278 Fdnr. 566; 3 Fdnr. 564). 


\begin{tabular}{|l|l|l|l|l|l|l|l|l|l|l|l|l|}
\hline \multicolumn{10}{|l|}{ Gew.- \% } \\
\hline Probe & $\mathbf{S i O}_{2}$ & $\mathbf{T i O}_{2}$ & $\mathbf{A l}_{\mathbf{2}} \mathbf{O}_{\mathbf{3}}$ & $\mathbf{F e O}$ & $\mathbf{M n O}$ & $\mathbf{M g O}$ & $\mathbf{C a O}$ & $\mathbf{N a}_{2} \mathbf{O}$ & $\mathbf{K}_{2} \mathbf{O}$ & $\mathbf{P}_{\mathbf{2}} \mathbf{O}_{\mathbf{5}}$ & $\mathbf{B a O}$ & gesamt \\
\hline NMH 1 & 22,19 & 0,06 & 0,92 & 69,08 & 1,13 & 0,20 & 2,52 & 0,10 & 0,28 & 3.04 & 0,10 & 99,62 \\
\hline HOL_12 & 21,07 & 0,05 & 1,10 & 70,20 & 0,53 & 0,16 & 2,10 & n.n. & 0,17 & 2,86 & 0,05 & 98,29 \\
\hline HOL_10 & 22,57 & 0,05 & 0,96 & 68,93 & 1,05 & 0,23 & 2,83 & 0,07 & 0,18 & 2,87 & 0,07 & 99,81 \\
\hline HOL_7 & 22,29 & 0,06 & 1,57 & 65,19 & 0,80 & 0,25 & 4,63 & 0,09 & 0,21 & 3,82 & 0,12 & 99,01 \\
\hline HOL_6 & 20,92 & 0,06 & 1,34 & 70,52 & 0,52 & 0,14 & 2,55 & 0,09 & 0,23 & 2,60 & 0,07 & 99,03 \\
\hline HOL_5 & 22,06 & 0,06 & 1,12 & 68,09 & 0,81 & 0,19 & 3,10 & 0,08 & 0,13 & 3,15 & 0,11 & 98,89 \\
\hline HOL_2 & 22,33 & 0,05 & 0,87 & 68,99 & 1,24 & 0,21 & 2,47 & 0,12 & 0,18 & 2,84 & 0,10 & 99,41 \\
\hline
\end{tabular}

Tab. 8

RFA- und pauschalchemische Analyse der Schlacken (in Gew.- \%)

HOL=Holtland; NMH=Nortmoor (Werte aus: BAUERMEISTER 2005, 33, Tab. 4.2).

Der Gesamteisengehalt wird bei Mikrosonden-Messungen als FeO berechnet, umfasst aber sowohl zweiwertiges als auch dreiwertiges Eisen. Durch Einschlüsse metallischen Eisens kann der FeO-Wert geringfügig zu hoch berechnet sein.

Die Schlacken zeichnen sich durch einen niedrige $\mathrm{TiO}_{2}$ Gehalt aus. Auch Aluminium und Kalium haben einen Anteil von 1-2\%. Der $\mathrm{SiO}_{2}$-Wert liegt um 22\%, und der FeO-Anteil zwischen 65 und 69\% reicht. Die Proben haben einen Phosphorgehalt von 2,8 und 3,8\%, während ihr CaO-Gehalt nicht unerheblich ist. Der Mangan- und Aluminium-Anteil ist sehr gering (Tab. 9).

\begin{tabular}{|l|l|l|}
\hline Probe & Phasenbestand & Kristallisationsreihenfolge \\
\hline NMH 1 & $\mathrm{Wu}, \mathrm{Fa}, \mathrm{Lc}, \mathrm{Sp} ; \mathrm{Oz}$ & $\mathrm{Wu}<\mathrm{LcFa}<\mathrm{Sp}$ \\
\hline HOL_12 & $\mathrm{Wu}, \mathrm{Fa}, \mathrm{C}_{3} \mathrm{P}, \mathrm{Lc} ; \mathrm{Oz}, \mathrm{HK}$ & $\mathrm{Wu}<[\mathrm{Fa}: \mathrm{Wu}]+\left(\mathrm{Fa} \mathrm{C}{ }_{3} \mathrm{P}: \mathrm{Lc}\right]$ \\
\hline HOL_10 & $\mathrm{Wu}, \mathrm{Fa}, \mathrm{C}_{3} \mathrm{P}$ & $\mathrm{Wu}<\mathrm{C}_{3} \mathrm{P}<[\mathrm{Fa}: \mathrm{Wu}]$ \\
\hline HOL_7 & $\mathrm{Wu}, \mathrm{Fa}, \mathrm{C}_{3} \mathrm{P}, \mathrm{Lc} ?$ & $\mathrm{Wu}<\left[\mathrm{Wu}: \mathrm{C}_{3} \mathrm{P}\right]+\left[\mathrm{Fa}+\mathrm{C}_{3} \mathrm{P}\right]+[\mathrm{Fa}: \mathrm{Wu}]$ \\
\hline HOL_6 & $\mathrm{Wu}, \mathrm{Fa}, \mathrm{C}_{3} \mathrm{P}, \mathrm{Lc} ?, \mathrm{Fe} \_m e t ?$ & $\mathrm{Wu}<\mathrm{Wu}: \mathrm{C}_{3} \mathrm{P}+\left[\mathrm{Fa}: \mathrm{C}_{3} \mathrm{P}\right]+[\mathrm{Fa}: \mathrm{Wu}]$ \\
\hline HOL_5 & $\mathrm{Wu}, \mathrm{Fa}, \mathrm{C}_{3} \mathrm{P}, \mathrm{Lc}$ & $\mathrm{Wu}<\mathrm{C}_{3} \mathrm{P}+[\mathrm{Wu}: \mathrm{Lc}]<[\mathrm{Fa}: \mathrm{Wu}]$ \\
\hline HOL_2 & $\mathrm{Wu}, \mathrm{Fa}, \mathrm{C}_{3} \mathrm{P}, \mathrm{Lc}, \mathrm{Fe} \_m e t$ & $\mathrm{Wu}<\mathrm{C}_{3} \mathrm{P}+[\mathrm{Wu}: \mathrm{Lc}]<[\mathrm{Fa}: \mathrm{Wu}]$ \\
\hline
\end{tabular}

Wu=Wüstit; Fa=Fayalit; Lc=Leucit; Sp=Spinell; $\mathrm{C}_{3} \mathrm{P}=$ =Phosphor; Fe_met=metallisches Eisen; Qz=Quarz; HK=Holzkohle (keine gebildeten

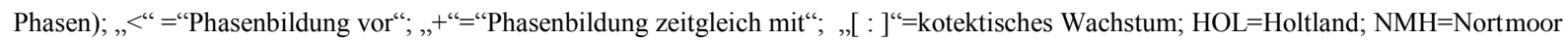

Tab. 9

Phasenbestand und Kristallisationsfolgen in Schlacken aus Holtland und Nortmoor

(Werte aus: Bauermeister 2005, 42, Tab. 4.3.2). 
Ein auffälliger Phosphorreichtum spiegelt sich in der Caliumphosphat-Phase $\mathrm{C}_{3} \mathrm{P}$ wieder (Tab. 9). Ein Vergleich der Schlacken aus Holtland und Nortmoor mit Schmiedeschlacken zeigt eine deutliche Ähnlichkeit in den $\mathrm{FeO}$ und $\mathrm{SiO}_{2}$-Gehalten. Die festgestellten Schlackeeigenschaften deuten auf einen primären Verhüttungsprozess hin. So weist die Mehrzahl der Schlacken ausgeprägte Fließwülste auf, die nach dem Abstich entstehen und das Produkt eines Verhüttungsprozesses im Rennfeuerofen sind. Die Homogenität der Proben aus Holtland und Nortmoor und ihre Pauschalchemie sprechen für einen Verhüttungsprozess, während Schmiedeschlacken eine heterogene Zusammensetzung aufweisen.

Niedrige Schwefel- wie auch Phosphorwerte sind typisch für Rennfeuereisen, während Sulfide eine Weiterverarbeitung des Erzes erschweren würden. Der ungewöhnliche Manganoxidanteil liegt bei $0,95+/-0,31 \%$ und verbessert die Effizienz des Eisengewinnungsverfahrens. In Holtland handelte es sich um Eisenschlacken aus einem Rennfeuerprozess. Sie sind aufgrund ihrer Form und des Chemismus als Produkt einer primären Verhüttung anzusprechen. Für lokale Lagerstätten spricht in beiden Fällen ein ursprünglich stark phosphorhaltiges und eisenreiches Raseneisenerz. Erst während des Verhüttungsprozesses entsteht nahezu phosphorfreies metallisches Eisen. Die Reduktion der Eisenoxide steht in unmittelbarer Verbindung zum Holzkohle-Erz-Verhältnis und dem daran angepassten Zusatz an Sauerstoff (LYCHATZ 1995, 247-248).

Holtland kann als ein Werkplatz der heimischen Eisenverarbeitung angesprochen werden. Die Brennstoffherstellung erfolgte vor Ort in Meilern. Mit der gewonnenen Holzkohle wurde das Erz verhüttet und anschließend das Roheisen in Ausheizanlagen weiterverarbeitet. Für Nortmoor gelang dieser Nachweis über die metallurgische Analyse. Im Siedlungsareal gab es keinen Hinweis auf Gusstiegeln, wie sie aus kaiserzeitlichen Siedlungen im Westerhammrich (BÄRENFÄNGER 1999a, 8081, Abb. 30) und von der Feddersen Wierde bekannt sind (SCHUSTER 2006, 136, Abb. 36-37).

Die aufgefundenen Schlacken in Holtland legen eine lokale Eisenverhüttung im Rennfeuerverfahren nahe, wobei Holzkohle als Brennstoff fungierte. Grundlage bildete das anstehende Raseneisenerz. Dieser natürlicher Rohstoff findet sich in der Geest unter podsolierten Böden und in Sandflächen von Flussniederungen. Östlich von Leer ist in Teilbereichen des Nortmoorer und Jümmiger Hammrichs eine recht beachtliches Vorkommen an Raseneisenerz bekannt, wo Weich- und Weißeisenerz abgebaut werden konnte (GRAUPNER 1982, Abb. 3). Raseneisenerz mit einem Eisenanteil von bis zu $40 \%$ bildet sich in Niederungen durch Ausfällen des gelösten Eisens aus dem Grundwasser und ist unmittelbar unter der Oberfläche erreichbar. Möglicherweise waren in Nortmoor für Rennfeueröfen, ähnlich wie in Gristede und Flögeln, eher Areale abseits der Höfe reserviert (ZOLLER 1970, 134; SCHMID / ZIMMERMANN 1976, 57). Vermutlich wurden in Nortmoor Halbfabrikate verarbeitet. Der Fund feinporiger Eisenschlacken ohne Fließstruktur deutet auf eine lokale Schmiedetätigkeit hin (WESTPHALEN 1989, 59; WEDEPOHL / SCHNEIDER 1986, 173). 
Eisenverhüttungsplätze sind in Norddeutschland seit Beginn der vorrömischen Eisenzeit anzutreffen (NiKULKA et al. 2000; ZIMMERMANN 1998, 73, Abb. 3). Im Laufe der Kaiserzeit erhöht sich in den Siedlungen die Anzahl der Rennfeueröfen. Wie intensiv dieses Handwerk schließlich im 4. und 5. Jahrhundert betrieben wurde, belegen die etwa 500 geophysikalisch entdeckten Schlackegruben in Joldelund (JÖNS 1993).

Hinweise auf eine etablierte Eisentechnologie in Ostfriesland finden sich von verschiedenen Fundstellen. Überreste von Schlackegruben und Ofenteilen weisen für Brill auf eine aktive Nutzung der Eisentechnologie hin. Es wurden zahlreiche Schlacken wie auch Schmelzöfen zur Eisenerzverarbeitung entdeckt, nicht jedoch oberirdische Ausheizanlagen (LEHMANN 2002, 88-90). Belege für eine lokale Eisenverarbeitung existieren aus Holtgast im Landkreis Wittmund (BÄRENFÄNGER 1997, 432-433). Neben einer Vielzahl an Schlacken kann ein Werkareal in der kaiserzeitlichen Siedlung lokalisiert werden. Eine 1m durchmessende Feuerstelle verfügte über einen randlichen Unterbau aus 14 verkohlten Hölzern. Darüber lagerte eine unregelmäßige Feldsteinpflasterung, die als Brennfläche genutzt wurde.

Eine lokale Buntmetallverarbeitung im südlichen Ostfriesland ist aus dem Westerhammrich bei Leer bekannt, wo sich Reste von Bronzeschmelze und Fragmente von Ofenkuppeln erhielten (BÄRENFÄNGER 1999a, 79-81, Abb. 30).

Aus benachbarten Regionen liegen u.a. aus Flögeln Zeugnisse kaiserzeitlicher Metallverarbeitung vor. Neben bronzenen Gussabfällen ist dies der Fund eines sogenannten Probiersteins mit dessen Hilfe man die Reinheit von Edelmetallen anhand einer Reibeprobe prüfen konnte (ZIMMERMANN 1992, 213-214, 314-315). Für die Feddersen Wierde setzte die Eisenverarbeitung erst im 3. Jahrhundert n. Chr. ein, wobei ein Nachweis an Rennfeueröfen auch hier fehlt (HAARNAGEL 1979, 195-197, 299).

\subsubsection{Glas}

Kat.Nr. 3-36; 78-1

Taf. $5 ; 12$

Insgesamt liegen zwei Glasobjekte römischer Provienienz aus Nortmoor vor. Es handelt sich um das Randstück eines kleinen Glasgefäßes und um eine Glasperle. Beide Objekte stammen aus gestörten Fundzusammenhängen, ein römischer Kontext ist jedoch aufgrund ihrer Form, Farbe und Oberflächenpatina anzunehmen.

Eine melonenförmige Glasperle fand sich in einer modernen Störung am Ostrand der Grabungsfläche (Kat.Nr. 78-1). Die hellblaue Perle ist mit einem blau-weiß gestreiften Überzug in Form vertikaler Streifen verziert. Die erhaltene Perlenhöhe beträgt 1,6cm, ihre Breite 1,6cm. Obwohl die Perle nur zur 
Hälfte erhalten ist, kann aufgrund der inneren Krümmung ihr Lochdurchmesser mit $0,8 \mathrm{~cm}$ angegeben werden.

Form und Farbgebung deuten auf eine römische Glasperle hin. Innerhalb dieser Gruppe machen die gestreiften Perlen den größten Anteil aus und verfügen über eine große Variantenzahl. Das Nortmoorer Exemplar gehört der Gruppe XXII der gestreiften Perlen von mittlerer Größe an. Ihre Vertreter finden sich von Stufe B2 bis D (TEMPELMANN-MACZYNSKA 1985, 53-54, vgl. Tafel 5, 249a). HARCK $(1972 / 73,123)$ stellt melonenförmige Perlen in die Stufe K III. Die lange Laufzeit des Perlentyps verhindert eine genaue Datierung.

Aus hellgrünlichem Glas ist das Fragment eines Gefäßrandes, welches als Streufund in Nortmoor geborgen wurde (Kat.Nr. 3-36). Der zierliche Gefäßrand (Durchmesser 1,7cm) besitzt eine kurze vorgewölbte Randlippe und gehörte vermutlich zu einem engmündigen Flaschenrand oder einem Glasflakon. Gefäße aus naturfarbenen blaugrünen Gläsern lösten ab dem letzten Viertel des 1. Jahrhunderts die bis dahin beliebten ein- bis mehrfarbigen Buntgläser ab (ROTTLOFF 2000, 134).

In Norddeutschland sind engmündige Glasgefäße dieser Art bisher selten. So stammt ein ähnlicher Flaschenrand aus blaugrünem Glas aus einem Grubenhaus in Oldendorf bei Melle im Landkreis Osnabrück. Der dem Typ Isings 50 angehörige Gefäßrest in das 1.-3. Jahrhundert datiert wird (ERDRICH 2002, 58). Ein Vergleich mit dem Inventar von Kölner Glasmanufakturen zeigt, dass diese Gefäßform im provinzialrömischen Bereich erst Anfang des 2. Jahrhunderts aufkommt. Dies deckt sich mit den Glasfunden aus der westfälischen Siedlung Zeche Erin in Castrop-Rauxel. Unter den dort entdeckten 252 Gefäßfragmenten finden sich einige engmündige Glasränder ähnlicher Ausgestaltung (FREMERSDORF 1970, 50-54). Möglicherweise gehörte das Nortmoorer Exemplar zur Gruppe der sogenannten Balsamarien, einer im 1.-4. Jahrhundert n. Chr. im römischen Reich weit verbreiteten Glasgefäßform. Diese zeichneten sich durch eine insgesamt sehr schlanke Form aus. Die kleinen Glasfläschchen besaßen einen langen Gefäßhals, der sich aus einem flachgewölbten Gefäßkörper auszog. Die für diese Gefäße typische kleine Gefäßöffnung von 2-4cm Durchmesser und der bis zu $12 \mathrm{~cm}$ lange Gefäßhals sollten die in ihnen aufbewahrten Essenzen, meist Duftöle, besser vor Verdunstung schützen (HONROTH 2007, 46-53).

Gaben lange Zeit nur Reste von Glasschmelzen aus kaiserzeitlichen Brandgräbern einen Hinweis auf diese Materialgruppe, so hat sich inzwischen die Anzahl an identifizierbaren Glasfunden im norddeutschen Küstengebiet erhöht (ERDRICH 2002, 211-212). Die Glasfunde decken dabei die gesamte Zeitspanne der römischen Kaiserzeit ab, wobei jüngerkaiserzeitliche Funde überwiegen.

Von der Feddersen Wierde stammt das Wandfragment einer bereits in das 1. Jahrhundert zu datierenden Rippenschale (ERDRICH 2002, 124). Das Randfragment eines 10cm durchmessenden römischen Glasbechers wurde 1993 in der kaiserzeitlichen Siedlung Westerhammrich entdeckt 
(BÄRENFÄNGER 1999a, 78, Abb. 27,7). Der keulenförmig verdickte und auswärts gewandte Rand gehört zu einem glattwandigen Becher aus hellblauem blasigem Glas und datiert in das 1.-2. Jahrhundert (ERDRICH 2002, 47). Spätkaiserzeitlich bzw. frühvölkerwanderungszeitlich datieren in Flögeln geborgenen Reste eines Glasgefäßes mit Fadenauflage (ERDRICH 2002, 113).

Für USLAR $(1938,134)$ galten kaiserzeitliche Glasperlen noch als Ausnahme. Inzwischen ist durch bessere Ausgrabungsmethoden ihr Anteil erheblich angestiegen. Erdrich führt allein in Niedersachsen und Bremen 45 Fundorte mit römischen Glasperlen auf (ERDRICH 2002, 221-222). Zumeist handelt es sich dabei um zerschmolzene kleine Glasklumpen, die in Brandgräbern geborgen worden sind. Glasperlen aus Siedlungen sind dagegen recht selten.

So sind derzeit in Ostfriesland Glasperlen nur von drei weiteren kaiserzeitlichen Siedlungen bekannt. Aus Brill stammt eine flachkugelige Glasperle von mittelblauer Farbe (LEHMANN 2002, 77), die dem Typ 35 nach TEMPELMANN-MACZYNSKA $(1985,29)$ angehört und vermutlich in die Stufen C und D datiert. Im südostfriesischen Backemoor fand man in einer Brunnenfüllung eine kleine doppelkonische blaue Perle, und aus dem Siedlungsareal liegen zudem zwei 1-2qcm große Fragmente von olivfarbenen Flachgläsern vor (BUSCH-HELLWIG 2008, 27). Aus der kaiserzeitlichen Siedlung Nenndorf stammt eine flache $2 \mathrm{~cm}$ große Glasscheibe, die als Wandscherbe interpretiert wird (KREIBIG 2006, 98). In Weener liegt eine dunkelblau opake Perle mit aufgelegten Schichtaugen vor (ERDRICH 2002, 46 (dort als Bentumersiel); Fundortakte der Archäologischen Landesaufnahme FStNr. 2810/4:25). Erst wieder aus der Wesermarsch ist für Huntebrück-Wührden eine hellblaue Glasperle in einem Siedlungskontext belegt (FöRST 1991, 52). Aus den Siedlungen in Leeste, Sudweyhe und Barrien im Landkreis Diepholz sind weitere hellblaue und dunkelblaue transluzide Glasperlen bekannt (BISCHOP 2001, 61-62, Abb. 40, 3-14).

Bereits in der älteren römischen Kaiserzeit gelangten gläserne Objekte als Import in das Barbaricum (EGGERS 1951, 48, Karte 4,49.50). In Niedergermanien sind erste glasherstellende Betriebe in der ersten Hälfte des 1. Jahrhunderts n. Chr. errichtet worden, die später auch rechtsrheinische Grenzgebiete versorgten (FREMERSDORF 1970, 54). Es waren zunächst die Provinzstädte am Rhein, wie Köln und Bonn, wo eine prosperierende Glasindustrie im 1. Jahrhundert entstand (LUND HANSEN 1989, 146). Ab dem 2. Jahrhundert nimmt der Handel mit römischen Glasperlen im Norden zu, wobei die Herkunft der verhandelten Ware bisher ungeklärt ist. In der jüngeren Kaiserzeit wird es nach LUND HANSEN $(1989,152)$ zu einer Glasperlenproduktion auch außerhalb des römischen Reiches gekommen sein.

\subsubsection{Steingeräte}

Aus dem Siedlungsareal Nortmoor liegt nur eine verhältnismäßig kleine Anzahl an Steingeräten vor. 
Sie gelangten eher zufällig in die Befunde, meist in sekundär genutzten Abfallgruben. Ein Großteil der Steingeräte wurde bei systematischen Oberflächenaufsammlungen zusammengetragen. Der überwiegende Teil der Steingeräte steht mit der Getreideverarbeitung in Verbindung.

\subsubsection{Mahlsteine}

Kat.Nr. 26 Fdnr. 145; 93 Fdnr. 201; 2 u. 3 Fdnr. 9; Qu. 52/52 Fdnr. 157; Qu 52/53 Fdnr. 32

Verhältnismäßig gering ist die Anzahl der in der Siedlung aufgefundenen Bruchstücke an Basaltlava (n=6). Meist handelte es sich um Oberflächenfunde. Ein Befundzusammenhang war nur für zwei Mahlsteine nachzuweisen (Kat.Nr. 26 Fdnr. 145; 93 Fdnr. 201). Die in der Siedlung aufgefundene geringe Anzahl von Mahlsteinen liegt möglicherweise in ihrer schlechten Erhaltung im Milieu saurer Sandböden begründet (vgl. LEHMANN 2002, 80).

Ein Basaltlavastein mit einem Gewicht von 1,25kg entstammt der Brunnengrube Kat.Nr. 26. Die Oberfläche des $40 \times 36 \mathrm{~cm}$ großen Bruchstückes ist teilweise mit konzentrisch angebrachten Rillen versehen. Der Durchmesser kann mit etwa $42 \mathrm{~cm}$ angegeben werden. Auf eine Handhabung als Oberlieger weist die zentrale Lochung hin (Abb. 52).

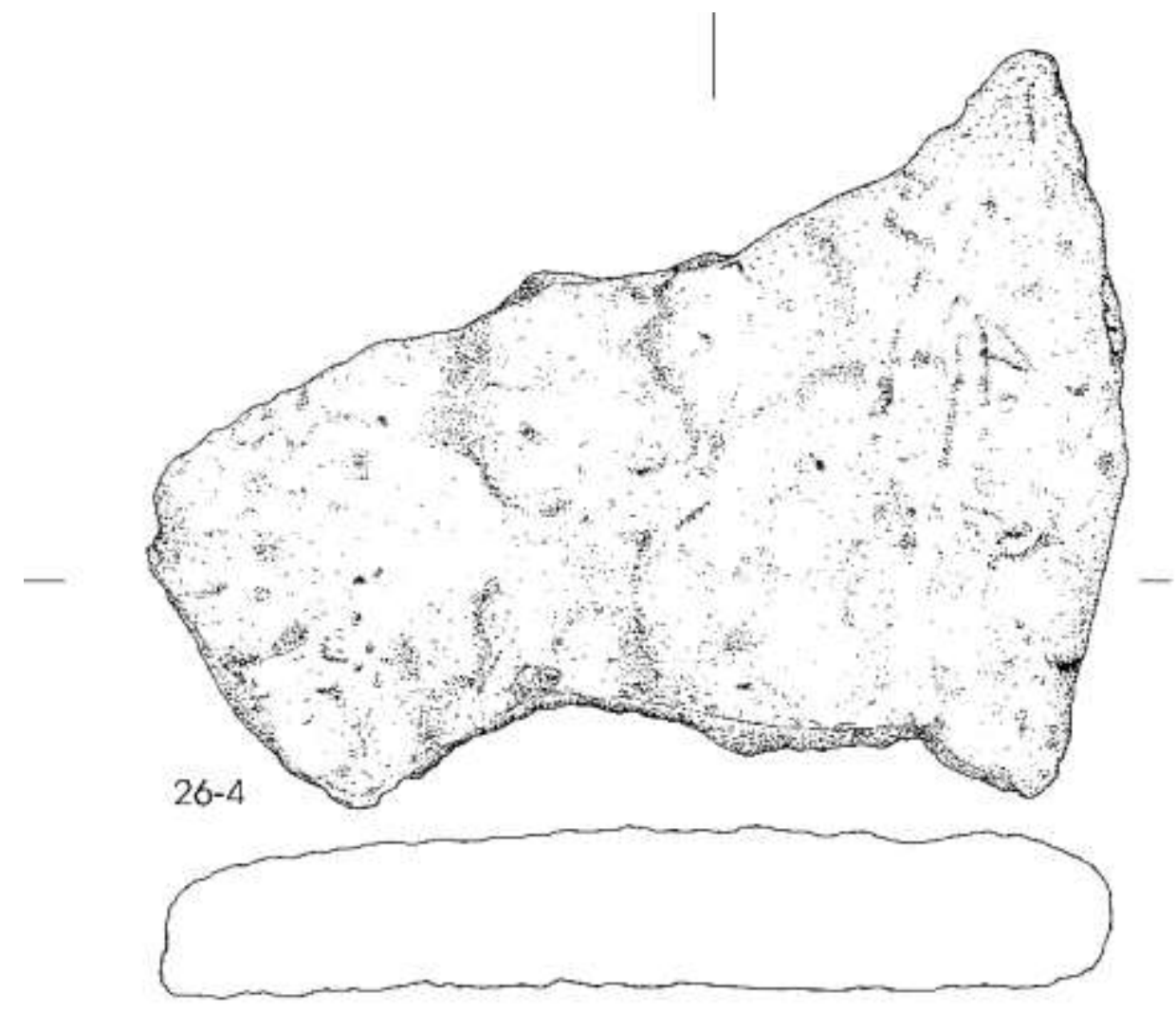

Abb. 52

Basaltlava Bruchstück aus einer mittelalterlichen Brunnengrube (Kat.Nr. 26); M 1: 4 
Ein 20x12cm großes Basaltlavafragment fand man in einer 200x60 cm großen Grube Kat.Nr. 93. Die als Oberflächenfunde entdeckten Mahlsteinfragmente waren mit wenigen Ausnahmen stark fragmentiert. Lediglich bei drei Basaltlavasteinen waren Oberfläche und Außenseiten noch erhalten. Ein Radius konnte jedoch nicht ermittelt werden. Ihre geringe Stärke von 2,8-3,1cm weist auf eine intensive Nutzung hin. Derartige Basaltlavasteine waren Bestandteil von ehemals 40kg schweren Handdrehmühlen. Für den Brunnen Kat.Nr. 26 liegt eine Datierung in das frühe Mittelalter vor.

Die Grube Kat.Nr. 93 findet sich in einem durch mittelalterliche Befunde dominierten Siedlungsareal am Ostrand der Düne. Die übrigen Mahlsteinfragmente können durchaus auch aus der kaiserzeitlichen Siedlungsphase stammen.

Die Nortmoorer Stücke bestehen aus Eifeler Weichbasalt Mayener Provenienz. Oberseitig mit Rillen verzierte Mahlsteine wurden sowohl als Fertigprodukte in schlichter Ausformung wie als Halbfertigprodukte gehandelt (LEHMANN 2002, 81). Wurde im 1. Jahrhundert in Mayen die Produktion von Handmühlen durch die Römer im Zuge ihres militärischen Bedarfes gefördert, lässt sich bereits für das 2. Jahrhundert eine Abnahme feststellen (MANGARTZ 2008, 101-102). Durch verstärkte Importe in die Germania libera wurden nun neue Märkte erschlossen und die Produktion auf hohem Niveau weitergeführt. Die Fundverteilung der Mahlsteine in Norddeutschland weist eine eindeutige flussorientierte Verbreitung auf.

Von den rheinischen Mühlsteinbrüchen erfolgte der Transport der Basaltsteine rheinabwärts, wurde im Rheindelta auf seetüchtige Transportschiffe umgeladen, um dann der Küstenlinie folgend, Handelsplätze entlang der in die Nordsee mündenden Flüsse zu erreichen. Die von BISCHOP (2001, 97, Abb. 71) kartierten kaiserzeitlichen Fundstellen im nordöstlichen Niedersachsen zeigen deutlich eine Häufung von Basaltmahlsteinen entlang der Weser.

Basaltmühlen finden sich während der gesamten Kaiserzeit. Sie sind u.a. in Wijster (VAN Es 1967, 148-149), Paddepoel (VAN Es 1968, 244) und Bennekom (VAN Es u.a. 1985, 613-615) belegt. In Gristede sind Basaltmahlsteine im 1. Jahrhundert n. Chr. dokumentiert (ZOLLER 1963, 42).

Bereits um Christi Geburt sind für die Feddersen Wierde wenige Basaltmahlsteine überliefert (HAARNAGEL 1979, 280-281). Im späten 2. und frühen 3. Jahrhundert erhöht sich ihr Anteil am Importgut wesentlich, wie ihre Vergesellschaftung mit Terra Sigillata recht gut zeigt. Danach sind nur noch vereinzelt Stücke belegt. Für Brill wird eine ansteigende Verwendung ab dem 3. Jahrhundert verzeichnet, die in den folgenden beiden Jahrhunderten wieder abnimmt (LEHMANN 2002, 82). Im späten 2. / frühen 3. Jahrhundert befindet sich der Höhepunkt im Importhandel mit Basaltlavasteinen in Niedersachsen (VON SCHNURBEIN / ERDRICH 1992, 25).

In Ostfriesland stellen provinzialrömische Basaltlavasteine eine Seltenheit dar. Kartiert sind bisher 
Fundorte in Brill (Landkreis Wittmund) und in Arle bei Aurich (ERDRICH 2002, 216). Inzwischen kann dieses Verbreitungsbild um einige Fundorte erweitert werden. LEHMANN $(2002,80)$ führt für den Landkreis Wittmund vier weitere Fundstellen mit Basaltlava an. Zuletzt gelang in Nenndorf der Nachweis einer Pendelmühle aus Basaltlava (KREIBIG 2006, 99). Derartige Mühlen datieren zwischen 200 vor und der Mitte des 1. Jahrhundert n. Chr. Bruchstücke von Mahlsteinen aus Eifeler Basaltlava fanden sich auch in einem kaiserzeitlichen Brunnen in Backemoor (BUSCH-HELLWIG 2008, 75).

Zwischen dem 5. und 7. Jahrhundert kam der Handel mit Eifeler Mühlsteinen weitgehend zum Erliegen (BISCHOP 2000, 28). Doch bereits für das frühe Mittelalter sind friesische Händler belegt, die Handelszentren am Mittelrhein und an der Mosel aufsuchten. Über Dorestad, Medemblik, Domburg und Haithabu wurde die begehrte Ware in den Norden weitergeleitet (MANGARTZ 2008, 125).

\subsubsection{Schleif- und Glättsteine}

Kat.Nr. 3-65; 11 Fdnr. 46; 120 Fdnr. 216; 140 Fdnr. 465; 160 Fdnr. 322/ 326; 305 Fdnr. 628, 402 Fdnr. 528; 1082 Fdnr. 957; 1113 Fdnr. 911; Altfund 1964/65 Fdnr. 1; Qu 56/54 Fdnr. 22; Qu 3 Fdnr. 521

Insgesamt liegen 12 Schleif- und Glättsteine aus feinkristallinem Sandstein aus der Siedlung vor. Meist handelt es sich um kleinere Fragmente von annähernd viereckiger Form mit scharfen bis gerundeten Kanten. Die Schliffflächen können gerade, nach innen oder nach außen gewölbt, ausgearbeitet sein. Mit ihnen schärfte man Gerätschaften aus Metall (HALPAAP 1992, 200).

Aus Siedlungsgruben stammen vier Schleifsteine (Kat.Nr. 120 Fdnr. 216, 1082 Fdnr. 957, 1113, Fdnr. 911 (2 Stk.)). Jeweils ein Exemplar fand sich in einer Pfostengrube (Kat.Nr. 305) und einem Graben (Kat.Nr. 402). Die übrigen stellen Oberflächenfunde dar. Ein langrechteckiger Schleifstein mit einer Größe von 11,4x3,4cm und einer Stärke von 2,3-4,4cm wurde als Oberflächenfund geborgen (Kat.Nr. 3-29). Sein Handstück ist mit einer Griffmulde auf der Oberseite ausgestattet. Auffällig sind seine abgerundeten Ecken an den Schleifflächen.

Mit einer Ausnahme liegen alle Schleifsteine fragmentiert vor. Vermutlich war dies auch der Grund sie zu entsorgen. Ihnen fehlen meist datierende Beifunde, so dass eine zeitliche Ansprache schwierig ist. Eine Ausnahme stellen die Schleifsteinbruchstücke aus den Fundkontext von Grube Kat.Nr. 120 und Graben Kat.Nr. 402 dar, die vermutlich bis ins Mittelalter datiert werden können. 


\subsubsection{Kochsteine}

Kat.Nr. 26 Fdnr. 144; 27 Fdnr. 198; 43 Fdnr. 116; 48 Fdnr. 104; 49 Fdnr. 111; 91 Fdnr. 378; 92 Fdnr. 356; 97 Fdnr. 321; 98 Fdnr. 266; 118 Fdnr. 353; 119 Fdnr. 193; 121 Fdnr. 331; 140 Fdnr. 455 u. 465; 141 Fdnr. 275/289/290; 145 Fdnr. 284; 178 Fdnr.384; 187 Fdnr. 461; 190 Fdnr. 402; 195 Fdnr. 426; 196 Fdnr. 451; 212 Fdnr. 418; 222 Fdnr.405; 223 Fdnr. 406/430; Qu 52/52 Fdnr. 5; Qu 52/55 Fdnr.70; Qu 52/53 Fdnr. 32; Qu 53/54 Fdnr. 53; Qu 53/53 Fdnr. 416

Kochsteine aus Quarz- oder Granitgestein besitzen eine meist rundliche Form. Ihre spröde kristalline Struktur bewirkte die Hitze des Herdfeuers. Allein aufgrund ihrer Form ist eine eindeutige Zeitstellung nicht möglich, weil sie funktionsbedingt ist. Der Befundzusammenhang erlaubt es in zwei Fällen Kochsteine zeitgleich anzusprechen. In dem mittelalterlichen Brunnen Kat.Nr. 26 konnten $7 \mathrm{~kg}$ Kochsteine geborgen werden, die wohl bei der Auflösung der Anlage in den Brunnenschacht gelangten. Auch aus dem Brunnen Kat.Nr. 140 stammen gebrannte Quarzgesteine. In der Grube Kat.Nr. 43 finden sich zwar nur geringe Mengen gebrannter Kochsteine, dafür aber $1 \mathrm{~kg}$ ungebrannter Granitbrocken.

\subsubsection{Schlagsteine}

Kat.Nr. 198 Fdnr. 456; 140 Fdnr. 310; 216 Fdnr. 533

Schlagsteine, auch Klopfsteine genannt, sind an ihren Schlagnarben erkennbar. Im Fundgut sind sie mit drei Exemplaren vertreten (Kat.Nr. 198 Fdnr. 456; 140 Fdnr. 310; 216 Fdnr. 533). Schlagsteine aus Granit haben meist eine rundlich-längliche Form. Daneben existieren kugelrunde Geräte. Schlagnarben, meist an einer Seite auf der Oberfläche zu finden, weisen auf ihre Funktion hin. Eine eindeutige Datierung ist nicht möglich.

\subsubsection{Flintartefakte}

Kat.Nr. 16 Fdnr. 59;17 Fdnr. 344 u. 366; 18 Fdnr. 124 u. 129; 19 Fdnr. 119; 25-1; 25 Fdnr. 83; 26 Fdnr. 37 u. 141; 27 Fdnr. 197; 29 Fdnr. 63; 91 Fdnr. 375, 92 Fdnr. 355; 93 Fdnr. 336; 95 Fdnr. 235; 96 Fdnr. 186, 97 Fdnr. 230; 98 Fdnr. 204; 99 Fdnr. 185; 106 Fdnr. 214 u. 256; 107 Fdnr. 229/233/294; 110-1; 110-2; 112 Fdnr. 350; 114 Fdnr. 255; 118 Fdnr. 352; 119 Fdnr. 193, 121 Fdnr. 330; 123 Fdnr. 260; 125 Fdnr. 226 u. 241; 140 Fdnr. 455; 141 Fdnr. 274/286/291; 145 Fdnr. 283; 152 Fdnr. 380; 153 Fdnr. 219; 158 Fdnr. 298 u. 389; 160 Fdnr. 278/280/324/325; 178 Fdnr. 383; 180 Fdnr. 412; 187 Fdnr. 433; 190 Fdnr. 401; 195 Fdnr. 902; 196 Fdnr. 456; 212 Fdnr. 417; 251 Fdnr. 622; 258 Fdnr. 855; 305 Fdnr. 627; 359 Fdnr. 620; 365 Fdnr. 627; 377 Fdnr. 614; 403 Fdnr. 419; 423 Fdnr. 854; 434 Fdnr. 740; 463 Fdnr. 560; 468 Fdnr. 832; 475 Fdnr. 828; 499 Fdnr. 696; 500a Fdnr. 696; 513 Fdnr. 829; 516 
Fdnr. 510; 757 Fdnr. 489; 1095 Fdnr. 934; Altfund 1964/65: Fdnr. 1; Bef. 7 Fdnr. 1115; Qu 52/52

Fdnr. 157; Qu 52/54 Fdnr.53; Qu 52/55 Fdnr. 70; Qu 53/52 Fdnr. 174; Qu 53/53 Fdnr. 161; Qu 56/53

Fdnr. 827; Qu 56/55 Fdnr. 27

Taf. 12

Unter dem Fundmaterial fanden sich eine Vielzahl von Flintartefakten, die sowohl im gebrannten wie ungebrannten Zustand vorliegen. Während einfache Abschläge überwiegen, kommen Klingen und Schaber verhältnismäßig selten vor (Kat.Nr. 25-1, 110-1, 110-2).

Aus 36 Befunden stammt nur jeweils ein Abschlag, weitere 23 Befunde enthielten 2-4 Abschläge. Zusätzlich wurde eine große Anzahl von Abschlägen bei Oberflächenbegehungen aufgesammelt. Kernsteine liegen in drei Exemplaren (Kat.Nr. 91 Fdnr. 375; 158 Fdnr. 298; 160 Fdnr. 325), Schaber in vier Fragmenten (Kat.Nr. 91 Fdnr. 376; 118 Fdnr. 352; 152 Fdnr. 380; Fl. 0-1 Fdnr. 1096) vor.

Die meist wenig signifikanten Flintartefakte sind in ihrer zeitlichen Stellung nicht zu klären. Vermutlich datieren sie in den Zeitraum vom Neolithikum bis in die Bronzezeit. Die räumliche Verteilung zeigt eine Bevorzugung des östlichen Dünenareals bis in den zentralen Bereich der kaiserzeitlichen Siedlung hinein. Die urgeschichtlichen Artefakte gelangten wohl durch Umlagerungen in die jüngeren Befunde.

\subsubsection{Holzfunde}

Kat.Nr. 26f; 140h; 195d-2,-3, 5, -6, -8, -9; 455 Fdnr. 1112; 1101a Fdnr. 1110; 1101b Fdnr. 1111 Taf. $54 ; 57$

Im Folgenden werden die hölzernen Fundobjekte vorgelegt, bei denen es sich nicht um Bauteile mit einer konstruktiven Funktion in Brunnenanlagen oder Werkgruben handelte. Diese sind bereits an gegebener Stelle aufgeführt (Kap. 5.2.9).

Aus dem Siedlungsareal stammen insgesamt drei hölzerne Rohlinge, bei denen es sich um Teilstücke von Wagenrädern handelte (Kat.Nr. 455 Fdnr. 1112; 1101a Fdnr. 1110; 1101 b Fdnr. 1111). Charakteristisch ist ihre gebogene Form und ihr trapezförmiger Querschnitt. Die erhaltene Länge liegt zwischen 46 und $63 \mathrm{~cm}$ (Außenmaß). Die aus Erlenholz gearbeiteten Felgensegmente sind flach ausgeführt und weisen noch eine Holzstärke von 3-6cm auf (Breite 11,4-15cm).

Am besten erhalten ist der hölzerne Rohling, der aus dem feuchten Bodenmilieu eines 4,2x0,7-1,1m großen Grabens stammt (Kat.Nr. 455). Das bereits kantig, auf eine Länge von 56,4cm zugebeilte Segment (Innendurchmesser 46,5cm) war an seiner Innenseite $5,4 \mathrm{~cm}$ stark, während die 
Laufflächenstärke noch bei $3 \mathrm{~cm}$ lag (Abb. 53). Sein abgeleitetes Fälldatum wird mit „nach $132 \mathrm{n}$. Chr.“ angegeben. Allerdings kann bei dieser dendrochronologischen Datierung der Terminus post quem eine erhebliche Toleranz aufweisen, die zwischen 50-100 Jahre beträgt (freundliche Mitteilung Dr. H.H. Leuschner 2002). Die außerdem aus dem Graben stammenden Keramikscherben stützen eine Datierung in das 1./2. Jahrhundert n. Chr.

Die beiden anderen Felgensegmente fanden sich am Rand der Siedlung in einer feuchten Moorsenke im Quadranten 51/42. Eine genaue Kartierung der Hölzer unterblieb. Sie sind in ihrer Oberfläche weniger sorgfältig bearbeitet und weisen eine etwas weniger starke Krümmung auf. Beide Segmente sind aufgrund ihres trapezförmigen Querschnittes $(3,6 \mathrm{~cm}$ zu $6 \mathrm{~cm})$ als Felgenrohlinge anzusprechen. Eine Bestimmung der Jahrringe durch das DELAG in Göttingen erbrachte keine verwendbaren Ergebnisse.

Das Segment Kat.Nr. 1101a Fdnr. 1110 ist mit $63 \mathrm{~cm}$ Länge (Innenradius L 51cm) etwas besser erhalten, während das zweite Exemplar Kat.Nr. 1101b Fdnr. 1111 eine beschädigte Oberfläche aufweist und nur noch in einer Länge von $46 \mathrm{~cm}$ erhalten vorliegt (Innendurchmesser L $36 \mathrm{~cm}$ ). Differenzen von bis zu $3 \mathrm{~cm}$ in der Felgenstärke sind eventuell überlieferungsbedingt (Fdnr. 1110, H 15cm; Fdnr. 1111, H 12cm). Auffällig ist die im Querschnitt der Hölzer bei beiden Segmenten nahezu identische Holzstärke von 3,6cm an der schmalsten Stelle und $6 \mathrm{~cm}$ an der Radaußenseite.

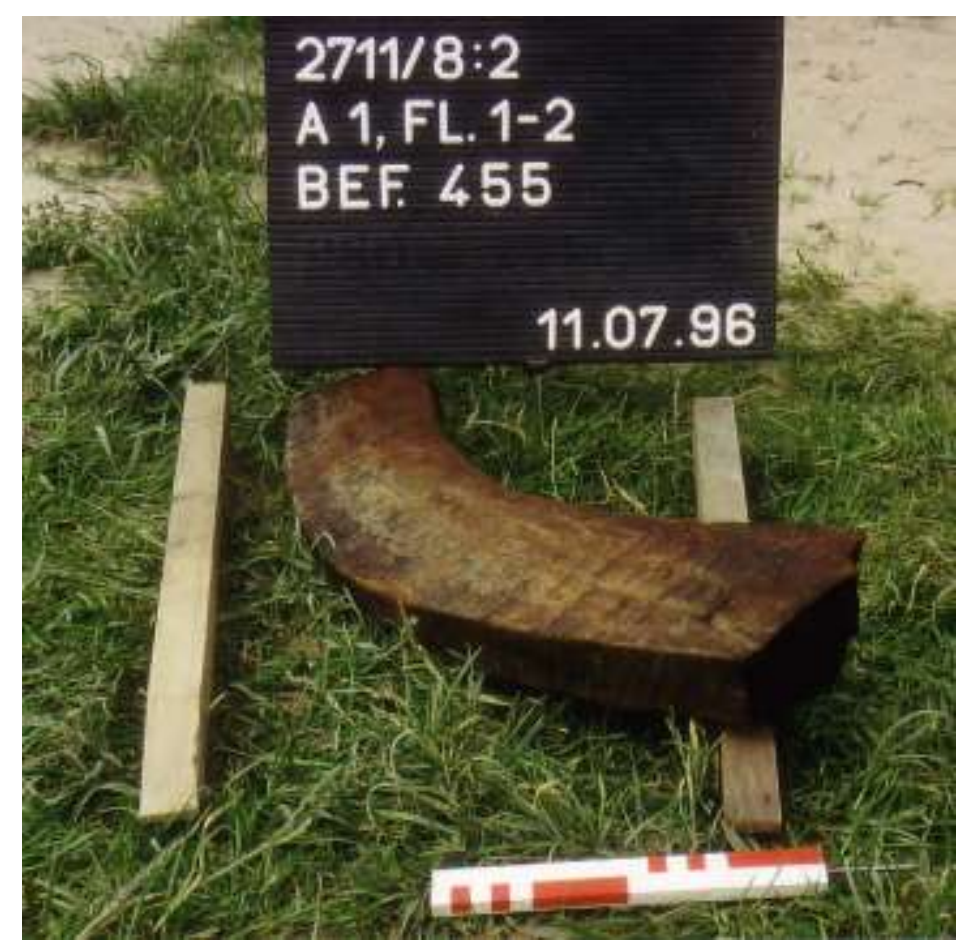

Abb. 53

Seitenansicht des Wagenradsegmentes Kat.Nr. 455 Fdnr. 1112 
Parallelen zu kaiserzeitlichen Felgen finden sich u.a. von der Feddersen Wierde (HAARNAGEL 1979, 345), der Barward nahe Cuxhaven und einigen ostfriesischen Fundorten, wie beispielsweise der Upleward in der Krummhörn. Die schlanke Formgebung dieser Felgen grenzt sich von mittelalterlichen Wagenrädern ab, die insgesamt breiter waren. Zum Vergleich sei auf das Exemplar von Oldendorp-Wischenborg hingewiesen. 1994 wurde dort ein spätmittelalterliches Wagenrad freigelegt von dem sich neben einem Felgensegment fünf hölzerne Speichen und die Radnabe erhalten haben (BÄRENFÄNGER 1999b, 105, Abb. 47).

Eine schlankere Radvariante stellt das erhaltene Exemplar aus Leer-Loga dar (vgl. BÄRENFÄNGER 1995, 32, Abb. 15). Das bei Ausgrabungen des mehrperiodigen Siedlungsplatzes Leer-Loga in einer Brunnenverfüllung entdeckte Wagenrad bestand ebenfalls aus fünf Felgensegmenten. Der Radquerschnitt eines Segmentes betrug nur 3,7cm. Der Kastenbrunnen, mit darüber gestelltem ausgehöhlten Baumstamm, kann dendrochronologisch um „1142+/-2، datiert werden (BÄRENFÄNGER 1998e, 293). Von derselben Fundstelle (FStNr. 2710/6:047) konnten u.a. Reste von wenigstens zwei völkerwanderungszeitlichen Hausgrundrissen festgestellt werden. Diverse Gräbchen überlagerten eine leicht konkave Fahrspur, die von völkerwanderungszeitlichen Befunden geschnitten wurde (BÄRENFÄNGER 2002, 34, Abb. 11).

Ein hölzernes Bauteil unbekannter Funktion stammt aus der Verfüllung eines mittelalterlichen Brunnens aus dem Ostteil der Siedlung Nortmoor. Das etwa $62 \mathrm{~cm}$ über der Brunnensohle bei einer NN-Höhe von $+0,55 \mathrm{~m}$ entdeckte Holz gelangte vermutlich während der Anlage des Brunnens in die Baugrube. Das flache langrechteckige Holzbrett Kat.Nr. 140h besitzt eine keilförmige Ausarbeitung mit einer Zapfengröße von 13,2-15x12cm an seiner kurzen Schmalseite (Abb. 54). An der langen Schmalseite befindet sich eine $6 \mathrm{~cm}$ große Bohrung. 


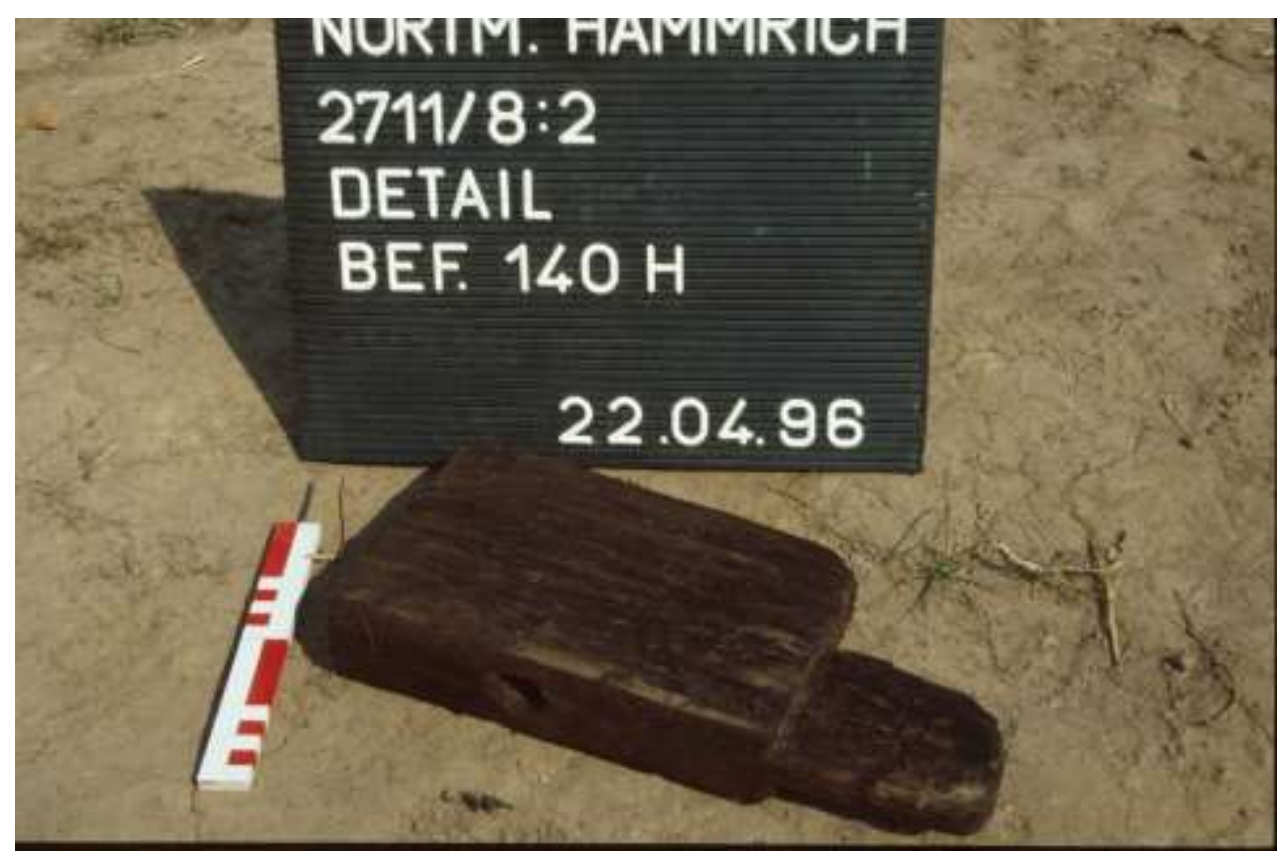

Abb. 54

Holzbrett Kat.Nr. 140h aus einer Brunnenverfüllung in Nortmoor

Mit einer maximalen Länge von 53,4cm und einer Höhe von $28-30 \mathrm{~cm}$ weist das Stück eine recht beachtliche Größe auf. Ungewöhnlich ist sein trapezförmiger Querschnitt, der auf der gebohrten Schmalseite bei $8,1 \mathrm{~cm}$ liegt und auf der gegenüberliegenden Seite nur noch $5,1 \mathrm{~cm}$ beträgt. Die Verwendung des so fertiggestellten Bauteiles wird im konstruktiven Bereich gelegen haben. Seine ursprüngliche Funktion ist nicht mehr zu erschließen.

Aus der kaiserzeitlichen Wasserstelle Kat.Nr. 195 stammen eine Vielzahl an Holzstaken unterschiedlicher Länge und Stärke (Taf. 54-55). Eine Auswahl an Holzpflöcken mit eindeutigen Bearbeitungsspuren wurde zeichnerisch dokumentiert (Kat.Nr. 195d-2; 195d-3; 195d-6; 195d-8; 195d9). Die schmalen Hölzer sind beidseitig spitz angebeilt und zwischen 1,05-1,42m lang. Neben rundlichen Querschnitten sind einige Pflöcke rechteckig-oval mit Stärken zwischen 8-20cm. Teilweise standen die Hölzer senkrecht. Viele lagen auch auf der Brunnensohle. Inwiefern es sich um sekundär verwendete Holzstaken handelt, ist nicht mehr feststellbar. Möglicherweise dienten sie zur Randbefestigung der Anlage. Vielleicht wurde die Wasserstelle nach ihrer Auflassung als Abfallgrube genutzt. Hierauf weist der Fund eines $91 \mathrm{~cm}$ langen und in seinem Querschnitt fast kreisrunden $(11 \mathrm{~cm})$ Holzstückes hin (Kat.Nr. 195 d-8). Dieses ist an einem Ende flach bebeilt, die andere Seite hat einen kleinen Zapfen.

Tiefe Kerben überziehen die Langseite eines $34,2 \times 15 \mathrm{~cm}$ großen und $9 \mathrm{~cm}$ durchmessenden Holzstückes (Kat.Nr. 26f). Die bis zu $12 \mathrm{~cm}$ langen und 0,6-1 cm breiten Hiebspuren sind eindeutig anthropogen verursacht (Abb. 55). Seine Oberfläche ist ansonsten unbearbeitet. Das Holz stammt aus 
dem feuchten Milieu eines mittelalterlichen Baumstammbrunnens (Kat.Nr. 26).

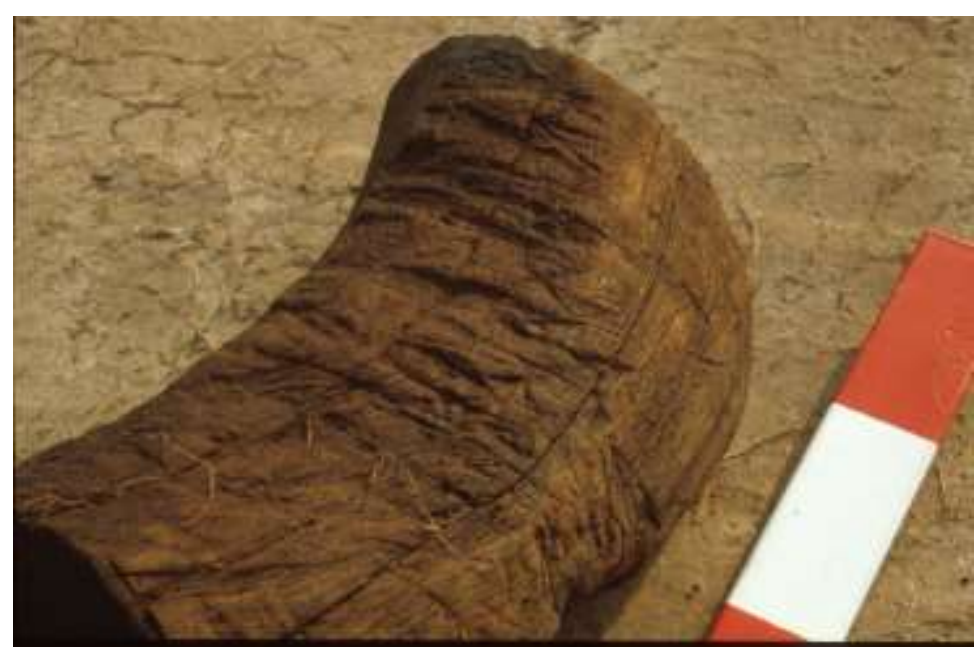

Abb. 55

Holz mit eindeutigen Hiebspuren aus einer mittelalterlichen Brunnenverfüllung $($ Maßstab weißes Feld $=10 \mathrm{~cm})$

Hinweise auf die Existenz eines Bohlenweges fanden sich an der südlichen Grabungsgrenze der Düne im Quadranten 50/38. Durch unsachgemäße Baggerarbeiten wurde der Befund bereits während der Ausgrabung weitgehend zerstört. So gelang es nur noch im grundwassernahen Bereich zwei flache Eichenhölzer zu dokumentieren (Kat.Nr. 1101a u. b).

Beide Hölzer wiesen eindeutige Bearbeitungsspuren auf und lagen in einem Abstand von $10-15 \mathrm{~cm}$ zueinander in der Torfschicht 5 etwa einen Meter über der Moorsohle (Abb. 56). Die SO-NW orientierten Eichenholzbretter waren zwischen 2,80m (Kat.Nr. 1101a: 21x17cm) und 4m (Kat.Nr. 1101b: 33x15cm) lang. Die dendrochronologische Untersuchung ergibt ein abgeleitetes Fälldatum von

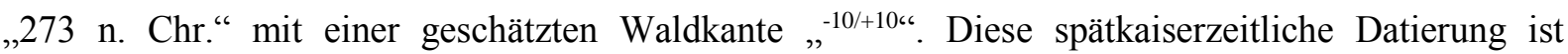
allerdings, da es sich um eine Einzelprobe handelte, in ihrer Aussagefähigkeit unter Vorbehalt zu sehen. 


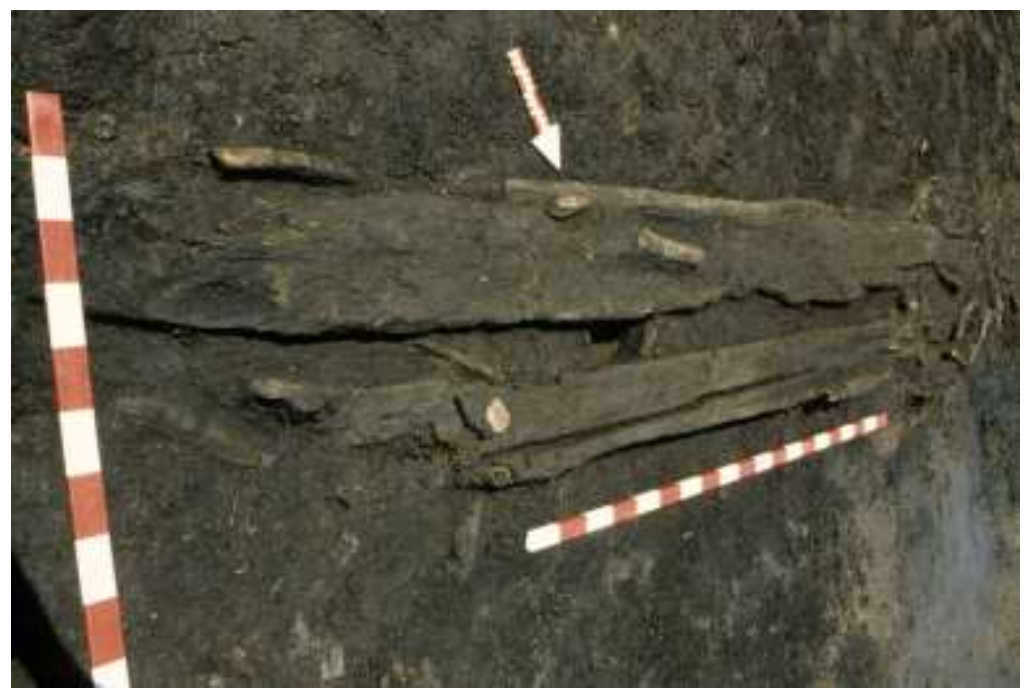

Abb. 56

Bohlenweg in einer Torfsenke vom südwestlichen Dünenrand

(Bild ist gedreht, rechter Bildrand ist oben)

Nortmoorer Hammrich, Quadrant 50/38

\subsubsection{Tierknochen}

Kat.Nr. 10; 18; 26; 27; 55; 121; 140; 160; 161; 187; 188; 195; 202; 223; 225; 243; 244; 245; 278; 345; 365; 397; 402; 409; 410; 462; 512; 581; 816; 1082a u. b; Fdnr. 9, 22, 26, 75

Vom Nortmoorer Hammrich liegen aus 15 Befunden kalzinierte Tierknochen vor (Kat.Nr. 10; 18; 26; $55 ; 121 ; 140 ; 202 ; 225 ; 278 ; 365 ; 402 ; 512 ; 581 ; 816 ; 1082$ a u. b). Unkalzinierte Knochenfragmente sind in der Minderzahl (Kat.Nr. 187; 195; 223; 397). Als Oberflächenfund sind Tierknochen in den Quadranten 56/54 und 56/55 sowie in den Bodenschichten 2 und 3 aufgesammelt wurden.

Die Knochenfragmente können zumeist den Tiergattungen Rind und Schwein zugeordnet werden, während Schaf und Vogel selten vertreten sind. Zumeist sind die Knochenstücke stark fragmentiert, so dass die im folgenden aufgeführten Quantitäten unter Vorbehalt vorgetragen werden.

Das Rind stellt mit 27 Knochenfragmenten die häufigste Art im Fundgut dar. Gut identifizierbar waren die aus zehn Befunden vorliegenden Rinderzähne (Kat.Nr. 10; 26; 27; 188; 243; 244; 245; 409; 410; 462). Nur in einem Fall fand man Röhrenknochen vom Rind in einem 400x50x20cm großer Graben (Kat.Nr. 202).

Die zweithäufigste Art ist mit 12 Knochenfragmenten das Hausschwein. Schweinezähne liegen aus drei Befunden vor (Kat.Nr. 160; 278; 345). Knochenfragmente von Schaf/Ziege entstammten drei Gruben aus dem östlichen Siedlungsareal (Kat.Nr. 223; 402; 512), wobei es sich lediglich in einem Befund um unverbrannte Knochenfragmente vom Schaf handelte (Kat.Nr. 223). Überreste einer 
unbestimmten Vogelart entstammen einer $55 \times 45 \times 20 \mathrm{~cm}$ großen Pfostengrube (Kat.Nr. 225). Möglicherweise sind sie durch Tierverschleppung hierher gelangt.

Im Fall einer Brandbestattung (Kat.Nr. 365), die kalzinierte Knochenfragmente von Rind und Schwein enthielt, stehen die Tierknochen wahrscheinlich im Zusammenhang mit den Bestattungsriten. Vermutlich wurde das Fleisch mit auf den Scheiterhaufen gegeben. Inwieweit jedoch die Tiere vollständig mitverbrannt wurden, ist nicht zu rekonstruieren.

Eine Vielzahl von Tierknochen konnte aufgrund ihres hohen Fragmentierungsgrades nicht mehr bestimmt werden. Die meist schlechte Erhaltung der unverbrannten Tierknochen erklärt sich durch den entkalkenden Einfluss des sandigen Terrains in Nortmoor. Oft haben sich nur die durch ihren Zahnschmelz geschützten Tierzähne erhalten, während das übrige Knochenmaterial sich auflöste.

Die Mehrzahl der kalzinierten Tierknochenfragmente gehört in einen mittelalterlichen Kontext (Kat.Nr. 10; 18; 26. 140; 243; 244; 245; 409), während aus kaiserzeitlichen Siedlungsbefunden nur wenige Tierknochenfunde vorliegen (Kat.Nr. 188; 195; 365).

Die geringe Materialbasis lässt eine statistische Auswertung dieser Fundgattung nicht zu. Es können jedoch Tendenzen aufgezeigt werden, die das Bild einer auf Viehhaltung ausgerichteten ländlichen Siedlung stützt.

\subsection{Zusammenfassung der relativ- und absolutchronologischen Ergebnisse}

Ein erstes Aufsuchen des Nortmoorer Hammrichs erfolgte bereits in neolithischer Zeit. Hiervon zeugt eine Vielzahl an Flintartefakten und -abschlägen, die als Oberflächenfunde von der Nortmoorer Düne stammen. Siedlungsreste dieser Phase zeichnen sich in der untersuchten Grabungsfläche nicht ab. Zwei Gebäudegrundrisse können hingegen der späten Bronze- bzw. älteren Eisenzeit zugewiesen werden.

Neben den wenigen Baubefunden dieser Siedlungsphase fanden sich im Nortmoorer Hammrich weitere Hinweise auf eine früh einsetzende Siedlungstätigkeit. Pollenprofile aus einer Torfsenke südlich der Düne belegen, dass es bereits in der Bronzezeit zum Eintrag von Getreidepollen und Ackerunkräuterpollen kam. Ein Rückgang an Baumpollen, wie Eichen, Buchen und Linden, weist auf eine lokale Rodungstätigkeit hin. Wahrscheinlich kam es in dieser Zeit zur Anlage von Ackerflächen in unmittelbarer Nähe der Nortmoorer Düne.

Erneut ansteigende Werte an Getreidepollen sind wieder in der vorrömischen Eisenzeit fassbar. Es finden sich daneben aber auch wasserliebende Arten. Funde von Rohrkolbenpollen und SüßwasserKieselalgen weisen auf nahe und offenstehende Wasserflächen hin. Deutet der hohe Baumpolleneintrag zunächst noch auf eine Bewaldung mit Eichen und wenigen Buchen hin, so folgt der zunehmenden Vernässung ein massives Baumsterben. Zeitlich fassbar ist dies durch im Niedermoortorf eingelagerte Eichen, wovon einige ein abgeleitetes Fälljahr zwischen ,,-663 ${ }^{+-6 ،}$, ,-467 +/-2، und ,-440 +/-6“ besitzen (DELAG, unpubl.). 
In der späten Latènezeit kam es zur Anlage einer kleinen Nekropole auf der Dünenkuppe. Eckwerte sind dabei ein ${ }^{14} \mathrm{C}$ datiertes Brandgrab $\left(, 20^{+/-40} \mathrm{n}\right.$. Chr. “), und die in das 1. Jahrhundert nach Christus zu datierenden Urnen benachbarter Gräber dieser Nekropole. Die Belegungsdauer kann mit etwa 120 Jahren angegeben werden.

Mit Beginn der römischen Kaiserzeit sind einzelne Hofkomplexe fassbar, die aus Hausplätzen mit angrenzenden Speicherbauten und Brunnen bestanden. Bereits in einer frühen Phase umhegten Zäune die Siedlung und grenzten sie zur Niederung ab. Die aufgedeckten Fundamentgräbchen gehörten zu wenigstens zwei Umzäunungskomplexen, die mehrfach erneuert wurden.

Zur Niederung wurde die Siedlung von langen, meist linear verlaufenden Zaunreihen umschlossen. In Richtung Jümme existierten drei parallel ausgerichtete Zäune, die 5-7m voneinander entfernt versetzt waren. Es ist unwahrscheinlich, dass die bis zu 90m langen Zäune gleichzeitig bestanden haben, stattdessen lösten sie sich nacheinander ab. Auffällig ist hierbei, dass die südlichen Zaunreihen nahezu dieselbe Orientierung wie die Längsseiten der kaiserzeitlichen Gebäude aufwiesen.

Die mittlere Zaunreihe lief stumpfwinklig aufeinander zu und traf sich vermutlich bei einem quer zur Düne verlaufenden Zaun, dessen Holzstaken sich auf $4 \mathrm{~m}$ Länge noch nach Norden verfolgen ließen. Auf der flussabgewandeten Dünenseite fanden sich wenige Meter nach Westen versetzt weitere Staken, die in Richtung Dünenkamm orientiert waren. Vermutlich gehörten beide Zaunreste zu einem gemeinsamen System und parzellierten die Siedlung in zwei Teile.

Weitere Einhegungen sind um die Wasserstelle und ein sich westlich daran anschließendes Areal festzustellen. Etwa 30m westlich davon umschloss ein Zaun im letzten Drittel seines Verlaufes bogenförmig eine Brunnenanlage. Südlich von Hausplatz III existierten Abzäunungen von kleineren Flächen, die vermutlich als Gartenareale anzusprechen sind. Generell dienten die Umzäunungen dazu, freilaufendes Vieh und Wild von den umhegten Bereichen fern zu halten.

In einem schematischen Übersichtsplan sind die Siedlungsstrukturen des Nortmoorer Hammrichs wiedergegeben (Tafel 119). Abgebildet ist die Anordnung der Bauten entlang des Dünenzuges. Standorte der Hausplätze, der Kurzhäuser, der Speicherbauten, eines Grubenhauses und einer rechteckigen Grabenanlage. Verzeichnet sind auch sämtliche Brunnenanlagen und die Fundamentgräben der Umzäunungen. Brandbestattungen einer kleinen späteisenzeitlich bis frühkaiserzeitlichen Nekropole entdeckte man in einem 10x20m großen Areal auf der Dünenkuppe. In die Jümme-Niederung erstreckte sich ein Bohlenweg. Reste des Weges fand man an der Südseite der Siedlung. Die Bohlenbretter können dendrochronologisch in das 3. Jahrhundert datiert werden. 
Gehöft II und III werden an drei Seiten auf einer Fläche von wenigstens 2400qm von Umhegungen umschlossen. Das rechtwinklige Zaunsystem verläuft annähernd analog zu den Gebäudeaußenseiten. Der innere Südzaun ist parallel zur Gebäudelängsseite von Hausplatz II ausgerichtet. Einen deutlichen Bezug zeigen auch die das Haus an Nord- und Südseite flankierenden Speicher. Vermutlich gehörte auch der Brunnen Kat.Nr. 650 zur ersten Hofanlage.

Hausplatz III löst den Vorgängerbau in demselben Hofkomplex ab. Ihm zugehörig sind vier Speicherbauten an seiner Nordseite und zwei Brunnenanlagen an der Südseite. Vermutlich wurde in dieser Phase auch der äußere Südzaun errichtet.

Ebenfalls von einer mehrphasigen Umhegung eingezäunt war ein weiterer Hofkomplex. Sein östlich der Hausplätze II und III gelegenes Langhaus war NNW-SSW orientiert. Neben dem Gebäude sind ein 3- und ein 12-Pfostenspeicher sowie die Brunnenanlage B 2 (Kat.Nr. 265) überliefert. In diesen Kontext gehörte auch die eingezäunte Wasserstelle B 11 (Kat.Nr. 195). Nach Süden schloss eine mehrphasige Umzäunung das Hofareal ab. Sie verlief stumpfwinkelig auf die benachbarte Zaunanlage zu. An ihrem Scheitelpunkt begann ein O-W orientierter Zaun, der vermutlich quer über den Dünenkamm verlief, sich jedoch nur an seinem Ost- und Westende erhalten hat.

Bei einer durchschnittlichen Phasendauer von 50-60 Jahren für die kaiserzeitliche Wohnbebauung ergibt sich eine Gesamtbesiedlungszeit von 150-180 Jahren. Berücksichtigung finden hierbei Überlegungen zur Lebensdauer von Pfostenbauten in der Siedlung Bennekom (VAN Es / MIEDEMA / WYNAM 1985, 627).

Für die Siedlung Nortmoor kann jeweils ein Gehöft den nachfolgenden Phasen zugeordnet werden.

Phase 1: Mitte 1. Jahrhundert bis Anfang 2. Jahrhundert n. Chr.

Phase 2: Anfang bis Mitte 2. Jahrhundert n. Chr.

Phase 3: Mitte 2. bis Anfang 3. Jahrhundert

Die kaiserzeitliche Siedlung begrenzte sich auf dem erhöht liegenden Dünenkamm. Nach Westen und Süden gilt die Siedlung als weitgehend erfasst; dort umschlossen Zäune das Siedlungsareal. Nördlich des Dünenkammes ging es zügig in die umgebende Niederung hinab; hier wurden jenseits der Brunnenanlage B 6 (Kat.Nr. 650) keine weiteren Befunde entdeckt.

$\mathrm{Ob}$ es in östlicher Richtung zu einer Erweiterung der kaiserzeitlichen Siedlung gekommen ist, kann nicht mehr festgestellt werden, es ist jedoch als wahrscheinlich anzusehen. Die dort in der Vergangenheit erfolgten massiven Bodeneingriffe haben sämtliche Besiedlungsspuren zerstört.

Soweit ersichtlich scheint die Siedlung in Laufe der römischen Kaiserzeit über den Mittelgrad der Sandkuppe verlegt worden zu sein.

Nachweisbar ist zunächst ein Einzelgehöft (Hausplatz II) mit umgebenden Speicherbauten (SP 1, 6, 7, 10) und zugehörigem Brunnen (B 6). In der Phase 2 wurde das Langhaus um wenige Meter nach 
Westen verlagert, behielt dabei seine Orientierung jedoch bei. Dem Hausplatz III können vier Speicher und zwei Brunnen zugeordnet werden. Zu beobachten ist eine nun von $25 \mathrm{~m}$ auf $45 \mathrm{~m}$ zunehmende Gebäudelänge, die sich in vergleichbarer Weise auch bei Flögelner Häusern findet. Giebelseitig abgetrennte Kammern kommen an beiden Schmalseiten in Nortmoor vor und stellen ein Bauelement des 2. / 3. Jahrhunderts da (BRABANDT 1993, 46-48). Denkbar ist jedoch auch, dass es bei Hausplatz III zu einer Längsverschiebung in der Hausachse gekommen ist. Demnach wären SP 3 und SP 4 gemeinsam mit Brunnen B 7 dem Westteil des Hauses zuordbar, während SP 11 und 12 mit Brunnen B 8 dem Erweiterungsbau angehören. Die Speicher finden sich alle an der Nordseite des Dünenkammes; mit Ausnahme von SP 5 der auf der Kuppe anzutreffen war und sich vor dem östlichen Giebel befand.

Bei beiden Fällen wurden die Speicherbauten in unmittelbarer Nachbarschaft zu den Gebäuden errichtet. Es überwogen 4- bis 9-Pfostenspeicher. Doch während bei Gehöft II sich die Postenspeicher um das Langhaus gruppieren und sich der benachbarte Brunnen auf der Nordseite des Gebäudes befindet, werden in Phase 2 sämtliche Speicherbauten auf der flussabgewandten Seite errichtet und die Brunnenanlagen am Südhang der Düne angelegt.

Gehöft 1 besteht aus einem nur rudimentär überlieferten Langhaus von wenigstens 26,5m Länge. Speicherbauten im näheren Umfeld fehlen. Dies kann jedoch überlieferungsbedingt sein, da sich in dem Areal fast ausschließlich nur stärker eingetiefte Pfosten, wie die des Hauptschiffes, erhalten haben. Eine Zugehörigkeit zum 20m entfernten Brunnen B 2 ist jedoch nicht auszuschließen.

Die Hauptelemente der kaiserzeitlichen Siedlung, die Langhäuser mit den benachbarten Speichern, konzentrierten sich auf einer Geländehöhe von $+1,40$ m bis maximal $+1,86 \mathrm{~m}$ NN, wobei Höhen von $+1,65 \mathrm{~m}$ überwiegen.

Der einzige tiefer liegende Baukomplex ist eine rechteckige Grabenanlage an der flusszugewandten Dünenseite. Sein von der Wohnbebauung abweichender Grundriss lässt vermuten, dass es sich nicht um ein Gebäude handelte. Hierauf deutet das Fehlen von Eingrabspuren eines Grubenhauses oder auch von Pfosten hin. Mit einer Innenfläche von 90qm ist die Anlage ungewöhnlich groß. Berücksichtigt man einen Abtrag des alten Laufhorizontes von wenigstens 0,4-0,7m, so wird der bei der Ausgrabung noch bis zu $0,6 \mathrm{~m}$ eingetiefte Graben ursprünglich bedeutend tiefer gewesen sein. Ähnliche Grabenanlagen finden sich im Küstengebiet der südlichen Nordsee von der vorrömischen Eisenzeit bis in die Völkerwanderungszeit. Ihre Deutung reicht von umhegten Werkstattarealen bis hin zu rituellen Stätten, kann jedoch aufgrund fehlender funktionaler Funde aus den Anlagen bisher nicht sicher gedeutet werden. Ob für die Nortmoorer Grabenanlage ein Bezug zur nahen Nekropole bestand, ist abschließend nicht zu klären. Einen Hinweis auf eine säpulkralen Kontext geben Quadratgräben von 
den eisenzeitlichen Gräberfeldern im ammerländischen Bad Zwischenahn -Halfstede und Querenstede (vgl. NORTMANN 1983, 99; FÖRST 1991, 108).

Drei der entdeckten Brunnenanlagen zeigten einen deutlichen Bezug zu den Langhäusern, so dass sie wohl in erster Linie zur Wasserversorgung dienten. Die Brunnen waren zwischen 5-10m von den Gebäuden entfernt und wurden bei einer Geländehöhe von $+1,2 \mathrm{~m}$ bis $+1,34 \mathrm{~m}$ NN angetroffen. Die geringe Größe der 40-60 cm durchmessenden Gruben (zwei bestanden aus einem ausgehöhlten Baumstamm, einer aus einer Flechtwerkskonstruktion), deutet darauf hin, dass hier lediglich Trinkwasser für den täglichen Bedarf entnommen wurde.

Der Nachweis eines Grubenhauses gelang in einem Fall. Es handelte sich um einen wohl 6-pfostigen Bau von geringer Größe (etwa 9,8qm), der $60-80 \mathrm{~cm}$ eingegraben erhalten war. Der Grundriss ist annähernd länglich-oval, zeichnet sich jedoch nicht eindeutig ab; möglicherweise ein Hinweis auf eine Mehrphasigkeit. Das reichhaltige Fundmaterial entstammt dem Zeitpunkt nach seiner Aufgabe. Deutlich überwiegen Keramikscherben vor Steinen. Artefakte, die mit seiner Funktion in Bezug standen, fehlen. Sein unregelmäßiger Umriss mit den randlichen Pfostengruben weist Ähnlichkeiten mit kaiserzeitlichen Grubenhäusern des 6-Pfosten-Typs in Flögeln auf (ZIMMERMANN 1992, 172, Abb. 133, GH 104).

Das Grubenhaus wurde auf dem Dünenkamm bei $+1,6 \mathrm{~m} \mathrm{NN}$ angelegt, somit haben seine Bauherren einen der höchsten Standorte gewählt den die Düne zu bieten hatte. Ob das Grubenhaus letztlich als Webhaus anzusprechen ist, wird sich nicht mehr klären lassen. Hauswerk in Form von Spinnwirtel und Webgewichten liegen als Einzelfunde von mehreren Stellen innerhalb der Siedlung vor. Darüber hinaus ist auch eine Nutzung als Erdkeller, Stall oder Werkraum denkbar. Weitere grubenhausähnliche Gruben liegen mit Kat.Nr. 928 und 939 aus dem westlichen Siedlungsareal vor. Doch auch hier fehlen eindeutige Funde, wie auch die Befundlage Raum für Interpretationen lässt. Eine gewerbliche Nutzung kann jedoch nicht ausgeschlossen werden.

Ein wichtiger Standortfaktor der kaiserzeitlichen Siedlung war neben dem trockenen Siedlungsgrund auf der Nortmoorer Düne die Nähe zur Flussmarsch. Die Jümme-Niederung bot gute Weidegründe für eine erfolgreiche Viehzucht. Das vorherrschende maritime Klima ermöglichte eine gute Versorgung mit Grünfutter, in den Wintermonaten erfolgte eine Zufütterung mit Heu. Zu ihrer Vorratshaltung boten die für kaiserzeitliche Siedlungen typischen gestelzten Pfostenspeicher ausreichend Platz.

Insgesamt zeichnet sich das Bild einer agrarisch ausgerichteten Siedlung ab, deren Basis in erster Linie Viehzucht war. Tierknochenfunde von Rind, Schwein, Ziege und Schaf belegen ihre Haltung in der Siedlung. Die weitläufige Niederungszone bot grasreiche Weidegründe und war ansonsten mit Bruchwald bewachsen. Da der Uferwall der Jümme im Unterschied zum Emsuferwall weniger breit ausgestaltet war, wurde Ackerbau vermutlich nicht dort, sondern am nahen Geestrand betrieben. 
Einige der zahlreichen Gruben, die in der Siedlung entdeckt wurden, können als Arbeitsgruben angesprochen werden. Im Feuchtbodensediment haben sich unterschiedliche Holz- und Flechtwerkskonstruktionen erhalten. Hier wurden sicherlich handwerkliche Tätigkeiten unterschiedlicher Art ausgeführt. Sind die Einbauten vergangen, gibt nur noch der Grubeninhalt einen Hinweis auf die ehemalige Nutzung. So fanden sich in einigen Gruben auffällig viel Holzkohle, verbrannter Lehm und Steine. Die so beschriebenen Werkgruben sind über die Siedlung verteilt, wobei die besser erhaltenen Anlagen sich meist im Randbereich befinden. Ein direkter Hinweis auf einen zentralen Werkstattbereich findet sich nicht.

Von der bekannten Wohnbebauung etwa $30 \mathrm{~m}$ südöstlich entfernt befand sich eine etwa $6 \mathrm{~m}$ große Wasserstelle. Ihre abgetrennte Lage an der Südseite der Düne wird betont durch einen die Anlage an vier Seiten umhegenden Zaun.

Als Randbefestigung der Wasserstelle dienten senkrecht eingetiefte Holzstaken. Weitere lose eingebrachte Holzstaken bedeckten die Sohle der muldenförmigen Grube; wohl um ein unnötiges Aufwirbeln des Brunnengrundes beim Wasserschöpfen zu verhindern. Ungewöhnlich war der Fund einer noch zweistufig erhaltenen hölzernen Treppenstufe. Vermutlich gelangte man über einen inzwischen verrotteten Holzsteg in das Zentrum der Wasserstelle. Die Anlage weist eine Nutzungsphase von wenigstens 100 Jahren auf. Aus ihr stammen mehrere Hölzer mit einem dendrochronologisch datierten Fälljahr von „97 n. Chr. “ bis „186 n. Chr.“. Dies legt nahe, dass die umhegte Anlage vermutlich während der 1-2 Phase von den Bewohnern der Siedlung genutzt.

Die lange Nutzungsphase und der letztlich große Aufwand der betrieben wurde, um die Wasserstelle über mehrere Generationen offen zu halten, weist auf ihre wichtige Funktion für die kaiserzeitliche Siedlung hin. Es wird sich bei der Anlage daher wohl nicht um eine Viehtränke bzw. einen Ententeich gehandelt haben. Vielmehr könnte die Wasserstelle für eine handwerkliche bzw. gewerbliche Nutzung in der unmittelbaren Umgebung von Bedeutung gewesen sein. Mit Ausnahme weniger Gruben und Gräben aus dem Nordbereich finden sich jedoch keine weiterführenden Hinweise auf einen Werkstattbereich innerhalb des etwa 120qm großen umhegten Areals.

Die recht große Freifläche mit integrierter Wasserstelle steht vielleicht in Verbindung mit zwei Kastenrahmenbrunnen, die sich ebenfalls an der südlichen Dünenseite befunden haben. Die nächste Anlage (Kat.Nr. 265) ist etwa 30m von der Wasserstelle entfernt und wurde von einem bogenförmig um sie herumgeführten Zaun eingefasst, der auch die Wasserstelle an ihrer Südseite begrenzt. Etwas weiter entfernt, und in einer torfigen Senke gelegen, befand sich ein zweiter Kastenrahmenbrunnen (Kat.Nr. 740). Den günstigen Erhaltungsbedingungen ist es zu verdanken, dass sich nördlich des 
Rahmens zwei senkrecht eingegrabene Eichenpfosten als die Überreste einer massiven Hebevorrichtung erhalten haben.

Beide Anlagen kennzeichnete ein rechteckiger Querschnitt mit einer lichten Sohlenweite von 1m. Ihre Brunnenwandung war sorgfältig mit dicht stehenden Birkenholzstaken verkleidet, während ein verzapftes Rahmenwerk die Konstruktion stabilisierte. Eine dritte Werkgrube stammt von der Nordseite der Düne und war mit Flechtwerk ausgekleidet (Kat.Nr. 395).

Aufgrund ihrer gering eingetieften Brunnensohle werden die Anlagen weniger eine primäre Funktion zur Trinkwassergewinnung übernommen haben, zumal sie in ein torfig-saures Umgebungsmilieu eingetieft waren. Es ist daher zu vermuten, dass die Gruben in einem handwerklichen Kontext standen. Möglicherweise diente der mit einer Hebevorrichtung ausgestattete Kastenbrunnen B 1 als Rottungsbzw. Gerbergrube.

Die Bodenfeuchtigkeit begünstigte einen Fäulnisprozess mit dem die Felle für die Entfernung der Haare vorbereitet wurden (vgl. HIRSCHBERG / JAKANTA 1979, 158). Nach dem „Schwitzen“ der Felle erfolgte durch das Abschaben der Oberhaut der eigentliche Gerbprozess. Die so behandelten Felle wurden im Anschluss ausgiebig gewässert, ausgewrungen und gestreckt, um eine Schrumpfung zu verhindern, bevor sie in der Sonne getrocknet wurden. Auffällig ist, dass die o.g. Gruben meist separat lagen. Ein Bezug zu Umgebungsbefunden fehlt. Die doch recht große Entfernung zur Wohnbebauung könnte einhergehen mit einer für den Menschen unangenehmen Geruchsbelästigung, wie er für Rottungsgruben typisch ist.

Es ist zu vermuten, dass auch die Lederbearbeitung in Nortmoor vertreten war, jedenfalls folgt man der Annahme, dass es sich bei dem Kastenbrunnen B 1 (Kat.Nr. 740) um eine Rottungsgrube gehandelt hat, in der Leder gegerbt wurde. Gegerbte Rinderhäute stellten im römischen Reich eine wichtige Handelsware dar. Ihre Bedeutung für das römische Militär, aus der insbesondere Marschzelte, Lederkoller und Stiefel gefertigt wurden, ist allgemein bekannt. Tacitus berichtet von einem erfolgreichen Aufstand an der niederländischen Nordseeküste bei dem gegerbte Tierfelle eine entscheidende Rolle spielten (Tac.ann. IV,72). Die Höhe der von den Friesen als Steuer abzugebenen Rinderhäute führte schließlich zum Aufstand, bei dem diese sich für 30 Jahre von der römischen Vorherrschaft befreien konnten und jegliche Abgaben an das römische Reich einstellten. Da der Bedarf an gegerbten Tierhäuten jedoch nach wie vor bestand, ist es durchaus denkbar, dass die benötigte Ware über chaukische Zwischenhändler eingekauft wurde. Die verkehrtechnisch günstige Anbindung über Jümme und Ems erleichterte sicherlich das Vertriebssystem. Vielleicht steht der ungewöhnliche Anteil römischen und provinzialrömischen Importes in Nortmoor damit in Verbindung. 
Wenige Schlackestücke legen eine lokale Metallverarbeitung nahe; es gelang jedoch nicht der Nachweis von Rennfeueröfen oder Ausheizherden. Diese waren aufgrund ihrer Feuergefährlichkeit vermutlich auch nicht im Siedlungsbereich untergebracht. Nach metallurgischen Untersuchungen eignet sich das in der Jümme-Niederung anstehende Raseneisenerz zur Verhüttung.

Fehlbrände aus einigen Siedlungsgruben deuten auf eine heimische Keramikproduktion hin; eindeutige Hinweise auf eine Töpferei fehlen jedoch. Die durch zahlreiche Spinnwirtel und den Fund von drei Webgewichten belegte Weberei stellte ein wichtiges Hand- und Hauswerk dar.

Aussagen zur Siedlungsgröße sind nur unter Vorbehalt zu treffen. Demnach kann für den Ostteil des Nortmoorer Dünenzuges von einem Einzelgehöft ausgegangen werden. Im Plan wird eine Längsverschiebung der Wohnbebauung auf dem Dünenkamm nachvollziehbar. Möglicherweise schlossen sich entlang der Dünenkuppe nach Osten weitere kaiserzeitliche Siedungsspuren an, so dass es sich in Nortmoor um eine kleine weilerähnliche Siedlung gehandelt haben könnte. Landschaftsprägende Überschwemmungen, die sich in zahlreichen Befunden als eingeschwemmte Kleischicht manifestieren, machen deutlich, dass die Siedlung infolge einer stärker werdenden Vernässung verlassen wurde. Vermutlich zog die Bevölkerung in der späten Kaiserzeit in geschütztere Regionen entlang des nahen Geestrandes. Ein in Nortmoor-Plaggenburg entdecktes kaiserzeitliches Gräberfeld könnte mit der dortigen Neugründung der Siedlung in Verbindung stehen.

Erst wieder im 9. Jahrhundert kommt es zu einer Wiederbesiedlung der Nortmoorer Düne. Hiervon zeugt eine beachtliche Anzahl Muschelgrus gemagerter Keramik und Pingsdorfer Ware. Darüber hinaus können der mittelalterlichen Siedlungsphase zwei Rutenberge (SP 14 u. 15) und diverse mit Holz ausgesteifte Brunnen (B 3, B 4) und eine Wasserstelle (B 10) zugeordnet werden. Dieser Siedlungsphase gehören aufgrund ihres keramischen Repertoires auch diverse Abfallgruben mittleren und größeren Durchmessers an.

Größere Baukomplexe zeichnen sich hingegen auf der untersuchten Fläche nicht ab. Auch gibt es keine Hinweise auf etwaige Zäune oder Einfriedungen aus dieser Zeit. Wenn auch davon auszugehen ist, dass einzelne Pfostensetzungen nicht als mittelalterlich erkannt worden sind, so zeigt sich für die untersuchte Fläche eine insgesamt recht geringe Befunddichte. Auffällig ist, dass sich die dem Mittelalter zugehörigen Befunde auf den östlichen Dünenbereich beschränken. Dieses Areal wurde bereits in den 60er Jahren des 20. Jahrhunderts stark durch Sandentnahmen gestört. Es ist daher zu vermuten, dass sich die mittelalterlichen Wohnbauten auf dem neuzeitlich abgebaggerten Dünenteil befanden. 
Parallelen zu den Gehöften I-III finden sich beispielsweise in Streusiedlungen wie sie in Bennekom, Provinz Gelderland (VAN ES 1985) oder im ammerländischen Flögeln (ZIMMERMANN 1992) vorliegen. Dort sind es nebeneinanderliegende Einzelgehöftbauten, die sich in einem lockeren Verbund zu einer weilerartigen Siedlung vereinigen.

In Nortmoor vermitteln die annähernd rechtwinkelig angelegten Flechtwerkzäune das Bild einer geschlossenen Gehöftformation, die jeweils aus einem Langhaus, benachbarten Speicherbauten, Werkgruben und ein bis zwei Brunnen bestand. Die Zäune umfassen dabei jeweils einzelne Hausplätze. Auch wenn es zur Verlagerung der Bebauung kommt (siehe Hausplätze II und III), erfolgt dies nur innerhalb des umzäunten Areals.

Vergleichbare Einzelbetriebsgehöfte mit umgebenden Außenzaun finden sich in Flögeln erst ab dem 2. Jahrhundert, in Bennekom sogar erst ab dem 3. Jahrhundert. Anders sieht die Situation in Nortmoor aus, wo diese Entwicklung bereits spätestens Ende des 1. Jahrhunderts einsetzt. Im kaiserzeitlichen Nortmoor hat sich prinzipiell diese Siedlungsstruktur bis in das 3. Jahrhundert hinein nicht wesentlich geändert.

Vermutlich setzte sich die Siedlung entlang des Dünenzuges fort, wobei mehrere Höfe gleichzeitig bestanden haben dürften. Hierauf weisen jedenfalls die von dort stammenden Lesefunde an kaiserzeitlicher Keramik hin.

Ganz im Unterschied zu Vorbasse gibt es in Nortmoor jedoch kaum Freiflächen zwischen den Höfen; möglicherweise eine Folge der speziellen topographischen Situation. Auf der Sanddüne ist die verfügbare Siedlungsfläche auf einen schmalen Streifen von etwa $40 \mathrm{~m}$ begrenzt. Die Wohnbauten sind erst oberhalb einer NN-Höhe über $+1,35 \mathrm{~m}$ anzutreffen und ziehen sich wie an einer Schnur aufgereiht entlang des Dünenrückens. Berücksichtigt man die vielen nicht zuordbaren Pfostengruben, die das Areal überziehen und ehemals zu Gebäuden oder Zäunen gehört haben dürften, erscheint die Besiedlung ungewöhnlich dicht.

Ein ähnliches Bild ergibt sich für die Geestsiedlung Brill. Im 1./2. Jahrhundert beträgt der Abstand zwischen den einzelnen Hausplätzen noch 40-70m, während in der zweiten Phase sich die Gebäude im südwestlichen Teil der Siedlungsfläche regelrecht ballen. Erst im 3.-5. Jahrhundert erfolgt wieder eine lockere Aufreihung der Hausplätze (LEHMANN 2002, 155).

Die Parzellengröße in Nortmoor variiert zwischen 2000-2400qm. Sie sind damit als relativ klein zu bezeichnen, vergleicht man sie mit umzäunten Parzellen in Bennekom, die zwischen 3000-3500qm Fläche einnehmen können (VAN ES 1985, 631). Selbst in Fochteloo umfasst die Hoffläche eines Einzelgehöftes, bei dem es sich vermutlich um den Häuptlingssitz handelte, im 1.-2. Jahrhundert bereits 3000qm (VAN GRIFFEN 1958, 53-57).

Eine Unterteilung der kaiserzeitlichen Siedlung durch Umzäunungen findet sich auch in Gristede (ZOLLER 1975, 149). Auffällig ist, dass bis zu fünf parallel verlaufende Zaungräbchen um einen 
Hofplatz anzutreffen sind. Das fortwährende Erneuern der Einzäunung weist auf eine längerfristige Parzellenkonstanz hin. Eine ähnliche Beobachtung ist auch in Soest-Ardey zu machen. Die dicht übereinanderliegenden Hausplätze Va-d geben nach REICHMANN $(1984,237)$ einen Hinweis auf „festgeschriebene Besitzverhältnisse“, wie sie bereits von der Feddersen Wierde bekannt sind.

In Nortmoor bilden Einzelgehöfte mit ihren Nebenbauten die dominante Wirtschaftsform. Zwar nutzte man wohl bestimmte Einrichtungen gemeinschaftlich, wie beispielsweise die über einen Zeitraum von 100 Jahren offenstehende Wasserstelle im Südostteil der Siedlung, zur Ausbildung einer dörflichen Anlage mit Mehrbetriebsgehöften kommt es jedoch nicht; jedenfalls unter Berücksichtigung der aufgedeckten Siedlungsstrukturen. Im Unterschied dazu sind die für die jüngere Kaiserzeit belegten Mehrbetriebsgehöfte zu sehen. Diese sind in Flögeln bereits ab dem 2./3. Jahrhundert und in Wijster im 3. Jahrhundert zu beobachten (ZIMMERMANN 1976; VAN ES 1967).

In Ostfriesland dominieren in der römischen Kaiserzeit kleine weilerartige Ansiedlungen in Streulage das Siedlungsbild. Selbst nahezu vollständig erfasste Siedlungen, wie das vom 1.-5. Jahrhundert bewohnte Brill, haben rein rechnerisch nicht mehr als drei gleichzeitige Gehöfte aufzuweisen. Diese Beobachtungen stützen auch die bisher teilergrabenen Siedlungen. Sowohl in Nenndorf wie in LeerLoga, Hollen oder Nortmoor finden sich selten mehr als zwei gleichzeitige Hausplätze. Einzige Ausnahmen sind Bentumersiel und Jemgum-Kloster im Reiderland. Während in Bentumersiel eine hohe Anzahl an Speicherbauten existierten, die wohl mit der Versorgung des römischen Militärs in der ersten Hälfte des 1. Jahrhunderts in Verbindung standen, ist auf den reiderländischen Wurten Siedlungsraum nur begrenzt verfügbar. Es entwickelten sich in der Marsch mit der Zeit dorfartige Gruppensiedlungen, wie es auch von der Feddersen Wierde bekannt ist.

Von der mittelalterlichen Siedlungsphase in Nortmoor sind nur zwei Speicher, wenige Brunnen und einige Gruben überliefert. Die Größe der Rutenberge mit ihren bis zu 1m durchmessenden Einzelpfosten zeugt jedoch von einer wirtschaftlichen Prosperität, die letztlich ihre Bestätigung in rheinländischen, vermutlich teuren, Importen findet. Entfernungen von 20-30m zwischen Speichern und Hausplätzen sind keine Seltenheit. Deswegen ist davon auszugehen, dass sich die Wohnbauten auf dem zerstörten Dünenareal befanden. Nach Auswertung der Keramik kann von einer Besiedlung vom 9. bis zum Ende des 11. Jahrhunderts ausgegangen werden. Frühmittelalterliche Höfe bestehen i.d.R., wie die kaiserzeitlichen, aus einem Hauptgebäude, um das sich diverse Nebengebäude, Speicher und Grubenhäuser gruppieren.

Wahrscheinlich handelte es sich in Nortmoor um Einzelgehöfte, die entlang der Dünenkuppe aufgereiht waren. Einschiffige Wohnhäuser mit einer maximalen Länge von 20m sind beispielsweise aus dem nahen Hesel belegt. Die dort aufgedeckte und fast schon als standardisiert zu bezeichnende Ausstattung der Gehöfte umfasste je einen Rechteckspeicher, einen Rutenberg und eine 
Brunnenanlage. Letztere bestand aus aufgeschichteten Gras- oder Torfsoden, die auf einem hölzernen Rahmen aufgesetzt waren. Auch die Rutenberge entsprachen in Ausmaß und Gestalt denen in Nortmoor. Da die aufgefundene Muschelgrus gemagerte Keramik keine feinchronologische Datierung erlaubt, ist nicht zu entscheiden, ob die 13 Heseler Gehöfte, die ein 800-1400qm großes Areal einnahmen, gleichzeitig bestanden oder sich ablösten (BÄRENFÄNGER 1994, 39-72).

Neben unstrukturierten Gruppensiedlungen wie sie in Hollen oder im niederländischen Odoorn vorliegen, finden sich auch Belege für aufgereihte und etwa gleichgroß eingezäunte Gehöfte. Hierzu zählt auch das vom 9.-12. Jahrhundert besiedelte Gasselte in der Provinz Drenthe. Die Siedlung war entlang einer $450 \mathrm{~m}$ langen Straße aufgereiht von wo aus die rückseitigen Ackerflächen erreicht werden konnten (BEHRE / KOSSACK / SCHMID 1984, 240).

$\mathrm{Ob}$ auch in Nortmoor von einer durchgängigen frühmittelalterlichen Besiedlung ausgegangen werden kann, ist letztlich nicht eindeutig zu entscheiden. Für eine andauernde Platzkontinuität bis zum Ende des 11. Jahrhunderts spricht das umfangreiche mittelalterliche Fundmaterial. Auf eine frühe Siedlungsgründung weist auch die Flureinteilung hin. Um den Nortmoorer Dünenzug zeichnen sich in der Preußische Landesaufnahme von 1898 deutlich blockförmige Parzellen ab, die erst mit größerer Entfernung in lange Streifen übergehen. Eine derartige Blockparzellierung findet man in Ostfriesland vorwiegend bei siedlungsnahem Kulturland, welches seit dem Frühmittelalter bewirtschaftet wurde (REINHARDT 1969, 243-248).

Relativchronologische Aussagen aufgrund stratigraphischer Abfolgen sind bei den Wohnbauten in Nortmoor aufgrund fehlender Grundrissüberschneidungen meist nicht möglich. Etwas günstiger ist die Situation bei den Speicherbauten. So schneidet der Traufgraben des Hausplatzes II einen Pfosten der Speicheranlage SP 8 (6-Pfostenspeicher), womit der Speicher als älter gelten kann.

Befundüberschneidungen finden sich bei der südöstlichen Zaunreihung. Das an seinem westlichen Ende nach innen gebogene Zaungräbchen Kat.Nr. 261 überlagert die Fundamentgräbchen Kat.Nr. 106 und 129b, womit letztere älter anzusetzen sind. Damit wird die Umhegung der Wasserstelle Kat.Nr. 195 insgesamt als jüngerkaiserzeitlich zu bezeichnen sein.

Befundüberlagerungen finden sich auch bei zwei Grabenanlagen nordöstlich von Hausplatz I. Der rechteckige Graben Kat.Nr. 455 schneidet die größere Grabenanlage Kat.Nr. 513; letztere ist als älter anzusehen. Dennoch kann der „Altersunterschied“ der Grabenverfüllung der Gräben wohl als marginal angesehen werden. Findet sich doch in dem geschnittenen Graben einen Denar Kaiser Trajans, der ein Prägedatum zwischen 97-113 n. Chr. aufweist, während aus dem oberen Graben der Eichenholzrohling eines Radsegmentes, welches „,nach 132 n. Chr.“ datiert, stammt. Diese Beobachtung wird auch von dem keramischen Fundmaterial aus den Gräben gestützt.

Mittelalterliche Befundüberlagerungen sind recht selten; dies wohl auch weil es insgesamt nur wenige Befunde aus diesem Zeithorizont in der Siedlung gibt. So wird beispielsweise der innere Südzaun 
Kat.Nr. 262 vom SP 14 überlagert; bei letzterem handelt es sich um einen mittelalterlichen Rutenberg. Doch nur SP 15 gilt als zweiphasig. Da seine Befundsituation durch eine Geländekante gestört wird, ist auch eine Dreiphasigkeit des mittelalterlichen Rutenberges nicht völlig auszuschließen.

Die fehlende stratigraphische Abfolge bei den Baubefunden erschwert ihre relativ chronologische Ansprache, die deshalb weitgehend über bautypologische Vergleiche erfolgen muss. Dies ist auch deshalb unumgänglich, da aus den Pfostenbefunden der Hausplätze kaum keramisches Material stammt.

Die wenigen in den Pfostenbefunden enthaltenen Scherben sind meist stark zerscherbt und eignen sich nicht für eine feinchronologische Datierung, sondern können nur allgemein in die römische Kaiserzeit datiert werden. Auch ist ihr Grubeninhalt i.d.R. erst nach Aufgabe in die Pfostengruben gelangt und kann somit lediglich als terminus ,post quem“ gelten.

Siedlungsgruben zeichnen sich häufig durch eine große Fundmenge aus. Sie können jedoch nur unter Vorbehalt zur Datierung herangezogen werden, da eine Gleichzeitigkeit mit den benachbarten Hausplätzen nicht generell vorauszusetzen ist. Oft kann weder der Zeitpunkt ihrer Anlage noch die Dauer ihrer Verfüllung erschlossen werden.

Bei der Beurteilung von Pfosten- und Grubenbefunden in dem o.g. Kontext sind unterschiedliche Vorgehensweisen zu beobachten. Während in Flögeln nur Funde innerhalb von Hausgrundrissen berücksichtigt werden, die am jüngsten sind und die mehrfach auftreten (ZIMMERMANN 1978, 377), werden in Brill auch diejenigen Funde in die Baudatierung mit einbezogen, die aus der näheren Umgebung der Hausplätze kommen, selbst wenn sie aus überbauten Flächen oberhalb des Gebäudes stammen (LEHMANN 2002, 163-164).

Eine horizontalstratigraphische Analyse soll im Folgenden klären, ob es in Bezug auf die Verteilung der keramischen Leitformen für die römische Kaiserzeit bestimmte Präferenzen innerhalb der Siedlung gibt.

Das keramische Inventar der kaiserzeitlichen Siedlung umfasst einen Zeitraum vom 1.-3. Jahrhundert. Bei einer Vielzahl an Randfragmenten von Trichterschalen und Töpfen überwiegen kurze vorwiegend verdickte Randformen, wie sie für das 1.-2. Jahrhundert kennzeichnend sind. Lange ausgewendete Gefäßränder der jüngeren Kaiserzeit sind deutlich in der Minderzahl.

Fast über die gesamte Grabungsfläche verteilen sich Randfragmente von Trichterschalen (GF 1) nahezu gleichmäßig. Eine Konzentration findet sich nördlich und südlich von Hausplatz II in den hausbegleitenden Gräben. Auch südlich von Hausplatz I sind vermehrt Trichterschalenfragmente zu beobachten. In dem vorgelagerten Areal befand sich eine kleine frühkaiserzeitliche Nekropole, von der vorwiegend Brandschüttungsgräber überliefert sind. 20m entfernt entdeckte man im südlichen Teil von Haus II zwei nicht in-situ befindliche Trichterschalen. Eine Häufung von Schalenrändern ist auch 
im Süden der Siedlung innerhalb der Wasserstelle Kat.Nr. 195 und den umliegenden Gräben festzustellen. Einzelränder stammen sowohl aus dem Grubenhaus wie auch aus der rechteckigen Grabenanlage.

Während sich Trichterschalenfragmente über das gesamte Siedlungsareal verteilen, sind Trichternäpfe (GF 2) und Trichterpokale (GF 3) nur in geringer Anzahl nachweisbar. Auffällig verdickt facettierte Ränder, wie die RF 7.3, 7.6, 8.2, in das 1. Jahrhundert n. Chr. datiert werden (SCHMID 1965, 35). Sie finden sich vorzugsweise in den größeren Gräben nördlich und südlich von Haus II. Ein Trichternapf mit gedrungenem trapezförmigen Rand stammt aus dem Areal südlich von Haus II und entspricht der RF 7.6. Eine ähnliche Randgestaltung findet sich bei einer hölzernen Schale der Feddersen Wierde, die frühkaiserzeitlich datiert wird (HAARNAGEL 1979, Taf. 44.2).

In Boomburg-Hatzum wird ein verzierter Trichternapf der Variante $7 \mathrm{~b}$ zugeordnet, die dem jüngeren Fundhorizont angehört (LÖBERT 1978, 73, 80, Tafel 41, Nr. 688). Ansonsten werden im südlichen Nordseeküstengebiet Trichternäpfe eher als typische Vertreter des 3. Jahrhunderts n. Chr. angesehen, die eine Übergangsform zu den Trichterpokalen darstellen (SCHMID 1965, 20-22).

Weitmündige Töpfe mit flacher Schulter und senkrechtem Rand (GF 7.6; RF 2.1; 5.1) gelten als Vertreter von Gefäßen, die in das 2.-3. Jahrhundert datieren. Die sich durch eine kleine vorgewölbte Randlippe auszeichnenden Töpfe sind nur in vier Exemplaren in Nortmoor belegt. Sie sind auf den westlichen Siedlungsbereich beschränkt und finden sich zwar in größeren Grubenkomplexen, diese enthalten jedoch zum überwiegenden Teil frühkaiserzeitliche Keramik.

Engmündige doppelkonische Töpfe (GF 7.9) des 2.-3. Jahrhunderts streuen in ihrer Verbreitung im südlichen Siedlungsbereich. Nur selten finden sich Vertreter dieser GF auf der Nordostseite der Düne. Beispielsweise enthielten zwei hausparallele Gräben (Kat.Nr. 702; 884) und ein größerer Grubenkomplex innerhalb des Gebäudes von Hausplatz III Randfragmente von doppelkonischen Töpfen. Auch südöstlich von Haus II finden sich vergleichbare Keramikformen (Kat.Nr. 432-3; 463-5; 468-5; 499-4), wenn auch in geringerer Anzahl. Die jeweiligen Baukomplexe gelten jedoch als bautypologisch älter.

Häufiger in Nortmoor vertreten sind die in die Mitte des 3. Jahrhunderts zu datierenden engmündigen Töpfe mit ausgewendetem Rand (GF 7.7). Ein deutlicher Schwerpunkt zeichnet sich im Westteil von Haus I und in den hausparallelen Gruben von Haus II ab. Ungewöhnlich ist die breite Streuung südlich und westlich von Haus III. Daneben kommen sie in zwei kaiserzeitlichen Brunnenanlagen vor (Kat.Nr. 195; 394), die ganz im Osten der Siedlungsfläche liegen.

Für die spätere Kaiserzeit sind Töpfe mit S-förmigem Oberteil (GF 7.4) überliefert. Diese konzentrieren sich auf Gruben nördlich und südlich von Hausplatz II (Ostseite) sowie in dem Areal südöstlich davon. Auch die dendrochronologisch in das 1.-2. Jahrhundert datierte Wasserstelle enthält wenige Randfragmente von der GF 7.4. Auch aus dem kaiserzeitlichen Brunnen Kat.Nr. 394 stammt ein Fragment. 
Nicht alle in Brill belegten Gefäßformen sind in Nortmoor anzutreffen. In der südostfriesischen Siedlung fehlen offenkundig zweigliedrige Schalen (GF 4) mit langem ausgewendeten Rand. Und auch Pokale (GF 5), situlenartige Gefäße der GF 6 sowie Terrinen (GF 8) sind augenscheinlich nicht im Fundbild vertreten. Sind aus Brill Tassen der GF 10 bekannt, so wird ihre Funktion in Nortmoor möglicherweise durch die dort aufgefundenen becherartigen Gefäße der Sonderform GF 14 übernommen. Keine Hinweise fanden sich in Nortmoor auf die Verwendung von einfachen runden Tonplatten, die in Brill als Teller angesprochen werden (GF 13).

Unter den Funden im Nortmoorer Hammrich fällt der stattliche Anteil nicht einheimischer Funde auf. Im zentralen Grabungsbereich dominiert unter den importierten Keramikfunden provinzialrömische Drehscheibenware. Terra Nigra und Terra nigra-artige Scherben sind in einigen Gruben mit bis zu 15 Fragmenten belegt. Ein nahezu vollständiges und ein Teilgefäß entstammen einer Brunnenverfüllung am Südrand der Siedlung. Das Verteilungsbild der Terra Nigra sowie ihrer Nachahmungen reichen vom östlichen Randbereich bis in den zentralen Teil der untersuchten Fläche.

In geringerer Anzahl liegt in Nortmoor Terra Sigillata, auch als rote Glanztonware bekannt, in Bruchstücken von wenigen Zentimetern Größe vor. Sie ist mit einer Ausnahme unverziert. Das verzierte Wandungsfragment schmückt ein schlichter Eierstab und gehörte vermutlich einer römischen Reliefschüssel an. Daneben existieren verschiedene Belege für provinzialrömische Haushaltsware in Form von helltoniger Keramik sowie einer römischen Reibschale.

Außergewöhnlich sind die in Nortmoor entdeckten Nachahmungen römischer Keramik. Es handelt sich um hochwertige Imitationen von Sigillata, die diese in Tonfarbe, Glanztonüberzug und Motivik nachahmen. Allein drei Wandungsscherben fanden sich aus der Wasserstelle Kat.Nr. 195. Sie zeichnen sich durch eine dünne Wandung und feingeschlemmten Ton aus. Ihr Dekor mit applizierten Bögen und Kreissegmenten fehlt in der römischen Formensprache. Deutlich barbarischen Einschlag haben die an einer Randscherbe eingeritzten umlaufenden Rillen mit angedeuteten hängenden Dreiecken.

Singulär sind zwei Wandungsscherben, die sich durch ihre Tonbeschaffenheit und Oberflächenbearbeitung auszeichnen. Der Dekor setzt sich aus Einzelstempeln zusammen, die zwar im römischen Formenkanon Vergleiche findet, jedoch spiegelbildlich wiedergegeben wurden. Dies lässt Rückschlüsse auf ihre Herstellung zu. Demnach hat der Töpfer die traditionelle Herstellung römischer Reliefware in einer Formschüssel nicht nachvollzogen, sondern seine Muster einzeln in die ungebrannte lederharte Schüsselwandung eingedrückt. Die Scherben entstammten einer $5 \mathrm{~m}$ südlich von Hausplatz II gelegenen Grube. Ein hausbegleitender Graben an der Gebäudenordseite enthielt Terra Nigra und wenige Meter nördlich fand man einen Denar Trajans. 
Römische Funde wie eine silberne Schmuckscheibe und Fragmente römischen Glases deuten auf einen gewissen Wohlstand der Siedlung hin und sind Zeugen für weitreichende Verbindungen. Im Vergleich zu ländlichen Siedlungen wie Brill, Gristede oder Backemoor fällt in Nortmoor der hohe Anteil an römischen wie provinzialrömischen Funden auf. In der bedeutend größeren Geestsiedlung Brill sind nur eine Sigillata und wenige Terra Nigra Scherben überliefert, wobei der Fund von Farbpigmenten „ägyptisch blau“ auch hier auf weitreichende Handelsverbindungen hinweist.

Einen ähnlichen Stellenwert wie Nortmoor in der Unteren Emsregion wird die kaiserzeitliche Siedlung Westerhammrich besessen haben. Auch dort fand sich importierte Drehscheibenware, wenige Sigillata Scherben und römisches Glas. Ausgesuchte Einzelfunde römischer Provinienz ergänzen das Fundbild. $\mathrm{Zu}$ nennen sind eine goldüberzogene Silbernadel und eine Bronzestatuette; letztere stammt aus einer Ofengrube, die vermutlich mit der Verarbeitung von Buntmetallen in Zusammenhang steht. Die stark bestoßene Statuette stellt vermutlich den römischen Kriegsgott Mars dar. Hierauf deutet ein typologischer Vergleich, da derartige Figuren in der einen Hand ein Schwert erhoben und im abgesenkten Arm ein Schild trugen. Vergleichbare Statuetten liegen aus Spahn, im Landkreis Emsland (ERDRICH 2002, Taf. 137 a-c) und von der Wurtensiedlung Ezinge, Provinz Groningen vor (VAN GRIFFEN 1936. 40, Abb. 1).

Die Verteilung figürlicher Bronzestatuetten in der Germania magna zeigt ansonsten einen deutlichen Fundschwerpunkt im Lippe-Gebiet und der Wesermarsch (STUPPERICH 1980, 20-21, Karte 5). Zumeist weisen die Bronzen deutliche Gebrausspuren auf. Eine Datierung der stilistisch unsensiblen Kleinbronzen fällt daher schwer.

Hinweise auf eine lokale Metallverarbeitung fanden sich in Nortmoor und der näheren Umgebung. Auffällig ist die große Anzahl an Brunnen, die sich in einem erhöhten Wasserbedarf der Siedlung begründet. Die in den Randbereichen liegenden Brunnenkonstruktionen eigneten sich aufgrund ihrer Lage in einem sauren Umgebungsmilieu des Niedermoortorfes kaum zur Trinkwasserversorgung der Bewohner. Eher vorstellbar ist daher, dass die Anlagen, die sich durch einen hohen Gerbsäureanteil auszeichneten, mit der Lederverarbeitung oder ähnlichem in Verbindung standen und als Rottungsgruben anzusprechen sind.

Somit bestand die wirtschaftliche Basis in Nortmoor nicht nur aus Viehzucht und, wenn auch im geringen Maße, Ackerbau. Die Siedlung war vermutlich im gewissen Umfang auch Produktionsort und diente möglicherweise aufgrund ihrer flussnahen Lage als Umschlagplatz. Auch der beachtliche Anteil römischer wie provinzialrömischer Waren lässt dies vermuten.

Insbesondere naturwissenschaftliche Datierungsmethoden können zur chronologischen Ansprache archäologischer Befunde herangezogen werden. An erster Stelle ist neben der ${ }^{14} \mathrm{C}-$ Methode die Dendrochronologie zu erwähnen (Tab. 10). 
Bei der Übertragung der so erzielten Ergebnisse auf Baustrukturen sind jedoch verschiedene Überlegungen einzubeziehen. Kommt es beispielsweise zu Mehrfachproben aus einem Befund, können ganz unterschiedliche Datierungen die Folge sein, die nicht ausschließlich mit der Erbauungsphase in Verbindung stehen müssen. Oft wurde Holz sekundär verwendet oder gelangte erst nach Aufgabe der Anlage in dieselbige. Beides kann zu divergierenden Datierungen führen hinter denen sich unterschiedliche Nutzungszeiten der Hölzer verbergen.

\begin{tabular}{|l|c|l|c|l|l|}
\hline Kat.Nr. & Endjahr & $\begin{array}{l}\text { abgeleitetes } \\
\text { Fälljahr }\end{array}$ & $\begin{array}{l}\text { Jahrring- } \\
\text { anzahl }\end{array}$ & $\begin{array}{l}\text { Baumringe bis } \\
\text { Waldkante }\end{array}$ & Bemerkungen \\
\hline 4 & -432 & $-440^{-6 /+6}$ & 104 & $8^{-6 /+6}$ & Eichenbaumstämme \\
& -452 & $-467^{-2 /+2}$ & 168 & $15^{-2 /+2}$ & aus einer Torfschicht \\
& -656 & $-663^{-6 /+6}$ & 159 & $7^{-6 /+6}$ & \\
\hline 100 & 118 & $136^{+/-10}$ & $75 \mathrm{~S} / \mathrm{K}$ & $18^{-10 /+10}$ & Eiche \\
& 108 & $126^{-6 /+8}$ & 108 & $18^{-6 /+8}$ & Zaungräbchen \\
\hline 195 & 131 & $>142$ & $>79$ & $>11$ & Wasserstelle \\
& 175 & $>186$ & 122 & $>11$ & \\
& 126 & $>132$ & 77 & $>6$ & Eiche / Holzbohle \\
\hline 455 & 248 & $272^{+/-10}$ & 154 & $25^{-10 /+10}$ & Eiche / Holzbohle \\
\hline 1113 & \multicolumn{2}{|c|}{ S/K = Splint/Grenze; Jahrringe = Angabe der Splintholz-Jahrringe; > mehr als.../ nach... } \\
\hline
\end{tabular}

Tab. 10

Ergebnisse der dendrochronologischen Untersuchung an Hölzern aus dem Nortmoorer Hammrich (DELAG)

Als Beispiel kann hier die große Wasserstelle B 11 (Kat.Nr. 195) angesprochen werden. Aus ihr stammt eine Vielzahl an Hölzern. Teilweise wurden diese gezielt in der Anlage verbaut; manches lag ohne Zusammenhang lose in der Verfüllung. Einige Hölzer wiesen Ausarbeitungen auf, die ursprünglich wahrscheinlich in einem anderen baulichen Verbund gestanden haben und erst später hierher gelangten.

Aus der Wasserstelle existieren vier dendrodatierte Hölzer, deren abgeleitete Fälljahre zwischen „97 n. Chr.“ bis „186 n. Chr.“ liegen. Demnach könnte von einer etwa 100-jährigen Nutzungsdauer der Anlage ausgegangen werden. Doch einzig das mit „126 n. Chr.“ datierte Holz der Treppenstufe, das in der Anlage verbaut wurde, gibt ein festes Eckdatum für die Nutzungsphase der Wasserstelle.

Die angeführten Endjahre geben die Datierung für den letzten gemessenen Jahrring der Proben an. Es entspricht in den vorliegenden Fällen nicht dem Fälljahr, da der Holzabschluss (,Waldkante“) unter 
der Rinde nicht mehr erhalten war. Die o.g. abgeleiteten Fälljahre geben eine geschätzte Anzahl (+/-) der bis zur Waldkante fehlenden Baumringe an. Dennoch ist es durchaus möglich, dass die Varianz der angegebenen Splintholzringe und somit auch das abgeleitete Datum als höher bzw. kleiner anzugeben ist.

Die mit der ${ }^{14} \mathrm{C}$ Methode untersuchte Holzkohle wurde während der Ausgrabung aus den o.g. Befunden entnommen. Die Holzkohle wurde im Anschluss getrocknet und in verschließbaren Gefrierguttüten verpackt, wo sie bis zur Probenentnahme 10 Jahre lang lagerten. Die Ergebnisse der ${ }^{14} \mathrm{C}$ Untersuchung des Isotopenlabors der Universität Köln gibt die o.g. Tabelle wieder (Tab. 11).

\begin{tabular}{|l|l|l|l|l|}
\hline Kat.Nr. & Probenmaterial & ${ }^{14}$ C Alter BP & Kalenderjahr & Bemerkungen \\
\hline $265 a$ & KN- 5630 & $1830^{+/-35}$ & $170^{+/-50} \mathrm{AD}$ & Brunnen, HK aus Schicht 265a \\
\hline 366 & KN - 5631 & $1965^{+/-35}$ & $20^{+/-40} \mathrm{AD}$ & Bestattung \\
\hline 378 & KN - 5632 & $1790^{+/-35}$ & $220^{+/-70} \mathrm{AD}$ & Feuerstelle (6kg HK) \\
\hline 435 & KN - 5633 & $1865^{+/-40}$ & $140^{+/-60} \mathrm{AD}$ & Hausplatz I \\
\hline 498 & KN - 5634 & ohne Angabe & ohne Angabe & $\begin{array}{l}\text { Bestattung } \\
\text { kein messbarer Kohlenstoff }\end{array}$ \\
\hline 747 & KN - 5635 & $1915^{+/-35}$ & $70^{+/-40} \mathrm{AD}$ & Brunnen \\
\hline 902 & KN - 5636 & $2045^{+/-85}$ & $-80^{+/-110} \mathrm{BC}$ & Wandgräbchen \\
\hline 902 & KN - 5637 & $695^{+/-27}$ & $1300^{+/-50} \mathrm{AD}$ & Wandgräbchen \\
\hline
\end{tabular}

Tab. 11

Ergebnisse der ${ }^{14} \mathrm{C}$ Untersuchung (Isotopenlabor Universität Köln).

Die Standartabweichungen werden mit +/- angegeben und schließen alle durch technische oder chemische Aufbereitungsmethodik entstandenen Fehler mit ein. Davon ausgenommen sind diejenigen Unsicherheiten, die durch Entnahme, Lagerung, Kontamination oder ähnlichem beeinflusst sind. $\mathrm{Zu}$ berücksichtigen ist zusätzlich, dass die Angabe des konventionelle ${ }^{14} \mathrm{C}$-Alters mit einer statistischen Sicherheit von $68 \%$ innerhalb des ermittelten Zeitintervall liegt. Kalibrierte Kalenderjahre sind mit historischen Daten zu vergleichen.

Die angegebenen Kalenderjahre der beprobten Holzkohle weisen in einigen Fällen eine Differenz zum archäologischen Datierungsansatz auf. Möglicherweise liegt dies darin begründet, dass die kalibrierten Daten mit der süddeutschen Eichenchronologie abgeglichen wurden, die ihrerseits mit dendrochronologischen Laboren in Belfast und Seattle abgesichert sind. Abweichungen von der archäologischen Datierung erklären sich u.a. durch den Fehler der kleinen Zahl, da jeweils nur eine Holzkohle-Probe je Befund untersucht wurde. 
Die Brandbestattung Kat.Nr. 366 (KN-5631) wird in die Zeit um Christi Geburt datiert und passt somit gut in den Kontext der kleinen kaiserzeitlichen Nekropole. Holzkohle aus der Bestattung Kat.Nr. 498 enthielt keinen messbaren Kohlenstoff (KN-5634). HK-Brocken aus einer etwa 8m südlich liegenden Grube Kat.Nr. 378 (KN-5632), die insgesamt 6kg Holzkohle enthielt, datieren in die mittlere römische Kaiserzeit; somit wird eine Deutung als Scheiterhaufenplatz obsolet. Ebenfalls in dieses Zeitfenster datiert die dem Brunnen B 2 entnommene HK-Probe (KN-5630).

Aus dem westlichen Bereich von Hausplatz I entstammt die einer Grube entnommene HK-Probe (KN5633), die um die Mitte des ersten Jahrhunderts datiert. Dass es sich bei der HK-Konzentration innerhalb der kastenförmigen Grube um einen ehemals sekundär verwendeten Pfosten handelte, ist zu vermuten.

In die Zeit um Christi Geburt datiert die aus dem Brunnen Kat.Nr. 747 entnommene Holzkohle (KN5635). Die vorgeschobene Position der Anlage steht vermutlich mit Hausplatz II in Verbindung, an dessen Südseite sie sich befand.

Aus Wandgräbchen Kat.Nr. 902 stammt eine Vielzahl verbrannter Holzstaken, die ehemals das Grundgerüst einer Flechtwerkswand bildeten. Zwei Holzkohleproben wurden ${ }^{14} \mathrm{C}$ untersucht. Die Proben KN-5636 und KN-5637 liegen ungewöhnlich weit auseinander. Während Probe KN- 5636 einen relativ langen Zeitraum abdeckt, der in das 1 . Jahrhundert v. Chr. bis in das 1 . Jahrhundert n. Chr. datiert, erbrachte die zweite Probe eine spätmittelalterliche Datierung. Letzteres ist aufgrund des in diesem Areal wiegenden kaiserzeitlichen Befundkontextes jedoch eher unwahrscheinlich. Die jüngere Datierung wird vermutlich auf eine Verunreinigung des Probenmaterials zurückzuführen sein. Relativchronologisch gehört das Wandgräbchen aus dem beide Proben stammen einer kaiserzeitlichen Umzäunung an.

Aussagen zum Siedlungsgeschehen sind in Nortmoor nur unter Vorbehalt zu treffen. So ist eine zeitliche Hausabfolge der Gebäude I bis III mangels stratigraphischer Überschneidungen aus sich heraus nicht vorzunehmen. Auch ist eine absolute Datierung der Baustrukturen allein anhand der Keramikanalyse in Nortmoor nicht möglich. Hierfür fehlen aus den Baubefunden entsprechende aussagefähige Funde.

Konstruktive Strukturen bei Reihen von Pfostengruben im Zusammenhang zu einem Gebäude bzw. Speicherbau oder einem Umgrenzungszaun ermöglichen jedoch die Zuordnung zu drei landwirtschaftlichen Gehöften. Die Gleichzeitigkeit einer solchen Betriebseinheit ergibt sich über ihren konstruktiven Verbund und Funktion sowie über zusammengehörende Funde bzw. dendrochronologische Fälldaten oder ${ }^{14} \mathrm{C}$ Datierungen. Dies erfolgt in Nortmoor unter Einbeziehung der hausbegleitenden Gräben, benachbarter Speicher und Brunnen. 
Vor der nachfolgenden Rekonstruktion des Siedlungsablaufes sind bezüglich der naturwissenschaftlichen Datierungen zwei grundsätzliche Überlegungen anzuführen. Die Ergebnisse der ${ }^{14} \mathrm{C}$ Datierung weisen in Nortmoor einen Toleranzwert auf, der je nach Probe zwischen „ ${ }^{+/ 40}$ “ und „ ${ }^{+/ 110 ~ " J a h r e n ~ b e t r a ̈ g t . ~ Z u d e m ~ i s t ~ z u ~ b e d e n k e n, ~ d a s s ~ d i e ~ b e p r o b t e ~ H o l z k o h l e ~ v o n ~ s e k u n d a ̈ r ~ v e r w e n d e t e m ~}$ Holz stammen kann und damit an sich bereits älter sein könnte als der durch sie datierte Befund.

Dendrochronologische Ergebnisse weisen einen wesentlich geringeren Toleranzwert auf und eignen sich daher eher zur absoluten Datierung der beprobten Baubefunde. Doch stellt die Zeitspanne zwischen Fälldatum und Verbauung der Hölzer eine unbekannte Größe dar. Dies betrifft auch die Sekundärverwendung von Holz oder mögliche Reparaturstellen. Insbesondere bei der Wasserstelle Kat.Nr. 195 ist auf diese Problematik hinzuweisen. Wird jedoch nur der jüngste Zeitansatz berücksichtigt, so blieben die 50-100 Jahre älteren Hölzer unbeachtet. Letztlich ist nicht zu entscheiden, ob die Wasserstelle eine wirkliche Nutzungsdauer von etwa 100 Jahren besaß oder ob ältere Hölzer verbaut bzw. in der Wasserstelle entsorgt wurden.

Bei dem anschließend vorzustellenden Modell zum Siedlungsablauf in Nortmoor wird von einer ununterbrochenen Siedlungsabfolge ausgegangen. Rekonstruiert wird eine platzkonstante Siedlung mit wenigstens zwei Gehöften.

Eine absolutchronologische Datierung der herausgearbeiteten Siedlungsphasen ist jedoch unter Vorbehalt zu sehen. Dies erklärt sich auch daraus, dass die aufgefundene Keramik nicht näher als bis auf 100 Jahre genau zu datieren ist. Berücksichtigt man die o.g. Faktoren ist eine, vermutlich geringfügige, Verschiebung der Phasen möglich.

Die kaiserzeitliche Besiedlung auf der untersuchten Fläche wird um die Mitte des 1. Jahrhunderts eingesetzt haben. Ihr gehörten der Hausplatz II mit vier Speichern (SP 1, 7, 6, 10) und zwei Brunnen (B 6 u. 8). B 8 kann in die Zeit um ,70 ${ }^{+/-40}$ n. Chr.“ datiert werden. Nach Osten und Süden begrenzten Zäune den Hofkomplex.

Doch bereits kurz vorher wurde die Düne von Menschen aufgesucht. So fanden sich zwei gestörte Urnenbestattungen im Westteil des später errichteten Hausplatzes II. Ebenfalls nicht mehr in-situ war eine wenig nördlich davon entfernte Leichenbrandschüttung. Die Bestattungen gehörten zu einer kleinen späteisen- bis frühkaiserzeitlichen Nekropole, die sich in östlicher Richtung entlang des Höhenrückens der Düne erstreckte. Die Brandgräber (Bestattung 4-8) fand man nördlich einer rechteckigen Grabenanlage; ob diese mit dem Totenkult in Verbindung stand, ist aufgrund fehlender Funde nicht mehr zu klären.

Der Nekropole gehörten insgesamt acht Brandgräber an, die anthropologische Untersuchung belegt 11 Individuen. Eine ${ }^{14} \mathrm{C}$ Analyse datiert Bestattung 6 (Kat.Nr. 366) in die Zeit um Christi Geburt 
(,20 +/-40 “ n. Chr.). Die in verzierten Trichterschalen bestatteten Urnengräber können in das 1. Jahrhundert $n$. Chr. datiert werden. Somit ergibt sich rechnerisch für die kleine Nekropole eine Belegdauer von der 2. Hälfte des 1. Jahrhundert v. Chr. bis in das 1. Jahrhundert n. Chr.

In der zweiten Siedlungsphase kommt es zur Verlagerung der Wohnbebauung und als Nachfolgebau zu Hausplatz II wird wenige Meter westlich Hausplatz III errichtet. Dem Gebäude sind drei Speicherbauten an seiner nördlichen Langseite (SP 3, 4, 11, 12) und einer an seinem östlichen Giebel zuzuordnen (SP 5). Die Speicher nahmen nun eine kleinere Grundfläche ein; möglicherweise ging dies einher mit Lagermöglichkeiten in dem größeren Wohnstallgebäude. Zugehörig zur Wohnbebauung waren die Brunnen B 1 und B 7; aus dem erst genannten stammen zwei Terra Nigra Gefäße des 2./3. Jahrhunderts. Nach Westen und Süden schlossen lange Zaunreihen das Areal ab. Gartenareale südlich des Gebäudes wurden zusätzlich eingezäunt.

Zwar ist für Hausplatz II und III prinzipiell eine Gleichzeitigkeit möglich. Aufgrund ihrer räumlichen Nähe von wenigen Metern ist es jedoch eher zu vermuten, dass die Gebäude nicht gleichzeitig bestanden, sondern in relativ kurzer Folge nacheinander errichtet wurden. Für eine platzkonstante Hofstruktur spricht, dass beide Hausplätze über ein gemeinsames Zaunsystem verfügten, das die Nebengebäude miteinschloss.

Spätestens Anfang des 2. Jahrhunderts wurde das östliche Dünenareal aufgesucht (Phase 2). Hinweise auf ein zweites Gehöft finden sich hier nur indirekt, da der Dünenkamm in diesem Bereich modern abgetragen und durch eine Teichanlage ersetzt wurde. Vergleichbar mit der bekannten Gehöftstruktur, war hier das Areal mit einem weitläufigen Zaun umgeben. Nach Süden wird das Areal durch Zäune begrenzt; der äußere Südzaun datiert „136 $6^{+/ 10 ، ~} n$. Chr. Das mehrmalige Erneuern des Hofzaunes weist auf eine Erweiterung des Hofareals hin. Möglicherweise gehörte das nahe der Abbruchkante liegende Grubenhaus in diese Siedlungsphase, in der es als Nebengebäude diente. In der östlichen Grabungsfläche findet sich ein separat liegender Pfostenspeicher (SP 2) und, wenige Meter östlich davon, das eingezäunte Areal einer Wasserstelle (B 11). Diese wird dendrochronologisch zwischen „>97 “ n. Chr. bis ,> 186 “ n. Chr. datiert.

In der dritten Phase wird an der Nordseite der Dünenkuppe ein weiteres Gehöft errichtet. Es handelt sich um ein 3-schiffiges Wohnstallhaus, wie sie vom 1.-3. Jahrhundert n. Chr. im südlichen Nordseeküstengebiet bekannt sind. Die gestörte Befundlage erschwert bei dem Hausplatz I eine nähere haustypologische Ansprache. Nach der ${ }^{14} \mathrm{C}$ Methode werden eine zum Haus gehörende Grube mit Innenpfosten Mitte des 2. Jahrhunderts bis Anfang des 3. Jahrhunderts, ein südlich liegender Brunnen Ende des 2. Jahrhunderts bis Anfang des 3. Jahrhunderts (B 2) datiert. Vermutlich gehörte auch der benachbarte Rutenberg (SP 9) zum Hofkomplex. Ein Grubenhaus findet sich an der östlichen 
Grabungskante (GH 1). Keramikscherben seiner Verfüllungsphase lassen sich in die mittlere Kaiserzeit datieren.

Noch Ende des 3. Jahrhunderts wurde die Siedlung bewohnt; hierauf weist u.a. die Unterhaltung eines Bohlenweges als Übergang zur Niederung hin. Eine an der Dünensüdseite entdeckte Holzbohle hat dendrochronologisch ein Fälldatum von „273 +/-10، n. Chr.“ Dies stellt die späteste naturwissenschaftliche Datierung der kaiserzeitlichen Siedlungsphase dar. Mit einem entgültigen Abbruch der Besiedlung ist in dem untersuchten Areal spätestens zu Beginn des 4. Jahrhunderts zu rechnen. Nur wenige völkerwanderungszeitliche Scherben gehören dieser Zeit an.

Nach einer Unterbrechung von etwa 500 Jahren erfolgte im 9. Jahrhundert n. Chr. eine Wiederbesiedlung der Nortmoorer Düne. Es fanden sich jedoch nur im östlichen Bereich der untersuchten Fläche frühmittelalterliche Siedlungsspuren. Nebenbauten, wie die Rutenberge SP 9, SP 14 und SP 15 sowie ein mit Pingsdorfer Keramik datierter Brunnen (B 4), gehörten ihr an. Zwei weitere mittelalterliche Brunnen fanden sich auf der Nordseite der Düne (B 3, B 9). Entdeckt wurden mittelalterliche Siedlungsgruben und zahlreiche Oberflächenfunde; Hinweise auf eine zugehörige Wohnbebauung fehlen jedoch. Möglicherweise befanden sich diese in dem bereits alt zerstörten Dünenareal.

Die mittelalterliche Siedlung auf der Nortmoorer Düne bestand vom 9. bis Ende des 11. Jahrhunderts, dann bricht die Besiedlung vollständig ab bzw. verlagert sich. Ihr Siedlungsmuster kann mangels Wohnbebauung anhand der weniger Befunde kaum beurteilt werden. Ob es sich um eine Gruppensiedlung oder um ein Einzelgehöft gehandelt hat, ist letztlich nicht mehr zu klären.

Das Ende dieser Besiedlungsphase ging mit großflächigen Überschwemmungen in der JümmeNiederung einher. Zahlreiche mittelalterliche Befunde waren in ihrem oberen Drittel mit einer Kleischicht überdeckt. Dies datiert eine der letzten landschaftsformenden Überflutungen im LedaJümme-Gebiet, die zur Aufgabe der Siedlung zwangen. In der mächtigen Sedimentablagerung waren Scherben einheimischer Kugeltopfware eingelagert. 


\section{Das frühmittelalterliche Gräberfeld Brinkum}

In den letzten 35 Jahren hat sich aufgrund intensiver Bautätigkeit die Gesamtzahl der archäologischen Fundstellen in Ostfriesland nahezu vervierfacht. Davon weitgehend ausgenommen sind jedoch frühmittelalterliche Besiedlungsspuren. Verschärft wird das Phänomen der sogenannten Siedlungslücke durch eine ungenügende Quellenlage. So setzen historische Schriftquellen über die Region der Unteren Ems erst um 800 ein. Die wenigen erhaltenen Quellen handeln von der Missionierung der heidnischen Friesen (Kap. 4.1). Schwierig ist in diesem Kontext auch die archäologische Quellenlage. Oft fehlen frühmittelalterliche Baubefunde oder diese sind nicht eindeutig als solche anzusprechen. Aussagekräftiges Fundmaterial aus Siedlungen ist selten. Meist erweist sich die aufgefundene Keramik feinchronologisch als unempfindlich (vgl. BÄRENFÄNGER 1999 d, 90, Abb. 36). Eine besondere Rolle spielen Importe und ihre Vergesellschaftung mit lokalen Funden. An erster Stelle zu nennen sind rheinländische Keramikgefäße, die im friesischen Raum im Sepulkralwesen als Urne oder Beigefäß Verwendung fanden. Daneben finden sich in Siedlungen nur geringe Mengen an zerscherbten Importgefäßen. Oft sind es nur wenige Scherben pingsdorfartiger oder Bardorfer Ware. Selten finden sich wie im Nortmoorer Hammrich nahezu intakte Gefäße.

Um einen bedeutenden Fundkomplex mit frühmittelalterlicher Importkeramik in Ostfriesland handelt es sich bei der Brinkumer Nekropole, die 5km nordöstlich von Leer liegt (Abb. 57). KLEEMANN berücksichtigte sie 2002 in seiner Dissertation Grabfunde des 8. und 9. Jahrhunderts im nördlichen Randgebiet des Karolingerreiches (KLEEMANN 2002, Kat.Nr. 96). Bei der Sichtung der Originalfunde im Landesmuseum Hannover im Rahmen der vorliegenden Studie zeigten sich jedoch diverse Abweichungen zu den von Kleemann publizierten Funden (KLEEMANn 2002, Taf. 33-35; KLEEMANN 1992 unpubl. Dissertationsdruck, Taf. 151-155). Die unvollständige Fundvorlage, sowie die zu hinterfragende Fundanalyse, führten zur Neuaufnahme des Fundkomplexes.

Aus Brinkum stammen neben vollständig erhaltenen Gefäßen auch Metallbeigaben, wie eine Lanzenspitze, Scheren, Laschenschnallen, u.a.m. Unter dem Leichenbrand fanden sich zwei Glasfragmente und mehrere goldüberzogene Perlrandnieten. Ergänzt wird das Repertoire der Beigaben aus Brinkum mit den Resten eines Knochenkammes und einer verzierten Knochenplatte. Die Restaurierungsarbeiten übernahm 2004 dankenswerterweise das Landesmuseum Hannover.

Der Fundkomplex besticht insgesamt durch seine Qualität und dem guten Erhaltungszustand der Funde, die seit 1906 im Landesmuseum Hannover aufbewahrt werden. Dies umfasst auch den überlieferten Leichenbrand, der 2005 anthropologisch durch Frau Dr. Birgit Großkopf vom Anthropologischen Institut der Universität Göttingen untersucht werden konnte. 
Die Quellenlage zu frühmittelalterlichen Gräberfeldern im Untersuchungsgebiet gilt als denkbar schlecht. Derzeit sind im Landkreis Leer, der immerhin eine Gesamtfläche von 1.085qkm umfasst, nur vier alt gegrabene Friedhöfe bekannt. Die Fundumstände sind meist unklar und viele der Funde gelten als verschollen.

Allein vom 1906 entdeckten Brinkumer Bestattungsplatz liegt eine detaillierte Beschreibung der Fundumstände in Form eines Briefwechsels mit dem Landesmuseum Hannover, dem Kreissekretär und dem Finder vor. Dies ermöglicht Aussagen zum Hügelaufbau, zur Bestattungsart und Fundzusammengehörigkeit, sowie in Ansätzen zur Rekonstruktion der Bestattungsfolge.

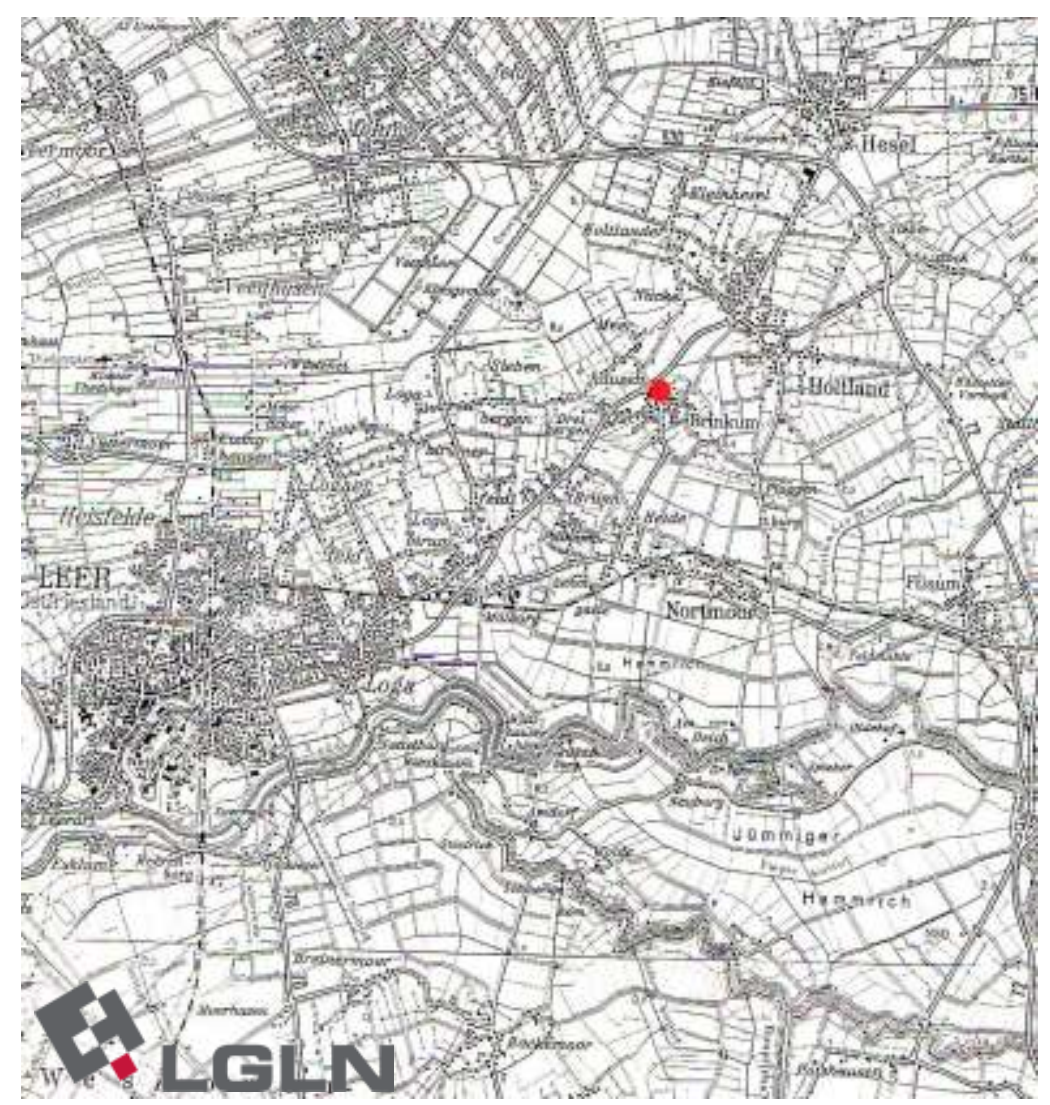

Abb. 57

Lage des Brinkumer Grabhügels

Die Bestattungen werden typologisch in das 7. und 8. Jahrhundert n. Chr. datiert. Soweit überliefert handelte es sich ausschließlich um Brandbestattungen, die in Urnen oder als Knochenlager in einem künstlich errichteten Hügel vorgenommen worden sind. Diese Bestattungsform ist kennzeichnend für das frühmittelalterliche Bestattungswesen in der von Friesen bewohnten Küstenregion der südlichen Nordsee. Größere gemischt belegte Brand- und Körpergräberfelder von der ostfriesischen Halbinsel liegen aus Dunum und Schortens vor. Die dortigen Brandbestattungen waren als Einzelgrab überhügelt oder wurden in Gruppen in Grabhügeln beigesetzt. Das kleine Gräberfeld von 
Schwittersum (Dornum) wies die ersten Gräber im 7. Jahrhundert auf, die übrigen Gefäße datieren in das 8. bis frühe 9. Jahrhundert (SCHWARZ (1999a, 174-177). Ein 1993 bei Filsum entdecktes Einzelgrab des 8. Jahrhunderts ist ein früher Beleg für das Einsetzen der Körperbestattung in Ostfriesland (KLEEMANN 2002, Kat.Nr. 96b). Der Fundort liegt nur etwa 1,5km östlich von Brinkum entfernt und wurde bei Grabungen entlang der Midal-Gastrasse entdeckt (Kat.Nr. 57; FStNr. 2711/6:049).

\subsection{Fundumstände}

Die Bedeutung der Brinkumer Nekropole für die ostfriesische Frühgeschichte, ihr guter Erhaltungszustand und die recht gute Quellenlage bezüglich der Fundsituation erlauben es näher auf die Fundumstände einzugehen; zumal letztere auch Hinweise auf den Hügelaufbau geben konnten. Dabei wurden Unterlagen des Denkmalamtes Hannover, des Staatsarchivs Aurich und der Stiftung Preußischer Kulturbesitz Berlin mit einbezogen. Aufschlussreich war insbesondere der aus der Zeit der Urnenbergung stammende Briefwechsel zwischen dem Kreissekretär Kuhn und dem Provinzialmuseum Hannover.

Zunächst beachtete man 1906 auf dem Grundstück „Kirchholz“ (auch „Lidde“ genannt), einem mit Kiefern bewachsenen Erdhügel nordöstlich der Ortschaft Brinkum, die bei Bodenarbeiten entdeckten Keramikscherben nicht.

Erst als der Landarbeiter Dodo Mansholt vollständige Tongefäße demDorflehrer in Heisfelde verkaufte, wurde das Landratsamt in Leer benachrichtigt, welches seinerseits das Provinzial-Museum Hannover informierte. Vermittelt durch den Kreissekretär Jan Kuhn gelang es einige Funde für das hannoversche Museum aufzukaufen.

Zwei Urnen mit Inhalt erhielt Kuhn direkt vom Ausgräber. Drei der fünf vorher veräußerten Urnen mit den drei zugehörigen Bronzegegenständen, erwarb Kuhn für 5 Reichsmark. Es gelang ihm auch eine bereits veräußerte eiserne Lanzenspitze, die leider rezent an beiden Längsseiten durch Schmiedefeuer beschädigt wurde, für die damals horrende Summe von 20 Reichsmark aufzukaufen.

Wie das Jahrbuch des Provinzial-Museums zu Hannover (1907, 15, 30) berichtete, erwarb das Provinzial-Museum Hannover aus dem Brinkumer Fundkomplex ,in etwa 12 zum Teil erheblich beschädigte Urnen nebst Beigaben “.

Bei der Sichtung des Fundkomplexes durch die Autorin waren 2004 im Landesmuseum Hannover acht Gefäße, vier Gefäßfragmente, drei Leichenbrände, ein Dreilagenkamm mit beinernem Kammetui, zwei Gürtelschnallen, zwei Scheren, ein Bronzeschlüssel, ein Feuerstahl, eine Lanzenspitze, zwei Messerbruchstïcke und diverse kleinteilige Metallfragmente inventarisiert. Zusätzlich fanden sich 2005 bei der anthropologischen Untersuchung des Brinkumer Leichenbrandes zwei Glasfragmente ( $1 \frac{2}{2}$ 
Glasperle und ein kleines Glasstück). Unter dem Leichenbrand verborgene Metallfragmente entpuppten sich bei einer Röntgenuntersuchung als Nietenfragmente. Bei der anschließenden Restaurierung konnte bei ihnen einen Goldüberzug freilegt werden.

Einer Aktennotiz zufolge soll auch das Emder Museum für Stadtgeschichte (Museum für ostfriesische Landesgeschichte) kurz nach der Bergung Keramikscherben aus Brinkum erhalten haben. Ihr Verbleib ist unbekannt, auch fehlen sie im Katalog der Emder Sammlungsbestände.

Da bei dem im Landesmuseum Hannover aufbewahrten Fundkomplex zerscherbtes Keramikmaterial, im Gegensatz zu den intakten Gefäßen, in der Minderzahl ist, kann von einer selektiven Auswahl beim Funderwerb ausgegangen werden.

\subsection{Forschungsgeschichte}

Die genaue Anzahl der in Brinkum entdeckten Funde ist nicht überliefert. In der Literatur wird sie mit 20-30 Töpfen angegeben ( BÄRENFÄNGER 1988, 351, Nr. 100; KLEEMANN 2002, Kat.Nr. 96).

Erhalten haben sich sechs komplette Töpfe, Gefäßreste von acht weiteren sowie Beigaben aus Metall und Knochenarbeiten. Als verschollen gelten das Bodenstück eines Pokalgefäßes, der als Urnendeckel verwendet wurde, eine geritzte Knochenplatte, eine Bronzekugel und ein Haken.

Die erste Erwähnung des Brinkumer Fundkomplexes erfolgte in der Weserzeitung vom 16.11.1906. In einer Urne fand man „eine große, stark verrostete Schere, einen eigenartigen Kamm von Horn und zwei schön verzierte Hornplatten. Ferner wurden gefunden in den Urnen, pechartige Erdstücke, die man für Steinkohlen halten könnte. Eine Urne war mit einem in eine abgestumpfte Spitze auslaufenden Deckel versehen.“

Auch in einem Briefwechsel 1906 von J. Kuhn mit dem damaligen Direktor des Provinzial-Museums Hannover, Dr. J. Reimers, wird erwähnt, dass ein Gefäß einen Knochenkamm, eine Eisenschere und ein „Stückchen einer leichten Masse, auf der leinenartige Abdrücke sind“ enthielt. Um was es sich bei dem letztgenannten Objekt handelte, ist nicht mehr zu klären; es fehlte 2005 unter den im Landesmuseum Hannover inventarisierten Funden.

Eine andere große Urne enthielt Knochenfragmente und eine mit eingeritzten Rauten verzierte rechteckige Knochenplatte. Letztere gilt heute als verschollen. Erstmalig publizierte KLEEMANN 2002 die Knochenplatte (KLEEMANN 2002, Tafel 35, 2). Ihm lag jedoch bei seiner Studie nicht mehr im Original vor, heute fehlt sie im Bestand des Landsmuseums Hannover. Ein Vergleich der Zeichnung mit dem Fundbucheintrag des Landesmuseums Hannover zeigte, dass es sich um eine Umzeichnung aus der Eintragung handelte. 
Auch eine Quelle im Staatsarchiv Aurich (Rep. 21a, 8214) berichtet von zwei beigabenführenden Urnen in Brinkum, wobei zusätzlich eine Lanzenspitze erwähnt wird. „In einer lagen formlose Eisenrestklumpen und daneben ein ca. $40 \mathrm{~cm}$ langes und $4 \mathrm{~cm}$ breites stark verrostetes Stück Eisen." Bei der Bergung brach das Fundstück in zwei Teile. Sein Finder, G. Düring, deutete das Objekt als Speerspitze, die ursprünglich mit einem hölzernen Stab versehen war, ,da sich in dem einen Teile dazu noch ein Höhlung befindet, der untere stärkere Teil ist 10 Zoll lang, der obere Teil ungefähr 9 Zoll, ist also ungefähr in der Mitte zerbrochen, die Spitze hat eine größte Breite von 1,1 Zoll, muss also ziemlich scharf gewesen sein, und in der Mitte einen stärkeren Rücken. “. Die Lanze wurde rezent beschädigt, als man kurz nach der Bergung beidseitig eine Spitze anschmiedete.

Laut dem Fundbuch des Landesmuseums Hannover von 1906 gehörten weitere Beigaben zum Brinkumer Fundkomplex. Erwähnt werden zwei eiserne Scheren, ein Schlüssel, zwei Knochenkämme und ein Gürtelhaken.

Erste skizzenhafte Fundzeichnungen der Brinkumer Funde wurden von ZYLMANN, dem Nestor der ostfriesischen Urgeschichte, publiziert (ZYLMANN 1933, 111, 113, 156, 184, Abb. 184-188). Bei den drehscheibengedrehten Gefäßen stellte ZYLMANN (1933, 113) eine Adaption an spätsächsische Warenarten fest, betonte jedoch zugleich den friesischen Einfluss, der in das 7. bis 8. Jahrhundert datierenden Töpfe.

1938 veröffentlichte Uenze einen Aufsatz zu frühmittelalterlichen Funden aus dem norddeutschen Küstengebiet, indem er u.a. auf die Brinkumer Nekropole einging. Erstmals wurden neun Brinkumer Gefäße als SW-Fotos reproduziert (UENZE 1938, 118-120, Abb. 1, 1-9). Heute verschollen ist der als Abdeckung verwendete schlanke Gefäßfuß (UENZE 1938, 119, Abb. 1,7). Die Vergesellschaftung sackförmiger Gefäße, wie sie aus Brinkum und Haddien vorliegen, mit rheinischen Importgefäßen diente dem Autor als Anfangsdatierung für die frühen Kugeltöpfe („,ächsische Kugeltöpfe“).

STEIN (1967) stellt in ihrer umfangreichen Publikation über Adelsgräber des 8. Jahrhunderts in Deutschland die frühmittelalterlichen Schwertfunde bei Leer, Stadt Leer und das Gräberfeld Dornum, Landkreis Norden vor. Der Brinkumer Friedhof bleibt unberücksichtigt. Dies ist insofern überraschend, da ihr die Arbeit von ZYLMANN bekannt war (STEIN 1967, 350). Grabfunde aus dem ostfriesischen Raum wurden von Stein nur vereinzelt berücksichtigt. Diese ,wurden hier nur soweit herangezogen, wie sie im Rahmen der angeschnittenen Probleme wichtig waren. ". Eine Fundaufnahme der friesischen Fundregion unterblieb. Dies vielleicht wohl auch, weil bekannte „sogenannte“ Adelsgräber mit Waffenbeigaben im friesischen Raum eine Ausnahme darstellen. 
SCHMID (1972) publizierte das frühmittelalterliche Gräberfeld Dunum. Die dortige Chronologie basierte auf eine Verbindung stratigraphischer Befunde mit datierten Importfunden, ein Bezug zu ostfriesischen Fundorten unterblieb.

Bereits 1969 kartierte SCHMID vor- und frühgeschichtliche Fundplätze nördlich der Jümme im Rahmen der archäologischen Landesaufnahme, in deren Zentrum die Gemarkungen Brinkum, Holtland und Logabirum standen (SCHMID 1969, Abb. 12). Deutlich zeichnete sich nordöstlich und südlich von Brinkum ein Schwerpunkt mittelalterlicher Funde ab. So waren bereits einige Jahre zuvor südlich der Brinkumer Nekropole die Überreste einer frühmittelalterlichen Siedlung entdeckt worden. REINHART $(1969,226)$ geht von einer Neuaufsiedlung der ostfriesischen Geest- und Marschgebiete aus und datiert die Brinkumer Funde in das. 8./9. Jahrhundert. Auf eine frühmittelalterliche Gründung weist der Ortsname Brinkum mit der Endung „-um“ (ehemals -heim; vgl. REINHART 1969, 228) hin. Auch bei einer späteren Studie zu friesischen Gräberfeldern und ihrer Importfunde in Bezug zur karolingischen und skandinavischen Sachkultur werden die Brinkumer Gräber nicht berücksichtigt (SCHMID 1986, 361-377; 1997).

Eine Neuaufnahme des Fundmaterials erfolgte 2004 durch die Autorin sowie die Fundrestaurierung durch das Landesmuseums Hannover. Dabei fanden sich zusätzliche Fundobjekte, die bisdato unbekannt waren: Ein Feuerstahl, zwei Messerschneiden und diverse Metallfragmente (u.a. Teile einer Gürtelgarnitur). Unter dem Leichenbrand fanden sich weitere Funde, so geschmolzenes Glas und kleinteilige Metallfragmente. Bei der Restaurierung der Metallfunde 2005 wurden vier goldüberzogene Halbkugelnieten freigelegt. Ferner haben sich einige Textilreste an der korrodierten Oberfläche einer Messerklinge erhalten. Vermutlich konservierten Metalloxide die anhaftenden Gewebereste und es drängt sich der Eindruck auf, dass die Messerschneide absichtlich in ein grob gewebtes Tuch eingewickelt worden war.

\subsection{Lage des Grabhügels}

Die Fundstelle des frühmittelalterlichen Gräberfeldes lag am nordöstlichen Rand der Gemarkungsgrenze von Brinkum und Holtland, etwa 400m vom alten Ortskern des Geestdorfes Brinkum entfernt, in dessen Zentrum eine der ältesten romanischen Kirchenbauten im ostfriesischen Raum steht. Die Flurbezeichnung „Kirchholz“ („Wald in Kirchenbesitz“) für den mit Kiefern bewachsenen Erdhügel (auch „Lidde“ genannt) deutet auf einen noch in der Neuzeit bekannten kirchlichen Bezug der Fundstelle hin.

Auf eine Fortsetzung des Gräberfeldes auf einem benachbarten Grundstück verweist eine Notiz in den Akten des Landesdenkmalamt Hannover. Unter „Brinkum“, Landkreis Leer ist folgendes abgelegt: „Urnen wurden beim Roden eines jungen Tannenbestandes gefunden. - Auf dem benachbarten 
Grundstück sind vor einigen Jahren Urnen in ca. 20cm Tiefe gefunden, welche das Prov. Museum erhalten hat. Waten sammelt die Urnen und bewahrt sie gut auf bis die Rodung vorbei ist - dann bekommt sie das Prov. Museum. R. (Reimers) “. Der Grundstücksbesitzer H. Watens fand nach 1906 weitere Urnen, davon behielt er ein vollständig erhaltenes flaschenförmiges Tongefäß. Vom Gefäßhals abwärts bis zum Bauchumbruch war der Topf mit einem dreizonigen Band (Linien umgrenzen hängende Dreiecke) verziert. Sowohl Maße wie Fundverbleib sind unbekannt.

Brinkum liegt auf der zentralen ostfriesischen Geest, die im Ort eine Höhe von maximal +7,8m NN aufweist und als Wasserscheide zwischen Jümme und Ems fungiert. Zur Niederung des Nortmoorer Hammrichs fällt das Gelände bis auf $-0,5 \mathrm{~m}$ NN ab.

Die Karte von Le Coq weist im Jahr 1805 für Brinkum insgesamt sechs Hofstellen auf. Zudem verzeichnet sie nördlich, nordöstlich und südlich von Brinkum kleinere punktierte Areale (Abb. 58). Vermutlich handelte es sich hierbei um landwirtschaftlich nicht nutzbare Geest- bzw. Heideböden. Sowohl nordöstlich wie auch südöstlich der Ortschaft wird ein lockerer Baumbewuchs ausgewiesen, der sich bis auf den 1906 entdeckten Bestattungsplatz „Lidde“ erstreckt.

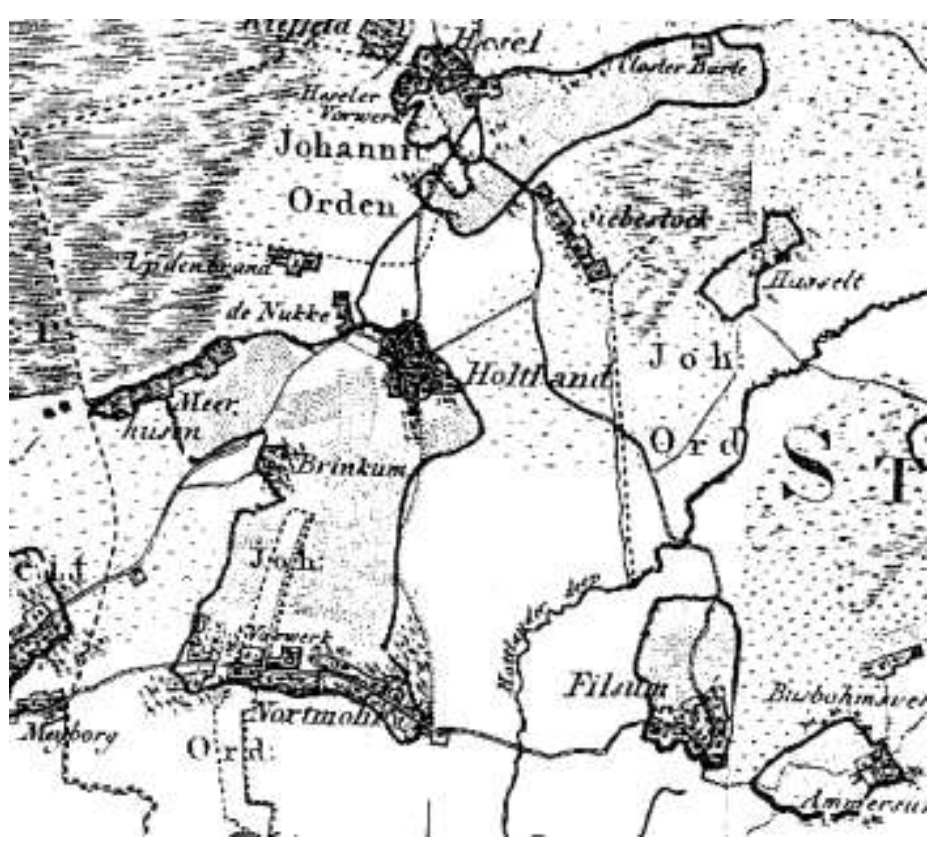

Abb. 58

Brinkum in der Karte von Le Coq 1805

Die Preußische Landesaufnahme von 1898 kartierte recht präzise die topographische Geländesituation im südlichen Ostfriesland. In der Brinkumer Gemarkung herrschte demnach eine unregelmäßige Blockparzellierung vor, die sich radial um das Haufendorf Brinkum mit 18 Hofstellen anordnete (Abb. 59). Für das nördlichste Ende der Brinkumer Flur zeichnete sich eine halbkreisförmige und mit 
Bäumen bewachsene Parzelle ab. Dort fand sich eine längliche 7x15m große Bodenerhebung, die sich landschaftlich so unauffällig einfügte, dass sie nicht als künstlicher Auftrag erkannt wurde. Die etwa +7,6m NN Höhe liegende Stelle markiert den erst beim Abtrag entdeckten Grabhügel.

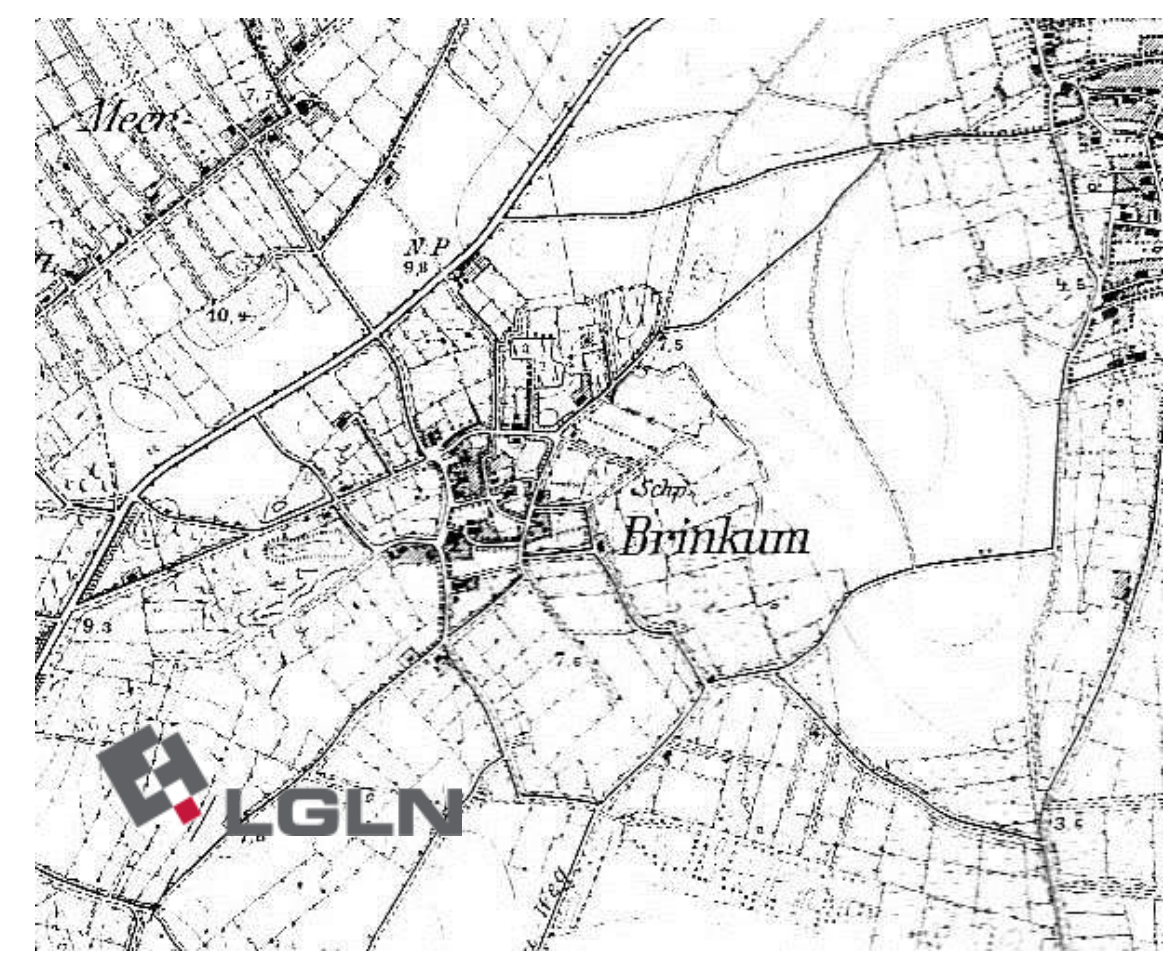

Abb. 59

Die Ortschaft Brinkum in der Preußischen Landesaufnahme von 1898

In die Karten der preußischen Landesvermessung wurden im Regelfall auch anthropogen geschaffene Bodenerhebungen, soweit sie den Vermessungstechnikern als solche ersichtlich waren, aufgenommen. Bestes Beispiel sind hierfür die nordöstlich und südwestlich von Brinkum in einem damals bewaldeten Gebiet befindlichen bronzezeitlichen Hügelgräber.

\subsection{Naturräumliche Verhältnisse}

Brinkum liegt auf einem zur Staunässe neigenden lehmigen Sandboden der ostfriesischen Geest. Das Ausgangsmaterial der Bodenbildung bildet Geschiebedecksand über Geschiebelehm. Vorherrschend sind Pseudogley-Braunerden, Plaggenesch und örtliche Pseudogleye. Nördlich der Holtländer Nücke bis nach Neuefehn erstrecken sich grundwasserbeeinflusste Sandböden. Östlich von Brinkum liegen lehmige und oft staunasse Sandböden vor, die südlich von Logabirum in wasserdurchlässige Tonböden und Moorböden übergehen. Die Holtlander Nücke entwässert westlich von Brinkum in die Ems; die Holtlander Ehe in die Jümme.

Die Geestgebiete des Oldenburgischen Geestrücken zwischen Leer und Hesel waren bis ins 18. Jahrhundert durch Hochmoore zergliedert. Nordwestlich von Brinkum liegende Fehnorte, wie 
Warsingfehn, Jhringsfehn und Neukamperfehn weisen auf neuzeitliche Moorkultivierungen hin. Ausgedehnte Moorgebiete dehnten sich Anfang des 20. Jahrhunderts noch von Detern bis zum Stapelermoor aus und bildeten eine natürliche Grenze zum Oldenburger Land. Übergangsmoor, also Niedermoor mit Hochmoortorfdecke, ging in Grundwasser beeinflusste Sandböden bei Hesel, Hasselt, Remels und Großoldendorf über.

\subsection{Fundbergung}

Bis zur Veräußerung des sich zuletzt in Kirchenbesitz befundenen Flurgrundstückes „Lidde“ nutzte man das Areal des frühmittelalterlichen Friedhofes in Brinkum als Gemeindeweide.

Erst die Kultivierung des ehemaligen Kirchenlandes durch den neuen Besitzer Dodo Mansholt hatte 1906 umfangreiche Bodeneingriffe und schließlich den kompletten Abtrag des Grabmonumentes zur Folge. Recht bald entdeckte D. Mansholt erste Urnen, die er samt Inhalt an einen Lehrer in Heisefeld veräußerte. Unter Anleitung des Kreissekretärs Jan Kuhn gelang es, die Gefäße weitgehend intakt zu bergen. Dies war unter anderem einer damals noch bestehenden Schmalspurbahn zu verdanken, die die Kreisstadt Leer mit Brinkum verband und so häufige Besuche des Kreissekretärs vor Ort ermöglichte. Berichte über Funde und Fundumstände, basierend auf Beobachtungen der Ausgräber, liegen als Korrespondenz des Kreisamtes Leer mit dem Provinzial-Museum Hannover vor. Demzufolge wurden erste Gefäßfragmente am 22.10.1906 geborgen und bereits knapp drei Wochen später, am 11.11.1906, war der Hügel vollständig abgetragen.

Nachdem die Bedeutung der Fundstelle erkannt war, suchte man mit großer Umsicht im Erdhügel nach Funden und barg die entdeckten Gefäße in-situ. Diese Vorgehensweise begünstigte die Erhaltung der fragilen Metall- und Knochenfunde und bewahrte letztlich den Fundzusammenhang. Für die keramischen Gefäße jedoch war der Hügelbewuchs mit tiefwurzelnden Kiefern nachteilig, die seit dem 18. Jahrhundert in Folge fortschreitender Bodendesertifikation und sich ausbreitender Heideflächen in der Region angepflanzt wurden.

Ungewöhnlich war bei der laienhaften Ausgrabung, für damalige Verhältnisse, die sorgfältige Fundbergung. Vermutlich kann dies als Folge der Mitte des 19. Jahrhunderts verstärkt einsetzenden Heimatforschung in Ostfriesland gesehen werden. So hatte sich bereits 1879 TERGAST intensiv den ostfriesischen Altertümern gewidmet und integrierte das heimische Fundmaterial in die Stufengliederung von MOMMSEN (1863). Insbesondere die ausführliche Erläuterung zur archäologischen Fundbergung, teilweise bebildert, erläuterte anschaulich die in-situ Bergung von Funden.

Aufgrund des allgemeinen Interesses erfolgte 1907 am Brinkumer Hügel eine Nachgrabung bei der man weiteres, jedoch stark zerscherbtes, Material auffand. Hierzu gehörte ein mit Dreiecksstempeln verziertes Gefäß. Die scheibengedrehten Keramikgefäße datieren den Urnenfriedhof in die spätsächsische Zeit. 


\subsubsection{Hügelaufbau}

Vor Beginn der Abgrabung wies der 6-7m x 12m große Grabhügel noch eine Höhe von 1-1,5m auf. Wie sich bald zeigte, war der Hügel direkt auf dem Heideboden errichtet worden und bestand aus humoser Erde, deren Humusgehalt für den anstehenden Geestuntergrund untypisch hoch war. Im Auftragsboden fanden sich weder Leichenbrand noch Holzkohle, auch Steinpackungen oder ähnliches wurden nicht beobachtet. Da ein Sieben des Erdabtrages ausblieb, ist es nicht auszuschließen, dass kleinere Objekte infolge des zügigen Bodenabtrages übersehen wurden.

In der Hügelostseite entdeckte man in einer Tiefe von $50-60 \mathrm{~cm}$ die ersten Gefäße. Man fand scheibengedrehte und handgefertigte Keramikgefäße, wobei vorwiegend die scheibengedrehten Töpfe Leichenbrand, Beigaben und Trachtbestandteile enthielten.

In dem bald halb abgetragenen Hügel entdeckte man in einem unversehrten Gefäß einen ,,eigenartigen Schlüssel und eine seltsam geformte Schere, sowie Knochenreste“ (Zitat J. Kuhn 1906). Das Jahrbuch des Provinzialmuseums Hannover (Jahrbuch Hannover 1907, 30) berichtet weiter, dass es sich hierbei um eine scheibengedrehte und mit Wellenlinien verzierten Urne handelte. Die Beigaben waren mit Leichenbrand bedeckt (Objekt 2 (Schere), Inv.Nr. 16859; L 10,5x2cm; Objekt 3 (Bronzeschlüssel) Inv.Nr. 16860; L 5cm).

An dem Bronzeschlüssel befand sich eine kleine Bronzekugel, die mit einem Haken befestigt war (Emder Zeitung vom 06.11.1906). Bronzekugel und Haken gelten als verschollen. Es ist zu vermuten, dass sie direkt nach der Bergung entnommen worden sind, da das Inventarbuch des Landesmuseum Hannover sie nicht aufführt. Im nördlichen Drittel entdeckte man bis zum endgültigen Abtrag des Bodendenkmals vier weitere Gefäße. Eine große Urne wurde in-situ geborgen und zu einem späteren Zeitpunkt untersucht.

Bei einer Nachgrabung, kurz nach dem völligen Einebnen des Hügels, fand sich ein kleiner handgefertigter Topf, der mit einem umgedrehten Pokalfußfragment bedeckt war. Beigegeben waren der Urne eine eiserne Schere, ein reich verzierter Knochenkamm sowie einige pechartige Erdstücke mit Leineneindrücken (Jahrbuch des Landesmuseums Hannover 1907, 30).

\subsection{Brinkumer Funde}

\subsubsection{Keramikgefäße}

Taf. $60-70$

Die erhaltenen 10 Keramikgefäße bzw. -fragmente liegen in scheibengedrehten, härter gebrannten Töpfen von hellgelben bis braungelben Ton und in handgefertigten, weniger hart gebrannten Töpfen von dunkelgrauschwarzen bis graubraunem Ton vor.

Die Magerung besteht aus einem Zusatz von Quarzsand, der in unterschiedlichen Mengen zugegeben wurde. Die scheibengedrehten Gefäße sind relativ fein gemagert, während die Freihand ausgeformten 
eine bis zu >2mm grobe Körnung aufweisen. Möglicherweise liegt dies darin begründet, das bei der Keramikproduktion fetter Ton verwendet wurde und somit eine künstliche Magerung mit Quarzsand bzw. größeren Brocken notwendig wurde (ORKUSCH u. a. 1986, 171).

Muschelgrus gemagerte Keramik fehlt unter dem Brinkumer Material. Neben der Möglichkeit, dass es sich bei der vorliegenden Keramik um eine selektive Auswahl hinsichtlich der Funktion handelte, kann die fehlende Kalkmagerung als Indiz dafür genommen werden, dass diese Magerungsart erst nach dem Auflassen der Brinkumer Nekropole aufgekommen ist.

Die als Importware angesprochenen Tongefäße sind hart gebrannt und auf der schnell rotierenden Drehscheibe hergestellt. Die Magerung besteht bei den Importgefäßen aus feinem Sand. Lediglich ein Gefäß weist grobe Magerungsbestandteile von bis zu 1,5mm auf.

Die Drehscheibengefäße weisen meist eine stark gebauchte Kubatur auf und besitzen einen kurzen, nach außen abknickenden gerundeten Rand. Es überwiegen kugelige Formen mit sehr flacher Schulter und gewölbtem Umbruch (Inv.Nr. 16858; 16861; 16866; 16877). Der Gefäßumbruch befindet sich mit einer Ausnahme (Inv.Nr. 16861) im oberen Drittel. Daneben kommen schlanke Topfformen mit steiler Schulter und nur leicht konvexem Unterteil vor (Inv.Nr. 16864, 16881).

Die Bodengestaltung ist bei den Importtöpfen vielfältig. Neben sogenannten Linsenböden (Inv.Nr. 16877) kommen leicht konvexe (Inv.Nr. 16861) oder flache Böden vor (Inv.Nr. 16881; 16866). Zwei Gefäße verfügen über leicht abgesetzte Böden (Inv.Nr. 16876; 16864).

Für die Entwicklung frühmittelalterlicher Keramik in Ostfriesland von besonderem Interesse sind die freihandgefertigten Keramikgefäße aus Brinkum, da sie vermutlich lokal produziert wurden. Es handelt sich zumeist um engmündige Töpfe mit tiefem Umbruch und stark gewölbter Wandung (Inv.Nr. 16868, 16875a, 16875b). In einem Fall war ein senkrechter, kaum abgesetzter Rand erhalten; die übrigen Gefäße waren unterhalb der Halspartie oder maximal bis in Höhe des Bauchumbruches erhalten.

Gefäß 8 (Inv.Nr. 16868), ein engmündiger Topf, weist Parallelen mit einem Gefäß aus BremenMahndorf (Grab 17) auf (GROHNE 1953, Abb. 74). Beide zeichnet eine gedrungene Gefäßform mit kugeliger Gestalt aus, wobei der Topf recht hart gebrannt ist. Die Gefäße sind kaum gegliedert. Übereinstimmungen finden sich mit Töpfen aus Liebenau. Bei dem dortigen Gefäßtyp H 11 überwiegt ein gestreckter Umbruch und ein bauchiges bis gestrecktes Unterteil (SCHLICKSBIER 2003, 76, Abb. 32), der zumeist bei weitmündigen Töpfen vorliegt. Eine Ausnahme stellt der dem Brinkumer Gefäß ähnliche LNR 243 dar, der in seiner Kubatur eher schlank wirkt und der GF H 11c angehört. Während die wenigen diesem Typen zugeordneten Töpfe in Liebenau in die 2. Hälfte des 4. bis 1. Hälfte des 5 . Jahrhunderts datiert werden, sind die schlichten Gefäßformen bis in die 2. Hälfte des 6. Jahrhunderts belegt (SCHLICKSBIER 2003, 122, Tab. 12). Es handelt sich hier, zusammen mit den Gefäßtypen H 1 
bis H 3 und H 11 bis H 13, um die langlebigsten Formen, die in Liebenau auftreten. Die hohen Töpfe und Schalen reichen zeitlich noch bis in die erste Hälfte des 7. Jahrhunderts (SCHLICKSBIER 2003, 132).

Von Gefäß 5 (Objekt 5; Inv.Nr. 16863) ist lediglich das bauchige Gefäßunterteil mit dem zugehörigen Flachboden erhalten. Ungewöhnlich ist bei dem freihandgefertigten Gefäß die aufwendige Verzierungszone oberhalb des Gefäßumbruches. Der wohl engmündige Topf besitzt wenigstens zwei Reihen dreieckiger Stempeleindrücke, die die Wandung umlaufend überziehen und einzeln nebeneinander in den feuchten Ton eingedrückt wurden. Die Einzelverzierung setzt sich aus einer Vielzahl des Hauptmotivs, eines umgedrehten Dreiecks, zusammen. Ein aus Dunum (Grab 573) stammendes Gefäß ist in gleicher Art mit gegitterten Dreiecksstempeln verziert (SCHMID 1972, Abb. $6.3)$.

Die gleichmäßig kugelige Kubatur ähnelt dem Liebenauer Topf LNR 209, der in die GF 12c einzuordnen ist (SCHLICKSBIER 2003, 188, LNR 209). Wie dieser besitzt das Brinkumer Gefäß einen relativ zentralen Umbruch und ein einziehendes Oberteil. In Liebenau treten auf der Schulter mit umlaufenden Rillen verzierte Töpfe dieses Typs Ende des 5. bzw. in der ersten Hälfte des 6. Jahrhunderts auf (SCHLICKSBIER 2003, 106). Die Stempelverzierung des Brinkumer Exemplars ist recht ungewöhnlich, da sie auf einem lokalen freihandgeformten Gefäß angebracht ist. Derartige Verzierungen findet man ansonsten bei scheibengedrehten Töpfen, die in der Regel importiert wurden. In Liebenau dominieren bei den freihandgeformten Gefäßen schlicht anmutende horizontal angeordnete Rillen auf der Schulter, während der Umbruch meist etwas variantenreicher mit hängenden/stehenden Bögen, Dellen und Stempeln verziert ist. Gefäße der Varianten H 1 bis H 4 und H 11 bis H 13 sind eher selten verziert (SCHLICKSBIER 2003, 134). Einzelstempel finden sich hingegen bei engmündigen Töpfen der Gefäßvarianten H 18a und H 19a, die in ihrer stark gebauchten Kubatur deutlich mehrgliedrig sind und auf Gefäßen des 5.-6. Jahrhunderts vorkommen (SCHLICKSBIER 2003, 127). Laut Katalog Liebenau ist LNR 1182 oberhalb des Umbruches mit einem unregelmäßig verteilten Gitterstempel verziert. Zwar handelt es sich um einen quadratischen Stempel, der jedoch ebenso wie die bei dem Brinkumer Exemplar aus kleinen Einzeleinstichen besteht, in diesem Fall um Quadrate. Das dem GF Typ D 4a zugeordnete Gefäß gehört zur Gruppe der „burgundischen“ Drehscheibengefäße. Gefäße der Gruppe D 4 datieren in Liebenau in das Ende des 5. bis Anfang des 7. Jahrhunderts (SCHLICKSBIER 2003, 137).

Nur rudimentär erhalten ist das Bodenfragment eines anderen Topfes (Objekt 14; Inv.Nr. 16876). Von dem recht steilwandigen Gefäß sind das untere Gefäßdrittel und der leicht abgesetzte Flachboden überliefert. Daher kann eine Ansprache nur unter Vorbehalt erfolgen. Die Gefäßform deutet jedoch darauf hin, dass es sich möglicherweise um eine Schale ähnlich LNR 370 gehandelt haben könnte. Das eventuell dem Gefäßtyp H 12b zugehörige Fragment bezeichnet weitmündige kugelige Töpfe mit 
deutlichem zentralen Umbruch und einem einziehenden Oberteil. Kennzeichnend ist ihre eher hohe Gestalt und der mehr oder weniger ausgebildete Standboden (SCHLICKSBIER 2003, 106). In Liebenau sind von der Variante nur zwei Gefäße bekannt, wovon eines aus einem undatierten Brandgrab stammt. Eine Datierung wird über die Vergesellschaftung mit einem Drehscheibengefäß der Gruppe D 3a in die zweite Hälfte des 5. bzw. Anfang des 6. Jahrhunderts vorgenommen. Zu steilwandigen Töpfen dieser Form gehören zwei Bodenfragmente aus Brinkum (Inv.Nr. 16875a u. b).

Mit Ausnahme von zwei Urnen (Inv.Nr. 16864; 16881) handelt es sich bei der Drehscheibenware in Brinkum um weitmündige Töpfe mit einem zentralen, oft stark gewölbten Umbruch, einem bauchigen Unterteil und einem betonten Rand.

Derartige Gefäße finden sich u.a. in Schwittersum, Schortens, Dunum und in Leer (Westfalen), wobei sich ein Fundschwerpunkt in der Provinz Groningen abzeichnet (KLEEMANN 2002, 161). Doch während in Liebenau der Anteil an drehscheibengedrehten Gefäßen gerade einmal 6\% ausmacht (SCHLICKSBIER 2003, 152), ist das Verhältnis in Brinkum zwischen den Warenarten annähernd ausgewogen. Die große Variationsbreite der Brinkumer Importware fällt zudem auf. Sie reicht von Walsumer Töpfen, zu Geseker Ware und rheinischen Importen. In Dunum, wie auch in Liebenau, ist bei Drehscheibenkeramik die Variationsbreite der Warenarten wesentlich geringer als bei der freihandgeformten Keramik (SCHMID 1972b; SCHLICKSBIER 2003, 81).

Gefäße mit Linsenboden/Wackelboden gehören zum Repertoire einer Vielzahl von Gräberfeldern, aber auch hier fällt für die kleine Nekropole Brinkum ihr insgesamt höherer Anteil auf. Zwar existiert nur ein komplettes Gefäß mit Linsenboden in Brinkum, es liegen jedoch Bodenscherben von wenigstens vier weiteren Gefäßen mit Wackelboden vor, der ein Stehen auf geraden Böden verhindert.

Das Gefäß mit Linsenboden ist sehr hart gebrannt und von rot-braunem Ton (Inv.Nr. 16877). Ein feiner hellbrauner Tonschlicker überzieht die Gefäßoberfläche. Charakteristisch ist der kurze ausbiegende Rand mit seiner gerundeten Randlippe und die stark s-förmige Gefäßprofilierung. Beide Merkmale finden sich auch bei den Wölbwandtöpfen vom Geseker Typ. Der niedrige Topf aus Drantum, Landkreis Cloppenburg stellt einen der ältesten Importgefäßfunde aus dem Frühmittelalter in Nordwestdeutschland dar. Ebenso wie das größere Exemplar aus Brinkum besitzt der nur 12,4cm große Topf einen hochliegenden Bauchumbruch, einen kurzen umbiegenden Rand und einen Linsenboden (Вотн 1999, 193, Abb. 5). Der in das späte 6. - 7. Jahrhundert datierte Topf aus dem Gräberfeld in Geseke (ZOLLER 1965) stellt aufgrund seines Wackelbodens eine frühe Adaption an den Geschmack der norddeutschen Abnehmer der in Mayen produzierten Töpfe dar (TISCHLER 1954, 84). Von den Proportionen her weist das Brinkumer Gefäß noch Übereinstimmungen mit dem Liebenauer Typ D 5b auf, der jedoch im Unterschied zu diesem einen lang ausgezogenen Rand besitzt (SCHLICKSBIER 2003, Abb. 33). Linsenböden sind an 43 von 473 klassifizierbaren Böden in Liebenau 
festgestellt worden und können mehr oder weniger stark ausgeprägt sein (SCHLICKSBIER 2003, 24, $45)$.

In Brinkum überwiegen flache Böden, nur zwei Exemplare sind abgesetzt (Inv.Nr. 16864, 16876). Zwei Gefäße besitzen einen Linsenboden (Inv.Nr. 16861, 16877). In Liebenau dominieren ebenfalls flache Böden, gefolgt von Linsenböden und schwach nach innen gewölbten Böden (SCHLICKSBIER 2003, 45).

Handhaben finden sich in Brinkum an zwei Amphoren. In beiden Fällen handelt es sich um randständige Bandhenkel, die antithetisch angebracht waren (Inv.Nr. 16861, 16858). In Liebenau sind 4,6\% der Gefäße mit Handhaben versehen (SCHLICKSBIER 2003, 45). Unter den bekannten 42 Handhaben überwiegen Griffknubben vor Henkeln, nur einmal wurde eine Griffleiste beobachtet.

Verzierungen sind generell selten bei freihandgefertigten Gefäßen. Lediglich ein Brinkumer Topf ist oberhalb des Gefäßumbruchs mit dreieckigen Einzelstempeln dekoriert (Inv.Nr. 16863). Ob die Verzierung sich bis in die Halszone erstreckte, ist unbekannt. Vollständig schmucklos ist der einzige komplett erhaltene freihandgefertigte Topf (Inv.Nr. 16868). Eine relativ dünnwandige Wandungsscherbe weist den Ansatz eines Wellenmusters und eines spitzwinkligen Dreiecks auf (Inv.Nr. 16875). Die übrigen Wandungsscherben sind unverziert.

Drehscheibenware ist meist schmucklos, sieht man von mehr oder weniger kräftigen Drehrillen ab. Bei der hartgebrannten Ware liegen nur in einem Fall umlaufende Zickzacklinien vor (Inv.Nr. 16858). Wohl als Dekor anzusprechen sind die im oberen Gefäßteil eng geführten Drehrillen bei einem Topf (Inv.Nr. 16861), wie auch die recht breit ausgeformten Drehrillen bei einem anderen (Inv.Nr. 16876). Flächig mit Drehrillen überzogen ist ein Topf aus Walsum (Inv.Nr. 16881) und ein ihm ähnliches Bodenstïck (Inv.Nr. 16884).

Einen hohen Wölbrandtopf mit Wellenbandmuster verziert findet man in Dunum (Grab 57). Das drehscheibengedrehte Importgefäß diente als Urne. Seine Beigaben (u.a. Knochenkamm, Messer, Pinzette) legen eine Datierung in die 2. Hälfte des 8. Jahrhunderts nahe (SCHMID 1970, 61-62, Tafel 2). Weitere scheibengedrehte Amphoren finden sich im ostfriesischen Schwittersum (SCHWARZ 1982, 78) und im westfälischen Bochum-Langendreer (KLEEMANN 2002, 160-161).

Um einen Walsumer Topf handelt es sich bei Objekt 15 (Inv.Nr. 16881). Das Tongefäß weist den typischen hellgrau-weißlichen Ton auf, dünnwandig auf der Drehscheibe hergestellt und hart gebrannt. Die Oberfläche ist im unteren Gefäßteil verstrichen. Grobe Drehrillen findet man an der Gefäßinnenseite. Die Randlippe biegt spitz nach außen aus und geht in einen kurzen schwach sförmigen Hals über. Der Brinkumer Topf zeichnet sich durch einen flachen Standboden aus. Vom namensgebenden Fundort Walsum stammen hingegen Gefäße mit gerundeter unregelmäßiger 
Standfläche, die durch Abschneiden der Bodenkante entstehen, wobei die Schnittpunkte am Gefäß erkennbar sind (STAMPFUß 1939, 42). Feine Drehrillen überziehen enggezogen den oberen Gefäßteil. Die bei Walsumer Gefäßen beobachteten Wellenlinien fehlen hingegen. Der engmündige Topf ist ohne Henkel ausgestattet und deshalb nicht der Gruppe der Amphoren zuzurechen. Aufgrund seiner Machart ist er als Importgefäß dem niederrheinischen Raum zuzuordnen. Von dem in der Urne enthaltenen LB haben sich 300 Gramm erhalten. Zugehörige Beigaben sind eine Bronzeschnalle (Inv.Nr. 16882), ein Messer (Inv.Nr. 16883 (a)), ein stark korrodiertes Metallfragment (Inv.Nr. 16883 (b)), line einzelne Niete (Inv.Nr. 16886 (a)) und sechs Nieten, die zu Dreiergruppen zusammengesetzt sind (Inv.Nr. 16883 (b-2; b-3)).

Eine doppelkonische Urne aus Schwittersum zeigt deutliche Drehrillen auf der Gefäßaußenseite und ist von gelber Tonfarbe. Im Unterschied zu dem Brinkumer Stück ist der Boden leicht konvex und die Randlippe rechtwinklig ausgestellt (SCHWARZ 1990, 226, Taf. 16-172).

Die frühe lokale ostfriesische Keramik wird geprägt durch relativ kleine Töpfe mit einem im oberen Gefäßdrittel liegenden Umbruch und einem fast senkrecht stehenden Rand. Um ein solches Exemplar handelt es sich bei Objekt 9 (Inv.Nr. 16868). Seine Randform entspricht Stilke RF 1, wie sie von Muschelgrus gemagerten Gefäßen aus der frühstädtischen Siedlung Emden bekannt sind (STILKE 1995, 60, Tab. 6a).

Da aus dem ostfriesischen Frühmittelalter nur wenige geschlossene Keramikbefunde vorliegen stellt die Ansprache, bzw. die zeitliche Tiefe der lokalen Keramikentwicklung, vor größeren Herausforderungen. Wie der Fund von sogenannten Eitöpfen bei Esens im Landkreis Wittmund zeigt, stellen plumpe, leicht bauchige Töpfe mit wenig ausbiegender Randlippe die bevorzugte Gefäßform dar (BÄRENFÄNGER 1998g, 75-76).

Die Kombination von hochwertiger Importkeramik mit einheimischen Gefäßen und datierenden Beigaben ermöglicht über das Gräberfeld Brinkum hinaus eine Ansprache frühmittelalterlicher Fundkomplexe in Ostfriesland vorzunehmen. Durch Töpfe vom Typ Geseke kann der Belegungsbeginn des Brinkumer Gräberfeldes ins späte 6. und 7. Jahrhundert datiert werden. Walsumer Ware tritt ab dem Ende des 7. Jahrhunderts auf; mache Formen gehören in das 3. Viertel des 8. Jahrhunderts. Die am Niederrhein produzierte Importkeramik wird als ein Beleg für den intensivierten Nordseeküstenhandel angesehen (SCHMID 1997, 29).

Insgesamt finden sich in Brinkum niedrige Töpfe für die, gemeinsam mit den Beigaben, eine Datierung in die Stufe I (670/80 - 700/10) und II (700/10/ - 730/40) nach KLEEMANN (2002) wahrscheinlich ist. Es gibt jedoch auch Hinweise auf einen früheren Belegungsbeginn des Gräberfeldes. So den antiquiert wirkenden einzigen verzierten lokalen Topf (Inv.Nr. 16863). Der Gefäßumbruch ist mit dreieckigen Eindrücken, die wiederum ein zweireihiges Dreiecksmuster bilden, bedeckt (Abb. 60). 
Eine vergleichbare Verzierung findet sich auch an wenigen Urnen aus Dunum, die in das frühe 6. Jahrhundert datieren. Auch in Liebenau stellen kugelige Gefäße vom Typ H 12 c eine bekannte Grabkeramik der 2. Hälfte des 5. bis Mitte des 6. Jahrhunderts dar (SCHLICKSBIER 2003, 188, 192, Fdnr. 211, 686).

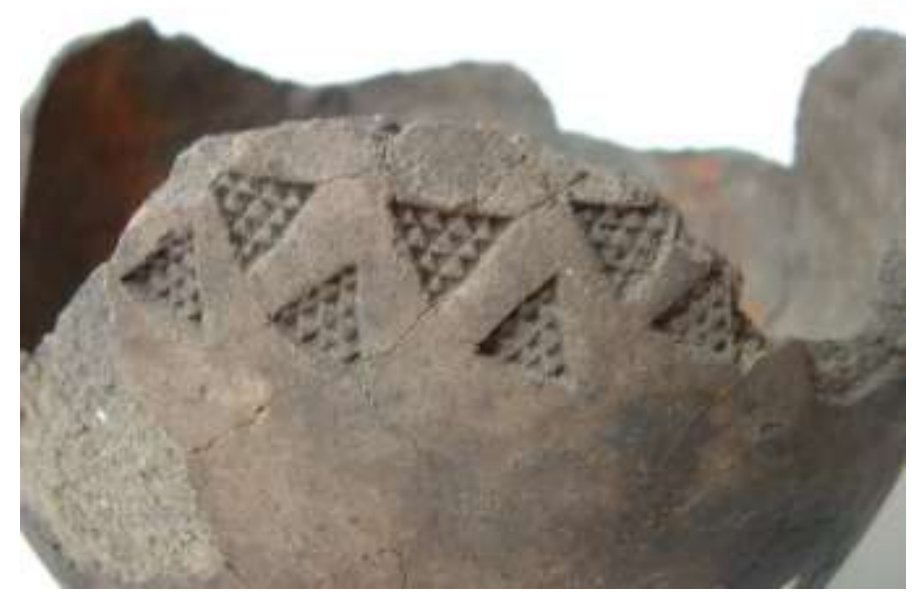

Abb. 60

Detailfoto des mit Dreiecksstempeln verzierten Gefäßes

Unter der aus Esens aufgefundenen Siedlungskeramik ist nur der kleinste Topf (H: $26 \mathrm{~cm})$ in seiner Kubatur mit den handgefertigten Töpfen in Brinkum zu vergleichen. Verwandt sind die gewölbte Gefäßwandung und ein senkrechter Gefäßrand; wobei der erhaltene Brinkumer Gefäßrand (Inv.Nr. 16868) stärker abgesetzt erscheint. Die Esener Eitöpfe sind jedoch insgesamt bedeutend gröber gearbeitet und weisen einen mehr oder weniger ausgeprägten Wackelboden auf. Nach dendrochronologischen Ergebnissen datieren die Esener Eitöpfe in das 7. Jahrhundert. Erst nach 700 wurden die Gefäßränder mehr vom Gefäßkörper abgesetzt.

Möglicherweise kann Gefäß Inv.Nr. 16866 als ein Vorläufer der sogenannten „weichen Grauware“ betrachtet werden. Seine gekehlte Randform findet eine Fortsetzung in Stilke Typ 3 (STILKE 1995, 113, Abb. 41). Ränder dieses Typs kommen in der Entwicklung des Emder Geschirrs ab dem 10. Jahrhundert vor.

Das Fehlen von Bardorfer Ware kennzeichnet die Aufgabe der Brinkumer Begräbnisstätte. Der Beginn dieser Ware wird um die Wende des 8. / 9. Jahrhunderts gesetzt. Begründet werden kann diese Datierung durch die Fundvergesellschaftung in einer Abfallgrube des Bonner Münsters, wo Bardorfer Ware zusammen mit einer Münze Ludwig des Frommen (814-840) gefunden wurde (HuSsONG 1944, 186 ff). Die Ablösung der Bardorfer Ware durch Pingsdorfer Keramik erfolgte um die Mitte des 9. Jahrhunderts (TISCHLER 1950, 215). 
Niederrheinische Nachahmungen imitieren u.a. Bardorfer Ware. Sie sind von dieser äußerlich kaum zu unterscheiden; möglicherweise liegt dies in dem lokal verwendeten Ton begründet (TISCHLER 1952, 196). Der niederrheinischen Gruppe II gehören einhenklige Ausgussgefäße und Flaschen an, die in das frühe bis mittlere 8. Jh. datieren. Ergänzt wird der Formenbestand durch schmale, eiförmige Amphoren und weitmündige Wölbwandtöpfe (Typ Walsum). Bereits früh werden Ähnlichkeiten zwischen Walsumer und Bardorfer Ware erkannt (TISCHLER 1952, 197), als deren Ursache die kulturelle Durchdringung, wie der Vorstoß der Franken und die Errichtung der Duis-Burg an der Ruhrmündung, gesehen wird. Die Verbreitung der Bardorfer Ware erfolgte durch friesischen Handel am Niederrhein.

Die einheimische Keramik ist von eher grober Form und nur wenig hart gebrannt. Ein Standfußpokal (Objekt 10), der als Deckel für eine Urne diente, fällt mit seiner groben Machart im Fundspektrum auf. Diverse Scherben zweier dickwandiger Gefäße sind von graubrauner Farbe. Ihr Habitus weist auf eine lokale Produktion hin (Objekt 4 u. 9).

Aus Schwittersum liegt ein beutelförmiges Tongefäß mit kurzem ausgestellten Rand und konvexem abgesetzten Boden vor. Der Tonfarbe ist rotbraun bis schwarzbraun. Das Granitgrus gemagerte Gefäß ist etwa $17 \mathrm{~cm}$ hoch und besitzt einen Randdurchmesser von 14cm (SCHWARZ 1990, 226, Taf. 16-174). Ein frühmittelalterliches Gefäß aus Grimersum besitzt ein s-förmiges Profil mit kurzem Hals, verdicktem Boden sowie abgerundeter ebener Standfläche (SCHWARZ 1990, 242, Taf. 24, Nr. 318). Ein weiteres Tongefäß zeigt umlaufende Einstiche auf der Gefäßschulter (SCHWARZ 1990, 242, Taf. 24, Nr. 320). Ein kugeliger Becher stammt aus einem frühmittelalterlichen Körpergrab in Filsum (BÄRENFÄNGER 1993, Abb. 2,9).

Im ostfriesischen Dunum sind zwei Reihen annähernd quadratischer Stempeleindrücke auf der Gefäßschulter eines kleinen bauchigen Topfs angebracht. Die Randform ist schwach ausbiegend, der Boden abgeflacht, ohne gewölbt zu sein (SCHMID 1970, 62-63, Tafel 2). Die Urne aus Grab 66 ist relativ dünnwandig und weist eine bräunliche Oberfläche auf. SCHMID verweist auf völkerwanderungszeitliche Formen, die noch im Frühmittelalter anzutreffen sind. Eine stempelverzierte Urne mit Beigefäß ist aus Schortens (Upjever), Landkreis Friesland bekannt. Die zwei Nachbestattungen des 8./9. Jahrhunderts wurden in Grabhügel 1 entdeckt (BRANDORFF 1986, 129-143). WALLER (1953, Taf. 19) vergleicht derartige Gefäße mit altsächsischer Grabkeramik und stellt sie frühestens in das 6. Jahrhundert (Grabfund von Sievern, Landkreis Wesermünde).

\subsubsection{Metallgegenstände}

\subsubsection{Schlüssel}

Objekt 3 (Inv.Nr. 16860)

Taf. 58; 67 
Aus Brinkum stammt ein kleiner Bronzeschlüssel, der im Vollgussverfahren in sogenannter verlorener Form hergestellt wurde. Der Schlüsselgriff ist profiliert, sein Steg mit Linien verziert. Der Brinkumer Schlüssel gehört der Gruppe der Bartschlüssel mit rundem Griff an und wird von KLEEMANN (2002, 98-99) dem Typ 1 Variante a zugeordnet. Vergleichbare Funde liegen aus Dunum, Grab 760, sowie Wijster, Grab 138, vor (SCHMID 1969b, 263; VAN ES 1967, Abb. 234,3). Im ostfriesischen Schwittersum fand man einen bronzenen Schlüssel mit durchbrochenem Griff und rechteckigem, zweimal durchbohrten Bart (SCHWARZ 1990, 225-226, Taf. 16-166). Aus Bremen-Mahndorf sind wenigsten zwei Ringschlüssel als Fragmente überliefert (GROHNE 1953, 148, Abb. 53, o u. p). Aus Urne D 9 stammt ein eiserner Hohlschlüssel (GROHNE 1953, 157, Abb. 58 A). Die Hauptverbreitung der Schlüssel findet sich in Gräbern Ostfrieslands und der nördlichen Niederlande. Aus Ostfriesland liegen insgesamt drei Gräber mit Schlüsselbeigaben vor. Neben Brinkum sind dies Schortens (RötTING 1983, 501-502) und Cleverns (KLEEMANN 2002, Taf. 23,2). Letztgenannte Orte liegen geographisch in Ostfriesland und sind deshalb hier aufgenommen. Aufgrund einer der Bestattung zugehörigen Amphore des Typs 2 wird der Schlüssel in die Stufe I (670/80-700/10), datiert (KLEEMANN 2002, 295).

Es stellt sich die Frage, ob der Schlüsselbeigabe eine Amulettfunktion zugewiesen werden kann wie in Dunum,. Sind Schlüssel mit der christlichen Kreuzsymbolik (Petrus- und Himmelsschlüssel) verziert, ist dies naheliegend. Auch Schlüssel mit stilisierter menschlicher Gestalt, die eine sogenannte „Orantenhaltung“ einnehmen, weisen in diese Richtung (SCHMID 1997, Abb. 26, 43). Hinzuweisen ist auf ihre möglicherweise geschlechtsspezifische Bedeutung, da sie als Beigabe in Frauengräbern belegt ist.

Der Größe und Form nach könnte es sich bei dem Brinkumer Schlüssel um einen Schlüssel für ein Schmuckkästchen handeln oder um ein Besitzstandszeichen. Hierauf weisen auch die in anderen Gräbern beigegebenen großen Hakenschlüssel, die in Art eines Hausschlüssels, ein Symbol für den Hausstand darstellen (STEIN 1967, Taf. 57,25; SCHMID 1970a, Abb. 4; SCHMID 1972, Abb. 8).

\subsubsection{Messer}

$\begin{array}{ll}\text { Objekt 6 } & \text { (Inv.Nr. 16864) } \\ \text { Objekt 7a } & \text { (Inv.Nr. 16865 (a)) } \\ \text { Objekt 17a } & \text { (Inv.Nr. 16883 (a)) } \\ \text { Objekt 20 } & \text { (Inv.Nr. 16872) }\end{array}$

Taf. $61 ; 65$

Insgesamt liegen vier Messerklingen in Brinkum vor. Ihre Erhaltung haben sie im vorliegenden Fall der konservierenden Feuerpatina zu verdanken. In Körpergräbern sind die dünn ausgeschmiedeten Messer meist vergangen bzw. oft nur als „Eisenrest“ erhalten. Korrosionsschäden haben zwei Brinkumer Messer bis zur Unkenntlichkeit geschädigt. Ein Messer ist mit Griffangel erhalten (Inv.Nr. 
16883 (a)). Sein Rücken ist geknickt. Eine genaue Typzuordnung wird durch die nur zu einem Drittel erhaltene Messerklinge behindert. Messer mit Rückenknick liegen in Liebenau bereits in Phase 1 vor (HÄßLER 1983, Taf. 5, H 11/A15.2), sie können jedoch auch noch bis 800/870 auftreten (KLEEMANN $2002,154)$.

Messer gelten als nicht geschlechtspezifische Beigabe. In Rödingen waren 90 Gräber mit Messern ausgestattet, wobei es sich sowohl um Frauen- als auch um Männerbestattungen handelte (JANSSEN 1993, 92). Im Gräberfeld Eichstätten wurde die Beobachtung gemacht, dass in Frauengräbern Messerklingen mit Längen von bis zu $12 \mathrm{~cm}$ (oft nur 8-9cm) kürzer als die in Männerbestattungen waren (SASSE 2001, 98).

\subsubsection{Bronzescheren}

Objekt 2 (Inv.Nr. 16859)

Objekt 19 (Inv.Nr. 16871)

Objekt 23b (Inv.Nr. 16874)

Taf. 58; 60; 67

Insgesamt liegen drei Scheren aus dem Brinkumer Gräberfeld vor, eine mehr als bekannt. Eine bronzene Miniaturschere mit einer Länge von $10,65 \mathrm{~cm}$ gelangte unverbrannt in das Brandgrab 1 (ZyLMANN 1933, Abb. 187). Sie ist derzeit Teil der Dauerausstellung im Landesmuseum Hannover (Objekt 2; Abb. 61). KLEEMANN $(2002,107)$ stellt sie als Beigabe einer Frauenbestattung vor und datiert sie anhand der als Urne verwendeten Amphore in die Stufe I.

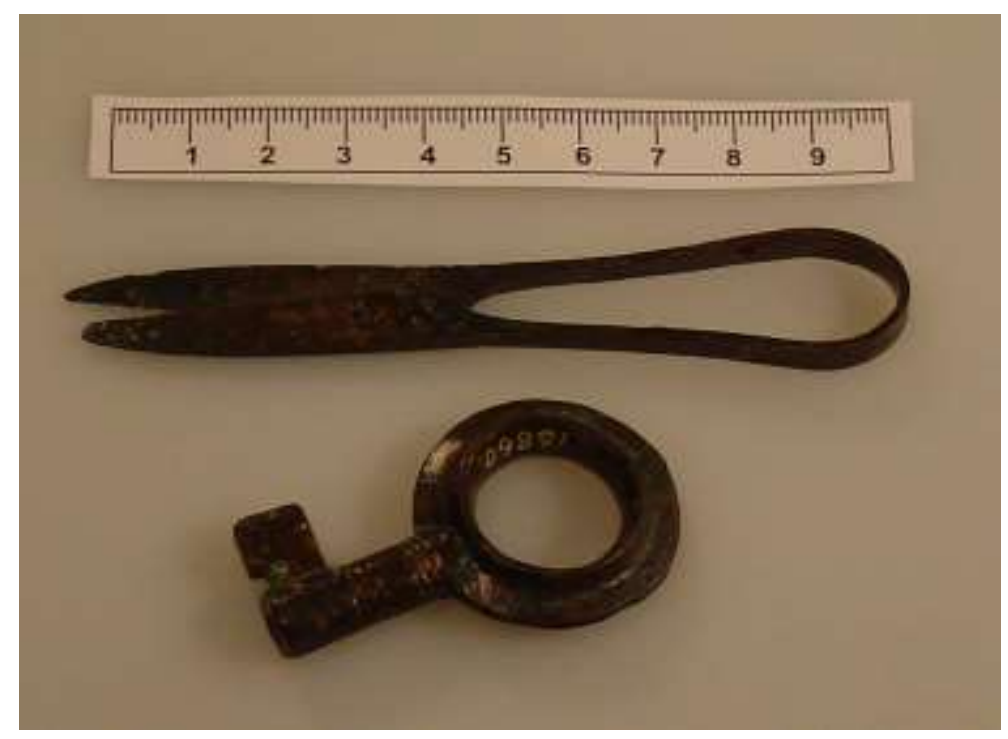

Abb. 61

Miniaturschere und Bronzeschlüssel aus Brinkum

Eine weitere Eisenschere lag in vier stark korrodierten Teilen vor (Objekt 18). Da genügend Substanz erhalten war, wurde die Schere 2004 restauriert. Bei der Freilegung entdeckte man an der Schere 
anhaftende organische Bestandteile. An dem $10 \mathrm{~cm}$ langen Scherenblatt haften eine leinenartige Gewebestruktur und zwei Knochenfragmente an. Metalloxide konservieren die Gewebereste an der Messerklinge (Abb. 62 u. 63). Es ist zu vermuten, dass die Schere intentionell in ein grob gewebtes Tuch eingewickelt war.

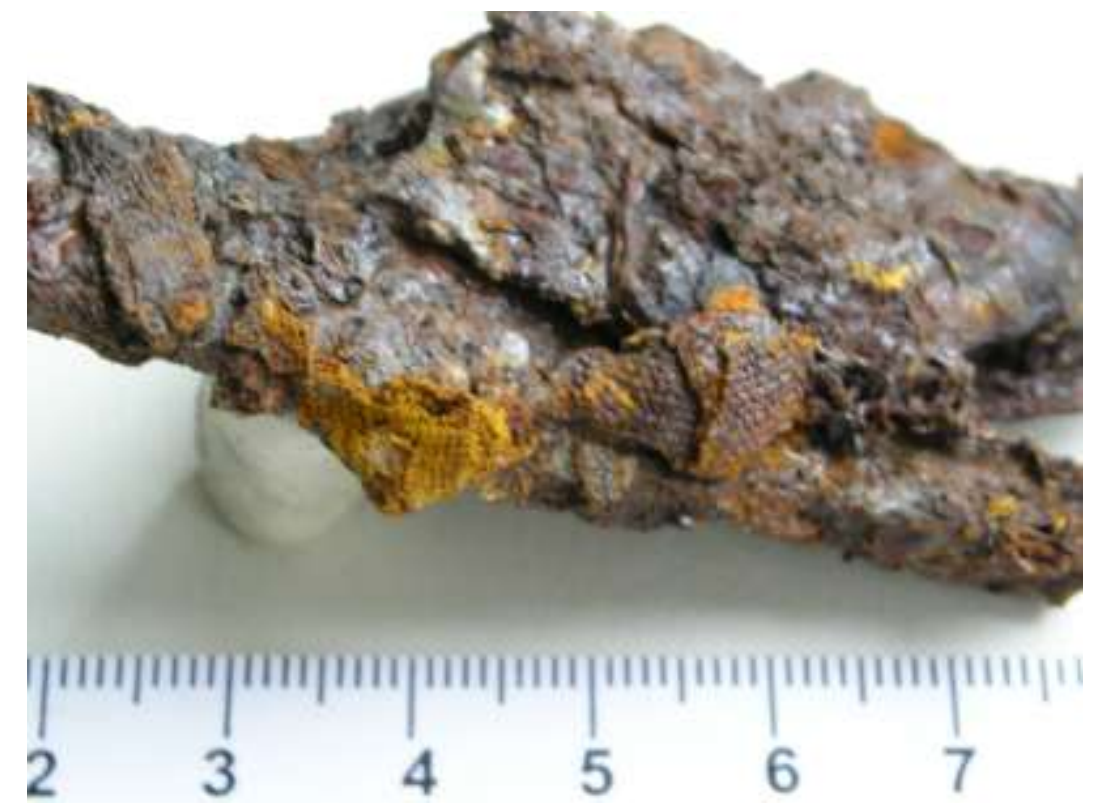

Abb. 62

Die restaurierte Brinkumer Bügelschere mit anhaftenden Textilresten

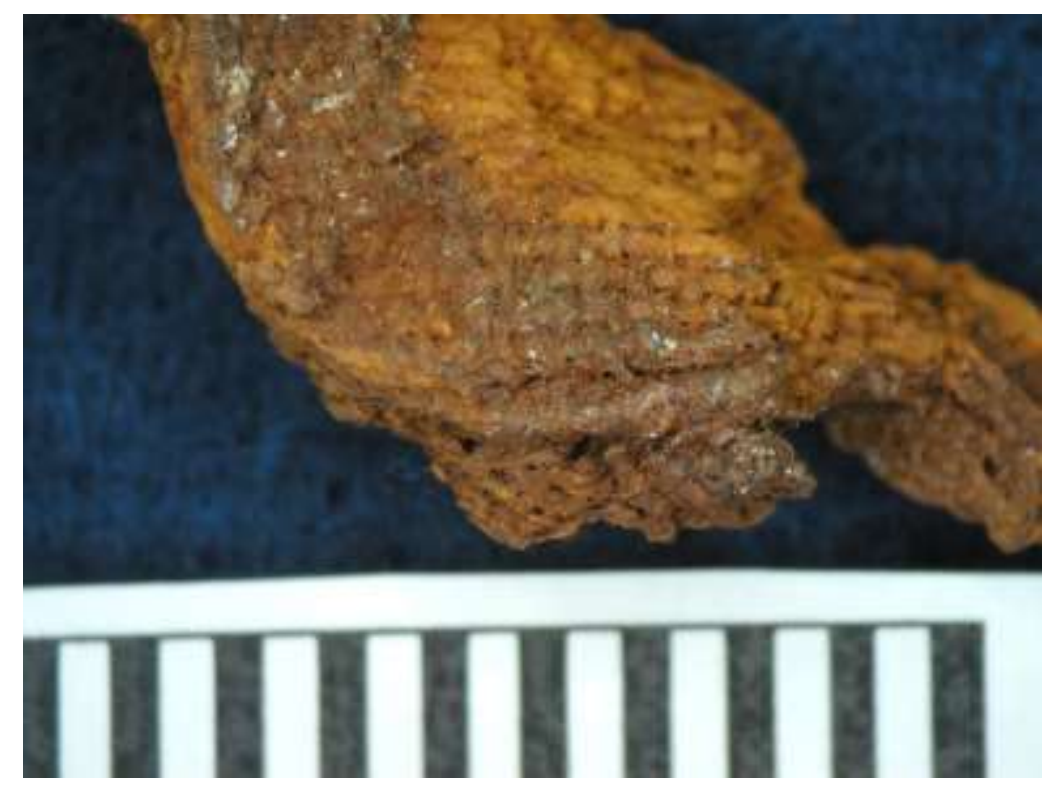

Abb. 63

Makroaufnahme frühmittelalterlicher Leinenreste auf einer Brinkumer Bronzeschere

(Foto: Dr. A. Kronz)

Das Webbild zeigt eine gruppenweise Anordnung mit wechselnder Spinndrehung einer Garnrichtung. 
$\mathrm{Zu}$ erkennen ist eine Webdichte von 10 Fäden auf $1 \mathrm{~cm}$. Kette und Schuss haben eine Stärke von 0,3$0,4 \mathrm{~cm}$. Es entsteht ein gleichmäßiges und dichtes Muster. Die heute braune Garnfarbe ist vermutlich das Ergebnis der Rostkorrosion.

Wie ein Vergleich mit Textilfunden aus Liebenau zeigt finden sich für die in Brinkum verwendete Webtechnik bereits frühe Belege. So aus Grab P 10/A1, einer um 400 datierten Körperbestattung (HundT 1994, 104, Abb. 4). In die 2. Hälfte des 6. Jahrhunderts datiert eine aus Liebenau in einem Körpergrab gefundene Schere, an der sich mehrere Lagen Leinengewebe erhalten haben (HUNDT 1994, 91, Fundnr. 15). Ob der sogenannte Leinenumschlag mit rituellen Vorgängen während der Bestattung in Verbindung steht oder sich zufällig erhalten hat, ist abschließend nicht zu klären.

Das Fragment einer weiteren Eisenschere liegt aus einem anderen Brinkumer Grab vor (Inv.Nr. 16874) vor. Es handelt sich hierbei um den Rest des federnden Scherenbügels.

Bügelscheren kommen in Ostfriesland, dem Hamburger Raum und im Nordharzvorland in wenigen Exemplaren vor. Die Scheren im nördlichen Randbereich des Karolingerreiches werden in die Stufen I-IV datiert (KLEEMANN 2002 139). Eiserne Scheren mit halbkreisförmigem Bügel treten bereits in der römischen Kaiserzeit auf, wie ein Fund von Markendorf bei Frankfurt a. d. Oder zeigt (LEUBE 1983, 335, Abb. 77 a).

\subsubsection{Schnallen}

Objekt $7 \mathrm{~b} \quad$ (Inv.Nr. 16865 (b))

Objekt 16 (Inv.Nr. 16882)

Objekt 20b (Inv.Nr. $16872(\mathrm{~b}))$

Taf. 60; 61; 65

Im Brinkumer Fundgut finden sich zwei Bronze- und eine Eisenschnalle. Eine rechteckige Grundplatte mit vier Nieten, der Schnallendorn und die Ansätze der Schnalle sind bei Objekt 20b erhalten (Inv.Nr. 16872 (b), Taf. 60). Das Fragment einer Bronzeschnalle (Objekt 16) war der Urne Inv.Nr. 16881 beigegeben. Die viereckige Gürtelschnalle ist mit Gürteldorn und Bügel erhalten (Inv.Nr. 16882, Taf. 61). Zwei Nietstifte heften die beiden Grundplatte zusammen. Die kleine Eisenschnalle ist mit einem rechteckigen Laschenbeschlag versehen. Der Dorn weist eine umgeschlagene Spitze mit einer Länge von $1,2 \mathrm{~cm}$ auf.

Vermutlich dienten beide als Laschenbeschlag, wobei die Metalllasche mittels Nieten um ein organisches Band, vermutlich aus Leder, befestigt war. Nur der Bügel mit Schnallendorn ist bei Objekt 7b erhalten (Inv.Nr. 16865 (b), Taf. 65). Ihr Fragmentierungsgrad steht eine Zuordnung entgegen.

Bei Schnallen handelt es sich um geschlechtsunspezifische Beigaben. Schnallen mit rechteckigen Laschenbeschlag sind als Typ 9 klassifiziert und treten bereits in der Stufe II auf, können sich jedoch 
bis in Stufe V halten (KLEEMANN 2002, 145). Schnallen diesen Typs sind in Norddeutschland regelmäßig verbreitet und datieren zwischen 700 bis 830 .

Möglicherweise stellten die Brinkumer Laschenschnallen einen Trachtbestandteil dar. Schnallen vergleichbarer Form finden sich in Dunum (SCHMID 1970, Taf. 4, Brandgrab 42, Schalle 6), dort u.a. auch mit vierreihigen Nieten auf der Grundplatte. Auf dem spätsächsischen Friedhof BremenMahndorf finden sich rechteckige Schnallen mit z.T. umgeschlagener Ansatzplatte (GROHNE 1953, 134, Abb. 45 c, f, i, m). Auch aus dem ostfriesischen Schwittersum liegt eine verwandte Form vor (SCHWARZ 1990, 224-225, Taf. 15-158).

\subsubsection{Gürtelbeschlag}

Objekt 15b (Inv.Nr. 16883 (b))

Objekt 15c (Inv.Nr. $16886(\mathrm{~b}-1 ; \mathrm{b}-2 ; \mathrm{b}-3))$

Taf. 61

Herausragend aus dem Fundensemble sind sieben Bronzeniete, die als Zierbesatz dienten. Auffallend sind ihre Grazilität und ihr dünner Goldüberzug, der sich bei der Restaurierung der Stücke offenbarte (Abb. 65; Taf. 61). Die nur 0,6cm durchmessenden Eisenniete sind mit einer Kappe aus Goldblech belegt. Erhalten haben sich zwei Dreiernietgruppen, die auf einem Metallblech angebracht waren und ein Einzelniet. Jede Nietenkappe ist von einem zierlichen, geriffelten Ring umkränzt. Der Durchmesser der Nieten beträgt $1 \mathrm{~cm}$ mit einer Höhe von $5 \mathrm{~mm}$. Sie sind auf Metallplatten befestigt und in Dreiergruppen angeordnet. Diese Stücke wurden nicht von KLEEMANN (2002, Katalognr. 96) erfasst, da sie sich im 2005 anthropologisch untersuchten Leichenbrand befanden.

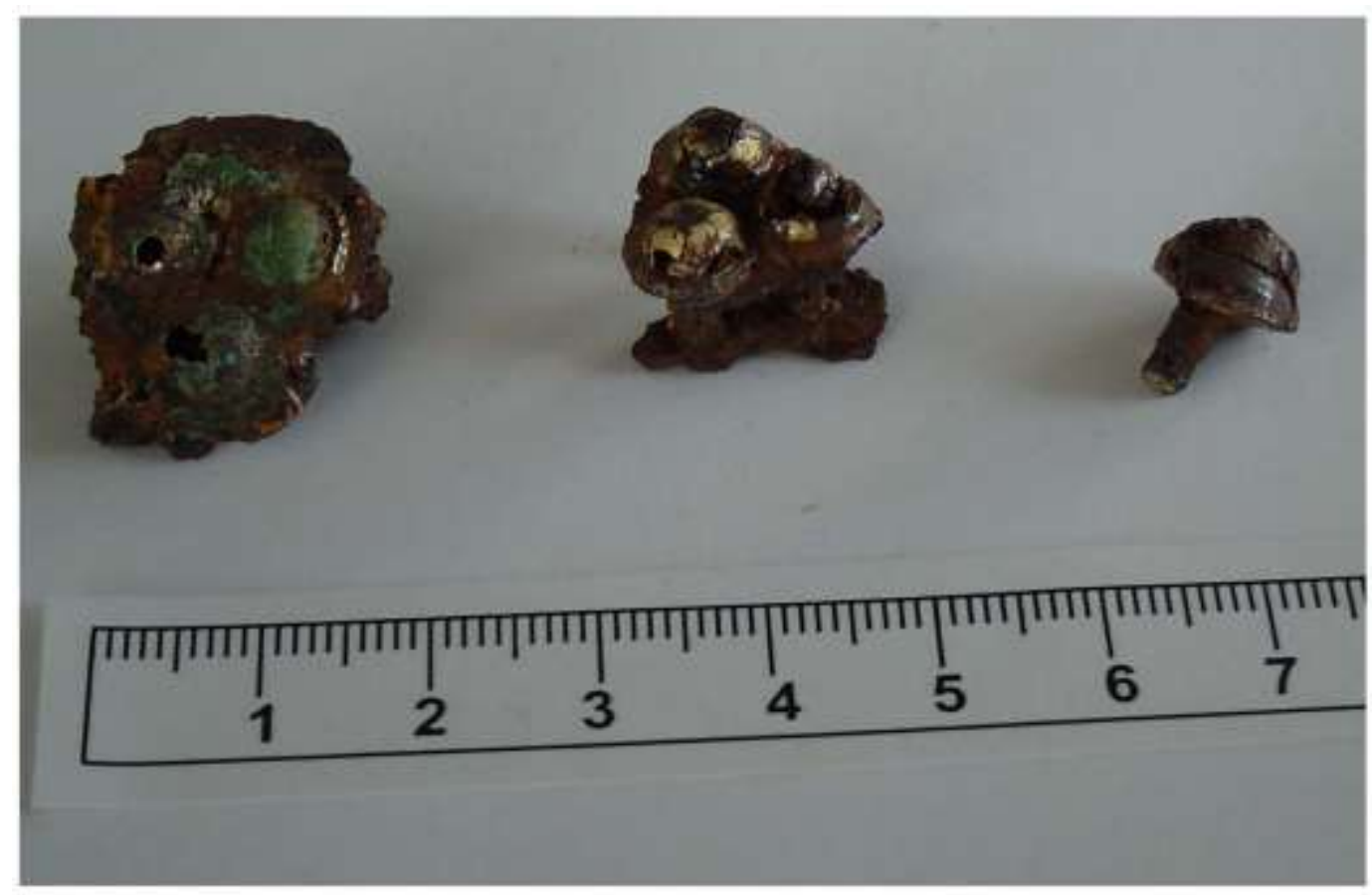

Abb. 65

Bronzeniete mit Blattgoldbelag aus Brinkum 
Einen mit Goldblech überzogenen Perlrandniet fand man 2003 bei Ausgrabungen im frühmittelalterlichen Gräberfeld Dorfhagen, Landkreis Cuxhaven (SCHÖN 2004, 91-94, Abb. 5). Dort verzierten die Niete den Randbeschlag einer Schwertscheide (Sax). Ein weiterer Beschlag seitlich der Griffangel weist drei Niete auf.

Aus dem alamanischen Bereich liegen verschiedene verzierte Gürtelbeschläge vor (Abb. 66). Ein besonders gut erhaltenes Stück stammt aus Schwenningen, Landkreis Schwarzwald-Baar-Kreis (OEHMiChEn / WeBER-Jensch 1997, 37, Abb. 24). Wie bei dem Brinkumer Stück sind um die Niete fein ziselierte Perldrahtumrandungen angebracht. Im Unterschied $\mathrm{zu}$ den vorliegenden Gürtelbeschlägen waren die ostfriesischen Niete mit Blattgold überzogen.

Nieten mit ziseliertem Rand finden sich auch auf einer Schwertscheide bzw. einen Gurtbeschlag in Röhdingen. Die Schauseite des Beschlages ist teilweise silbertauschiert, während die Bronzeniete der reich ausgestatteten Männerbesattung mit Perldraht umrandet sind. Datiert wird das Grab „um 600“ (vgl. JANSSEN 1993, 148, Tafel 32, Grab 97-3a u.b). Auch das „Adelsgrab“ des Herrn von Morken zeigt ebensolche Niete, die auf Rückenbeschlägen angebracht waren (BÖHNER 1959, Abb. 6a). Die auf $3,3 \times 5,5 \mathrm{~cm}$ großen Beschlägen angebrachten Niete waren vermutlich Bestandteil eines Leibriemens.
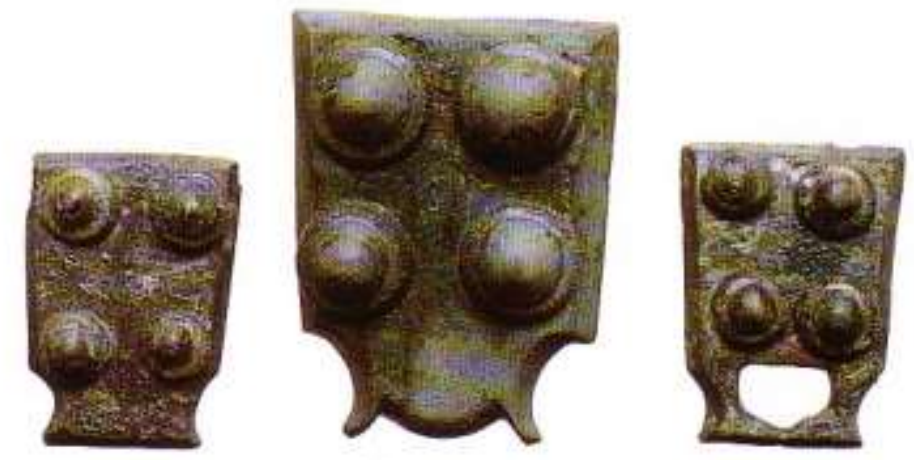

Abb. 66

Beschläge von Männergürteln aus Schwenningen mit deutlich erkennbaren Perlrand

In Grab 126 von Eichstetten fanden sich bei einer Körperbestattung drei Niete mit Perlrandringen aus Bronze. Aufgrund der verzierten Schnalle mit Angelbeschlag und Tierstil II Dekor kann das Grab in die Stufe JM II datiert werden (SASSE 201, 190, Taf. 48).

\subsubsection{Lanzenspitze}

Objekt 22 (Inv.Nr. 16880)

Taf. 59 
Die in zwei Teilen zerbrochene Lanzenspitze ist an den Enden durch ein (rezentes) Schmiedefeuer in ihrer Form verändert worden. Der obere Teil der Lanzenspitze zeichnet sich durch ein langes Blatt mit flachem Mittelgrad aus. Bei einer Blattlänge von 22,4cm und einer Blatthöhe von $3 \mathrm{~cm}$ liegt der Blattquerschnitt bei max. 0,5cm. Die Lanzenspitze weist auf einer Länge von $3,8-4,2 \mathrm{~cm}$ eine Umformung auf; dies gibt der ehemaligen Spitze ein vierkantiges Aussehen. Das zugehörige Tüllenfragment hat einen sechseckigen Querschnitt, dessen oberer Teil sich im Querschnitt von 2 auf $3 \mathrm{~cm}$ verbreitert. Die unteren $5 \mathrm{~cm}$ der Tülle wurden rezent zusammengeschmiedet und rechtwinklig umgebogen. Die Gesamtlänge beider Fragmente beträgt ca. $48 \mathrm{~cm}$. Aufgrund gestörter Fundumstände kann die Lanze keiner Bestattung zugeordnet werden.

Die Brinkumer Lanzenspitze mit langem weidenblattförmigen Blatt und langer Tülle gehört dem Typ Bremen-Mahndorf an. Die Verbreitung begrenzt sich bis dato auf je ein einmaliges Vorkommen in Ostfriesland, Westfriesland und Westfalen (KLEEMANN 2002, 117). An der Unterelbe und im Bremer Raum finden sich Lanzen dieses Typs in zwei Exemplaren. Das Brinkumer Objekt gehört in die Stufe I (KLEEMANN 2002, 298).

Lanzenfunde in Ostfriesland sind nicht so rar wie der Publikationsstand es vermittelt. Bei der Sichtung der Ortsakten im archäologischen Dienst der Ostfriesischen Landschaft finden sich wenigstens fünf frühmittelalterliche Lanzenfunde. Aus Hesel stammt eine $33 \mathrm{~cm}$ lange Lanzenspitze (FStNr. 2611/5:003). Die 1962 gefundene Waffe wird heute im Institut für historische Küstenforschung in Wilhelmshaven aufbewahrt. Eine Lanzenspitze aus dem ostfriesischen Großoldendorf (FStNr. 2612/8:026) gilt als verschollen. Im Landkreis Leer sind keine weiteren frühmittelalterlichen Lanzenspitzen bekannt.

Als frühkaiserzeitlich wird eine geflügelte Lanzenspitze aus Bühren (FStNr. 2612/9:026) bestimmt, dies ist jedoch nicht zu prüfen, da die 1948 gefundene Lanze verschollen ist. Eine eiserne Lanzenspitze liegt von der Alten Warft Dunum vor (FStNr. 2411/3:003). Die frühmittelalterliche Waffe stammt von der dortigen Geestsiedlung und wurde bei $+5 \mathrm{~m}$ NN von P. Schmid 1970 bei Ausgrabungen entdeckt. Fragmente einer weiteren frühmittelalterlichen Lanzenspitze stammen aus der Kirche Middels-Osterlog, Stadt Aurich (FStNr. 2411/6:064). Die 40cm lange Lanzenspitze ist im Heimatmuseum Aurich inventarisiert.

Altfunde der Emder Sammlung weisen auf weitere Lanzenfunde in Ostfriesland hin. Zu nennen sind Funde aus Grothusen (FStNr. 2508/5:006) und Upgant-Schott (FStNr. 2409/8:001), die zwischen 1879 und 1905 in die Sammlung gelangten. Die Lanzenspitze in Hagemarsch (FStNr. 2309/6:003) wurde 1877 von Rose entdeckt. In Berumbur fand man 1975 eine Tüllenspitze (FStNr. 2311/6:094), die heute im Heimatmuseum Norden aufbewahrt wird. 


\subsubsection{Feuerstahl}

Objekt 23a (Inv.Nr. 16874 (a))

Taf. 60

Der Brinkumer Feuerstahl wies nach der Restaurierung eine Länge von 6,4cm auf. Die Schlagfläche ist mittig verdickt und weist auf drei Seiten anoxidierte textile Reste auf, die auf eine ehemalige Umwicklung des Werkzeugs hindeuten. Die im Profil ovale Form (B 1,4cm) verjüngt sich nach innen (B 0,6cm). Die ehemals hochgebogenen Enden sind lediglich im Ansatz erhalten. Dieses Stück wurde nicht im Katalogteil von KLEEMANN zum Brinkumer Gräberfeld (2002, Katalognr. 96) erfasst.

Unterschieden werden können zwei Typen von Feuerstahl. Während Typ 1 eine dreieckige Verdickung in der Schlagseiten-Mitte aufweist, verfügt Typ 2 über eine ungegliederte Schlagseite, also ohne Verdickung. Die Verbreitung begrenzt sich bei Typ 1 auf den Küstenraum, die Niederlande und Süddeutschland. Ein Feuerstahl ist aus Bremen-Mahndorf (Grab 332) belegt (vgl. GROHNE 1953, 148, Abb. 53 i, k, 1). Die Datierung von Typ 1 reicht von der Stufe I bis zur Stufe IV (KLEEMANN 2002, 137, 295). In Eichstetten wird die Feuerstahlform mit hochaufgebogenen Enden in das 7. Jahrhundert datiert (SASSE 2001, 100). Vom Rödingener Gräberfeld im Kreis Dürren sind es vorzugsweise merowingerzeitliche Männergräber, die mit einem Feuerstahl ausgestattet waren (JANSSEN 1993, 63).

Nach KLEEMANN $(2002,138)$ zeichnet sich Typ 1 durch ein „fast völliges Fehlen im friesischen Küstenraum“ und den Niederlanden aus, tritt jedoch in Nordfriesland auf. Der Brinkumer Feuerstrahl gehört durch seine mittige Verdickung Typ 1 an und kann damit die Verbreitung in die friesische Region belegen.

\subsubsection{Holzgegenstand (Gerät)}

Objekt 20a (Inv.Nr. 16872 (a))

Taf. 60

Vermutlich um ein Gerät handelt es sich bei dem botanischen Fragment Objekt 20a. Hierauf deutet seine Form und die textile Umwicklung im oberen Drittel des Stückes hin (Abb. 67). Es verdankt seine Erhaltung dem Kontakt mit den Oxiden metallerner Grabbeigaben.

Mit Metallbestandteilen in den Gräbern in Kontakt stehende Holzreste können sich recht gut erhalten. Durch chemische Prozesse bildete sich aus diesen Metallen eine Auflage um die organischen Strukturen. Die ursprünglichen Zellwände vergehen meist vollständig. Zwar zeichnet sich die äußere Holzschicht noch ab, die für Holzartenbestimmung erforderlichen Schnitte können jedoch nicht mehr gewonnen werden (FEINDT / FIEDLER 1994, 19). 


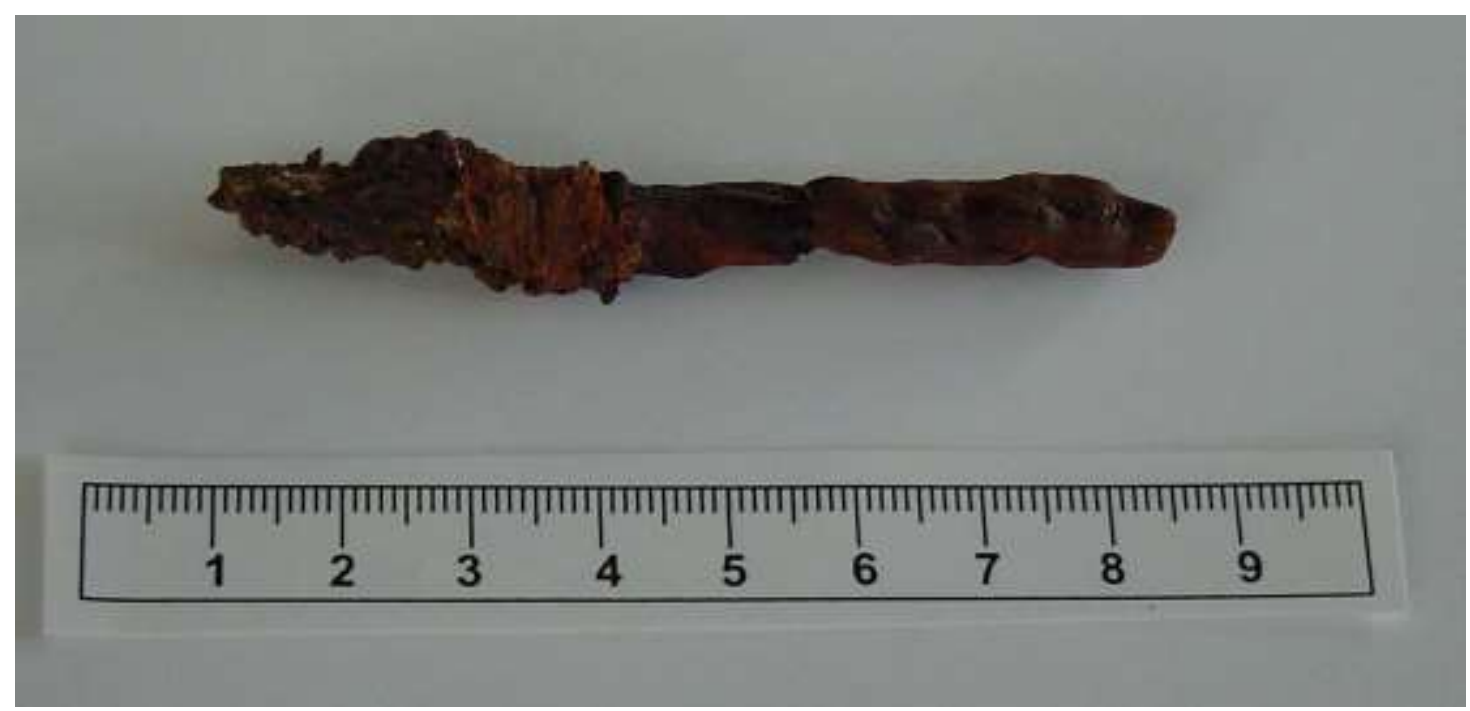

Abb. 67

Ein schnurumwickeltes Holzstück aus Brinkum

Finanzielle Mittel für einen Mirkrotomschnitt oder eine REM, wie sie bei Holzproben in Liebenau angefertigt wurden, standen nicht zur Verfügung. Um Aufschluss über die Artzugehörigkeit des verwendeten Holzes zu gewinnen wurde eine Makroaufnahme angefertigt (Abb. 68), die jedoch kein verwertbares Ergebnis hatte.

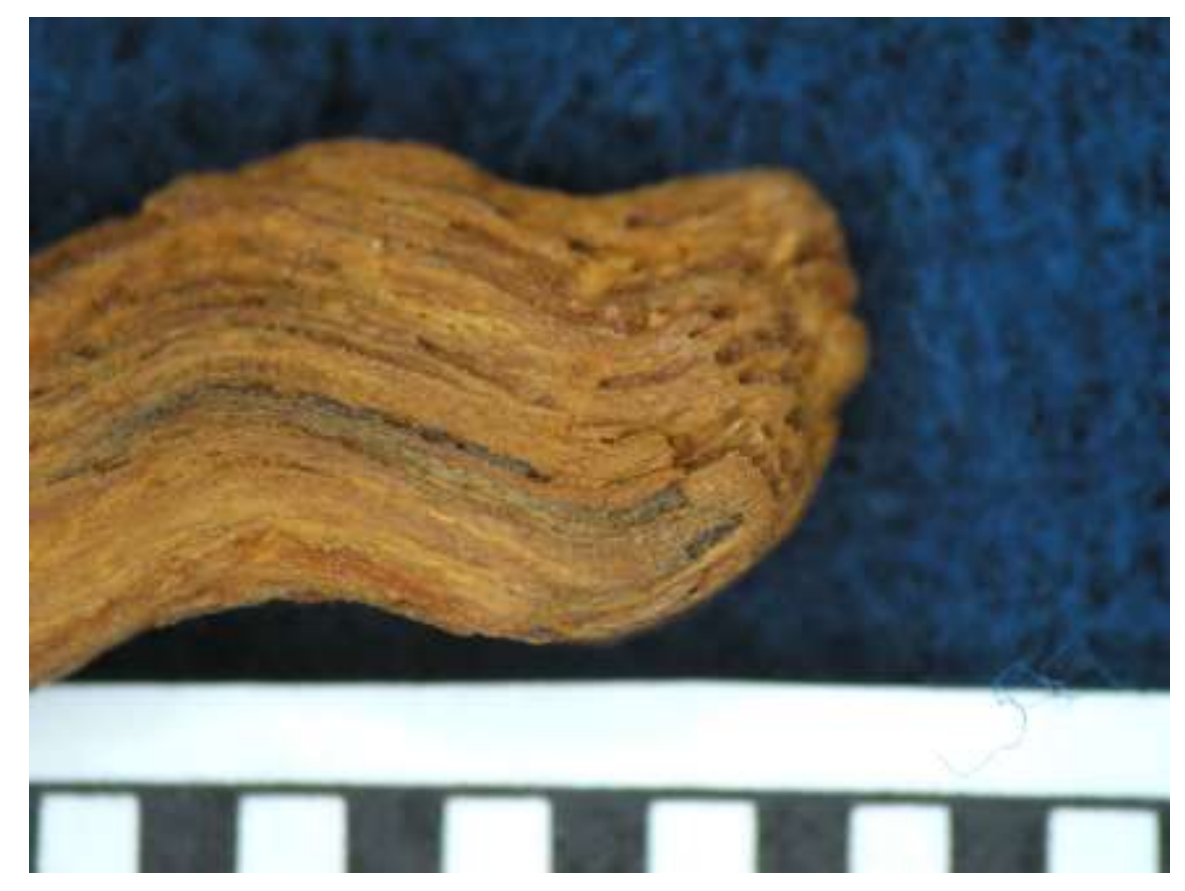

Abb. 68

Makroaufnahme der botanischen Probe Objekt 20a aus Brinkum

(Foto: Dr. A. Kronz)

Unter dem Fundmaterial in Liebenau existiert ein schnurumwickeltes Holzstück mit einer Länge von 8,5cm (FEINDT / FISCHER 1994, 43). Eine Holzanalyse zeigte die Verwendung von Holz der 
Kornelkirsche (gelber Hartriegel), einer für Drechslerarbeiten besonders geeigneten harten Holzart. Möglicherweise handelte es sich um den Holzschaft einer Handspindel, wie er aus mittelalterlichem Kontext bekannt ist.

\subsubsection{Kämme}

Objekt $11 \quad$ (Inv.Nr.16869)

Objekt 21 (Inv.Nr.16867)

Taf. 58; 63

Herausragend ist ein mit Futteral erhaltender doppelzinkiger Kamm (Objekt 11; Inv.Nr.16869). Kamm und Hülle sind aus Kochen und mit einem feinen Linienmuster verziert. Das Etui diente als Schutz der empfindlichen Kammzinken. Verziert ist die Griffplatte des Etuis mit Rautenmuster, die randlich eingefasst sind von parallelen Doppelstrichen und Querrauten. Die Endplatten des Futterals sind durchlocht (Abb. 69). Das historische SW-Foto von 1906 zeigt den ehemals besseren Erhaltungszustand.

Nur fragmentiert überliefert ist der Rest eines weiteren Knochenkammes (Objekt 21; Inv.Nr. 16867). Der auf seiner Schauseite mit einem rautenförmigen Muster verzierte Kamm gilt als verschollen. Seine Zuordnung als Kamm ohne Futteral Typ 1b nach KLEEMANN $(2002,168)$ stellt sich als fraglich dar. Er war möglicherweise Beigabe zu Objekt 8 (vgl. KlEEMANN 2002, Katalogseite 174, Nr. 96, Grab 5 , Tafel 35,2).

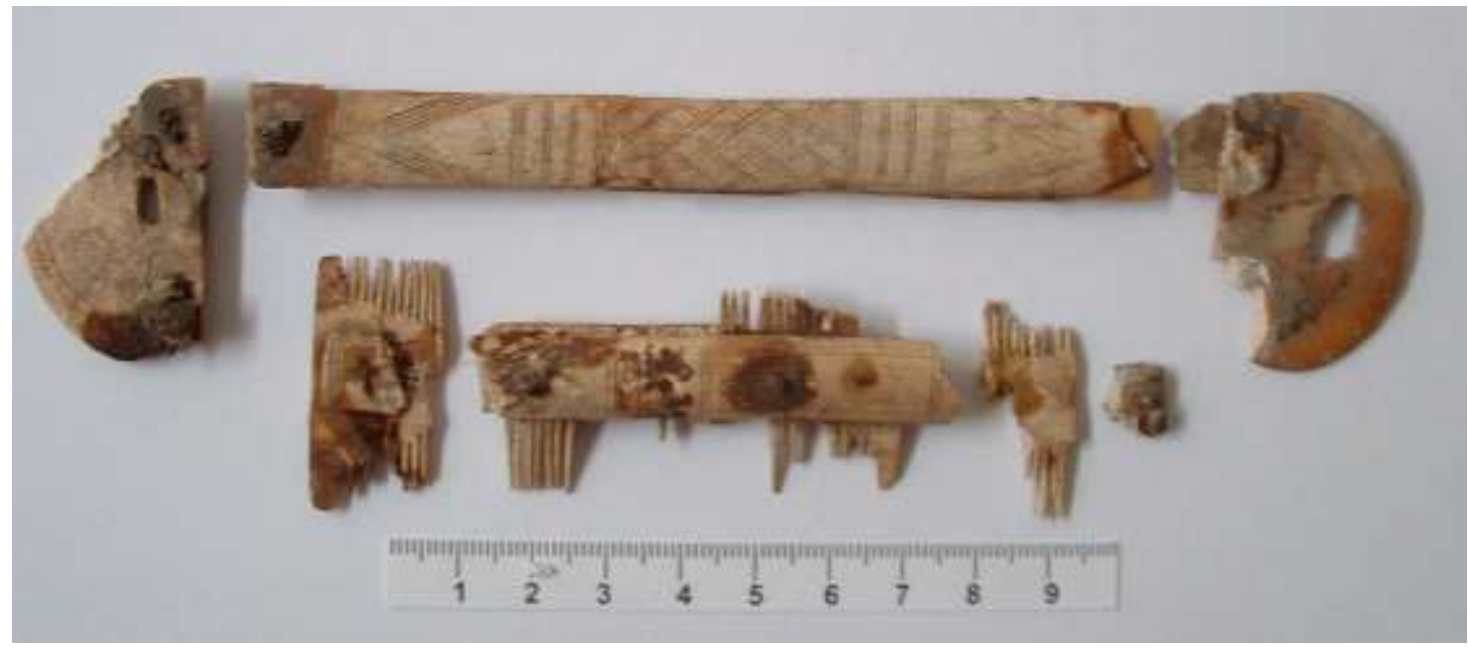

Abb. 69

Der verzierte Brinkumer Knochenkamm mit Futteral

Kämme stellen keine geschlechtsspezifischen Beigaben dar, daher treten sie sowohl bei Männer- als auch bei Frauenbestattungen auf. Die Beigabe eines Kammes ist lokalen Bestattungssitten unterworfen. Da es sich bei Kämmen um ein persönliches Toilettegerät handelte, ist zu vermuten das 
Bestattete jeweils einen zur Verfügung hatten. In Eichstetten am Kaiserstuhl gehörten Knochenkämme mit 46 Exemplaren zu den häufigsten Beigaben (SASSE 2001, 100).

Kämme mit Klappfutteralen gehörten zum Gürtelgehänge. In dem durch Brandbestattungen geprägten norddeutschen Raum haben sich nur selten Kämme erhalten. Aussagen zur Tragweise sind daher nicht möglich.

Dreilagenkämme sind i.d.R. mit Eisennieten zusammengefügt und zumeist nur einseitig auf den Griffund Futteralleisten ritzverziert (KLEEMANN 2002, 157). Derartige Kämme mit Schutzhülle sind seit dem 6. Jh. n. Chr. belegt (ZYLMANN 1938, 69). Doch bereits vom Gräberfeld Bremen-Mahndorf stammen aus zwei Urnenbestattungen die fragilen Reste eines mit Kreisaugen verzierten Knochenetuis (GROHNE 1953, 155, Abb. 57 A, B, C). Insgesamt enthielten sechs Urnenbestattungen auf dem Bremer Gräberfeld Dreilagenkammreste.

Futteralkämme finden sich überwiegend bei Grabfunden in Groningen und Ostfriesland. Aus der Siedlung Grimersum liegt ein Dreilagenkamm vor, der einseitig mit linearen Mustern verziert ist. Er besitzt eine gerade Bügelbasis und einen dreieckig-stumpfwinkligen Rücken mit 9 Nieten. Die Kammzähne waren z. T. ausgebrochen (SCHWARZ 1990, 239, Taf. 23-280). Das eingeritzte Muster weist auffällige Übereinstimmungen zum Brinkumer Kammetui auf.

Die Warft wurde zwischen 1878-1886 komplett abgetragen, wobei 20 Skelette entdeckt worden sind. Es wurden Funde aus Keramik, Horn und Beinarbeiten beobachtet. KLEEMANN $(2002,157)$ ordnet den Brinkumer Kamm dem Typ 1 Variante a zu. Als zeitliche Begrenzung treten zumeist die Stufen II - III auf. Aufgrund der Keramikbeigabe (Typ 2,17 und Sonderform) wird der Brinkumer Kamm in die Stufe I datiert; ebenso wie die Gräber von Hohenkirchen-Gottels.

Ein mit Ritzlinien verzierter Knochenkamm liegt aus dem Brandgrab 57 vom Gräberfeld von Dunum vor (SCHMID 1970, 62, Tafel 2). Wie in Brinkum werden zwei Knochenplatten von Metallnieten zusammengehalten. Die Schauseite ist mit linear eingeritzten Kreuzlinien verziert. Der Bestattung zugehörig sind ein Messer, ein Klappmesser und eine Pinzette.

\subsubsection{Glas}

Objekt 15c (Inv.Nr. 16881)

Unter dem Leichenbrand (Inv.Nr. 16881) in einem Walsumer Topf fand sich $1 / 2$ geschmolzene Glasperle von hellgrünlichem, schwach transluziden Glas (Abb. 70). Es handelt sich bei dem $1 \mathrm{~cm}$ großen Glas eindeutig um ein technisches Glas. Eine Entstehung infolge von Glasschmelze während der Verbrennung kann wegen seiner Größe ausgeschlossen werden.

Da eine typologische Ansprache aufgrund fehlender funktionaler Merkmale nicht mehr möglich war, empfahl sich eine pauschalchemische Analyse, die dankenswerterweise Herr Dr. Andreas Kronz vom 
Geowissenschaftlichen Zentrum der Universität Göttingen durchführte.

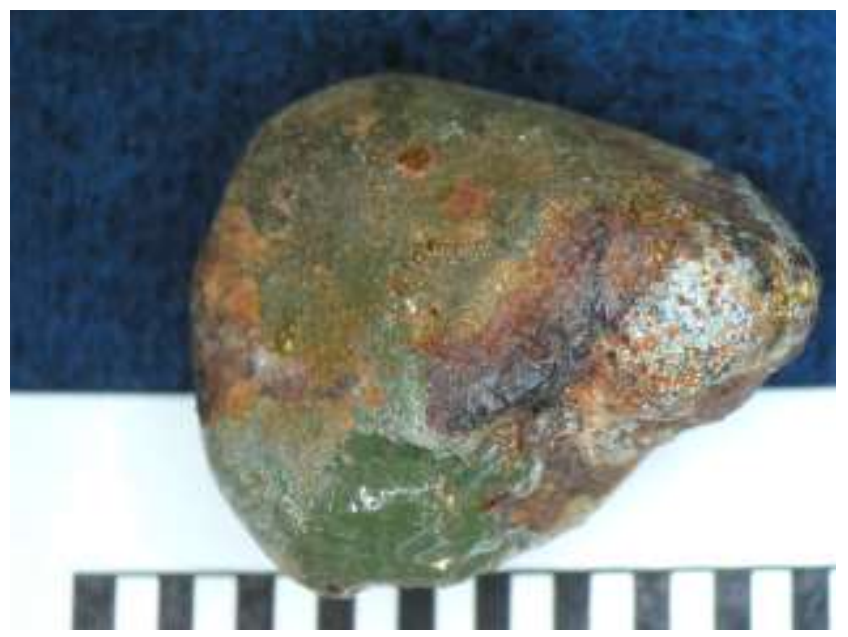

Abb. 70

Makroaufnahme vom Glas aus einer Brinkumer Brandbestattung

Das Glasfragment besteht aus einem Soda-Kalk-Glas (Tab. 12). Hierfür sprechen seine deutlichen MnO-Gehalte, deutliche Mengen an Trübungsmittel ( $\mathrm{Sn}$ und $\mathrm{Sb}$ ) sowie ein $\mathrm{CaO} / \mathrm{Na}_{2} \mathrm{O}-$ Verhältnis von 0,39. Als farbgebende Elemente wurden $\mathrm{Co}$ und $\mathrm{Cu}$ zugegeben.

Ein Vergleich mit Gläsern aus frühmittelalterlichen und römischen Fundzusammenhängen stellt die Tabelle 13 dar. Dabei wird deutlich, dass das Brinkumer Stück in seiner Rezeptur römischemSodaKalk-Glas entspricht (WEDEPOHL 1998, 12). Im Unterschied zu Gläsern aus vorchristlicher Zeit streuen jedoch die $\mathrm{SiO}_{2}$-Gehalte weit weniger (vgl. SANKE / WEDEPOHL/ KRONZ 2003, 169-174).

Zwar ist für das Brinkumer Glas eine römische Herkunft wahrscheinlich, dies betrifft jedoch nur das Material. Als Farbzusatz wurde römisches Tesserae verwendet (WEDEPOHL 2003, 265). Die Glasperle selbst ist aufgrund ihrer Zusammensetzung nicht von römischen Handwerkern hergestellt worden. Bei ihr wird es sich vermutlich um ein umgearbeitetes Glas aus einer frühmittelalterlichen Werkstatt gehandelt haben. 


\begin{tabular}{|c|c|c|c|c|c|c|c|c|}
\hline Analyse & PR 16881.1 & PR 16881.2 & PR 16881.3 & PR 16881.4 & PR 16881.5 & Mittelwert & St.-abse. & NWG \\
\hline $\mathrm{SiO}_{2}$ & 67,20 & 67.56 & 66,92 & 67,48 & 67,49 & 67,33 & 0,3 & 0.05 \\
\hline $\mathrm{TiO}_{2}$ & 0,10 & 0,14 & 0,12 & 0,13 & 0,09 & 0,12 & 0,02 & 0,02 \\
\hline $\mathrm{Al}_{2} \mathrm{O}_{3}$ & 2,52 & 2,46 & 2.39 & 2,42 & 2,46 & 2,45 & 0.05 & 0,02 \\
\hline $\mathrm{Fe}_{2} \mathrm{O}_{3}$ & 0,95 & 0,86 & 0.92 & 0,94 & 0,93 & 0,92 & 0,03 & 0,04 \\
\hline $\mathrm{MnO}$ & 0,66 & 0,68 & 0,63 & 0,60 & 0.61 & 0,63 & 0.03 & 0,03 \\
\hline $\mathrm{MgO}$ & 0,83 & 0,85 & 0,80 & 0,83 & 0,88 & 0,84 & 0.03 & 0,02 \\
\hline $\mathrm{CaO}$ & 6,84 & 6,86 & 6.66 & 6.75 & 6,79 & 6,78 & 0.08 & 0,02 \\
\hline $\mathrm{Na}_{2} \mathrm{O}$ & 17,17 & 17,35 & 16,98 & 17,35 & 17,17 & 17,20 & 0,15 & 0,03 \\
\hline $\mathrm{K}_{2} \mathrm{O}$ & 0,94 & 0,98 & 0,99 & 0,96 & 0,95 & 0,96 & 0,02 & 0,01 \\
\hline $\mathrm{P}_{2} \mathrm{O}_{3}$ & 0.15 & 0,12 & 0,16 & 0,19 & 0,18 & 0,16 & 0,02 & 0,03 \\
\hline $\mathrm{SO}_{3}$ & 0,28 & 0,26 & 0.26 & 0.25 & 0.29 & 0,27 & 0.014 & 0,03 \\
\hline $\mathrm{Cl}$ & 0,786 & 0,741 & 0,794 & 0,810 & 0,762 & 0,779 & 0,027 & 0,005 \\
\hline Sro & $<\mathrm{DL}$ & $<\mathrm{DL}$. & $\angle \mathrm{DL}$ & 0,09 & 0,08 & 0,083 & 0,042 & 0,04 \\
\hline $\mathrm{BaO}$ & 0,03 & $\angle D L$ & 0,03 & 0,07 & 0,04 & 0,04 & 0.024 & 0,03 \\
\hline $\mathrm{CoO}$ & 0,02 & $\angle D L$ & $<\mathrm{DL}$ & $\triangle \mathrm{DL}$ & $\angle \mathrm{DL}$ & 0.02 & 0,009 & 0.02 \\
\hline CuO & 0,36 & 0,28 & 0,28 & 0,36 & 0.35 & 0,33 & 0,041 & 0,03 \\
\hline $\mathrm{PbO}$ & 0,7 & 0,4 & 0.7 & 1,2 & 0,7 & 0,7 & 0.3 & 0.14 \\
\hline $\mathrm{SnO}_{2}$ & 0,06 & 0,09 & 0,07 & 0,08 & 0,12 & 0,09 & 0,022 & 0.02 \\
\hline$S b_{2} O_{2}$ & 0.40 & 0.43 & 0,41 & 0,43 & 0.43 & 0,42 & 0,013 & 0,02 \\
\hline Summe & 99,98 & 100,10 & 99,09 & 100,89 & 100,33 & 100,15 & 0,66 & \\
\hline $\mathrm{CaO} / \mathrm{Na}_{2} \mathrm{O}$ & 0.40 & 0.40 & 0,39 & 0,39 & 0.40 & 0,39 & & \\
\hline
\end{tabular}

Tab. 12

Pauschalchemische Analyse an einer Glasperle aus dem Gräberfeld Brinkum

(Tabelle erstellt durch Dr. A. Kronz)

\begin{tabular}{|c|c|c|c|c|c|c|c|c|}
\hline Analyse & Brinkum & Lorsch & Fulda & Zalavar & Gellep & Gellep & Mittelw. & Mittelw \\
\hline Alter & 7.8. Jh. & 8.-9.Jh. & 8.-10, Jh. & 9. Jh. & 5,-6. Jh. & rŏmisch & römisch & 5.-9.Jh \\
\hline Anzahl & 1 & 20 & 12 & 6 & 16 & 12 & 781 & 159 \\
\hline $\mathrm{SiO}_{2}$ & 67,33 & 67,59 & 67,90 & 67,96 & 67,47 & 68,70 & 69,41 & 68.20 \\
\hline $\mathrm{TiO}_{2}$ & 0,12 & 0,14 & 0,16 & 0,21 & 0,13 & 0,13 & 0,12 & 0,14 \\
\hline $\mathrm{A}_{2} \mathrm{O}_{3}$ & 2,45 & 2,42 & 2,39 & 2,77 & 2,35 & 2,20 & 2,35 & 2,47 \\
\hline $\mathrm{Fe}_{2} \mathrm{O}_{3}$ & 0,92 & 1,04 & 0,94 & 1,27 & 1,22 & 0,70 & 0,69 & 1,01 \\
\hline $\mathrm{MnO}$ & 0.63 & 0,60 & 0,67 & 0.66 & 0.92 & 1,00 & 0,56 & 0,61 \\
\hline $\mathrm{MgO}$ & 0,84 & 0,81 & 0,88 & 0,92 & 0,96 & 0,78 & 0.54 & 0,84 \\
\hline $\mathrm{CaO}$ & 6,78 & 7,12 & 7,75 & 7,79 & 7,29 & 5,70 & 6.79 & 7,47 \\
\hline $\mathrm{Na}_{2} \mathrm{O}$ & 17.20 & 16,71 & 16,40 & 17,18 & 16,32 & 18.60 & 17,47 & 16,48 \\
\hline $\mathrm{K}_{2} \mathrm{O}$ & 0,96 & 1,01 & 1,11 & 0.87 & 0,76 & 0,44 & 0,61 & 0.89 \\
\hline $\mathrm{P}_{2} \mathrm{O}_{5}$ & 0,16 & 0,18 & 0,16 & 0,16 & 0,16 & 0,06 & 0,09 & 0,14 \\
\hline $\mathrm{SO}_{3}$ & 0,27 & 0,25 & & & & & & \\
\hline $\mathrm{Cl}$ & 0,779 & 0.779 & $\theta, 82$ & 0,80 & 0.91 & 1,10 & 0,99 & 0,83 \\
\hline Sro & 0,08 & 0,07 & & 0,05 & & & & \\
\hline $\mathrm{BaO}$ & 0,04 & 0,10 & & & & & & \\
\hline $\mathrm{CoO}$ & 0.02 & & & 0,01 & & & & \\
\hline Cuo & 0.33 & 0,60 & 0,77 & 0,26 & & & & \\
\hline $\mathrm{PbO}$ & 0.7 & 0,4 & 0,6 & 0.2 & & & & \\
\hline $\mathrm{SnO}_{2}$ & 0,09 & 0,19 & var. & & & & & \\
\hline $5 b \mathrm{O}_{2}$ & 0,42 & 0,98 & 0.19 & 0.22 & & & & \\
\hline Summe & 100.15 & 100,42 & 100,69 & 101,36 & 98,49 & 99,41 & 99,62 & 99,08 \\
\hline $\mathrm{MnO} \mathrm{Fe}_{2} \mathrm{O}_{3}$ & 0,69 & 0.58 & 0,71 & 0.52 & 0,75 & 1.43 & 0.81 & 0,60 \\
\hline $\mathrm{CaO} / \mathrm{Na}_{2} \mathrm{O}$ & 0,39 & 0.43 & 0,47 & 0,45 & 0,45 & 0.31 & 0.39 & 0.45 \\
\hline
\end{tabular}

Tab. 13

Pauschalchemie der Gläser von verschiedenen Fundorten im Vergleich

(Tabelle erstellt durch Dr. A. Kronz) 


\subsection{Anthropologische Untersuchung}

Im Brinkumer Grabhügel wurden ausnahmslos Brandbestattungen gefunden. Überliefert ist der Leichenbrand von 3 Bestattungen (Inv.Nr. 16862, 16868, 16881). Die Quantität der Leichenbrände erreicht nicht annähernd die eines komplett verbrannten Menschen, die bei etwa 1,5 kg liegt; das Gewicht der Brinkumer Partien liegt zwischen 20 und 300 Gramm (Tab. 14).

Es liegen Fragmente von verschiedenen Skelettregionen vor. Eine Geschlechtsbestimmung war an keiner Partie möglich. Es handelt sich bei allen um erwachsene Individuen. Mit einem Sterbealter von spätadult (34-39 Jahre) und früh- bis mittelmatur (40-54 Jahre) können zwei Individuen für die damalige Zeit als relativ alt gelten. In einem Fall wird die an einem Diaphysenfragment festgestellte periostale Reaktion auf ein stumpfes Trauma zurückzuführen sein (Inv.Nr. 16881). Die Bestattung wurde in einem Walsumer Tontopf vorgenommen, dem eine Bronzeschnalle, eine Gürtelgarnitur mit goldüberzogenen Perlrandnieten sowie ein Messer und eine Glasperle beigegeben waren. Das spätadulte Individuum verstarb zwischen dem 34 und 40 Lebensjahr. Auffällig ist das hohe Leichenbrandgewicht. Dies und die beigegebene kostbare Gürtelgarnitur deuten darauf hin, dass es sich um eine männliche Bestattung gehandelt hat.

\begin{tabular}{|l|c|l|l|l|l|}
\hline Inv.Nr & Objektnr. & $\begin{array}{l}\text { Gewicht } \\
\text { LB } \\
\text { in } \\
\text { Gramm }\end{array}$ & Sterbealter & $\begin{array}{l}\text { Pathologische } \\
\text { Veränderungen }\end{array}$ & Funde unter dem LB \\
\hline 16862 & 4 & 20 & $\begin{array}{l}\text { erwachsenes } \\
\text { Individuum }\end{array}$ & ---- & $\begin{array}{l}\text { Schwarze holzkohlehaltige } \\
\text { Fragmente }\end{array}$ \\
\hline 16868 & 9 & 107 & $\begin{array}{l}\text { früh- bis } \\
\text { mittelmatur }\end{array}$ & ---- & $\begin{array}{l}\text { Knochen mit Eisenverfärbung, } \\
\text { Eisenfragmente, textile Abdrücke }\end{array}$ \\
\hline 16881 & 15 & 300 & spätadult & Periostale & $\begin{array}{l}\text { Knochen mit Bronzeverfärbung } \\
\text { Reaktion } \\
\text { Metallnieten, Keramikhenkel, } \\
\text { Glas- und Holzkohlefragmente, } \\
\text { ein Fischwirbel }\end{array}$ \\
\hline
\end{tabular}

Tab. 14

Angabe zum Leichenbrandgewicht, Sterbealter, pathologischen Veränderungen,

Funde unter dem Leichenbrand der Brinkumer Bestattungen

Bei dem mit 107 Gramm erhaltenen Leichenbrand (Inv.Nr. 16868) sind die Knochen unvollständig verbrannt, mit deutlichen Resten primärer Kohlenstoffverbindungen neben vollständig verbrannten 
Knochen von kreidiger Konsistenz. Ein Fragment enthält sogenannte klinkerartige Aufschmelzungen, wie sie erst ab 1000 Grad entstehen (vgl. HuMmel / SchuTKOwSK 1986, 1-9). Auf einen recht ungleichmäßigen Verbrennungsprozess von einer Brenntemperatur deutlich unter $800 \mathrm{Grad}$ weisen jedoch die aus der gleichen Knochenpartie stammenden primären Kohlenstoffverbindungen hin.

Das recht geringe Gewicht der Leichenbrandpartien könnte überlieferungsbedingt sein; es kann jedoch nicht ausgeschlossen werden, dass es mit den Bestattungsriten in Verbindung steht.

Unter dem Leichenbrand fanden sich Reste verschiedener Objekte, die zwar mit ins Feuer gelangten, jedoch nicht vollständig verbrannt sind. Wahrscheinlich waren sie in den Randbereichen des Scheiterhaufens geringeren Temperaturen ausgesetzt. Durch die Feuerpatina haben sich Metall- und Glasfragmente erhalten (Objekt 15 a und b, Inv.Nr. 16881). Es finden sich auch Eisenfragmente mit durch Oxidation erhaltenen Textilreste (Objekt 9 und 17; Inv.Nr. 16868, 16883 (b)). Eine Bestattung enthielt schwarze Fragmente von holzkohlehaltiger Konsistenz (Objekt 4 b, Inv.Nr. 16862).

Während kaiserzeitliche Brandbestattungen ein Gewicht von bis zu 1,7kg erreichen können, fällt das geringe Leichenbrandgewicht der Brinkumer Bestattungen auf. Doch auch bei Leichenbränden anderer frühgeschichtlicher Gräberfelder ist ein geringeres Gewicht zu vermerken. So liegt in Liebenau das Leichenbrandgewicht im Mittel bei $127 \mathrm{Gramm}$. Bei 1/4 der Leichenbrände beträgt es nur 5 Gramm und bei 50\% sind noch bis zu 32 Gramm erhalten (RösING 1994, 201). Möglicherweise steht dies mit dem angewendeten Verbrennungsprozess in Verbindung.

Die meisten Brandbestattungen $(n=162)$ in Liebenau wurden unter einem Scheiterhaufenplatz vorgenommen, weitere 97 zusätzlich in einer Urne. Reine Urnengräber liegen in einer nur geringen Anzahl vor $(\mathrm{n}=5)$. Bei der zwischen dem 4. und 9. Jahrhundert durchgängig genutzten Nekropole ist unter den 259 Brandbestattungen eine deutliche Dominanz von weiblichen Individuen festzustellen (RÖSING 1994, 210).

\subsection{Zusammenfassung}

Im ostfriesischen Raum stammen frühmittelalterliche Brandbestattungen mehrheitlich aus alt gegrabenen Fundkomplexen. Dies implizierte eine unsachgemäße Fundbergung und eine fehlende bzw. mangelhafte Dokumentation. Zumeist sind zusammengehörige Funde auseinandergerissen worden und z.T. bis heute verschollen. Insbesondere der Leichenbrand wurde selten aufbewahrt. Vor diesem Hintergrund stellt die anthropologische Untersuchung der Brinkumer Brandbestattungen und die Restaurierung der Metallfunde ein Novum dar.

Ein Vergleich mit Gräberfeldern der norddeutschen Geest ist jedoch nur in Ansätzen möglich. Eine abschließende Publikation und anthropologische Auswertung des Gräberfeldes Dunum steht aus. Für die Leichenbrandserien aus Schortens, Landkreis Friesland liegt eine Auswertung vor, ist jedoch nicht verfügbar (HERRMANN 1976, unpubl). Fundmaterial vom Gräberfeld Bremen-Mahndorf wurde von 
GROHNE bereits 1953 publiziert, eine Analyse des Leichenbrandes fand ebenso wenig statt, wie eine Gesamtvorlage des Gräberfeldes oder eine Neubearbeitung der Bestattungen nach heutigem Forschungsstand. Ein Vergleich musste daher mit dem anthropologisch untersuchten Leichenbrand aus Liebenau erfolgen.

Frühmittelalterliche Gebrauchskeramik der Nordseeregion zeichnet sich durch einen oft nur mäßigen Brand sowie durch grob mit Granitgrus gemagerter und verhältnismäßige dicker Gefäßwandung aus. STILKE (1993) ordnet Wackelbodengefäße, die ein „Eiboden“ auszeichnet, der „weichen Grauware“ $\mathrm{zu}$.

Die Brinkumer Gefäße fallen aus dem bisherigen bekannten frühmittelalterlichen Keramikrepertoire Ostfrieslands heraus. Sie sind hart gebrannt, fein geschlemmt, dünnwandig und scheibengedreht. Ihre Oberfläche ist zum Teil glatt verstrichen und mit Stempelmustern verziert. In Liebenau finden sich erste Hinweise auf eine sich im 5./6. Jahrhundert abzeichnende Keramikentwicklung für die auch in Ostfriesland anzutreffende lokale Keramik.

Schalen vom Typ H 1 bis H 4 reichen vom Ende des 4. Jahrhunderts bis ins 7. Jahrhundert. In dieses Zeitfenster gehören auch hohe Töpfe vom Typ H 11, wobei hohe Schalen und Töpfe dieser Typen bis in die 2. Hälfe des 7. Jahrhunderts vorkommen können, aber deutlicher in die 1. Hälfte des 7. Jahrhunderts datieren (SCHLICKSBIER 2003, 149). Die kumpfartigen Töpfe kommen mit leichten Rund- oder mit abgesetzten Flachboden vor. Nur zwei Varianten verfügen über einen kurzen ausbiegenden Rand. Sie stellen wohl die Vorläufer der späteren hohen beutelförmigen Töpfe dar. Die handgeformte lokale Tonware wird durch weitmundige, flachbodige Eitöpfe und später von Muschelgrus gemagerten Kugeltöpfen abgelöst (SCHMID 1997). Im südlichen Ostfriesland überwiegt ab dem 9. Jahrhundert Muschelgrus gemagerte Ware mit kugeligem Boden. Auf ein früheres Einsetzen dieser Ware weist der Fund eines Töpferofens mit einer hohen Zahl Muschelgrus gemagerter Keramik in Hesel hin, der in das Ende des 8. Jahrhunderts datiert werden kann (BÄRENFÄNGER 1994).

Frühmittelalterliche Metallfunde sind in Ostfriesland eine Seltenheit. Die schlechte Quellenlage gründet sich u.a. auf die mangelhaften Erhaltungsbedingungen von Metallobjekten im Geestboden und den hohen Wiederverwertungs-Wert des Materials. Aus frühmittelalterlichen Siedlungen fehlen daher meist Metallfunde. Metallene Trachtbestandteile, Knochenkämme u.a. fanden sich dagegen häufiger beim Abtrag ostfriesischer Wurten gegen Ende des 19. und Anfang des 20. Jahrhunderts. Hier stellt die Überlieferungslage der alt gegrabenen Friedhöfe die Forschung vor Probleme, da selten gesicherte Fundumstände vorliegen und die zugehörigen Funde oft als verschollen gelten. Umso höher ist die Bedeutung des Brinkumer Fundkomplexes, da er nicht nur nahezu komplett erhalten ist, sondern auch ein seltenes Zeugnis frühmittelalterlicher Bestattungssitten ist. Neben den Trachtbestandteilen, wie den Resten einer Gürtelgarnitur und mehreren Messern fand sich eine Lanzenspitze. 
Waffenbeigaben stellen unter den ostfriesischen Brandgräbern des Frühmittelalters eine Besonderheit dar. In Dunum sind es nur zwei bis drei Urnenbestattungen die über Schwert, Lanze und Schild verfügen (SCHMID 1999b, 170). In Middels können zwei weitere Männergräber des BrandgrabHorizontes durch Waffenreste in die 2. Hälfte des 8. Jahrhunderts datiert werden. Mit dem Ende der Brandgrabsitte im 9. Jahrhundert und der stärkeren Hinwendung zum christlichen Glauben verschwinden die Waffenbeigaben schließlich (BÄRENFÄNGER 1999e, 107). Diese Entwicklung vollzog sich schrittweise. Zunächst wurden sogenannte echte Beigaben aufgegeben, dann erfolgte eine Reduktion der Beigaben und endet schließlich mit der völligen Aufgabe der regelhaften Beigaben. Hierunter fallen in Ostfriesland auch personenbezogene Geräte wie Gürtel, Messer und Perlenketten.

Während im südlichen Niedersachsen die neuen Bestattungssitten der Körperbestattung in Folge des fränkischen Einflusses früher einsetzten, fand in der Küstenregion der Bestattungswechsel erst mit zeitlicher Verzögerung statt. Bei der Entwicklung von Beigabensitten und Grabsitten sind zwar Parallelen festzustellen, der Wandel aber muss sich in der Grabsitte nicht zwingend auf die Beigabensitte auswirkt haben.

Der frühmittelalterliche Grabbau in der ostfriesischen Halbinsel findet verschiedene Belege für den Bau von sogenannten Totenhäuschen. So fanden sich auffällige Pfostensetzungen bei Urnengräbern in Dunum (SCHMID 1999b, 170), wie auch auf einem jüngst in Dorfhagen, Landkreis Cuxhaven entdeckten frühmittelalterlichen Gräberfeld, wo Gruppierungen von vier bis sechs Pfostengruben nachgewiesen wurden. Zwischen zusammengehörenden Pfostengruben fand man ,,regelhafte Reste von Brandbestattungen“ (SCHÖN 2004, 91-94). Die Phosphatkartierung belegt im Innenbereich der Pfostenanlagen einen erhöhten Calciumphosphatanteil.

Das vermehrte Auftreten fränkischer Importgüter und ein Wechsel von Brand- zu Körperbestattungen deuten einen kulturellen Wandel im Frühmittelalter an. Die Verwendung niederrheinischer Gefäße als Urnen zeigt deren besondere Wertschätzung und belegt die bis in die ostfriesischen Geestrandgebiete reichenden Fernhandelsbeziehungen. Hierhin ist eher eine Übernahme „fränkisch-christlicher“ Bestattungssitten im Bereich der Akkulturation, d. h. der kulturellen Selbstanpassung an eine andere Ethnie ohne die eigene Zugehörigkeit aufzugeben, zu sehen. Ein umfassender fränkischer Herrschaftsanspruch konnte sich in dieser frühen Zeit noch nicht manifestieren. Denn d facto erfolgte mit Einverleibung sächsischer und friesischer Siedlungsgebiete keine umfassende Übernahme christlicher Riten; hierfür fehlte in den neuen fränkischen Grafschaften eine kirchliche Infrastruktur.

Als ein erster Rückschlag der Friesen-Mission wird der Tod Bonifatius bei Dokkum 754 n. Chr. angeführt. Die Eingliederung des Emsgaus, dem auch die Unteremsregion angehörte, in das Bistum 
Münster erfolgte nach 800. Die Diözese umfasste weite Teile Westfriesland in der Provinz Groningen, einen Großteil des Landkreis Leer und die Krummhörn. Die noch im 9. Jahrhundert übliche Beigabensitte und die traditionelle Art der Brandbestattung verdeutlicht demnach das friesische Selbstverständnis.

Nach dem germanischen Rechtsverständnis stellten Beigaben unmittelbar mit dem Toten verbundene Gegenstände dar, die nicht vererbt werden durften. Somit gaben frühe Christen aus traditionellen Beweggründen den Toten personengebundene Objekte mit in die gemeinschaftlich genutzten Grabstätten. Erst mit der Gründung von Ortskirchen und angrenzenden Kirchhöfen verschwand dieser Brauch. Das Verschwinden beigabenführender Reihengräberfelder des 6. und 7. Jahrhunderts im süddeutschen Raum steht mit dem Übergang zur Sepulturen der Kirchen in unmittelbarer Verbindung (REINECKE 1925, 103-105; vgl. STEIN 1967, 181-183).

Die persönliche Totengabe ,pro saltute anima“ belegt eine erstarkende kirchliche Organisation. Für den friesischen Raum ist explizit am Dunumer Gräberfeld mit seinen 778 Bestattungen ein langsamer Wandel vom beigabenreichen Brandgrab hin zu Körpergräbern mit vereinzelten Beigaben bzw. Trachtbestandteilen zu beigabenlosen Körperbestattungen feststellbar.

Bis dato wird in der Übernahme fränkischer Grabriten, dem Wechsel von Brand- zu Körperbestattung, sowie dem Wandel der Graborientierung und der Beigabensitte ein intensivierter christlicher Einfluss konstatiert. Inwieweit sich hinter diesem veränderten Grabritus rechtliche, soziale bzw. trachtgeschichtliche Gründe verbergen, ist bisher nicht untersucht worden. Hier stellt sich die Frage, inwiefern ein christliches Glaubensbekenntnis vom Grabritus des 7./8. Jahrhunderts n. Chr. abgeleitet werden kann.

\section{Siedlungsvorgang im Landkreis Leer}

Ziel der siedlungsarchäologischen Untersuchung ist es unter Berücksichtigung der geomorphologischen und klimatischen Verhältnisse den Besiedlungsablauf im Unteren Emsgebiet von der römischen Kaiserzeit bis in das Frühmittelalter nachzuvollziehen, wobei wirtschafts- und sozialgeschichtliche Fragen randlich thematisiert werden.

Die Wahl der Siedlungsplätze in einem so gegensätzlichen Naturraum, der von Marsch, Moor und Geest geprägt wird und zahlreiche Übergangsräume aufweist, stellte die Anpassungsfähigkeit des Menschen immer wieder vor neue Herausforderungen.

Die hydrologischen Verhältnisse haben auf die Besiedelbarkeit der Region einen wesentlichen Einfluss genommen. Weite Bereiche liegen zwischen $-0,5 \mathrm{~m}$ NN und $+3 \mathrm{~m}$ NN und waren vor Beginn der künstlichen Entwässerung und der Bedeichung Überschwemmungen schutzlos ausgeliefert. Hingegen kann der Höhenunterschied und mit ihm die Reliefenergie innerhalb des Untersuchungsgebietes als relativ gering bezeichnet werden. Auf der Geest sind es innerhalb eines 
Quadratkilometers meist nicht mehr als vier Meter $(+3 \mathrm{~m} \mathrm{NN}$ und $+7 \mathrm{mNN})$. Nordöstlich von Hesel können maximal NN-Höhen von $+16 \mathrm{~m}$ erreicht werden, während wenige Kilometer südlich der Jümmiger Hammrich (eine 7kqm große Niederung) bei +/-0m NN liegt.

In der Vergangenheit fand stets eine Wechselbeziehung zwischen Umwelt und Mensch statt, der sich unterschiedlich erfolgreich veränderten Lebensbedingungen anzupassen hatte. Dies änderte sich erst mit einer planvollen Einflussnahme des Menschen auf seinen Lebensraum. Ab dem 10. Jahrhundert begann man im Marschland mit dem Deichbau, während auf der Geest neue Wirtschaftsflächen durch Auftragsböden aus Plaggen entstanden. So entstand eine bis heute landschaftsprägende Kulturlandschaft.

Einbezogen werden die bisher bekannten, sicheren Fundstellen der römischen Kaiserzeit, der Völkerwanderungszeit und des Frühmittelalters (Tab. 16). Insgesamt 69 Fundstellen aus dem Landkreis Leer wurden für die nachfolgende Analyse aufgenommen. Es handelt sich um Siedlungen, Gräberfelder und Depotfunde. Die Quellenlage basiert auf der archäologischen Landesaufnahme. Eine quellenkritische Vorlage der Fundstellen erfolgte im Kapitel 4.2 (Archäologische Quellenlage).

\begin{tabular}{|l|c|c|c|c|c|c|}
\hline \multirow{2}{*}{ Zeitstufe } & \multicolumn{7}{|c|}{ Fundgattung } \\
\cline { 2 - 8 } & Siedlung & Nekropole & Depot & Gewässerfund & Werkplatz & Bohlenweg \\
\hline Rkz & 34 & 11 & 7 & 1 & 2 & 1 \\
\hline Vwzt & 10 & 2 & 2 & --- & --- & --- \\
\hline F-Ma & 19 & 5 & 3 & --- & --- & 1 \\
\hline
\end{tabular}

Rkz = römische Kaiserzeit; Vwzt $=$ Völkerwanderungszeit; Fma $=$ Frühmittelalter

Tab. 16

Aufgliederung der Fundgattungen nach Zeitstufen

Das Untere Emsgebiet bildet eine naturräumlich durch Niederungen und Moore weitgehend abgeschlossene Siedlungskammer. Dennoch war die Region verkehrstechnisch zu allen Zeiten gut erschlossen.

Hauptströme wie Ems, Jümme und Leda durchfließen den südlichen und südwestlichen Teil. Größere Binnenflüsse stellen das in die Jümme entwässernde Holtlander Ehetief und der Nordgeorgsfehnkanal dar. In die Leda entwässert u.a. das Langholter Tief und die Sater-Ems. Seit der Bronzezeit wurden Fernwege über den Höhenrücken von Leer über Hesel in die zentralostfriesische Geest sowie entlang des Geestrandes in die Hunteregion genutzt. Bohlenwege in Oltmannsfehn belegen eine bereits seit der Bronzezeit genutzte Wegeanbindung im Nordosten des Arbeitsgebietes. Die Verbindung diente dazu, isoliert liegende Geestdurchragungen im Moor zu erreichen, die erstmals in der älteren Eisenzeit 
aufgesiedelt wurden. Bohlenwege erschlossen in der frühen Kaiserzeit und auch noch im Frühmittelalter die als siedlungsfeindlich gelten Hochmoorareale im südlichen Ostfriesland.

Sämtliche Fundstellen aus dem Untersuchungsgebiet sind im Katalogteil II aufgeführt, wo auch der Fundbestand dokumentiert vorliegt. Unsicher datierte Plätze oder Fundstreuungen blieben unberücksichtigt. Für das frühmittelalterliche Gräberfeld Brinkum erfolgt zusätzlich eine separate Betrachtung, da im Rahmen dieser Studie umfangreiche pauschalchemische und anthropologische Untersuchungen durchgeführt worden sind und sich neue Erkenntnisse zum frühmittelalterlichen Grabbrauch ergeben haben.

Die Keramik wird den Fundstufen römische Kaiserzeit, Völkerwanderungszeit und Frühmittelalter zugewiesen. Während die römische Kaiserzeit in eine ältere und jüngere Phase gegliedert werden kann, ist eine weitere Unterteilung für die nachfolgenden beiden Zeitepochen nur in Ansätzen möglich. Dies liegt u.a. begründet in der geringen Fundmenge und der noch nicht hinreichend geklärten Keramikchronologie für diese Epochen. Das Keramikmaterial wird nach der bestehenden Typochronologie eingeordnet. Besonderen Wert wurde auf die Anteile an Feinkeramik, Import und die jeweils auftretenden Gefäßgattungen gelegt. Eine Quantifizierung konnte aufgrund der Fundmengen nur in Ausnahmen erfolgen.

Ausgewählte Altfunde, die vor 1972 entdeckt wurden, liegen im Tafelteil erstmals dokumentiert vor (Tafel 58-82). Für die Bereitstellung des Materials sei Herrn Dr. Wolfgang Schwarz an dieser Stelle herzlich gedankt. Später entdeckte Fundkomplexe sind zeichnerisch z.T. anhand publizierter Vorberichte erfasst. Eine darüberhinausgehende Dokumentation war aufgrund bestehender Publikationsrechte des archäologischen Dienstes der ostfriesischen Landschaft nicht möglich.

Die exakte Fundstellenkartierung ist über einen Faltplan im Anhang zu erschließen (Taf. 129). Für die Auswertung im Textteil wird eine verkleinerte Fundstellenkarte gewählt, um Fundstellenhäufungen besser darstellen zu können. Da nicht alle nah beieinanderliegenden Fundstellen grafisch im verkleinerten Fundbild zu markieren sind, wird ihre Anzahl über ein Symbol wiedergegeben. Als Kartierungsbasis dient eine vereinfachte naturräumliche Karte des Landkreises Leer, in die alle Hauptbodenarten zur besseren Anschauung aufgeführt sind.

\subsection{Naturräumliche Bedingungen im Untersuchungsraum}

Im südlichen Ostfriesland wird die naturräumliche Gliederung von den Landschaftseinheiten Geest, Marsch und Moor bestimmt (Kap. 2 Geologie). Zahlreiche Übergangszonen, wie Kalk-, Knick-, Brack- und Moormarsch, Hochmoor, lehmige Schluffböden sowie Sandböden verschiedener Kategorien, zeugen von einer landschaftlichen Vielfalt, die ihresgleichen sucht. Stellenweise findet sich ein starker Wechsel der Bodentypen und -arten auf kleinstem Raum. 
Die Bodenqualität war für die Wahl der Siedlungsplätze ein wichtiger Standortfaktor, stand sie doch für die wirtschaftliche Versorgung der Bevölkerung bis zum Aufkommen des Kunstdüngers im Vordergrund (DENECKE 1994, 248). Dies impliziert jedoch nicht, dass sich die Siedlungen auf den als hochwertig angesehenen Böden befanden; insbesondere dann nicht, wenn der landwirtschaftlich nutzbare Raum nur in geringem Umfang verfügbar war. So lässt sich für das Untersuchungsgebiet feststellen, dass Siedlungen zu verschiedenen Zeiten tendenziell auf weniger ertragreichen Böden angelegt wurden. Ausschlaggebend war die Nähe zum Wirtschaftsraum; dies bezieht sowohl Weidewirtschaft als auch Ackerbau mit ein.

Ein Ausläufer der oldenburgisch-ostfriesischen Geest erstreckt sich von Leer über Hesel in Richtung Aurich. Hier bestimmen sandige und lehmige Ablagerungen der Saale-Eiszeit die Oberflächenstruktur. Auf der niederen Geest dominieren mäßig trockene, teils lehmig-schluffige grundwassernahe Sandböden, die stellenweise in staunasse Böden übergehen.

Grundwasserferne Böden finden sich versprengt in höherliegenden Arealen um Brinkum, Hesel, Hasselt, Großoldendorf und Remels. Es überwiegen dort nährstoffarme staunasse lehmige Sandböden. Als Bodentypen vertreten sind Podsol-Braunerden und Pseudogleye, wiederholt auch Plaggenesch. Mäßig trockene Sandböden liegen um Logabirum, zwischen Nortmoor/Brinkum, Hesel/Schwerins und nordöstlich von Hollen. Im Süden sind diese Böden bei Steenfelde, zwischen Collinghorst/Backemoor und bei Ramsloh anzutreffen.

In den NO-SW gebildeten spätglazialen Tälern kam es im Atlantikum zur Hochmoorbildung. Bis zu ihrer Abtorfung im 18. Jahrhundert bedeckten Hochmoore im Norden, Süden und Westen weite Bereiche des Untersuchungsgebietes. So war ein Großteil des Moormerlandes nördlich von Leer mit Moor und vernässten Niederungen bedeckt. Als siedlungsfeindlich galten weite Areale im Nordosten, von denen sich mit dem Uplenger und Königsfehner Moor größere Moorgebiete erhalten haben. Auch im Süden begrenzten im heutigen Rhauderfehn die wie Barrieren wirkenden Hochmoore den trockenen Siedlungsraum auf wenige Geestinseln. Nach Osten schlossen sich in den Oldenburger Raum hinein weitere Moorgebiete an. Ein Großteil des Reiderlandes war von Hochmoor bedeckt.

Den großen Moorgebieten vorgelagert waren ehemals Flachmoore, die oftmals in nasse Niederungen und stellenweise in Anmoorgleye übergingen. Auf der Geest fanden sich Niedermoorböden meist in vermoorten Senken. Auch in den Flusstälern um Ems, Jümme und Leda ist die Bodengesellschaft der Niedermoore verbreitet. Der zwischen Jümme und Leda liegende Jümmiger Hammrich bedeckt eine 7qkm große Fläche und stellt die größte zusammengehörige Niederung im südlichen Ostfriesland dar. Nach Osten geht die Niederung in den Barger Hammrich über. Nördlich der Jümme schließt sich auf einer Länge von $5 \mathrm{~km}$ mit dem Nortmoorer Hammrich eine flussparallele Niederung an, die im Osten bei Stickhausen beginnt und erst kurz vor Leer in den Loganer Hammrich übergeht. Niedermoorböden 
finden sich südlich der Leda in der Region zwischen Mark-Milting, Breinermoor bis Backemoor.

Eine bis zu 2m hoch aufgeschlickte Flussmarsch findet sich am linken Ufer der Unteren Ems auf einer Breite von bis zu $1,5 \mathrm{~km}$, während das gegenüberliegende Ufer eine weniger als halb so große Marsch ausweist. Die Ems hat in ihrem Unterlauf eine schmal ausgebildete Kalk-Brackmarsch, die im Binnenland bis Nettelburg/Amdorf reicht. Ab dem Zusammenfluss von Jümme und Leda geht diese in eine gering mächtige Flussmarsch über, die sich bis Stickhausen/Velde erstreckt.

Mittelalterliche Überschwemmungen haben in der maritimen Flachlandregion des Unteren Emsgebietes teils zu mächtigen Sedimentablagerungen geführt. Die letzte landschaftsprägende Überschwemmung stellt der Dollarteinbruch im 15. Jahrhundert. Darüber hinaus wurden die Böden im Untersuchungsraum in einzelnen Regionen bis in eine Tiefe von $2 \mathrm{~m}$ durch den Auftrag von Plaggen, den Abtrag von Soden und / oder der künstlichen Entwässerung der Torfe nachhaltig anthropogen verändert. Vielfach erfolgte eine Degradierung der Oberböden, die Veränderungen der Gefüge- und Nährstoffverhältnisse nach sich zog. Hiervon kaum betroffen waren die niedrig liegenden Geestränder.

Lokal bestimmend für den Siedlungsstandort waren die Wasserverhältnisse, da sie eine grundlegende Ressource darstellten (DENECKE 1994, 244). In der Flussmarsch und am Geestrand stellte der Zugang zu Wasser aufgrund des hohen Grundwasserstandes kein Problem dar. Auf der Geest wurde die Nähe zu Wasserläufen gesucht. War dies nicht möglich errichtete man Brunnen, um grundwasserführende Schichten zu erreichen, oder Zisternen zur Sammlung von Regenwasser.

In der reliefarmen Region Südostfrieslands waren die hydrologischen Bedingungen noch aus einem anderen Grund für die Standortwahl entscheidend. Oftmals war es nötig sich vor Staunässe oder temporären Überflutungen zu schützen. So zeigt sich bei der Siedlungsverteilung eine deutliche Bevorzugung von Arealen, die im Verhältnis zur Umgebung als relativ hoch angesehen werden können. Hierbei handelte es sich jedoch oftmals um geringe Höhendifferenzen, die zwischen 2 und 4m lagen.

\subsection{Fundstellen der römischen Kaiserzeit}

Von 50 der 69 Fundstellen im Landkreis Leer stammen Funde der römischen Kaiserzeit (Taf. 130). Bei 34 Stellen handelt es sich um Siedlungen, wovon 17 dem gesamten Zeitraum zugeordnet werden können (FStNr. 01-05; 07; 19-28; 30; 31; 34 (34a u. 34b); 35-37; 39; 43; 47; 53; 55; 60; 61; 64-67; 69). Die übrigen verteilen sich auf sieben frühkaiserzeitliche Siedlungen, denen sechs mittel- bis spätkaiserzeitliche gegenüberstehen. Früh- bis mittelkaiserzeitlich datieren vier Fundstellen.

Es existieren darüber hinaus elf Bestattungsplätze (FStNr. 02; 09; 20; 29; 35; 51; 56; 58; 59; 61; 62), von denen vier in der frühen Kaiserzeit enden. Früh- bis mittelkaiserzeitliche Brandbestattungen liegen aus zwei Nekropolen vor, mittelkaiserzeitliche finden sich in vier Nekropolen. Lediglich ein 
Gräberfeld wird in der gesamten Kaiserzeit belegt. Ein ungewöhnlich frühes Zeugnis der einsetzenden Körpergrabsitte in der späten Kaiserzeit stammt aus dem Westerhammrich.

Auffällig ist die Diskrepanz zwischen Siedlungen und Gräberfeldern. Da Grabkeramik und die aufgefundenen Beigaben sich besser chronologisch einordnen lassen als Siedlungsfunde, die sich häufig einer genaueren Datierung entziehen, ist diese Unstimmigkeit vermutlich forschungsbedingt zu deuten. Doch auch eine Belegung von zwei benachbarten Siedlungsplätzen ist denkbar.

Für die Niederlegung kaiserzeitlicher Depotfunde gibt es im Untersuchungsgebiet keine bestimmte Präferenz bei der Wahl des Naturraumes. Sie sind sowohl im Moor (FStNr. 18), der Ems (FStNr. 32), auf der Geest (FStNr. 12) oder in der Flussmarsch (FStNr. 40) belegt. Meist handelt es sich um Objekte, die bewusst niedergelegt worden sind, wie zwei Hemmoorer Eimer in der Nähe des Leeraner Bahnhofs (FStNr. 42). Ob es sich bei dem fragmentierten Eimer, um einen Depotfund oder Teil einer mittelkaiserzeitlichen Brandbestattung handelte, ist nicht zu entscheiden (FStNr. 42).

Von vier Fundorten sind Denarhorte größeren Umfangs bekannt (FStNr. 12; 32; 40; 54). Sie setzen sich vorzugsweise aus Münzen der römischen Republik des 1. Jahrhunderts v. Chr. bis in die Kaiserzeit des 2. Jahrhunderts n. Chr. zusammen. Nur in zwei Fällen fanden sich Einzelmünzen im Siedlungskontext (FStNr. 02; 61).

Außergewöhnlich ist der Fund eines goldenen römischen Fingerringes aus dem Stapelermoor nordöstlich von Remels (FStNr. 18). Ganz in der Nähe gelang der Nachweis einer prähistorischen Wegeverbindung. Der durch das Moor von Meinersfehn führende Bohlenweg wurde zwischen $300 \mathrm{v}$. Chr. bis 100 n. Chr. genutzt (FStNr. 17).

Zeugnis einer lokalen Buntmetallverarbeitung entdeckte man im Westerhammrich (FStNr. 35). Neben Schmelztiegeln fanden sich als Rohstoff wiederverwendete Bronzefragmente, darunter auch eine fragmentierte Marsstatuette. Kaiserzeitlich wird ein nahe Holtland entdeckter Eisenverhüttungsplatz mit 16 Ausheizherden, zwei Meilergruben und einer Ofenkuppel datiert (FStNr. 48). Auf eine lokale Eisenverarbeitung deuten Schlackefunde im Nortmoorer Hammrich und in Backemoor hin (FStNr. 61; 69). Vermutlich kaiserzeitlich werden Schlackefunde von vier weiteren Fundstellen (FStNr. 03; 19; 25; 65) datiert. Da mit Ausnahme von Holtland und Nortmoor keine metallurgischen Untersuchungen der Schlacken erfolgten, kann bei mehrperiodigen Siedlungsstellen eine mittelalterliche Metallverarbeitung nicht ausgeschlossen werden (FStNr. 02; 27; 33; 34; 36; 51; 53; 55).

\subsubsection{Das 1. Jahrhundert n. Chr. (Stufe 1)}

40 Fundstellen gehören in das 1. Jahrhundert n. Chr., 22 davon bestehen bis in das 3./4. Jahrhundert. Frühkaiserzeitlich datieren 32 Siedlungen (FStNr. 02-05; 07; 19-28; 30; 31; 34 (34a u. b); 35-37; 39; $43 ; 47 ; 53 ; 55 ; 60 ; 61 ; 64 ; 65 ; 66 ; 67)$. Ein Siedlungsabbruch im 1. Jahrhundert ist nur bei sechs Siedlungen zu beobachten; der überwiegende Teil besteht früh- bis wenigstens mittelkaiserzeitlich. 
Elf Siedlungen wurden vermutlich bereits in der Spätlatènezeit gegründet. Es überwiegen hierbei Siedlungen in der Flussmarsch des Reiderlandes (FStNr. 03; 04; 19; 20; 21; 24; 28; 34a). Doch auch auf der gegenüberliegenden Emsuferseite im Westerhammrich finden sich eisenzeitlichen Baubefunde (FStNr. 35). Aus der Jümme-Niederung liegen von verschiedenen Stellen eisenzeitliche Siedlungskeramik vor, so in Filsum und Amdorf (FStNr. 55; 60).

Bestattungen der frühen Kaiserzeit liegen im Untersuchungsgebiet bei Warsingfehn, AmdorfBonnhausen, Detern, Midlum-Eppingawehr und im Nortmoorer Hammrich vor. Eine Belegungskontinuität von der späten Eisenzeit an findet sich bei allen fünf Plätzen (FStNr. 09; 20 (?); 58; 61; 62 (62a)), wobei die Nekropole in Amdorf-Bonnhausen als einzige bis in die Völkerwanderungszeit genutzt wurde. Sollte auch das sich auf der gegenüberliegenden Ledaseite befindliche Urnengrab von Nettelburg zur Nekropole gehört haben, wäre dies ein Beleg für eine nachkaiserzeitliche Verlandung der Leda, der in diesem Bereich die Herausbildung eine neuen Ledaschleife zur Folge hatte.

Münzen der römischen Republik (150-10 v. Chr.) bis in die frühaugustäische Zeit finden sich in einem reiderländischen Denarhort (FStNr. 40). Der 1863 in Holtgaste nahe Jemgum entdeckte Schatz steht möglicherweise mit der römischen Anwesenheit im Unteren Emsgebiet während der Germanenkriege in Zusammenhang.

Mit Ausnahme eines umfangreichen Münzschatzfundes nahe Filsum, der Einzelmünzen mit Prägedatum um 70 n. Chr. enthielt, datieren die übrigen Denarfunde in das 2.-3. Jahrhundert n. Chr.

Einzelne Münzfunde aus der frühen römischen Republik konzentrieren sich auf reiderländische Fundorte in Bentumersiel, Bingum, Wischenborg sowie einem Gewässerfund in der Ems.

Bevorzugter Siedlungsraum der Stufe 1 war die Marschenzone am Unterlauf von Ems, Jümme und Leda. Frei von kaiserzeitlichen Besiedlungsspuren sind die in vorangegangenen Epochen alt besiedelten Geestflächen. Fundleere Zonen finden sich südöstlich der Leda und nordöstlich der Jümme. Die in der Eisenzeit aufgesuchten sandigen Böden werden nun zugunsten von Niederungen und lehmigen (kleihaltigen) Böden gemieden. Bei der Siedlungsverteilung fällt zudem eine Bevorzugung der Wassernähe auf.

Es handelt sich i.d.R. um Flachsiedlungen, die meist in Geländehöhen von $+1,2 \mathrm{~m}$ bis $+3,6 \mathrm{~m}$ angelegt worden sind. In der Emsmarsch sind nur wenige Fundstellen in einer NN-Höhe von $+0,4 \mathrm{~m}$ anzutreffen. Dabei wird jedoch eine rezente Bodensenkung wegen der Torfrückbildung zu berücksichtigen sein, die aufgrund intensiver Entwässerungen der Region seit der Neuzeit stattfinden. Tendenziell ist zu beobachten, dass in dem weitgehend flachen Terrain bei der Siedlungswahl stets auf eine leicht erhöhte Lage gegenüber der Umgebung geachtet wurde. 
Erwähnenswert ist der Eisenverhüttungsplatz bei Holtland (FStNr. 47). Zwar fanden sich nur wenige Keramikscherben, diese lassen jedoch eine Datierung in die späte Eisen- bis frühe Kaiserzeit wahrscheinlich erscheinen. In das selbe Zeitfenster gehörte auch der Bohlenweg bei Meinersfehn. Eine ${ }^{14} \mathrm{C}$ Datierung belegt eine Nutzungsdauer zwischen 300 v. Chr. bis 100 n. Chr. (FStNr. 17).

In Siedlungen wie auch in den Gräbern der frühen Kaiserzeit überwiegen in dieser Zeit Keramikgefäße mit kurzen kaum facettierten Rändern. Beispielhaft sei auf Grabkeramik der Nekropole von Bonnhausen bei Amdorf verwiesen (ROSENPLÄNTER 2002, Taf. 1-5). Hier sind an schwach s-förmigen Gefäßen mit hohem Umbruch schlichte Fingertupfenränder anzutreffen.

Neben weitmündigen Töpfen finden sich flache Schalen mit innen leicht abgesetzter Randlippe. Verzierungen sind selten. Römischer Import in Form einer Barbotine-Schüssel des 2. Jahrhunderts und eine völkerwanderungszeitliche Riemenzunge weisen auf eine längere Belegungsdauer hin (FStNr. 58). In der Siedlung Eppingawehr fand sich eine vergleichbare Ware, die jedoch in ihrer Ausformung gröber ausgearbeitet war (FStNr. 20, Taf. 76-82). Hinzuweisen sei auf einen mit Dekor verzierten Backteller und die Reste eines tönernen Feuerbockes.

\subsubsection{Das 2.-3. Jahrhundert n. Chr. (Stufe 2)}

In Stufe 2 existieren die bestehenden Siedlungen mit wenigen Ausnahmen an ihren Standorten fort (FStNr. 01-05; 19-23; 25-28; 31; 34 (34a u. b); 35-36; 39; 47 (?); 53; 55; 60; 61; 64-67; 69). Im Binnenland entsteht mit Backemoor eine neue Siedlung; jedenfalls soweit der kleinräumige Grabungsschnitt eine Aussage zur Anfangsdatierung der Siedlung zulässt. Bei sechs Siedlungen ist hingegen ein Siedlungsabbruch festzustellen, und auch die Anzahl der Bestattungsplätze nimmt ab, während sich die Zahl der Hortfunde im Unteren Emsgebiet deutlich erhöht.

Ein ungewöhnlich reicher Münzschatz wurde um 1850 nahe Filsum am Geestrand gefunden, bedauerlicherweise jedoch in einem nahen Bach versenkt. Überliefert sind 25 Münzen mit einem Prägedatum zwischen 69/70 n. Chr. bis 190/191 n. Chr., wobei sich ein deutlicher Schwerpunkt im 2. Jahrhundert zeigt.

In Phase II liegen Siedlungen mehrheitlich auf fruchtbaren Flussmarschböden. Weiterhin relativ dicht besiedelt ist die Emsmarsch, wobei sich eine deutliche Bevorzugung des linken Emsufers zeigt, während sich auf der gegenüberliegenden Seite nur vereinzelt Siedlungsbefunde finden. Möglicherweise liegt dies an der dort nur halb so breiten Marschenzone. Die sogenannte Fundarmut kann durch die weitgehende Erosion des rechten Emsufers zwischen Leer und Emden, mit wenigen Ausnahmen, bedingt sein. Auch eine forschungsgeschichtliche Beeinflussung nicht auszuschließen; das Reiderland wurde in den 20er Jahren des 20. Jahrhunderts durch VAN GIFFEN und ZYLMANN intensiv erforscht. 
Ebenfalls weiter besiedelt sind die Flussmarschareale von Leda und Jümme bis in die Umgebung von Stickhausen-Detern. Zwar erscheint die naturräumliche Lage bei den Geeststandorten zunächst aus dem bekannten Siedlungsbild zu fallen, aber sowohl die Siedlung in Loga, Hollen, Weener und Backemoor hatten einen unmittelbaren Zugang zur nahen Niederungszone (FStNr. 53; 64; 65; 69).

Das Siedlungsmuster findet seine Erklärung in der Verteilung und Zugänglichkeit der Wirtschaftflächen. Diese lagen vorzugsweise in Flussauen und Niederungen; ein Indiz für die vermutlich dominierende Weidewirtschaft, gefolgt von Ackerbau und Fischfang. Auch am Geestrand wird, wohl im begrenztem Umfang, Ackerbau möglich gewesen sein. Zu beobachten ist bei nahezu allen Siedlungen eine Lage in Randbereichen mit verschiedenen geomorphologischen Gegebenheiten. Dabei spielten die kleinräumigen Ausprägungen der Bodenarten eine wichtige Rolle. In erster Linie sind es kalkhaltige Marschenböden, gefolgt von nährstoffreichen Niedermooren und lehmigen Sandböden.

Klimatische Veränderungen in der römischen Kaiserzeit haben zu einer allgemein feuchteren Witterung geführt. Auch die rückstauende Wirkung der D-II Transgression wird sicherlich Einfluss auf die Standortwahl gehabt haben. Die bereits in höheren Lagen besiedelten Plätze blieben weiterbestehen; bei Flachsiedlungen wurde eine Verlagerung nötig. Ausschlaggebend für die Aufgabe der Siedlungen wird die längerfristige Vernässung der Wirtschaftsflächen gewesen sein.

In der Emsmarsch sind kaiserzeitliche Flachsiedlungen zwischen $+0,4$ bis $+1,5 \mathrm{~m} \mathrm{NN}$, mit einer Häufung zwischen $+0,8 \mathrm{~m}$ bis $+1,5 \mathrm{~m} \mathrm{NN}$, anzutreffen. Während dessen weisen zeitgleiche Wurten in der Region Geländehöhen von $+3 \mathrm{~m}$ bis $+4,1 \mathrm{~m}$ NN auf. Bei mehrperiodigen Wurten bezieht sich die NN-Höhe zumeist auf die oberste Siedlungsschicht; dies kann im ungünstigsten Fall die mittelalterliche Siedlungsphase sein. Da jedoch auch andernorts kaiserzeitlich besiedelte Wurten eine mittlere Höhe von $+3 \mathrm{~m}$ NN aufweisen, ist wohl davon auszugehen, dass der maximale Sturmflutpegel unter dieser Höhe lag. Auch der Westerhammrich berücksichtigt mit $+3 \mathrm{~m}$ NN diese wichtige Höhenmarke. Selbst relativ weit von der ostfriesischen Küste entfernte Siedlungen wie Brill $(+2,75 \mathrm{~m}$ NN) scheinen die Extremwasserstände einbezogen zu haben (vgl. LEHMANN 2002, 185).

Im Unteren Emsgebiet finden sich Binnensiedlungen in der Flussmarschzone bereits ab einer Höhe von $+1,2 \mathrm{~m}$ NN, während näher zur Ems hin in Loga sogar Siedlungshöhen von $+6 \mathrm{~m} \mathrm{NN}$ aufgesucht wurden. Weiter landeinwärts überwiegen am Geestrand Siedlungen in Höhenlagen zwischen $+2 \mathrm{~m}$ bis $+3,5 \mathrm{~m} \mathrm{NN}$.

Insgesamt zeigt sich eine Verdichtung des Siedlungsbildes im Laufe der Kaiserzeit. Dies entspricht einer allgemeinen Beobachtung im Küstengebiet der nördlichen Nordsee (SCHMID 1984). In der 
mittleren Kaiserzeit reduzierte sich die Anzahl der Siedlungsplätze und zunehmend wurden Einzelgehöfte von dorfartigen Siedlungen abgelöst. Diese Entwicklung scheint im Unteren Emsgebiet jedoch weniger stark ausgeprägt gewesen zu sein. Auch in Stufe II dominieren Einzelgehöfte das Siedlungsbild und nur wenige Siedlungen können als Weiler angesprochen werden.

Aussagen zur Siedlungsgröße sind jedoch unter Vorbehalt zu treffen. Es ist bisher nicht gelungen im Untersuchungsgebiet eine kaiserzeitliche Siedlung komplett freizulegen. Meist handelt es sich um Teilgrabungen bzw. war die Befundlage bereits vor Entdeckung der Siedlung gestört. Es ist daher nicht auszuschließen, dass die Interpretation durch die Quellenlage beeinflusst wird.

Hinweise auf eine Bevölkerungskontinuität seit der vorrömischen Eisenzeit erschließen sich auch durch die Weiterbelegung von Gräberfeldern im Untersuchungsgebiet. So sind von Amdorf, dem Nortmoorer Hammrich und Detern sowohl späteisen- wie auch kaiserzeitliche Gräber überliefert. In Amdorf/Bonnhausen wurde sogar bis in die frühe Völkerwanderungszeit hinein bestattet, während es im Nortmoorer Hammrich im 1. Jahrhundert n. Chr. zu einem Abbruch der Bestattungsfolge kam. Möglicherweise kam es zur Verlegung des Gräberfeldes an einen anderen Platz.

Kaiserzeitliche Gräberfelder liegen meist in unmittelbarer Nachbarschaft zu den Siedlungen. Dies ist in Amdorf, Eppingawehr, Midlum, Logabirum und im Westerhammrich der Fall. Somit wäre auch für die Nekropolen in Detern nahe Stickhausen und in Isbargen-Plaggenburg nördlich von Nortmoor eine benachbarte Siedlung zu erwarten. Beide Standorte zeichnen sich durch ihre Lage im Übergangsbereich von der Flussmarsch zur niederen Geest aus, die sich ebenfalls gut in den bekannten Siedlungsablauf einfügen würde. Eventuell handelt es sich bei Isbargen-Plaggenburg um die Nachfolgenekropole für den kaiserzeitlichen Bestattungsplatz.

Das alt gegrabene Gräberfeld Isbargen-Plaggenburg (FStNr. 56; Taf. 78) befand sich am Geestrand nördlich vom Ortskern Nortmoor und etwa $2 \mathrm{~km}$ von der kaiserzeitlichen Siedlung Nortmoorer Hammrich entfernt. In der Nähe dreier in Isbargen geborgenen Urnen fand man eine halbkreisförmige Feuerstelle; eventuell der zugehörige Scheiterhaufen.

Der in den Urnen enthaltene Leichenbrand wurde 2004 von Frau Dr. Birgit Großkopf anthropologisch untersucht (Tab. 15). Die Leichenbrände waren unvollständig erhalten. Es sind Knochen aus allen Skelettregionen überliefert. Da die Knochen fast vollständig verbrannt sind, kann auf eine hohe und gleichmäßige Verbrennungstemperatur geschlossen werden.

Mit einem Gewicht zwischen 348 und 494 Gramm ist keine der Bestattungen repräsentativ überliefert. Die Bestatteten in Urne I und III ist vollständig verbrannt; d.h. sie waren komplett dem Scheiterhaufenfeuer ausgesetzt. Am Knochenmaterial der maskulinen Individuen finden sich pathologische Veränderungen. Der Bestattete von Grab I weist eine Randleistenbildung an einem 
Fragment des Lendenwirbels und am Brustwirbel auf, die auf degenerative Veränderungen hinweisen. Möglicherweise war dies altersbedingt oder durch eine länger andauernde Fehlbelastung verursacht. Hinzu kam ein Zahnverlust im Oberkiefer.

Eine meningiale Reaktion zeigte die Schädelkalotte der anderen männlichen Bestattung; ähnlich dem Befund einer Hirnhautentzündung, wie ihn ein weibliches Individuum in der nahen Nortmoorer Nekropole aufwies.

\begin{tabular}{|l|c|c|l|l|l|}
\hline $\begin{array}{l}\text { Inv. } \\
\text { Nr }\end{array}$ & $\begin{array}{l}\text { Grab } \\
\text { Nr. }\end{array}$ & $\begin{array}{l}\text { Gewicht LB } \\
\text { in Gramm }\end{array}$ & $\begin{array}{l}\text { Sterbealter } \\
\text { Geschlecht }\end{array}$ & $\begin{array}{l}\text { Pathologische } \\
\text { Veränderungen }\end{array}$ & Funde unter dem LB \\
\hline $135: 35$ & I & 494 & $\begin{array}{l}\text { spätadult } \\
\text { maskulin }\end{array}$ & $\begin{array}{l}\text { Intralverlust 1. } \\
\text { Molar links; } \\
\text { Spondylose am } \\
\text { Lendenwirbel }\end{array}$ & - --- \\
\hline $136: 35$ & II & 403 & $\begin{array}{l}\text { mitteladult } \\
\text { Tendenz } \\
\text { feminin }\end{array}$ & $\begin{array}{l}\text { Fragmente von Knochennadeln, } \\
\text { Reste eines Knochenkammes } \\
\text { (verziert, mit Metallaufschmel- } \\
\text { zung), Holzkohleartige Substanz } \\
\text { mit glatter Oberfläche }\end{array}$ \\
\hline $134: 35$ & III & 348 & $\begin{array}{l}\text { frühmatur } \\
\text { Tendenz } \\
\text { maskulin }\end{array}$ & $\begin{array}{l}\text { Meningiale } \\
\text { Reaktion }\end{array}$ & $\begin{array}{l}\text { Wandscherbe mit Punktmuster, } \\
\text { Holzkohle, Getreidespelzen } \\
\text { (evtl. rezent?) }\end{array}$ \\
\hline
\end{tabular}

Tab. 15

Angabe Leichenbrandgewicht, Sterbealter, Pathologische Veränderungen, Funde im Leichenbrand vom Gräberfeld Isbargen-Plaggenburg bei Nortmoor, Ldkr. Leer

Die Bestattung II gehört einer mittelaldulten Frau. Eine vollständige Verbrennung kann aufgrund der festgestellten Kohlenstoffverbindungen ausgeschlossen werden. Diesem Umstand ist es wohl zu verdanken, dass sich Überreste der mitverbrannten Beigaben unter dem Leichenbrand erhielten. Neben Fragmenten von Knochennadeln und einem Knochenkamm sind dies Metallaufschmelzungen und eine holzkohleartige Substanz. Hinweis auf eine sorgfältige Auflesung nach dem Verbrennungsprozess geben die zahlreichen Finger- und Zehenknochen unter dem Leichenbrand.

Frühkaiserzeitliche Bestattungen liegen von fünf Plätzen vor. Selten finden sich jedoch mehr als 3-5 Gräber. Einzige Ausnahme stellen Nortmoor mit elf Individuen und Amdorf-Bonnhausen mit 15 Brandbestattungen dar. Aufgrund der geringen Größe der kaiserzeitlichen Nekropolen im Untersuchungsgebiet kann wohl auf Familien- bzw. Sippen-Friedhöfe geschlossen werden, die von ein 
bis zwei Gehöften aus der Umgebung frequentiert wurden.

Die einzige größere Nekropole wurde 1936 bei Ausgrabungen in Amdorf-Bonnhausen freigelegt (FStNr. 58). Die ursprünglich wohl überhügelten Gräber fanden sich am Zusammenfluss von Jümme und Leda. Es handelte sich um Brandgrubengräber, Knochenlager und Urnenbestattungen. Sämtliche Bestattungen enthielten Beigaben, u.a. Knochenkämme, Spinnwirtel oder Bronzegegenstände, die jedoch nur teilweise den einzelnen Bestattungen zugeordnet werden können. Der vermutlich zugehörige Siedlungsplatz wurde 1996 etwa 300m nordöstlich bei Erdarbeiten entdeckt, jedoch nicht ausgegraben und dokumentiert (FStNr. 60).

Beigaben sind nur von wenigen Bestattungsplätzen überliefert. Neben dem Gräberfeld in AmdorfBonnhausen und ist dies eine Urne in Warsingsfehn; letztere enthielt eine Bronzefibel Typ Nauheim.

Neu im Fundrepertoire ist ein häufiges Auftreten von Terra Nigra und Nachahmungen von Terra Sigillata (FStNr. 19; 22; 23; 26; 29; 32; 33; 34; 35; 53; 58; 61; 69). Die Importe sind eher in Siedlungen anzutreffen, nur in einem Fall findet sich römischer Import in einer Bestattung (Brandgräberfeld Amdorf-Bonnhausen). Insgesamt zeugt die große Verbreitung sogenannter Luxusgüter im Unteren Emsgebiet von wirtschaftlichem Wohlstand.

Feinkeramik lokaler Provienienz zeichnet sich durch weitmündige Trichterschalen mit dreifach facettiertem Rand aus (RF 7.1; 7.3; 7.6), der stellenweise stark ausgewendet und lang ausgezogen sein kann. Sie findet sich in Siedlungen und auch in Gräbern. An der Grobkeramik ändert sich wenig; tendenziell sind die Gefäßkonturen stärker gebaucht, die Ränder verdickt und länger ausgezogen.

\subsubsection{Siedlungsmuster in der Römischen Kaiserzeit}

In der Spätlatènezeit begann eine neue Siedlungsperiode, die sich nur in wenigen Fällen mit der von Vorgängersiedlungen im Unteren Emsgebiet deckte. Erstmals in der älteren Kaiserzeit kommt es zur Ausbildung einer Gebäudereihung bei den Ansiedlungen, die sich eindeutig an den Flussläufen orientieren und dem Geländerelief entsprechend sich aufreihen. Hierbei wird ein bis in die späte Eisenzeit wenig genutzter Naturraum verstärkt aufgesiedelt. Es finden auch gezielte Neuansiedlungen am Geestrand und im Flussmarschgebiet der Leda-Jümme-Niederung statt. Für Siedler kaum von Interesse waren dagegen die hohe Geest sowie die dortigen Flach- und Hochmoore; jedenfalls nach Auswertung der bisher bekannten Fundstellen.

Sind in der Emsmarsch charakteristische Abstände von 1,5-3km zwischen den Fundstellen anzutreffen, so finden sich im Binnenland Distanzen von 3-6km. Neben der Möglichkeit, dass die größere Entfernung der Siedlungen zueinander eine forschungsgeschichtliche Lücke anzeigt, könnte die ungleiche Siedlungsdichte mit der Verfügbarkeit von Wirtschaftsflächen in Verbindung stehen. 
Zum einen war die Jümme-Marsch weniger stark aufgeschlickt und demzufolge auch nicht so kalkreich wie die Emsmarsch, zum anderen aufgrund ihrer geringen Höhenlage stärker von Vernässung bedroht. Insgesamt also der weniger günstige Siedlungsort.

Für die Jümme-Region sind stärker wechselnde geomorphologische Verhältnisse auf relativ kleinem Raum charakteristisch. Jenseits der Flussmarsch finden sich zur Nässe neigende saure Ton- und Moorböden, die in Niedermoorböden übergehen.

Dies mag der Grund sein, warum als Siedlungsstandorte Sanddurchragungen oder Geestzungen gewählt wurden, die in der Flussmarsch oder nahe bei dieser lagen und von wo aus eine gute Erreichbarkeit der Wirtschaftsflächen gewährleistet war.

Die weniger günstigen naturräumlichen Bedingungen in der Jümme-Niederung hatten vermutlich einen höheren Flächenbedarf zur Bewirtschaftung zur Folge. Dem entspricht eine geringere Siedlungsdichte, die sich auch in der isolierten Lage der Siedlungen wiederfindet.

Waren in den vorangegangen Stufen Wandersiedlungen verbreitet, so bildeten sich im Untersuchungsraum nun vermehrt platzkonstante Siedlungen heraus. Ihre wirtschaftliche Basis war in erster Linie die Weidewirtschaft, die in den grasreichen Niederungen ideale Bedingungen fand. Das milde Küstenklima erlaubte eine weitgehende Außenhaltung der Tiere. Die unbedeichte Flussmarsch bot hinreichend Flächen für Ackerbau, der auch entlang der Geestränder in geringem Umfang möglich war. Bauholz u.a. bezog man von der Geest.

Die Kolonisation des Unteren Emsgebietes, die sich in zahlreichen Siedlungsneugründungen manifestiert, steht eventuell mit der in der Mitte des 1. Jahrhunderts überlieferten Abwanderung der lokalen Bevölkerung in Verbindung (TAAYKE 1996, 191). Römische Quellen berichten von einer $56 \mathrm{n}$. Chr. erfolgten Vertreibung der hier ansässigen Amsivarier durch die Chauken (vgl. Kap. 4.1 Schriftquellen). Es ist jedoch fraglich, ob es zu einem völligen Exodus der lokalen Bevölkerung im 1. Jahrhundert kam. So ist sowohl bei einigen Siedlungen in der Emsmarsch, wie bei Gräberfeldern in der Jümme-Marsch eine Platzkontinuität zu beobachten. Eine kontinuierliche Fortdauer der Besiedlung kann wenigstens von der Spätlatènezeit bis in die frühe und mittlere Kaiserzeit und an einigen Plätzen auch darüber hinaus angenommen werden.

Im niedersächsischen Küstengebiet wird in der Kaiserzeit allgemein eine Aufsiedlung der Marschen und benachbarter Geestränder beobachtet (SCHMID 1984; SCHWARZ 1999). Ob sich dahinter, wie vermutet, eine Siedlungskonzentration an zentralen Orten verbirgt oder eine Bevölkerungsreduktion, ist bisher nicht eindeutig geklärt. Die Anlage größerer Wurten in der Seemarsch oder der Ausbau der Geestsiedlung in Flögeln scheint dem ersteren zu entsprechen (SCHMID 1979, 407). Eine 
Fundstellenauszählung im Landkreis Wittmund bestätigt eine starke Abnahme jüngerkaiserzeitlicher Stellen (SCHWARZ 1997, 265-274). Sowohl in Flögeln wie im jütländischen Vorbasse finden sich größere dorfartige Siedlungen, die über 400 Jahre bestanden. Ein derartiger Siedlungsausbau war jedoch nur dort möglich, wo es eine wirtschaftliche Basis gab, eine entsprechende Bevölkerungsstärke (80-120 Personen) auch zu versorgen. Dies kann jedoch in weniger ertragreichen Regionen kaum der Fall gewesen sein. Deswegen haben kaum mehr als zwei bis drei Gehöfte zeitgleich in kaiserzeitlichen Siedlungen bestanden.

Im Unteren Emsgebiet bestimmten weilerartige Siedlungen und Einzelgehöfte das Siedlungsbild. Hier sind die naturräumlichen Bedingungen insgesamt als günstiger anzusehen. Dennoch scheint es nicht zur Herausbildung dorfartiger Ansiedlungen zu kommen. Ob man die kaiserzeitliche Siedlung Westerhammrich als größeren Zentralort ansprechen darf, wird erst die abschließende wissenschaftliche Publikation der Befunde zeigen. Nach den publizierten Vorberichten fügt sich die Siedlung jedoch in das bekannte Siedlungsmuster ein.

Es ist zu überlegen, ob sich hinter der regelhaften Siedlungstruktur der Familiengruppen bzw. Sippen im Untersuchungsgebiet territoriale Gemeinschaften verbergen. Schließt man sich der von WATERBOLK $(1979$, 4) vertretenden These an, so bilden sich in benachbarten oder nahe beieinanderliegenden Siedlungsräumen, die vergleichbare naturräumliche Bedingungen aufweisen, an die Umgebung angepasste Gemeinschaften heraus, die nicht nur über eine vergleichbare wirtschaftliche Basis verfügen, sondern auch in einem kulturellen Austausch stehen. Fundleere Zonen zwischen Territorialgruppen sind dabei als Grenzbereiche anzusehen. Vermutlich trennende Funktion hatten Hoch- und Flachmoore, die die zentrale Flussmarsch im südlichen Ostfriesland umgaben.

Als Siedlungsgefilde sind das linke Emsufer, die Region um Leer, die Flussmarsch zwischen Loga und Nortmoor sowie der Geestrand zwischen Filsum und Velde zu nennen. Einige Siedler kolonisierten die Niederung südwestlich der Leda. Größere Einheiten stellten vermutlich die Emsmarsch und die LedaJümme-Niederung dar, die als Siedlungskammern eine Fläche von 80-100qkm abdeckten. Damit reichen sie an die Größe von eisenzeitlichen Siedlergemeinschaften heran (vgl. WATERBOLK 1979, 5).

Der Übergang vom älteren Abschnitt der vorrömischen Eisenzeit in den jüngeren ist nicht Bestandteil der Untersuchung. Es ist jedoch auffällig, dass sich Fundstellen der älteren Eisenzeit hauptsächlich in den höher liegenden Geestgebieten im Norden des Arbeitsgebietes befinden (SCHWARZ 1995, 183, Karte 3). Bevorzugt aufgesiedelt wurden leichte Sandböden auf den Hochflächen des Moormer- und Overledigerlandes. Neugründungen auf Sandinseln im Moor zeigen einen erhöhten Bedarf an Siedlungsareal an, wobei ihre wegetechnische Anbindung über Bohlenwege, wie in Ockenhausen, erfolgte. 
Die bereits in der Bronze- und Steinzeit aufgesuchten Siedlungs- und Wirtschaftsflächen auf der Geest wurden in der jüngeren Eisenzeit verlassen; möglicherweise infolge einer ökologischen Krise, die eine landwirtschaftliche Nutzung des kargen Naturraumes nicht mehr erlaubte.

$\mathrm{Ob}$ es in Ostfriesland, ähnlich wie in den Nordostniederlanden, zu großflächigen Sandverwehungen kam oder die durch Ackerbau ausgelaugten Böden nur noch geringe Erträge brachten, ist letztlich ungeklärt (WATERBOLK 1962; SCHWARZ 1995, 181).

Bereits früh fanden vereinzelte Ausweichbewegungen in die Flussmarsch der Unteren Ems statt. Die früheisenzeitlichen Siedlungen von Jemgum und Hatzum scheinen dabei eine Vorreiterrolle übernommen zu haben. Es entstanden zunächst temporäre Sommersiedlungen. Hierauf weisen die kleinen Wohnbauten der Siedlung Jemgum hin, während Hatzum als Dauersiedlung anzusprechen ist.

In den kaiserzeitlichen Siedlungen der Region erfolgte die gemeinschaftliche Nutzung des Wirtschaftsraumes und vermutlich auch der Gräberfelder. Insbesondere dauerbelegte Gräberfelder zeugen von einer Bevölkerungskontinuität. Neben platzkonstanten Siedlungen wird es sicherlich auch zu kleinräumigen Siedlungsverlagerungen gekommen sein; dies vermutlich vorzugsweise innerhalb einer Territorialgemeinschaft.

Die am keramischen Fundgut festzumachende recht einheitliche Prägung findet ihren Höhepunkt in zwei Trichterschalen mit nahezu identischem Dekor, die aus zwei $15 \mathrm{~km}$ voneinander entfernten Siedlungen vorliegen. Sowohl die Schale in Nortmoor wie auch die in Hatzum-Boomborg zieren vertikal herabhängende Dekorstreifen mit verschiedenen Füllmustern.

Gegen Ende des 3. Jahrhunderts kommt es zur Ausdünnung des dargestellten Siedlungsbildes. Die Aufgabe der bestehenden Siedlungen scheint dabei friedlich vonstatten gegangen zu sein. Hinweise auf Brandschichten in den Siedlungen fehlen jedenfalls. Allgemein nimmt die Fundstellendichte deutlich ab und nur wenige Plätze bestehen bis in das 4. Jahrhundert fort. Gründe mögen in den Folgen der D-II Transgression und letztlich in der Vernässung des Wirtschaftsraumes zu suchen sein. Vermutlich kam es zunächst zu Ausweichbewegungen hin zu höher liegenden Arealen. Zwar bot sich der nahe Geestrand als Siedlungsraum an, die dort anzutreffenden staunassen lehmigen Sandböden waren jedoch schwierig zu bewirtschaften, so dass eine Weiternutzung der Wirtschaftsflächen in der Marsch wie in der Niederung unumgänglich war. Die sich mit der Zeit verschlechternde Versorgungslage, u.a. Reduktion der Wirtschaftsflächen, wird schließlich eine Abnahme der Bevölkerungszahl nach sich gezogen haben.

\subsection{Fundstellen der Völkerwanderungszeit}

\subsubsection{Das 4.-5. Jahrhundert n. Chr. (Stufe 3)}

In der Völkerwanderungszeit geht der Anteil der Fundstellen stark zurück (Taf. 131). Dabei ist zu beobachten, dass im Unteren Emsgebiet nicht nur die Anzahl der Fundstellen insgesamt abnimmt, 
sondern auch die von den 14 Plätzen stammende Fundzahl drastisch reduziert ist. Stellenweisen finden sich in den Plätzen der Stufe 3 nur 1-5 Funde, die eindeutig als völkerwanderungszeitlich anzusprechen sind.

Deutlich zeigt sich weiterhin eine Bevorzugung der Flussmarsch als Siedlungsraum, wo acht der zehn Siedlungen dieser Stufe existierten (FStNr.: 01; 21; 23; 24; 26; 34 (34b); 36; evtl. 61). Die meisten Siedlungen reihen sich entlang des altbesiedelten Emsuferwalles. Nur zwei Siedlungen fanden sich auf der Geest (FStNr.: 37; 47).

Als „binnenländische“ Siedlungen können neben Loga, nur Holtland und der Nortmoorer Hammrich angesprochen werden. Die Siedlung Nortmoor wird bereits in der frühen Völkerwanderungszeit aufgegeben.

Anders als in Stufe 1 und 2 finden sich keine vorgeschobenen Siedlungen mehr östlich der Linie Holtland/Nortmoor/Backemoor. Auch Siedlungsflächen am Geestrand oder auf Geestkuppen in der Leda-Marsch wurden nicht mehr genutzt.

Der Rückgang der Fundstellen zeigt eine deutliche Abnahme der Besiedlungsdichte an. Siedlungsräume im Binnenland wurden bewusst verlassen; möglicherweise zugunsten des bereits altbesiedelten Emsuferwalles. Sämtliche dort bekannten Siedlungen der Stufe 3 sind bereits in der römischen Kaiserzeit besiedelt (in zwei Fällen sogar seit der vorrömischen Eisenzeit), so dass eine Siedlungskonzentration im Altsiedelland durchaus denkbar erscheint, geht man nicht von einer Abwanderung der Bevölkerung aus.

Grabfunde aus dieser Zeit sind ausgesprochen selten. Lediglich zwei Fundstellen im Landkreis Leer sind bekannt. In die frühe Völkerwanderung datiert eine Riemenzunge vom ansonsten kaiserzeitlichen Brandgräberfeld Amdorf (FStNr.: 58). Ein doppelkonisches Gefäß fand man 1953 in Holtgaste (FStNr.: 38). Größere Nekropolen dieser Zeit liegen aus dem Landkreis Leer nicht vor bzw. wurden nicht als solche erkannt.

Depotfunde der Stufe 3 finden sich nur vereinzelt. Zu dem bereits genannten Moorfund aus Meinersfehn (Stufe 2) gehört ein frühvölkerwanderungszeitlicher Fingerring (FStNr.: 18). Als Streufund gilt ein in Völlen gefundener völkerwanderungszeitlicher Fibelkopf des 4. Jahrhunderts (FStNr.: 68).

Bei 38\% der kaiserzeitlichen Siedlungen ist eine bis in die Völkerwanderungszeit hineinreichende Siedlungskontinuität $\mathrm{zu}$ vermerken. Die in der Kaiserzeit sich herausbildenden linearen Siedlungsmuster blieben nur stellenweise bestehen. Der Großteil der räumlichen Einheiten löst sich mit Ausnahme der Emsmarsch auf. Weiter besiedelt wurden nur die siedlungsgünstigsten Stellen der Vorgängerstufen 1 und 2, wobei jedoch auch hier eine Abnahme der Siedlungsdichte zu vermerken ist. 
Hinweise auf eine Kolonisation neuer Siedlungsräume fanden sich nicht.

Im Binnenland wurden naturräumlich schlechter ausgestattete Plätze spätestens in der frühen Völkerwanderungszeit aufgegeben. Insgesamt deutet die Fundstellenverteilung auf eine weiträumige Entsiedelung der Unteren Emsregion in der Völkerwanderungszeit hin. Anfang des 5. Jahrhunderts werden die Siedlungen verlegt und/oder aufgegeben. Ein aus Hollen stammender Baumstammbrunnen mit einem Dedrodatum von „>478 “ gehört zu den spätesten Siedlungszeugen der Stufe 3 im Arbeitsgebiet.

Gründe für die starke Abnahme der Fundstellen im Untersuchungsgebiet, bei der sich die Anzahl um $62 \%$ verringerte, sind wohl in den sich durch die D-II Transgression nun geänderten hydrologischen Bedingungen zu sehen. Einsetzende Versalzung der Marsch und Vernässung der Siedlandzone hinter der Marsch haben sicherlich an erster Stelle den Siedlungsablauf im Unteren Emsgebiet beeinflusst. Ein monokausales Modell wird den vielerorts zu beobachtenden Abbruch der Besiedlung jedoch nicht hinreichend gerecht. Möglicherweise sind es zudem gesellschaftspolitische Veränderungen die einhergehend mit einer geänderten Wirtschaftsweise den Wandel beschleunigten.

So wird der Zusammenbruch des römischen Reiches auch für die grenznahen Regionen nicht ohne Folgen geblieben sein. Insbesondere die wirtschaftlichen Verflechtungen, z. Bsp. im Bereich des Handels, endeten und Absatzmärkte brachen zusammen.

\subsection{Fundstellen des Frühmittelalters}

\subsubsection{Das 7.-10. Jahrhundert n. Chr. (Stufe 4)}

Erst im Frühmittelalter ist ein deutlicher Anstieg der Fundstellen im Landkreis Leer zu vermerken. 40,5\% ( $\mathrm{n}=28)$ der 69 Fundstellen datieren ins Frühmittelalters (Taf. 132). Bei 19 Stellen handelt es sich um Siedlungen (FStNr.: 01; 06; 07; 11; 13; 14; 16; 21 (?); 23; 31; 34 (34b); 37; 45; 46; 49; 50; 52; $61 ; 64)$.

Frühste Siedlungsspuren fanden sich in der Emsmarsch bei Pogum, sowie an den Geestorten Großoldendorf und Brinkum (FStNr.: 01; 16; 44). Ein kompletter Eitopf, der Vorgänger des erst im 9. Jahrhundert auftretende Muschelgrus gemagerten Kugeltopfes, stammt aus Pogum. Zwar sind der frühen Siedlungsphase des 7./8. Jahrhunderts nur wenige Standorte zuzuordnen, dies kann aber auch eine Folge der als schwierig zu bezeichnenden Ansprache lokaler frühmittelalterlicher Keramik sein. Die frühe weiche Grauware charakterisiert grob Granitgrus gemagerte Töpfe, die dickwandig und meist nur mäßig hart gebrannt waren (STILKE 1993a). Vertreter dieser Ware finden sich unter der Brinkumer Grabkeramik. Die Randgestaltung ist schlicht und nahezu ohne Profilierung. Bei der Gefäßkubatur überwiegen kugelige Gefäße vor länglich-bauchigen. Es kommen sowohl Flachböden wie leicht konvex gewölbte Böden vor; letztere stellen vermutlich ein Reflex auf die bei rheinischen Importgefäßen vorkommenden Linsenböden dar. 
Ab dem Ende des 8. / Anfang des 9. Jahrhunderts steigt die Anzahl der entdeckten Siedlungen deutlich an. In dieser Zeit ist ein Aufkommen Muschelgrus gemagerter Töpfe festzustellen. In 15 Fundstellen findet sich Muschelgrusware, wenn auch oft in geringer Anzahl und zerscherbt (FStNr.: 06; 07; 11; $13 ; 14 ; 16 ; 23 ; 27 ; 31 ; 37 ; 45 ; 46 ; 50 ; 52 ; 61)$. Eine Ausnahme stellt eine mit Fehlbränden von 700 Scherben dieser Ware gefüllte Grube dar (FStNr.: 11), die auf eine lokale Herstellung der Muschelgrus gemagerten Keramik in Hesel hinweist.

Technische Innovationen im Bereich der Brenntechnik und eine feinere Magerung, nun mit Granitstatt Muschelgrus, führen zur Entwicklung einer dünnwandigen Keramik. Ab dem 10. Jahrhundert setzt sich die harte Grauware allmählich durch und verdrängt die Muschelgruskeramik.

Früher rheinischer Import, wie Walsumer und Bardorfer Ware, ist nur von wenigen Stellen im Arbeitsgebiet bekannt, weist aber für die Brinkumer Nekropole auf einen recht intensiven Austausch hin. Jedoch erst mit dem Auftreten von Pingsdorfer Keramik im 9./10. Jahrhundert kommt es verstärkt zu Handelsbeziehungen mit rheinischen Töpferorten.

Eine ab dem 9. Jahrhundert zu beobachtende Aufsiedlung erschließt nun neue Standorte auf der hohen Geest. So gelang es in Hesel eine dörfliche Struktur freizulegen, die aus an einer Längsachse aufgereihte Einzelgehöften bestand (FStNr.: 11; 13; 14; 46; 49; 50). Es sind bäuerliche Betriebe, deren wirtschaftliche Basis Ackerbau und Viehzucht waren. Die Wohngebäude verfügten über eine eigene Wasserstelle bzw. einen Brunnen und mehrere benachbarte Speicherbauten. Umhegt waren die Einzelhausplätze mit einer Graben- und Palisadenanlage. Dieses Siedlungsbild findet sich auch in Hollen; hier bei locker verstreuten Einzelgehöften.

Wenige Siedlungen sind durchgängig vom 7. bis zum 12. Jahrhundert bewohnt. Meist enden die frühmittelalterlichen Gründungen bereits im Laufe des 10./11. Jahrhunderts. Dahinter verbirgt sich wohl eine letztmalige Verlagerung hin zu einer ab dem 11./12. Jahrhundert weitgehend platzkonstanten Siedlungslage. Dieser Prozess verlief parallel mit der Entwicklung neuer Düngetechniken. Die Plaggendüngung ermöglichte nun eine Dauerbewirtschaftung der Äcker.

An einigen Standorten ist eine Siedlungslücke zwischen dem 11. und 12. Jahrhundert zu beobachten. Insbesondere niedrig gelegene Siedlungen scheinen in dieser Zeit aufgeben worden zu sein. Vermutlich führten steigende Grundwasserstände im Hinterland der Ems zur Aufgabe von Altsiedelflächen in der Jümme-Flussmarsch. Im Nortmoorer Hammrich bricht die Besiedlung spätestens Mitte des 11. Jahrhunderts ab, nur vereinzelt finden sich noch Keramikscherben des 12. Jahrhunderts. Die Bewohner zogen vermutlich zum nahen Geestrand des heutigen Nortmoor. Erhöht liegende Lehmdielen mit hochmittelalterlicher Keramik und erste Backsteinfunde belegen dort eine Neuansiedlung. Die recht bald wieder sinkenden Wasserstände ermöglichten Mitte des 12 . 
Jahrhunderts sogar die Kolonisation des nahen Jümmiger Hammrichs, der mit zahlreichen Gräben urbar gemacht wurde. Zu einer Rückkehr auf die Nortmoorer Düne kam es jedoch nicht.

Frühmittelalterliche Gräberfelder sind im Untersuchungsgebiet nur in geringer Anzahl bekannt (FStNr.: 02; 10; 27; 44; 57). Es handelte sich sowohl um Körper- als auch um Brandbestattungen. Neben zwei Friedhöfen in der Emsmarsch sind drei Nekropolen von der Geest überliefert. Sie sind mit einer Ausnahme alt gegraben und i.d.R. nicht oder nur unzureichend dokumentiert.

Der 1887 auf der Klunderborg im Reiderland entdeckte Friedhof wird in das 6. bis 8. Jahrhundert datiert. Beobachtet wurden zwei durch eine Siedlungsschicht getrennte Bestattungshorizonte, deren älterer frühmittelalterliche Urnengräber aufwies. Ebenfalls Beigaben enhielten in Critzum aufgefundene Körpergräber des frühmittelalterlichen Friedhofes. Um einen vermutlich frühmittelalterlichen Grabhügel handelte es sich beim Heidenkarkhoff nahe Hesel. Eine frühmittelalterliche Körperbestattung aus Filsum zeugt von der frühen Hinwendung zur neuen Bestattungsart in der Region (FStNr.: 57).

Die in das 7. bis 8. Jahrhundert datierte Nekropole Brinkum stellt mit ihren erhaltenen Urnen und reichen Beigaben einen der wenigen gut erhaltene alt gegrabene Gräberkomplexe in Ostfriesland dar (siehe Kap. 6 Brinkum). Trachtbestandteile, wie Schnallen, Riemen oder Beschläge (Perlrandniete), weisen eine auch im karolingischen Reich bekannte Qualität auf. Importfunde süddeutscher Keramik belegen dazu nicht nur Handelsbeziehungen, sondern auch eine soziale Oberschicht im Unteren Emsgebiet, die sich derartige Luxusgüter leisten konnte.

Zwar wird die Friesenmission mit dem Bau einer Kirche bei Leer und dem sogenannten Fischwunder des Hl. Luitgers Ende des 8. Jahrhunderts als abgeschlossen angesehen; dass dem nicht so war, belegen die sogenannte heidnischen Bestattungsbräuche in Brinkum wie auch im bedeutend größeren Gräberfeld Dunum. Die Christianisierung Ostfrieslands und die Herausbildung einer kirchlichen Organisation auf regionaler Ebene sollte noch wenigstens ein Jahrhundert auf sich warten lassen.

Zwar gelang es für zahlreiche Kirchen im ostfriesischen Raum hölzerne Vorgängerbauten nachzuweisen, diese können jedoch kaum vor das 10. Jahrhundert datiert werden (HAIDUCK 1992). Diese Anfangsdatierung findet sich auch für den älteren Holzkirchenbau in Leer. Wenige Scherben des 7. bis 8. Jahrhundert entstammen der Auftragsschicht des Leeraner Kirchhügels. Die erste Erwähnung von Leer als „Hleri“ erfolgte in den Urbaren der Abtei Werden um 900, wobei Leer als eine frühmittelalterliche Gründung gilt (REINHART 1969, 227).

Eine sich im Frühmittelalter langsam herausbildende soziale Differenzierung der Bevölkerung findet sich wieder im Bau erster Herrensitze, in Ostfriesland auch Häuptlingsborg genannt. Der Grundriss eines frühmittelalterlichen Steinhauses kennzeichnet den Standort der Burg von Hatzum (FStNr.: 6). 
Die bis auf die Grundmauern abgetragene Burganlage belegt einen extremen Materialmangel, der sicherlich auch zum Abriss anderer Häuptlingssitze (wenige sind archivalisch belegt) führte. Allein das spätmittelalterliche Steinhaus von Bunderhee und der Burgfried von Stickhausen sind als Zeugen mittelalterlicher Baukunst im Landkreis Leer erhalten.

Depotfunde liegen von drei Fundstellen vor (FStNr.: 08; 15; 41). Hier fällt im Unterschied zu den kaiserzeitlichen Hortfunden ihre geringe Anzahl auf. Andererseits stellen die Funde selbst im überregionalen Vergleich kostbare Preziosen dar.

Aus dem Landkreis Leer liegen für den Untersuchungszeitraum ein bronzener Halsring, der aus dem Moor bei Warsingsfehn stammt, ein umfangreicher Münzschatz von der Geest mit 752 Sceattas und zwei fränkische Schwerter vor. Letztere wurden am Ledaufer bei Leer geborgen (BÄRENFÄNGER 1999b, 95, Abb. 41).

\subsubsection{Siedlungsmuster im Frühmittelalter}

Erstmals für das 7. Jahrhundert wird eine Aufsiedlung der in der Völkerwanderungszeit verlassenen Region an der Unteren Ems fassbar. Zunächst wurden die bereits in der Stufe 3 bekannten Siedlungsstellen in der Emsmarsch aufgesucht; wenig später wurde auch entlang der Jümme-Marsch gesiedelt.

Zu einer Siedlungsverdichtung im Altsiedelland kam es in der frühen Phase nicht; diese ist erst für das Hoch- und Spätmittelalter nachweisbar. Zunächst wurde der in der Kaiserzeit besiedelte Geestrand gemieden. Dies und die zeitgleich erfolgte Erschließung neuer Standorte auf der Geest weisen auf ein neues Siedlungsmuster hin.

Eine frühmittelalterliche Kolonisationsbewegung nahm die Geest nach einer etwa 700 Jahre dauernden Unterbrechung wieder in Besitz. Die Wiederbesiedlung des in der Eisenzeit verlassenen Siedlungsraumes mit seinen wenig nährstoffreichen Böden wurde durch die lange Regenerationsphase der Böden erleichtert. Die vorherrschenden sandigen, teils staunassen und lehmigen Böden mit gering mächtiger Humusschicht benötigten längere Brachezeiten und/oder künstliche Düngung, um bei intensiver landwirtschaftlicher Bewirtschaftung eine erneute ökologische Krise zu verhindern.

Das Verbreitungsbild der Siedlungen auf der Geest zeigt eine Bevorzugung meist sehr trockener Standorte. Dabei orientierten sich die Siedlungen nicht ausschließlich an Flussläufen. Für die Wasserversorgung wurden Brunnen oder Wasserloch bzw. Wasserschöpfstelle o.ä. errichtet. Die Lage der Wohnplätze auf nährstoffarmen Geestböden, die ohne Düngung landwirtschaftlich nicht sehr ertragreich zu nutzen waren, lassen vermuten, dass es andere Gründe gab diese Standorte auszuwählen.

Es fällt auf, dass die frühmittelalterlichen Siedler bevorzugt in den Randbereichen zu unterschiedlichen Landschaftstypen ansässig wurden. So finden sich siedlungsnah meist lehmige 
Sandböden, die teils in lehmig-schluffige Böden übergehen. Als Bodentypen existieren Braunerden, Podsol-Braunerden, sowie Pseudogleye und Podsole. Die verbreiteten mäßig trockenen Sandböden weisen Gley-Podsole und in tieferen Lagen Gleye auf. Auch wird die Geest von Niedermooren durchzogen, die sich als Weideflächen anbieten. Nahezu regelhaft wechseln sich die o.g. Bodentypen im Nordosten der südostfriesischen Geest miteinander ab.

Für die Herausbildung von Siedlungsgefilden war der Naturraum mit seinen vielfältigen Landschaftstypen auf engstem Raum ausschlaggebend. Der bäuerlichen Gesellschaft wird die Bedeutung eines naturräumlich abwechslungsreichen Wirtschaftsraumes bewusst gewesen sein, wobei insbesondere den sandig-tonigen Böden eine wichtige Bedeutung zukam. Möglicherweise steht die Aufsiedlung der Geest mit der Einführung neuer Getreidesorten in Verbindung. So zeichnet sich Wintergetreide durch einen geringeren Wasserbedarf aus. Roggen, Saatweizen und Erbsen begnügen sich mit den trockenen Böden der Geest. Ein Anbau in der Marsch war aufgrund ihrer Nässe- und Salzempfindlichkeit nicht möglich. Zwar wird erst ab dem 10. Jahrhundert eine deutliche Zunahme des Roggenanbaues vermerkt (BEHRE 1976), dies schließt jedoch nicht aus, dass bereits vorher diese Getreidesorte angebaut wurde. Pollenanalysen vom Nortmoorer Hammrich zeigen einen deutlichen Anstieg der Cerealia auf über $12 \%$ in den beiden obersten Ablageschichten, die vermutlich als mittelalterlich anzusehen sind. Der schwache Anteil an Roggenpollen lässt eine frühmittelalterliche Datierung wahrscheinlich erscheinen (FREUND 1996a, unpubl.).

Bezüglich der Höhenlagen der Siedlungen kann mit wenigen Ausnahmen nur auf die absoluten Werte zurückgegriffen werden. Die frühen Siedlungsgründungen auf der Geest erfolgten bei $+5 \mathrm{~m}$ bis $+7 \mathrm{~m}$ NN. Im 9. Jahrhundert bestand in Hesel bereits eine dörfliche Siedlungsstruktur mit wenigstens drei zeitgleichen Gehöften bei einer Geländehöhe von $+10 \mathrm{~m}$ NN. Zeitgleich siedelte man auf einem Geesthöhenrücken in Hollen noch bei $+3,5 \mathrm{~m}$ NN. Diese Höhenmarke stellt für die Untere Emsregion jedoch einen wichtigen Wert dar, da sie sich am damaligen maximalen Sturmflutpegel orientiert.

So wurde auch in der Emsmarsch im 9./10 Jahrhundert eine Erhöhung der Flachsiedlung Hatzum notwendig; vermutlich kam es auch zu Aufträgen bei benachbarten Wurten. Eine einsetzende Feuchtigkeitsphase wird als Grund anzunehmen sein. So kommt es im Jümmiger Hammrich zu starken Überschwemmungen, wie die mächtigen Sedimentationsschichten in frühmittelalterlichen Befunden des Nortmoorer Hammrichs zeigen. Der Siedlungsplatz musste schließlich im 11. Jahrhundert komplett aufgegeben werden.

Die geomorphologischen Verhältnisse erlaubten im frühen Frühmittelalter auf der Geest nicht die Gründung ortsfester Ansiedlungen. Es herrschten Wandersiedlungen und eine rotierende Feldbewirtschaftung vor, um immer wieder unverbrauchte Böden zu bewirtschaften. Selbst beim Anbau anspruchsloser Getreidesorten kam es bei einer Dauerfeldwirtschaft schnell zur 
Bodenverarmung, der nur durch Dünung entgegen zu wirken war.

Eine Konstante bildeten die gemeinschaftlich genutzten Grabhügel, denen eine wichtige Funktion zukam. Besaßen sie doch innerhalb der frühmittelalterlichen Siedlungsweise eine platzkonstante Stellung. Ein Beispiel für die Mobilität der Siedlungsstellen, aber eine sogenannte Standorttreue und der des Bestattungsplatzes findet man in Dunum. Das dortige Gräberfeld wurde von fünf benachbarten Siedlungsstellen, die in das 8 . bis 10. Jahrhundert datieren, genutzt. Soweit diese annähernd gleichzeitig bestanden, könnte es sich um eine Bestattungsgemeinschaft mehrerer Siedlungsstellen gehandelt haben (vgl. SCHMID 1972, 211-240).

Lässt sich bei den Großgräberfeldern Dunum, Schortens und Groß-Mahndorf an den Gräbern eine soziale Differenzierung der Bestatteten in der Beigabenausstattung erkennen, so zeichnen sich die Bestattungen im Untersuchungsgebiet durch ein recht einheitliches Beigabenspektrum aus. Meist sind es Kämme, wenige Metallbeigaben und Tongefäße. Waffenbeigaben sind nur im Fall der Brinkumer Lanzenspitze bekannt. Die wenigen bekannten frühmittelalterlichen Nekropolen sind zudem von recht geringer Größe, so dass eher an die Anlage von Familiengrabhügeln zu denken ist.

Die kostbaren Beigaben, die sowohl aus Brinkum wie auch vom Upstalsboom (SCHWARZ 2003a, 404421) vorliegen, zeugen von wirtschaftlich gut situierten Großfamilien. Diese können in erster Linie als großbäuerlicher Familienverband angesprochen werden; möglicherweise handelt es sich auch um Mitglieder der Gründungsfamilie. Ein Gentilwesen ist für diese Zeit in Ostfriesland nicht nachweisbar, aber wahrscheinlich. Im Spätmittelalter kommt es zur Herausbildung einer bäuerlichen Häuptlingsschicht (siehe Kap. 4.1.2 Überlieferungen).

Wie man sich die Gründungsphase im Frühmittelalter im Einzelnen vorstellen hat, kann aufgrund der schwierigen Befundlage nur ansatzweise erörtert werden. Vermutlich kam es anfangs zur Anlage von Einzelgehöften an günstig gelegenen Stellen, später bildeten sich weilerartige Siedlungen wie in Hesel mit wenigstens drei zeitgleichen Gehöften heraus. Erst im hohen Mittelalter fand dann auf der Geest eine Siedlungskonzentration statt und es entstanden reguläre Dörfer. In der Marsch wird dieser Prozess aufgrund der räumlichen Enge auf den Wurten vermutlich früher eingesetzt haben.

Als Siedlungsraum für eine Wiederbesiedlung bot sich die Emsmarsch mit Zugang zur Brack- und Moormarsch an, die als Weideland genutzt wurden. Siedlungen und Ackerflächen lagen auf dem hoch aufgeschlickten Emsuferwall. Zuerst wurden die kaiserzeitlichen Wurten in der Emsmarsch aufgesiedelt. Dies hatte nicht nur den Vorteil geschützt vor temporären Überflutungen zu sein, sondern es wurden auch die zur Verfügung stehenden Wirtschaftsflächen nicht durch eine Siedlung zusätzlich verkleinert. 
Stellenweise zwang der Sturmflutpegel die Bewohner zu weiteren Erhöhungen. Bereits um 700 setzte die D-III Transgression ein, die sich regional jedoch recht unterschiedlich auswirkte. In Reersum, Gemeinde Schwittersum, wurden zwischen dem 7. und 10. Jahrhundert wenigstens sechs Auftragsschichten beobachtet (SCHWARZ/STUTZKE 1992, 265-266).

In der Emsmarsch mögen die Folgen eines ansteigenden Meeresspiegels weniger stark ausgeprägt gewesen sein. Anders ist nicht zu erklären, dass noch im 9. Jahrhundert ebenerdige Gründungen stattfanden. In Hatzum wurde beispielsweise eine Erhöhung zur Wurt erst im 10./11. Jahrhundert notwendig.

Vorzugsweise wurde der linke Emsuferwall aufgesiedelt, u.a. nahe der bis heute bestehenden Dörfer Pogum, Midlum, Oldendorp bei Ditzum, Critzum, Jemgum, Hatzum, Bingum und Kirchbogum. Auf der gegenüberliegenden Seite sind nur in Rorichum frühmittelalterliche Siedlungsreste belegt; wahrscheinlich stellten jedoch auch die nördlich davon liegenden Orte Oldersum und Gandersum frühmittelalterliche Gründungen dar. Zudem weisen die Ortsnamen mit ihrer Endung „um“ auf frühmittelalterliche Gründungen hin (REINHARDT 1969, 217).

Geomorphologisch finden sich beiderseits der Ems ähnliche Verhältnisse, sogar die Breite der Flussmarsch von etwa $1,5 \mathrm{~km}$ entspricht dem gegenüberliegenden Marschensaum. Südlich von Rorichum, wo die Emsmarsch nur noch zwischen 500-800m breit ist, fehlen hingegen Zeugen einer frühen Kolonisation; vermutlich aufgrund mangelnder Wirtschaftlichkeit der nutzbaren Flächen, wie noch auszuführen sein wird.

Berechnungen für die Feddersen Wierde zeigen, dass der Siedlung mit einer Wirtschaftsfläche von etwa 294ha wohl nur durch Nutzung des Vorlandes als Sommerweide dieses Areal genügte (HARRNAGEL 1979, 253). Im Unterschied zur Seemarsch verfügt die Emsmarsch nicht über ein derartiges Ausweichareal; jedenfalls nicht auf der flusszugewandten Seite.

Das Hinterland des frühmittelalterlich besiedelten Emsufers zeichnet sich durch nasse, aber wasserdurchlässige Tonböden aus, die in Moorböden mit toniger Oberfläche übergehen. Diese sind jedoch nicht überall anzutreffen. Zwischen Terborg und Nüttermoor am rechten Emsufer fehlen diese Böden bzw. sind kaum nennenswert ausgeprägt; auch waren keine frühmittelalterlichen Siedlungen anzutreffen.

Erst wieder nordwestlich von Leer und zwischen Logabirum und Nortmoor sind der Marsch Tonböden in Richtung Geest vorgelagert, dort sind frühmittelalterliche Ansiedlungen belegt.

Auch südlich von Esklum, einer kleinen Ortschaft an der Leda nahe Leer, findet sich dieselbe Landschaftsgliederung. Parallel zur Emsmarsch erstreckt sich eine bis nach Milting- Mark reichende Zone mit den o.g. Ton- und tonigen Moorböden. Zwar steht gegenwärtig die Entdeckung frühmittelalterlicher Siedlungsstrukturen in dieser Region noch aus. Muschelgrus gemagerte Keramik, 
die man bei Erdarbeiten in Grotegaste und in Ihrhove fand (SCHWARZ/STUTZKE 1998, 58; 71), legt jedoch eine frühe Besiedlung nahe.

Vergleicht man die geomorphologischen Verhältnisse mit der Verteilung frühmittelalterlicher Siedlungsspuren, so zeigen sich deutliche Übereinstimmungen. Wie es scheint, wurden im Frühmittelalter dort bevorzugt Siedlungen angelegt, wo es Flussmarsch und im Hinterland wasserdurchlässige Tonböden gab. Dabei war die Breite der Flussmarsch nicht / kaum entscheidend.

Am Ende des Frühmittelalters erfolgte auf der Geest die Umstellung der Wirtschaftsweise zum „ewigen Roggenanbau“ (BEHRE 1976). Der bereits im Oktober eingesäte und im August des Folgejahres geerntete Roggen ließ praktisch nur eine zweimonatige Brachezeit zu, die jedoch nicht zur Regenerierung des Bodens ausreichte.

Es entstanden mit den Gasten gemeinschaftlich genutzte Ackerflächen, deren Düngung mit Aufträgen von Plaggen oder Soden (oft vermengt mit Viehdung) eine Bewirtschaftung ohne Brache gestatteten. Dies hatte ab dem 10. Jahrhundert eine vollkommen neue Siedlungsstruktur zur Folge. Platzkonstante Felder erlaubten die Anlage beständiger Siedlungsplätze. Es entwickelten sich Haufendörfer und Dorfplatzsiedlungen (REINHARDT 1969).

Zur siedlungsgeographischen Analyse können historische Flurkarten und insbesondere die preußische Landesaufnahme von 1898 herangezogen werden. So finden sich im Altsiedelland der Geest wie auch auf den Uferwällen der Flussmarsch häufig noch die im Frühmittelalter entstandenen unregelmäßigen Blockfluren. Zur planvollen Anlage neuer Wirtschaftsflächen in Streifenform kam es am Ende des frühen Mittelalters (WASSERMANN 1985). Als Beispiel des nun beginnenden Landesausbaues kann auf Middels, eine bereits im 8. Jahrhundert auf der ostfriesischen Geest bei Aurich bestehenden Siedlergemeinschaft, verwiesen werden. Im 10. Jahrhundert bildeten sich dort vier zwischen 500 und $1000 \mathrm{~m}$ voneinander entfernte Ansiedlungen, die Ortskerne der mittelalterlichen Siedlungen (VAN LENGEN 1973). Für Middels-Osterloog ist eine Reihung von Höfen um einen Dorfplatz festzustellen. Anordnung und Orientierung weisen auf eine gemeinschaftliche Planung der Dorfanlage hin. Die gemeinsamen Ackerflächen lagen zwischen den einzelnen Ortskernen.

Bei Neugründungen im Untersuchungsgebiet entstanden am Geestrand und in der Flussmarsch nun straßenparallele Siedlungen, deren wirtschaftliche Basis durch Handel und Handwerk ergänzt wurde. Deutlich zeigte sich dabei ihre Ausrichtung an Fernwege und regionale Verkehrsverbindungen.

Die bald einsetzende Siedlungskonzentration ließ in Marsch und Geest kaum Platz für neue Gründungen, so dass als Siedlungsraum nur die Niedermoore entlang der See- und Flussmarschen in Frage kamen. Für das 10./11. Jahrhundert sind für den Riepster Hammrich und in der Gemarkung Boen im Reiderland erste Fundstellen bekannt, wobei es sich zunächst wohl noch um keine planmäßige Siedlungsbewegung gehandelt haben wird, da scheinbar regellos günstige Stellen 
ausgewählt wurden (SCHWARZ 2003, 77-83). Von einer planmäßigen Kolonisation der Niedermoore kann im Untersuchungsgebiet erst ab dem 12. Jahrhundert ausgegangen werden (ROSENPLÄNTER 2002).

\subsection{Ergebnisse der siedlungsarchäologischen Untersuchungen}

Im Untersuchungsgebiet waren die besiedelbaren Flächen begrenzt, da sie zwischen Wasserläufen, mit ihren nur in trockenen Phasen passierbaren Niederungen, und unwegsamen Hochmooren lagen. Das Untere Emsgebiet wird durch breite Marschenzonen von Ems und Jümme dominiert. Der natürlich hohe Grundwasserstand, der auch beeinflusst wird durch Bodenrelief, -substrat u.a.m, hat im Flussdelta entscheidenden Einfluss auf die Besiedelbarkeit dieses Naturraumes.

Es stellt sich die Frage, welche Faktoren die Sielungsplatzwahl entscheidend beeinflussten. Das von einer bewussten Auswahl ausgegangen werden kann, zeigt die hohe Anzahl der Siedlungen mit gleichen Standortkriterien. Die Analyse der geomorphologischen Verhältnisse berücksichtigt dabei die topographische Situation (Geländeform, Höhenlage, Exposition, Lagebezug zu Gewässern), wobei den hydrologischen und klimatischen Bedingungen im Küstenraum eine besondere Rolle zukommt. Je nach Wirtschaftsweise können dieselben Kriterien auch siedlungshemmende Faktoren darstellen.

Bis in das Hochmittelalter wirkten sich die ausgedehnten Moorflächen im Norden und Süden siedlungshemmend aus. Aus der Region um Remels im Lengenerland liegen nur in geringem Umfang kaiserzeitliche oder frühmittelalterliche Plätze vor. Diese relative Fundstellenarmut ist vermutlich nicht das Ergebnis eine Forschungslücke, sondern stellt eine Folge des nur bedingt nutzbaren Naturraumes dar. Auch größere Niedermoore fungierten sicherlich als Überquerungshindernisse, da sie häufig vernässt und kaum passierbar waren. So finden sich südlich von Jümme und Leda nur wenige Fundstellen.

Die oft zu beobachtende Nähe der Ansiedlungen zu Wasserläufen steht neben ihrer Nutzung als Verkehrsweg wahrscheinlich in Verbindung mit der Ableitung des Oberflächenwassers. Die Lage an Prielen in der Emsmarsch erlaubte es schnell trockenes Siedlungsland zu erhalten.

Selbst geringe Geländehöhen stellen im schwach reliefierten Ostfriesland einen wichtigen Indikator für einen Siedlungsstandort dar. Die Bedrohung durch Winterhochwasser, Grundwasser oder Staunässe machten eine erhöhte Wohnlage unumgänglich.

Günstige Standorte sind in der Flussmarsch von Ems und Jümme sowie entlang kleinerer Flüsse (z. B. Holtlander Ehe) zu finden. Marschen und nahe Niederungen dienten als Viehweide und zur Heugewinnung. Fließgewässer zeichnen sich durch Fischreichtum aus. Größere Gewässer dienten als Transportwege. Schiffbare Flüsse wie Ems und Jümme hatten eine überregionale Bedeutung als 
Handelswege.

Im Untersuchungsgebiet ist ein hoher Bestand an archäologischen Fundstellen festzustellen. Auffällig ist die Verteilung auf bestimmte Naturräume. Die Siedlungen konzentrierten sich auf begrenzt verfügbare Areale in den Übergangslandschaften von Flussmarsch/Moormarsch/Niederung und Geest/Niedermoor/Hochmoor. Wichtig waren dabei auch die Zugangsmöglichkeiten zu günstigen Wirtschaftsräumen.

Hydrologische und klimatische Veränderungen führten in dem sich durch geringe Höhenunterschiede auszeichnenden Gebiet rasch zu einem Ungleichgewicht. Naturräumliche Grenzbereiche wurden stellenweise durch einen Anstieg des Grundwasserstandes bzw. des Meeresspiegels nicht mehr bewirtschaftbar. Soweit die naturräumlichen Gegebenheiten es ermöglichten, wanderten die Siedlungen hangaufwärts. In der Emsmarsch errichtete man Wohnpodeste (Wurten, Warften), um die fruchtbaren Überschwemmungsgebiete nicht verlassen zu müssen. Erst wenn der Wirtschaftsraum durch höhere Wasserstände längerfristig bedroht war, wurden die gefährdeten Siedlungsstandorte aufgegeben.

Oft entscheidend für die Wahl eines neuen Standortes war die Nähe zu einem Fließgewässer oder einer Frischwasserquelle, die z. T. durch Brunnen erschlossen wurde, wobei trockene Siedlungsstandorte bevorzugt wurden. Waren Bodenfruchtbarkeit und Zugang zu Frischwasser gewährleistet, behielt man Standorte auch bei veränderten hydrologischen Bedingungen bei.

Bereits in der jüngeren Eisenzeit verließen die Menschen die Hohe Geest und siedelten in niedrigeren Gebieten. Bevorzugt wurden seit der Spätlatènezeit leicht erhöhte Lagen in der Marsch, auf Uferwällen und Flugsanddünen sowie entlang der Geestränder. In der Kaiserzeit verdichtete sich das Siedlungsbild in der Flussmarsch, während die Geest weitgehend gemieden wurde. In der Völkerwanderungszeit blieb das Siedlungsbild prinzipiell bestehen, wenn es auch zu einer beträchtlichen Siedlungsausdünnung kam. Für das 5./6. Jahrhundert kann ein weitgehender Siedlungsabbruch konstatiert werden. Eine Aufsiedlung der Region erfolgte erst wieder ab dem Frühmittelalter. Erneut ist die Emsmarsch Ziel der ersten Siedlungswelle, bevor die Geest nach einer Pause von etwa einem Jahrtausend erstmalig wieder aufgesiedelt wurde.

Archäologische Quellen zeigen für die verschiedenen Zeitepochen ein Aufsuchen unterschiedlicher Naturräume an.

Die Fundstellen der TBK begrenzen sich auf das Moormer- und Overledingerland. Bevorzugt wurden sandige Uferregionen der Holtlander Ehe und Jümme. Lage und Dichte der Besiedlung sind nicht bekannt. Die Einzelgrabkultur bevorzugte denselben Naturraum, weitete jedoch ihr Siedlungsareal 
aus. Fundstellen liegen aus dem Raum der Hollener Ehe, dem Lengenerland und südlich der Leda vor (STUTZKE/SCHWARZ 1998, 16).

Randbereiche der Moore wurden in der älteren Bronzezeit erstmals besiedelt, während man in der jüngeren Phase auch trockene Geestgebiete aufsuchte. In der mittleren Bronzezeit kam es zu einer konstruktionellen Veränderung der Großgebäude, deren größerer Stallteil eine Ausrichtung zugunsten der Viehwirtschaft belegt.

Fundstellen der älteren Eisenzeit liegen vorwiegend auf den Sandplateaus des Moormer- und Overledingerlandes. Ähnlich wie in der Stein- und Bronzezeit zeigt sich eine Platzkonstanz, wonach das bewirtschaftete Land (bevorzugt wurden leichte Sandböden) anwuchs, aber nicht verlegt wurde. Die Siedlungsplätze waren seit der Bronzezeit variabler und wanderten in der Feldflur. Gräberfelder wurden weitaus seltener verlegt.

Eine Klimaverschlechterung, erkennbar an einem beschleunigten Wachstum der Torfmoose, fällt in die Zeit zwischen 700 v. Chr. und kurz nach Christi Geburt (BEHRE 2000, 34). Ab der späten Eisenzeit besiedelte man die bis dahin gemiedene Leda-Jümme-Niederung, die bewirtschafteten Areale der Geest wurden dagegen weitgehend verlassen. Als Ursache dieser Verlagerung wird ein Wechsel in der Wirtschaftsweise vermutet (vgl. SCHWARZ 1995; STUTZKE/SCHWARZ 1998, 25).

In der römischen Kaiserzeit ist eine deutliche Intensivierung der Siedlungsdichte bemerkbar. Die Besiedlung orientierte sich an den Niederungszonen der Ems- und Leda-Jümme-Marsch sowie an direkt an der Marsch angrenzende Geestdurchragungen. Viehhaltung stellt die Basis der bäuerlichen Wirtschaftsweise dar, deren Produkte über Absatzmärkte in den römischen Provinzen verhandelt wurden. Nach einem deutlichen Siedlungsrückgang in der Völkerwanderungszeit kam es im Laufe des Frühmittelalters zu einer erneuten Aufsiedlung im Bereich der Flussmarsch und der Geestränder. Im Verlauf des Mittelalters wurde die hohe Geest aufgesiedelt. Im Unterschied zu den ortsgebundenen Wurten, fand dort innerhalb der Siedlungskammern immer noch eine Verlagerung der Höfe statt (BÄRENFÄNGER 1998c, 29-30). Dies änderte sich erst mit Einführung des ewigen Roggenbaus, der eine Düngung der Geestböden notwendig machte, welche die durch Humussoden und Heideplaggen erfolgte. Der ständige Nährstoffentzug ließ die Heide stetig weiter degradieren und veränderte den Naturraum nachhaltig (BEHRE 1976; 1998).

Abschließend lässt sich feststellen, dass im Untersuchungsgebiet leichte Sandböden in der Steinzeit und der vorrömischen Eisenzeit verstärkt aufgesucht wurden; kaum jedoch in der römischen Kaiserzeit.

Lehmböden weisen hingegen eine geringe Fundstellenzahl auf. Oft sind sie aufgrund von Staunässe vermoort. Ihre heutige Nutzung als Weideland behindert ihre Prospektion. Dieser Naturraum wurde durch Aufhebung der Allmende, im Zuge der Verkopplung, und durch die intensiver werdende 
landwirtschaftliche Nutzung bereits zu Beginn des 19. Jahrhunderts teilweise so umgestaltet, dass dort vermutlich archäologische Fundplätze bereits vor ihrer Entdeckung zerstört worden sind.

$\mathrm{Zu}$ beobachten ist bei nahezu allen Siedlungen eine Lage in Randbereichen mit verschiedenen geomorphologischen Gegebenheiten. Dabei spielten die kleinräumigen Ausprägungen der Bodensubstrate eine wichtige Rolle. Bevorzugt wurden kalkhaltige Marschenböden, gefolgt von nährstoffreichen Niedermooren und lehmigen Sandböden, die jedoch gut durchlüftet sein mussten.

Tendenziell als siedlungsgünstiger erachtet wurden trockene Standorte. Waren diese nur kleinräumig in dem durch Staunässe geprägten Unteren Emsgebiet vorhanden, kam es zu einer Verdichtung von Fundstellen, die sich als Cluster wiedergeben lassen.

Die Fundstellenverteilung gibt deutlich wieder, dass mit der Permanenz der Siedlungen sich die Siedlungsdichte erhöhte und erst im Anschluss daran auch weniger günstige Stellen besiedelt wurden (vgl. SCHWARZ 1989, 61).

Nun zeigt ein Vergleich der Besiedlungsmuster eine Bevorzugung der Emsmarsch in allen behandelten Stufen an. Doch während man in der Kaiserzeit die Jümme-Marsch und den nahen Geestrand als Ausweichareale aufsiedelte, finden sich im Frühmittellater bereits schon in der ersten Phase der Aufsiedlung (7./8. Jahrhundert) erste Fundstellen auf der Geest. Dies ist ein Hinweis darauf sein, dass das fruchtbare Altsiedelland in der Marsch zu diesem Zeitpunkt bereits aufgesiedelt war.

Doch warum kam es zu Siedlungsgründungen auf den sandigen und weit schlechteren Böden, anstatt die fruchtbare Jümme-Niederung zu kolonisieren? Siedlungsspuren vor dem 9. Jahrhundert fehlen hier jedoch. Erst mit der Siedlung Nortmoorer Hammrich beginnt die Aufsiedlung der Region.

Vermutlich muss dies in Verbindung mit den im Frühmittelalter herrschenden hydrologischen Verhältnissen gesehen werden. Wurde der Emsuferwall durch zahlreiche Priele durchzogen und entwässerte nach Überflutungen relativ schnell (wobei zugleich die Binnenmoore als Wasserspeicher fungierten), so stellt sich die Situation in der Jümme-Marsch vollständig anders dar. Der flache Uferwall bot hohen Wasserständen kein nennenswertes Hindernis. War die tiefliegende Niederung erst einmal überflutet, behinderten ein hoher Grundwasserspiegel und das reliefarme Areal einen zügigen Abfluss des Oberflächenwassers.

Die Sedimentationsschichten erhöhten ihrerseits zwar die Bodenfruchtbarkeit. Dieser Standortvorteil war aber erst mit sinkenden Wasserständen zu nutzen. Es ist wohl davon auszugehen, dass dieser Prozess erst im 9. Jahrhundert abgeschlossen war. Nun herrschten für etwa zwei Jahrhunderte in der Leda-Jümme-Niederung gute Siedlungsbedingungen vor. Erneut einsetzende Überflutungen und anhaltende Staunässe haben erst im 11. Jahrhundert die Siedler im Nortmoorer Hammrich zur Aufgabe 
gezwungen.

Auffällig ist auch, dass sich auf dem linken Emsufer eine Verdichtung des Siedlungsbildes abzeichnet, während von der gegenüberliegenden Flussseite nur vereinzelt Siedlungsbefunde bekannt sind. Dieses Ungleichgewicht betrifft aber nur die Region zwischen Rorichum und Hohegaste, wo bei einer schmalen Marschenzone die rückwärtige Niederung kaum ausgebildet ist. Anders als in der Seemarsch standen im Unteren Emsgebiet kein unbedeichtes Vorland als zusätzlicher Wirtschaftsraum zur Verfügung.

Das Siedlungsmuster findet seine Erklärung in der Verteilung und Zugänglichkeit der Wirtschaftsflächen. Diese lagen vorzugsweise in einer breiten Flussmarsch und den benachbarten großflächigen Niederungszonen. Insbesondere die Niederungsgebiete waren für die Bewohner von erheblicher Bedeutung. In der Kaiserzeit bildet sich eine lineare Siedlungsstruktur wegen der naturräumlichen Bedingungen entlang der Marschenzone und entlang des Geestrandes heraus. Es dominieren Einzelgehöfte und kleinere Weiler. Zwar zeigt sich im Laufe der Kaiserzeit eine Verdichtung des Siedlungsbildes, dorfartige Siedlungen sind jedoch bisher nicht aus dem Untersuchungsgebiet belegt.

Die frühmittelalterlichen Standorte auf der Geest verfügten über ein ausgewogeneres Verhältnis von Sand, Geschiebelehm und Niedermoortorf. Für die Geestsiedlungen stand die gute Erreichbarkeit der Acker-, Wald- und Heideflächen im Vordergrund.

Bereits im Frühmittelalter zeichnete sich eine beginnende Differenzierung ab. Aufgrund unterschiedlich genutzter Naturräume wurde je nach Standort eine ertragreichere Wirtschaftsweise bevorzugt; Ackerbau oder Weidewirtschaft. Eine weitere Spezialisierung fand in den Siedlungen entlang der Emsmarsch statt. Hier bildeten sich, möglicherweise bedingt durch die bessere Verkehrsanbindung an den Handel und einen höheren Bedarf an handwerklichen Traditionen, sogenannte Handwerkersiedlungen heraus.

\section{Zusammenfassung}

Die Siedlungsgrabung auf einem ehemals mehrere hundert Meter langen Dünenzug im Nortmoorer Hammrich nahe der Jümme bildet den Ausgangspunkt für eine siedlungsarchäologische Untersuchung, in deren Zentrum die kaiserzeitliche Aufsiedlung der Unteren Emsregion steht.

Aufgrund der günstigen topographischen Bedingungen entwickelte sich in der älteren römischen Kaiserzeit auf dem Dünenzug im Nortmoorer Hammrich eine platzkonstante Siedlung. Doch bereits vorher wurde die Düne als späteisen- bis frühkaiserzeitlicher Bestattungsplatz genutzt. Es ist davon 
auszugehen, dass in der näheren Umgebung eine zeitgleiche Ansiedlung bestand; vermutlich auf dem modern zerstörten Areal der ehemals 800m langen Nortmoorer Düne.

Auf der Restdüne gelang der Nachweis einer etwa 200 Jahre dauernden kaiserzeitlichen Siedlungsphase. Zeitgleich bestanden ein bis zwei Gehöfte mit ihren Nebengebäuden, Brunnen und Werkgruben. Mehrfach erneuerte Zäune umgaben das Siedlungsareal. Ob sich weitere Gehöfte entlang des Dünenkammes befanden ist in Betracht zu ziehen. Insbesondere die separate Lage des Grubenhauses und der Brunnenanlage (B 5) sowie ihre Distanz zu Hausplatz I lassen im alt zerstörten Dünenareal ein weiteres Wohngebäude vermuten.

Während in der vorrömischen Eisenzeit und frühen Kaiserzeit eine hohe Mobilität bei den Siedlungen wie der Ackerfluren zu beobachten ist, nimmt diese im Laufe der Kaiser- und Völkerwanderungszeit ab und es entwickeln sich zunehmend platzkonstante Siedlungen mit Mehrgehöftsbetrieben (SCHMID 1984. 220).

Die Siedlung Nortmoor kann hier als ein Beispiel einer platzkonstanten Siedlung gelten, wie sie in den Küstengebieten der südlichen Nordsee bekannt sind. Der kleinräumige Grabungsschnitt und die feinchronologisch wenig aussagefähige Keramik innerhalb der Baubefunde erschweren für Nortmoor eine eindeutige Ansprache als Mehrgehöftsiedlung. Die hier anzutreffende und auch von anderen kaiserzeitlichen Siedlungen bekannte Siedlungsstruktur lassen jedoch auch für Nortmoor ein Mehrbetriebsgehöft mit umgebenden Nebengebäuden und Brunnen geprägtes Siedlungsbild wahrscheinlich erscheinen (vgl. SCHMID 1982, 88-96).

Waren es zunächst lineare Siedlungsstrukturen, die in den Flachsiedlungen entlang der Küste zu beobachten sind, so entstehen in den Marschengebieten mit der Zeit kreisförmig und erhöht liegende Dörfer (BANTELMANN 1955; HAARNAGEL 1979). Die gemeinschaftliche Erhöhung der Wohnfläche war für platzkonstante Siedlung im küstennahen Marschengebiet die einzige Chance den Standort weiter zu nutzen, wobei sich die Wirtschaftsweise den temporären Überschwemmungen anzupassen hatte.

In Nortmoor wurde ein Dünenzug inmitten einer umgebenden Niederung mit südlich anschließender Flussmarsch als Siedlungsstandort von seinen Bewohnern ausgewählt, eine künstliche Erhöhung erübrigte sich. Sowohl der nahe Geestrand wie die wenige hundert Meter entfernte Jümme ermöglichten eine gute Verkehrsanbindung. Die bevorzugte Wirtschaftsweise war vermutlich Graslandwirtschaft und Viehzucht. Ackerbau war vermutlich nur in geringem Umfang in den vernässten Niederungen möglich. Die in zahlreichen Befunden angetroffene Kleischicht weist auf intensive Überschwemmungen selbst der Dünenränder hin. Zunehmende Überflutungen führten schließlich zur Aufgabe der Siedlung an der Jümme wie auch bei zahlreichen zeitgleichen Siedlungen 
in der Emsmarsch; übrigens ein Naturraum der der Jümme-Niederung sehr ähnlich war.

Dagegen überwiegt in Geestsiedlungen die Landwirtschaft, Hauswerk und meist eine einfache Metallverarbeitung. In Brill nimmt verarbeitendes Handwerk im 3.-4. Jahrhundert insgesamt zu und siedelt sich nahe der Wohnbebauung an (LEHMANN 2002, 185). In Nortmoor finden sich „technische Anlagen“ wie die Rottungsgruben u.a. eher in den Randbereichen der Siedlung. Diese Beobachtung wurde auch in Bennekom gemacht (VAN Es 1985, 575-583).

Der Wandel zu einer dorfartigen Siedlungsstruktur, wie er sich für Flögeln und Vorbasse seit dem 2. Jahrhundert n. Chr. abzeichnet, findet sich nur in Ansätzen in Ostfriesland. Anders als in Wijster (VAN Es 1967, 374-390) dominieren im Untersuchungsgebiet Einzelgehöfte und kleine weilerartige Siedlungen. Die in Backemoor etwa 200 Jahre bewohnte Siedlung bestand vermutlich nur aus einem Einzelgehöft mit mehreren Nebengebäuden, welche am selben Ort erneuert wurden bevor die Siedlung um 300 n. Chr. aufgegeben wurde (BUSCH-HELLWIG 2007). Hingegen sind von der Geest weilerartige Siedlungen in Brill (LEHMANN 2002) und Nenndorf (GROTELÜSCHEN 2000; KREIBIG 2006) belegt. Möglicherweise waren die unterschiedlichen Herausforderungen, die der jeweilige Naturraum an die Siedler stellte, ein Grund für die regional differenzierte Siedlungsweise.

Während beispielsweise Brill über 450 Jahre eine platzkonstante Siedlung darstellte, fanden sich zeitgleich anderen Ortes Wandersiedlungen, die innerhalb der Feldflur ihren Standort verlegten. Für die ältere römische Kaiserzeit sind Streusiedlungen belegt, wobei Gehöfte in Streulage sich auch noch in der Völkerwanderungszeit finden (SCHMID 1978, 345; ZIMMERMANN 1997, 421-425). Anders als in Flögeln, Hijken und Grontorf, wo sich im Umfeld der sogenannten Celtic Fields Wandersiedlungen in Streulage befanden (BEHRE, KOSSACK, SCHMID 1984, 220) fehlt diese frühgeschichtliche Wirtschaftsform in weiten Teilen Ostfrieslands.

Im 4./5. Jahrhundert kommt es zu einem allgemein beobachteten Umbruch in den bestehenden Siedlungsgemeinschaften. Welche sozialen oder wirtschaftlichen Ursachen ihnen zugrunde lagen, ist bisher ungeklärt. Als Ergebnis des Siedlungswandels lösten sich die bestehenden Siedlungsweisen vielerorts auf (BEHRE / KOSSACK / SCHMID 1984, 226-234).

Die vom 1. bis zur Mitte des 3. Jahrhundert bestehende Siedlung Nortmoor fügt sich weitgehend in das bekannte Siedlungsschema ein, wie es im südlichen Nordseeküstengebiet von der römischen Kaiserzeit bis zur Völkerwanderungszeit bestanden hat. Im Unterschied zur Gristeder Esch, wo sich bereits im 1. Jahrhundert v. Chr. geschlossene Siedlungsstrukturen abzeichnen (ZOLLER 1972a; 1975), dominieren im Untersuchungsgebiet Einzelgehöfte oder kleinere weilerartige Siedlungen. Nortmoor ist hierbei ein Beispiel für eine platzkonstante Gehöftsiedlung mit wenigstens einem Hausplatz, den zugehörigen Nebengebäuden, Brunnen und Werkgruben. Das Siedlungsareal wurde bereits früh von 
der Umgebung durch lange Zaunreihen abgegrenzt.

In der Jümme-Niederung waren die Siedlungsmöglichkeiten aufgrund des natürlich hoch anstehenden Grundwasserstandes begrenzt. Der Nortmoorer Dünenzug bot sich daher als erhöht liegende Siedlungsfläche an. Allein auf der untersuchten Restdüne gelang es drei kaiserzeitliche Hausplätze herauszuarbeiten. Nach Auswertung der Befundlage handelte es sich um ein Einzelgehöft mit mehreren Bauphasen, welches seine Position entlang des Dünenzuges verlagerte. Da es im östlichen Grabungsbereich von der Wohnbebauung separat liegende kaiserzeitliche Nebengebäude und Speicherbauten gab, kann dies als ein Hinweis auf weitere kaiserzeitliche Hausplätze gelten.

Dies alles weist für Nortmoor auf eine Gehöftsiedlung entlang des Dünenrückens hin. Demnach könnte es sich um eine strukturierte Gruppensiedlung handeln; die jedoch im Unterschied zu den bekannten nicht eine geschlossene Formation bildete, sondern deren Gebäudeorientierung dem knapp bemessenden Platz auf der Nortmoorer Düne folgte.

Somit finden sich auch im Binnenland des Unteren Emsgebietes Beispiele für eine flussorientierte Besiedlung, die nicht nur Flussmarsch und Niederungszone, sondern den nahen Geestrand als Wirtschaftsraum nutzte. Diese breite wirtschaftliche Basis erklärt den relativen Wohlstand der Nortmoorer Bewohner. Vermutlich übersiedelten sie nach Aufgabe der flussnahen Siedlung an den nahen Geestrand. Die kaiserzeitlichen Brandgräberfelder von Nortmoor-Isbargen, Detern-Stickhausen, Bonnhausen-Amdorf sowie Nettelburg bezeugen für die Region Nortmoor von ein intensives Siedlungsgeschehen.

Seit dem Neolithikum hat der Mensch die Landschaftsgestalt Ostfrieslands entscheidend mitgestaltet. Mit der Schaffung einer Kulturlandschaft wurde dabei auf vielfältige Art und Weise in die Entwicklung der Böden eingegriffen.

Durch den anthrogenen Eingriff auf natürliche bodenbildende Prozesse, wie Änderungen im Bodenwasserhaushalt oder Zerstörung der Vegetationsdecke, wurden nachhaltig Böden verändert. Hinzu kommen tiefgreifende Veränderungen durch Eingriffe in den sogenannten Pflughorizont mit der Beseitigung von wasserstauenden Schichten. In der ostfriesischen Geest sind dies vorzugsweise staunasse Lehmböden, die durch teilweise tiefgreifende Umbruchmaßnahmen landwirtschaftlich nutzbar gemacht worden sind. Meist folgte im Anschluss ein Auftrag von Plaggen oder mit Mist vermischter Erde mit dem Ziel nährstoffreiche Böden zu erhalten. Dies hinterließ jedoch am Abtragsort Böden, die ihres Ah-Horizonts beraubt und dem Klima ungeschützt ausgeliefert waren. Insbesondere die in Ostfriesland ursprünglich landschaftstypischen Moorböden wurden Opfer einer massiven Umgestaltung. Mittels großflächiger Entwässerungen, gefolgt von Bodenabtrag des Moorkörpers und anschließender Vermischung mit Sand oder Muschelkalk, entstand ein neuer Bodentyp, der jedoch ohne regelmäßige Düngung schnell verarmte. 
Die bereits in der Latènezeit einsetzende Meeresspiegelsenkung fand im küstennahen Gebiet mit solcher Schnelligkeit statt, dass sich nur an wenigen Stellen Vermoorungen nachweisen ließen. Mit fortschreitender Bodenbildung und infolge schnell fallender Grundwasserstände bot der kalkreiche Marschboden einen besseren landwirtschaftlichen Ertrag als die nährstoffarme Geest. Eine allgemein positive Klimaentwicklung begünstigt die niedrig liegenden Siedlungsräume im Küstengebiet (UERKVITZ 1997, 265). Der zwischen dem 2. und 1. Jahrhundert v. Chr. auf $+1,6 \mathrm{~m} \mathrm{NN}$ abnehmende Sturmflutpegel förderte die Besiedlung entlang der Küsten.

Natürlich begünstigt wurde der mit einer breiten Marschenzone und großen Niederungen ausgestattete linke Emsuferwall bevorzugt aufgesiedelt. Vielfach kann hier ab dem 1. Jahrhundert v. Chr. von dem Beginn einer etwa 400 Jahre andauernden Siedlungsperiode ausgegangen werden.

Annähernd zeitgleich erfolgte die Aufsiedlung vergleichbarer Naturräume in der nahen Leda-JümmeNiederung und wenig später entlang des Geestrandes. Wichtig war den Siedlern ein direkter Zugang zu den Niederungen, denen neben der Marsch eine zentrale Rolle als Wirtschaftsfläche für die verbreitete Viehhaltung zukam.

Zwar wird ab dem 1. Jahrhundert n. Chr. ein erneuter Anstieg der Sturmfluthöhe festgestellt, aber zunächst waren die Siedlungen an Ems und Jümme davon kaum betroffen. Erfolgte an anderen Küstenstandorten mit steigendem MThw und Sturmflutpegel eine Aufhöhung der Wohnplätze, so war dies im Unteren Emsgebiet nicht notwenig.

Zum einen schützte der damals noch stark meandrierende Emsverlauf die Region vor einlaufenden Fluten, zum anderen lagen die Siedlungen meist bereits auf natürlichen Erhöhungen, wie Geestdurchragungen oder Flugsanddünnen. Diese trockenen Standorte wurden nicht nur wegen ihrer prädestinierten Lage gewählt, sondern auch um wertvolles Acker- und Weideland durch Siedlungsflächen zu verschwenden.

Auf Dauer boten jedoch weder natürlich erhöhte Siedlungsplätze noch mehrmalig künstlich angepasste Niveauerhöhungen einen Schutz vor der zunehmenden Versalzung des Grundwassers; eine „schleichende“ Folge der im 3. Jahrhundert n. Chr. einsetzenden D-II-Transgression (vgl. BEHRE / HAARNAGEL 1984, 74, Abb. 2). In welchem Umfang dies für die Jümmemarsch relevant war, ist noch zu klären.

Die altbesiedelten Flächen in der Emsmarsch blieben auch weiterhin, wenn auch in geringerem Umfang, besiedelt. Erst beständig verschlechternde Bedingungen führten spätestens im 5. Jahrhundert n. Chr. zur Abwanderung der Bevölkerung bzw. zu einer höheren Sterblichkeitsrate, letztlich mit der Folge der Bevölkerungsreduktion. 
Trotz der einsetzenden Regression 5 (350-700 n. Chr.) wurde die Marsch wohl erst ab dem 7. Jahrhundert wieder aufgesiedelt (SCHMID 1988, 133-164). Dies verdeutlicht auch, dass der einmal begonnene Prozess der Versalzung nicht direkt reversibel war, sondern seine ungünstige Wirkung über lange Zeit beharrlich behielt.

Im 7. Jahrhundert wurden erste Flachsiedlungen angelegt, doch auch höhere Gebiete auf der Geest erstmals seit der Eisenzeit wieder in Besitz genommen. Ein Beispiel sind frühmittelalterliche Siedlungsspuren in Brinkum und Filsum nördlich der Jümme. Der sich seit der Eisenzeit regenerierte Boden bot den frühen Bauern zunächst ein erträgliches Auskommen. Die nur gering nährstoffhaltigen Sandböden waren jedoch ohne eine ausreichende Brachzeit von 5-8 Jahren auf Dauer von Verwitterung betroffen.

Möglicherweise war dies auch mit ein Grund wieder in der Jümme-Niederung zu siedeln. Inzwischen hatte sich die tiefliegende Flussmarsch von den Folgen der D-II Transgression erholt.

Erstmals seit der frühen Völkerwanderungszeit finden sich auf der Nortmoorer Düne Siedlungsspuren. Große Rutenberge und Brunnenanlagen weisen auf recht günstige Bedingungen hin, zudem sich die Bewohner Pingsdorfer Krüge leisten konnten. Auch dieses Mal wird die Viehhaltung vor dem Ackerbau in der durch grasreiche Niederungen geprägten Marsch die Hauptwirtschaftsbasis gestellt haben.

Jedoch war auch diese Siedlungsphase von einem jähen Ende bedroht. Mächtige Sedimentschichten weisen auf eine unerwartete Naturkatastrophe hin. Zahlreiche Befunde sind mit einer Kleischicht verfüllt. Folge war eine ökologische Krise, da in dem Niederungstal die Hochwasser nicht zügig ablaufen konnten.

Ein ähnliches, wenn auch nicht vergleichbares Ereignis hatte in der späten Kaiserzeit bereits die Jümme-Niederung heimgesucht. Auch in dieser Phase waren es extreme Überschwemmungen, die schließlich zur Aufgabe der Siedlung führten. Die küstenvorgelagerte Insel Burcana bestand zu dieser Zeit noch (Strabo VII 290). Die Insel und die zahlreichen Emsschleifen fungierte zur Nordsee als Sturmflutenschutz. Es ist daher zu vermuten, dass die Überschwemmungen im Hinterland ihren Ursprung hatten.

Aus dieser Phase stammen zahlreiche Funde, wobei keramisches Material den Großteil ausmacht. Hierunter fallen auch Fragmente römischer und provinzialrömischer Provinence, wie Terra Sigillata, Terra Nigra und Drehscheibenware. Ungewöhnlich ist eine gestempelte Terra Sigillata Nachahmung, die bis dato ein Unikat im germanischen Barbaricum darstellt und auch im provinzialrömischen Raum ohne Vergleich ist. Daneben finden sich seltene Einzelstücke, wie der Glasrand eines römischen Balsamarien (Salbgefäß) und einer silbernen Zierscheibe. U.a. gehören ein Denar Trajans, eine Kupfermünze, Basaltlava von römischen Drehmühlen und römisches Haushaltsgeschirr zum Fundgut der Siedlung. 
Nur von wenigen Plätzen im Küstengebiet der südlichen Nordsee sind römische Funde bekannt, während weite Gebiete der ostfriesischen Halbinsel nahezu fundleer blieben. Noch 2002 war römische Keramik lediglich von zwei Plätzen im Landkreis Aurich (Großheide, Middels) und von drei Fundstellen im Landkreis Leer (Bentumersiel, Holtgaste, Jemgum) bekannt (ERDRICH 2002, 34-35, 44-46). Inzwischen kann das Verbreitungsbild für den Landkreis Leer durch weitere Fundorte ergänzt werden (u. a. Amdorf, Nortmoorer Hammrich, Westerhammrich).

Welche Bedeutung der Umschlagplatz Bentumersiel mit seinen reichen römischen Funden hatte, zeigt sich auch an ausgesprochen qualitätsvollen römischen Funden aus dem südostfriesischen Hinterland. Aus dem Westerhammrich bei Leer stammen u.a. eine provinzialrömische Tutulus-Fibel des 3. Jahrhunderts n. Chr. und das Fragment einer Marsstatuette. Einen massiv gearbeiteten und mit einer Schmuckscheibe versehenen Goldfingerring fand man in Meinersfehn (FStNr. 2613/7:003). Die Einlegearbeit aus blauem Glasbelag stellt noch eine Imitation eines braunen Onyxes dar (SCHLICHT 1964, 382). Der Ringreif ist mit aufgelöteten Kügelchen verziert, die für spätrömische Ringe typisch sind.

Unter dem Fundmaterial von Nortmoor ist eine Vielzahl an Trichterschalen mit geradem Unterteil und kurz ausbiegendem Rand belegt, die auf ihrem gerundeten Bauchumbruch mit schraffierten hängenden Dreiecken und punktgesäumten Linien verziert sind. Ornamente dieses Typs sind im Weser-EmsGebiet allgemein verbreitet.

Die chaukische Bevölkerung im unteren Emsgebiet war Rhein-Weser-germanischen Einflüssen gegenüber aufgeschlossen, wie sich in typischen Verzierungen insbesondere der Grabkeramik zeigt. Charakteristisch ist der scharf kantige Schulterumbruch und der kurze umbiegende Rand (Kat.Nr. 317; 216-6), die der Form Uslar I entspricht. Auch steil aufstellende Standfüße weisen darauf hin (Kat.Nr. 627-13; 698a-2). Eingliedrige Töpfe mit hohem, fast kantigem Umbruch, wie sie USLAR (1938, Taf. 33,2) aufführt, finden sich in wenigen Exemplaren (Kat.Nr. 140-9).

Für die zentrale ostfrische Geest war dies weit weniger der Fall und erst südlich von Brill gewinnen Rhein-Weser-germanische Verzierungsmuster an Bedeutung (LEHMANN 2002, 183).

Eine kleine doppelkonische Schale mit ausgeprägtem Umbruch ungefähr in der Mitte der Gefäßhöhe darunter ist mit horizontalen Rillen verziert (Kat.Nr. 369-4). Ungewöhnlich sind die ockerfarbene, glatte Ware und der sehr fein geschlämmte Ton. Diese technischen Merkmale machen den Import des Gefäßes wahrscheinlich. Schalen mit unverdicktem Rand und kurzer konischer Schulter treten in der Wesermarsch bereits im 2./3. Jahrhundert auf. Dort dem Typ HW 13 zugeordnet wird sie der Form Uslar II zugerechnet und kommt bis in die Mitte des 4. Jahrhunderts vor (FöRST 1991, 95, Taf. 11, 24; Taf. 56, 425). Kleine Schalen mit hochliegendem Bauchumbruch und kurzer Schulter werden in Hatzum-Boomborg in der Rubrik Trichterschale als HB 18 geführt (LÖBERT 1982, 60 Taf. 53, 923), 
während im Wendland weitmündige Schalen bereits dem Horizont 10 angehören und völkerwanderungszeitlich datiert werden (NÜSSE 2002, 64, Abb. 51).

Die kaiserzeitliche Siedlung nutzte den Höhenrücken für ihre Wohnbebauung. Speicherbauten und Brunnen lagen in tieferen Arealen. Große Wohn-Stall-Häuser, wenigstens zehn Brunnen und eine Wasserstelle, 12 Speicher und ein Grubenhaus sind, umgeben von drei hofumgrenzenden Zaunanlagen, Zeugen einer etwa 200 Jahre platzkonstanten Siedlung. Die frühmittelalterliche Siedlungsphase wird von heimischer Muschelgrus gemagerter Keramik dominiert. Harte Grauware und importierte Pingsdorfer Gefäße belegen eine bis ins 11. Jahrhundert reichende Besiedlung, die durch eine Überflutungsphase im Leda-Jümme-Gebiet beendet wurde.

Neben einer auf Viehhaltung und Landwirtschaft ausgerichteten Gehöftsiedlung, wobei nach bisherigem Stand kaum mehr als ein bis zwei Höfe gleichzeitig bestanden, weisen die zahlreichen Gruben, einige mit Holz- und Flechtwerkseinbauten, auf handwerklich genutzte Bereiche hin. Möglicherweise dienten die Gruben als Rottegruben (Lederverarbeitung) oder wurden für andere produzierende Abläufe genutzt. Auch zur Vorratshaltung und sekundär zur Abfallentsorgung eigneten sie sich.

Die guten wirtschaftlichen Bedingungen haben eine konstante Besiedlung ermöglicht, während andernorts Wandersiedlungen das Siedlungsbild prägten. Für den ostfriesischen Raum scheinen platzkonstante Siedlungen jedoch weniger ungewöhnlich zu sein. Sie sind sowohl von der Geest in Brill und Nenndorf, als auch aus der Marsch bekannt. Backemoor, etwa $2 \mathrm{~km}$ südlich der Leda gelegen, zeigt eine vergleichbare Konstanz in Siedlungsart und -dauer besessen zu haben. Eine an den Naturraum angepasste Wirtschaftsweise ermöglichte dies.

Angaben über die frühmittelalterliche Siedlung Nortmoorer Hammrich sind aufgrund des doch stark rudimentären Charakters der wenigen Baubefunde kaum zu treffen. Sicherlich kann von wenigstens einem Gehöft ausgegangen werden, über die Siedlungs- und Wirtschaftsform sind jedoch keine Aussagen möglich. Hier bleibt nur ein Verweis auf die wenigen bekannten Siedlungen aus dieser Zeit. Aber ob ein Vergleich mit der Geestsiedlung Hesel den in der Flussmarsch herrschenden Siedlungsbedingungen nahekommt, darf bezweifelt werden. Auch die aus Emden bekannten frühstädtischen Strukturen sind kaum auf eine ländliche Binnensiedlung zu übertragen. Erst mit neuen Grabungen in ungestörten historischen Ortskernen wäre dem abzuhelfen.

In der vorrömischen Eisenzeit war das Arbeitsgebiet Teil eines Kultur- und Verkehrsraumes, der das Küstengebiet der südlichen Nordsee, entlang der niederländisch-norddeutsch-dänischen Gebiete, bis hinab in das norddeutsche Tiefland miteinander verband (HARCK 1972/73; NÜSSE 2002; SCHWARZ 1995). Dies hat sich für die nachfolgenden Epochen kaum geändert, wobei dem kulturellen Austausch eine stärker werdende Bedeutung zukam. 
In der älteren Eisenzeit wurden die bis dahin bewirtschafteten Geestareale verlassen und stattdessen die vorher wenig genutzten Niederungsgebiete von Jümme und Leda aufgesiedelt (SCHWARZ 1998, 25). Bereits besiedeltes Altsiedelland in der Flussmarsch blieb besiedelt, wie die Siedlung HatzumBoomburg in der reiderländischen Emsmarsch belegt. Auch Stellen nahe Detern und Velde in der Jümmemarsch zeigen eine längere Platzkonstanz. Der Emslauf verbreiterte sich in dieser Zeit und damit auch der Einfluss des Tidenhubs (BEHRE 1970). Für den damals noch stark mäandrierenden Flusslauf der Jümme wird es jedoch kaum zu einer Beeinflussung gekommen sein.

$\mathrm{Zu}$ Beginn der Kaiserzeit war der Siedlungsraum in der Küstenmarsch erweiterungsfähig. Eine Regressionsphase der Nordsee machte die niedrig liegenden Küstengebiete erneut nutzbar (BEHRE 1986b, 51). Spätestens um Christi Geburt konnte nach der D-I Transgression das Land nahe der Küste besiedelt werden, während die Ems-Uferwälle bereits im 1. Jahrhundert v. Chr. aufgesiedelt werden konnten. Insgesamt wurde die Nahrungswirtschaft intensiviert.

In der Kaiserzeit verstärkte sich im unteren Emsgebiet die Aufsiedlung in der Flussmarsch und entlang der Geestränder. Die Hinwendung zu Siedlungsstandorten in der Niederungszone liegt möglicherweise auch in einem Wandel der Wirtschaftweise begründet. Für die kaiserzeitliche Siedlungsentwicklung im Landkreis Wittmund kann SCHWARZ (1999) dies glaubhaft machen. Eine verstärkte Aufsiedlung ist für die Flussmarschgebiete entlang der Wesermarsch, insbesondere im Mündungsbereich der Hunte festzustellen (FöRST 1991, 109). Auch Fundstellen in der Elbmarsch zeigen, dass weiter östlich die Marschen aufgesiedelt wurden.

Im Landkreis Leer sind 34 kaiserzeitliche Siedlungen bekannt, meist handelte es sich um Standorte in der Flussmarsch oder im Niederungsbereich. Bevorzugt wurde eine Lage im Übergangsbereich von Geestrand und Niederung. Siedlungen legte man auf Uferwällen oder Geestdurchragungen bzw. flussparallelen Dünen an, um so einen trockenen Baugrund bei gleichzeitig guter Zugänglichkeit zum Wirtschaftraum zu gewährleisten.

Ergänzt werden kann das von RÖTTING 1985 kartierte Siedlungsbild um weitere Siedlungen auf dem rechten Emsufer und im Hinterland von Jümme und Leda (Westerhammrich, Amdorf, Nortmoor, Detern-Hafercamp, Backemoor). Kaiserzeitlichen Geestsiedlung im Untersuchungsgebiet sind nur von wenigen Plätzen bekannt (Holtland-Kampeeschen, Ihrhove-Lütjegaste, Kirchbogum-Weener).

Kaiserzeitliche Gräberfelder haben zumeist den Nachteil alt gegraben zu sein, wobei die Dokumentation zu wünschen übriglässt (Amdorf-Bonnhausen, Leer-Schießstand, Nettelburg, Nortmoor-Isbargen, Detern-Hafercamp, Detern, Filsum, Weener-Norder-Hilgenholt). Eine Nekropole mit elf Brandbestattungen im Nortmoorer Hammrich sowie die aus dem Westerhammrich vorliegende 
Körperbestattung stellen die einzigen modern gegrabenen Bestattungsplätze dar. Ebenso wie die Siedlungen finden sich sämtliche Bestattungsplätze in der Flussmarsch.

Aufgrund der insgesamt geringen Anzahl der völkerwanderungszeitlichen Siedlungsplätze können Aussagen zum Siedlungswesen nur unter Vorbehalt erfolgen. Ein Vergleich mit der in der Kaiserzeit günstigen Lage von Wohnplätzen zeigt auch für diese Besiedlungsepoche eine Bevorzugung von sandigen Uferrandstandorten, wobei sich eine Präferenz zu höher liegenden Arealen abzeichnet. Von 14 Fundstellen liegen zehn im Reiderland bei Geländehöhen zwischen $+1,5$ bis $+3 \mathrm{~m} \mathrm{NN}$. Da es sich um alt gegrabene Fundstellen handelt, erfolgt die Datierung anhand signifikanter Keramik, Baubefunde sind nicht überliefert. Etwas höher liegt mit $+3,5 \mathrm{~m} \mathrm{NN}$ der bereits zur Völkerwanderungszeit besiedelte Geestort Hollen (SCHÄFER in Vorbereitung). Allein von einer Siedlung im Stadtgebiet Leer liegen dokumentierte Baubefunde, wie die Reste zweier Hausgrundrisse und eines Brunnens, vor. Keramikfunde, u.a. sächsische Buckelkeramik, sowie die erfolgten dendrochronologischen Untersuchungen an Hölzern (416 +8/-2 und $417+8 /-6$ n. Chr.) datieren die bei Loga-Leegcamp entdeckte Siedlung in die Völkerwanderungszeit. Der gewählte Siedlungsstandort bei einer Höhenlage von $\mathrm{NN}+7 \mathrm{~m}$ auf der Geestzunge weist bereits auf eine naturräumlich veränderte Siedlungssituation hin, möglicherweise beeinflusst durchsteigende Grundwasserstände infolge eines ansteigenden Meeresspiegels. Doch auch hier zeigt sich eine bleibende bevorzugte Siedlungswahl niederungsnaher Standorte, ist doch die Jümme-Niederung im Süden nur wenige hundert Meter entfernt.

Die Fundplatzanzahl zeugt von einer recht deutlichen Abnahme der im Unteren Emsgebiet ansässigen Bevölkerung. Anders als in der römischen Kaiserzeit ist nicht von einer Konzentration verschiedener Ansiedlungen zu gemeinsamen Siedlungen auszugehen. Vielfach wurden die ortsfesten Siedlungen der Kaiserzeit nicht in der Völkerwanderungszeit fortgeführt. Eine Ausnahme bildete das Altsiedelland am Emsufer, wobei sich sicherlich die Intensität der völkerwanderungszeitlichen Besiedlung reduzierte, wie die geringe Fundmenge andeutet. Im Binnenland werden zunächst höhere Lagen aufgesucht. Im Zuge des starken Bevölkerungsrückganges kommt es schließlich zu einem regelrechten Siedlungsabbruch zwischen dem 5. und 7. Jahrhundert.

Eine fluktuierende Siedlungsweise ist bei frühmittelalterlichen Fundstellen auf der Geest festzustellen. Bisher gehören fünf Fundstellen südöstlich von Hesel dieser frühen Siedlungsphase an. Jeweils handelt es sich um Einzelgehöfte mit Speicherbauten und Brunnen, die meist eine Umhegung durch Zaun oder Graben aufwiesen. Ob es sich um gleichzeitige Bauten oder um sich zeitlich ablösende Gebäude handelt, kann anhand des zeitlich indifferenten keramischen Materials derzeit noch nicht geklärt werden. Möglicherweise zog die Siedlung hangaufwärts bis sie im Mittelalter schließlich ihren Standort im heutigen Nortmoor erreichte. 


\section{Quellenverzeichnis}

\subsection{Schriftquellen}

Strabon: Geographika. Prolegomena. Buch I-IV: Text und Übersetzung. Stefan Radth (Hrsg.), Strabons Geographika, Bd.1, Göttingen 2002.

Tacitus, ANN. C. Tacitus: Annalium libri XVI. H. Heubner (Hrsg.), Stuttgart 1983.

Tacitus, Germ. C. Tacitus: Germania. M. Fuhrmann (Hrsg.), Lateinisch-Deutsch. Erläutert und mit Nachwort versehen, Stuttgart 1972.

GoETZ, H.-W. / WelWEI, K.-W. 1995: Altes Germanien. Auszüge aus den Antiken Quellen über die Germanen und ihre Beziehungen zum römischen Reich. Quellen der alten Geschichte bis zum Jahre 238 n. Chr., Bd. 1 u. 2, Darmstadt 1995.

BeCKER, A. 1992: Rom und die Chatten. Quellen und Forschungen. Hessische Geschichte 88. Darmstadt-Marburg 1992.

\subsection{Literaturverzeichnis}

AHRENS, C. 1974: Die eisenzeitlichen Hausgrundrisse im Harburger Raum. Hammaburg N.F. 1, 1994, 77-92.

AlBERS, H. 2004: Der Siedlungshügel von Driever, Westoverledingen. 26 Seiten (unpubl.).

ALbERS, H. 2003: Die Datierung des Kleihorizontes von Völlen. 14 Seiten (unpubl.).

Almgren, F. 1923: Studien über nordeuropäische Fibelformen. Manusbibliothek 32. 1923.

Von Alten, F. 1874: Ausgrabungen bei Haddien im Jeverland, nebst einigen Nachrichten über ähnliches im Herzogthum Oldenburg. Zeitschrift für Anthropologie VII, 1874, 24 - 30, 180 - 198.

Van Alten, F. 1888: Die Bohlenwege im Flussgebiet der Ems und Weser. Jahrbuch für die Geschichte des Herzogtums Oldenburg 6, 1888, 1-47.

AOUNI, H. 1999: Das Weser-Ems-Gebiet und das Frankenreich. In: M. Fansa (Hrsg.), Über allen Fronten. Nordwestdeutschland zwischen Augustus und Karl dem Große. Oldenburg 1999, 163 - 190.

ATICUS, R. 2003: Das Urnengräberfeld von Kassendorf, Ldkr. Ostholstein. Die Entwicklung des südöstlichen Schleswig-Holsteins während der jüngeren römischen Kaiserzeit. Raden 2003.

BAKKER, A. 1979: Ein vergessenes Megalithgrab zu Leer (Ostfriesland). Probleme der Küstenforschung im südlichen Nordseegebiet 13, 85-97, Oldenburg 1979.

BantelmanN, A. 1955: Tofting, eine vorgeschichtliche Warft an der Eidermündung. Offa 12, Neumünster 1955.

BantelmanN, A. 1978: Zur Abgrenzung und Interpretation archäologischer Fundgruppen der älteren römischen Kaiserzeit im freien Germanien. Bonner Jahrbuch 178, 335-346.

BantelmanN, A. 1988: Süderbrarup. In Gräberfeld der römischen Kaiserzeit und Völkerwanderungszeit in Angeln. 1 Archäologische Untersuchungen. Offa 63, 1988.

Bantelmann, A. 1989: Zur relativen Chronologie der älteren römischen Kaiserzeit im Gebiet der unteren Elbe. Offa 46, 1989, 95-110. 
BÄRENFÄNGER, R. 1988: Siedlungs- und Bestattungsplätze des 8. bis 10. Jahrhunderts in Niedersachsen und Bremen. British Archaeological Reports, International Series 398, Teil 1 u. 2, Oxford 1988.

BÄRENFÄNGER, R. 1992: Frühmittelalterliche Siedlungsfunde und hölzerne Eggenteile aus Hattersum, Landkreis Wittmund. Archäologische Mitteilungen aus Nordwestdeutschland 15, 1992, 215-229.

BÄRENFÄNGER, R. 1992a: Befunde und Funde der älteren vorrömischen Eisenzeit aus Brinkum, Ldkr. Leer. Archäologische Mitteilungen aus Nordwestdeutschland 15, 1992, 201-215.

BÄRENFÄNGER, R. 1993a: Der Westerhammrich bei Leer. Ein bedeutendes Fundgebiet an der unteren Ems. Berichte zur Denkmalpflege 2, 1993, 52-55.

BÄRENFÄNGER, R. 1993b: Holtland, Gde. Hesel, FStNr. 2711/2:131, Eisenverhüttungsplatz der Römischen Kaiserzeit. Archäologische Mitteilungen aus Nordwestdeutschland 16 (Fundchronik 1992), 1993, 79-82.

BärENFÄNGER, R. 1994: Vier Gehöfte des 9. Jahrhunderts aus Hesel, Ldkr. Leer. Nachrichten aus Niedersachsens Urgeschichte 63 (1), 1994, 39-72.

BÄRENFÄNGER, R. 1994a: 1.7 Eisenverhüttungsplatz der Römischen Kaiserzeit. Holtland, Landkreis Leer (FStNr. 2711/2:131). Nachrichten aus Niedersachsens Urgeschichte 62 (2), 204.

BÄRENFÄNGER, R. 1995: Pütt und Sod - Mittelalterliche Brunnen in Ostfriesland als Geschichtsquelle. In: H. van Lengen (Hrsg.), Collectanea Frisica, Beiträge zur historischen Landeskunde Ostfrieslands. W. Deeters zur 65. Geburtstag. Aurich 1995, 11-43.

BÄRENFÄNGER, R. 1996: Loga-Leegcamp. Fundchronik. Nachrichten aus Niedersachsens Urgeschichte 64 (2), 358, 1996.

BÄrENFÄNGER, R. 1996a: Nortmoor, Samtgde. Jümme, FStNr. 2111/8:2. Ur- und Frühgeschichtlicher Siedlungsplatz. Nachrichten des Marschenrat 33, 1996, 34.

BÄRENFÄNGER, R. 1997: Aus der Geschichte der Wüstung „Kloster Barthe“, Landkreis Leer, Ostfriesland. Ergebnisse der archäologischen Untersuchungen in den Jahren 1988 bis 1992. Probleme der Küstenforschung im südlichen Nordseegebiet 24, 9-252, Oldenburg 1997.

Bärenfänger, R. / Burkhardt, A. / Carli-Thiele, P. / Freund, H. / Grefen-Peters, S. / SCHULTZ, M. 1997a: Zwei völkerwanderungszeitliche Körpergräber aus dem ostfriesischen Wattenmeer - archäologischer, anthropologischer, paläopathologischer und paläo-ethnobotanischer Befund. Studien zur Sachsenforschung 10, 1-47, 1997.

BÄRENFÄNGER, R. 1997b: Loga-Leegcamp. Fundchronik 1996. Nachrichten aus Niedersachsens Urgeschichte 65 (2), 457-458, 1997.

BÄRENFÄNGER, R. 1997c: Nortmoor, Gde. Nortmoor, FStNr. 2111/8:2. Ein Siedlungsplatz der Römischen Kaiserzeit und des Mittelalters. Nachrichten des Marschenrat 34, 1997, 24.

BÄRENFÄNGER, R. 1997d: Ein vergessenes Keramikschiffchen aus Pogum, Landkreis Leer. NNU 1997/1, 299-302.

BäreNFÄNGER, R. 1997e: Leer OL-Nr. 2710/5:10, Gde. Stadt Leer (Ostfriesland), Ldkr. Leer, 
Reg.Bez. W-E. NNU 1997 (2), 440-441, Abb. 56 u. 57.

BÄRENFÄNGER, R. u.a. 1997f: Zwei völkerwanderungszeitliche Körpergräber aus dem ostfriesischen Wattenmeer - archäologischer, anthropologischer, paläopathologischer und paläoethnobotanischer Befund. Studien zur Sachsenforschung 10, 1997, 1-47.

BÄRENFÄNGER, R. 1998: “Mars” an der unteren Ems. Archäologie in Niedersachsen 1, 1998, 56-60.

BÄRENFÄNGER, R. 1998b: Von der Steinzeit bis zum Mittelalter: Ergebnisse archäologischer Forschung in Hesel (Rolf Bärenfänger). In: Gemeinde Hesel (Hrsg.), Hesel - Wüste Fläche, dürre Wildnis und magere Heidepflanzen. Der Weg eines Bauerndorfes in die Moderne. Weener 1998, 1971.

BäreNFÄNGER, R. 1998c: Mittelalter. In: SCHWARZ, W. / STUTZKE, R. 1998: Archäologische Funde aus dem Landkreis Leer. Archäologische Mitteilungen aus Nordwestdeutschland, Beiheft 21, 1998, 29-32.

BÄRENFÄNGER, R. 1998d: 169 Leer OL-Nr. 2710/5:10; Gde. Stadt Leer (Ostfriesland), Ldkr. Leer, Reg.Bez. W-E. Fundchronik Niedersachsen 1997. Nachrichten aus Niedersachsens Urgeschichte 1999, 105-107.

BÄRENFÄNGER, R. 1998e: Archäologisches zur frühen Wasserversorgung in Ostfriesland. In: G.M. Veh / H.J. Rapsch (Hrsg.), Von Brunnen und Zucken, Piepen und Wasserkünsten. Die Entwicklung der Wasserversorgung in Niedersachsen. Neumünster 1998, 288-294.

BÄRENFÄNGER, R. 1998f: Nortmoor, Gde. Nortmoor, FStNr. 2111/8:2. Siedlungsspuren der Römischen Kaiserzeit. Nachrichten des Marschenrat 35, 1998, 19.

BÄRENFÄNGER, R. 1998g: Am Anfang war der Eitopf. Archäologie in Niedersachsen 1, 1998, 75-76.

BÄRENFÄNGER, R. 1999: 271 Leer OL-Nr. 2710/5:10; Gde. Stadt Leer (Ostfriesland), Ldkr. Leer, Reg.Bez. W-E. Fundchronik Niedersachsen 1998. Nachrichten aus Niedersachsens Urgeschichte 1999, 166-168.

BÄRENFÄNGER, R. 1999a: Römische Kaiserzeit und Völkerwanderungszeit. In: Ostfriesland. Führer zu archäologischen Denkmälern in Deutschland 35, Stuttgart, 72-89.

BÄRENFÄNGER, R. 1999b: Mittelalter. In: Archäologische Funde aus dem Landkreis Leer. Archäologische Mitteilungen aus Nordwestdeutschland, Beiheft 21, 1998, 29-32.

BÄRENFÄNGER, R. 1999c: Hinweise auf Handel und Handwerk der Kaiserzeit an der unteren Ems. In: M. Fansa (Hrsg.), Über allen Fronten, Nordwestdeutschland zwischen Augustus und Karl dem Großen, Archäologische Mitteilungen aus Nordwestdeutschland, Beiheft 26, Oldenburg 1999, 39-44

BÄRENFÄNGER, R. 1999d: Mittelalter. In: Ostfriesland. Führer zu archäologischen Denkmälern in Deutschland 35, Stuttgart, 90-106.

BÄRENFÄNGER, R. 1999e: Archäologie in Kirchen und Klöstern. In: Ostfriesland. Führer zu archäologischen Denkmälern in Deutschland 35, Stuttgart, 107-116.

BÄRENFÄNGER, R. 2000: Backemoor. Fundchronik 1999. Nachrichten aus Niedersachsens Urgeschichte 67 (2), 2000, 99-102. 
BÄRENFÄNGER, R. 2000a: Kaiserzeitlicher Brunnenbau im ostfriesischen Backemoor. Archäologie in Niedersachsen 3, 2000, 75-77.

BÄRENFÄNGER, R. 2000b: Befunde der Römischen Kaiserzeit im Westerhammrich bei Leer / Ostfriesland. Archäologische Mitteilungen in Nordwestdeutschland, Beiheft 42, Oldenburg 2004, 420422.

BÄRENFÄNGER, R. 2001: Befunde einer frühmittelalterlichen Siedlung bei Esens, Ldkr. Wittmund (Ostfriesland). Probleme der Küstenforschung im südlichen Nordseegebiet 27, 2001, 249-300.

BÄRENFÄNGER, R. 2001a: Backemoor, Gde. Rhauderfehn, FStNr. 2811/1:33. Gebäude der Römischen Kaiserzeit und des späteren Mittelalters. Nachrichten des Marschenrates 38, 2001, 21-25.

BÄRENFÄNGER, R. 2002: Völkerwanderungszeit. Archäologie in Niedersachsen 5, 2002, 27-37.

BAUERMEISTER, R. 2005: Archäometallurgische Untersuchung an Eisenschlacken aus Holtland / Kreis Leer. Bachelor Geowissenschaften. Universität Göttingen. 2005 (unveröffentlichte Bachelorarbeit).

BAZELMANS, J. 2001: Die spätrömische Besiedlungslücke im niederländischen Küstengebiet und das Fortbestehen des Friesennamens. Emder Jahrbuch für historische Landeskunde Ostfriesland 81, 2001, 7-86.

BECKER, M. 2001: Klasse und Masse - Überlegungen zu römischem Sachgut im germanischen Milieu. Germania 81, 2003.1, 277-288.

BECKER, M / RASBACH G. 1998: Der spätaugustäische Stützpunkt Lahnau-Waldgirmis. Vorbericht über die Ausgrabungen 1996-1997. Germania 76, 673-692.

Bechert, T. / VANDERhoeven, M. 1988: Töpferstempel aus Südgallien. In: T. Bechert / G. Tromnau (Hrsg.), Funde aus Asciburgium 9, Duisburg 1988.

BeCherT, T. / Williams J.H. (Hrsg.) 1995: Die römische Reichsgrenze zwischen Mosel und Nordseeküste 1995.

BEHN, F. 1910: Römische Keramik mit Einflüssen der hellenistischen Vorstufen. Kataloge des Römisch-Germanischen-Zentral Museums. Mainz 1910.

BEHRE, K.-E. 1966: Untersuchungen zur spätglazialen und frühpostglazialen Vegetationsgeschichte Ostfrieslands. Eiszeitalter und Gegenwart 17, 69-84.

BEHRE, K.-E. 1970: Die Entwicklungsgeschichte der natürlichen Vegetation im Gebiet der unteren Ems und ihre Abhängigkeit von den Bewegungen des Meeresspiegels. Probleme der Küstenforschung im südlichen Nordseegebiet 9, 1970, 13-48.

BEHRE, K.-E. 1972: Kultur- und Wildpflanzenreste aus der Marschsiedlung Jemgumkloster/Ems (um Christi Geburt). Neue Ausgrabungen und Forschungen in Niedersachen 7, 1972, 164-184.

BEHRE, K.-E. 1973: Mittelalterliche Kulturpflanzenfunde aus der Kirche von Middels (Stadt Aurich / Ostfriesland). Probleme der Küstenforschung im südlichen Nordseegebiet 10, 39-48, Oldenburg 1973. 
BEHRE, K.-E. 1976: Beginn und Form der Plaggenwirtschaft in Nordwestdeutschland nach pollenanalytischen Untersuchungen in Ostfriesland. Neue Ausgrabungen und Forschungen in Niedersachsen 10, 1976, 197-224.

BEHRE, K.-E. 1976b: Pollenanalytische Untersuchungen zur Vegetations- und Siedlungsgeschichte bei Flögeln und im Ahlenmoor (Elb-Weser-Winkel), Probleme der Küstenforschung im südlichen Nordseegebiet 11, 101-118, Oldenburg 1976.

BEHRE, K.-E. 1977: Acker, Grünland und natürliche Vegetation während der römischen Kaiserzeit im Gebiet der Marschsiedlung Bentumersiel/Unterems. Probleme der Küstenforschung im südlichen Nordseegebiet 12, 1977, 67-84.

BEHRE, K.-E. 1979: Zur Rekonstruktion ehemaliger Pflanzengesellschaften an der deutschen Nordseeküste. Tüxen, R. (Hrsg.), Werden und Vergehen von Pflanzengesellschaften, 181-214, Vaduz 1979.

Behre, K.-E. / STREIF, H. 1980: Kriterien zum Meeresspiegel und darauf bezogene Grundwasserabsenkungen. Eiszeiten und Gegenwart 30, 153-160.

Behre, K.-E. / HAARnAGEL, W. 1984: Veränderungen des Küstenverlaufs. Ursachen und Auswirkungen III: Niedersachsen. In: G. Kossack, K.E. Behre, P. Schmid (Hrsg.), Archäologische und naturwissenschaftliche Untersuchungen an ländlichen und frühstädtischen Siedlungen im deutschen Küstengebiet vom 5. Jahrhundert v. Chr. bis zum 11. Jahrhundert n. Chr. Band 1: Ländliche Siedlungen. Weinheim 1984, 68-82.

BEHRE, K.-E. 1985: Die ursprüngliche Vegetation in den deutschen Marschgebieten und deren Veränderung durch prähistorische Besiedlung und Meeresspiegelbewegungen. Verhandlungen der Gesellschaft für Ökologie 13, Göttingen 1985, 85-96.

BEHRE, K.-E. 1986: Ackerbau, Vegetation und Umwelt im Bereich früh- und hochmittelalterlicher Siedlungen im Flußmarschgebiet der unteren Ems. Probleme der Küstenforschung im südlichen Nordseegebiet 16, 1986, 99-125.

BEHRE, K.-E. 1986b: Meeresspiegelverhalten und Besiedlung während der Zeit um Christi Geburt in den Nordseemarschen. Offa 43, 45-53.

BEHRE, K.-E. 1987: Meeresspiegelschwankungen und Siedlungsgeschichte in den Nordseemarschen. Vortrag vor der 20. Landschaftsversammlung der Oldenburger Landschaft. Oldenburg 1987.

BEHRE, K.-E. 1988: Die Umwelt prähistorischer und mittelalterlicher Siedlungen - Rekonstruktionen aus botanischen Untersuchungen an archäologischem Material. Siedlungsforschung, ArchäologieGeschichte-Geographie 6, 1988, 57-80.

BEHRE, K.-E. 1990: Kulturpflanzen und Unkräuter der vorrömischen Eisenzeit aus der Siedlung Rullstorf, Ldkr. Lüneburg. Nachrichten aus Niedersachsens Urgeschichte 59, 141-165.

BEHRE, K.-E. 1991: Umwelt und Ernährung der frühmittelalterlichen Wurt Niens/Butjadingen nach den Ergebnissen der botanischen Untersuchungen. Probleme der Küstenforschung im südlichen Nordseegebiet 18, 1991, 141-168. 
BEHRE, K.-E. 1995: Die Entstehung und Entwicklung der Natur- und Kulturlandschaft der ostfriesischen Halbinsel. In: K.-E. Behre, H. van Lengen (Hrsg.), Ostfriesland, Geschichte und Gestalt einer Kulturlandschaft. Aurich 1995, 5-36.

BEHRE, K.-E. 1999: Die Veränderung der niedersächsischen Küstenlinie in den letzten 3000 Jahren und ihre Ursachen. Probleme der Küstenforschung im südlichen Nordseegebiet 26, 1999, 9-34.

BEHRE, K.-E. 2000a: Die Geschichte der Vegetation und der Kulturlandschaft im Weser-Ems-Gebiet. Oldenburger Forschungen, Bd. 13 u. Beiheft der Archäologischen Mitteilungen aus Nordwestdeutschland 34, Archäologische Denkmäler zwischen Weser und Ems, 2000, 32-43.

BEHRE, K.-E. 2000b: Flussmarschlandschaft Rheiderland. Oldenburger Forschungen, Bd. 13 u. Beiheft der Archäologischen Mitteilungen aus Nordwestdeutschland 34, Archäologische Denkmäler zwischen Weser und Ems, 2000, 313-318.

BEHRE, K.-E. 2003: Eine neue Meeresspiegelkurve für die südliche Nordsee. Transgression und Regression in den letzten 10.000 Jahren. Probleme der Küstenforschung im südlichen Nordseegebiet 28, 9-63.

BEHRE, K.-E. 2005: Meeresspiegelbewegungen, Landverluste und Landgewinnungen an der Nordsee. Siedlungsforschung. Archäologie-Geschichte-Geographie 23, 2005, 19-46.

BEHRE, K.-E. 2005a: Meeresspiegelanstieg - Marschenentwicklung - Küstenlinien. Die letzten 10000 Jahre an der deutschen Nordseeküste im Zeitraffer. In: Mamoun Fansa (Hrsg.), Kulturlandschaft Marsch. Natur - Geschichte - Gegenwart. Symposium vom 3. bis 5. Juni 2004, Oldenburg 2005, 2536.

BEMMANN, J. 1999: Körpergräber der jüngeren römischen Kaiserzeit und Völkerwanderungszeit aus Schleswig-Holstein. Zum Aufkommen einer neuen Bestattungssitte im überregionalen Vergleich. Studien zur Sachsenforschung 13, 1999, 5-45.

Berger, F. / Stoess, CH. 1988: Die Fundmünzen der Römischen Kaiserzeit in Deutschland. Abteilung VII Niedersachsen und Bremen 1-3. Berlin 1988.

BERGER, F. 1992: Untersuchungen zu römerzeitlichen Fundmünzen in Nordwestdeutschland. Studien zu Fundmünzen der Antike 9, Berlin 1992.

Berghaus, P. 1958: Die ostfriesischen Münzfunde. Jahrbuch der Gesellschaft für bildende Kunst und vaterländische Altertümer zu Emden 38, 1958, 9-73.

Berghaus, P. 1958: Die ostfriesischen Münzfunde. Friesisches Jahrbuch 1958. Jahrbuch der Gesellschaft für bildende Kunst und vaterländische Altertümer zu Emden, Emden 1958, 9-73.

BERENGER, D. 2000: Zur Chronologie der vorrömischen Eisenzeit und römischen Kaiserzeit in Nordost-Westfalen. Bodenaltertümer Westfalens 38, Mainz 2000.

BerneCKer, A. 1989: Die Feldzüge des Tiberius und die Darstellung der unterworfenen Gebiete in der „Geographie des Ptolemaeus“. Bonn 1989.

BERKE, ST. 1990: Römische Bronzegefäße und Terra Sigillata in der Germania Libera. BOREAS Münstersche Beiträge zur Archäologie Beiheft 7. Münster 7. 
Biegert, S. / Schnurbein, S. von / STEIDEL, B. / WALTER. D. 2000: Beiträge zur germanischen Keramik zwischen Donau und Teutoburger Wald. Kolloquium zur germanischen Keramik des 1.-5. Jahrhunderts. 17.-18. April 1998. Kolloquium zur Vor- und Frühgeschichte Bd. 4, Bonn 2000.

BISCHOP, D. 2000: Siedler, Söldner und Piraten. Chauken und Sachsen im Bremer Raum. Bremer Archäologische Blätter Beiheft 2, 2000, 9-82.

BISCHOP, D. 2001: Die römische Kaiserzeit zwischen Weser und Hunte. Eine archäologische Bestandsaufnahme des Landkreises Diepholz. Oldenburg 2001.

BLOEMERS, H.J.F. 1978: Rijswijk (Z.H.), „De Bult“ Eine Siedlung der Cananefaten. Nederlandse Oudheden 8, Teil 1-3, Amersfoort 1978.

BlOEMERS, H.J.F. / THIJSSEN, J.R.A.M. 1990: Facts and Reflections on the Continuity of Settlement at Nijmegen between $\mathrm{AD} 400$ and 700. In: J.C. Besteman et al. (eds.), Medieval Archaeology in the Netherlands, Assen, 1990, 133-150.

BODE, M.-J. 1998: Ein Urnengräberfeld der Kaiser- und Völkerwanderungszeit. Urnenfriedhöfe Schleswig-Holsteins 14, Offa 78, Neumünster 1998.

BOELES, P.C.J.A. 1951: Friesland tot de elfde eeuw. Gravenhage 1951.

BöHME, A. 1972: Die Fibeln der Kastelle Saalburg und Zugmantel. Saalburg Jahrbuch 29, 5-112.

BöHME, H. W. 1974: Germanische Grabfunde des 4. bis 5. Jh. zwischen Elbe und Loire. Studien zur Chronologie und Bevölkerungsgeschichte. Münchner Beiträge Vor- und Frühgeschichte 19, München 1974.

BöHME, H.W. 1999a: Franken und Sachsen. Beiträge zur Siedlungs- und Bevölkerungsgeschichte in Westfalen vom 4.-7. Jahrhundert. Studien zur Sachsenforschung 12, 1999, 43-74.

BöHME, H.W. 1999b: Sächsische Söldner im römischen Heer. Das Land zwischen Ems und Niederelbe während des 4. und 5. Jahrhunderts. In: Nordwestdeutschland im Spannungsfeld der römischen Politik der Kaiserzeit. In: M. Fansa (Hrsg.), Über allen Fronten. Nordwestdeutschland zwischen Augustus und Karl dem Großen. Archäologische Mitteilungen aus Nordwestdeutschland, Beiheft 26. Oldenburg 1999, 49-74.

BÖHME, K.-E. 2003: Das nördliche Niedersachsen zwischen Spätantike und dem frühen Mittelalter. Zur Ethnogenese der Sachsen aus archäologischer Sicht. Probleme der Küstenforschung im südlichen Nordseegebiet 28, 251-270.

BöHNER, K. 1959: Das Grab eines fränkischen Herren aus Morken im Rheinland. Führer des Rheinischen Landesmuseums in Bonn 4, Köln 1959

BORN, H. 1975: Materialien und Herstellungstechniken antiker Melonenperlen. Jahrbuch RGZM 22, 1975, 134-140.

Bотн, F. 1996: Düna II. Untersuchungen zur Keramik des 1. bis 14. nachchristlichen Jahrhunderts. Mit einem Beitrag von Stefanie Koerfer. Materialhefte zur Ur- und Frühgeschichte Niedersachsens 24, Hannover 1996. 
Bотн, F. 1997: Die Keramik der Spätlatène- und Älteren Kaiserzeit aus dem Bohlenweg VI (Pr). Archäologische Mitteilungen aus Nordwestdeutschland 20, 1997, 77-79.

Вотн, F. 1999: Keramik und Glasimporte aus dem fränkischen Reich. Zeugnisse des Nordseeküstenhandels. In: M. Fansa (Hrsg.), Über allen Fronten. Nordwestdeutschland zwischen Augustus und Karl dem Große. Oldenburg 1999, 191-208.

BrABANDT, J. 1993: Hausbefunde der römischen Kaiserzeit im freien Germanien. Ein Forschungsstand. Veröffentlichungen des Landesamtes für archäologische Denkmalpflege SachsenAnhalt. Landesamt für Vorgeschichte Bd. 10, Halle (Saale) 1993.

Brackhausen, J. / Müller, H. 1982: Ein Pollenprofil aus der Leybucht. Probleme der Küstenforschung im südlichen Nordseegebiet 15, 1982, 127-134.

BRANDORFF, H. 1986: Ausgrabungen eines Grabhügels im Staatsforst Upjever, Landkreis Friesland. Nachrichten aus Niedersachsens Urgeschichte 55, 1986, 129-143.

BRANDES, H. 1878: Das Steingrab in Tannenhausen und Notizen über Ausgrabungen. In: Jahrbuch der Gesellschaft für bildende Kunst und vaterländische Altertümer zu Emden 3, Heft 1, 119-129.

BRANDT, K. 1958: Eine völkerwanderungszeitliche Siedlung von Bremen-Grambke. Germania 36, 205-215.

BRANDT, K. 1963: Stand der Untersuchungen der völkerwanderungszeitlichen Siedlung BremenGrambke. Germania 43, 395-401.

BRANDT, K. 1972: Untersuchungen zur kaiserzeitlichen Besiedlung bei Jemgumkloster und Bentumersiel (Gem. Holtgaste, Kreis Leer) im Jahre 1970. Ausgrabungen und Forschungen in Niedersachsen 7, 1972, 145-163.

BRANDT, K. 1974: Die Marschensiedlung Bentumersiel an der unteren Ems. Archäologisches Korrespondenzblatt 4, 1974, 73-80.

BRANDT, K. / BEHRE, K.-E. 1976: Eine Siedlung der älteren vorrömischen Eisenzeit bei Olendorp (Unterems) mit Aussagen zur Umwelt, Ackerbau und Viehzucht. Nachrichten aus Niedersachsens Urgeschichte 45, 1976, 447-458, Abb. 1-5, Tab. 1.

BRANDT, K. 1977a: Die Ergebnisse der Grabung in der Marschsiedlung Bentumersiel/Unterems in den Jahren 1971-1973. Probleme der Küstenforschung im südlichen Nordseegebiet 12, 1977, 1-31.

BRANDT, K. 1977b: Handelsplätze des frühen und hohen Mittelalters in der Marsch zwischen Emsund Wesermündung. Ein Vorbericht über archäologisch-historische Untersuchungen. Zeitschrift für Archäologie des Mittelalters 5, 1977, 121-144.

BRANDT, K. 1979: Siedlung und Wirtschaft in der Emsmarsch während des frühen und hohen Mittelalters. Historisch - siedlungsarchäologische Untersuchungen. Probleme der Küstenforschung im südlichen Nordseegebiet 13, 1979, 155-185.

BRANDT, K. 1979a: Notgrabung auf einer Siedlung der vorrömischen Eisenzeit und der römischen Kaiserzeit bei Jemgum (Jemgum III). Jahrbuch der Gesellschaft für Bildende Kunst und Vaterländische Altertümer zu Emden 59, 112-113, 1979. 
BRANDT, K. 1979b: Römische Funde im Lande Bremen. Jahrbuch der Wittheit zu Bremen XXIII, 1979, 36-39.

BRANDT, K. 1984: Siedlungsentwicklung. Geologische Karte von Niedersachsen 1:25000, Erläuterungen zu Blatt Nr. 2609 Emden, 66-75.

BRANDT, K. 1999: Ethnische Vielfalt an der Weser. Siedlung und Gräberfeld Bremen-Mahndorf. In: M. Fansa (Hrsg.), Über allen Fronten. Nordwestdeutschland zwischen Augustus und Karl dem Große. Oldenburg 1999, 113 - 133.

BEREITSPECHTER, U. 1997: Zum Problem der geschlechtspezifischen Bestattung in der Römischen Kaiserzeit. Ein Beitrag zur Forschungsgeschichte und Methoden. BAR Series 376, Oxford 1987.

Buma, W.J. / EbEL, W. 1963: Das Rüstringer Recht. Altfriesische Rechtsquellen 1, Texte und Übersetzungen. Göttingen 1963.

BUSCH, R. (Hrsg.) 1995: Rom an der Niederelbe. Harburg 1995.

BUSCH-HeLlWIG, S. 2007: Ein Siedlungsplatz der jüngeren Kaiserzeit n Backemoor, Ldkr. Leer. Beiträge zur Archäologie in Niedersachsen 13. Rahden/Westf. 2007.

CALlies, H. 1995: Römer und Germanen im nördlichen Deutschland. In: R. Busch (Hrsg.), Rom an der Niederelbe. Harburg 1995, 15-23.

CASELITZ, P. 2000: Die jüngerkaiser- bis völkerwanderungszeitliche Bevölkerungsstichprobe von Sates, Gde. Wingst, Ldkr. Cuxhaven. Die Kunde N.F. 51, 63-94.

CosACK, E. 1979: Die Fibeln der älteren Römischen Kaiserzeit in der Germania libera (Dänemark, DDR, BRD, Niederlande, CSSR). Teil 1. Göttinger Schriften zur Vor- und Frühgeschichte 19, Neumünster 1979.

DENECKE, D. 1994: Interdisziplinäre historisch-geographische Umweltforschung: Klima, Gewässer und Böden im Mittelalter und der frühen Neuzeit. Siedlungsforschung 12, 1994, 235-263.

DonAT, P. 1980: Haus, Hof und Dorf in Mitteleuropa vom 7. bis 12. Jh. Schriften zur Ur- und Frühgeschichte 33, 1980.

Donat, P. 1991: Zur Entwicklung germanischer Siedlungen östlich des Rheins bis zum Ausgang der Merowingerzeit. Zeitschrift für Archäologie 25, 1991, 149-207.

DöRFLER, W. 1995: Versuch einer Modellierung des Energieflusses und des Rohstoffverbrauchs während der römisch-kaiserzeitlichen Eisenverhüttung in Joldelund, Ldkr. Nordfriesland. Probleme der Küstenforschung im südlichen Nordseegebiet 23, 1995, 175-185.

VAN DoORSelaer, A. / ROgGe, M. 1991: Spätrömische und völkerwanderungszeitliche handgefertigte Keramik im Gebiet zwischen Scheldelta und Nordseeküste. Studien zur Sachsenforschung 7, 113-120, 1991.

DUINEN, L. / ZEIST, W. VAN 1961: Some pollen diagrams from the clay district in the provinzes Groningen, Friesland and North-Holland (Neatherlands). Palaeohistoria 8, 127-137. 
DuSEK, S. 1992: Römische Handwerker im germanischen Thüringen. Ergebnisse der Ausgrabungen in Harrhausen, Kreis Arnstadt. Weimarer Monographien zur Ur- und Frühgeschichte 27.1 u. 27.2, Stuttgart 1992.

EGGERS, H. J. 1951: Der römische Import im freien Germanien. Atlas der Urgeschichte 1, Hamburg 1951.

EGGERS, H. J. 1955: Zur absoluten Chronologie der römischen Kaiserzeit im freien Germanien. Jahrbuch RGZM 2, 1955, 196-244.

EGGENSTEIN, G. 2003: Das Siedlungswesen der jüngeren vorrömischen Eisenzeit und der frühen römischen Kaiserzeit im Lippebereich. Bodenaltertümer Westfalens 40, 2003.

ELlENbERG, H. 1963: Vegetation Mitteleuropas mit den Alpen in kausaler, dynamischer und historischer Sicht. In: H. Walter (Hrsg.), Einführung in die Phytologie IV (2), Stuttgart 1963. 704-721. Ellmers, D. 1978: Shipping on the Rhine during the Roman period. The pictoral evidence. In: Roman shipping and trade. Britain and the Rhine provinces. CBA recherch report 24, London 1978, 114.

ELLMERS, D. 1986: Die Bedeutung der Friesen für die Handelsverbindungen des Ostseeraumes bis zur Wikingerzeit. Emder Jahrbuch 66, 1986, 1-43.

ELLMERS, D. 1988: Archäologischer Kommentar zu dem Gedicht des Venatius Fortunatas über seine Moselreise. In: K. Schäfer (Hrsg.), Andernach im Frühmittelalter. Andanacher Beiträge 3, 1988, 25 68. ELLMERS, D. 1999: Handelsschifffahrt: In: Hoops Reallexikon der Germanischen Altertumskunde (13), 595-609.

ERDNIß, J. 1939: Die Chauken, ihre räumliche Abgrenzung auf Grund der Bodenfunde. Würzburg 1939.

ERDRICH, M. 1990: Einige Bemerkungen zu kaiserzeitlichen Bestattungen mit römischen Beigaben im nordwestlichen Niedersachsen. Archäologische Mitteilungen aus Nordwestdeutschland 13, 1990, 33-52.

ERdRICH, M. / SChNURbein, S. Von 1992: Vortrag zur Jahressitzung 1992 der RömischGermanischen Kommission. Das Projekt: Römische Funde im mitteleuropäischen Barbaricum, dargestellt am Beispiel Niedersachsen. Bericht der RGK 73, 1992, 5-27.

ERDRICH, M. 1995: Rom und die germanischen Stämme in Niedersachsen. In: R. Busch (Hrsg.), Rom an der Niederelbe. Harburg 1995, 47-70.

ERDRICH, M. 1996: Rom und die Barbaren. Das Verhältnis zwischen dem Imperium Romanum und den angrenzenden germanischen Stämmen vor seiner Nordwestgrenze seit der späten römischen Republik bis zum Gallischen Sonderreich. Amsterdam 1996.

ERDRICH, M. 1997: Terra Nigra-Fußschalen wie Chanet 342 oder Gellep 273: eine salisch-fränkische Keramikgattung. Germania 76.2, 1997, 875-884. 
ERdRICH, M. / VerLinde, A. D. 1997: Eine germanische Siedlung der späten Kaiserzeit mit umwehrter Anlage und umfangreicher Eisenindustrie in Heeten, Provinz Overijssel, Niederlande. Germania 76.2, 1997, 693-719.

ERDRICH, M. 2000: Oldenburg und Rom im 1. Jahrhundert. Archäologische Denkmäler zwischen Weser und Ems, Oldenburger Forschung N.F. 13, 96-107.

ERDRICH, M. 2001: Rom und die Barbaren. Das Verhältnis zwischen dem Imperium Romanum und den Germanischen Stämmen vor seiner Nordwestgrenze von der römischen Republik bis zum Gallischen Sonderreich. Mainz 2001.

ERDRICH, M. 2002: Hansestadt Bremen und Niedersachsen. Deutschland Band 4. Corpus der römischen Funde im europäischen Barbaricum. Frankfurt a. M. 2002.

EThelberg, P. VAN 1988: Die eisenzeitliche Besiedlung von Hjemsted Banke, Skærbæk sogn, Sønderjyllands amt. Offa 1988, 119-154.

VAN ES, W.A. 1965: Hand-Made pottery of the Roman Period from Kootwijksche Zand near Kootwijk, Gelderland. Berichten van de Rijksdienst voor het Oudheidkundig Bodemonderzoek 15-16, 1965-1966, 6-233.

VAN ES, W.A. 1966: Friesland in roman times. Berichten van de Rijksdienst voor het Oudheidkundig Bodemonderzoek 15-16, 1965-1966, 37-68.

VAN ES, W.A. 1967: Wijster, a nativ village beyond the imperial frontier 150-425 A.D. Palaeohistoria 11. (1965) 1967.

VAN ES, W.A. 1968: Paddepoel. Exavations of frustrated terps, 200 B.C.-250 A.D. Paleohistoria 14, 1968, 187-352.

VAN ES, W.A. 1970: Grabsitten und Christianisierung in den Niederlanden. Probleme der Küstenforschung im südlichen Nordseegebiet 9, 1970, 77-90.

VAN Es, W.A. / Miedema, M. (Hrsg.) 1970/71: Leeuwarden: Small terp under the Oldenhove Cementry. Berichten van de Rijksdienst voor het Oudheidkundig Bodemonderzoeg 20/21, 1970/71, 89-117.

VAN ES, W.A. 1981: De Romeinen in Nederland. 1981.

VAN Es, W.A. 1982: Ländliche Siedlungen der Kaiserzeit in den Niederlanden. Offa 39, 139-162, 1982.

VAN ES, W.A. / MiedeMA, M., Wynia, S.L. 1985: Eine Siedlung der römischen Kaiserzeit in Bennekom, Prov. Gelderland. Berichten van de Rijksdienst voor het Oudheidkundig Bodemonderzoek 35, 533-652, 1985.

VAN ES, W.A. 1988: Genetische Siedlungsforschung in den Niederlanden mit besonderer Berücksichtigung der ländlichen Siedlungsarchäologie im ersten Jahrtausend n. Chr. In: K. Fehn u. a. (Hrsg.), Genetische Siedlungsforschung in Mitteleuropa und seinen Nachbarräumen, Bonn 1988, 345364. 
ETHelberg, P. 1988: Die eisenzeitliche Besiedlung von Hjemsted Banke, Skǽrǽk sogn, Sǿnderjyllands amt. Offa 45, 1988, 119-154.

ETHELberG, P. 2001: Haus und Siedlung der älteren Römischen Kaiserzeit im ehemaligen Herzogtum Schleswig. Probleme der Küstenforschung im südlichen Nordseegebiet 27, 2001, 57-73.

FALK, A. 1983: Holzgeräte und Holzgefäße des Mittelalters und der Neuzeit aus Lübeck. Zeitschrift der Archäologie des Mittelalters 11, 31-48.

FANSA, M. 1986: Ein Siedlungsplatz aus der Zeit um Christi Geburt in Quendorf, Ldkr. Grafschaft Bentheim. Archäologischen Mitteilungen aus Nordwestdeutschland 9, 1986, 47-62.

FANSA, M. / SCHUSTER, R. 1993: Die Bohlenwege bei Ockenhausen / Oltmannsfehn, Gde. Uplengen, Ldkr. Leer. Archäologische Mitteilungen aus Nordwestdeutschland 16, 1993, 23-44.

Wildvang, D. / Schroller, H. 1936: Der Bohlenweg von Oltmannsfehn-Ockenhausen, Kr. Leer. Die Kunde 4, 1936, 73-81.

FAENSEN, B. 1993: Die Keramik einer kaiserzeitlichen Lehmgrube aus der Siedlung Mahlstaedt, Landkreis Oldenburg. Unveröffentlichte Diplomarbeit Halle/Saale 1993.

FEINDT, S. / FISCHER, M.G. 1994: Untersuchungen von Holzproben aus dem völkerwanderungs- bis karolingischen Gräberfeld Liebenau, Ldkr. Nienburg. Studien zur Sachsenforschung 5,4. 89-132.

FlACH, D. 1995: Der taciteische Zugang zu der Welt der Germanen. In: R. Wiegels, W. Woesler, Arminius und die Varusschlacht. Geschichte-Mythos-Literatur. Paderborn 1995, 143-166.

FöRST, E. 1988: „Briquetage“-Funde im Weser-Ems-Gebiet. Archäologisches Korrespondenzblatt 18, 357-364, 1988.

FöRST, E. 1991: Zur Besiedlungsgeschichte der Flußmarsch im Kreis Wesermarsch. Veröffentlichungen der urgeschichtlichen Sammlung des Landesmuseums zu Hannover 37, Hildesheim 1991.

FranZISKuS, G. 1992: Die römischen Funde aus Kalkriese. In: W. Schlüter (Hrsg.), Kalkriese Römer im Osnabrückerland. Bramsche 1992, 107-198.

FREMERSDORF, F. 1970: Die germanische Siedlung auf dem Gelände der Zeche Erin in CastropRauxel. Die antiken Glasfunde. Bodenaltertümer Westfalens 12, Münster.

FREUND, H. 1994: Bericht zur pollenanalytischen Bearbeitung von Bodenproben aus der Grabung Hesel-Meeräcker. Nachrichten aus Niedersachsens Urgeschichte 63, 71-72, 1994.

FREUND, H. 1995: Pollenanalytische Untersuchungen zur Vegetations- und Siedlungsentwicklung im Moor am Upstaltsboom, Ldkr. Aurich (Ostfriesland, Niedersachsen). Probleme der Küstenforschung im südlichen Nordseegebiet 23, 1995, 117-152.

FREUND, H. 1995a: Pollenanalytische Untersuchungen eines Niedermoortorfes im Nortmoorer Hammrich (Ldkr. Leer): Bericht für die Archäologische Forschungsstelle der Ostfriesischen Landschaft, 6 Seiten (unpubl.).

FREUND, H. 1996: Verkohlte Pflanzenreste aus der Grabung „Am Großen Stein“, Gde. Hesel, Ldkr. Leer/Ostfriesland. Die Kunde 47, 1996, 51-56. 
FREUND, H. 1996a: Pollenanalytische Untersuchungen eines Niedermoortorfes im Nortmoorer Hammrich (Ldkr. Leer). Bericht für die Archäologische Forschungsstelle der Ostfriesischen Landschaft (unveröffentlicht), 6 Seiten.

FREUND, H. 1997: Pollenanalytische Untersuchungen zur Vegetations- und Siedlungsentwicklung bei Kloster Barthe, Ldkr. Leer (Niedersachsen), unter besonderer Berücksichtigung des WeichselSpätglazials. Probleme der Küstenforschung im südlichen Nordseegebiet 24, 1997, 253-273.

GABRIEL, I. 1964 (unpubl. Bericht): Pogum, Kr. Leer. Bericht über Beobachtungen zur Vor- und Frühgeschichte während der Baggerarbeiten in Pogum von Juni bis September 1964. Maschinenschriftliches Manuskript, Ortsakten der Archäologischen Forschungsstelle der Ostfriesischen Landschaft, Aurich.

GAEDTKE-ECKARDT, D. 1991: Der Pfingstberg bei Helmstedt. Studien zu einem Gräberfeld der Römischen Kaiserzeit und Völkerwanderungszeit. Forschungen und Berichte des Braunschweigischen Landesmuseum 2, 1991.

GAEDTKE-ECKARDT，D. 1992: Zur Interpretation spätkaiserzeitlicher Drehscheibenware im braunschweigischen Raum. Braunschweiger Heimat 78, 1992, 6-11.

GALESTIN, M.C. 2001/2002: Winsum-Bruggeburen, second report on the excavation. The roman Pottary. Palaeohistoria 43/44, 2001/2002, 435-467.

GARBERS, H.-V. 1996: Frühe Eisentechnologie. In: Experimentelle Archäologie in Deutschland. Archäologische Mitteilungen Nordwestdeutschland, Beiheft 13. Münster 1996, 101-103.

GEBERS, W. 1977: Die kaiserzeitlichen Funde der Grabung 1971-1975. In: H. Hinz (Hrsg.), Bosau. Untersuchungen einer Siedlungskammer in Ostholstein 2, Neumünster 1977, 10-21.

GEBERS, W. 1985: Grabungen im Bereich einer Siedlung der jüngeren römischen Kaiserzeit und der Völkerwanderungszeit in Rullstorf, Landkreis Lüneburg. In: K. Wilhelmi, Ausgrabungen in Niedersachsen. Archäologische Denkmalpflege 1979-1984, 191-196, Stuttgart 1985.

GENRICH, A. 1941: Bericht über die Untersuchungen auf der Barward (Gemarkung Imsum, Kreis Wesermünde). Probleme der Küstenforschung im südlichen Nordseegebiet 2, 1941, 157-170.

GEHRUG, U. 1995: Römische Bronzestatuetten. In: R. Busch (Hrsg.), Rom an der Harburg 1995, 125 129; Kat.Nr.81-8.17.

GlasbergeN, W. 1943/44: Terra-Sigillata uit de Provinzie Groningen. Jaarsverslag van de Vereiniging voor Terpenonderzock, 1943/44, 27/28.

GLÜSING, P. 1989: Die Germanen im Spannungsfeld der römischen Okkupation. In: B. Trier (Hrsg.), 2000 Jahre Römer in Westfalen. Mainz 1989, 70-84.

VAN GRIFFEN, A.E. 1931: Mededeeling omtrent het systemmatisch Onderzoek, verricht in de Jaaren 1928, 1929 en 1930. In 13., 14. en 15. Jahrverlag van de Vereeniging voor Terpenonderzoek. Groningen.

Van Griffen, A.E. 1936: Der Warf in Ezinge, Provinz Groningen, Holland, und seine westgermanischen Häuser. Germania 20, 1936, 40-47. 
VAN GRIFFEN, A.E. 1950: De nedersettingsoverblijfselen in het Bolleveen en de versterking, de zgn. „leggerplatts“, aan het Witteveen op het Noordse Veld, beide bij Zeijen, Gem. Vries. Nieuwe Drentsche Volksalmanak, Jg. 68, Assen 1950.

VAN GrIFFEN, A.E. 1958: Prähistorische Hausformen auf Sandböden in den Niederlanden. Germania 36, 1958, 35-71.

GoDLOWSKI, K. 1970: The Chronology of the Late Roman an Earley Migration Periods in Central Europe, Krakow 1970.

GonZALEZ, V. u.a. 2001: Saint-Ouen-du-Breuil (Haute-Normandie, Frankreich) - eine germanische Siedlung aus der Mitte des 4. Jahrhunderts in der Lugdunensis Secunda. Neue Ergebnisse zur Eingliederung von Germanien in den nordwestlichen Provinzen des römischen Reiches. Germania 79, 2001, 43-61.

GRAUPNER, A. 1982: Raseneisenstein in Niedersachsen - Entstehung, Vorkommen, Zusammensetzung und Verwendung. Veröffentlichungen des niedersächsischen Institutes für Landeskunde und Landesentwicklung an der Universität Göttingen. Forschungen zur niedersächsischen Landeskunde 118. Göttingen 1982.

GROENENDIJK, H.A. 1993: Landschapsontwikkeling en bewoning in het Herinrichtingsgebied OostGroningen 8000 BC-1000 AD. Groningen 1993.

GroHNE, E. 1953: Mahndorf. Frühgeschichte des bremischen Raumes. Bremen 1953.

GroHNE, U. 1952: Zur Datierung der Küstenmoore zwischen Jadebusen und Dollart. Abhandlungen des naturwissenschaftlichen Verein Bremen 33, 121-132.

GroHNE, U. 1957: Zur Entwicklung des ostfriesischen Küstengebietes auf Grund botanischer Untersuchungen. Probleme der Küstenforschung im südlichen Nordseegebiet 6, 1957, 1-46.

GROßKOPF, B. 2007: Leichenbrand: biologisches und kulturhistorisches Quellenmaterial zur Rekonstruktion vor- und frühgeschichtlicher Populationen und ihrer Funeralpraktiken. Leipzig 2007.

GroTE, K. 2000: Das Römerlager im Werratal bei Hedemünden (Ldkr. Göttingen). Ein neuentdeckter Stützpunkt der augusteischen Okkupationsvorstöße im rechtsrheinischen Germanien. Germania 84, 1, 2006, 27-59.

GrotelüSChen, S. 2000: Die kaiserzeitliche Siedlung von Nenndorf, Kreis Wittmund. Archäologische Mitteilungen aus Nordwestdeutschland 23, 2000, 17-57.

GoSE, E. 1950: Gefäßtypen der römischen Keramik. Rheinisches Landesmuseum Bonn. Bonner Jahrbücher Beiheft 1, Kevelaer 1950.

HAARNAGEL, W. 1941: Die Grabung auf der Wurt Hessens und ihr vorläufiges Ergebnis. Probleme der Küstenforschung im südlichen Nordseegebiet 2, 117-152.

HAARNAGEL, W. 1955: Die frühgeschichtliche Handels-Siedlung Emden und ihre Entwicklung bis ins Mittelalter. Darstellung der Grabungen auf der Stadtwarft Emden aus den Jahren 1951 bis 1953 und ihre Ergebnisse. Jahrbuch der Gesellschaft für bildende Kunst und vaterländische Altertümer zu Emden, 1955, 9-78. 
HAARNAGEL, W. 1957: Die spätbronze-, früheisenzeitliche Gehöftsiedlung Jemgum bei Leer auf dem linken Ufer der Ems. Die Kunde N.F. 8, 1957, 2-44.

HAARNAGEL, W. 1959: Die einheimische frühgeschichtliche und mittelalterliche Keramik aus den Wurten "Hessens" und "Emden" und ihre zeitliche Gliederung. Praehistorische Zeitschrift 37, 1959, 41-56.

HAARNAGEL, W. 1964: Die spätlatène- und kaiserzeitlichen Siedlungen am westlichen Geestrand der Hohen Lieth im Wesergebiet zwischen den Ortschaften Midlum und Langen, Kr. Wesermünde. Varia Archaeologica, Festschrift W. Unverzagt. Schriften der Sektion für Vor- und Frühgeschichte 16, Berlin 1964, 111-147.

HaARNAGEL, W. 1969: Die Ergebnisse der Grabung aus der ältereisenzeitlichen Siedlung Boomborg/Hatzum, Kr. Leer, in den Jahren 1965 bis 1967. Neue Ausgrabungen und Forschungen in Niedersachsen 4, 1969, 58-97.

HaARnagel, W. 1979: Die Grabung Feddersen Wierde. Methode, Hausbau, Siedlungs- und Wirtschaftsformen sowie Sozialstruktur. Feddersen Wierde 2. Wiesbaden 1979.

HAARNAGEL, W. 1980: Brucana, Hoops Reallexikon 4, 1980, 114-118.

HAARNAGEL, W. 1984: Die frühgeschichtliche Handelssiedlung Emden und ihre Entwicklung bis zum Mittelalter. In: H. Jankuhn, K. Schietzel, R. Reichstein (Hrsg.), Archäologische und naturwissenschaftliche Untersuchungen an ländlichen und frühstädtischen Siedlungen im deutschen Küstengebiet vom 5. Jahrhundert v. Chr. bis zum 11. Jahrhundert n. Chr. Bd. 2., Handelsplätze des frühen und hohen Mittelalters 5, 1984, 114-135.

HaARNAGEL, W. 1984b: Hausbau. In: G. Kossack, K.-E. Behre, P. Schmid (Hrsg.), Archäologische und naturwissenschaftliche Untersuchungen an ländlichen und frühstädtischen Siedlungen im deutschen Küstengebiet vom 5. Jahrhundert v. Chr. bis zum 11. Jahrhundert n. Chr. Bd. 1., Ländliche Siedlungen. Weinheim 1984, 167-193.

HAIDUCK, H. 1986: Die Architektur der mittelalterlichen Kirchen im ostfriesischen Küstenraum. Abhandlungen und Vorträge zur Geschichte Ostfriesland 63, 1986.

HAIDUCK, H. 1992: Beginn und Entwicklung des Kirchenbaues im Küstengebiet zwischen Ems- und Wesermündung bis zum Anfang des 13. Jahrhunderts. Quellen zur Geschichte Ostfrieslands 15, Aurich 1992.

HAIDUCK, H. 1995: Ritzzeichnungen auf zwei kaiserzeitlichen Kuppelöfen aus dem Reiderland. Ein Beitrag zur Herstellung eines unbekannten Ofentyps. In: M. Fansa (Hrsg.), Experimentelle Archäologie, Bilanz 1994, Symposion in Duisburg August 1993. Archäologische Mitteilungen aus Nordwestdeutschland, Beiheft 8, 1995, 205-222.

HALPAAP, R. 1994: Der Siedlungsplatz Soest-Ardey. Bodenaltertümer Westfalens 30, Mainz 1994.

HARCK, O. 1972/73: Nordostniedersachsen vom Beginn der jüngeren Bronzezeit bis zum frühen Mittelalter. Materialhefte zur Ur- und Frühgeschichte Niedersachsens, Hildesheim 1972/73.

HaRTKe, W. 1984: Das Winterlager des Tiberius in Germanien im Jahre 4/5 u. Philologus 128, 111 - 
118.

HÄßLER, H.-J. 1983: Das sächsische Gräberfeld in Liebenau, Kreis Nienburg/Weser. Teil 2. Studien zur Sachsenforschung 5,1. Hannover 1983.

HAYEN, H. 1959: Pollenanalytische Untersuchungen zur Klappe aus Bargerfehn (Ostfriesland). Die Kunde 10, 112-126.

HAYEN, H. 1966: Menschenförmige Holzfiguren an einem Bohlenweg des dritten Jahrhunderts vor Christi. Nachrichten aus Niedersachsens Urgeschichte 35, 1967, 138-141, Abb. 1-2.

HAYEN, H. 1966b: Moorbotanische Untersuchungen zum Verlauf des Niederschlagsklimas und seiner Verknüpfung mit der menschlichen Siedlungsaktivität. Neue Ausgrabungen und Forschungen in Niedersachsen 3, 280-307.

HAYEN, H. 1975: Neue Untersuchungen am Bohlenwege I (Le) im Lengener Moor. Sommer 1973 und 1974. Mitteilungen der Arbeitsgruppen der Ostfriesischen Landschaft 6, 1975, 12-18.

HAYEN, H. 1985: Bergung, wissenschaftliche Untersuchung und Konservierung moorarchäologischer Funde. Vorbericht zu einem Forschungsunternehmen. Archäologische Mitteilungen aus Nordwestdeutschland 8, 1985, 1-43.

Hegenhorst, K. / BrockneR, W. 1995: Archäometrische Untersuchungsergebnisse an dem Verhüttungsplatz der Grabung Lütetsburg, Ldkr. Aurich. Archäologische Mitteilungen aus Nordwestdeutschland 18, 1995, 110-116.

HEgewiSCH, M. 2004: Das kaiser- und völkerwanderungszeitliche Gräberfeld Plänitz, Kr. Ostprignitz-Ruppin. Zugleich eine Studie zur Entwicklung der spätkaiserzeitlichen elbgermanischen Keramik. Dissertation Humboldt-Universität zu Berlin. Archäologisches Nachrichtenblatt 9, 3/2004, 223-228.

HEGEWISCH, M. 2005: Germanische Nachahmungen römischer metall-, Glas- und Keramikgefäße eine kurze Übersicht. Pamatky Archeologicke XCVI, Praha 2005, 79-104.

HeUn, S. 1995: Archäologische Untersuchungsergebnisse auf dem Hüttenplatz in Lütetsburg, Ldkr. Aurich. Archäologische Mitteilungen aus Nordwestdeutschland 18, 1995, 87-110.

HiNGST, H. 1987: Eisenzeitliche Siedlungen auf Amrum, Kr. Nordfriesland. Offa 44, Neumünster, 75-100.

Hirschberg, W. / JAKAnTa, A. 1979: Technologie und Ergologie in der Völkerwanderung. Berlin 1979.

Hoevenberg, J. 1987a: Metalen voorwerpen uit de noordelike Zijtak van de Rijn. Graven bij Valkenburg II. Het archeologisch onderzoek in 1986. Stichting onderzoek romeise bewoning Valkenburg Z.H., 28-33, 1987.

HoevenberG, J. 1987b: Romeins schoeisel uit de noordelike Zijtak van de Rijn. Graven bij Valkenburg II. Het archeologisch onderzoek in 1986. Stichting onderzoek romeise bewoning Valkenburg Z.H., 36-41, 1987. 
HoffmanN, B. 1983: Die Rolle handwerklicher Verfahren bei der Formgebung reliefverzierter Terra Sigillata. Berlin 1983.

HoMEIER, H. 1969: Der Gestaltwandel der ostfriesischen Küste im Laufe der Jahrhunderte. Ein Jahrtausend ostfriesischer Deichgeschichte. Ostfriesland im Schutze des Deiches 2, 1969, 1-75.

HonRoTh, M. 2007: Vom Luxusobjekt bis zum Gebrauchsgefäß. Vorrömische und römische Gläser. Stuttgart 2007.

HUNDT, H.-J. 1980: Textilfunde aus dem frühgeschichtlichen Kriegergrab von Sievern, Kr. Wesermünde. Studien zur Sachsenforschung 2, 1954, 151 - 160.

HunDT, H.-J. 1994: Die Textilfunde aus den Körpergräbern von Liebenau. Studien zur Sachsenforschung 5,4. 89-132.

HuIJTS, C. S. T. J. 1982: De voor-historische boerderijbouw in Drenthe, Reconstructiemodellen van 1300 voor tot 1300 na Chr. Arnhem 1982.

Hummel, S. I SchutKowsK H. 1996: Das Verhalten von Knochengewebe unter dem Einfluß höherer Temperaturen. Zeitschrift für Morphologie und Anthropologie 77, 1986, 1-9.

HvaSS, S. 1975: Das eisenzeitliche Dorf Hodde, Westjütland. Acta Archaeologica 46, 1975, 142-158.

HVASS, S. 1978: Die völkerwanderungszeitliche Siedlung Vorbasse, Westjütland. Acta Archaeologica 49, Kopenhagen 1978, 61-111.

Hvass, S. 1980: Die Struktur einer Siedlung der Zeit von Christi Geburt bis ins 5. Jahrhundert nach Christus. Ausgrabungen in Vorbasse, Jütland, Dänemark. Studien zur Sachsenforschung 2, 1980, 161 180.

IHNEN, K. 1939: Landwirtschaftliche Erläuterungen. Erläuterungen zu Blatt Nortmoor / Nr. 1283 der Geologischen Karte von Preußen und den benachbarten Ländern. Lieferung 334, 35-40.

JACOB-FrIESEN, K.H. 1931: Einführung in Niedersachsens Urgeschichte. Hildesheim und Leipzig 1931.

JACOB-FriESEN, G. 1974: Einführung in Niedersachsens Urgeschichte. Teil III. Eisenzeit. Hildesheim 1974.

JACOBSEN, GURLI. 1995: Primitiver Austausch oder freier Markt? Untersuchungen zum Handel in den gallisch-germanischen Provinzen während der römischen Kaiserzeit. Pharos. Studien zur griechisch-römischen Antike, Bd. V, 1995.

JAGER, S.W. 1985: A Prehistoric Route and Ancient Cart-track in the gemeente of Anloo (Provincie of Drenthe), Palaeohistoria 27, 185-245.

JAHN, R 2001: Der Römisch-Germanische Krieg (9 - 16 n. Chr.). Bonn 2001.

JANKUHN, H. 1977: Einführung in die Siedlungsarchäologie. Berlin/New York 1977.

JANSSEN, W. 1968: Mittelalterliche Dorfsiedlungen als archäologisches Problem. Frühmittelalterliche Studien 2, 305-367, 1968. 
JANSSEN, W. 1976: Dorf und Dorfform des 7. bis 12. Jahrhunderts im Lichte neuer Ausgrabungen in Mittel- und Nordeuropa. H. Jankuhn et al. (Hrsg.), Das Dorf der Eisenzeit und des frühen Mittelalters, 285-365, 1976.

JANSSEN, W. 1993: Das fränkische Reihengräberfeld von Röhdingen, Kr. Düren. Stuttgart 1993.

JOHNE, K. P. 1976: Kaiserbiographien und Senatsaristokratie. Untersuchungen zur Datierung und sozialen Herkunft der Historia Augusta. Schriften zur Geschichte und Kultur der Antike 16, Berlin 1976.

JoHNE, K. P. 2006: Die Römer an der Elbe. Das Stromgebiet der Elbe im geographischen Weltbild und im politischen Bewusstsein der griechisch-römischen Antike. Berlin 2006.

JöNS, H. 1993: Ausgrabungen in Osterrönfeld. Ein Fundplatz der Stein-, Bronze- und Eisenzeit im Kreis Rendsburg-Eckernförde. Universitätsforschungen zur Prähistorischen Archäologie 17, Bonn 1993.

KEHNE, P. 1995: Geographie und ethnographische Informationen über das nördliche Germanien und die Elbregion. In: R. Busch (Hrsg.), Rom an der Niederelbe. Harburg 1995.

KEHNE, P. 1997: Die Eroberung Galliens, die zeitweilige Unterwerfung Germaniens, die Grenzen des Imperium Romanum und seine Beziehungen zu germanischen gentes im letzten Jahrzehnt der Forschung. Germania 75, 1997, 265-284.

KIRSCH, E. 1986: Germanische Kastenbrunnen von Berlin-Kaulsdorf. Zeitschrift für Archäologie 20, 103-119, 1986.

KNOL, E. 1993: De Noordnederlandse kustlanden in de Vroege Middeleuwen. Groningen 1993.

KNORR, H. 2001: Die Chronologie der Römischen Kaiserzeit in Mitteleuropa: Grundlagen, Quellenkritik und Folgen für die Geschichtsschreibung. Berlin 2001.

KREIBIG, N. 2006: Die bronze- und kaiserzeitliche Siedlung von Nenndorf, Ldkr. Wittmund. Beiträge zur Archäologie in Niedersachsen, Bd. 10, 2006.

KroNZ, A. 2006: Phasenbeziehungen und Kristallisationsmechanismen in fayalitischen Schmelzsystemen - Untersuchungen an Eisen- und Buntmetallschlacken. Dissertation. Mainz 1995.

KORPILLA, M. 2004: Paläoökologische Untersuchungen zur Landschaftsgenese der JümmeNiederung (Ldkr. Leer) unter Anwendung eines Geographischen Informationssystems (GIS). Universität Hannover, unpubl. Diplomarbeit.

Kossack, G. / BeHRE, P. / SCHMID. P (Hrsg.) 1984: Archäologische und naturwissenschaftliche Untersuchungen an ländlichen und frühstädtischen Siedlungen im deutschen Küstengebiet vom 5. Jahrtausend v. Chr. bis zum 11. Jahrhundert n. Chr. Bd.1. Ländliche Siedlungen, Weinheim 1984.

KowARIK, I. 1987: Kritische Anmerkungen zum theoretischen Konzept der potentiellen natürlichen Vegetation mit Anregungen zu einer zeitgemäßen Modifikation. Tuexenia 7, 53-67.

KUNOW, J. 1983: Der römische Import in die Germania libera bis zu den Markomannenkriegen. Studien zu Bronze- und Glasgefäßen. Göttinger Schriften der Vor- und Frühgeschichte 21, Neumünster, 1983. 
LANGE, E. 1971: Botanische Beiträge zur mitteleuropäischen Siedlungsgeschichte. Schriften zur Urund Frühgeschichte 27, Berlin 1971.

VAN Lengen, H. 1973: Zur mittelalterlichen Siedlungsgeschichte von Middels (Stadt Aurich/Ostfriesland). Probleme der Küstenforschung im südlichen Nordseegebiet 10, 49-57.

VAN LENGEN, H. 1995: Bauernfreiheit und Häuptlingsherrlichkeit. In: K.-E. Behre / H. v. Lengen (Hrsg.), Ostfriesland, Geschichte und Gestalt einer Kulturlandschaft, Aurich 1995, 113-134.

LehmanN, G.A. 1995: Das Ende der römischen Herrschaft über das „westelbische“ Germanien: Von der Varus-Katastrophe zur Abberufung des Germanicus Caesar 16/7 n. Chr. In: R. Wiegels / W. Wolters W. 1995 (Hrsg.): Arminius und die Varusschlacht: Geschichte, Mythos, Literatur. Kolloquium Dezember 1990, Osnabrück 1995, 123-142.

LehmanN, T.D. 1996: Die Fundstellen-Verteilung in Gebieten mit großflächigen Auftragsböden am Nordrand der ostfriesischen Geest. Archäologische Mitteilungen aus Nordwestdeutschland 19, 1996, 95-98.

LehmanN, T.D. 2003: Verwendung von Ägyptisch Blau in Brill, Ldkr. Wittmund, Niedersachsen. Germania 80/2 (2002), Mainz 2003, 615-621.

LehmanN, T.D. 2002: Brill, Ldkr. Leer. Ein Siedlungsplatz der Römischen Kaiserzeit am ostfriesischen Geestrand. Beiträge zur Archäologie in Niedersachsen 2, 2002.

LENZ, K.H. 1999: Siedlungen der Römischen Kaiserzeit auf der Aldenhover Platte. Mit Beiträgen von H. Berke und B. Heußner. Rheinische Ausgrabungen 45, Köln 1999.

LEUBE, A. 1983: Tracht und Schmuck. In: Joachim Hermann (Hrsg.), Die Germanen. Geschichte und Kultur der germanischen Stämme in Mitteleuropa. X. Materielle und geistige Kultur. Stammesgebiete im 1. und 2. Jahrhundert. 336 - 346, 1983.

LeUbe, A. (Hrsg.) 1998: Haus und Hof im östlichen Germanien (Tagung Berlin vom 4. bis 8. Oktober 1994). Universitätsforschungen zur prähistorischen Archäologie 50, Bonn 1998.

LÖBERT, H.W. 1982: Die Keramik der Vorrömischen Eisenzeit und der Römischen Kaiserzeit von Hatzum-Boomborg (Kr. Leer). Zugleich ein Beitrag zur Theorie und Methode der Bearbeitung von Siedlungskeramik. Probleme der Küstenforschung im südlichen Nordseegebiet 14, 1982, 11-122.

LudowicI, B. 2005: Grabfunde zwischen Harz und Aller. Die Entwicklung der Bestattungssitten im südöstlichen Niedersachsen von der jüngeren römischen Kaiserzeit bis zur Karolingerzeit. Materialhefte zur Ur- und Frühgeschichte Niedersachsens 33, Rahden/Westf. 2005.

LULEY, H. 1992: Urgeschichtlicher Hausbau in Mitteleuropa. Universitätsforschungen zur prähistorischen Archäologie 7. Bonn 1992.

LUND-HANSEN, U. 1987: Römischer Import im Norden. Warenaustausch zwischen dem römischen Reich und dem freien Germanien während der römischen Kaiserzeit unter besonderer Berücksichtigung Nordeuropas. Nordiske Fortidsminder Serie B 10, Koebnhavn 1987.

LyCHATZ, B. 1995: Rekonstruktionsversuch zur Eisengewinnung im Rennfeuerofen mit eingetiefter Schlackengrube. In: Experimentelle Archäologie. Bilanz 1994. Archäologische Mitteilungen 
Nordwestdeutschland, Beiheft 8, Münster 1995, 247-253.

MAIER, R. 1974: Ur- und Frühgeschichtliche Denkmäler und Funde aus Ostfriesland. Wegweiser zu Vor- und Frühgeschichte Niedersachsens 8, 1974.

MANGARTZ, R. 2008: Römischer Basaltlava-Abbau zwischen Eifel und Rhein. RGZM 75, Mainz 2008.

MECKE, A. 1995: Pollenanalytische Untersuchungen zur spät- und postglazialen Vegetations- und Klimageschichte im Landkreis Friesland. Probleme der Küstenforschung im südlichen Nordseegebiet 23, 1995, 11-49.

MEISEL, S. 1962: Die Hunte-Leda-Niederung. Handbuch der naturräumlichen Gliederung Deutschlands 2, Bad Godesberg, 915-916.

MENGHIN,W. 1985: Die Langobarden. Archäologie und Geschichte. Stuttgart 1985.

MIEDEMA, M. 1974: A Native Roman Settlement at Ermelo. BROB 24, 25-41.

MiedemA, M. 1990: Oost-Frivelingo 250v.C.-1850 n. C. Archeologische kartering en beschrijving van 2100 jaar bewoning in Nordoost-Groningen. Paleohistoria 32, 111-145.

MEYER, K.D. / STEIF, H. 1977: Geologischer Überblick des Raumes zwischen Unterweser und Ems. Mitteilungen der Deutschen Bodenkundlichen Gesellschaft 24, 3-10.

MOMMSEN, H. 1885: Die Örtlichkeit der Varusschlacht. Berlin 1885.

MüLlER, H.J. / REIMERS, J. 1893: Vor- und frühgeschichtliche Alterthümer der Provinz Hannover. Hannover 1893.

MüLLER-WILLE, M. 1977: Bäuerliche Siedlungen der Bronze- und Eisenzeit in den Nordseegebieten.

In: H. Jankuhn / R. Schützeichel / F. Schwind (Hrsg.): Das Dorf der Eisenzeit und des frühen Mittelalters. Göttingen 1977, 153-218.

MüLlER-WILLE, M. 1981: Zehn Karten zur Besiedlung der Nordseemarschen. Offa 38, 193-210, 1981.

NiEMEIER, G. 1972: Probleme der Siedlungskontinuität und der Siedlungsweise in Norddeutschland. Göttinger geographische Abhandlungen 60 (Hans-Poser-Festschrift), 1972, 437-466.

NiKULKA, F. et al. 2000: Zur Genese der Eisenmetallurgie in Nordwestdeutschland. Die

Rennfeueröfen von Heek-Nienburg, Kr. Borken. Archäologische Mitteilungen aus

Nordwestdeutschland 23, 59-106.

NiTZ, H.-J. 1984: Die mittelalterliche und frühneuzeitliche Besiedlung von Marsch und Moor zwischen Ems und Weser. Siedlungsforschung 2, 1984, 43-76.

NoRTMAnN, H. 1983: Die vorrömische Eisenzeit zwischen Weser und Ems. Römisch-Germanische Forschungen 41, Mainz 1983.

O'CONNEL, M. 1986: Pollenanalytische Untersuchungen zur Vegetations- und Siedlungsgeschichte aus dem Lengener Moor, Friesland (Niedersachsen). Probleme der Küstenforschung im südlichen Nordseegebiet 16, 1995, 171-193. 
OKRUSCH, M., Wilke-SchiEgRies, R., RöTting, H. 1986: Archäometrie früh- und hochmittelalterlicher Keramik des Gräberfeldes Schortens, Ldkr. Friesland. Nachrichten aus Niedersachsens Urgeschichte 55, 1986, 145-189.

Oehmichen, G. / Weber-JensCh G. 1997: Die Alamannen an der Neckarquelle. Das frühmittelalterliche Gräberfeld von „Schwenningen“ Auf der Lehr“. Archäologische Informationen aus Baden-Württemberg 35.

Overbeck, F. / SCHMitz, H. 1931: Zur Geschichte der Moore, Marschen und Wälder Norddeutschland 1. Das Gebiet der Niederweser bis zur Ems. Mitteilungen der Provinzstelle für Naturdenkmalpflege 3, 1-179.

Overbeck, F. 1944: Die Moore. Geologie und Lagerstätten Niedersachsens. II. Auflage, Niedersächsisches Amt für Landesplanung und Statistik, Reihe A 1, Band 3, 4. Abteilung, Hannover 1944.

Petzelberger, B.E.M. / Behre, K.-E. / GeYH, M.A. 1999: Beginn der Hochmoorentwicklung und Ausbreitung der Hochmoore in Nordwestdeutschland - Erste Ergebnisse eines neuen Projekts. Telma 29, 1999, 21-38.

PletTKe, A. 1921: Ursprung und Ausbreitung der Angeln und Sachsen. Beiträge zur Siedlungsarchäologie der Ingväonen. Urnenfriedhöfe in Niedersachsen 3,1. Hannover 1921.

PolaK, M. 1995: De gestemplede zuidgalische Terra Sigillata uit Vechten. Een wetenschappelijke proeve op het gebied van de Letteren. Nijmegen 1995.

PyRitZ, E. 1972: Binnendünen und Flugsandebenen im niedersächsischen Tiefland. Göttinger Geographische Abhandlungen 61, Göttingen 1972.

RAMM, H. 1995: Die Anfänge von Aurich. Collectanea Frisica. Bd. 74, 101-162.

RADDATZ, K. 1976: Grabfunde der römischen Kaiserzeit und der Völkerwanderungszeit von Kirchweyhe und Osterholz, Kreis Grafschaft Hoya. Materialhefte zur Ur- und Frühgeschichte Niedersachsens 10, 1976.

RADDATZ, K. 1981: Die römische Kaiserzeit im mittleren Niedersachsen. Führer zu vor- und frühgeschichtlichen Denkmälern 48. Hannover, Nienburg, Hildesheim, Alfeld. Teil 1: Einführende Aufsätze, 113-134, 1981.

RASBACH, G. / BECKER, A. 2003: Die spätaugustäische Stadtgründung in Lahnau-Waldgirmes. Archäologische, architektonische und naturwissenschaftliche Untersuchungen. Germania 81, 2003, 147-199.

REINHARDT, W. 1969: Die Orts- und Flurformen Ostfrieslands in ihrer siedlungsgeschichtlichen Entwicklung. In: J. Ohling (Hrsg.), Ostfriesland im Schutze des Deiches 1, Leer 1969, 201-375.

REINHARDT, W. 1979: Küstenentwicklung und Deichbau während des Mittelalters zwischen Maade, Jade und Jadebusen. Jahrbuch der Gesellschaft für bildende Kunst und vaterländische Altertümer zu Emden 59, 1979, 17-61. 
REUTII, F. 1983: Tonverarbeitende Industrie im römischen Rheinzabern. Vorbericht für die Grabungen der Jahre 1978-1981. Germania 61, 1983, 33-69.

Ricken, H. / FisCHER, CH. 1963: Die Bilderschüsseln der römischen Töpfer von Rheinzabern. Textband mit Typenbildern zu Katalog VI der Ausgrabungen von Wilhelm Ludowici in Rheinzabern 1901-1914. Materialien zur römisch-germanischen Keramik 7, Bonn 1963.

RöSING, F. W. 1994: Die Menschen in Liebenau.: Paläodemographie und Grabsitte. Das sächsische Gräberfeld bei Liebenau, Kreis Nienburg/Weser. Teil 5, Studien zur Sachsenforschung 5,4, 189-245.

RobRA, G. 1996: Die Liutger-Kirche von Holtgaste im Reiderland. Holtgaste 1996.

Rose, F. 1878: Ergebnisse der zufolge in Auftrag angestellten Untersuchungen. Heft 12. Unveröffentlichter Bericht in den Akten der Gesellschaft für bildende Kunst und vaterländische Altertümer zu Emden. 1878.

ROSENPLÄNTER, P. 2002: Archäologische Untersuchungen $\mathrm{zu}$ den spätmittelalterlichen Ausbausiedlungen im Jümmiger Hammrich, Ldkr. Leer, Ostfriesland. Ein siedlungsarchäologischer Beitrag zur mittelalterlichen Moorkolonisation in Ostfriesland. Neue Ausgrabungen und Forschungen in Niedersachsen, Bd. 23, 231 - 323, Neumünster 2002.

ROSENPLÄNTER, P. 2002: Die Slawen in Franken. Das Gräberfeld auf dem Barbaraberg. In: Haus der Bayerischen Geschichte (Hrsg.), Kaiser Heinrich II, Bamberg 2002, 135 - 136.

RoSENPLÄNTER, P. 2005: Jörg Kleemann, Sachsen und Friesen im 8. und 9. Jahrhundert - Eine archäologisch-historische Analyse der Grabfunde. Veröffentlichung der urgeschichtlichen Sammlungen des Landesmuseums zu Hannover, Bd. 50 (Oldenburg 2002). Buchrezension, 6 Textseiten. Nachrichten zu Niedersachsens Urgeschichte 74/2, 2005.

RoskaMP, H. 1964: Der Münzfund von Filsum, Kreis Leer (Ostfriesland). Niedersachsen 64, 32-33, 1964.

RotTloff, A. 2000: Römisches Glas. In: Ludwig Wamser u.a. (Hrsg.): Die Römer zwischen Alpen und Nordmeer. Zivilisatorisches Erbe einer europäischen Militärmacht. Mainz 2000, 133-137.

RöTtING, H. 1983: Archäologische Anmerkungen zu Grab 217: Schortens, Kreis Friesland, frühmittelalterliches Gräberfeld. In: B. Herrmann, Ein Leichenschatten mit besonderer Aussagemöglichkeit. Archäologisches Korrespondenzblatt 13, 501-502.

RöTTING, H. 1985: Siedlungen und Gräberfelder der Römischen Kaiserzeit. Studien und Vorarbeiten zum Historischen Atlas Niedersachsens 31, Hildesheim 1998.

RITTER, F., JACOB-FrIESEN, K.H. 1925: Der frühgeschichtliche und mittelalterliche Dollartfund aus dem Nesserlander Watt im Mai 1921 und 1922. Jahrbuch der Gesellschaft für bildende Kunst und vaterländische Altertümer zu Emden 21, 1925, 237-245.

RuPP, V. 1987: Wetterauer Ware. Eine römische Keramik im Rhein-Main-Gebiet. Schriften des Frankfurter Museums für Vor- und Frühgeschichte 10, 1987.

SAGGAU, H.E. 1981: Bordesholm, Der Urnenfriedhof am Brautberg bei Bordesholm. Teil 2: Katalog, Tafel und Plan des Gräberfeldes. Offa 48, Neumünster 1981. 
SAGGAU, H.E. 1986: Bordesholm, Der Urnenfriedhof am Brautberg bei Bordesholm. 1 Text und Karten. Offa 60, Neumünster 1986.

SANKe, M. / WedePOHL, K.H. / Kronz A. 2003: Karolingisches Glas aus dem Kloster Lorsch. Korrektur Nachtrag. Zeitschrift für Archäologie des Mittelalters 31, 2003, 169-174.

SASSE, B. 2001: Ein frühmittelalterliches Reihengräberfeld bei Eichstetten am Kaiserstuhl. Stuttgart 2002.

SCHLICKSBIER, G. 2003: Die Keramik des sächsischen Gräberfeldes bei Liebenau, Kreis Nienburg/Weser. Studien zur Sachsenforschung 5.7, Oldenburg 2003.

SCHLICHT, E. 1965: Ein Goldring der späten Kaiserzeit von Stapelmoor, Kr. Leer. Germania 43, 382 $383,1965$.

SCHLÜTER, W. 1976: Die Vor- und Frühgeschichte der Stadt und des Landkreises Osnabrück. In: Führer zu vor- und frühgeschichtlichen Denkmälern 42, 43-155, 1976.

SCHLÜTER, W. 1982: Das Osnabrücker Land während der jüngeren römischen Kaiserzeit und der Völkerwanderungszeit. Osnabrïcker Mitteilungen 88, 1982, 13-29.

SCHLÜTER, W. / WIEGELS, R. 1999 (eds.): Rom, Germanien und die Ausgrabungen von Kalkriese. Osnabrück 1999.

SCHMID, P. 1957: Die vorrömische Eisenzeit im nordwestdeutschen Küstengebiet. Probleme der Küstenforschung im südlichen Nordseegebiet 6, 1957, 49-129.

SCHMID, P. 1958: Ein Gefäßtyp der frühen Kaiserzeit von der Feddersen Wierde bei Bremerhaven. Die Kunde, N.F. 9, 67-71.

SCHMID, P. 1965a: Neolithische und kaiserzeitliche Funde aus dem Westerhammrich bei Leer. Germania 43, 1965, 358-361.

SCHMID, P. 1965b: Die Keramik des 1. bis 3. Jahrhunderts n. Chr. im Küstengebiet der südlichen Nordsee. Probleme der Küstenforschung im südlichen Nordseegebiet 8, 1965, 9-72.

SCHMID, P. 1969a: Die vor- und frühgeschichtlichen Grundlagen der Besiedlung Ostfrieslands nach der Zeitenwände. In: J. Ohling (Hrsg.), Ostfriesland im Schutze des Deiches 1. Leer 1969, 107-200.

SchMid, P. 1969b: Zum heidnischen und frühchristlichen Bestattungsbrauch auf dem frühmittelalterlichen Gräberfeld von Dunum/Ostfriesland. Frühmittelalterliche Studien 3, 1969, 257 276.

SCHMID, P. 1969c: Die Siedlungskeramik von Mucking (Essex) und Feddersen Wierde (Kr. Wesermünde) - Ein Formenvergleich. Berichten van de Rijksdienst voor het Oudheidkundig Bodemonderzoek 19, 1969, 135-144.

SCHMID, P. 1969d: Bemerkungen zur Datierung der jüngerzeitlichen Siedlungsphase auf der Dorfwurt Feddersen Wierde, Kreis Wesermünde. Neue Ausgrabungen und Forschungen in Niedersachsen 4, 1969, 158-169.

SCHMID, P. 1970: Die Keramik aus dem frühmittelalterlichen Gräberfeld von Dunum, Kr. Wittmund. Probleme der Küstenforschung im südlichen Nordseegebiet 9, 1970, 59-76. 
SCHMID, P. 1970a: Das frühmittelalterliche Gräberfeld von Dunum, Kreis Wesermarsch (Ostfriesland). Neue Ausgrabungen und Forschungen 5, 40-52.

SCHMID, P. 1972: Zur Datierung und Gliederung der Grabanlagen von Dunum, Kr. Wittmund. Neue Ausgrabungen und Forschungen in Niedersachsen 7, 211-240.

SChMid, P. / ZimmermanN, W.H. 1976: Flögeln - zur Struktur einer Siedlung des 1. bis 5. Jhs. n. Chr. im Küstengebiet der südlichen Nordsee. Probleme der Küstenforschung im südlichen Nordseegebiet 11, 1976, 1-77.

SCHMID, P. 1977a: Zum Siedlungssystem einer dörflichen Anlagen des 2.-3. Jahrhunderts n. Chr. im Küstengebiet zwischen Elbe und Weser. Studien zur Sachsenforschung 1, 1977, 357-378.

SCHMID, P. 1977b: Zur chronologischen Auswertung von Siedlungsfunden des 4.-5. Jahrhunderts n. Chr. im Küstengebiet zwischen Elbe und Weser. In: G. Kossack u. J. Reichstein (Hrsg.), Archäologische Beiträge zur Chronologie der Völkerwanderungszeit, Antiquitas Reihe 3, 20, 29-41.

SCHMID, P. 1978: Siedlungs- und Wirtschaftsstruktur auf dem Kontinent. Sachsen und Angeln, Veröffentlichungen des Helms-Museums 32. Ausstellungskatalog Hamburg 1978, 345-361.

SCHMID, P. 1980: Ein Stempelgerät aus der Wurtensiedlung Feddersen-Wierde, Kreis Cuxhaven. Beiträge zur Archäologie Nordwestdeutschland und Mitteleuropas. Materialhefte zur Ur- und Frühgeschichte Niedersachsens 16, 331-339, 1980.

SCHMID, P. 1981: Chauken. III . Historisches. In: Reallexikon der germanischen Altertumskunde, Bd. 4. Berlin / New York 1981, 398-413.

SCHMID, P. 1981a: Some Bowls from the Excavations of the Terp at Feddersen Wierde near Bremerhaven. In: V.I. Evision (ed.), Angles, Saxions and Jutes: Essays presented to J.N.L. Myres, Oxford, 39-58, 1981.

SCHMID, P. 1982: Ländliche Siedlungen der vorrömischen Eisenzeit bis Völkerwanderungszeit im niedersächsischen Küstengebiet. Offa 39, 1982, 73-96.

SchMID, P. 1984a: Siedlungsstrukturen. In: G. Kossack, K.-E. Behre, P. Schmid (Hrsg.), Archäologische und naturwissenschaftliche Untersuchungen an ländlichen und frühstädtischen Siedlungen im deutschen Küstengebiet 1, 1984, 193-244.

SCHMID, P. 1984b: Friesische Gräberfelder und das Verhältnis ihrer Funde zur Sachkultur im Karolingerreich und in Skandinavien. In: G. Kossack, K.-E. Behre, P. Schmid (Hrsg.), Archäologische und naturwissenschaftliche Untersuchungen an ländlichen und frühstädtischen Siedlungen im deutschen Küstengebiet 1, 1984, 361-377.

SCHMID, P. 1988: Die mittelalterliche Neubesiedlung der niedersächsischen Marsch. Archeologie en landschap. Festschrift H.T. Waterbolk. Groningen 1988, 133-164.

SCHMID, P. 1994: Oldorf - eine frühmittelalterliche friesische Wurtsiedlung. Germania 72/1, 1994, 231-267. 
SCHMID, P. 1997: Friesische Grabfunde im Zeichen früher Christianisierung. In: A. Sander-Berke (Hrsg.), Fromme Friesen. Mittelalterliche Kirchengeschichte Frieslands. Katalog und Schriften des Schlossmuseums H. 17. Oldenburg 1997, 26-50.

SCHMID, P. 1999: Forschungsgeschichte. Ostfriesland, Führer zu archäologischen Denkmälern in Deutschland, Bd. 35, 1999, 28-37.

SCHMID, P. 1999a: Friesische Grabbrauch in Karolingischer Zeit. In: M. Fansa (Hrsg.), Über allen Fronten. Nordwestdeutschland zwischen Augustus und Karl dem Große. Oldenburg 1999, 213 - 229.

SCHMID, P. 1999b: Die frühmittelalterlichen Gräberfelder von Dunum und 12a Middels. Führer zu archäologischen Denkmälern in Deutschland 35, Ostfriesland, 1999, 169-173.

SCHMID, P. 2006: Die Keramik der Feddersen Wierde. Probleme der Küstenforschung Bd. 31, 2006, 7-83.

SChMidT, B / GRUHLE, W. 2003: Klimaextreme in römischer Zeit. Eine Strukturanalyse dendrochronologischer Daten. Archäologisches Korrespondenzblatt 33, 2003, 431-426.

SCHMIDT, H. 1975: Politische Geschichte Ostfrieslands. In: J. Ohling (Hrsg.), Ostfriesland im Schutz des Deiches 5, Pewsum 1975.

SCHMIDT, H. 1977: Über Christianisierung und gesellschaftliches Verhalten in Sachsen und Friesland. Niedersächsisches Jahrbuch für Landesgeschichte 49, 1977, 1-44.

SCHMIDT, H. 1987: Kirchenbau und „Zweite Christianisierung“ im friesisch-sächsischen Küstengebiet während des hohen Mittelalters. Niedersächsisches Jahrbuch für Landesgeschichte 59, Hildesheim 1987, 63-93.

SCHMIDT, H. 1997: Christianisierung im östlichen Friesland. In: A. Sander-Berke (Hrsg.), Fromme Friesen. Mittelalterliche Kirchengeschichte Frieslands. Katalog und Schriften des Schlossmuseums H. 17. Oldenburg 1997, 9 - 25.

SCHMIDT, L. 1938: Die Westgermanen. Geschichte der Deutschen Stämme bis zum Ausgang der Völkerwanderung. München 1938.

SCHMIDT, S. 2002: Die ältere Römische Kaiserzeit in Südniedersachsen. Materialhefte zur Ur- und Frühgeschichte Niedersachsen 30. Rahden / Westf. 2002.

SCHNEIDER, R. 2008: Archäologische Spurensuche in den Großen Mooren Nordwestdeutschlands. Die 321 m-Ausgrabung von 1985/1988 am Bohlenweg VI (Pr) -6- im Großen Moor am Dümmer. Selbstverlag, 2008 Oldenburg.

SCHNURBEIN, S. von u.a. (Hrsg.) 2000: Beiträge zur germanischen Keramik zwischen Donau und Teutoburger Wald. Kolloquium zur Vor- und Frühgeschichte 4, Bonn 2000.

SснӧN, M. D. 1988: Gräberfelder der Römischen Kaiserzeit und frühen Völkerwanderungszeit aus dem Zentralteil der Siedlungskammer von Flögeln, Landkreis Cuxhaven. Neue Ausgrabungen und Forschungen in Niedersachsen 18, 1988, 181-297. 
SснÖN, M. D. 1999: Gräber und Siedlungen bei Otterndorf-Westerwörden, Landkreis Cuxhaven. Mit einem Beitrag von Bernd Herrmann und Birgit Großkopf. Probleme der Küstenforschung im südlichen Nordseegebiet 26, 1999, 123-208.

SснӧN, М. D. 2001: Grabfunde der Römischen Kaiserzeit und der Völkerwanderungszeit bei Sievern, Ldkr. Cuxhaven. Mit Beiträgen von Birgit Großkopf u.a. Probleme der Küstenforschung im südlichen Nordseegebiet 27, 2001, 75-248.

SCHÖN, M. D. 2004: Überraschung am Rande einer Sandgrube. Ein frühmittelalterliches Gräberfeld bei Dorfhagen, Landkreis Cuxhaven. Archäologie in Niedersachsen, Bd. 7, 91-94, 2004.

SCHÖNBERGER, H. 1985: Die römischen Truppenlager der frühen und mittleren Kaiserzeit zwischen Nordsee und Inn. BRGK 66 (1985), 321-497.

SCHÖNINGH, E. 1973: Der Johanniterorden in Ostfriesland. Aurich 1973.

SCHREG, R. 1998: Keramik aus Südwestdeutschland. Eine Hilfe zur Beschreibung, Bestimmung und Datierung archäologischer Funde vom Neolithikum bis zur Neuzeit. Schönaich 1998.

SCHOPPA, H. 1953: Rezension zu H.J. Eggers: Der römische Import ins freie Germanien. Nassauische Annalen 64, 1953, 185-192.

SCHROLLER, H. 1933: Eine Siedlung bei Eppingawehr, Gemeinde Midlum, Kr. Leer. Die Kunde, Jg. 1, Heft 3/4, 1933, 9-10.

SCHROLLER, H. 1933b: Die Marschenbesiedlung des Jever- und Harlingerlandes. Oldenburger Jahrbuch 37, 160-187.

SCHroller, H. 1936: Das Hügelgräberfeld von Logabirum, Kr. Leer. Nachrichten aus Niedersachsens Urgeschichte 10, 1936, 1-21.

Schroller, H. / Wildfang, D. / Grüss, K. 1936: Der Bohlenweg von Oltmannsfehn-Ockenhausen, Kr. Leer. Die Kunde 4, 1936, 73-81.

SCHUCANY, C. 1996: Aquae Helveticae. Zum Romanisierungsprozess am Beispiel des römischen Baden. Antiqua 27. Basel 1996.

SchütTE, U. 1935: Das Alluvium des Jade-Weser-Gebietes : ein Beitrag zur Geologie der deutschen Nordseemarschen. Niedersachsens Heimatschutz 6, Oldenburg 1935.

SCHWARZ, G. 1989: Die ländlichen Siedlungen. Allgemeine Siedlungsgeographie 1, Berlin / New York 1989.

SchWARZ, W. 1979: Notbergungen in Brill, Gemeinde Dunum, Ldkr. Friesland. Archäologische Mitteilungen aus Nordwestdeutschland 2, 1979, 21-26.

SCHWARZ, W. 1981: Nr. 34. 2711/1:65 Brinkum, Gem. Brinkum. Fundchronik 1980. Jahrbuch der Gesellschaft für bildende Kunst und vaterländische Altertümer zu Emden 61, 1981, 192.

SCHWARZ, W. 1982: Die Altfunde vom Upstaltboom-Hügel (Stadt Aurich / Ostfriesland) und die frühmittelalterlichen Bestattungen mit Waffenbeigaben in Ostfriesland. Nachrichten aus Niedersachsens Urgeschichte 51, 1982, $81-99$.

SCHWARZ, W. 1990: Besiedlung Ostfrieslands in ur- und frühgeschichtlicher Zeit. Klassifikation des Feuersteinmaterials von Oberflächenfundstellen. Abhandlungen und Vorträge zu Geschichte Ostfrieslands 71, Aurich 1990.

Schwarz, W., Stutzke, R. 1992: Reersum, Gde. Schwittersum, Fundchronik 1991, Ostfriesland. Archäologische Mitteilungen aus Nordwestdeutschland 15, 1992, 265-266. 
SCHWARZ, W. 1995a: Die Urgeschichte in Ostfriesland. Leer 1995.

SCHWARZ, W. 1995b: Archäologische Quellen zur Besiedlung Ostfrieslands im frühen und hohen Mittelalter. In: K.-E. Behre, H. van Lengen (Hrsg.), Ostfriesland, Geschichte und Gestalt einer Kulturlandschaft. Aurich $1995,75-92$.

SCHWARZ, W. 1996: Bronzezeitliche Hausgrundrisse von Hesel im Landkreis Leer. Die Kunde 47, 1996, 21 -50.

SCHWARZ, W. 1997: Fundstellen der Römischen Kaiserzeit und der Völkerwanderungszeit im Küstengebiet des Landkreises Wittmund, Niedersachsen. Studien zur Sachsenforschung 10, 1997, 265-274.

SchWARz, W., Stutzke, R. 1998: Archäologische Funde aus dem Landkreis Leer. Archäologische Mitteilungen aus Nordwestdeutschland, Beiheft 21, 1998.

SchWARZ, W. 1999: Archäologische Fundstellen zwischen Nesse, Ldkr. Aurich, und Esens, Ldkr. Wittmund. Ein Beitrag zur archäologischen Landesaufnahme in Ostfriesland. Archäologische Mitteilungen aus Nordwestdeutschland 22, 1999, 5-32.

SCHWARZ, W. 1999a: Der Galgenberg bei Schwittersum. Führer zu archäologischen Denkmälern in Deutschland, Ostfriesland, 174-177.

SCHWARZ, W. 2000: Nr. 66. Hügelgräberfeld „Siebenbergen“ in Logabirum. Archäologische Denkmäler zwischen Weser und Ems. Archäologische Mitteilungen aus Nordwestdeutschland, Beiheft 34, 2000, $310-312$.

SCHWARZ, W. 2002: Siedlung, Grab und Heiligtum von Wiesens, Stadt Aurich. Ein prähistorischer Lebensraum vom mittleren Neolithikum bis zum Ende der frühen Eisenzeit. Materialhefte zur Ur- und Frühgeschichte Niedersachsen 29. Rahden / Westf. 2002.

SCHWARZ, W. 2003: Mittelalterliche Funde am und im Großen Meer, Landkreis Aurich. Archäologische Mitteilungen aus Nordwestdeutschland 26, 63-113, 2003.

SchWARZ, W. 2003: Die Stätte des Upstalsbooms. Die archäologische Wahrnehmung des Upstalsboom. In: H. van Lengen (Hrsg.), Die Friesische Freiheit des Mittelalters - Leben und Legende. 404 - 421, Aurich 2003.

SCHWARZ, W. 2005: Von der Archäologischen Landesaufnahme zum Archäologischen Dienst. Archäologie in Ostfriesland. Nachrichten aus Niedersachsens Urgeschichte 74, 2005, 60-65.

SINDOSWKI, K. H. 1969: Geologische Entwicklung von Ostfriesland. In: J. Ohling (Hrsg.), Ostfriesland im Schutze des Deiches 1, Leer 1969, 1-48.

SEIDEL, M 2006: Das Südharzvorland von der vorrömischen Eisenzeit bis zur Völkerwanderungszeit. Zur Besiedlungsgeschichte einer Altsiedellandschaft im nördlichen Thüringen. Weimarer Monographien zur Ur- und Frühgeschichte Band 41, Weimar 2006.

STAMPFUSS, R. 1939: Der spätfränkische Sippenfriedhof von Walsum. Quellenschriften zur westdeutschen Vorund Frühgeschichte. Leipzig 1939.

STEFFENS, H.G. 1966: Die Oldenburger Keramik des 6. - 9. Jahrhundert. Neue Ausgrabungen und Forschungen in Niedersachsen 3, 1966, 180 - 194.

STEFFEnS, H.G. 1969: Die Oldenburger Keramik des 9. - 12. Jahrhundert. Neue Ausgrabungen und Forschungen in Niedersachsen 4, 1969, 276-286.

STEIDL, B. 2000: Die Wetterau vom 3. bis 5. Jahrhundert n. Chr. Materialien zur Vor- und Frühgeschichte von Hessen 22, Wiesbaden 2000.

STEIN, F. 1967: Adelsgräber des achten Jahrhunderts in Deutschland. Germanische Denkmäler der Völkerwanderungszeit, Serie A, Bd. IX, 1967. 
STEUER, F. 1974: Die Südsiedlung von Haithabu. Studien zur frühmittelalterlichen Keramik im Nordseeküstenbereich und in Schleswig-Holstein. Die Ausgrabungen in Haithabu 6, Neumünster 1974.

STEUER, F. 1979: Die Keramik aus der frühmittelalterlichen Wurt Elisenhof. Studien zur Küstenarchäologie Schleswig-Holsteins A3, 3-147. Frankfurt/M., Bern, Las Vegas 1979.

STEUPPERICH, R. 1980: Römische Funde in Westfalen und Nordwest-Niedersachsen. Boreas, Münsterische Beiträge zur Archäologie, Beiheft 1, Münster 1980.

STIEF, M. 1988: Zur inneren Gliederung und Abgrenzung kaiserzeitlicher Gruppen. Siedlungsarchäologische Untersuchung zur römischen Kaiserzeit im südlichen Niederelbegebiet. Dissertation Universität Hamburg 1988.

STILKE, H. 1991: Leistenverzierte Grauware des späten Mittelalters im Nordseeküstengebiet. Archäologisches Korrespondenzblatt 21, 1991, 121-132.

STILKE, H. 1993a: Die frühmittelalterliche Keramik von Oldorf, Gde. Wangerland, Ldkr. Friesland. Nachrichten aus Niedersachsens Urgeschichte 62, 1993, 135-168.

STILKE, H. 1993b: Spätmittelalterliche Siedlungsbefunde aus Holtgaste, Kr. Leer. Archäologische Mitteilungen aus Nordwestdeutschland 16, 1998, 45-60.

STILKE, H. 1994: Eine iberische Olivenamphore aus Emden. Archäologische Mitteilungen aus Nordwestdeutschland 17, 1994, 61-70.

STILKE, H. 1995a: Die früh- bis spätmittelalterliche Keramik von Emden. Probleme der Küstenforschung im südlichen Nordseegebiet 22, 1995, 9-200.

STILKE, H. 1995b: Siedlungsfunde der Römischen Kaiserzeit und der Völkerwanderungszeit aus Holtgaste, Stadt Leer. Probleme der Küstenforschung im südlichen Nordseegebiet 22, 1995, 203-219.

STRAHL, E. 1990: Das Endneolithikum im Elb-Weser-Dreieck. Veröffentlichungen der urgeschichtlichen Sammlungen des Landesmuseums zu Hannover 36, Hildesheim 1990.

STRAHL, E. 1995: Eine Bestattung der Einzelgrabkultur bei Logabirum, Stadt Leer (Ostfr.), Ldkr. Leer. Probleme der Küstenforschung im südlichen Nordseegebiet 23, 1995, 227-242.

STRAHL, E. 2002: Erste Bauern in der Marsch - Die Siedlung Hahnenknooper Mühle bei Rodenkirchen, Ldkr. Wesermarsch. Wilhemshavener Tage 8, 2002, 76-83.

STRAHL, E. 2003: Eppingawehr. In: Reallexikon der Germaischen Altertumskunde, Bd. 24, 2003, 356-357.

STREIF, H. 1990: Das ostfriesische Küstengebiet. Sammlung geologischer Führer 57, 2. Aufl. Berlin-Stuttgart.

STREIF, H. 2000: Geologie und Landschaftsgeschichte des Weser-Ems-Gebietes. Archäologische Denkmäler zwischen Weser und Ems, Oldenburg 2000, 15-31.

STReURman, H.J. / TAAYKe, M. 1989: Vegetation Horizons and >Frustrated Terps<: New Radiocarbon Ages from the Paddepoel Area near Groningen. BROB 39, 345-356.

STUPPERICH, R. 1980: Römische Funde in Warsingfehn und Nordwest-Niedersachen. Boreas, Münsterische Beiträge zur Archäologie, Beiheft 1, Münster 1980.

TAAYKe, E. 1990: Die einheimische Keramik der nördlichen Niederlande, 600 v. Chr. bis 300 n. Chr.. Teil I: Westergo (Friesland). Berichten van de Rijksdienst voor het Oudheitskundig Bodemondezoek 40, 1990, 109222.

TAAYKE, E. 1995: Die einheimische Keramik der nördlichen Niederlande, 600 v. Chr. bis 300 n. Chr. Teil II: Nord-Drenthe. Berichten van de Rijksdienst voor het Oudheitskundig Bodemondezoek 41, 1995, 9-112. 
TAAYKE, E. 1996a: Die einheimische Keramik der nördlichen Niederlande, 600 v. Chr. bis 300 n. Chr. Teil III: Mittel-Groningen. Berichten van de Rijksdienst voor het Oudheitskundig Bodemondezoek 42, 1996, 9-69.

TAAYKE, E. 1996b: Die einheimische Keramik der nördlichen Niederlande, 600 v. Chr. bis 300 n. Chr. Teil IV: Übersicht und Schlußfolgerungen. Berichten van de Rijksdienst voor het Oudheitskundig Bodemondezoek 42, 1996, 163-208.

TACKEnberG, K. 1934: Die Kultur der frühen Eisenzeit in Mittel- und Westhannover. Hildesheim, Leipzig 1934.

TACKEnBERG, K. 1978: Drehscheibenkeramik der späten Kaiserzeit aus Osnabrück-Atter. Bonner Jahrbücher $178,1978,367-371$.

TEEGEN, W.E. 1992: Das provinzialrömische Emailgefäß aus dem Vehner Moor I. Fundgeschichte und kulturgeschichtliche Auswertung. Archäologische Mitteilungen aus Nordwestdeutschland 15, 1992, 89-107.

TEEGEN, W.E. 1995: Die historisch-geographische Situation zu Zeiten Augustus in der Germania magna. In: R. Busch (Hrsg.), Rom an der Niederelbe. Harburg 1995, 32-46.

TEEgen, W.E. / Fendel, H. 1997: Das provinzialrömische Emailgefäß aus dem Vehner Moor II. Technologische Untersuchungen. Archäologische Mitteilungen aus Nordwestdeutschland 20, 1997, 109-114.

Tempelmann-MaczynSKA, M. 1985: Die Perlen der römischen Kaiserzeit und der frühen Phase der Völkerwanderungszeit im mitteleuropäischen Barbaricum. Römisch-Germanische Forschungen 43, Mainz 1985.

TERGAST, W. 1879: Die heidnischen Alterthümer Ostfrieslands. Emden 1879.

THIEME, W. 1976: Untersuchungen an eisenzeitlichen Siedlungen in Süd-Holstein. Kiel 1976 (Magisterarbeit).

TILlEY, A. 2004: Seafaring on the ancient Mediterranean. New thoughts on triremes and other ancient ships. Hedges. Oxford 2004.

TiMPE, D. 1968: Der Triumph des Germanicus. Untersuchung zu den Feldzügen der Jahre 14 - 16 n. Chr. in Germanien. Abhandlungen zur alten Geschichte.

TIMPE, D. 1971: Der römische Verzicht auf die Okkupation Germaniens. Chiron 1, 1971, 267-284.

TIMPE, D. 1989: Wegeverhältnisse und römische Okkupation Germaniens. Untersuchungen zu Handel und Verkehr der vor- und frühgeschichtlichen Zeit in Mittel- und Nordeuropa. Teil V. In: H. Jankuhn u.a. (Hrsg.), Untersuchungen zu Handel und Verkehr der vor- und frühgeschichtlicher Zeit in Mittel- und Nordeuropa, (Abhandlungen der Akademie der Wissenschaften Göttingen, phil.-hist. Klasse 3, Folge 180), Göttingen 1989, 83-107.

TIMPE, D. 1995: Romano-Germanica. Gesammelte Studien zur Germania des Tacitus. Stuttgart/Leipzig 1995.

TIMPE, D. 1999: Die Schlacht im Teutoburger Wald: Geschichte, Tradition, Mythos. In: W. Schlüter / R. Wiegels (Hrsg.), Rom, Germanien und die Ausgrabung von Kalkriese. Internationaler Kongress der Universität Osnabrück und des Landschaftsverbandes Osnabrücker Land e. V. vom 2. bis 5. September 1995, Osnabrücker Forschungen zu Altertum und Antiken-Rezeption 1, Osnabrück 1999, 717-737.

TISCHLER, F. 1952: Zur Datierung der frühmittelalterlichen Tonware aus Bardorf, Landkreis Köln. Germania 30, 1952, $194-200$.

TISCHLER, F. 1954: Der Stand der Sachsenforschung, archäologisch gesehen. Berichte der RGK 35, 1954,21 215.

TrIER, B. 1969: Das Haus im Nordwesten der Germania Libera. Veröffentlichungen der Altertumskommission im Provinzialinstitut für westfälische Landes- und Volkskunde 4, Münster 1969. 
UENZE, O. 1938: Zur Anfangsdatierung der sächsischen Kugeltöpfe. Germania 22, 118 - 120.

UERKVITZ, R. 1997: Norddeutsche Wurten-Siedlungen im Archäologischen Befund: Analyse und Interpretation aufgrund siedlungsgeographischer Modelle. Arbeiten zur Urgeschichte des Menschen 20, Frankfurt am Main 1997.

UlberT, G. 1977: Die römischen Funde von Bentumersiel. Probleme der Küstenforschung im südlichen Nordseegebiet 12, 1977, 33-65.

USINGER, H. 1982: Pollenanalytische Untersuchungen an einem vorgeschichtlichen Sandweg im Meerhusener Moor / Ostfriesland. Abhandlungen des Naturwissenschaftlichen Verein Bremen 39, 404-423.

VON USLAR, R. 1934: Die germanische Keramik in den Kastellen Zugmantel und Saalburg. Saalburg Jahrbuch $8,1934,61$.

VON USLAR, R. 1938: Westgermanische Bodenfunde des ersten und dritten Jahrhunderts nach Christus aus Mittel- und Westdeutschland. Germanische Denkmäler der Frühzeit 3, Berlin 1938.

VoN USLAR, R. 1977: $\mathrm{Zu}$ einer Fundkarte der jüngeren Kaiserzeit in der westlichen Germania libera. Prähistorische Zeitschrift 52, 1977, 121-147.

VoN USLAR, R. 1977a: Zur spätkaiserzeitlichen Drehscheibenkeramik in West- und Mitteldeutschland. Germania 19, 249-256.

VON USLAR, R. 1979/80: Germanische Keramik aus Steinkastell und vicus in Heddernheim und aus Osthafen in Frankfurt. Zur Entstehung der rhein-wesergermanischen Keramik. Mit einem Beitrag von Jürgen Wahl. Fundberichte Hessen 19/20, 697-724.

VON USLAR, R. 1988: Kuhbier in der Prignitz. Ein Urnengräberfeld des 1.-2. Jahrhunderts n. Chr. Offa 45, 1988, $181-282$.

VANDERHOEVEN, M. 1978: Terra sigillata aus Südgallien: Die reliefverzierten Gefäße III. In: T. Bechert / G. Tromnau (Hrsg.), Funde aus Asciburgium 7, Duisburg 1978.

VERLINDE, A. 1991: De prehistorische bewoning van Ittersumerbroek. In: H. Clevis / A. Verlinde (Red.), Bronstijdboeren in Ittersumerbroek. Kampen 1991, 22-69.

VERLINDE, A. / ERDRICH, M. 1998: Eine germanische Siedlung der späten Kaiserzeit mit umwehrter Anlage und umfangreicher Eisenindustrie in Heeten, Provinz Overijssel, Niederlande. Germania 76, 1998, 683-719.

VERWERS, G.J. 1972: Das kamps Veld in Haps in Neolithikum, Bronzezeit und Eisenzeit. Analecta Praehistorica Leidensia V.

VerWers, G.J. / KoOISTRA, L.I. 1992: Native House Plans from the Roman Period in Boxtel and Oosterhout. Berichten ROB 40, 1990, 251-284, Amersfoort.

VoGT, U. 1999: Zur Entwicklung der Hausformen im Gebiet der nordwestlichen Germania magna. Ethnographisch-Archäologische Zeitschrift 40, 1999, 21-42.

Voigt, H. / Roeschmann, G. 1969: Die Böden Ostfrieslands. In: J. Ohling (Hrsg.), Ostfriesland im Schutze des Deiches 1, Leer 1969, 51-104.

VOLKERS, T. B. 1991: Terra Sigillata aus den Friesischen Wurten in den Niederlanden. Germania 1991, 176186.

WALLER, K. 1933: Chaukische Gräberfelder an der Nordseeküste. Manus 25, 1933, 40-59.

WALLER, K. 1936: Friesische Gräberfelder an der Nordseeküste. Prähistorische Zeitschrift 27, 1936, $227-251$.

WALLER, K. 1953/55: Ein Gemischtgräberfeld bei Sievern. Hammaburg 4, 1953/55, 45-53. 
WALLER, K. 1959: Die Gräberfelder von Hemmoor, Quelkhorn, Gundendorf und Duhnen-Wehrberg in Niedersachsen. Beiheft Atlas Urgeschichte 8, 1959.

WALlER, K. 1960: Das Chaukische Gräberfeld von Oxstedt und seine Bedeutung für die Sachsenforschung. Die Kunde N.F. 11, 1960, 13-28.

WALTER, D. 2000: Germanische Keramik zwischen Main und Taunuslimes. Untersuchungen zu rheinwesergermanischen Gefäßen in römischen Siedlungen des Rhein-Main-Gebietes. Freiburger Beiträge zur Archäologie und Geschichte des ersten Jahrtausends 3, 2000.

WASSERMANN, E. 1985: Aufstrecksiedlungen in Ostfriesland. Ein Beitrag zur Erforschung mittelalterlicher Moorkolonisation. Abhandlungen und Vorträge zur Geschichte Ostfrieslands 61. 1985.

WATERbOLK, H. T. 1962: Hauptzüge der eisenzeitlichen Besiedlung der nördlichen Niederlande. Offa 19, 9-46.

WATERbolk, H. T. 1965: Ein eisenzeitliches Gräberfeld bei Ruinen, Provinz Drenthe, Niederlande. In: R. v. Uslar (Hrsg.), Studien zu Alteuropa II, Köln, 34-53.

WATERbOLK, H. T. 1973: Odoorn im frühen Mittelalter. Bericht der Grabung 1966. Neue Ausgrabungen und Forschungen in Niedersachsen 8, 1973, 25-89.

WAterbolK, H. T. 1978: Walles Enclosures of the Iron Age in the Northern Netherlands. Palaeohistoria 19, 1977, 97-172.

WATERbOLK, H.T. 1979: Siedlungskontinuität im Küstengebiet der Nordsee zwischen Rhein und Elbe. Probleme der Küstenforschung im südlichen Nordseegebiet 13, 1979, 1-21.

WATERbOLK, H.T 1982: Mobilität von Dorf, Ackerflur und Gräberfeld in Drenthe seit der Latènezeit. Archäologische Siedlungsforschungen auf der nordniederländischen Geest. Offa 39, 97-137, 1982.

WAterbolK, H.T. / HARSEMA, O.H. 1979: Medieval farmsteads in Gasselte (province of Drenthe). Palaeohistoria 21, 1979, 227-265.

WEBER, M. 1996: Das Gräberfeld von Issendorf, Kr. Stade. Kulturgeschichtliche Studien an Brandgräbern in der Zeit der angelsächsischen Landnahme. Hamburg 1996.

WEDEPOHL, K.H. / SCHNEIDER, A. 1986: Die Untersuchung jungeisenzeitlicher Schlacken von Eisenproduktion aus der Umgebung von Nörten-Hardenberg bei Göttingen. Die Kunde N.F. 37, 1986, 173-190.

WEDEPOHL, K. H. 1998: Mittelalterliches Glas in Mitteleuropa. Zusammensetzung, Herstellung, Rohstoffe. Nachrichten der Akademie der Wissenshaften in Göttingen II. Mathematisch-Physikalische Klasse, 1998, 3-56.

WEDEPOHL, K. H. 2003: Glas in Antike und Mittelalter. Geschichte des Werkstoffs. Stuttgart 2003.

WEGNER, G. 1981: Eine Siedlung der römischen Kaiserzeit und der Völkerwanderungszeit in Mahlstedt, Gemeinde Winkelsett, Ldkr. Oldenburg. Vorbericht über die Grabung. Archäologische Mitteilungen aus Nordwestdeutschland 4, 1981, 43-63.

WeIDEMANN, K. 1966: Die frühe Christianisierung zwischen Schelde und Elbe im Spiegel der Grabsitten des 7. bis 9. Jahrhundert. Neue Ausgrabungen und Forschungen in Niedersachsen 3, 1966, 195-211.

WELWEI, K.-W. 1999: Probleme römischer Grenzziehung am Beispiel der Germanenpolitik des Augustus. In: W. Schlüter / R. Wiegels (Hrsg.), Rom, Germanien und die Ausgrabung von Kalkriese. Internationaler Kongress der Universität Osnabrück und des Landschaftsverbandes Osnabrücker Land e. V. vom 2. bis 5. September 1995, Osnabrücker Forschungen zu Altertum und Antiken-Rezeption 1, Osnabrück 1999, 675-688.

WensKus, R. 1961: Stammesbildung und Verfassung. Das Werden der frühmittelalterlichen Gentes. Köln / Wien 1961. 
WENSKUS, R. 1981: Chauken. II . Historisches. In: Reallexikon der germanischen Altertumskunde, Bd. 4. Berlin / New York 1981, 394-398.

WestPhalen, P. 1989: Die Eisenschlacken von Haithabu. Bericht über die Ausgrabungen in Haithabu 26, Neumünster 1989.

WEßELS, P. 1997: Barthe. Zur Geschichte eines Klosters und der nachfolgenden Domäne auf Grundlage der Schriftquellen. Norden 1997.

Wiegels, R. / WoESler, W. (Hrsg.) 1995: Arminius und die Varusschlacht: Geschichte, Mythos, Literatur. Kolloquium Dezember 1990, Osnabrück 1995.

Wiemann, H. / EngelmanN, J. 1974: Alte Wege und Straßen in Ostfriesland. In: J. Ohling (Hrsg.), Ostfriesland im Schutze des Deiches 8, Pewsum 1974.

WiLdVANG, D. 1915: Das Alluvium zwischen der Ley und der nördlichen Dollartküste. Upleward 1915.

WiLdVANG, D. 1920: Das Reiderland. Eine geologische, gemeinverständliche Abhandlung. Aurich 1920.

WiLDVANG, D. 1924: Ein Endmoränenzug beiderseits der unteren Ems und sein Einfluss auf Besiedelung und Wirtschaft. Aurich 1924.

WildVAnG, D. 1926: Der Jümmiger Hammrich. Ein Beitrag zur ostfriesischen Heimatkunde. Ostfriesisches Schulblatt, Beilage 3, 61-68.

WiLdVANG, D. 1927: Erläuterungen zur geologischen Karte Nortmoor. Preussische geologische Landesanstalt, Berlin 1927, 1-39.

WiLdVANG, D. 1935: Über Flugsande der ostfriesischen Geest. Abhandlungen des Naturwissenschaftlichen Vereins zu Bremen 29, Heft 3 / 4, 293-309.

WiLdVAng, D. 1938: Die Geologie Ostfrieslands. Abhandlungen der Preußischen Geologischen Landesanstalt NF 181. 1938.

WiLdVANG, D. 1939: Zur Geologie des unteren Ledatales. Abhandlungen des naturwissenschaftlichen Vereins zu Bremen 31, Heft 2 / 3, 1939, 286-305.

WiLhELMI, K. 1967: Die vorrömische Eisenzeit zwischen Sieg und Mittelweser. Kleine Schriften aus dem vorgeschichtlichen Seminar Marburg 8, 1967.

WILL, W. 1987: Römische Klientel-Randstaaten am Rhein? Eine Bestandsaufnahme. Bonner Jahrbücher 187, 1987, 1-61.

WiLlERDING, U. 1977: Über Klimaentwicklung und Vegetationsverhältnisse im Zeitraum Eisenzeit bis Mittelalter. In: H. Jankuhn et al. (Hrsg.), Das Dorf der Eisenzeit und des frühen Mittelalters, Göttingen 1977, 357-405.

WiLlERDING, U. 1992: Klima und Vegetation in der Germania nach paläo-ethnobotanischen Quellen. In: Neumann u. Seedorf (Hrsg.), Beiträge zum Verständnis der Germania bei Tacitus II. Bericht über die Kolloquien der Kommission für Altertumkunde. Nord- und Mitteleuropas im Jahre 1986 und 1987 (Göttingen 1992), 332-374.

WiLlRoth, K.-H. 1992: Untersuchungen zur Besiedlungsgeschichte der Landschaften Angeln und Schwansen von der älteren Bronzezeit bis zum frühen Mittelalter. Offa-Bücher 72, Neumünster 1992.

WiERSCHOWSKI, L. 1999: Germanen und Römer. Nordwestdeutschland im Spannungsfeld der römischen Politik der Kaiserzeit. In: M. Fansa (Hrsg.), Über allen Fronten. Nordwestdeutschland 
zwischen Augustus und Karl dem Großen. Archäologische Mitteilungen aus Nordwestdeutschland, Beiheft 26. Oldenburg 1999, 9-18.

WITTE, H. 1991: Ein Beitrag zur Datierung völkerwanderungszeitlicher Keramik auf dem Siedlungsplatz Bremen-Grambke. Die Kunde N.F. 41/42, 1990/91, 461-492.

WITTE, H. 2000: Frühgeschichtliche Besiedlung in Bremen-Grambke. In: D. Bischop, Siedler, Söldner und Piraten. Bremer Archäologische Blätter, Beiheft 2, Bremen 2000.

Wolfram, H. 1991: Das Reich und die Germanen. Zwischen Antike und Mittelalter. Berlin 1991.

WOLTERS, R. 1990: Römische Eroberungen und Herrschaftsorganisation in Gallien und Germanien. Zur Entstehung und Bedeutung der sogenannten Klientel-Randstaaten. Bochumer Historische Studien Alte Geschichte 8, Bochum 1990.

Wolters, R. 1999: Germanien im Jahre 8 v. Chr. In: W. Schlüter / R. Wiegels (Hrsg.), Rom, Germanien und die Ausgrabung von Kalkriese. Internationaler Kongress der Universität Osnabrück und des Landschaftsverbandes Osnabrücker Land e. V. vom 2. bis 5. September 1995, Osnabrücker Forschungen zu Altertum und Antiken-Rezeption 1, Osnabrück 1999, 637-674.

WOLTERS, R. 2000: Römer in Germanien. München 2000.

WULF, F.-W. 1991: Karolingische und ottonische Zeit. Ur- und Frühgeschichte in Niedersachsen. Stuttgart 1991, 321-368.

ZIMMER-LiNFELDT, K. 1960: Westerwanna I:9. Beiheft zum Atlas der Urgeschichte. 1960.

ZimmermanN, W.H. 1976: Die kaiserzeitlich-völkerwanderungszeitliche Siedlung FlögelnEekhöltjen. Probleme der Küstenforschung im südlichen Nordseegebiet 11, 1976, 2-61.

ZimMERMANN, W.H. 1976b: Archäologische Untersuchungen zur früh- bis hochmittelalterlichen Besiedlung im Elbe-Weser-Dreieck. Führer zu vor- und frühgeschichtlichen Denkmälern 30, 46-58, Mainz.

ZIMMERMANN, W.H. 1986: Zur funktionalen Gliederung völkerwanderungszeitlicher Langhäuser in Flögeln-Eekhöltjen, Kr. Cuxhaven. Probleme der Küstenforschung im südlichen Nordseegebiet 16, 1986, 55-86.

ZIMMERMANN, W.H. 1988: Regelhafte Innengliederung prähistorischer Langhäuser in den Nordseeanrainerstaaten. Ein Zeugnis enger, lang andauernder kultureller Kontakte. Germania 66, 1988, 456-488.

ZimmermanN, W.H. 1991: Die früh bis hochmittelalterliche Wüstung Dalem, Gem. LangenNeuenwalde, Kr. Cuxhaven. Archäologische Untersuchungen in einem Dorf des 7.-14. Jh. n. Chr. In: H.W. Böhme (Hrsg.), Siedlungen und Landesausbau zur Salierzeit, Bd. 1. In den nördlichen Landschaften des Reiches. Monographien RGMZ Mainz 27, 1991, 37-46.

ZimmeRManN, W.H. 1992: Die Siedlungen des 1. bis 6. Jahrhunderts nach Christus von FlögelnEekhöltjen, Niedersachsen: Die Bauformen und ihre Funktionen. Probleme der Küstenforschung im südlichen Nordseegebiet 19, 1992. 
ZimmermanN, W.H. 1997: Haus, Hof und Siedlungsstruktur auf der Geest vom Neolithikum bis in das Mittelalter im Elbe-Weser-Dreieck. In: H. Beck u. H. Steuer (Hrsg.), Haus und Hof in ur- und frühgeschichtlicher Zeit. Abhandlungen der Akademie der Wissenschaften in Göttingen, Philosophisch-Historische Klasse, 3. Folge, Nr. 218, 414-460, Göttingen 1997.

ZIMmeRMANN, W.H. 1998: Pfosten, Ständer und Schwelle und der Übergang vom Pfosten- zum Ständerbau - Eine Studie zu Innovation und Beharrung im Hausbau. Zu Konstruktion und Haltbarkeit prähistorischer bis neuzeitlicher Holzbauten von den Nord- und Ostseeländern bis zu den Alpen. Probleme der Küstenforschung im südlichen Nordseegebiet 25, 9-241, 1998.

ZimmermanN, W.H. 2001: Phosphatkartierung mit großem und kleinem Probenraster in der Siedlungsarchäologie. Ein Erfahrungsbericht. In: C. Dobiat u. K. Leidorf (Hrsg.), Trans Albim Fluvium. Festschrift für Achim Leube. Internationale Archäologie 10, 69-79, 2001 Rahden.

ZimmermanN, W.H. 2015: Miszellen zu einer Archäologie des Wohnens. „Das Reinlichste in der ganzen Haushaltung ist oft noch der Stall... (Söllner 2001). Archäologie in Niedersachsen, Bd. 18, 825 .

ZOLLER, D. 1963: Gristede. Ein Beitrag zur Siedlungsarchäologie auf der Nordoldenburger Geest. Archaeologia Geographica 10/11. 1961/63, 39-50.

ZOLLER, D. 1965: Das sächsisch-karolingische Gräberfeld bei Drantum, Gem. Emstek, Kr. Cloppenburg. Nachrichten aus Niedersachsens Urgeschichte 34, 1965, 34-47.

ZOLLER, D. 1969a: Siedlungsarchäologische Untersuchungen im Bereich der nordoldenburgischen Geest als Beitrag zum Problem der Siedlungskontinuität im ersten nachchristlichen Jahrtausend. Oldenburger Jahrbuch 68, 327-330, 1969.

ZOLLER, D. 1969b: Untersuchungen von Dorfkern und Wirtschaftsflur mit archäologischen Mitteln. Neue Ausgrabungen und Forschungen in Niedersachsen 4, 131-149, 1969.

ZOLLER, D. 1970: Arbeitsbericht 1970. Staatliches Museum für Naturkunde und Vorgeschichte. Oldenburger Jahrbuch 69, 1970, 131-134.

ZoLlER, D. 1972a: Die Ergebnisse der Grabung Gristede, Kreis Ammerland 1967-70. Neue Ausgrabungen und Forschungen in Niedersachsen 7, 1972, 111-134.

ZOLLER, D. 1972b: Halbbogenförmige Bauten in der kaiser- und völkerwanderungszeitlichen Siedlung auf dem Gristeder Esch, Kr. Ammerland/Oldenburg. Archäologisches Korrespondenzblatt 2, 1972, 323-325.

ZOLLER, D. 1975: Die Ergebnisse der Grabung Gristede, Kreis Ammerland 1971-73. Neue Ausgrabungen und Forschungen in Niedersachsen 9, 1975, 35-57.

ZOLLER, D. 1977: Neue kaiserzeitliche Siedlungs- und Grabfunde im nordoldenburgischen Geestgebiet. Nachrichten aus Niedersachsens Urgeschichte 46, 1977, 241-251.

ZOLLER, D. 1980: Keramische Bodenfunde vom frühen Mittelalter bis zum 17. Jahrhundert im Nordoldenburger Geestgebiet. In: W. Lehmann (Hrsg.), Töpferei in Nordwestdeutschland, 2. Aufl. Münster 1980, 9-66. 
ZYLMANN, P. 1927: Aus der in der Hanenburg zu Leer befindlichen Sammlung. Blätter des Vereins für Heimatschutz und Heimatgeschichte Leer in Ostfriesland e.V. 7, 1926/1927, 190-193.

ZylmanN, P. 1928: Urgeschichtliche Funde bei Jemgumkloster. Rheiderland Zeitung 68 Jg. Nr. 146 (23.06.1928).

ZylmanN, P. 1930: Zur Urgeschichte des Reiderlandes. In: B.E. Siebs (Hrsg.), Das Reiderland. Beiträge zur Heimatkunde des Kreises Weener, Kiel 1930, 27-34.

Zylmann, P. 1933: Ostfriesische Urgeschichte. Darstellungen aus Niedersachsens Urgeschichte 2. Hildesheim/Leipzig 1933.

ZyLmanN, P. 1938: Der karolingerzeitliche Urnenfriedhof von Brinkum, Kreis Leer. Blätter des Vereins für Heimatschutz und Heimatgeschichte Leer in Ostfriesland 3, 1938, 66-71. 